\title{
STATE OF THE CLIMATE IN 2019
}

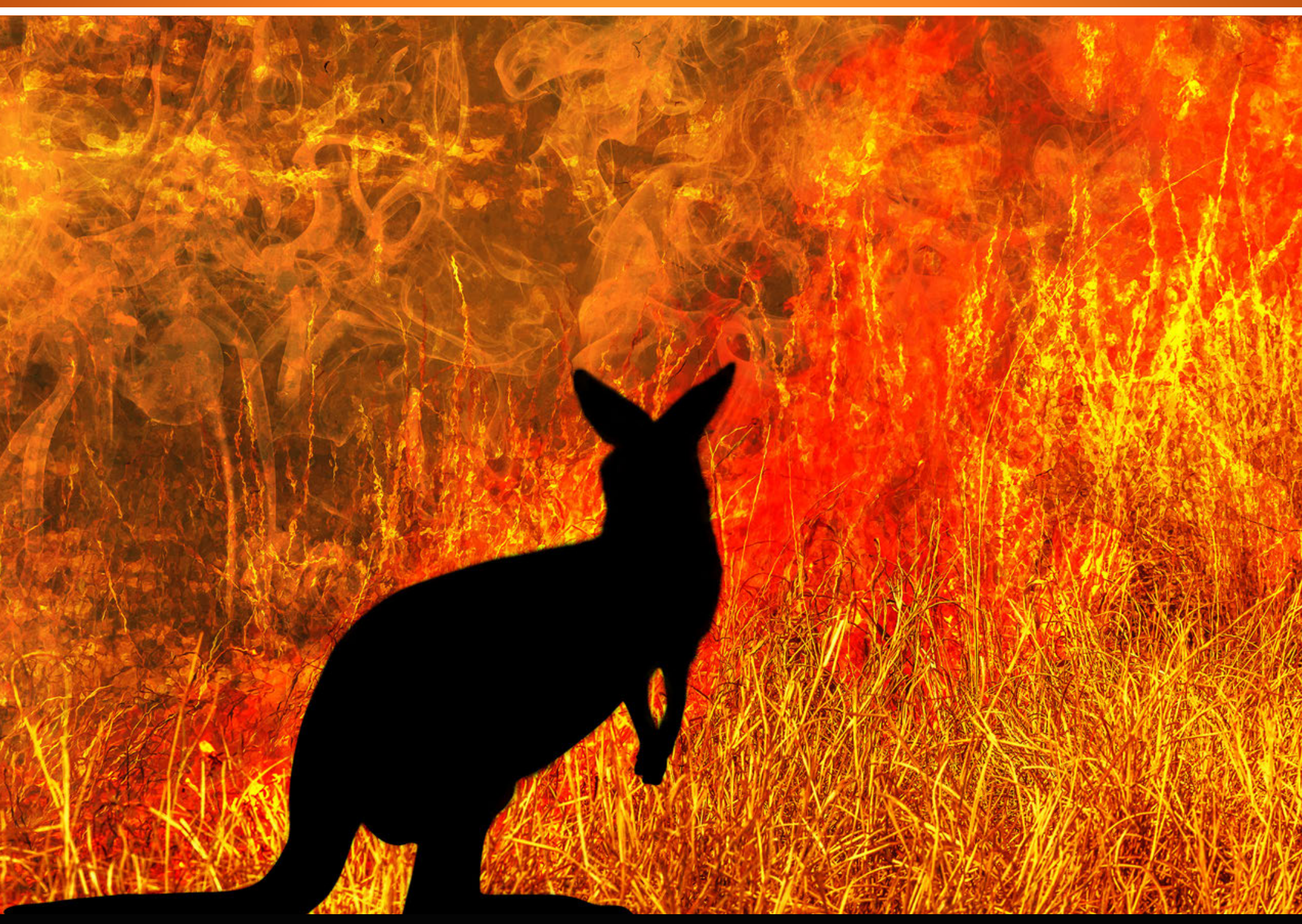

Special Supplement to the Bulletin of the American Meteorological Society Vol. 101, No. 8, August 2020 
Cover credit: Kangaroo silhouette looking a fire in Australia forests. Australian wildlife in bushfires 2019 and 2020. Credit: Benny Marty iStock/Getty Images Plus; Location: Australia/via Getty Images

How to cite this document:

Citing the complete report:

Blunden, J. and D. S. Arndt, Eds., 2020: State of the Climate in 2019. Bull. Amer. Meteor. Soc., 101 (8), Si-S429 https://doi.org/10.1175/2020BAMSStateoftheClimate.1

Special Online Supplement to the Bulletin of the American Meteorological Society, Vol.101, No. 8, August, 2020

https://doi.org/10.1175/2020BAMSStateoftheClimate.1 Corresponding author: Full report: Jessica Blunden / jessica.blunden@noaa.gov @2020 American Meteorological Society For information regarding reuse of this content and general copyright information, consult the AMS Copyright Policy. 


\section{STATE OF THE CLIMATE IN 2019 TABLE OF CONTENTS}

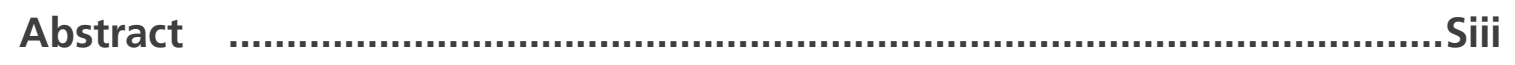

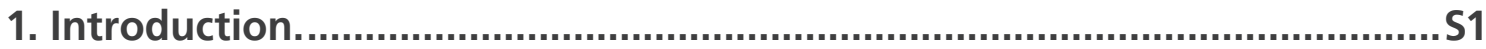

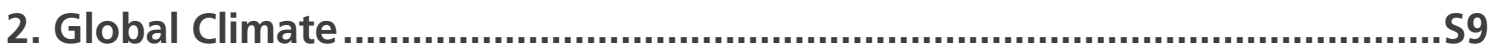

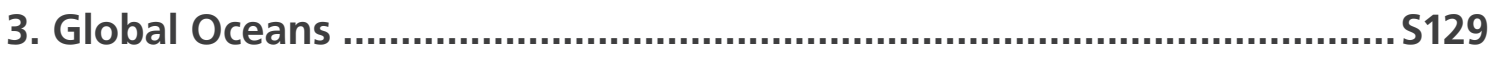

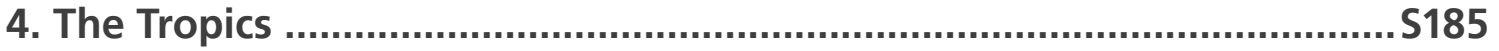

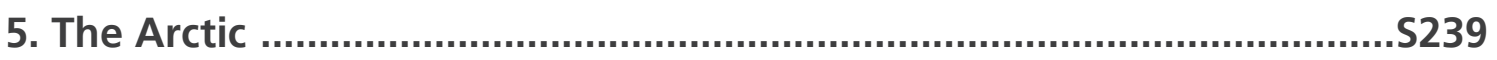

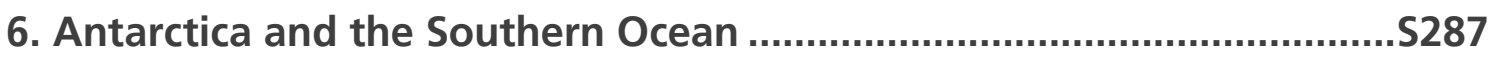

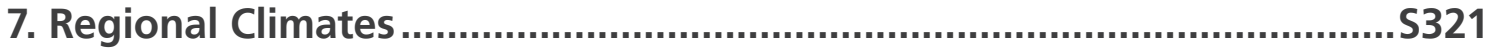

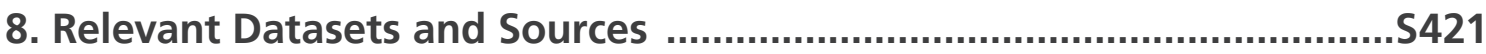




\section{ABSTRACT—J. BLUNDEN AND D. S. ARNDT}

In 2019, the dominant greenhouse gases released into Earth's atmosphere continued to increase. The annual global average carbon dioxide concentration at Earth's surface was $409.8 \pm 0.1 \mathrm{ppm}$, an increase of $2.5 \pm 0.1 \mathrm{ppm}$ over 2018, and the highest in the modern instrumental record and in ice core records dating back 800000 years. Combined, greenhouse gases and several halogenated gases contributed $3.14 \mathrm{~W} \mathrm{~m}^{-2}$ to radiative forcing, representing a $45 \%$ increase since 1990 . Carbon dioxide is responsible for about $65 \%$ of this radiative forcing. The annual net global uptake of $\sim 2.4$ billion metric tons of carbon dioxide by oceans was the highest in the record dating to 1982 and 33\% higher than the 1997-2017 average.

A weak El Niño at the beginning of 2019 transitioned to ENSO-neutral conditions by mid-year. Even so, the annual global surface temperature across land and oceans was still among the three highest in records dating to the mid- to late 1800s. July 2019 was Earth's hottest month on record. Well over a dozen countries across Africa, Europe, Asia, Australia, and the Caribbean reported record high annual temperatures. In North America, Alaska experienced its warmest year on record, while the high northern latitudes that encompass the Arctic were second warmest, behind only 2016. Stations in several countries, including Vietnam, the Netherlands, Belgium, Luxembourg, France, and the United Kingdom, set new all-time daily high temperature records for their nations. Australia set a new nationally averaged daily maximum temperature record of $41.9^{\circ} \mathrm{C}$ on 18 December, breaking the previous record set in 2013 by $1.6^{\circ} \mathrm{C}$. Daily temperatures surpassed $40^{\circ} \mathrm{C}$ for the first time in Belgium and the Netherlands.

Lake temperatures increased on average across the globe in 2019; observed lakes in the Northern Hemisphere were covered in ice seven days fewer than the 1981-2010 average, according to phenological indicators. Over land, the growing season was an average of eight days longer than the 2000-10 average in the $\mathrm{NH}$.

Above Earth's surface, the annual lower troposphere temperature was third highest to record high, and the lower stratosphere temperature was third lowest to record low, depending on the dataset analyzed. Middle- and upper-stratospheric temperatures were lowest on record since satellite records began in 1979. In September, Antarctica experienced a dramatic upper-atmosphere warming event that led to the smallest ozone hole since the early 1980 s.

Below-average Antarctic sea ice extent persisted throughout 2019, continuing a trend that began in September 2016. Net sea ice extent was below the 1981-2010 average for all days of the year, and January and June each set a new low monthly mean sea ice extent record. The Antarctic ice sheet continued to lose mass, with the highest rates of loss occurring in West Antarctica and Wilkes Land, East Antarctica.

Across the cryosphere, alpine glaciers continued to lose mass for the 32nd consecutive year. Permafrost temperatures in the European Alps were slightly below the record temperatures measured in 2015, while record high permafrost temperatures were observed at a majority of the observation sites across the high northern latitudes. For the first time in the observational record at 26 sites in interior Alaska and the Seward Peninsula, the active layer did not freeze completely, a result of long-term permafrost warming and back-to-back relatively mild and snowy winters.

In March, when Arctic sea ice reached its annual maximum extent, thin, first-year ice comprised $\sim 77 \%$ of all ice, compared to about $55 \%$ in the 1980 s. In September, the minimum sea ice extent tied for the second smallest extent in the 41-year satellite record. In the Bering Sea, increasing ocean temperatures and reduced sea ice-which was the lowest on record there for the second consecutive winter-are leading to shifts in fish distributions within some of the most valuable fisheries in the world. Larger and more abundant boreal species, as opposed to smaller and less abundant Arctic species, dominated a large portion of the Arctic shelf in 2018 and 2019.

During the 2019 melt season, the extent and magnitude of ice loss over the Greenland ice sheet rivaled 2012, the previous year of record ice loss. Melting of glaciers and ice sheets, along with warming oceans, account for the trend in rising global mean sea level.

In 2019, global mean sea level set a new record for the eighth consecutive year, reaching $87.6 \mathrm{~mm}$ above the 1993 average when satellite measurements began, with an annual average increase of $6.1 \mathrm{~mm}$ from 2018. Ocean heat content measured to $700 \mathrm{~m}$ depth was record high, and the globally averaged sea surface temperature was the second highest on record, surpassed only by the record El Niño year of 2016. In October, the Indian Ocean dipole exhibited its greatest magnitude since 1997, associated with dramatic upper ocean warming in the western Indian Ocean basin.

While ENSO conditions during 2019 appeared to have limited impacts, many climate events were influenced by the strong positive IOD, which contributed to a large rainfall deficit from the eastern Indian Ocean to the South Pacific Ocean east of Australia. Record heat and dryness in Australia intensified drought conditions already in place following below-average rainfall in 2017 and 2018, leading to severe impacts during late austral spring and summer, including catastrophic wildfires. 
Smoke from these wildfires, along with the volcanic eruptions of Raikoke (Russia) and Ulawun (Papua New Guinea), helped load the stratosphere with aerosol levels unprecedented since the post-Mt. Pinatubo era of the early 1990s. Indonesia also suffered severe drought and extreme wildfires toward the end of 2019; no rainfall was observed in the East Sumba District of the East Nusa Tenggara Province for 263 days.

Conversely, the positive IOD also contributed to excess rainfall over the Horn of Africa from August through December, resulting in widespread flooding across East Africa. Elsewhere, India experienced one of its heaviest summer monsoon rains since 1995 despite a delayed and suppressed monsoon during June. In the United States, rapid snowmelt in the spring, as well as heavy and frequent precipitation in the first half of the year, contributed to extensive flooding in the Midwest throughout spring and summer, notably the Mississippi and Missouri basins.

Dry conditions persisted over large parts of western South Africa, in some locations having continued for approximately seven years. Antecedent dry conditions and extreme summer heat waves pushed most of Europe into extreme drought.

Due in part to precipitation deficits during December 2018 to January 2019-the peak of the rainy season-wildfires scorched vast areas of the southern Amazonian forests in Bolivia, Brazil, and Peru, as well as in northern Paraguay, later in 2019. Millions of trees and animals perished, with some local extinctions reported. In Siberia, fire activity during the summer was both strong and farther north than usual. This led to a new record of 27 teragrams $\left(10^{12} \mathrm{~g}\right)$ of carbon emitted from fires in the Arctic, which was more than twice as high than in any preceding year.

Closer to the equator, 96 named tropical storms were observed during the Northern and Southern Hemisphere storm seasons, well above the 1981-2010 average of 82. Five tropical cyclones reached Saffir-Simpson scale Category 5 intensity. In the North Atlantic basin, Hurricane Dorian caused unprecedented and tremendous devastation, with over 70 fatalities and damages totaling \$3.4 billion (U.S. dollars) in The Bahamas. Tropical Cyclones Idai and Kenneth severely impacted southeastern Africa in March and April, respectively. Idai resulted in total damages of at least $\$ 2.2$ billion (U.S. dollars), the costliest storm on record for the South Indian Ocean basin, as well as the deadliest with over 1200 fatalities across Mozambique, Zimbabwe, Malawi, and Madagascar. 


\section{STATE OF THE CLIMATE IN 2019}

\section{INTRODUCTION}

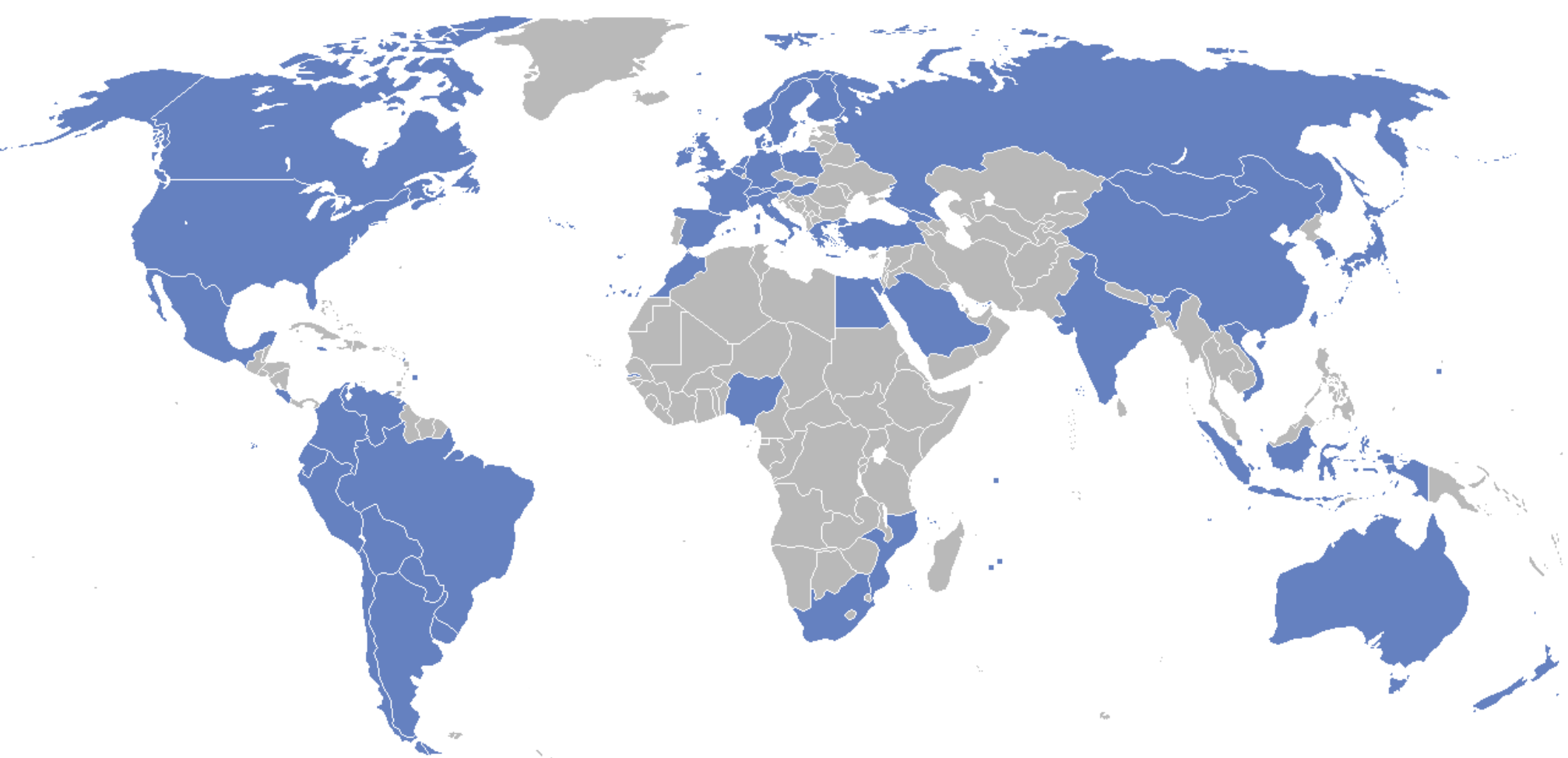

The countries highlighted in blue indicate each of the 61 nations contributing an author and/or chapter editor to the State of the Climate in 2019.

Citing this chapter: Arndt, D. S., J. Blunden, and R. J. H. Dunn. 2020: Introduction [in "State of the Climate in 2019"]. Bull. Amer. Meteor. Soc., 101 (8), S1-S8, https://doi.org/10.1175/2020BAMSStateoftheClimate_Intro.1.

Special Supplement to the Bulletin of the American Meteorological Society, Vol.101, No. 8, August, 2020

The Introduction is one chapter from the State of the Climate in 2019 annual report. Compiled by NOAA's National Centers for Environmental Information, State of the Climate in 2019 is based on contributions from scientists from around the world. It provides a detailed update on global climate indicators, notable weather events, and other data collected by environmental monitoring stations and instruments located on land, water, ice, and in space. The full report is available from https://doi.org/10.1175/2020BAMSStateoftheClimate.1.

https://doi.org/10.1175/2020BAMSStateoftheClimate_Intro.1

Corresponding author, Introduction: Jessica Blunden / jessica.blunden@noaa.gov

(C2020 American Meteorological Society

For information regarding reuse of this content and general copyright information, consult the AMS Copyright Policy. 


\title{
STATE OF THE CLIMATE IN 2019 \\ Introduction
}

\author{
Editors \\ Jessica Blunden \\ Derek S. Arndt

\section{Chapter Editors} \\ Peter Bissolli \\ Howard J. Diamond \\ Matthew L. Druckenmiller \\ Robert J. H. Dunn \\ Catherine Ganter \\ Nadine Gobron \\ Rick Lumpkin \\ Jacqueline A. Richter-Menge \\ Tim Li \\ Ademe Mekonnen \\ Ahira Sánchez-Lugo \\ Ted A. Scambos \\ Carl J. Schreck III \\ Sharon Stammerjohn \\ Diane M. Stanitski \\ Kate M. Willett \\ Technical Editor \\ Andrea Andersen
}

BAMS Special Editor for Climate

Richard Rosen 
Arndt, Derek S., NOAA/NESDIS National Centers for Environmental Information, Asheville, North Carolina

Blunden, Jessica, NOAA/NESDIS National Centers for Environmental Information, Asheville, North Carolina

Dunn, Robert J. H., Met Office Hadley Centre, Exeter, United Kingdom

\section{Editorial and Production Team}

Andersen, Andrea, Technical Editor, Innovative Consulting Management Services, LLC, NOAA/NESDIS National Centers for Environmental Information, Asheville, North Carolina

Griffin, Jessicca, Graphics Support, Cooperative Institute for Satellite Earth System Studies, North Carolina State University, Asheville, North Carolina

Hammer, Gregory, Content Team Lead, Communications and Outreach, NOAA/ NESDIS National Centers for Environmental Information, Asheville, North Carolina

Love-Brotak, S. Elizabeth, Lead Graphics Production, NOAA/NESDIS National Centers for Environmental Information, Asheville, North Carolina
Misch, Deborah J., Graphics Support, Innovative Consulting Management Services, LLC, NOAA/NESDIS National Centers for Environmental Information, Asheville, North Carolina

Riddle, Deborah B., Graphics Support, NOAA/NESDIS National Centers for Environmental Information, Asheville, North Carolina

Veasey, Sara W., Visual Communications Team Lead, Communications and Outreach, NOAA/NESDIS National Centers for Environmental Information, Asheville, North Carolina 


\section{INTRODUCTION—D. S. Arndt, J. Blunden, and R. J. H. Dunn}

This is the 30th edition of what is now known as the State of the Climate report, marking a 30-year period of record for a document that routinely uses 30-year base periods to help contextualize today's climate. Compared to that 30-year record, this 2019 edition is the richest report in the series, well above climatological averages, and indeed setting records for climate variables tracked and for author participation. This year, 528 authors and editors contributed to the report, together representing 61 countries, including for the first time in this series' history authors from the nations of Georgia and Vietnam.

One of the touchpoints of 2019's climate-the Indian Ocean-may turn the globe upside-down for our North American readership. The body of water, cleaved into distinct halves marked by the strongest Indian Ocean Dipole in more than two decades, behaved as something of a center of gravity in this report, as many of the extremes and related phenomena seemed to emanate from it. The strength of its signal was seen throughout the system and throughout this report: in nuisance flooding and unusual chlorophyll concentrations in and around the basin; in unprecedented tropical cyclone activity in the Arabian Sea; as historic fire and drought in Australia; and in back-to-back devastating tropical cyclones in southeast Africa.

In early 2020, our community was likewise turned upside-down, but on a personal level, with the passing of New Zealand's Brett Mullan, himself an accomplished contributor to the understanding of Southern Hemisphere climate and variability, but also a beloved contributor to the Tropics chapter for many years. Its editors have memorialized his contributions and their appreciation in the chapter introduction.

It was also in early 2020 when a global contagion turned upside-down the professional worlds of our many authors and editors, who crafted and shaped their contributions in a much different way, and from much different settings, than anticipated. In an era for which "isolation" took on widespread new contexts, we are forever thankful for the connections among these authors, editors, their expertise, and their dedication to publishing this most comprehensive annual diagnostic of the climate system available.

In service to them, the State of the Climate report has taken several steps to acknowledge the importance of our diverse authorship. The report will now be catalogued as independent chapters, allowing for more full recognition of authorship in the various citation indices. Each of these chapters now has its own cover image, most of which were provided by an author in that very chapter. Finally, the public rollout of this manuscript in the Northern Hemisphere summer of 2020 will consciously attempt to increase awareness of the authors and chapter editors that drive this report.

As is the case every year, several chapter editors have chosen to make adjustments to their chapter's roster and organization of content. This may be to take advantage of analyses made newly available to this report, such as the global lake water levels section and marine heat waves analyzed in Chapter 2; and the polar chapters' commissioning of sections on non-Greenlandic ice in the Arctic, and changes and trends in the Antarctic ice sheet. In some cases, data availability does not allow every-year analysis in this report, requiring occasional appearances. These factors explain the return of the Mauna Loa solar transmission record to the global chapter and the Atlantic Meridional Overturning Circulation to the oceans chapter, and this year's exclusion of Arctic-specific river discharge. 
This year, for the first time in the supplement's 30-year history and in the spirit of minimizing our own impact on climate change, the report is published in digital format only. The general layout, however, remains largely the same. An overview of findings is presented in the Abstract, Fig. 1.1, and Plate 1.1. Chapter 2 features global-scale climate variables; Chapter 3 highlights the global oceans; and Chapter 4 discusses tropical climate phenomena including tropical cyclones. The Arctic and Antarctica respond differently through time and are reported in separate chapters (5 and 6, respectively). Chapter 7 provides a regional perspective authored largely by regional government climate specialists. A list of relevant datasets and their sources for all chapters is provided as an Appendix. Authors, acknowledgments, and references are now listed with each individual chapter.

Time series of major climate indicators are again presented in this introductory chapter. Many of these indicators are essential climate variables, originally defined in GCOS (2003) and updated again by GCOS (2010). As their name indicates, these variables are essential for a full understanding of the changing climate system. However, some of them are not available on the immediate timescales of this report, and others, particularly those dealing with the living world, are outside the scope of this report.

\section{Acknowledgments}

The editors thank the BAMS editorial staff, in particular Bryan Hanssen, who provided technical guidance, oversaw publication of the report, and helped us shepherd the report into a new digital publishing era, Hannah Kleppner, who provided peer review support, and Nicole Rietmann, who oversaw the hundreds of citations and references this year, and the NCEI Graphics team for facilitating the construction of the report and executing the countless number of technical edits needed. We thank our technical editor Andrea Andersen for her dedication and attention to detail. We also express our gratitude to Dr. Rick Rosen, who again served as the AMS special editor for this report. Finally, we thank all of the authors and chapter editors who provide these valuable contributions each year, always with an aim to improve and expand their analyses for the readers. 


\section{Essential Climate Variables—D. S. ARNDT, J. BLUNDEN, AND R. J. H. DUNN}

The following variables are considered fully monitored in this report, in that there are sufficient spatial and temporal data, with peer-reviewed documentation to characterize them on a global scale:

- Surface atmosphere: air pressure, precipitation, temperature, water vapor, wind speed and direction

- Upper atmosphere: Earth radiation budget, temperature, water vapor, wind speed and direction

- Atmospheric composition: carbon dioxide, methane and other greenhouse gases, ozone

- Ocean physics: ocean surface heat flux, sea ice, sea level, surface salinity, sea surface temperature, subsurface salinity, subsurface temperature, surface currents, surface stress

- Ocean biogeochemistry: ocean color

- Ocean biogeosystems: plankton

- Land: albedo, river discharge, snow

The following variables are considered partially monitored, in that there is systematic, rigorous measurement found in this report, but some coverage of the variable in time and space is lacking due to observing limitations or availability of data or authors:

- Atmospheric composition: aerosols properties, cloud properties, precursors of aerosol and ozone

- Ocean physics: subsurface currents

- Ocean biogeochemistry: inorganic carbon

- Land: above-ground biomass, anthropogenic greenhouse gas fluxes, fire, fraction of absorbed photosynthetically active radiation, glaciers, groundwater, ice sheets and ice shelves, lakes, permafrost, soil moisture

The following variables are not yet partially covered in this report, or are outside the scope of it.

- Surface atmosphere: surface radiation budget

- Upper atmosphere: lightning

- Ocean physics: sea state

- Ocean biogeochemistry: nitrous oxide, nutrients, oxygen, transient tracers

- Ocean biogeosystems: marine habitat properties

- Land: anthropogenic water use, land cover, land surface temperature, latent and sensible heat fluxes, leaf area index, soil carbon

Plate 1.1. (next page) Global (or representative) average time series for essential climate variables through 2019. Anomalies are shown relative to the base period in parentheses although base periods used in other sections of the report may differ. The numbers in the square brackets that follow in this caption indicate how many reanalysis (blue), satellite (red), and in situ (black) datasets are used to create each time series in that order. (a) NH polar stratospheric ozone (Mar) $[0,0,1]$; (b) SH polar stratospheric ozone (Oct) [0,0,1]; (c) apparent transmission (Mauna Loa) [0,0,1]; (d) surface temperature [3,0,4]; (e) lower tropospheric temperature [3,2,3]; (f) lower stratospheric temperature [3,3,3]; (g) extremes (warm days (solid) and cool days (dotted)) [0,0,1]; (h) Arctic sea ice extent (max [solid]) and min [dashed]; [0,0,1]); (i) Antarctic sea ice extent (max [solid] and min [dashed]; [0,0,1]); (j) glacier cumulative mean specific balance $[0,0,1]$; $(\mathrm{k}) \mathrm{NH}$ snow cover extent $[0,1,1]$; $(\mathrm{l})$ lower stratospheric water vapor $[0,0,1] ;(\mathrm{m})$ cloudiness $[0,10,0] ;(\mathrm{n})$ total column water vapor - land $[3,1,1] ;(0)$ total column water vapor - ocean $[3,2,0]$; (p) upper tropospheric humidity [1,2,0]; (q) specific humidity - land [4,0,1]; (r) specific humidity - ocean $[4,0,2]$; (s) relative humidity - land [3,0,4]; (t) relative humidity - ocean [3,0,1]; (u) precipitation - land $[0,0,3] ;(v)$ precipitation - ocean $[0,0,1] ;(w)$ ocean heat content $(0-700 \mathrm{~m})[0,0,6] ;(x)$ sea level rise $[0,0,1] ;(y)$ tropospheric ozone $[0,1,0]$; (z) tropospheric wind speed at $850 \mathrm{hPa}$ for $20^{\circ}-40^{\circ} \mathrm{N}[4,0,0]$; (aa) land wind speed [0,0,1]; (ab) ocean wind speed [3,1,0]; (ac) biomass burning $[0,2,0]$; (ad) soil moisture $[0,1,0]$; (ae) terrestrial groundwater storage $[0,1,0]$; (af) fraction of absorbed photosynthetically active radiation (FAPAR) $[0,1,0]$; (ag) land surface albedo - visible (solid) and infrared (dashed) $[0,1,0]$. 

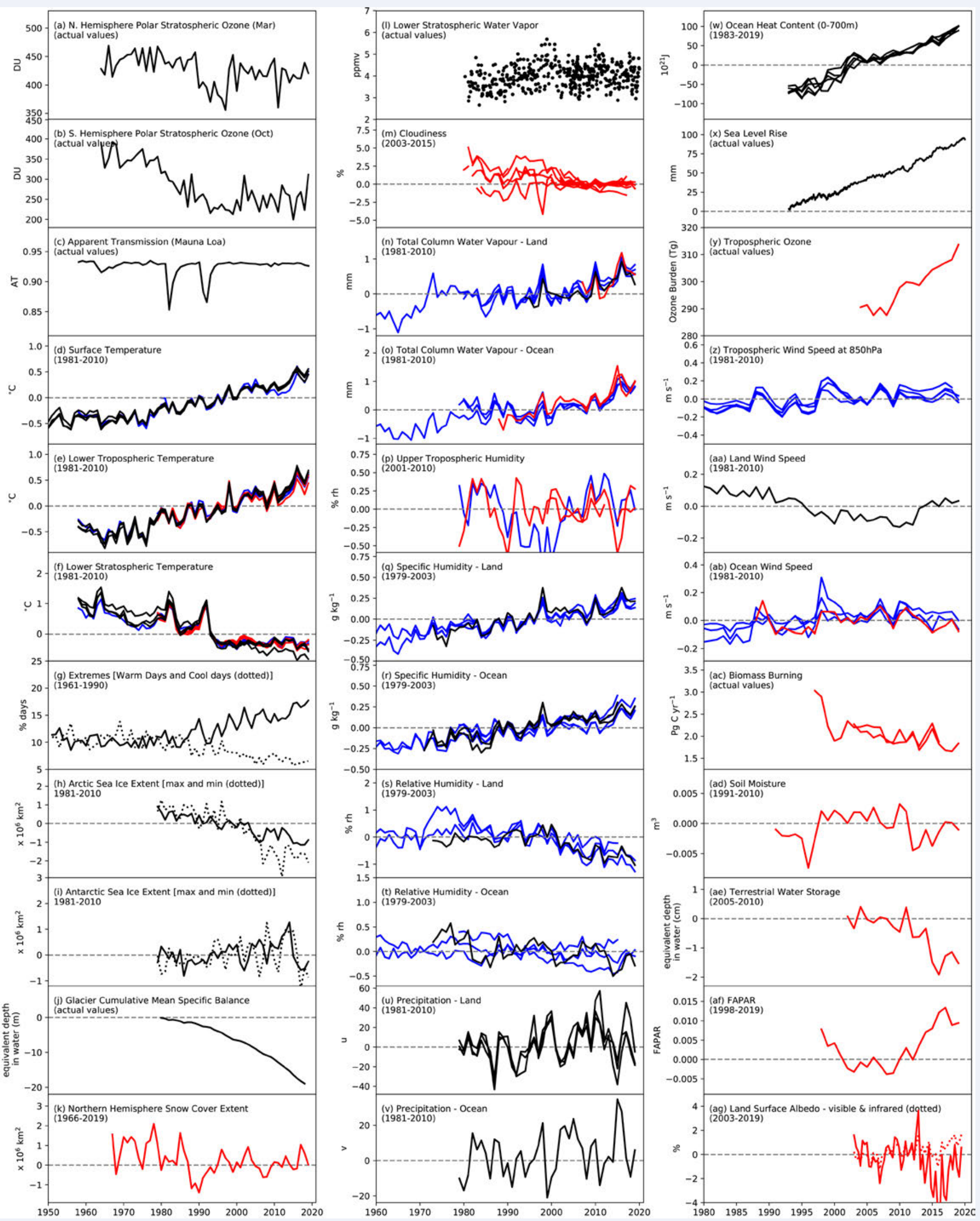


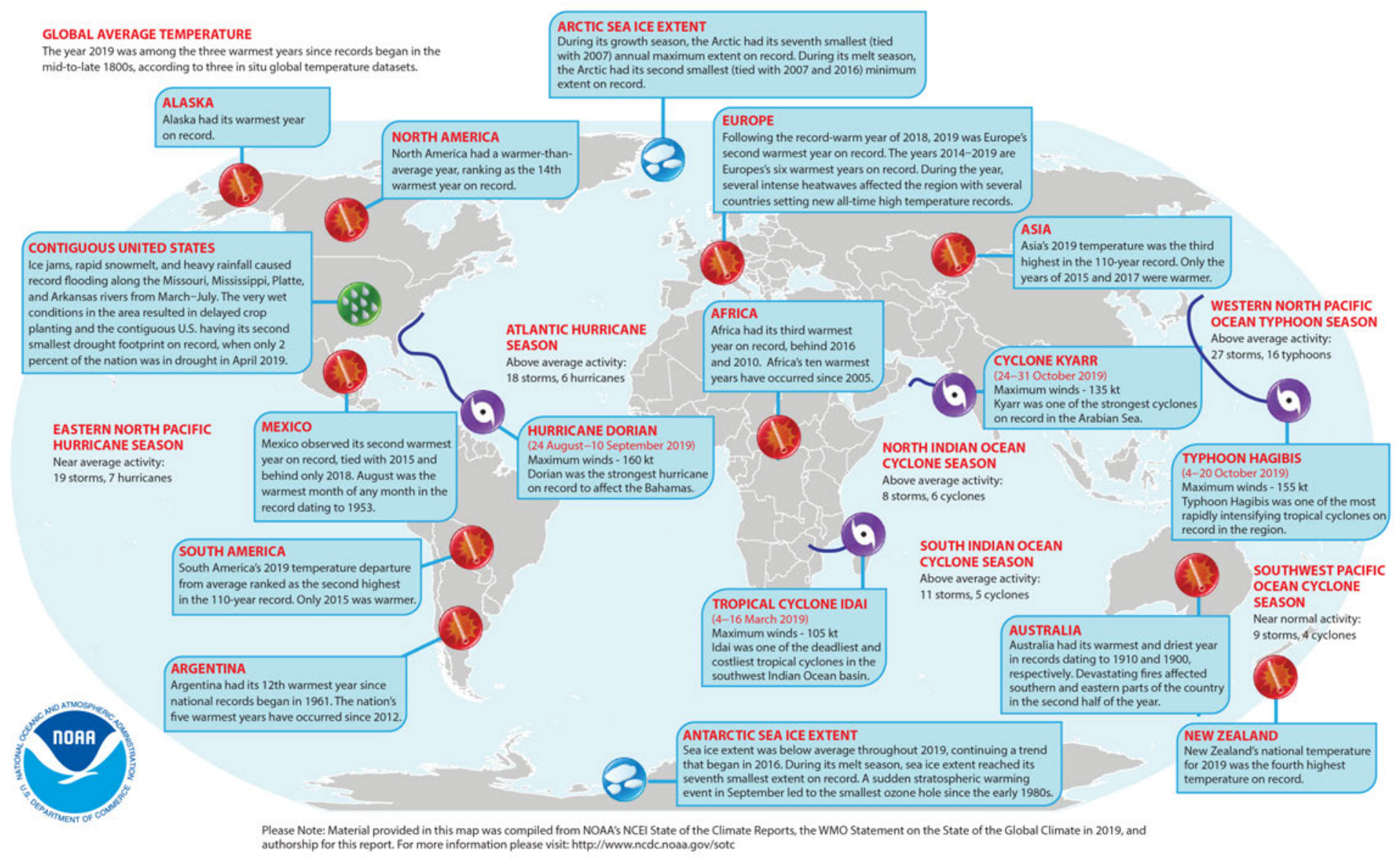

Fig. 1.1. Geographical distribution of selected notable climate anomalies and events in 2019.

\section{References}

GCOS, 2003: The second report on the adequacy of the global observing systems for climate in support of the UNFCCC. GCOS-82 (WMO/TD-1143). World Meteorological Organization, 74 pp., http://www.wmo.int/pages/prog/gcos/Publications/gcos -82_2AR.pdf.
, 2010: Implementation plan for the global observing system for climate in support of the UNFCCC (2010 Update). GCOS-138 (GOOS-184, GTOS-76, WMO/TD-1523). World Meteorological Organization, 180 pp., http://www.wmo.int/pages/prog/gcos/ Publications/gcos-138.pdf. 


\title{
STATE OF THE CLIMATE IN 2019 Global Climate
}

\author{
Editors \\ Jessica Blunden \\ Derek S. Arndt \\ Chapter Editors \\ Peter Bissolli \\ Howard J. Diamond \\ Matthew L. Druckenmiller \\ Robert J. H. Dunn \\ Catherine Ganter \\ Nadine Gobron \\ Rick Lumpkin \\ Jacqueline A. Richter-Menge \\ Tim Li \\ Ademe Mekonnen \\ Ahira Sánchez-Lugo \\ Ted A. Scambos \\ Carl J. Schreck III \\ Sharon Stammerjohn \\ Diane M. Stanitski \\ Kate M. Willett \\ Technical Editor \\ Andrea Andersen
}

BAMS Special Editor for Climate

Richard Rosen

American Meteorological Society 


\section{Cover credit:}

The cover shows a cropped image of the warming stripes (seen in full below), as developed by Ed Hawkins (Reading University, UK). Each vertical line shows the global average temperature of a whole year, starting at 1850 on the far left and ending with 2019 on the far right. The underlying data are from the HadCRUT4.6 dataset of the UK Met Office Hadley Centre. To create stripes of other regions and countries visit https://showyourstripes.info/. Image created on 23 June 2020 by https://showyourstripes.info/ under a CC BY 4.0 licence.
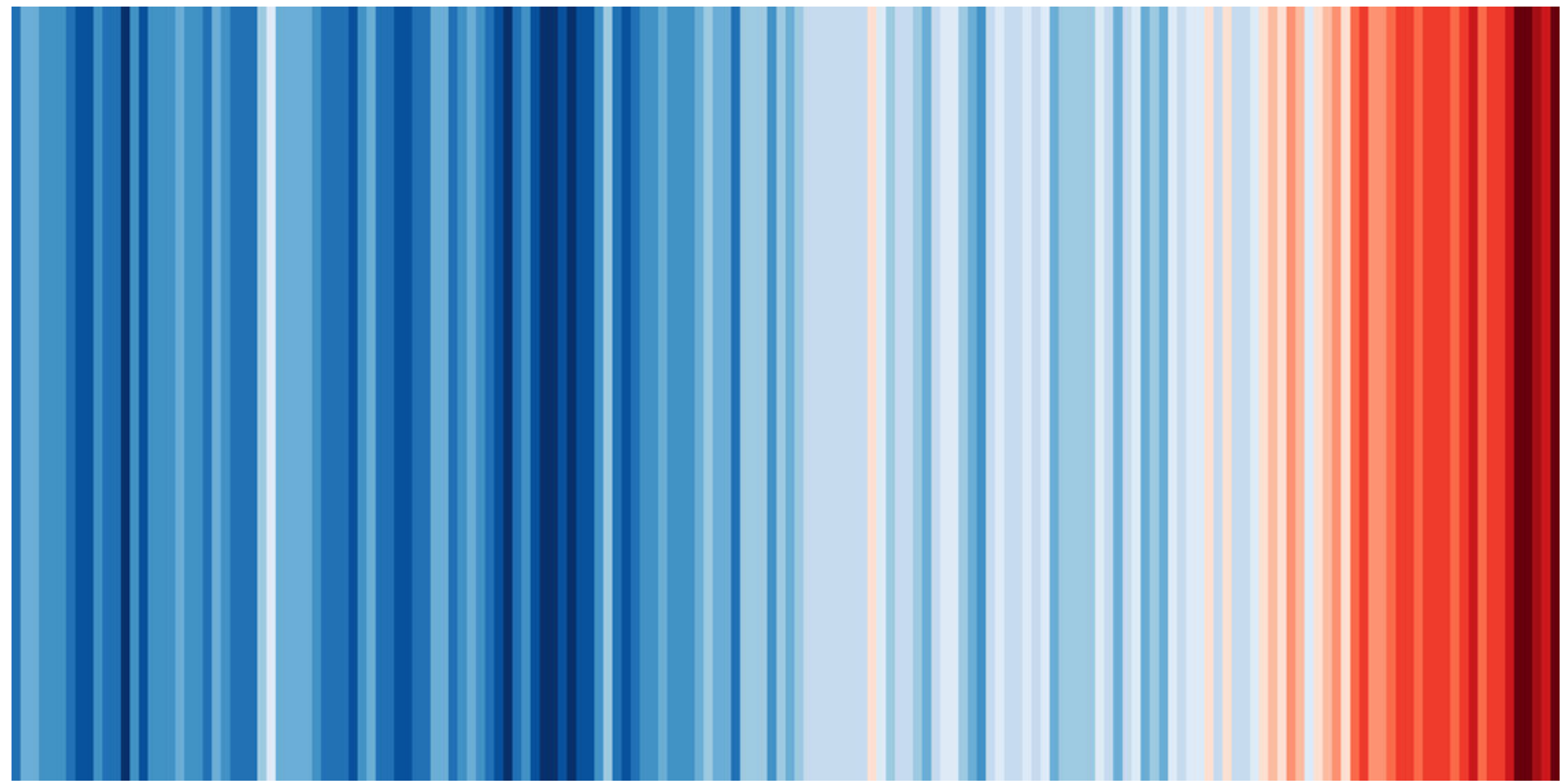

Global Climate is one chapter from the State of the Climate in 2019 annual report and is available from https://doi.org/10.1175/BAMS-D-20-0104.1 Compiled by NOAA's National Centers for Environmental Information, State of the Climate in 2019 is based on contributions from scientists from around the world. It provides a detailed update on global climate indicators, notable weather events, and other data collected by environmental monitoring stations and instruments located on land, water, ice, and in space.

The full report is available from https://doi.org/10.1175/2020BAMSStateoftheClimate.1.

\section{How to cite this document:}

\section{Citing the complete report:}

Blunden, J. and D. S. Arndt, Eds., 2020: State of the Climate in 2019. Bull. Amer. Meteor., 101 (8), Si-S429 doi:10.1175/2020BAMSStateoftheClimate.1

\section{Citing this chapter:}

Dunn, R. J. H., D. M. Stanitski, N. Gobron, and K. M. Willett, Eds., 2020: Global Climate [in "State of the Climate in 2019"]. Bull. Amer. Meteor., 101 (8), S9-S127, https://doi.org/10.1175/BAMS-

\section{D-20-0104.1}

\section{Citing a section (example):}

Davis, M., K. H. Rosenlof, D. F. Hurst, H. Vömel, and H.B. Selkirk, 2020: Stratospheric water vapor [in "State of the Climate in 2019"]. Bull. Amer. Meteor., 101 (8), S81-S83, https://doi.org/10.1175/ BAMS-D-20-0104.1. 
Ades, M., European Centre for Medium-Range Weather Forecasts, Reading, United Kingdom

Adler, R., University of Maryland, College Park, Maryland

Allan, Rob, Met Office Hadley Centre, Exeter, United Kingdom

Allan, R. P., University of Reading, Reading, United Kingdom

Anderson, J., Department of Atmospheric and Planetary Science, Hampton University, Hampton, Virginia

Argüez, Anthony, NOAA/NESDIS National Centers for Environmental Information, Asheville, North Carolina

Arosio, C., University of Bremen, Bremen, Germany

Augustine, J. A., NOAA/OAR Earth System Research Laboratories, Boulder, Colorado

Azorin-Molina, C., Centro de Investigaciones sobre Desertificación - Spanish National Research Council, Moncada (Valencia), Spain; and Regional Climate Group, Department of Earth Sciences, University of Gothenburg, Gothenburg, Sweden

Barichivich, J., Instituto de Geografía, Pontificia Universidad Católica de Valparaíso, Valparaíso, Chile

Barnes, J., NOAA/OAR ESRL Global Monitoring Laboratory, Boulder, Colorado

Beck, H. E., Department of Civil and Environmental Engineering, Princeton University, Princeton, New Jersey

Becker, Andreas, Global Precipitation Climatology Centre, Deutscher Wetterdienst, Offenbach, Germany

Bellouin, Nicolas, University of Reading, Reading, United Kingdom

Benedetti, Angela, European Centre for Medium-Range Weather Forecasts, Reading, United Kingdom

Berry, David I., National Oceanography Centre, Southampton, United Kingdom

Blenkinsop, Stephen, School of Engineering, Newcastle University, Newcastleupon-Tyne, United Kingdom

Bock, Olivier, Université de Paris, Institut de physique du globe de Paris, CNRS, IGN, Paris, France, and ENSG-Géomatique, IGN, Marne-la-Vallée, France

Bosilovich, Michael G., Global Modeling and Assimilation Office, NASA Goddard Space Flight Center, Greenbelt, Maryland

Boucher, Olivier, Sorbonne Université, Paris, France

Buehler, S. A., Universität Hamburg, Hamburg, Germany

Carrea, Laura, Department of Meteorology, University of Reading, Reading, United Kingdom

Christiansen, Hanne H., Geology Department, University Centre in Svalbard, Longyearbyen, Norway

Chouza, F., Jet Propulsion Laboratory, California Institute of Technology, Wrightwood, California

Christy, John R., The University of Alabama in Huntsville, Huntsville, Alabama

Chung, E.-S., IBS Center for Climate Physics, Busan, South Korea

Coldewey-Egbers, Melanie, German Aerospace Center (DLR) Oberpfaffenhofen, Wessling, Germany

Compo, Gil P., Cooperative Institute for Research in Environmental Sciences, University of Colorado Boulder, and Physical Sciences Division, NOAA/Earth System Research Laboratory, Boulder, Colorado

Cooper, Owen R., Cooperative Institute for Research in Environmental Sciences, University of Colorado Boulder, and NOAA/OAR Earth System Research Laboratories, Boulder, Colorado

Covey, Curt, Lawrence Livermore National Laboratory, Livermore, California

Crotwell, A., Cooperative Institute for Research in Environmental Sciences, University of Colorado, and NOAA/OAR Global Monitoring Division, Boulder, Colorado

Davis, Sean M., Cooperative Institute for Research in Environmental Sciences, University of Colorado Boulder, and NOAA/OAR Earth System Research Laboratory, Boulder, Colorado

de Eyto, Elvira, Marine Institute, Furnace, Newport, Ireland de Jeu, Richard A. M., VanderSat B.V., Haarlem, the Netherlands

DeGasperi, Curtis L., King County Water and Land Resources Division, Seattle, Washington

Degenstein, Doug, University of Saskatchewan, Saskatoon, Saskatchewan, Canada

Di Girolamo, Larry, University of Illinois at Urbana-Champaign, Champaign, Illinois

Dokulil, Martin T., Research Department for Limnology, University of Innsbruck, Austria

Donat, Markus G., Barcelona Supercomputing Centre, Barcelona, Spain

Dorigo, Wouter A., Department of Geodesy and Geoinformation, TU Wien Vienna University of Technology, Vienna, Austria

Dunn, Robert J. H., Met Office Hadley Centre, Exeter, United Kingdom

Durre, Imke, NOAA/NESDIS National Centers for Environmental Information, Asheville, North Carolina

Dutton, Geoff S., Cooperative Institute for Research in Environmental Sciences, University of Colorado Boulder, and NOAA/OAR Earth System Research Laboratories, Boulder, Colorado

Duveiller, G., European Commission, Joint Research Centre, Ispra, Italy

Elkins James W., NOAA/OAR Earth System Research Laboratories, Boulder, Colorado,

Fioletov, Vitali E., Environment and Climate Change Canada, Toronto, Canada

Flemming, Johannes, European Centre for Medum-Range Weather Forecasts, Reading, United Kingdom

Foster, Michael J., Cooperative Institute for Meteorological Satellite Studies, Space Science and Engineering Center, University of Wisconsin-Madison, Madison, Wisconsin

Frey, Richard A., Cooperative Institute for Meteorological Satellite Studies, Space Science and Engineering Center, University of Wisconsin-Madison, Madison, Wisconsin

Frith, Stacey M., Science Systems and Applications, Inc, Lanham, Maryland, NASA Goddard Space Flight Center, Greenbelt, Maryland

Froidevaux, Lucien, Jet Propulsion Laboratory, California Institute of Technology, Pasadena, California

Garforth, J., Woodland Trust, Grantham, United Kingdom

Gobron, Nadine, European Commission, Joint Research Centre, Ispra, Italy

Gupta, S. K., Science Systems and Applications, Inc., Hampton, Virginia

Haimberger, Leopold, Department of Meteorology and Geophysics, University of Vienna, Vienna, Austria

Hall, Brad D., NOAA/OAR Earth System Research Laboratories, Boulder, Colorado

Harris, Ian, National Centre for Atmospheric Science (NCAS), University of East Anglia, Norwich, United Kingdom and Climatic Research Unit, School of Environmental Sciences, University of East Anglia, Norwich, United Kingdom

Heidinger, Andrew K., NOAA/NESDIS/STAR University of Wisconsin - Madison, Madison, Wisconsin

Hemming, D. L., Met Office Hadley Centre, Exeter, United Kingdom; Birmingham Institute of Forest Research, Birmingham University, Birmingham, United Kingdom

Ho, Shu-peng (Ben), NOAA/NESDIS Center for Satellite Applications and Research, College Park, Maryland

Hubert, Daan, Royal Belgian Institute for Space Aeronomy (BIRA), Brussels, Belgium

Hurst, Dale F., Cooperative Institute for Research in Environmental Sciences, University of Colorado Boulder, and NOAA/OAR Earth System Research Laboratories, Boulder, Colorado

Hüser, I., Deutscher Wetterdienst, Offenbach, Germany

Inness, Antje, European Centre for Medium Range Weather Forecasts, Reading, United Kingdom 
Isaksen, K., Norwegian Meteorological Institute, Blindern, Oslo, Norway John, Viju, EUMETSAT, Darmstadt, Germany

Jones, Philip D., Climatic Research Unit, School of Environmental Sciences, University of East Anglia, Norwich, United Kingdom

Kaiser, J. W., Deutscher Wetterdienst, Offenbach, Germany

Kelly, S., Dundalk Institute of Technology, Dundalk, Ireland

Khaykin, S., LATMOS/IPSL, UVSQ, Sorbonne Université, CNRS, Guyancourt, France

Kidd, R., Earth Observation Data Centre GmbH, Vienna, Austria

Kim, Hyungiun, Institite of Industrial Science, The University of Tokyo, Tokyo, Japan

Kipling, Z., European Centre for Medium-Range Weather Forecasts, Reading, United Kingdom

Kraemer, B. M., IGB Leibniz Institute for Freshwater Ecology and Inland Fisheries, Berlin, Germany

Kratz, D. P., NASA Langley Research Center, Hampton, Virginia

La Fuente, R. S., Dundalk Institute of Technology, Dundalk, Ireland

Lan, Xin, Cooperative Institute for Research in Environmental Sciences, University of Colorado Boulder, and NOAA/OAR Earth System Research Laboratories, Boulder, Colorado

Lantz, Kathleen 0., NOAA/OAR Earth System Research Laboratory, and Cooperative Institute for Research in the Environmental Sciences, University of Colorado, Boulder, Colorado

Leblanc, T., Jet Propulsion Laboratory, California Institute of Technology, Wrightwood, California

Li, Bailing, Hydrological Sciences Laboratory, NASA Goddard Space Flight Center, Greenbelt, Maryland, USA; Earth System Science Interdisciplinary Center, University of Maryland, College Park, Maryland

Loeb, Norman G., NASA Langley Research Center, Hampton, Virginia

Long, Craig S., NOAA/NWS National Centers for Environmental Prediction, College Park, Maryland

Loyola, Diego, German Aerospace Center (DLR) Oberpfaffenhofen, Wessling, Germany

Marszelewski, Wlodzimierz, Department of Hydrology and Water Management, Nicolaus Copernicus University, Toruń, Poland

Martens, B., Hydro-Climate Extremes Lab (H-CEL), Ghent University, Ghent, Belgium

May, Linda, Centre for Ecology \& Hydrology, Edinburgh, United Kingdom

Mayer, Michael, Department of Meteorology and Geophysics, University of Vienna, Austria; European Centre for Medium-Range Weather Forecasts, Reading, United Kingdom

McCabe, M. F., Division of Biological and Environmental Sciences and Engineering, King Abdullah University of Science and Technology, Thuwal, Saudi Arabia

McVicar, Tim R., CSIRO Land and Water, Canberra, Australian Capital Territory; and Australian Research Council Centre of Excellence for Climate Extremes, Sydney, New South Wales, Australia

Mears, Carl A., Remote Sensing Systems, Santa Rosa, California

Menzel, W. Paul, Space Science and Engineering Center, University of Wisconsin-Madison, Madison, Wisconsin

Merchant, Christopher J., Department of Meteorology, and National Centre for Earth Observation, University of Reading, Reading, United Kingdom

Miller, Ben R., Cooperative Institute for Research in Environmental Sciences, University of Colorado Boulder, and NOAA/OAR Earth System Research Laboratories, Boulder, Colorado

Miralles, Diego G., Hydro-Climate Extremes Lab (H-CEL), Ghent University, Ghent, Belgium

Montzka, Stephen A., NOAA/OAR Earth System Research Laboratories, Boulder, Colorado
Morice, Colin, Met Office Hadley Centre, Exeter, United Kingdom

Mühle, Jens, Scripps Institution of Oceanography, University of California, San Diego, La Jolla, California

Myneni, R., Department of Earth and Environment, Boston University, Boston, Massachusetts

Nicolas, Julien P., European Centre for Medium-Range Weather Forecasts, Reading, United Kingdom

Noetzli, Jeannette, WSL Institute for Snow and Avalanche Research SLF, Davos-Dorf, Switzerland

Osborn, Tim J., Climatic Research Unit, School of Environmental Sciences, University of East Anglia, Norwich, United Kingdom

Park, T., NASA Ames Research Center, and Bay Area Environmental Research Institute, Moffett Field, California

Pasik, A., Department of Geodesy and Geoinformation, TU Wien - Vienna University of Technology, Vienna, Austria

Paterson, Andrew M., Dorset Environmental Science Centre, Ontario Ministry of the Environment and Climate Change, Dorset, Ontario, Canada

Pelto, Mauri S., Nichols College, Dudley, Massachusetts

Perkins-Kirkpatrick, S., University of New South Wales, Sydney, Australia

Pétron, G., Cooperative Institute for Research in Environmental Sciences, University of Colorado, and NOAA/OAR Global Monitoring Laboratory, Boulder, Colorado

Phillips, C., Department of Atmospheric and Oceanic Sciences, University of Wisconsin-Madison, Madison, Wisconsin

Pinty, Bernard, European Commission, Joint Research Centre, Ispra, Italy

Po-Chedley, S., Lawrence Livermore National Laboratory, Livermore, California

Polvani, L., Columbia University, New York, New York

Preimesberger, W., Department of Geodesy and Geoinformation, TU Wien Vienna University of Technology, Vienna, Austria

Pulkkanen, M., Finnish Environment Institute SYKE, Freshwater Centre, Helsinki, Finland.

Randel, W. J., National Center for Atmospheric Research, Boulder, Colorado

Rémy, Samuel, Institut Pierre-Simon Laplace, CNRS / UPMC, Paris, France

Ricciardulli, L., Remote Sensing Systems, Santa Rosa, California

Richardson, A. D., School of Informatics, Computing, and Cyber Systems and Center for Ecosystem Science and Society, Northern Arizona University, Flagstaff, Arizona

Rieger, L., University of Saskatchewan, Saskatoon, Canada

Robinson, David A., Department of Geography, Rutgers University, Piscataway, New Jersey

Rodell, Matthew, Hydrological Sciences Laboratory, NASA Goddard Space Flight Center, Greenbelt, Maryland

Rosenlof, Karen H., NOAA/OAR Earth System Research Laboratories, Boulder, Colorado

Roth, Chris, University of Saskatchewan, Saskatoon, Saskatchewan, Canada

Rozanov, A., University of Bremen, Bremen, Germany

Rusak, James A., Dorset Environmental Science Centre, Ontario Ministry of the Environment and Climate Change, Dorset, Ontario, Canada

Rusanovskaya, $\mathbf{0}$., Institute of Biology, Irkutsk State University, Russia

Rutishäuser, T., Institute of Geography and Oeschger Center, University of Berne, Berne, Switzerland

Sánchez-Lugo, Ahira, NOAA/NESDIS National Centers for Environmental Information, Asheville, North Carolina

Sawaengphokhai, P., Science Systems and Applications, Inc., Hampton, Virginia

Scanlon, T., Department of Geodesy and Geoinformation, TU Wien - Vienna University of Technology, Vienna, Austria

Schenzinger, Verena, Department of Meteorology and Geophysics, University of Vienna, Austria 
Schladow, S. Geoffey, Tahoe Environmental Research Center, University of California at Davis, Davis, California

Schlegel, R. W., Physical Oceanography Department, Woods Hole Oceanographic Institution, Woods Hole, Massachusetts

Schmid, Martin, Eawag, Swiss Federal Institute of Aquatic Science and Technology, Kastanienbaum, Switzerland

Selkirk, H. B., Universities Space Research Association, NASA Goddard Space Flight Center, Greenbelt, Maryland

Sharma, S., York University, Toronto, Ontario, Canada

Shi, Lei, NOAA/NESDIS, National Centers for Environmental Information, Asheville, North Carolina

Shimaraeva, S. V., Institute of Biology, Irkutsk State University, Russia

Silow, E. A., Institute of Biology, Irkutsk State University, Russia

Simmons, Adrian J., European Centre for Medium-Range Weather Forecasts, Reading, United Kingdom

Smith, C. A., Cooperative Institute for Research in Environmental Sciences, University of Colorado Boulder, and Physical Sciences Laboratory, NOAA/ Earth System Research Laboratories, Boulder, Colorado

Smith, Sharon L., Geological Survey of Canada, Natural Resources Canada, Ottawa, Ontario, Canada

Soden, B. J., Rosenstiel School of Marine and Atmospheric Science, University of Miami, Key Biscayne, Florida

Sofieva, Viktoria, Finnish Meteorological Institute (FMI), Helsinki, Finland

Sparks, T. H., Poznań University of Life Sciences, Poznań, Poland

Stackhouse, Jr., Paul W., NASA Langley Research Center, Hampton, Virginia

Stanitski, Diane M., NOAA/OAR Earth System Research Laboratories, Boulder, Colorado

Steinbrecht, Wolfgang, German Weather Service (DWD), Hohenpeissenberg, Germany

Streletskiy, Dimitri A., Department of Geography George Washington University, Washington D.C.

Taha, G., GESTAR, Columbia, Maryland

Telg, Hagen, NOAA/OAR Earth System Research Laboratories and Cooperative Institute for Research in the Environmental Sciences, University of Colorado, Boulder, Colorado

Thackeray, S. J., Centre for Ecology and Hydrology, Lancaster, United Kingdom

Timofeyev, M. A., Institute of Biology, Irkutsk State University, Russia

Tourpali, Kleareti, Aristotle University, Thessaloniki, Greece

Tye, Mari R., Capacity Center for Climate and Weather Extremes (C3WE), National Center for Atmospheric Research, Boulder, Colorado

van $\operatorname{der}$ A, Ronald J., Royal Netherlands Meteorological Institute (KNMI), De Bilt, Netherlands van der Schalie, Robin, VanderSat B.V., Haarlem, Netherlands

van der Schrier, Gerard, Royal Netherlands Meteorological Institute (KNMI), De Bilt, Netherlands

van der Werf, Guido R., Vrije Universiteit Amsterdam, Amsterdam, Netherlands

Verburg, Piet, National Institute of Water and Atmospheric Research, Hamilton, New Zealand

Vernier, Jean-Paul, NASA Langley Research Center, Hampton, Virginia

Vömel, Holger, Earth Observing Laboratory, National Center for Atmospheric Research, Boulder, Colorado

Vose, Russell S., NOAA/NESDIS National Centers for Environmental Information, Asheville, North Carolina

Wang, Ray, Georgia Institute of Technology, Atlanta, Georgia

Watanabe, Shohei G., Tahoe Environmental Research Center, University of California at Davis, Davis, California

Weber, Mark, University of Bremen, Bremen, Germany

Weyhenmeyer, Gesa A., Department of Ecology and Genetics/Limnology, Uppsala University, Uppsala, Sweden

Wiese, David, Jet Propulsion Laboratory, California Institute of Technology, Pasadena, California

Wilber, Anne C., Science Systems and Applications, Inc., Hampton, Virginia

Wild, Jeanette D., NOAA Climate Prediction Center, College Park, Maryland; ESSIC/University of Maryland, College Park, Maryland

Willett, Kate M., Met Office Hadley Centre, Exeter, United Kingdom

Wong, Takmeng, NASA Langley Research Center, Hampton, Virginia

Woolway, R. Iestyn, Dundalk Institute of Technology, Dundalk, Ireland

Yin, Xungang, ERT Inc., NOAA/NESDIS National Centers for Environmental Information, Asheville, North Carolina

Zhao, Lin, School of Geographical Sciences, Nanjing University of Information Science \& Technology, Nanjing, China

Zhao, Guanguo, University of Illinois at Urbana-Champaign, Champaign, Illinois

Zhou, Xinjia, Center for Satellite Applications and Research, NOAA, College Park, Maryland

Ziemke, Jerry R., Goddard Earth Sciences Technology and Research, Morgan State University, Baltimore, Maryland, and NASA Goddard Space Flight Center, Greenbelt, Maryland

Ziese, Markus, Global Precipitation Climatology Center, Deutscher Wetterdienst, Offenbach am Main, Germany

\section{Editorial and Production Team}

Andersen, Andrea, Technical Editor, Innovative Consulting Management Services, LLC, NOAA/NESDIS National Centers for Environmental Information, Asheville, North Carolina

Griffin, Jessicca, Graphics Support, Cooperative Institute for Satellite Earth System Studies, North Carolina State University, Asheville, North Carolina

Hammer, Gregory, Content Team Lead, Communications and Outreach, NOAA/NESDIS National Centers for Environmental Information, Asheville, North Carolina

Love-Brotak, S. Elizabeth, Lead Graphics Production, NOAA/NESDIS National Centers for Environmental Information, Asheville, North Carolina
Misch, Deborah J., Graphics Support, Innovative Consulting Management Services, LLC, NOAA/NESDIS National Centers for Environmental Information, Asheville, North Carolina

Riddle, Deborah B., Graphics Support, NOAA/NESDIS National Centers for Environmental Information, Asheville, North Carolina

Veasey, Sara W., Visual Communications Team Lead, Communications and Outreach, NOAA/NESDIS National Centers for Environmental Information, Asheville, North Carolina 


\section{Table of Contents}

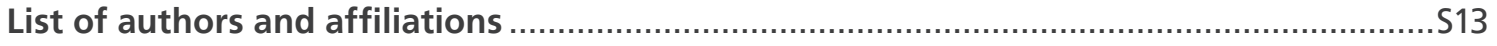

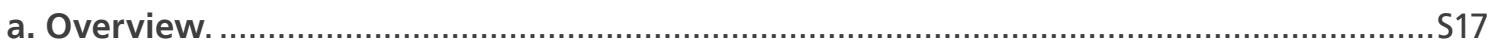

b. Temperature

1. Global surface temperature ...................................................................... S24

2. Lake surface temperature......................................................................... S26

3. Land and marine temperature extremes ..................................................... S28

4. Tropospheric temperature .......................................................................... 330

5. Stratospheric temperature ........................................................................ 332

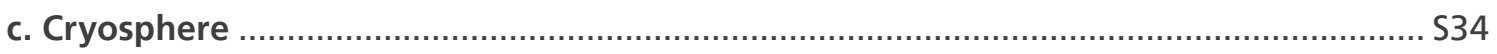

1. Permafrost thermal state........................................................................... S34

2. Northern Hemisphere snow cover extent ……….......................................... 336

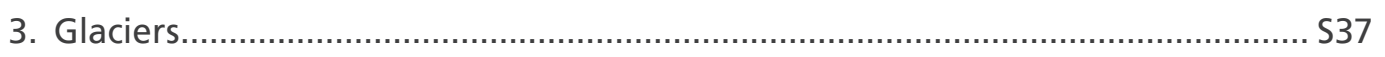

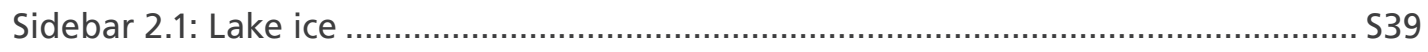

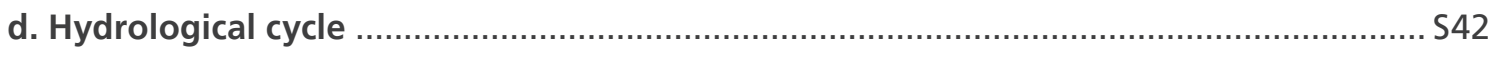

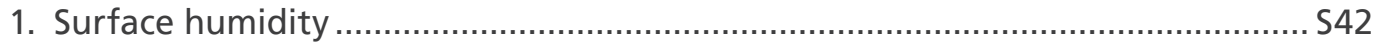

2. Total column water vapor ............................................................................ $\mathrm{S} 44$

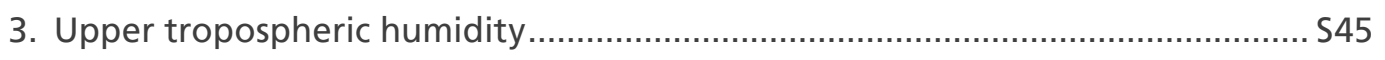

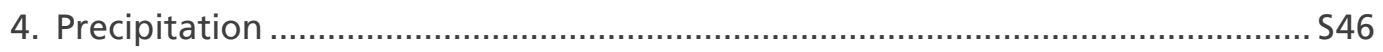

5. Land surface precipitation extremes ............................................................ S47

6. Lake water levels ...................................................................................... $\$$

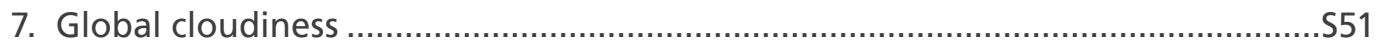

8. River discharge and runoff............................................................................ S53

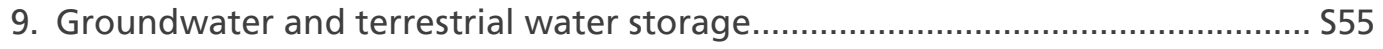

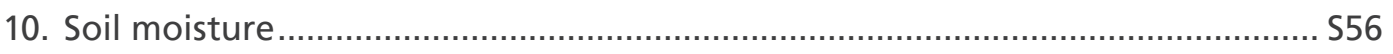

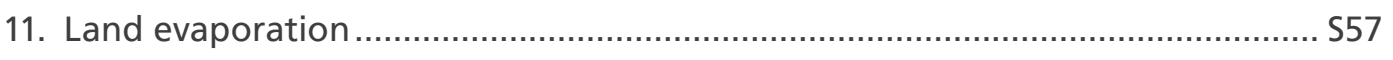

12. Monitoring global drought using the self-calibrating
Palmer Drought Severity Index ................................................................ 559

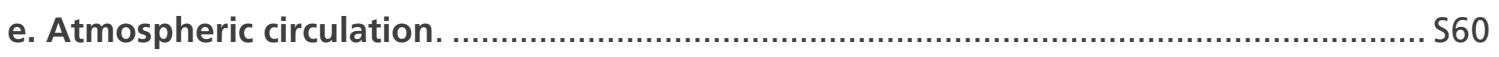

1. Mean sea level pressure and related modes of variability ................................. $S 60$

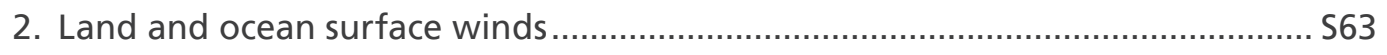

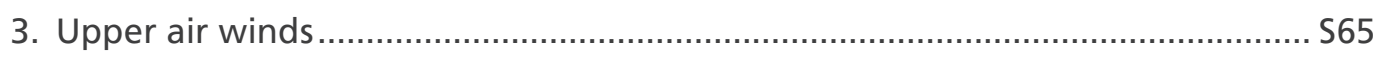

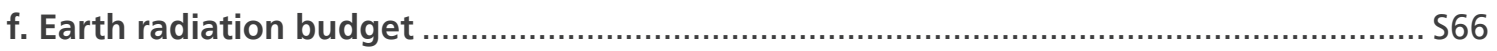

1. Earth radiation budget at top of atmosphere .................................................... 566

2. Mauna Loa clear-sky "apparent" solar transmission .......................................... S69 


\section{Table of Contents}

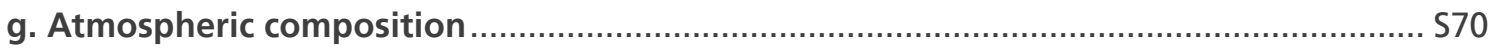

1. Long-lived greenhouse gases.................................................................... S70

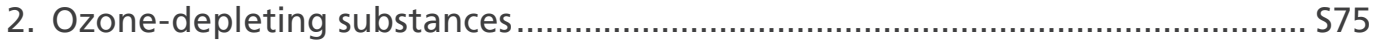

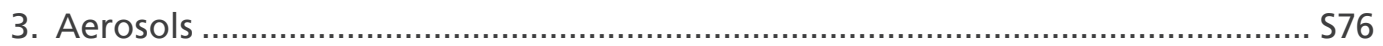

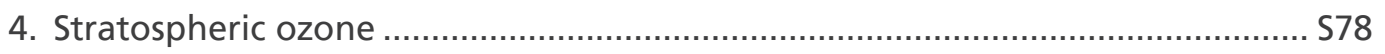

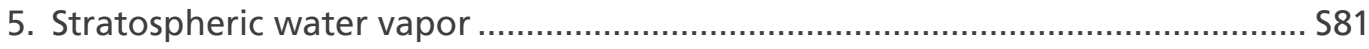

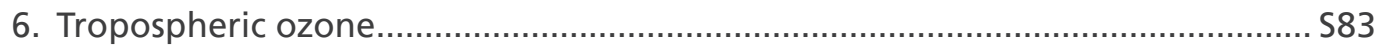

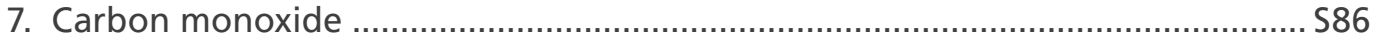

Sidebar 2.2: 2019: A 25-year high in global stratospheric aerosol loading .................. S88

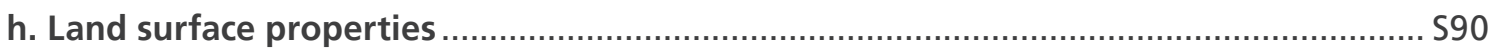

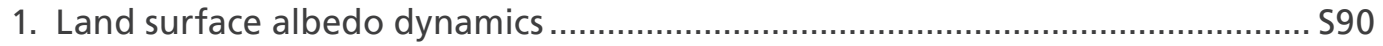

2. Terrestrial vegetation dynamics ................................................................ $\mathrm{S} 92$

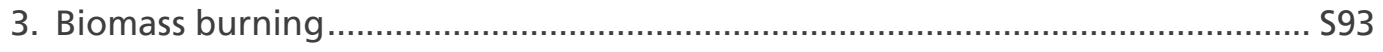

4. Phenology of primary producers ................................................................. $\mathrm{S} 95$

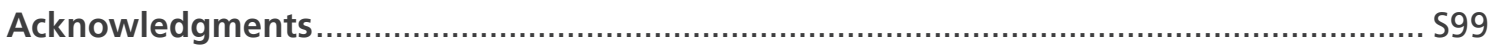

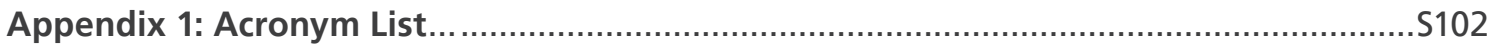

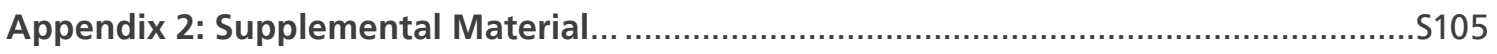

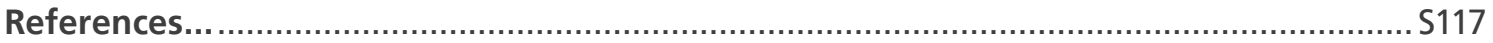

*Please refer to Chapter $\mathbf{8}$ (Relevant datasets and sources) for a list of all climate variables and datasets used in this chapter for analyses, along with their websites for more information and access to the data. 


\section{GLOBAL CLIMATE}

R. J. H. Dunn, D. M. Stanitski, N. Gobron, and K. M. Willett, Eds.

\section{a. Overview—R. J. H. Dunn, D. M. Stanitski, N. Gobron, and K. M. Willett}

The assessments and analyses presented in this chapter focus predominantly on the measured differences of climate and weather observables from previous conditions, years, and decades to place 2019 in context. Many of these differences have direct impacts on people, for example, their health and environment, as well as the wider biosphere, but are beyond the scope of these analyses.

For the last few State of the Climate reports, an update on the number of warmer-than-average years has held no surprises, and this year is again no different. The year 2019 was among the three warmest years since records began in the mid-to-late 1800s. Only 2016, and for some datasets 2015, were warmer than 2019; all years after 2013 have been warmer than all others back to the mid-1800s. Each decade since 1980 has been successively warmer than the preceding decade, with the most recent (2010-19) being around $0.2^{\circ} \mathrm{C}$ warmer than the previous (2000-09).

This warming of the land and ocean surface is reflected across the globe. For example, lake and permafrost temperatures have increased; glaciers have continued to lose mass, becoming thinner for the 32nd consecutive year, with the majority also becoming shorter during 2019. The period during which Northern Hemisphere $(\mathrm{NH})$ lakes were covered in ice was seven days shorter than the 1981-2010 long-term average, based on in situ phenological records. There were fewer cool extremes and more warm extremes on land; regions including Europe, Japan, Pakistan, and India all experienced heat waves. More strong than moderate marine heat waves were recorded for the sixth consecutive year. And in Australia (discussed in more detail in section 7h4), moisture deficits and prolonged high temperatures led to severe impacts during late austral spring and summer, including devastating wildfires. Smoke from these wildfires was detected across large parts of the Southern Hemisphere (SH).

The year 2019 was also one of the three warmest above Earth's surface and within the troposphere, while middle and upper stratospheric temperatures were at their lowest recorded values since 1979, as is expected because of the increasing concentration of greenhouse gases in the atmosphere.

The continuing warm conditions also influenced water around the globe, with atmospheric water vapor (specific humidity) being high over the ocean surface (one of the moistest years on record) and also aloft, and well above average near the land surface. However, in terms of saturation (relative humidity), the atmosphere was very dry near the land surface, setting a new record low for the global average, and about average over the ocean surface and aloft. There were strong hemispheric differences in soil moisture anomalies with, on average, negative anomalies in the south and positive anomalies in the north. Globally, the second half of 2019 saw an increase in the land area experiencing drought to higher, but not record, levels by the end of the year, but annual precipitation amounts were around average, with regional peaks in intense rainfall from, for example, Cyclones Idai and Kenneth in southeastern Africa.

Many climate events in Africa, Asia, and Australia were influenced by the strong positive Indian Ocean dipole (IOD), while the weak-to-neutral prolonged El Niño-Southern Oscillation (ENSO) conditions during 2019 appeared to have only limited impacts. 
As a primary driver for our changing climate, the abundance of many long-lived greenhouse gases continues to increase. Globally averaged $\mathrm{CO}_{2}$ at Earth's surface reached $409.8 \pm 0.1 \mathrm{ppm}$, a $2.5 \pm 0.1 \mathrm{ppm}$ increase from 2018; and $\mathrm{CH}_{4}$ reached $1866.6 \pm 0.9 \mathrm{ppb}$ in 2019, a 9.2 \pm 0.9 ppb increase from 2018, which is among the three largest annual increases (with 2014 and 2015) since 2007, when a rapid rise in methane concentration began. The mean global atmospheric $\mathrm{N}_{2} \mathrm{O}$ abundance in 2019 was $331.9 \pm 0.1 \mathrm{ppb}$, an increase of $1.0 \pm 0.2 \mathrm{ppb}$ from 2018. However, the atmospheric abundances of most ozone-depleting substances (ODS) are declining or leveling off, decreasing the stratospheric halogen loading and radiative forcing associated with ODS.

Stratospheric water vapor variability is strongly affected by the absolute humidity of air entering the stratosphere in the tropics, which is in turn largely determined by the temperature of the tropical cold point tropopause. Following 2018, a year in which lower stratospheric water vapor in the tropics dropped to a very low value ( $20 \%$ below the $2004-19$ average in December), water vapor abundance in the tropical lower stratosphere increased during 2019 to about 10\% above average in the latter half of the year.

Both hemispheric average and global average tropospheric ozone in 2019 indicate a continuing increase from previous years based on satellite measurements (starting year 2004) and surface measurements (starting in the mid-1970s). The largest trends in tropospheric ozone over the last 15 years occurred above India and East/Southeast Asia at a rate of $\sim+3.3 \mathrm{DU} \operatorname{decade}^{-1}\left(\sim+1 \% \mathrm{yr}^{-1}\right)$; these increases are consistent with expected increases of ozone precursor emissions across this region.

The year saw exceptional fire events over Australia, Indonesia, and parts of Siberia, but was also marked by lower amounts of dust over most of the Sahara. In the latter part of 2019, the Raikoke (Russia) and Ulawun (Papua New Guinea) volcanic eruptions and the large Australian wildfires loaded the stratosphere with aerosol levels unprecedented since the post-Mt. Pinatubo era 25 years ago. Despite this, 2019 was near-record warm at the surface.

The responses of the terrestrial biosphere to climatic conditions were also visible. Phenological land indicators show an average excess of eight days for the duration of the growing season in the NH in 2019 relative to the 2000-10 baseline. A deficit of plant productivity in the SH resulted in a lighter surface and hence higher albedo, whereas northern latitudes presented a darker surface and lower albedo, largely due to below-average snow cover. However, the rate of photosynthesis increased in eastern China with vegetation growth due to major human changes in land use.

New additions to this chapter in 2019 include lake water levels (last included in 2011) and sidebars on lake ice cover and stratospheric aerosols. Marine temperature extremes are also included this year alongside the land-surface indices, and we see the return of an update on the Mauna Loa solar transmission record.

Time series and anomaly maps for many of the variables described in this chapter are shown in Plates 1.1 and 2.1, respectively. A number of sections refer to supplemental figures that can be found in Appendix 2. 
(a) Surface Temperature

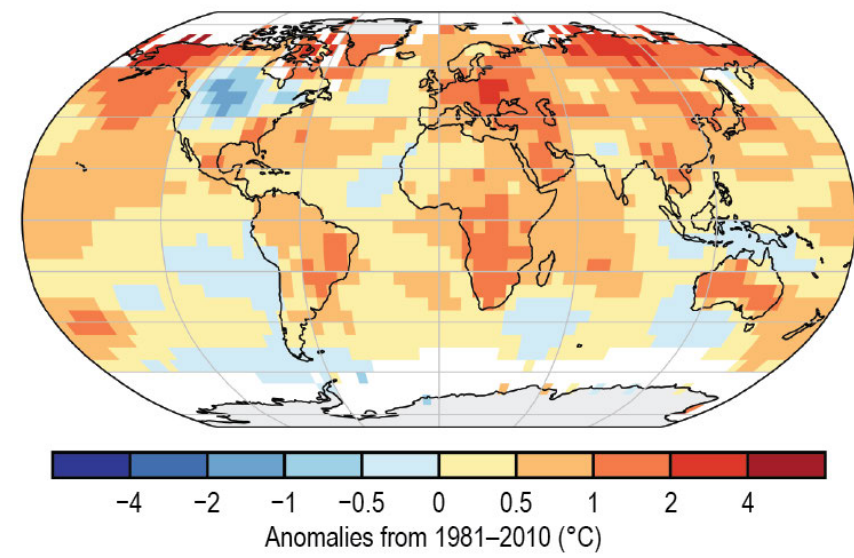

(c) Warm Days

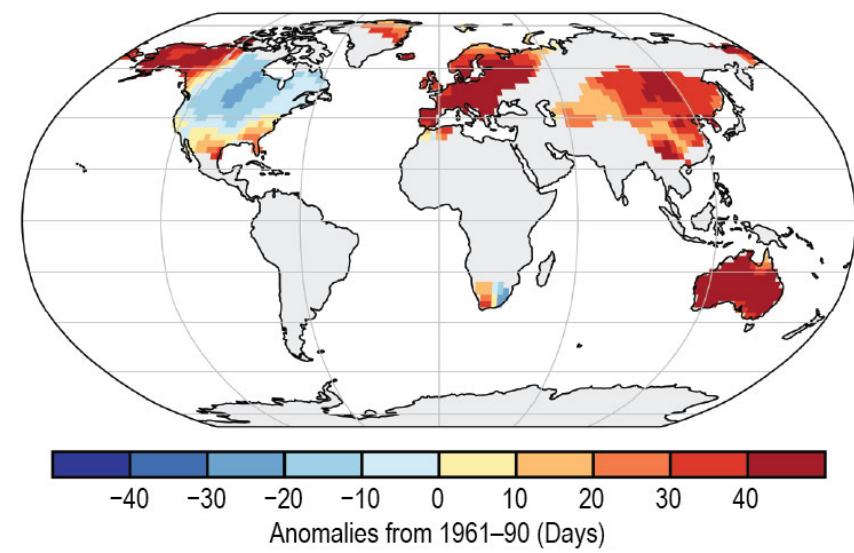

(e) Lower Tropospheric Temperature

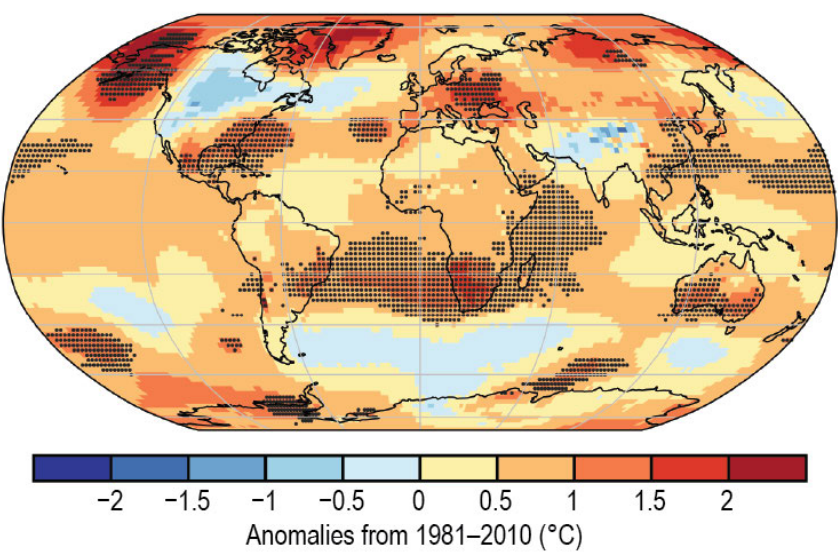

(g) Surface Specific Humidity

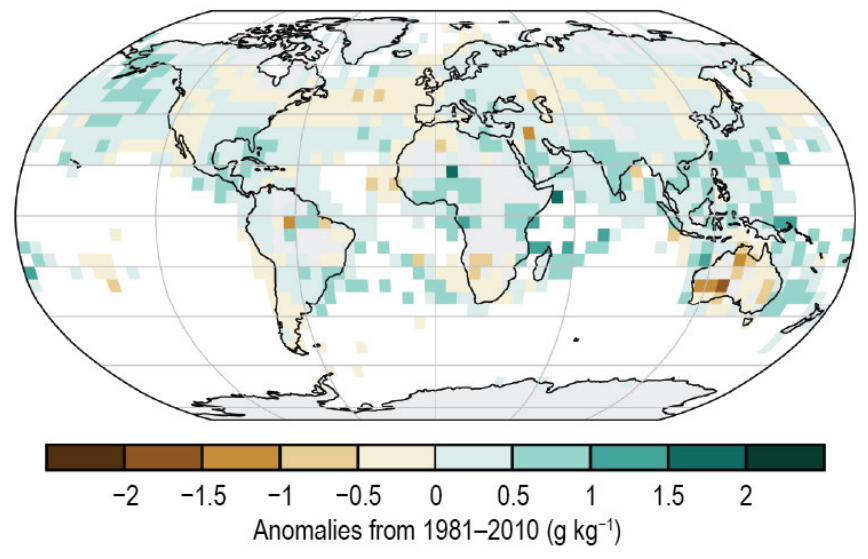

(b) Lake Temperatures

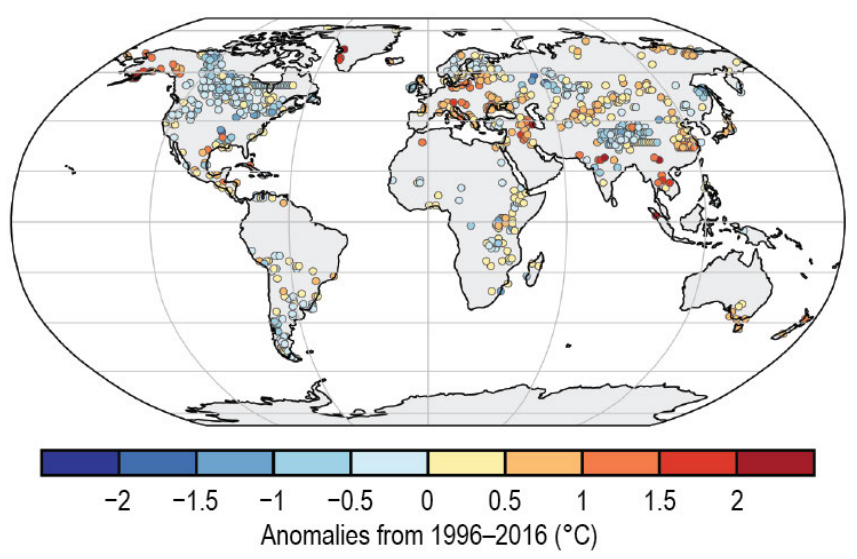

(d) Cool Nights

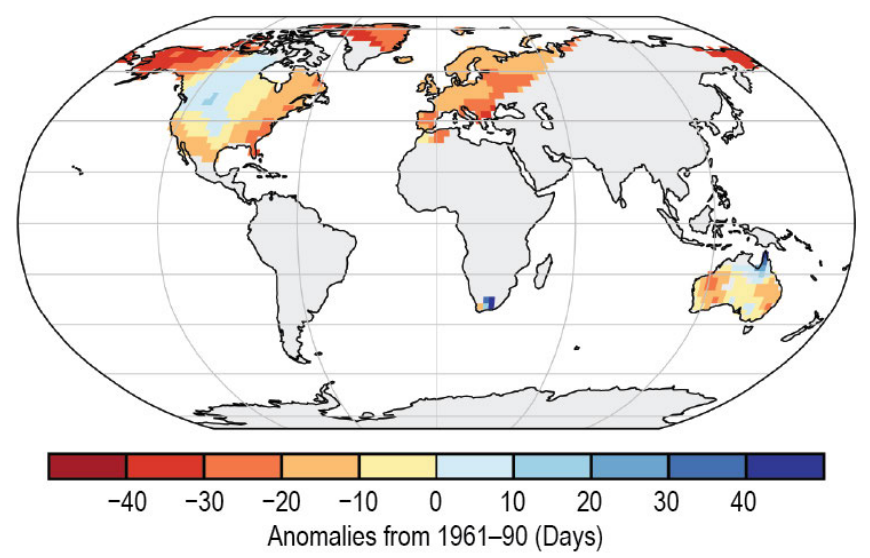

(f) Lower Stratospheric Temperature

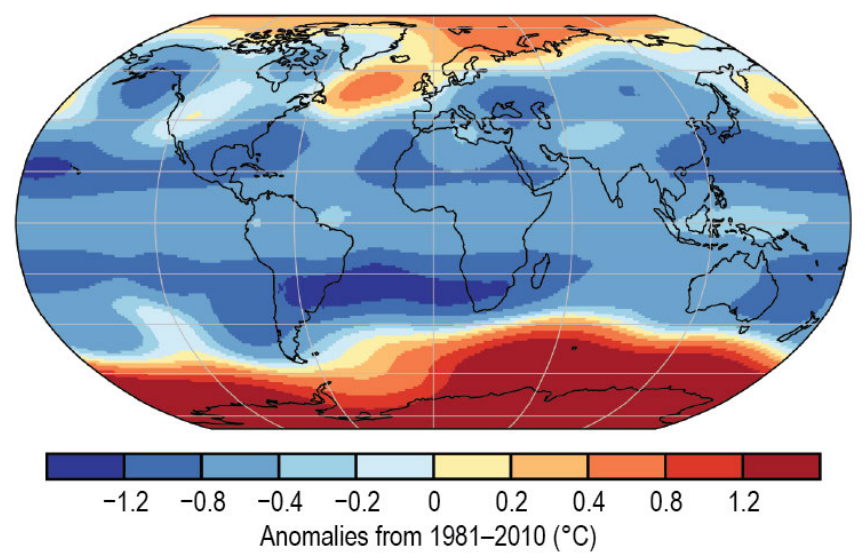

Plate 2.1. (a) NOAA NCEI Global land and ocean surface annual temperature anomalies $\left({ }^{\circ} \mathrm{C}\right)$; (b) Satellite-derived lake surface water temperature anomalies $\left({ }^{\circ} \mathrm{C}\right)$ in 2019 . The anomalies are calculated for the meteorological warm season (JJA in NH; DJF in $\mathrm{SH}$, and over Dec-Aug 2018/19 within $23.5^{\circ}$ of the equator). The longitude of some of the lakes has been shifted slightly to enable them to be displayed clearly. The latitude has been maintained; (c) GHCNDEX warm day threshold exceedance (TX90p); (d) GHCNDEX cool night threshold exceedance (TN10p); (e) ERA5 annual temperature anomalies of LTT $\left({ }^{\circ} \mathrm{C}\right)$. Stippling indicates grid points in which the 2019 value was the highest of the 41-year record; (f) ERA5 annual temperature anomalies of LST $\left({ }^{\circ} \mathrm{C}\right)$; $(\mathrm{g})$ HadISDH surface specific humidity anomalies $\left(\mathrm{g} \mathrm{kg}^{-1}\right)$; 
(h) Surface Relative Humidity

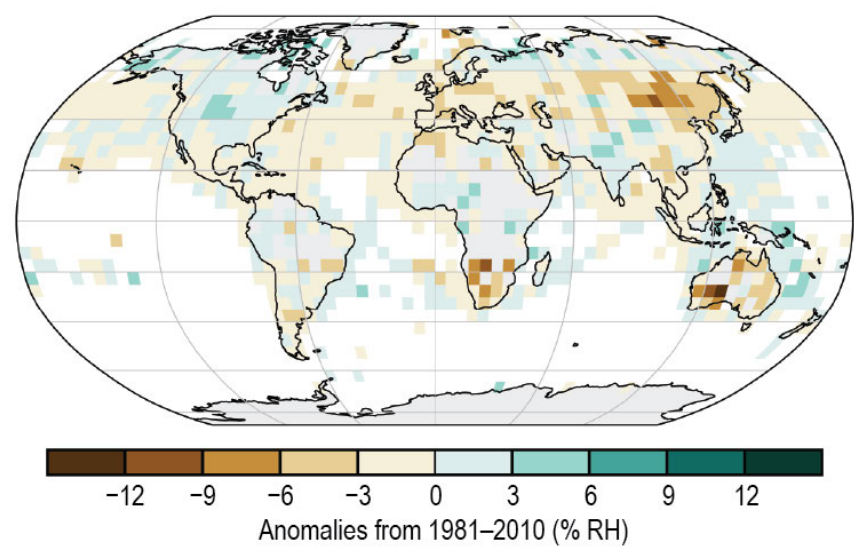

(j) Upper Tropospheric Humidity

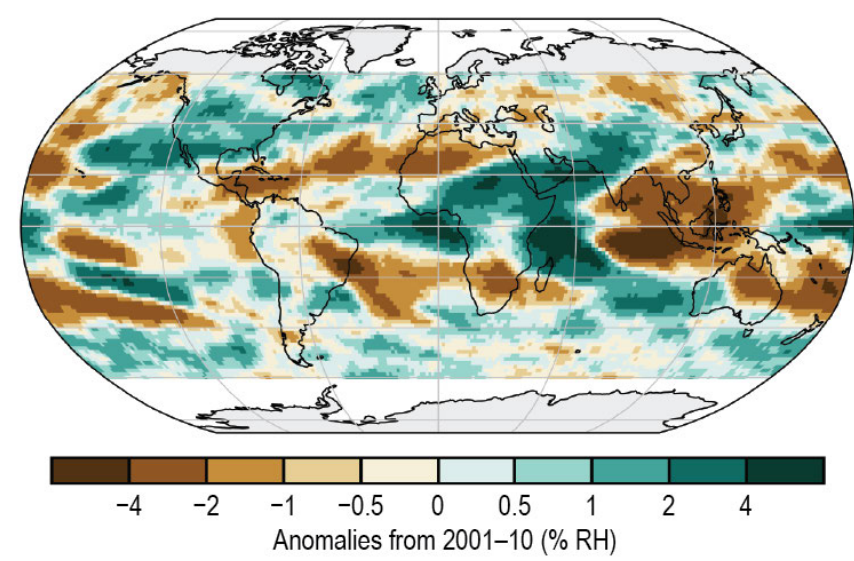

(I) R10mm

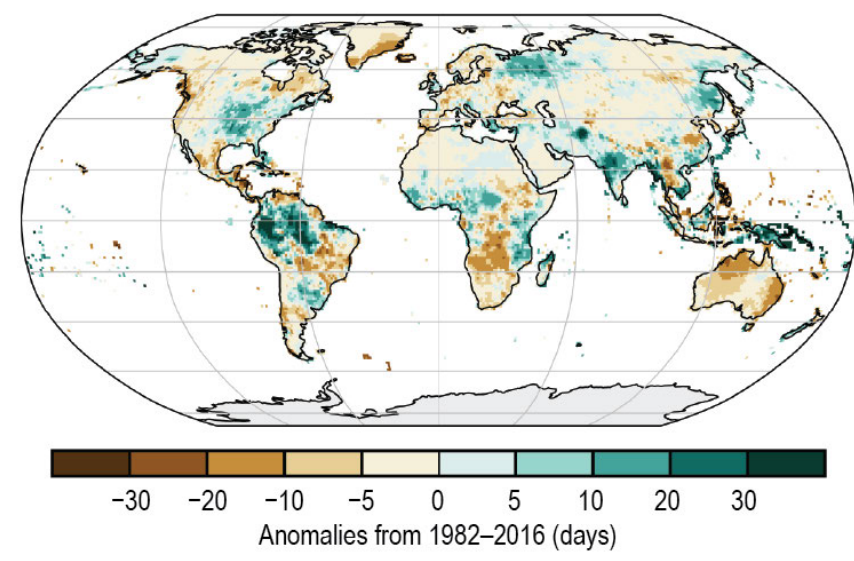

(n) Cloudiness

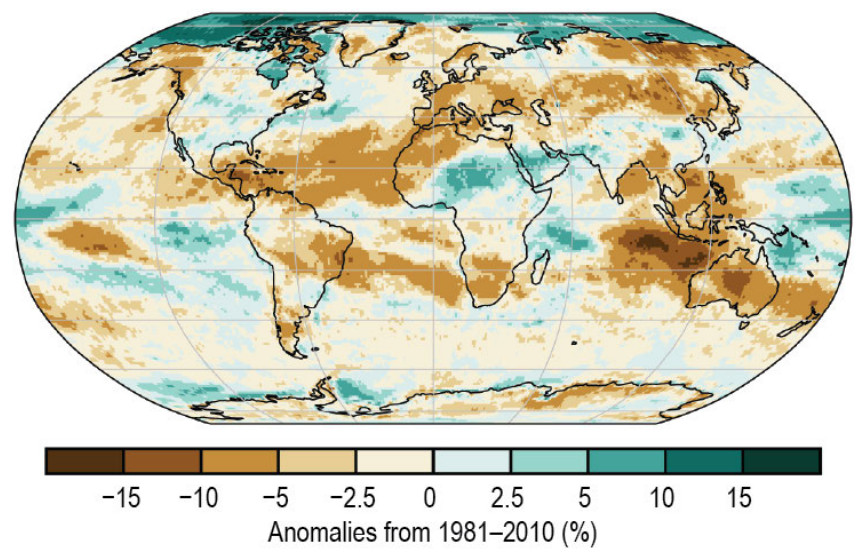

(i) Total Column Water Vapor

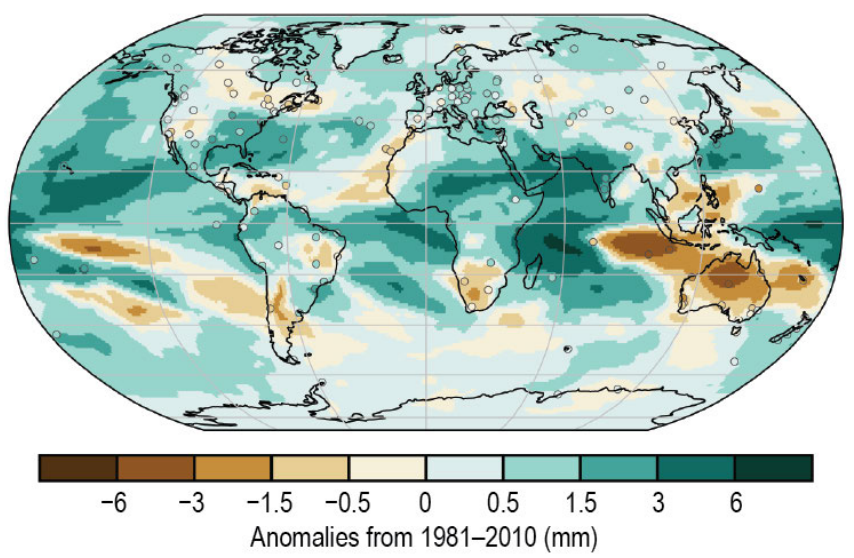

(k) Precipitation

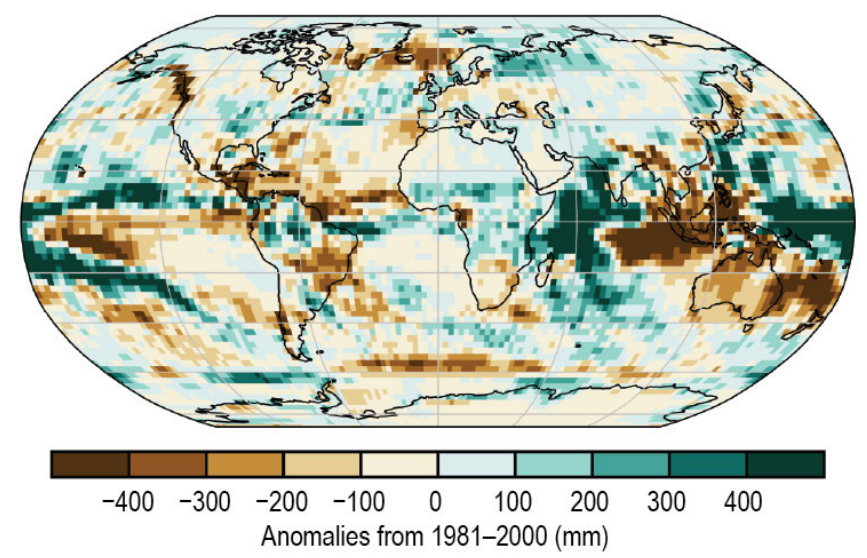

(m) Lake Water Level

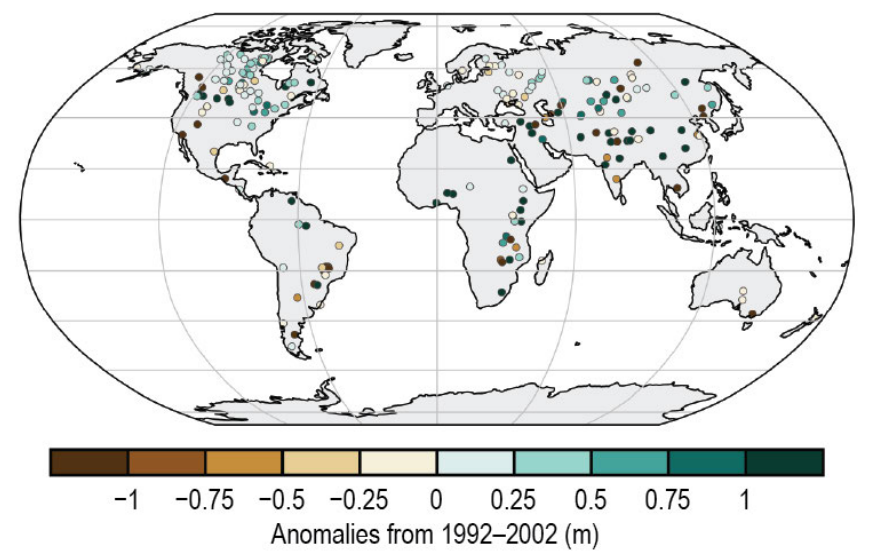

Plate 2.1. (cont.) (h) HadISDH surface relative humidity anomalies (\% RH); (i) ERA5 reanalysis of TCWV anomalies $(\mathrm{mm})$. Data from GNSS stations are plotted as filled circles; (j) "All sky" microwave-based UTH dataset annual average UTH anomalies (\% RH); (k) GPCP v2.3 annual mean precipitation anomalies for $2019\left(\mathrm{~mm} \mathrm{yr}^{-1}\right)$; (l) Anomalies for the 2019 GPCC-First Guess Daily R10mm index (days); (m) Lake water level anomalies (meters) based on satellite altimeters for 198 large lakes; (n) Global cloudiness anomalies (\%) generated from the 30-year PATMOS-x/AVHRR cloud climatology; 
(o) River Discharge

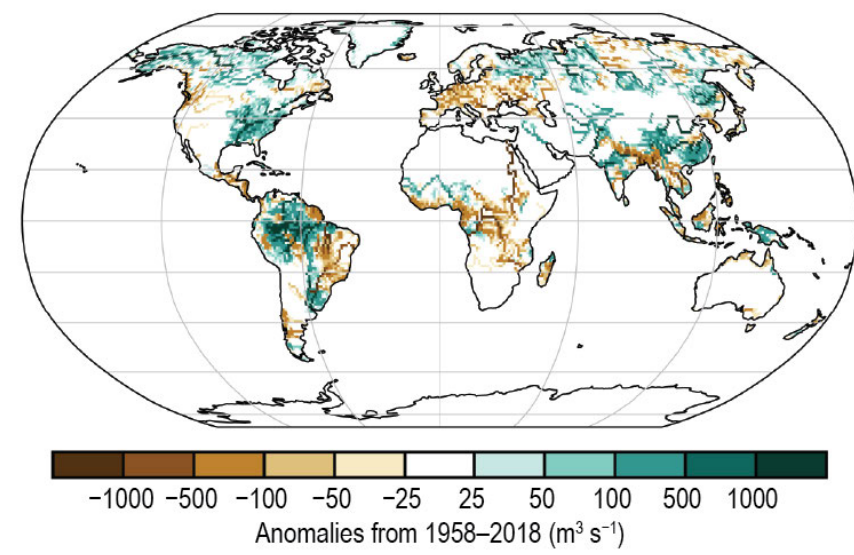

(q) Terrestrial Water Storage

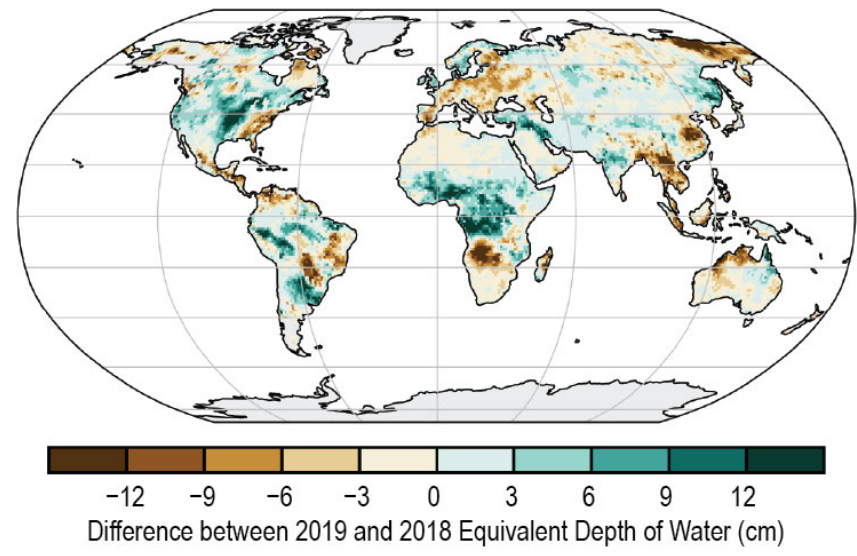

(s) Land Evaporation

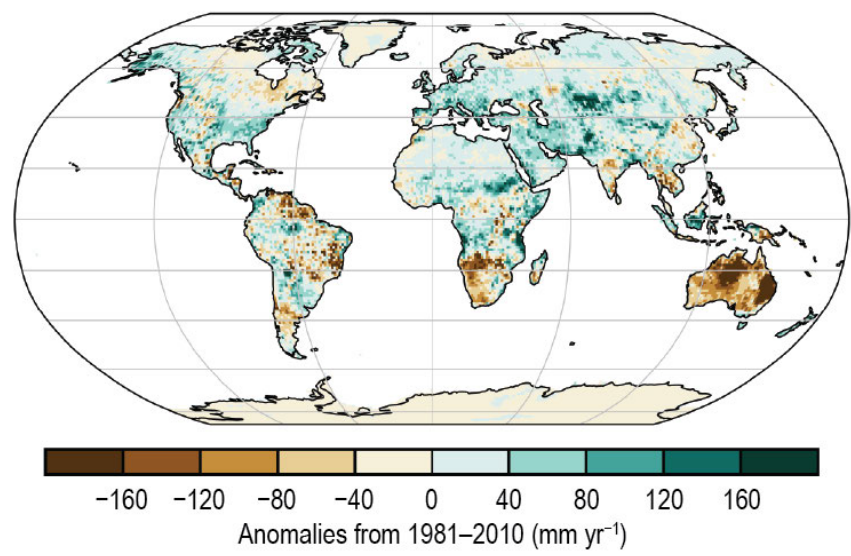

(p) Runoff

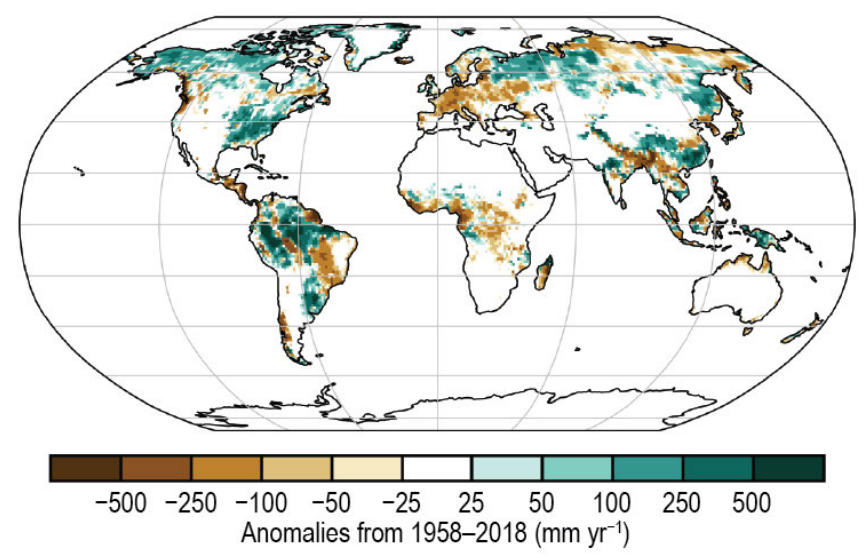

(r) Soil Moisture

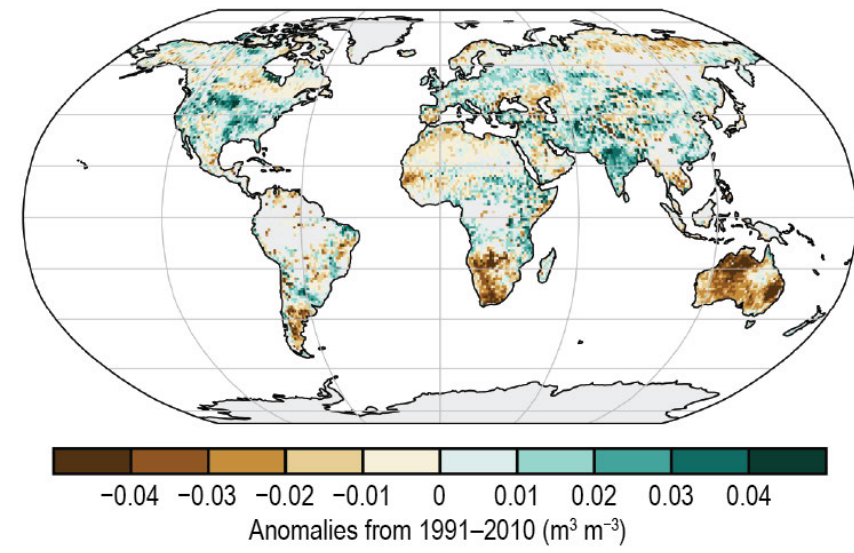

(t) Drought

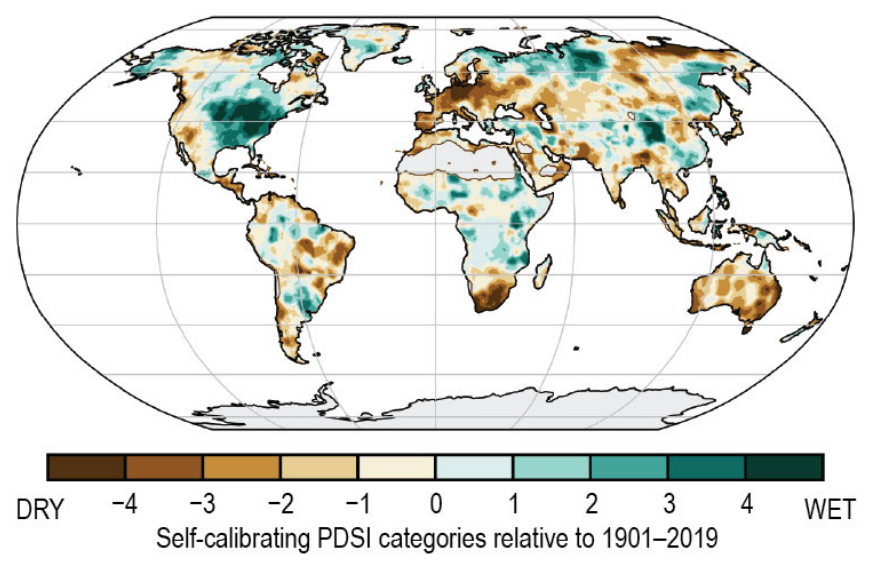

Plate 2.1. (cont.) (o) Global distribution of river discharge anomalies $\left(\mathrm{m}^{3} \mathrm{~s}^{-1}\right)$ from JRA-55; (p) Global distribution of runoff anomalies $\left(\mathrm{mm} \mathrm{yr}^{-1}\right)$ from JRA-55; (q) Changes in annual-mean terrestrial water storage (the sum of groundwater, soil water, surface water, snow, and ice, as an equivalent height of water in $\mathrm{cm}$ ) between 2018 and 2019, based on output from a GRACE and GRACE-FO data-assimilating land surface model. No data are shown over Greenland, Antarctica, the gulf coast of Alaska, parts of Patagonia, and most polar islands; (r) ESA CCI Soil Moisture average surface soil moisture anomalies $\left(\mathrm{m}^{3} \mathrm{~m}^{-3}\right)$. Data were masked as missing where retrievals are either not possible or of very low quality (dense forests, frozen soil, snow, ice, etc.); (s) GLEAM land evaporation anomalies ( $\left.\mathrm{mm} \mathrm{yr}^{-1}\right)$; ( $\mathrm{t}$ ) Mean scPDSI for 2019. Droughts are indicated by negative values (brown), wet episodes by positive values (green). No calculation is made where a drought index is meaningless (gray areas: ice sheets or deserts with approximately zero mean precipitation); 
(u) Sea Level Pressure

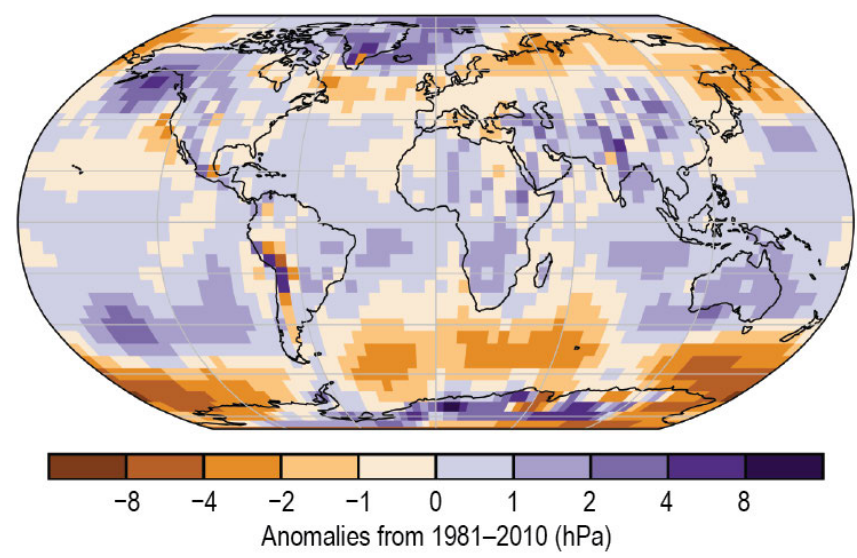

(w) Upper Air (850-hPa) Winds

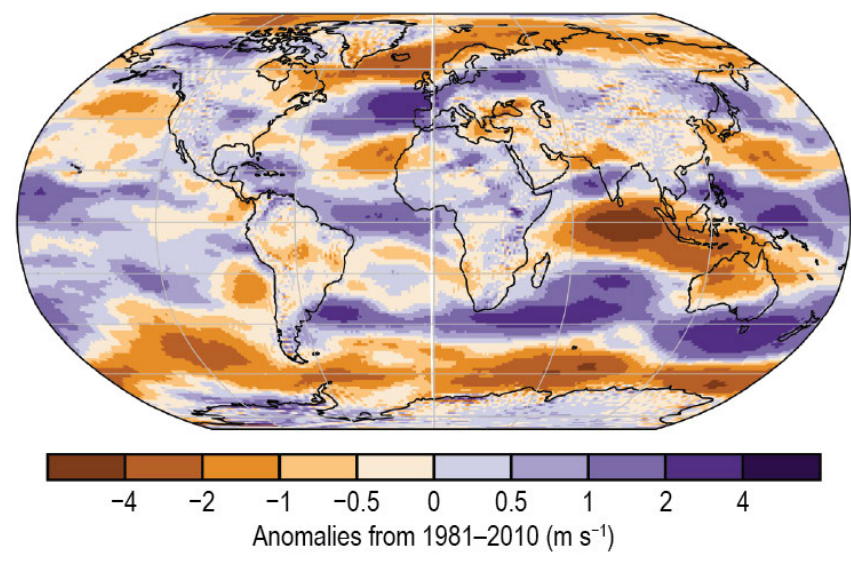

(y) Extreme Aerosol Days

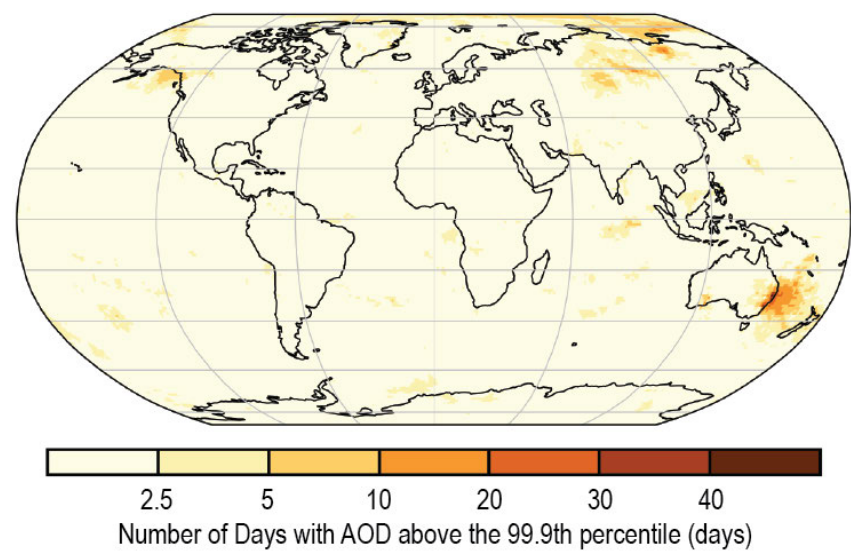

(v) Surface Winds

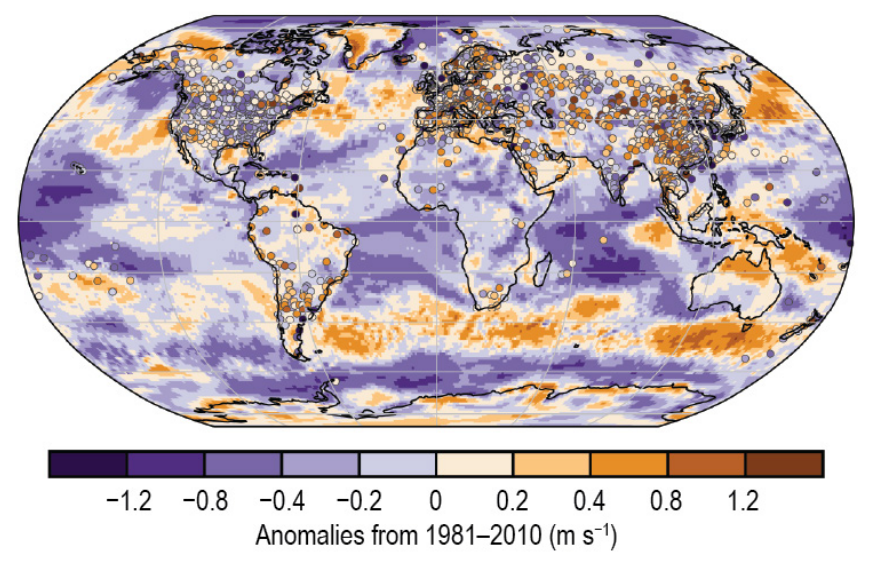

(x) Total Aerosol

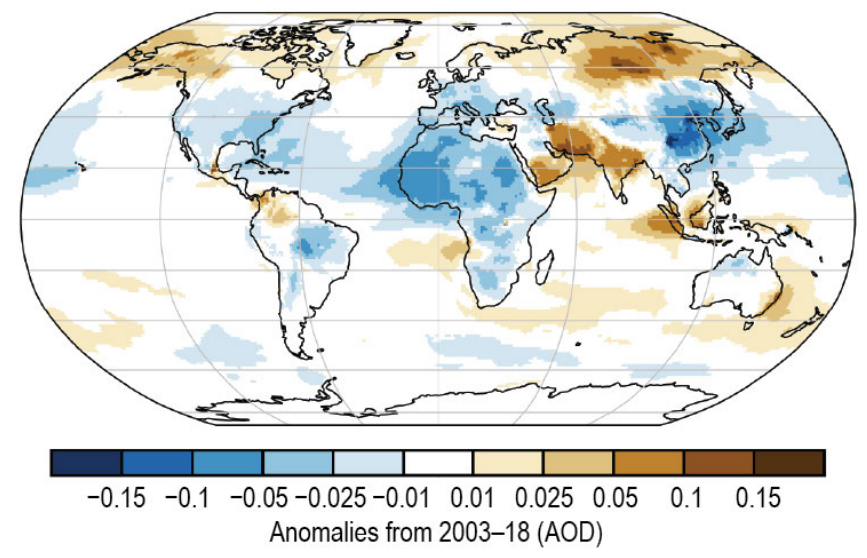

(z) Stratospheric (Total Column) Ozone

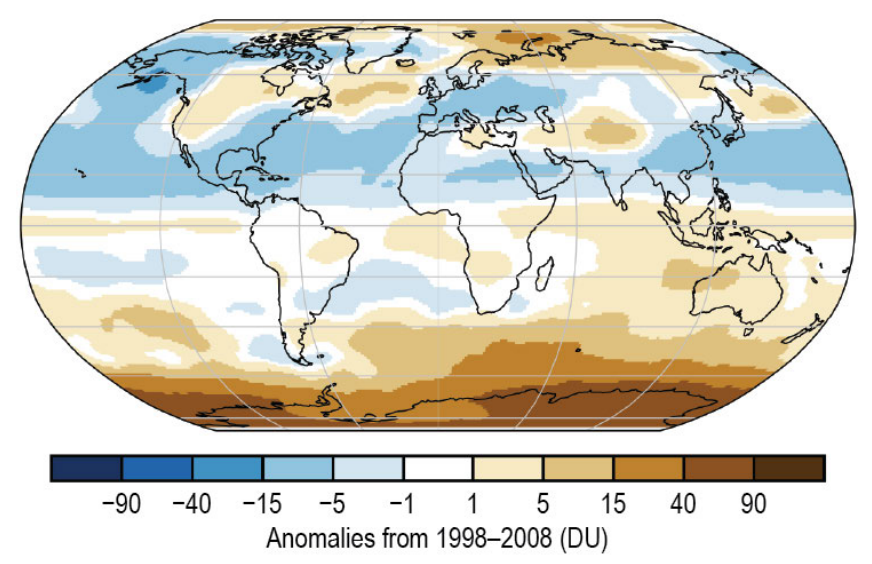

Plate 2.1. (cont.) (u) HadSLP2r surface pressure anomalies (hPa); (v) Surface wind speed anomalies $\left(\mathrm{m} \mathrm{s}^{-1}\right.$ ) from the observational HadISD3 dataset (land, circles), the MERRA-2 reanalysis output (land, shaded areas), and RSS satellite observations (ocean, shaded areas); (w) ERA5 Aug-Dec average 850-hPa eastward wind speed anomalies $\left(\mathrm{m} \mathrm{s}^{-1}\right)$; (x) Total aerosol optical depth (AOD) anomalies at $550 \mathrm{~nm}$; (y) Number of days with extremely high AOD (extreme being defined as above the local 99.9th percentile of the 2003-18 average; (z) Total column ozone anomalies (DU) in 2019 from Global Ozone Monitoring Experiment-2 (GOME-2A) measurements with respect to the 1998-2008 mean determined from the merged multi-sensor data combining GOME, SCIAMACHY, and GOME-2 (GSG, Weber et al. 2018); 
(aa) OMI/MLS Tropospheric Column Ozone

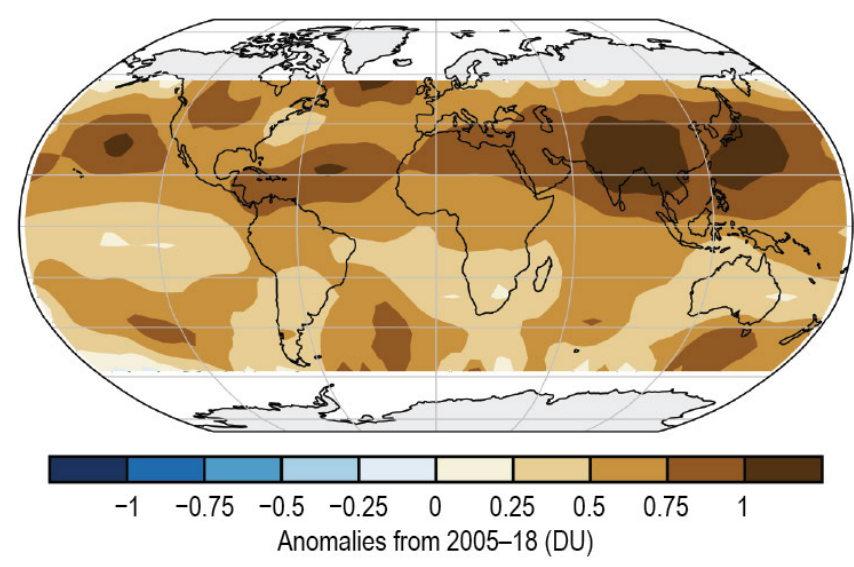

(ac) Land Surface Albedo in the Visible

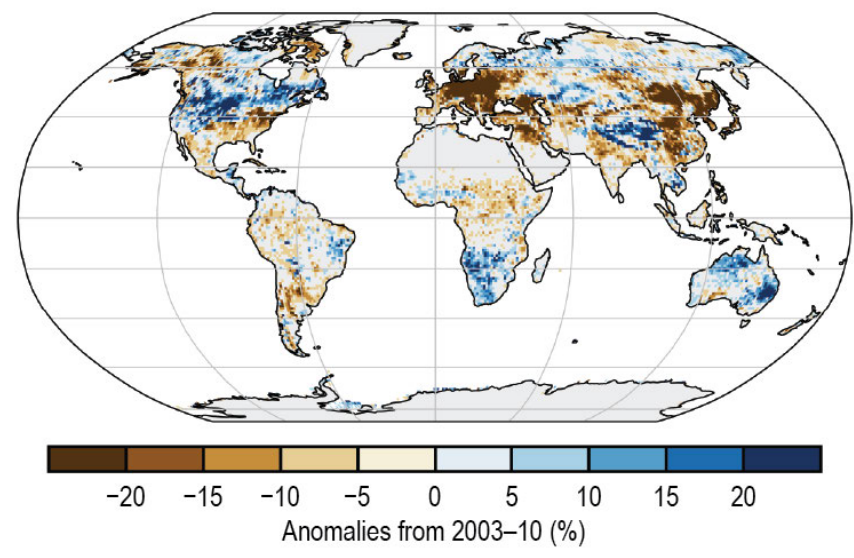

(ae) Fraction of Absorbed Photosynthetically Active Radiation

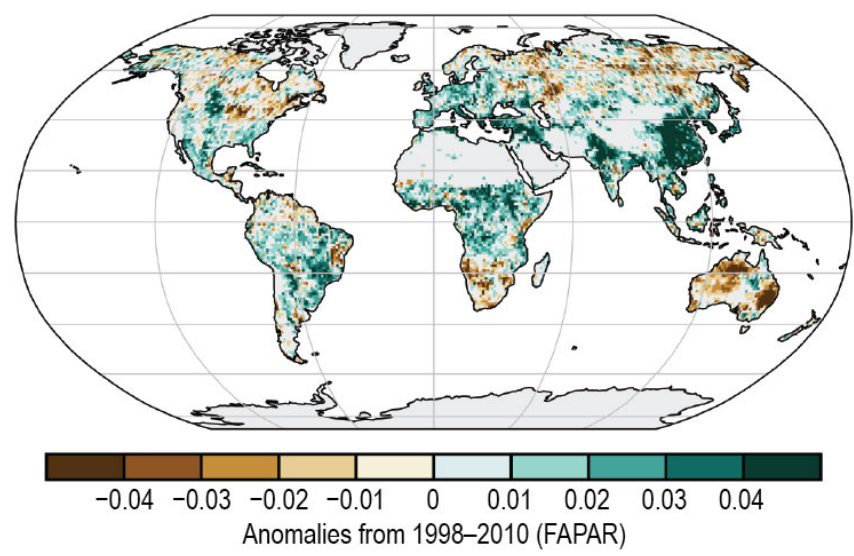

(ab) Carbon Monoxide

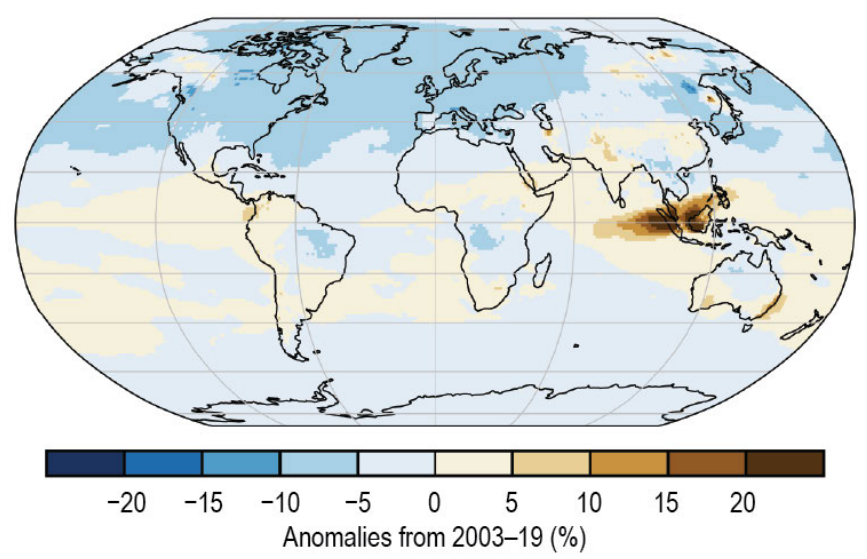

(ad) Land Surface Albedo in the Near-Infrared

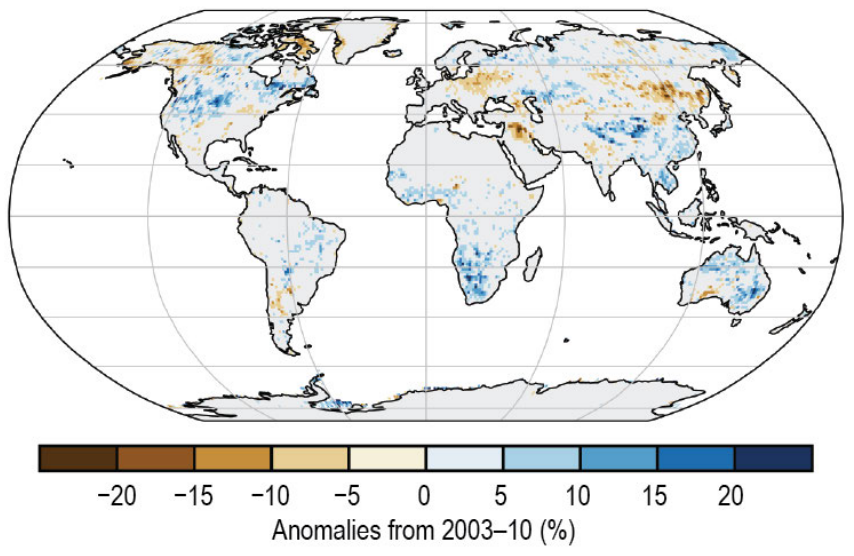

(af) Carbon Emissions from Biomass Burning

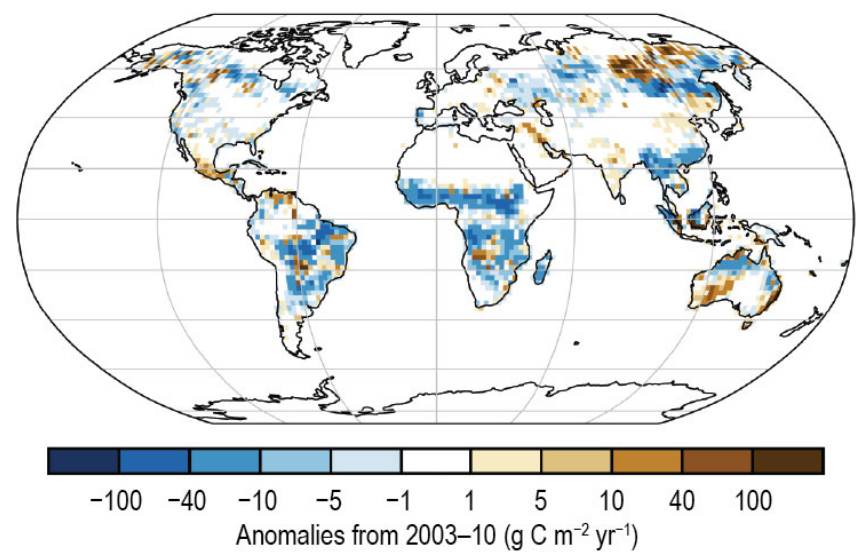

Plate 2.1. (cont.) (aa) Tropospheric ozone anomalies (DU) for 2019, relative to 2005-18 average, as detected by the OMI/MLS satellite instruments; (ab) CAMS reanalysis total column CO anomalies (\%); (ac) Land surface visible albedo anomalies (\%); (ad) Land surface near-infrared albedo anomalies (\%); (ae) FAPAR anomalies; (af) GFAS1.4 carbonaceous emission anomalies $\left(\mathrm{g} \mathrm{C} \mathrm{m}^{-2} \mathrm{yr}^{-1}\right)$ from biomass burning. 


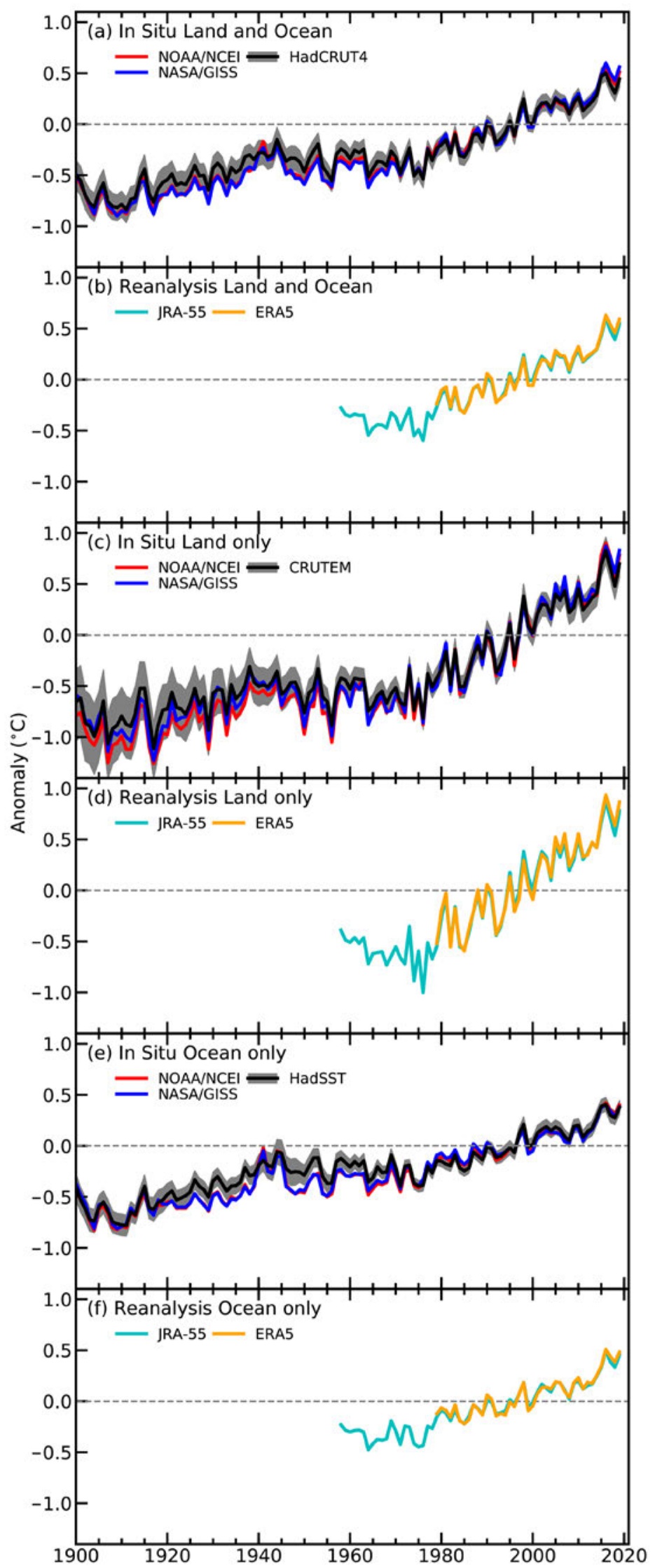

Fig. 2.1. Global average surface air temperature anomalies $\left({ }^{\circ} \mathrm{C}\right.$; 1981-2010 base period). In situ estimates are shown from NOAA/ NCEI (H.-M. Zhang et al. 2019), NASA-GISS (Lenssen et al. 2019), HadCRUT4 (Morice et al. 2012), CRUTEM4 (Jones et al. 2012), HadSST3 (Kennedy et al. 2011a,b). Reanalyses estimates are shown from ERA5 (Hersbach et al. 2020), and JRA-55 (Kobayashi et al. 2015).

\section{b. Temperature}

1) Global surface temperature-

A. Sánchez-Lugo, C. Morice, J. P. Nicolas, and A. Argüez

The 2019 global land and ocean surface temperature was $0.44^{\circ}-0.56^{\circ} \mathrm{C}$ above the 1981-2010 average (Table 2.1) and was among the three highest yearly temperatures since global records began in the mid-to-late $1800 \mathrm{~s}$ (Fig. 2.1), according to three independent in situ analyses (NASA-GISS, Lenssen et al. 2019; HadCRUT4, Morice et al. 2012; NOAAGlobalTemp, H.-M. Zhang et al. 2019). The NOAAGlobalTemp and NASA-GISS datasets ranked 2019 as the second-warmest year on record, just $0.04^{\circ} \mathrm{C}$ behind 2016. The HadCRUT4 dataset ranked 2019 as the third-warmest year, behind $2016\left(+0.50^{\circ} \mathrm{C}\right)$ and 2015 $\left(+0.47^{\circ} \mathrm{C}\right)$. A weak El Niño was present across the tropical Pacific Ocean at the start of the year (see section 4b). The presence of an El Niño (La Niña) typically has a warming (cooling) influence on global temperatures (e.g., Foster and Rahmstorf 2011). The El Niño transitioned to El Niño-Southern Oscillation (ENSO) neutral by mid-2019.

The three in situ global surface temperature analyses assessed here are derived from air temperatures observed at weather stations over land and sea surface temperatures (SSTs) observed from ships and buoys. Differences between analyses are mainly due to how each methodology treats areas with little to no data and how each analysis accounts for changes in measurement methods (for more details see Kennedy et al. [2010]; Hansen et al. [2010]; and Sánchez-Lugo et al. [2017]). Although each analysis differs in methodology, leading to minor differences in temperature anomalies and ranks, the three in situ datasets are overall in close agreement (Fig. 2.1), with an average rate of increase of $0.07^{\circ} \mathrm{C}$ per decade since 1880 and a little over double that rate at $0.18^{\circ}-0.19^{\circ} \mathrm{C}$ per decade since 1971 . The 
last six years (2014-19) were the six warmest years since global records began in the mid-to-late 1800 s, contributing to the warmest decade on record with a decadal temperature of $0.32^{\circ}-0.39^{\circ} \mathrm{C}$ above the 1981-2010 mean. Each decade since 1980 has been successively warmer than the preceding decade, with the 2010-19 decadal temperature departure from average surpassing the previous record warm decade of $2000-09$ by $0.15^{\circ}-0.22^{\circ} \mathrm{C}$.

While annual temperature rankings provide a simple measure of the state of global temperatures, a recently introduced global annual temperature score (Argüez et al. 2020) complements the annual temperature ranking by providing a basic characterization of the impacts of natural variability on global temperature relative to the sustained upward trend since the mid-1970s. Scores range from 1 to 10, with a score of 1 (10) indicating the coldest (warmest) 10\% of anomalies relative to the trend line. In an era of seemingly perpetual near-record warm rankings, the annual temperature scores can help characterize whether the annual temperature ranking attained in a given year was due primarily to continuation of the trend, natural variability, or both. For example, 2016 was not only the warmest year on record, but it also exhibited a temperature score of 10, whereas 2014 previously attained a ranking of warmest yet exhibits a temperature score of 4 (on the colder half of the scale). This indicates that, on top of the long-term upward trend, natural variability had a prominent contribution to the record temperature in 2016, whereas natural variability did not have a prominent contribution to 2014's previous record temperature. Using global annual time series from 1975 through 2019, the year 2019 registers a global annual temperature score of 9 (corresponding to the 80th to 90th percentile) in the NASA-GISS and NOAAGlobalTemp datasets and a score of 7 (60th to 70th percentile) in the HadCRUT4 dataset. This indicates that 2019 was moderately-to-considerably warmer than we would expect due to continuation of the upward trend alone, suggesting that its ranking as second or third warmest was attributable to the combined effects of natural variability and progression of the upward temperature trend.

The 2019 annual surface temperatures were above average across much of the world's land and ocean surfaces (Plate 2.1a; Figs. A2.1, A2.2). The most notable positive anomalies $\left(+1.0^{\circ} \mathrm{C}\right.$ or higher) were observed across Alaska, the Gulf of Alaska, northeastern Canada, Baffin Bay, Greenland, Europe, the Middle East, Russia, eastern Asia, Australia, southern Africa, and parts of Brazil. In contrast, near- to below-average conditions were present across a large swath of North America and across parts of the southeastern and southwestern Pacific Ocean, the Atlantic Ocean, and Indian Ocean.

The global temperature over land surfaces was $0.70^{\circ}-0.83^{\circ} \mathrm{C}$ above average-the second highest on record, behind 2016. The global ocean temperature was $0.38^{\circ}-0.40^{\circ} \mathrm{C}$ above average and the second or third highest on record, depending on the dataset.

Globally averaged surface air temperatures are also estimated using full-input reanalyses. A full-input reanalysis uses an objective algorithm and a weather prediction model to combine information from a range of satellite, aircraft, and in situ observational data sources to reconstruct historical weather and climate across the whole globe. A surface-input reanalysis is similar but combines information from only surface-based observations. Both can suffer from regional model biases and the effects of changes in the observation network during the analysis period. However, surface temperatures from reanalyses should be consistent with in situ analyses in regions of good observational coverage. Here, two full-input reanalyses are considered: ERA5 (Hersbach et al. 2020) and JRA-55 (Kobayashi et al. 2015). Currently, these reanalyses provide data from 1979 onward for ERA5 and from 1958 onward for JRA-55.

For both reanalyses, the globally averaged annual mean 2-m air temperature over land and ocean for 2019 was the second highest since the start of their respective records, being $0.59^{\circ} \mathrm{C}$ above average in ERA 5 and $0.51^{\circ} \mathrm{C}$ above average in JRA-55 (Table 2.1). These estimates fall within the range of those derived from the three observational datasets mentioned above. Comparatively, the two reanalysis temperatures for 2016 (the warmest year on record) were $0.63^{\circ} \mathrm{C}$ and $0.56^{\circ} \mathrm{C}$ above average, respectively. 
Table 2.1. Temperature anomalies $\left({ }^{\circ} \mathrm{C}\right)$ and uncertainties (where available) for 2019 w.r.t. the 1981-2010 base period. Where uncertainty ranges are provided, the temperature anomalies correspond to the central values of a range of possible estimates. Uncertainty ranges represent a $95 \%$ confidence interval. Note that for the HadCRUT4 column, land values were computed using the CRUTEM.4.6.0.0 dataset (Jones et al. 2012), ocean values were computed using the HadSST.3.1.1.0 dataset (Kennedy et al. 2011a,b), and global land and ocean values used the HadCRUT4.6.0.0 dataset (Morice et al. 2012).

\begin{tabular}{|cccccc} 
Global & $\begin{array}{c}\text { NASA-GISS } \\
\left({ }^{\circ} \mathrm{C}\right)\end{array}$ & $\begin{array}{c}\text { HadCRUT4 } \\
\left({ }^{\circ} \mathrm{C}\right)\end{array}$ & $\begin{array}{c}\text { NOAA } \\
\text { GlobalTemp } \\
\left({ }^{\circ} \mathrm{C}\right)\end{array}$ & $\begin{array}{c}\text { ERA5 } \\
\left({ }^{\circ} \mathrm{C}\right)\end{array}$ & $\begin{array}{c}\text { JRA-55 } \\
\left({ }^{\circ} \mathrm{C}\right)\end{array}$ \\
Land & +0.83 & $+0.70 \pm 0.13$ & $+0.78 \pm 0.14$ & +0.87 & +0.78 \\
Ocean & +0.38 & $+0.38 \pm 0.07$ & $+0.40 \pm 0.16$ & +0.48 & +0.39 \\
Land and Ocean & +0.56 & $+0.44 \pm 0.08$ & $+0.51 \pm 0.15$ & +0.59 \\
\end{tabular}

For 2019, the reanalyses also show warmer-than-average conditions over many regions of the world (Figs. A2.3, A2.4), particularly over high northern latitudes. Over both global ocean and global land, the two reanalyses agree that the 2019 2-m air temperature was the second highest on record and that the last five years (2015-19) were the five warmest years on record over both global ocean and global land (as well as globally).

\section{2) Lake surface temperature-L. Carrea, R. I. Woolway, C. J. Merchant, M. T. Dokulil, C. L. DeGasperi, E. de Eyto,}

S. Kelly, R.S. La Fuente, W. Marszelewski, L. May, A. M. Paterson, M. Pulkkanen, J. A. Rusak, O. Rusanovskaya, S. G. Schladow,

M. Schmid, S. V. Shimaraeva, E. A. Silow, M. A. Timofeyev, P. Verburg, S. Watanabe, and G. A. Weyhenmeyer

In 2019, the worldwide averaged satellite-derived lake surface water temperature (LSWT) warmseason (June-August in the Northern Hemisphere [NH]; December-February 2018/19 in the Southern Hemisphere [SH]; and December-August 2018/19 for the tropical region of $23.5^{\circ} \mathrm{N}-23.5^{\circ} \mathrm{S}$ ) anomaly was $+0.025 \pm 0.022^{\circ} \mathrm{C}$ compared with the $1996-2016$ base period. The mean warming trend from 1995 to 2019 was $0.21 \pm 0.02^{\circ} \mathrm{C}$ decade ${ }^{-1}$, broadly consistent with previous analyses (Woolway et al. 2017, 2018; Carrea et al. 2019). On average, anomalies (with respect to the 1996-2016 baseline) in 2019 were less positive than in 2018 and in $2017,0.23^{\circ} \mathrm{C}$ and $0.19^{\circ} \mathrm{C}$ less, respectively. The warm-season anomalies for each lake are shown in Plate 2.1b. Per lake, the LSWT anomaly was positive for $47 \%$ of lakes, and negative for 53\%. Some similarities between the 2019 warm-season lake temperature anomalies and the ice cover anomalies, in terms of spatial distribution in the NH (Sidebar 2.1; Fig. SB2.1), can be observed in regions where longer ice duration is related to negative lake water temperature anomalies.

In the $\mathrm{NH}$, distinctive warmer and cooler regions can be identified: Alaska, Greenland, Europe (except the northeast) show clearly positive anomalies, while Tibet and parts of North America show clear

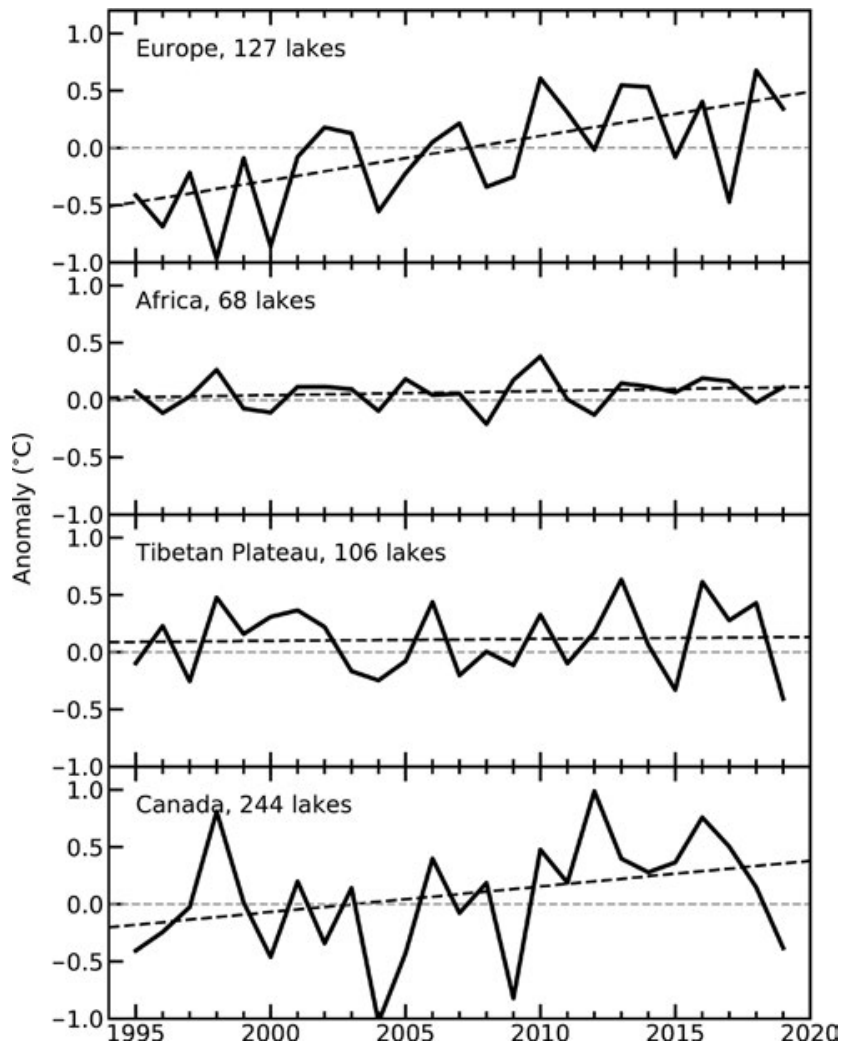

Fig. 2.2. Satellite-derived annual LSWT anomalies ( ${ }^{\circ} \mathrm{C}$; relative to 1996-2015) from 1995 to 2019 for Europe, Africa, Tibet, and Canada. These values were calculated for the meteorological warm season (Jun-Aug in the NH; Dec-Feb in the $\mathrm{SH}$; and over the whole year in the tropics). 
negative anomalies. Four regions are shown in more detail: Europe $(n=127)$, Tibet $(n=106)$, Africa $(n=68)$, and Canada $(n=244)$. The warm-season LSWT calculated from the satellite data shows a warming tendency of $+0.39 \pm 0.03^{\circ} \mathrm{C}$ decade $^{-1}$ in Europe and $+0.22 \pm 0.04^{\circ} \mathrm{C}$ decade $^{-1}$ in Canada. In Africa and Tibet the tendency is more neutral (Fig. 2.2.). The year 2018 was the warmest since records began in 1995 for European lakes over the June-August (JJA) period (similar to the finding for July-September [JAS] in Carrea et al. 2019). The anomaly in Europe in 2019 was more moderately positive than in 2018, due to the contribution of cooler lakes in northern Europe and Ireland (see section $7 \mathrm{f}$ for details). In particular, the border between Scandinavia and Finland delimits regions with contrasting behaviors, i.e., positive anomalies for Scandinavia and a few negative anomalies for Finland and the Karelia region of Russia, respectively. Modeled lake temperature anomalies in the ECMWF ERA5 reanalysis (Hersbach et al. 2020) are available that include lakes smaller than are observable in the satellite data $\left(\geq \sim 1 \mathrm{~km}^{2}\right)$, modeled as the fraction of each land surface grid cell covered by inland water (so-called "lake tiles"). The reanalysis lake tile temperatures are shown in Fig. 2.3. For the lakes in Ireland, the observed LSWT anomalies are moderately negative in contrast to the moderately positive ERA5 modeled data, while LSWT anomalies from satellite data are generally consistent with the ERA5 data in Canada, Tibet, and Africa (Fig. 2.3). ERA5 data are driven by the reanalysis surface meteorological conditions (Balsamo et al. 2012) and in general, the lake temperature anomalies broadly track observed air temperature, although factors such as wind speed, humidity, insolation, and the thermal time constants of lakes influence variations within this broad pattern.

LSWT time series were derived from satellite observations from the series of Along Track Scanning Radiometers (ATSR) and the Advanced Very High Resolution Radiometers (AVHRR) on MetOp A and B platforms. The retrieval method of MacCallum and Merchant (2012) was applied on image pixels filled with water according to both the inland water dataset of Carrea et al. (2015) and a reflectance-based water detection scheme. The satellite-derived LSWT data are spatial averages for each of a total of 927 lakes, for which high-quality temperature records were available through August 2019. Lake-wide average surface temperatures have been shown to give a more representative picture of LSWT responses to climate change than single-point measurements (Woolway and Merchant 2018). In addition, in situ LSWT observations have been analyzed $(n=32)$ for which long time-series are available.

Eighty-one percent $(n=26)$ of lakes with in situ LSWT measurements were found to have positive anomalies in

(a) Europe

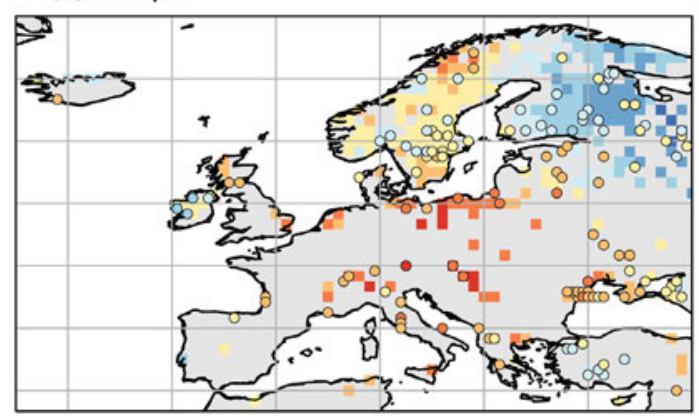

(c) Canada

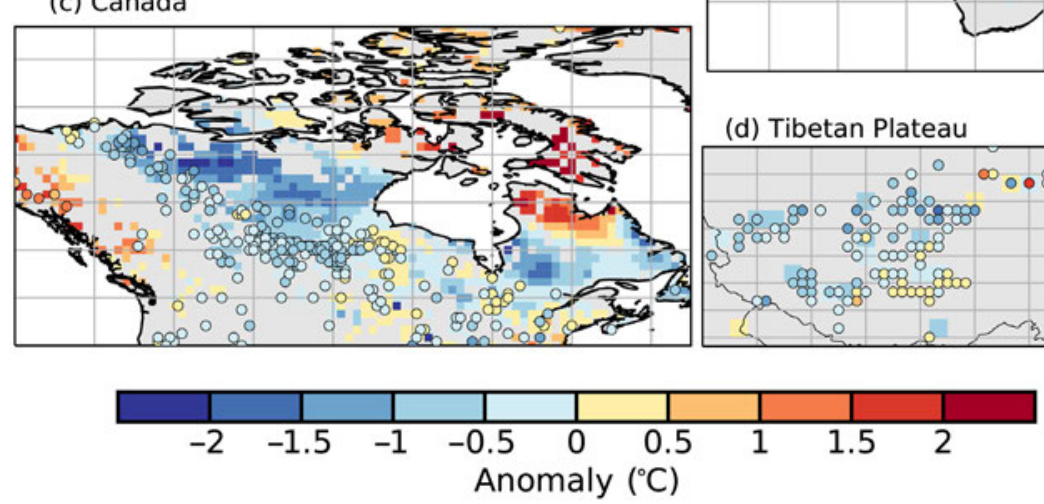

Fig. 2.3. Satellite-derived LSWT anomalies in 2019 (colored points) together with surface lake water temperature from the ECMWF ERA5 modeled data in Europe, Africa, Canada, and Tibet. The two sets of LSWT anomalies $\left({ }^{\circ} \mathrm{C}\right.$; relative to 1996-2015) are calculated for the meteorological warm season (Jun-Aug in NH; Dec-Feb in SH; and over the whole year in the tropics). 
2019. Similar to the satellite data, positive anomalies were found for Europe in 2019. For example, the second-largest lake in Sweden by surface area, Vättern, experienced an LSWT anomaly of $+0.98^{\circ} \mathrm{C}$ in 2019 , while that of Mondsee, Austria, was $+2.1^{\circ} \mathrm{C}$. The average LSWT anomaly in lakes with in situ data was $+0.6 \pm 0.15^{\circ} \mathrm{C}$ in 2019 , which is substantially higher than the global average anomaly calculated from the satellite-derived observations $\left(+0.025^{\circ} \mathrm{C}\right)$. This difference can be due to various factors, including the restricted global coverage of lakes with in situ data (these lakes are primarily situated in Europe and North America), the difference in lake size among the datasets (more lakes with in situ data tend to be small) and, unlike the in situ observations, which are restricted to a single point within a lake, the satellite data capture the intra-lake heterogeneity of LSWT anomalies, thus capturing within-lake regions that are either warming rapidly or experiencing relatively minimal change (Woolway and Merchant 2018).

3) Land and marine temperature extremes-R. J. H. Dunn, S. Perkins-Kirkpatrick, R. W. Schlegel, and M. G. Donat

Over land, 2019 recorded the most number of warm days (TX90p, see Table 2.2 for definition) in the record dating to 1950, with over 60 days compared to the average of 36.5 (Fig. 2.4). The

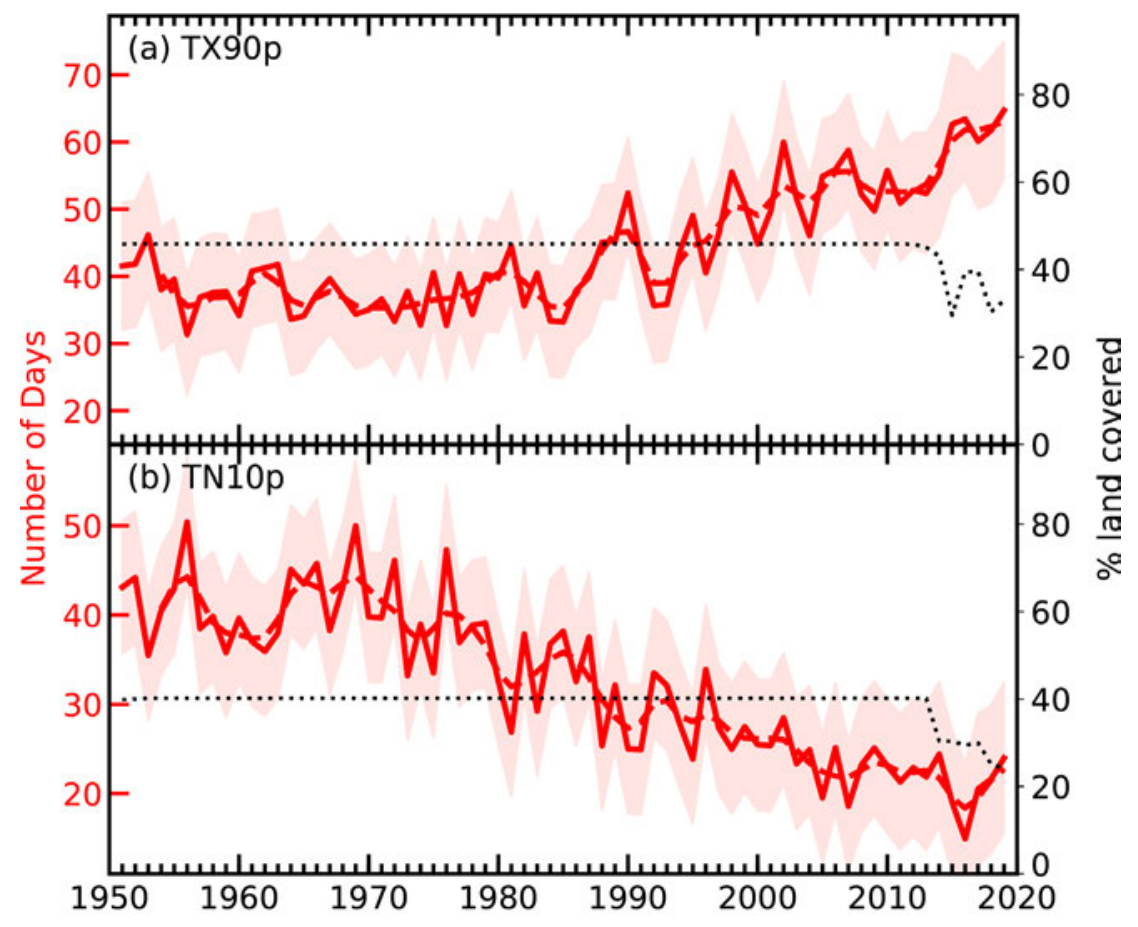

Fig. 2.4. Time series of (a) TX90p (warm days) and (b) TN10p (cool nights). The red dashed line shows a binomial smoothed variation, and the shaded band the uncertainties arising because of incomplete spatio-temporal coverage estimated using ERA5 following Brohan et al. (2006). The dotted black line shows the percentage of land grid boxes with valid data in each year. (Source: GHCNDEX.) number of cool nights (TN10p) was low compared the last 70 years, but above average for the most recent decade. As the spatial coverage of the in situ GHCNDEX (Donat et al. 2013) dataset is not complete due to delayed or lacking report of up-to-date station data in many regions, the time series from the ERA5 reanalysis (Hersbach et al. 2020; Fig. 2.5; Fig. A2.5) is also shown. A similar picture emerges, but the number of warm days does not exceed the record maximum set in 2016. Similarly, the number of cool nights is also close behind the record minimum of 2016. Differences with GHCNDEX may be the result of the more complete coverage of ERA5.

The number of warm days is high over Europe and Australia from GHCNDEX (Plate 2.1c),

Table 2.2. WMO Expert Team on Climate Change Detection and Indices (ETCCDI; Zhang et al. 2011) temperature indices used in this section and their definitions.

\begin{tabular}{|ccc|}
\hline Index & Name & Definition \\
\hline TX90p & Warm days & $\begin{array}{c}\text { Count of days where the maximum temperature was above the } \\
\text { climatological 90th percentile (defined over 1961-90, days) } \\
\text { Count of days where the minimum temperature was below the } \\
\text { climatological 10th percentile (defined over 1961-90, days) }\end{array}$ \\
\hline TNx & $\begin{array}{c}\text { Maximum "night-time" } \\
\text { temperature }\end{array}$ & Warmest minimum temperature (TN, $\left.{ }^{\circ} \mathrm{C}\right)$ \\
\hline
\end{tabular}


corresponding with the strong heat wave events in both these regions during 2019. In June large parts of Europe experienced daily maximum temperatures over $35^{\circ} \mathrm{C}$, and France broke its national record with $46.0^{\circ} \mathrm{C}$ at Vérargues on the 28th. In July, France also sweltered under its record warmest night (TNx), with a national average of $21.4^{\circ} \mathrm{C}$ on $24-25 \mathrm{July}$, and a new maximum temperature record of $42.6^{\circ} \mathrm{C}$ was set for Paris on the 25th. Many other nations also experienced temperatures over $40^{\circ} \mathrm{C}$ during this period, with national station records broken in the United Kingdom $\left(38.7^{\circ} \mathrm{C}\right)$, Germany $\left(42.6^{\circ} \mathrm{C}\right)$, the Netherlands $\left(40.7^{\circ} \mathrm{C}\right)$, Belgium $\left(41.8^{\circ} \mathrm{C}\right)$, and Luxembourg $\left(40.8^{\circ} \mathrm{C}\right)$. The World Meteorological Organization (WMO) declared the month of July 2019 tied as the hottest on record for the globe (WMO 2019), based on ERA5 (Hersbach et al. 2020).

Australia experienced heat waves both early and late in the year. A prolonged and extensive heat wave affected much of the country from late December 2018 through January 2019. Records set include Adelaide's hottest day on record at $46.6^{\circ} \mathrm{C}$ on 24 January (with new records also set at neighboring stations) and Canberra's longest run of days above $40^{\circ} \mathrm{C}$ on four consecutive days (14-17 January 2019). The all-time national average maximum temperature record was set on 17 December 2019 at $41.9^{\circ} \mathrm{C}, 1.59^{\circ} \mathrm{C}$ above the 2013 record, and $2.09^{\circ} \mathrm{C}$ above average (1961-90). January, March, and December 2019 were nationally the warmest on record for the respective months, with February, April, July, October, and November each among their respective 10 warmest. The most recent Australian heat wave in summer 2019/20 is presented in detail in Sidebar 7.6.

Heat waves also occurred in May and June in Japan, with a maximum temperature of $39.5^{\circ} \mathrm{C}$ (Saroma, Hokkaido) on $26 \mathrm{May}$ (monthly record for this site), and also Pakistan $\left(51.1^{\circ} \mathrm{C} \mathrm{Jacobabad}\right.$ on 1 June) and India with $\left(50.8^{\circ} \mathrm{C}\right.$ Churu, 2 June). In February, the United Kingdom experienced above-average temperatures with maxima of $21.2^{\circ} \mathrm{C}$ recorded in London on the 26th (monthly record), around $14^{\circ} \mathrm{C}$ above average. Extreme temperatures also occurred over South America in 2019. Overall, the continent observed its second-warmest year on record, with heat waves during January in Chile and southeastern Brazil contributing to the warmth. Santiago, Chile, set a new maximum temperature record of $38.3^{\circ} \mathrm{C}$ on 27 January. In North America, the state of Alaska experienced its warmest year on record. Please refer to the relevant sections in Chapter 7 for more regional temperature details.

GHCNDEX (Donat et al. 2013), a gridded dataset of ETCCDI (Expert Team on Climate Change Detection and Indices) extremes indices, was used to characterize the extreme temperatures over land. Indices are calculated from daily temperature values from the GHCND (Menne et al. 2012) and have been interpolated onto a $2.5^{\circ} \times 2.5^{\circ}$ grid. As can be seen in Plates $2.1 \mathrm{c}$, d, the spatial coverage is sparse, with available data for 2019 restricted to North America and parts of Eurasia and Australia. This lack of coverage arises both from gaps in the historical coverage (e.g., sub-Saharan 
(a)

ঠ $80 \%$ -

$198^{\prime} 19^{\prime} 8719 \dot{9} 19^{\prime} 9720{ }^{\prime} 02200720122017$ (b)

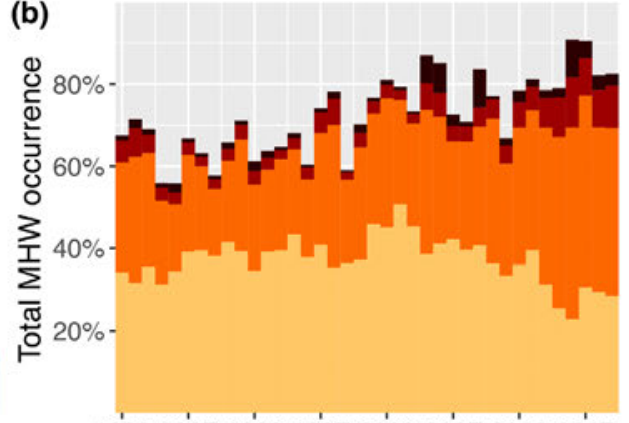

19821987199219972002200720122017 (c)

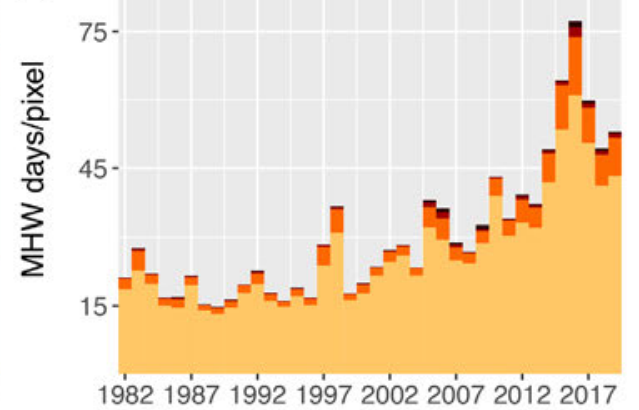

\section{Category $\square$ I Moderate $\square$ II Strong $\square$ III Severe $\square$ IV Extreme}

Fig. 2.6. Annual MHW occurrence using a climatology base period of 1982-2011. (a) Daily average percent of the ocean that experienced a MHW. (b) Total percent of the ocean that experienced a MHW at some point during the year. The values shown are for the highest category of MHW experienced. (c) Total average of daily MHW occurrence throughout the entire ocean. (Source: NOAA OISST.)

Africa) and also from delays in data transmission. ERA5 reanalysis (Hersbach et al. 2020) can be used to fill in some of these gaps, but because this dataset has a shorter temporal coverage, the reference period is necessarily different (1981-2010 compared to 1961-90 in GHCNDEX), which can lead to apparently different temporal behavior (Dunn et al. 2020).

Extreme heat, known as marine heat waves (MHWs), may enter the oceans through surface heat flux or advection. Satellite observations of SST can be used to monitor and categorize MHWs, as defined in Hobday et al. (2016, 2018). A category “I Moderate” MHW is defined as a period of time in which SST is above the 90th-percentile threshold of temperatures at a given location and day-of-year for five days or longer (Hobday et al. 2018). The MHW is categorized as "II Strong” if the largest temperature anomaly during the event is more than twice as large as the difference between the seasonally varying climatology and the 90th-percentile threshold. The MHW is "III Severe" if the largest anomaly is more than triple the difference, and "IV Extreme" if four times the difference or greater. Using NOAA OISST v2.1 (Banzon et al. 2020), the MHW category recorded most often in the ocean for 2019 was "II Strong" (41\% of ocean surface), exceeding the lower category "I Moderate” (30\%) for the sixth consecutive year (Fig. 2.6). Category "III Strong” MHWs (2\%) were exceeded by "IV Extreme" MHWs (3\%) for the fourth consecutive year. In total, $84 \%$ of the surface of the ocean experienced an MHW in 2019. There was an average of $74 \mathrm{MHW}$ days per ocean pixel, an increase from 61 in 2018, but below the 2016 record of 83 . The average daily MHW occurrence throughout the ocean was 20\%, an increase over the 2018 average of $17 \%$, and less than the 2016 record of $23 \%$.

4) Tropospheric temperature-J.R. Christy, C. A. Mears, S. Po-Chedley, and L. Haimberger

The 2019 global lower tropospheric temperature (LTT), which encompasses the atmosphere from the surface to $\sim 10 \mathrm{~km}$, ranked second warmest in seven datasets and first or third in the remaining two (Fig. 2.7). These records extend back to 1958 using radiosonde (balloon-borne instrumentation) data and one reanalysis dataset (JRA55), which demonstrate reasonable agreement with the 40+ year satellite record (since late 1978) and two other reanalysis datasets (since 1979 and 1980, ERA5 and MERRA2, respectively). A weak El Niño contributed to increased global temperatures as 2019 values were $+0.44^{\circ}$ to $+0.68^{\circ} \mathrm{C}$ higher than the $1981-2010$ average (depending on the dataset), being just slightly cooler $\left(\sim 0.07^{\circ} \mathrm{C}\right.$ on average) than the record warm year of 2016. At least four of the five globally complete datasets (ERA5, MERRA2, JRA55, RSS, UAH) recorded each of the four months-June, September, November, and December-as experiencing their warmest monthly global LTT. 


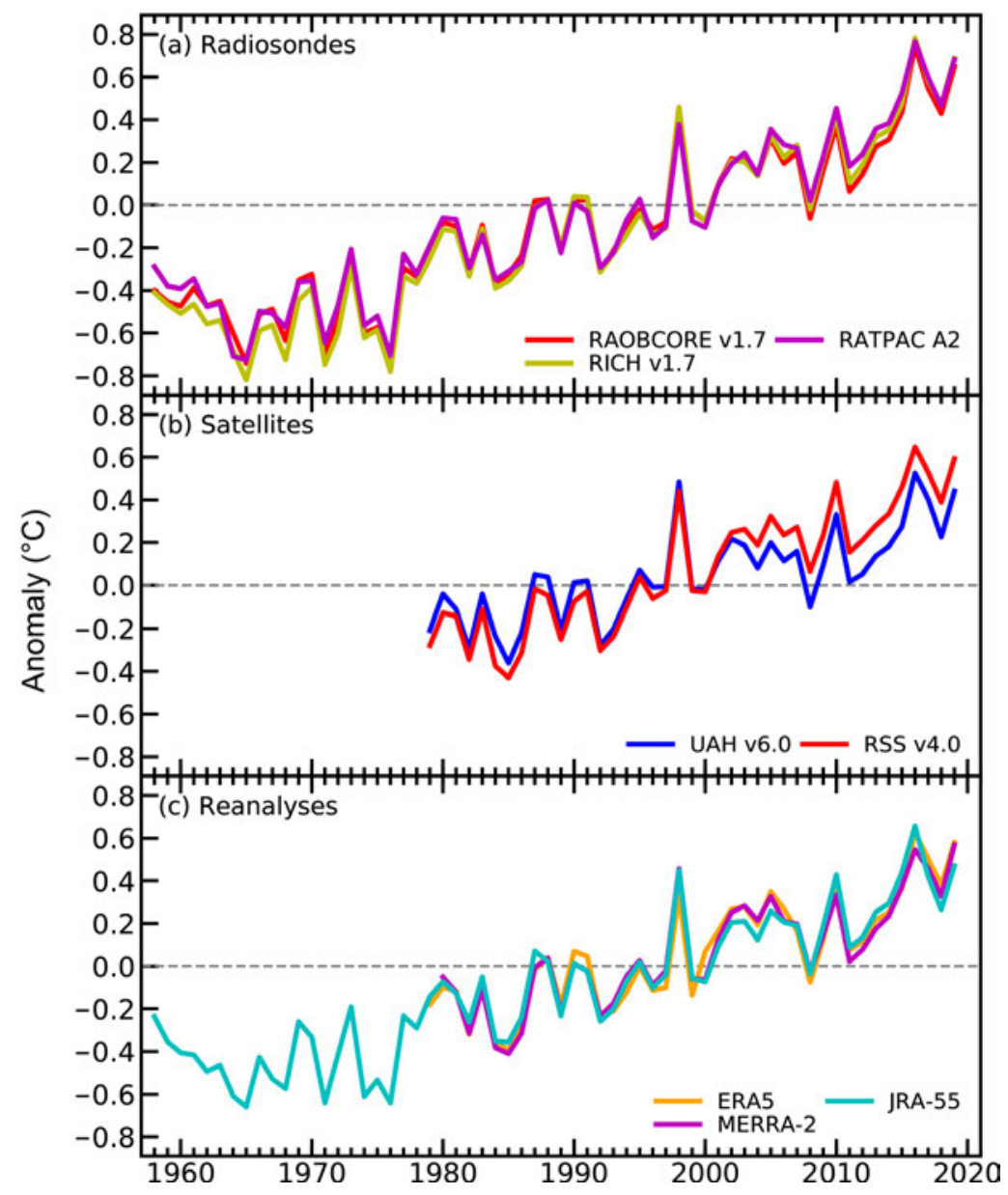

Fig. 2.7. Time series of global annual temperature anomalies $\left({ }^{\circ} \mathrm{C}\right)$ for the lower troposphere from (a) radiosondes, (b) satellite microwave emissions, and (c) reanalyses.

\begin{tabular}{|c|c|c|c|c|c|}
\hline \multicolumn{2}{|l|}{ Area } & Global & Global & Tropical & Tropical \\
\hline \multicolumn{2}{|l|}{ Layer } & LTT & LTT & TTT & TTT \\
\hline \multicolumn{2}{|l|}{ Start Year } & 1958 & 1979 & 1958 & 1979 \\
\hline \multirow[t]{3}{*}{ Radiosonde } & NOAA/RATPACvA2 & +0.18 & +0.21 & +0.16 & +0.16 \\
\hline & RAOBCOREv1.7 & +0.18 & +0.19 & +0.15 & +0.15 \\
\hline & RICHv1.7 & +0.20 & +0.21 & +0.19 & +0.22 \\
\hline \multirow[t]{4}{*}{ Satellite } & RSSv4.0 & - & +0.21 & - & +0.18 \\
\hline & UAHv6.0 & - & $+0.13^{1}$ & - & +0.13 \\
\hline & NOAA/STARv4.1 & - & - & - & +0.23 \\
\hline & UWv1.0 & - & - & - & +0.17 \\
\hline \multirow[t]{3}{*}{ Reanalyses } & ERA5 & - & +0.17 & - & +0.16 \\
\hline & JRA-55 & +0.16 & +0.16 & +0.16 & +0.15 \\
\hline & NASA/MERRA- $2^{2}$ & - & +0.17 & - & +0.16 \\
\hline \multicolumn{2}{|l|}{ Median } & +0.18 & +0.18 & +0.16 & +0.16 \\
\hline \multicolumn{6}{|c|}{$\begin{array}{l}\text { The UAH LTT weighting function is slightly different in order to reduce the impact of surface } \\
\text { emissions and enhance the tropospheric signal, resulting in a global trend value typically cooler } \\
\text { by } 0.01^{\circ} \mathrm{C} \text { decade }{ }^{-1} \text { relative to the standard LTT weighting function. }\end{array}$} \\
\hline \multicolumn{6}{|c|}{ ²NASA/MERRA-2 begins in 1980.} \\
\hline
\end{tabular}

The warming rate of the global troposphere since 1958, as the median of available datasets, is +0.18 (range +0.16 to +0.20$){ }^{\circ} \mathrm{C}$ decade $^{-1}$. The median warming rate since 1979 is also +0.18 (range +0.13 to +0.21$)^{\circ} \mathrm{C}$ decade ${ }^{-1}$, which includes records derived from microwave satellite measurements (Table 2.3). Taking into consideration the temporary cooling due to volcanic aerosols caused by eruptions in 1982 and 1991, as well as the El Niño/La Niña cycle, there remains a global warming trend since 1979 of $+0.12 \pm 0.04^{\circ} \mathrm{C}$ decade $^{-1}$ unexplained by these ephemeral, natural phenomena (Christy and McNider 2017, updated and calculated using ERA5, RSS, and UAH datasets).

The spatial details of the departures of LTT from the 1981-2010 mean are depicted in Plate 2.1e as provided by the European Centre for Medium-Range Forecasts Reanalysis version 5 (ERA5). Above-average anomalies dominate the 2019 ERA5 map with negative regions occupying only $8.1 \%$ of the global surface area, including much of North America, a portion of South Asia, and midlatitude regions of the southern oceans. These belowaverage LTTs comprise the third-smallest such area after 2016 and 2017.

Much higher-than-average temperatures included several regions that experienced record high temperatures relative to this 41-year period of observations. Alaska, Greenland, central Europe, and southern Africa were especially warm. The broad warmth of the tropical belt is a typical signature of an El Niño year.

The warming trend may be depicted in a geographical context by determining 
the year in which the extreme high (and low) annual values at each grid point occurred, then summing those areally-weighted grids by year. If all regions of Earth experienced a monotonically increasing temperature, then each new year would see $100 \%$ of the global area achieving a record high temperature; however, if the global trend were zero over the 41-year period of record but characterized by random inter-annual variability, each year would experience, on average, an area of $2.4 \%$ of record high (or low) temperatures. With our climate system characterized by both an increasing trend and inter-annual variations since 1979, the area in 2019 of record high temperatures was 15.6\% (calculated as the average of ERA5, RSS, and UAH). The stippling in Plate 2.1e identifies these grids (see also Fig. A2.6). Two years with major El Niño events, 1998 and 2016, recorded areal extents for the highest temperatures of $16.9 \%$ and $20.1 \%$, respectively (no repeated records). Since 1979, the year with the largest coverage of record low annual-average temperatures was 1985 with $19.8 \%$ due in part to a concurrent La Niña event.

Global and tropical trends are listed in Table 2.3. When examining the time series of these three methods (radiosondes, satellites, reanalyses), the radiosondes display an increasing trend over the past 10 years relative to the other methods (see trend values in column Global LTT 1979 and Fig. A2.7) This may be related to a change in software installed after 2009 in many stations to improve the tropospheric humidity and temperature values (Christy et al. 2018).

The tropical $\left(20^{\circ} \mathrm{N}-20^{\circ} \mathrm{S}\right)$ tropospheric temperature (TTT, surface to $\sim 15 \mathrm{~km}$ ) variations and trends are similar to those of the global values. The median TTT trends from the available datasets since 1958 and 1979 are both $+0.16^{\circ} \mathrm{C}$ decade ${ }^{-1}$ with ranges of +0.15 to +0.19 and +0.13 to $+0.23^{\circ} \mathrm{C}$ decade $^{-1}$, respectively (Table A2.1). This layer in the tropics is a key area of interest due to its expected significant response to forcing, including that of increasing greenhouse gas concentrations (McKitrick and Christy 2018; see Fig. A2.8).

Radiosondes provide coverage wherever the stations exist. Considerable areas of the globe are thus not sampled, and this can lead to a misrepresentation of the global average. Satellites essentially observe the entire Earth each day, providing excellent geographic coverage, but whose radiances provide bulk-layer atmospheric measurements only. There are some key adjustments that are required too, and the methods adopted by different teams lead to the range in the results (Haimberger et al. 2012; Po-Chedley et al. 2015; Mears and Wentz 2016; see also Figs. A2.7 and A2.9). Full input reanalyses use essentially all available data, including radiosonde and satellite, ingested into a continuously updated global circulation model, thus providing full geographic and vertical coverage. Given the many differences in how the reanalyses are constructed from center to center, the consistency among their 41-year trends is encouraging.

\section{5) Stratospheric temperature-W. J. Randel, C. Covey, and L. Polvani}

Temperatures in the middle and upper stratosphere continued to decline to their lowest recorded values since 1979, i.e., the beginning of the satellite era. Lower stratosphere temperatures have been relatively constant since $\sim 1998$, with small interannual changes. The polar stratospheric regions were influenced by sudden stratospheric warming (SSW; Charlton and Polvani 2007) events in both hemispheres, in the Arctic in January 2019 and in the Antarctic in September 2019. The Antarctic event was highly unusual, being only the second SSW observed in the SH since 1979 (see Sidebar 6.1 for more details).

Time series of annual anomalies of middle and upper stratosphere temperatures from satellite observations are shown in Figs. 2.8a-c. These data represent $\sim 20-\mathrm{km}$ thick layer measurements from the Stratospheric Sounding Unit (SSU) merged with more recent satellite measurements (Randel et al. 2016; Zou and Qian 2016). Middle and upper stratospheric temperatures show distinctive cooling since 1979, with stronger negative trends at higher altitudes, which is a characteristic response to increases in atmospheric $\mathrm{CO}_{2}$ (Manabe and Wetherald 1967). The cooling is modulated by upper stratospheric ozone changes, with somewhat weaker stratospheric cooling after 1998 tied to observed increases in ozone. The ozone is evolving as a response to changes 


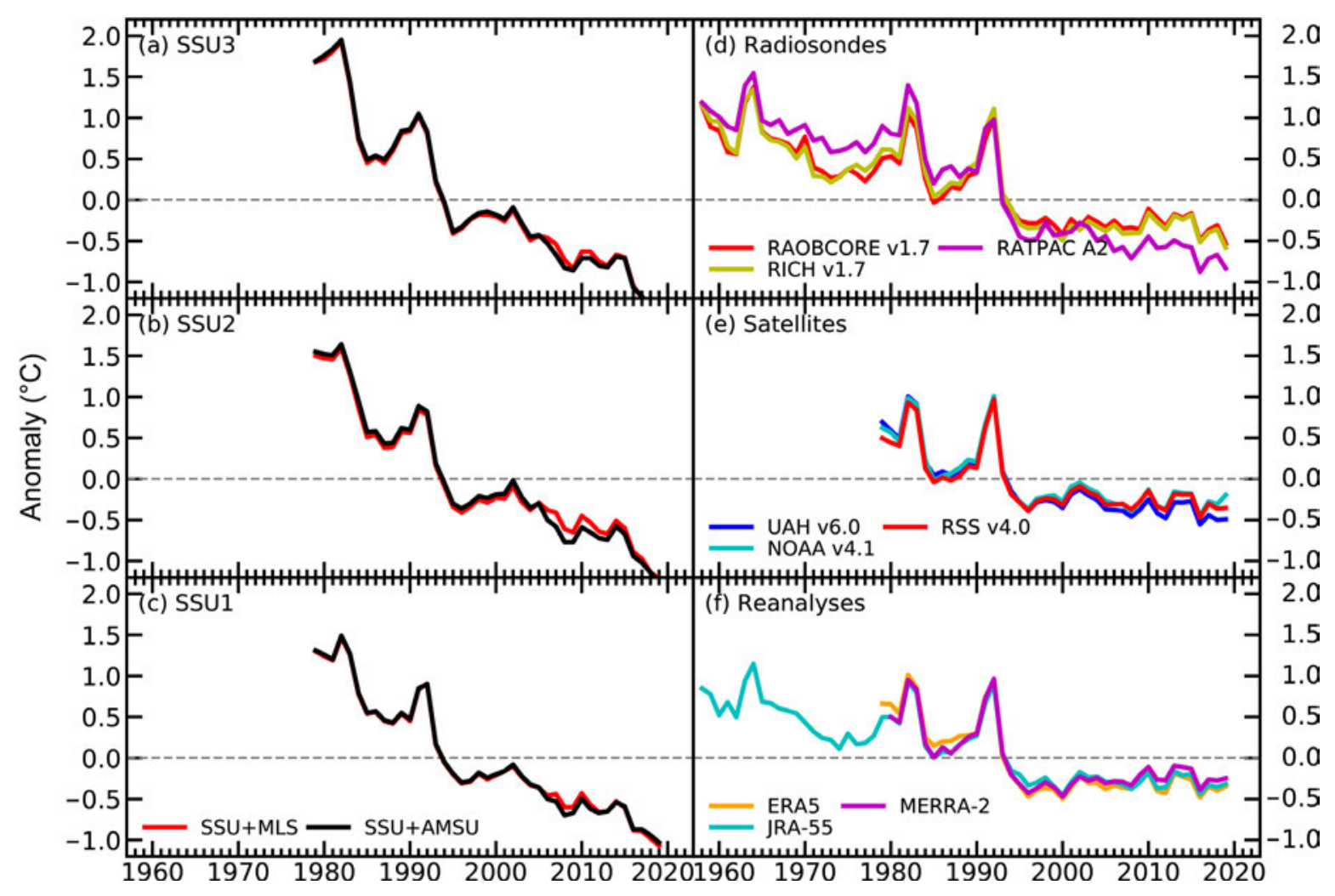

Fig. 2.8. (a)-(c) Annual anomalies of global middle to upper stratospheric temperatures from Stratospheric Sounding Unit channels 1-3, representing thick-layer averages centered near 30, 38, and 45 km (SSU1, SSU2, and SSU3, respectively). Results from two different merged datasets are shown (Randel et al. 2016; Zou and Qian 2016). (d)-(f) Annual anomalies of global lower stratosphere temperature (LST; 13-22-km layer average) from (a),(d) radiosondes; (b),(e) satellites; and (c),(f) reanalyses. For direct comparison, the radiosondes and reanalyses have been convolved with the satellite LST weighting function.

in ozone depleting substances (ODS) linked to the Montreal Protocol (see section 2g4; Maycock et al. 2018; WMO 2018). In addition to long-term cooling, the time series highlight modulation by the 11-year solar cycle in the upper stratosphere and transient warming from volcanic eruptions in 1982 and 1991.

Time series of global lower stratospheric temperature (LST; layer mean over $\sim 13-22 \mathrm{~km}$ ) from satellites, radiosondes, and reanalyses in Figs. 2.8d-f all show long-term cooling trends, in addition to transient warming events tied to large volcanic eruptions in 1963, 1982, and 1991. The time series also show very small changes since 1998. Over most of the globe the LST layer more or less spans the cross-over between tropospheric warming and stratospheric cooling associated with $\mathrm{CO}_{2}$ increases; long-term LST cooling prior to 1998 is tied to observed ozone decreases in the lower stratosphere, while small ozone changes thereafter are linked to nearly constant temperatures (Maycock et al. 2018).

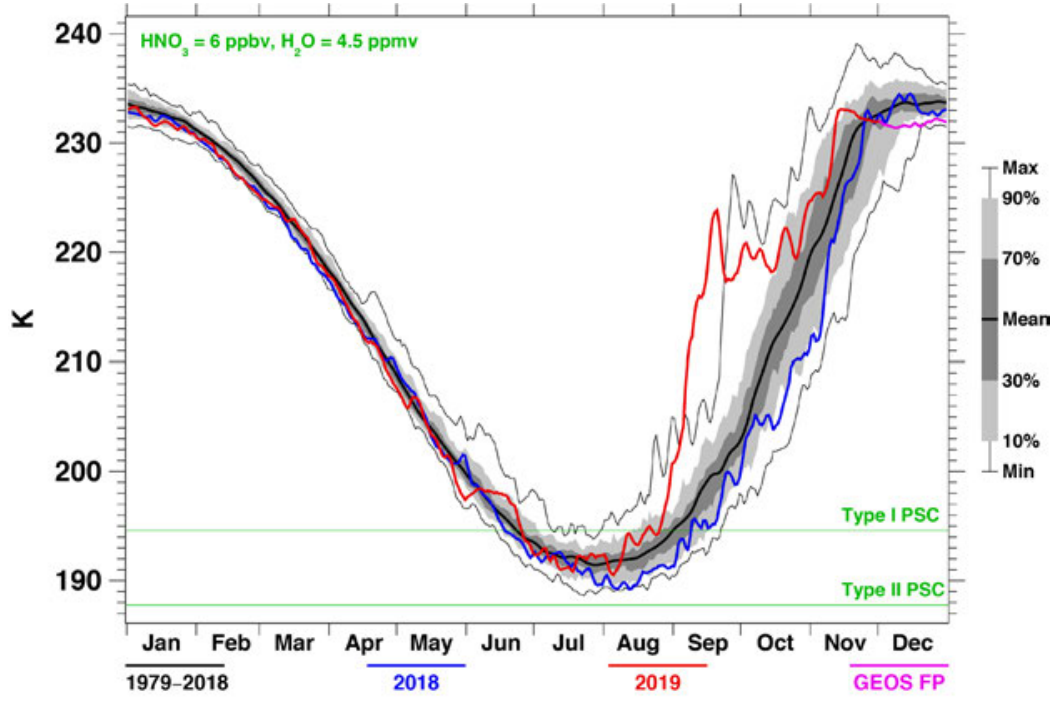

Fig. 2.9. Daily time series of $50-\mathrm{hPa}$ temperatures for $60^{\circ}-90^{\circ} \mathrm{S}$ for 2018 (blue) and 2019 (red), against the background of percentile variability (gray lines and shades) since 1980. 
Transient but common features of stratospheric temperature variability are polar SSWs that occur episodically during winter, mainly in the NH. At least one SSW occurred in 34 of the past 62 winters in the $\mathrm{NH}$, while only one was observed in the SH (in 2002) prior to 2019. Time series of 50-hPa temperature over the Antarctic during the last several years are shown in Fig. 2.9, in the context of the historical average and range of observations. The September 2019 SSW resulted in a 50-hPa temperature increase over the polar cap of $\sim 30^{\circ} \mathrm{C}$ over two weeks, with temperatures well outside the range of previous variability. While these SSW events have strong effects on polar temperatures, they have minimal influence on global mean stratospheric temperatures. However, Australian hot and dry extremes are statistically associated with weakening and warming of the Antarctic stratospheric polar vortex (Lim et al. 2019). The September 2019 SSW is one of many possible factors contributing to this year's eastern Australian bushfires (see section $7 \mathrm{~h} 4$ for more details; Phillips and Bogrady 2020).

\section{c. Cryosphere}

1) Permafrost thermal state-J. Noetzli, H. H. Christiansen, K. Isaksen, S. Smith, L. Zhao, and D. A. Streletskiy

The global picture of permafrost state and changes continued in 2019: permafrost is warming in both mountain and polar regions, and the highest increase is observed where permafrost temperatures and ice contents are lowest. At warmer and ice-rich locations the temperature change is smaller due to the energy uptake during ice melt processes. The thickness of the active layer (ALT) - the uppermost ground layer above the permafrost subject to positive temperatures during summer-is globally increasing.

In the Arctic regions, permafrost temperatures measured at 20-m depth at many of the monitoring sites during 2019 were the highest observed during the observation period, continuing the trend reported by Meredith et al. (2019). Observations now cover up to four decades at several sites. At some locations, temperatures were $2^{\circ}-3^{\circ} \mathrm{C}$ higher than 30 years ago. More details on the Arctic region are given in Chapter 5. For Antarctica, increasing permafrost temperatures were reported for the past decade (cf. Noetzli et al. 2019). However, for 2019 no data update is available yet.

Mountain permafrost accounts for nearly $30 \%$ of the global permafrost area (Hock et al. 2019), but datasets for many mountain regions are obtained at only a limited number of sites. Data are primarily available from boreholes and networks in the European Alps, the Nordic countries, and central Asia (Qinghai-Tibetan Plateau, QTP). A general warming trend during recent decades until 2016 is also reported for mountain ranges in Canada, Mongolia, and Tien Shan in central Asia (Hock et al. 2019). Due to the high spatial variability in characteristics and permafrost temperatures, warming rates are highly heterogeneous, depending on topography, snow regime, and ground ice content.

Permafrost temperatures observed in the European Alps in 2019 were influenced by an early and long-lasting snow cover-trapping the heat from summer 2018-followed by another extremely warm summer in 2019. Permafrost temperatures continued the increasing trend since 2010 after a temporary interruption of the warming trend due to snow-poor winters reported in 2017 (Fig. 2.10; Noetzli et al. 2018; PERMOS 2019). At most sites, the temperatures at 10-m depth in 2019 were slightly below the record temperatures measured in 2015 (updated from PERMOS 2019). Likewise, permafrost temperatures at 20-m depth increased since 2018, but not above the previous high from 2015. Repeated electrical resistivity tomography at several borehole sites indicate a decrease in ice content, particularly for sites close to $0^{\circ} \mathrm{C}$ (Mollaret et al. 2019; PERMOS 2019). Permafrost temperatures measured at steep bedrock sites at high elevation are typically not influenced by annual snow conditions and have continuously increased, with 2019 values higher than those previously recorded down to 10-m depth (updated from PERMOS 2019; Magnin et al. 2015). Further, rock glacier creep velocities generally follow permafrost temperatures and have increased considerably in the past decade (PERMOS 2019). 

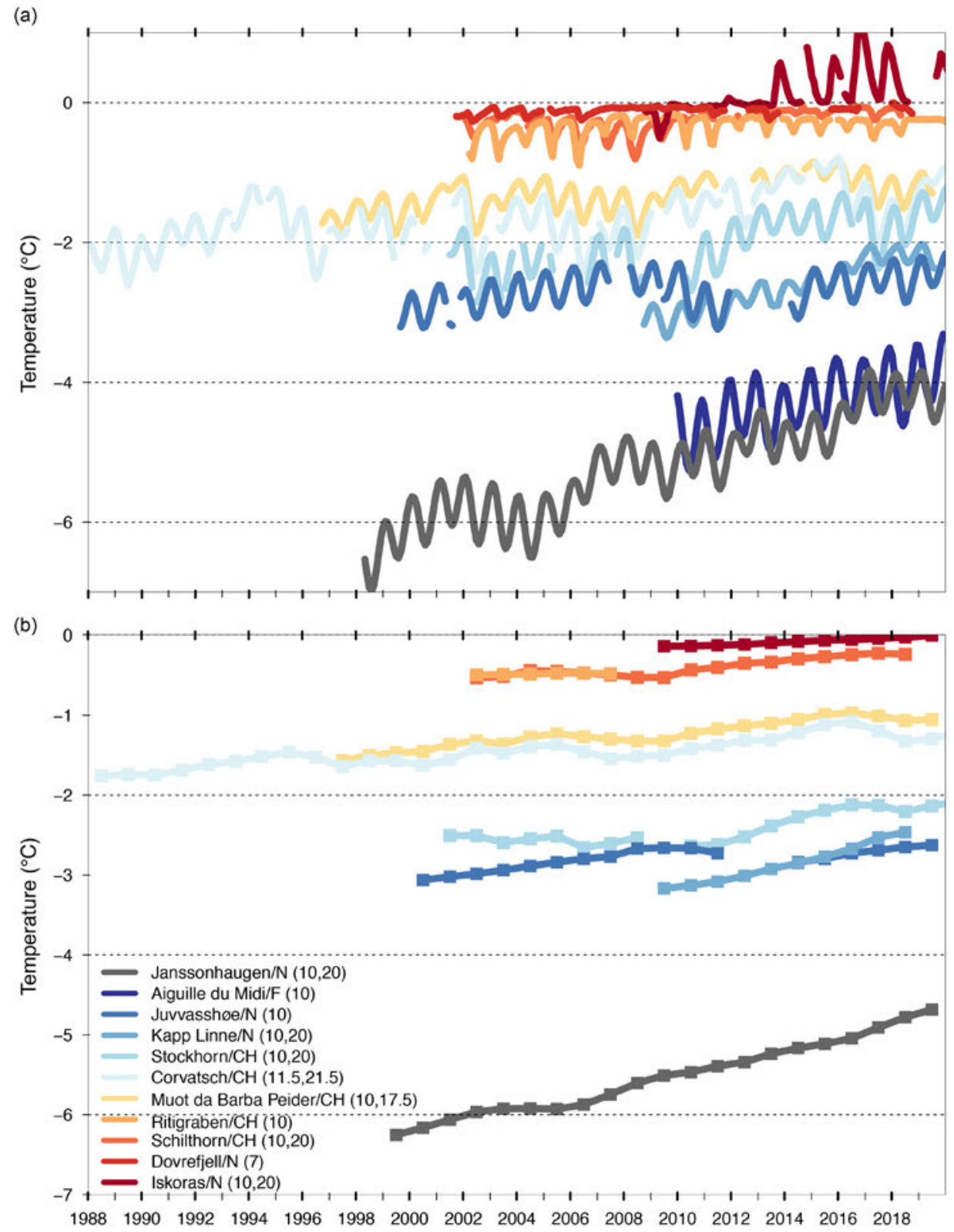

Fig. 2.10. Permafrost temperature $\left({ }^{\circ} \mathrm{C}\right)$ measured in boreholes in the European Alps and the Nordic countries at a depth of approximately $10 \mathrm{~m}$ (monthly means) and $20 \mathrm{~m}$ (annual means). (Sources: Swiss Permafrost Monitoring Network PERMOS; Norwegian Meteorological Institute and the Norwegian Permafrost Database NORPERM, updated from Magnin et al. 2015.)
In Nordic countries, permafrost temperatures increased to their highest levels in both cold and warm permafrost (updated from Isaksen et al. 2007; Christiansen et al. 2010). In southern Norway, permafrost at 20-m depth warmed between 2015 and 2019 (for Juvvasshøe $+0.04^{\circ} \mathrm{C} \mathrm{yr}^{-1}$ ), following a period of cooling between 2010 and 2014 (Fig. 2.10). In northern Norway (Iškoras since 2008), latent heat exchanges appeared to dominate the annual temperature amplitude at 10 - $\mathrm{m}$ depth in the beginning of the series. Since 2013/14, an increase in annual temperature amplitude has been observed with present temperatures well above $0^{\circ} \mathrm{C}$ (Fig. 2.10). At 20-m depth, ground temperatures have risen to $0^{\circ} \mathrm{C}$. Borehole temperatures measured in the hinterland of the QTP showed remarkable warming tendencies with variable rates that are highest in lowertemperature permafrost (Cheng et al. 2019; Sun et al. 2019).

The ALT continued to increase in 2019 for the majority of the observational sites. Out of 92 sites that reported data in 2018/19 in the Northern Hemisphere (NH), only a few had below-average ALT relative to the 2003-12 period. About $66 \%$ of the sites had larger 2019 ALT than in 2018. At North American sites, ALT continues to increase since the beginning of the observations in the mid-1990s, with the highest increase in the Alaskan Interior and smaller increases in the Mackenzie Valley of northwestern Canada and the Alaska North Slope. In 2019, ALT was close to maximum values at the group of sites located in the Pacific Arctic sector (Alaska, Chukotka). At many interior Alaska sites, the active layer did not freeze completely down to the underlying permafrost due to a combination of long-term warming and the relatively mild and snowy past two winters (2017/18 and 2018/19). During all previous years of observations, complete active layer freeze-up was observed. North Atlantic Arctic sites had the largest or close-to-largest ALT in 2019; sites in Svalbard and Greenland show at least $0.05 \mathrm{~m}$ larger ALT than average. The Russian Arctic, with the exception of northeast Siberia, experienced a 


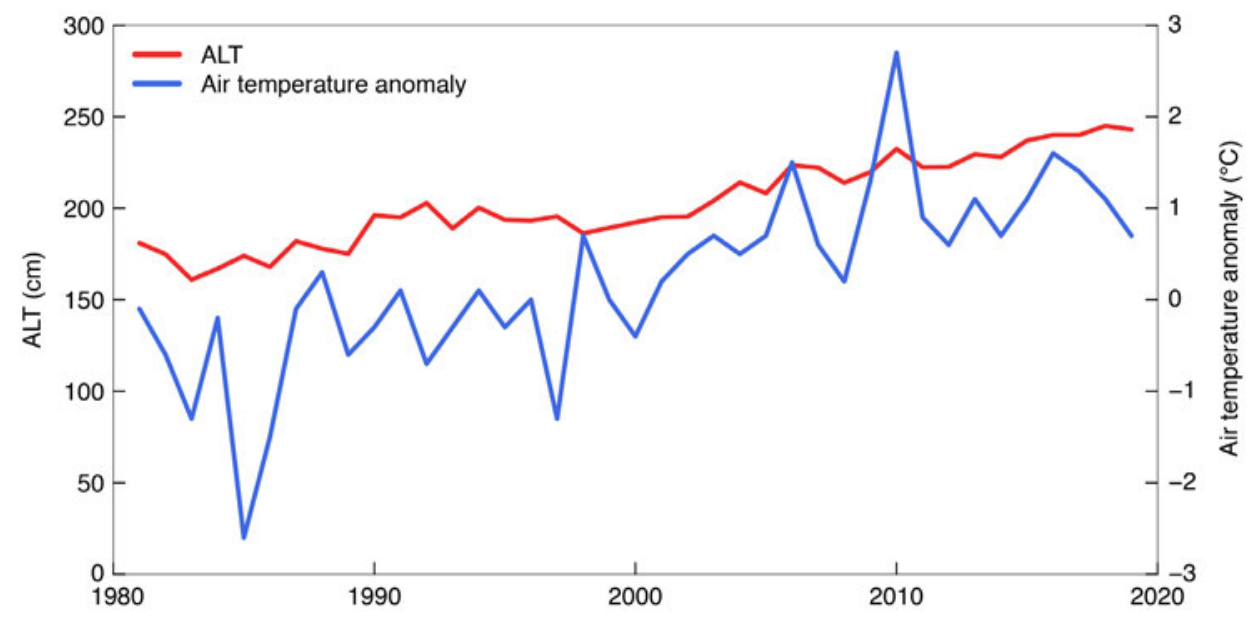

Fig. 2.11. Annual ALT $(\mathrm{cm})$ and air temperature anomaly $\left({ }^{\circ} \mathrm{C}\right)$ across the Qinghai Tibet Highway. larger-than-average ALT, with deviations from the mean of $0.05 \mathrm{~m}$ in northern European Russia to $0.02 \mathrm{~m}$ in West Siberia (see section $5 \mathrm{~h}$ for more details). In Scandinavia and the European Alps, values up to about 0.05 $\mathrm{m}$ above or near-record maximum values were observed at many of the sites. ALT also continued to increase at sites located in permafrost regions of the hinterland of the QTP

by about $0.2 \mathrm{~m}^{\text {decade }}{ }^{-1}$ since the 1980s (Fig. 2.11; Cheng et al. 2019; Zhao et al. 2019). In 2019, ALT was, on average, slightly smaller in the QTP than in 2018 (0.02 m).

Long-term observation of permafrost change relies on ground temperatures measured in boreholes, which are collected in the framework of the Global Terrestrial Network for Permafrost (GTN-P) as part of the Global Climate Observing System of the World Meteorological Organization. Borehole temperatures are logged manually or continuously using multi-sensor cables down to at least the depth of the zero annual amplitude (ZAA), the depth where seasonal variations become negligible. An assessment of the measurement accuracy of borehole temperatures in permafrost worldwide varied from $0.01^{\circ}$ to $0.25^{\circ} \mathrm{C}$ and a mean overall accuracy of about $0.1^{\circ} \mathrm{C}$ can be assumed (Biskaborn et al. 2019; Romanovsky et al. 2010). The current global coverage of permafrost temperature monitoring in boreholes is sparse and very limited in regions such as Siberia, central Canada, Antarctica, and the Himalayan and Andes Mountains. The distribution of observation sites is typically biased to accessible locations (highways or cable cars).

\section{2) Northern Hemisphere snow cover extent-D.A. Robinson}

Annual snow cover extent (SCE) over NH lands averaged 24.8 million $\mathrm{km}^{2}$ in 2019. This is 0.8 million $\mathrm{km}^{2}$ smaller than the 2018 mean extent and 0.3 million $\mathrm{km}^{2}$ smaller than the 50 -year average (mapping extends back to late 1966; however, several early years in the record are incomplete) and ranks 2019 as having the 17th-least extensive cover on record (Table 2.4). SCE over Eurasia and North America, including the Greenland ice sheet (GrIS), is considered in this analysis. Monthly SCE in 2019 ranged from 47.2 million $\mathrm{km}^{2}$ in January to 2.5 million $\mathrm{km}^{2}$ in August.

January 2019 NH SCE was near average, ranking as the 27th-most extensive over the past 53 years. Both Eurasia and North America ranked similarly. The NH as a whole had near-average SCE in February; however, North America and Eurasia ranked fourth and 42nd largest, respectively. The continental disparity continued into March with the combined rank falling into the lowest third. This decline became greater through the spring and early summer, with both continents ranking in the lower tercile throughout this interval. June had the largest negative monthly $\mathrm{NH}$ anomaly of the year (3.6 million $\mathrm{km}^{2}$ or $38 \%$ below normal). NH SCE has been below average for 14 of the past 15 years in May and all of the past 15 years in June (Fig. 2.12).

Autumn SCE emerged at an average pace in September but increased rapidly in October, having the largest positive monthly anomaly of 2019 at 3.8 million $\mathrm{km}^{2}$. October and November SCE each ranked fifth largest of the satellite era for their respective months. NH SCE has now been above average in 10 of the past 11 years in October and all of the past 11 years in November. December SCE was also above average over North America, but Eurasian cover increased slowly during 
Table 2.4. Monthly and annual NH and continental snow extent (million $\mathbf{~ k m}^{2}$ ) between Nov 1966 and Dec 2019. Included are the numbers of years with data used in the calculations, means, standard deviations, 2019 values, and rankings. The years 1968, 1969, and 1971 have 1, 5, and 3 missing months respectively, thus are not included in the annual (Ann) calculations. Ranks are from most extensive (1) to least (ranges from 50 to 54 depending on the month).

\begin{tabular}{|cccccccc|}
\hline & $\begin{array}{c}\text { Years } \\
\text { of data }\end{array}$ & $\begin{array}{c}\text { Mean } \\
\text { SCE }\end{array}$ & Std. dev. & 2019 & $\begin{array}{c}2019 \\
\text { NH } \\
\text { rank }\end{array}$ & $\begin{array}{c}2019 \\
\text { Eurasia } \\
\text { rank }\end{array}$ & $\begin{array}{c}2019 \\
\text { N Am. } \\
\text { rank }\end{array}$ \\
\hline Jan & 53 & 47.2 & 1.5 & 47.2 & 26 & 25 & 27 \\
\hline Feb & 53 & 46.0 & 1.8 & 46.0 & 23 & 42 & 4 \\
\hline Mar & 53 & 40.5 & 1.8 & 39.5 & 37 & 47 & 9 \\
\hline Apr & 53 & 30.5 & 1.7 & 29.1 & 42 & 41 & 35 \\
\hline May & 53 & 19.2 & 1.9 & 17.1 & 44 & 46 & 46 \\
\hline Jun & 52 & 9.5 & 2.4 & 5.9 & 49 & 46 & 50 \\
\hline Jul & 50 & 3.9 & 1.2 & 2.6 & 44 & 38 & 47 \\
\hline Aug & 51 & 3.0 & 0.7 & 2.5 & 41 & 40 & 34 \\
\hline Sep & 51 & 5.4 & 0.9 & 5.1 & 32 & 27 & 36 \\
\hline Oct & 52 & 18.5 & 2.7 & 22.3 & 5 & 7 & 3 \\
\hline Nov & 54 & 34.2 & 2.1 & 37.1 & 5 & 14 & 3 \\
\hline Dec & 54 & 43.7 & 1.8 & 43.5 & 36 & 42 & 18 \\
\hline Ann & 50 & 25.1 & 0.8 & 24.8 & 34 & 40 & 20 \\
\hline
\end{tabular}

the month, resulting in the 13th-smallest December extent (Table 2.4).

The 2019 SCE over the contiguous United States was near average in January. February and March had their fourth- and sixth-most extensive SCE, respectively. April SCE returned to near average, while May SCE was quite low. While not much in terms of coverage, September SCE was record large for the month, followed by the third-largest October extent, and 11th-largest November extent, which was similar to Canada. SCE was near-average in December.

SCE is calculated at the Rutgers Global Snow Lab from daily SCE maps produced by meteorologists at the National Ice Center (a U.S. joint NOAA, Navy, and Coast Guard facility), who rely primarily on visible satellite imagery to construct the maps (https://snowcover.org).

\section{3) Glaciers-M. S.Pelto and World Glacier} Monitoring Service

The World Glacier Monitoring Service (WGMS) record of mass balance and terminus behavior (WGMS 2017) provides a global index for alpine glacier behavior. Glacier mass balance is the difference between accumulation and ablation, reported here in millimeter of water equivalence (mm). In 2019, a negative annual mass balance was reported from all 45 glaciers where annual mass balance was measured and reported to the WGMS, including 26 glaciers of the reference glacier network. The mean mass balance of the reference glaciers reporting for the 2018/19 hydrological year is $-1241 \mathrm{~mm}$; this includes data from 12 nations on four continents. This makes 2019 the 32nd consecutive year with

a global alpine reference glacier mass balance loss and the 10th consecutive year with a mean global mass balance loss greater than $700 \mathrm{~mm}$.

Figure 2.13 illustrates glacier mass balance for a set of global reference glaciers with more than 30 continuous observation years for the time period 1950-2019. Global values are calculated using 


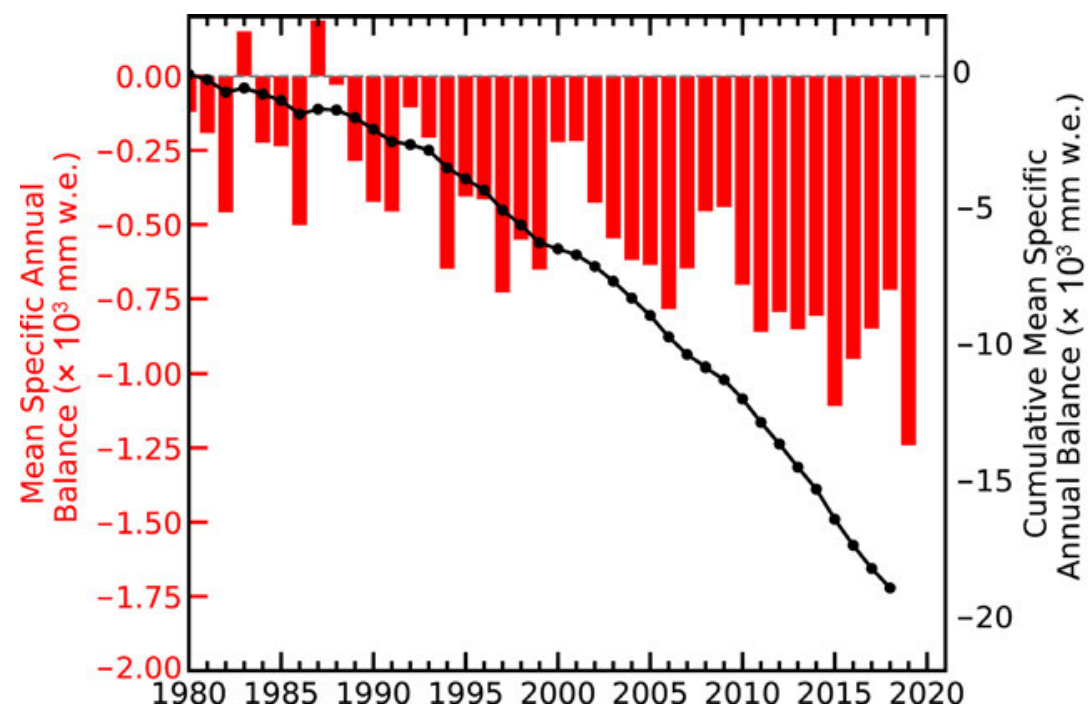

Fig. 2.13. Global alpine glacier annual mean mass balance record $\left(\times 10^{3}\right.$ $\mathrm{mm}$ w.e.) of reference glaciers submitted to the WGMS 1980-2018, based on average annual value determined for 19 different alpine regions. The 2019 value is the mean of all reporting reference glaciers. a single value (averaged) for each of 19 mountain regions in order to avoid a bias to well-observed regions. In the hydrological year 2016/17, all observed glaciers experienced an ice loss of $-550 \mathrm{~mm}$, and $2017 / 18$ of $-720 \mathrm{~mm}$. For the 2018/19 hydrological year, a regionally averaged value will become available in late 2020; however, the overall mean of all reference glaciers was $-1241 \mathrm{~mm}$, compared to $-1183 \mathrm{~mm}$ in $2017 / 18$. Zemp et al. (2019) calculated that the collective loss of alpine glaciers from 2006 to 2016 contributed to a global sea level rise of $0.92 \pm 0.39 \mathrm{~mm} \mathrm{yr}^{-1}$.

The decadal-averaged annual mass balance for the reference glaciers was $-172 \mathrm{~mm}$ in the $1980 \mathrm{~s},-460 \mathrm{~mm}$ in the $1990 \mathrm{~s},-500 \mathrm{~mm}$ for the $2000 \mathrm{~s}$, and $-889 \mathrm{~mm}$ for the 2010s. The increasing rate of glacier mass loss, with 8 out of the 10 most negative mass balance years recorded after 2010, during a period of retreat, indicates that alpine glaciers are not approaching equilibrium and retreat will continue to be the dominant terminus response (WGMS 2017). The lack of retained snow cover on two WGMS reference glaciers is a visual illustration of the mass balance loss (Fig. 2.14).

All 14 glaciers in the Alps with mass balance observations had negative measurements, averaging $-1100 \mathrm{~mm}$ in 2019. In Austria in 2018, of the 93 glaciers with annual terminus observations, 89 (95.7\%) withdrew and four remained stationary (Lieb and Kellerer-Pirklbauer 2019). This retreat trend has continued in 2019 based on preliminary observations. The 2018/19 winter in the Alps featured above-average snowpack. During several heat waves in the summer of 2019, glacier melt peaked, leading to another year with large losses in ice mass balance loss.

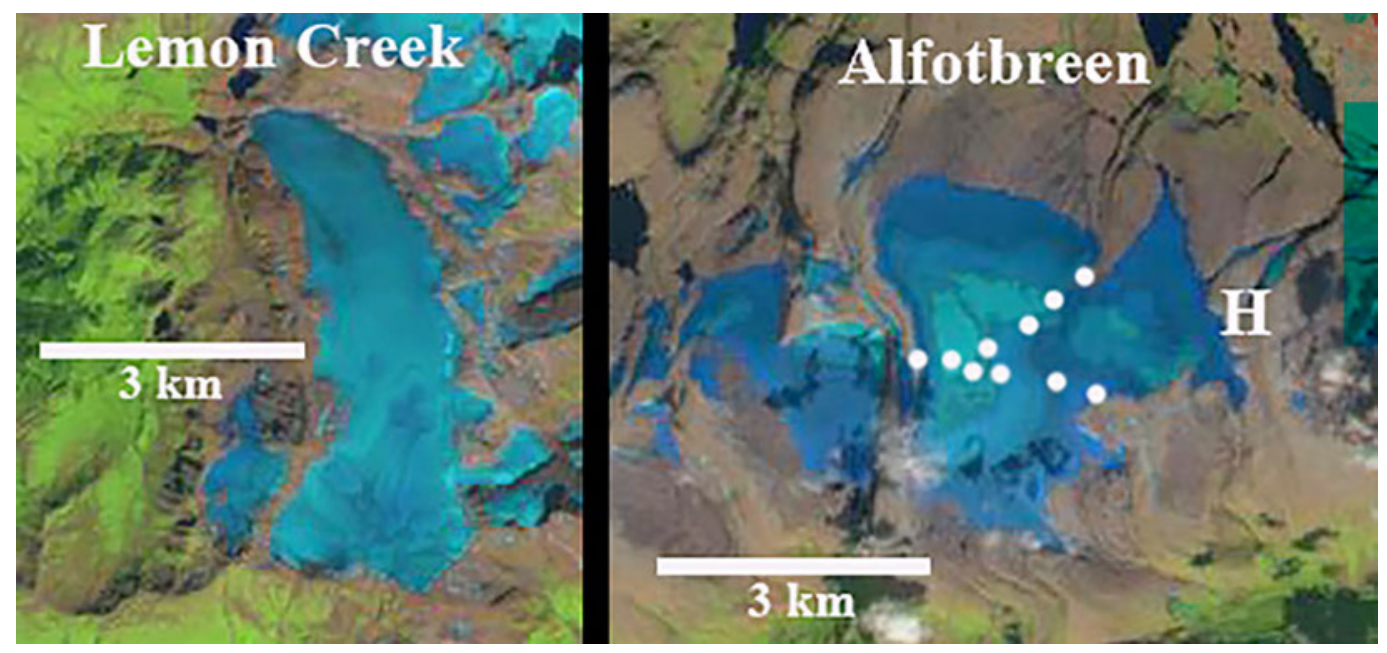

Fig. 2.14. Lemon Creek Glacier, United States, and Alfotbreen, Norway, had significant negative annual mass balance in 2019 at $-2400 \mathrm{~mm}$ and $-3400 \mathrm{~mm}$. Alfotbreen's boundary is marked by white dots. On Alfotbreen, less than $20 \%$ of the glacier has retained snow cover in this 26 Aug Landsat image. On Lemon Creek Glacier, there is no significant snow accumulation retained in this 8 Aug Landsat image. The darkest blue color is bare glacier ice, with firn that is more than year old a medium blue and snow from the 2019 winter a light blue. 
In Norway, the seven glaciers reporting mass balance had an average loss of $-1354 \mathrm{~mm}$ in 2019. This loss leads to continued retreat; in 2018, of 32 glaciers measured, 28 retreated more than $10 \mathrm{~m}$, and four were approximately stationary, retreating, or advancing less than $6 \mathrm{~m}$ (Kjøllmoen et al. 2019).

In Alaska and Washington, all 15 glaciers observed in 2019 had a negative mass balance, averaging $-1372 \mathrm{~mm}$. This is significantly larger than the long-term average of four USGS benchmark glaciers, which have a cumulative mass loss since the mid-twentieth century that average from -580 to $-300 \mathrm{~mm} \mathrm{yr}^{-1}$ (O’Neel et al. 2019). During the 74-year annual mass balance record for Taku Glacier, Alaska, the end of summer snowline, which is the equilibrium line altitude, had never exceeded $1225 \mathrm{~m}$ until 2018, when it reached $1425 \mathrm{~m}$, and then reached a new maximum of $1450 \mathrm{~m}$ in 2019 (Pelto 2019).

In South America, 2019 mass balance data were reported from one glacier in Chile and three in Argentina, and indicate a mean of $-1559 \mathrm{~mm}$. This is greater than the 2000-18 average loss observed in the Andes of $-720 \pm 220 \mathrm{~mm}$, with the Patagonia Andes having the highest rate of loss at $-780 \pm 250 \mathrm{~mm}$ (Dussaillant et al. 2019).

In High Mountain Asia, all five reporting glaciers had negative mass balances. King et al. (2019) found no substantial difference in the mass loss of debris-covered and clean-ice glaciers but more negative mass balances for lake-terminating glaciers for the 1974-2015 period. The continued expansion of established proglacial lakes and the formation of new proglacial lakes will enhance ice mass loss from the region in coming decades (King et al. 2019).

\section{Sidebar 2.1: Lake Ice-S. SHARMA AND R.I. WOOLWAY}

Lake ice is a sensitive indicator of climate as it integrates antecedent air temperatures in the range of weeks to months prior to ice breakup and closely tracks the $0^{\circ} \mathrm{C}$ isotherm (Brown and Duguay 2010). Lake ice has long fascinated people because of its importance to transportation, refrigeration, and recreation, thus comprising some of the earliest records of climate before the advent of meteorological stations (Magnuson et al. 2000; Sharma et al. 2016). Records of lake ice phenology (defined as the timing of ice-on and ice-off) benefit from in situ records with high temporal resolution, satellite records, and reanalyses (i.e., ERA5) with high spatial resolution. This section covers the 2018/19 Northern Hemisphere (NH) winter, with ice-on data from autumn 2018 and ice-off from spring 2019. The winter season spans two years and is defined as the time lakes experience seasonal ice cover, typically between November and April. For example, the 1981 winter would typically begin in November 1980 and end in April 1981.

In 2019, lake ice phenology anomalies across the $\mathrm{NH}$, derived from ice cover data from ERA5 reanalysis (Hersbach et al. 2020), showed that on average, ice-on was one day later and ice-off was two days earlier than the 1981-2010 base period over the winter season (Figs. SB2.1 and SB2.2). Lake ice froze later, melted earlier, and had shorter seasonal ice duration over western North America, northern Europe, and northern Asia. In contrast, lake ice-on was earlier, ice-off was later, and ice duration was longer across Canada (except the west), the northern United States, and southern Eurasia (Fig. SB2.1).
Ice-on was four days later and ice-off was three days earlier on average for lakes distributed across the NH in 2019 based on long-term in situ phenological records (Fig. SB2.2). For monitored lakes in Europe, ice duration was 18 days shorter than the 1981-2010 base period. In contrast, for North American lakes, ice duration was nine days longer. Generally, across the $\mathrm{NH}$, lake ice cover followed the long-term warming trend such that since 1981, lake ice duration is seven days shorter per decade on average for the 18 lakes with in situ measurements. Lake ice-on is five days later decade ${ }^{-1}$, with the most negative trend at 0.2 days earlier decade $^{-1}$ ( $95 \%$ confidence interval: $-3.6,3.3$ days decade ${ }^{-1}$ ) and the most positive trend at 11 days later decade ${ }^{-1}$ ( $95 \%$ confidence interval: 5,17 days decade $\left.{ }^{-1}\right)$. Lake ice-off is on average two days earlier decade ${ }^{-1}$, but varies from 4.1 days earlier decade ${ }^{-1}(95 \%$ confidence interval: $-5.9,-2.3$ days decade ${ }^{-1}$ ) to 1.2 days later decade $^{-1}$ (95\% confidence interval: $-2.1,4.5$ days decade $^{-1}$ ).

This year, the Great Lakes of North America had greater maximum ice cover, suggesting a cooler winter. On average, the Great Lakes had $30.1 \%$ additional ice coverage than the 1981-2010 normal. The larger and most northern of the Great Lakes had the highest positive anomaly, such that Lake Superior (82 $\left.103 \mathrm{~km}^{2}\right)$ had $34.2 \%$ more ice cover, whereas the smaller southern lakes, such as Lakes Erie $\left(25744 \mathrm{~km}^{2}\right)$ and Ontario $\left(18960 \mathrm{~km}^{2}\right)$, had $13 \%$ additional maximum ice coverage (Fig. SB2.3). During the 2019 winter, Lakes Superior, Huron, and Erie had ice coverage across more than $90 \%$ of their respective surfaces. 

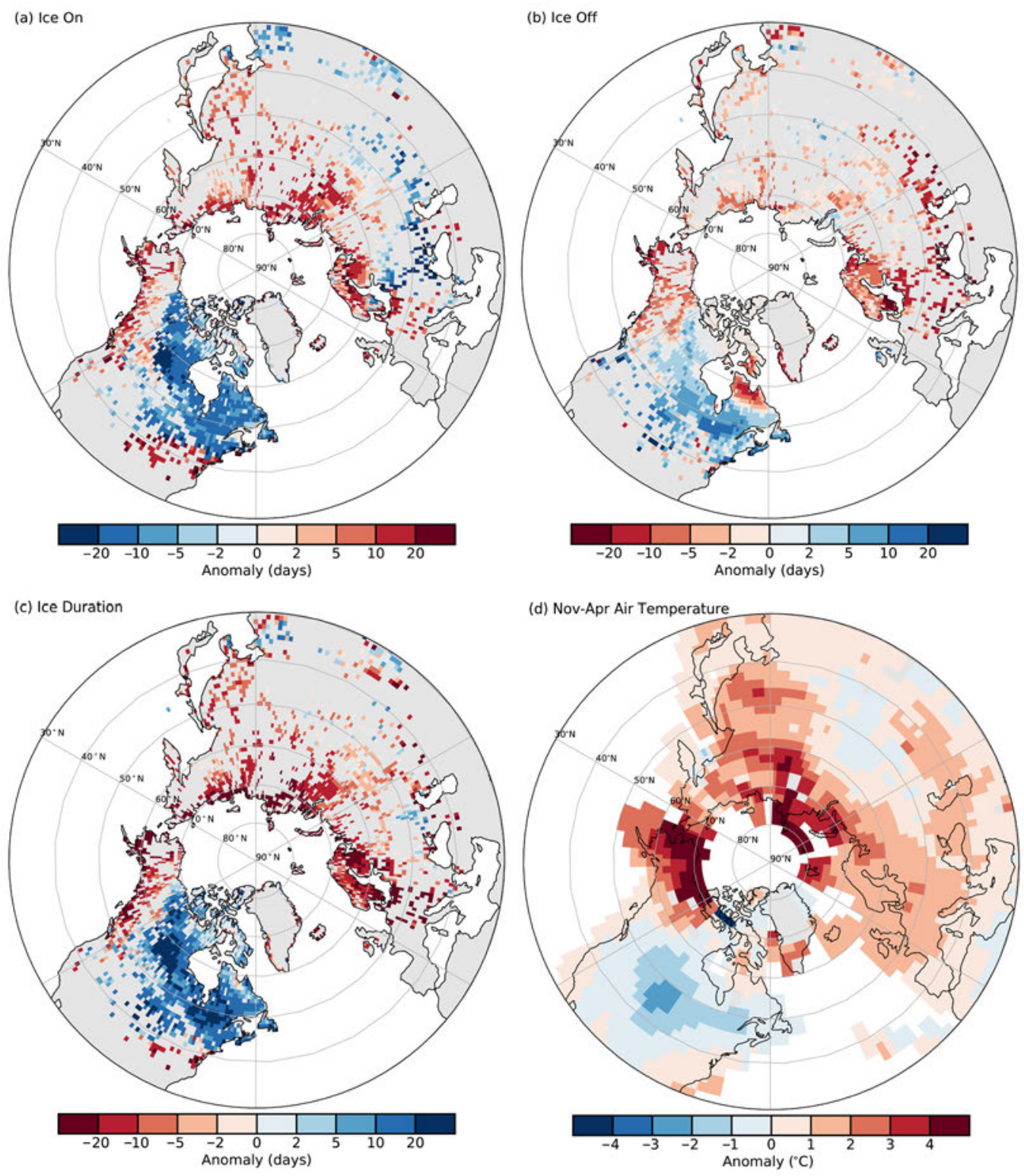

Fig. SB2.1. Lake ice 2019 anomalies for (a) ice-on, (b) ice-off, and (c) ice duration for lakes across the NH (base period: 1981-2010). (Source: ERA5.) (d) Nov-Apr 2018/19 air temperatures. (Source: GISTEMP.)

The changes in ice cover in 2019 relate to air temperature anomalies across the NH. Specifically, the spatial pattern in iceon, ice-off, and ice duration are consistent with NH cold season (November-April) averaged surface air temperature anomalies (Fig. SB2.1). Regions with shorter ice duration, later ice-on, and earlier ice-off, such as northern Eurasia and western North America, are those with positive air temperature anomalies during the cold season in 2019 (Fig. SB2.1d). Conversely, regions with longer ice cover duration, such as the Great Lakes region, are those with negative air temperature anomalies during the cold season in 2019. Thus, lake ice cover anomalies in 2019 broadly track surface air temperatures (section 2b1), although factors such as wind speed, humidity, snow cover, hydrology, and lake morphometry contribute to variations in ice cover (Brown and Duguay 2010). The relationship between air temperature and lake ice cover, published in previous studies (Palecki and Barry 1986; Weyhenmeyer et al. 2004; Brown and Duguay 2010), suggest that antecedent air temperatures are the most important drivers of ice cover and phenology in 2019. For example, in past years, winter air temperatures alone explain $93 \%$ of variation in ice duration in Lake Muggelsee, Germany (Adrian and Hintze 2000), and in 55 Alaskan lakes, air temperature, along with lake area, explain over $80 \%$ of the variation in ice-off dates (Arp et al. 2013).

Ice-on, ice-off, and ice duration were derived from ECMWF's ERA5 reanalysis product for land pixels filled with water $\left(>1 \%\right.$ coverage) on a $0.25^{\circ} \times 0.25^{\circ}$ latitude-longitude grid 


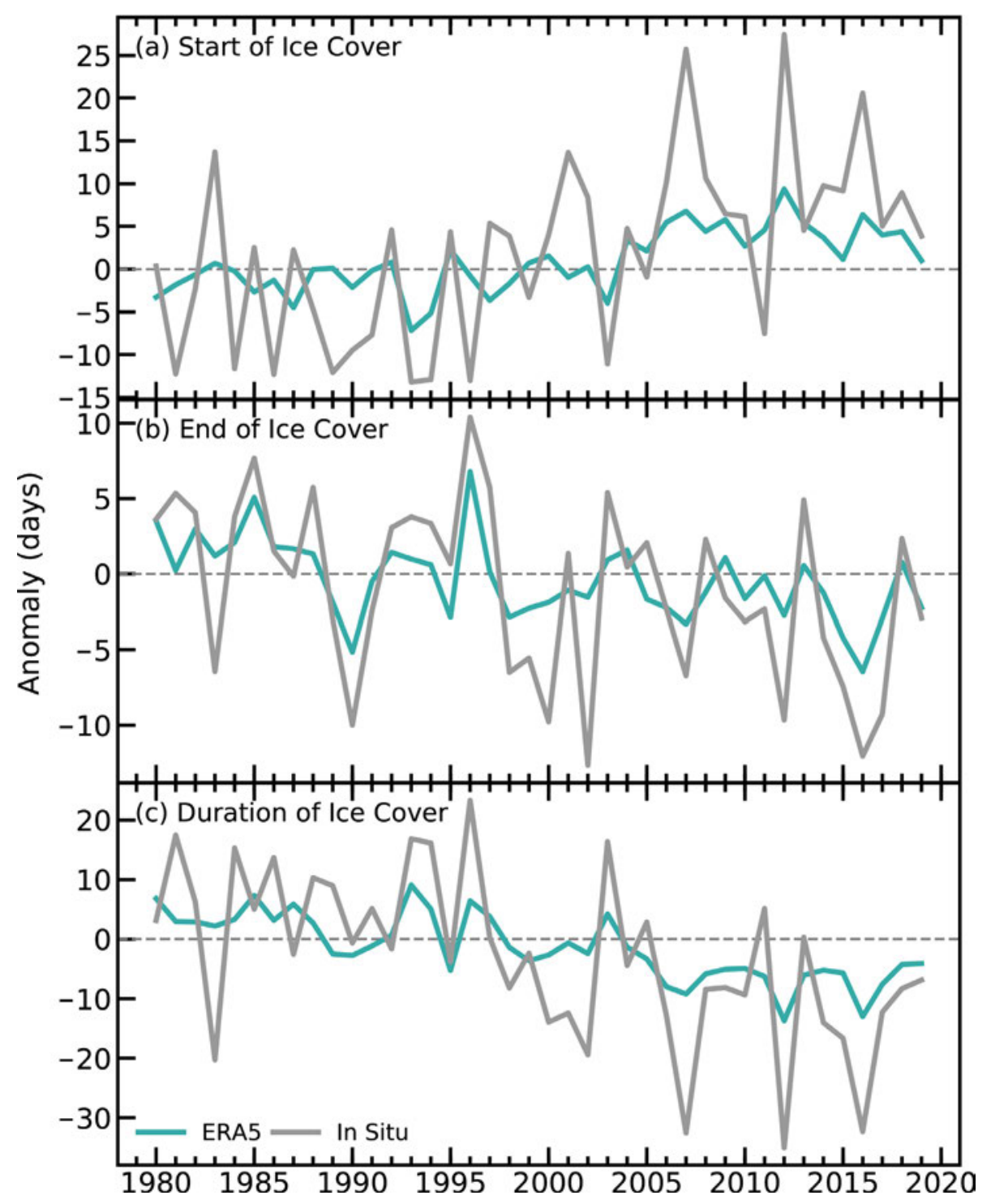

Fig. SB2.2. ERA5 (teal line) and in situ-derived (gray line) anomalies (days) based on an arithmetic mean for (a) ice-on, (b) ice-off, and (c) ice duration from 1980 to 2019.

(Hersbach et al. 2020). Ice cover within ERA5 is simulated via the Freshwater Lake model (FLake; Mironov 2008; Mironov et al. 2010), which is implemented within the Hydrology Tiled ECMWF Scheme for Surface Exchanges over Land (HTESSEL; Dutra et al. 2010; Balsamo et al. 2012) of the European Centre for Medium-Range Weather Forecasts (ECMWF) Integrated Forecasting System (IFS). A detailed description of the model and its implementation in ECMWF's IFS is provided by ECMWF (2018).

In situ ice phenology data were acquired for 18 lakes across the NH where ice-on, ice-off, and ice duration have been collected for at least 130 years (Benson et al. 2000). We updated ice phenology data to 2019 for 10 lakes in Sweden and Finland, one lake in Russia, and seven lakes in the United States. We calculated trends using linear regression models and calculated $95 \%$ confidence intervals for the slope of the line. Lastly, we acquired annual maximum ice cover for the Great Lakes encompassing 1973-2019 from the Great Lakes Environmental Research Laboratory. The maximum amount of ice coverage observed over the winter season is calculated across the entire area of each of the Great Lakes by using a combination of composite ice charts and observations from satellites, ships, and air craft (https://www .glerl.noaa.gov/data/ice/).

Surface air temperature data for November-April were downloaded from the NASA Goddard Institute for Space Studies (GISS) surface temperature analysis (Lenssen et al. 2019). Temperature anomalies were calculated relative to the 1981-2010 average. 


\section{d. Hydrological cycle}

1) Surface humidity —K. M. Willett, A. J. Simmons, M. Bosilovich, and D. I. Berry

Surface specific humidity remained high in 2019 (Fig. 2.15). Over land, the global average anomaly relative to the 1981-2010 average was between 0.14 and $0.25 \mathrm{~g} \mathrm{~kg}^{-1}$ across all estimates, slightly higher than in 2018. Over ocean, 2019 had higher anomalies than 2018 and was one of the moistest years on record, between 0.21 and $0.35 \mathrm{~g} \mathrm{~kg}^{-1}$.

Simultaneously, 2019 was the driest year on record in terms of relative humidity over land for all products, ranging between -0.86 and $-1.27 \% \mathrm{RH}$ below average, albeit not significantly so given the $2 \mathrm{std}$. dev. uncertainty spread for HadISDH at least (Fig. 2.15). Over ocean, relative humidity anomalies were close to or below average, between -0.29 and $0.03 \% \mathrm{RH}$. This moister, yet less saturated, land surface atmosphere occurred along with near-record temperatures over land and ocean (section 2b).

Collectively, 2019 humidity continued the long-term trends of increasing moisture over land and ocean while decreasing levels of saturation over land. From HadISDH, the corresponding 1973-2019 trends (90th percentile confidence intervals) are 0.09 (0.07 to 0.11$) \mathrm{g} \mathrm{kg}^{-1} \mathrm{decade}^{-1}$,

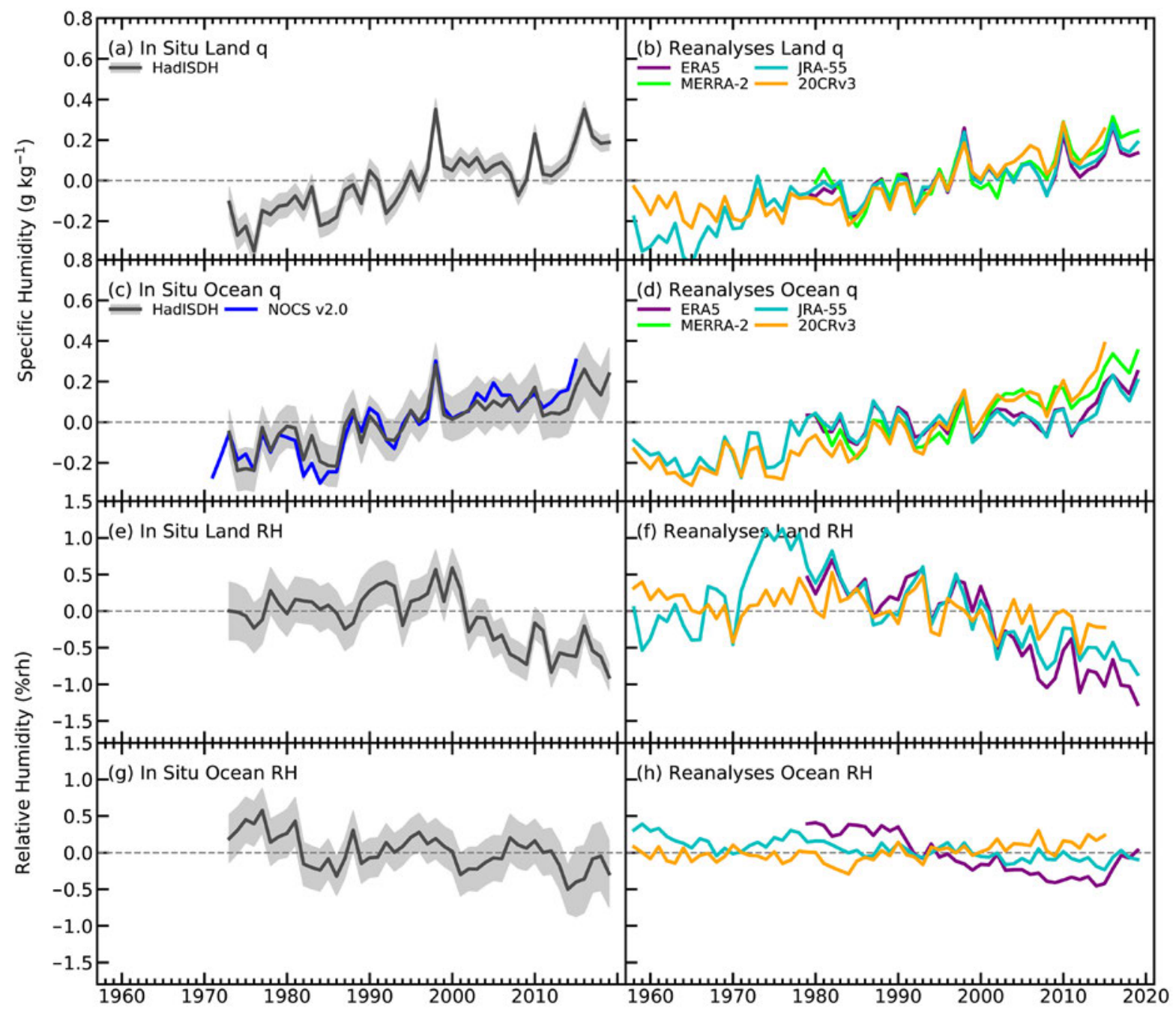

Fig. 2.15. Global average surface humidity annual anomalies (1981-2010 base period). For the in situ datasets, 2-m surface humidity is used over land and $\sim 10-\mathrm{m}$ over the oceans. A 2 std. dev. uncertainty range is shown for HadISDH, capturing the observation, gridbox sampling, and spatial coverage uncertainty. For the reanalysis, 2-m humidity is used over the whole globe. For ERA5 ocean series, only points over open sea are selected, and background forecast values are used as opposed to analysis values because of unreliable use of ship data in producing the analysis. (Sources: HadISDH [Willett et al. 2013, 2014, in review]; NOCSv2.0 [Berry and Kent 2009, 2011]; ERA5 [C3S 2017; Hersbach et al. 2020]; JRA-55 [Ebita et al. 2011]; MERRA-2 [Gelaro et al. 2017]; and 20CRV3 [Slivinski et al. 2019].) 
0.08 (0.06 to 0.09$) \mathrm{g} \mathrm{kg}^{-1}$ decade $^{-1}$, and $-0.16(-0.29$ to -0.03$) \% \mathrm{RH}$ decade $\mathrm{e}^{-1}$, respectively. Water vapor increased relative to 2018 far more over ocean compared to land. The 2019 record low land relative humidity is consistent with the small land specific humidity increase. Global specific humidity values over both land and ocean have remained above the 1981-2010 average for a decade now, and land relative humidity values have remained below average since the early 2000s, although HadISDH uncertainty spread crosses the zero-line periodically, particularly for ocean specific humidity. Both ERA 5 and HadISDH suggest that ocean relative humidity has been lower in recent years, but the wide uncertainty spread suggests low confidence in this. Overall, the 2010s were the moistest yet least saturated decade since records began (Fig. 2.15).

Spatially (Plates 2.1g,h; Figs. A2.10-A2.13), 2019 specific humidity was moister than average over the tropical Pacific Ocean and drier than average over Australia. Although such features are often seen during El Niño years, generally, spatial patterns were not ENSO-like.

The high specific humidity signal came largely from the Indian Ocean and is consistent with other variables (see section $2 \mathrm{~d}$ ) and the strong Indian Ocean dipole (IOD). There were also very strong moist anomalies over southern Asia, the central and northeastern Pacific Ocean, the Gulf of Mexico, and the southern tropical Atlantic to some extent. These ocean regions were also anomalously warm during 2019. Aside from southern Asia and especially India, much of the land had weaker moister-than-average anomalies with widespread drier-than-average anomalies that were particularly strong over southern Africa and Australia. The very high specific humidity anomalies over India were associated with much higher-than-average relative humidity anomalies. Conversely, most of the land and oceans had lower-than-average relative humidity anomalies. HadISDH has uncertainty estimates from observation quality, gridbox sampling, and spatio-temporal coverage (Willett et al. 2014, 2020 - in review; Fig. 2.15). These uncertainties are larger for relative humidity than specific humidity and larger over ocean than land, particularly for recent years when digital ocean metadata are unavailable. They do not bring the long-term trend into question nor the fact that 2019 was much moister and yet less saturated than average.

The degree to which the products agree or disagree also provides uncertainty information. Although there is reasonable agreement in the year-to-year variability and long-term trends, there are differences between the in situ and reanalysis products and between the reanalyses themselves. Relative humidity is particularly problematic, with MERRA-2 showing moistening over Asia, unlike ERA5, and HadISDH land and ocean relative humidity showing quite different features. It is not clear which is most reliable. Recently, Freychet et al. (2020) found and adjusted inhomogeneities in Chinese stations. Resulting long-term relative humidity trends were near constant and were larger in wet-bulb temperature compared to ERA5. These trends also differ from those in HadISDH where homogenization was necessarily automated and, therefore, unlikely to be as powerful as regionally applied methods that utilize known changes.

This year version 3 of the 20th Century Reanalysis (20CRv3) is included. Although ending in 2015, it is a useful monitoring tool to compare with other products. ERA-Interim (Dee et al. 2011) is no longer being updated and has been replaced by ERA5. These are similar for the global land surface but differ over ocean, especially for relative humidity (Willett et al. 2019). Greater temporal stability is expected in ERA5 compared to ERA-Interim, and ERA5 assimilates more data, generally. However, uncertainties remain, especially for hydrological cycle variables. These uncertainties arise from errors remaining in the assimilated data, changing data streams over time, and the fact that ERA5 does not impose balance on its water or energy budget (Gelaro et al. 2017; Hersbach et al. 2020). 
2) Total column water vapor-C. Mears, S. P. Ho, Olivier Bock, Xinjia Zhou, and Julien P. Nicolas

In 2019, total column water vapor (TCWV) anomalies were below the record levels observed in 2016, but remained above the 1981-2010 climatological average in most locations (Plate 2.1i; Fig. A2.14). TCWV estimates are available from satellite-borne microwave radiometers over ocean (Mears et al. 2018); from COSMIC; Metop-A,-B, and -C; and COSMIC2 GPS-RO (Global Positioning System-Radio Occultation) over land and ocean (Ho et al. 2010a,b, 2020; Teng et al. 2013; Huang et al. 2013; Ho et al. 2020, submitted to Remote Sens.); and from ground-based Global Navigation Satellite System (GNSS) stations (Bock and Parracho 2019; Bock 2019). In addition, TCWV data from three global atmospheric reanalysis products are also used here: ERA5 (Hersbach et al. 2020), MERRA-2 (Gelaro et al. 2017), and JRA-55 (Kobayashi et al. 2015). Note that all three reanalyses assimilate satellite microwave radiometer and GPS-RO data and are therefore not independent from these two datasets.

The most prominent feature in Plate 2.1i for 2019 was the strong east-west dipole in the equatorial Indian Ocean, associated with the positive phase of the IOD mode observed in late 2019 (see section 4h). A similar dipole feature was also observed in precipitation (section 2d4). A positive IOD phase has been linked to reduced precipitation over Australia (Ashok et al.2003), as depicted in Plate 2.1i. There were also moderate wet anomalies in the western tropical Pacific and in sub-Saharan Africa. Other regions showed a mix of smaller wet and dry anomalies, with more regions slightly wetter than the 1981-2010 normal. The patterns in TCWV from ERA5 (Plate 2.1i) over the ocean are confirmed by microwave radiometers (Fig. A2.14), COSMIC ocean measurements, and by output from the three additional reanalyses. Over land, the patterns from COSMIC and other RO missions (satellite RO) are generally similar to the reanalysis output except over northern Africa, where RO shows a pronounced dry anomaly not present in reanalysis. The ground-based GNSS results are also in good agreement with reanalysis.

Over the ocean, the TCWV anomaly time series (Figs. 2.16a,b) from reanalyses and microwave radiometers show maxima in 1983/84, 1987/88, 1997/98, 2009/10, and 2015/16 associated with El Niño events, with 2019 approaching the 2015/16 record levels. The radiometer data show an increasing trend of $0.43 \mathrm{~mm}$ decade ${ }^{-1}$ over their period of record (1988-2019). The different reanalysis products, on the other hand, show a wide range of long-term trends over the entire period, but agree well with the radiometer data after the mid1990s. The satellite RO data are in relative agreement with both the radiometer and reanalysis data after COSMIC began in 2006. Note that the uncertainty in these large-scale averages is larger at the beginning and end of the time

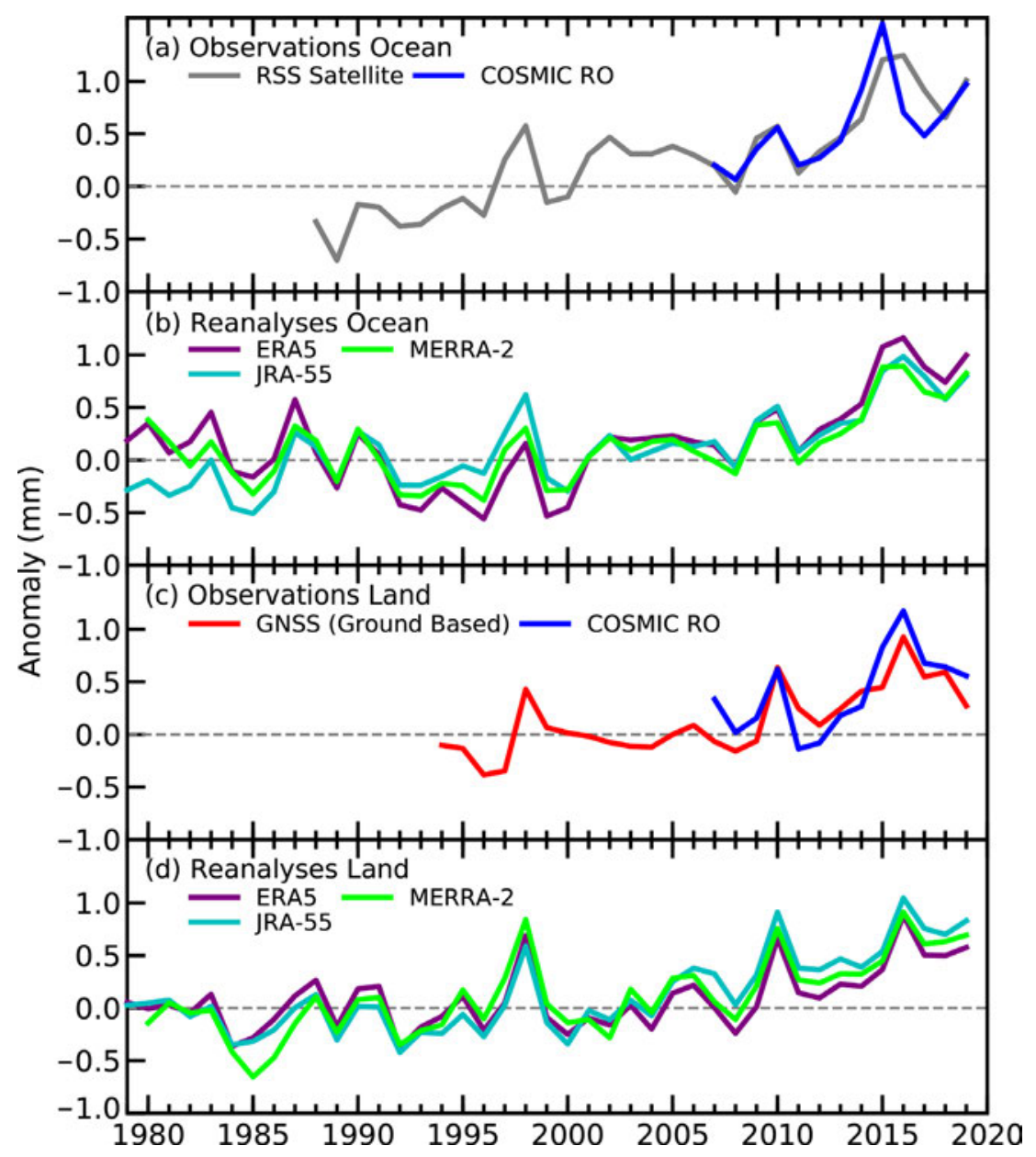

Fig. 2.16. Global mean TCWV annual anomalies ( $\mathrm{mm}$ ) for (a) ocean observations, (b) ocean reanalysis, (c) land observations, and (d) land reanalysis averaged over $60^{\circ} \mathrm{N}-60^{\circ} \mathrm{S}$. The shorter time observational series have been adjusted so that there is zero mean difference relative to the ERA5 results during their respective periods of record. 
series due to reduced sampling. TCWV is strongly driven by ENSO conditions and to a lesser extent by stratospheric aerosols from volcanic eruptions. After the 2015/16 El Niño peak, all datasets show a return to drier conditions due to generally neutral/weak La Niña conditions in 2017/18, followed by wetter conditions linked to the weak El Niño in winter-spring 2018/19.

Over land, the three reanalyses, satellite RO missions, and GNSS are in good agreement (Figs. 2.16c,d). The small differences in GNSS anomalies are due to asymmetry in the spatial sampling (more stations are located in the Northern Hemisphere $[\mathrm{NH}]$ ), but the general trend and inter-annual variability are well observed. A latitude-time Hövmuller plot of TCWV anomalies over land and ocean derived from ERA5 (Fig. 2.17) indicates that the long-term increase in TCWV is occurring at all latitudes, with less variability outside the tropics. Following the most recent El Niño in 2015/16, elevated moisture has persisted in the tropics, particularly north of the equator.

\section{3) Upper tropospheric humidity-V. O. John, L. Shi, E.-S. Chung, R. P. Allan, S. A. Buehler, and B. J. Soden}

The 2019 global-average upper tropospheric (relative) humidity (UTH) continued to stay close to the 2001-10 average (+0.016 \% RH for the microwave dataset; Fig. 2.18). This implies a continued moistening of the upper troposphere with warming. A near-zero decadal trend in the UTH indicates an increase in absolute (specific) humidity in line with the warming mid- and upper troposphere (about $0.2 \mathrm{~K} \mathrm{decade}^{-1}$ as shown for example in Santer et al. [2017]; section 2b4), and hence is consistent with a positive (amplifying) water vapor feedback (Chung et al. 2016). The water vapor feedback is determined mainly by the mid- to upper-troposphere (Allan et al. 1999; Held and Soden 2000), because the radiative effect of water vapor is proportional to relative changes in water vapor (John and Soden 2007) and not to the absolute amount.

During the first half of 2019, the anomalies were slightly below average $(-0.071 \% \mathrm{RH}$ compared to $0.103 \% \mathrm{RH}$ in the second half for the microwave dataset), indicating weak El Niño-like conditions, in which an intensified Hadley circulation leads to enhanced subsidence in dry zones (e.g., Tivig et al. 2020). During the second half of the year, the anomalies were generally above average, associated with ENSO-neutral conditions.

There is broad agreement among the three available datasets (HIRS infrared satellite [Shi and Bates, 2011]; microwave satellite data [Chung et al. 2013]; ERA5

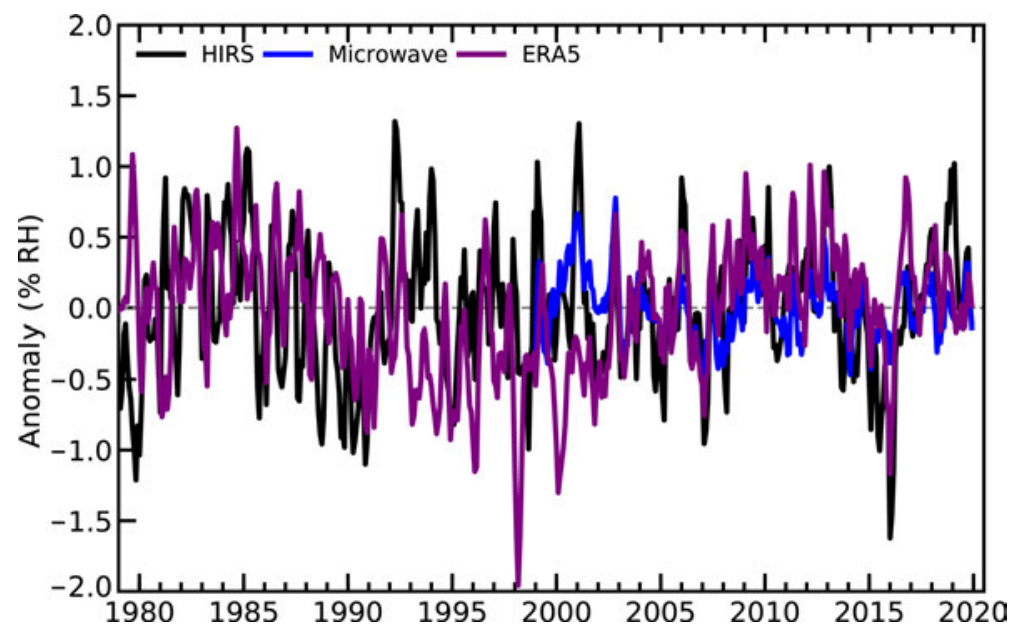

Fig. 2.18. Global $\left(60^{\circ} \mathrm{N}-60^{\circ} \mathrm{S}\right)$ average time series of UTH anomalies (\%RH) using HIRS (black), microwave (blue), and ERA5 (purple) datasets. Anomalies are computed with respect to the 2001-10 average, and the time series are smoothed to remove variability on time scales shorter than three months. 
reanalysis [Hersbach et al. 2020]) in the interannual variability despite their structural differences. During their common period, there is a correlation of 0.6 between the two satellite datasets and 0.5 between ERA5 and either of the satellite datasets. The inter-satellite calibrated and bias-corrected infrared and microwave satellite measurements sample a broad upper tropospheric region (roughly between 500 and $200 \mathrm{hPa}$, but this layer varies slightly depending upon the atmospheric humidity profile) two times per day, and infrared observations only sample clear-sky scenes (John et al. 2011). The ERA5 reanalysis is based on model runs constrained with in situ and satellite data including the HIRS and microwave radiances. ERA5 samples all regions every hour, but here only displayed at $400 \mathrm{hPa}$. During the common period (1999-2019), the mean and standard deviation of the anomaly time series are $-0.39 \pm 0.48,0.08 \pm 0.61$, and $0.00 \pm 0.34 \%$ RH for the ERA5, HIRS, and microwave datasets, respectively. Compared to its previous version (ERA-Interim), the ERA5 time series shows improved consistency with the satellite datasets but displays anomalies more negative than HIRS or the microwave data.

Annual anomalies of UTH for 2019 are shown in Plate 2.1j and Fig. A2.15 for the microwave and HIRS datasets, respectively. Positive anomalies in central and eastern Africa reflect above-average precipitation and flooding events in those areas. Negative anomalies over southern Africa indicate the drought conditions there (see section 2d12). The strong positive phase of IOD can also clearly be seen in the anomalies. During the positive phase of IOD, sea surface temperatures (SSTs) in the Indian Ocean near Africa's east coast are higher than usual, while SSTs in the waters northwest of Australia are comparatively lower. These conditions led to below-average precipitation across Australia, which is also reflected in the negative UTH anomalies over most of Australia. The close connection of UTH to convection makes it suitable for monitoring large-scale dynamics of the troposphere.

\section{4) Precipitation-R. S. Vose, R. Adler,}

\section{A. Becker, and X. Yin}

Precipitation over global land areas in 2019, as estimated from three different monitoring products, was below the 1981-2000 long-term average (Fig. 2.19a). The observational datasets with the most complete global coverage, that is, the gauge-based product from the Global Precipitation Climatology Centre (GPCC; Becker et al. 2013) and the blended gaugesatellite product from the Global Precipitation Climatology Project (GPCP; Adler et al. 2018), had almost identical anomalies for 2019 (-16.57 $\mathrm{mm}$ and $-18.32 \mathrm{~mm}$, respectively). The gauge-based Global Historical Climatology Network (GHCN; Peterson and Vose 1996) dataset was closer to the long-term average, with an anomaly of $-4.80 \mathrm{~mm}$. All three products indicate that 2019 was marginally drier than 2018.

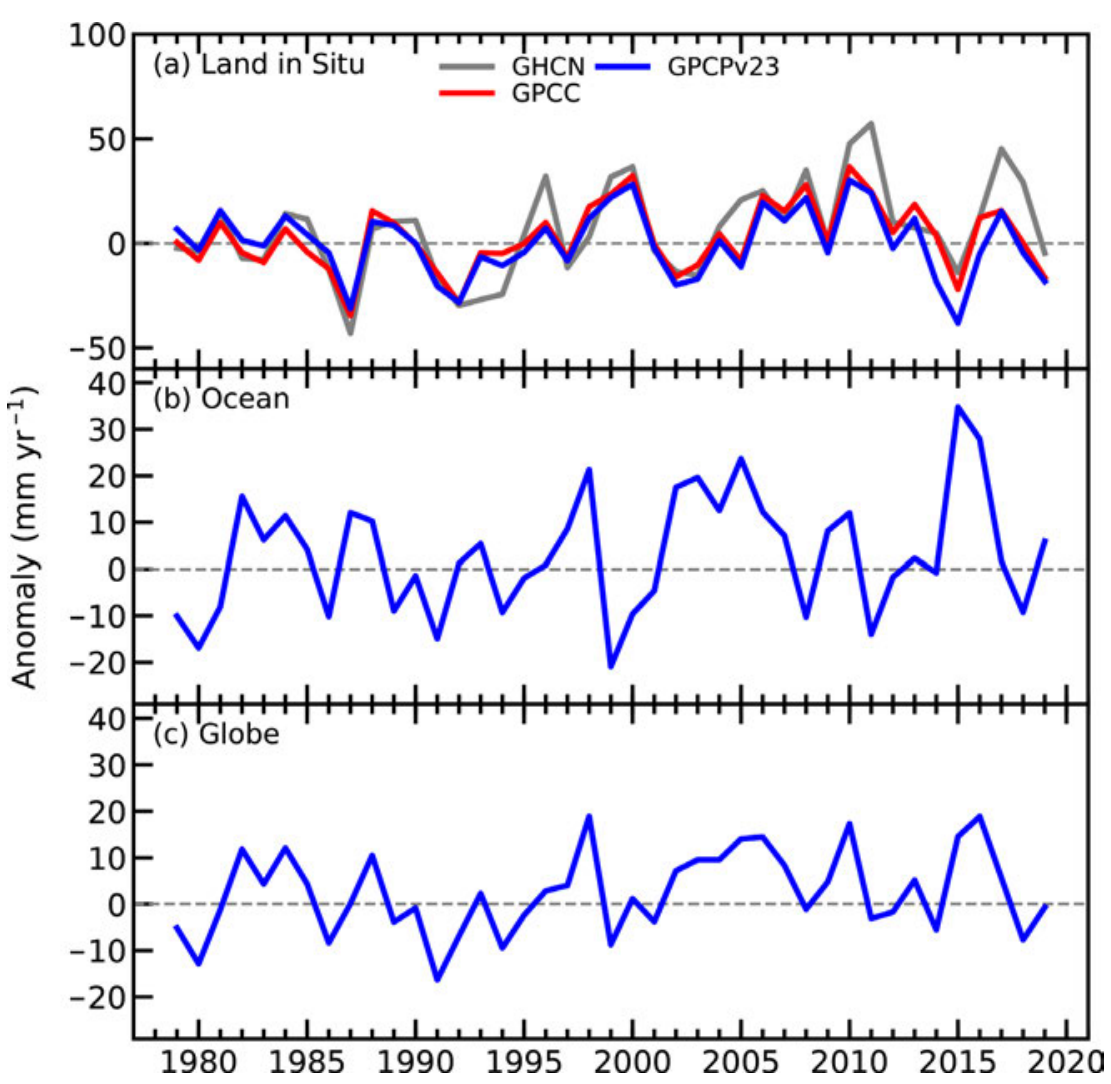

Fig. 2.19. Globally averaged precipitation anomalies $\left(\mathrm{mm} \mathrm{yr}^{-1}\right)$ relative to the 1981-2000 base period over (a) land, (b) ocean, and (c) globe. Land and ocean time series were created using a proportional land/ sea mask at the $1^{\circ} \times 1^{\circ}$ scale. 
According to the GPCP dataset, the precipitation anomaly over the global ocean (Fig. 2.19b) was $+5.9 \mathrm{~mm}$ and the global combined land and ocean anomaly (Fig. 2.19c) was $-0.68 \mathrm{~mm}$, both of which were slight increases from the previous year.

As is always the case, there was substantial variability across the planet in 2019. Much of Africa, Eurasia, North America, and the Amazon basin were wetter than normal, as were the equatorial western Pacific Ocean and the western Indian Ocean (Plate 2.1k). The wet anomaly in the Indian Ocean extended into east Africa, where floods were prevalent during 2019, including floods in March 2019 associated with Cyclone Idai, which killed over 1200 people in Mozambique, Zimbabwe, Malawi, and Madagascar (see Sidebar 7.3 for details). The eastern Indian Ocean, the Maritime Continent, and Australia all experienced much-below-normal precipitation; likewise, Australia had its driest year on record and a very active wildfire season. Parts of the western Atlantic and central Pacific Oceans were also much drier than normal. Large-scale anomaly patterns for 2019 were generally comparable to those of 2018, with notable exceptions; for instance, departures from normal in 2018 were less extreme in the Indian Ocean, the Maritime Continent, and Australia, and the region of drier-than-normal conditions in the equatorial Pacific was deeper and extended farther to the west.

The most striking feature in 2019 was the large rainfall deficit from the eastern Indian Ocean to the South Pacific Ocean east of Australia. With weak El Niño or neutral ENSO conditions during the year, the strong features in this area were driven by conditions in the Indian Ocean; notably, the IOD was strongly positive during the last few months of the year, indicating higher-thannormal SSTs in the western Indian Ocean and lower-than-normal SSTs closer to Australia. The IOD index decreased to near neutral by the end of December, but the rainfall patterns persisted (see section $4 \mathrm{~h}$ for details).

5) Land surface precipitation extremes-S. Blenkinsop, M. R. Tye, M. G. Bosilovich, M. G. Donat, I. Durre,

\section{A. J. Simmons, and M. Ziese}

Precipitation extremes in 2019 were typically mixed, with strong regional signals of both above- and below-average anomalies of frequency (R10mm, R20mm) and intensity (Rx1day, Rx5day; Table 2.5). In many regions, above-average anomalies of either, or both, components led to flooding events. Overall, these extremes' anomalies contributed to a global mean precipitation anomaly below the climatological mean (see section $2 \mathrm{~d} 4$ ).

The data used include gauge (GHCNd; Menne et al. 2012) and gridded (GPCC-First Guess Daily; Schamm et al. 2013) observations, GHCNd-derived gridded extremes (GHCNDEX; Donat et al. 2013), and reanalysis products (ERA5; Hersbach et al. 2020; MERRA-2; Gelaro et al. 2017).

Observational and reanalysis estimates of 2019 R10mm (Plate 2.1l; Fig. 2.20a) and R20mm (not shown) frequency anomalies revealed fewer-than-average heavy (and very heavy) precipitation days over Australia, Japan, most of Europe, and interior Russia, with above-average frequencies over much of the United States and northeast Russia. There is broad agreement between the global datasets and the more limited coverage of GHCNDEX (not shown) over these areas, but disagreement on the sign of anomalies over Scandinavia and southeast Asia. The above-average heavy precipitation days in the United States were consistent with extensive flooding in the Midwest

\begin{tabular}{|c|c|c|}
\hline Index & Name & Definition \\
\hline Rx1day & Max 1-day precipitation amount & Highest 1-day precipitation amount (mm) \\
\hline Rx5day & Max 5-day precipitation amount & Highest 5-day precipitation amount (mm) \\
\hline $\mathrm{R} 10 \mathrm{~mm}$ & Heavy precipitation days & Heavy precipitation days > 10 mm (days) \\
\hline $\mathrm{R} 20 \mathrm{~mm}$ & Very heavy precipitation days & Very heavy precipitation days $>20 \mathrm{~mm}$ (days) \\
\hline
\end{tabular}


(a) MERRA-2 R10mm - Number of heavy precipitation days

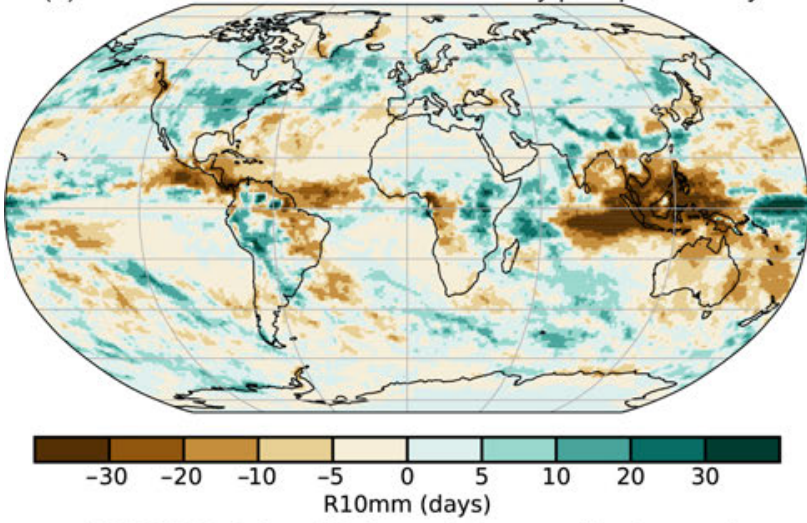

(c) ERA5 Rx1day - Maximum 1 day precipitation total

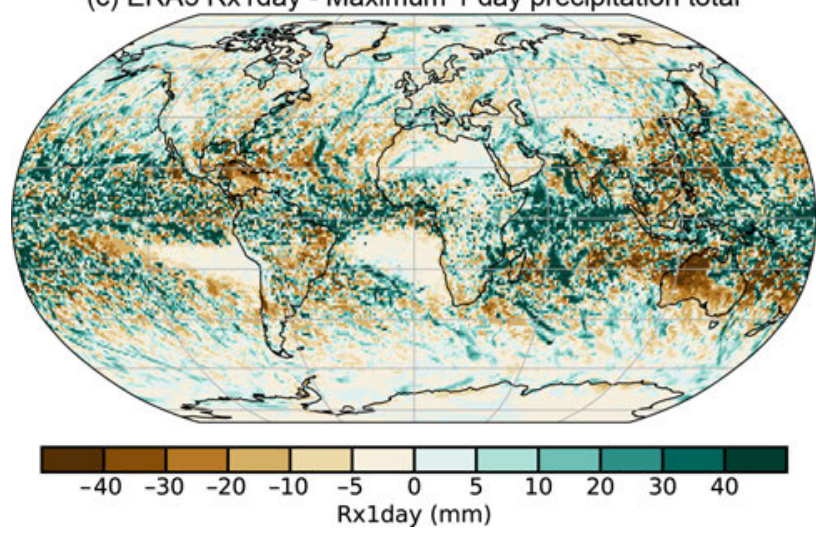

(b) GHCNDEX Rx1day - Maximum 1 day precipitation total

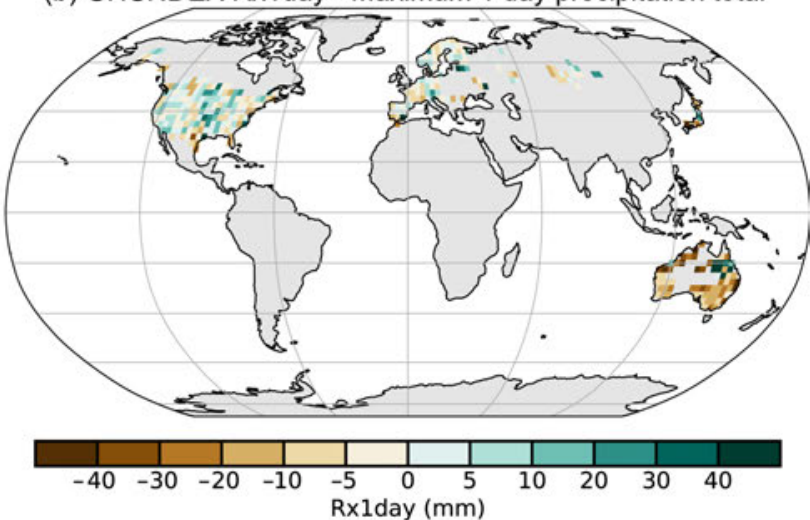

(d) GHCNDEX Rx1day - Maximum 1 day precipitation total

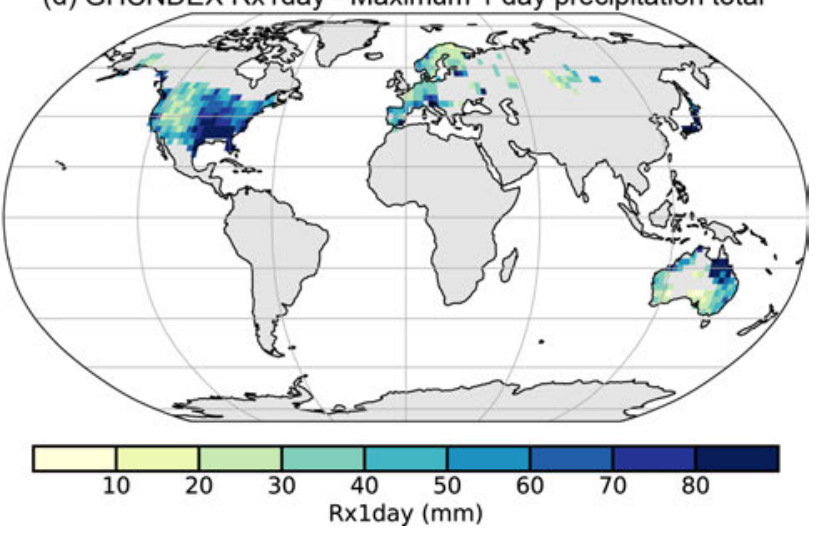

Fig. 2.20. Anomalies of 2019 indices for (a) R10mm derived from MERRA-2 relative to a 1981-2010 baseline and Rx1day derived from (b) GHCNDEX relative to 1961-90 and (c) ERA5 relative to 1981-2010. (d) 2019 absolute Rx1day values from GHCNDEX.

throughout spring and summer, notably the Mississippi and Missouri basins. The globally complete datasets indicated above-average frequencies over Peru, western Brazil, and eastern Africa, all areas affected by flooding in 2019. High frequencies over northern India were associated with late monsoon rainfall and resulted in extensive flooding. There were additional localized areas of high frequency over Afghanistan and Iran, also resulting in flash floods throughout the spring (Floodlist 2019).

Maximum intensity anomalies of Rx1day (Figs. 2.20b,c) and Rx5day (not shown) were noisier than the frequency indices, but largely consistent. GHCNDEX (Fig. 2.20b) shows below-average intensities for most of Australia and western Europe and areas of above-average intensity across the United States. The values of Rx1day for 2019 shown in Fig. 2.20d provide a reference point for these anomalies in absolute terms to enable an estimation of proportional anomalies. The GPCC dataset and the ERA5 (Fig. 2.20c) and MERRA-2 reanalysis products broadly agree and, in particular, confirm a consistent signal over Australia. This reflects the record dry conditions there described in section $7 \mathrm{~h} 4$ and suggests that severe drought conditions were at least partly related to an absence of heavy precipitation events (see also R10 mm). Only over northern Queensland is there a positive anomaly of Rx1day across all data products due to a notable extreme event (e.g., $562 \mathrm{~mm}$ at Mossman at the end of January, see section 7h4), contrasting with a closer-to-average signal for R10mm over this part of the state. The more extensive coverage provided by the reanalyses also suggests maxima of below-average intensity over India (contrasting with higher frequency extreme precipitation), parts of China, and central and southern Brazil (see section 2d4); GPCC-First Guess Daily (not shown) also indicates more extensive areas of below-average intensity in tropical and equatorial regions compared with other datasets, which may reflect its coarser resolution and highlighting some of the uncertainty in estimates of precipitation extremes, particularly where gauge data are sparse. Above-average Rx1day intensities were also 
clearly identifiable in the reanalysis and GPCC products over Mozambique, producing a stronger signal there than R10mm. This was associated with the destructive tropical cyclones Idai and Kenneth, in March and April, respectively (see section 4f6 and Sidebar 7.3 for more details).

The spatial and temporal variability of precipitation extremes and relatively short records makes detection of long-term change difficult; historical context for 2019 is only provided for available long series of indices ( $\geq 50$ years) over Europe, Australia, and the United States. Ranking 2019 extreme precipitation indices over Europe from the European Climate Assessment and Dataset blended time series (Klein Tank et al. 2002) revealed 76 (1.3\% of gauges) new Rx1day and $16(0.3 \%)$

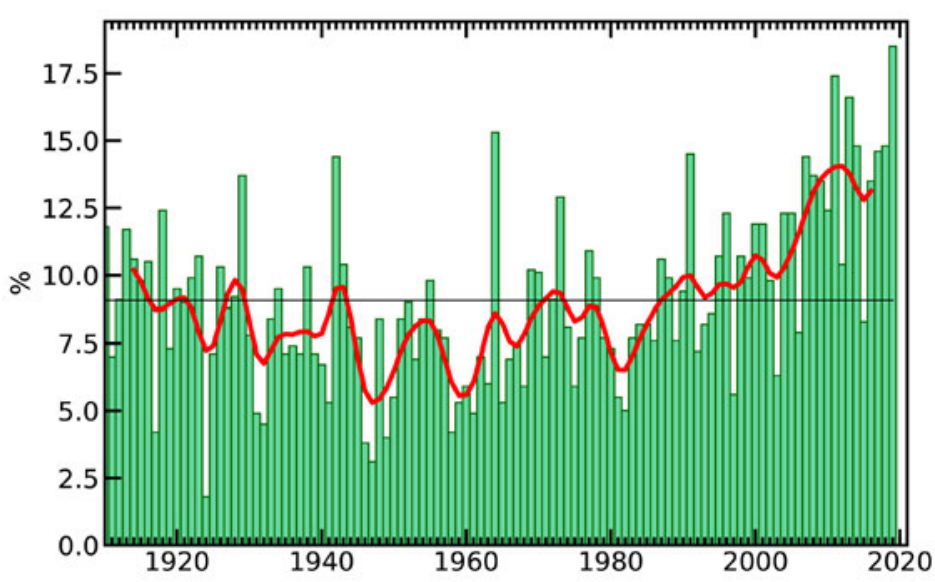

Fig. 2.21. Percentage (\%) of the contiguous United States with a much-greater-than-normal proportion of precipitation derived from extreme (highest 10th percentile) 1-day precipitation events in MAM for the period 1910-2019. Red line denotes smoothed Gaussian filter and the black horizontal line denotes the series mean. new Rx5day records, although some were likely from the same event (for example, the Rx1day total includes new records at five gauges in Murcia, Spain, in September; see section $7 \mathrm{f} 4$ for details). In total, 10.6\% (5.1\%) of Rx1day (Rx5day) values ranked in the top decile for an individual gauge in 2019 compared with 15.4\% (16.8\%) in 2017; 2018 was anomalously dry (Vose et al. 2019) and saw only 7.9\% (4.4\%) of gauges in the top decile. The R10mm and R20mm frequency indices also confirmed fewer heavy precipitation days in 2019 , with only $3.9 \%$ of gauges recording frequencies in the top decile compared with $14.7 \%$ in 2017. This is consistent with Plate 2.11 in suggesting that 2019 saw relatively few heavy precipitation days across much of Europe but with localized high annual maxima.

Australian GHCNd observations also included few new records for Rx1day (3 from 1359 gauges) and Rx5day (10), as ENSO moved from a weak El Niño to a neutral state and due to the influence of a strong positive IOD in late 2019. Only 3\% (2.5\%) of locations experienced Rx1day (Rx5day) in their top decile compared with $13.7 \%$ (11.2\%) in 2017. The new records were set in northern Australia where, for example, in early February, Yabulu, Queensland, received $948 \mathrm{~mm}$ over a 5-day period.

An updated assessment of the U.S. NOAA Climate Extremes Index (Gleason et al. 2008) indicated that annually, component 4 of the index (area of the United States that experienced 1-day precipitation totals exceeding the 90th percentile) ranked 20th in the 110-year record (CEI4 = $13.6 \%$ ) compared to the 2018 ranking of eighth (17.7\%). However, the spring CEI4 of $18.5 \%$ was the highest spring value on record for the contiguous United States, with 6 of the 10 highest spring totals occurring in the 2010s (Fig. 2.21). The season also saw record highs in the South (30.6\%) and Southwest (38.0\%) climate regions.

\section{6) Lake water levels-B. M. Kraemer}

Near real-time variation in lake water levels can serve as an integrative indicator of current global hydrological change. Based on nearly three decades of water level variation analysis for 198 of Earth's largest lakes with publicly available satellite altimetry data (U.S. Department of Agriculture G-REALM project), the annual average water level across these lakes for 2019, giving equal weight to each lake, was $1.70 \mathrm{~m}$ higher than the mean water level for each lake from 1992 to 2002 (minimum level: $-23.55 \mathrm{~m}$; first quartile: $-0.13 \mathrm{~m}$; median: $+0.26 \mathrm{~m}$; third quartile: $+1.05 \mathrm{~m}$; maximum: $+114.04 \mathrm{~m}$ ). Water levels were above average in $68 \%$ of the lakes analyzed here (134 out of the 198). However, the average volumetric anomaly across lakes (calculated as an approximate 
(a)

(b)

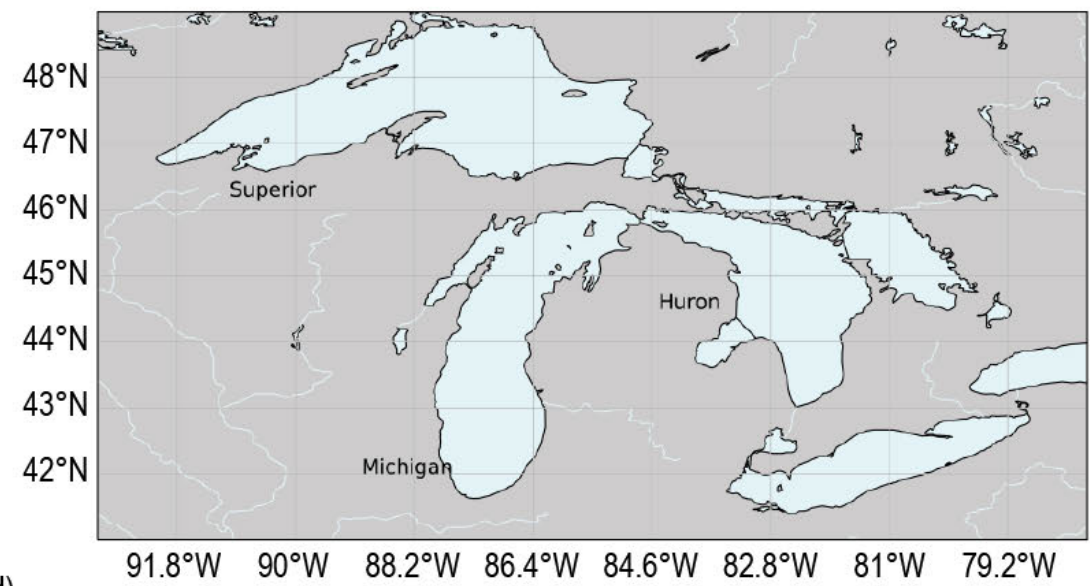

(c)

(d)

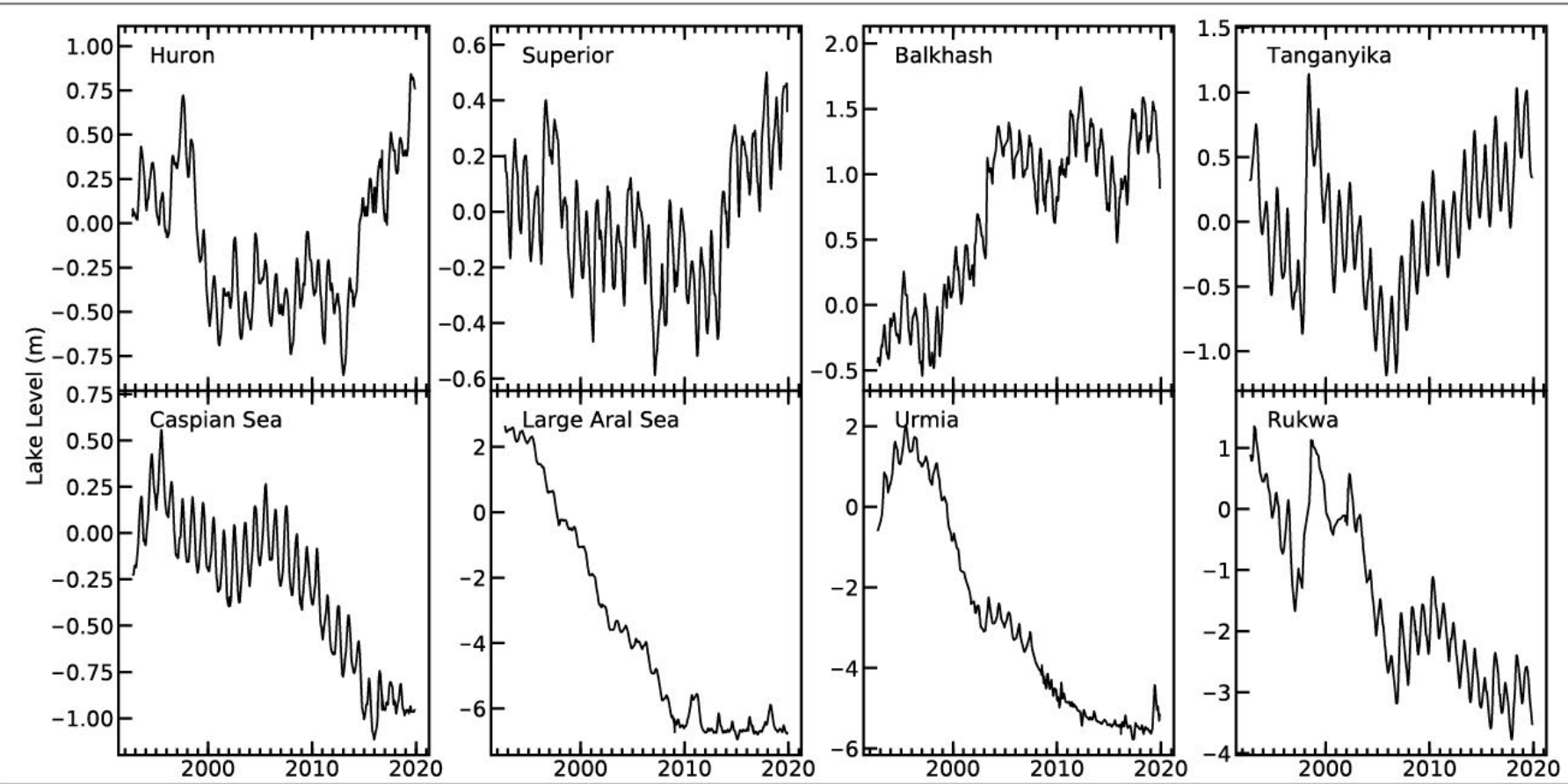

Fig. 2.22. Time series of lake water level $(\mathrm{m})$ for the lakes with the largest volumetric anomalies (2019 water level anomaly $x$ average lake surface area). The top four panels in (d) show lakes with the four largest positive anomalies The bottom four panels in (d) show the lakes with the largest negative anomalies. "Large" Aral Sea is meant to distinguish the lake water level data shown here from water level data for the two other basins formed as the Aral Sea desiccated. Lake Michigan is excluded from the time series because it is hydrologically connected to Lake Huron and its water level variation is nearly equivalent. 
estimate by multiplying the water level anomalies for each lake by their average surface area) was $-0.46 \mathrm{~km}^{3}$, and the cumulative volumetric change was $-91.2 \mathrm{~km}^{3}$. The contrast between the 2019 positive mean water level anomaly and negative mean volumetric anomaly arises from the large volumetric decrease in the Caspian Sea, which offsets the numerically more increases in less voluminous lakes.

The water level anomaly estimates presented here differ widely across lakes and across regions, reflecting the heterogeneity of underlying changes in regional hydrological fluxes. As shown in Fig. 2.22, the lakes with the largest positive volumetric anomalies occurred in Huron-Michigan (North America), Superior (North America), Balkash (central Asia), and Tanganyika (eastern Africa) while the largest negative volumetric anomalies occurred in the Caspian Sea (central Asia), Large Aral Sea (central Asia), Urmia (western Asia), and Rukwa (eastern Africa). Some regions showed coherent changes across lakes in their water level anomalies. Lakes in central Brazil, the southwestern United States, Ukraine, and eastern China had consistent negative water level anomalies while equatorial Africa, eastern Kazakhstan, the northeastern United States, and central Canada had consistent positive water level anomalies (Plate 2.1m). Conversely, lake water level anomalies varied substantially within other regions. For example, Tanganyika and Rukwa, the lakes with the fourth-largest positive volumetric anomaly and the fourth-largest negative volumetric anomaly, respectively, are within only $85 \mathrm{~km}$ of each other. The Tibetan plateau, the Middle East, and southern Africa all included lakes with both strong positive water level anomalies and strong negative anomalies often in close proximity, highlighting the strong lake-to-lake variation within regions. Variation in water level anomalies across lakes is also partially attributable to upstream land use and land cover change as well as anthropogenic water extractions and diversions.

Water level data were acquired from the NASA/CNES Topex/Poseidon and Jason-1 satellite missions via the Global Reservoir and Lake Monitoring (G-REALM) project version 2.3 (Crétaux et al. 2016). Although these altimeters were developed to map ocean surface height, they have also been used to detect water level changes in lakes (Crétaux et al. 2016). Only a small subset of the world's lakes is monitored in this way because the space-borne sensors must pass directly over the lake with sufficient regularity to produce accurate and complete time series. The lakes in this study comprise the 198 lakes with the longest (>28 years) and highest temporal resolution time series. Comparing satellite altimeter measurements derived from the NASA/CNES Topex/ Poseidon and Jason-1 satellite missions to in situ measurements, the root mean-squared error of elevation variations is $\sim 5 \mathrm{~cm}$ for large lakes. Water levels are typically measured every 10 days, but the exact dates on which water levels are measured vary from lake to lake. To make water level data temporally consistent, each lake's time series was linearly interpolated to the daily scale so that all lakes had time series of the same interval. Seventy-two of the 198 water level time series had substantial data gaps from 2003 through the middle of 2008, so a period prior to these gaps (1992-2002) was used as the baseline for calculating 2019 water level anomalies.

7) Global cloudiness-M. J. Foster, L. Di Girolamo, R. A. Frey, A. K. Heidinger, C. Phillips, W. P. Menzel, and G. Zhao Global cloudiness in 2019 decreased relative to 2018 (-0.3 $\pm 0.3 \%)$, based on several satellite cloud records including PATMOS-x/AVHRR (Pathfinder Atmospheres Extended/Advanced Very High Resolution Radiometer), Aqua MODIS C6 (Moderate Resolution Imaging Spectroradiometer Collection 6), MISR (Multi-angle Imaging SpectroRadiometer), HIRS High Cloud (High Resolution Infrared Sounder), and PATMOS-x/Aqua MODIS (this last record applies the PATMOS-x algorithms to Aqua MODIS measurements and was created for this report). Figure 2.23 shows global cloudiness from 1979 to 2019, with additional long-term records that do not currently extend through 2019: CALIPSO (Cloud-Aerosol Lidar and Infrared Pathfinder Satellite Observation), CERES (Clouds and the Earth's Radiant Energy System), CLOUD_CCI (Cloud Climate Change Initiative AVHRR-PM v3.0), CLARA-A2 (cloud, albedo and radiation dataset), and SatCORPS (satellite cloud and radiative property retrieval system). 
A decrease in global annual cloudiness from 2018 to 2019 of $0.3 \%$ seems like a small change; however, mean annual cloudiness tends to be very stable. Several of the cloud records shown in Fig. 2.23 are derived from sensors on satellites flown as part of NASA's Earth Observing System (EOS) project. The EOS satellites represented here include Terra, Aqua, and CALIPSO and the records begin as early as 2000. The standard deviations of mean annual cloudiness for these records range from $0.2 \%$ to $0.3 \%$. These records show that 2019 was the least cloudy year in over a decade. Cloud records that rely on the NOAA Polar Operational Environmental Satellites (POES) begin as far back as 1979, and these standard deviations range from $0.7 \%$ to $1.5 \%$. These records have more variability due to less stability in the 1980s and 1990s. Large-scale events, such as the volcanic eruptions of El Chichón and Pinatubo, and strong El Niños, may contribute to some of this variability. Instrumental factors such as fewer measurements (from fewer available satellites), increased orbital drift (satellites drift from their original orbit resulting in an aliasing effect), fewer available spectral channels (e.g., 5-channel AVHRR versus the 36-channel MODIS), and the lack of on-board visible calibration systems may also contribute to increased variability (Stubenrauch et al. 2012). It should be noted that the convergence of the records seen in Fig. 2.23 beginning after 2000 is partly due to the use of a common period (2003-15) when creating the cloudiness anomalies.

Although globally-averaged cloudiness does not tend to change much year-to-year, the global distribution of clouds can vary significantly. The distribution of clouds over the Pacific Ocean is affected by the phase of ENSO. The gradients of SST and low-level wind between the central equatorial Pacific and Indonesia serve to enhance or suppress convection, which drives the formation of clouds. During years where there is a strongly positive or negative phase of ENSO, this can result in statistically significant cloudiness anomalies over the Pacific. This can be seen in Fig. 2.24, where positive and negative cloudiness anomalies are consistent with phases of ENSO in the PATMOS-x/AVHRR record. In 2019, the ENSO index was weakly positive or neutral throughout the year

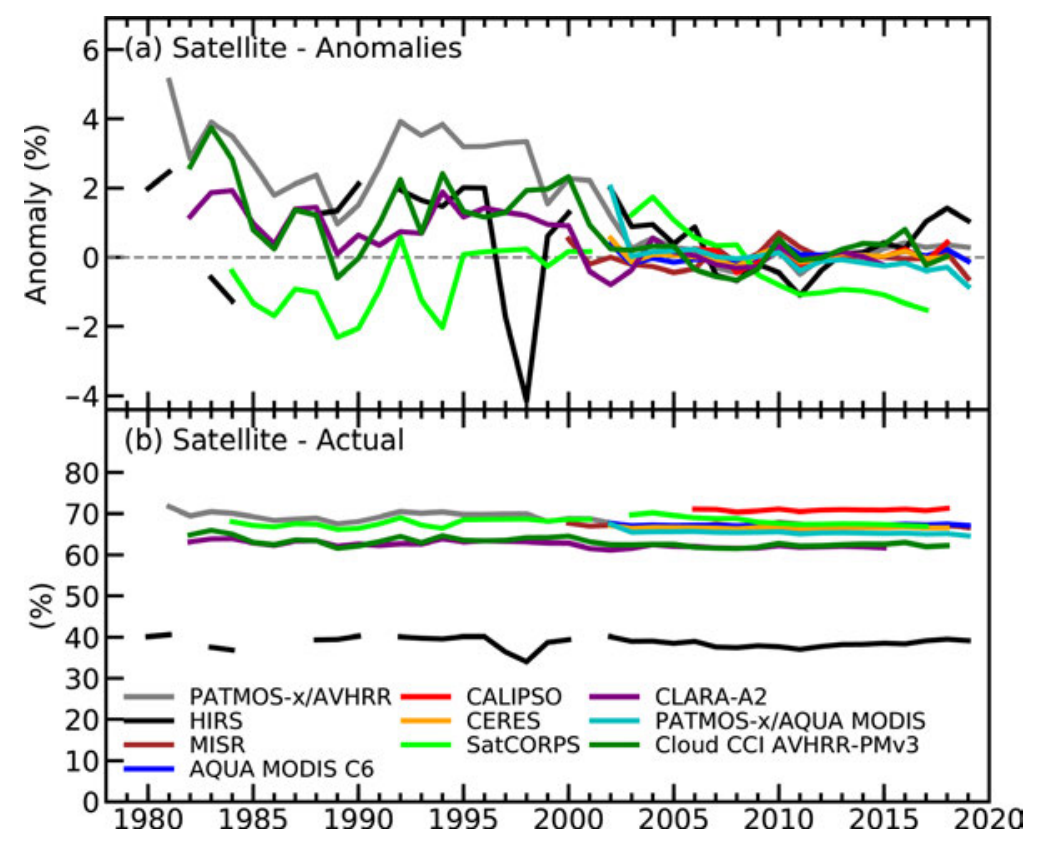

Fig. 2.23. Annual global cloudiness anomalies (\%) for 1980-2019, defined as the annual value minus the mean, derived between 2003 and 2015, a period common to the satellite records excluding CALIPSO, where the entire record was used instead. (b) Annual actual global cloudiness (\%).

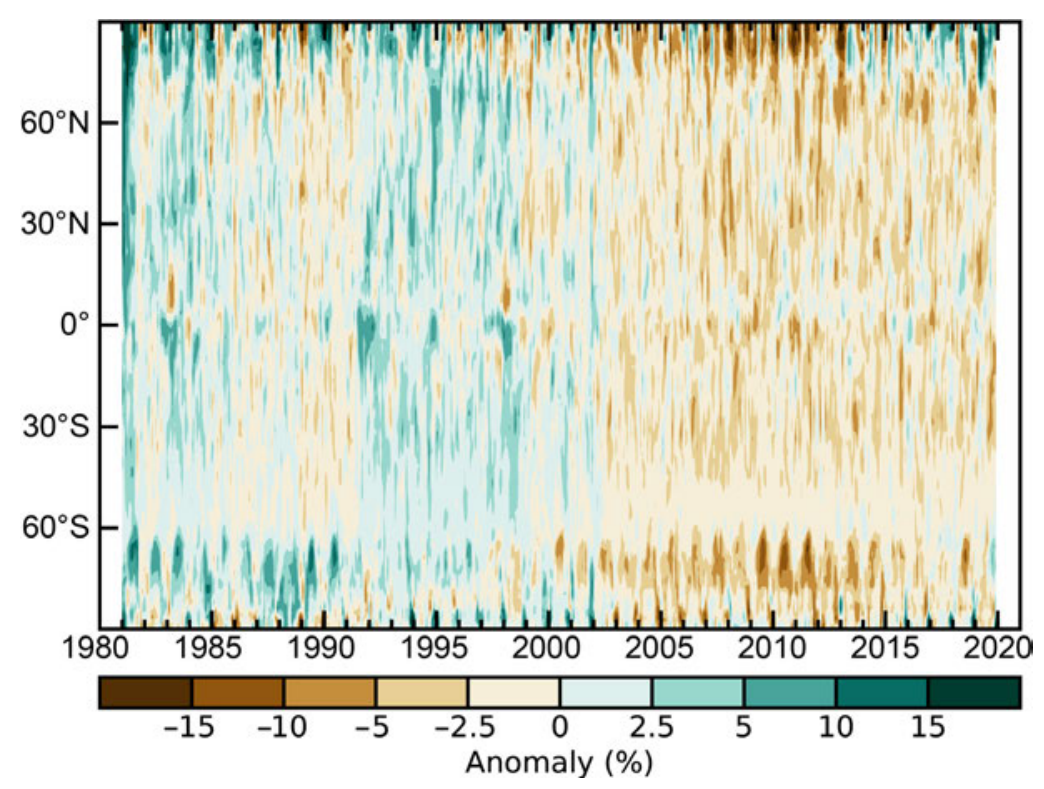

Fig. 2.24. Annual global cloudiness anomalies (\%, relative to the 1981-2010 base period) from the PATMOS-x/AVHRR record calculated using the same method as Plate 2.1n but zonally for each degree latitude. 
(a) DJF

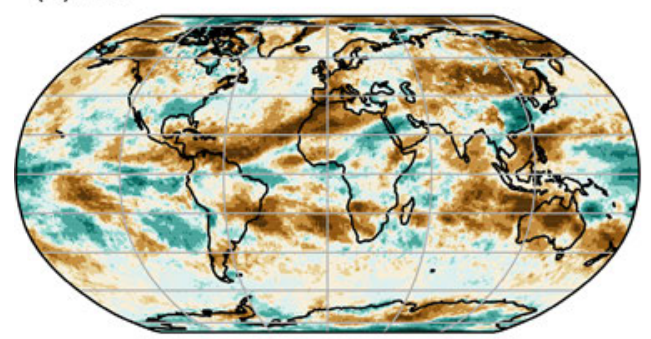

(c) JJA
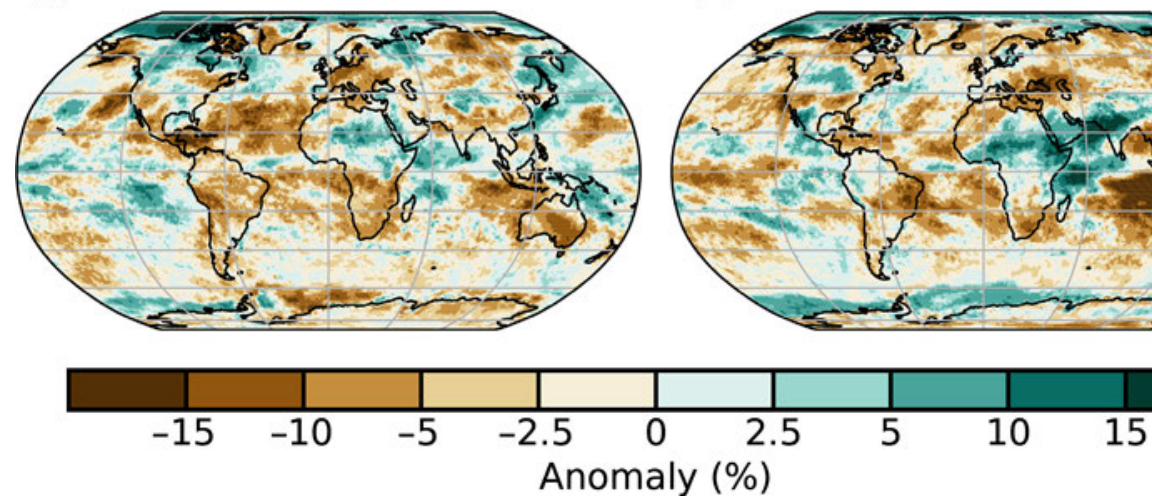

Fig. 2.25. Global seasonal cloudiness anomalies (\% relative to 1981-2010) for 2019 from the 30-year PATMOS-x/AVHRR cloud climatology. (b) MAM

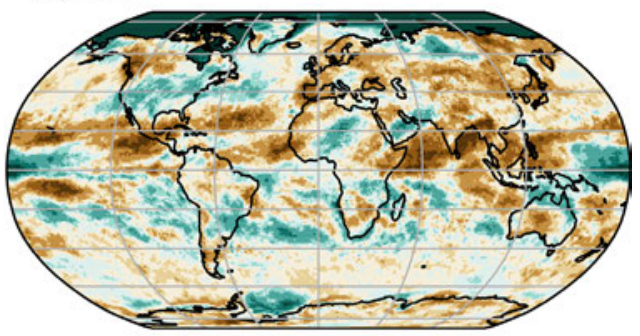

(d) SON

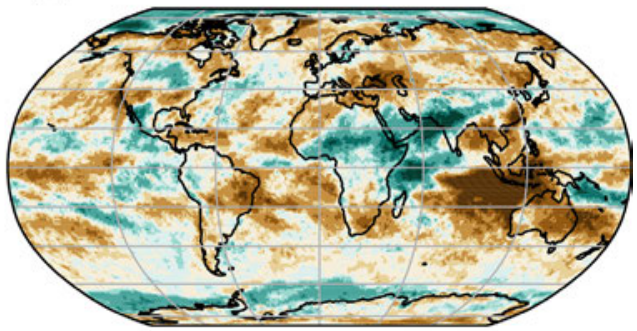

15

erage temperatures relative to the western part, the IOD is considered to be in a positive phase. In this event, eastern Africa frequently experiences positive cloudiness anomalies while southeast Asia and Australia experiences negative cloudiness anomalies. In 2019, the IOD index became positive in the boreal summer and continued to increase, peaking in October in a strong positive phase (BoM 2020; see section 4h). In terms of cloudiness, the positive phase IOD coincided with a significant negative cloudiness anomaly in the eastern Indian Ocean that had the largest spatial extent of any anomaly observed in 2019 (Fig. 2.25). Cloudiness in this area was reduced by $10 \%$ to $20 \%$ for the year. This extended into Australia, which experienced dry conditions and severe wildfires (see section 7 h4 and Sidebar 7.6). There were also significant negative anomalies in the Atlantic Ocean, ranging from 5\% to 10\%, the largest being located in the tropics north of the equator and extending into the northern subtropics. Minimum cloudiness in this region occurred in the boreal winter, but much of the year saw reduced cloudiness. Combined, these anomalies and the lack of positive anomalies, contributed to the overall decrease in global cloudiness.

\section{8) River discharge and runoff-H. Kim}

Runoff is a key component in the water cycle: it balances precipitation with evapotranspiration and storage changes through the energy and water balance at Earth's surface. In numerical models, it is defined as water draining out from a soil column when infiltration capacity is exceeded. A river is an integrated transport of runoff to the ocean. It has important roles, not only the lateral distribution of water (Kim et al. 2009) but also energy (Tokuda et al. 2019) and biogeochemical constituents (Beusen et al.2016). In this section, we focus on mass transportation (i.e., freshwater discharge) which is more directly related with both climate variability and society (e.g., Hirabayashi et al. 2013; Dankers et al. 2014; Schewe et al. 2014; Madakumbura et al. 2019).

Global distributions of discharge (Plate 2.10) and run off (Plate2.1p) anomalies for 2019 (compared to the 1961-90 reference period) indicate many regions where anomalies are opposite to those in 2018. In 2019, large areas of eastern North America and southern China became anomalously wetter (under strong dry conditions in 2018; Kim 2019), while areas including the Indochina peninsula, the western Maritime Continent, northern India, and eastern Siberia became anomalously drier. 


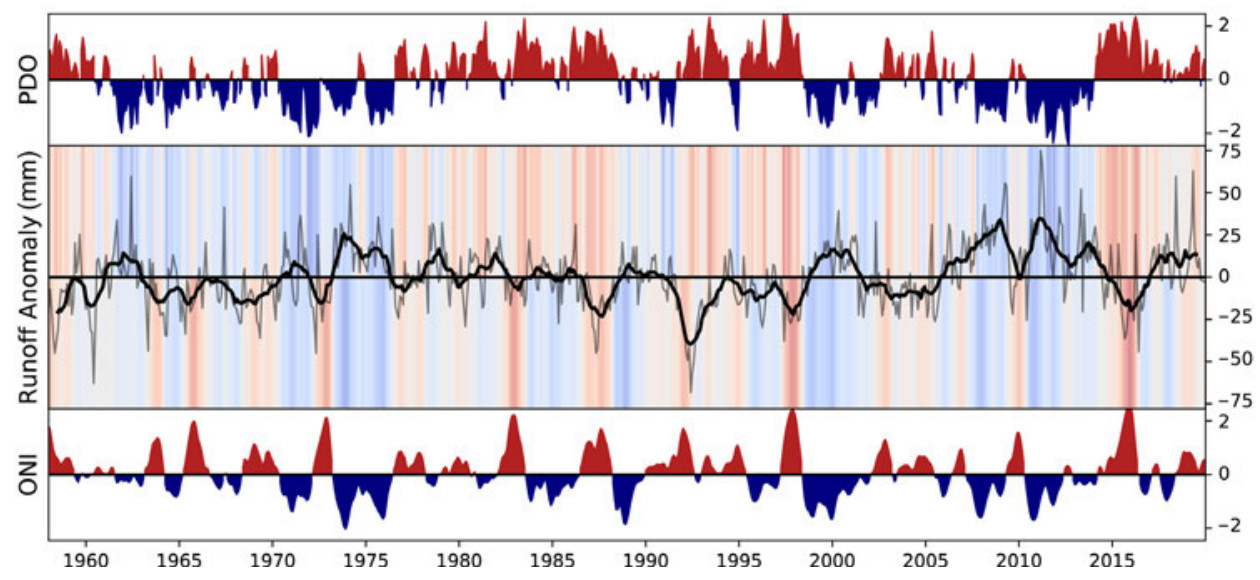

Fig. 2.26. Interannual variability of ONI (lower), PDO (upper), and global runoff (middle; $\mathrm{mm}$; thick line is 12-month moving average). ONI and PDO are shaded red (positive phase) or blue (negative phase). Shading above and below the zero-line of global runoff is proportional to PDO and ONI, respectively.

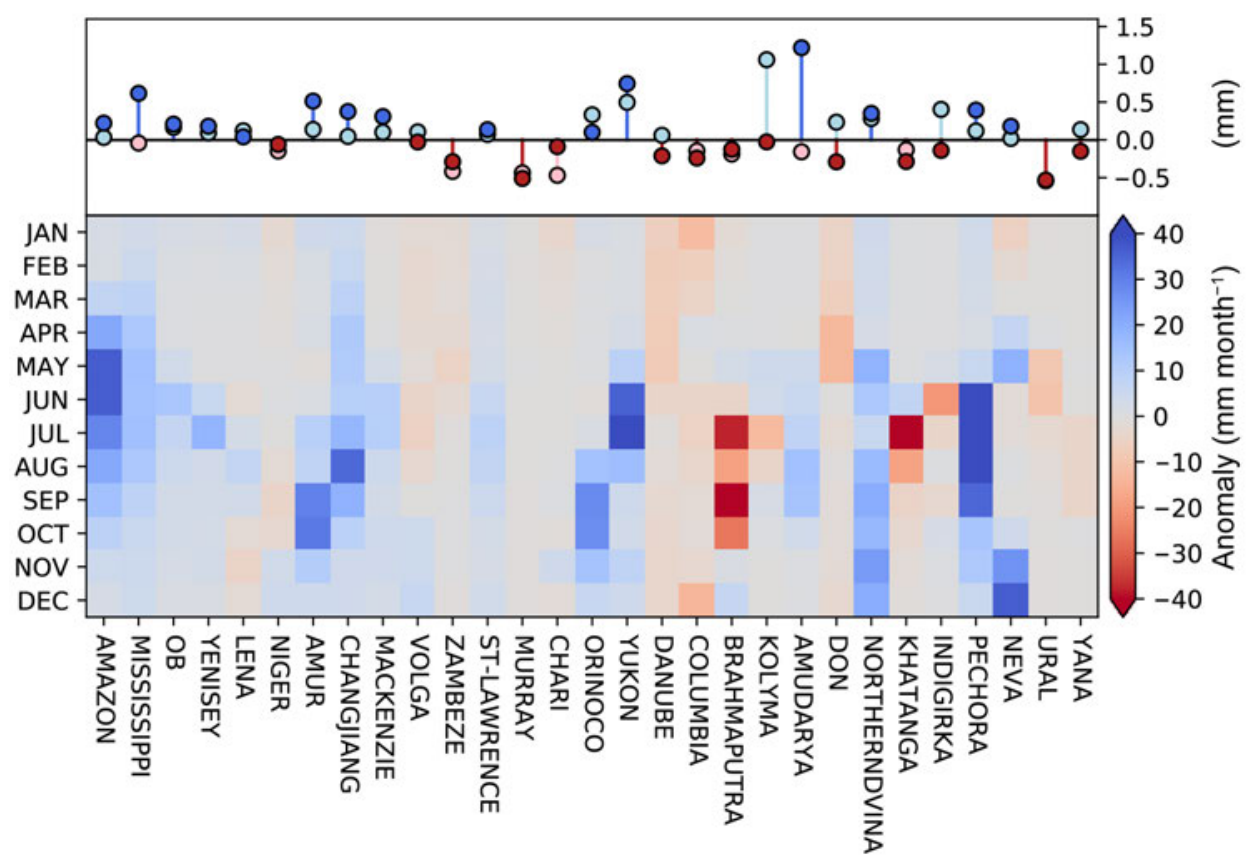

Fig. 2.27. Monthly anomaly for the long-term seasonality (lower, $\mathrm{mm} \mathrm{month}^{-1}$ ) and relative annual anomaly (upper, \%; open [uncolored] and closed [colored] circles indicate 2018 and 2019, respectively) of 30 major global rivers' discharge. The basin mask used in the analysis is referred to here: http://hydro.iis.u-tokyo .ac.jp/ hjkim/soc/30basins.png.
Northern North America, western Siberia, and northern South America (wet), and eastern South America, central Africa, Europe, eastern Siberia, and the Korean Peninsula (dry) saw greater intensification of their hydrologic states compared to 2018.

Global total freshwater discharge is strongly correlated with ENSO and the Pacific Decadal Oscillation (PDO; Zhang et al. 1997; e.g., Kim 2017, 2018, 2019). Figure 2.26 shows the longterm variability of the total runoff, with the ONI and PDO indices indicating that in the global average, dry and wet states tend to be in accord with positive and negative phases of ENSO and PDO, respectively. According to multivariate regression analysis, the variance contribution of the Oceanic Niño Index (ONI) and PDO together comprises $\sim 49 \%$ of the total variance of global runoff. In 2019, the average global runoff remained at a level similar to the previous year after a bounce-back from the anomalous dry state in 2016 that was associated with the strong El Niño. The ONI and PDO indices also remained in a slightly warm phase, similar to 2018, and the global runoff anomaly increased from $1032 \mathrm{~km}^{3} \mathrm{yr}^{-1}$ to $1758 \mathrm{~km}^{3} \mathrm{yr}^{-1}$.

The state of wetness in 2019 was analyzed for 30 major global basins with consideration of geographical distributions and quality of the estimations, as suggested by Kim et al. (2009; Fig. 2.27). In general, the wet deviations were stronger, but the discharge increases were typically less than $50 \%$ when compared to their climatological means for the given reference period. In 2019, the wet state of the rivers in South America (i.e., Amazon and Orinoco) was due to the wetterthan-average wet season. In contrast, the African rivers (i.e., Niger, Zambezi, and Chari) were relatively dry, and seasonal discharge was persistently below average throughout the year, except during the wet seasons (September-December) for the Niger and Chari. In the United States, the Mississippi River was irregularly wet throughout the year (see section 7b2), while the Columbia River was dry due to the Pacific Northwest drought in 2018-19 and 2019-20. The Mackenzie and 
Yukon Rivers in northern North America had above-average discharge, with an anomalous wet season contributing to the Yukon's high discharge. The major Arctic basins, including the Ob, Yenisei, and Lena, were in slightly wet states during 2018 and 2019, and the rivers in eastern Siberia (Kolyma, Indigirka, and Yana) shifted to weak dry states in 2019. Rivers affected by the Asian summer monsoon system (i.e., Amur, Brahmaputra, and Changjiang) experienced opposing states during the boreal summer of 2019. The Amur and Changjiang during the East Asian Monsoon were wetter than their mean states, while the Brahmaputra was in a drier state during the South Asian Monsoon. The Mekong was in a dry but near-normal state in 2019; it is speculated that the severe drought in 2019 in this region was heavily affected by human impacts (e.g., dam operation).

The 62-year (1958-2019) record is based on off-line land surface simulations of the Ensemble Land State Estimator (ELSE; Kim et al. 2009) over $1^{\circ}$ grids globally. To produce the atmospheric boundary conditions, the Japanese global atmospheric reanalysis (JRA-55; Kobayashi et al. 2015) and the GPCC Monitoring Product version 6 (Schneider et al. 2018) were combined. The configurations of the modeling system remain the same as previously (e.g., Kim 2018), and human interventions are not considered.

\section{9) Groundwater and terrestrial water storage-M. Rodell, B. Li, and D. Wiese}

Groundwater, soil moisture, surface water, snow, and ice are the components of terrestrial water storage (TWS). On multi-annual timescales, groundwater typically controls TWS variability, except in permanently frozen regions (Li et al. 2015). Even on an annual basis, TWS changes are a reasonable proxy for groundwater storage changes, the latter being insufficiently observed in most of the world. From 2002 to 2017, the Gravity Recovery and Climate Experiment (GRACE; Tapley et al. 2004) and since 2018 the GRACE Follow On (GRACE-FO) satellite missions have enabled estimation of TWS anomalies (departures from the long-term mean) based on precise observations of variations in Earth's gravity field. To bridge the 11-month gap between GRACE and GRACE-FO, we make use of output from a land surface model that assimilates data from both missions (Li et al. 2019).

Plate 2.1q maps the changes in annual mean TWS between 2018 and 2019, as equivalent heights of water in centimeters, based on the data assimilation results. TWS changes reflect integrated hydrometeorological variations, including precipitation, solar radiation, air temperature, and other model forcings.

Australia had its warmest and driest year on record (dating to 1910 and 1900, respectively), with TWS losses almost everywhere save for the northeast of the country, contributing to notorious wildfire damage (see Sidebar 7.6). Central Africa saw TWS gains following two dry years, while Angola and Zambia in southern Africa dried considerably. Conditions were mixed in South America, with drought accompanying heat across southeastern Brazil, leading to TWS losses in that region, and TWS gains in many other parts of the continent. The effects of heavy precipitation and subsequent record spring and summer flooding in the midwestern United States can be seen in Plate 2.1q, as well as a return

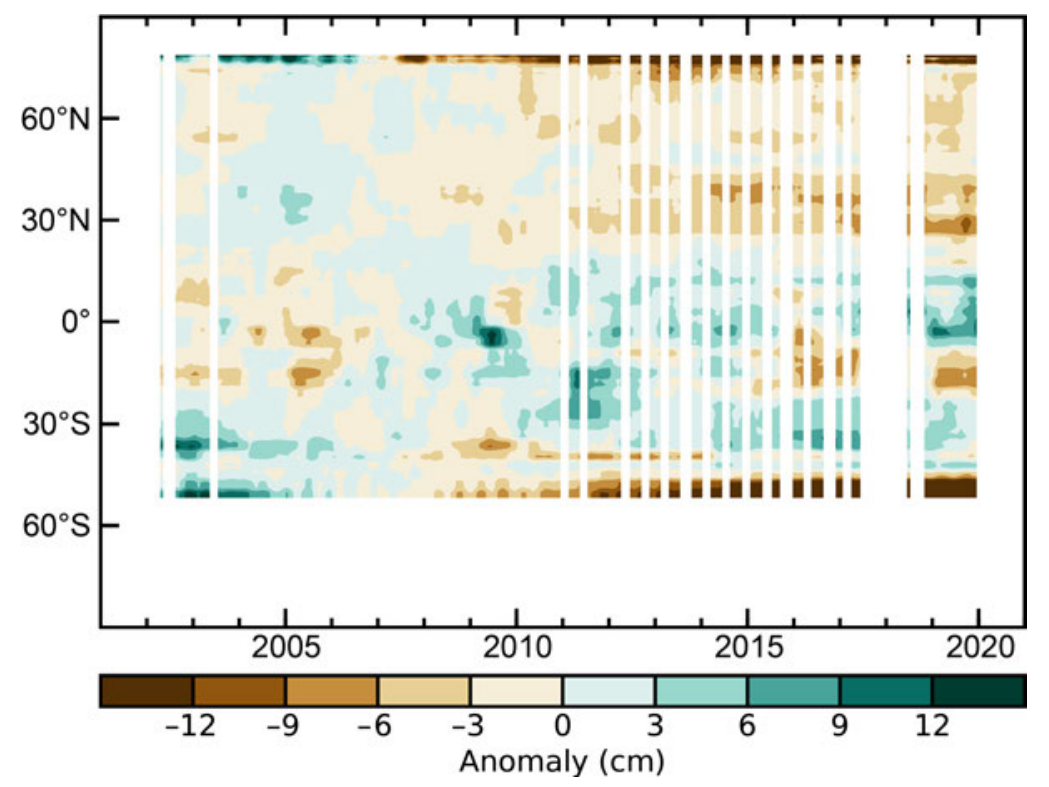

Fig. 2.28. Zonal mean terrestrial water storage anomalies (cm equivalent height of water), based on observations from GRACE (through Jun 2017) and GRACE-FO (beginning Jun 2018), excluding the previously identified ice-covered regions. Anomalies are relative to a 2005-10 base period. 
to normal conditions after a particularly wet 2018 in the East. Near-record heat drove TWS losses across most of Europe despite nearnormal precipitation. In Siberia and parts of southeastern Asia, drought caused water storage declines. TWS in Iraq and western Iran, on the other hand, was replenished by increased rainfall.

TWS changes in ice-covered regions have been dominated by ice sheet and glacier losses during the past two decades, to the point that annual hydroclimates there must be interpreted from the GRACE and GRACEFO observations with caution. Hence, TWS changes in Greenland, Antarctica, the Gulf Coast of Alaska, parts of Patagonia, and

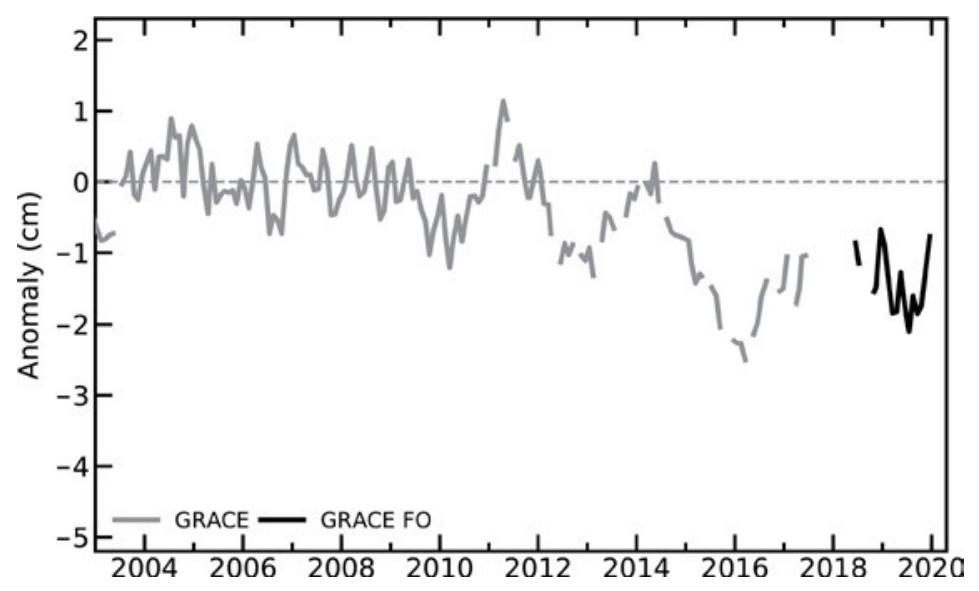

Fig. 2.29. Global average terrestrial water storage anomalies from GRACE (gray lines) and GRACE-FO (black lines), excluding the previously identified ice-covered regions, in cm equivalent height of water relative to a 2005-10 mean base period.

most polar islands are omitted here. Despite those omissions, ice losses continue to contribute to the high latitude trends (Fig. 2.28) and to the global mean, deseasonalized, monthly TWS anomaly time series (Fig. 2.29). Drying across three continents centered near $15^{\circ} \mathrm{S}$, as seen in Plate 2.1q, is evident in Fig. 2.28, as is wetting just north of that. Most of the NH resumed a long-term drying trend, and, overall, 2019 was near the lower end of the range of global mean TWS since 2002, with monthly anomalies that ranged from -2.10 to $-0.77 \mathrm{~cm}$ equivalent height of water.

10) Soil moisture-W. Preimesberger, A. Pasik, R. van der Schalie, T. Scanlon, R. Kidd, R. A. M. de Jeu, and W. A. Dorigo

Global soil moisture in 2019 was characterized by significant differences between the two hemispheres: this discrepancy was the largest yet recorded. The strongest negative anomalies were recorded throughout Australia, southern Africa, and Argentinian Patagonia in the Southern Hemisphere (SH), while parts of North America, East Africa, and Asia in the Northern Hemisphere (NH) experienced above-average soil moisture conditions due to an increase in precipitation (section 2d4; Plate 2.1k). A continuation of drier-than-usual conditions observed in 2018 across the $\mathrm{SH}$ (Scanlon et al. 2019) is evident, with anomalies in 2019 being even stronger and more widespread. Meanwhile, the 2019 global average soil moisture conditions were close to the 1991-2010 mean despite the evident difference between the hemispheres (Fig. 2.30).

Australia experienced both its driest and warmest year since records began (section $7 \mathrm{~h} 4$ ), resulting in strong negative soil moisture anomalies throughout the continent and priming the land for

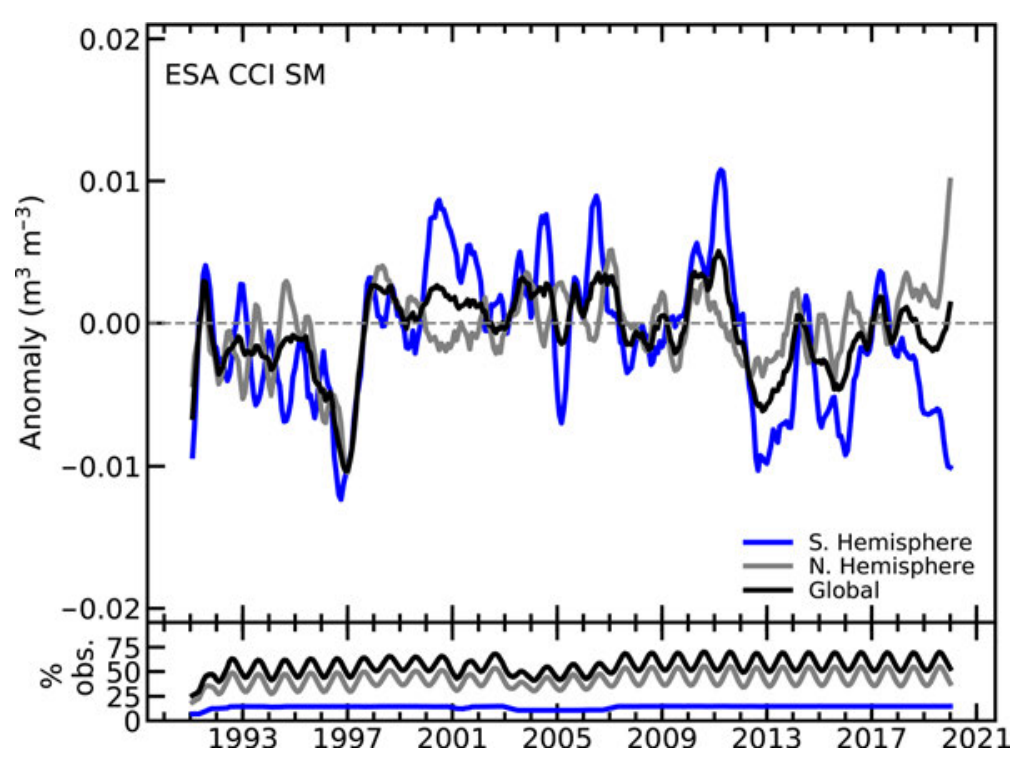

Fig. 2.30. Time series of average $\mathrm{NH}, \mathrm{SH}$, and global surface soil moisture anomalies for 1991-2019 (upper, $\mathrm{m}^{3} \mathrm{~m}^{-3}$; 1991-2010 base period) and the percentage of land points with valid observations (lower, \%). Data were masked as missing where retrievals were either not possible or of low quality due to dense forests, frozen soil, snow, ice, etc. (Source: ESA CCI Soil Moisture.) 


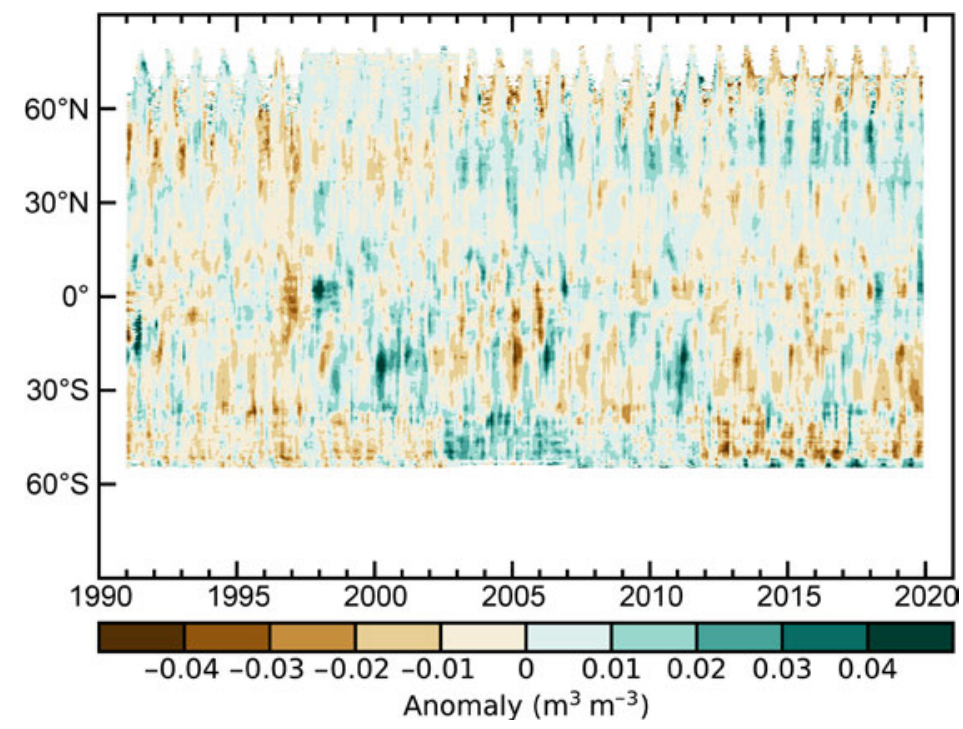

Fig. 2.31. Time-latitude diagram of surface soil moisture anomalies $\left(\mathrm{m}^{3} \mathrm{~m}^{-3} ; 1991-2010\right.$ base period). Data were masked as missing where retrievals are either not possible or of low quality due to dense forests, frozen soil, snow, ice, etc. (Source: ESA CCI Soil Moisture.) catastrophic wildfires in the latter part of the year. One of the climatic drivers responsible for this situation was a strong positive phase of the IOD, an index of SST difference between the eastern and western Indian Ocean influencing rainfall patterns in Australia and the Indian Ocean basin.

While contributing to a reduction in precipitation over Australia, the positive IOD also contributed to excess rainfall to the Greater Horn of Africa from August through December. This resulted in widespread flooding across East Africa (see section 7e4 for details and impacts). The influence of IOD on soil moisture in India and East Africa is manifested as a strong positive anomaly in the latitudes between the equator and $30^{\circ} \mathrm{N}$ visible in Fig. 2.31.

Heavy rains led to severe floods in parts of India, especially during August and Septem-

ber (Figs. A2.16h,i). Soil moisture measurements show extremely wet conditions from September through December (Figs. A2.16i-1), largely due to rainfall driven by the positive IOD. Soil moisture conditions for the year as a whole were also above average (Plate 2.1r).

Very dry soil moisture conditions continued in southern Africa for the fifth consecutive year (Dorigo et al. 2017b, 2018). The resulting prolonged and increasingly severe drought was especially apparent in Namibia. Zambia was also among the most affected countries in the region after the 2018/19 rainfall season was among the driest since 1981; the consequent soil moisture deficit is visible in the annual anomalies (Plate 2.1r).

In 2019, the United States received above-average rainfall, with many precipitation records set, especially in the north and the Midwest (see section 7b2). This excess precipitation resulted in above-average soil moisture conditions across large parts of the country throughout the year.

In March, large parts of Iran recorded above-average precipitation, leading to nationwide floods following this period (Fig. A2.16c). Soil moisture conditions were exceptionally high between February and May, declining to around average in November (Figs. A2.16b,e,k, respectively).

Soil moisture observations for this analysis were obtained from the COMBINED product of ESA's Climate Change Initiative for Soil Moisture (ESA CCI SM) v04.7. The product merges measurements from passive and active microwave remote sensing instruments into a single long-term data product based on the quality of available observations (Dorigo et al. 2017a; Gruber et al. 2019). ESA CCI SM therefore achieves higher spatial and temporal (more than 40 years) data coverage than the single-satellite sensor products and is validated against in situ soil moisture measurements and multiple reanalysis products (Dorigo et al. 2017a). Satellite soil moisture observations are representative of the surface layer only $(\sim 5 \mathrm{~cm})$ and are masked in cases of snow coverage or frozen soil conditions and for areas covered by dense vegetation or with high topographic complexity (mountains).

\section{1) Land evaporation-D. G. Miralles, B. Martens, H. E. Beck, and M. F. McCabe}

At the planetary scale, terrestrial evaporation comprises about two-thirds of terrestrial precipitation. This "loss of water" from the land surface to the atmosphere plays a key role in water management (Teuling et al. 2013) and agricultural planning (Liu et al. 2015), and it is also central in modulating the strength and behavior of the water cycle (Huntington 2006) and associated 
extreme events (Miralles et al. 2019). Currently, in the same way that evaporation is invisible to our eyes, it remains invisible to our satellite sensors, making it one of the most uncertain components of Earth's energy and water balance (Dolman et al. 2014). However, models that combine satellite-observed landscape attributes with meteorological drivers of terrestrial evaporation (e.g., vegetation cover, solar radiation, temperature) are often applied to yield global climatological records of the flux (McCabe et al. 2016; Miralles et al. 2016). Based on simulations from one of the few regularly updated and long-term global records, namely the Global Land Evaporation Amsterdam Model (GLEAM; Miralles et al. 2011), Plate 2.1s illustrates the geographical

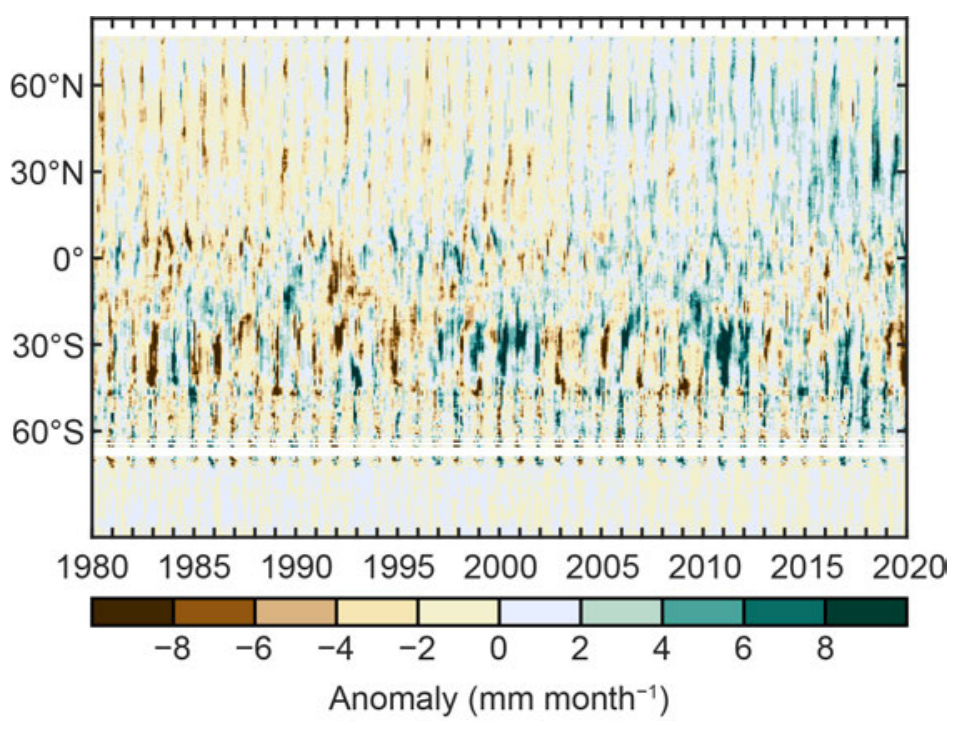

Fig. 2.32. Zonal mean terrestrial evaporation anomalies $(\mathrm{mm}$ month $^{-1}$; relative to 1981-2010 base period). (Source: GLEAM.) patterns of land evaporation anomalies for 2019.

During the year, several regions in the tropics and the $\mathrm{SH}$ subtropics experienced anomalously low values of evaporation (Plate 2.1s), in particular, southern Africa (mainly Namibia and Botswana), Australia, and parts of South America (including northern Amazonia). All of these regions suffered from intense drought conditions during 2019. In Australia, the extraordinary drought (see sections $2 \mathrm{~d} 12$ and $7 \mathrm{~h} 4$ ) led to a decline in terrestrial evaporation, which itself was mostly attributed to anomalies in plant transpiration (Fig. A2.17). In accordance with these global patterns (Plate 2.1s), the latitudinal distribution in Fig. 2.32 highlights unusually low values around $30^{\circ} \mathrm{S}$, which were exacerbated at the beginning of the austral summer due to water stress. At the other end of the distribution, unusually high values of land evaporation can be observed in Plate 2.1s, concentrated over the Horn of Africa, the east Sudanian Savanna, and central Asia, among other less extensive regions. The spatially extensive positive anomaly in central Asia was one of the most pronounced in 2019. Initiated during the first half of the year, as shown in Fig. 2.32 (see anomaly around $30^{\circ} \mathrm{N}$ ), it was associated with a combination of positive temperature and precipitation anomalies. In Europe and North America, mild positive anomalies were widespread, except for a few regions such as Canada and the Iberian Peninsula (see Plate 2.1s), which were drier.

The 40-year (1980-2019) evolution of evaporation shown in Fig. 2.33 illustrates the statistically significant long-term tendency toward higher annual values that has been reported extensively in the literature (Y. Zhang et al. 2016; Miralles et al. 2014; Brutsaert 2017; Anabalón and Sharma 2017). The average terrestrial evaporation in 2019 was $77 \times 10^{3} \mathrm{~km}^{3}$, slightly below this long-term global trend, yet still higher than the long-term mean (Fig. 2.33). The positive trend is more pronounced in the $\mathrm{NH}$ and mostly related to increasing temperatures and global greening (Cheng et al. 2017; Zhang

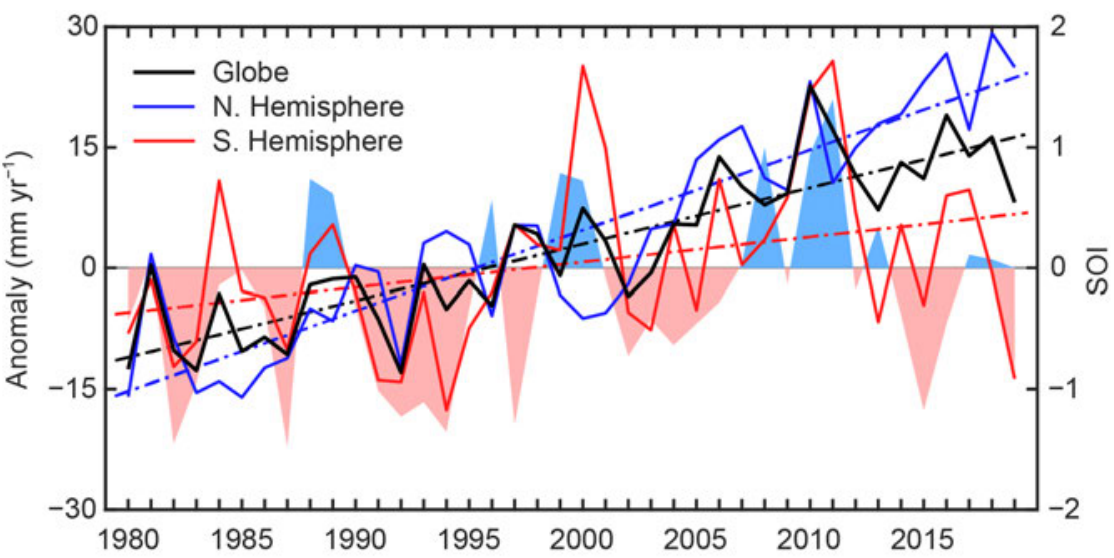

Fig. 2.33. Land evaporation anomaly ( $\mathrm{mm} \mathrm{yr}^{-1} ; 1981-2010$ base period) for the $\mathrm{NH}, \mathrm{SH}$, and the entire globe (blue, red, and black solid lines, respectively). Linear trends in evaporation (dashed lines) and the SOI from CRU (right axis, shaded area) are also shown. (Source: GLEAM.) 
et al. 2016; Miralles et al. 2014). Indeed, for the NH, 2019 represented the third-largest positive anomaly on record after 2018 and 2016. On the other hand, the year-to-year variability in the SH has previously been reported to be dictated largely by ENSO, due to the drought conditions it triggers in regions such as South Africa and Australia (Martens et al. 2018; Miralles et al. 2014). In agreement with that thesis, prevailing marginal El Niño conditions in 2019 appear once again to be influencing the below-average mean values in the SH. In fact, the geographical patterns of evaporation anomalies shown in Plate 2.1s closely mimic those characteristic of El Niño years (Miralles et al. 2014), and thus may relate to the weak El Niño that developed in 2019 (see SOI [Southern Oscillation Index] in Fig. 2.33).

The results shown here are based on recent simulations of GLEAM v3.4a (Martens et al. 2017). Its accuracy has been reported to be on the order of $0.7 \mathrm{~mm} \mathrm{day}^{-1}$ (unbiased root mean square error), with correlations against in situ eddy covariance measurements of around 0.8 on average (Martens et al. 2017). Notwithstanding the steady progress in remote-sensing and modeling communities to improve the product accuracy and spatial resolution of land evaporation estimates (McCabe et al. 2019; Fisher et al. 2017; McCabe et al. 2017), trends and patterns in satellite-based evaporation should be interpreted with care, and a weighting based on multiple retrieval approaches is usually recommended (Jiménez et al. 2018). Still, as of today, the algorithms dedicated to estimating evaporation using satellite observations at global scales are mostly intended for research applications and are not regularly updated (Fisher et al. 2017), which constrains the undertaking of a comprehensive analysis that would ensure a more thorough uncertainty appraisal.

\section{2) Monitoring global drought using the self-calibrating Palmer Drought Severity Index-}

J. Barichivich, T. J. Osborn, I. Harris, G. van der Schrier, and P. D. Jones

Hydrological drought results from a period of abnormally low precipitation, sometimes exacerbated by additional evapotranspiration (ET), and its occurrence can be apparent in reduced river discharge, soil moisture, and/or groundwater storage, depending on the season and duration of the event. Here, an estimate of drought called the self-calibrating Palmer Drought Severity Index (scPDSI; Wells et al. 2004; van der Schrier et al. 2013) is presented, using precipitation and Penman-Monteith Potential ET from an early update of the CRU TS 4.04 dataset (Harris et al. 2020). Moisture categories are calibrated over the complete 1901-2019 period to ensure that "extreme" droughts and pluvials (wet periods) relate to events that do not occur more frequently than in approximately $2 \%$ of the months. This affects direct comparison with other hydrological cycle variables in Plate 2.1 that use a different baseline period.

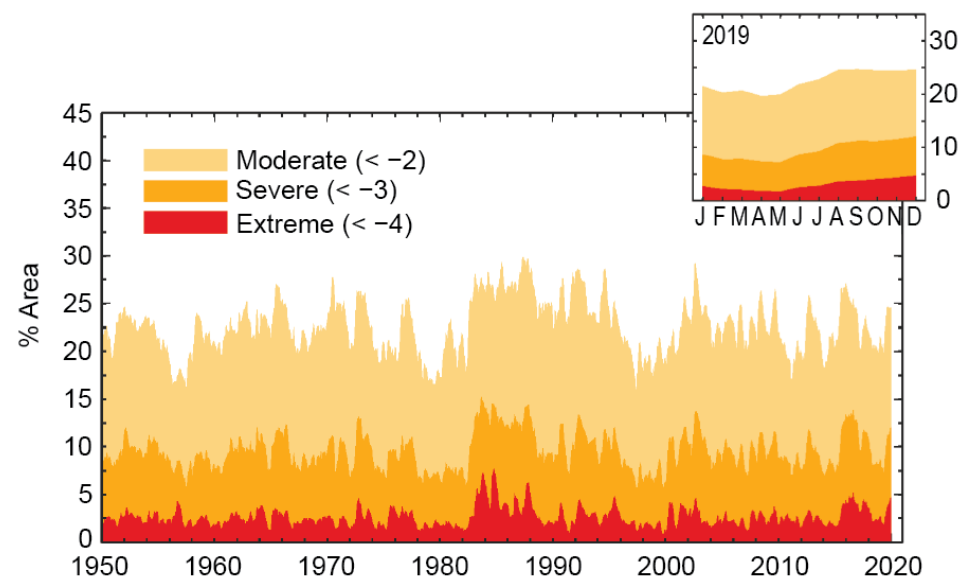

Fig. 2.34. Percentage of global land area (excluding ice sheets and deserts) with ScPDSI indicating moderate $(<-2)$, severe $(<-3)$, and extreme $(<-4)$ drought for each month of 19502019. Inset: Each month of 2019.
Drought area according to the scPDSI decreased slightly across the globe in 2018 (Barichivich et al. 2019) and continued decreasing through early 2019, but then rose sharply after May (Fig. 2.34). The global land area undergoing extreme drought conditions increased from a minimum of $1.7 \%$ in May to $4.7 \%$ in December, surpassing the most recent previous peak of $4.3 \%$ in October 2017, but not as extensive as some earlier periods of extreme drought. Also from May to December 2019, the area including severe and extreme drought conditions increased from $7.2 \%$ to $12 \%$ of the global land area, while moderate or worse drought conditions increased from a minimum of $19.2 \%$ to $24.6 \%$ of the global land area. 


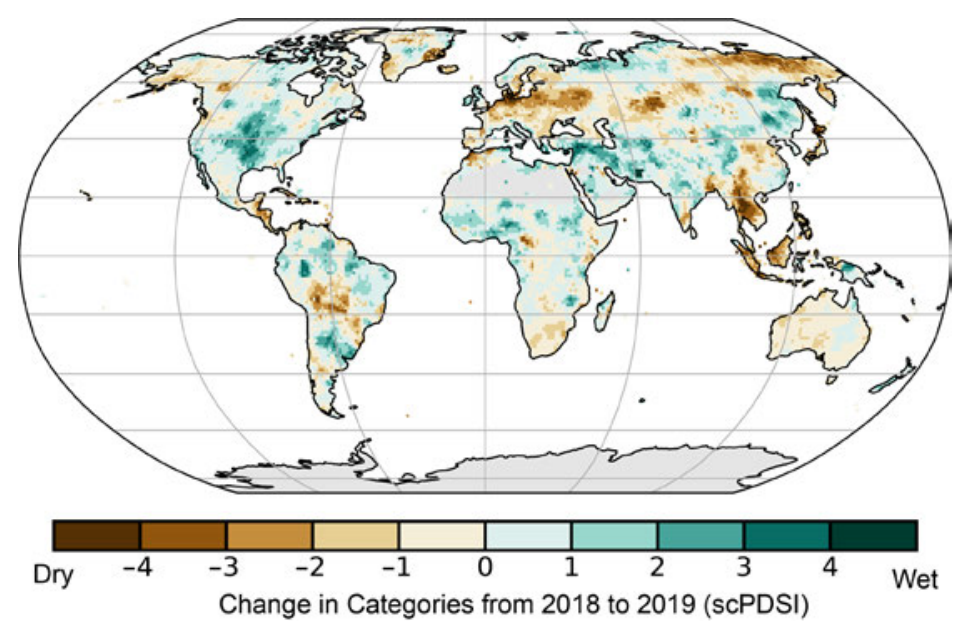

Fig. 2.35. Change in drought from 2018 to 2019 (mean scPDSI for 2019 minus mean scPDSI for 2018). Increases in drought severity are indicated by negative values (brown), decreases by positive values (green). No calculation is made where a drought index is meaningless (gray areas: ice sheets or deserts with approximately zero mean precipitation).
Similar to 2018, moderate to severe drought conditions during 2019 were extensive in South America, the western United States, and the Middle East. Previous moderate to severe drought conditions over Europe, southern Africa, and Australia intensified to extreme drought (Plate 2.1t). The east-west moisture contrast observed across the United States since 2017 further strengthened in 2019, with extensive wetter conditions extending over the whole eastern half and drier in the west. Protracted drought over most of the semiarid northeastern region of Brazil (Jimenez-Muñoz et al. 2016) and central Chile (Garreaud et al. 2017) intensified again in 2019 (Fig. 2.35).

A large part of South Africa experienced extreme drought during 2019 (Plate 2.1t), continuing or intensifying (Fig. 2.35) dry

conditions from previous years. In the Cape region, this is consistent with a long-term drying associated with human-caused climate change (Seager et al. 2019), which increases the risk of such rare events (Otto et al. 2018). Previous moderate to severe drought along parts of the west coast of Africa appear to have eased, while wetter conditions in most of central and eastern Africa persisted in 2019 (Fig. 2.35). However, these changes should be interpreted with caution as station data are sparse in these regions. See section 7 e for more detailed precipitation analyses for Africa.

Extreme drought conditions that affected Afghanistan in 2018 eased through 2019, and the area under drought was reduced and concentrated mostly over the south of the country. Drought severity also decreased in parts of the Arabian Peninsula that have seen dry conditions since 2017 (Fig. 2.35). Most of Australia saw an increase in drought intensity to severe and extreme conditions due to the continuation of the rainfall deficit combined with record high temperatures. These extreme conditions contributed to the most devastating fire season on record. Fire spread through the southeastern states causing unprecedented devastation. Extreme drought in the Murray-Darling Basin has been characterized as the worst on record. See section 7 h4 and Sidebar 7.6 for details.

Antecedent dry conditions, below-average spring precipitation, and extreme summer heat waves pushed most of Europe into drought during 2019 (Plate 2.1t). The most intense drought in the annual average occurred across northern Germany and Poland, where there was already a strong soil moisture deficit in 2018 (Fig. 2.35). The sustained low precipitation in spring and summer in combination with exceptionally high temperatures in late winter-early spring-especially February-and the record-breaking temperatures in June and July further intensified the drought conditions in much of midlatitude Europe.

\section{e. Atmospheric circulation}

\section{1) Mean sea level pressure and related modes of variability-R. Allan}

Mean sea level pressure (MSLP) data can be used to derive indices of many regional modes of variability that drive significant weather and climate events (Kaplan 2011) such as El NiñoSouthern Oscillation (ENSO), the Arctic Oscillation (AO), the North Atlantic Oscillation (NAO), and the Antarctic Oscillation (AAO; Fig. 2.36). ENSO, which is measured in the atmosphere by the sea level pressure derived Southern Oscillation Index (SOI; Allan et al. 1996; Kaplan 2011), arguably has the most global impact. 
ENSO describes a variety of events and episodes that, individually, can exhibit wide-ranging characteristics across the Indo-Pacific region and have teleconnections to higher latitudes in both hemispheres (Capotondi et al. 2015; L'Heureux et al. 2017; Wang et al. 2017; Timmermann et al. 2018; Santoso et al. 2019). These different "flavors" of ENSO include protracted El Niño and La Niña episodes (Allan and D’Arrigo 1999; Allan et al. 2019), which are manifest by persistent sea surface temperature (SST) anomalies in the Niño 4 region in the western equatorial Pacific.

Some international ENSO forecasts and outlooks have deemed 2019 conditions as starting with a weak El Niño and changing to ENSO-neutral in July. However, since March-April 2018, monthly Niño 4 SST anomalies have remained positive and, if they continue to be so for 24 months or more (March-April 2020), they will pass one criterion for this period being indicative of a protracted El Niño episode (Allan et al. 2019). The second criterion, for the SOI to have acted similarly by being consistently negative (allowing for only any two months to have gone positive), has held since June 2018 (https://iridl.ldeo.columbia.edu/maproom/ENSO/Time_Series/SOI.html), and this is reflected in Plate 2.1u. This period of continuously warm Niño 4 SST anomalies has led to enhanced atmospheric convection over that region and the generation of a teleconnection that caused large-scale subsidence and suppressed rainfall across eastern Australia in the early-2018 to early-2020 period (see section 7 h 4 and Sidebar 7.6 for more details). The Niño 4 SST response during the 2018-20 "protracted" El Niño episode may also have been possibly enhanced by anthropogenic forcing, as suggested by Newman et al. (2018).

In the Northern Hemisphere $(\mathrm{NH})$, the last several boreal winters have displayed a variety of AAO and NAO conditions (Figs. 2.36, 2.37). Over the 2017/18 boreal winter (Figs. 2.37a,d), the NAO was mainly positive except in late February (Fig. 2.37d), with temperatures in Europe mostly mild to warm, and the region experienced its fifth-warmest year on record. In particular,

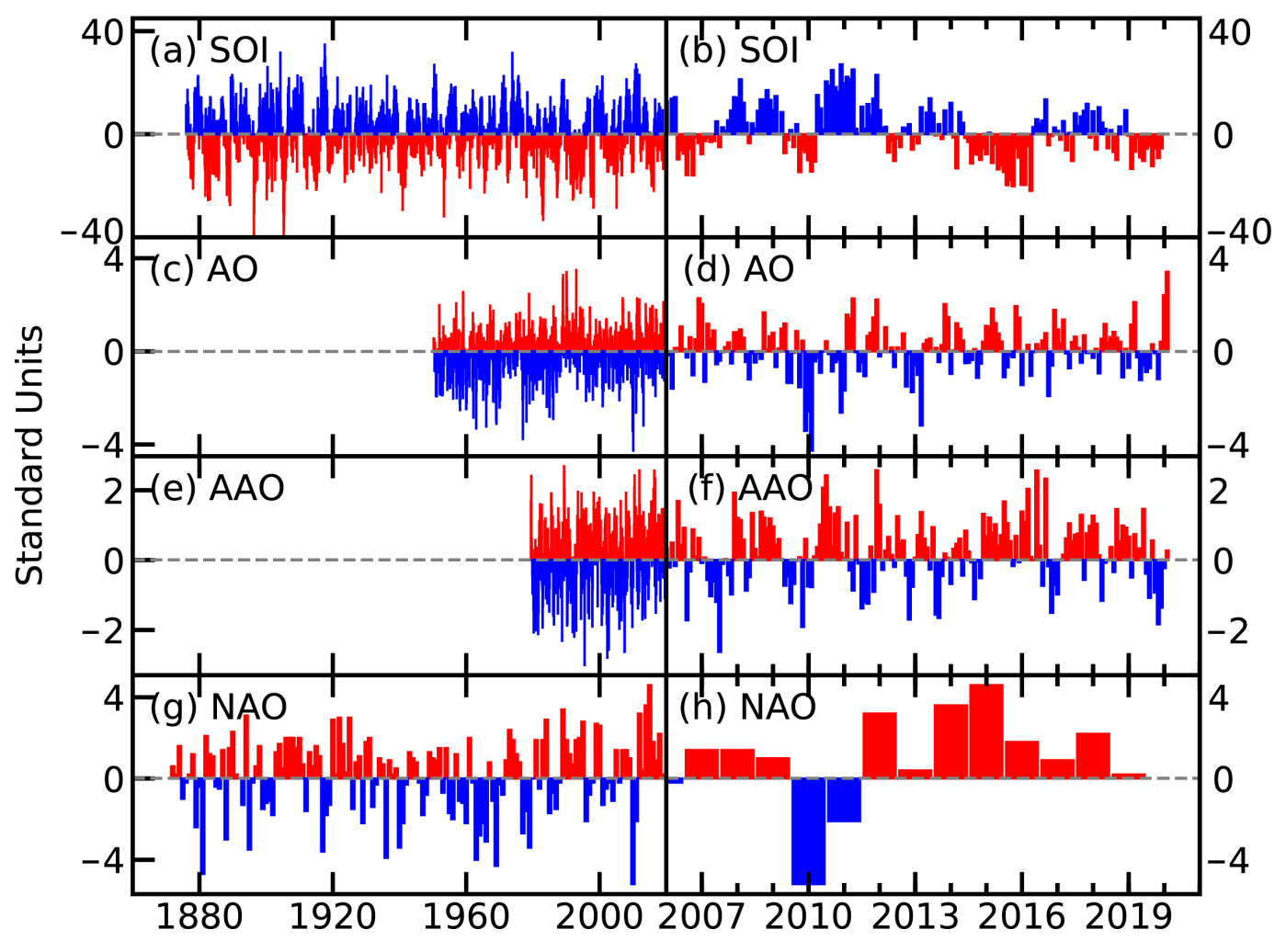

Fig. 2.36. Time series for modes of variability described using sea level pressure for the (left) complete period of record and (right) 2006-19. (a),(b) SOI (provided by the Australian Bureau of Meteorology); (c),(d) AO (NOAA NCEP Climate Prediction Center); (e),(f) AAO (NOAA NCEP Climate Prediction Center); (g),(h) winter (Dec-Feb) NAO average (NCAR; presented for winter at the beginning of each year so winter $2019 / 20$ is not shown). 
France, Germany, Switzerland, the Netherlands, and Denmark experienced record or near-record warm conditions in 2018.

During the 2018/19 boreal winter (Figs. 2.37b,e), the NAO swung from moderate positive values in early-to-mid-December to moderate negative values from late December to mid-January 2019, fluctuating between positive and negative values thereafter (Fig. 2.37e). The anticyclonic circulation was dominated by southerly flow over Europe, which led to exceptionally high temperatures in February 2019.

The 2019/20 boreal winter (Figs. 2.37c,f) was characterized by a persistent, mainly positive NAO, which led to warm and mild conditions across the entire European region, with heavy rainfall leading to flooding, and a series of deep Atlantic cyclones. The winter was dominated by a strong stratospheric polar vortex extending down through the troposphere, associated with one of the coldest Arctic winters in the last 10 years.

In the Southern Hemisphere (SH) during the latter half of 2019, the AAO transitioned from being predominantly in its positive phase since 2015/16 (Figs. 2.36f) to negative. This favored a

(a) $2017 / 18$

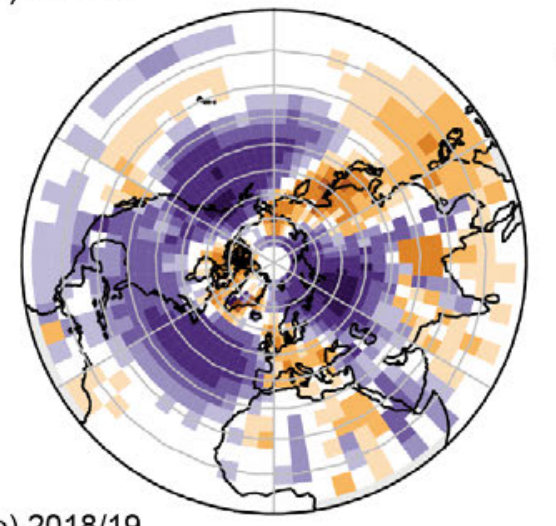

(b) $2018 / 19$

(c) $2019 / 20$
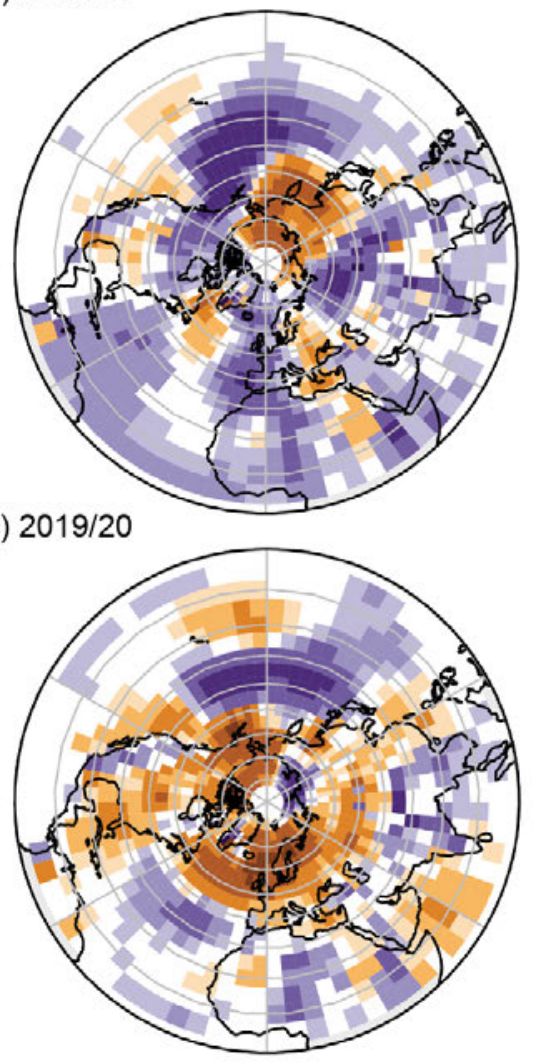

Anomaly

$(\mathrm{hPa})$

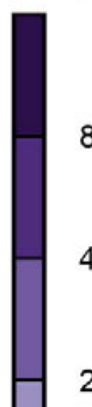

2

1

0.5

$-0.5$

$-1$

$-2$

$-4$

$-8$

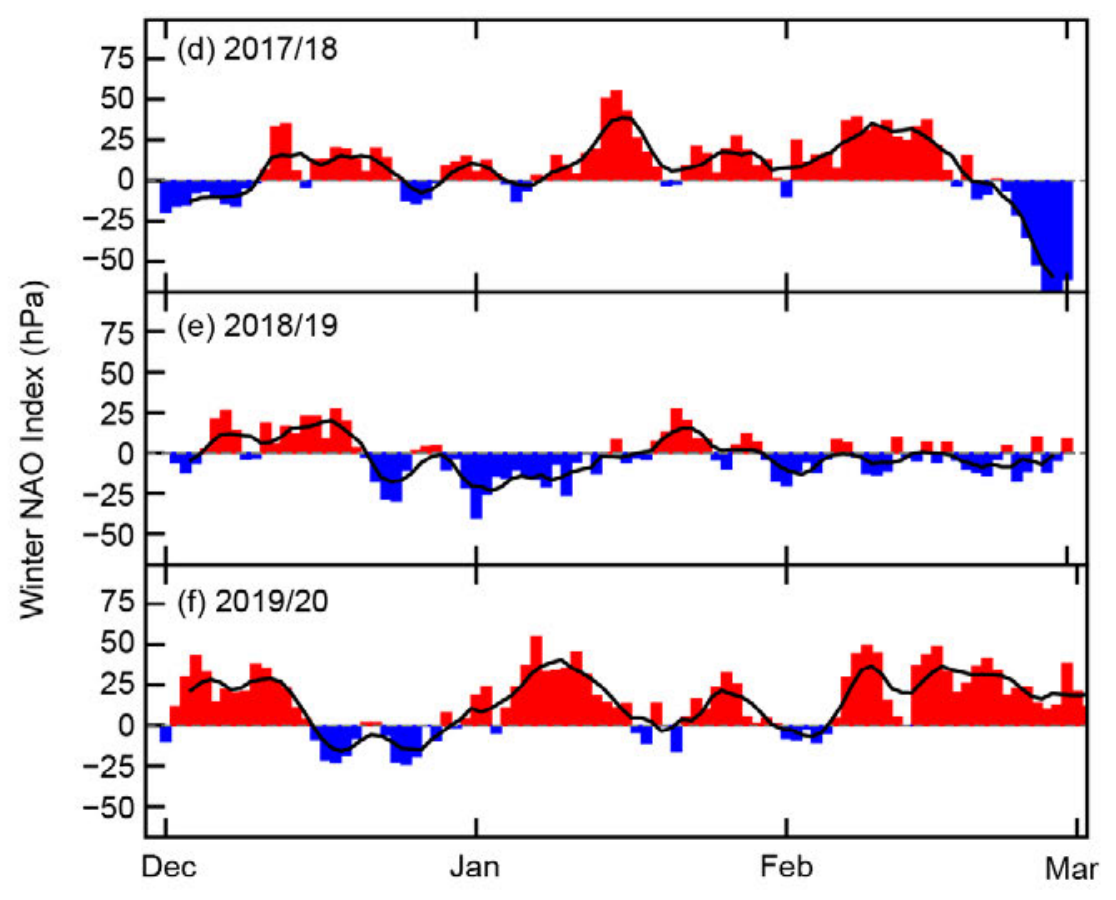

Fig. 2.37. Boreal winter sea level pressure anomalies (hPa; 1981-2010 base period) around the $\mathrm{NH}$ ( $\mathrm{hPa}$; $1981-2010$ base period) averaged over Dec-Feb for (a) 2017/18, (b) 2018/19, and (c) 2019/20. NAO daily time series (hPa) for boreal winter (d) 2017/18, (e) 2018/19, and (f) 2019/20. The 5-day running mean is shown by the solid black line. (Source: HadSLP2r [Allan and Ansell 2006].) 


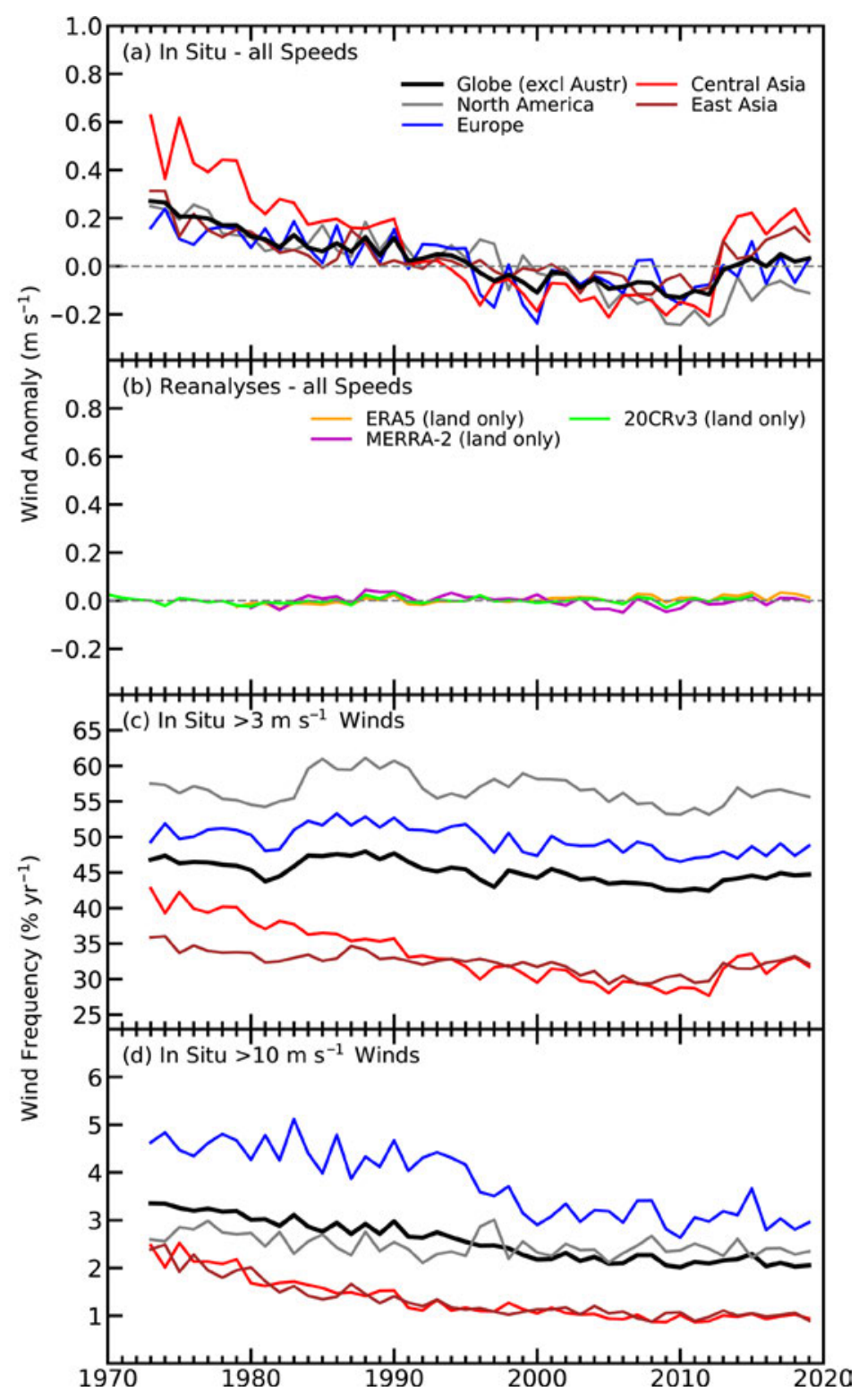

lack of rainfall-bearing systems across eastern Australia and a reinforcement of the drought conditions prevailing in 2019 (see also Sudden Stratospheric Warming discussion in section 2b5).

\section{2) Land and ocean surface winds-}

C. Azorin-Molina, R. J. H. Dunn, L. Ricciardulli, C. A. Mears, T. R. McVicar, J. P. Nicolas, G. P. Compo, and C. A. Smith

Global average near-surface wind speed over land (i.e., $\sim 10 \mathrm{~m}$ above the ground) has continued the reversal described in previous reports (e.g., Azorin-Molina et al. 2019), which started around 2010 (Zeng et al. 2019; Fig. 2.38a). The 30-50 years leading up to 2010 were dominated by a gradual reduction in surface winds over land, termed global terrestrial stilling (Roderick et al. 2007). In 2019, the global (excluding Australia) average wind speed anomaly was $+0.033 \mathrm{~m} \mathrm{~s}^{-1}$ with respect to the 1981-2010 climatology (Table 2.6), the third-largest positive wind speed anomaly since 2010. Regionally, Europe showed the largest rebound as the negative anomaly in 2018 became positive in 2019. In contrast, the positive anomalies in central Asia and east Asia were smaller than in 2018. Lastly, North America still showed a negative anomaly yet smaller than the lowest one recorded in 2012 (Iacono and Azorin-Molina

Fig. 2.38. Global (excluding Australia in panels [a], [c], and [d]) and regional annual time series of land surface wind speed anomaly ( $\mathrm{m} \mathrm{s}^{-1}$; relative to 1981-2010) using (a) HadISD3 (1973-2019), and (b) ERA5 (1979-2019), MERRA-2 (1980-2019), and 20CRv3 (1836-2015, only 1970-2015 shown here). HadISD3 occurrence frequencies (in \%) for wind speeds (c) $>3 \mathrm{~m} \mathrm{~s}^{-1}$ and (d) $>10 \mathrm{~m} \mathrm{~s}^{-1}$.

\begin{tabular}{|c|c|c|c|c|}
\hline Region & $\begin{array}{c}\text { Mean } \\
1981-2010 \\
\left(\mathrm{~m} \mathrm{~s}^{-1}\right)\end{array}$ & $\begin{array}{c}\text { Anomaly } 2019 \\
\qquad\left(\mathrm{~m} \mathrm{~s}^{-1}\right)\end{array}$ & $\begin{array}{l}\text { Trend 1979-2019 } \\
\left(\mathrm{m} \mathrm{s}^{-1} \text { decade }{ }^{-1}\right) \\
\text { and 5th-95th } \\
\text { percentile confidence range }\end{array}$ & $\begin{array}{l}\text { Number of } \\
\text { stations }\end{array}$ \\
\hline $\begin{array}{l}\text { Globe (excluding } \\
\text { Australia) }\end{array}$ & 3.326 & +0.033 & $\begin{array}{c}-0.058 \\
(-0.067 \rightarrow-0.046)\end{array}$ & 2536 \\
\hline North America & 3.705 & -0.112 & $\begin{array}{c}-0.081 \\
(-0.091 \rightarrow-0.072)\end{array}$ & 569 \\
\hline Europe & 3.689 & +0.028 & $\begin{array}{c}-0.046 \\
(-0.058 \rightarrow-0.036)\end{array}$ & 759 \\
\hline Central Asia & 2.897 & +0.134 & $\begin{array}{c}-0.100 \\
(-0.127 \rightarrow-0.076)\end{array}$ & 257 \\
\hline East Asia & 2.719 & +0.104 & $\begin{array}{c}-0.031 \\
(-0.040 \rightarrow-0.019)\end{array}$ & 458 \\
\hline
\end{tabular}




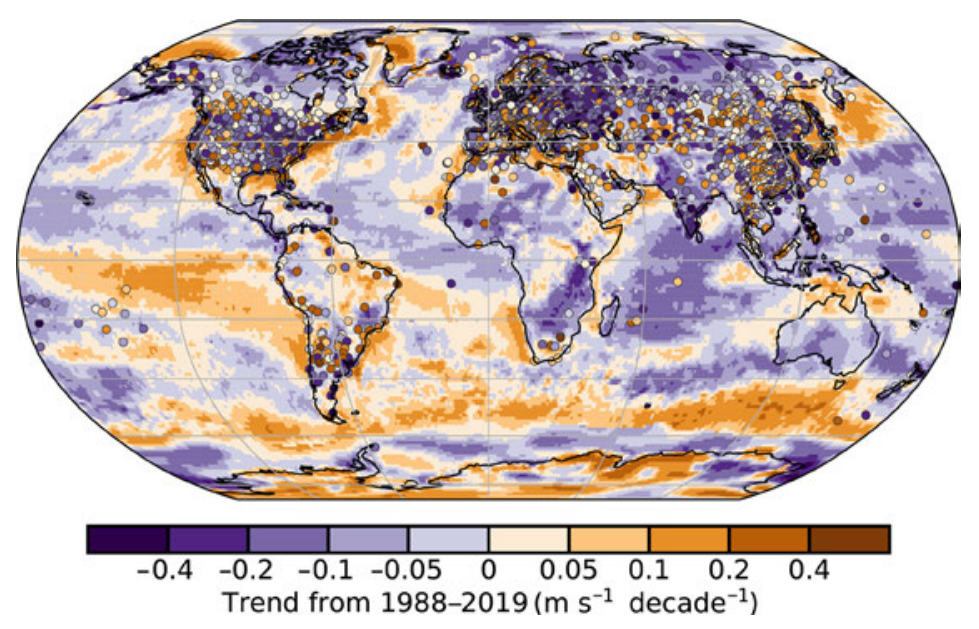

Fig. 2.39. Wind speed trends $\left(\mathrm{m} \mathrm{s}^{-1}\right.$ decade $\left.^{-1}\right)$ for the observational HadISD3 dataset (circles) over land, and MERRA-2 reanalysis output over land/ice and Remote Sensing Systems (RSS) satellite radiometers (SSM/I, SSMIS, TMI, GMI, AMSR2, ASMR-E, and WindSat) over ocean for 1988-2019 (shaded areas).

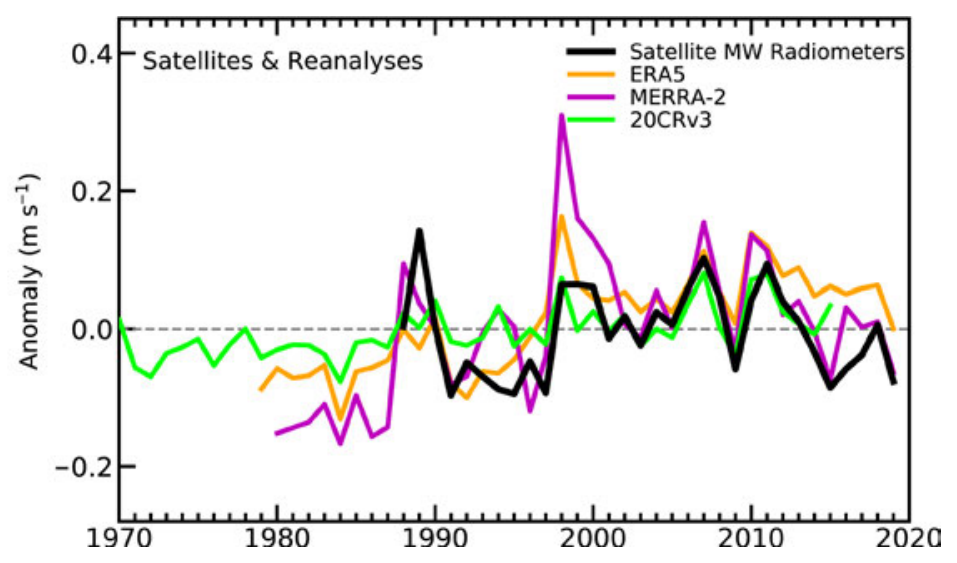

Fig. 2.40. Annual anomalies of global mean wind speed $\left(\mathrm{m} \mathrm{s}^{-1} ; 1981-2010\right.$ base period) over the ocean from satellite radiometers and reanalysis outputs.
2014). The recovery observed since 2010 was discussed in regional (e.g., Kim and Paik 2015; Azorin-Molina et al. 2018a; R. Zhang et al. 2019) and global (Zeng et al. 2019) studies. As in previous years, this recovery comes from an increase in the frequency of moderate winds around 2013 (>3 $\mathrm{m} \mathrm{s}^{-1}$; e.g., see central and east Asia in Fig. 2.38c), whereas strong winds $\left(>10 \mathrm{~m} \mathrm{~s}^{-1}\right.$; Fig. 2.38d) are still declining (Azorin-Molina et al. 2016).

The multi-decadal variability and trends of surface winds over land during the 19792019 period have been assessed here using station-based observations and gridded reanalysis products. The observations consist of global quality-controlled anemometer observations from 2536 stations from the HadISD3 dataset (1973-2019, Dunn et al. 2016; Dunn 2019). The reanalysis data are based on three products: the full-input ERA5 (1979-2019, Hersbach et al. 2020), MERRA-2 (1980-2019, Gelaro et al. 2017), and the surface-input 20CRv3 (1836-2015, Slivinski et al. 2019, the latter of which is included to reinforce the other products in common years). The reanalyses provide complete spatial and temporal coverage; however, their inability to reproduce the observed long-term changes in wind anomalies (Fig. 2.38b) is a limitation (Torralba et al. 2017; Ramon et al. 2019; Wohland et al. 2019).

One of the key effects of the recent reversal and stabilization of land surface wind speeds is a lower magnitude of the negative trends. Globally, terrestrial surface winds declined at a rate of $-0.058 \mathrm{~m} \mathrm{~s}^{-1}$ decade $^{-1}$ during 1979-2019 (Table 2.6), which is close to half of the lowest trend recorded for 1981-2012 (-0.111 $\mathrm{m} \mathrm{s}^{-1}$ decade $^{-1}$; see Table 2.4 in McVicar et al. 2013). Regionally, the magnitude of negative trends is slightly weaker than in previous years, being most negative in central Asia, followed by North America and Europe, and least negative in East Asia. The 5th to 95th percentile confidence ranges also shifted toward less negative trend values. In order to compare with Remote Sensing Systems (RSS), Fig. 2.39 shows HadISD and MERRA-2 trends over the 1988-2019 period. Negative trends (59.0\% of stations) dominated northern midlatitude regions, with MERRA-2 also showing declining values for regions with scarce observations, e.g., South America, Africa, and Australia.

Over ocean, the three above-mentioned reanalyses and satellite-based products were used to assess surface winds for the period 1987-2019: the Special Sensor Microwave/Imager (SSM/I), the Special Sensor Microwave Imager/Sounder (SSMIS), the Advanced Microwave Scanning Radiometer (AMSRE and AMSR2), Tropical Rainfall Measuring Mission Microwave Imager (TMI), and WindSat (Wentz 1997, 2015; Wentz et al. 2007). The 2019 mean global mean wind speed anomaly over the ocean (Fig. 2.40) shows negative values for satellite radiometers and MERRA-2, but only 
a weak negative anomaly for ERA5. According to the satellite measurements, 2019 marked the second-lowest wind speed anomaly over ocean in the twenty-first century. The global spatial anomalies (Plate 2.1v) show a dominance of negative anomalies, in particular over the western Pacific and over the Indian Ocean $\left(<-1 \mathrm{~m} \mathrm{~s}^{-1}\right)$, due to an intense positive phase of the Indian Ocean dipole (IOD), and in the central Pacific and South Atlantic Ocean; in contrast, positive anomalies $\left(>+1 \mathrm{~m} \mathrm{~s}^{-1}\right)$ occurred over the Southern Ocean, North Atlantic Ocean, and the Bering, Mediterranean, and Coral Seas. As in 2018, ocean wind speed trends for 1988-2019 (Fig. 2.39) were mostly dominated by weak negative values along with a clear tendency toward a strengthening of winds in the Southern Ocean, the trade winds in the Pacific and Atlantic Oceans, and some isolated regions (Young and Ribal 2019).

The potential causes underlying global terrestrial stilling and its reversal over the last decade are varied (Azorin-Molina et al. 2018b) and likely not all presently known. Recently, Zeng et al. (2018) rejected the attribution of the slowdown of winds to the increase of terrestrial surface roughness due to vegetation/urbanization growth (Vautard et al. 2010), and Zeng et al. (2019) proposed that the major driving force of wind speed changes (i.e., both the stilling and the recent rebound of winds) is associated with decadal ocean-atmosphere oscillations and changes in large-scale atmospheric circulation patterns. Moreover, Zeng et al. (2019) concluded that the relationship of ocean-atmosphere oscillations to anthropogenic warming and the impact on surface wind speed variability remains unclear, representing a large scientific challenge.

\section{3) Upper air winds - L. Haimberger, M. Mayer, and V. Schenzinger}

As in past years, we examine the 200-hPa velocity potential to evaluate the imprint of tropical climate anomalies on upper air divergent winds. A strong positive IOD event developed in the course of 2019, peaking in boreal autumn (see section 4h). Figure 2.41 displays anomalous 200-hPa velocity potential and divergent winds for August-December 2019 and shows a clear imprint of the IOD event. The positive IOD event occurred in the absence of classical El Niño conditions, which is relatively rare but linked to the protracted El Niño (section 2e1). Consequently, the strongest velocity potential anomalies were found over the Indian Ocean. There is a prominent dipole in the velocity potential, with positive anomalies over the Indo-Pacific Warm Pool and negative anomalies over the western Indian Ocean, which leads to a westerly divergent wind anomaly over the Indian Ocean. The positive anomalies and associated wind convergence over the Warm Pool are indicative of reduced

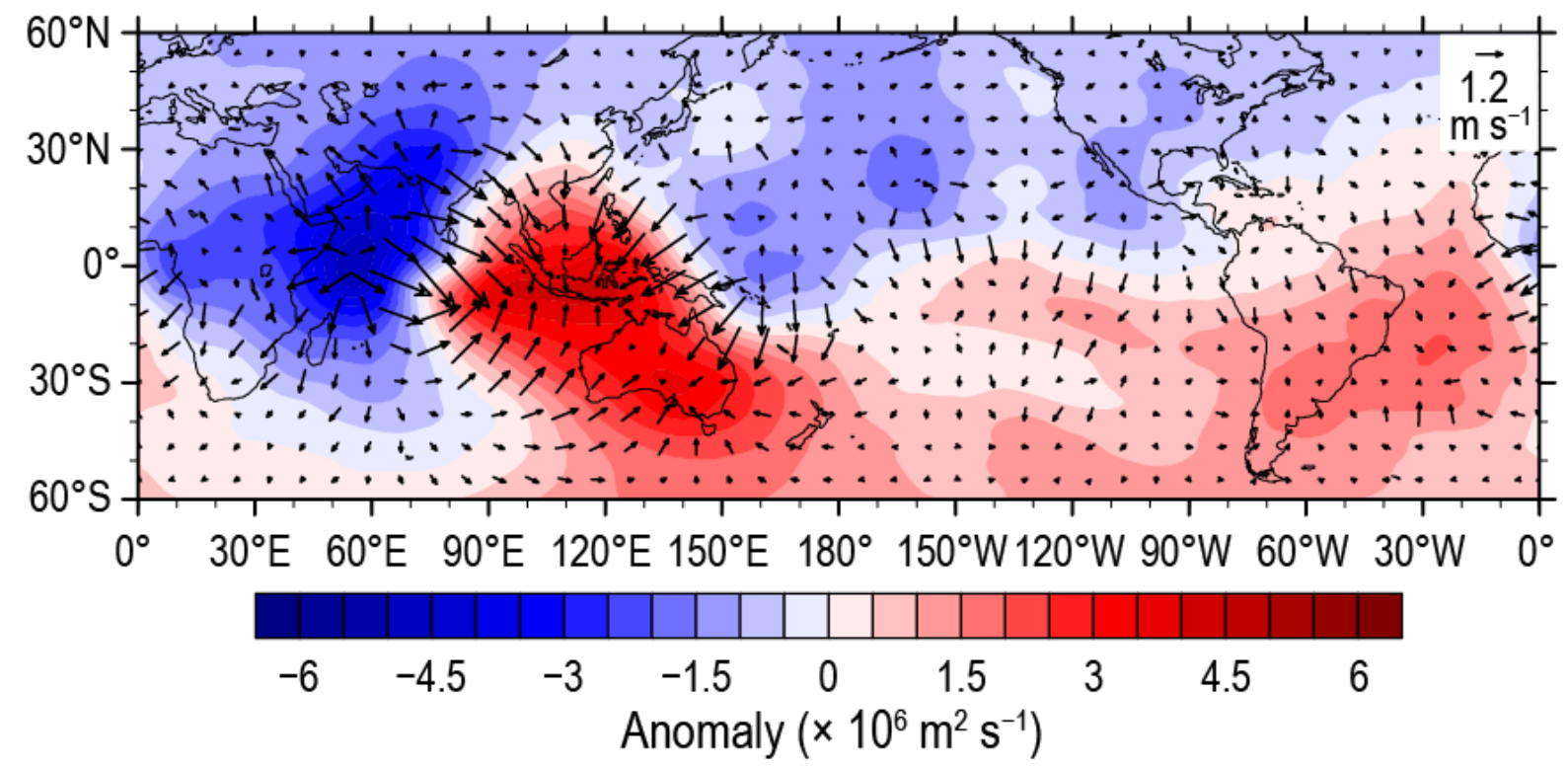

Fig. 2.41. Anomalous $200-\mathrm{hPa}$ velocity potential $\left(\times 10^{6} \mathrm{~m}^{2} \mathrm{~s}^{-1}\right)$ and divergent winds $\left(\mathrm{m} \mathrm{s}^{-1}\right)$ averaged over Aug-Dec 2019 (1981-2010 base period) based on ERA5 data. 


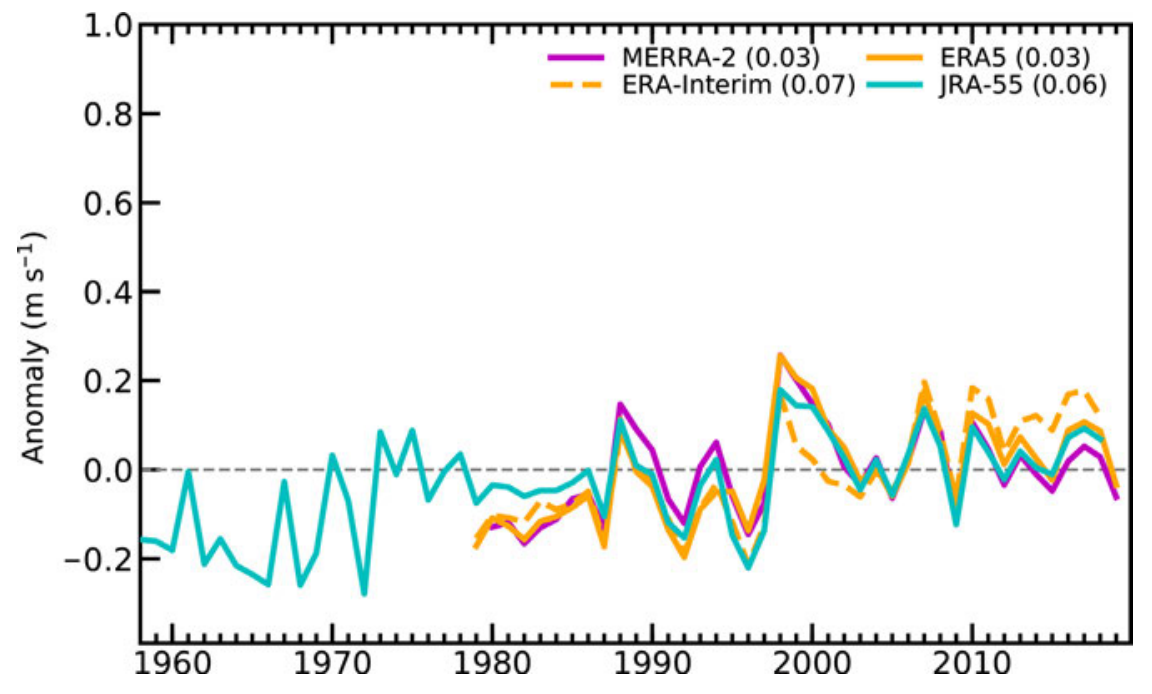

Fig. 2.42. Annual anomalies of global mean wind speed $\left(\mathrm{m} \mathrm{s}^{-1} ;\right.$ 1981-2010 base period) at $850 \mathrm{hPa}$ from four reanalyses (ERA5, ERA-Interim, MERRA-2, JRA-55). The numbers in parentheses are linear trends in $\mathrm{m} \mathrm{s}^{-1}$ decade $^{-1}$ for the period 1980-2019. convection in this region, consistent with negative SST anomalies in the eastern Indian Ocean.

The positive velocity potential anomalies extend well over Australia, with a secondary maximum over the south of the continent. The associated upper air wind convergence and sinking motion is consistent with the persistent dry conditions over the Australian continent (see section 7 h4 for more details).

Plate 2.1w shows the $850-\mathrm{hPa}$ eastward wind patterns in autumn 2019. The most obvious feature is the anticyclonic structure over Australia and the Indian

Ocean, with strong easterly anomalies over the equator south of India and over northern Australia together with strong westerly anomalies over the southern Indian Ocean and south of Australia, which is perhaps enhanced by the negative Antarctic Oscillation in 2019. This indicates a strong anomalous anticyclonic circulation over the Australian continent, which is consistent with the drought conditions observed there (Ummenhofer et al. 2009). Together with the patterns shown in Fig. 2.41, the easterly 850-hPa wind anomaly over the equatorial Indian Ocean completes the picture of the perturbed Walker circulation in this region, with anomalous upward motion in the western Indian Ocean and anomalous sinking motion over the Maritime Continent.

The 2019 global mean wind speed at $850 \mathrm{hPa}$ was lower than in 2018 and slightly below the 1981-2010 average (Fig. 2.42). The positive trend over the past 40 years still remains in all four reanalyses presented here.

The 2019 behavior of the Quasi-Biennial Oscillation (QBO) can be described as being fairly regular (see Fig. A2.18). The westerly phase had a maximum amplitude of $17 \mathrm{~m} \mathrm{~s}^{-1}$, which is comparably high (mean $14.8 \pm 1.8 \mathrm{~m} \mathrm{~s}^{-1}$ ), but not at record levels. It descended with about $1 \mathrm{~km} \mathrm{yr}^{-1}$ on average, well within the long-term range of descent rates $\left(1.2 \pm 0.6 \mathrm{~km} \mathrm{yr}^{-1}\right)$ and lasted for 25.8 months in total, which is about 2.5 months shorter than on average. At $10 \mathrm{hPa}$, the easterly phase started in April, which is a common month for a phase transition at this height. Its descent progressed with $0.8 \mathrm{~km} \mathrm{yr}^{-1}$ so that it reached the $30 \mathrm{hPa}$ level by the end of the year. However, one noteworthy behavior was the onset of the easterly phase at $45 \mathrm{hPa}$ at the end of October, which means that it developed within a zone of westerly winds, similar to the anomaly in the 2015/16 boreal winter.

\section{f. Earth radiation budget}

1) Earth radiation budget at top of atmosphere-T. Wong, P. W. Stackhouse, Jr., D. P. Kratz,

P. Sawaengphokhai, A. C. Wilber, S. K. Gupta, and N. G. Loeb

The energetic state of the Earth-atmosphere system is defined by the balance of the incoming total solar irradiance (TSI) and the reflected shortwave (RSW) and outgoing longwave radiation (OLR) from Earth. This balance defines Earth's radiation budget (ERB) at the top of the atmosphere (TOA), and its regional distribution drives atmosphere and ocean circulations.

An analysis of all CERES ERB measurements (Table 2.7) shows that 2019 global annual mean OLR increased by $\sim 0.60 \mathrm{~W} \mathrm{~m}^{-2}$ and RSW decreased by $\sim 0.55 \mathrm{~W} \mathrm{~m}^{-2}$ relative to their corresponding values in 2018 (rounded to nearest $0.05 \mathrm{~W} \mathrm{~m}^{-2}$ ). Over the same timeframe, the global annual mean TSI remained nearly unchanged. The sum of these components amounts to a near zero 


\begin{tabular}{|c|c|c|c|}
\hline & $\begin{array}{l}\text { One-year change } \\
(2019 \text { minus 2018) } \\
\left(\mathrm{W} \mathrm{m}^{-2}\right)\end{array}$ & $\begin{array}{l}2019 \text { Anomaly } \\
\text { (relative to climatology) } \\
\left(\mathrm{W} \mathrm{m}^{-2}\right)\end{array}$ & $\begin{array}{l}\text { Interannual variability } \\
(2001-18) \\
\left(\mathrm{W} \mathrm{m}^{-2}\right)\end{array}$ \\
\hline OLR & 0.60 & +0.55 & \pm 0.60 \\
\hline TSI & 0.00 & -0.10 & \pm 0.15 \\
\hline RSW & -0.55 & -1.20 & \pm 0.95 \\
\hline Net & -0.05 & +0.55 & \pm 0.80 \\
\hline
\end{tabular}

(a)

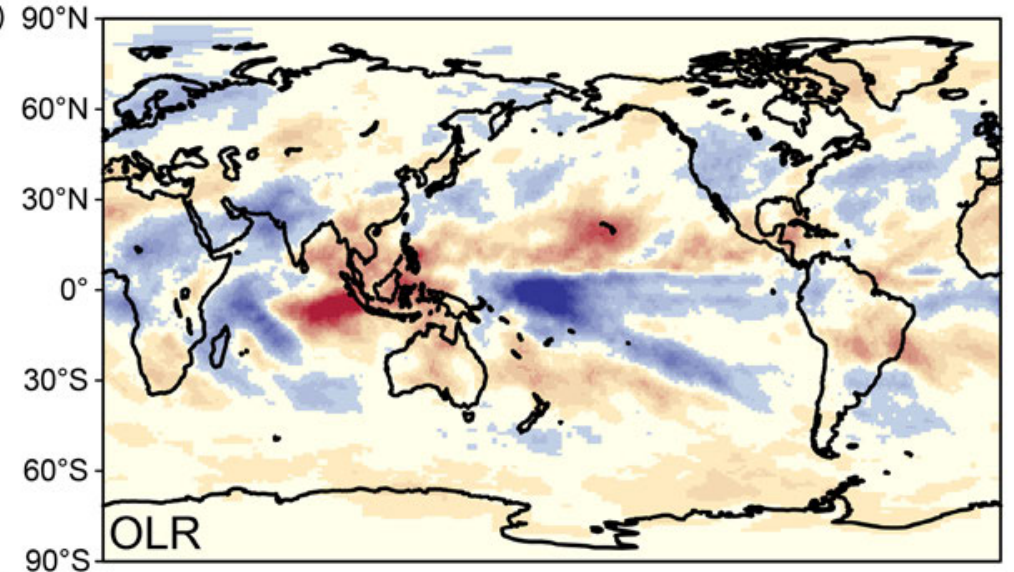

(b)

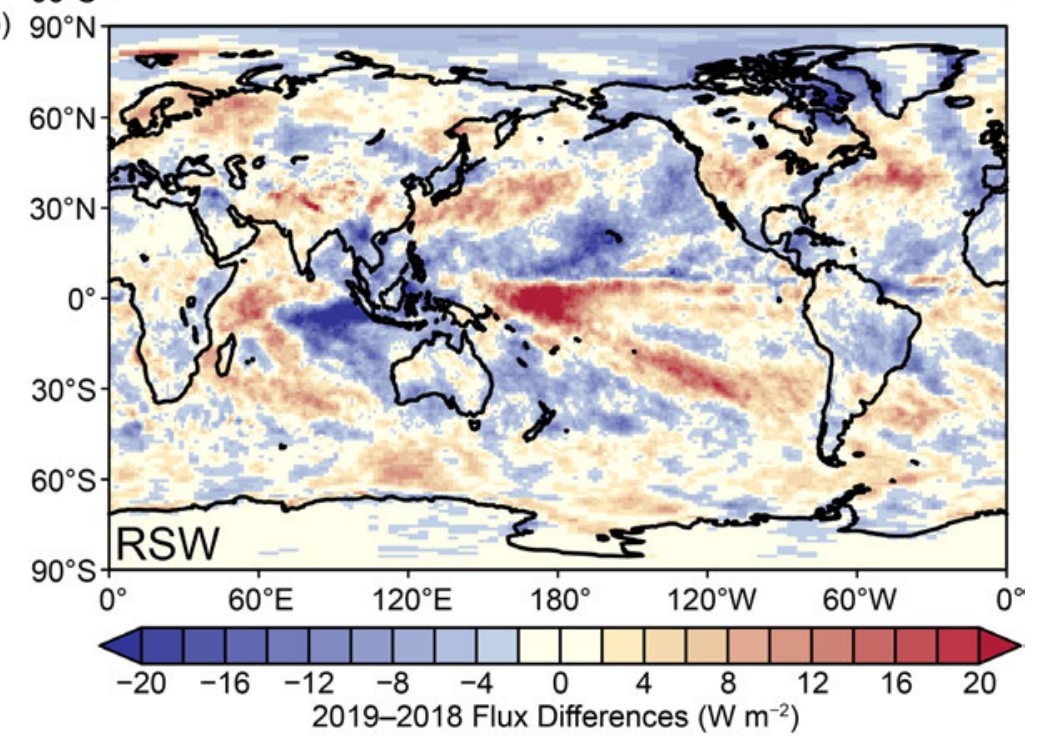

Fig. 2.43. Annual average TOA flux differences between 2019 and 2018 for the (a) OLR (top panel) and (b) TOA RSW (bottom panel). The pattern of differences shows several significant features including changes over the tropical Pacific, Indian, and North Atlantic Oceans. The tropical Pacific pattern is dominated by an atmospheric shift from La Niña conditions during the first half of 2018, to weak El Niño in the first half of 2019, to near-neutral condition by the end of 2019. change (decrease of $\sim 0.05 \mathrm{~W} \mathrm{~m}^{-2}$ ) in the global annual mean total net radiation into Earth's climate system for 2019 compared with 2018. Figure 2.43 shows the annual mean regional difference maps in the OLR and RSW between 2019 and 2018. Peak OLR flux changes are largely compensated by RSW changes, but OLR increases are spread over broader areas including the Indian Ocean, continental Asia, Australia, and South America. Large reductions in OLR and increases in RSW are observed over large areas of the Pacific that stretch from east of New Guinea to the eastern equatorial Pacific and from east of New Guinea to the southern Pacific. These regional changes are associated with the tropical climate oscillation between minor La Niña conditions in early 2018, weak El Niño conditions during the first half of 2019, and near-neutral conditions by the end of 2019. Relative to the multiyear data average from 2001 to 2018, the 2019 global annual mean flux anomalies (Table 2.7) are $+0.55,-0.1$, -1.20 , and $+0.55 \mathrm{~W} \mathrm{~m}^{-2}$ for OLR, TSI, RSW, and total net flux, respectively. With the exception of RSW, these global annual averaged anomalies are within the corresponding 2-sigma interannual variability (Table 2.7) for this period. The 2-sigma anomaly in the RSW relative to climatology indicates significant variability that could 
be indicative of cloud and/or snow/ice changes. More analysis is needed to attribute the source of the variability.

The global monthly mean anomaly time series of TOA fluxes (Fig. 2.44) reveal that the global monthly mean OLR anomaly remained mostly positive throughout 2019. The OLR anomalies in 2019 began with a value of $+0.10 \mathrm{~W} \mathrm{~m}^{-2}$, reached $+0.77 \mathrm{~W} \mathrm{~m}^{-2}$ in March, dropped to $-0.10 \mathrm{~W} \mathrm{~m}^{-2}$ in June, then mostly increased each month for the rest of the year. It ended the year with a very large positive OLR anomaly $\left(\sim+1.62 \mathrm{~W} \mathrm{~m}^{-2}\right)$. This large December OLR anomaly is consistent with the values obtained from the NOAA HIRS OLR (Lee and NOAA CDR Program 2011) and NASA AIRS OLR (Susskind et al. 2012) dataset. The global monthly mean absorbed shortwave (TSI - RSW) anomaly remained entirely positive during 2019, and the magnitudes of this anomaly were larger than the corresponding OLR anomaly. The absorbed shortwave anomaly began with a value of $+0.58 \mathrm{~W} \mathrm{~m}^{-2}$, oscillated around the value of $+1.0 \mathrm{~W} \mathrm{~m}^{-2}$ throughout the year, reached its maximum value of $+1.71 \mathrm{~W} \mathrm{~m}^{-2}$ in October, ending the year with a value of $+1.40 \mathrm{~W} \mathrm{~m}^{-2}$. For the year as a whole, the 2019 global annual mean absorbed shortwave anomaly was $+1.1 \mathrm{~W} \mathrm{~m}^{-2}$. The global monthly mean total net anomaly, which is calculated from the absorbed shortwave anomaly minus the OLR anomaly, began 2019 with a value of $+0.48 \mathrm{~W} \mathrm{~m}^{-2}$, remained positive throughout the year, reached a maximum value of $+1.51 \mathrm{~W} \mathrm{~m}^{-2}$ in October, and ended the year with a value of $-0.22 \mathrm{~W} \mathrm{~m}^{-2}$. The positive absorbed shortwave anomalies in 2019 dominated the negative effect of the OLR anomaly and resulted in the positive 2019 global annual mean total net anomaly of $+0.55 \mathrm{~W} \mathrm{~m}^{-2}$. This was the sixth consecutive year that the TOA global annual mean total net anomaly was positive relative to climatology. Long-term trend analyses that include the last two months of the merged dataset are discour-

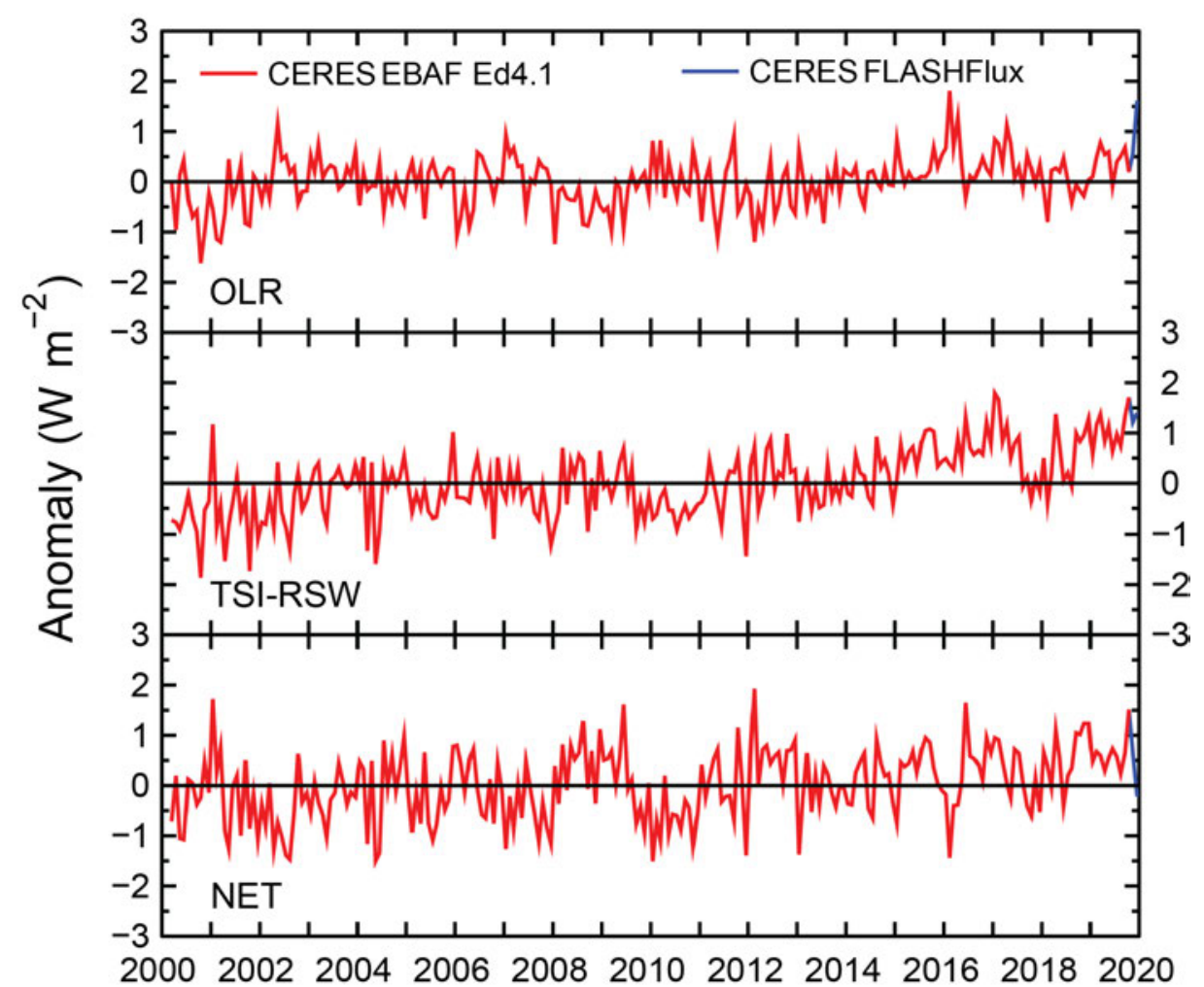

Fig. 2.44. Time series of global monthly mean deseasonalized anomalies $\left(\mathrm{W} \mathrm{m}^{-2}\right)$ of TOA Earth radiation budget for OLR (upper), absorbed shortwave (TSI-RSW; middle), and total net (TSI-RSW-OLR; lower) from Mar 2000 to Dec 2019. Anomalies are relative to their calendar month climatology (2001-18). Time series shows the CERES EBAF Ed4.1 $1^{\circ}$ data (Mar 2000-Oct 2019) in red and the CERES FLASHFlux version $3 \mathrm{C}$ data (Nov-Dec 2019) in blue; see text for merging procedure. (Sources: https://ceres-tool.larc.nasa.gov/ord-tool/jsp/EBAF41Selection.jsp and https://ceres-tool.larc.nasa.gov/ord-tool/jsp/FLASH_TISASelection.jsp.) aged because of the natural fluctuation in ERB components, uncertainty from the data merging process, and potential for drift in the FLASHFlux product.

The TSI data used in this study are provided by the Total Irradiance Monitor aboard the Solar Radiation and Climate Experiment (SORCE) mission (Kopp and Lean 2011) and the Royal Meteorological Institute of Belgium composite dataset (Dewitte et al. 2004), both renormalized to the SORCE Version 15. The RSW and OLR data were obtained from the CERES mission (Wielicki et al. 1996, 1998) aboard Terra and Aqua spacecraft.

The time series (Fig. 2.44) were constructed from the CERES EBAF (Energy Balanced And Filled) Ed4.1 product (Loeb et al. 2009, 2012, 2018) for March 
2000-October 2019 and from the CERES Fast Longwave and Shortwave Radiative Fluxes (FLASHFlux) version 3C product (Kratz et al. 2014) for November-December 2019. The normalization of the FLASHFlux data (Stackhouse et al. 2016) results in 2-sigma monthly uncertainties of $\pm 0.42, \pm 0.08$, \pm 0.22 , and $\pm 0.52 \mathrm{~W} \mathrm{~m}^{-2}$ for the OLR, TSI, RSW, and total net radiation, respectively. Global annual averaged maps were normalized on a region-by-region basis for November and December 2019.

2) Mauna Loa clear-sky "apparent" solar transmission-J. A. Augustine, K. O. Lantz, J.-P. Vernier, and

H. Telg

Apparent solar transmission has been measured at the Mauna Loa Observatory in Hawaii by NOAA's Global Monitoring Division and its predecessors since the International Geophysical Year in 1958. It is the longest record of its kind. Because the observatory is in a pristine environment, elevated far above the marine boundary layer, the Mauna Loa apparent transmission is an effective proxy for stratospheric aerosol loading, although it is affected each spring by perennial tropospheric Asian dust events (Bodhaine et al. 1981). It has been used primarily to track background stratospheric aerosols and the decay of volcanic plumes that had been injected into the stratosphere. Other studies have examined the influence of water vapor, ozone, and the Quasi-Biennial Oscillation (QBO) on the transmission at Mauna Loa (Dutton et al. 1985; Dutton and Bodhaine 2001; Dutton 1992).

Figure 2.45 presents monthly averages of the apparent transmission through December 2019 in time series along with a locally weighted scatterplot smoothing (LOWESS) fit smoothed with six-month filter. The high frequency variability of the fit reveals the springtime minimum each year as dust from Asia passes over. The cleanest extended period of the record is its first five years prior to the Agung eruption (Indonesia, 1963-64). After the recovery from Agung, that level of "background" stratospheric cleanliness, delineated by the horizontal dotted line in Fig. 2.45, has only been achieved for brief periods. The largest anomalies are from the eruptions of El Chichón (Mexico, 1982) and Mt. Pinatubo (Philippines, 1991), for which minimum transmissions of 0.80 and 0.82, respectively, were realized. Recoveries from those events lasted five to six years. About five years after the stratosphere recovered from the effects of Pinatubo, a series of medium-scale volcanic events, some of which were at high latitudes (Vernier et al. 2011; Andersson et al. 2015), impacted the stratosphere over Mauna Loa. Their combined effect was a small downward trend in transmission of -0.001 decade $^{-1}$ from 2002 through 2012 (large shaded area in Fig. 2.45) that is consistent with a reported increase in stratospheric aerosols of $4 \%-7 \%$ per year during the first half of the period (Hofmann et al. 2009). The anchor of that small trend is the effect from the plume of the Nabro eruption (Eritrea, June 2011) that lasted through 2012. The largest anomaly after Pinatubo was when transmission values of 0.90 and 0.91 in March and April of 2009 matched the maximum effect from Agung. Mt. Redoubt

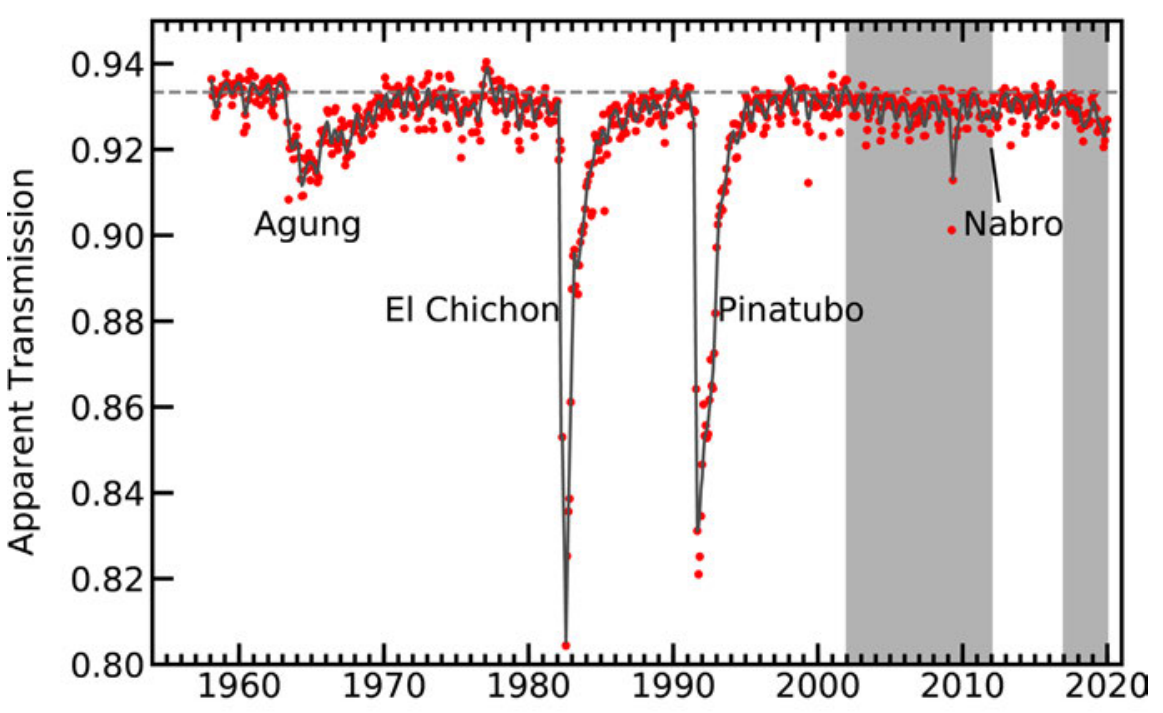

Fig. 2.45. Time series of the clear-sky apparent transmission at MLO, Hawaii, for 1958-2019. Red circles represent monthly means. The gray curve is a six-month smoothed LOWESS fit to the time series. The horizontal dotted line represents the mean pre-Agung "background" transmission from 1958 to 1962 (0.934). Major events that impacted the transmission record are labeled, and shaded areas are relevant to the discussion. 
(Alaska) erupted in March 2009 and did reach the stratosphere, but trajectories show that its plume did not escape the high latitudes. Because this short-term anomaly was not seen by the Mauna Loa stratospheric lidar, tropospheric events may be responsible for the observed reduction in transmission. Kilauea ( $\sim 32 \mathrm{~km}$ east of Mauna Loa) was highly active during that period, and effluent from its lava flowing into the sea $\sim 40 \mathrm{~km}$ southeast of Mauna Loa and strong Asian dust events are both evident in satellite imagery (https://worldview.earthdata.nasa.gov) during those two months.

After the effect from Nabro subsided in 2012, the transmission over Mauna Loa was relatively high through 2016. However, since 2017 the transmission has been generally decreasing (small shaded area in Fig. 2.45). The initial decrease in 2017 may be from Asian dust, but the decrease in the latter half of that year is likely due an active wildfire season and associated pyro-thunderstorm activity in British Columbia and the northwestern United States. Those events lofted smoke into the stratosphere that was observed by CALIPSO, SAGE III, and surface-based lidars in France into 2018 (Khaykin et al. 2018). The minimum transmission in September 2019 is very likely associated with the Raikoke eruption on the Kuril Islands on 22 June 2019, which was larger than Sarychev (Kuril Islands, 2009) and Nabro. Balloon measurements in Virginia on 4 October 2019, three months after the eruption, show the Raikoke plume residing in the lower stratosphere between 15 and $25 \mathrm{~km}$ above ground level. A combination of the CALIPSO space-borne lidar and a trajectory model (Vernier et al. 2013) shows the plume over Hawaii on that day, and as of January 2020 it was still significantly impacting the composition of the stratosphere (see Fig. SB2.5).

The observatory is located near the top of the Mauna Loa volcano on the island of Hawaii at $3400 \mathrm{~m}$ above mean sea level. "Apparent transmission" is calculated from the ratio of solar beam measurements at two fixed solar elevations (Ellis and Pueschel 1971), which is mathematically equivalent to a traditional vertical column transmission calculation. For this application, representative daily transmissions are computed as the mean of three such ratios from pyrheliometer measurements at solar pathlengths of 2, 3, 4, and 5 atmospheres. To avoid contamination from afternoon upslope winds, only morning measurements are used. This method minimizes error because neither the calibration of the pyrheliometer nor the solar intensity at TOA are needed, resulting in a precise time series back to 1958. The monthly product reported is the average of all acceptable clear-sky morning transmissions of a particular month.

\section{g. Atmospheric composition}

\section{1) Long-lived greenhouse gases-X. Lan, B. D. Hall, G. Dutton, J. Mühle, and J. W. Elkins}

Increases in atmospheric greenhouse gas burdens, especially the long-lived greenhouse gases (LLGHGs) carbon dioxide $\left(\mathrm{CO}_{2}\right)$, methane $\left(\mathrm{CH}_{4}\right)$, and nitrous oxide $\left(\mathrm{N}_{2} \mathrm{O}\right)$, are mainly the result of human activity since the industrial revolution and largely responsible for increasing global temperature (IPCC 2013).

The atmospheric pre-industrial abundance of $\mathrm{CO}_{2}$ is estimated to be $\sim 278 \mathrm{ppm}$ (parts per million by moles in dry air), based on air extracted from ice in Greenland and Antarctica (Etheridge et al. 1996). Systematic measurements of atmospheric $\mathrm{CO}_{2}$ began at Mauna Loa, Hawaii (MLO), in 1958, when the atmospheric $\mathrm{CO}_{2}$ abundance was about 315 ppm. In 2019, annually averaged $\mathrm{CO}_{2}$ at MLO reached $411.4 \pm 0.1 \mathrm{ppm}$ (all uncertainties are 68\% confidence intervals), while globally averaged $\mathrm{CO}_{2}$ at Earth's surface was $409.8 \pm 0.1$ ppm (Fig. 2.46a).

Annual growth in global mean $\mathrm{CO}_{2}$ has risen steadily from $0.6 \pm 0.1 \mathrm{ppm} \mathrm{yr}^{-1}$ in the early $1960 \mathrm{~s}$ to an average of $2.3 \mathrm{ppm} \mathrm{yr}^{-1}$ during 2009-18, with large interannual variability (Fig. 2.46a). The increase in global mean $\mathrm{CO}_{2}$ from 2018 to 2019 was $2.5 \pm 0.1$ ppm (Table 2.8).

Variations in the atmospheric $\mathrm{CO}_{2}$ show the changing imbalance between its emissions and sinks. From 1850 to $2018,440 \pm 20 \mathrm{Pg} \mathrm{C}\left(1 \mathrm{Pg} \mathrm{C}=10^{15} \mathrm{~g} \mathrm{C}\right)$ were emitted as $\mathrm{CO}_{2}$ from fossil fuel burning (Friedlingstein et al. 2019). For 2018 alone, global fossil fuel emissions reached $10 \pm 0.5$ $\mathrm{Pg} \mathrm{C} \mathrm{yr}{ }^{-1}$ for the first time in history (Friedlingstein et al. 2019). About half of the $\mathrm{CO}_{2}$ emitted 


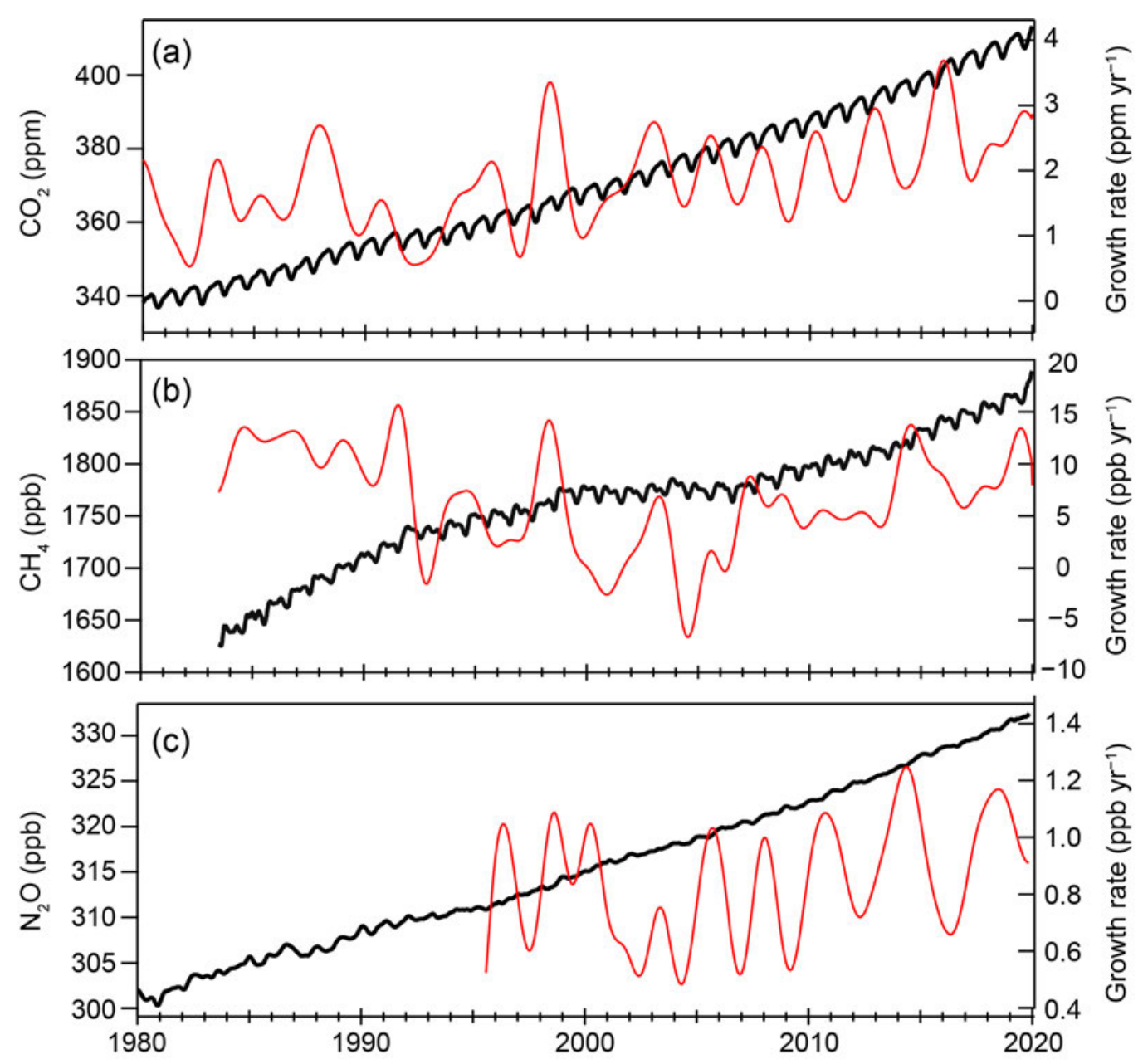

Fig. 2.46. Global monthly mean dry-air surface mole fractions (black) of (a) $\mathrm{CO}_{2}$, (b) $\mathrm{CH}_{4}$, and (c) $\mathrm{N}_{2} \mathrm{O}$ derived from the NOAA air-sampling network. Instantaneous growth rates (red), calculated as time-derivatives of deseasonalized trend curves (see Dlugokencky et al. 1994b for methods), are shown on the right axis (insufficient and noisy $\mathrm{N}_{2} \mathrm{O}$ data prior to 1995 hinder calculation of a growth rate).

\begin{tabular}{|c|c|c|c|c|c|}
\hline $\begin{array}{c}\text { Industrial } \\
\text { designation or } \\
\text { common name }\end{array}$ & $\begin{array}{l}\text { Chemical } \\
\text { formula }\end{array}$ & 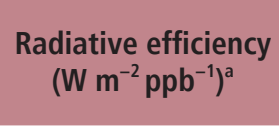 & $\begin{array}{l}\text { Radiative forcing } \\
\qquad\left(\mathrm{W} \mathrm{m}^{-2}\right)\end{array}$ & $\begin{array}{c}\text { Mean surface mole } \\
\text { fraction, } 2019 \\
\text { (change from prior year) }^{\mathrm{b}}\end{array}$ & $\begin{array}{l}\text { Lifetime } \\
\text { (years) }\end{array}$ \\
\hline Carbon Dioxide & $\mathrm{CO}_{2}$ & $1.37 \times 10^{-5}$ & 2.08 & $409.8(2.5)$ & - \\
\hline Methane & $\mathrm{CH}_{4}$ & $3.63 \times 10^{-4}$ & 0.52 & $1866.6(9.2)$ & 9.1 \\
\hline Nitrous Oxide & $\mathrm{N}_{2} \mathrm{O}$ & $3.00 \times 10^{-3}$ & 0.20 & $331.9(1.0)^{c}$ & 123 \\
\hline \multicolumn{6}{|c|}{ Chlorofluorocarbons } \\
\hline CFC-11 & $\mathrm{CCl}_{3} \mathrm{~F}$ & 0.26 & 0.059 & $226.5(-1.6)^{c}$ & 52 \\
\hline CFC-12 & $\mathrm{CCl}_{2} \mathrm{~F}_{2}$ & 0.32 & 0.161 & $501.5(-4.2)^{c}$ & 102 \\
\hline CFC-113 & $\mathrm{CCl}_{2} \mathrm{FCClF}_{2}$ & 0.30 & 0.021 & $69.7(-0.6)^{c}$ & 93 \\
\hline \multicolumn{6}{|c|}{ Hydrochlorofluorocarbons } \\
\hline HCFC-22 & $\mathrm{CHClF}_{2}$ & 0.21 & 0.052 & $246.8(2.7)$ & 11.9 \\
\hline HCFC-141b & $\mathrm{CH}_{3} \mathrm{CCl}_{2} \mathrm{~F}$ & 0.16 & 0.004 & $24.4(0.0)$ & 9.4 \\
\hline HCFC-142b & $\mathrm{CH}_{3} \mathrm{CClF}_{2}$ & 0.19 & 0.004 & $22.0(0.0)$ & 18 \\
\hline
\end{tabular}


The global mean $\mathrm{CH}_{4}$ abundance at Earth's surface increased from $722 \pm 15$ ppb (parts per billion) in 1750 to $1866.6 \pm 0.9 \mathrm{ppb}$ in 2019 (Fig. 2.46b). The growth rate of $\mathrm{CH}_{4}$ varies decadally and interannually. A stabilization in $\mathrm{CH}_{4}$ burden was observed during 1999-2006 after a large rise in the 1980s and 1990s, followed by a period of rapid increase since 2007. The increase in global mean $\mathrm{CH}_{4}$ from 2018 to 2019 was $9.2 \pm 0.9 \mathrm{ppb}$, which is among the three largest annual increases (with 2014 and 2015) since 2007. The drivers behind the changing $\mathrm{CH}_{4}$ growth rates are still being debated, mainly due to the complexity and uncertainty in the atmospheric $\mathrm{CH}_{4}$ budget. Although total global emissions of $\mathrm{CH}_{4}$ are well-constrained by the current network of atmospheric measurements and an estimate of its lifetime (Dlugokencky et al. 2011), the magnitude and trend in emissions from individual sources and trends in $\mathrm{CH}_{4}$ atmospheric lifetime are still uncertain. The sources of atmospheric $\mathrm{CH}_{4}$ are from anthropogenic (50\%-65\%) and natural origins (Saunois et al. 2016). The $\mathrm{CH}_{4}$ loss process is atmospheric oxidation, mainly through reaction with the short-lived ( $\sim$ second lifetime) hydroxyl radical $(\mathrm{OH})$, which is poorly constrained by observations. Other processes are destruction by bacteria in soils and reaction with chlorine radicals in the atmosphere, both of which are highly uncertain. The large variability in the $\mathrm{CH}_{4}$ growth rate results predominantly from changes in emissions from wetlands and biomass burning driven by meteorology, but it has also been affected by volcanic eruptions (Banda et al. 2013; Dlugokencky et al. 1994) and fossil fuel emissions (Dlugokencky et al. 1998). Measurements of $\mathrm{CH}_{4}$ abundance and its isotopic composition suggest the drivers behind the post-2006 rise are mainly increased emissions from biogenic sources and from natural and/or anthropogenic origins (Nisbet et al. 2019; Schaefer et al. 2016; Schwietzke et al. 2016), while a decrease in biomass burning and a small increase in fossil fuel emissions (Worden et al. 2017) can also play a minor role. Some studies have proposed a significant role of increased shale gas emissions from the United States (Franco et al. 2016; Hausmann et al. 2016; Helmig et al. 2016) in the past decade, but Lan et al. (2019) argue that this assertion is inconsistent with $\mathrm{CH}_{4}$ measurements from aircraft and tall towers from NOAA's North American Network.

Nitrous oxide $\left(\mathrm{N}_{2} \mathrm{O}\right)$ is an ozone-depleting LLGHG (Ravishankara et al. 2009) mainly produced from natural and agriculture soils, animal manure (Davidson 2009), and from the oceans. The observed increase in atmospheric $\mathrm{N}_{2} \mathrm{O}$ over its preindustrial level (at $270 \mathrm{ppb}$ ) is mostly caused by nitrogencontaining fertilizers and manure used for agriculture (Davidson 2009). Atmospheric $\mathrm{N}_{2} \mathrm{O}$ has been increasing steadily throughout the industrial era except for a brief period in the

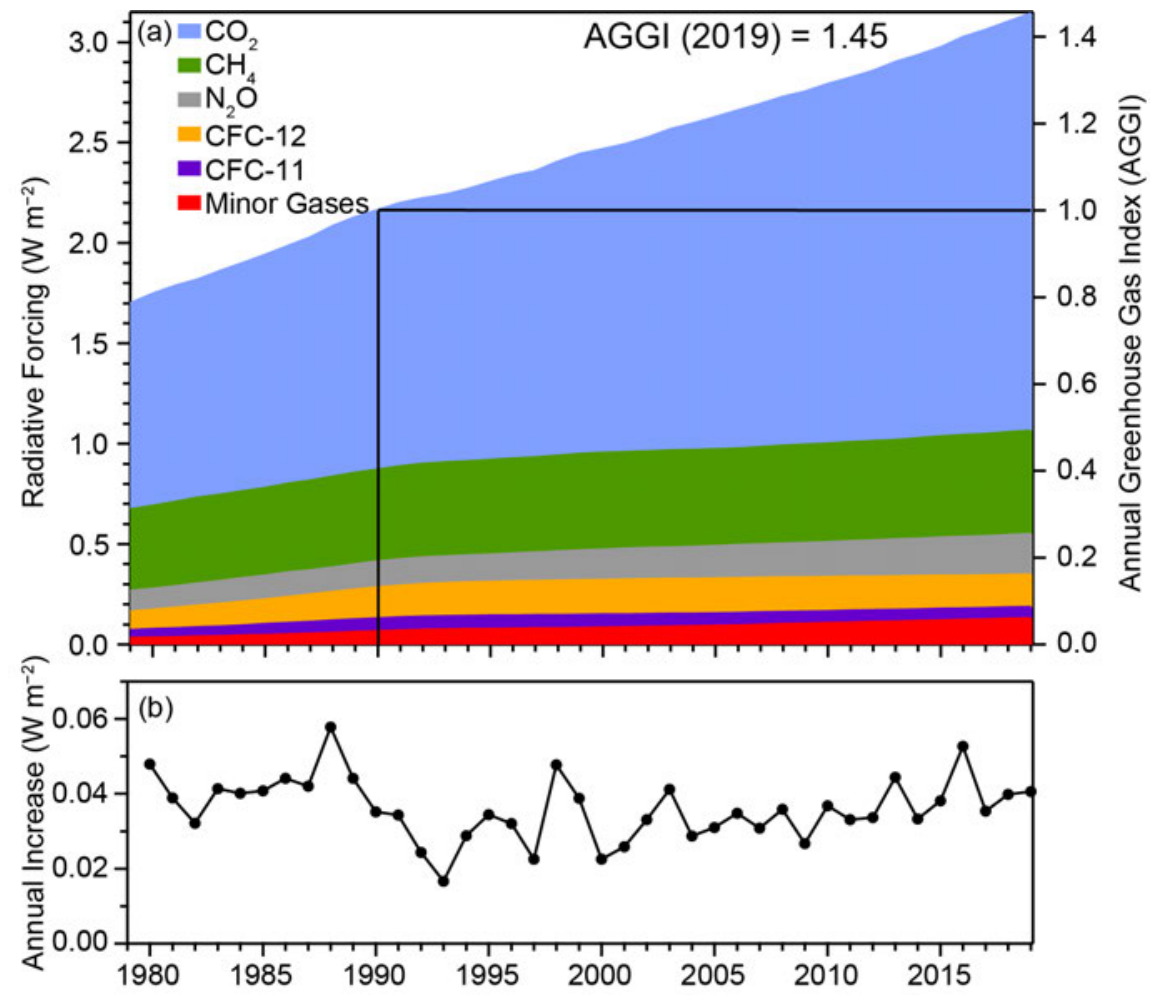

2.47. (a) Direct radiative forcing $\left(\mathrm{W} \mathrm{m}^{-2}\right)$ due to five major LLGHG and 15 minor gases (left axis) and the associated values of the NOAA AGGI (right axis). The five major LLGHG include $\mathrm{CO}_{2}, \mathrm{CH}_{4}, \mathrm{~N}_{2} \mathrm{O}, \mathrm{CFC}-11$, and CFC-12. The 15 minor gases consist of halogenated gases (CFC-113, $\mathrm{CCl}_{4}, \mathrm{CH}_{3} \mathrm{CCl}_{3}, \mathrm{HCFCs}$ 22, 141b and 142b, HFCs 134a, 152a, 23, 143a, and 125, SF ${ }_{6}$, and halons 1211, 1301 and 2402). (b) Annual increase in direct radiative forcing referenced to 1990 (solid black line). 
1940s (MacFarling Meure et al. 2006; Thompson et al. 2019). The mean global atmospheric $\mathrm{N}_{2} \mathrm{O}$ abundance in 2019 was $331.9 \pm 0.1$ ppb, an increase of $1.0 \pm 0.2$ ppb from 2018 (Fig. 2.46c). This $1.0 \mathrm{ppb}$ increase in the annual mean is similar to the average annual increase over 2009-18 $(1.0 \pm 0.2 \mathrm{ppb})$ but larger than the average annual increase over 1995-2008 (0.8 $\pm 0.2 \mathrm{ppb})$.

The impacts of these LLGHGs on global climate is estimated by their abilities to change the global radiative energy. Compared with preindustrial times, increasing atmospheric $\mathrm{CO}_{2}$ has increased radiative forcing by $>2.0 \mathrm{~W} \mathrm{~m}^{-2}$. The increase in $\mathrm{CH}_{4}$ has contributed to a $0.51 \mathrm{~W} \mathrm{~m}^{-2}$ increase in direct radiative forcing while the $\mathrm{CH}_{4}$-related production of tropospheric ozone $\left(\mathrm{O}_{3}\right)$ and stratospheric water $\left(\mathrm{H}_{2} \mathrm{O}\right)$ also contributes to $\sim 0.30 \mathrm{~W} \mathrm{~m}^{-2}$ indirect radiative forcing (Myhre et al. 2014). NOAA's Annual Greenhouse Gas Index (AGGI; Fig. 2.47) summarizes trends in the combined direct radiative forcing by $\mathrm{CO}_{2}, \mathrm{CH}_{4}, \mathrm{~N}_{2} \mathrm{O}, \mathrm{CFC}-11, \mathrm{CFC}-12$, and 15 minor gases (Table 2.8; Hofman et al.2006). This index represents the annual cumulative radiative forcing of these gases relative to the Kyoto Protocol baseline year of 1990. The 2019 AGGI was 1.45, suggesting a 45\% increase in radiative forcing since 1990 (combined radiative forcing in 2019 was $3.14 \mathrm{~W} \mathrm{~m}^{-2}$ ). While the atmospheric burdens of some greenhouse gases such as chlorofluorocarbons have declined in recent decades (Fig. 2.48), the combined radiative forcing of LLGHGs has increased each year (Fig. 2.47). Year-to-year variations in the AGGI increment correspond roughly with variability in $\mathrm{CO}_{2}$, since $\mathrm{CO}_{2}$ is responsible for about $65 \%$ of radiative forcing by LLGHGs and its rate of increase during 2014-19 accounts for 82\% of total increase in radiative forcing (Fig. 2.46).

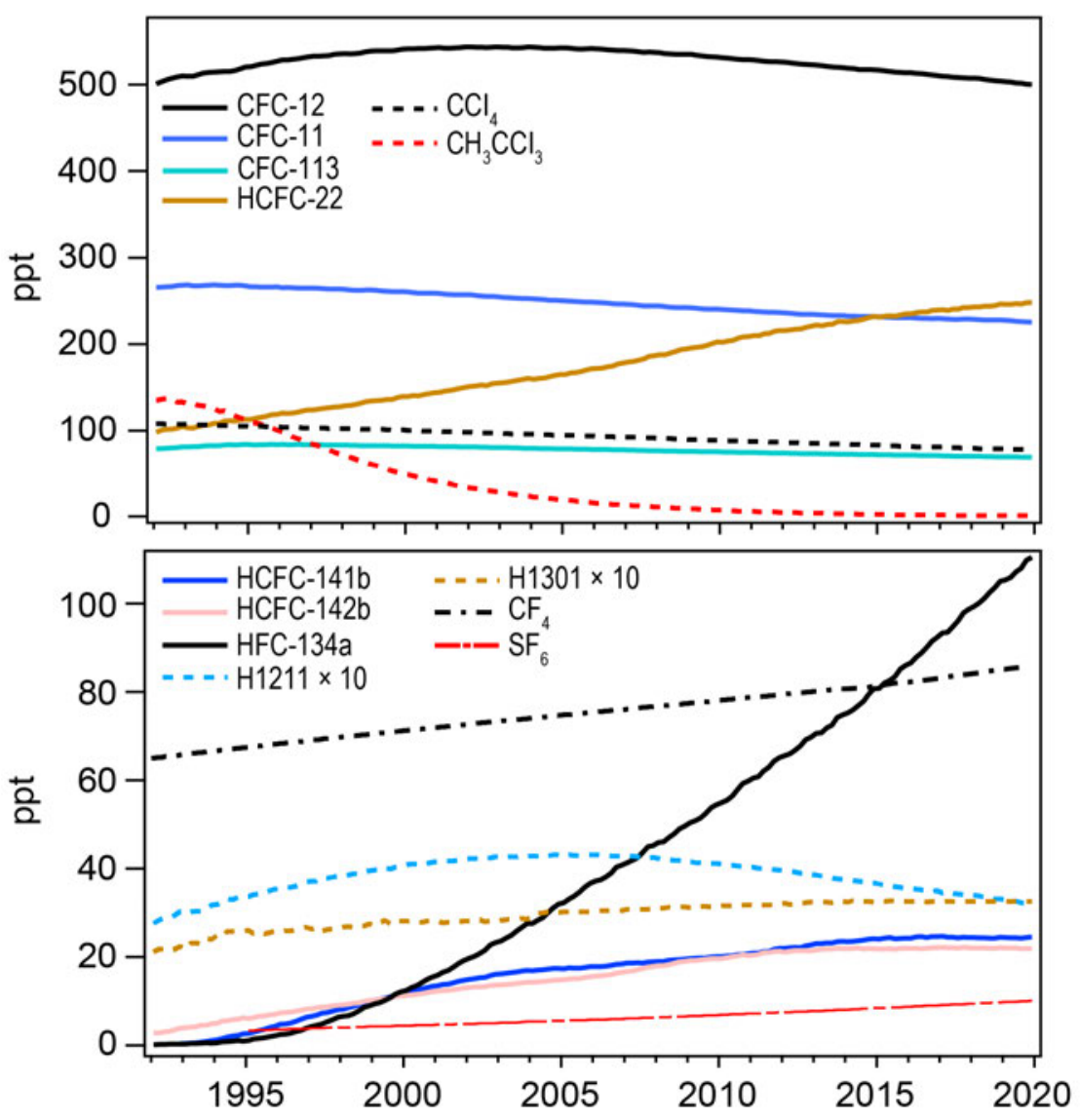

Fig. 2.48. Global mean mole fractions at Earth's surface (ppt; dry air) for several LLGHG, many of which also deplete stratospheric ozone. See Table $\mathbf{2 . 8}$ for the $\mathbf{2 0 1 9}$ global mean mole fractions of these and other gases. 
2) Ozone-depleting substances-B. D. Hall, S. A. Montzka, G. Dutton, B. R. Miller, and J. W. Elkins

Halogenated gases, such as CFCs and HCFCs, influence climate directly through radiative forcing and indirectly by contributing to stratospheric ozone depletion (Karpechko et al. 2018). The emissions and atmospheric abundances of most ozone depleting substances (ODS) are declining as expected due to controls implemented in the Montreal Protocol (Engel et al. 2018). By mid-2019, tropospheric CFC-11 and CFC-12 declined 15\% and 7.5\% from their maximum abundances in the mid-1990s and early 2000s, respectively (see Fig. 2.48). However, CFC-11 has not been declining as fast after 2012, likely indicating a resumption of production, in violation of the Montreal Protocol (Montzka et al. 2018a; Rigby et al. 2019), which banned production for emissive use starting in 2010. Global CFC-11 emissions, derived from atmospheric data, were 13\%-25\% higher during 2014-16 compared to 2008-12 (Montzka et al. 2018a). The globally averaged decline in CFC-11 from 2018 to 2019 (1.6 ppt; Table 2.8) is slightly larger than in previous years (Hall et al. 2019), although the significance of this difference and the influence of potential emission changes and atmospheric processes (Ray et al. 2020) on these recent observations have not yet been determined.

Atmospheric abundances of HCFCs, which are replacements for CFCs, increased as CFC production was phased out. In recent years the rates of increase of HCFC-22, HCFC-141b, and HCFC-142b have slowed (Fig. 2.48). In fact, globally averaged abundances of HCFC-141b and HCFC-142b did not change between 2018 and 2019 (Table 2.8). Substitutes for HCFCs, known as HFCs, do not deplete ozone, but do contribute to radiative forcing. Abundances of many HFCs are increasing at rates of several percent per year, although as a group their contribution to current forcing is still small relative to that from ozone-depleting gases ( 11\%; Montzka et al. 2018b). Of the HFCs, HFC-134a contributes most to radiative forcing (17 $\mathrm{mW} \mathrm{m}^{-2}$ in 2019). Its abundance increased by $5.8 \mathrm{ppt}$ from 2018 to 2019, which is similar to the average increase (5.6 $\mathrm{ppt} \mathrm{yr}^{-1}$ ) since 2010 .

Equivalent effective stratospheric chlorine (EESC) is a measure of the ozone-depleting potential of the stratospheric halogen loading at a given time and place. EESC is calculated from global average surface mole fractions of long-lived ozone-depleting gases and weighting factors that include surface-to-stratosphere transport times, mixing during transit, photolytic reactivity, and ozone-destruction efficiency (Montzka et al. 1996; Newman et al. 2007). EESC is typically calculated for two regions that differ in total available reactive halogen: the Antarctic and the midlatitude stratosphere (Fig. 2.49). EESC is larger in the Antarctic compared to the midlatitudes because a larger fraction of ODSs are converted into reactive halogen as they are transported to the Antarctic. Even though the abundances of CFCs are decreasing, their contribution to EESC is still substantial because of their long atmospheric lifetimes (Table 2.8). In contrast, the contribution
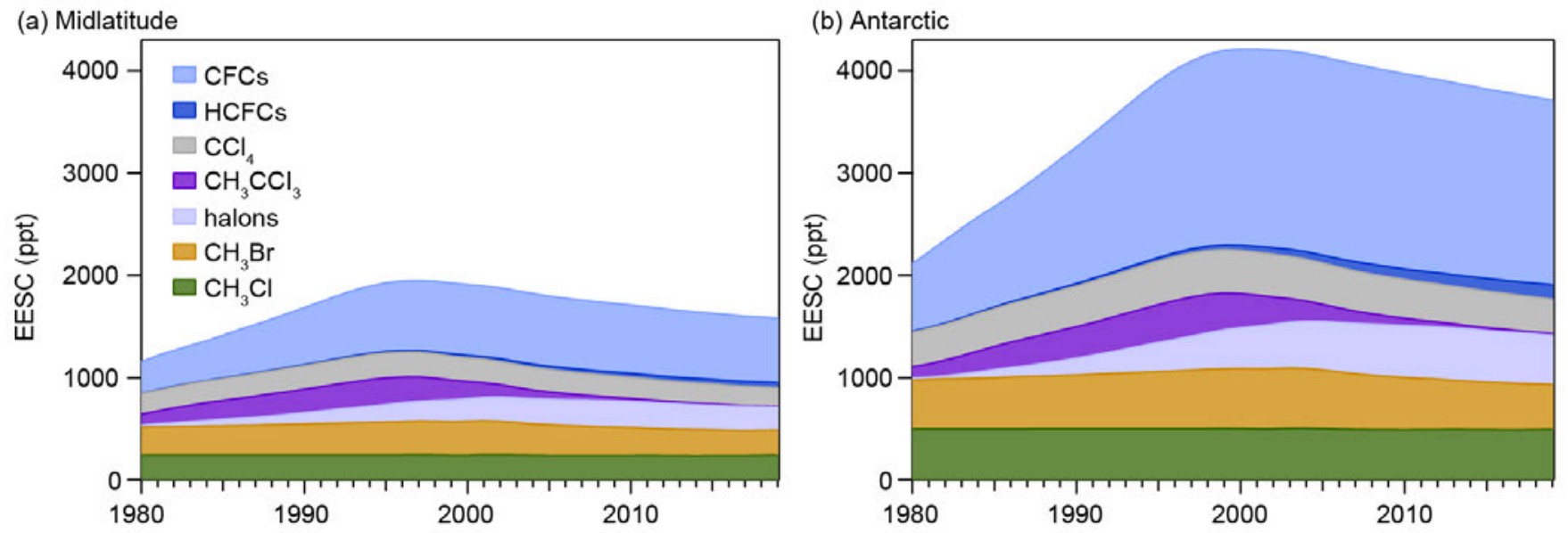

Fig. 2.49. EESC for the midlatitude and Antarctic stratosphere derived from NOAA surface measurements of long-lived ODSs, supplemented with data from the WMO A1 scenario (Carpenter et al. 2018). EESC values correspond to Jan of each year. In this context, Antarctic and midlatitude represent regions of the stratosphere having a mean age-of-air equal to 5.5 and 3 years, respectively. 
of methyl chloroform $\left(\mathrm{CH}_{3} \mathrm{CCl}_{3}\right)$ to EESC is now very small because emissions have decreased to near zero and its lifetime is relatively short (five years).

By the beginning of 2019, EESC decreased to 3710 ppt and 1575 ppt in Antarctic and midlatitude regions, respectively. These represent $22 \%$ and $47 \%$ reductions from the peak values in EESC over Antarctica and the midlatitudes, respectively, toward the 1980 benchmark values (see also www.esrl.noaa.gov/gmd/odgi/). EESC is expected to return to 1980 benchmark levels around 2050 in the midlatitudes and around 2075 in the Antarctic (Carpenter et al. 2018).

3) Aerosols—S. Rémy, N. Bellouin, Z. Kipling, M. Ades, A. Benedetti, and O. Boucher

Atmospheric aerosols play an important role in the climate system by scattering and absorbing radiation, and by affecting the life cycle, optical properties, and precipitation activity of clouds. Aerosols also represent a serious public health issue in many countries, and hence are subject to monitoring and forecasting as part of air quality policies.

The Copernicus Atmosphere Monitoring Service (CAMS) runs a near-real time global analysis of aerosols and trace gases. The CAMS project also produced a reanalysis of glob-

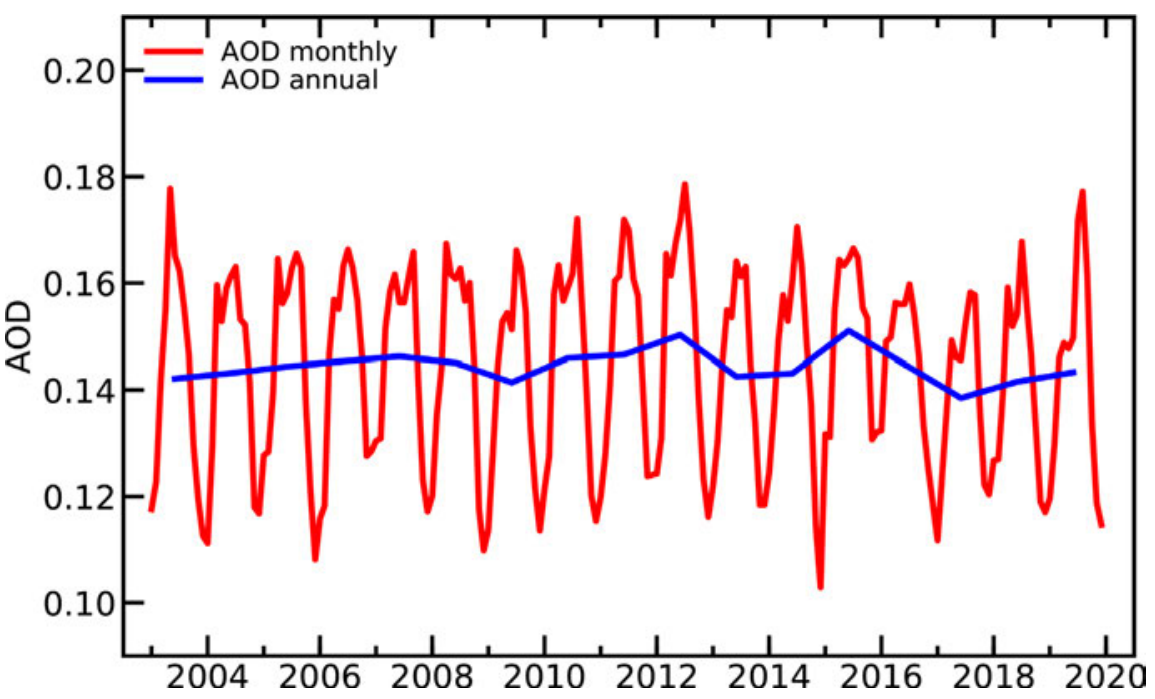

Fig. 2.50. Globally averaged total AOD at $550 \mathrm{~nm}$ over monthly (red) and annual (blue) periods for 2003-19.

al aerosols and trace gases

that covers the years 2003-19, named the CAMS reanalysis (CAMSRA; Inness et al. 2019) by combining state-of-the-art numerical modeling and aerosol remote-sensing retrievals from MODIS (Levy et al. 2013) and the Advanced Along Track Scanning Radiometer (AATSR; Popp et al. 2016). Other reanalysis products, such as MERRAero (Buchard et al. 2016), are also available. Verification of aerosol optical depth (AOD) at $550 \mathrm{~nm}$ against independent AERONET observations shows that the CAMS reanalysis has a smaller bias and error than its predecessors, the CAMS interim reanalysis (Flemming et al. 2017) and the Monitoring Atmospheric Composition and Climate (MACC) reanalysis (Inness et al. 2013). This section uses data exclusively from the CAMS reanalysis.

The time series of monthly and yearly globally averaged total AOD during 2003-19 (Fig. 2.50) shows strong seasonality, driven mainly by dust episodes between March and July in the Sahara, Middle East, and Taklimakan/Gobi and seasonal biomass burning in Africa, South America, Indonesia, and other regions. There is no significant trend over the period, but extreme events such as the September-October 2015 fires over Indonesia associated with El Niño are prominent. The summer maximum was very pronounced in 2019 mainly because of the large fires in July and August, particularly over Alaska, Siberia, and in the Amazon basin.

The AOD climatology between 2003 and 2019 (Fig. 2.51a) is marked by high values over the highly populated regions of India and China, mainly caused by anthropogenic emissions. High AOD over the Sahara and Middle East is primarily from dust, while the maxima over central Africa, Indonesia, the Amazon basin, and parts of Siberia are caused by fire emissions. The high values over Hawaii and close to Mexico City are a known artefact of the CAMS reanalysis related to volcanic outgassing. 


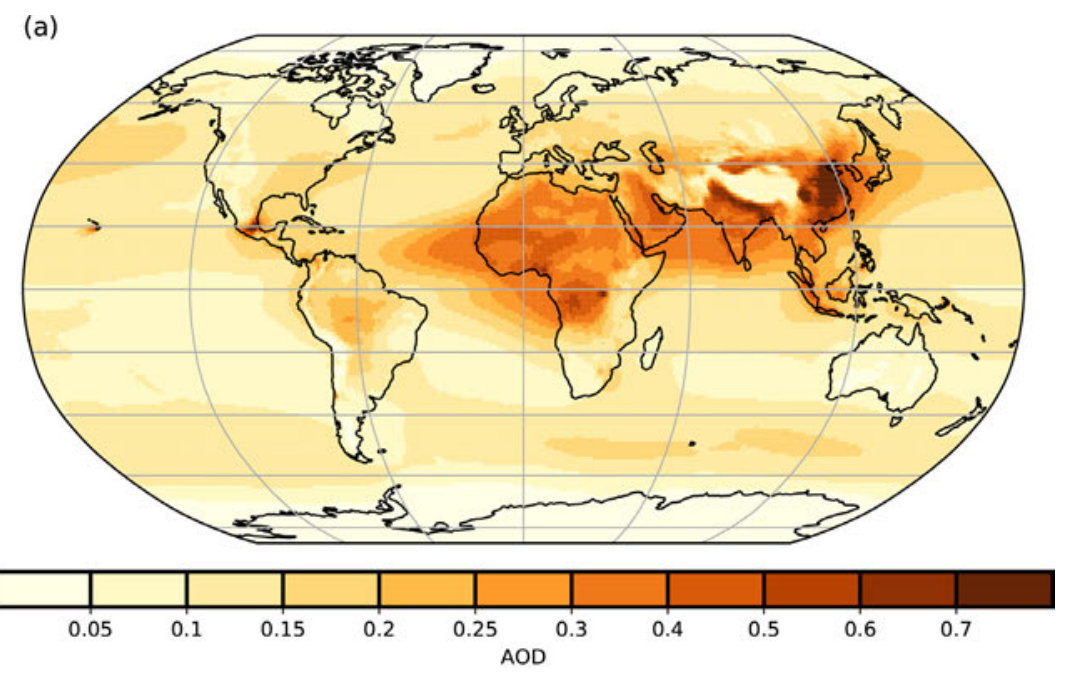

(b)
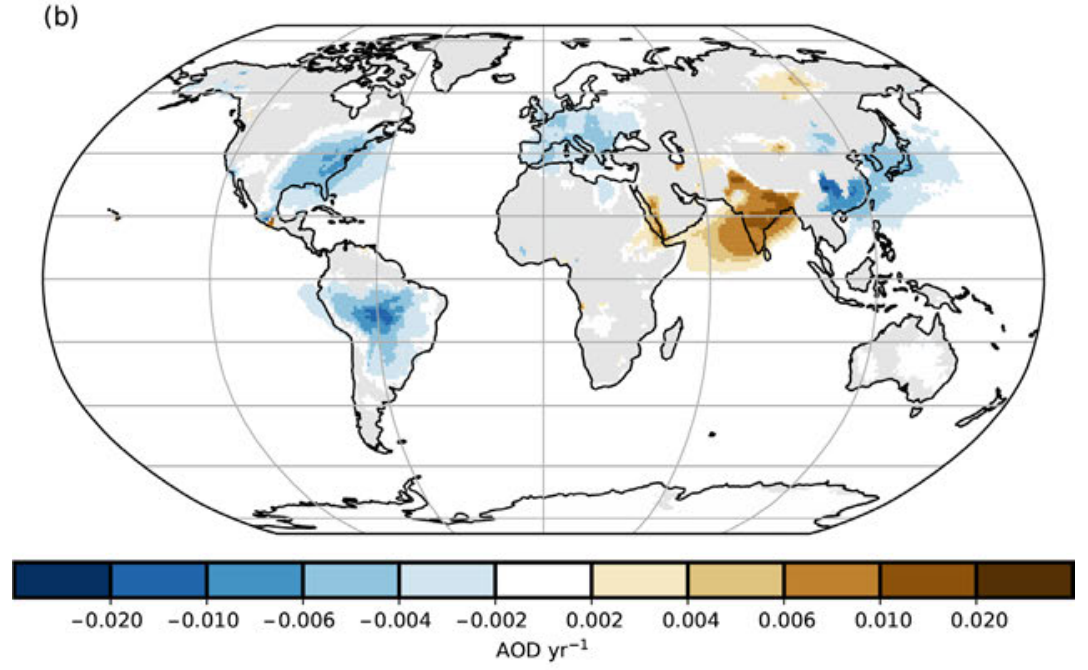

(c)
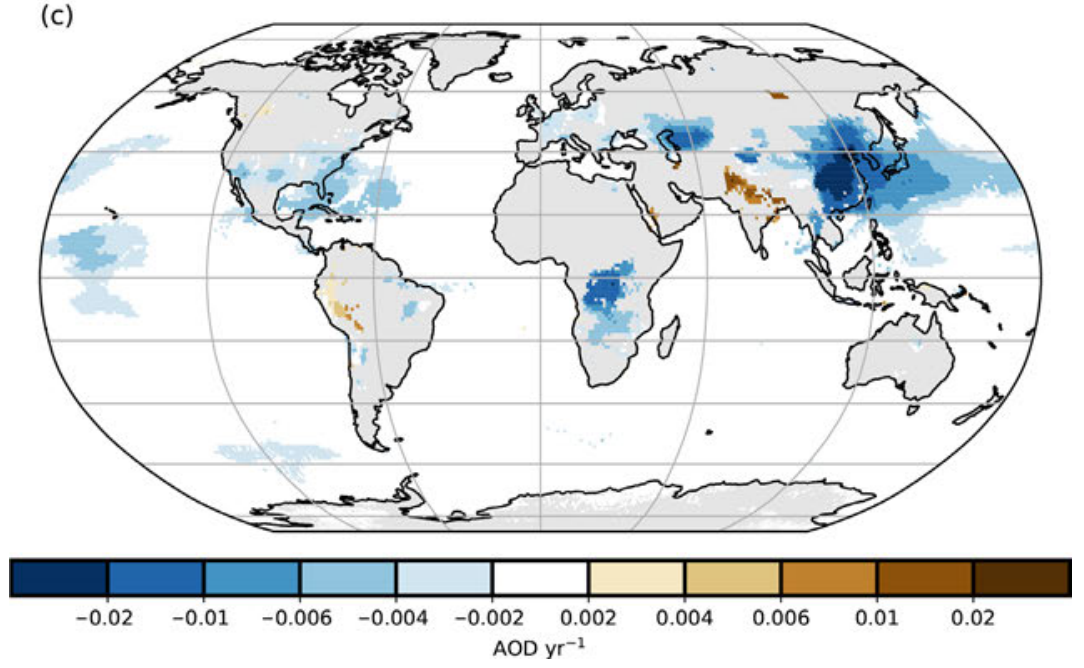

Fig. 2.51. (a) Total AOD at $550 \mathrm{~nm}$ averaged over the period 2003-19. Note the regional differences, with much greater total AOD values over parts of northern Africa, the Arabian Peninsula, southern Asia, and eastern China. Linear trends of total AOD (AOD yr ${ }^{-1}$ ) for (b) 2003-19 and (c) 2012-19. Only trends that are statistically significant (95\% confidence) are shown. Color scales have been constructed to highlight trends.
As compared to the 2003-18 average from the CAMS reanalysis, 2019 saw negative anomalies of total AOD over most of the United States, Europe, and Africa, as well as China, Korea, Japan, and parts of the Amazon basin (Plate 2.1x), although AOD in the last was significantly higher than in 2018. The negative anomalies over Brazil, the United States, Europe, and China are part of a longer trend over these regions, as shown in Fig. 2.51b. Figure 2.51c indicates that the trend is much more negative over China for 2012-19 than for 2003-19, which is consistent with the observed decrease in industrial sulfur dioxide $\left(\mathrm{SO}_{2}\right)$ emissions driven by tighter emission standards (Karplus et al. 2018). The 2012-19 trends are not significant over much of the Amazon basin, showing that most of the decrease in AOD occurred before 2012. The negative anomaly over the Sahel and Sahara (Plate 2.1x) was caused by reduced dust production in 2019, while the negative anomaly over most of west Africa is explained by a less active biomass burning season than usual there.

Positive anomalies of total AOD in 2019 (Plate 2.1x) are found in the southern part of the Arabian Peninsula, Iran, Pakistan, northern India, and parts of Iran, caused by more active dust production over these regions. The positive anomaly over the Indian subcontinent corresponds to a long-term trend of increasing anthropogenic emissions (Satheesh et al. 2017), as shown in Figs. 2.51b,c. Positive anomalies (Plate 2.1x) were also caused by extreme fires, such as over Alaska, northern Canada, and large parts of Siberia during boreal summer, and over Australia and Indonesia from October to December. Some of these events even led to the injection of aerosol in the stratosphere (see Sidebar 2.2). The drought that provoked the increased occurrence of fires over southeastern Australia and Indonesia was caused in part 
by a strong anomaly of the Indian Ocean dipole (IOD), the main cause of extreme droughts over Australia (Ummenhofer et al. 2009). The exceptional severity of the Australian fires is highlighted in Plate 2.1y, which shows the number of days with daily AOD at $550 \mathrm{~nm}$ above $99.9 \%$ of the daily record between 2003 and 2018. Sidebar 7.6 discusses these fires in more detail.

Radiative forcing resulting from aerosol-radiation (RFari) and aerosol-cloud interactions (RFaci) for the period 2003-19 is shown in Fig. 2.52, as estimated using the methods described in Bellouin et al. (2020). The year 2019 was close to the long-term average in terms of both RFari and RFaci. Time series indicate no statistically significant trends in aerosol radiative forcing because the radiative impact of decreasing trends over Europe, North America, and China is offset by increasing trends over India. Evaluating trends remains statistically challenging because of large uncertainties in the estimates, which are mostly due to lack of knowledge of the anthropogenic fraction of the aerosol and its radiative forcing efficiency.
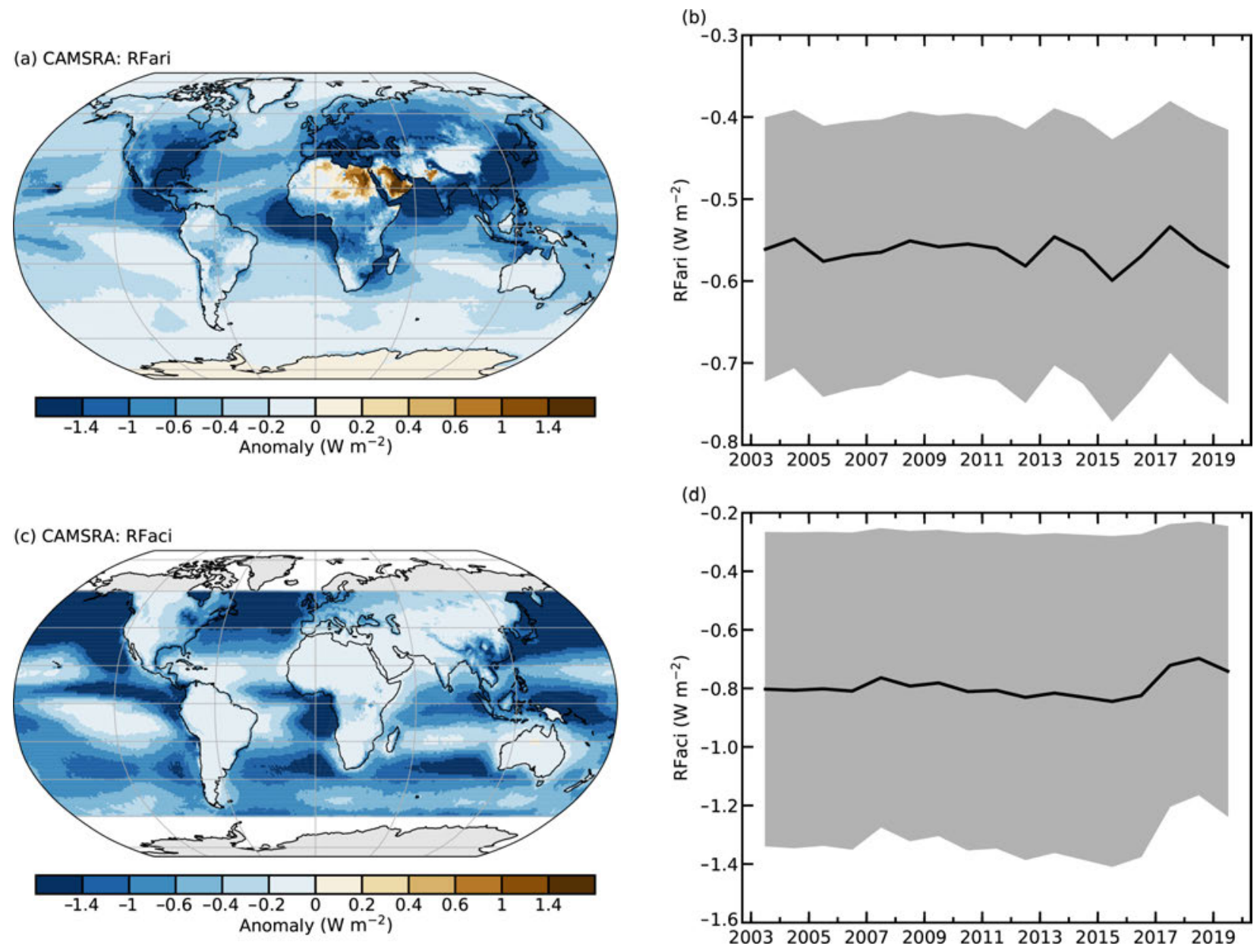

Fig. 2.52. Radiative forcing in the shortwave spectrum of (a), (b) aerosol-radiation (RFari) and (c), (d) aerosol-cloud interactions (RFaci) for 2003-19. The left column shows the average distribution. The right column shows time series of global averages, with the uncertainties of these estimates shown in gray.

4) Stratospheric ozone-M. Weber, W. Steinbrecht, C. Arosio, R. van der A, S. M. Frith, J. Anderson, M. Coldewey-Egbers, S. Davis, D. Degenstein, V. E. Fioletov, L. Froidevaux, D. Hubert, C. S. Long, D. Loyola, A. Rozanov, C. Roth, V. Sofieva, K. Tourpali, R. Wang, and J. D. Wild

The ozone layer that protects the biosphere from the harmful effects of ultraviolet radiation (UV) resides in the stratosphere. The total ozone column, with its main contributions from lower stratospheric ozone, determines how much UV reaches the surface. Over recent decades, changes in the upper stratospheric ozone have shown the clearest signs of ozone recovery due to the phasing out of ODSs since the late 1980s, following the Montreal Protocol (section 2g2). The total ozone 
column annual mean anomaly distribution for 2019 in Plate $2.1 \mathrm{z}$ shows opposite behavior in the two hemispheres. While the Southern Hemisphere (SH) shows positive anomalies with respect to the long-term mean, steadily increasing towards the South Pole and over Australia, negative anomalies cover most of the Northern Hemisphere (NH) with some positive values, mostly at high

(a)

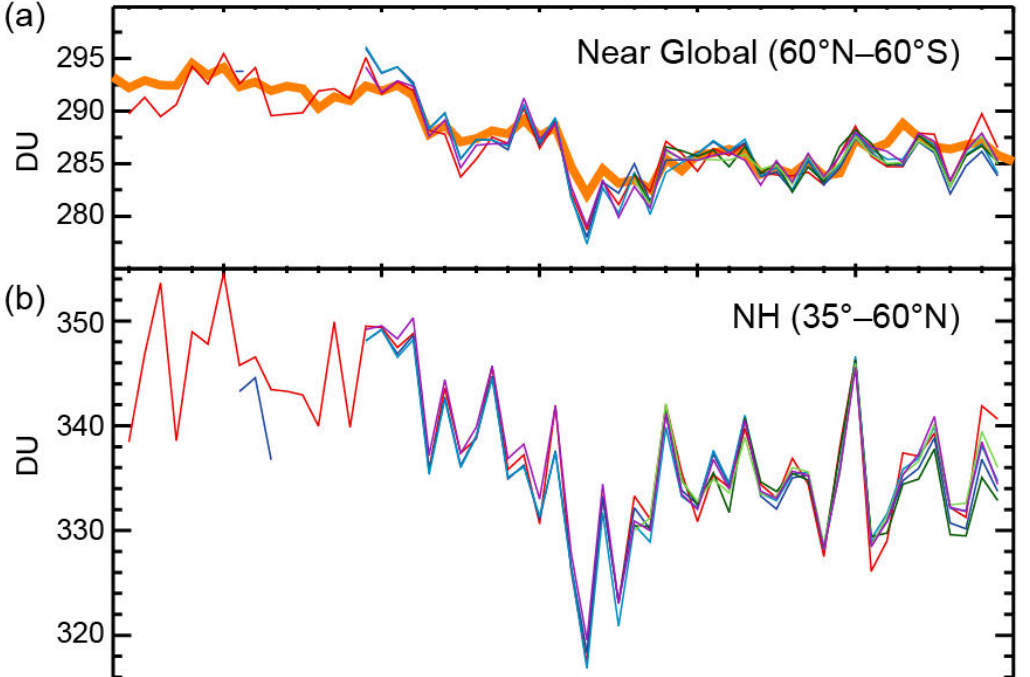

(c)

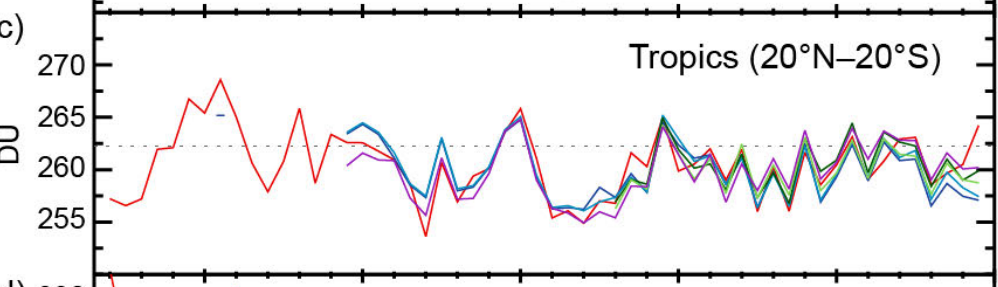

(d)

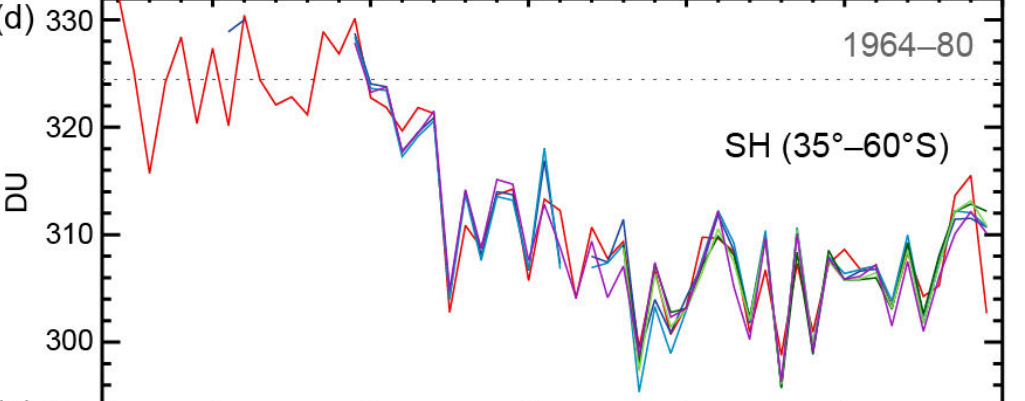

(e)

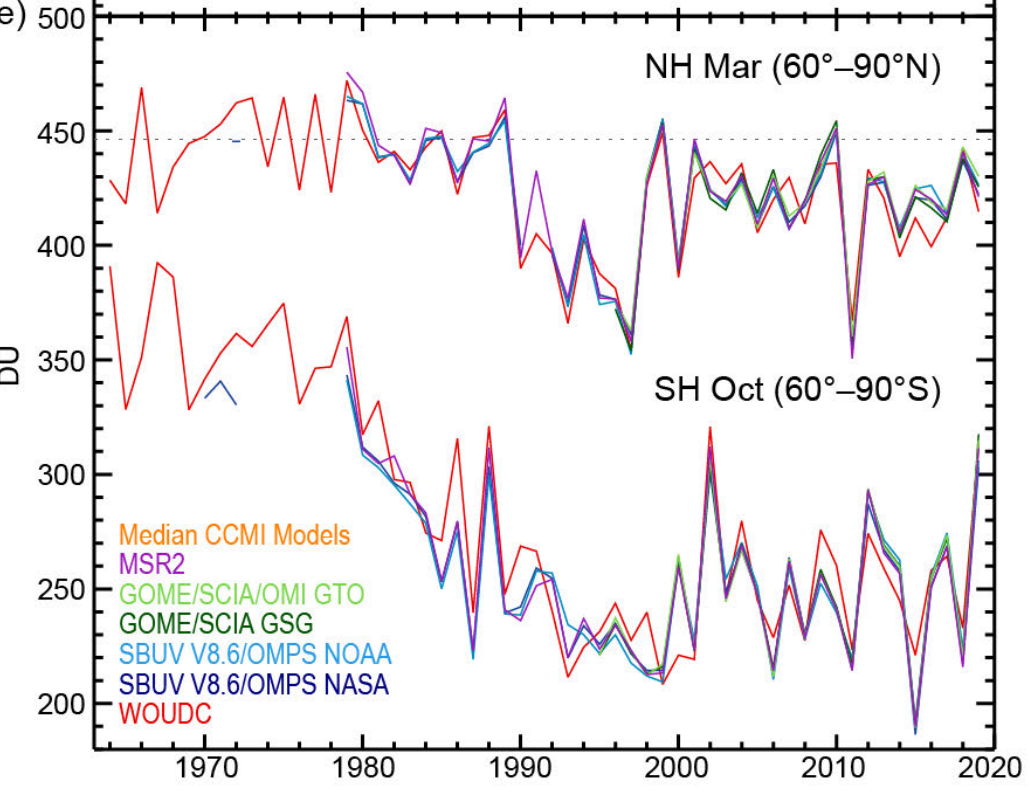

Fig. 2.53. Time series of annual mean total ozone (DU) in (a)-(d) four zonal bands, and (e) polar $\left(60^{\circ}-90^{\circ}\right)$ total ozone in Mar (NH) and Oct (SH), the months when polar ozone losses usually are largest. Data are taken from WOUDC (World Ozone and Ultraviolet Radiation Data Centre) ground-based measurements combining Brewer, Dobson, SAOZ (Système D'Analyse par Observations Zénithales), and filter spectrometer data (red; Fioletov et al. 2002; 2008); the BUV/SBUV/SBUV2 V8.6/OMPS merged products from NASA (MOD V8.6, dark blue; Frith et al. 2014, 2017) and NOAA (light blue; Wild and Long, pers. comm., 2019); the GOME/ SCIAMACHY/GOME-2 products GSG from University of Bremen (dark green; Weber et al. 2018) and GTO from ESA/DLR (light green, Coldewey-Egbers et al. 2015; Garane et al. 2018). MSR-2 (purple) assimilates nearly all ozone datasets after corrections with respect to the ground data (van der A et al. 2015). All six datasets have been bias corrected by subtracting averages for the reference period 1998-2008 and adding back the mean of these averages. The dotted gray lines in each panel show the average ozone level for 1964-80 calculated from the WOUDC data. The thick orange lines shows the average from chemistry-climate (CCMI) model runs (Eyring et al. 2013; Morgenstern et al. 2017; WMO 2018; SPARC/ IO3C/GAW 2019). All observational data for 2019 are preliminary. 
northern latitudes. Total ozone levels vary from year to year, depending on the dynamical state of the global atmosphere mainly determined by El Niño-Southern Oscillation (ENSO) and the Quasi-Biennial Oscillation (QBO). Both ENSO and the QBO are tropical phenomena that have a strong influence on the Brewer-Dobson circulation (BDC) determining the global stratospheric ozone distribution (e.g., Diallo et al. 2018; Olsen et al. 2019). Throughout 2019, the QBO was in its west phase, which generally leads to higher total ozone in the inner tropics and lower ozone in the subtropics and beyond (Plate 2.1z). The extended regions of below-average total ozone at low to middle NH latitudes are possibly linked to the weak ENSO condition in 2019 (Olsen et al. 2019). A major feature of 2019 is the very weak stratospheric SH winter polar vortex, a very small ozone hole (see Sidebar 6.1), and above-average total ozone at high southern latitudes during austral winter/spring as well as in the annual mean (Plate 2.1z). During the 2019 Antarctic winter/spring season, a stratospheric warming event, which is rare in the $\mathrm{SH}$ but frequent in the $\mathrm{NH}$, strongly perturbed the polar vortex. A persistent weak polar vortex in winter/spring, as in 2019, is associated with a stronger hemispheric BDC, occurring usually during west QBO phases, that leads to more ozone being transported into middle to high latitudes throughout much of the SH. In addition, higher polar winter stratospheric temperatures also reduce polar chemical ozone loss (e.g., Weber et al. 2011). As a consequence, annual mean total ozone in 2019 was fairly high, by up to 65 DU above the long-term average, at high southern latitudes (Plate 2.1z).

Figure 2.53 displays the annual mean total column ozone time series from various merged datasets for the near-global $\left(60^{\circ} \mathrm{N}-60^{\circ} \mathrm{S}\right)$ average, tropics, extratropics, and selected months in the polar regions. In October 2019, the SH polar cap total ozone (Fig. 2.53e) was as high as in 2002 and 1988, both years characterized by high dynamical activity and perturbed winter vortices (Schoeberl et al. 1989; Sinnhuber et al. 2003) and about 100 DU above the value in October 2015, a year with substantial polar ozone loss (Solomon et al. 2016). On the global scale (Fig. 2.53a), total ozone mean values in 2019 were lower than the previous year but within the variability observed during the last two decades. The same is true for the NH midlatitudes and the tropics (Figs. 2.53b,c) while midlatitude SH values were above the post-1990 average (Fig. 2.53d). In Fig. 2.53a, the median of 17 climate-chemistry model CCMI runs are also shown (Eyring et al. 2013; Morgenstern et al. 2017; WMO 2018; SPARC/IO3C/GAW 2019). The agreement of the observations with models that account for changes in ODS and greenhouse gases gives strong evidence that total ozone is on its slow path of recovery. However, in 2019 and previous years, the global ozone means from observations, as well from the CMI models, are still about $3 \%$ below the average from the period 1964-1980, when ODS levels were low.

Figure 2.54 shows ozone changes at two different altitudes, in the upper stratosphere (panels $\mathrm{a}-\mathrm{c}, 42 \mathrm{~km}$ altitude) and in the lower stratosphere (panels d-f, $22 \mathrm{~km}$ ). Ozone in the upper stratosphere shows the larger decline due to ODS increases until the late 1990s (WMO 2018). This large decline was stopped as a result of measures mandated in the international Montreal Protocol to phase-out ODS. Since about 2000, we have been in a phase of slow ozone recovery. In 2019, ozone values in the upper stratosphere were above the 1998-2008 average. In the lower stratosphere, long-term ozone variations are dominated by meteorological variations and transport (e.g., Chipperfield et al. 2018). Figures 2.54d-f show no clear sign of ozone increases in the lower stratosphere over the last 20 or so years. In 2019, the lower stratospheric values were at the lower end of expectations (gray shaded area of model predictions) in the $\mathrm{NH}$ and tropical bands (Figs. $2.54 \mathrm{~d}, \mathrm{e})$. The continuing tropical decline $\left(20^{\circ} \mathrm{N}-20^{\circ} \mathrm{S}\right)$ has been linked to climate change-related acceleration of the meridional BDC (Ball et al. 2018; Chipperfield et al. 2018; WMO 2018). Large interannual variations, as well as uncertainties in the observational data records (spread between different datasets), make reliable detection of the expected small underlying trends rather difficult, especially in the lower stratosphere. 

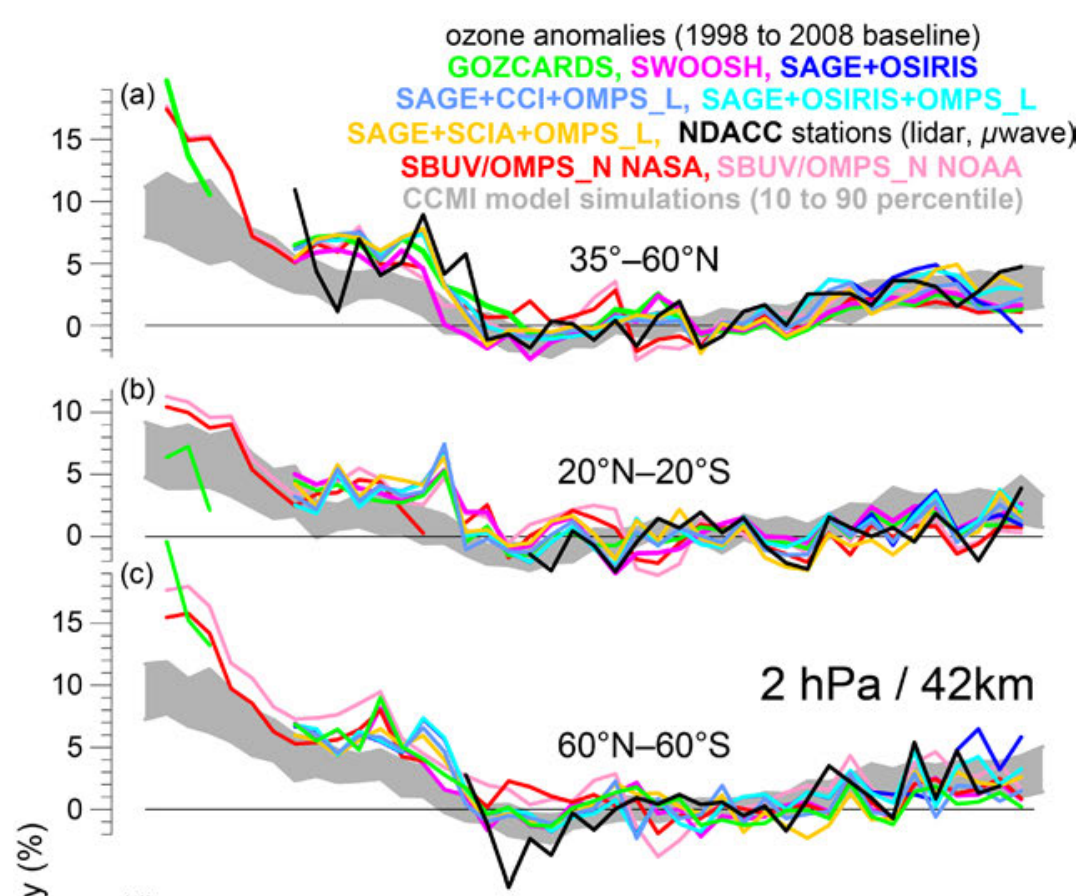

(d)

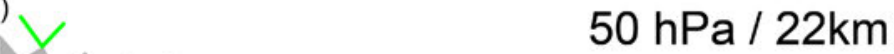

$\frac{c^{2}}{\not{c}}$

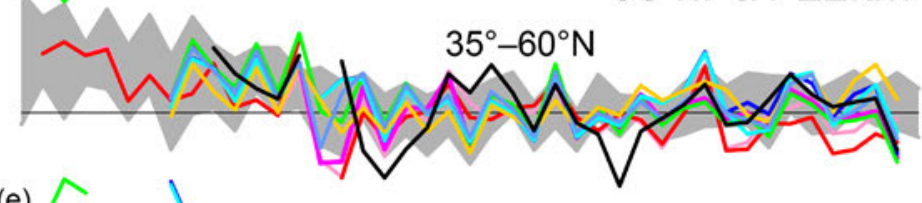

(e) $/$

10

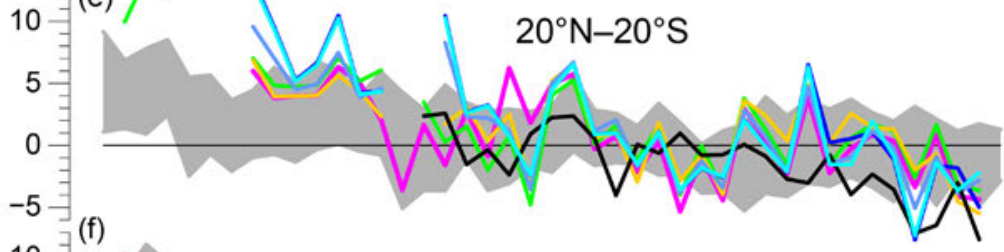

ro

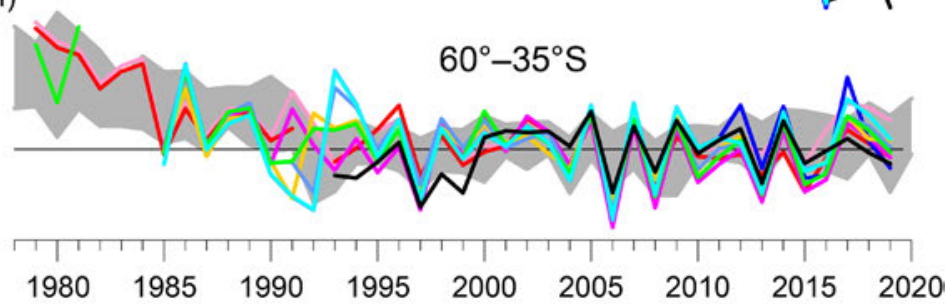

Fig. 2.54. Annual mean anomalies of ozone in the upper stratosphere (a)-(c) near $42 \mathrm{~km}$ altitude or $2 \mathrm{hPa}$ pressure and in the lower stratosphere (d)-(f) near $22 \mathrm{~km}$ or $50 \mathrm{hPa}$, for three zonal bands: $35^{\circ}-60^{\circ} \mathrm{N}, 20^{\circ} \mathrm{N}-20^{\circ} \mathrm{S}$ (tropics), $35^{\circ}-60^{\circ} \mathrm{S}$, respectively. Anomalies are referenced to the 1998-2008 baseline. Colored lines are for long-term records obtained by merging different limb (GOZCARDS, SWOOSH, SAGE+OSIRIS, SAGE+CCI+OMPS-L, SAGE+SCIAMACHY+OMPS-L) or nadir viewing (SBUV, OMPS-N) satellite instruments. Black line is from merging ground-based ozone records at seven NDACC stations employing differential absorption lidars and microwave radiometers. See Steinbrecht et al. (2017), WMO (2018), and Arosio et al. (2018) for details on the various datasets. Gray-shaded area shows the range of chemistry-climate model from CCMI (WMO 2018; SPARC/IO3C/GAW 2019; Dhomse et al. 2018). Ozone data for 2019 are not yet complete for all instruments and are still preliminary.

5) Stratospheric water vapor-S. M. Davis, K. H. Rosenlof, D. F. Hurst, H. Vömel, and H. B. Selkirk

Stratospheric water vapor (SWV) is a radiatively and chemically important trace gas with its variability strongly affected by the absolute humidity of air entering the stratosphere in the tropics, which is in turn largely determined by the temperature of the tropical cold point tropopause. Following 2018, a year in which lower stratospheric water vapor in the tropics dropped to a near-record low for the Aura Microwave Limb Sounder (MLS) satellite record (2004-19), water vapor abundance in the tropical lower stratosphere increased slightly during 2019 (Fig. 2.55). In January 2019, the Aura MLS monthly mean tropical $\left(15^{\circ} \mathrm{N}-15^{\circ} \mathrm{S}\right)$ lowermost SWV anomaly (at 82 $\mathrm{hPa}$, or $\sim 17 \mathrm{~km}$ ) was $-0.6 \mathrm{ppm}$ (parts per million, equivalent to a mole fraction of $\mu \mathrm{mol} \mathrm{mol}{ }^{-1}$ ), about 20\% below the 2004-19 January average. The tropical lower SWV anomaly transitioned to positive in April and remained between +0.3 and $+0.4 \mathrm{ppm}$ (within $10 \%$ of the average value for each month) for the remainder of the year (Fig. 2.55).

In general, the qualitative behavior of lowermost SWV observed by Aura MLS is consistent with balloon-borne frost-point hygrometer soundings at five locations (Fig. 2.56), although a small drift in MLS relative to the balloon measurements noted in earlier work persists (Hurst et al. 2016). The 
(a) $\mathrm{MLS} 15^{\circ} \mathrm{N}-15^{\circ} \mathrm{S}$

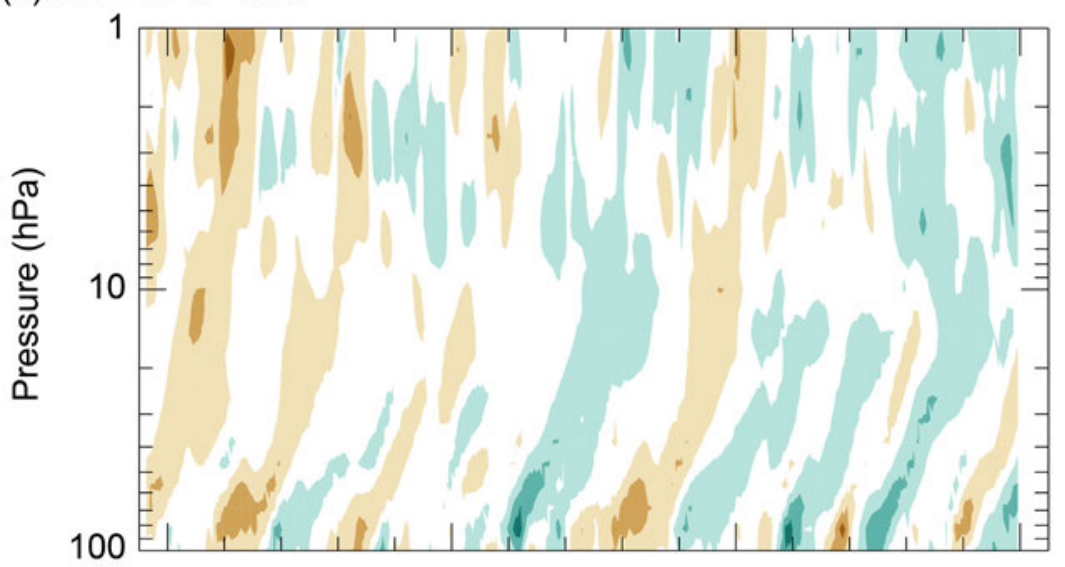

(b) MLS $82 \mathrm{hPa}$

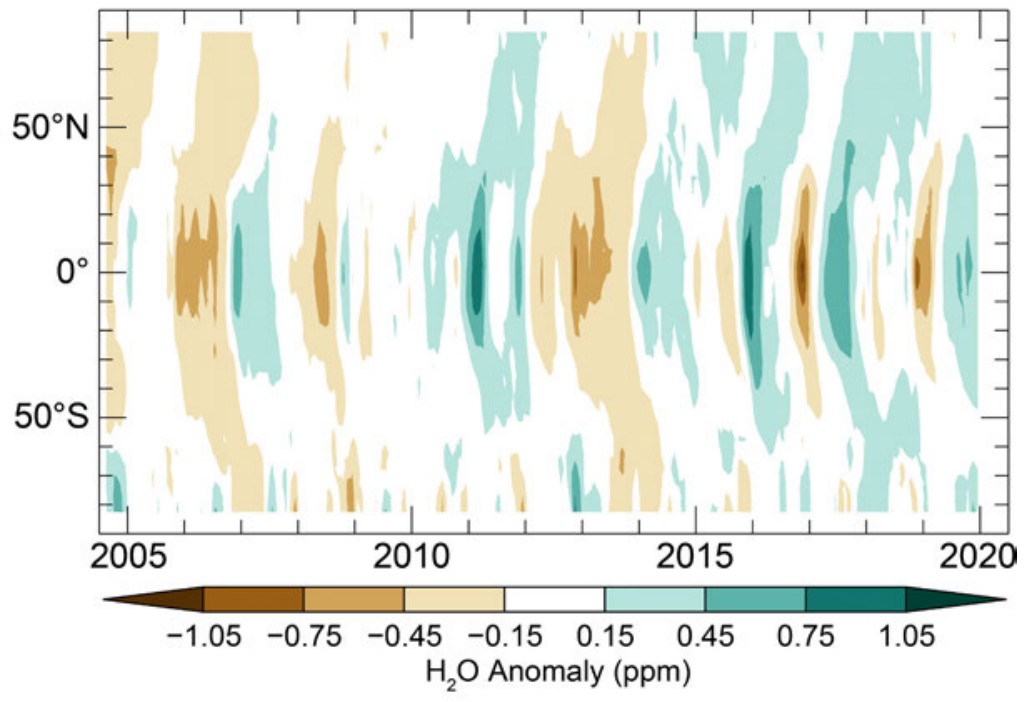

Fig. 2.55. (a) Time series of vertical profiles of tropical $\left(15^{\circ} \mathrm{N}-15^{\circ} \mathrm{S}\right) \mathrm{SWV}$ anomalies and (b) latitudinal distributions of SWV anomalies at $82 \mathrm{hPa}$. Both are based on Aura MLS data. Anomalies are differences from the mean 2004-19 water vapor mixing ratios (ppm) for each month. Panel (b) shows the propagation of tropical lower SWV anomalies to higher latitudes in both hemispheres as well as the influences of dehydrated air masses from the Antarctic polar vortex as they are transported toward the SH midlatitudes at the end of each year. dry anomaly at San José, Costa Rica $\left(10^{\circ} \mathrm{N}\right)$, at the start of 2019 propagates northward to progressively reach Hilo, Hawaii $\left(20^{\circ} \mathrm{N}\right)$, Boulder, Colorado $\left(40^{\circ} \mathrm{N}\right)$, and then Lindenberg, Germany $\left(52^{\circ} \mathrm{N}\right)$, by mid-2019 (Figs. 2.55b, 2.56). In contrast, the dry anomaly was barely observed in the southern midlatitude records from MLS (Fig. 2.55b, Fig. 2.56e) and frost point hygrometers launched at Lauder, New Zealand $\left(45^{\circ} \mathrm{S}\right.$, Fig. 2.56e). Similarly, the subsequent wet anomaly at San José starting in April 2019 propagates poleward and can be seen at Boulder by the end of the year.

At the tropical sites Hilo and San José, the seasonal and interannual variability of SWV is well correlated with variations in the cold-point temperature (CPT), as expected (Fig. 2.56d). Monthly mean tropical CPT anomalies increased from very cold at the beginning of 2019 ( $-1 \mathrm{~K})$ to moderately warm at the end of the year $(+0.5 \mathrm{~K})$, congruent with the dry-to-wet transition in tropical lower SWV.

In general, interannual variations in CPTs are correlated with those observed in several modes of large-scale climate variability such as tropical lower stratospheric upwelling rates, an important part of the BDC, ENSO, and QBO in tropical

stratospheric winds (Dessler et al. 2014). After January 2019, the QBO was in its westerly (warm) phase at $50 \mathrm{hPa}$. ENSO was in a weak El Niño phase for the first half of the year, followed by six months in its neutral phase. Reduced tropical upwelling due to the QBO westerly phase may have produced warming tropical tropopause temperatures and, therefore, the positive tropical lower SWV anomalies during the latter half of the year. Additionally, it is worth noting that the IOD was in its positive phase from May 2019 through the end of the year, including record-setting positive indices in October and November (see section $4 \mathrm{~h}$ for details). It is unknown whether the IOD impacts SWV, but there is some indication of correlation between SWV and Indian Ocean sea surface temperatures (SSTs; Garfinkel et al. 2018). 


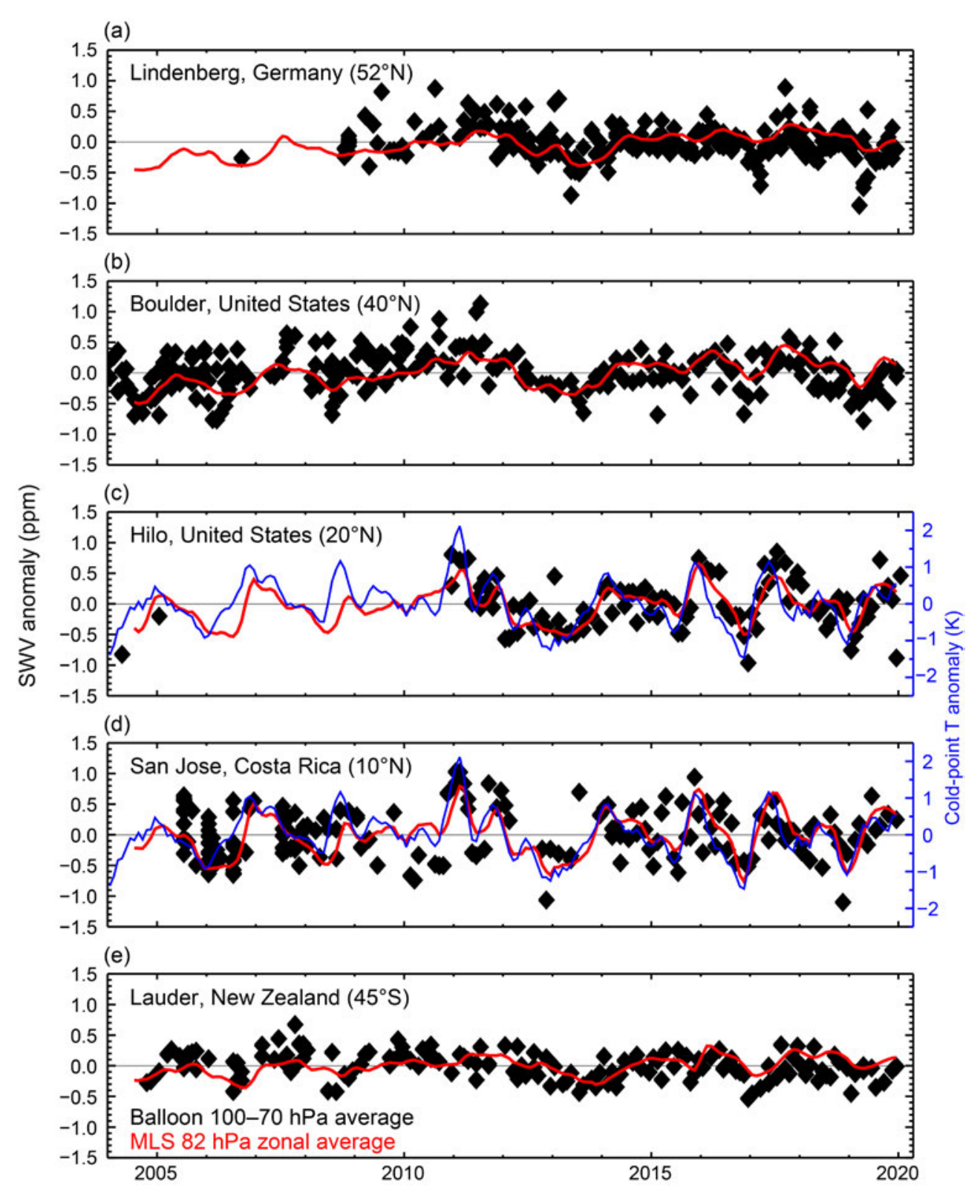

Fig. 2.56. Lower SWV anomalies over five balloon-borne frost-point (FP) hygrometer stations. Each panel shows the lower stratospheric anomalies of individual FP soundings (black) and of monthly zonal averages of MLS retrievals at $82 \mathrm{hPa}$ in the $5^{\circ}$ latitude band containing the FP station (red). High-resolution FP vertical profile data were averaged between 70 and $100 \mathrm{hPa}$ to emulate the MLS-averaging kernel for $82 \mathrm{hPa}$. Each MLS monthly zonal mean was determined from 2000-3000 profiles. Anomalies for MLS and FP data are calculated relative to the 2004-19 period for sites except for Lindenberg (2009-19) and Hilo (2011-19). Tropical CPT anomalies based on the MERRA-2 reanalysis (d; blue curve), which are generally well correlated with the tropical lower SWV anomalies, are the driving force behind the variations in tropical SWV during 2019.

\section{6) Tropospheric ozone-J. R. Ziemke and O. R. Cooper}

The Intergovernmental Panel on Climate Change identifies tropospheric ozone as the third most influential greenhouse gas, following carbon dioxide and methane (IPCC 2013). Tropospheric ozone contributes to net warming of the atmosphere, with average global radiative forcing of $0.4 \pm 0.2 \mathrm{~W} \mathrm{~m}^{-2}$. While tropospheric ozone is a surface pollutant detrimental to human health and vegetation (Fleming et al. 2018; Mills et al. 2018), it is also the dominant producer of the hydroxyl radical $(\mathrm{OH})$, the primary oxidant of pollutants in the troposphere. Sources for tropospheric ozone include ozone from the stratosphere and photochemical production from precursors in the troposphere including methane, volatile organic compounds, biogenic hydrocarbons, lightning NOx, and emissions generated from combustion of fossil fuels and biomass burning (Neu et al. 2014; 


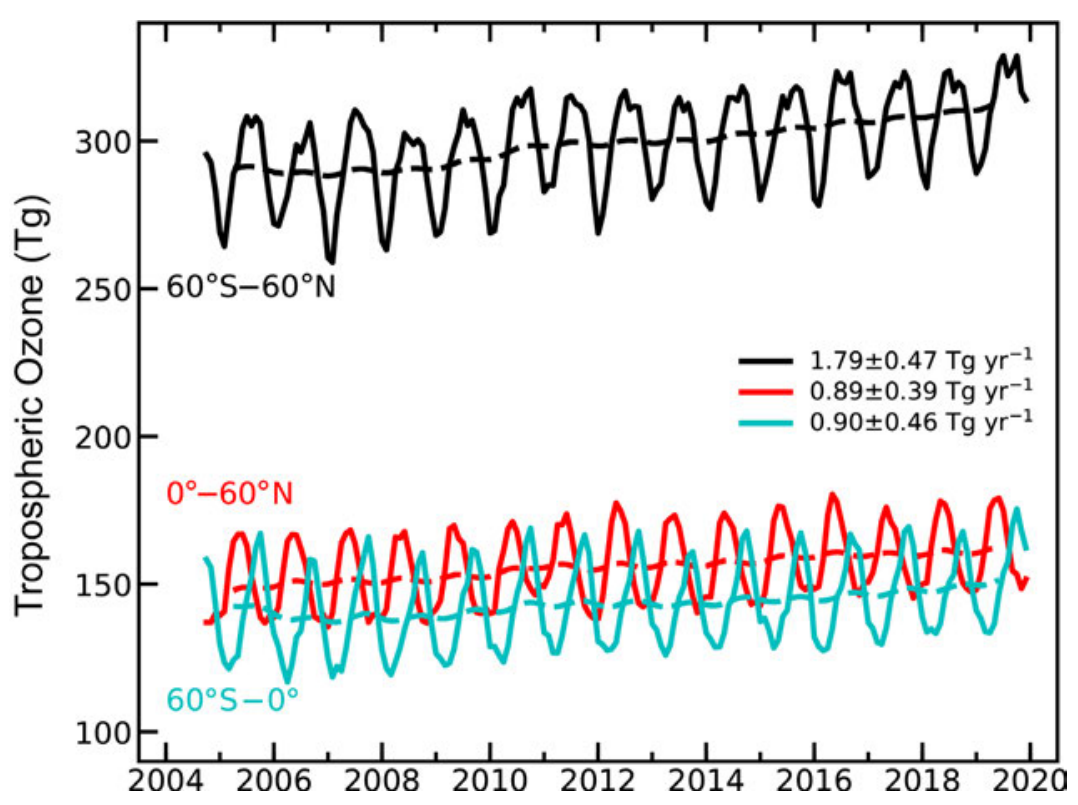

Fig. 2.57. Monthly averages of OMI/MLS tropospheric ozone burdens (Tg) from Oct 2004 through Dec 2019. The top curve (black) shows $60^{\circ} \mathrm{N}-60^{\circ} \mathrm{S}$ monthly averages (solid line) with 12-month running mean (dashed line). The bottom two curves show monthly averages (solid lines) and running means (dashed lines) for the NH (red) and SH (blue). Slopes of linear fits to the data are presented with their $95 \%$ confidence-level uncertainties. All three trends are deemed statistically significant at the $95 \%$ confidence level.

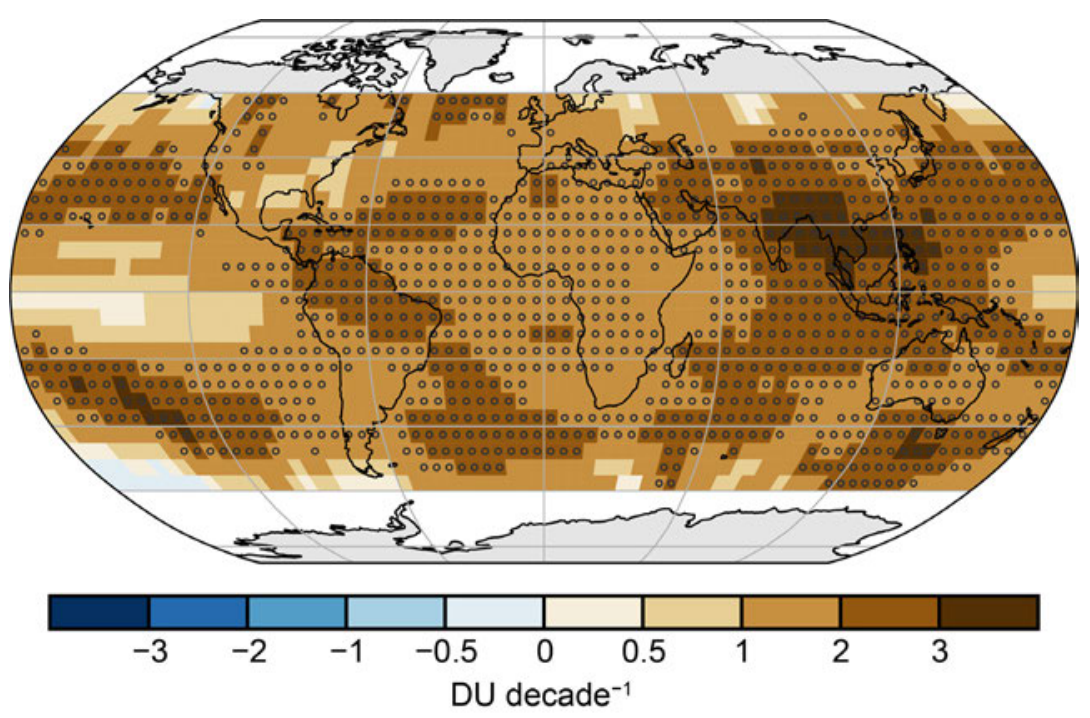

Fig. 2.58. Linear trends in OMI/MLS tropospheric column ozone (DU decade $^{-1}$ ) on a $5^{\circ} \times 5^{\circ}$ grid from Oct 2004 through Dec 2019. Circles denote trends with $p$-values less than 0.05 . Trends were calculated using a multivariate linear regression model (e.g., Randel and Cobb 1994, and references therein) that includes a seasonal cycle fit and the Niño 3.4 index as an ENSO proxy; trend uncertainties include autoregressive adjustment via Weatherhead et al. (1998).
Young et al. 2013, 2018; Monks et al. 2015). The main drivers of planetaryscale variability of tropospheric ozone include dynamical forcing from ENSO and the Walker circulation in the tropics, and baroclinic waves in midlatitudes (Chandra et al. 1998, 2009; Sun et al. 2014; Ziemke et al. 2015). Main drivers of small-scale patterns are largely dependent on local emissions of ozone precursors, both anthropogenic and natural, such as fossil fuel combustion and biomass burning. The high temporal and spatial variability of tropospheric ozone makes it difficult to determine decadal trends on regional or global scales based solely on in situ observations (Cooper et al. 2014; Lin et al. 2014; Barnes et al. 2016; Strode et al. 2019; Gaudel et al. 2018; Tarasick et al. 2019).

All State of the Climate reports since 2012 have provided updates on global tropospheric ozone based on independent measurements from ground- and satellite-based instruments (Ziemke and Cooper 2018). Due to limited spatial coverage and annual updates of groundbased observations, these reports have relied primarily on combined Aura Ozone Monitoring Instrument (OMI) and MLS satellite ozone measurements (Ziemke et al. 2019). OMI/MLS data show broad regions of positive 2019 tropospheric ozone column anomalies (relative to the 2005-18 average) of $~ 1.3$ DU (4\%) in the NH midlatitudes, with smaller anomalies of $\sim 1$ DU or less elsewhere (Plate 2.1aa). Hemispheric and global average tropospheric ozone burdens and their 95\% confidence levels for 2019 were $162 \pm 7 \mathrm{Tg}$ $\left(0^{\circ}-60^{\circ} \mathrm{N}\right), 151 \pm 8 \mathrm{Tg}\left(0^{\circ}-60^{\circ} \mathrm{S}\right)$, and $313 \pm 8 \mathrm{Tg}\left(60^{\circ} \mathrm{N}-60^{\circ} \mathrm{S}\right)$ (Fig. 2.57).

Trends in hemispheric and global burdens from October 2004 through December 2019 indicate clear increases of $\sim 0.6 \% \mathrm{yr}^{-1}$. Spatially, trends are overwhelmingly positive, the strongest of which are $\sim+3.3 \mathrm{DU}_{\text {decade }}{ }^{-1}\left(\sim+1 \% \mathrm{yr}^{-1}\right)$ above India and east/southeast Asia, extending eastward over 
the North Pacific Ocean (Fig. 2.58). These trends are consistent with model estimates based on strengthening emissions of ozone precursors from southeast, east, and south Asia, primarily due to fossil fuel combustion (Zhang et al. 2016; Lin et al. 2017). The models indicate that ozone produced in these areas is transported eastward in the free troposphere over the North Pacific Ocean, supported by the trends in Fig. 2.58. Positive trends in the SH extra-tropics have been linked to a broadening of the Hadley circulation (Lu et al. 2018a).

Three long-term baseline monitoring sites, with quality-assured data, are available for updating surface ozone trends through 2019: 1) Mauna Loa Observatory (MLO), Hawaii (19.5 N, 155.6 ${ }^{\circ} \mathrm{W}, 3397$ $\mathrm{m}$ a.s.1.); 2) South Pole Observatory (SPO), Antarctica ( $90^{\circ} \mathrm{S}, 59^{\circ} \mathrm{E}, 2840 \mathrm{~m}$ a.s.1.); and 3) Barrow Atmospheric Baseline Observatory, Utqiagivik, Alaska $\left(71.3^{\circ} \mathrm{N}, 156.6^{\circ} \mathrm{W}, 11 \mathrm{~m}\right.$ a.s.1.). Continuous measurements began at MLO in September 1973, at SPO in January 1975, and at Barrow in March 1973, with additional observations available at SPO for the years 1961-63 and at MLO for the years 1957-59 (Tarasick et al. 2019).

The limited data at MLO and SPO from the 1950s/1960s indicate that ozone at these remote highelevation sites was similar in the mid-twentieth century despite being located in different hemispheres. Ozone at SPO has changed little since the exploratory measurements of the early 1960s, with only a slight increase of $\sim 2$ ppbv during the period of continuous measurements (1975-2019; Fig. 2.59). In contrast, ozone at MLO increased at the rate of $0.14 \pm 0.05 \mathrm{ppbv} \mathrm{yr}^{-1}$, resulting in a $17 \%$ (6.4 ppbv) increase since 1973. MLO experiences high inter-annual ozone variability due to its location in the transition region between tropical and extratropical air masses. The ozone trend in the extratropical air masses can be isolated by focusing on the dry air masses, which tend to originate at higher altitudes and latitudes to the west and northwest of MLO (Gaudel et al. 2018). The trend in the dry air masses (23\%, or 9.9 ppbv, total increase since 1974$)$ is $50 \%$ greater compared to the trend using all air masses, which implies that the site is influenced by ozone increases in upwind regions to the west and northwest, most likely Asia where surface and free tropospheric ozone has generally increased over the past two decades (Cohen et al. 2018; Lu et al. 2018b; Gaudel et al. 2018).

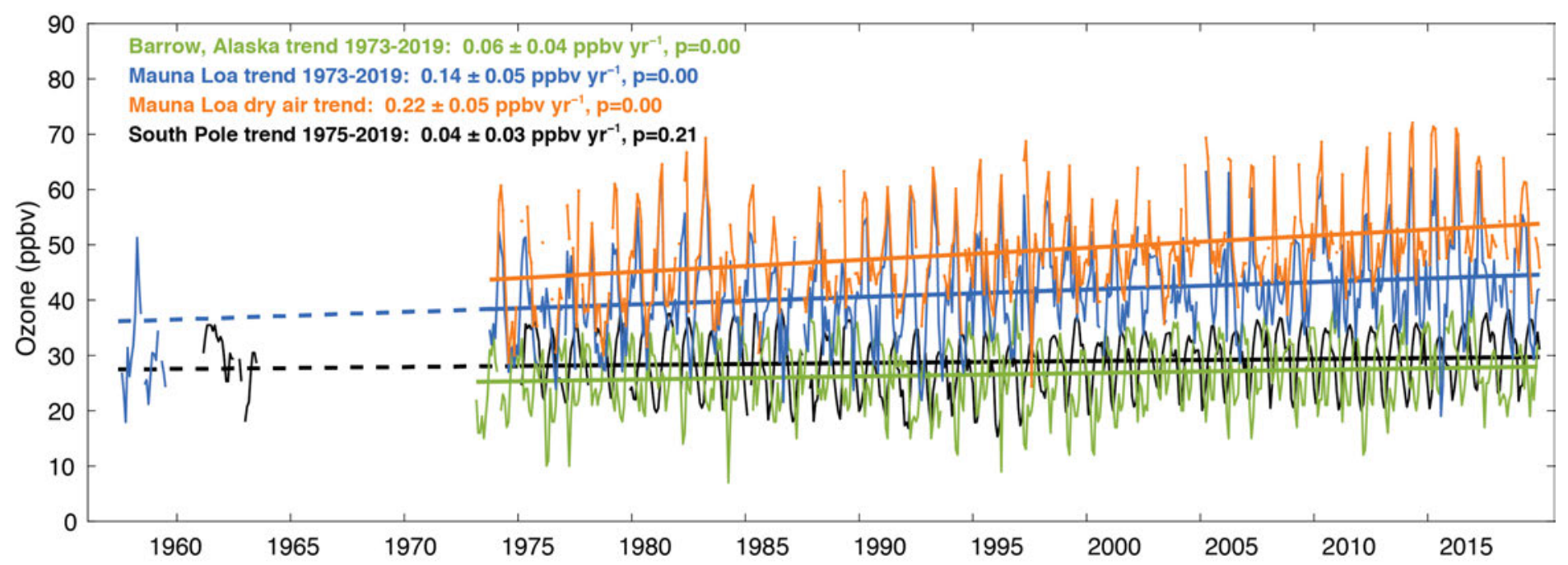

Fig. 2.59. Monthly median ozone at Utqiagivik (Barrow), Alaska (Mar 1973-Dec 2019, green) and South Pole (Jan 1975-Dec 2019, black) using data from all hours of the day. Additional data from South Pole are shown for the early 1960s. Also shown are nighttime monthly median ozone values at MLO calculated with all available data for months with at least $50 \%$ data availability, Oct 1973-Dec 2019 (blue), with early observations from the late 1950s. MLO data are limited to nighttime observations to focus on free tropospheric air masses. In addition, the monthly median values associated with dry air masses (orange) at MLO are included (dewpoint < the climatological monthly 40th percentile, and a sample size of at least 24 individual hourly nighttime observations). Trends (solid straight lines) are based on least-squares linear regression fit through the monthly values (1970s-2019), and reported with $95 \%$ confidence intervals and $p$-values. The MLO and South Pole trend lines are extrapolated back in time to the late 1950s (dashed lines). 
7) Carbon monoxide-J. Flemming, A. Inness, A. Crotwell, and G. Pétron

Carbon monoxide (CO) is a short-lived air pollutant with indirect impacts on climate forcing. $\mathrm{CO}$ is emitted by incomplete combustion sources and produced during the oxidation of methane and nonmethane hydrocarbons (Hartmann et al. 2013). In the troposphere CO has a lifetime of one to three months. It is destroyed mostly by hydroxyl radicals, $\mathrm{OH}$, which are also the main sink for $\mathrm{CH}_{4}$. Due to its short lifetime, atmospheric levels of $\mathrm{CO}$ reflect the distribution and seasonality of its sources and the $\mathrm{OH}$ sink.

Unusually strong wildfire activity in 2019, especially over Indonesia, eastern Siberia, Alaska, Amazonia, and Australia led to regional $\mathrm{CO}$ anomalies at the seasonal time scale, as shown in Plate 2.1ab, which is based on CAMS reanalysis. On the other hand, tropical and southern Africa, an area that generally has one of the largest contributions from fires to the global CO burden, did not have increased emission in 2019.

The most pronounced CO anomaly in 2019 appeared over Maritime Southeast Asia in autumn because of intense wildfires in the region, which were the third strongest since 2003. The firedriven $\mathrm{CO}$ anomalies occurred against a background of a continually decreasing $\mathrm{CO}$ burden in the $\mathrm{NH}$.

Figure 2.60a shows a time series of the monthly mean global burden of CO from the CAMS reanalysis for the period 2003-19 (Inness et al. 2019). Approximated with a linear trend over the whole period, the total global CO burden has declined by $-1.7 \mathrm{Tg} \mathrm{yr}^{-1}$, and as piecewise trends following Flemming and Inness (2018) for the periods 2003-07, 2008, and 2009-19 by -3.1, -14.0, and $+0.1 \mathrm{Tg} \mathrm{yr}^{-1}$, respectively. The global CO burden in 2019 was similar to most years in the last decade, with the exception of 2015 when wildfires in Indonesia led to exceptionally large burdens. Clean marine boundary layer observations of CO are shown in Fig. 2.61. Background CO declined at an average rate of $-1 \mathrm{ppb} \mathrm{yr}^{-1}$ in the $\mathrm{NH}$ temperate latitudes and $-1.5 \mathrm{ppb} \mathrm{yr}^{-1}$ for latitudes north of $53^{\circ} \mathrm{N}$ (Novelli et al. 2003; Pétron et al. 2019). Based on measurements of Greenland firn air (old air trapped in perennial snowpack), this negative trend in the NH started in the 1970s or 1980s and is likely explained by decreasing anthropogenic CO emissions (Petrenko et al. 2013).

The spatial distribution of the 2019 CO anomalies with respect to the period 2003-19 is shown in Plate 2.1ab. Small negative anomalies of up to $-5 \%$ were seen for most of the NH. 2019 was a year of increased fire activity in areas experiencing positive temperature anomalies and dry conditions. Intensive fire activity in Indonesia during September-November increased the CO burden in this region by up to $20 \mathrm{Tg}$, which was the third highest since 2003 after the two El Niño years 2006 and 2015 (Fig. 2.60b). Furthermore, unusually strong fires in Alaska, Siberia, and

(a)

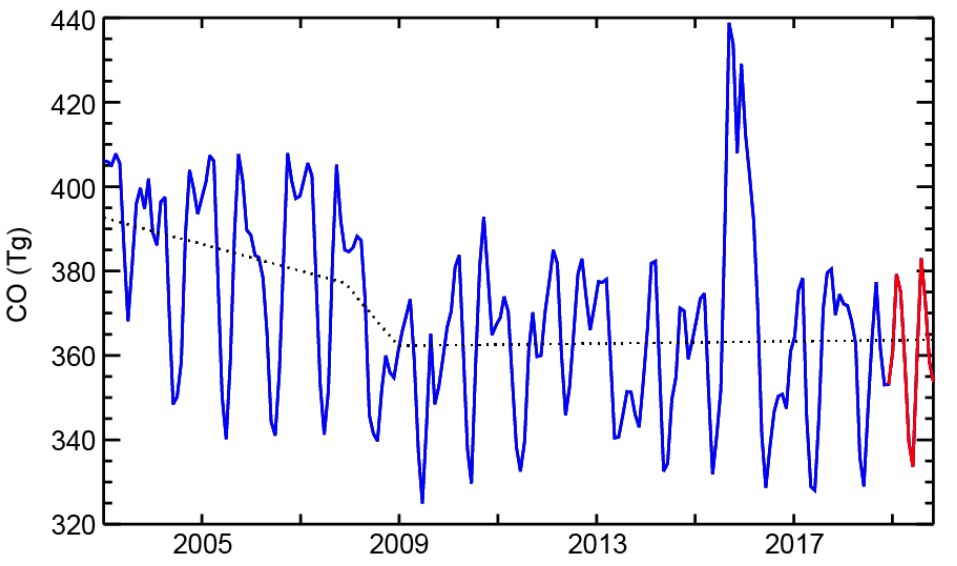

(b)

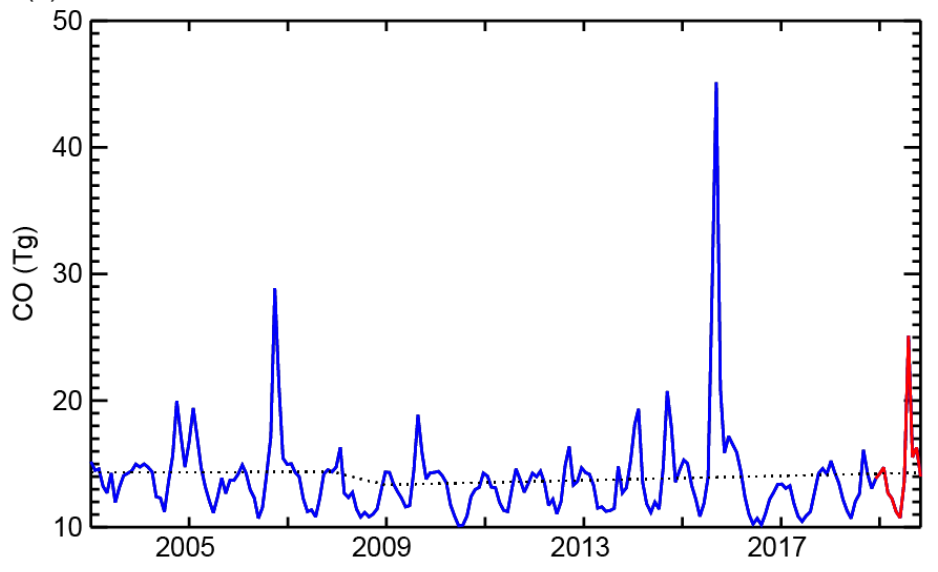

Fig. 2.60. Time series of monthly CO burdens (Tg) for (a) the whole globe and (b) over Maritime Southeast Asia from the CAMS reanalysis for 2003-19 (2019 is shown in red) and a piecewise linear trend (dotted line) for the periods 2003-07, 2008, and 2009-19. 


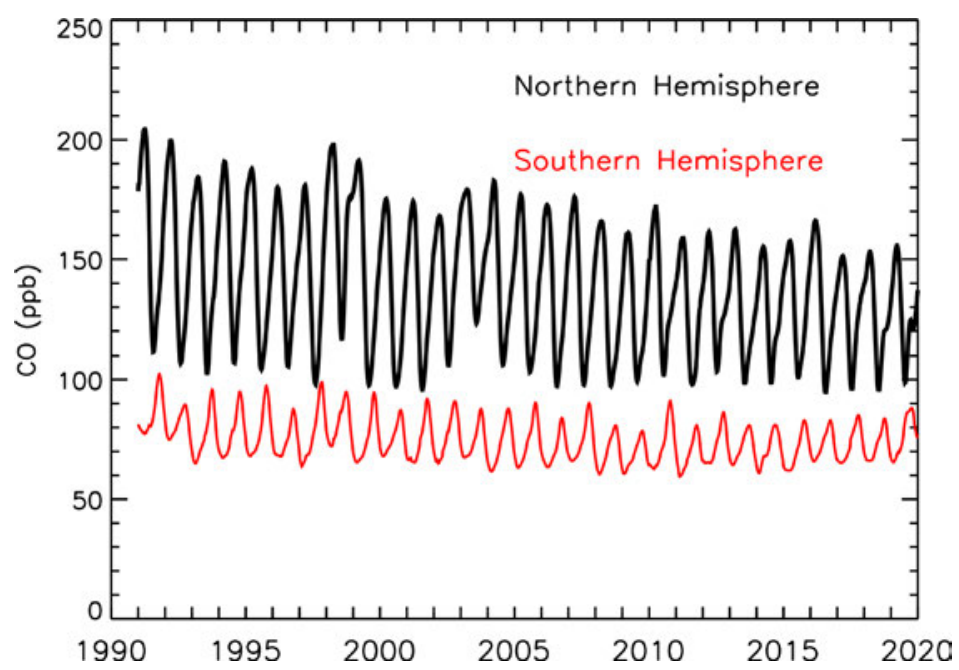

Fig. 2.61. Time series of surface $\mathrm{CO}(\mathrm{ppb})$ measured at 31 NOAA in situ flask observations sites and averaged over the clean marine boundary layer for the $\mathrm{NH}\left(0^{\circ}-90^{\circ} \mathrm{N}\right.$, black) and SH $\left(0^{\circ}-90^{\circ} \mathrm{S}\right.$, red) for the period 1991-2019. western South America in northern summer and in southwest (January 2019) and southeast (December 2019) Australia led to localized positive anomalies of up to $10 \%$ on the annual time scale and of more than $30 \%$ on the seasonal time scale, but which had insignificant impact on the global or hemispheric $\mathrm{CO}$ burdens.

The global CO burden since the early 2000s has been recorded by reanalyses of atmospheric composition, which assimilate CO satellite retrievals in chemistry transport modeling systems (Miyazaki et al. 2015; Flemming at al. 2017; Gaubert et al. 2017; Inness et al. 2019). The CAMS reanalysis assimilated TIR version 6 total column CO retrievals of the Measurement of Pollution in the Troposphere (MOPITT) instrument (Deeter et al. 2014) globally, only excluding observations poleward of $65^{\circ} \mathrm{N} / \mathrm{S}$ using the ECWMF 4D-VAR data assimilation system. The CAMS reanalysis can be compared with independent CO column retrievals, xCO, at the ground-based Total Carbon Column Observing Network (TCCON) site, Park Falls, Wisconsin, for the 2003-19 period. At Parks Falls retrieved xCO decreased with

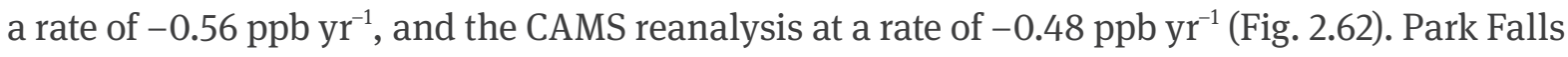
was chosen to illustrate the quality of the CAMS reanalysis because it has the longest record, dating to 2004. More comprehensive validation of the CAMS reanalysis against TCCON data can be found in Inness et al. (2019).

Surface CO dry air mole fractions are measured using in situ sensors and discrete air analysis using flask samples. NOAA and its cooperative air-sampling partners have been monitoring CO levels since 1991 through a global network of remote surface sites (Novelli et al. 2003; Pétron et al. 2019). The long-term calibrated CO measurements are available through the WMO Global Atmospheric Watch Programme World Data Center for Greenhouse Gases (https://gaw.kishou.go.jp/).

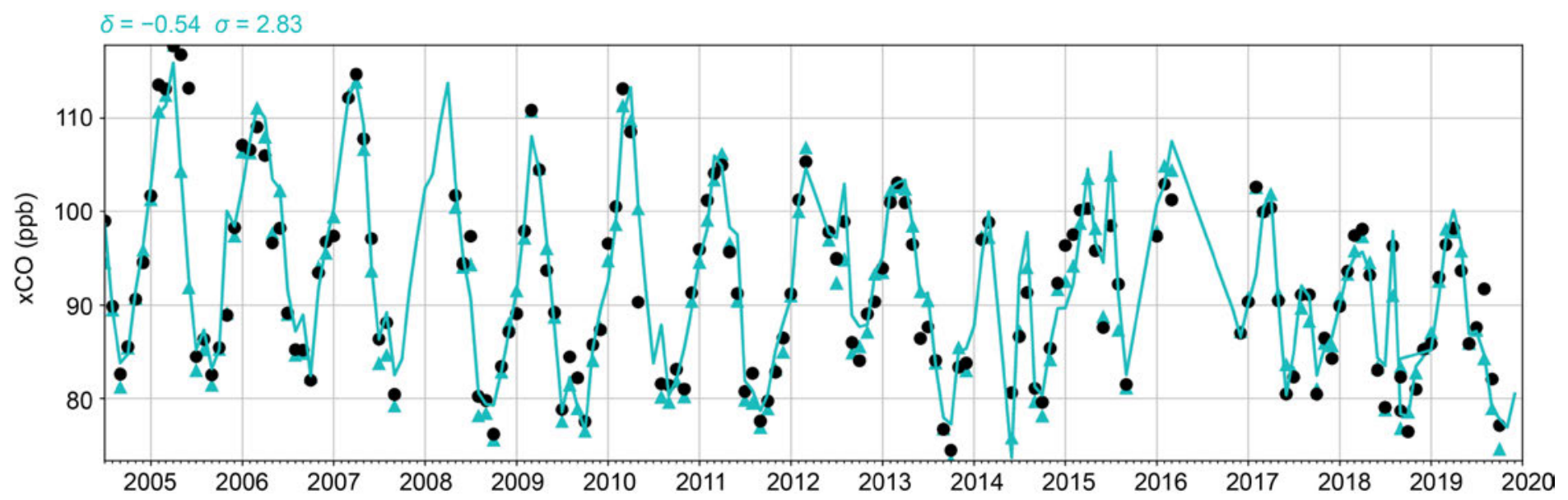

Fig. 2.62. Column-averaged $\mathrm{CO}$ ( $x \mathrm{CO}$, in ppb) at the Park Falls TCCON station. Monthly mean observations are shown by the black dots, and corresponding monthly mean xCO columns calculated using the TCCON-averaging kernels are shown by the blue triangles. The continuous blue line is the monthly xCO from the CAMS reanalysis. 


\section{Sidebar 2.2. 2019: A 25-year high in global stratospheric aerosol loading-T. LEBLANC,}

\section{F. CHOUZA, G. TAHA, S. KHAYKIN, J. BARNES, J.-P. VERNIER, AND L. RIEGER}

The role of stratospheric aerosols in Earth's radiative budget and chemistry has long been recognized (Mitchell 1971; Robock 2000; Hofmann and Solomon 1989; Aquila et al. 2013). Their presence in the stratosphere is mainly driven by the injection from below of tropospheric aerosols and sulphur-containing compounds (e.g., sulfur dioxide [ $\left.\mathrm{SO}_{2}\right]$ and carbonyl sulfide [OCS]) that act as precursors for the formation of sulfuric acid droplets in the stratosphere. Explosive volcanic eruptions are the major source of stratospheric sulfur, but in volcanic quiescent periods, OCS and other non-sulfate compounds such as ash, black carbon, organic aerosols, and smoke particles from biomass burning contribute to the background stratospheric aerosol burden. The last major volcanic eruption that critically affected stratospheric aerosol loading was Mt. Pinatubo in 1991, which resulted in an estimated total mass injection of nearly $20 \mathrm{Tg}$, i.e., 30-60 times the estimated background content (Guo et al. 2004). As a result of the Pinatubo eruption, the global surface temperature was estimated to have decreased by $0.4^{\circ} \mathrm{C}$ after two years (Thompson et al. 2009). Stratospheric aerosol loading did not return to background levels until 1997, when nearly a decade of volcanic quiescence started. After this period, several eruptions moderately impacted the midlatitudes of both hemispheres between 2005 and 2012, and the Southern Hemisphere (SH) between 2012 and 2017. The past 2-3 years, however, have shown a break from the previous years, with several volcanic and biomass burning events that loaded the stratosphere with aerosol levels unprecedented since the Mt. Pinatubo era. Results from ground-based lidar and satellite measurements provide a fresh, near-real-time view of these recent events.

Ground-based data come from two lidars located at Mauna Loa (MLO; $19.5^{\circ} \mathrm{N}, 155.6^{\circ} \mathrm{W}$ ), namely the Jet Propulsion Laboratory's (JPL) Mauna Loa Stratospheric Ozone Lidar (MLSOL; McDermid et al. 1995), and the NOAA Aerosol Lidar (Barnes and Hofmann 1997), which have monitored stratospheric aerosols for several decades for the global Network for the Detection of Atmospheric Composition Change (NDACC). The satellite data come from 1) GloSSAC v1.1, a merged dataset combining the measurements of SAGE and SAGE-II between 1979 and mid2005, and OSIRIS and CALIPSO since 2005 (Thomasson et al. 2018), and 2) OMPS/LP (2012-present; Chen et al. 2018).

Figure SB2.4a shows a time-altitude cross-section of monthly-mean aerosol extinction at MLO derived from MLSOL. MLO is located in a region of stratospheric aerosol minimum, on the edge of the tropical reservoir and away from the main entry pathways (Tropical Tropopause Layer [TTL], Asian Summer Monsoon Anticyclone [ASMA], volcanoes, and wildfires), thus facilitating detection of background levels. The injection of aerosols from below is clearly characterized by transient plumes

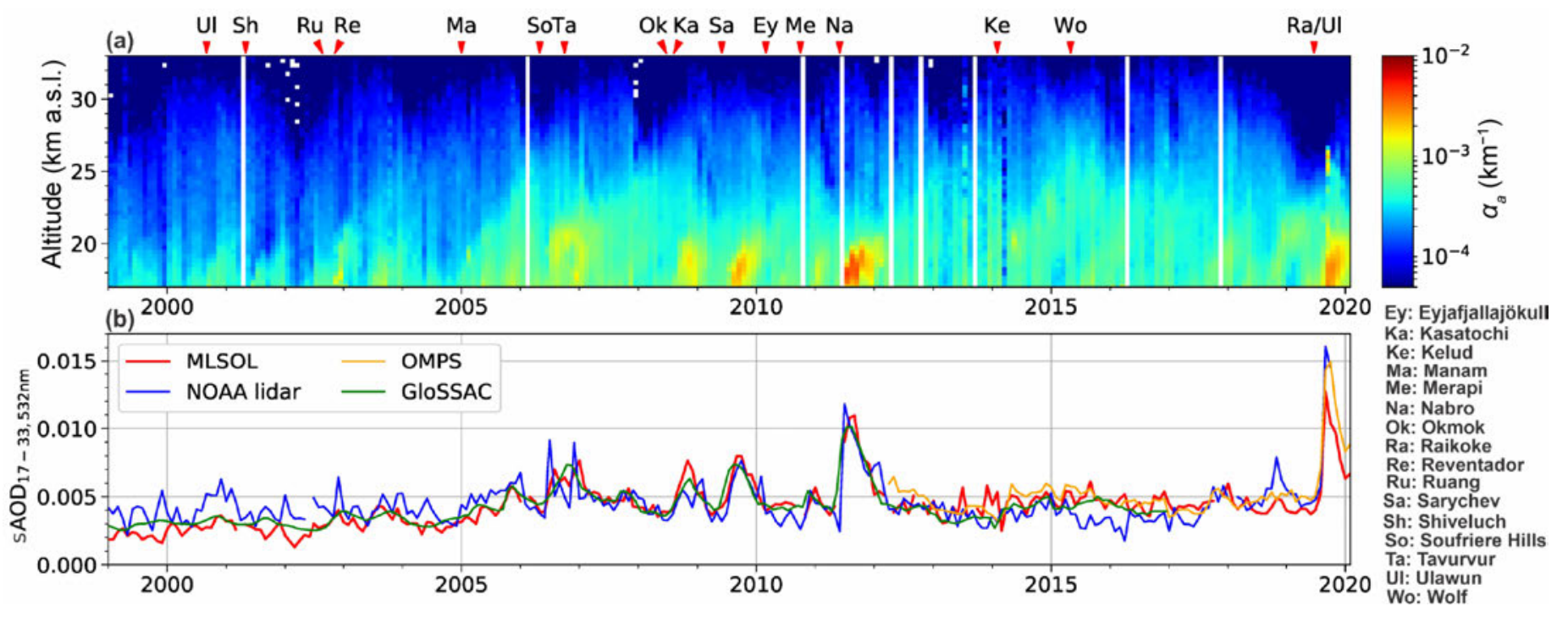

Fig. SB2.4. (a) Time-altitude cross-section of the monthly mean aerosol extinction profiles at MLO derived from the MLSOL lidar. (b) Time series of stratospheric aerosol optical depth (sAOD; 17-33 km) from the MLSOL lidar, NOAA lidar, GloSSAC at $17.5^{\circ} \mathrm{N}$, and OMPS/LP near MLO (see text for coincidence criterion). Significant volcanic eruptions are denoted by red arrows and letters in (a). White lines represent gaps in the data. 
spreading upwards with time, mostly visible below $23 \mathrm{~km}$. The upward propagation speed depends on the timing of the injection (Vernier et al. 2011b; Trepte and Hitchman 1992) and roughly ranges between 3 and $6 \mathrm{~km}$ per year, consistent with Quasi-Biennial Oscillation- (QBO) modulated Brewer-Dobson circulation (BDC) ascent rates inferred from water vapor and CO measurements in the tropical lower stratosphere (Minschwaner et al. 2016).

The stratospheric aerosol optical depth (SAOD) time series (1999-present) derived from MLSOL, the NOAA lidar, Global Space-based Stratospheric Aerosol Climatology (GloSSAC; zonal mean at $17.5^{\circ} \mathrm{N} \pm 2.5^{\circ}$ ), and Ozone Mapping and Profiler Suite/Limb Profiler (OMPS/LP; $\pm 1^{\circ}$ latitude, $\pm 12.5^{\circ}$ longitude), is shown in Fig. SB2.4b. With the exception of a few points, all datasets remain within $10 \%$ of each other, well within measurement uncertainties. The time series is characterized by a quiescent period before 2005, a period of moderate volcanic activity between 2005 and 2013, and another period of low aerosol loading between 2013 and 2017 (Chouza et al. 2020), also observed at other Northern Hemisphere (NH) sites (Khaykin et al. 2017). The background level during that time is noticeably higher than that in the pre-2005 quiescent period. But most importantly, the time series is strongly disturbed in the summer of 2019 by the Raikoke eruption, with SAOD reaching 0.015 , a level not reached at this latitude since 1995, i.e., the postPinatubo area. Chouza et al. (2020) showed that the Raikoke plume ascended rapidly into the mid-stratosphere, reaching an altitude of $27 \mathrm{~km}$ within two months. During that period, the

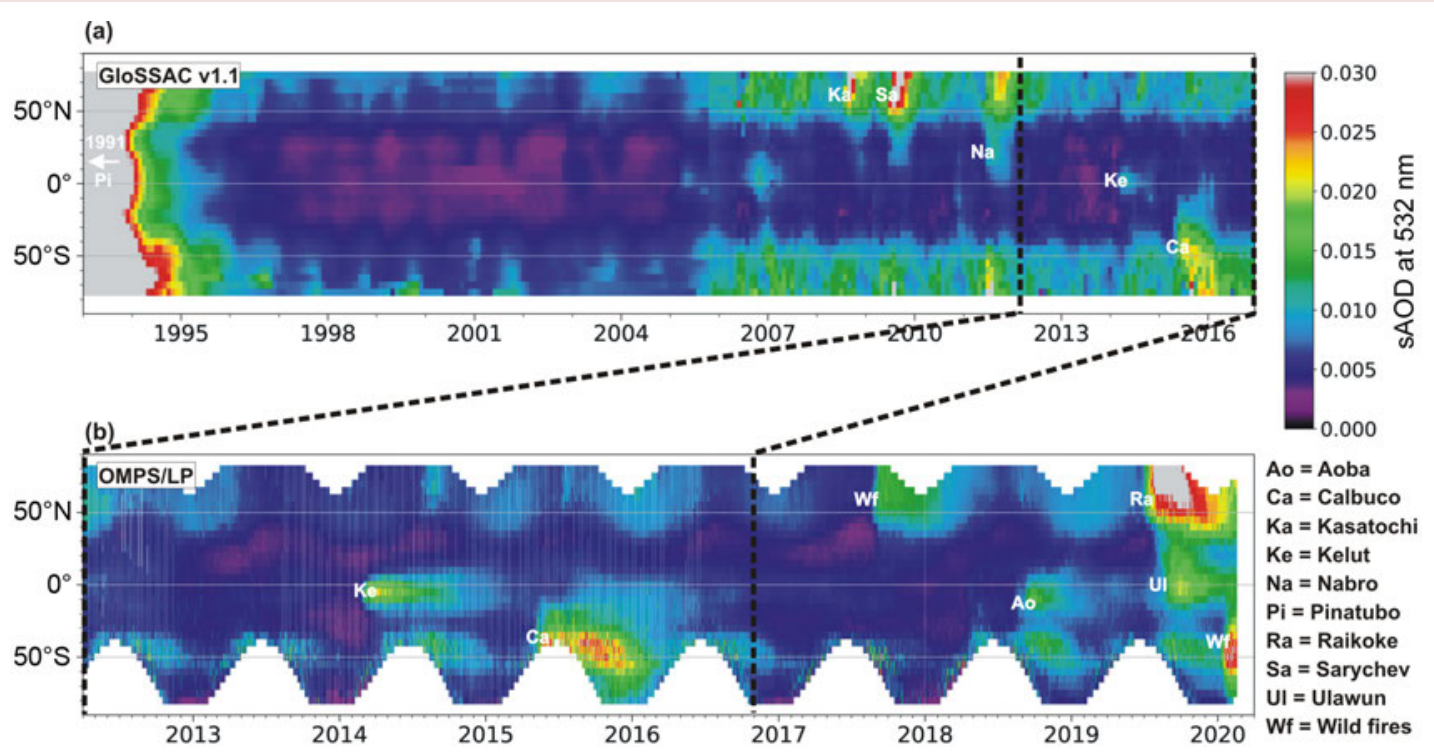

Fig. SB2.5. Time-latitude 2-D contour of the monthly mean SAOD derived from (a) GloSSAC and (b) OMPS/LP. Significant volcanic and biomass burning events are annotated by white letters. main plume transited gradually from $55^{\circ} \mathrm{N}$ to $19^{\circ} \mathrm{N}$ and circled Earth three times. A strong extinction signature is noticeable at $27 \mathrm{~km}$ on the MLSOL extinction time series (Fig. SB2.4a).

Figure SB2.5a shows the SAOD derived from GloSSAC as a function of time and latitude since the post-Pinatubo era. Fig. SB2.5b shows the SAOD derived from OMPS/LP. The signatures of Kelut and Calbuco eruptions are visible in the southern tropics and midlatitudes in 2014 and 2015, respectively. The signature of the 2017 Pacific Northwest wildfires is visible at high and midlatitudes of the NH. The signature of the Aoba eruption extends in the SH in late 2018. But the most prominent feature is the very large signature of the Raikoke eruption, which yields an SAOD larger than 0.025 for at least four to five months. The second most prominent feature is the large signature of the Australian fires in late 2019 (see Sidebar 7.6), with values of sAOD exceeding 0.025 for several weeks. The Ulawun eruption also caused high sAOD values in the tropics starting in mid-2019. Altogether, these major events have caused SAOD to exceed 0.012 for several months in 2019 at almost all latitudes between $60^{\circ} \mathrm{S}$ and $90^{\circ} \mathrm{N}$, simultaneously, a level of global aerosol loading unseen since 1994.

Although the occurrence and frequency of large volcanic eruptions remain random, there is a concern that favorable conditions (e.g., increase of surface temperature or drought) may lead to an increase in the occurrence and strength of pyrocumulonimbus events and its associated stratospheric aerosol injection (Peterson et al. 2018). Early estimates of the 2019/20 Australian wildfires total mass injected in the stratosphere point to the equivalent of a mid-size, possibly larger, volcanic eruption (see Sidebar 7.6). Although the composition of fire-type and volcanic-type aerosols is different, an increase in the strength and/or frequency of aerosol injection into the stratosphere may have an impact on climate and ozone that is yet to be quantified and understood. The continuation of key stratospheric aerosol measurements such as those described here is undoubtedly of crucial importance. 


\section{h. Land surface properties}

\section{1) Land surface albedo dynamics-G. Duveiller, N. Gobron, and B. Pinty}

Albedo is the fraction of shortwave radiation reflected by the surface and depends on a number of surface attributes such as snow cover, vegetation cover, and soil moisture among others. The year 2019 exhibited large regional contrasts in terms of land surface albedo in the visible part of the spectrum (see Plate 2.1ac), with the Northern Hemisphere (NH) overall darker (i.e., less reflective) and the Southern Hemisphere (SH) brighter that the baseline period 2003-10. Strong negative anomalies in visible albedo (on the order of -30\%) were especially noticeable in central and eastern Europe. Similarly, high negative values were observed in the Caucasus and the Middle East; in eastern Asia (western China and Mongolia, Korea, and Japan); northwestern America (Alaska, Yukon, and Northwest Territories); eastern United States; and parts of Argentina and Chile. Milder negative anomalies (-10\%) were found in Canada's Baffin Island, Mexico, much of northern South America, central Africa, and India. Large positive anomalies (up to $+30 \%$ ) were found in North America, in the Himalayas and eastern China, in eastern Australia, southern Africa, and sporadically in South America. The near-infrared anomalies follow the same general patterns as for the visible albedo but with moderate amplitudes (see

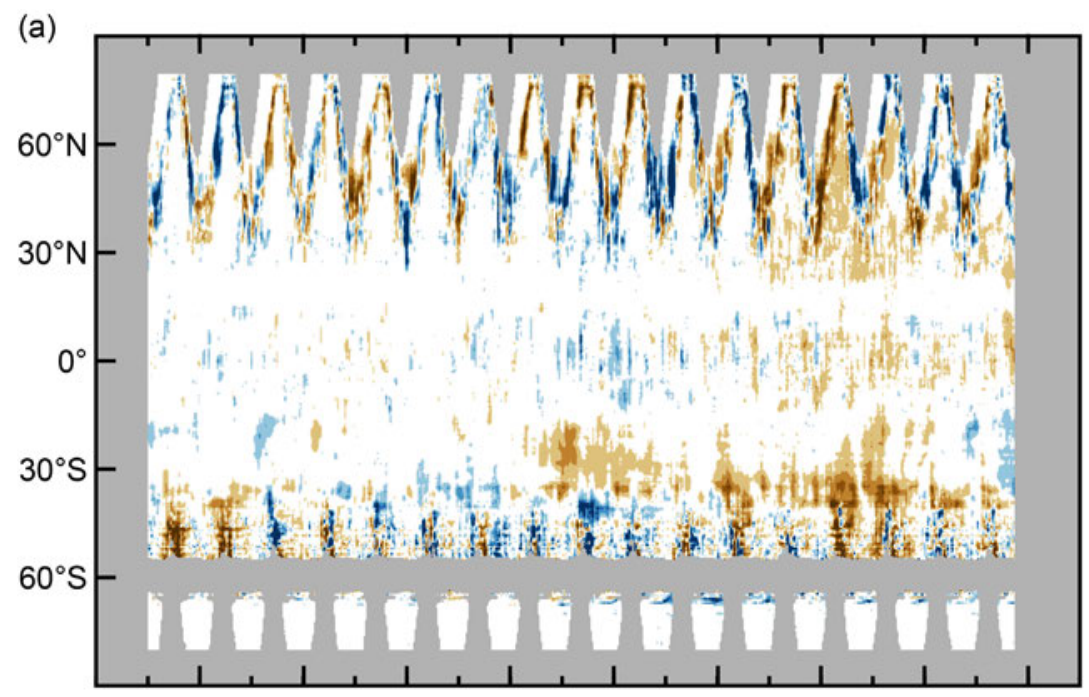

(b)

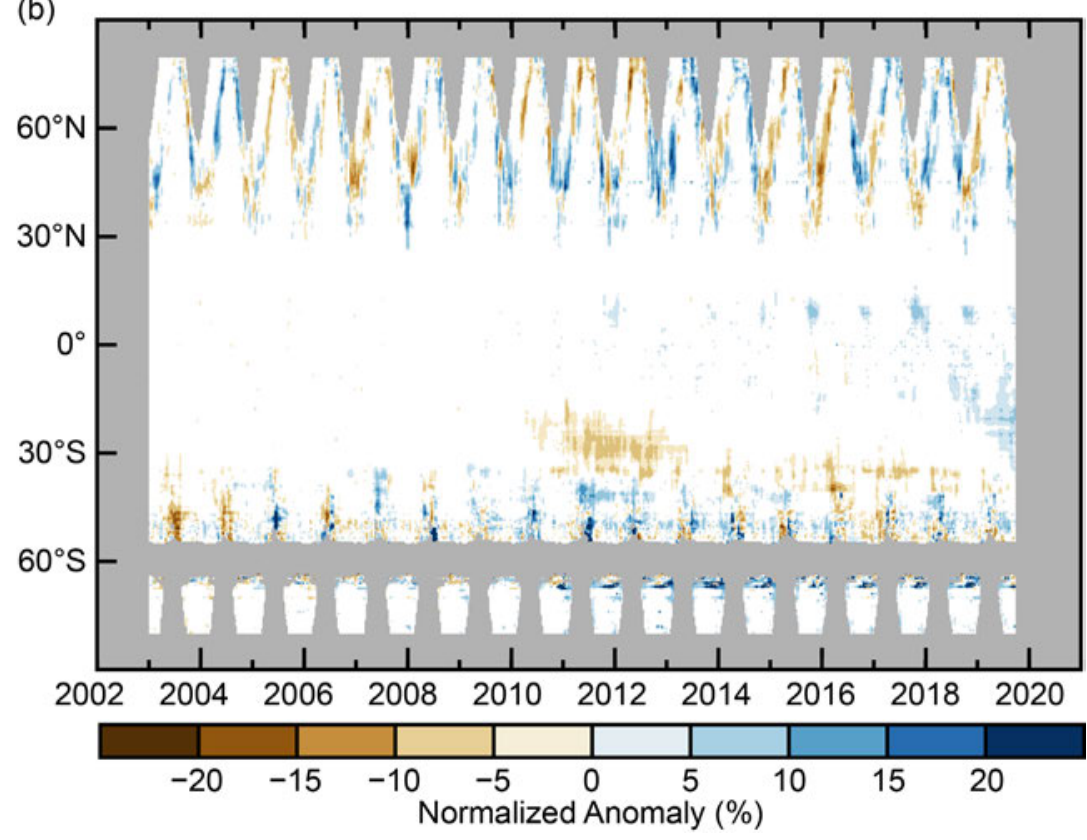

Fig. 2.63. Zonally averaged surface albedo anomalies (\%; 2003-10 base period) in (a) visible and (b) near-infrared broadband.
Plate 2.1ad) and a relative tendency toward brightening.

The large albedo anomalies in northern latitudes largely follow those of snow cover. With the exception of January, Europe experienced much less snow cover than usual in both the early and late months of 2019 (see section 2c2 for an overall hemispheric and continental summary), resulting in an overall darker surface than the baseline. Northeastern China, Korea, and Mongolia similarly saw much reduced snow cover during the beginning of the year with respect to the 2003-10 baseline, which was not compensated by above-average snow cover in October-December. On the contrary, large areas of North America were more extensively covered with snow than usual in early and late 2019, which translated to brighter surfaces over these areas (section 2c2). The same is true for the Tibetan Plateau and neighboring areas. The fact that the northernmost latitudes were less extensively covered with snow than usual from May to June probably explains the darker surfaces in various areas nearer to the North Pole (Alaska, Baffin Island, and the northern tip of Siberia). 
For regions not affected by snow cover, the main driver affecting land albedo is the relative vigor and health of vegetation, which itself largely depends on water availability. The drought that led to the disastrous fire season in Australia during late 2019 and early 2020 (see Sidebar 7.6) is responsible for brightening the surface, while the potential darkening effect of the fires is not significant enough to be observed in the yearly averaged data. Southern Africa has also seen clear reductions in soil moisture (section 2d10) and vegetation photosynthesis activity (section 2h2) during 2019, resulting in a relative brightening of the surfaces. India and China have seen significant trends in greening over the recent years due to intensified agriculture, translating to a reduction of surface visible albedo (Chen et al. 2019). In Europe, the strong summer drought (section 2d11) may have brightened the surface, partly by accelerating the end of the season (see Fig. 2.69d), but this was insufficient to counter the strong overall darkening effect generated by the reduction of snow cover in the cold months.

The separate contribution of snow occurrence and vegetation cover to albedo anomalies can be represented in a multiannual perspective using latitudinal averages for the entire record (Fig. 2.63). The effect of snow cover in the NH follows a clear seasonal cycle that is in phase between the visible and the near-infrared parts of the spectrum, and for which there is no clear trend. Aside from that, the rest of the world shows a slight overall negative trend in visible albedo and a lightly rising trend in near-infrared, which is consistent with the enhanced greening observed in the fraction of absorbed photosynthetically active radiation (FAPAR) estimates (section $2 \mathrm{~h} 2$ ). The year 2019 does stand out by showing a contrasting pattern between North and South, respectively darker and brighter than the baseline (which is again consistent with the FAPAR anomalies in 2019). The global average shows a higher albedo in the SH for both the visible and near-infrared albedo, while the $\mathrm{NH}$ is slightly brighter in the near-infrared and darker in the visible (Fig. 2.64).

The albedo anomalies are calculated based on the NASA Collection 6 MCD43C3 products derived from satellite observations of the Moderate Resolution Imaging Spectroradiometer (MODIS) instrument on-board of the Terra and Aqua platforms (Schaaf et al. 2002; Schaaf and Wang 2015). The retrieval algorithm delivers visible albedo $(0.3-$ $0.7 \mathrm{~nm})$ and near-infrared albedo (0.7-5.0 nm) values, in addition to both black-sky albedo and whitesky albedo values, the latter estimates of which are used in this report. The anomalies are calculated at a 10-daily frequency, based on the 2003-10 reference period.

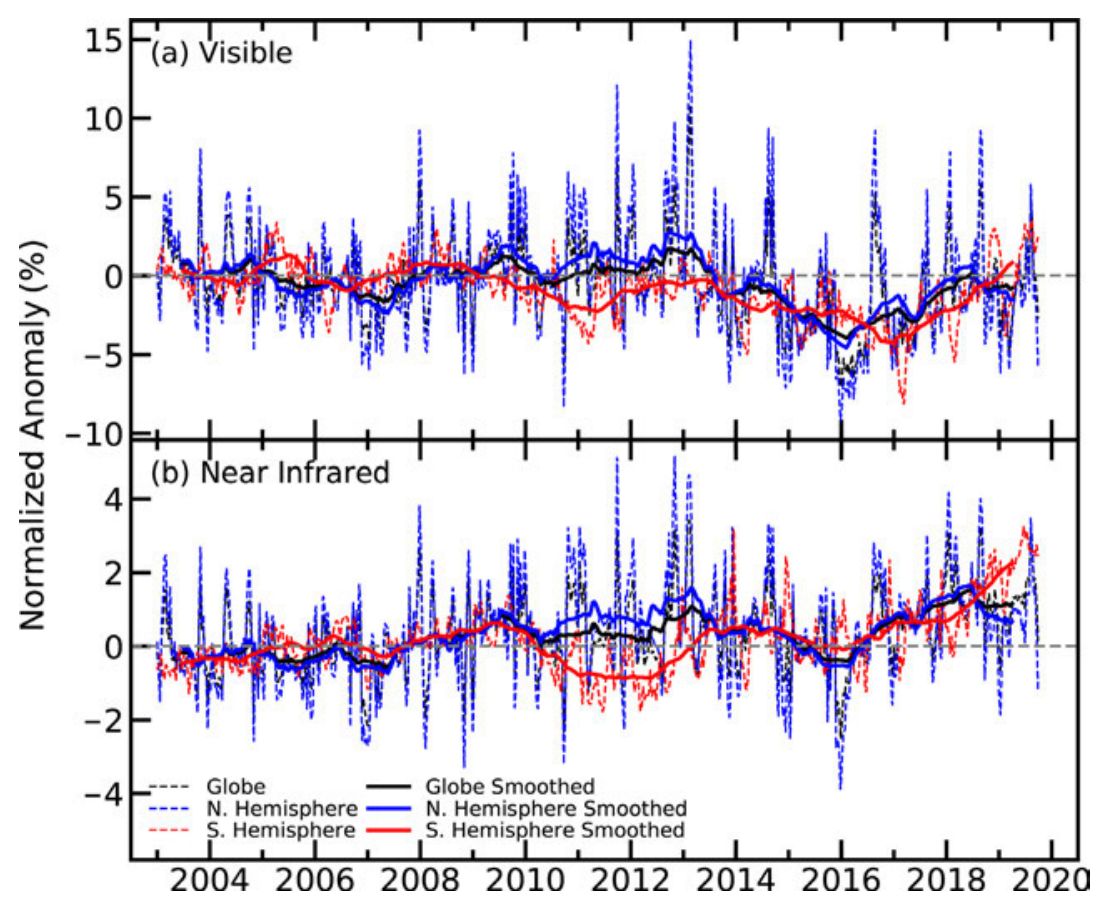

Fig. 2.64. Global and bi-hemispherical averaged surface albedo (\%; 2003-10 base period) in (a) visible and (b) near-infrared broadband. 


\section{2) Terrestrial vegetation dynamics-N. Gobron}

Fraction of absorbed photosynthetically active radiation (FAPAR) anomalies exhibited significant regional variations in vegetation conditions worldwide in 2019 (Plate 2.1ae). The greatest negative anomalies (brown: not favorable for vegetation) were observed in Australia, southern Africa, Kostanay (northern Kazakhstan), and eastern Russia (from Krasnoyarsk eastward around $60^{\circ} \mathrm{N}$ ). Local negative anomalies affected northern China, Iowa and Wisconsin (United States), Bahia State (Brazil), Bolivia, La Pampa (Argentina), and Kenya. The greatest positive anomaly (green) was again observed in eastern China (as during the last four years) as well as northern India (Rajasthan, Uttar Pradesh, and Punjab), Bangladesh, Syria, and northern Iraq. To a lesser magnitude, the entire central region of the African continent and the region surrounding the Black Hills (South Dakota, United States) also had positive deviations.

The strongest negative annual anomaly, with a maximum absolute value of 0.15 , occurred in Australia, possibly due to the strongly positive Indian Ocean dipole (IOD; section 4h) that influenced severe extreme weather events. This year was the warmest and driest year on record there, which implied drought, heat waves, and devastating bushfires. Over Botswana, Namibia, Zambia, and southern Mozambique, the negative anomalies were due to very dry conditions (section 2d12). Dry conditions and high temperatures from January to June over Kenya resulted in negative annual anomalies.

In the northern part of Kazakhstan and eastern Russia, the hot and dry climatic conditions hindered vegetation during the growing season (spring), which strongly affected the annual anomaly. Bad weather conditions with heavy spring rains in Wisconsin in the United States, and some adjoining regions delayed planting and affected crops. High temperatures associated with SH winter rainfall deficits had significant negative regional impacts on vegetated conditions such as over Bahia State (Brazil), Bolivia, and Argentina.

Terrestrial photosynthesis was again enhanced over eastern China with vegetation growth in 2019, similar to 2017 and 2018 (Gobron 2018, 2019) due to important changes in the overall land use (Chen et al. 2019). In addition, northern Turkey got an increase of vegetation activity for the last two years. Late in the year, the central region of the African continent had high positive anomalies, due to high temperatures and heavy rainfall that impacted the annual results.

Figure 2.65 displays the zonal average anomalies from 1998 to 2019 compared to the 1998-2010 base period. Strong seasonal deviations include mainly positive anomalies north of $20^{\circ} \mathrm{N}$ after 2014. Negative anomalies from 2002 to 2014 affected the $\mathrm{SH}$, except in 2010-12. In contrast to the positive anomalies around $30^{\circ} \mathrm{S}$ from 2014 to 2017, anomalies turned negative again in 2018, with strongest values in 2019.

Figure 2.66 shows the global and bi-hemispheric anomalies, revealing more oscillations between the seasons in the $\mathrm{SH}$ with its smaller land area than in the $\mathrm{NH}$. The $\mathrm{NH}$ had fewer negative events than the $\mathrm{SH}$, and its plant activity increased from 2010 to 2017 and, after a short decline in late 2017/early 2018, increased again afterward. Analysis

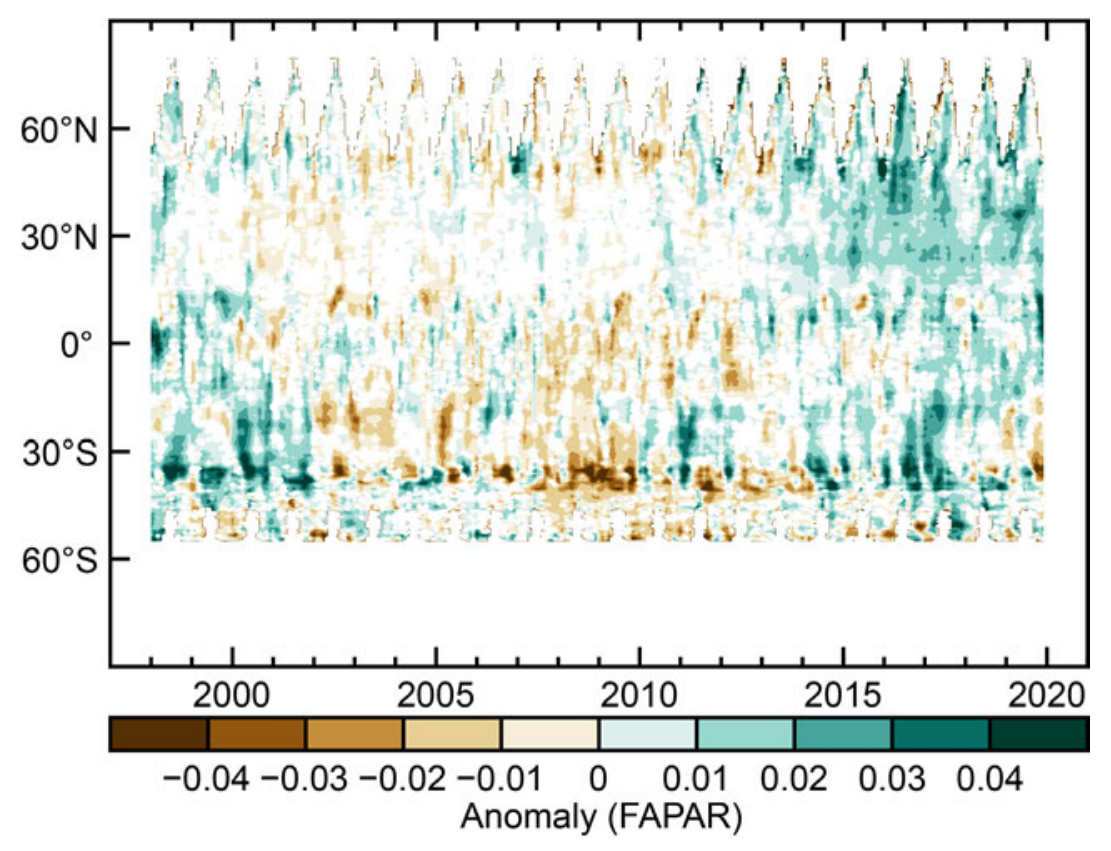

Fig. 2.65. Zonally averaged FAPAR anomalies for 1998-2019 (1998-2010 base period). 


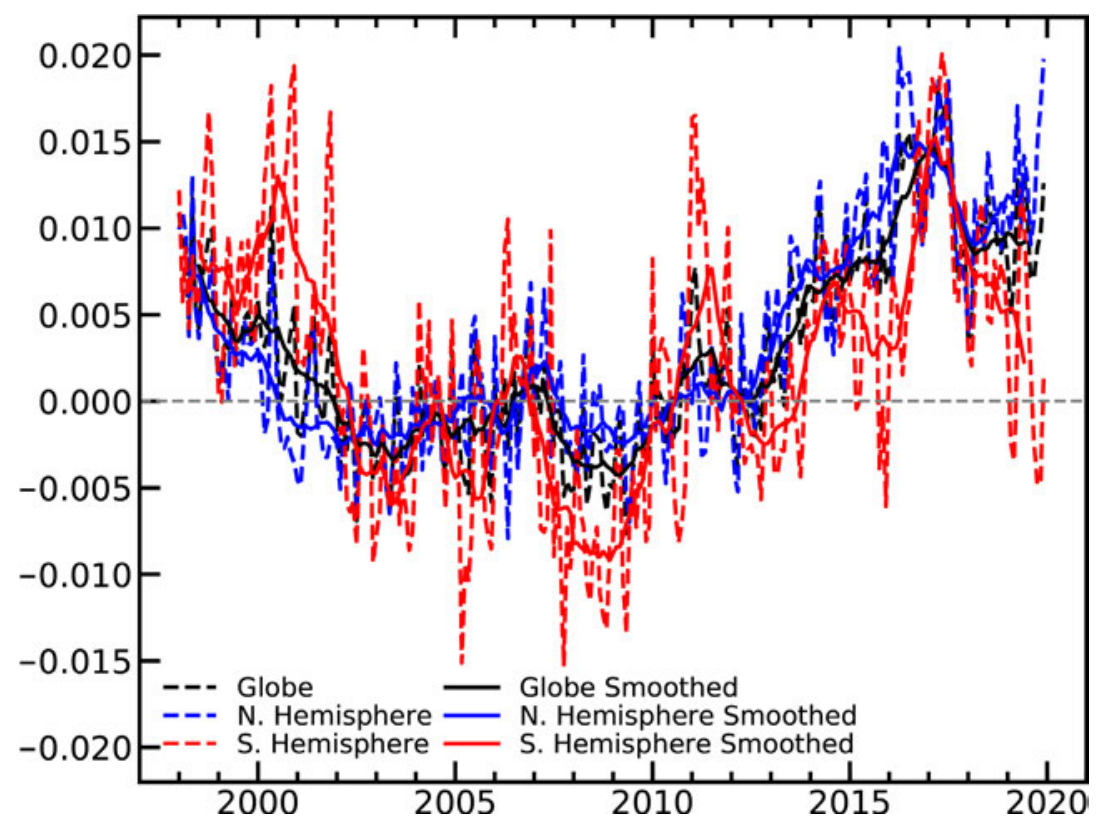

Fig. 2.66. Global (black lines), NH (blue), and SH (red) FAPAR anomalies for 1998-2019 (1998-2010 base period). Dotted lines denote each monthly period; solid lines indicate the six-month running averaged mean. of $\mathrm{SH}$ data reveals two positive extreme peaks in 2000 and 2017, while extreme minimum events occurred in 2008-09. Following the decline from positive anomalies with negative values between 2002 and 2009, there has been an increase in positive values since 2011. Since 2017 the global anomalies have decreased but are still positive with 2019 equal to those in 2018; however, SH anomalies have decreased sharply since 2017.

Space-based measurements are essential for monitoring the activity of terrestrial plants worldwide. These observations are used to recover FAPAR, an essential climate variable (as defined by GCOS [2016]). The 2019 analysis merged 22 years of global FAPAR products

based on three optical sensors from 1998 to 2019 (Gobron et al. 2010; Pinty et al. 2011; Gobron and Robustelli 2013; the base period is 1998-2010). Comparisons between each dataset and with multiple surrogates using ground measurements provide an estimate of the uncertainties and biases. Given the biases between the various sensor products, this long-term global dataset presents an estimated average uncertainty close to $5 \%-10 \%$.

\section{3) Biomass burning -J. W. Kaiser, G. R. van der Werf, and I. Hüser}

During 2019, anomalously high vegetation fire emissions in several forested regions of Indonesia, Russia, Australia, Brazil, and Bolivia (Plate 2.1af) compensated the long-term global downward trend in emissions from savanna regions. The global annual emission of $1836 \mathrm{TgC}$ was $9 \%$ lower than the average for the reference period 2003-10 (Table 2.9). The emission in 2019 was, however, substantially increased compared to 2018 and 2017 with $1600 \mathrm{TgC}$ and $1680 \mathrm{TgC}$, respectively. Despite the declining trend in savanna regions, upward trends related to climate change with more extreme fire weather and longer fire seasons are emerging in several regions. Biomass burning displays large interannual variability driven by fire weather and human behavior. Its global distribution in 2019 is shown in Fig. 2.67.

Indonesia experienced a relatively long dry spell in September, which led to above-average emissions (Fig. 2.68). Usually, such dry spells are associated with El Niño years, which was not the case in 2019. Rather, it was related to the strong positive IOD (see section 4h). Annual emissions in the larger tropical Asian region were dominated by fires in eastern Sumatra and southern Borneo, which elevated the emissions by $62 \%$ to the third-largest value (191 $\mathrm{TgC}$ ) since at least 2003, with larger values of $425 \mathrm{TgC}$ and $228 \mathrm{TgC}$ in 2015 and 2006, respectively.

Strong fire activity in Siberia led to a 62\% increase in emissions from the northern Asia region. Many fires during June-August burnt farther north than usual, which led to a new record of $27 \mathrm{TgC}$ for fire emissions from the Arctic. The emissions have increased in every year since 2015 and were more than twice as high in 2019 than in any preceding year (Fig. 2.68).

In December 2019, the Australian states of New South Wales and Victoria experienced their highest monthly fire activity since at least 2003 (Fig. 2.68, Sidebar 7.6). Their annual emission of $29 \mathrm{TgC}$ more than doubled the previous record of $13 \mathrm{TgC}$ set in 2003 and made up almost all of the 


\begin{tabular}{|c|c|c|c|c|}
\hline \multirow{2}{*}{$\begin{array}{l}\text { Time period } \\
\text { Quantity in } \\
\text { Tg C yr }\end{array}$} & \multirow[b]{2}{*}{$\begin{array}{l}\text { Latitude/ } \\
\text { longitude }\end{array}$} & \multirow{2}{*}{$\begin{array}{c}\text { 2003-10 } \\
\text { Mean value } \\
\text { (range) }\end{array}$} & \multicolumn{2}{|c|}{2019} \\
\hline & & & Value & $\begin{array}{l}\text { Anomaly } \\
\text { (percent) }\end{array}$ \\
\hline Global & & $\begin{array}{c}2010 \\
(1828-2272)\end{array}$ & 1836 & $-174(-9 \%)$ \\
\hline North America & $\begin{array}{c}30^{\circ}-75^{\circ} \mathrm{N} \\
190^{\circ}-330^{\circ} \mathrm{E}\end{array}$ & $\begin{array}{c}79 \\
(63-109)\end{array}$ & 70 & $-9(-12 \%)$ \\
\hline Central America & $\begin{array}{c}0^{\circ}-30^{\circ} \mathrm{N} \\
190^{\circ}-330^{\circ} \mathrm{E}\end{array}$ & $\begin{array}{c}88 \\
(71-122)\end{array}$ & 106 & $+18(+20 \%)$ \\
\hline S. Hem. America & $\begin{array}{c}0^{\circ}-60^{\circ} \mathrm{S} \\
190^{\circ}-330^{\circ} \mathrm{E}\end{array}$ & $\begin{array}{c}381 \\
(214-473)\end{array}$ & 274 & $-107(-28 \%)$ \\
\hline $\begin{array}{l}\text { Europe and } \\
\text { Mediterranean }\end{array}$ & $\begin{array}{c}30^{\circ}-75^{\circ} \mathrm{N} \\
330^{\circ}-60^{\circ} \mathrm{E}\end{array}$ & $\begin{array}{c}37 \\
(29-62)\end{array}$ & 36 & $-1(-2 \%)$ \\
\hline N. Hem. Africa & $\begin{array}{c}0^{\circ}-30^{\circ} \mathrm{N} \\
330^{\circ}-60^{\circ} \mathrm{E}\end{array}$ & $\begin{array}{c}419 \\
(353-453)\end{array}$ & 296 & $-123(-29 \%)$ \\
\hline S. Hem. Africa & $\begin{array}{c}0^{\circ}-35^{\circ} \mathrm{S} \\
330^{\circ}-60^{\circ} \mathrm{E}\end{array}$ & $\begin{array}{c}484 \\
(444-528)\end{array}$ & 428 & $-56(-12 \%)$ \\
\hline Northern Asia & $\begin{array}{l}30^{\circ}-75^{\circ} \mathrm{N} \\
60^{\circ}-190^{\circ} \mathrm{E}\end{array}$ & $\begin{array}{c}176 \\
(99-418)\end{array}$ & 214 & $+38(+21 \%)$ \\
\hline South-East Asia & $\begin{array}{l}10^{\circ}-30^{\circ} \mathrm{N} \\
60^{\circ}-190^{\circ} \mathrm{E}\end{array}$ & $\begin{array}{c}128 \\
(107-150)\end{array}$ & 87 & $-41(-32 \%)$ \\
\hline Tropical Asia & $\begin{array}{l}10^{\circ} \mathrm{N}-10^{\circ} \mathrm{S} \\
60^{\circ}-190^{\circ} \mathrm{E}\end{array}$ & $\begin{array}{c}118 \\
(38-228)\end{array}$ & 191 & $+73(+62 \%)$ \\
\hline Australia & $\begin{array}{l}10^{\circ}-50^{\circ} \mathrm{S} \\
60^{\circ}-190^{\circ} \mathrm{E}\end{array}$ & $\begin{array}{c}99 \\
(47-137)\end{array}$ & 133 & $+34(+35 \%)$ \\
\hline
\end{tabular}

$35 \%$ anomaly in fire emissions from all of Australia. The fires started in September, i.e., relatively early, were strongest in December, and continued into 2020. The extreme fire weather was linked to the strong positive IOD anomaly and record temperatures in Australia.

Substantial media attention was also given to fires burning in the Amazon. Significant positive anomalies occurred in Bolivia and the Brazilian states of Amazonas and Roraima (see Plate 2.1af),

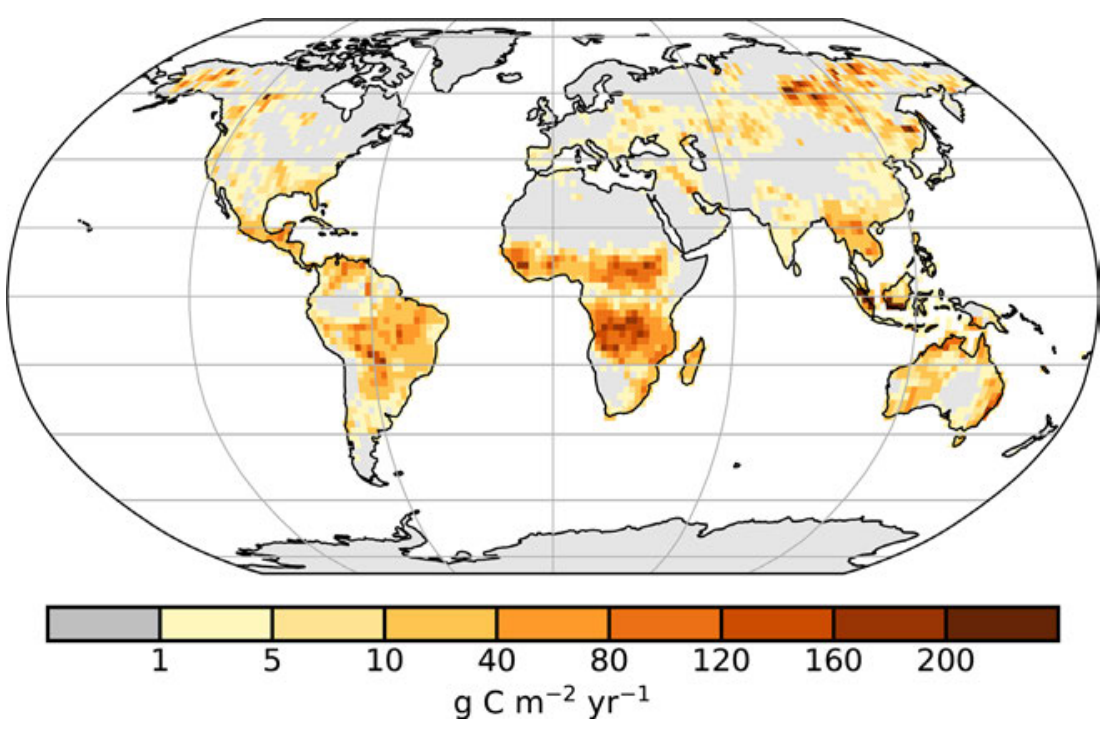

Fig. 2.67. Global map of fire activity $\left(\mathrm{g} \mathrm{C} \mathrm{m}^{-2} \mathrm{yr}^{-1}\right)$ in 2019 in terms of carbon consumption. (Source: GFASv1.4.) although south of the equator there was an overall strong negative anomaly of $-28 \%$ compared to the 2003-10 reference period. This period was characterized by high deforestation and drought years in Brazil. After 2010, emissions dropped significantly (Fig. 2.68), and emissions in 2019 were still in the typical range of its decade, albeit at the upper limit. An increase of deforestation in 2019 was reported by the PRODES program of the Brazilian space agency INPE (http://terrabrasilis.dpi.inpe.br /app/dashboard/deforestation / biomes/legal_amazon / rates). Whether 2019 marked a 


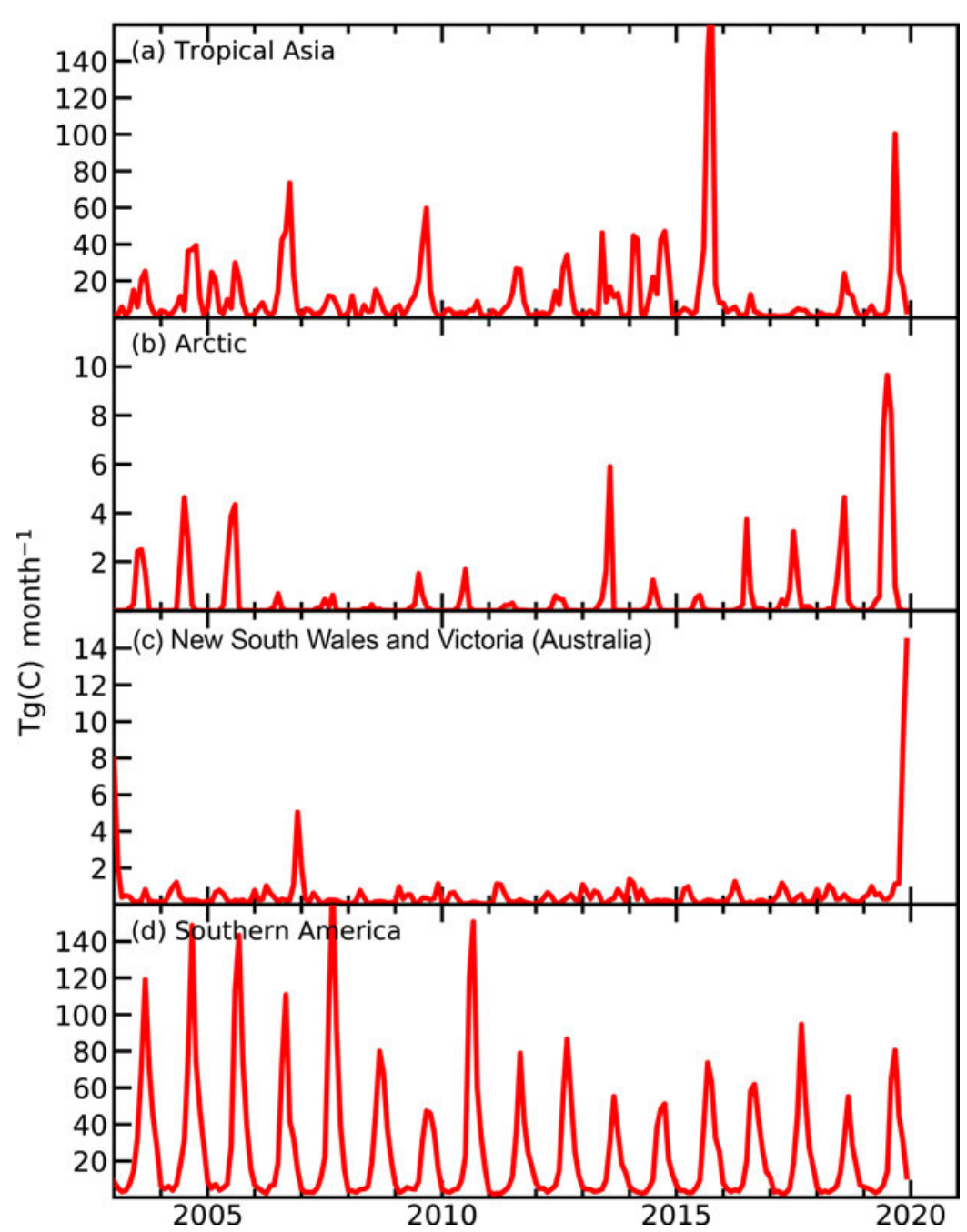

Fig. 2.68. Time series of monthly open biomass burning in (a) tropical Asia, (b) the Arctic, (c) New South Wales and Victoria, Australia, and (d) Southern hemispheric America. The Arctic is bounded by the Arctic Circle $\left(66.5^{\circ} \mathrm{N}\right)$; the definitions of the other regions are provided in Table 2.9. (Source: GFASv1.4.) corresponding reversal of the decreasing long-term trend remains to be seen.

The established long-term downward trend related to changes in land use in frequently burning savannas (Andela et al. 2017), in combination with a delay in the start of the fire season in sub-Saharan Africa, led to a $29 \%$ decrease $(123 \mathrm{TgC})$ in fire emissions from NH Africa. Fires here normally burn in December and January but started weeks later related to wet conditions that were associated with the strong positive anomaly of the IOD.

The fire emission estimates have been derived from the Global Fire Assimilation System (GFAS; Kaiser et al. 2012, 2017), which uses satellite data of active fire detections and its intensity and is calibrated against the Global Fire Emissions Database (van der Werf et al. 2017). Here, vegetation fire activity is reported in terms of carbon emissions. Most biomass is released as $\mathrm{CO}_{2}$, but substantial amounts of other gases and aerosols are emitted as well. Most of the carbon released into the atmosphere is taken up again by vegetation regrowth. However, tropical rain forests and peat lost to fires regrow on time scales

longer than a few hundred years or not at all. Their emissions are, therefore, practically irreversible. Given the large spatio-temporal variability in fire activity and the difficulty to constrain those with ground measurements, emission estimates are notoriously uncertain. The presented estimates of relative anomalies in entire regions are more reliable because they are derived from consistent observations by NASA's two satellite-based MODIS instruments. The launch dates of the satellites carrying these instruments restrict the GFAS dataset to the period starting in 2003.

4) Phenology of primary producers-D. L. Hemming, J. Garforth, T. Park, A. D. Richardson, T. Rutishäuser,

T. H. Sparks, S. J. Thackeray, and R. Myneni

Climate and nature are mutually dependent. This is visible from global to organism scales by phenological indicators-events in nature (Demarée and Rutishäuser 2011). Here, the timing of $\mathrm{NH}$ spring and autumn events of primary producers (terrestrial vegetation and lake plankton) is compared, utilizing records that reach across spatial scales from satellite remote sensing to site-level monitoring.

For 2019, the satellite-derived (MODIS) normalized difference vegetation index (NDVI; Park et al. 2016) revealed the earliest average start of season since the beginning of the record in 2000 (SOSM, 4.3 days) and a later-than-average end of season (EOSM , 2.4 days) across the $\mathrm{NH}\left(>30^{\circ} \mathrm{N}\right)$, 
(a) Start of Season (SOS)

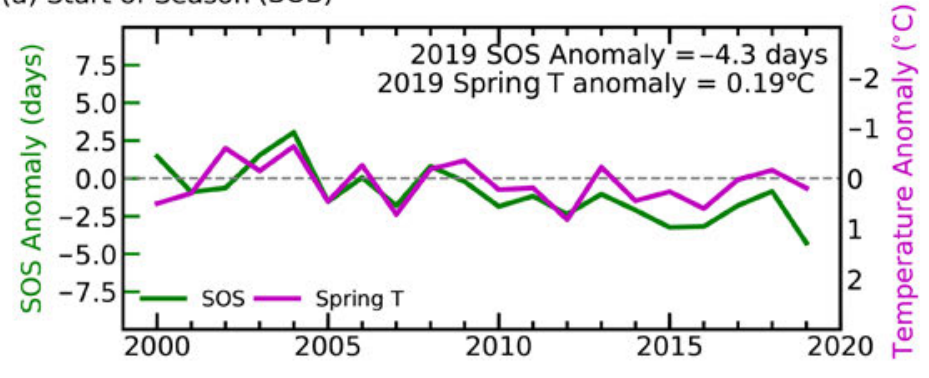

(c) Start of Season

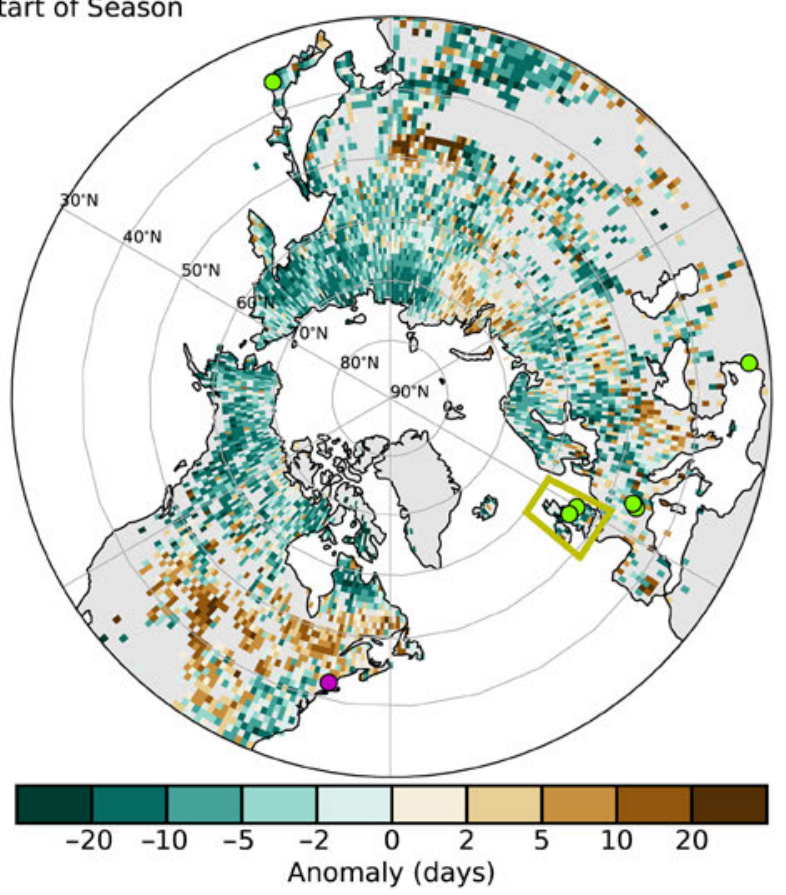

(b) End of Season (EOS)

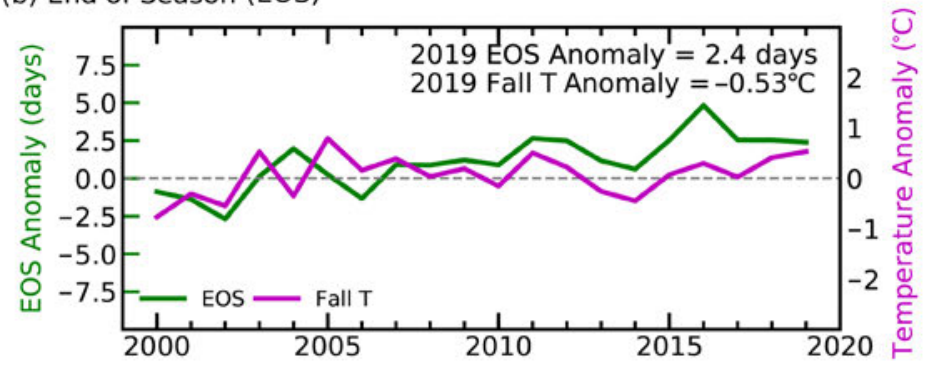

(d) End of Season

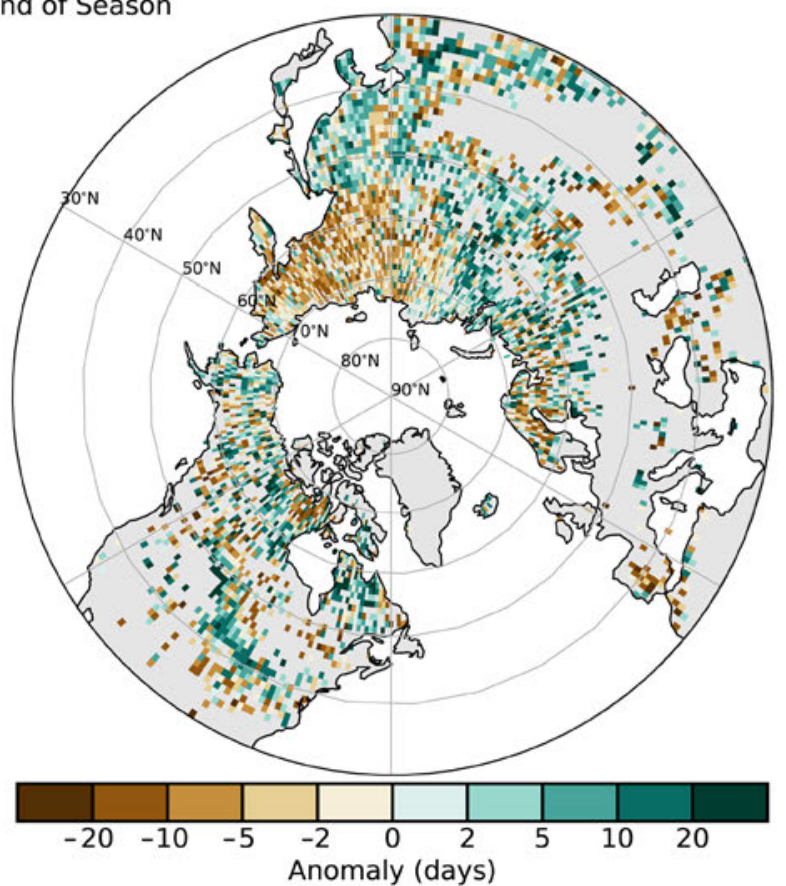

Fig. 2.69. (a) Time series of area mean anomalies (days relative to 2000-09 baseline) in MODIS NDVI-based vegetation growing season onset (SOS; purple) and MERRA-2 spring (Mar-May, green) temperature for $\mathrm{NH}\left(>30^{\circ} \mathrm{N}\right)$. (b) Same as (a) but for end of growing season (EOS) and autumn (Sep-Nov) temperature. Note temperature scale reversal in panel (b). Spatial pattern of (c) SOS and (d) EOS anomaly in 2019 with respect to the baseline. Note the color bar reversal in (d) to highlight the longer growing season as green. Colored circles and box in (c) identify the location of sites shown in Figs. 2.70 and 2.71: Harvard Forest PhenoCam site (pink circle), UK phenology network (yellow box), lake phytoplankton NH monitoring sites (green circles).

relative to the 2000-09 baseline (SOS = day of year [DOY] 137, 17 May; and EOS = DOY 283, 10 October; Figs. 2.69a,b). This resulted in an 8-day longer growing season, relative to the baseline (161 days, estimated for all NH pixels and averaged over the baseline). Overall, about 65\% and $56 \%$ of the NH region showed earlier $\mathrm{SOS}_{\mathrm{M}}$ and later $\mathrm{EOS}_{\mathrm{M}}$ in 2019, respectively (Figs. 2.69c,d). Regionally, earlier $\mathrm{SOS}_{\mathrm{M}}$ occurred across northwestern North America (NA) and most of Eurasia, and later $\mathrm{SOS}_{\mathrm{M}}$ occurred over central and eastern NA. A contrasting pattern of earlier and later $\mathrm{EOS}_{\mathrm{M}}$ was observed in eastern and western Eurasia, whereas EOS $\mathrm{M}_{\mathrm{M}}$ in NA was spatially heterogeneous. Interannual variations in $\mathrm{SOS}_{\mathrm{M}}$ and $\mathrm{EOS}_{\mathrm{M}}$ correlate with changes in spring and autumn temperatures from MERRA-2 reanalysis (Gelaro et al. 2017). For 2019, SOSM and EOS ${ }_{M}$ are broadly consistent with spatial temperature patterns noted in section $2 \mathrm{~b}$ of this report.

Two case studies for ground-based phenology observations are compared with the satellite data. PhenoCam data across NA (Richardson et al. 2018a) show similar spatial and temporal patterns to satellite-derived phenology data (Zhang et al. 2018; Richardson et al. 2018b), although the agreement tends to be better in spring than autumn (Melaas et al. 2016; Moon et al. 2019). Here, we compare site PhenoCam estimates for start of season $\left(\mathrm{SOS}_{\mathrm{PC}}\right)$ and end of season $\left(\mathrm{EOS}_{\mathrm{PC}}\right)$ 
(a)
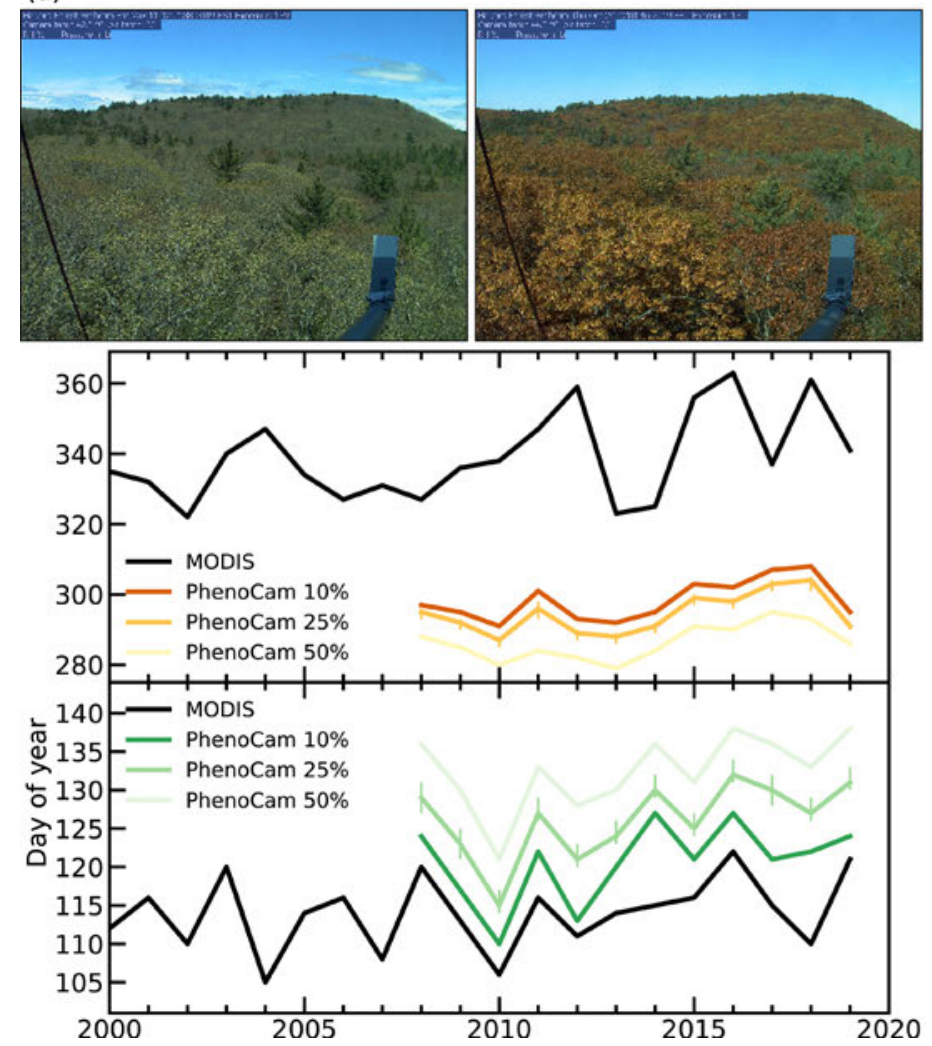

(b)
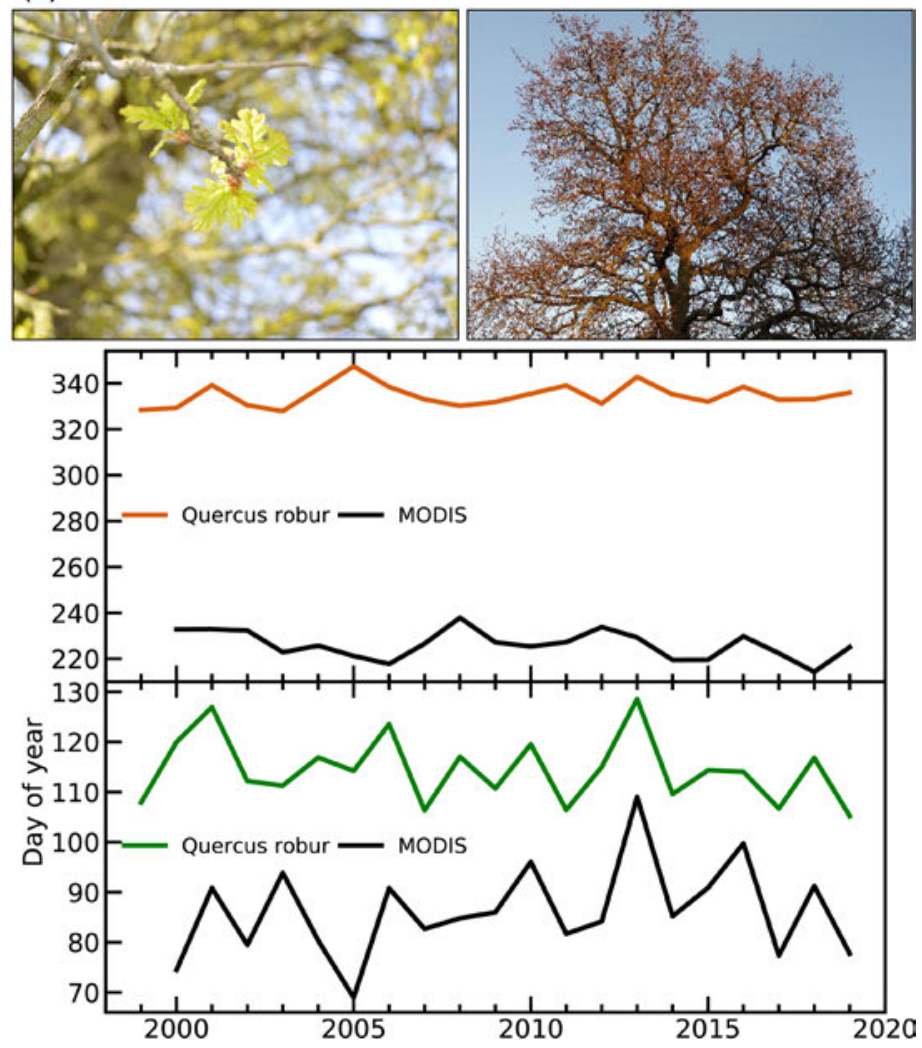

Fig. 2.70. Day of year (DOY) of spring and autumn vegetation phenology indicators and associated 2019 images for (a) Harvard Forest, Massachusetts, United States, SOS (green, bottom) and EOS (orange, top) days derived from PhenoCam and MODIS remote sensing (black), and (b) UK mean oak (Quercus robur) "first leaf" (bottom, green), "bare tree" (top, orange), and MODIS (black).

at Harvard Forest, a deciduous forest in Massachusetts (United States) with the same indicators derived from MODIS (Figs. 2.70a,b). $\mathrm{SOS}_{\mathrm{PC}}$ and $\mathrm{SOS}_{\mathrm{M}}$ are strongly correlated $(\mathrm{r}=0.83, \mathrm{n}=12$ ), although SOSPC is later by $11 \pm 3$ days, relative to $\operatorname{SOS}_{M}$ (Fig. 2.70a). The correlation between $\mathrm{EOS}_{\mathrm{PC}}$ and $\mathrm{EOS}_{\mathrm{M}}$ is weaker $(\mathrm{r}=0.46)$, and $\mathrm{EOS}_{\mathrm{PC}}$ is $48 \pm 12$ days earlier on average relative to $\mathrm{EOS}_{\mathrm{M}}$ (Fig. 2.70b). In 2019, SOS $_{\mathrm{PC}}$ for Harvard Forest (DOY 131, 11 May, \pm 2 days) was four days later

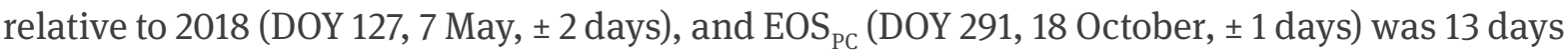
earlier relative to 2018 (DOY 304, 31 October, \pm 2 days). The MODIS changes for this site were more extreme: SOS $_{M}$ was 11 days later and $\mathrm{EOS}_{\mathrm{M}} 20$ days earlier in 2019 relative to 2018 (Figs. 2.70a,b). PhenoCam-derived total growing season length in 2019 was more than two weeks shorter than 2018, mostly because of the earlier EOS. This is the shortest growing season observed at Harvard Forest in the 12-year PhenoCam record.

Across the United Kingdom (UK), mean dates of oak (Quercus robur) "first leaf" and "bare tree" (indicators of start and end of season) recorded by citizen scientists have been collated by the Woodland Trust since 1999. Over the 2000-09 baseline, the mean first leaf and bare tree dates were 26 April (DOY 116) and 30 November (DOY 334), respectively, giving a 218-day season length (Figs. 2.70b). Both events are strongly influenced by prevailing temperature; first leaf advances by about six days for every $1^{\circ} \mathrm{C}$ increase in mean February-April temperature, and bare tree dates are delayed by about three days for every $1^{\circ} \mathrm{C}$ increase in October temperature. In 2019, the very warm spring resulted in mean first leaf nearly 11 days earlier than the baseline. In contrast, October temperature was similar to recent years and bare dates were delayed by about one day compared to the baseline. The net result was an "oak season" 12 days longer than the 10-year mean. These results are qualitatively comparable with UK mean MODIS NDVI SOS and EOS anomalies. 


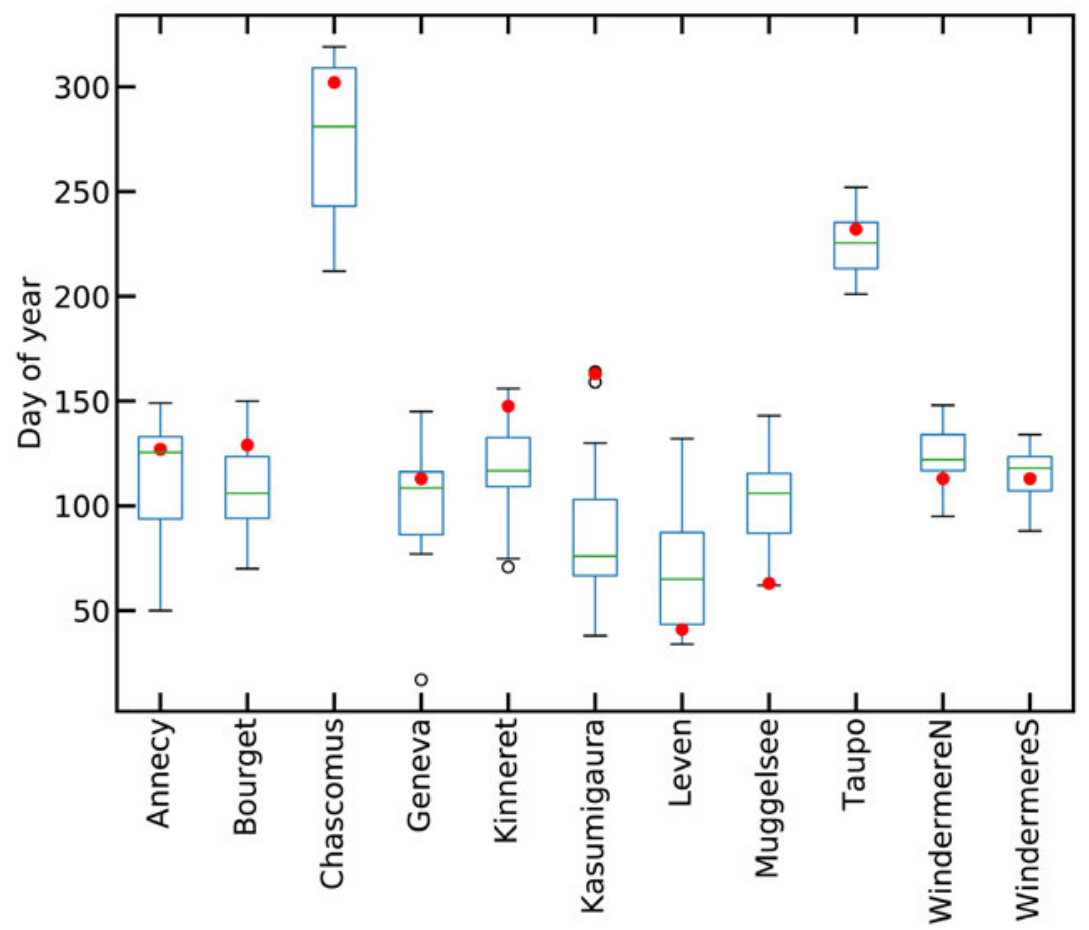

Fig. 2.71. Box-whisker plot showing the DOY of mean (green line), 50th (box), 90th (whiskers), and 99th (black open circles) percentiles of spring phytoplankton peak for 2000-10, and the 2019 mean day (red circles) for nine global lake basins: Annecy and Bourget (France), Chascomus (Argentina), Geneva (France-Switzerland), Kinneret (Israel), Kasumigaura (Japan), Loch Leven (UK), Muggelsee (Germany), Taupo (New Zealand), and Windermere north and south basins (UK).

Long-term (fortnightly-monthly) monitoring data on lake water concentrations of the photosynthetic pigment chlorophyll- $a$ can be used to derive the seasonality of phytoplankton growth and the timing of the spring phytoplankton peak in lake ecosystems (Winder and Cloern 2010; Thackeray et al. 2013). We present such data from 11 lake basins (Fig. 2.71): Lakes Annecy and Bourget (France), Chascomus (Argentina), Geneva (France-Switzerland), Kinneret (Israel), Kasumigaura (Japan), Loch Leven (UK), Müggelsee (Germany), Taupo (New Zealand), and the north and south basins of Windermere (UK). During the 2000-10 baseline, the mean day of year of the spring bloom in the nine NH basins ranged from 76 (17 March, Loch Leven) to 122 (2 May, Windermere North Basin). In lakes Chascomus and Taupo, in the SH, the corresponding means were 274 (1 October) and 222 (10 August), respectively. In 2019, the day of year of the spring peak was later than the base period in eight lake basins (by 1 to 82 days), but earlier for Müggelsee, Loch Leven, and Windermere North Basin (by 37, 35, and 9 days, respectively). This site-based variability suggests the agency of additional factors, such as nutrient availability (Thackeray et al. 2008), that interact with climate to influence seasonal ecosystem behavior. 


\section{Acknowledgments}

\section{2a (Overview)}

Robert Dunn and Kate Willett acknowledge support from the Joint BEIS/Defra Met Office Hadley Centre Climate Programme under (GA01101).

We thank our internal reviewers, David Parker, John Kennedy, Roger Saunders, Mark McCarthy, and Christoforos Tsamalis for their detailed suggestions.

We also thank the following authors for providing data included at multiple points in this chapter: Gil Compo and Cathy Smith, 20CRv3; Mike Bosilovich, MERRA2; Julien Nicholas, ERA5; and Atsushi Goto, JRA-55 data

\section{2b2 (Lake Temperature)}

Lake surface water temperatures from satellite data have been generated within the GloboLakes project funded by the UK National Environment Research Council (NE/J023345/2) with extensions funded by the EU Copernicus Climate Change Service (C3S) programme. Lake temperature data from Baikal was supported by grant of Foundation for support of applied ecological studies (https://baikalfoundation.ru/project/tochka-1/). Data from the Swedish Lake Vättern were received from the Lake Vättern's Society for Water Conservation. Collection of data from Loch Leven, Scotland, was supported by award number NE/R016429/1 as part of the UK-SCaPE programme, which is delivering UK National Capability.

\section{2b3 (Land and marine temperature extremes)}

Robert Dunn acknowledges support from the Joint BEIS/Defra Met Office Hadley Centre Climate Programme under (GA01101).

Research funding for R. W. Schlegel was provided by the Ocean Frontier Institute, through an award from the Canada First Research Excellence Fund.

\section{2c1 (Permafrost thermal state)}

PERMOS is financially supported by MeteoSwiss in the framework of GCOS Switzerland, the Federal Office for the Environment and the Swiss Academy of Sciences and acknowledges the important contribution of the partner institutions and principal investigators. The French Network PermaFRANCE is financially supported by Observatoire des Sciences de I'Univers Grenoble (OSUG) and the French Research Infrastructure OZCAR.

\section{2c2 (Northern Hemisphere snow cover extent)}

This work is funded in part by NOAA's Climate Data Record (CDR) Program located in Asheville, NC, at the National Centers for Environmental Information (NCEI).

\section{Sidebar 2.1 (Lake Ice)}

We thank John Magnuson, Kevin Blagrave, Nikolay Granin, Johanna Korhonen, Lars Rudstam, and Gesa Weyhenmeyer for providing updates to in situ lake ice phenology records. Funding to Sapna Sharma was provided by the Natural Sciences and Engineering Research Council Discovery Grant. R. lestyn Woolway received funding from the European Union's Horizon 2020 research and innovation programme under the Marie Skłodowska-Curie grant agreement No. 791812.

\section{2d1 (Surface humidity)}

Kate Willett was supported by the Met Office Hadley Centre Climate Programme funded by BEIS and Defra. Adrian Simmons was supported by the Copernicus Climate Change Service implemented by ECMWF on behalf of the European Commission. The NOAA-CIRES-DOE Twentieth Century Reanalysis Project version 3 used resources of the National Energy Research Scientific Computing Center managed by Lawrence Berkeley National Laboratory, which is supported by the Office of Science of the U.S. Department of Energy under Contract No. DE-AC02-05CH11231 and used resources of NOAA's Remotely Deployed High Performance Computing Systems. Support for the Twentieth Century Reanalysis Project version 3 dataset is provided by the U.S. Department of Energy, Office of Science Biological and Environmental Research (BER), by the National 
Oceanic and Atmospheric Administration Climate Program Office, and by the NOAA Earth System Research Laboratory Physical Sciences Division

\section{2d5 (Land surface precipitation extremes)}

Stephen Blenkinsop is funded by the U.K. Natural Environment Research Council FUTURE-STORMS project under grant number NE/R01079X/1. The National Center for Atmospheric Research is supported by the National Science Foundation.

\section{2d6 (Lake water levels)}

B. M. Kraemer received support from the German Research Foundation through the LimnoScenES project (AD 91/22-1). This work benefited from B. M. Kraemer's participation in the Global Lake Ecological Observatory Network (GLEON).

\section{2d8 (River discharge and runoff)}

Hyungjun Kim was supported by the Japan Society for the Promotion of Science KAKENHI (16H06291 and 18KK0117).

\section{2d10 (Soil moisture)}

The ESA CCI SM datasets and the authors were supported by ESA's Climate Change Initiative for Soil Moisture (Contract No. 4000104814/11//-NB and 4000112226/14/I-NB). We would also like to thank support from the Copernicus Climate Change Service implemented by ECMWF.

\section{2d11 Land evaporation}

D. G. Miralles acknowledges support from the European Research Council (ERC) under grant agreement no. 715254 (DRY-2-DRY), and the Belgian Science Policy Office (BELSPO) in the frame of the STEREO III program projects ET-Sense (SR/02/377) and ALBERI (SR/00/373).

2d12 (Monitoring global drought using the self-calibrating Palmer Drought Severity Index)

Tim Osborn received funding from UK NERC (NE/P006809/1). Ian Harris received funding from the UK National Centre for Atmospheric Science (NCAS).

\section{2e2 (Land and ocean surface winds)}

The NOAA-CIRES-DOE Twentieth Century Reanalysis Project version 3 used resources of the National Energy Research Scientific Computing Center managed by Lawrence Berkeley National Laboratory, which is supported by the Office of Science of the U.S. Department of Energy under Contract No. DE-AC02-05CH11231 and used resources of NOAA's Remotely Deployed High Performance Computing Systems. Support for the Twentieth Century Reanalysis Project version 3 dataset is provided by the U.S. Department of Energy, Office of Science Biological and Environmental Research (BER), by the National Oceanic and Atmospheric Administration Climate Program Office, and by the NOAA Earth System Research Laboratory Physical Sciences Division

\section{$2 \mathrm{f1}$ (Earth radiation budget at top of atmosphere)}

This research has been supported by the NASA CERES project. The NASA Langley Atmospheric Sciences Data Center processed the instantaneous Single Scanner Footprint (SSF) data used as input to EBAF Ed4.1 and processed the FLASHFlux TISA version 3C.

\section{2g3 (Aerosols)}

The CAMS reanalysis has been produced by the Copernicus Atmosphere Monitoring Services (CAMS), which is a program funded by the European Union. The European Centre for Medium-Range Weather Forecast (ECMWF) operates CAMS on behalf of the European Commission. Melanie Ades, Olivier Boucher, Zak Kipling and Samuel Rémy are funded by CAMS. 


\section{$2 g 4$ (Stratospheric ozone)}

Carlo Arosio, Melanie Coldewey-Egbers, Daan Hubert, Diego Loyola, Victoria Sofieva, Alexei Rozanov, and Mark Weber are grateful to ESA's Climate Change Initiative Ozone project and to the EU Copernicus Climate Change Service 312b Lot4 Ozone project for supporting the generation and extension of the GTO-ECV total ozone and SAGE-CCI-OMPS data records. Stacey M. Frith is supported by the NASA Long Term Measurement of Ozone program WBS 479717. Lucien Froidevaux's contribution, with the assistance of Ryan Fuller, was performed at the Jet Propulsion Laboratory, California Institute of Technology, under contract with NASA. Daan Hubert acknowledges the partial support by the EU/ERC Horizon 2020 project GAIA-CLIM.

\section{2g5 (Stratospheric water vapor)}

The authors would like to thank NASA's Upper Atmosphere Composition Observations program and NOAA's Climate Program Office for funding that helps sustain the frost point hygrometer soundings at Boulder, Lauder, Hilo, and Costa Rica.

\section{Sidebar 2.2 (Stratospheric Aerosols)}

This research was in part carried out at the Jet Propulsion Laboratory, California Institute of Technology, under a contract with the National Aeronautics and Space Administration, and by the National Oceanic and Atmospheric Administration Global Monitoring Laboratory. G. Taha's work is supported by NASA grant number 80NSSC18K0847. (C) 2020. All rights reserved.

\section{2h1 (Land surface albedo dynamics)}

The authors thank Monica Robustelli for her technical support.

\section{2h2 (Terrestrial vegetation dynamics)}

The author thanks Monica Robustelli for her technical support and the providers of the remote-sensing dataset needed to perform this research, i.e., the SeaWiFS Project (Code 970.2) and the Goddard Earth Sciences Data and Information Services Center/Distributed Active Archive Center (Code 902) at the Goddard Space Flight Center, Greenbelt, MD. MERIS products were processed at the Grid On Demand facility of European Space Agency (ESA/ESRIN) using JRC software code.

\section{2h3 (Biomass burning)}

The GFASv1.4 dataset was developed by the GFAS-CLIM project, funded by the German Bundesministerium für Wirtschaft und Energie (BMWi/DLR FKZ 50EE1543).

\section{2h4 (Phenology)}

Debbie Hemming acknowledges support from the Met Office Hadley Centre Climate Programme funded by BEIS and Defra, and thanks all co-authors for their interesting and helpful contributions, and Robert Dunn for his expertise finalizing the figures for this section. Taejin Park acknowledges support from the NASA Earth Science Directorate (grants NNX16A034H and 80NSSC18K0173-CMS). Andrew Richardson acknowledges support from the National Science Foundation through the Macrosystems Biology (award 1702697) and LTER (award 1832210) programs. Nature's Calendar thanks all of its volunteer recorders, without whom it could not function. Stephen Thackeray thanks Heidrun Feuchtmayr, Mitzi De Ville, Ben James, Ellie Mackay, Mike Clarke, Bev Dodd, Anne Dobel, Laurence Carvalho, Piet Verburg, Orlane Anneville, Tamar Zohary, Nadia Diovisalvi, Leonardo Lagomarsino, Shin-ichiro Matsuzaki, Rita Adrian, and Daniel Langenhaun for collecting and providing lake chlorophyll-a data. Windermere data collection was supported by the Natural Environment Research Council award number NE/R016429/1 as part of the UK-SCaPE programme delivering National Capability. 


\section{Appendix 1: Acronyms}

20CRv3

ALT

AMSRE and AMSRE2

AO

AOD

ASMA

ATSR

AVHRR

BDC

CALIPSO

CAMS

CAMSRA

CCMI

CERES

$\mathrm{CH}_{3} \mathrm{CCl}_{3}$

$\mathrm{CH}_{4}$

CLARA-A2

CLOUD_CCI

$\mathrm{CO}$

$\mathrm{CO}_{2}$

CPT

EBAF

ECMWF

EESC

ELSE

ENSO

EOS

EOS

ERA5

ERB

ESA CCI SM

ET

ETCCDI

FAPAR

FLASHFlux

GFAS

GHCN

GISS

GLEAM

GLOSSAC

GNSS

GPCC

GPCP

GPS-RO 20th Greenhouse Gas Index

active layer thickness

Advanced Microwave Scanning Radiometer

Arctic Oscillation

aerosol optical depth

Asian summer monsoon anticyclone

Along Track Scanning Radiometer

Advanced Very High Resolution Radiometers

Brewer-Dobson circulation

Cloud-Aerosol Lidar and Infrared Pathfinder Satellite

Observation

Copernicus Atmosphere Monitoring Service

CAMS reanalysis

Chemistry-Climate Model Initiative

Clouds and the Earth's Radiant Energy System

methyl chloroform

methane

cloud, albedo and surface radiation dataset

Cloud Climate Change Initiative

carbon monoxide

carbon dioxide

cold-point temperature

Energy Balanced And Filled

European Centre for Medium-Range Weather Forecasts

equivalent effective stratospheric chlorine

Ensemble Land State Estimator

El Niño-Southern Oscillation

Earth Observing System

end of season

European Centre for Medium-Range Forecasts Reanalysis

version 5

Earth's radiation budget

European Space Agency Climate Change Initiative for

Soil Moisture

evapotranspiration

Expert Team on Climate Change Detection and Indices

Fraction of absorbed photosynthetically active radiation

Fast Longwave and Shortwave Radiative Fluxes

Global Fire Assimilation System

Global Historical Climatology Network

Goddard Institute for Space Studies

Global Land Evaporation Amsterdam Model

Global Space-based Stratospheric Aerosol Climatology

Global Navigation Satellite System

Global Precipitation Climatology Centre

Global Precipitation Climatology Project

Global Positioning System-Radio Occultation 


\begin{tabular}{|c|c|}
\hline GRACE & Gravity Recovery and Climate Experiment \\
\hline GRACE-FO & GRACE Follow On \\
\hline G-REALM & Global Reservoir and Lake Monitoring \\
\hline GrIS & Greenland ice sheet \\
\hline GTN-P & Global Terrestrial Network for Permafrost \\
\hline $\mathrm{H}_{2} \mathrm{O}$ & water \\
\hline HIRS & High Resolution Infrared Sounder \\
\hline IFS & Integrated Forecasting System \\
\hline IOD & Indian Ocean dipole \\
\hline JAS & July, August, September \\
\hline JJA & June, July, August \\
\hline JPL & Jet Propulsion Laboratory \\
\hline JRA-55 & Japanese global atmospheric reanalysis \\
\hline LLGHGs & long-lived greenhouse gases \\
\hline LST & lower stratospheric temperature \\
\hline LSWT & lake surface water temperature \\
\hline LTT & lower tropospheric temperature \\
\hline MACC & Monitoring Atmospheric Composition and Climate \\
\hline MHW & marine heat wave \\
\hline MISR & Multi-angle Imaging SpectroRadiometer \\
\hline MLO & Mauna Loa (Hawaii) \\
\hline MLS & Microwave Limb Sounder \\
\hline MLSOL & Mauna Loa Stratospheric Ozone Lidar \\
\hline MODIS C6 & $\begin{array}{l}\text { Moderate Resolution Imaging Spectroradiometer } \\
\text { Collection } 6\end{array}$ \\
\hline MOPITT & Measurement of Pollution in the Troposphere \\
\hline MSLP & mean sea level pressure \\
\hline $\mathrm{N}_{2} \mathrm{O}$ & nitrous oxide \\
\hline NA & North America \\
\hline NAO & North Atlantic Oscillation \\
\hline NDACC & $\begin{array}{l}\text { Network for the Detection of Atmospheric } \\
\text { Composition Change }\end{array}$ \\
\hline NDVI & normalized difference vegetation index \\
\hline $\mathrm{NH}$ & Northern Hemisphere \\
\hline $\mathrm{O}_{3}$ & ozone \\
\hline OCS & carbonyl sulfide \\
\hline ODS & ozone depleting substance \\
\hline $\mathrm{OH}$ & hydroxyl \\
\hline OLR & outgoing longwave radiation \\
\hline OMI & Ozone Monitoring Instrument \\
\hline OMPS/LP & Ozone Mapping and Profiler Suite/Limb Profiler \\
\hline ONI & Oceanic Niño Index \\
\hline PATMOS-x/AVHRR & $\begin{array}{l}\text { Pathfinder Atmospheres Extended/Advanced Very High } \\
\text { Resolution Radiometer }\end{array}$ \\
\hline PDO & Pacific Decadal Oscillation \\
\hline POES & Polar Operational Environmental Satellites \\
\hline ppb & parts per billion \\
\hline ppm & parts per million \\
\hline QBO & Quasi-Biennial Oscillation \\
\hline
\end{tabular}




\begin{tabular}{|c|c|}
\hline QTP & Qinghai-Tibetan Plateau \\
\hline RFaci & radiative forcing resulting from aerosol-cloud interactions \\
\hline RFari & radiative forcing resulting from aerosol-radiation \\
\hline RSS & Remote Sensing Systems \\
\hline RSW & reflected shortwave \\
\hline sAOD & stratospheric aerosol optical depth \\
\hline SatCORPS & satellite cloud and radiative property retrieval system \\
\hline SCE & snow cover extent \\
\hline sCPDSI & self-calibrating Palmer Drought Severity Index \\
\hline $\mathrm{SH}$ & Southern Hemisphere \\
\hline $\mathrm{SO}_{2}$ & sulfur dioxide \\
\hline SOI & Southern Oscillation Index \\
\hline SORCE & Solar Radiation and Climate Experiment \\
\hline SOS & start of season \\
\hline SPO & South Pole Observatory \\
\hline SSM/I & Special Sensor Microwave/Imager \\
\hline SSMIS & Special Sensor Microwave Imager/Sounder \\
\hline SST & sea surface temperature \\
\hline SSU & Stratospheric Sounding Unit \\
\hline SSW & sudden stratospheric warming \\
\hline SWV & stratospheric water vapor \\
\hline TCCON & Total Carbon Column Observing Network \\
\hline TCWV & total column water vapor \\
\hline TMI & Tropical Rainfall Measuring Mission Microwave Imager \\
\hline TOA & top of the atmosphere \\
\hline TSI & total solar irradiance \\
\hline TTL & tropical tropopause layer \\
\hline TTT & tropical trophospheric temperature \\
\hline TWS & terrestrial water storage \\
\hline UTH & upper troposphere (relative) humidity \\
\hline UV & ultraviolet \\
\hline WGMS & World Glacier Monitoring Service \\
\hline WMO & World Meteorological Organization \\
\hline ZAA & zero annual amplitude \\
\hline
\end{tabular}




\section{Appendix 2: Supplemental Material}

2b1 Surface air temperature

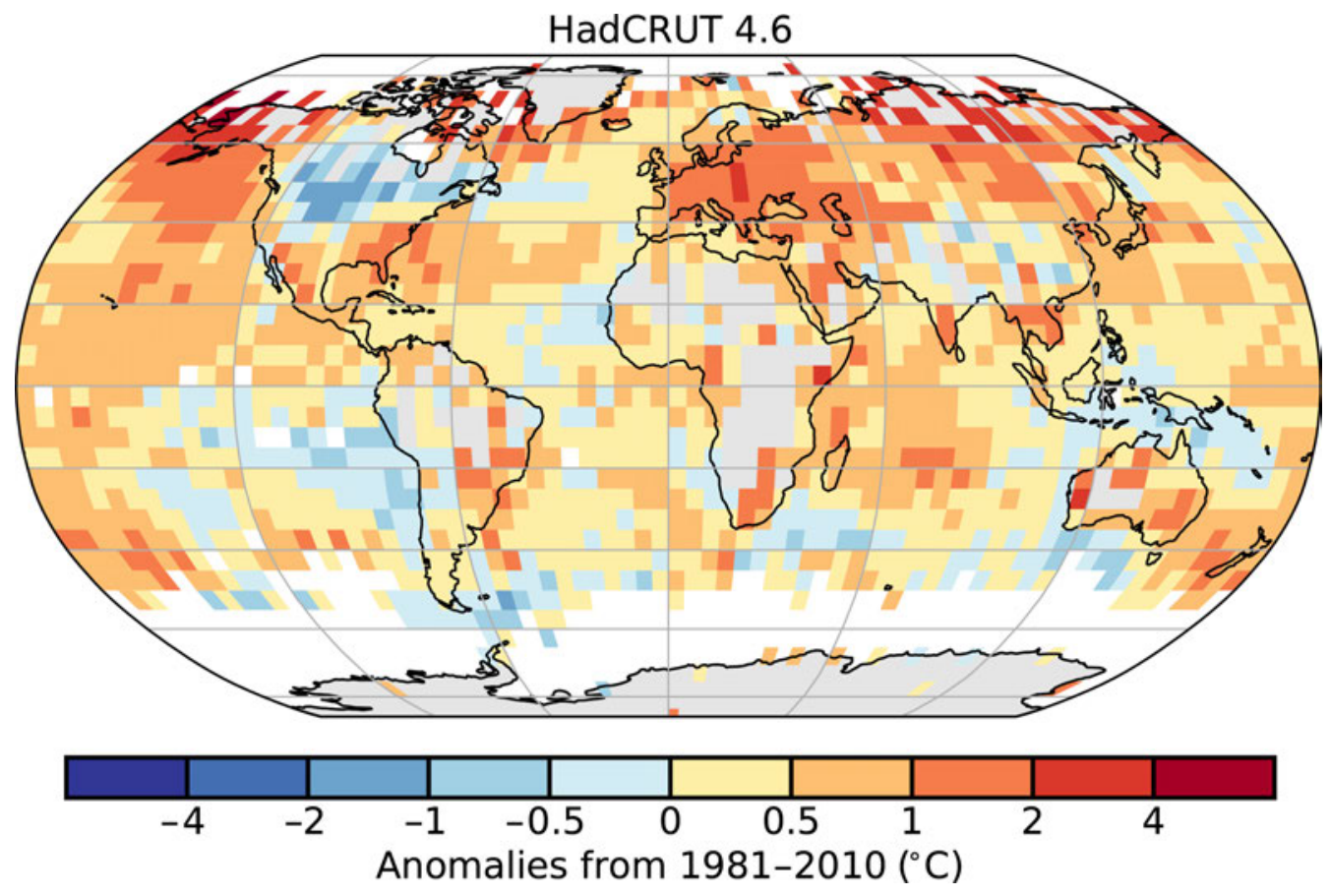

Fig. A2.1. Global land and ocean surface annual temperature anomalies for 2019 ( ${ }^{\circ} \mathrm{C}$; 1981-2010 base period). (Source: HadCRUT4.)

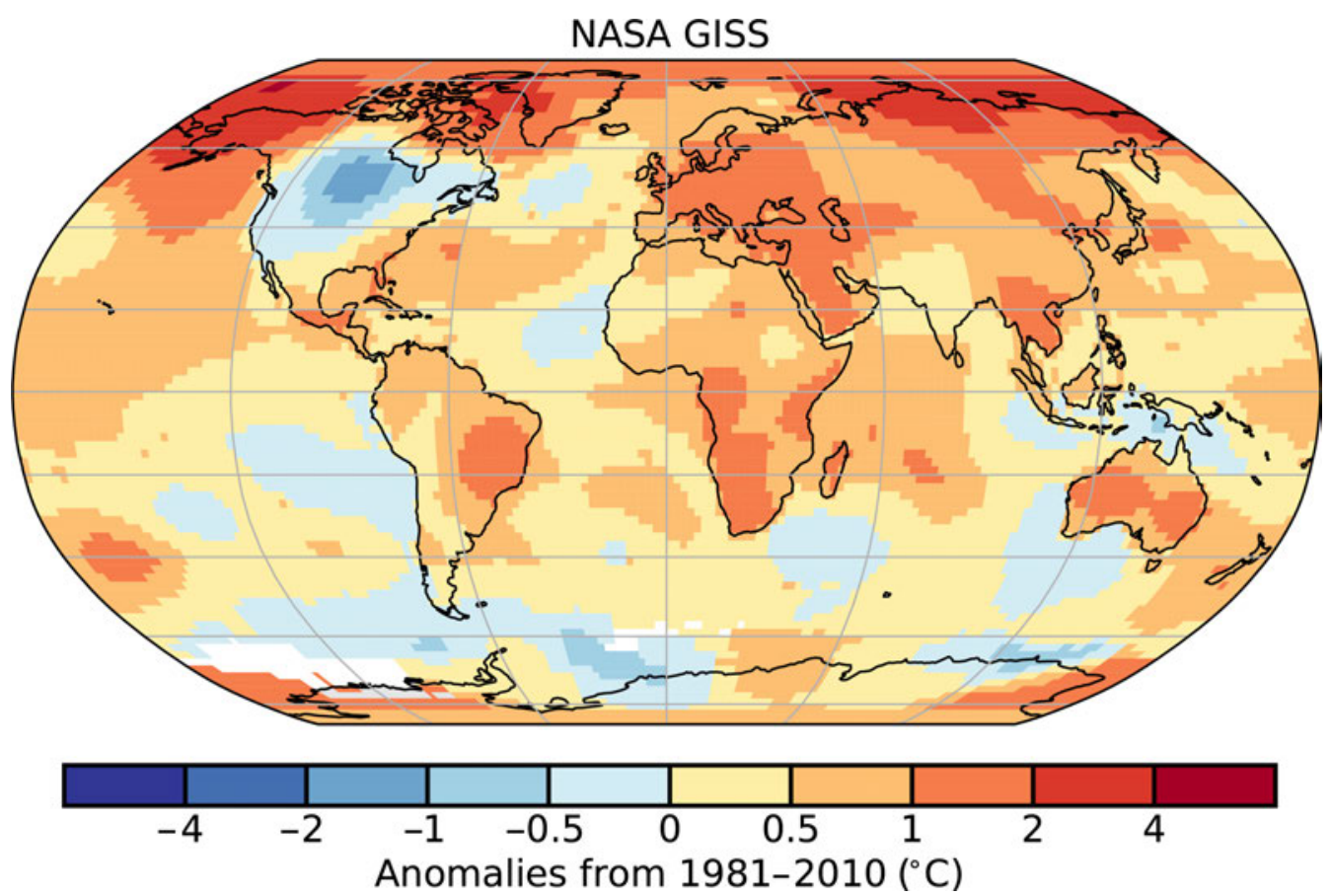

Fig. A2.2. Global land and ocean surface annual temperature anomalies for 2019 ( ${ }^{\circ} \mathrm{C}$; 1981-2010 base period). (Source: NASA GISTEMP.) 


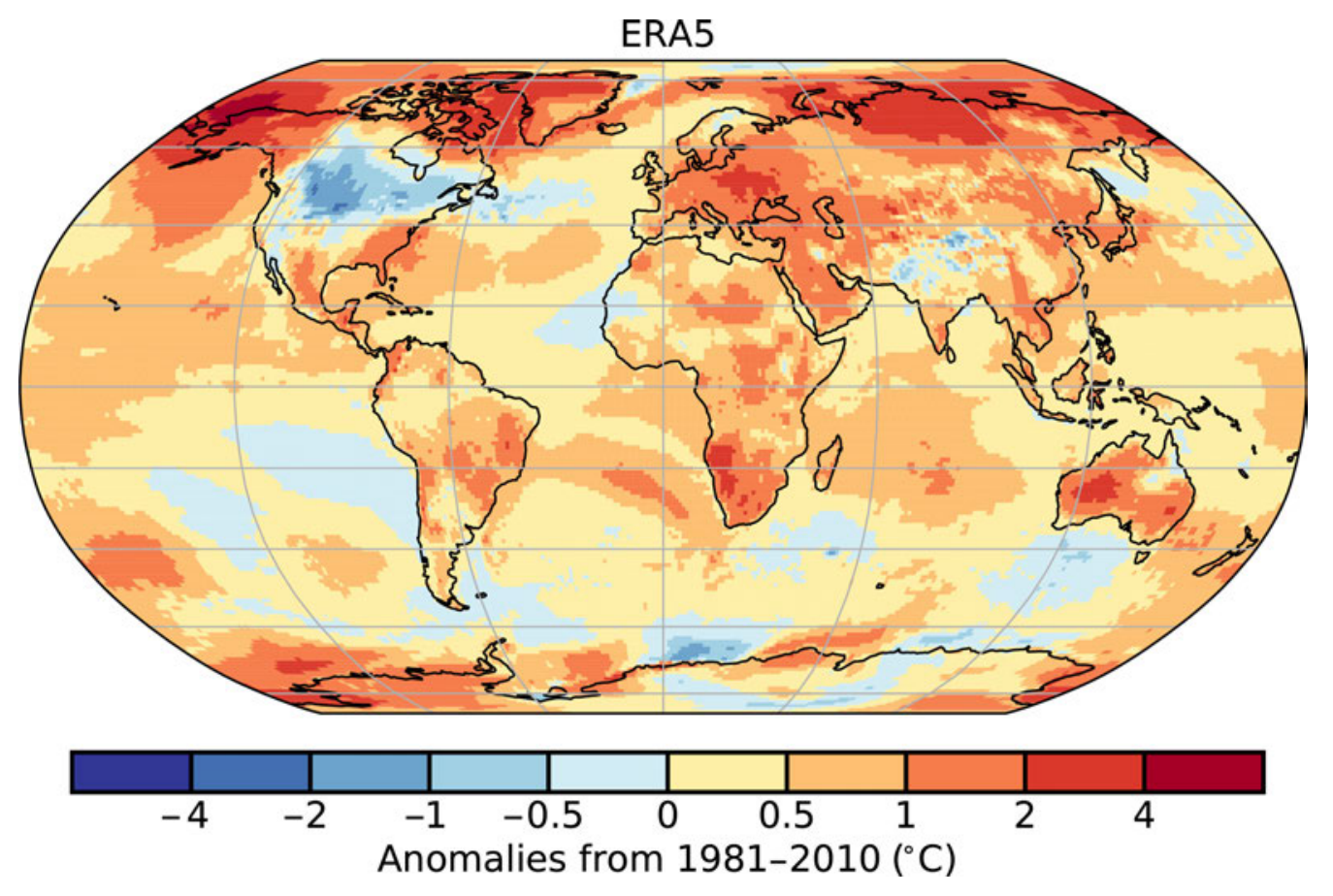

Fig. A2.3. Global land and ocean surface annual temperature anomalies for 2019 ( ${ }^{\circ} \mathrm{C}$; 1981-2010 base period). (Source: ERA5.)

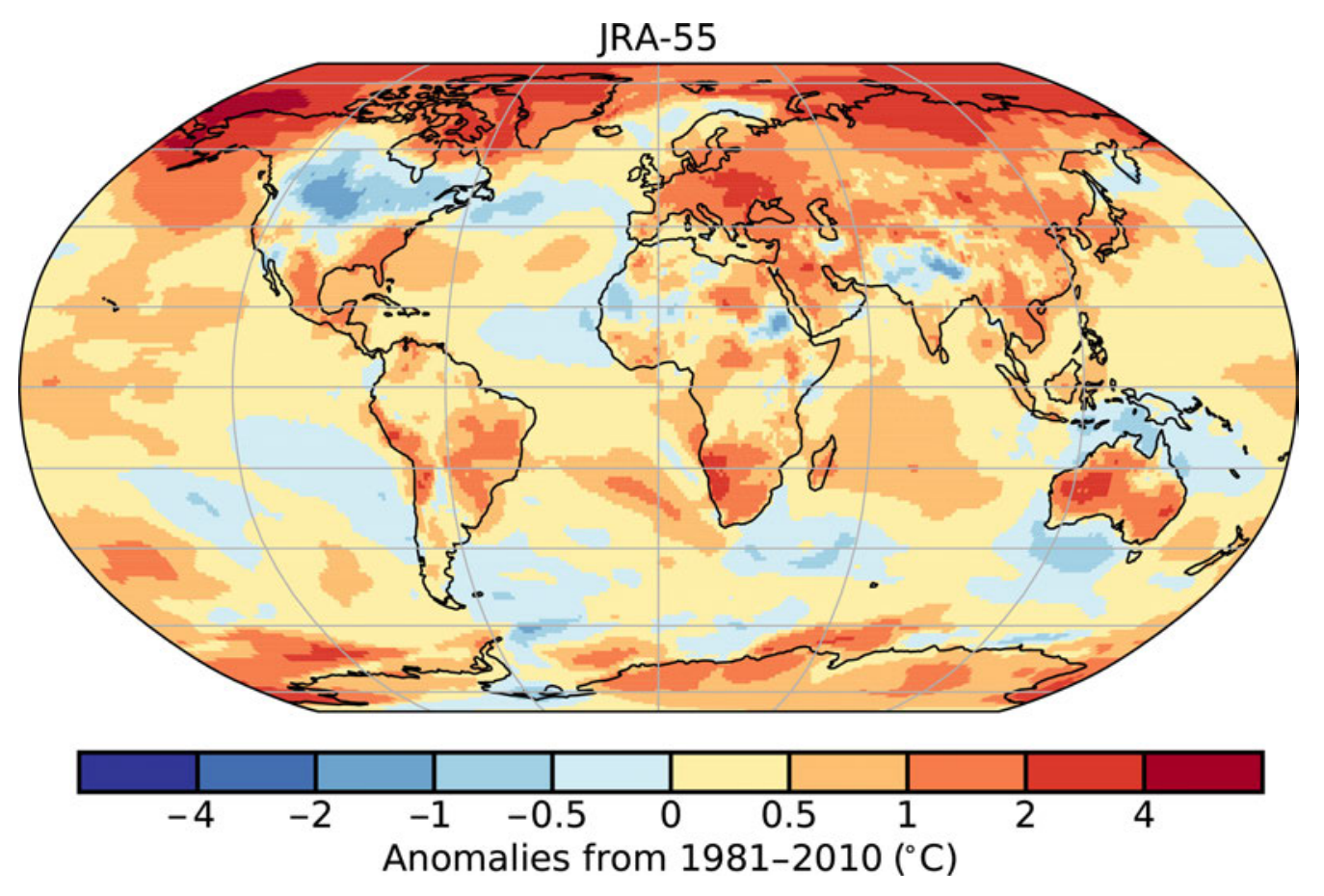

Fig. A2.4. Global land and ocean surface annual temperature anomalies for 2019 ( ${ }^{\circ} \mathrm{C}$; 1981-2010 base period). (Source: JRA-55.) 
(a) ERA5 TX90p - Warm Days
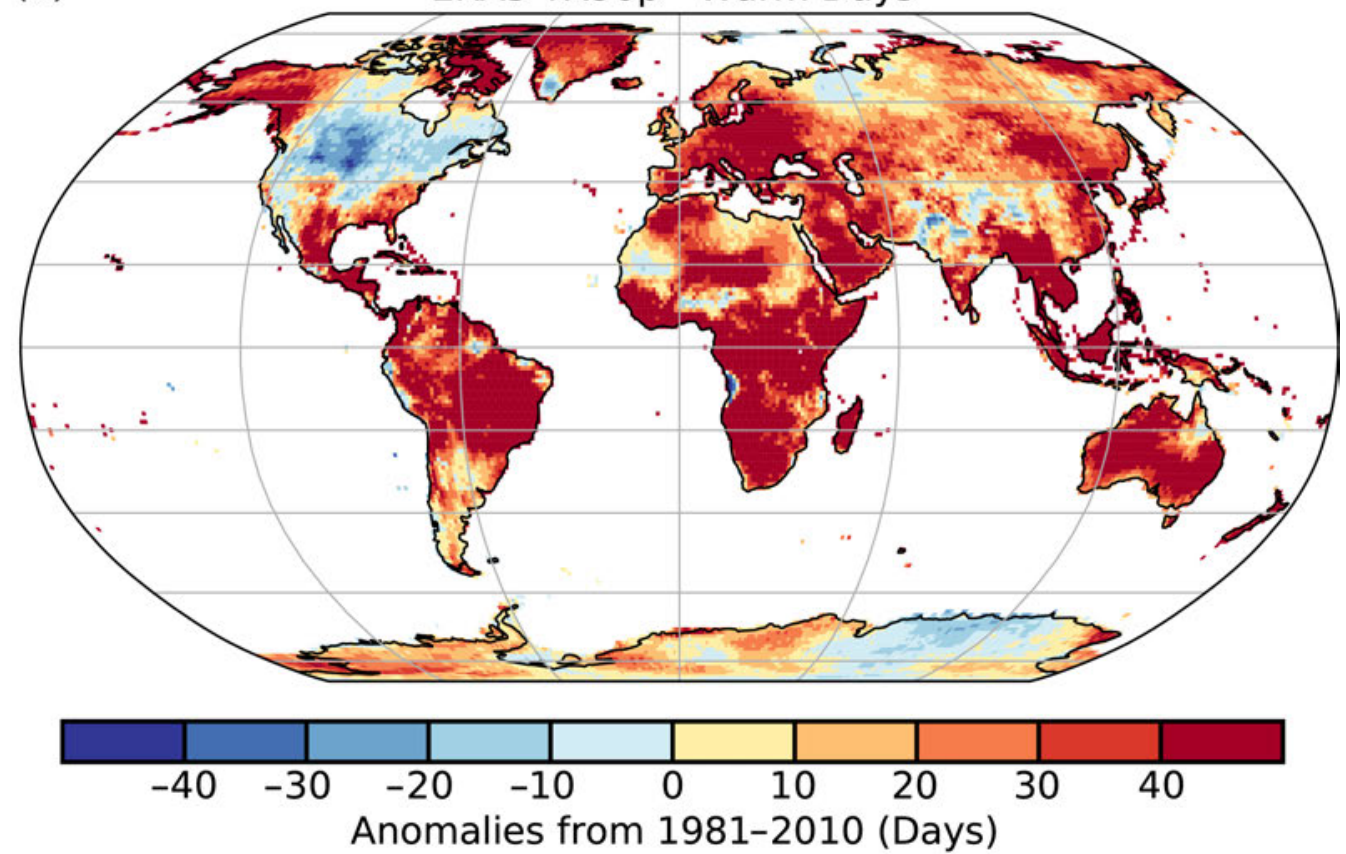

(b)
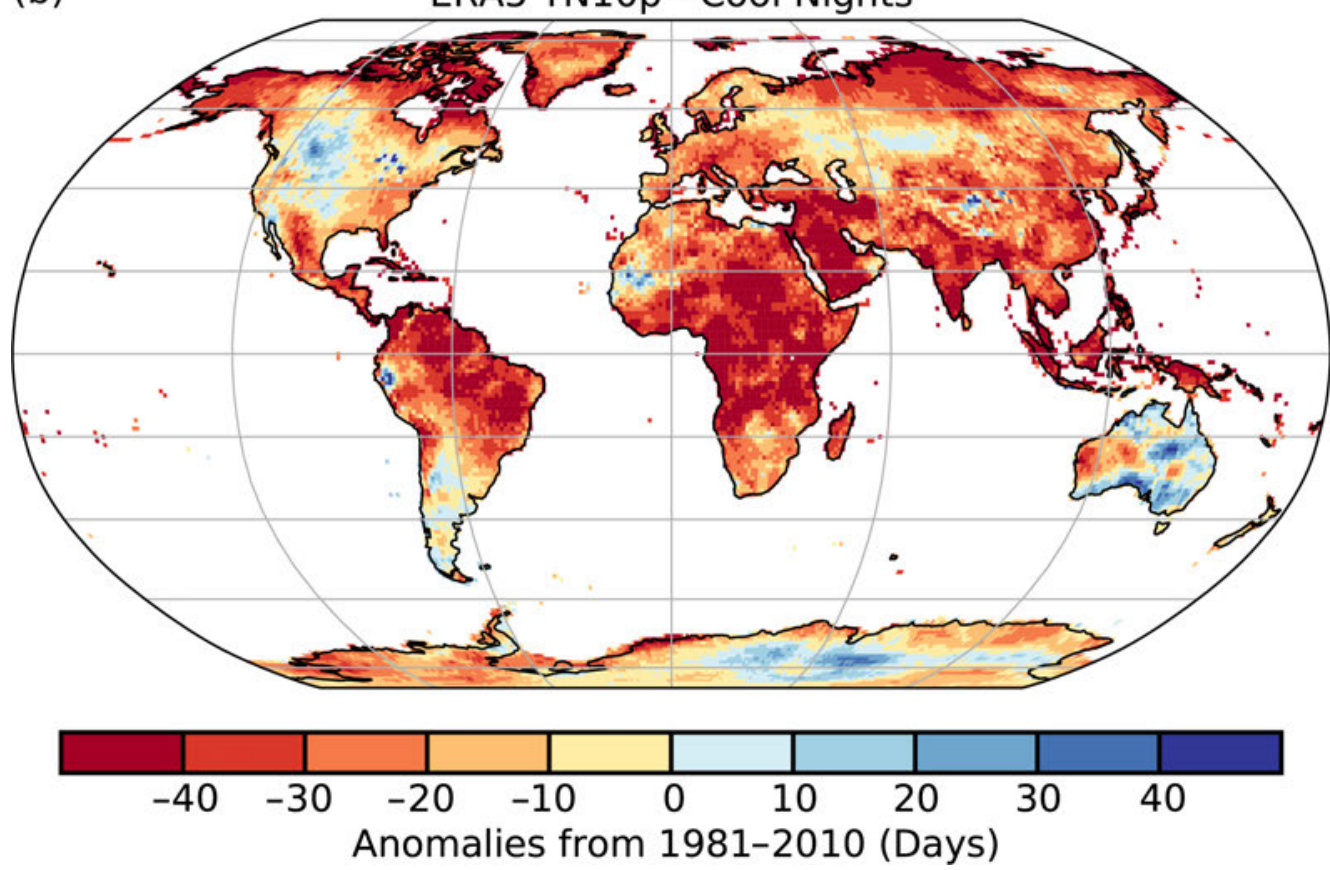

Fig. A2.5. (a) warm day threshold exceedance (TX90p), (b) cool night threshold exceedance (TN10p) in 2019. (Source: ERA5.) 


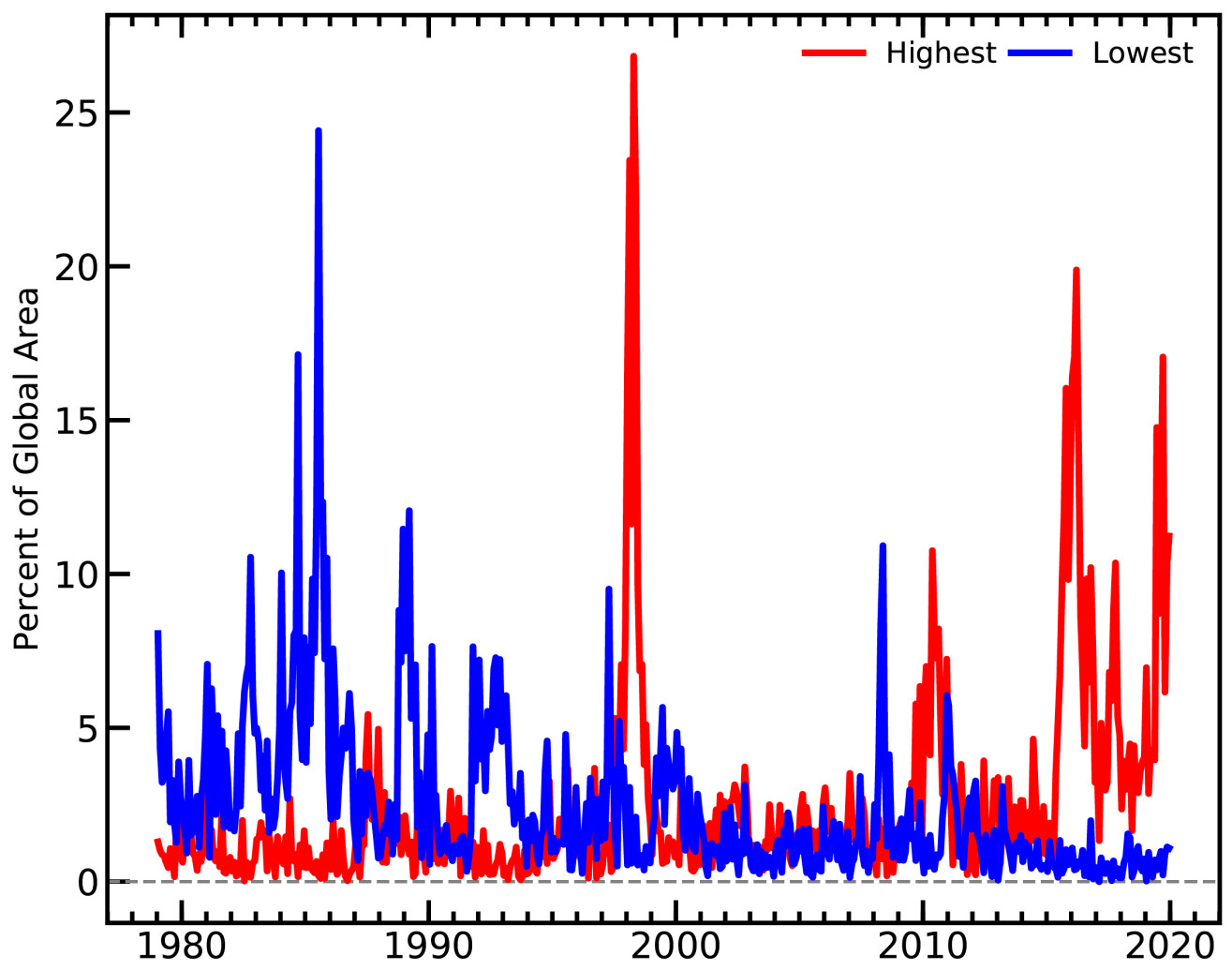

Fig. A2.6. Average area of highest (red) (blue) and lowest temperatures by month for the 41 years of observations in ERA5, RSS, and UAH datasets. This is an update of the figure from SotC 2018 (Christy et. al. 2019).

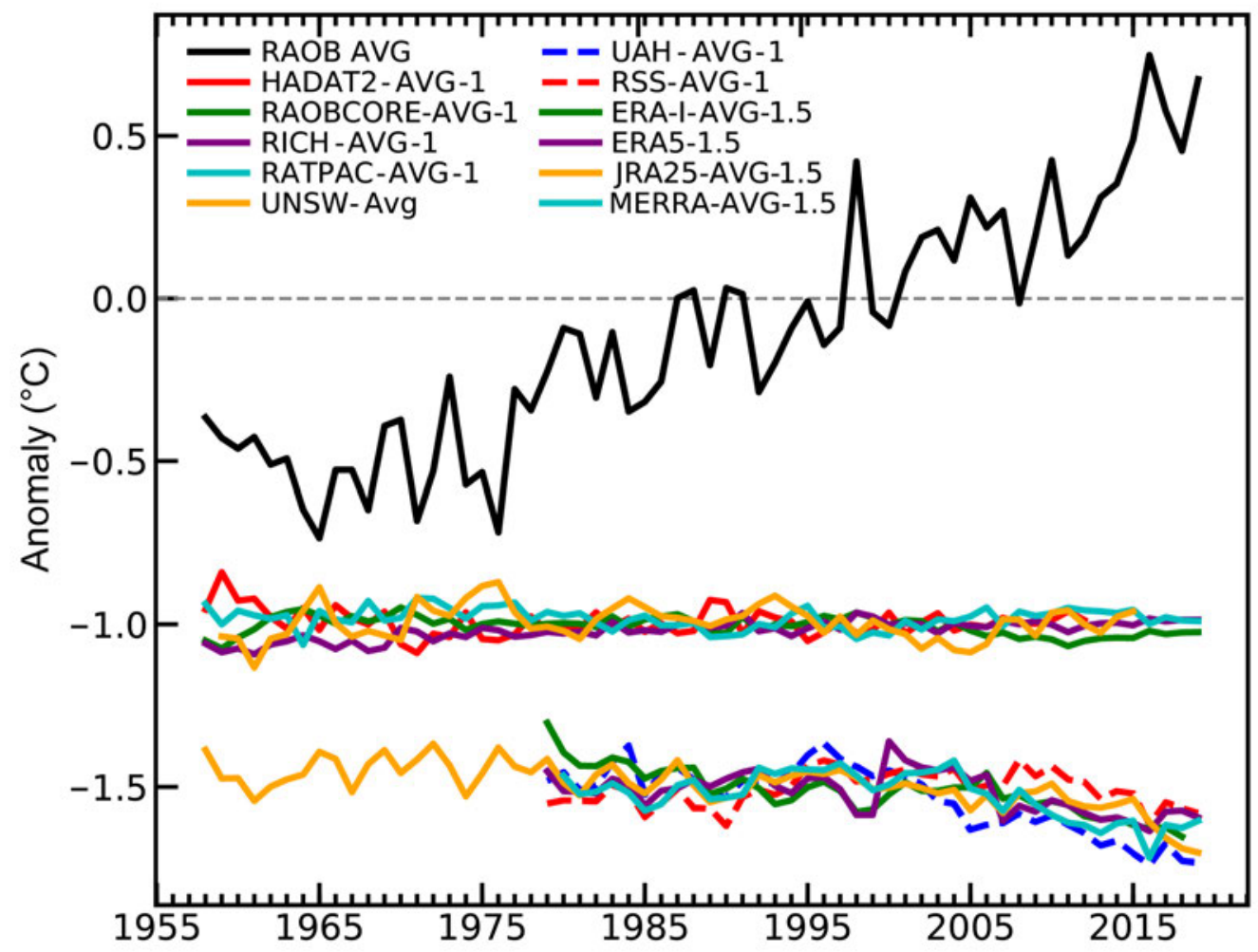

Fig. A2.7. (Top) Time series of annual anomalies of global lower tropospheric temperature $\left({ }^{\circ} \mathrm{C}\right)$ from radiosonde datasets only. (Middle) Differences of individual radiosonde datasets (at $-1.0^{\circ} \mathrm{C}$ axis) versus the radiosonde average. (Bottom) Differences relative to the radiosonde average (top) for satellite and reanalyses (at $-1.5^{\circ} \mathrm{C}$ axis). As noted in the text, those datasets that are not exclusively radiosondes (bottom) show decreasing values after 2009 possibly related to spurious warming in the radiosondes as a consequence of a change in the software processing system at many of the stations. 


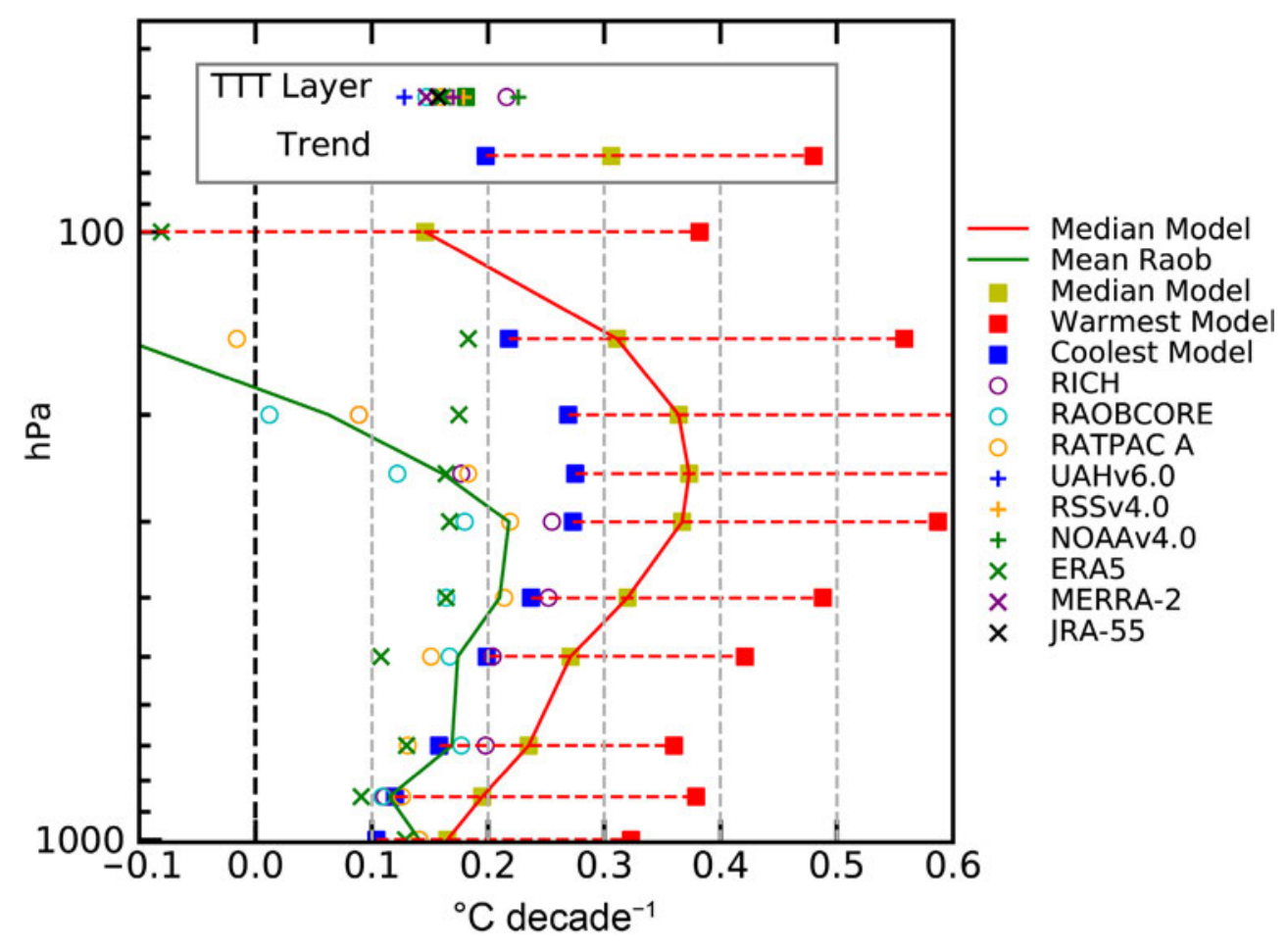

Fig. A2.8. Update of tropical temperature (TTT) trend comparisons (1979-2019) from SotC 2016 (Christy 2017) between observational datasets and the Climate Model Intercomparison Project version 6 (CMIP-6). The trend values for each pressure level are shown from 1000 to $100 \mathrm{hPa}$ with central values represented by the green (mean radiosondes) and red (median model) lines. The upper box provides the trends for the average of the bulk atmospheric layer TTT as described in the text. The model time series are constructed with historical forcings from 1850 to 2014 and after 2014 with forcing scenario ssp245. The 30 CMIP-6 models used are ACCESS-CM2, ACCESS-ESM1-5, AWI-CM-1-1-MR, BCC-CSM2-MR, CanESM5 (warmest), CanESM5-OE, CESM2, CESM2-WACCM, CNRM-CM6-1, CNRM-ESM2, EC-EARTH3, EC-EARTH3-VEG, FGOALS, FIO, GFDL-CM4, GFDL-ESM, GISS-E2-1-G, HadGEM, INM-CM4-8, INM-CM5-0, IPSL-CM6A-LR, MCM-UA, MIROC6, MIROC6-2L MPI-ESM1-2-HR, MPI-ESM1-2-LR, MRI-ESM2-0 (coolest), NESM, NorESM2-LM, and UKESM1-0-LL.

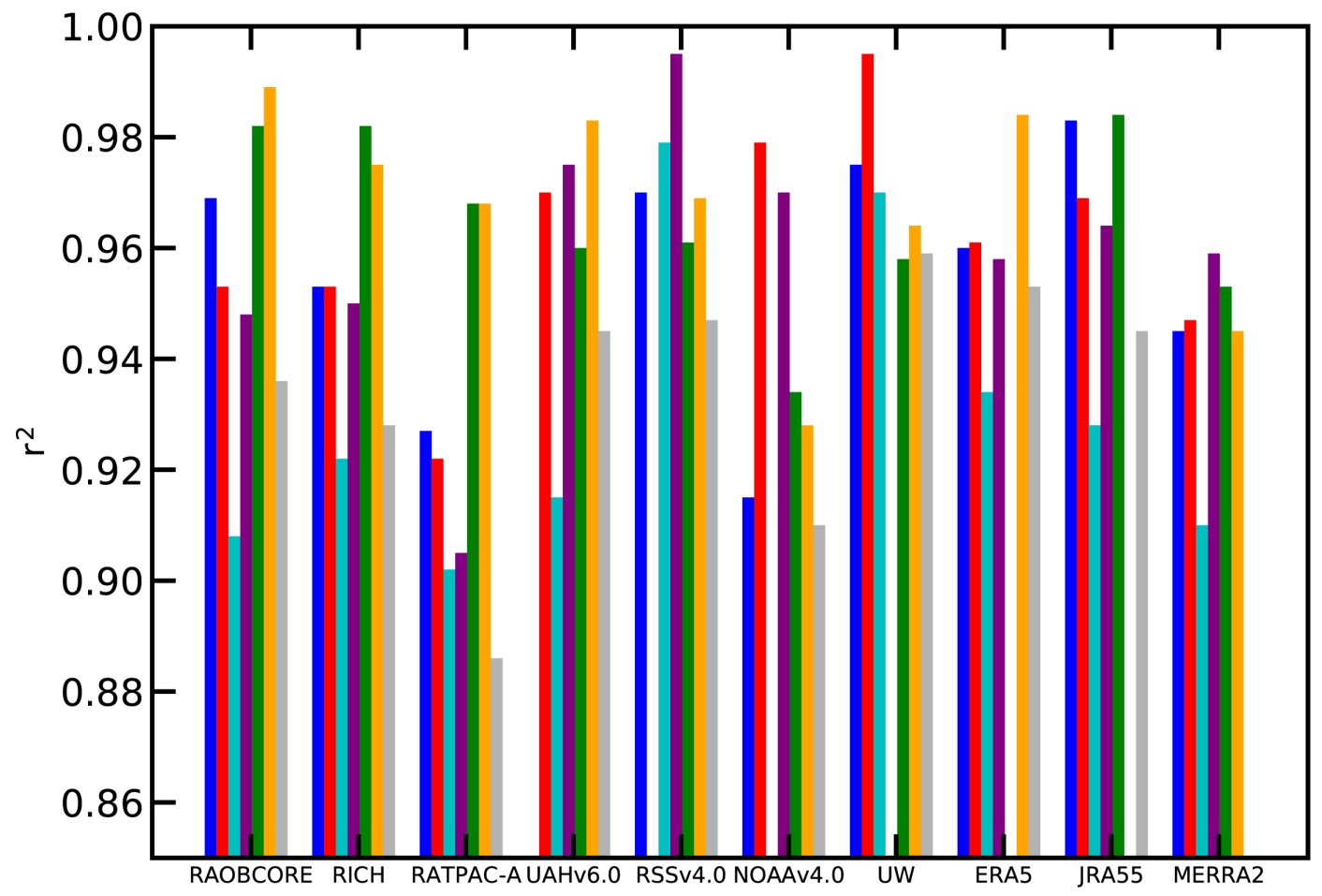

Fig. A2.9. Paired intercomparisons of the datasets utilized here for the tropical TTT metric, calculating the extent to which the identified paired datasets agree in terms of common variance $\left(r^{2}\right)$. 


\begin{tabular}{|c|c|c|c|c|c|}
\hline Area & & Global & Global & Tropical & Tropical \\
\hline Layer & & LTT & LTT & TTT & TTT \\
\hline Start year & & 1958 & 1979 & 1958 & 1979 \\
\hline Median & Observations & +0.18 & +0.18 & +0.16 & +0.16 \\
\hline Median & $\begin{array}{c}\text { CMIP6 } \\
\text { (30 models) }\end{array}$ & +0.20 & +0.29 & +0.22 & +0.32 \\
\hline
\end{tabular}




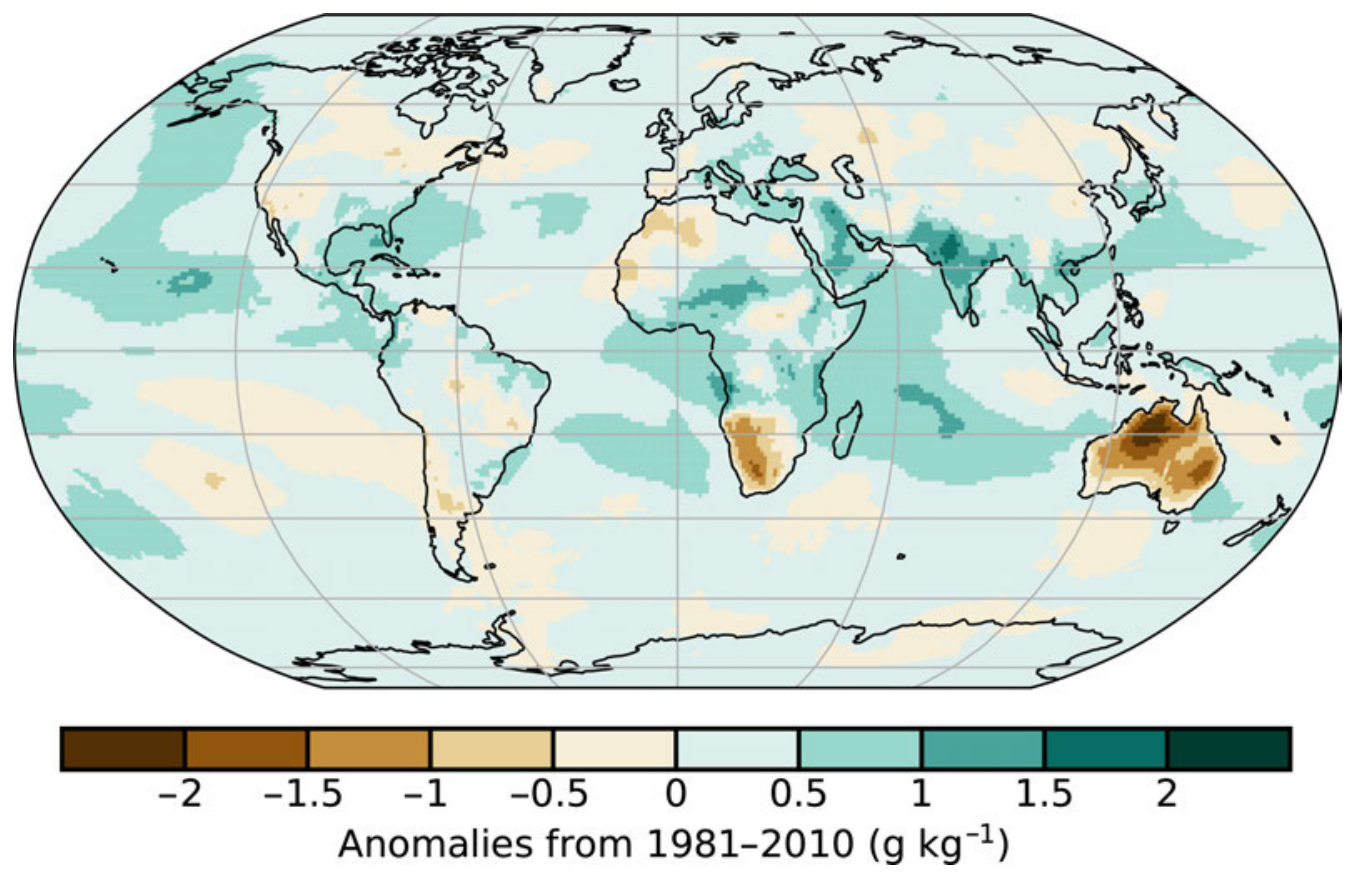

Fig. A2.10. Surface specific humidity anomalies for 2019. (Source: ERA5.)

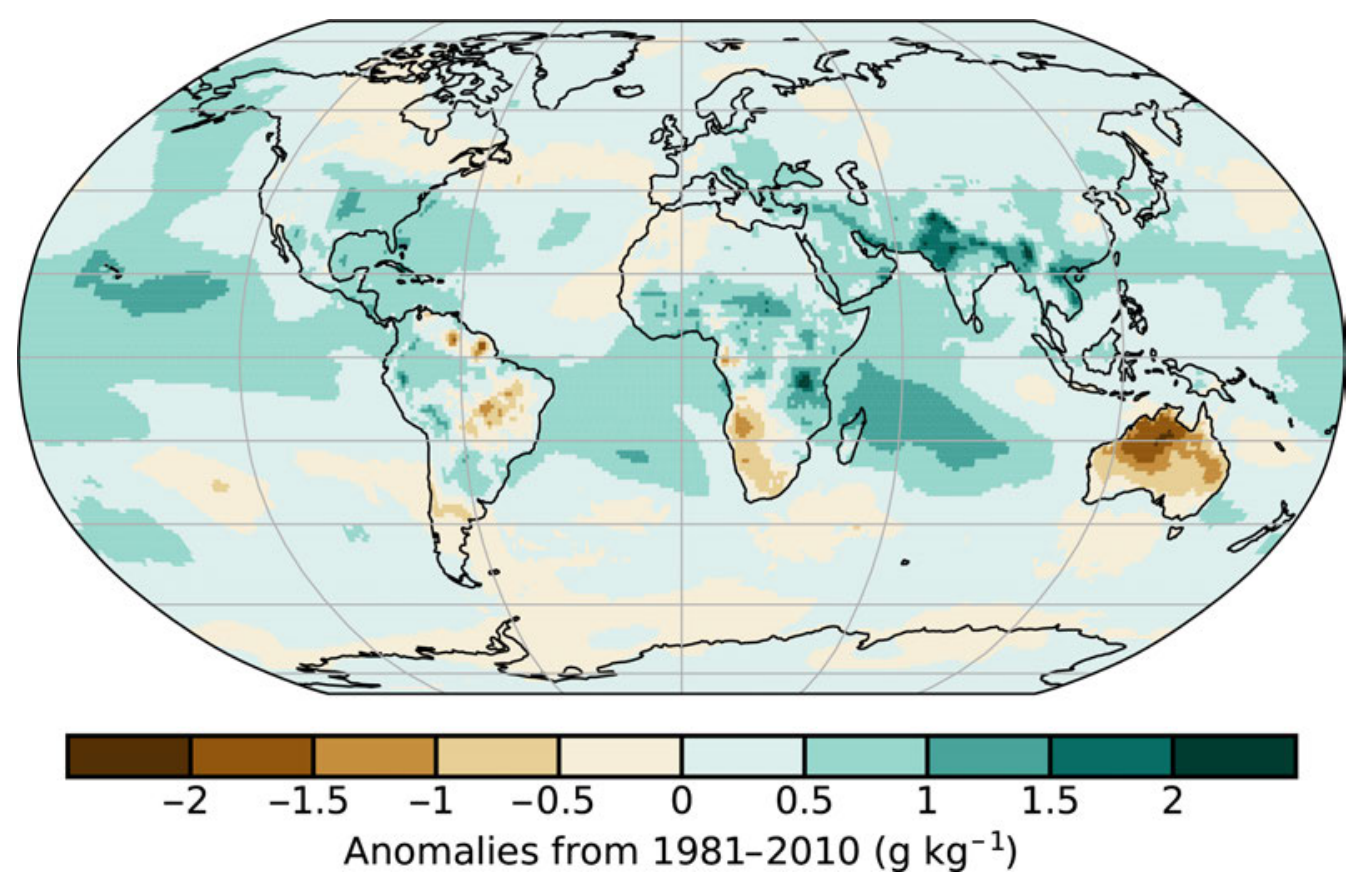

Fig. A2.11. Surface specific humidity anomalies for 2019. (Source: MERRA-2.) 


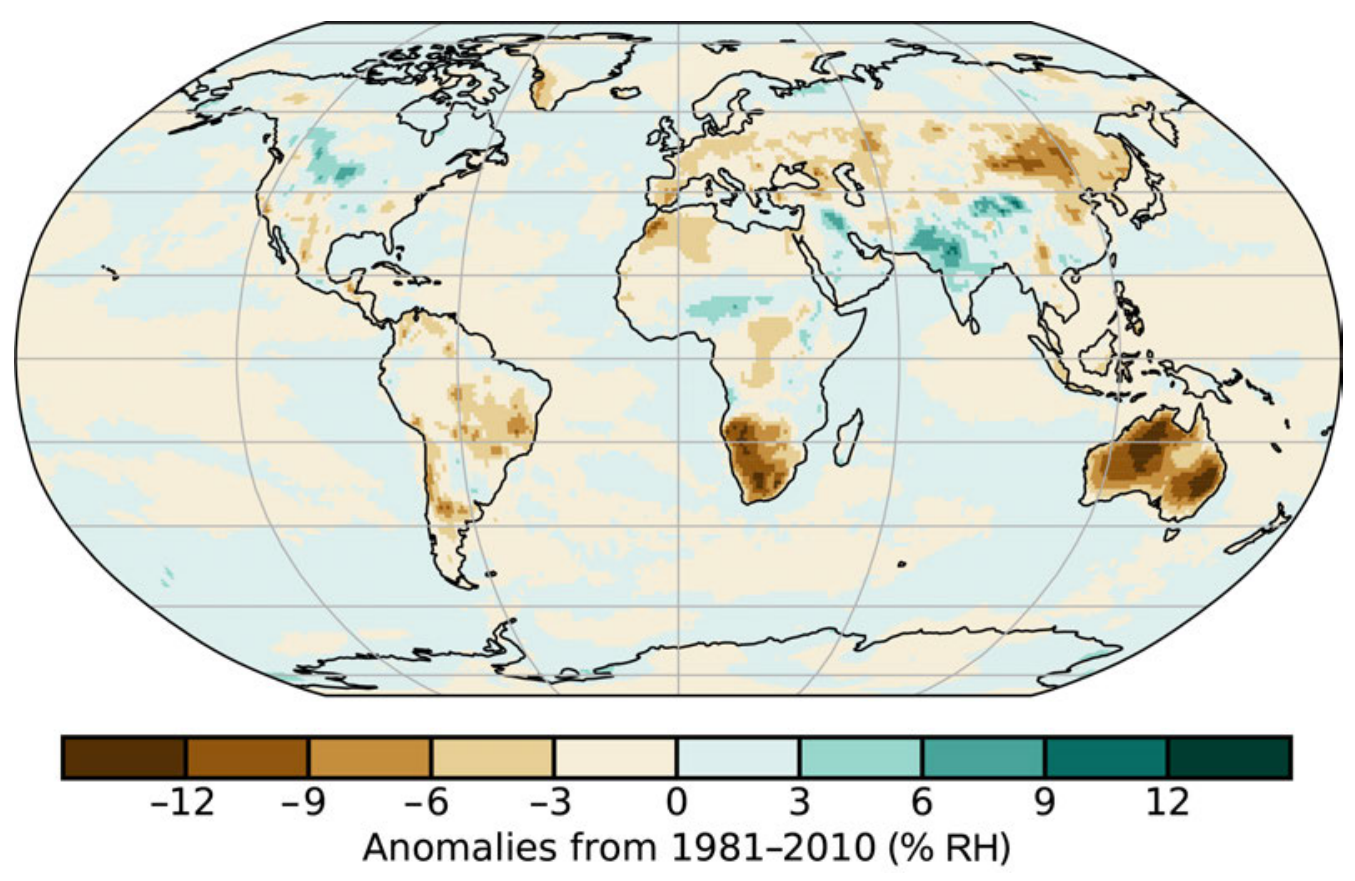

Fig. A2.12. Surface relative humidity anomalies for 2019. (Source: ERA5.)

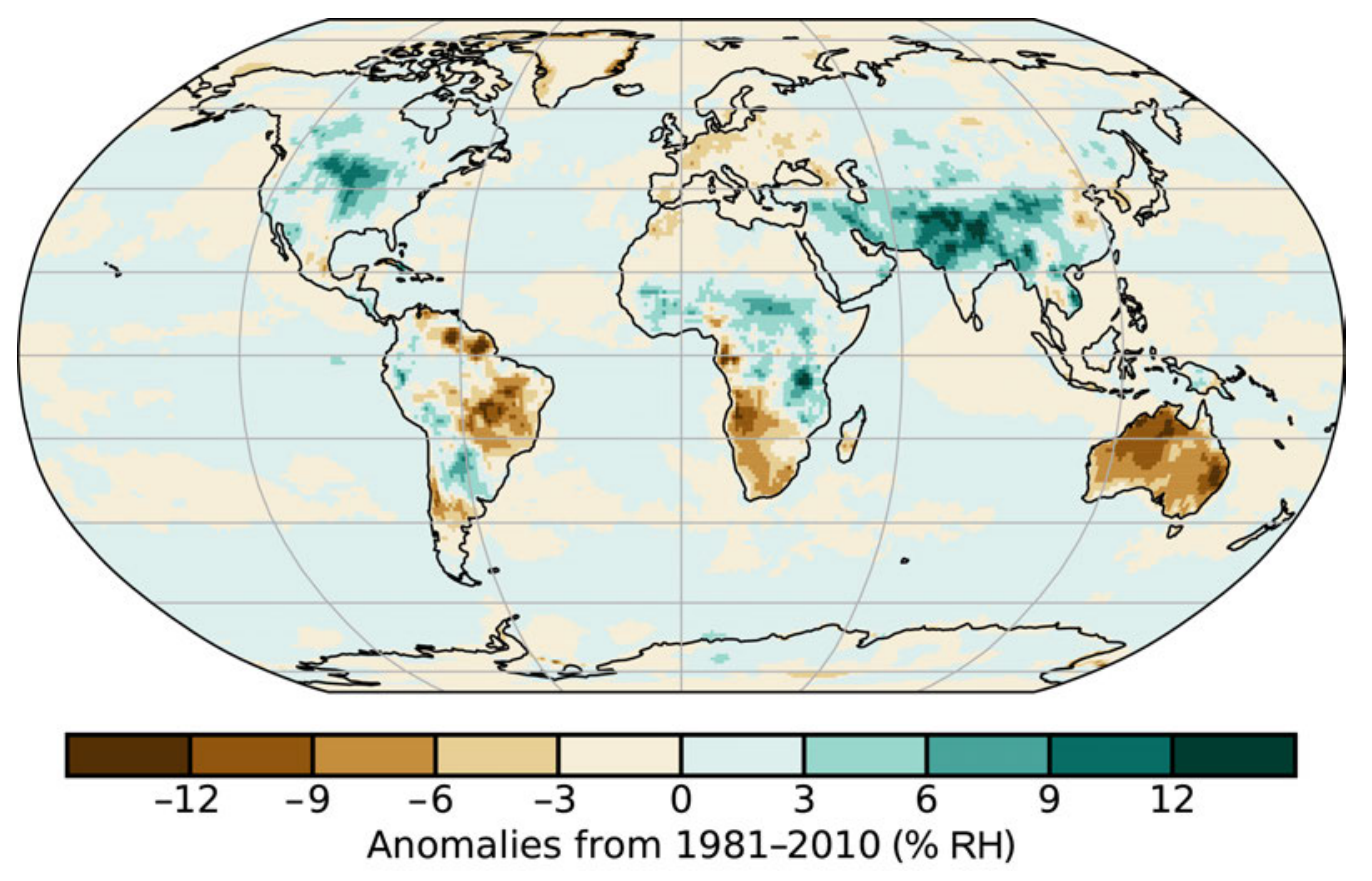

Fig. A2.13. Surface relative humidity anomalies for 2019. (Source: MERRA-2.) 

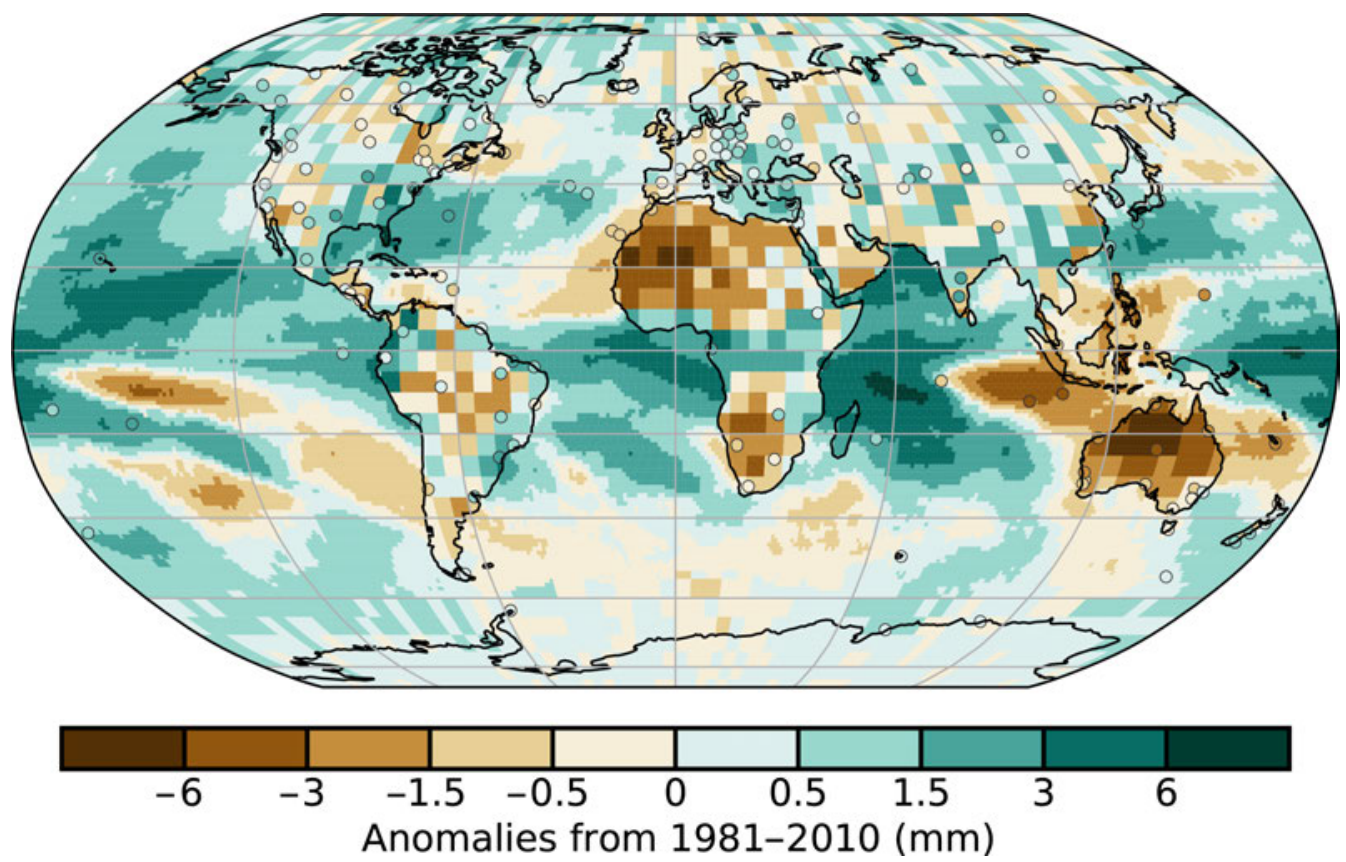

Fig. A2.14. Total column water vapor anomalies for 2019 relative to a 1981-2010 base period. Over the oceans, the data are from COSMIC, GPS RO, and satellite radiometers, and from COSMIC and GPS RO over land.

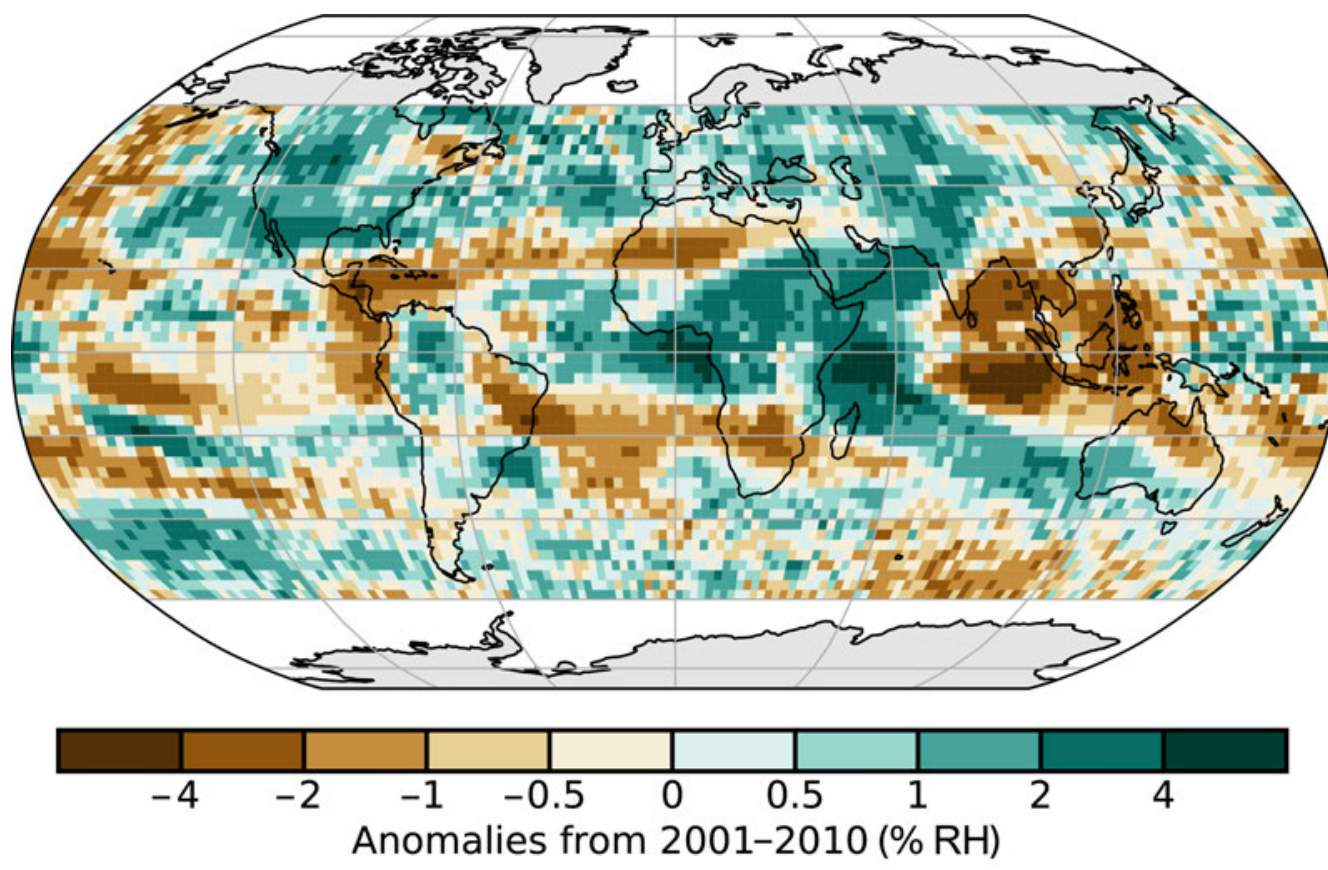

Fig. A2.15. Annual average upper tropospheric humidity anomalies anomaly map for 2019 relative to the 2001-10 climatology based on the HIRS dataset. 

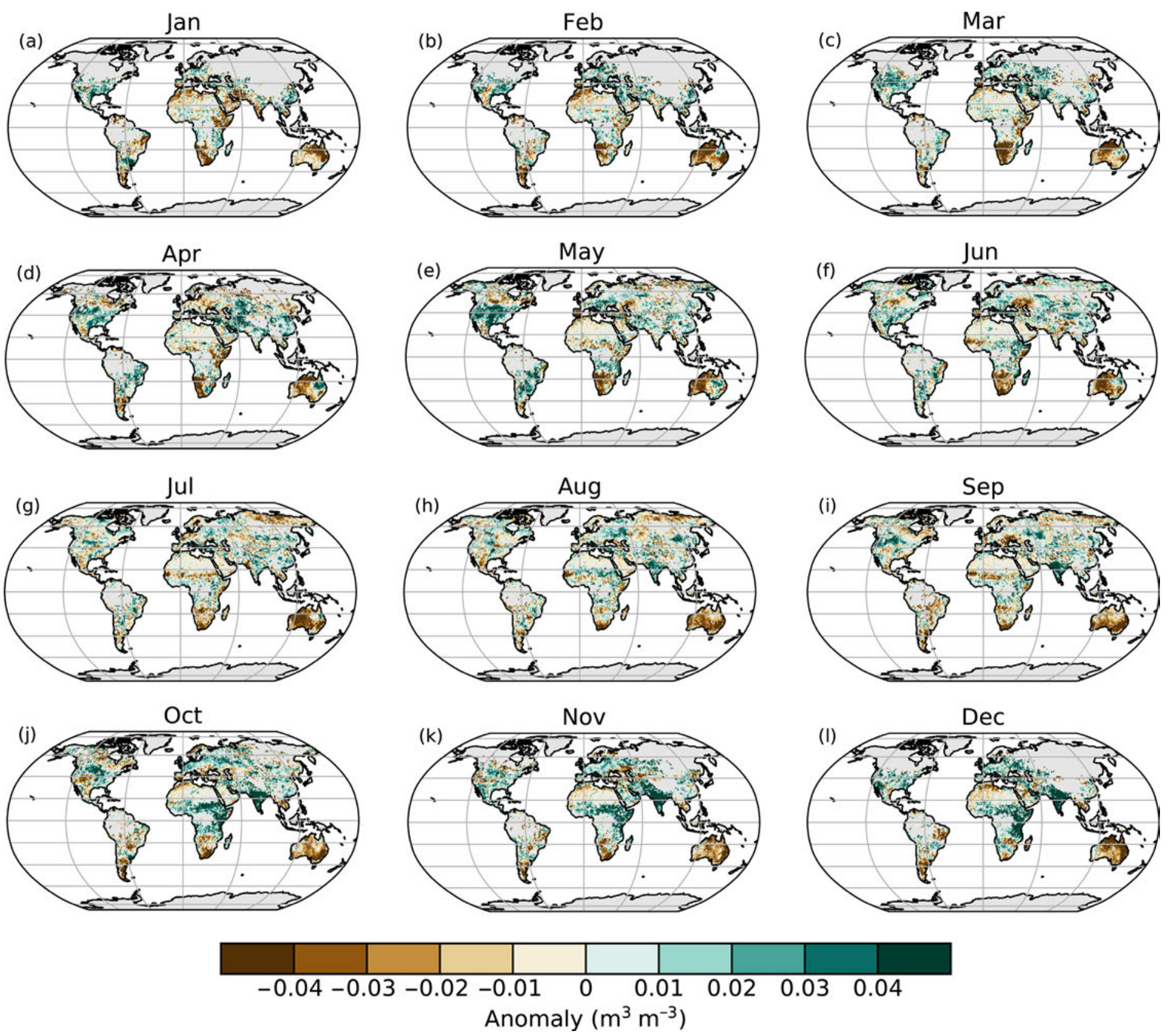

Fig. A2.16. Monthly soil moisture anomalies for 2019 (base period: 1991-2010). Data were masked as missing where retrievals are either not possible or of very low quality (dense forests, frozen soil, snow, ice, etc.). (Source: ESA CCI Soil Moisture.) 


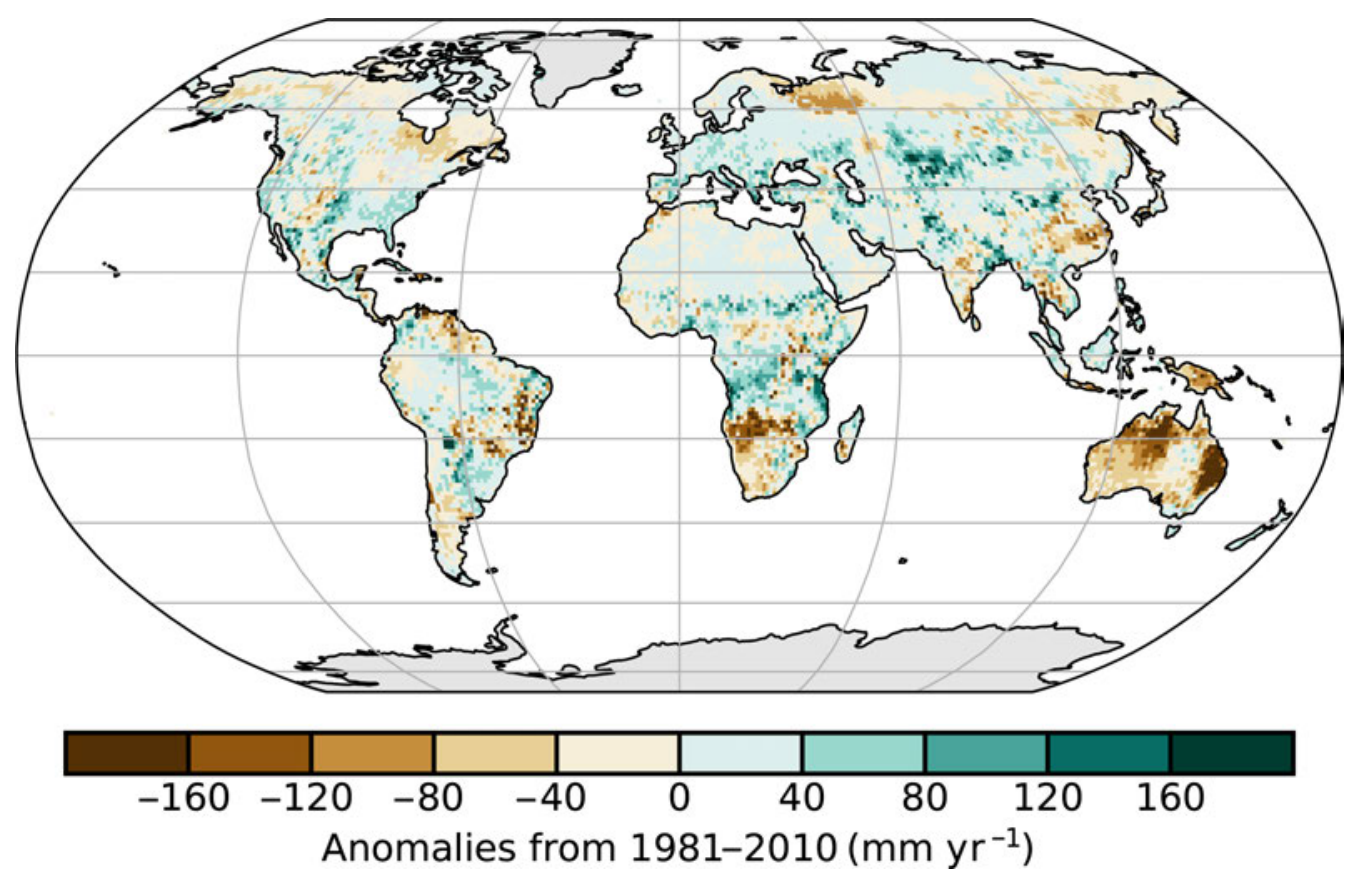

Fig A2.17. Plant transpiration anomalies ( $\left.\mathrm{mm} \mathrm{yr}^{-1}\right)$. (Source: GLEAM.) 


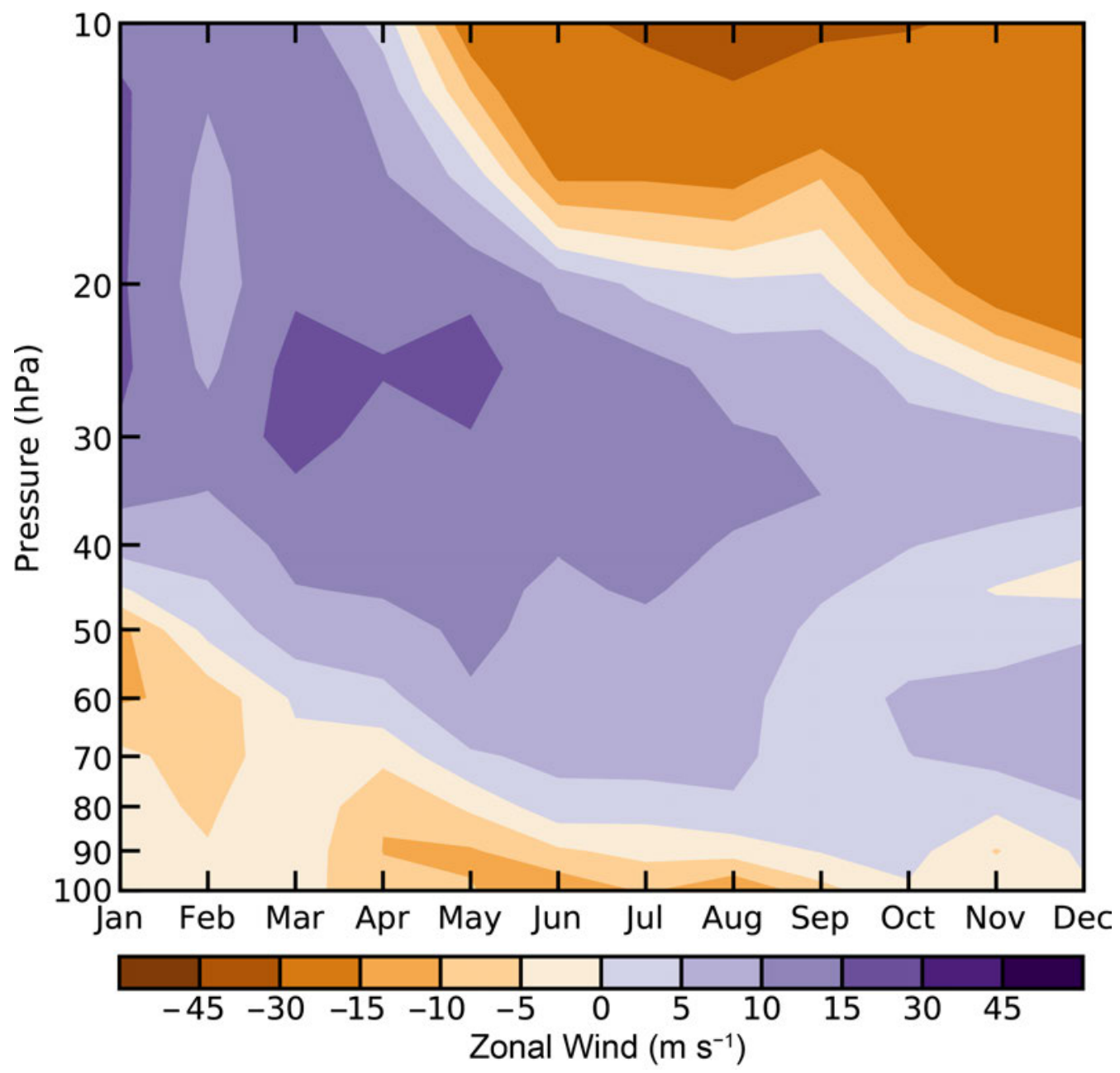

Fig. A2.18. Stratospheric monthly mean zonal winds over Singapore in 2019. Purple depicts westerly, brown easterly wind. 
Adler, R., and Coauthors, 2018: The Global Precipitation Climatology Project (GPCP) monthly analysis (new version 2.3) and a review of 2017 global precipitation. Atmosphere, 9, 138, https://doi.org/10.3390/atmos9040138.

Adrian, R., and T. Hintze, 2000: Effects of winter air temperature on the ice phenology of the Müggelsee (Berlin, Germany). SIL Proc., 27, 2808-2811, https://doi.org/10.1080/03680770.1998.11898178.

Allan, R. J., and R. D. D'Arrigo, 1999: 'Persistent' ENSO sequences: How unusual was the 1990-1995 El Niño? Holocene, 9, 101-118, https://doi. org/10.1191/095968399669125102.

— ded mean sea level pressure dataset (HadSLP2): 1850-2004. J. Climate, 19, 5816-5842, https://doi.org/10.1175/JCLI3937.1.

— , J. A. Lindesay, and D. E. Parker, 1996: El Niño Southern Oscillation and Climatic Variability. CSIRO Publishing, 405 pp.

— J. Gergis, and R. D. D'Arrigo, 2019: Placing the 2014-2016 'protracted' El Niño episode into a long-term context. Holocene, 30, 90-105, https://doi. org/10.1177/0959683619875788.

Allan, R. P., K. P. Shine, A. Slingo, and J. A. Pamment, 1999: The dependence of clear-sky outgoing longwave radiation on surface temperature and relative humidity. Quart. J. Roy. Meteor. Soc., 125, 2103-2126, https://doi.org/ 10.1002/qj.49712555809.

Anabalón, A., and A. Sharma, 2017: On the divergence of potential and actual evapotranspiration trends: An assessment across alternate global datasets. Earth's Future, 5, 905-917, https://doi.org/10.1002/2016EF000499.

Andela, N., and Coauthors, 2017: A human-driven decline in global burned area. Science, 356, 1356-1362, https://doi.org/10.1126/science.aal4108.

Andersson, S. M., B. G. Martinsson, J.-P. Vernier, J. Friberg, C. A. M. Brenninkmeijer, M. Hermann, P. F. J. van Velthoven, and A. Zahn, 2015: Significant radiative impact of volcanic aerosol in the lowermost stratosphere. Nat. Commun., 6, 7692, https://doi.org/10.1038/ncomms8692.

Aquila, V., L. D. Oman, R. Stolarski, A. R. Douglass, and P. A. Newman, 2013: The response of ozone and nitrogen dioxide to the eruption of Mt. Pinatubo at southern and northern midlatitudes. J. Atmos. Sci., 70, 894-900, https:// doi.org/10.1175/JAS-D-12-0143.1.

Arguez, A., S. Hurley, A. Inamdar, L. Mahoney, A. Sanchez-Lugo, and L. Yang, 2020: Should we expect each year in the next decade (2019-2028) to be ranked among the top 10 warmest years globally? Bull. Amer. Meteor. Soc., 101, E655-E663, https://doi.org/10.1175/BAMS-D-19-0215.1.

Arosio, C., A. Rozanov, E. Malinina, M. Weber, and J. P. Burrows, 2019: Merging of ozone profiles from SCIAMACHY, OMPS and SAGE II observations to study stratospheric ozone changes. Atmos. Meas. Tech., 12, 2423-2444, https://doi.org/10.5194/amt-12-2423-2019.

Arp, C. D., B. M. Jones, and G. Gross, 2013: Recent lake ice-out phenology within and among lake districts of Alaska, U.S.A. Limnol. Oceanogr., 58, 2013-2028, https://doi.org/10.4319/lo.2013.58.6.2013.

Ashok, K., Z. Guan, and T. Yamagata, 2003: Influence of the Indian Ocean Dipole on the Australian winter rainfall. Geophys. Res. Lett., 30, 1821, https:// doi.org/10.1029/2003gl017926.

Azorin-Molina, C., J. A. Guijarro-Pastor, T. R. McVicar, S. M. Vicente-Serrano, D. Chen, S. Jerez, and F. Espirito-Santo, 2016: Trends of daily peak wind gusts in Spain and Portugal, 1961-2014. J. Geophys. Res. Atmos., 121, 1059-1078, https://doi.org/10.1002/2015jd024485.

— S. Rehman, J. A. Guijarro, T. R. McVicar, L. Minola, D. Chen, and S. M. Vicente-Serrano, 2018a: Recent trends in wind speed across Saudi Arabia, 1978-2013: A break in the stilling. Int. J. Climatol., 38, e966-e984, https:// doi.org/10.1002/joc.5423.

_ , J. Asin, T. R. McVicar, L. Minola, J. I. Lopez-Moreno, S. M. Vicente-Serrano, and D. Chen, 2018b: Evaluating anemometer drift: A statistical approach to correct biases in wind speed measurement. Atmos. Res., 203, 175-188, https://doi.org/10.1016/j.atmosres.2017.12.010.
— R. J. H. Dunn, C. A. Mears, P. Berrisford, T. R. McVicar, and J. P. Nicolas, 2019: Surface winds [in "State of the Climate in 2018"]. Bull. Amer. Meteor. Soc., 100 (9), S43-S45, https://doi.org/10.1175/2019BAMSStateoftheClim ate.1.

Ball, W. T., and Coauthors, 2018: Evidence for a continuous decline in lower stratospheric ozone offsetting ozone layer recovery. Atmos. Chem. Phys., 18, 1379-1394, https://doi.org/10.5194/acp-18-1379-2018.

Balsamo, G., R. Salgado, E. Dutra, S. Boussetta, T. Stockdale, and M. Potes, 2012: On the contribution of lakes in predicting near-surface temperature in a global weather forecasting model. Tellus, 64A, 15829, https://doi. org/10.3402/tellusa.v64i0.15829.

Bândă, N., M. Krol, M. van Weele, T. van Noije, and T. Röckmann, 2013: Analysis of global methane changes after the 1991 Pinatubo volcanic eruption. Atmos. Chem. Phys., 13, 2267-2281, https://doi.org/10.5194/acp-13-22672013.

Banzon, V., T. M. Smith, T. M. Chin, C. Liu, and W. Hankins, 2016: A long-term record of blended satellite and in situ sea-surface temperature for climate monitoring, modeling and environmental studies. Earth Syst. Sci. Data, 8, 165-176, https://doi.org/10.5194/essd-8-165-2016.

— — - M. Steele, B. Huang, and H. M. Zhang, 2020: Improved estimation of proxy sea surface temperature in the Arctic. J. Atmos. Oceanic Technol., 37, 341-349, https://doi.org/10.1175/JTECH-D-19-0177.1.

Barichivich, J., T. J. Osborn, I. Harris, G. van der Schrier, and P. D. Jones, 2019: Drought [in "State of the Climate in 2018"]. Bull. Amer. Meteor. Soc., 100 (9), S39-S40, https://doi.org/10.1175/2019BAMSStateoftheClimate.1.

Barnes, E. A., A. M. Fiore, and L. W. Horowitz, 2016: Detection of trends in surface ozone in the presence of climate variability. J. Geophys. Res. Atmos., 121, 6112-6129, https://doi.org/10.1002/2015jd024397.

Barnes, J. E., and D. J. Hofmann, 1997: Lidar measurements of stratospheric aerosol over Mauna Loa Observatory. Geophys. Res. Lett., 24, 1923-1926, https://doi.org/10.1029/97GL01943.Becker, A., P. Finger, A. Meyer-Christoffer, B. Rudolf, K. Schamm, U. Schneider, and M. Ziese, 2013: A description of the global land-surface precipitation data products of the Global Precipitation Climatology Centre with sample applications including centennial (trend) analysis from 1901-present. Earth Syst. Sci. Data, 5, 71-99, https:// doi.org/10.5194/essd-5-71-2013.

Bellouin, N., and Coauthors, 2020: Radiative forcing of climate change from the Copernicus reanalysis of atmospheric composition. Earth Syst. Sci. Data Discuss., https://doi.org/10.5194/essd-2019-251.

Benson, B., J. Magnuson, and S. Sharma, 2000: Global lake and river ice phenology database, version 1. National Snow and Ice Data Center, accessed 20 January 2020, https://doi.org/10.7265/N5W66HP8.

Berry, D. I., and E. C. Kent, 2009: A new air-sea interaction gridded dataset from ICOADS with uncertainty estimates. Bull. Amer. Meteor. Soc., 90, 645-656, https://doi.org/10.1175/2008BAMS2639.1.

$\longrightarrow$, and — 2011: Air-sea fluxes from ICOADS: The construction of a new gridded dataset with uncertainty estimates. Int. J. Climatol., 31, 987-1001, https://doi.org/10.1002/joc.2059.

Betts, R. A., C. D. Jones, J. R. Knight, R. F. Keeling, and J. J. Kennedy, 2016: El Niño and a record CO2 rise. Nat. Climate Change, 6, 806-810, https://doi. org/10.1038/nclimate3063.

Beusen, A. H. W., A. F. Bouwman, L. P. H. Van Beek, J. M. Mogollón, and J. J. Middelburg, 2016: Global riverine $N$ and $P$ transport to ocean increased during the 20th century despite increased retention along the aquatic continuum. Biogeosciences, 13, 2441-2451, https://doi.org/10.5194/bg-132441-2016.

Biskaborn, B. K., and Coauthors, 2019: Permafrost is warming at a global scale. Nat. Commun., 10, 264, https://doi.org/10.1038/s41467-018-08240-4.

Bock, 0., 2019: Global GNSS IWV data at 436 stations over the 1994-2018 period. AERIS, accessed 7 July 2020, https://doi.org/10.25326/18. 
- and A. C. Parracho, 2019: Consistency and representativeness of integrated water vapour from ground-based GPS observations and ERA-Interim reanalysis. Atmos. Chem. Phys., 19, 9453-9468, https://doi.org/10.5194/ acp-19-9453-2019.

Bodhaine, B. A., B. G. Mendonca, J. M. Harris, and J. M. Miller, 1981: Seasonal variations in aerosols and atmospheric transmission at Mauna Loa Observatory. J. Geophys. Res., 86, 7395-7398, https://doi.org/10.1029/ JC086iC08p07395.

BoM, 2020: Climate monitoring graphs. Australian Bureau of Meteorology. www.bom.gov.au/climate/enso/indices.shtml?bookmark=iod.

Brohan, P., J. J. Kennedy, I. Harris, S. F. Tett, and P. D. Jones, 2006: Uncertainty estimates in regional and global observed temperature changes: A new data set from 1850. J. Geophys. Res., 111, D12106, https://doi. org/10.1029/2005JD006548.

Brown, L. C., and C. R. Duguay, 2010: The response and role of ice cover in lake-climate interactions. Prog. Phys. Geogr., 34, 671-704, https://doi. org/10.1177/0309133310375653.

Brutsaert, W., 2017: Global land surface evaporation trend during the past half century: Corroboration by Clausius-Clapeyron scaling. Adv. Water Resour., 106, 3-5, https://doi.org/10.1016/j.advwatres.2016.08.014.

Buchard, V., A. M. da Silva, C. A. Randles, C. Colarco, R. Ferrare, J. Hair, C. Hostetler, J. Tackett, and D. Winker: Evaluation of the surface PM2.5 in version 1 of the NASA MERRA aerosol reanalysis over the United States. Atmos. Environ., 125, 100-111, https://doi.org/10.1016/j.atmosenv.2015.11.004.

Capotondi, A., and Coauthors, 2015: Understanding ENSO diversity. Bull. Amer. Meteor. Soc., 96, 921-938, https://doi.org/10.1175/BAMS-D-13-00117.1.

Carpenter, L. J., and J. S. Daniel, 2018: Scenarios and information for policy makers. Scientific Assessment of Ozone Depletion: 2018, Global Ozone Research and Monitoring Project Rep. 58, 6.1-6.69, https://ozone.unep.org/ sites/default/files/2019-05/SAP-2018-Assessment-report.pdf.

Carrea, L., O. Embury, and C. J. Merchant, 2015: Datasets related to in-land water for limnology and remote sensing applications: Distance-to-land, distance-to-water, water-body identifier and lake-centre co-ordinates. Geosci. Data J., 2, 83-97, https://doi.org/10.1002/gdj3.32.

— in 2018"]. Bull. Amer. Meteor. Soc., 100 (9), S13-S14, https://doi.org/10.117 5/2019BAMSStateoftheClimate.1.

Chandra, S., J. R. Ziemke, W. Min, and W. G. Read, 1998: Effects of 1997-1998 El Niño on tropospheric ozone and water vapor. Geophys. Res. Lett., 25, 3867-3870, https://doi.org/10.1029/98GL02695.

—_ - B. N. Duncan, T. L. Diehl, N. Livesey, and L. Froidevaux, 2009: Effects of the $2006 \mathrm{El}$ Niño on tropospheric ozone and carbon monoxide: Implications for dynamics and biomass burning. Atmos. Chem. Phys., 9, 4239-4249, https://doi.org/10.5194/acp-9-4239-2009.

Charlton, A. J., and L. M. Polvani, 2007: A new look at stratospheric sudden warmings. Part I. Climatology and modeling benchmarks. J. Climate, 20, 449-469, https://doi.org/10.1175/JCLI3996.1.

Chen, C., and Coauthors, 2019: China and India lead in greening of the world through land-use management. Nat. Sustain., 2, 122-129, https://doi. org/10.1038/s41893-019-0220-7.

Chen, Z., P. K. Bhartia, R. Loughman, P. Colarco, and M. DeLand, 2018: Improvement of stratospheric aerosol extinction retrieval from OMPS/LP using a new aerosol model. Atmos. Meas. Tech., 11, 6495-6509, https://doi. org/10.5194/amt-11-6495-2018.

Cheng, G., and Coauthors, 2019: Characteristic, changes and impacts of permafrost on Qinghai-Tibet Plateau. Chin. Sci. Bull., 64, 2783-2795, https://doi. org/10.1360/TB-2019-0191.

Cheng, L., and Coauthors, 2017: Recent increases in terrestrial carbon uptake at little cost to the water cycle. Nat. Commun., 8, 110, https://doi.org/10.1038/ s41467-017-00114-5.

Chipperfield, M. P., and Coauthors, 2018: On the cause of recent variations in lower stratospheric ozone. Geophys. Res. Lett., 45, 5718-5726, https://doi. org/10.1029/2018GL078071.
Chouza, F., T. Leblanc, J. Barnes, M. Brewer, P. Wang, and D. Koon, 2020: Longterm (1999-2019) variability of stratospheric aerosol over Mauna Loa, Hawaii, as seen by two co-located lidars and satellite measurements. Atmos. Chem. Phys., 20, 6821-6839, https://doi.org/10.5194/acp-20-6821-2020.

Christiansen, H. H., and Coauthors, 2010: The thermal state of permafrost in the nordic area during the international polar year 2007-2009. Permafrost Periglacial Processes, 21, 156-181, https://doi.org/10.1002/ppp.687.

Christy, J. R., 2017: Lower tropospheric temperature [in "State of the Climate in 2016"]. Bull. Amer. Meteor. Soc., 98 (8), S16-S17, https://doi.org/10.1175/2 017BAMSStateoftheClimate.1.

— a metric for climate sensitivity. Asia-Pacific J. Atmos. Sci., 53, 511-518, https://doi.org/10.1007/s13143-017-0070-z.

_ R. W. Spencer, W. D. Braswell, and R. Junod, 2018: Examination of spacebased bulk atmospheric temperatures for climate research. Int. J. Remote Sens., 39, 3580-3607, https://doi.org/10.1080/01431161.2018.1444293.

_, S. Po-Chedley, C. Mears, and L. Haimberger, 2019: Lower tropospheric temperature [in "State of the Climate in 2018"]. Bull. Amer. Meteor. Soc., 100 (8), S16-S17, https://doi.org/10.1175/2019BAMSStateoftheClimate.1.

Chung, E., B. Soden, and V. O. John, 2013: Intercalibrating microwave satellite observations for monitoring long-term variations in upper- and midtropospheric water vapor. J. Atmos. Oceanic Technol., 30, 2303-2319, https:// doi.org/10.1175/JTECH-D-13-00001.1.

—_ - X. Huang, L. Shi, and V. O. John, 2016: An assessment of the consistency between satellite measurements of upper tropospheric water vapor. J. Geophys. Res. Atmos., 121, 2874-2887, https://doi. org/10.1002/2015jd024496.

Cohen, Y., and Coauthors, 2018: Climatology and long-term evolution of ozone and carbon monoxide in the UTLS at northern mid-latitudes, as seen by IAGOS from 1995 to 2013. Atmos. Chem. Phys., 18, 5415-5453, https://doi. org/10.5194/acp-18-5415-2018.

Coldewey-Egbers, M., and Coauthors, 2015: The GOME-type Total Ozone Essential Climate Variable (GTO-ECV) data record from the ESA climate change initiative. Atmos. Meas. Tech., 8, 3923-3940, https://doi.org/10.5194/amt8-3923-2015.

Cooper, O. R., and Coauthors, 2014: Global distribution and trends of tropospheric ozone: An observation-based review. Elem. Sci. Anthropocene, 2, 29, http://doi.org/10.12952/journal.elementa.000029.

Crétaux, J.-F., R. Abarca-del-Río, M. Bergé-Nguyen, A. Arsen, V. Drolon, G. Clos, and P. Maisongrande, 2016: Lake volume monitoring from space. Surv. Geophys., 37, 269-305, https://doi.org/10.1007/s10712-016-9362-6.

Dankers, R., and Coauthors, 2014: First look at changes in flood hazard in the Inter-Sectoral Impact Model Intercomparison Project ensemble. Proc. Natl. Acad. Sci. USA, 111, 3257-3261, https://doi.org/10.1073/pnas.1302078110.

Davidson, E. A., 2009: The contribution of manure and fertilizer nitrogen to atmospheric nitrous oxide since 1860. Nat. Geosci., 2, 659-662, https://doi. org/10.1038/ngeo608.

Dee, D. P., and Coauthors, 2011: The ERA-Interim reanalysis: Configuration and performance of the data assimilation system. Quart. J. Roy. Meteor. Soc., 137, 553-597, https://doi.org/10.1002/qj.828.

Deeter, M. N., and Coauthors, 2014: The MOPITT Version 6 product: Algorithm enhancements and validation. Atmos. Meas. Tech., 7, 3623-3632, https:// doi.org/10.5194/amt-7-3623-2014.

Demarée, G., and T. Rutishauser, 2011: From "Periodical Observations" to "Anthochronology" and "Phenology" - The scientific debate between Adolphe Quetelet and Charles Morren on the origin of the word "Phenology". Int. J. Biometeor., 55, 753-761, https://doi.org/10.1007/s00484-011-0442-5.

Dessler, A. E., M. R. Schoeberl, T. Wang, S. M. Davis, K. H. Rosenlof, and J. P. Vernier, 2014: Variations of stratospheric water vapor over the past three decades. J. Geophys. Res. Atmos., 119, 12588-12598, https://doi. org/10.1002/2014JD021712. 
Dewitte, S., D. Crommelynck, and A. Joukof, 2004: Total solar irradiance observations from DIARAD/VIRGO. J. Geophys. Res., 109, A02102, https://doi. org/10.1029/2002JA009694.

Dhomse, S. S., and Coauthors, 2018: Estimates of ozone return dates from Chemistry-Climate Model Initiative simulations. Atmos. Chem. Phys., 18, 8409-8438, https://doi.org/10.5194/acp-18-8409-2018.

Diallo, M., and Coauthors, 2018: Response of stratospheric water vapor and ozone to the unusual timing of El Niño and the QBO disruption in 20152016. Atmos. Chem. Phys., 18, 13055-13073, https://doi.org/10.5194/acp18-13055-2018.

Di Girolamo, L., A. Menzies, G. Zhao, K. Mueller, C. Moroney, and D. J. Diner, 2010: MISR level 3 cloud fraction by altitude algorithm theoretical basis document. Jet Propulsion Laboratory Rep. JPL D-62358, 24 pp., https:// pdfs.semanticscholar.org/afa4/b593c759d1ef451e9dc194028cd581f367b5. pdf.

Dlugokencky, E. J., L. P. Steele, P. M. Lang, and K. A. Masarie, 1994: The growth rate and distribution of atmospheric methane. J. Geophys. Res., 99, $17021-$ 17 043, https://doi.org/10.1029/94JD01245.

—, K. A. Masarie, P. M. Lang, and P. P. Tans, 1998: Continuing decline in the growth rate of the atmospheric methane burden. Nature, 393, 447-450, https://doi.org/10.1038/30934.

_ - E. G. Nisbet, R. Fisher, and D. Lowry, 2011: Global atmospheric methane: Budget, changes and dangers. Philos. Trans. Roy. Soc., 369A, 2058-2072, https://doi.org/10.1098/rsta.2010.0341.

Dolman, A. J., D. G. Miralles, and R. A. M. De Jeu, 2014: Fifty years since Monteith's 1965 seminal paper: The emergence of global ecohydrology. Ecohydrology, 7, 897-902, https://doi.org/10.1002/eco.1505.

Donat, M., L. Alexander, H. Yang, I. Durre, R. Vose, and J. Caesar, 2013: Global land-based datasets for monitoring climatic extremes. Bull. Amer. Meteor. Soc., 94, 997-1006, https://doi.org/10.1175/BAMS-D-12-00109.1.Dorigo, W. A., and Coauthors, 2017: ESA CCI Soil Moisture for improved Earth system understanding: State-of-the art and future directions. Remote Sens. Environ., 203, 185-215, https://doi.org/10.1016/j.rse.2017.07.001.

— , and Coauthors, 2018: Soil moisture [in "State of the Climate in 2017"]. Bull. Amer. Meteor. Soc., 99 (8), S150-S152, https://doi.org/10.1175/2018B AMSStateoftheClimate.1.

_ Bull. Amer. Meteor. Soc., 98 (8), S30-S32, https://doi.org/10.1175/2017BA MSStateoftheClimate.1.

Dunn, R. J. H., 2019: HadISD version 3: Monthly updates. Hadley Centre Tech. Note 103, 10 pp., www.metoffice.gov.uk/research/library-and-archive/publications/science/climate-science-technical-notes.

— , K. M. Willett, D. E. Parker, and L. Mitchell, 2016: Expanding HadISD: Quality-controlled, sub-daily station data from 1931. Geosci. Instrum. Methods Data Syst., 5, 473-491, https://doi.org/10.5194/gi-5-473-2016.

— based dataset of temperature and precipitation extremes: HadEX3. J. Geophys. Res. Atmos., https://doi.org/10.1029/2019JD032263, in press.

Dussaillant, I., and Coauthors, 2019: Two decades of glacier mass loss along the Andes. Nat. Geosci., 12, 802-808, https://doi.org/10.1038/s41561-0190432-5.

Dutra, E., and Coauthors, 2010: An offline study of the impact of lakes on the performance of the ECMWF surface scheme. Boreal Environ. Res., 15, $100-112$.

Dutton, E. G., 1992: A coherence between the QBO and the amplitude of the Mauna Loa atmospheric transmission annual cycle. Int. J. Climatol., 12, 383-396, https://doi.org/10.1002/joc.3370120406.

_ sky transmission variations above Mauna Loa: 1958-1999. J. Climate, 14, 3255-3262, https://doi.org/10.1175/1520-0442(2001)014<3255:siacbc >2. $0 . c 0 ; 2$.
_ J. J. Deluisi, and A. P. Austring, 1985: Interpretation of Mauna Loa atmospheric transmission relative to aerosols, using photometric precipitable water amounts. J. Atmos. Chem., 3, 53-68, https://doi.org/10.1007/ BF00049368.

Ebita, A., and Coauthors, 2011: The Japanese 55-year reanalysis "JRA-55": An interim report. SOLA, 7, 149-152, https://doi.org/10.2151/sola.2011-038.

ECMWF, 2018: Part IV: Physical processes. IFS Documentation CY45R1, ECMWF, 223 pp., www.ecmwf.int/node/18714.

Ellis, H. T., and R. F. Pueschel, 1971: Solar radiation: Absence of air pollution trends at Mauna Loa. Science, 172, 845-846, https://doi.org/10.1126/science.172.3985.845.

Engel, A., and M. Rigby, 2018: Update on ozone-depleting substances (ODSs) and other gases of interest to the Montreal protocol. Scientific Assessment of Ozone Depletion: 2018, Global Ozone Research and Monitoring Project Rep. 58, 1.1-1.66, https://ozone.unep.org/sites/default/files/2019-05/SAP2018-Assessment-report.pdf.

Etheridge, D. M., L. P. Steele, R. L. Langenfelds, R. J. Francey, J. M. Barnola, and V. I. Morgan, 1996: Natural and anthropogenic changes in atmospheric CO2 over the last 1000 years from air in Antarctic ice and firn. J. Geophys. Res., 101, 4115-4128, https://doi.org/10.1029/95JD03410.

Eyring, V., and Coauthors, 2013: Long-term ozone changes and associated climate impacts in CMIP5 simulations. J. Geophys. Res. Atmos., 118, 50295060, https://doi.org/10.1002/jgrd.50316.

Fioletov, V. E., G. E. Bodeker, A. J. Miller, R. D. McPeters, and R. Stolarski, 2002: Global and zonal total ozone variations estimated from ground-based and satellite measurements: 1964-2000. J. Geophys. Res., 107, 4647, https:// doi.org/10.1029/2001JD001350.

— network assessed using satellite data. J. Geophys. Res., 113, D14313, https://doi.org/10.1029/2008JD009809.

Fisher, J. B., and Coauthors, 2017: The future of evapotranspiration: Global requirements for ecosystem functioning, carbon and climate feedbacks, agricultural management, and water resources. Water Resour. Res., 53, 2618-2626, https://doi.org/10.1002/2016WR020175.

Flemming, J., and A. Inness, 2018: Carbon monoxide [in "State of the Climate in 2018"]. Bull. Amer. Meteor. Soc., 100 (9), S181-S185, https://doi.org/10. 1175/2019BAMSStateoftheClimate.1.

_ ozone and aerosol for 2003-2015. Atmos. Chem. Phys., 17, 1945-1983, https://doi.org/10.5194/acp-17-1945-2017.

Fleming, Z. L., and Coauthors, 2018: Tropospheric ozone assessment report: Present-day ozone distribution and trends relevant to human health. Elem. Sci. Anthropocene, 6, 12, https://doi.org/10.1525/elementa.273.

Floodlist, 2019: Afghanistan-More flash floods leave 24 dead, houses destroyed. Floodlist, accessed 11 February 2020, http://floodlist.com/asia/ afghanistan-flash-floods-may-2019.

Foster, G., and S. Rahmstorf, 2011: Global temperature evolution 19792010. Environ. Res. Lett., 6, 044022, https://doi.org/10.1088/17489326/6/4/044022.

Franco, B., and Coauthors, 2016: Evaluating ethane and methane emissions associated with the development of oil and natural gas extraction in North America. Environ. Res. Lett., 11, 044010. https://doi.org/10.1088/17489326/11/4/044010.

Freychet, N., S. F. B. Tett, Z. Yan, and Z. Li, 2020: Underestimated change of wet-bulb temperatures over East and South China. Geophys. Res. Lett., 47, e2019GL086140, https://doi.org/10.1029/2019GL086140.

Friedlingstein, P., and Coauthors, 2019: Global carbon budget 2019. Earth Syst. Sci. Data, 11, 1783-1838, https://doi.org/10.5194/essd-11-1783-2019.

Frith, S. M., N. A. Kramarova, R. S. Stolarski, R. D. McPeters, P. K. Bhartia, and G. J. Labow, 2014: Recent changes in total column ozone based on the SBUV Version 8.6 Merged Ozone Data Set. J. Geophys. Res. Atmos., 119, 9735-9751, https://doi.org/10.1002/2014jd021889. 
- R. S. Stolarski, N. A. Kramarova, and R. D. McPeters, 2017: Estimating uncertainties in the SBUV Version 8.6 merged profile ozone data set. Atmos. Chem. Phys., 17, 14695-14707, https://doi.org/10.5194/acp-17-146952017.

Garane, K., and Coauthors, 2018: Quality assessment of the Ozone_cci Climate Research Data Package (release 2017): 1. Ground-based validation of total ozone column data products. Atmos. Meas. Tech., 11, 1385-1402, https:// doi.org/10.5194/amt-11-1385-2018.

Garfinkel, C. I., A. Gordon, L. D. Oman, F. Li, S. Davis, and S. Pawson, 2018: Nonlinear response of tropical lower-stratospheric temperature and water vapor to ENSO. Atmos. Chem. Phys., 18, 4597-4615, https://doi.org/10.5194/acp18-4597-2018

Garreaud, R. D., and Coauthors, 2017: The 2010-2015 megadrought in central Chile: Impacts on regional hydroclimate and vegetation. Hydrol. Earth Syst. Sci., 21, 6307-6327, https://doi.org/10.5194/hess-21-6307-2017.

Gaubert, B., and Coauthors, 2017: Chemical feedback from decreasing carbon monoxide emissions. Geophys. Res. Lett., 44, 9985-9995, https://doi. org/10.1002/2017GL074987.

Gaudel, A., and Coauthors, 2018: Tropospheric ozone assessment report: Present-day distribution and trends of tropospheric ozone relevant to climate and global atmospheric chemistry model evaluation. Elem. Sci. Anthropocene, 6, 39, http://doi.org/10.1525/elementa.291.

GCOS, 2016: The global observing system for climate: Implementation needs. Tech. Rep. GCOS-200, 341 pp., https://library.wmo.int/doc_num. php?explnum_id $=3417$.

Gelaro, R., and Coauthors, 2017: The Modern-Era Retrospective Analysis for Research and Applications, version 2 (MERRA-2). J. Climate, 30, 5419-5454, https://doi.org/10.1175/JCLI-D-16-0758.1.

Gleason, K. L., J. H. Lawrimore, D. H. Levinson, T. R. Karl, and D. J. Karoly, 2008: A revised U.S. climate extremes index. J. Climate, 21, 2124-2137, https:// doi.org/10.1175/2007JCLI1883.1.

Gobron, N., 2018: Terrestrial vegetation activity [in "State of the Climate in 2017"]. Bull. Amer. Meteor. Soc., 99 (8), S62-S63, https://doi.org/10.1175/2 018BAMSStateoftheClimate.1.

Gobron, N., 2019: Terrestrial vegetation activity [in "State of the Climate in 2018"]. Bull. Amer. Meteor. Soc., 100 (9), S63-S64, https://doi.org/10.1175 /2019BAMSStateoftheClimate.1

- , and M. Robustelli, 2013: Monitoring the state of the global terrestrial surfaces. Proc. 2013 ESA Living Planet Symp., Edinburgh, United Kingdom, ESA, http://seom.esa.int//ps13/abstracts/850030.html.

- A. S. Belward, B. Pinty, and W. Knorr, 2010: Monitoring biosphere vegetation 1998-2009. Geophys. Res. Lett., 37, L15402, https://doi. org/10.1029/2010gl043870.

Gruber, A., T. Scanlon, R. van der Schalie, W. Wagner, and W. Dorigo, 2019: Evolution of the ESA CCI Soil Moisture climate data records and their underlying merging methodology. Earth Syst. Sci. Data, 11, 717-739, https://doi. org/10.5194/essd-11-717-2019.

Guo, S., G. J. S. Bluth, W. I. Rose, I. M. Watson, and A. J. Prata, 2004: Re-evaluation of SO2 release of the 15 June 1991 Pinatubo eruption using ultraviolet and infrared satellite sensors. Geochem. Geophys. Geosyst., 5, Q04001, https://doi.org/10.1029/2003GC000654.

Haimberger, L., C. Tavolato, and S. Sperka, 2012: Homogenization of the Global Radiosonde Temperature dataset through combined comparison with reanalysis background series and neighboring stations. J. Climate, 25, 81088131, https://doi.org/10.1175/JCLI-D-11-00668.1.

Hall, B. D., S. A. Montzka, G. Dutton, B. R. Miller, and J. W. Elkins, 2019: Ozonedepleting substances [in "State of the Climate in 2018"]. Bull. Amer. Meteor. Soc., 100 (9), S50-S52, https://doi.org/10.1175/2019BAMSStateofthe Climate.1.

Hansen, J., R. Ruedy, M. Sato, and K. Lo, 2010: Global surface temperature change. Rev. Geophys., 48, RG4004, https://doi.org/10.1029/2010RG000345.
Harris, I., T. J. Osborn, P. D. Jones, and D. H. Lister, 2020: Version 4 of the CRU TS monthly high-resolution gridded multivariate climate dataset. Sci. Data, 7, 109, https://doi.org/10.1038/s41597-020-0453-3.

Hartmann, D. L., and Coauthors, 2013: Observations: Atmosphere and surface. Climate Change 2013: The Physical Science Basis, T. F. Stocker et al., Eds., Cambridge University Press, 159-254.

Hausmann, P., R. Sussmann, and D. Smale, 2016: Contribution of oil and natural gas production to renewed increase in atmospheric methane (2007-2014): Top-down estimate from ethane and methane column observations. Atmos. Chem. Phys., 16, 3227-3244, https://doi.org/10.5194/acp-16-3227-2016.

Heidinger, A. K., M. J. Foster, A. Walther, and X. Zhao, 2013: The pathfinder atmospheres-extended AVHRR climate dataset. Bull. Amer. Meteor. Soc., 95, 909-922, https://doi.org/10.1175/BAMS-D-12-00246.1.

Held, I. M., and B. J. Soden, 2000: Water vapor feedback and global warming. Annu. Rev. Energy Environ., 25, 441-475, https://doi.org/10.1146/annurev. energy.25.1.441.

Helmig, D., and Coauthors, 2016: Reversal of global atmospheric ethane and propane trends largely due to US oil and natural gas production. Nat. Geosci., 9, 490-495, https://doi.org/10.1038/ngeo2721.

Hersbach, H., and Coauthors, 2020: The ERA5 global reanalysis. Quart. J. Roy. Meteor. Soc., https://doi.org/10.1002/qj.3803, accepted.

Hirabayashi, Y., R. Maendran, S. Koirala, L. Konoshima, D. Yamazaki, S. Watanabe, H. Kim, and S. Kanae, 2013: Global flood risk under climate change. Nat. Climate Change, 3, 816-821, https://doi.org/10.1038/nclimate1911.

Ho, S.-P., Y.-H. Kuo, W. Schreiner, and X. Zhou, 2010a: Using SI-traceable global positioning system radio occultation measurements for climate monitoring [In "States of the Climate in 2009]. Bull. Amer. Meteor. Soc., 91 (7), S36S37.

— X. Zhou, Y.-H. Kuo, D. Hunt, and J.-H. Wang, 2010b: Global evaluation of radiosonde water vapor systematic biases using GPS radio occultation from COSMIC and ECMWF analysis. Remote Sens., 2, 1320-1330, https:// doi.org/10.3390/rs2051320.

- and Coauthors, 2020: The COSMIC/FORMOSAT-3 radio occultation mission after 12 years: Accomplishments, remaining challenges, and potential impacts of COSMIC-2. Bull. Amer. Meteor. Soc., 101, E1107-E1136, https:// doi.org/10.1175/BAMS-D-18-0290.1.

Hobday, A. J., and Coauthors, 2016: A hierarchical approach to defining marine heatwaves. Prog. Oceanogr., 141, 227-238, https://doi.org/10.1016/j. pocean.2015.12.014.

Oceanography, 31, 162-173, https://doi.org/10.5670/oceanog.2018.205.

Hock, R., and Coauthors, 2020: High mountain areas. IPCC Special Report on the Ocean and Cryosphere in a Changing Climate, H.-0. Pörtner et al., Eds., IPCC, in press.

Hofmann, D., J. Barnes, M. O'Neill, M. Trudeau, and R. Neely, 2009: Increase in background stratospheric aerosol observed with lidar at Mauna Loa Observatory and Boulder, Colorado. Geophys. Res. Lett., 36, L15808, https://doi. org/10.1029/2009GL039008.

— istry following the eruption of El Chichon. J. Geophys. Res., 94, 5029-5041, https://doi.org/10.1029/JD094iD04p05029.

_ J. H. Butler, E. J. Dlugokencky, J. W. Elkins, K. Masarie, S. A. Montzka, and P. Tans, 2006: The role of carbon dioxide in climate forcing from 1979 to 2004: Introduction of the annual greenhouse gas index. Tellus, 58B, 614-619, https://doi.org/10.1111/j.1600-0889.2006.00201.x.

$\mathrm{Hu}$, L., and Coauthors, 2019: Enhanced North American carbon uptake associated with El Niño. Sci. Adv., 5, eaaw0076, https://doi.org/10.1126/sciadv. aaw0076.

Huang, C.-Y., W.-H. Teng, S.-P. Ho, and Y.-H. Kuo, 2013: Global variation of COSMIC precipitable water over land: Comparisons with ground-based GPS measurements and NCEP reanalyses. Geophys. Res. Lett., 40, 5327-5331, https://doi.org/10.1002/grl.50885. 
Huntington, T. G., 2006: Evidence for intensification of the global water cycle: Review and synthesis. J. Hydrol., 319, 83-95, https://doi.org/10.1016/j.jhydrol.2005.07.003.

Hurst, D. F., and Coauthors, 2016: Recent divergences in stratospheric water vapor measurements by frost point hygrometers and the Aura Microwave Limb Sounder. Atmos. Meas. Tech., 9, 4447-4457, https://doi.org/10.5194/ amt-9-4447-2016.

Iacono, M. J., and C. Azorin-Molina, 2014: Long-term declining trends in historical wind measurements at the Blue Hill Meteorological Observatory, 1885-2013. 2014 Fall Meeting, San Francisco, CA, Amer. Geophys. Union, Abstract A23C-3241.

Inness, A., and Coauthors, 2013: The MACC reanalysis: An 8-year data set of atmospheric composition. Atmos. Chem. Phys., 13, 4073-4109, https://doi. org/10.5194/acp-13-4073-2013.

— , and Coauthors, 2019: The CAMS reanalysis of atmospheric composition. Atmos. Chem. Phys., 19, 3515-3556, https://doi.org/10.5194/acp-19-35152019.

IPCC, 2013: Climate Change 2013: The Physical Science Basis. Cambridge University Press, $1535 \mathrm{pp}$.

Isaksen, K., J. L. Sollid, P. Holmlund, and C. Harris, 2007: Recent warming of mountain permafrost in Svalbard and Scandinavia. J. Geophys. Res., 112, F02S04, https://doi.org/10.1029/2006JF000522.

Jiménez, C., B. Martens, D. M. Miralles, J. B. Fisher, H. E. Beck, and D. Fernández-Prieto, 2018: Exploring the merging of the global land evaporation WACMOS-ET products based on local tower measurements. Hydrol. Earth Syst. Sci., 22, 4513-4533, https://doi.org/10.5194/hess-22-4513-2018.

Jiménez-Muñoz, J. C., C. Mattar, J. Barichivich, A. Santamaría-Artigas, K. Takahashi, Y. Malhi, J. A. Sobrino, and G. van der Schrier, 2016: Record-breaking warming and extreme drought in the Amazon rainforest during the course of El Niño 2015-2016. Sci. Rep., 6, 33130, https://doi.org/10.1038/srep33130.

John, V. O., and B. J. Soden, 2007: Temperature and humidity biases in global climate models and their impact on climate feedbacks. Geophys. Res. Lett., 34, L18704, https://doi.org/10.1029/2007GL030429.

_ , G. Holl, R. P. Allan, S. A. Buehler, D. E. Parker, and B. J. Soden, 2011: Clear-sky biases in satellite infra-red estimates of upper tropospheric humidity and its trends. J. Geophys. Res., 116, D14108, https://doi. org/10.1029/2010JD015355.

Jones, P. D., D. H. Lister, T. J. Osborn, C. Harpham, M. Salmon, and C. P. Morice, 2012: Hemispheric and large-scale land surface air temperature variations: An extensive revision and an update to 2010. J. Geophys. Res., 117, D05127, https://doi.org/10.1029/2011JD017139.

Kaiser, J. W., and Coauthors, 2012: Biomass burning emissions estimated with a global fire assimilation system based on observed fire radiative power. Biogeosciences, 9, 527-554, https://doi.org/10.5194/bg-9-527-2012.

— - W. Xu, A. Heil, T. Nikonovas, I. Hüser, and M. J. Wooster, 2017: How to use SEVIRI fire radiative power in the Copernicus Atmosphere Monitoring Service. 2017 EUMETSAT Meteorological Satellite Conf., Rome, Italy, EUMETSAT, www.eumetsat.int/website/home/News/ConferencesandEvents/ DAT_3212307.html.

Kaplan, A., 2011: Patterns and indices of climate variability [in "State of the Climate in 2010"]. Bull. Amer. Meteor. Soc., 92 (6), S20-S25, https://doi. org/10.1175/1520-0477-92.6.S1.

Karlsson, K.-G., and Coauthors, 2017: CLARA-A2: The second edition of the CM SAF cloud and radiation data record from 34 years of global AVHRR data. Atmos. Chem. Phys., 17, 5809-5828, https://doi.org/10.5194/acp-175809-2017.

Karpechko, A. Y., and A. C. Maycock, 2018: Stratospheric ozone changes and climate. Scientific Assessment of Ozone Depletion: 2018, Global Ozone Research and Monitoring Project Rep. 58, 5.1-5.50, https://ozone.unep.org/ sites/default/files/2019-05/SAP-2018-Assessment-report.pdf.
Karplus, V. J., S. Zhang, and D. Almond, 2018: Quantifying coal power plant responses to tighter $\mathrm{SO} 2$ emissions standards in China. Proc. Natl. Acad. Sci. USA, 115, 7004-7009, https://doi.org/10.1073/pnas.1800605115.

Kennedy, J. J., and Coauthors, 2010: How do we know the world has warmed [in "State of the Climate in 2009"]? Bull. Amer. Meteor. Soc., 91 (7), S26S27, https://doi.org/10.1175/BAMS-91-7-StateoftheClimate.

_ , N. A. Rayner, R. O. Smith, M. Saunby, and D. E. Parker, 2011a: Reassessing biases and other uncertainties in sea surface temperature observations measured in situ since 1850: 1. Measurement and sampling uncertainties. J. Geophys. Res., 116, D14103, https://doi.org/10.1029/2010JD015218.

—, N. A. Rayner, R. O. Smith, M. Saunby, and D. E. Parker, 2011b: Reassessing biases and other uncertainties in sea surface temperature observations measured in situ since 1850: 2. Biases and homogenization. J. Geophys. Res., 116, D14104, https://doi.org/10.1029/2010JD015220.

Khaykin, S. M., and Coauthors, 2017: Variability and evolution of the midlatitude stratospheric aerosol budget from 22 years of ground-based lidar and satellite observations. Atmos. Chem. Phys., 17, 1829-1845, https://doi. org/10.5194/acp-17-1829-2017.

_ , S. Godin-Beekmann, A. Hauchecorne, J. Pelon, F. Ravetta, and P. Keckhut, 2018: Stratospheric smoke with unprecedentedly high backscatter observed by lidars above southern France. Geophys. Res. Lett., 45, 1639 1646, https://doi.org/10.1002/2017GL076763.

Kim, H., 2017: River discharge [in "State of the Climate in 2016"]. Bull. Amer. Meteor. Soc., 98 (8), S28-S30, https://doi.org/10.1175/2017BAMSStateoft heClimate.1.

_ 2018: River discharge and runoff [in "State of the Climate in 2017"]. Bull. Amer. Meteor. Soc., 99 (8), S33-S34, https://doi.org/10.1175/2018BAMSSt ateoftheClimate.1.

_ , 2019: River discharge and runoff [in "State of the Climate in 2018"]. Bull. Amer. Meteor. Soc., 100 (9), S35-S36, https://doi.org/10.1175/2019BAMSS tateoftheClimate.1

— variations of terrestrial water storage over global basins. Geophys. Res. Lett., 36, L17402, https://doi.org/10.1029/2009GL039006.

Kim, J., and K. Paik, 2015: Recent recovery of surface wind speed after decadal decrease: A focus on South Korea. Climate Dyn., 45, 1699-1712, https://doi. org/10.1007/s00382-015-2546-9.

King, O., A. Bhattacharya, R. Bhambri, and T. Bolch, 2019: Glacial lakes exacerbate Himalayan glacier mass loss. Sci. Rep., 9, 18145, https://doi. org/10.1038/s41598-019-53733-x.

Kjøllmoen, B., L. Andreassen, H. Elvehøy, and M. Jackson, 2019: Glaciological investigations in Norway 2018. NVE Rep. 46-2019, 84 pp., http://publikasjoner.nve.no/rapport/2019/rapport2019_46.pdf.

Klein Tank, A. M. G., and Coauthors, 2002: Daily dataset of 20th-century surface air temperature and precipitation series for the European Climate Assessment. Int. J. Climatol., 22, 1441-1453, https://doi.org/10.1002/joc.773.

Kobayashi, S., and Coauthors, 2015: The JRA- 55 reanalysis: General specifications and basic characteristics. J. Meteor. Soc. Japan, 93, 5-48, https://doi. org/10.2151/jmsj.2015-001.

Kopp, G., and J. L. Lean, 2011: A new, lower value of total solar irradiance: Evidence and climate significance. Geophys. Res. Lett., 38, L01706, https:// doi.org/10.1029/2010GL045777.

Kratz, D. P., P. W. Stackhouse Jr., S. K. Gupta, A. C. Wilber, P. Sawaengphokhai, and G. R. McGarragh, 2014: The Fast Longwave and Shortwave Flux (FLASHFlux) data product: Single Scanner Footprint Fluxes. J. Appl. Meteor. Climatol., 53, 1059-1079, https://doi.org/10.1175/JAMC-D-13-061.1.

Lan, X., and Coauthors, 2019: Long-term measurements show little evidence for large increases in total us methane emissions over the past decade. Geophys. Res. Lett., 46, 4991-4999, https://doi.org/10.1029/2018GL081731.

Lee, H.-T., and NOAA CDR Program, 2011: NOAA Climate Data Record (CDR) of monthly outgoing longwave radiation (OLR), version 2.2-1. NOAA National Climatic Data Center, accessed 23 January 2020, https://doi.org/10.7289/ V5222RQP. 
Lenssen, N., G. Schmidt, J. Hansen, M. Menne, A. Persin, R. Ruedy, and D. Zyss, 2019: Improvements in the GISTEMP uncertainty model. J. Geophys. Res. Atmos., 124, 6307-6326, https://doi.org/10.1029/2018jd029522.

Levy, R. C., S. Mattoo, L. A. Munchak, L. A. Remer, A. M. Sayer, F. Patadia, and N. C. Hsu, 2013: The Collection 6 MODIS aerosol products over land and ocean. Atmos. Meas. Tech., 6, 2989-3034, https://doi.org/10.5194/amt-62989-2013.

L'Heureux, M. L., and Coauthors, 2017: Observing and predicting the 2015/16 El Niño. Bull. Amer. Meteor. Soc., 98, 1363-1382, https://doi.org/10.1175/ BAMS-D-16-0009.1.

Li, B., M. Rodell, and J. S. Famiglietti, 2015: Groundwater variability across temporal and spatial scales in the central and northeastern U.S. J. Hydrol., 525, 769-780, https://doi.org/10.1016/j.jhydrol.2015.04.033.

- , and Coauthors, 2019: Global GRACE data assimilation for groundwater and drought monitoring: Advances and challenges. Water Resour. Res., 55, 7564-7586, https://doi.org/10.1029/2018WR024618.

Lieb, G. K., and A. Kellerer-Pirklbauer, 2019: Gletscherbericht 2017/18 Sammelbericht über die Gletschermessungen des Österreichischen Alpenvereins im Jahre 2018. Letzter Bericht: Bergauf 2/2018, Jg. 73 (143), 20-29, www. alpenverein.at/portal_wAssets/docs/service/presse/2019/gletscherbericht/ Gletscherbericht_2_19.pdf.

Lim, E., H. H. Hendon, G. Boschat, D. Hudson, D. W. J. Thompson, A. J. Dowdy, and J. M. Arblaster, 2019: Australian hot and dry extremes induced by weakenings of the stratospheric polar vortex. Nat. Geosci., 12, 896-901, https:// doi.org/10.1038/s41561-019-0456-x.

Lin, M., L. W. Horowitz, S. J. Oltmans, A. M. Fiore, and S. Fan, 2014: Tropospheric ozone trends at Mauna Loa Observatory tied to decadal climate variability. Nat. Geosci., 7, 136-143, https://doi.org/10.1038/ngeo2066.

_ _ _ - R. Payton, A. M. Fiore, and G. Tonnesen, 2017: US surface ozone trends and extremes from 1980 to 2014: Quantifying the roles of rising Asian emissions, domestic controls, wildfires, and climate. Atmos. Chem. Phys., 17, 2943-2970, https://doi.org/10.5194/acp-17-2943-2017.

Liu, Y., and Coauthors, 2015: Agriculture intensifies soil moisture decline in Northern China. Sci. Rep., 5, 11 261, https://doi.org/10.1038/srep11261.

Loeb, N. G., B. A. Wielicki, D. R. Doelling, G. L. Smith, D. F. Keyes, S. Kato, N. Manalo-Smith, and T. Wong, 2009: Toward optimal closure of the Earth's top-of-atmosphere radiation budget. J. Climate, 22, 748-766, https://doi. org/10.1175/2008JCLI2637.1.

— , S. Kato, W. Su, T. Wong, F. Rose, D. R. Doelling, and J. Norris, 2012: Advances in understanding top-of-atmosphere radiation variability from satellite observations. Surv. Geophys., 33, 359-385, https://doi.org/10.1007/ s10712-012-9175-1.

- and Coauthors, 2018: Clouds and the Earth's Radiant Energy System (CERES) Energy Balanced and Filled (EBAF) top-of-atmosphere (TOA) Edition-4.0 data product. J. Climate, 31, 895-918, https://doi.org/10.1175/ JCLI-D-17-0208.1.

Lu, X., and Coauthors, 2018: Severe surface ozone pollution in China: A global perspective. Environ. Sci. Technol. Lett., 5, 487-494, https://doi. org/10.1021/acs.estlett.8b00366.

Southern Hemisphere since 1990: Possible linkages to poleward expansion of the Hadley Circulation. Sci. Bull., 64, 400-409, https://doi.org/10.1016/j. scib.2018.12.021.

MacCallum, S. N., and C. J. Merchant, 2012: Surface water temperature observations of large lakes by optimal estimation. Can. J. Remote Sens., 38, 25-45, https://doi.org/10.5589/m12-010.

MacFarling Meure, C., D. Etheridge, C. Trudinger, P. Steele, R. Langenfelds, T. van Ommen, A. Smith, and J. Elkins, 2006: Law Dome CO2, CH4 and N2O ice core records extended to 2000 years BP. Geophys. Res. Lett., 33, L14810, https://doi.org/10.1029/2006GL026152.
Madakumbura, D. G., H. Kim, N. Utsumi, H. Shiogama, E. M. Fischer, Ø. Seland, J. F. Scinocca, D. M. Mitchell, Y. Hirabayashi, and T. Oki, 2019: Event-toevent intensification of the hydrologic cycle in $1.5^{\circ} \mathrm{C}$ and $2{ }^{\circ} \mathrm{C}$ warmer worlds. Sci. Rep., 9, 3483, https://doi.org/10.1038/s41598-019-39936-2.

Magnin, F., P. Deline, L. Ravanel, J. Noetzli, and P. Pogliotti, 2015: Thermal characteristics of permafrost in the steep alpine rock walls of the Aiguille du Midi (Mont Blanc Massif, 3842 m a.s.l). Cryosphere, 9, 109-121, https://doi. org/10.5194/tc-9-109-2015.

Magnuson, J. J., and Coauthors, 2000: Historical trends in lake and river ice cover in the Northern Hemisphere. Science, 289, 1743-1746, https://doi. org/10.1126/science.289.5485.1743.

Manabe, S., and R. Wetherald, 1967: Thermal equilibrium of the atmosphere with a given distribution of relative humidity. J. Atmos. Sci., 24, 241-259, https://doi.org/10.1175/1520-0469(1967)024<0241:TEOTAW>2.0.C0;2.

Martens, B., and Coauthors, 2017: GLEAM v3: Satellite-based land evaporation and root-zone soil moisture. Geosci. Model Dev., 10, 1903-1925, https:// doi.org/10.5194/gmd-10-1903-2017.

_ W. Waegeman, W. A. Dorigo, N. E. C. Verhoest, and D. G. Miralles, 2018: Terrestrial evaporation response to modes of climate variability. npj Climate Atmos. Sci., 1, 43, https://doi.org/10.1038/s41612-018-0053-5.

Maycock, A. C., and Coauthors, 2018: Revisiting the mystery of recent stratospheric temperature trends. Geophys. Res. Lett., 45, 9919-9933, https:// doi.org/10.1029/2018GL078035.

McCabe, A., A. Ershadi, C. Jimenez, D. G. Miralles, D. Michel, and E. F. Wood, 2016: The GEWEX LandFlux project: Evaluation of model evaporation using tower-based and globally-gridded forcing data. Geosci. Model Dev., 9, 283-305, https://doi.org/10.5194/gmd-9-283-2016.

- and Coauthors, 2017: The future of Earth observation in hydrology. $\mathrm{Hy}$ drol. Earth Syst. Sci., 21, 3879-3914, https://doi.org/10.5194/hess-21-38792017.

— D. G. Miralles, T. R. H. Holmes, and J. B. Fisher, 2019: Advances in the remote sensing of terrestrial evaporation. Remote Sens., 11, 1138, https:// doi.org/10.3390/rs11091138.

McDermid, I. S., T. D. Walsh, A. Deslis, and M. L. White, 1995: Optical-systems design for a stratospheric lidar system. Appl. Opt., 34, 6201-6210, https:// doi.org/10.1364/A0.34.006201.

McKitrick, R., and J. R. Christy, 2018: A test of the tropical 200- to 300-hPa warming rate in climate models. Earth Space Sci., 5, 529-536, https://doi. org/10.1029/2018ea000401.

McVicar, T. R., R. Vautard, J.-N. Thépaut, P. Berrisford, and R. J. H. Dunn, 2013: Surface winds [in "State of the Climate in 2012"]. Bull. Amer. Meteor. Soc., 94 (8), S27-S29, https://doi.org/10.1175/2013BAMSStateoftheClimate.1.

Mears, C., D. K. Smith, L. Ricciardulli, J. Wang, H. Huelsing, and F. J. Wentz, 2018: Construction and uncertainty estimation of a satellite-derived total precipitable water data record over the world's oceans. Earth Space Sci., 5, 197-210, https://doi.org/10.1002/2018EA000363.

_ perature trends to the diurnal cycle adjustment. J. Climate, 29, 3629-3646, https://doi.org/10.1175/JCLI-D-15-0744.1.

Melaas, E. K., D. Sulla-Menashe, J. M. Gray, T. A. Black, T. H. Morin, A. D. Richardson, and M. A. Friedl, 2016: Multisite analysis of land surface phenology in North American temperate and boreal deciduous forests from Landsat. Remote Sens. Environ., 186, 452-464, https://doi.org/10.1016/j. rse.2016.09.014.

Menne, M. J., I. Durre, R. S. Vose, B. E. Gleason, and T. G. Houston, 2012: An overview of the global historical climatology network-daily database. J. Atmos. Oceanic Technol., 29, 897-910, https://doi.org/10.1175/JTECHD-11-00103.1.

Menzel, W. P., R. A. Frey, E. E. Borbas, B. A. Baum, G. Cureton, and N. Bearson, 2016: Reprocessing of HIRS satellite measurements from 1980 to 2015: Development toward a consistent decadal cloud record. J. Appl. Meteor. Climatol., 55, 2397-2410, https://doi.org/10.1175/JAMC-D-16-0129.1. 
Meredith, M., and Coauthors, 2020: Polar regions. IPCC Special Report on the Ocean and Cryosphere in a Changing Climate, H.-0. Pörtner et al., Eds., IPCC, in press.

Miller, B. R., and Coauthors, 2010: HFC-23 (CHF3) emission trend response to HCFC-22 (CHClF2) production and recent HFC-23 emission abatement measures. Atmos. Chem. Phys., 10, 7875-7890, https://doi.org/10.5194/acp-107875-2010.

Mills, G., and Coauthors, 2018: Tropospheric ozone assessment report: Present-day tropospheric ozone distribution and trends relevant to vegetation. Elem. Sci. Anthropocene, 6, 47, https://doi.org/10.1525/elementa.302.

Minnis, P., and Coauthors, 2008: Cloud detection in nonpolar regions for CERES using TRMM VIRS and Terra and Aqua MODIS data. IEEE Trans. Geosci. Remote Sens., 46, 3857-3884, https://doi.org/10.1109/TGRS.2008.2001351.

- K. Bedka, Q. Trepte, C. R. Yost, S. T. Bedka, B. Scarino, K. Khlopenkov, and M. M. Khaiyer, 2016: A consistent long-term cloud and clear-sky radiation property dataset from the Advanced Very High Resolution Radiometer (AVHRR). Climate Algorithm Theoretical Basis Doc. CDRP-ATBD-0826, NOAA, 159 pp., www.ncdc.noaa.gov/sites/default/files/cdr-documentation/CDRP-ATBD-0826\%20AVHRR\%20Cloud\%20Properties $\% 20-\% 20$ NASA\%20C-ATBD\%20(01B-30b)\%20(DSR-1051).pdf.

Minschwaner, K., H. Su, and J. H. Jiang, 2016: The upward branch of the Brewer-Dobson circulation quantified by tropical stratospheric water vapor and carbon monoxide measurements from the Aura Microwave Limb Sounder. J. Geophys. Res. Atmos., 121, 2790-2804, https://doi. org/10.1002/2015jd023961.

Miralles, D. G., T. R. H. Holmes, R. A. M. De Jeu, J. H. Gash, A. G. C. A. Meesters, and A. J. Dolman, 2011: Global land-surface evaporation estimated from satellite-based observations. Hydrol. Earth Syst. Sci., 15, 453-469, https:// doi.org/10.5194/hess-15-453-2011.

continental evaporation. Nat. Climate Change, 4, 122-126, https://doi. org/10.1038/nclimate2068.

- , and Coauthors, 2016: The WACMOS-ET project - Part II: Evaluation of global terrestrial evaporation data sets. Hydrol. Earth Syst. Sci., 20, 823842, https://doi.org/10.5194/hess-20-823-2016.

- P. Gentine, S. I. Seneviratne, and A. J. Teuling, 2019: Land-atmospheric feedbacks during droughts and heatwaves: State of the science and current challenges. Ann. New York Acad. Sci., 1436, 19-35, https://doi.org/10.1111/ nyas.13912.

Mironov, D., 2008: Parameterization of lakes in numerical weather prediction. Part 1: Description of a lake mode. COSMO Tech. Rep. 11, 47 pp., www.cosmo-model.org/content/model/documentation/techReports/docs/ techReport11.pdf.

- , and Coauthors, 2010: Implementation of the lake parameterisation scheme FLake into the numerical weather prediction model COSMO. Boreal Environ. Res., 15, 218-230.

Mitchell, J. M. J., 1971: The effect of atmospheric aerosols on climate with special reference to temperature near the Earth's surface. J. Appl. Meteor., 10, 703-714, https://doi.org/10.1175/1520-0450(1971)010<0703:TEOAA0>2.0 .CO;2.

Miyazaki, K., H. J. Eskes, and K. Sudo, 2015: A tropospheric chemistry reanalysis for the years 2005-2012 based on an assimilation of OMI, MLS, TES, and MOPITT satellite data. Atmos. Chem. Phys., 15, 8315-8348, https://doi. org/10.5194/acp-15-8315-2015.

Mollaret, C., C. Hilbich, C. Pellet, A. Flores-Orozco, R. Delaloye, and C. Hauck, 2019: Mountain permafrost degradation documented through a network of permanent electrical resistivity tomography sites. Cryosphere, 13, 25572578, https://doi.org/10.5194/tc-13-2557-2019.

Monks, P. S., and Coauthors, 2015: Tropospheric ozone and its precursors from the urban to the global scale from air quality to short-lived climate forcer. Atmos. Chem. Phys., 15, 8889-8973, https://doi.org/10.5194/acp-15-88892015.
Montzka, S. A., J. H. Butler, R. C. Myers, T. M. Thompson, T. H. Swanson, A. D. Clarke, L. T. Lock, and J. W. Elkins, 1996: Decline in the tropospheric abundance of halogen from halocarbons: Implications for stratospheric ozone depletion. Science, 272, 1318-1322, https://doi.org/10.1126/science.272.5266.1318.

_- and Coauthors, 2018a: An unexpected and persistent increase in global emissions of ozone-depleting CFC-11. Nature, 557, 413-417, https://doi. org/10.1038/s41586-018-0106-2.

_ and Coauthors, 2018b: Hydrofluorocarbons (HFCs). Scientific Assessment of Ozone Depletion: 2018, Global Ozone Research and Monitoring Project Rep. 58, 2.1-2.47, https://ozone.unep.org/sites/default/files/2019-05/SAP2018-Assessment-report.pdf.

Moon, M., X. Zhang, G. M. Henebry, L. Liu, J. M. Gray, E. K. Melaas, and M. A. Friedl, 2019: Long-term continuity in land surface phenology measurements: A comparative assessment of the MODIS land cover dynamics and VIIRS land surface phenology products. Remote Sens. Environ., 226, 74-92, https://doi.org/10.1016/j.rse.2019.03.034.

Morgenstern, 0., and Coauthors, 2017: Review of the global models used within phase 1 of the Chemistry-Climate Model Initiative (CCMI). Geosci. Model Dev., 10, 639-671, https://doi.org/10.5194/gmd-10-639-2017.

Morice, C. P., J. J. Kennedy, N. A. Rayner, and P. D. Jones, 2012: Quantifying uncertainties in global and regional temperature change using an ensemble of observational estimates: The HadCRUT4 dataset. J. Geophys. Res., 117, D08101, https://doi.org/10.1029/2011JD017187.

Mühle, J., and Coauthors, 2010: Perfluorocarbons in the global atmosphere: Tetrafluoromethane, hexafluoroethane, and octafluoropropane. Atmos. Chem. Phys., 10, 5145-5164, https://doi.org/10.5194/acp-10-5145-2010.

Myhre, G., and Coauthors, 2013: Anthropogenic and natural radiative forcing. Climate Change 2013: The Physical Science Basis, T. F. Stocker et al., Eds., Cambridge University Press, 659-740.

Neu, J., T. Flury, G. L. Manney, M. L. Santee, N. J. Livesey, and J. Worden, 2014: Tropospheric ozone variations governed by changes in stratospheric circulation. Nat. Geosci., 7, 340-344, https://doi.org/10.1038/ngeo2138.

Newman, M., A. T. Wittenberg, L. Cheng, G. P. Compo, and C. A. Smith, 2018: The extreme 2015/16 El Niño, in the context of historical climate variability and change. Bull. Amer. Meteor. Soc., 99 (1), S16-S20, https://doi. org/10.1175/BAMS-D-17-0116.1.

Newman, P. A., J. S. Daniel, D. W. Waugh, and E. R. Nash, 2007: A new formulation of equivalent effective stratospheric chlorine (EESC). Atmos. Chem. Phys., 7, 4537-4552, https://doi.org/10.5194/acp-7-4537-2007.

Nisbet, E. G., and Coauthors, 2019: Very strong atmospheric methane growth in the 4 years 2014-2017: Implications for the Paris Agreement. Global Biogeochem. Cycles, 33, 318-342, https://doi.org/10.1029/2018GB006009.

Noetzli, J., and Coauthors, 2018: Permafrost thermal state [in "State of the Climate in 2017"]. Bull. Amer. Meteor. Soc., 99 (8), S20-S22, https://doi.or $\mathrm{g} / 10.1175 / 2018$ BAMSStateoftheClimate.1.

— in 2018"]. Bull. Amer. Meteor. Soc., 100 (9), S21-S22, https://doi.org/10.11 75/2019BAMSStateoftheClimate.1

Novelli, P. C., K. A. Masarie, P. M. Lang, B. D. Hall, R. C. Myers, and J. W. Elkins, 2003: Reanalysis of tropospheric CO trends: Effects of the 1997-1998 wildfires. J. Geophys. Res., 108, 4464, https://doi.org/10.1029/2002jd003031.

Olsen, M. A., G. L. Manney, and J. Liu, 2019: The ENSO and QBO impact on ozone variability and stratosphere-troposphere exchange relative to the subtropical jets. J. Geophys. Res. Atmos., 124, 7379-7392, https://doi. org/10.1029/2019jd030435.

O'Neel, S., and Coauthors, 2019: Reanalysis of the US Geological Survey Benchmark Glaciers: Long-term insight into climate forcing of glacier mass balance. J. Glaciol., 65, 850-866, https://doi.org/10.1017/jog.2019.66.

Otto, F. E. L., and Coauthors, 2018: Anthropogenic influence on the drivers of the Western Cape drought 2015-2017. Environ. Res. Lett., 13, 124010, https://doi.org/10.1088/1748-9326/aae9f9. 
Palecki, M. A., and R. G. Barry, 1986: Freeze-up and break-up of lakes as an index of temperature changes during the transition seasons: A case study for Finland. J. Climate Appl. Meteor., 25, 893-902, https://doi.org/10.1175/15200450(1986)025<0893:FUABU0>2.0.CO;2.

Park, T., and Coauthors, 2016: Changes in growing season duration and productivity of northern vegetation inferred from long-term remote sensing data. Environ. Res. Lett., 11, 084001, https://doi.org/10.1088/17489326/11/8/084001.

Pelto, M., 2019: Exceptionally high 2018 equilibrium line altitude on Taku Glacier, Alaska. Remote Sens., 11, 2378, https://doi.org/10.3390/rs11202378.

PERMOS, 2019: Permafrost in Switzerland 2014/2015 to 2017/2018. Glaciological Rep. Permafrost 16-19, 104 pp., https://doi.org/10.13093/permosrep-2019-16-19.

Peterson, D. A., J. R. Campbell, E. J. Hyer, M. D. Fromm, G. P. Kablick III, J. H. Cossuth, and M. T. DeLand, 2018: Wildfire-driven thunderstorms cause a volcano-like stratospheric injection of smoke. npj Climate Atmos. Sci., 1, 30, https://doi.org/10.1038/s41612-018-0039-3.

Peterson, T. C., and R. S. Vose, 1997: An overview of the Global Historical Climatology Network temperature database. Bull. Amer. Meteor. Soc., 78, 2837-2849, https://doi.org/10.1175/1520-0477(1997)078<2837:AOOTGH> 2.0.CO;2.

Petrenko, V. V., and Coauthors, 2013: A 60 yr record of atmospheric carbon monoxide reconstructed from Greenland firn air. Atmos. Chem. Phys., 13, 7567-7585, https://doi.org/10.5194/acp-13-7567-2013.

Pétron, G., A. M. Crotwell, E. Dlugokencky, and J. W. Mund, 2019: Atmospheric carbon monoxide dry air mole fractions from the NOAA ESRL Carbon Cycle Cooperative Global Air Sampling Network, 1988-2018, version: 2019-08. NOAA, accessed 9 July 2020, https://doi.org/10.15138/33bv-s284.

Phillips, N., and B. Nogrady, 2020: The race to decipher how climate change influenced Australia's record fires. Nature, 577, 610-612, https://doi. org/10.1038/d41586-020-00173-7.

Pinty, B., and Coauthors, 2011: Exploiting the MODIS albedos with the Twostream Inversion Package (JRC-TIP): 2. Fractions of transmitted and absorbed fluxes in the vegetation and soil layers. J. Geophys. Res., 116, D09106, https://doi.org/10.1029/2010jd015373.

Platnick, S., P. Hubanks, K. Meyer, and M. D. King, 2015: MODIS atmosphere L3 monthly product (08_L3). NASA MODIS Adaptive Processing System, Goddard Space Flight Center, https://doi.org/10.5067/MODIS/MOD08_M3.006.

Po-Chedley, S., T. J. Thorsen, and Q. Fu, 2015: Removing diurnal cycle contamination in satellite-derived tropospheric temperatures: Understanding tropical tropospheric trend discrepancies. J. Climate, 28, 2274-2290, https://doi. org/10.1175/JCLI-D-13-00767.1.

Popp, T., and Coauthors, 2016: Development, production and evaluation of aerosol climate data records from European satellite observations (Aerosol_cci). Remote Sens., 8, 421, https://doi.org/10.3390/rs8050421.

Prather, M. J., C. D. Holmes, and J. Hsu, 2012: Reactive greenhouse gas scenarios: Systematic exploration of uncertainties and the role of atmospheric chemistry. Geophys. Res. Lett., 39, L09803, https://doi.org/10.1029/2012GL051440.

Ramon, J., L. Lledó, V. Torralba, A. Soret, and F. J. Doblas-Reyes, 2019: What global reanalysis best represents near-surface winds? Quart. J. Roy. Meteor. Soc., 145, 3236-3251, https://doi.org/10.1002/qj.3616.

Randel, W. J., and J. B. Cobb, 1994: Coherent variations of monthly mean total ozone and lower stratospheric temperature. J. Geophys. Res., 99, 54335447, https://doi.org/10.1029/93jd03454.

— A. K. Smith, F. Wu, C.-Z. Zou, and H. Qian, 2016: Stratospheric temperature trends over 1979-2015 derived from combined SSU, MLS and SABER satellite observations. J. Climate, 29, 4843-4859, https://doi.org/10.1175/ JCLI-D-15-0629.1.

Ravishankara, A. R., J. S. Daniel, and R. W. Portmann, 2009: Nitrous oxide (N20): The dominant ozone-depleting substance emitted in the 21st century. Science, 326, 123-125, https://doi.org/10.1126/science.1176985.
Ray, E. A., F. L. Moore, J. W. Elkins, K. H. Rosenlof, J. C. Laube, T. Röckmann, D. R. Marsh, and A. E. Andrews, 2017: Quantification of the SF6 lifetime based on mesospheric loss measured in the stratospheric polar vortex. J. Geophys. Res. Atmos., 122, 4626-4638, https://doi.org/10.1002/2016jd026198.

_ Oscillation on trace gas levels at the Earth's surface. Nat. Geosci., 13, 22-27, https://doi.org/10.1038/s41561-019-0507-3.

Richardson, A. D., and Coauthors, 2018a: Tracking vegetation phenology across diverse North American biomes using PhenoCam imagery. Sci. Data, 5, 180028, https://doi.org/10.1038/sdata.2018.28.

- K. Hufkens, T. Milliman, and S. Frolking, 2018b: Intercomparison of phenological transition dates derived from the PhenoCam Dataset V1.0 and MODIS satellite remote sensing. Sci. Rep., 8, 5679, https://doi.org/10.1038/ s41598-018-23804-6.

Rigby, M., and Coauthors, 2019: Increase in CFC-11 emissions from eastern China based on atmospheric observations. Nature, 569, 546-550, https:// doi.org/10.1038/s41586-019-1193-4.

Robock, A., 2000: Volcanic eruptions and climate. Rev. Geophys., 38, 191-219, https://doi.org/10.1029/1998RG000054.

Roderick, M. L., L. D. Rotstayn, G. D. Farquhar, and M. T. Hobbins, 2007: On the attribution of changing pan evaporation. Geophys. Res. Lett., 34, L17403, https://doi.org/10.1029/2007GL031166.

Romanovsky, V. E., and Coauthors, 2010: Thermal state of permafrost in Russia. Permafrost Periglacial Processes, 21, 136-155, https://doi.org/10.1002/ ppp.683.

Sánchez-Lugo, A., C. Morice, P. Berrisford, and A. Argüez, 2017: Global surface temperatures [in "State of the Climate in 2016"]. Bull. Amer. Meteor. Soc., 98 (8), S11-S13, https://doi.org/10.1175/2017BAMSStateoftheClimate.1.

Santer, B. D., S. Solomon, F. J. Wentz, Q. Fu, S. Po-Chedley, C. Mears, J. F. Painter, and C. Bonfils, 2017: Tropospheric warming over the past two decades. Sci. Rep., 7, 2336, https://doi.org/10.1038/s41598-017-02520-7.

Santoso, A., and Coauthors, 2019: Dynamics and predictability of the El NiñoSouthern Oscillation: An Australian perspective on progress and challenges. Bull. Amer. Meteor. Soc., 100, 403-420, https://doi.org/10.1175/BAMSD-18-0057.1.

Satheesh, S. K., and Coauthors, 2017: Variability of atmospheric aerosols over India. Observed Climate Variability and Change over the Indian Region, M. Rajeevan and S. Nayak, Eds., Springer, 221-248, https://doi. org/10.1007/978-981-10-2531-0_13.

Saunois, M., and Coauthors, 2016: The global methane budget 2000-2012. Earth Syst. Sci. Data, 8, 697-751, https://doi.org/10.5194/essd-8-697-2016.

Scanlon, T., and Coauthors, 2019: Soil moisture [in "State of the Climate in 2018"]. Bull. Amer. Meteor. Soc., 100 (9), S38-S39, https://doi.org/10.1175 /2019BAMSStateoftheClimate.1.

Schaaf, C. B., and Z. Wang, 2015: MCD43C3 MODIS/Terra+Aqua BRDF/Albedo Albedo Daily L3 Global 0.05Deg CMG. NASA EOSDIS Land Processes DAAC, accessed 1 February 2020, https://doi.org/10.5067/MODIS/MCD43C3.006.

_ products from MODIS. Remote Sens. Environ., 83, 135-148, https://doi. org/10.1016/S0034-4257(02)00091-3.Schaefer, H., and Coauthors, 2016: A 21st-century shift from fossil-fuel to biogenic methane emissions indicated by 13CH4. Science, 352, 80-84, https://doi.org/10.1126/science.aad2705.

Schamm, K., M. Ziese, A. Becker, P. Finger, A. Meyer-Christoffer, B. Rudolf, and U. Schneider, 2013: GPCC first guess daily product at 1.0 $0^{\circ}$ : Near real-time first guess daily land-surface precipitation from rain-gauges based on SYNOP data. Deutscher Wetterdienst, accessed 12 February 2020, https://doi. org/10.5676/DWD_GPCC/FG_D_100.

Schewe, J., and Coauthors, 2014: Multi-model assessment of water scarcity under climate change. Proc. Natl. Acad. Sci., 111, 3245-3250, https://doi. org/10.1073/pnas.1222460110. 
Schneider, U., A. Becker, P. Finger, A. Meyer-Christoffer, M. Ziese, 2018: GPCC Monitoring product: Near real-time monthly land-surface precipitation from rain-gauges based on SYNOP and CLIMAT data. Deutscher Wetterdienst, accessed 4 March 2020, http://doi.org/10.5676/DWD_GPCC/MP_M_V6_100.

Schoeberl, M. R., R. S. Stolarski, and A. J. Krueger, 1989: The 1988 Antarctic ozone depletion: Comparison with previous year depletions. Geophys. Res. Lett., 16, 377-380, https://doi.org/10.1029/GL016i005p00377.

Schwietzke, S., and Coauthors, 2016: Upward revision of global fossil fuel methane emissions based on isotope database. Nature, 538, 88-91, https://doi. org/10.1038/nature19797.

Seager, R., T. J. Osborn, Y. Kushnir, I. R. Simpson, J. Nakamura, and H. Liu, 2019: Climate variability and change of Mediterranean-type climates. J. Climate, 32, 2887-2915, https://doi.org/10.1175/JCLI-D-18-0472.1.

Sharma, S., J. J. Magnuson, R. D. Batt, L. A. Winslow, J. Korhonen, and Y. Aono, 2016: Direct observations of ice seasonality reveal changes in climate over the past 320-570 years. Sci. Rep., 6, 25061, https://doi.org/10.1038/ srep25061.

Shi, L., and J. J. Bates, 2011: Three decades of intersatellite-calibrated highresolution infrared radiation sounder upper tropospheric water vapor. J. Geophys. Res., 116, D04108, https://doi.org/10.1029/2010JD014847.

Sinnhuber, B.-M., M. Weber, A. Amankwah, and J. P. Burrows, 2003: Total ozone during the unusual Antarctic winter of 2002. Geophys. Res. Lett., 30, 1580, https://doi.org/10.1029/2002GL016798.

Slivinski, L. C., and Coauthors, 2019: Towards a more reliable historical reanalysis: Improvements for version 3 of the twentieth century reanalysis system. Quart. J. Roy. Meteor. Soc., 145, 2876-2908, https://doi.org/10.1002/ qj.3598.

Solomon, S., D. J. Ivy, D. Kinnison, M. J. Mills, R. R. Neely, and A. Schmidt, 2016: Emergence of healing in the Antarctic ozone layer. Science, 353, 269-274, https://doi.org/10.1126/science.aae0061.

SPARC/I03C/GAW, 2019: SPARC/I03C/GAW report on long-term ozone trends and uncertainties in the stratosphere. SPARC Rep. 9, WCRP-17/2018, GAW Rep. 241, 102 pp., https://doi.org/10.17874/f899e57a20b.

Stackhouse, P. W., T. Wong, D. P. Kratz, P. Sawaengphokhai, A. C. Wiber, S. K. Gupta, and N. G. Loeb, 2016: Earth radiation budget at top-of-atmosphere [in "State of the Climate in 2015"]. Bull. Amer. Meteor. Soc., 97 (8), S41S43, https://doi.org/10.1175/2016BAMSStateoftheClimate.1.

Steinbrecht, W., and Coauthors, 2017: An update on ozone profile trends for the period 2000 to 2016. Atmos. Chem. Phys., 17, 10675-10690, https://doi. org/10.5194/acp-17-10675-2017.

Stengel, M., and Coauthors, 2017: Cloud property datasets retrieved from AVHRR, MODIS, AATSR and MERIS in the framework of the Cloud_cci project. Earth Syst. Sci. Data, 9, 881-904, https://doi.org/10.5194/essd-9-8812017.

Strode, S. A., J. R. Ziemke, L. D. Oman, L. N. Lamsal, M. A. Olsen, and J. Liu, 2019: Global changes in the diurnal cycle of surface ozone. Atmos. Environ., 199, 323-333, https://doi.org/10.1016/j.atmosenv.2018.11.028.

Stubenrauch, C., and Coauthors, 2012: Assessment of global cloud datasets from satellites. World Climate Research Programme Rep. 23/2012, 175 pp., www.wcrp-climate.org/documents/GEWEX_ Cloud_Assessment_2012. pdf.

Sun, W., P. Hess, and B. Tian, 2014: The response of the equatorial tropospheric ozone to the Madden-Julian Oscillation in TES satellite observations and CAM-chem model simulation. Atmos. Chem. Phys., 14, 11775-11790, https://doi.org/10.5194/acp-14-11775-2014.

Sun, Z., L. Zhao, G. Hu, Y. Qiao, E. Du, D. Zou, and C. Xie, 2020: Modeling permafrost changes on the Qinghai-Tibetan plateau from 1966 to 2100: A case study from two boreholes along the Qinghai-Tibet engineering corridor. Permafrost Periglacial Processes, 31, 156-171, https://doi.org/10.1002/ ppp. 2022.

Susskind, J., G. Molnar, L. Iredell, and N. G. Loeb, 2012: Interannual variability of outgoing longwave radiation as observed by AIRS and CERES. J. Geophys. Res., 117, D23107, https://doi.org/10.1029/2012JD017997.
Tans, P., 2009: An accounting of the observed increase in oceanic and atmospheric $\mathrm{CO} 2$ and an outlook for the future. Oceanography, 22, 26-35, https://doi.org/10.5670/oceanog.2009.94.

Tapley, B. D., S. Bettadpur, J. C. Ries, P. F. Thompson, and M. M. Watkins, 2004: GRACE measurements of mass variability in the Earth system. Science, 305, 503-505, https://doi.org/10.1126/science.1099192.

Tarasick, D. W., and Coauthors, 2019: Tropospheric ozone assessment report: Tropospheric ozone from 1877 to 2016, observed levels, trends and uncertainties. Elem. Sci. Anthropocene, 7, 39, https://doi.org/10.1525/elementa.376.

Teng, W.-H., C.-Y. Huang, S.-P. Ho, Y.-H. Kuo, and X.-J. Zhou, 2013: Characteristics of global precipitable water in ENSO events revealed by COSMIC measurements. J. Geophys. Res. Atmos., 118, 8411-8425, https://doi. org/10.1002/jgrd.50371.

Teuling, A. J., and Coauthors, 2013: Evapotranspiration amplifies European summer drought. Geophys. Res. Lett., 40, 2071-2075, https://doi.org/10.1002/ grl.50495.

Thackeray, S. J., I. D. Jones, and S. C. Maberly, 2008: Long-term change in the phenology of spring phytoplankton: Species-specific responses to nutrient enrichment and climatic change. J. Ecol., 96, 523-535, https://doi. org/10.1111/j.1365-2745.2008.01355.x.

_ , P. A. Henrys, H. Feuchtmayr, I. D. Jones, S. C. Maberly, and I. J. Winfield, 2013: Food web de-synchronization in England's largest lake: An assessment based on multiple phenological metrics. Global Change Biol., 19, 3568-3580, https://doi.org/10.1111/gcb.12326.

Thomason, L. W., and Coauthors, 2018: A global space-based stratospheric aerosol climatology: 1979-2016. Earth Syst. Sci. Data, 10, 469-492, https:// doi.org/10.5194/essd-10-469-2018.

Thompson, D. W. J., J. M. Wallace, P. D. Jones, and J. J. Kennedy, 2009: Identifying signatures of natural climate variability in time series of global-mean surface temperature: Methodology and insights. J. Climate, 22, 6120-6141, https://doi.org/10.1175/2009JCLI3089.1.

Thompson, R. L., and Coauthors, 2019: Acceleration of global N2O emissions seen from two decades of atmospheric inversion. Nat. Climate Change, 9, 993-998, https://doi.org/10.1038/s41558-019-0613-7.

Timmermann, A., and Coauthors, 2018: El Niño-Southern Oscillation complexity. Nature, 559, 535-545, https://doi.org/10.1038/s41586-018-0252-6.

Tivig, M., V. Grützun, V. O. John, and S. A. Buehler, 2020: Trends in uppertropospheric humidity: Expansion of the subtropical dry zones? J. Climate, 33, 2149-2161, https://doi.org/10.1175/JCLI-D-19-0046.1.

Tokuda, D., H. Kim, D. Yamazaki, and T. Oki, 2019: Development of a global river water temperature model considering fluvial dynamics and seasonal freeze-thaw cycle. Water Resour. Res., 55, 1366-1383, https://doi. org/10.1029/2018WR023083.

Torralba, V., F. J. Doblas-Reyes, and N. Gonzalez-Reviriegol, 2017: Uncertainty in recent near-surface wind speed trends: A global reanalysis intercomparison. Environ. Res. Lett., 12, 114019, https://doi.org/10.1088/1748-9326/ aa8a58.

Trepte, C. R., and M. H. Hitchman, 1992: Tropical stratospheric circulation deduced from satellite aerosol data. Nature, 355, 626-628, https://doi. org/10.1038/355626a0.

Trepte, Q. Z., P. Minnis, C. R. Trepte, S. Sun-Mack, and R. Brown, 2010: Improved cloud detection in CERES Edition 3 algorithm and comparison with the CALIPSO Vertical Feature Mask. 13th Conf. on Atmospheric Radiation and Cloud Physics, Portland, OR, Amer. Meteor. Soc., JP1.32, https://ams. confex.com/ams/13CldPhy13AtRad/webprogram/Paper171785.html.

Ummenhofer, C. C., M. H. England, P. C. McIntosh, G. A. Meyers, M. J. Pook, J. S. Risbey, A. S. Gupta, and A. S. Taschetto, 2009: What causes southeast Australia's worst droughts? Geophys. Res. Lett., 36, L04706, https://doi. org/10.1029/2008GL036801.

van $\operatorname{der}$ A, R. J., M. A. F. Allaart, and H. J. Eskes, 2015: Extended and refined multi sensor reanalysis of total ozone for the period 1970-2012. Atmos. Meas. Tech., 8, 3021-3035, https://doi.org/10.5194/amt-8-3021-2015. 
van der Schrier, G., J. Barichivich, K. R. Briffa, and P. D. Jones, 2013: A scPDSIbased global dataset of dry and wet spells for 1901-2009. J. Geophys. Res. Atmos., 118, 4025-4048, https://doi.org/10.1002/jgrd.50355.

van der Werf, G. R., and Coauthors, 2017: Global fire emissions estimates during 1997-2016. Earth Syst. Sci. Data, 9, 697-720, https://doi.org/10.5194/ essd-9-697-2017.

Vautard, R., J. Cattiaux, P. Yiou, J. N. Thépaut, and P. Ciais, 2010: Northern Hemisphere atmospheric stilling partly attributed to an increase in surface roughness. Nat. Geosci., 3, 756-761, https://doi.org/10.1038/ngeo979.

Vernier, J. P., J.-P. Pommereau, L. W. Thomason, J. Pelon, A. Garnier, T. Deshler, J. Jumelet, and J. K. Nielsen, 2011a: Overshooting of clean tropospheric air in the tropical lower stratosphere as seen by the CALIPSO lidar. Atmos. Chem. Phys., 11, 9683-9696, https://doi.org/10.5194/acp-11-9683-2011.

_ and Coauthors, 2011b: Major influence of tropical volcanic eruptions on the stratospheric aerosol layer during the last decade. Geophys. Res. Lett., 38, L12807, https://doi.org/10.1029/2011gl047563.—_, and Coauthors, 2013: An advanced system to monitor the 3D structure of diffuse volcanic ash clouds. J. Appl. Meteor. Climatol., 52, 2125-2138, https://doi. org/10.1175/JAMC-D-12-0279.1.

Vose, R. S., R. Adler, G. Gu, A. Becker, X. Yin, and M. Bosilovich, 2019: Precipitation [in "State of the Climate in 2018"]. Bull. Amer. Meteor. Soc., 100 (9), S29-S30, https://doi.org/10.1175/2019BAMSStateoftheClimate.1.

Wang, C., C. Deser, J. Y. Yu, P. DiNezio, and A. Clement, 2017: El Niño and Southern Oscillation (ENSO): A review. Coral Reefs of the Eastern Tropical Pacific, P. Glynn, D. Manzello, and I. Enochs, Eds., Vol. 8, Coral Reefs of the World, Springer, 85-106, https://doi.org/10.1007/978-94-017-7499-4_4.

Weatherhead, E. C., and Coauthors, 1998: Factors affecting the detection of trends: Statistical considerations and applications to environmental data. J. Geophys. Res., 103, 17149-17 161, https://doi.org/10.1029/98JD00995.

Weber, M., S. Dikty, J. P. Burrows, H. Garny, M. Dameris, A. Kubin, J. Abalichin, and U. Langematz, 2011: The Brewer-Dobson circulation and total ozone from seasonal to decadal time scales. Atmos. Chem. Phys., 11, 1122111235 , https://doi.org/10.5194/acp-11-11221-2011.

_ M. Coldewey-Egbers, V. E. Fioletov, S. M. Frith, J. D. Wild, J. P. Burrows, C. S. Long, and D. Loyola, 2018: Total ozone trends from 1979 to 2016 derived from five merged observational datasets - The emergence into ozone recovery. Atmos. Chem. Phys., 18, 2097-2117, https://doi.org/10.5194/acp18-2097-2018.

Wells, N., S. Goddard, and M. J. Hayes, 2004: A self-calibrating palmer drought severity index. J. Climate, 17, 2335-2351, https://doi.org/10.1175/15200442(2004)017<2335:ASPDSI>2.0.C0;2.

Wentz, F. J., 1997: A well calibrated ocean algorithm for special sensor microwave/imager. J. Geophys. Res. Oceans, 102, 8703-8718, https://doi. org/10.1029/96JC01751.

_ 2015: A 17-year climate record of environmental parameters derived from the Tropical Rainfall Measuring Mission (TRMM) microwave imager. J. Climate, 28, 6882-6902, https://doi.org/10.1175/JCLI-D-15-0155.1.

- L. Ricciardulli, K. A. Hilburn, and C. A. Mears, 2007: How much more rain will global warming bring? Science, 317, 233-235, https://doi.org/10.1126/ science. 1140746.

Weyhenmeyer, G. A., A. M. Meili, and D. M. Livingstone, 2004: Nonlinear temperature response of lake ice breakup. Geophys. Res. Lett., 31, L07203, https://doi.org/10.1029/2004GL019530.

WGMS, 2017: Global Glacier Change Bulletin 2. ICSU(WDS)/IUGG(IACS)/UNEP/ UNESCO/WMO, World Glacier Monitoring Service, 244 pp., https://doi. org/10.5904/wgms-fog-2017-10.

Wielicki, B. A., B. R. Barkstrom, E. F. Harrison, R. B. Lee III, G. L. Smith, and J. E. Cooper, 1996: Clouds and the Earth's Radiant Energy System (CERES): An earth observing system experiment. Bull. Amer. Meteor. Soc., 77, 853-868, https://doi.org/10.1175/1520-0477(1996)077<0853:CATERE>2.0.C0;2.

— , and Coauthors, 1998: Clouds and the Earth's Radiant Energy System (CERES): Algorithm overview. IEEE Trans. Geosci. Remote Sens., 36, 1127-1141, https://doi.org/10.1109/36.701020.
Willett, K. M., C. N. Williams Jr., R. J. H. Dunn, P. W. Thorne, S. Bell, M. de Podesta, P. D. Jones, and D. E. Parker, 2013: HadISDH: An updated land surface specific humidity product for climate monitoring. Climate Past, 9, 657-677, https://doi.org/10.5194/cp-9-657-2013.

— , R. J. H. Dunn, P. W. Thorne, S. Bell, M. de Podesta, D. E. Parker, P. D. Jones, and C. N. Williams Jr., 2014: HadISDH land surface multi-variable humidity and temperature record for climate monitoring. Climate Past, 10, 1983-2006, https://doi.org/10.5194/cp-10-1983-2014.

- D. I. Berry, M. Bosilovich, and A. Simmons, 2019a: Surface humidity [in "State of the Climate in 2018"]. Bull. Amer. Meteor. Soc., 100 (9), 25-27, https://doi.org/10.1175/2019BAMSStateoftheClimate.1.

— R. J. H. Dunn, J. Kennedy, and D. Berry, 2019b: Development of the HadISDH marine humidity climate monitoring dataset. Earth Syst. Sci. Data Discuss., https://doi.org/10.5194/essd-2019-190.

Winder, M., and J. E. Cloern, 2010: The annual cycles of phytoplankton biomass. Philos. Trans. Roy. Soc., 365B, 3215-3226, https://doi.org/10.1098/ rstb.2010.0125.

Winker, D. M., W. Hunt, and M. J. McGill, 2007: Initial performance assessment of CALIOP. Geophys. Res. Lett., 34, L19803, https://doi. org/10.1029/2007GL030135.

WMO, 2018: Scientific Assessment of Ozone Depletion: 2018. Global Ozone Research and Monitoring Project Rep. 58, 588 pp., https://ozone.unep.org/ sites/default/files/2019-05/SAP-2018-Assessment-report.pdf.

_ 2019: July matched, and maybe broke, the record for the hottest month since analysis began. WMO, accessed 2 December 2020, https://public. wmo.int/en/media/news/july-matched-and-maybe-broke-record-hottestmonth-analysis-began.

Wohland, J., N.-E. Omrani, D. Witthaut, and N.-S. Keenlyside, 2019: Inconsistent wind speed trends in current twentieth century reanalyses. J. Geophys. Res. Atmos., 124, 1931-1940, https://doi.org/10.1029/2018jd030083.

Woolway, R. I., and C. J. Merchant, 2018: Intralake heterogeneity of thermal responses to climate change: A study of large Northern Hemisphere lakes. J. Geophys. Res. Atmos., 123, 3087-3098, https://doi. org/10.1002/2017jd027661.

— - and Coauthors, 2017: Lake surface temperature [in "State of the Climate in 2016"]. Bull. Amer. Meteor. Soc., 98 (8), S13-S14, https://doi.org/10.1175 /2017BAMSStateoftheClimate.1.

_ mate in 2017"]. Bull. Amer. Meteor. Soc., 99 (8), S13-S15, https://doi.or g/10.1175/2018BAMSStateoftheClimate.1.Wylie, D. P., D. L. Jackson, W. P. Menzel, and J. J. Bates, 2005: Trends in global cloud cover in two decades of HIRS observations. J. Climate, 18, 3021-3031, https://doi.org/10.1175/ JCLI3461.1.

Worden, J. R., and Coauthors, 2017: Reduced biomass burning emissions reconcile conflicting estimates of the post-2006 atmospheric methane budget. Nat. Commun., 8, 2227, https://doi.org/10.1038/s41467-017-02246-0.

Young, I., and A. Ribal, 2019: Multiplatform evaluation of global trends in wind speed and wave height. Science, 364, 548-552, https://doi.org/10.1126/science.aav9527.

Young, P. J., and Coauthors, 2013: Pre-industrial to end 21st century projections of tropospheric ozone from the Atmospheric Chemistry and Climate Model Inter-comparison Project (ACCMIP). Atmos. Chem. Phys., 13, 2063-2090, https://doi.org/10.5194/acp-13-2063-2013.

_ ment of global-scale model performance for global and regional ozone distributions, variability, and trends. Elem. Sci. Anthropocene, 6, 10, https:// doi.org/10.1525/elementa.265.

Zemp, M., and Coauthors, 2019: Global glacier mass changes and their contributions to sea-level rise from 1961 to 2016. Nature, 568, 382-386, https:// doi.org/10.1038/s41586-019-1071-0.

Zeng, Z., and Coauthors, 2018: Global terrestrial stilling: Does Earth's greening play a role? Environ. Res. Lett., 13, 124013, https://doi.org/10.1088/17489326/aaea84. 
- and Coauthors, 2019: A reversal in global terrestrial stilling and its implications for wind energy production. Nat. Climate Change, 9, 979-985, https://doi.org/10.1038/s41558-019-0622-6.

Zhang, H.-M., and Coauthors, 2019: Updated temperature data give a sharper view of climate trends. Eos, 100, https://doi.org/10.1029/2019E0128229.

Zhang, R., S. Zhang, J. Luo, Y. Han, and J. Zhang, 2019: Analysis of near-surface wind speed change in China during 1958-2015. Theor. Appl. Climatol., 137, 2785-2801, https://doi.org/10.1007/s00704-019-02769-0.

Zhang, T., A. Hoell, J. Perlwitz, J. Eischeid, D. Murray, M. Hoerling, and T. Hamill, 2019: Towards probabilistic multivariate ENSO monitoring. Geophys. Res. Lett., 46, 10532-10540, https://doi.org/10.1029/2019gl083946.

Zhang, X.., L. Alexander, G. C. Hegerl, P. Jones, A. K. Tank, T. C. Peterson, B. Trewin, and F. W. Zwiers, 2011: Indices for monitoring changes in extremes based on daily temperature and precipitation data. Wiley Interdiscip. Rev.: Climate Change, 2, 851-870, https://doi.org/10.1002/wcc.147.

Zhang, X.-Y., and Coauthors, 2018: Evaluation of land surface phenology from VIIRS data using time series of PhenoCam imagery. Agric. For. Meteor., 256-257, 137-149, https://doi.org/10.1016/j.agrformet.2018.03.003.

Zhang, Y., J. M. Wallace, and D. S. Battisti, 1997: ENSO-like interdecadal variability: 1900-93. J. Climate, 10, 1004-1020, https://doi.org/10.1175/15200442(1997)010<1004:ELIV>2.0.CO;2.

Zhang, Yo., and Coauthors, 2016: Multi-decadal trends in global terrestrial evapotranspiration and its components. Sci. Rep., 6, 19124, https://doi. org/10.1038/srep19124.
Zhang, Yu., O. R. Cooper, A. Gaudel, A. M. Thompson, P. Nédélec, S.-Y. Ogino, and J. J. West, 2016: Tropospheric ozone change from 1980 to 2010 dominated by equatorward redistribution of emissions. Nat. Geosci., 9, 875-879, https://doi.org/10.1038/ngeo2827.

Zhao, L., and Coauthors, 2019: Permafrost changes and its effects on hydrological processes on Qinghai-Tibet Plateau. Bull. Chin. Acad. Sci., 34, $1233-1246$.

Ziemke, J. R., and O. R. Cooper, 2018: Tropospheric ozone [in "State of the Climate in 2017"]. Bull. Amer. Meteor. Soc., 99 (8), S56-S59, https://doi.or g/10.1175/2018BAMSStateoftheClimate.1.

— A. R. Douglass, L. D. Oman, S. E. Strahan, and B. N. Duncan, 2015: Tropospheric ozone variability in the tropics from ENSO to MJO and shorter timescales. Atmos. Chem. Phys., 15, 8037-8049, https://doi.org/10.5194/ acp-15-8037-2015.

_ composite record of TOMS/OMI/MLS/OMPS satellite measurements and the MERRA-2 GMI simulation. Atmos. Chem. Phys., 19, 3257-3269, https://doi. org/10.5194/acp-19-3257-2019.

Zou, C.-Z., and H. Qian, 2016: Stratospheric temperature climate data record from merged SSU and AMSU-A observations. J. Atmos. Oceanic Technol., 33, 1967-1984, https://doi.org/10.1175/JTECH-D-16-0018.1. 


\title{
STATE OF THE CLIMATE IN 2019 Global Oceans
}

\author{
Editors \\ Jessica Blunden \\ Derek S. Arndt \\ Chapter Editors \\ Peter Bissolli \\ Howard J. Diamond \\ Matthew L. Druckenmiller \\ Robert J. H. Dunn \\ Catherine Ganter \\ Nadine Gobron \\ Rick Lumpkin \\ Jacqueline A. Richter-Menge \\ Tim Li \\ Ademe Mekonnen \\ Ahira Sánchez-Lugo \\ Ted A. Scambos \\ Carl J. Schreck III \\ Sharon Stammerjohn \\ Diane M. Stanitski \\ Kate M. Willett \\ Technical Editor \\ Andrea Andersen
}

BAMS Special Editor for Climate

Richard Rosen

American Meteorological Society 
Global Oceans is one chapter from the State of the Climate in 2019 annual report and is available from https://doi.org/10.1175/BAMS-D-20-0105.1. Compiled by NOAA's National Centers for Environmental Information, State of the Climate in 2019 is based on contr1ibutions from scientists from around the world. It provides a detailed update on global climate indicators, notable weather events, and other data collected by environmental monitoring stations and instruments located on land, water, ice, and in space. The full report is available from https://doi.org /10.1175/2020BAMSStateoftheClimate.1.

\section{How to cite this document:}

\section{Citing the complete report:}

Blunden, J. and D. S. Arndt, Eds., 2020: State of the Climate in 2019. Bull. Amer. Meteor. Soc., 101 (8), Si-S429, https://doi.org/10.1175/2020BAMSStateoftheClimate.1.

\section{Citing this chapter:}

Lumpkin, R. L., Ed., 2020: Global Oceans [in "State of the Climate in 2019"]. Bull. Amer. Meteor. Soc., 101 (8), S129-S183, https://doi.org/10.1175/BAMS-D-20-0105.1.

\section{Citing a section (example):}

Franz, B. A., I. Cetinić, J. P. Scott, D. A. Siegel, and T. K. Westberry, 2020: Global ocean phytoplankton [in "State of the Climate in 2019"]. Bull. Amer. Meteor. Soc., 101 (8), S163-S169, https:// doi.org/10.1175/BAMS-D-20-0105.1. 


\section{Editor and Author Affiliations (alphabetical by name)}

Baringer, Molly, NOAA/OAR Atlantic Oceanographic and Meteorological Laboratory, Miami, Florida

Bif, Mariana B., Monterey Bay Aquarium Research Institute, Moss Landing, California

Boyer, Tim, NOAA/NESDIS National Centers for Environmental Information, Silver Spring, Maryland

Bushinsky, Seth M., University of Hawai'i at Mānoa, Honolulu, Hawai'i

Carter, Brendan R., Joint Institute for the Study of the Atmosphere and Ocean, University of Washington, and NOAA/OAR Pacific Marine Environmental Laboratory, Seattle, Washington

Cetinić, Ivona, NASA Goddard Space Flight Center, Greenbelt, Maryland, and Universities Space Research Association, Columbia, Maryland

Chambers, Don P., College of Marine Science, University of South Florida, St. Petersburg, Florida

Cheng, Lijing, International Center for Climate and Environment Sciences, Institute of Atmospheric Physics, Chinese Academy of Sciences, Beijing, China

Chiba, Sanai, Japan Agency for Marine-Earth Science and Technology, Yokosuka, Japan

Dai, Minhan, Xiamen University, Xiamen, China

Domingues, Catia M., Institute for Marine and Antarctic Studies, University of Tasmania, Antarctic Climate and Ecosystems Cooperative Research Centre, and Australian Research Council's Centre of Excellence for Climate System Science, Hobart, Tasmania, Australia

Dong, Shenfu, NOAA/OAR Atlantic Oceanographic and Meteorological Laboratory, Miami, Florida

Fassbender, Andrea J., Monterey Bay Aquarium Research Institute, Moss Landing, California

Feely, Richard A., NOAA/OAR Pacific Marine Environmental Laboratory, Seattle, Washington

Frajka-Williams, Eleanor, National Oceanography Centre, Southampton, United Kingdom

Franz, Bryan A., NASA Goddard Space Flight Center, Greenbelt, Maryland

Gilson, John, Scripps Institution of Oceanography, University of California at San Diego, La Jolla, California

Goni, Gustavo, NOAA/OAR Atlantic Oceanographic and Meteorological Laboratory, Miami, Florida

Hamlington, Benjamin D., NASA Jet Propulsion Laboratory, Pasadena, California

Hu, Zeng-Zhen, NOAA/NCEP Climate Prediction Center, College Park, Maryland

Huang, Boyin, NOAA/NESDIS National Centers for Environmental Information, Asheville, North Carolina

Ishii, Masayoshi, Department of Atmosphere, Ocean and Earth System Modeling Research, Meteorological Research Institute, Japan Meteorological Agency, Tsukuba, Japan

Jevrejeva, Svetlana, National Oceanography Centre, Liverpool, United Kingdom

Johns, William E., Rosenstiel School of Marine and Atmospheric Science, University of Miami, Miami, Florida

Johnson, Gregory C., NOAA/OAR Pacific Marine Environmental Laboratory, Seattle, Washington

Johnson, Kenneth S., Monterey Bay Aquarium Research Institute, Moss Landing, California

Kennedy, John, Met Office Hadley Centre, Exeter, United Kingdom

Kersalé, Marion, Cooperative Institute for Marine and Atmospheric Studies, University of Miami, Miami, Florida and NOAA/OAR Atlantic Oceanographic and Meteorological Laboratory (AOML), Miami, Florida

Killick, Rachel E., Met Office Hadley Centre, Exeter, United Kingdom

Landschützer, Peter, Max Planck Institute for Meteorology, Hamburg, Germany
Lankhorst, Matthias, Scripps Institution of Oceanography, University of California at San Diego, La Jolla, California

Lee, Tong, NASA Jet Propulsion Laboratory, Pasadena, California

Leuliette, Eric, NOAA/NESDIS Center for Satellite Applications and Research, College Park, Maryland

Li, Feili, College of Sciences, Georgia Institute of Technology, Atlanta, Georgia

Lindstrom, Eric, Saildrone Inc., Alameda, California

Locarnini, Ricardo, NOAA/NESDIS National Centers for Environmental Information, Silver Spring, Maryland

Lozier, Susan, College of Sciences, Georgia Institute of Technology, Atlanta, Georgia

Lumpkin, Rick, NOAA/OAR Atlantic Oceanographic and Meteorological Laboratory, Miami, Florida

Lyman, John M., NOAA/OAR Pacific Marine Environmental Laboratory, Seattle, Washington, and Joint Institute for Marine and Atmospheric Research, University of Hawai'i, Honolulu, Hawai'i

Marra, John J., NOAA/NESDIS National Centers for Environmental Information, Honolulu, Hawai'i

Meinen, Christopher S., NOAA/OAR Atlantic Oceanographic and Meteorological Laboratory, Miami, Florida

Merrifield, Mark A., Scripps Institution of Oceanography, University of California at San Diego, La Jolla, California

Mitchum, Gary T., College of Marine Science, University of South Florida, St. Petersburg, Florida

Moat, Ben, National Oceanography Centre, Southampton, United Kingdom

Monselesan, Didier, CSIRO Oceans and Atmosphere, Hobart, Tasmania, Australia

Nerem, R. Steven, Colorado Center for Astrodynamics Research, Cooperative Institute for Research in Environmental Sciences, University of Colorado Boulder, Boulder, Colorado

Perez, Renellys C., NOAA/OAR Atlantic Oceanographic and Meteorological Laboratory, Miami, Florida

Purkey, Sarah G., Scripps Institution of Oceanography, University of California at San Diego, La Jolla, California

Rayner, Darren, National Oceanography Centre, Southampton, United Kingdom

Reagan, James, Earth System Science Interdisciplinary Center/Cooperative Institute for Satellite Earth System Studies, University of Maryland, College Park, Maryland and NOAA/NESDIS National Centers for Environmental Information, Silver Spring, Maryland

Rome, Nicholas, Consortium for Ocean Leadership, Washington, D.C.

Sanchez-Franks, Alejandra, National Oceanography Centre, Southampton United Kingdom

Schmid, Claudia, NOAA/OAR Atlantic Oceanographic and Meteorological Laboratory, Miami, Florida

Scott, Joel P., NASA Goddard Space Flight Center, Greenbelt, Maryland and Science Application International Corporation, Beltsville, Maryland

Send, Uwe, Scripps Institution of Oceanography, University of California at San Diego, La Jolla, California

Siegel, David A., University of California at Santa Barbara, Santa Barbara, California

Smeed, David A., National Oceanography Centre, Southampton, United Kingdom

Speich, Sabrina, École Normale Supérieure Laboratoire de Météorologie Dynamique, Paris, France

Stackhouse Jr., Paul W., NASA Langley Research Center, Hampton, Virginia

Sweet, William, NOAA/NOS Center for Operational Oceanographic Products and Services, Silver Spring, Maryland

Takeshita, Yuichiro, Monterey Bay Aquarium Research Institute, Moss Landing, California 
Thompson, Philip R., Department of Oceanography, University of Hawai'i at Mānoa, Honolulu, Hawai'i

Triñanes, Joaquin A., Laboratory of Systems, Technological Research Institute, Universidad de Santiago de Compostela, Campus Universitario Sur, Santiago de Compostela, Spain; NOAA/OAR Atlantic Oceanographic and Meteorological Laboratory, Miami, Florida, and Cooperative Institute for Marine and Atmospheric Studies, University of Miami, Miami, Florida

Visbeck, Martin, GEOMAR Helmholtz Centre for Ocean Research Kiel, Kiel, Germany

Volkov, Denis L., Cooperative Institute for Marine and Atmospheric Studies, University of Miami, Miami, Florida and NOAA/OAR Atlantic Oceanographic and Meteorological Laboratory (AOML), Miami, Florida

Wanninkhof, Rik, NOAA/OAR Atlantic Oceanographic and Meteorological Laboratory, Miami, Florida
Weller, Robert A., Woods Hole Oceanographic Institution, Woods Hole, Massachusetts

Westberry, Toby K., Oregon State University, Corvallis, Oregon

Widlansky, Matthew J., Joint Institute for Marine and Atmospheric Research, University of Hawai'i at Mānoa, Honolulu, Hawai'i

Wijffels, Susan E., Woods Hole Oceanographic Institution, Woods Hole, Massachusetts

Wilber, Anne C., Science Systems and Applications, Inc., Hampton, Virginia

Yu, Lisan, Woods Hole Oceanographic Institution, Woods Hole, Massachusetts

Yu, Weidong, National Marine Environmental Forecasting Center, State Oceanic Administration, Beijing, China

Zhang, Huai-Min, NOAA/NESDIS National Centers for Environmental Information, Asheville, North Carolina

\section{Editorial and Production Team}

Andersen, Andrea, Technical Editor, TeleSolv Consulting LLC, NOAA/NESDIS National Centers for Environmental Information, Asheville, North Carolina

Griffin, Jessicca, Graphics Support, Cooperative Institute for Satellite Earth System Studies, North Carolina State University, Asheville, North Carolina

Hammer, Gregory, Content Team Lead, Communications and Outreach, NOAA/ NESDIS National Centers for Environmental Information, Asheville, North Carolina

Love-Brotak, S. Elizabeth, Lead Graphics Production, NOAA/NESDIS National Centers for Environmental Information, Asheville, North Carolina
Misch, Deborah J., Graphics Support, Innovative Consulting \& Management Services, LLC, NOAA/NESDIS National Centers for Environmental Information, Asheville, North Carolina

Riddle, Deborah B., Graphics Support, NOAA/NESDIS National Centers for Environmental Information, Asheville, North Carolina

Veasey, Sara W., Visual Communications Team Lead, Communications and Outreach, NOAA/NESDIS National Centers for Environmental Information, Asheville, North Carolina 


\section{Table of Contents}

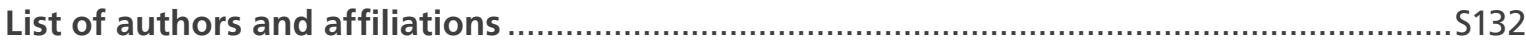

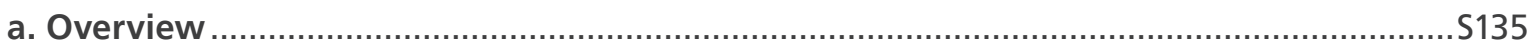

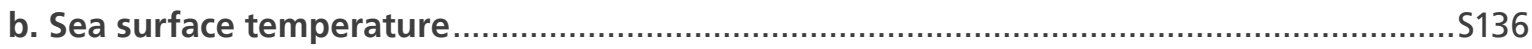

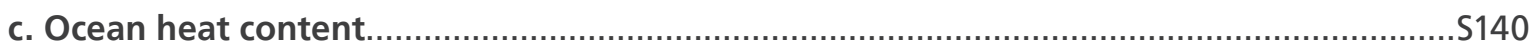

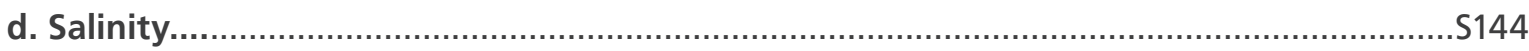

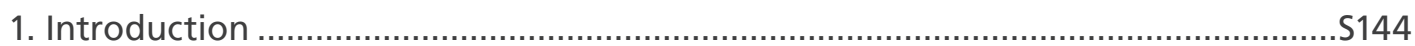

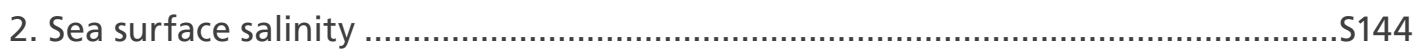

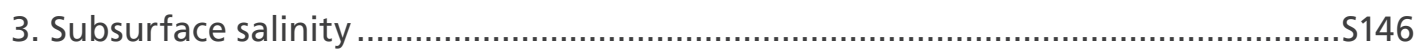

e. Global ocean heat, freshwater, and momentum fluxes ............................................S149

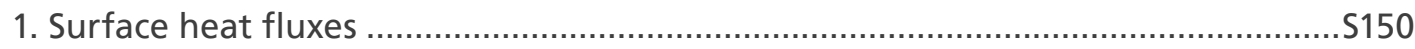

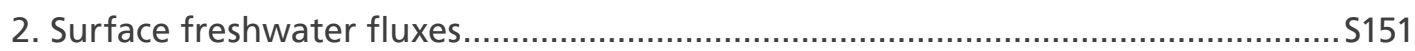

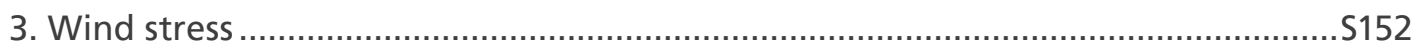

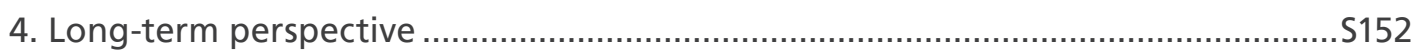

f. Sea level variability and change ............................................................................ 153

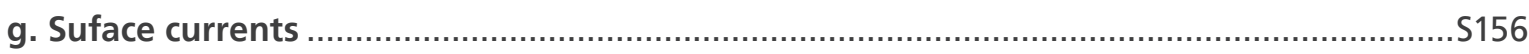

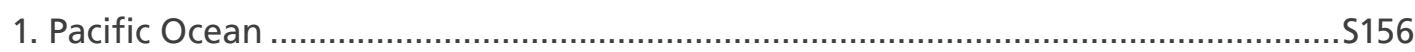

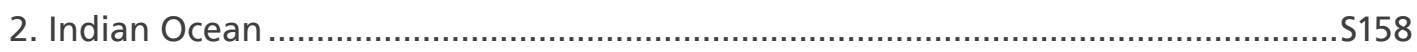

3. Atlantic Ocean............................................................................................... 158

h. Atlantic meridional overturning circulation and associated heat transport ....................S159

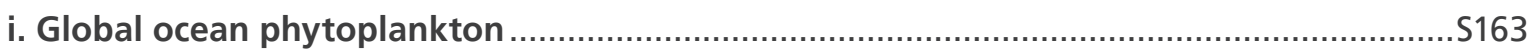

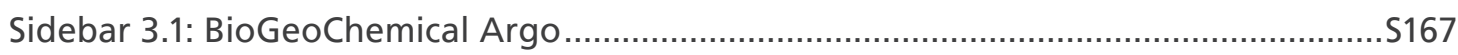

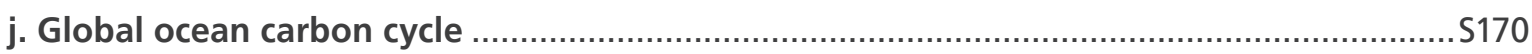

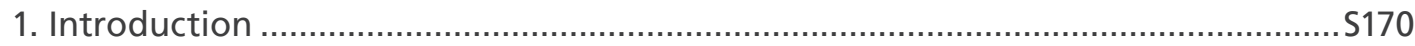

2. Air-sea carbon dioxide fluxes ......................................................................... 5170

3. Large-scale carbon and $\mathrm{pH}$ changes in the ocean interior ...................................S173

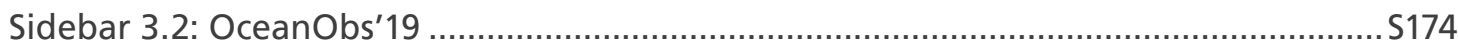

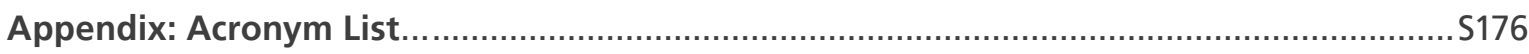

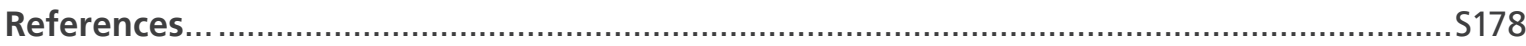

*Please refer to Chapter 8 (Relevant datasets and sources) for a list of all climate variables and datasets used in this chapter for analyses, along with their websites for more information and access to the data. 


\section{GLOBAL OCEANS}

Rick Lumpkin, Ed.

\section{a. Overview-R. Lumpkin}

In this chapter, we examine the state of the global oceans in 2019, focusing both on changes from 2018 to 2019 and on the longer-term perspective. Sidebars focus on the significant and ongoing scientific results from the growing array of Argo floats measuring biogeochemical properties, and on the OceanObs'19 conference, a once-per-decade event focusing on sustaining and enhancing the global ocean-observing system.

The year 2019 marks the eighth consecutive year that global mean sea level increased relative to the previous year, reaching a new record: $87.6 \mathrm{~mm}$ above the 1993 average (Fig. 3.14a) and peaking in the middle of the year. The globally averaged 2019 sea surface temperature anomaly (SSTA) was the second highest on record, surpassed only by the record El Niño year of 2016. The warming trend of ocean heat content (OHC) from 2004 to 2019 corresponds to a rate exceeding $0.20^{\circ} \mathrm{C}$ decade $^{-1}$ near the surface, declining to $<0.03^{\circ} \mathrm{C}_{\text {decade }}{ }^{-1}$ below $300 \mathrm{~m}$ (Fig. 3.5). Over the period 1993-2019, 2019 was a record high for OHC from 0-700 m depth (Fig. 3.6a) and from 700-2000 m depth (Fig. 3.6b), consistent with heat gain of approximately $0.4 \mathrm{~W} \mathrm{~m}^{-2}$ applied over the surface of Earth from 1993 to 2019 (Table 3.2). The year also set a new record for net ocean uptake of $\mathrm{CO}_{2}$ for the period 1982-present, 2.4 Pg C (Fig. 3.26), an increase of $0.2 \mathrm{Pg} \mathrm{C}$ from 2018. This continues a trend that started in 2000-02. As a consequence of the increased oceanic $\mathrm{CO}_{2}$, surface ocean $\mathrm{pH}$ has declined by $0.018 \pm 0.004$ units decade $^{-1}$ in most of the ocean since the pre-industrial period, particularly in colder water (Fig. 3.28b).

The Indian Ocean dipole (IOD), defined as the difference between western and eastern Indian Ocean basin SSTAs, reached its highest level since 1997 in October 2019, associated with dramatic upper ocean warming in the western Indian Ocean basin (Figs. 3.1a, 3.4a). This SSTA pattern resulted in a significant weakening of the trade winds (Fig. 3.12a), more precipitation in the west, and drier conditions in the east in 2019 (Fig. 3.11), and thus anomalously salty surface waters in the east and fresh in the west (Figs. 3.7a,b). Indian Ocean net heat gain anomalies for 2019 reached maxima of $>30 \mathrm{~W} \mathrm{~m}^{-2}$ and were much larger than climatology in most of the central and eastern tropical Indian Ocean basin (Fig. 3.10a). This heat gain was associated with increased surface radiation (Fig. 3.10c) and drove increased turbulent heat loss to the atmosphere (Fig. 3.10d). In the lead-up to the extreme dipole event, westward geostrophic current anomalies developed across the basin, reaching maxima of $\sim 40 \mathrm{~cm} \mathrm{~s}^{-1}$ at the peak of the dipole (Fig. 3.18). By the end of the year, there was a significant east-to-west sea level anomaly gradient across the tropical Indian Ocean (Fig. 3.15d).

The tropical Pacific was characterized by a transition from a diminishing La Niña in 2018 to the development of a weak El Niño by early 2019. Sustained negative values of the Oceanic Niño Index over the last decade produced positive anomalies in the flux of $\mathrm{CO}_{2}$ from the ocean to the atmosphere in the eastern tropical Pacific (Fig. 3.27c). In the North Pacific, sea surface temperatures (SSTs) increased significantly in the latter half of 2019 (Figs. 3.2c,d), leading to the reemergence of a "warm blob" that was associated with a decrease in precipitation (Fig. 3.11d) and winds (Fig. 3.12a). In the northwest subpolar Pacific and western Bering Sea, positive anomalies in the flux of $\mathrm{CO}_{2}$ from the ocean to the atmosphere were related to sustained above-average SSTA there (Fig. 3.27c). 
Positive SSTAs were observed in the tropical Atlantic, corresponding to the development of an Atlantic Niño. The North Atlantic was characterized by a tripole-like SSTA pattern (Fig. 3.1a), associated with positive net heat flux anomalies from $30^{\circ} \mathrm{S}$ to $60^{\circ} \mathrm{N}$ (Figs. 3.10a,b). Dramatic SST increase in the Labrador Sea (Fig. 3.1a) was associated with the reduction of sea ice coverage. Upper ocean heat content south of Greenland, which had been anomalously low since 2009, increased in 2019 (Fig. 3.4a).

The October 2018-September 2019 globally-averaged concentration of chlorophyll- $a$ (chla) varied from its 22-year monthly climatology by $\pm 6 \%$ (Fig. 3.25b), while the concentration of phytoplanktonic carbon $\left(\mathrm{C}_{\mathrm{phy}}\right)$ varied by $\pm 2 \%$ (Fig. 3.25d), indicating neutral El Niño-Southern Oscillation conditions. Regionally, chla was suppressed by 10\%-30\% where SST anomalies were positive, while variations of $\mathrm{C}_{\text {phy }}$ were far less dramatic. This is because above-average SST anomalies are associated with shallow mixed layers and thus increased light exposure to phytoplankton in that layer, leading in turn to reduced cellular chl $a$ and a decoupling of chl $a$ and $\mathrm{C}_{\text {phy }}$ concentrations.

For this year's report, we are pleased to re-introduce a section focusing on the Atlantic meridional overturning circulation (AMOC). In this section, we learn that decadal-scale variability of the southward deep western boundary current in the subtropical North Atlantic is poorly correlated with the relatively constant (at these time scales) northward-flowing Florida Current, and that rapid changes in the Florida Current can be driven by hurricanes; the passage of Hurricane Dorian coincided with the lowest transport measurement of the current ever recorded. The strength of the AMOC in the subtropical North Atlantic significantly decreased between 2004-08 and 2008-12 (Smeed et al. 2018) and has remained lower since then (Moat et al. 2019, 2020), consistent with a reduction of deep water production farther north. Direct measurements in the subpolar North Atlantic, collected by the Overturning in the Subpolar North Atlantic Program (OSNAP) array, challenge the conventional wisdom that deep water formation changes are strongly associated with changes in convection in the Labrador Sea, instead pointing to changes solely in the Irminger and Iceland basins (Lozier et al. 2019b). In the South Atlantic, interannual variations in the AMOC strength are associated with both density-driven and pressure-driven fluctuations (Meinen et al. 2018).

\section{b. Sea surface temperature-B. Huang, Z.-Z. Hu, J. J. Kennedy, and H.-M. Zhang}

The sea surface temperature (SST) over the global ocean (all water surfaces, including seas and great lakes) in 2019 is assessed using three updated products of SST and its uncertainty. These products are the Extended Reconstruction Sea-Surface Temperature version 5 (ERSSTv5; Huang et al. 2017, 2020), Daily Optimum Interpolation SST version 2 (DOISST; Reynolds et al. 2007), and U.K. Met Office Hadley Centre SST (HadSST.3.1.1.0 and HadSST.4.0.0.0; Kennedy et al. 2011a,b, 2019). See the State of the Climate in 2018 report for details of these calculations. SST anomalies (SSTAs) are calculated relative to their own climatologies over 1981-2010. The magnitudes of SSTAs are compared against SST standard deviations (std. dev.) over 1981-2010.

Averaged over the global oceans, ERSSTv5 analysis shows that SSTAs increased significantly from $0.33^{\circ} \pm 0.03^{\circ} \mathrm{C}$ in 2018 to $0.41^{\circ} \pm 0.03^{\circ} \mathrm{C}$ in 2019 . The uncertainty in ERSSTv5 is slightly smaller than that in ERSSTv4, as determined by a Student's t-test using a 1000-member ensemble based on ERSSTv5 with randomly drawn parameter values within reasonable ranges in the SST reconstructions (Huang et al. 2015, 2020).

Figure 3.1a shows annually averaged SSTA in 2019. In most of the North Pacific, SSTAs were between $+0.5^{\circ} \mathrm{C}$ and $+1.0^{\circ} \mathrm{C}$ except for near the Bering Strait $\left(+1.5^{\circ} \mathrm{C}\right)$, about $+0.5^{\circ} \mathrm{C}$ in the western South Pacific, and between $-0.2^{\circ} \mathrm{C}$ and $+0.2^{\circ} \mathrm{C}$ in the eastern South Pacific. The extreme warm event in the northeast Pacific is referred to as Blob 2.0 (Amaya et al. 2020). In the Atlantic, SSTAs were between $+0.2^{\circ} \mathrm{C}$ and $+0.5^{\circ} \mathrm{C}$ except for the tropical North Atlantic and near the coast of Africa $\left(-0.2^{\circ} \mathrm{C}\right.$ to $\left.0^{\circ} \mathrm{C}\right)$, central North Atlantic near $45^{\circ} \mathrm{N}$ and $30^{\circ} \mathrm{W}\left(0^{\circ} \mathrm{C}\right)$, and the Labrador Sea (about $+1.5^{\circ} \mathrm{C}$ ). In the Indian Ocean, SSTAs were $+0.5^{\circ} \mathrm{C}$ west of $90^{\circ} \mathrm{E}$ and slightly below average 
(a)

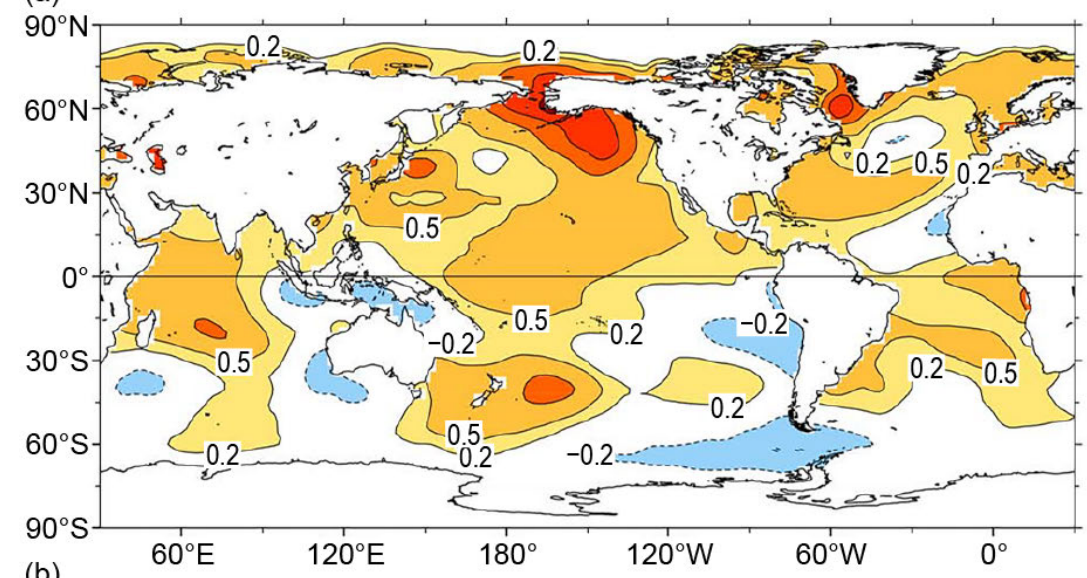

(b)

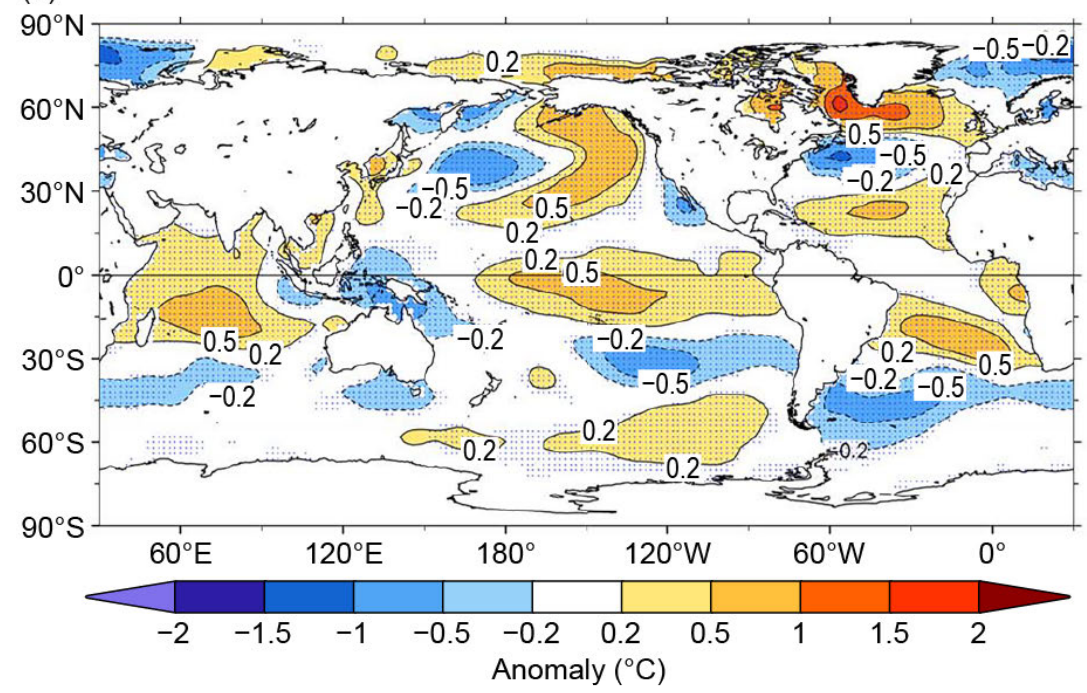

Fig. 3.1. (a) Annually averaged SSTAs $\left({ }^{\circ} \mathrm{C}\right)$ in 2019 and (b) difference of annually averaged SSTAs between 2019 and 2018. SSTAs are relative to 1981-2010 climatology. The SST difference in (b) is significant at 95\% level in stippled areas. $\left(-0.2^{\circ} \mathrm{C}\right)$ in the regions surrounding the Maritime Continent and western Australia.

In comparison with averaged SST in 2018, the averaged SST in 2019 increased by $+1.0^{\circ} \mathrm{C}$ to $+1.5^{\circ} \mathrm{C}$ south of Greenland (Fig. 3.1b) and was $+0.2^{\circ} \mathrm{C}$ to $+0.5^{\circ} \mathrm{C}$ higher in the northeastern Pacific stretching from Alaska and Canada toward the central North Pacific, in the central-eastern tropical Pacific, in the Pacific sector of the Southern Ocean south of $50^{\circ} \mathrm{S}$, in the tropical North Atlantic over $10^{\circ}-30^{\circ} \mathrm{N}$, in the tropical South Atlantic over $10^{\circ}-30^{\circ} \mathrm{S}$, in the eastern equatorial Atlantic, and in most of the Indian Ocean. In contrast, the SST decreased by $-0.2^{\circ} \mathrm{C}$ to $-0.5^{\circ} \mathrm{C}$ in the North Atlantic poleward of $60^{\circ} \mathrm{N}$, in the subtropical North Atlantic between $30^{\circ} \mathrm{N}$ and $45^{\circ} \mathrm{N}$, in the subpolar South Atlantic south of $35^{\circ} \mathrm{S}$, in the northwestern North Pacific between $30^{\circ} \mathrm{N}$ and $65^{\circ} \mathrm{N}$, in the western tropical Pacific, in the subtropical South Pacific between $20^{\circ} \mathrm{S}$ and $40^{\circ} \mathrm{S}$, and in the southern Indian Ocean between $30^{\circ} \mathrm{S}$ and $45^{\circ} \mathrm{S}$. These SST changes are statistically significant at the $95 \%$ confidence level based on an ensemble analysis of 1000 members.

The pattern of cooling in the western North Pacific and warming in the eastern North Pacific (Fig. 3.1b) may be associated with a shift of the Pacific Decadal Oscillation (PDO; Mantua and Hare 2002) index from a negative phase in 2018 to near neutral in 2019. The warming in the centraleastern tropical Pacific (Fig. 3.1b) is associated with a transition from the weak La Niña over 2017/18 to the weak El Niño over 2018/19. The warming in the western Indian Ocean is associated with an enhanced Indian Ocean dipole (IOD; Saji et al. 1999; see section $4 \mathrm{~h}$ ) from $0.3^{\circ} \mathrm{C}$ in 2018 to $0.8^{\circ} \mathrm{C}$ in 2019. The monthly IOD index reached its highest level since 1997 in October 2019 that affected patterns of precipitation and precipitation-minus-evaporation over the Maritime Continent and Australia (Fig. 3.11, see section 7h4).

The seasonal variations in SST in 2019 were profound. In most of the North Pacific, SSTAs were $+0.2^{\circ} \mathrm{C}$ to $+0.5^{\circ} \mathrm{C}$ ( $1 \mathrm{std}$. dev. above average) in December-February (DJF) and March-May (MAM) (Figs. 3.2a,b). The anomaly increase ranged from $+0.5^{\circ} \mathrm{C}$ to $+2.0^{\circ} \mathrm{C}(2 \mathrm{std}$. dev.) in June-August (JJA) and September-November (SON; Figs. 3.2c,d). In contrast, in the western South Pacific, SSTAs were high $\left(+1.0^{\circ} \mathrm{C} ; \geq 2 \mathrm{std}\right.$. dev. $)$ in DJF, MAM, and JJA and lower in SON, albeit still above average $\left(+0.5^{\circ} \mathrm{C} ; \geq 1 \mathrm{std}\right.$. dev.). In the eastern South Pacific, SSTAs persisted at about $-0.2^{\circ} \mathrm{C}$, although these anomalies stretched farther westward and equatorward in JJA and SON (Figs. 3.2c,d) than in DJF and MAM (Figs. 3.2a,b) following the evolution of the equatorial Pacific cold tongue. In the 
Southern Ocean between the date line and $30^{\circ} \mathrm{W}$, SSTAs were $-0.5^{\circ} \mathrm{C}$ to $-1.5^{\circ} \mathrm{C}(1 \mathrm{std}$. dev. below average) in DJF and MAM but were closer to average in JJA and SON.

It should be noted that there was an unusual heat content anomaly during the summer and spring around New Zealand (Figs. 3.2a,b). The Tasman Sea has seen a series of marine heatwaves in the past few years (Oliver et al. 2017; Perkins-Kirkpatrick et al. 2019; Babcock et al. 2019). In December 2019, SSTAs to the east of New Zealand were significantly above average.

In the western Indian Ocean, SSTAs persisted in the range of $+0.5^{\circ} \mathrm{C}$ to $+1.0^{\circ} \mathrm{C}(1-2 \mathrm{std}$. dev. above average) throughout all seasons (Fig. 3.2), while SSTAs were from $-0.5^{\circ} \mathrm{C}$ to $-1.0^{\circ} \mathrm{C}$ (1-2 std. dev. below average) in the eastern Indian Ocean and regions of the Maritime Continent. The warm western Indian Ocean and the cold southeastern Indian Ocean resulted in an extremely strong positive phase of the IOD event and the highest IOD index value since 1997.

Along the coasts of the Arctic, SSTs were near average in DJF and MAM (Figs. 3.2a,b) but above average $\left(+1.0^{\circ} \mathrm{C}\right.$ to $+2.0^{\circ} \mathrm{C}$; $\geq 2 \mathrm{std}$. dev.) in JJA and SON (Figs. 3.2c,d), which may be directly associated with the reduction of sea ice concentration. Similarly, south of Greenland, SSTs were near average in DJF and MAM but significantly above average in JJA and SON $\left(+1.0^{\circ} \mathrm{C}\right.$ to $+2.0^{\circ} \mathrm{C} ; \geq 2 \mathrm{std}$. dev.), associated with the reduction of sea ice concentration in these areas. In the Labrador Sea, SSTAs were high in JJA and SON but lower in DJF and MAM.

In the northern North Atlantic between $60^{\circ} \mathrm{N}$ and $80^{\circ} \mathrm{N}$, above-average SSTs persisted throughout all seasons $\left(+0.5^{\circ} \mathrm{C}\right.$ to $1.0^{\circ} \mathrm{C} ; 1$ to $2 \mathrm{std}$. dev.). In the North Atlantic between $30^{\circ} \mathrm{N}$ and $60^{\circ} \mathrm{N}$, SSTAs were negative $\left(-0.5^{\circ} \mathrm{C}\right)$ in DJF, MAM, and JJA (Figs. 3.2a,b,c) but closer to average in SON (Fig. 3.2d). In the tropical North Atlantic, SSTAs were slightly below average $\left(-0.5^{\circ} \mathrm{C}\right)$ throughout all seasons. In the equatorial Atlantic, SSTAs were $+0.5^{\circ} \mathrm{C}$ above average in DJF and MAM, weakening in JJA, and strengthening again in SON, associated with the emergence of a weak Atlantic Niño that usually peaks in JJA (Chang et al. 2006). In the subtropical South Atlantic, SSTAs were

(a)

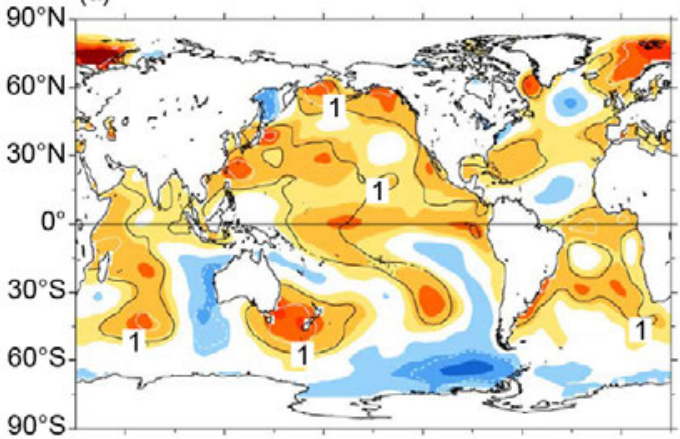

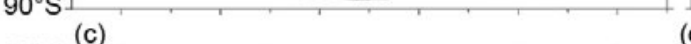

(b)

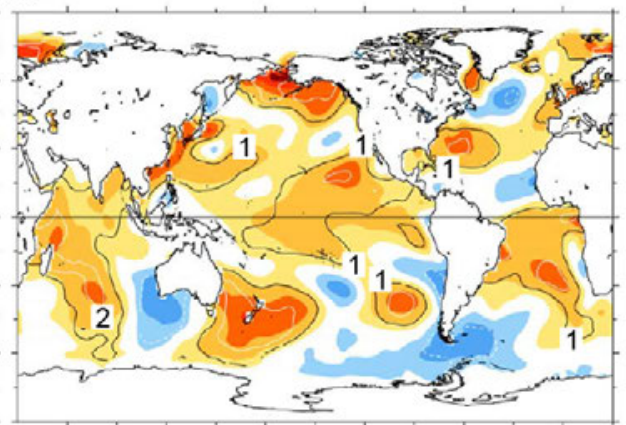

(d)

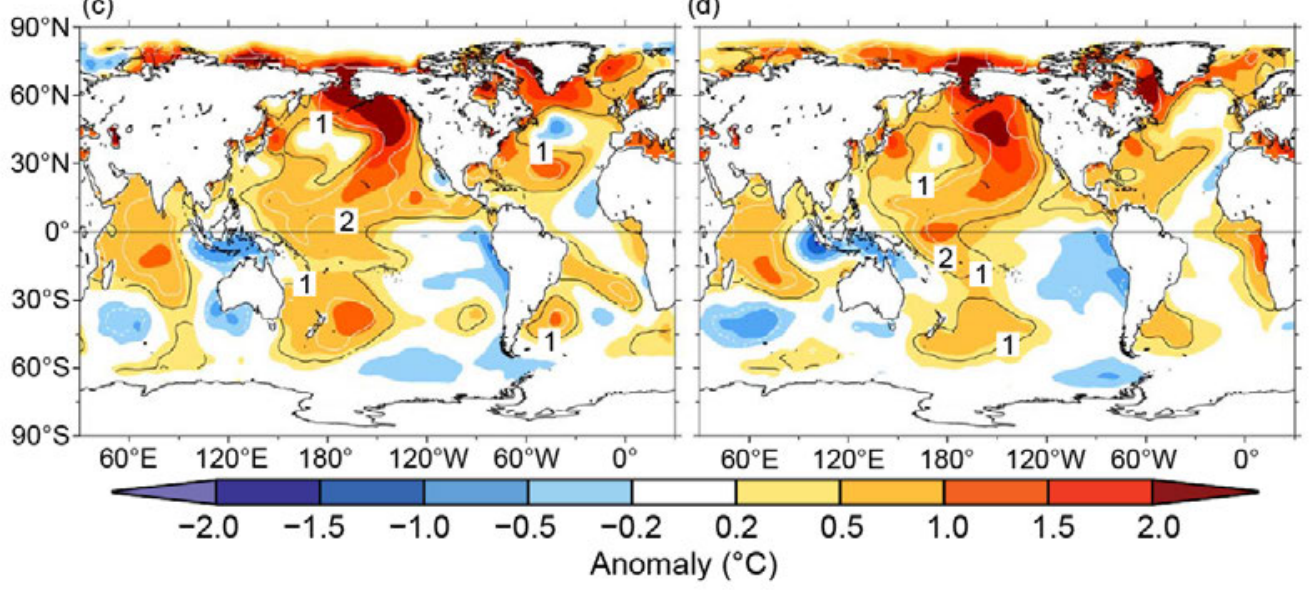

Fig. 3.2. Seasonally averaged SSTAs of ERSSTv5 ( ${ }^{\circ} \mathrm{C}$; shading) for (a) Dec-Feb 2018/19, (b) Mar-May 2019, (c) Jun-Aug 2019, and (d) Sep-Nov 2019. The normalized seasonal mean SSTA based on seasonal mean 1 std. dev. over 1981-2010, indicated by contours of -1 (dashed white), 1 (solid black), and 2 (solid white). 
$+0.5^{\circ} \mathrm{C}$ to $+1.0^{\circ} \mathrm{C}$ ( 1 to $2 \mathrm{std}$. dev.) in DJF and MAM, and the area of warm SSTAs was reduced in JJA and further diminished in SON.

Overall, the global ocean warming trends of SSTs since the 1950s remained significant (Figs. 3.3a,b; Table 3.1), with noticeably higher SSTAs in $2019\left(+0.41^{\circ} \mathrm{C}\right)$ than in $2018\left(+0.33^{\circ} \mathrm{C}\right)$. The year 2019 was the second-warmest year since 1950 after the record year of $2016\left(+0.44^{\circ} \mathrm{C}\right)$. The linear trends of globally annually averaged SSTAs were $0.10^{\circ} \pm 0.01^{\circ} \mathrm{C}$ decade $^{-1}$ over $1950-2019$ (Table 3.1). The warming appeared largest in the tropical Indian Ocean (Fig. 3.3e; $0.14^{\circ} \pm 0.02^{\circ} \mathrm{C}$ decade $^{-1}$ ) and smallest in the North Pacific (Fig. 3.3d; $0.09^{\circ} \pm 0.03^{\circ} \mathrm{C} \mathrm{decade}^{-1}$ ). The uncertainty of the trends represents the $95 \%$ confidence level of the linear fitting uncertainty and 1000-member data uncertainty.

\begin{tabular}{|c|c|c|c|}
\hline \multicolumn{4}{|c|}{$\begin{array}{l}\text { Table 3.1. Linear trends }\left({ }^{\circ} \mathrm{C} \text { decade }{ }^{-1}\right) \text { of annually and regionally averaged SSTAs from ERSSTV5, HadSST3, } \\
\text { and DOISST. The uncertainties at } 95 \% \text { confidence level are estimated by accounting for the effective } \\
\text { sampling number quantified by lag- } 1 \text { auto correlation on the degrees of freedom of annually-averaged } \\
\text { SST series. }\end{array}$} \\
\hline Product & Region & 2000-2019 ( ${ }^{\circ} \mathrm{C}$ decade $\left.^{-1}\right)$ & $1950-2019\left({ }^{\circ} \mathrm{C}\right.$ decade $\left.^{-1}\right)$ \\
\hline HadSST.3.1.1.0 & Global & $0.140 \pm 0.065$ & $0.086 \pm 0.016$ \\
\hline DOISST & Global & $0.156 \pm 0.058$ & $\mathrm{~N} / \mathrm{A}$ \\
\hline ERSSTv5 & Global & $0.170 \pm 0.075$ & $0.101 \pm 0.013$ \\
\hline ERSSTv5 & Tropical Pacific $\left(30^{\circ} \mathrm{N}-30^{\circ} \mathrm{S}\right)$ & $0.188 \pm 0.185$ & $0.102 \pm 0.028$ \\
\hline ERSSTv5 & North Pacific $\left(30^{\circ}-60^{\circ} \mathrm{N}\right)$ & $0.287 \pm 0.172$ & $0.087 \pm 0.028$ \\
\hline ERSSTV5 & Tropical Indian Ocean $\left(30^{\circ} \mathrm{N}-30^{\circ} \mathrm{S}\right)$ & $0.199 \pm 0.098$ & $0.141 \pm 0.018$ \\
\hline ERSSTV5 & North Atlantic $\left(30^{\circ}-60^{\circ} \mathrm{N}\right)$ & $0.142 \pm 0.087$ & $0.101 \pm 0.034$ \\
\hline ERSSTv5 & Tropical Atlantic $\left(30^{\circ} \mathrm{N}-30^{\circ} \mathrm{S}\right)$ & $0.133 \pm 0.097$ & $0.109 \pm 0.020$ \\
\hline ERSSTV5 & Southern Ocean $\left(30^{\circ}-60^{\circ} \mathrm{S}\right)$ & $0.129 \pm 0.060$ & $0.099 \pm 0.016$ \\
\hline
\end{tabular}

In addition to the long-term SST trend and interannual variability, interdecadal variations of SSTAs can be seen in all ocean basins, although the amplitude of the variations was smaller in the Southern Ocean (Fig. 3.3h). The variations associated with the Atlantic Multidecadal Variability (Schlesinger and Ramankutty 1994) can be identified in the North Atlantic with warm periods in the 1950s and over the 1990s-2010s, and a cold period over the 1960s-80s (Fig. 3.3f). Similarly, SSTAs in the North Pacific (Fig. 3.3d) decreased from the 1950s to the late 1980s, followed by an increase from the later 1980s to the 2010s.

SSTAs in ERSSTv5 were compared with those in DOISST, HadSST3.1.1.0, and HadSST.4.0.0.0. All data sets were averaged to an annual $2^{\circ} \times 2^{\circ}$ grid for comparison purposes. Comparisons (Fig. 3.3) indicate that the SSTA departures of DOISST and HadSST.3.1.1.0 from ERSSTv5 are largely within 2 std. dev. (gray shading in Fig. 3.3). The 2 std. dev. was derived from a 1000-member ensemble analysis based on ERSSTv5 (Huang et al. 2020) and centered to SSTAs of ERSSTv5. Overall, the HadSST4.0.0.0 is more consistent with ERSSTv5 than HadSST.3.1.1.0. In the 2000s-10s, SSTAs in the Southern Ocean were slightly higher in DOISST than in ERSSTv5. Previous studies (Huang et al. 2015; Kent et al. 2017) have indicated that these SSTA differences are mostly attributed to the differences in bias corrections to ship observations in those products. These SST differences resulted in a slightly weaker SSTA trend in HadSST.3.1.1.0 over both 1950-2019 and 2000-19 (Table 3.1). In contrast, SST trends were slightly higher in DOISST over 2000-19. 


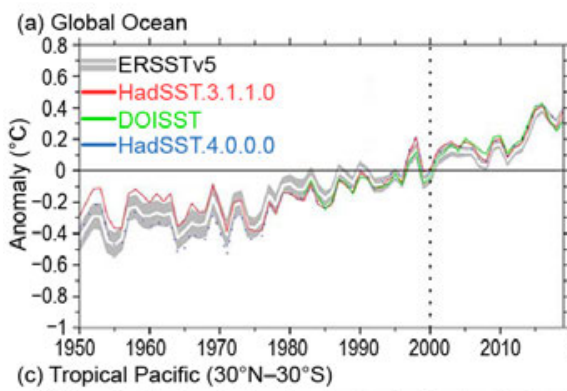

(b) Global Ocean
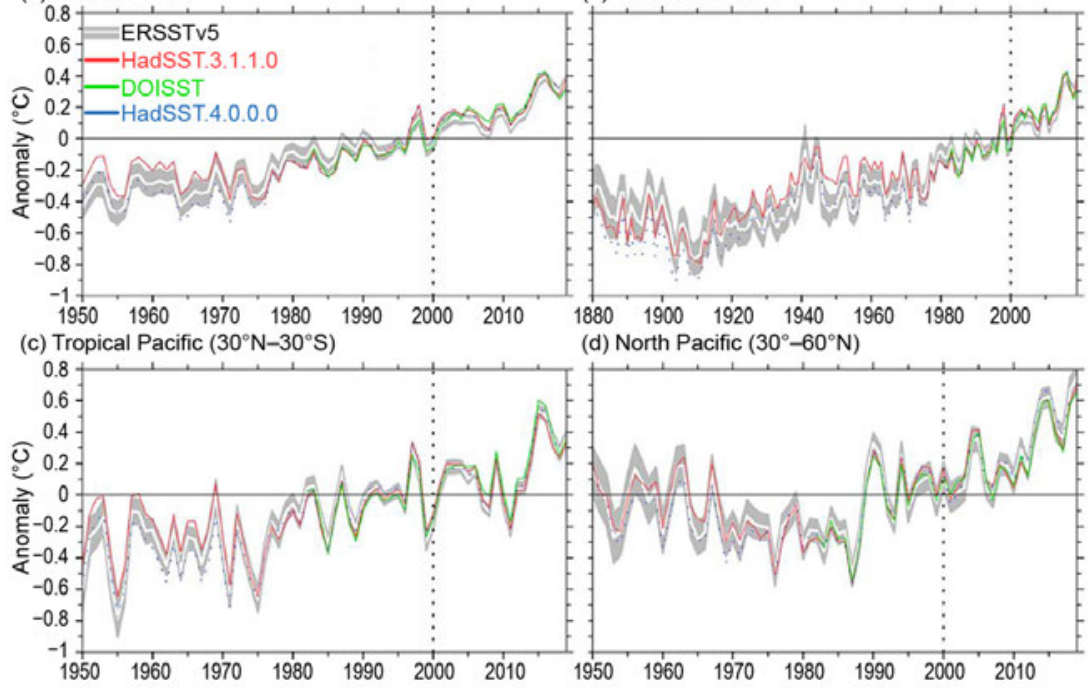
(d) North Pacific $\left(30^{\circ}-60^{\circ} \mathrm{N}\right)$

(e) Tropical Indian Ocean $\left(30^{\circ} \mathrm{N}-30^{\circ} \mathrm{S}\right)$
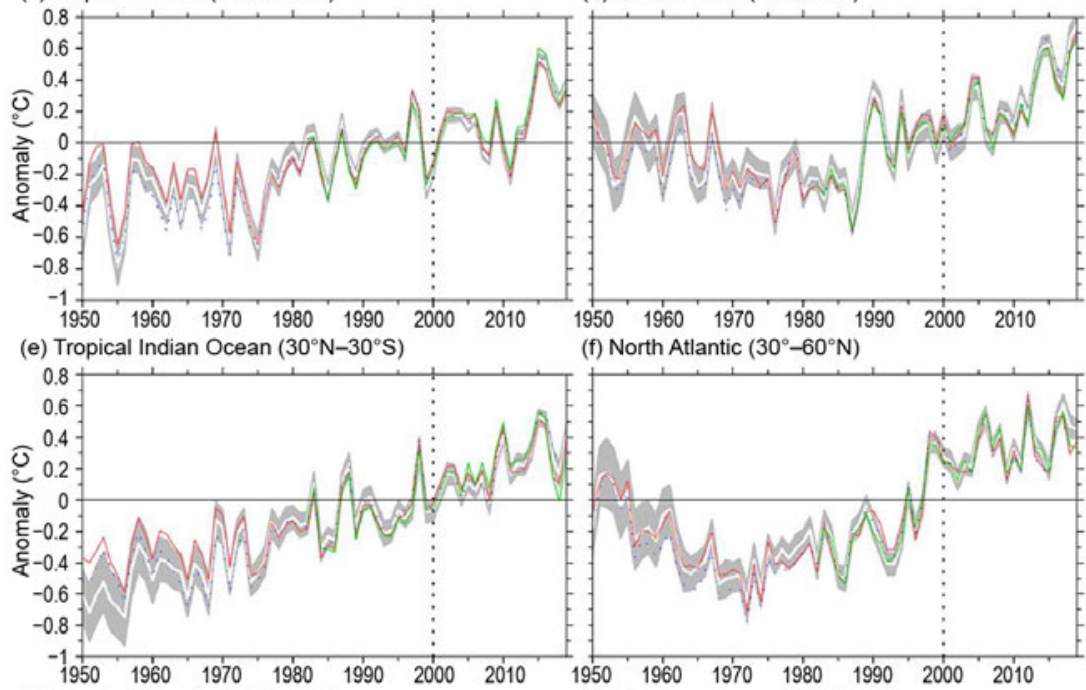

(g) Tropical Atlantic $\left(30^{\circ} \mathrm{N}-30^{\circ} \mathrm{S}\right)$
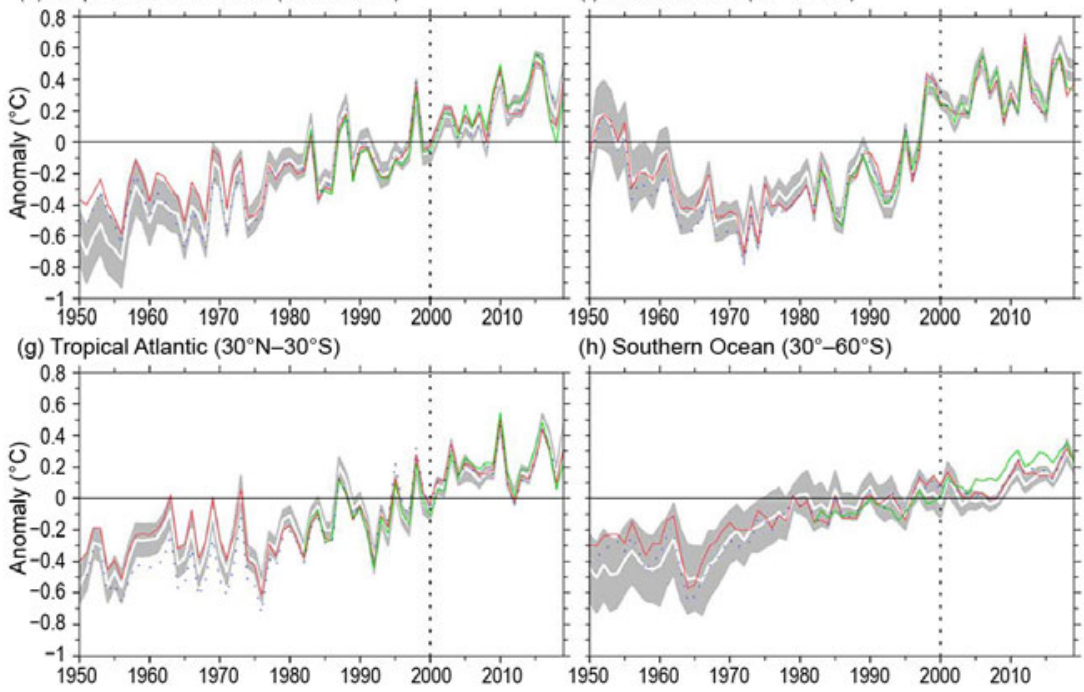

(h) Southern Ocean $\left(30^{\circ}-60^{\circ} \mathrm{S}\right)$

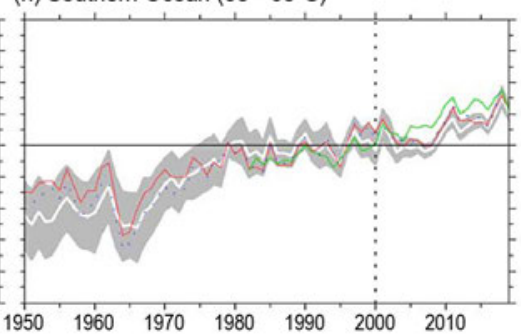

Fig. 3.3. Annually averaged SSTAs $\left({ }^{\circ} \mathrm{C}\right)$ of ERSSTv5 (solid white) and $2 \mathrm{std}$. dev. (gray shading) of ERSSTv5, SSTAs of DOISST (solid green), and SSTAs of HadSST.3.1.1.0 (solid red) and HadSST.4.0.0.0 (dotted blue) in 1950-2019 except for (b). (a) Global, (b) global in 1880-2019, (c) tropical Pacific Ocean, (d) North Pacific Ocean, (e) tropical Indian Ocean, (f) North Atlantic Ocean, (g) tropical Atlantic Ocean, and (h) Southern Ocean. The year 2000 is indicated by a vertical black dotted line.

c. Ocean heat content-G. C. Johnson, J. M. Lyman, T. Boyer, L. Cheng, C. M. Domingues, J. Gilson, M. Ishii, R. E. Killick, D. Monselesan, S. G. Purkey, and S. E. Wijffels

One degree of warming in the global ocean stores more than 1000 times the heat energy of one degree of warming in the atmosphere owing to the higher mass of the ocean (280 times that of the atmosphere) and the larger heat capacity of water (four times that of air). Ocean warming accounts for about 89\% of the total increase in Earth's energy storage from 1960 to 2018, compared to the atmosphere's 1\%. Ocean currents also transport substantial amounts of heat (Talley 2003). Ocean heat storage and transport play large roles in the El Niño-Southern Oscillation (ENSO; Johnson and Birnbaum 2017), tropical cyclone activity (Goni et al. 2009), sea level variability and rates of change (section 3f), and melting of ice sheet outlet glaciers around Greenland (Castro de la Guardia et al. 2015) and Antarctica (Schmidtko et al. 2014).

Maps of annual (Fig. 3.4) upper (0-700 m) ocean heat content anomaly (OHCA) relative to a 1993-2019 baseline mean are generated from a combination of in situ ocean temperature data and satellite altimetry data following Willis et al. (2004), but using Argo (Riser et al. 2016) data downloaded in January 2020. Near-global average seasonal temperature anomalies (Fig. 3.5) versus pressure from Argo data (Roemmich and Gilson 2009, updated) since 2004 and in situ global 
(a) 2019

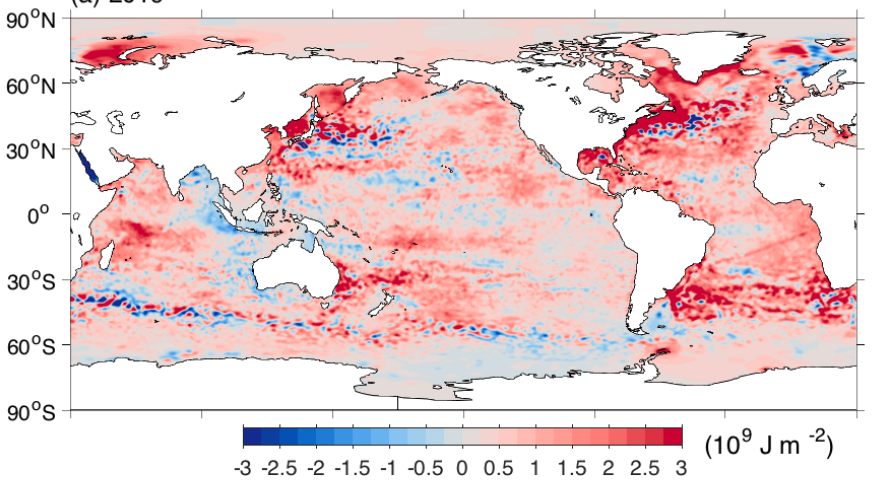

(b) 2019 minus 2018

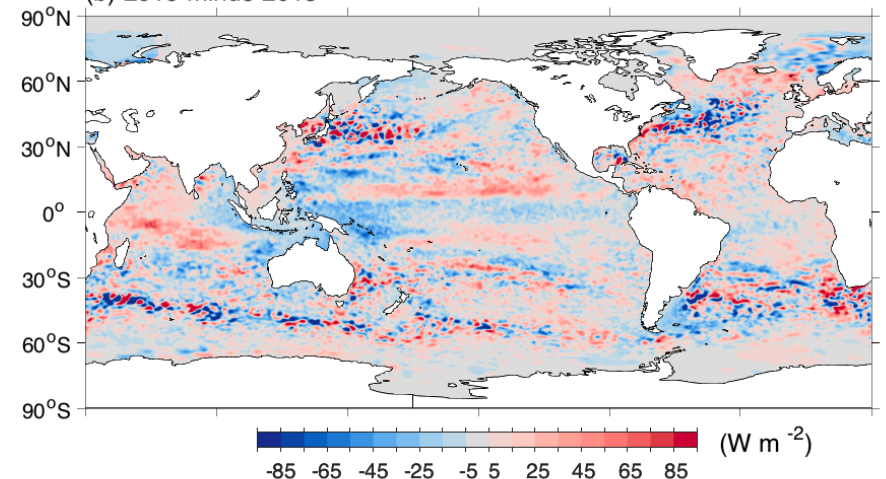

(c) 1993-2019 trend

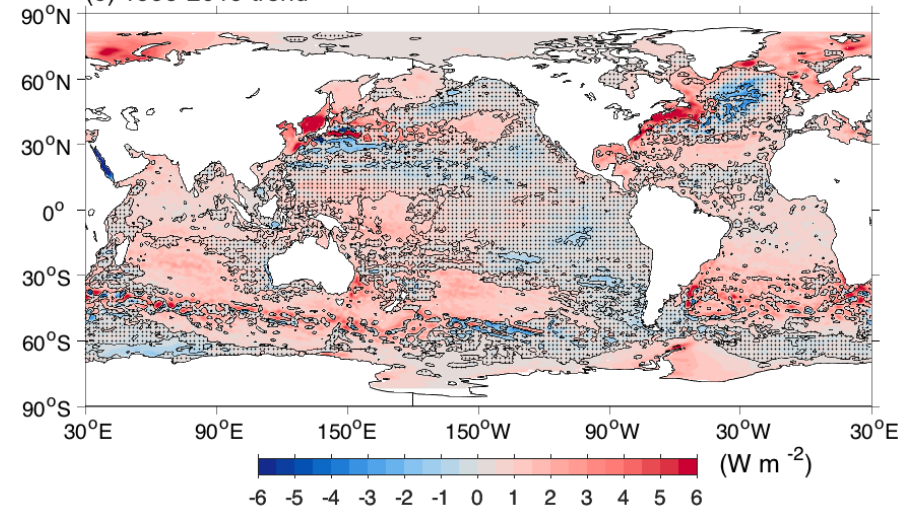

Fig. 3.4. (a) Combined satellite altimeter and in situ ocean temperature data estimate of upper (0-700 m) OHCA $\left(\times 10^{9} \mathrm{~J} \mathrm{~m}^{-2}\right)$ for 2019 analyzed following Willis et al. (2004), but using an Argo monthly climatology and displayed relative to the 1993-2019 baseline. (b) 2019 minus 2018 combined estimates of OHCA expressed as a local surface heat flux equivalent $\left(\mathrm{W} \mathrm{m}^{-2}\right)$. For (a) and (b) comparisons, note that $95 \mathrm{~W} \mathrm{~m}^{-2}$ applied over one year results in a $3 \times$ $10^{9} \mathrm{~J} \mathrm{~m}^{-2}$ change of OHCA. (c) Linear trend from 1993-2019 of the combined estimates of upper $(0-700 \mathrm{~m})$ annual OHCA $\left(\mathrm{W} \mathrm{m}^{-2}\right)$. Areas with statistically insignificant trends are stippled.

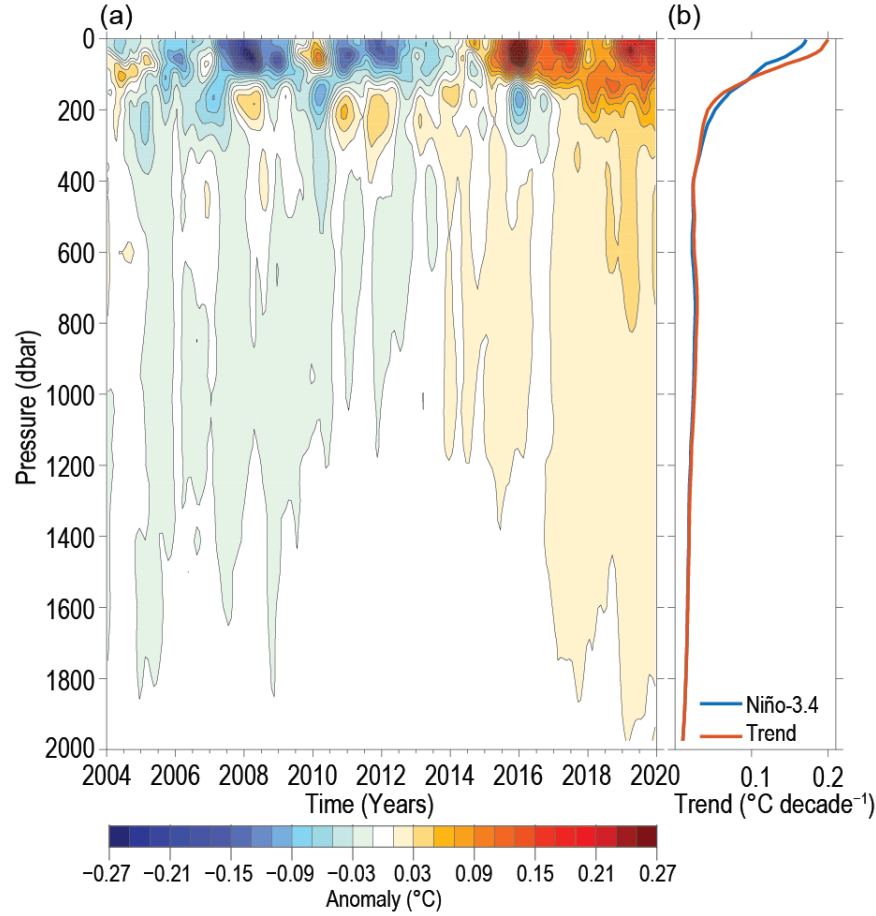

Fig. 3.5. (a) Near-global $\left(80^{\circ} \mathrm{N}-65^{\circ} \mathrm{S}\right.$, excluding continental shelves, the Indonesian seas, and the Sea of Okhostk) integrals of monthly ocean temperature anomalies $\left({ }^{\circ} \mathrm{C}\right.$; updated from Roemmich and Gilson 2009) relative to record-length average monthly values, smoothed with a 5-month Hanning filter and contoured at odd $0.02^{\circ} \mathrm{C}$ intervals (see color bar) versus pressure and time. (b) Linear trend of temperature anomalies over time for the length of the record in (a) plotted versus pressure in ${ }^{\circ} \mathrm{C}$ decade ${ }^{-1}$ (orange line), and trend with a Niño3.4 regression removed (blue line) following Johnson and Birnbaum (2017).

estimates of OHCA (Fig. 3.6) for three pressure layers (0-700 m, 700-2000 m, and 2000-6000 m) from seven different research groups are also discussed.

The 2018/19 tendency of 0-700 m OHCA (Fig. 3.4b) in the Pacific shows a decrease along the equator, with a near-zonal band of increase just to the north, consistent with the discharge of heat from the equatorial region after the weak El Niño of 2018/19 and a decrease in eastward surface current anomalies north of the equator from 2018 to 2019 (see Fig. 3.17b). Outside of the equatorial region in the Pacific, there are nearly zonal bands of increases and decreases that tend to tilt equatorward to the west. Structures like these are quite common in the OHCA tendency maps from previous years and are reminiscent of Rossby wave dynamics. There are also, as usual, small-scale increases and decreases at eddy scales especially visible in and poleward of the subtropical gyres. Throughout much of the Pacific, the 2019 upper OHCA is generally above the long-term average (Fig. 3.4a), with the most notable departures being patches of below-average values southwest and south of Hawaii and low values in the Southern Ocean from Drake Passage to about $150^{\circ} \mathrm{W}$. 

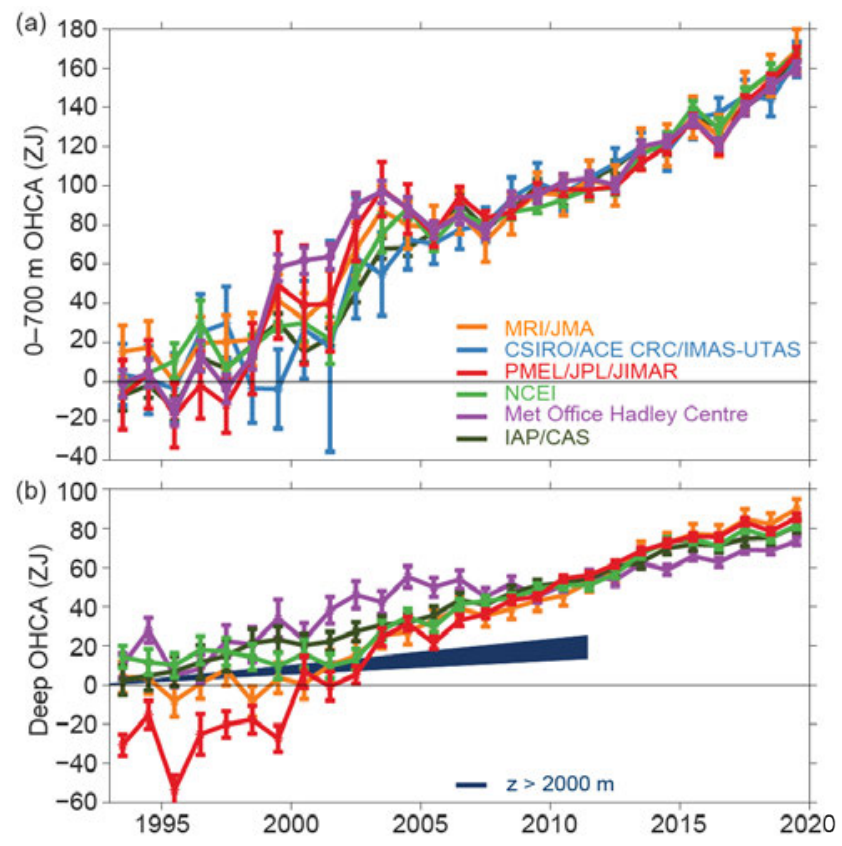

Fig. 3.6. (a) Annual average global integrals of in situ estimates of upper (0-700 m) OHCA (ZJ; $\left.1 \mathrm{ZJ}=10^{21} \mathrm{~J}\right)$ for 1993-2019 with standard errors of the mean. The MRI/JMA estimate is an update of Ishii et al. (2017). The CSIRO/ACE CRC/IMAS-UTAS estimate is an update of Domingues et al. (2008). The PMEL/JPL/JIMAR estimate is an update and refinement of Lyman and Johnson (2014). The NCEI estimate follows Levitus et al. (2012). The Met Office Hadley Centre estimate is computed from gridded monthly temperature anomalies (relative to 1950-2019) following Palmer et al. (2007). The IAP/CAS estimate is reported in Cheng et al. (2020). See Johnson et al. (2014) for details on uncertainties, methods, and datasets. For comparison, all estimates have been individually offset (vertically on the plot), first to their individual 2005-19 means (the best-sampled time period), and then to their collective 1993 mean. (b) Annual average global integrals of in situ estimates of intermediate (700-2000 m) OHCA for 1993-2018 with standard errors of the mean, and a long-term trend with one standard error uncertainty shown from 1992.4-2011.5 for deep and abyssal ( $z>2000 \mathrm{~m}$ ) OHCA following Purkey and Johnson (2010) but updated using all repeat hydrographic section data available from https://cchdo.ucsd.edu/as of January 2020.

In the Indian Ocean, the 2018/19 tendency of 0-700-m OHCA (Fig. 3.4b) shows the strongest increases in a near-zonal band that again tilts equatorward to the west, starting at about $12^{\circ} \mathrm{S}$ well off the west coast of Australia and ending at about $6^{\circ} \mathrm{S}$ near Africa. The largest decreases are observed in the eastern portion of the basin, just to the west of Indonesia and Australia, as well as patchy decreases between $35^{\circ} \mathrm{S}$ and $20^{\circ} \mathrm{S}$ across the basin and south of Australia. Smaller increases are evident across much of the Arabian Sea and the western portion of the Bay of Bengal. Upper OHCA values for 2019 were above the 1993-2019 mean in much of the Indian Ocean (Fig. 3.4a), with especially high values northeast of Madagascar and below-average values mostly found west of Indonesia and Australia. This pattern is consistent with a positive Indian Ocean dipole (IOD) pattern of SSTs (section 3b), which has been linked to bushfires in Australia and flooding in East Africa (see sections $7 \mathrm{~h} 4$ and 7e3, respectively). It is also consistent with the increase in westward surface current anomalies along and south of the equator in the Indian Ocean from 2018 to 2019 (see Fig. 3.17b).

The 2018/19 tendencies of 0-700-m OHCA (Fig. 3.4b) in the Atlantic Ocean are generally toward warming in the tropics and subtropics, as well as in the subpolar North Atlantic from northern Europe to northern Canada. Large-scale 2018/19 cooling tendencies are located east of Argentina and east of Canada from Nova Scotia to St. John's, Newfoundland. The only large-scale regions in the Atlantic with below-average heat content in 2019 (Fig. 3.4a) were east of Argentina and north of Norway. In a change from recent years, upper OHCA in 2019 was above the 1993-2019 average south of Greenland, in the vicinity of the Irminger Sea, where a cold area had persisted since around 2009 (see previous State of the Climate reports). However, the warm conditions off the east coast of North America that have also persisted since around 2009 intensified further. In 2019, there were no large areas in the North Atlantic that were cooler than average.

The large-scale statistically significant (Fig. 3.4C) regional patterns in the 1993-2019 local linear trends of upper OHCA are quite similar to those from 1993-2018 (Johnson et al. 2019). The limited areas with statistically significant negative trends are found mostly south of Greenland in the North Atlantic, south of the Kuroshio Extension across the North Pacific, in portions of the eastern South Pacific, and in the Red Sea. The much larger areas with statistically significant positive trends include much of the rest of the Atlantic Ocean, the western tropical Pacific, the central North Pacific, most of the Indian Ocean, most of the marginal seas except the Red Sea, and 
much of the South Pacific Ocean. The Arctic and portions of the Southern Ocean show warming as well, although those regions have limited in situ data.

Near-global average seasonal temperature anomalies (Fig. 3.5a) from the start of 2004 through the end of 2019 exhibit a clear record-length warming trend (Fig. 3.5b, orange line). In addition, during El Niño events (e.g., 2009/10 and 2014-16) the surface-to-100-dbar is warmer than surrounding years and 100-400 dbar is cooler as the east-west tilt of the equatorial Pacific thermocline flattens out (e.g., Roemmich and Gilson 2011; Johnson and Birnbaum 2017). The opposite pattern holds during La Niña events (e.g., 2007/08 and 2010-12) as the equatorial Pacific thermocline shoals in the east and deepens in the west. The overall warming trend (Fig. 3.5b, orange line) from 2004 to 2019 exceeds $0.2^{\circ} \mathrm{C}$ decade ${ }^{-1}$ near the surface, declining to less than $0.03^{\circ} \mathrm{C} \mathrm{decade}^{-1}$ below $300 \mathrm{dbar}$ and about $0.01^{\circ} \mathrm{C}$ decade $^{-1}$ by 2000 dbar. Removing a linear regression against the Niño3.4 index, which is correlated with ocean warming rates (e.g., Johnson and Birnbaum 2017), results in a decadal warming trend (Fig. 3.5b, blue line) that is slightly smaller in the upper 100 dbar, at about $0.18^{\circ} \mathrm{C}$ decade ${ }^{-1}$ near the surface and slightly larger than the simple linear trend from about 100 dbar to 300 dbar, as expected given the large El Niño near the end of the record. Since the start of 2017, temperatures from the surface to almost 2000 dbar are higher than the 2004-19 average (Fig. 3.5a). While 2018 was slightly warmer than 2019 from 110-225 dbar, 2019 was as warm or warmer than all other years over the full measured depth range.

The analysis is extended back in time from the Argo period to 1993 using sparser, more heterogeneous historical data collected mostly from ships (e.g., Abraham et al. 2013). The six different estimates of annual globally integrated 0-700-m OHCA (Fig. 3.6a) all reveal a large increase since 1993, with all of the analyses reporting 2019 as a record high. The globally integrated 700-2000-m OCHA annual values (Fig. 3.6b) vary more among analyses, but all report 2019 as a record high, and the long-term warming trend in this layer is also clear. Globally integrated OHCA values in both layers vary more both from year to year for individual years and from estimate to estimate in any given year prior to the achievement of a near-global Argo array around 2005. The water column from 0-700 and 700-2000 m gained $14( \pm 5)$ and $6( \pm 1)$ Zettajoules (ZJ), respectively (means and standard deviations given) from 2018 to 2019. Causes of differences among estimates are discussed in G. C. Johnson et al. (2015).

The rate of heat gain from linear fits to each of the six global integral estimates of $0-700 \mathrm{~m}$ OHCA from 1993 through 2019 (Fig. 3.6a) ranges from $0.36( \pm 0.06)$ to $0.41( \pm 0.04) \mathrm{W} \mathrm{m}^{-2}$ applied over the surface area of Earth (Table 3.2). Linear trends from $700 \mathrm{~m}$ to $2000 \mathrm{~m}$ over the same time period range from $0.14( \pm 0.04)$ to $0.32( \pm 0.03) \mathrm{W} \mathrm{m}^{-2}$. Trends in the $0-700$-m layer all agree within their 5\%-95\% uncertainties, but as noted in previous reports, the Pacific Marine Environmental Laboratory/Joint Institute of Marine and Atmsopheric Research/Jet Propulsion Laboratory (PMEL/JIMAR/ JPL) trend in the 700-2000 m layer, which is quite sparsely sampled prior to the start of the Argo era (circa 2005), does not. Different methods for dealing with under-sampled regions in analyses likely cause this disagreement. For 2000-6000 m, the linear trend is $0.06( \pm 0.03) \mathrm{W} \mathrm{m}^{-2}$

\begin{tabular}{|c|c|c|c|}
\hline \multirow[b]{2}{*}{ Research Group } & \multicolumn{3}{|c|}{$\begin{array}{l}\text { Global ocean heat content trends }\left(\mathrm{W} \mathrm{m}^{-2}\right) \\
\text { for three depth ranges }\end{array}$} \\
\hline & $0-700 \mathrm{~m}$ & $700-2000 \mathrm{~m}$ & $2000-6000 \mathrm{~m}$ \\
\hline MRI/JMA & $0.36 \pm 0.06$ & $0.24 \pm 0.05$ & - \\
\hline CSIRO/ACE/CRC/IMAS/UTAS & $0.40 \pm 0.06$ & - & - \\
\hline PMEL/JPL/JIMAR & $0.39 \pm 0.13$ & $0.32 \pm 0.03$ & - \\
\hline NCEI & $0.39 \pm 0.06$ & $0.19 \pm 0.06$ & - \\
\hline Met Office Hadley Centre & $0.37 \pm 0.13$ & $0.14 \pm 0.04$ & - \\
\hline IAP/CAS & $0.41 \pm 0.04$ & $0.19 \pm 0.01$ & - \\
\hline Purkey and Johnson & 一 & & $0.06 \pm 0.03$ \\
\hline
\end{tabular}


from June 1992 to July 2011, using repeat hydrographic section data collected from 1981 to 2019 to update the estimate of Purkey and Johnson (2010). Summing the three layers (with their slightly different time periods), the full-depth ocean heat gain rate for the period from approximately 1993 to 2019 ranges from 0.55 to $0.79 \mathrm{~W} \mathrm{~m}^{-2}$. Estimates starting circa 2005 have much smaller uncertainties (e.g., Johnson et al. 2016).

\section{d. Salinity-G. C. Johnson, J. Reagan, J. M. Lyman, T. Boyer, C. Schmid, and R. Locarnini}

\section{1) Introduction-G. C. Johnson and J. Reagan}

Salinity, the fraction of dissolved salts in water, and temperature determine the density of seawater at a given pressure. At high latitudes where vertical temperature gradients are small, low near-surface salinity values can be responsible for much of the density stratification. At lower latitudes, fresh near-surface barrier layers can limit the vertical extent of ocean exchange with the atmosphere (e.g., Lukas and Lindstrom 1991). Salinity variability can alter the density patterns that are integral to the global thermohaline circulation (e.g., Gordon 1986; Broecker 1991). One prominent limb of that circulation, the Atlantic meridional overturning circulation (AMOC; section 3h), is particularly susceptible to changes in salinity (e.g., Liu et al. 2017). Salinity is a largely conservative water property, indicating where a water mass was originally formed at the surface and subducted into the ocean's interior (e.g., Skliris et al. 2014). Where precipitation dominates evaporation, near-surface conditions are fresher (i.e., along the Intertropical Convergence Zone [ITCZ] and at high latitudes), and where evaporation dominates precipitation, they are saltier (i.e., in the subtropics). With $\sim 80 \%$ of the global hydrological cycle taking place over the ocean (e.g., Durack 2015), near-surface salinity changes over time can serve as a broad-scale rain gauge (e.g., Terray et al. 2012) used to diagnose hydrological cycle amplifications associated with global warming (e.g., Durack et al. 2012). Finally, besides atmospheric freshwater fluxes, other factors modify salinity, such as advection, mixing, entrainment, sea ice melt/freeze, and river runoff (e.g., Ren et al. 2011).

To investigate interannual changes of subsurface salinity, all available salinity profile data are quality controlled following Boyer et al. (2018) and then used to derive $1^{\circ}$ monthly mean gridded salinity anomalies relative to a long-term monthly mean for the period 1955-2012 (World Ocean Atlas 2013 version 2 [WOA13v2]; Zweng et al. 2013) at standard depths from the surface to 2000-m depth (Boyer et al. 2013). In recent years, the largest source of salinity profiles is the profiling floats of the Argo program (Riser et al. 2016). These data are a mix of real-time (preliminary) and delayed-mode (scientific quality controlled) observations. Hence, the estimates presented here could change after all data are subjected to scientific quality control. The sea surface salinity (SSS) analysis relies on Argo data downloaded in January 2020, with annual maps generated following Johnson and Lyman (2012) as well as monthly maps of bulk (as opposed to skin) SSS data from the Blended Analysis of Surface Salinity (BASS; Xie et al. 2014). BASS blends in situ SSS data with data from the Aquarius (Le Vine et al. 2014; mission ended in June 2015), Soil Moisture and Ocean Salinity (SMOS; Font et al. 2013), and recently from Soil Moisture Active Passive (SMAP; Fore et al. 2016) satellite missions. Despite the larger uncertainties of satellite data relative to Argo data, their higher spatial and temporal sampling allows higher spatial and temporal resolution maps than are possible using in situ data alone at present. All salinity values used in this section are dimensionless and reported on the Practical Salinity Scale-78 (PSS-78; Fofonoff and Lewis 1979).

\section{2) Sea surface salinity—G. C. Johnson and J. M. Lyman}

Unlike sea surface temperature (SST), for which anomalies tend to be damped by air-sea heat exchanges, SSS has no direct feedback with the atmosphere, so large-scale SSS anomalies can more easily persist over years. For instance, the 2019 fresh subpolar SSS anomaly observed in the northeast Pacific (Fig. 3.7a) arguably began in 2016, centered more in the central subpolar North Pacific, shifting eastward and building somewhat in strength and size between then and 

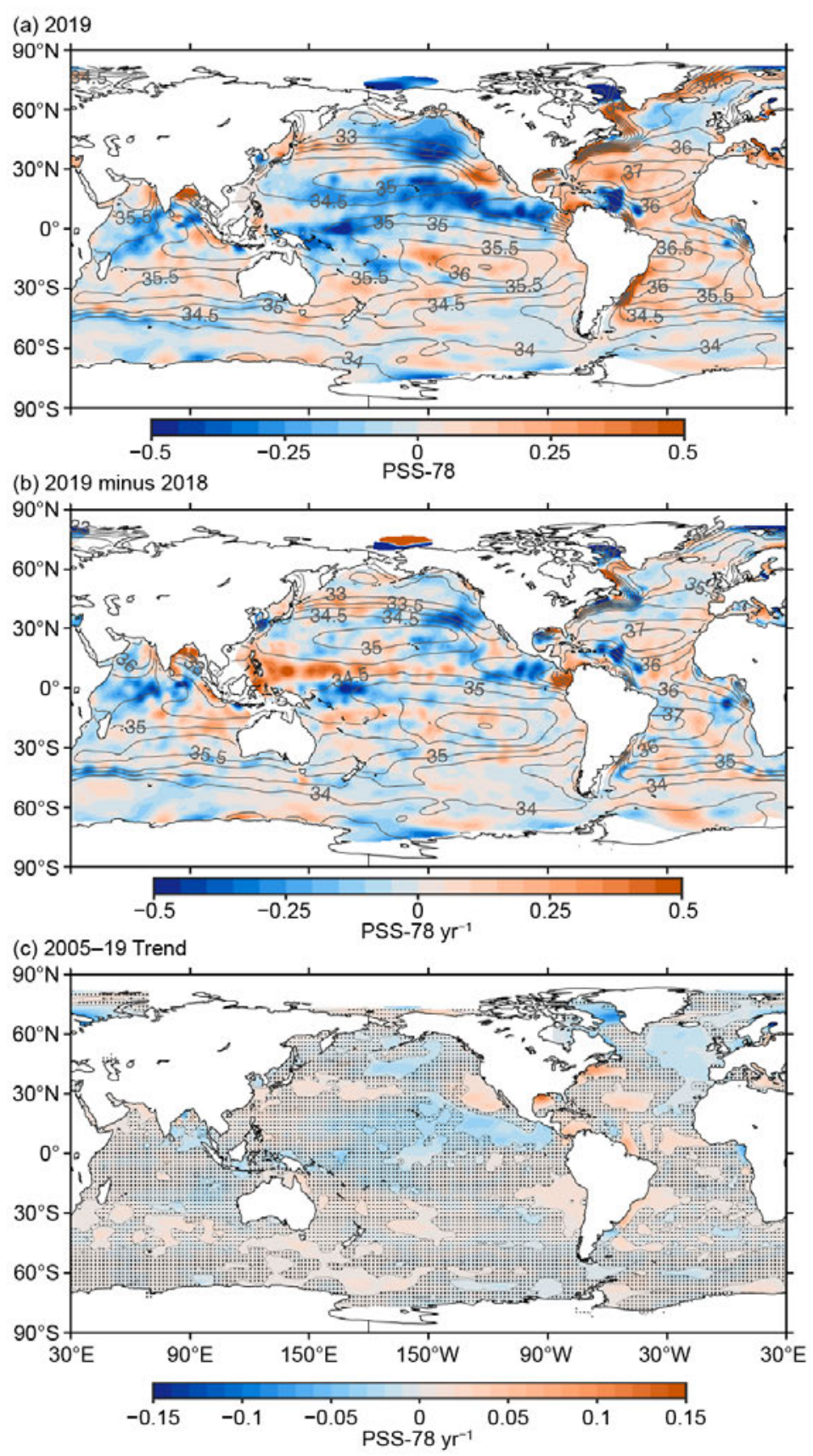

Fig. 3.7. (a) Map of the 2019 annual surface salinity anomaly (colors, PSS-78) with respect to monthly climatological 1955-2012 salinity fields from WOA13v2 (yearly average, gray contours at 0.5 intervals, PSS-78). (b) Difference of 2019 and 2018 surface salinity maps (colors, PSS-78 $\mathrm{yr}^{-1}$ ). White ocean areas are too data-poor (retaining $<80 \%$ of a large-scale signal) to map. (c) Map of local linear trends estimated from annual surface salinity anomalies for 2005-19 (colors, PSS-78 $\mathrm{yr}^{-1}$ ). Areas with statistically insignificant trends at $5 \%-95 \%$ confidence are stippled. All maps are made using Argo data. now (see previous State of the Climate reports). This fresh anomaly may be associated with the marine heat waves in the area that occurred in 2014-16 (e.g., Gentemann et al. 2017) and again in 2019 (see Fig. 3.1a). A fresh anomaly like this one would tend to increase stratification and reduce the ability of storms to deepen the mixed layer into colder subsurface water during winter, possibly even promoting warm SST anomalies.

In the tropical Pacific, the fresh 2019 SSS anomaly (Fig. 3.7a) observed over much of the ITCZ and South Pacific Convergence Zone (SPCZ) began around 2015 (see previous State of the Climate reports). While the location and strength have fluctuated somewhat, the persistence of this feature may be linked to increased precipitation in the area expected during El Niño conditions, which have occurred twice between 2015 and 2019. In the tropical Atlantic, the fresh anomaly north of the Amazon and Orinoco River outlets has grown from 2016 to 2019. In contrast to these longer-term patterns, the tropical Indian Ocean was mostly anomalously salty in the east and anomalously fresh in the west in 2019 (Fig. 3.7a), a pattern dominated by the changes from 2018 to 2019 (Fig. 3.7b) and perhaps related to the strongly positive phase of the Indian Ocean dipole (IOD) in 2019 (Fig. 3.1), which brings more precipitation to the west and drier conditions to the east (Fig. 3.11).

In 2019, salty SSS anomalies are associated with the subtropical salinity maxima in the South Indian, the South Pacific, and the North and South Atlantic Oceans (Fig. 3.7a), patterns that have largely persisted since at least 2006, the first year the State of the Climate reported on SSS. Also in the subtropics, the 2005-19 SSS trend is toward saltier conditions, with some subtropical regions in all of those oceans exhibiting salinification statistically significantly different from zero with 5\%-95\% uncertainty ranges (Fig. 3.7c,

unstippled orange areas). In contrast, the subpolar North Pacific and North Atlantic both have large regions with statistically significant freshening trends over 2005-19. These patterns are all consistent with an increase in the hydrological cycle over the oceans as the atmosphere warms and, therefore, can carry more water from regions (i.e., subtropical) where evaporation dominates to regions (i.e., subpolar) where precipitation (and river runoff) dominates (Rhein et al. 2013). In 
the Indian Ocean, there are also 2005-19 trends toward saltier values in the already salty Arabian Sea and fresher values in the already fresh Bay of Bengal. Finally, both the Brazil Current in the subtropical South Atlantic and the Gulf Stream extension are anomalously salty in 2019 (Fig. 3.7a) and show statistically significant trends toward saltier values from 2005 to 2019, with both areas having strong warming trends from $0-700 \mathrm{~m}$ as well (Fig. 3.4c).

In 2019, the seasonal BASS (Xie et al. 2014) SSS anomalies (Fig. 3.8) show the persistence of the Northern Hemisphere (NH) subpolar fresh anomalies and subtropical salty anomalies in both hemispheres. Tropical anomalies tend to be more seasonal, with the fresh anomaly in the Pacific ITCZ being strongest in boreal winter and spring, and the fresh anomaly north of the Amazon and Orinoco outflows in the western tropical Atlantic being strongest in boreal summer and autumn. With their higher spatial and temporal resolution, BASS data also confirm the persistent salty anomalies in the Brazil Current and the Gulf Stream extension, both regions with large SSS gradients near the coast, where the relatively sparse Argo sampling could cause mapping artifacts.

(a)

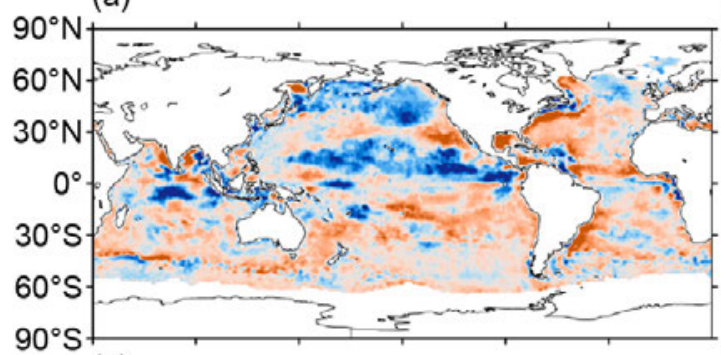

(c)

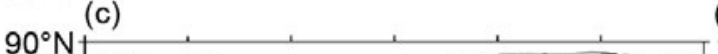

(b)

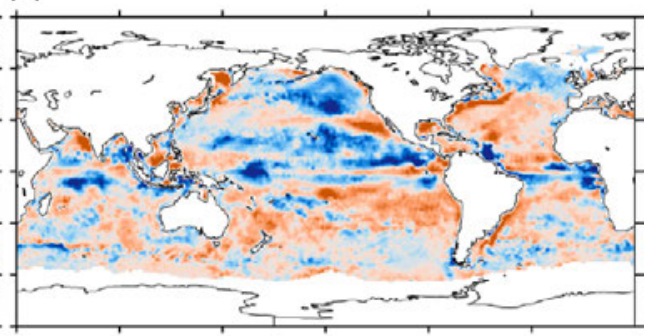

(d)

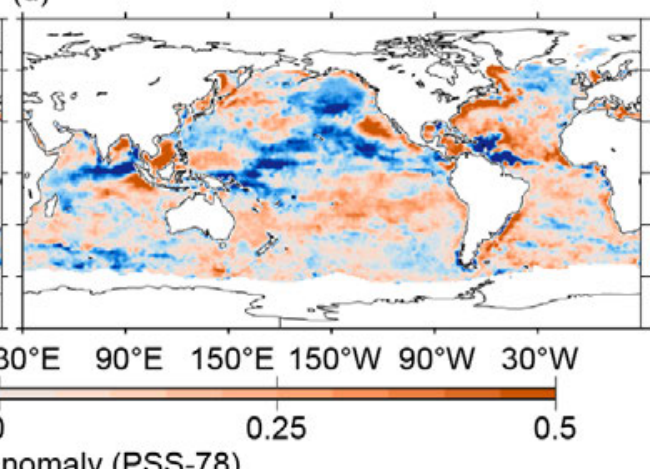

Fig. 3.8. Seasonal maps of SSS anomalies (colors, PSS-78) from monthly blended maps of satellite and in situ salinity data (BASS; Xie et al. 2014) relative to monthly climatological 1955-2012 salinity fields from WOA13v2 for (a) Dec-Feb 2018/19, (b) Mar-May 2019, (c) Jun-Aug 2019, and (d) Sep-Nov 2019. Areas with maximum monthly errors exceeding 10 PSS-78 are left white.

\section{3) Subsurface salinity-J. Reagan, T. Boyer, C. Schmid, and R. Locarnini}

Subsurface salinity anomalies primarily originate near the surface where they are largest and then weaken with depth; however, as these anomalies enter ocean's deeper depths they may persist for years or even decades. The Atlantic basin-average monthly salinity anomalies (relative to the long-term mean from the World Ocean Atlas 2013; Zweng et al. 2013) exhibited a similar pattern for the entire 2010-19 decade (Fig. 3.9a). Salty (>0.01) anomalies dominated the upper $500 \mathrm{~m}$ with increasing salty anomalies near the surface $(>0.05)$ and mostly weak anomalies $(<|0.005|)$ at depths greater than $500 \mathrm{~m}$ throughout the decade. In 2019, and for the second consecutive year, the Atlantic Ocean basin experienced salty anomalies throughout the year from 0-1500 m. Since late 2015, large salinity anomalies (>0.04) that initially only existed near the surface have deepened to $\sim 200 \mathrm{~m}$ in late 2019 . There is also evidence of salty anomalies (>0.01) deepening 
between 200 and 600 m from 2018 to 2019 (Figs. 3.9a,b). The progression of these deepening salinity anomalies since 2015 can be seen in prior year-to-year changes (Figs. 3.9b in Reagan et al. 2017, 2018, 2019). From 2018 to 2019 there was also an increase in salinity of $\sim 0.15$ in the upper 50 $\mathrm{m}$ of the Atlantic Ocean (Fig. 3.9b), which is a reversal of the freshening seen between 2017 and 2018 (Fig. 3.9b in Reagan et al. 2019).

The 2018-19 statistically significant ( $> \pm 1$ std. dev., see description of significance in Fig. 3.9) changes in the Atlantic basin zonal-average salinity anomalies (Fig. 3.9c) show salinification $\left(>0.03\right.$ ) between $7^{\circ}-20^{\circ} \mathrm{N}$ from the surface down to $250 \mathrm{~m}$, which may be the main driver for the salinification in the upper $50 \mathrm{~m}$ of the Atlantic basin (Fig. 3.9b), and freshening from $40^{\circ}-45^{\circ} \mathrm{N}$ extending from the surface (maximum of $\sim-0.15)$ down to $300 \mathrm{~m}(\sim-0.03)$. There also is salinification in the upper $100 \mathrm{~m}$ north of $60^{\circ} \mathrm{N}$. In the South Atlantic, weak salinification ( 0.03) from the surface to $\sim 200 \mathrm{~m}$ centered near $45^{\circ} \mathrm{S}$ and subsurface freshening $(\sim-0.03)$ centered near $25^{\circ} \mathrm{S}$ and $150 \mathrm{~m}$ are evident.

The 2019 Pacific basin-average monthly salinity anomalies revealed a similar pattern to that present since mid-2014 (Fig. 3.9d). There were large fresh anomalies $(<-0.02)$ in the upper $100 \mathrm{~m}$, salty anomalies (>0.01) from 125 to $225 \mathrm{~m}$, fresh anomalies $(<-0.005)$ from 300 to $550 \mathrm{~m}$, and mostly weak anomalies $(<|0.005|)$ below $700 \mathrm{~m}$. From 2017 to 2018 there was a notable deepening of salty anomalies in the Pacific centered around $200 \mathrm{~m}$ (Figs. 3.9c,d in Reagan et al. 2019); however, this deepening of salty anomalies ceased in 2019 (Figs. 3.9d,e). Additionally, from 2018 to 2019 there is freshening ( -0.01 maximum at $75 \mathrm{~m}$ ) between 50 and $125 \mathrm{~m}$ (Fig. 3.9e) corresponding to a slight deepening of freshening in the Pacific (Fig. 3.9d).
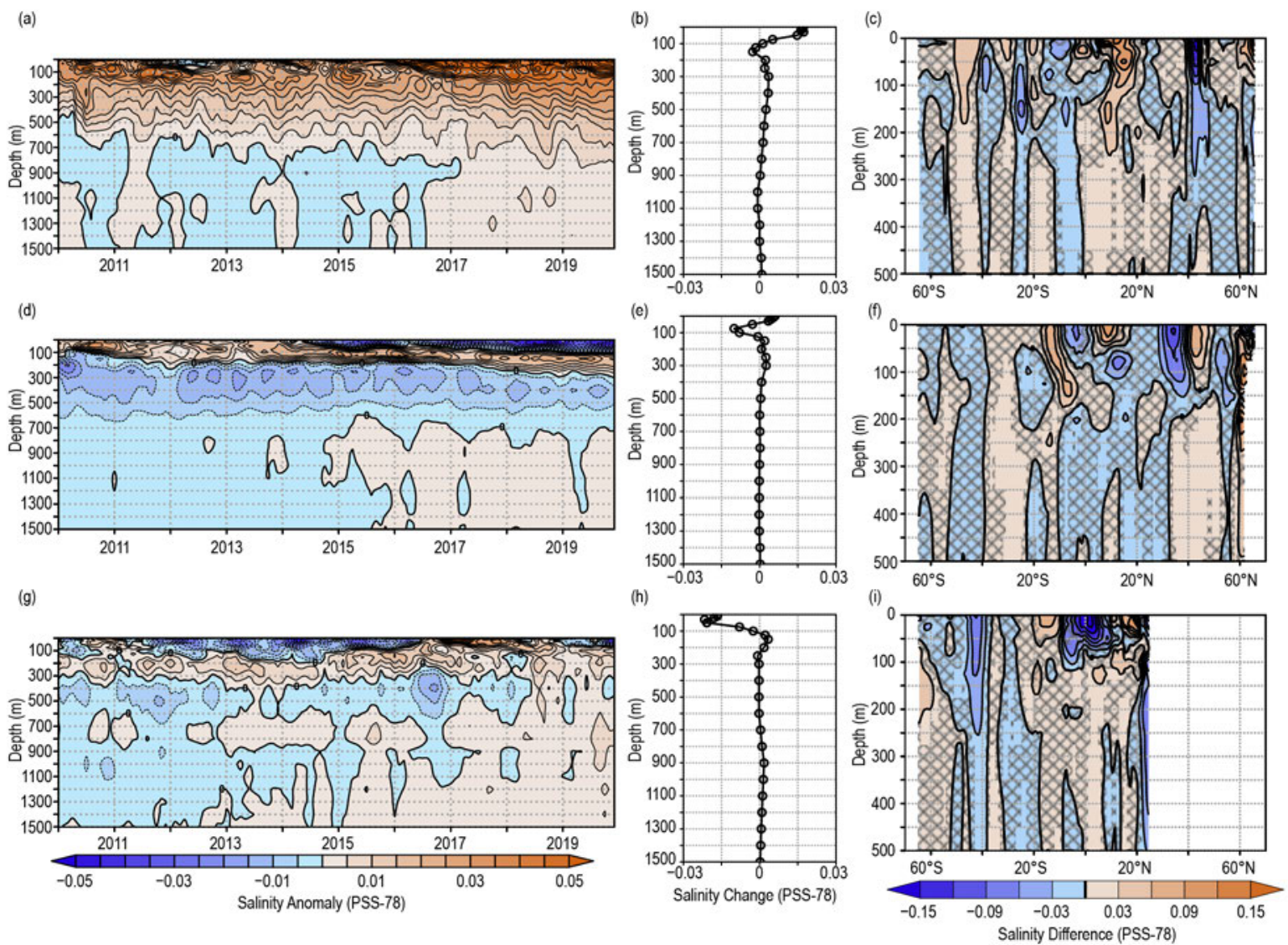

Fig. 3.9. Average monthly salinity anomalies from 0-1500 m for 2010-19 for the (a) Atlantic, (d) Pacific, and (g) Indian basins. Change in salinity from 2018 to 2019 for the (b) Atlantic, (e) Pacific, and (h) Indian basins. Change in the 0-500 m zonalaverage salinity from 2018 to 2019 in the (c) Atlantic, (f) Pacific, and (i) Indian basins with areas of statistically insignificant change, defined as $< \pm 1$ std. dev. and calculated from all year-to-year changes between 2005 and 2019, stippled in dark gray. Data were smoothed using a 3-month running mean. Anomalies are relative to the long-term (1955-2012) WOA13v2 monthly salinity climatology (Zweng et al. 2013). 
However, in the upper $30 \mathrm{~m}$ there was slight salinification between 2018 and 2019 ( 0.005 maximum at $0 \mathrm{~m}$, Fig. 3.9e), which is the first basin-average sea surface salinification in the Pacific since 2015-16 (Fig. 3.9d in Reagan et al., 2017).

The statistically significant changes in the Pacific basin zonal-average salinity anomalies (Fig. 3.9f) from 2018 to 2019 are mainly confined to the upper $200 \mathrm{~m}$. There is salinification $(>0.06)$ in a narrow zonal band near $13^{\circ} \mathrm{S}$ (at $0 \mathrm{~m}$ ) extending to $\sim 150 \mathrm{~m}$ at $8^{\circ} \mathrm{S}$, as well as salinification $(>0.06)$ in the upper $40 \mathrm{~m}$ between $5^{\circ} \mathrm{N}$ and $15^{\circ} \mathrm{N}$, between $40^{\circ} \mathrm{N}$ and $47^{\circ} \mathrm{N}$ extending from the surface to $\sim 75 \mathrm{~m}$, and finally in the subsurface north of $58^{\circ} \mathrm{N}$. The main region of freshening $(<-0.03)$ is between $28^{\circ} \mathrm{N}$ and $39^{\circ} \mathrm{N}$, extending from the surface to $150 \mathrm{~m}$. Other statistically significant freshening tendencies occurred in a subsurface pocket centered at $12^{\circ} \mathrm{N}$ and $75 \mathrm{~m}$ and near the surface at $5^{\circ} \mathrm{S}$.

The 2019 Indian basin-average monthly salinity anomalies (Fig. 3.9g) revealed freshening $(<-0.02)$ during the later months (October-December) of 2019 in the upper $50 \mathrm{~m}$, with salinification $(>0.005)$ at deeper depths. Unlike the Atlantic and Pacific, the Indian basin has not demonstrated repeating patterns of basin-average monthly salinity anomalies throughout this past decade. The change in the basin-average salinity between 2018 and 2019 reveals strong freshening $(<-0.015)$ in the upper $50 \mathrm{~m}$ (Fig. 3.9h), with weak salinification (<0.005) between 125-200 m.

Statistically significant changes in zonal-average monthly salinity anomalies from 2018 to 2019 (Fig. 3.9i) in the Indian basin show that much of the near-surface freshening in Fig. 3.9h is a product of freshening $(<-0.03)$ between $10^{\circ} \mathrm{S}$ and $10^{\circ} \mathrm{N}$, extending from the surface down to 75 $\mathrm{m}$, which may be related to the positive IOD in 2019 (Fig. 3.1) and its accompanying anomalous precipitation (Fig. 3.11) and zonal currents (Fig. 3.17). Additional freshening $(<-0.03)$ occurred between $47^{\circ} \mathrm{S}$ and $39^{\circ} \mathrm{S}$ that extends from the surface to $250 \mathrm{~m}$, narrowing with increasing depth. Salinification ( $>0.03$ ) occurred in multiple pockets south of $60^{\circ} \mathrm{S}$ centered at $150 \mathrm{~m}$ and in two areas near the surface centered at $15^{\circ} \mathrm{S}$ and $18^{\circ} \mathrm{N}$.
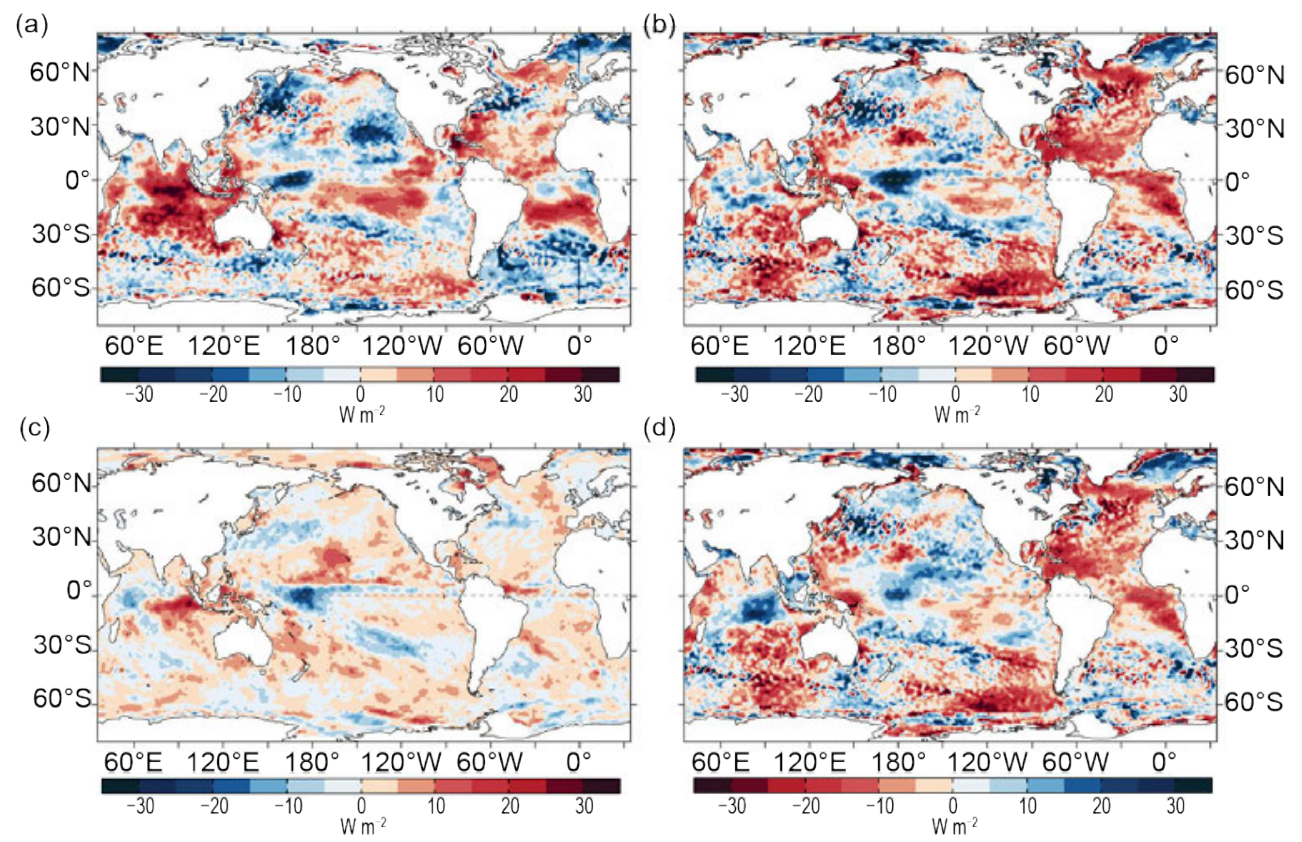

(d)

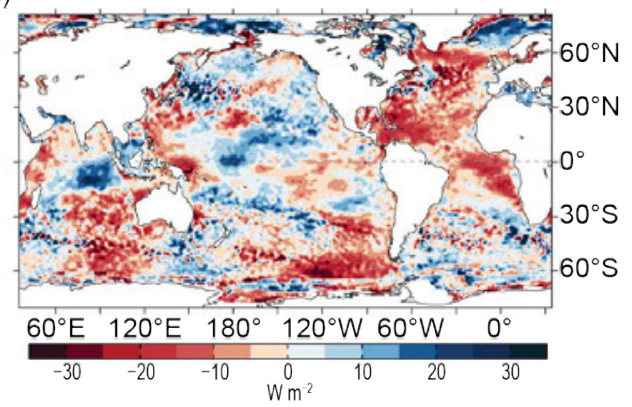

Fig. 3.10. (a) Surface heat flux $\left(Q_{\text {net }}\right)$ anomalies $\left(\mathrm{W} \mathrm{m}^{-2}\right)$ for 2019 relative to the 2001-15 climatology. Positive values denote ocean heat gain. (b) 2019 minus 2018 change for $Q_{\text {net }}$ (c) surface radiation (SW+LW), and (d) turbulent heat fluxes (LH+SH), respectively. Positive (negative) changes denote more ocean heat gain (loss) in 2019 than in 2018, consistent with the reversal of the color scheme in (d). LH+SH are produced by the OAFlux2 satellite-based high-resolution analysis, and SW+LW by the NASA FLASHFlux project. 
(a)
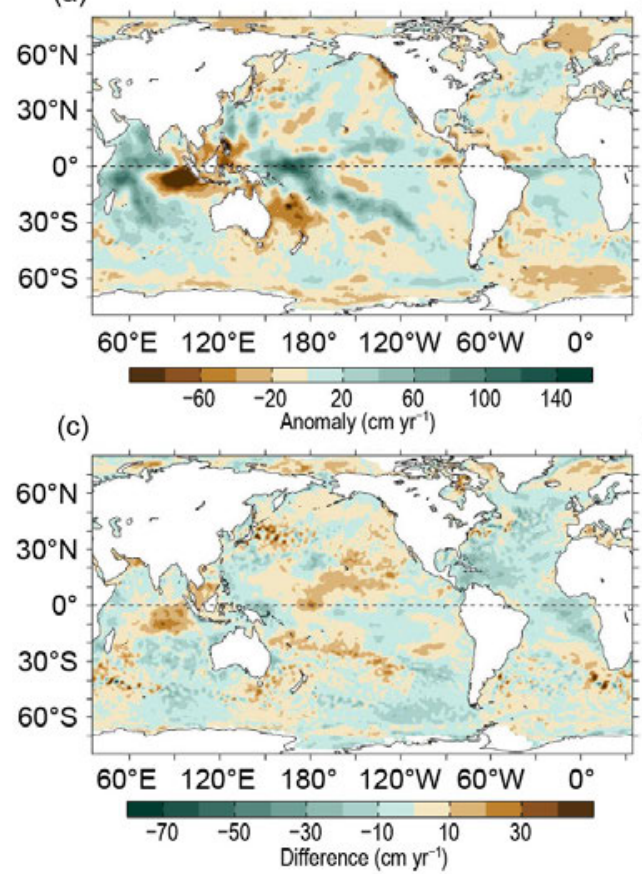

(b)
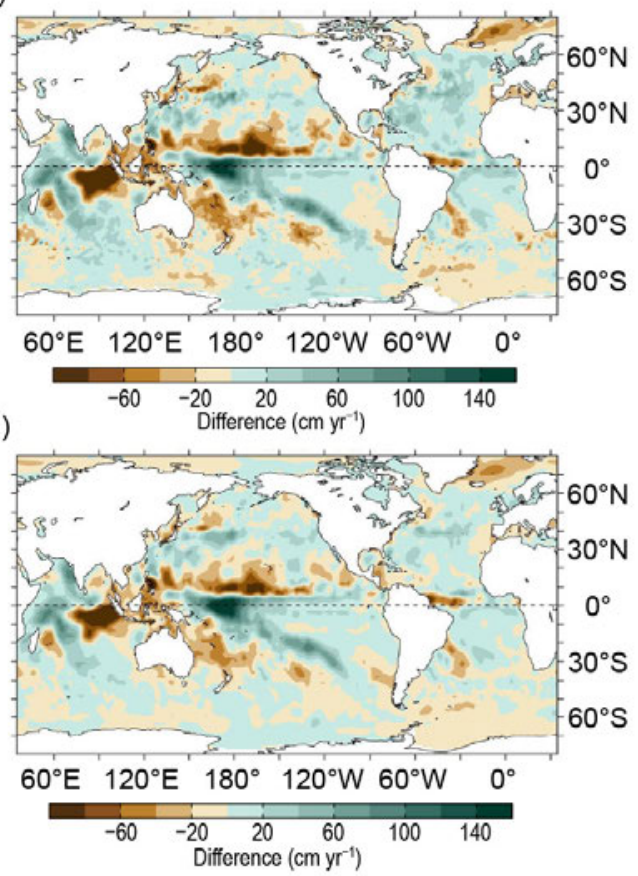

Fig. 3.11. (a) Surface freshwater $(P-E)$ flux anomalies $\left(\mathrm{cm} \mathrm{yr}^{-1}\right)$ for 2019 relative to the 1988-2015 climatology. 2019 minus 2018 changes for (b) $P-E$, (c) evaporation $(E)$, and (d) precipitation $(P)$. Green colors denote anomalous ocean fresh water gain, and browns denote loss, consistent with the reversal of the color scheme in (c). $P$ is computed from the GPCP version 2.3 product, and $E$ from OAFlux 2 .

e. Global ocean heat, freshwater, and momentum fluxes-L. Yu, P. W. Stackhouse, A. C. Wilber, and R. A. Weller

The ocean and the atmosphere communicate via interfacial exchanges of heat, freshwater, and momentum. These air-sea fluxes are the primary mechanisms for keeping the global climate system in balance with the incoming insolation at Earth's surface. Most of the shortwave radiation (SW) absorbed by the ocean's surface is vented into the atmosphere by three processes: longwave radiation (LW), turbulent heat loss by evaporation (latent heat flux, or LH), and by conduction (sensible heat flux, or SH). The residual heat is stored in the ocean and redistributed by the ocean's circulation, forced primarily by the momentum transferred to the ocean by wind stress. Evaporation connects heat and moisture transfers, and the latter, together with precipitation, determines the local surface freshwater flux. Identifying changes in the air-sea fluxes is essential in deciphering observed changes in ocean circulation and its transport of heat and salt from the tropics to the poles.

Air-sea heat flux, freshwater flux, and wind stress in 2019 and their relationships with ocean surface variables are examined here. The net surface heat flux, $Q_{\text {net }}$, is the sum of four terms: $\mathrm{SW}+\mathrm{LW}+\mathrm{LH}+\mathrm{SH}$. The net surface freshwater flux into the ocean (neglecting riverine and glacial fluxes from land) is simply precipitation $(P)$ minus evaporation $(E)$, or the $P-E$ flux. Wind stress is computed from satellite wind retrievals using the bulk parameterization of Edson et al. (2013). The production of the global maps of $\mathrm{Q}_{\mathrm{net}}, P-E$, and wind stress (Figs. 3.10-3.13) and the long-term perspective of the change of the forcing functions (Fig. 3.13) are made possible through integrating multi-group efforts. Ocean-surface LH, SH, E, and wind stress are from the Objectively Analyzed air-sea Fluxes (OAFlux) project's second-generation products (hereafter OAFlux2). Surface SW and LW radiative fluxes are from the Clouds and the Earth's Radiant Energy Systems (CERES) Fast Longwave And Shortwave Radiative Fluxes (FLASHFlux) Ed3A product (Stackhouse et al. 2006). Global $P$ is from the Global Precipitation Climatology Project (GPCP) version 2.3 products (Adler et al. 2018). The CERES Energy Balanced and Filled (EBAF) surface SW and LW version 4.1 products (Loeb et al. 2018; Kato et al. 2018) are used in the time series analysis. 
(b)
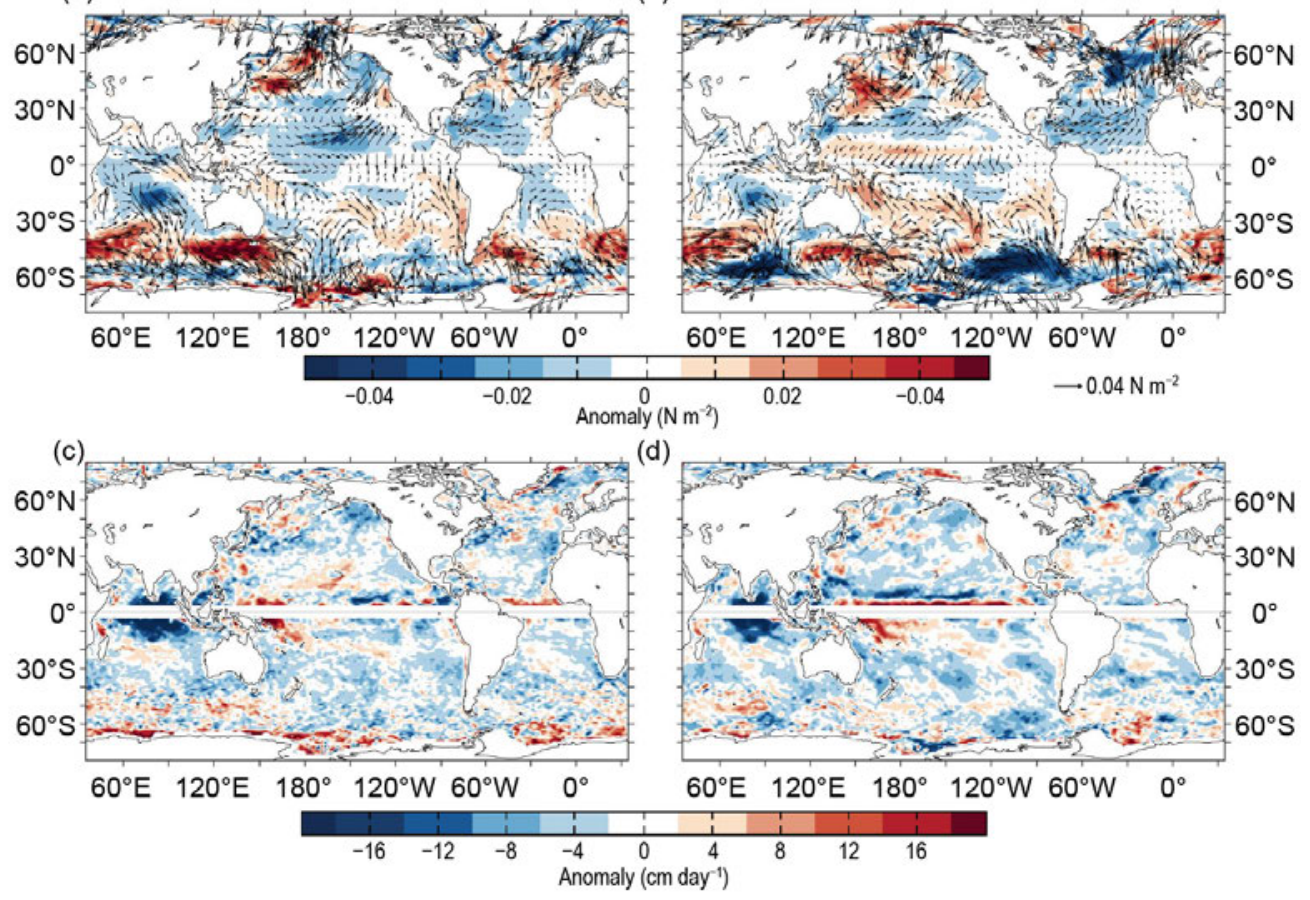

Fig. 3.12. (a) Wind stress magnitude (colors) and vector anomalies $\left(\mathrm{N} \mathrm{m}^{-2}\right)$ for 2019 relative to the 1988-2015 climatology, (b) 2019 minus 2018 changes in wind stress, (c) Ekman vertical velocity ( $W_{\mathrm{EK}} ; \mathrm{cm}$ day $^{-1}$ ) anomalies for 2019 relative to the 1988-2015 climatology, and (d) 2019 minus 2018 changes in $W_{\mathrm{EK}}$. In (c) and (d), positive values denote upwelling change, and negative downwelling change. Winds are computed from OAFlux 2.

\section{1) Surface heat fluxes}

The 2019 anomaly field (Fig.3.10a) is dominated by pronounced oceanic heat gain anomalies (positive $\mathrm{Q}_{\text {net }}$ anomalies) in the tropical Indian Ocean, with the maximum anomalies exceeding $30 \mathrm{~W} \mathrm{~m}^{-2}$ located off the equator near $5^{\circ} \mathrm{S}$. These anomalies were associated with an unusually strong positive Indian Ocean dipole (IOD) event in 2019, featuring warmer-than-average waters in the western Indian Ocean and cooler waters in the eastern Indian Ocean. The positive event started to develop in June 2019 and peaked in October-November 2019. The Dipole Mode Index (DMI; Saji et al. 1999; see section 4h) suggested that the event was one of the strongest in history. A positive IOD is typically characterized by higher pressures, less cloud, and less rain over the cooler waters in the eastern basin and vice versa in the western basin. Both SW+LW and $\mathrm{LH}+\mathrm{SH}$ 2018/19 changes (Figs. 3.10c,d) displayed a dipole-like pattern in the tropical Indian Ocean corresponding to the changing sea surface temperature anomaly (SSTA) pattern. In the east, SW+LW increased and had a warming effect on the surface water. Meanwhile, ocean turbulent heat loss (positive $\mathrm{LH}+\mathrm{SH}$ anomalies, blue colors) also increased, which tended to vent the surface radiative flux back to the atmosphere and cool the surface water. Note that the color scheme for $\mathrm{LH}+\mathrm{SH}$ is reversed so that increased $\mathrm{LH}+\mathrm{SH}$ (positive anomalies) have a cooling effect (blue colors) on the ocean surface and, conversely, reduced LH+SH (negative anomalies) have a warming effect (red colors). The competing effects between SW+LW and LH+SH 2018/19 changes canceled out the impacts of each other, leading to slight net heat loss changes over most of the tropical basin. The $Q_{\text {net }} 2018 / 19$ change map in the Indian Ocean differs considerably from the $Q_{\text {net }}$ anomaly map (Figs. 3.10a,b). The reason is that there was a short-lived IOD event in 2018; although it was weak, a similar SSTA pattern triggered similar responses in the atmosphere (Yu et al. 2019). Thus, the eastern Indian Ocean received anomalous heating in both 2018 and 2019, and the differences in $\mathrm{Q}_{\text {net }}$ between the two years were relatively small.

The equatorial Pacific experienced a transition from a diminishing La Niña in 2018 to the development of a weak El Niño in 2019. Both SW+LW and LH+SH showed a tendency to induce an anomalous ocean warming in the central and eastern equatorial Pacific where SSTA were 

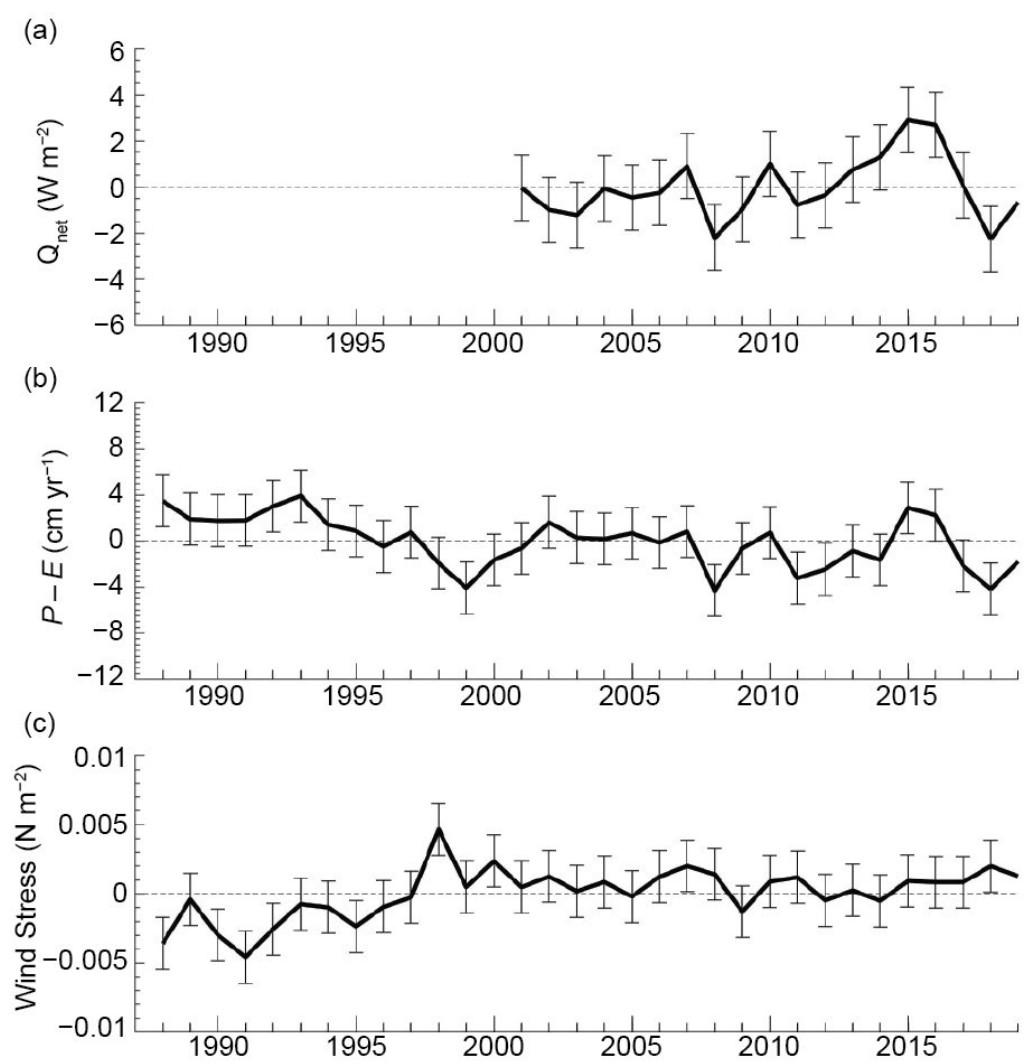

Fig. 3.13. Annual-mean time series of global averages of (a) net surface heat flux $\left(\mathrm{Q}_{\text {net }} ; \mathrm{W} \mathrm{m}^{-2}\right)$ from the combination of CERES EBAF4.1 SW+LW and OAFlux2 $\mathrm{LH}+\mathrm{SH}$. The $2019 \mathrm{Q}_{\text {net }}$ estimate is based on FLASHFlux and OAFlux-HR. (b) Net freshwater flux $\left(P-E ; \mathrm{cm} \mathrm{yr}^{-1}\right)$ from the combination of GPCP $P$ and OAFlux $2 E$ and (c) wind stress magnitude $\left(\mathrm{N} \mathrm{m}^{-2}\right)$ from OAFlux2. The shaded area denotes $1 \mathrm{std}$. dev. of annual mean variability.

positive, and an anomalous ocean cooling in the western Pacific warm pool where SSTA were negative. $Q_{n e t}$ is positively correlated with El Niño-Southern Oscillation (ENSO) SSTA. Outside of the equatorial Pacific, the radiative and turbulent heat flux 2018/19 changes both created a cooling effect in the vicinity of the Kuroshio-Oyashio Extension. Weak positive $Q_{\text {net }}$ anomalies were observed in the northeast Pacific off the shores of Alaska where a "warm blob" (Bond et al. 2015) with weak SSTAs anomalies surged back briefly. In general, $\mathrm{LH}+\mathrm{SH}$ changes dominated the $\mathrm{Q}_{\text {net }}$ changes. The large oceanic turbulent heat loss (blue colors) in the central Pacific between the equator and $30^{\circ} \mathrm{N}$ appears to be associated with the Pacific Meridional Mode (PMM; Chiang and Vimont 2004).

In the Atlantic Ocean, 2019 started with a positive phase of the North Atlantic Oscillation (NAO), switched to negative in May, and then was slightly positive in November-December, with an annual mean index of $\sim-0.3$. There was a tripole-like SSTA pattern in the North Atlantic, showing negative SSTA in the Gulf Stream and extension and positive SSTAs elsewhere between the equator and $60^{\circ} \mathrm{N}$ (see Fig. 3.1). Positive SSTA occurred also in the tropical Atlantic corresponding to the development of an Atlantic Niño. Corresponding to the SSTA pattern, there were widespread positive $\mathrm{Q}_{\text {net }} 2018 / 19$ changes from $30^{\circ} \mathrm{S}$ to $60^{\circ} \mathrm{N}$, and this anomalous oceanic heat gain was also large compared to the climatological mean condition.

\section{2) Surface freshwater fluxes}

The $2019 P-E$ anomaly fields (Fig. 3.11a) show that net freshwater input at the ocean surface increased in the western tropical Indian Ocean (positive anomalies, green colors) but decreased considerably in the eastern Indian Ocean (negative anomalies, brown colors). The pattern was the result of the unusually strong 2019 IOD. The colder sea surface in the eastern Pacific corresponded with enhanced evaporation and reduced precipitation, both of which produced anomalously evaporative conditions in the region. In the tropical Pacific, the oceanic net freshwater input was slightly above the climatological condition along the Intertropical Convergence Zone (ITCZ) and South Pacific Convergence Zone (SPCZ). 
The 2018/19 changes in the tropical Pacific (Fig. 3.11b) were associated with the transition of the ENSO cycle from a diminishing La Niña in 2018 to the development of a weak El Niño in 2019. The $P-E$ changes are attributable to the $P$ changes (Fig. 3.11d) and are consistent with the SW+LW changes, showing that SW+LW decreased in areas of increased ITCZ rainfall and increased in areas of reduced ITCZ rainfall.

Outside the tropics, the largest evaporative 2018/19 changes occurred in the Nordic Seas, produced by the combined effect of an increase of $E$ and a reduction of $P$, indicating that the region had a deficit in surface freshwater input in 2019. In the Gulf of Alaska where a "warm blob" surged back briefly, a weak evaporative condition was induced by a weak reduction in $P$ flux. The $E$ anomalies pattern in the North Pacific resemble the SSTA associated with the PMM, indicating that ocean evaporation was enhanced when SST increased in this region.

\section{3) Wind stress}

The 2019 wind stress anomaly pattern (Fig. 3.12a) shows that the trade winds weakened (negative anomalies) in two major regions: the central tropical North Pacific and the tropical South Indian Ocean. The former is related to the PMM (Chiang and Vimont 2004) and the latter to the IOD. Marked increase of westerly winds is noted in the Indian $\left(20^{\circ}-160^{\circ} \mathrm{E}\right)$ and Atlantic $\left(60^{\circ} \mathrm{W}-30^{\circ} \mathrm{E}\right)$ sectors along the Atlantic Circumpolar Current (ACC; $40^{\circ}-60^{\circ} \mathrm{S}$ ). Weakening of surface winds in the North Atlantic is also seen, as is the weakening of surface winds in the northeast Pacific associated with the occurrence of the "warm blob." The 2018/19 wind stress changes (Fig. 3.12b) show a similar pattern, except for the band of positive anomalies located north of the equator in the Pacific. The trade winds in this region, although still weaker than the climatological mean state, enhanced slightly from the 2018 condition.

The spatial variations of winds cause divergence and convergence of the Ekman transport, leading to a vertical velocity, denoted by Ekman pumping (downward) or suction (upward) velocity $W_{\mathrm{EK}}$ at the base of the Ekman layer. Computation of $W_{\mathrm{EK}}$ follows the equation: $W_{\mathrm{EK}}=1 / \rho \nabla \times(\tau / f)$, where $\rho$ is the density, $\tau$ is the wind stress magnitude, and $f$ the Coriolis parameter. The 2019 $W_{\mathrm{EK}}$ anomaly pattern (Fig. 3.12c) is dominated by large downwelling (negative) anomalies in the equatorial Indian Ocean, indicating that the typical upwelling conditions in the region weakened considerably during the 2019 IOD event. Outside the tropical region, the $2019 W_{\mathrm{EK}}$ anomalies were generally weak and less organized except for the Indian Ocean sector along the ACC, where the typical upwelling condition was slightly enhanced. The 2018/19 $W_{\mathrm{EK}}$ change pattern (Fig. 3.12d) has similar features.

\section{4) Long-term perspective}

A long-term perspective on the change of ocean-surface forcing functions in 2019 is examined in the context of multi-decade annual-mean time series of $\mathrm{Q}_{\text {net }}, P-E$, and wind stress averaged over the global ice-free oceans (Figs. 3.13a-c). The $Q_{\text {net }}$ time series commenced in 2001, when CERES EBAF4.1 surface radiation products became available. The $P-E$ and wind stress time series are each 32 years long, starting from 1988 when higher quality global flux fields can be constructed from Special Sensor Microwave/Imager (SSM/I) satellite retrievals. $\mathrm{Q}_{\text {net }}$ anomalies are relative to the 2001-15 climatology, with positive (negative) anomalies denoting increased (reduced) net downward heat flux into the ocean. $P-E$ anomalies are relative to the 1988-2015 climatology, with positive (negative) anomalies denoting increased (reduced) freshwater flux into the ocean. Wind stress anomalies are also relative to the 1988-2015 climatology, with positive (negative) anomalies denoting increased (reduced) wind stress magnitude over the ocean.

$\mathrm{Q}_{\text {net }}$ was relatively constant between 2001 and 2007 but had large interannual fluctuations thereafter. The total downward heat flux into the global ocean increased by about $3 \mathrm{~W} \mathrm{~m}^{-2}$ during 2011-16, when the tropical Pacific switched from a strong La Niña event in 2011 to a strong El Niño event in 2016. This period of increasing oceanic heat gain coincided with an increase of global 
mean SST by about $0.35^{\circ} \mathrm{C}$ (Fig. 3.3). $\mathrm{Q}_{\text {net }}$ reduced sharply by about $4 \mathrm{~W} \mathrm{~m}^{-2}$ during the $2017 / 18 \mathrm{La}$ Niña but bounded back slightly in 2019. $P-E$ shows similar interannual variability to that of $\mathrm{Q}_{\text {net }}$. In particular, the freshwater input into the ocean increased during the transition from the 2011 La Niña to the 2016 El Niño, reduced during the 2017/18 La Niña, and bounced back slightly in the 2019 weak El Niño phase. It should be noted that the interannual variability in the $Q_{\text {net }}$ record is dominated by turbulent heat flux components (LH and SH), while that in the $P-E$ record is governed by the $P$ component. The time series of wind stress was flat in the most recent two decades after a regime shift around 1999, and the 2019 winds were slightly down from the 2018 level.

f. Sea level variability and change-P. R. Thompson, M. J. Widlansky, E. Leuliette, W. Sweet, D. P. Chambers,

B. D. Hamlington, S. Jevrejeva, J. J. Marra, M. A. Merrifield, G. T. Mitchum, and R. S. Nerem

Global mean sea level (GMSL) during 2019 became the highest annual average in the satellite altimetry record (1993-present), rising to $87.6 \mathrm{~mm}$ (3.4 in) above the 1993 average (Fig. 3.14a). This marks the eighth consecutive year (and 24th out of the last 26) that GMSL increased relative to the previous year. The new high reflects an ongoing multi-decadal trend in GMSL during the satellite altimetry era, $3.2 \pm 0.4$ $\mathrm{mm} \mathrm{yr}^{-1}$ (Fig. 3.14a). Acceleration in GMSL (i.e., two times the quadratic coefficient in a secondorder polynomial fit) during the altimetry era is $0.097 \pm 0.04 \mathrm{~mm} \mathrm{yr}^{-2}$. When effects of the Pinatubo volcanic eruption and El Niño-Southern Oscillation (ENSO) are subtracted from GMSL variability, the estimated climate-changedriven rise in GMSL over the altimeter record is $2.3 \pm 0.7 \mathrm{~mm} \mathrm{yr}^{-1}$ with an acceleration of 0.084 $\pm 0.025 \mathrm{~mm} \mathrm{yr}^{-2}$ (Nerem et al. 2018).

Variations in GMSL (Fig. 3.14a) result from changes in both the mass and density of the global ocean (Leuliette and Willis 2011; Cazenave et al. 2018). Steric (i.e., density-related) sea level rise observed by the Argo profiling float array during 2005-19, $1.3 \pm 0.2 \mathrm{~mm}$ $\mathrm{yr}^{-1}$, which is mostly due to ocean warming, accounted for about one-third of GMSL change since 2005, $3.7 \pm 0.4 \mathrm{~mm} \mathrm{yr}^{-1}$. Increasing global ocean mass observed by the NASA Gravity Recovery and Climate Experiment (GRACE) and GRACE Follow-On (GRACE-FO) missions, 2.8 $\pm 0.4 \mathrm{~mm} \mathrm{yr}^{-1}$, contributed the remaining twothirds of the GMSL trend during 2005-19. The positive trend in ocean mass primarily resulted from melting of glaciers and ice sheets (see sections 5e,f, 6e), which was partially offset by increased hydrological storage of fresh water on land, $-0.7 \pm 0.2 \mathrm{~mm} \mathrm{yr}^{-1}$ (Reager et al. 2016).
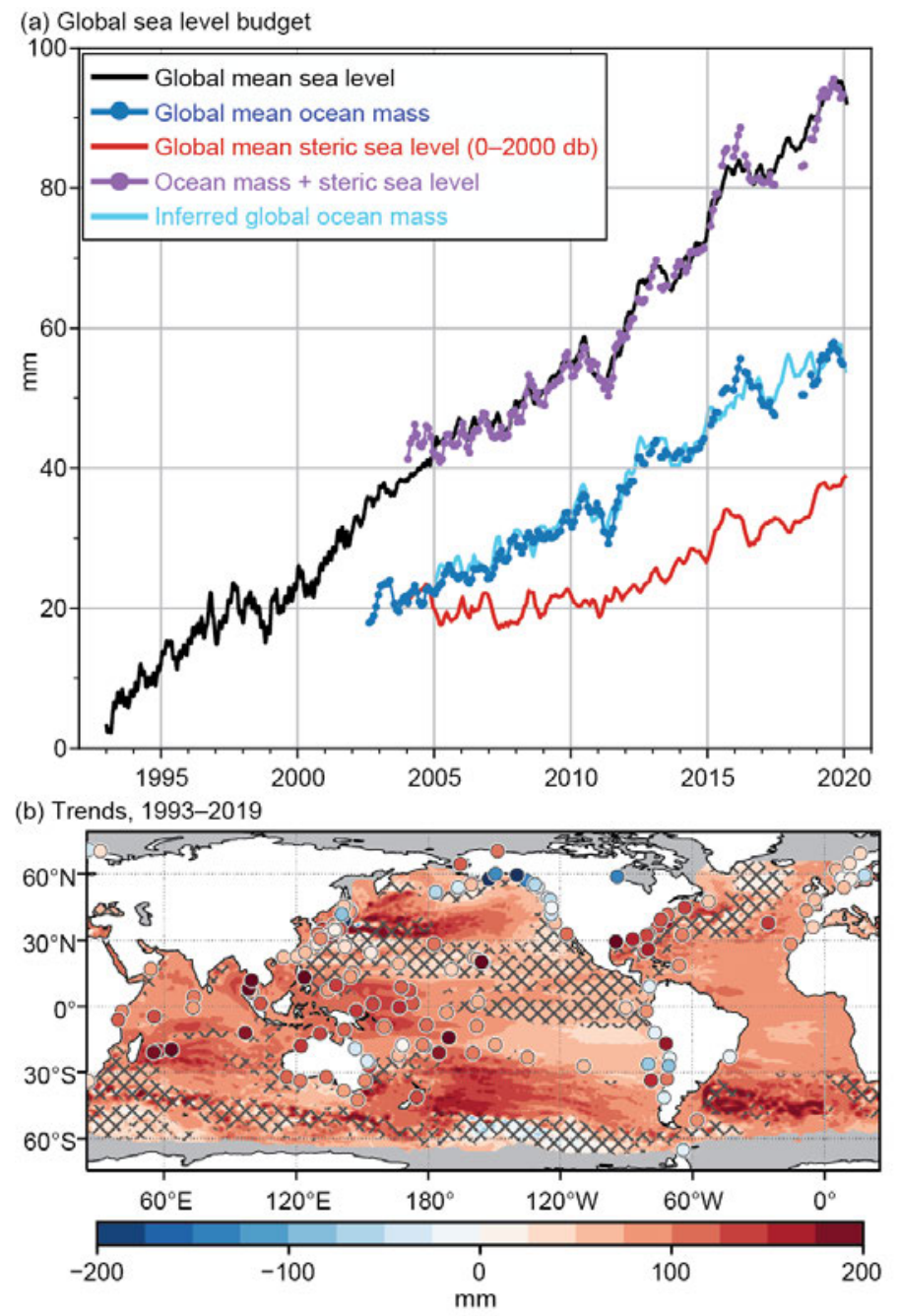

Fig. 3.14. (a) Monthly averaged GMSL observed by satellite altimeters (black, 1993-2019 from the NOAA Laboratory for Satellite Altimetry), global ocean mass (blue, 2003-19 from the Gravity Recovery and Climate Experiment), global mean steric sea level (red, 2004-19) from the Argo profiling float array, mass plus steric (purple), and inferred global ocean mass (cyan) calculated by subtracting global mean steric sea level from global mean sea level. All time series have been smoothed with a 3-month filter. (b) Total local sea level change during 1993-2019 as measured by satellite altimetry (contours) and tide gauges (circles). Hatching indicates trends that are not statistically significant. 
Annually averaged GMSL from satellite altimetry increased by $6.1 \mathrm{~mm}$ from 2018 to 2019 (Fig. 3.14a). Annual global mean steric sea level observed by Argo (0-2000 m) increased by $4.5 \mathrm{~mm}$ from 2018 to 2019 (Fig. 3.14a), which was primarily due to an increase in heat content over the upper $700 \mathrm{~m}$ of the ocean (see Fig. 3.6a). Due to lack of complete GRACE data during 2018, we cannot directly assess the contribution of global mean ocean mass to GMSL change from 2018 to 2019. Failure of an accelerometer and degrading batteries resulted in a lack of valid data after June 2017 and termination of the original GRACE mission in October 2017. GRACE-FO first provided valid ocean mass estimates in June 2018 after an 11-month gap in ocean mass data. Despite this gap, we can attempt to infer the contribution from ocean mass by subtracting global mean steric sea level from GMSL (Fig. 3.14a) and assuming no steric change below $2000 \mathrm{~m}$. The inferred ocean mass curve suggests a modest contribution of $1.5 \mathrm{~mm}$ from ocean mass to the year-over-year increase in GMSL.

The spatial structure in sea level change over the relatively short altimeter record is primarily due to natural fluctuations in coupled modes of atmosphere-ocean variability, such as the relationship between east-west differences in Pacific trends and a multidecadal tendency toward La Niña-like conditions and stronger Pacific trade winds (e.g., Merrifield 2011, Fig. 3.14b). However, there is growing evidence that at least a portion of the sea level trend pattern from altimetry, particularly in the Indian Ocean and southwest Pacific, represents the response of the ocean to anthropogenic forcing (Fasullo and Nerem 2018; Hamlington et al. 2019), which may continue into future decades. The natural and forced contributions combine to produce substantial spatial differences in rates of rise. For example, sea surface height from satellite altimetry has increased $150 \mathrm{~mm}$ since 1993 around Sydney, while Los Angeles has experienced just over $20 \mathrm{~mm}$ during that time. It is also important to note that sea level change relative to land (i.e., relative sea level, the quantity measured by tide gauges) is most relevant for societal impacts and can differ substantially from satellite-derived changes in tectonically active regions (e.g., Japan) and areas strongly affected by glacial isostatic adjustment (e.g., Alaska; Fig. 3.14b).

Positive annual sea level anomalies occurred almost everywhere during 2019 (Fig. 3.15a), which is consistent with the global pattern of sea level rise since 1993 (Fig. 3.14b). Other than isolated negative anomalies associated with upwelling mesoscale eddies (mostly in midlatitudes), the only large-scale region of negative height anomalies during 2019 is near the equator in the
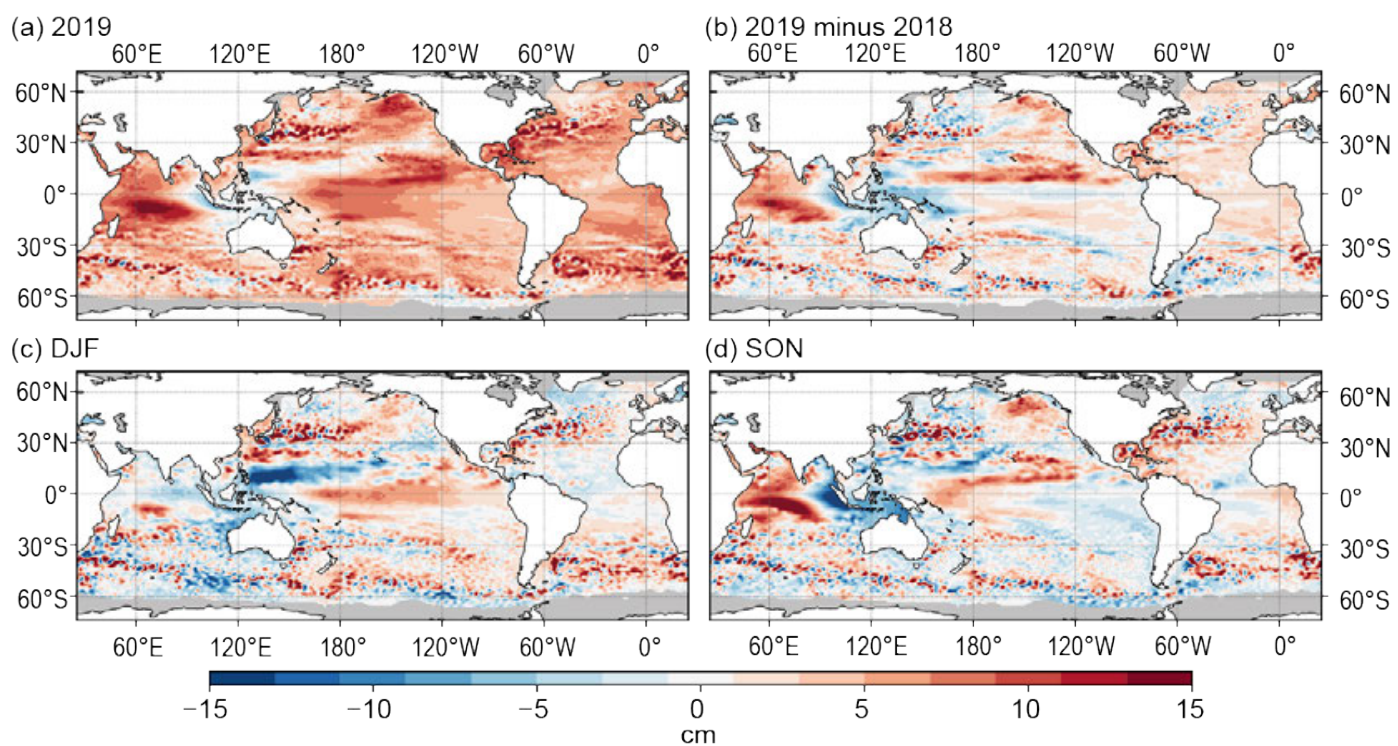

(d) SON

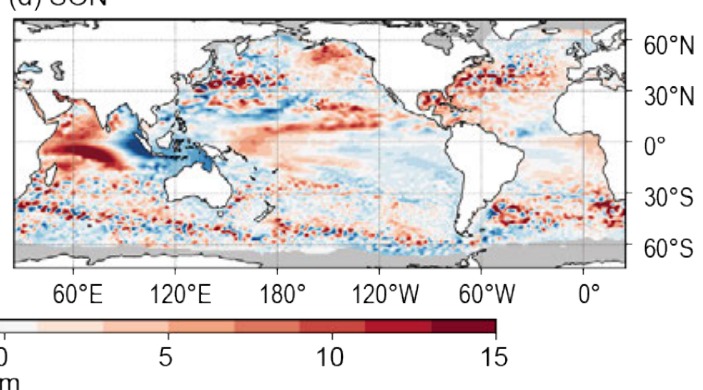

Fig. 3.15. (a) Annual average sea level anomaly during 2019 relative to the average sea level at each location during 1993-2019. (b) Average 2019 sea level anomaly minus 2018. (c) Average sea level anomaly during DJF 2019 relative to 1993-2019 average. (d) Same as (c), but for SON. GMSL was subtracted from panels (c),(d) to emphasize regional, nonsecular change. Altimetry data were obtained from the gridded, multi-mission product maintained by the Copernicus Marine and Environment Monitoring Service (CMEMS). 
eastern Indian and western Pacific Oceans. In this broad region of below-normal sea levels that includes around parts of Indonesia, the Philippines, and New Guinea, the annual mean sea level decreased 5-10 cm from 2018 to 2019 (Fig. 3.15b) and reached the lowest levels near the end of the year (exceeding $15 \mathrm{~cm}$ below normal in the eastern Indian Ocean; Figs. 3.15c,d). To the west, in much of the remainder of the tropical Indian Ocean, sea levels increased by up to $15 \mathrm{~cm}$ relative to 2018 (Fig. 3.15b). Above- and below-normal sea levels in the Indian Ocean correspond to the regions of largest ocean heat content (OHC) anomalies (see Fig. 3.4a; higher in the west, lower in the east) and are consistent with the positive phase of the Indian Ocean dipole (IOD) that emerged in sea surface temperature (SST) observations during the second half of 2019 (see Figs. 3.2c,d).

Elsewhere in the Pacific Ocean, changes from 2018 to 2019 were for higher sea levels in much of the Northern Hemisphere (NH) away from the equator (Fig. 3.15b). In the tropical and central North Pacific, including around Hawaii, sea levels rose from below to above normal during 2019 (reaching as much as $15 \mathrm{~cm}$ above normal by the end of the year; Figs. 3.15c,d). A similar rise in sea level occurred in the Gulf of Alaska, whereas, along the equator east of the date line, sea levels dropped during the year (Figs. 3.15c,d). Overall, the Pacific sea level 2018/19 changes (i.e., lowering in the equatorial eastern Pacific and rising in the eastern half of the North Pacific) are consistent with the ending of El Niño (see section 3b; Fig. 3.1b) and ongoing positive Pacific Meridional Mode (PMM) conditions, which are both known to affect the OHC tendency (see Fig. 3.4b) in the respective regions (Long et al. 2020). In the tropical South Pacific, especially near the date line (i.e., between Fiji and the Samoan Islands), 2019 sea levels continued to rise from 2018 anomalies, which were already above normal due to wind stress curl anomalies there (see Fig. 3.12d).

In the Atlantic Ocean, the basin-scale change was for sea levels to rise from 2018 to 2019 (Fig. 3.15b). The increase was largest in the Caribbean Sea, Gulf of Mexico, and along the U.S. East Coast with the increase in these regions occurring primarily toward the end of 2019 (Figs. 3.15c,d). Including the long-term sea level rise trend (Fig. 3.14b), sea level anomalies generally exceeded $10 \mathrm{~cm}$ above the 1993-2019 average along the U.S. Gulf and East Coasts (Fig. 3.15a). Ocean heat content anomalies were similarly high in this region during 2019 (Fig. 3.4a), although changes relative to 2018 were small (see Fig. 3.4b). Ekman-pumping anomalies across the tropical North Atlantic were weakly negative (i.e., downward; Fig. 3.12d) and may have contributed
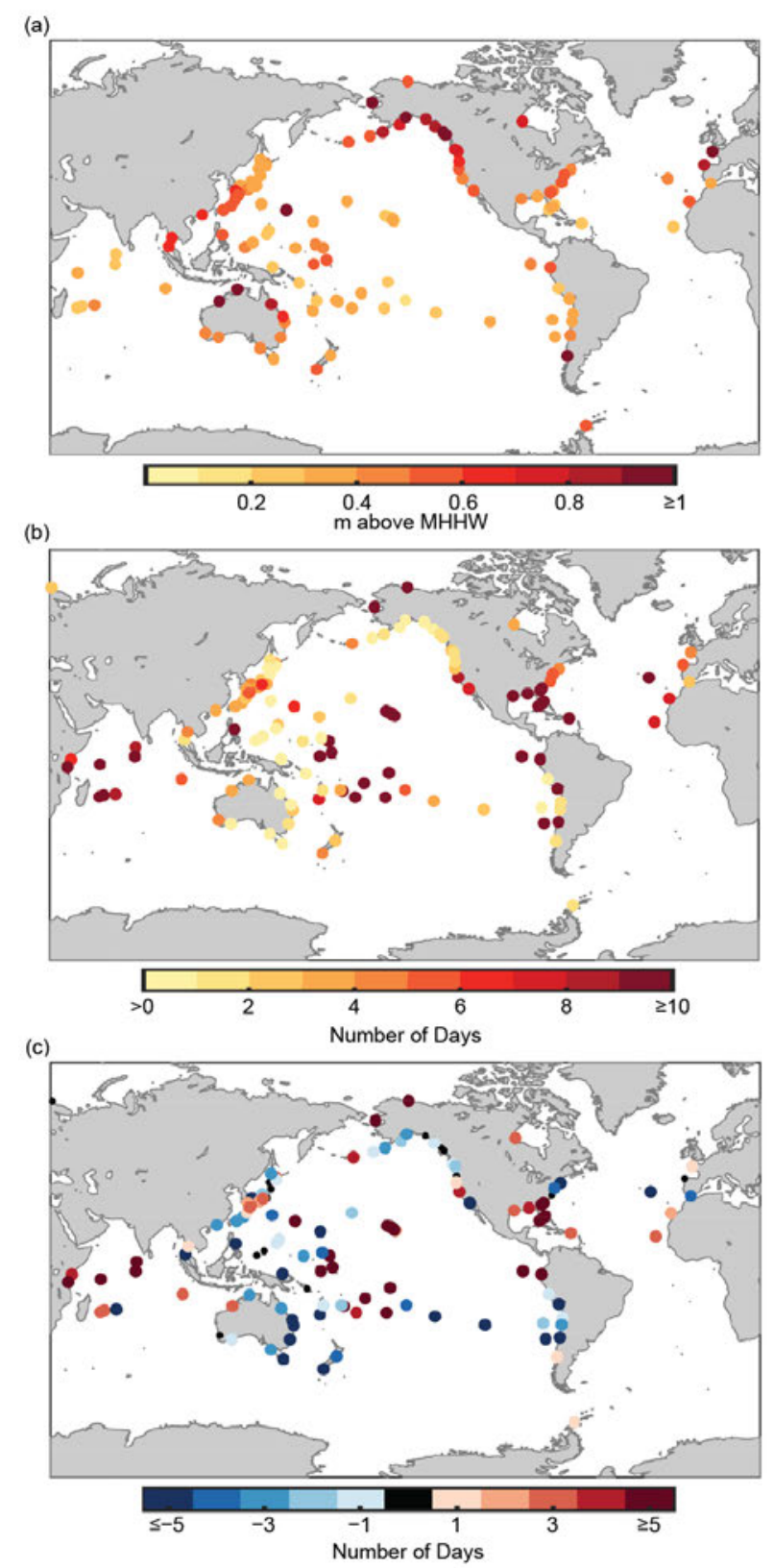

Fig. 3.16. (a) Nuisance-level flooding thresholds defined by the level of the top $1 \%$ of observed daily maxima during 2000-18 from tide gauge records. Units are in meters above mean higher high water (MHHW) calculated over 2000-18. (b) Number of daily maximum water levels during 2019 above the thresholds in (a). Small, black circles in (b) and (c) indicate a value of zero. (c) Same as in (b), but for 2019 minus 2018. Daily maximum water levels were calculated from hourly tide gauge observations obtained from the University of Hawaii Sea Level Center Fast Delivery database. Only records with at least $80 \%$ completeness during 2000-18 and 80\% completeness during 2019 were analyzed. 
to the high sea levels in the western North Atlantic via generation of downwelling Rossby waves (e.g., Calafat et al. 2018). Surface heat flux into the western Atlantic Ocean increased substantally in 2019 relative to 2018 (Figs. 3.10b,d), which likely contributed to higher sea levels as well via warming and expansion of the upper ocean.

Ongoing trends and year-to-year changes in sea level impact coastal communities by increasing the magnitude and frequency of positive sea level extremes that cause flooding and erosion. In many areas, coastal infrastructure is currently exposed to minor high tide flooding when water levels exceed a threshold defined by the top $1 \%$ of observed daily maxima from a global network of tide gauges (Sweet et al. 2014). These thresholds vary geographically (Fig. 3.16a) but are typically around $0.5 \mathrm{~m}$ above mean higher high water (MHHW) - the average of observed daily maxima-and are expected to be exceeded 3-4 times per year. The Gulf of Mexico and southeast U.S. coasts experienced greater-than-expected numbers of threshold exceedances during 2019 (Fig. 3.16b), which is directly related to positive sea level trends (Fig. 3.14b) and 2019 anomalies (Fig. 3.15a) in the region. Year-over-year increases in threshold exceedances occurred at a variety of locations, many of which correspond to regions in which mean sea level increased from 2018 to 2019. Specifically, the increase in mean sea level in the central North Pacific (Fig. 3.15b) contributed to an increase of more than five threshold exceedances in Hawaii compared to the previous year (Fig. 3.16b). Likewise, stations in the western Indian Ocean experienced a substantial increase in threshold exceedances related to high mean sea levels associated with the IOD event. In general, the changes in minor threshold exceedances highlight the importance of large-scale mean sea level anomalies for producing extremes.

\section{g. Surface currents-R. Lumpkin and G. Goni}

This section describes ocean surface current changes, transports derived from ocean surface currents, and features such as rings inferred from surface currents. Surface currents for this analysis are obtained from in situ (global array of drogued drifters and moorings) and satellite (altimetry and wind stress) observations. Transports are derived from a combination of sea surface height anomaly (from altimetry) and climatological hydrography. See the State of the Climate in 2011 report for details of these calculations. Geostrophic zonal surface current anomalies are calculated with respect to 1993-2007 climatology and are discussed below for individual ocean basins.

\section{1) Pacific Ocean}

In 2019, the equatorial Pacific basin exhibited an annual mean zonal eastward geostrophic current anomaly of 10-12 cm $\mathrm{s}^{-1}$ from $152^{\circ} \mathrm{E}-180^{\circ}$ (Fig. 3.17a). Between $112^{\circ}-156^{\circ} \mathrm{W}$, alternating eastward (at $10^{\circ} \mathrm{N}$ ) and westward $\left(6^{\circ}-7^{\circ} \mathrm{N}\right)$ anomalies of $6-8 \mathrm{~cm}$ $\mathrm{s}^{-1}$ indicate that the North Equatorial Countercurrent (NECC) was shifted north of its climatological position, a pattern also seen in 2018. Because 2018 was characterized by
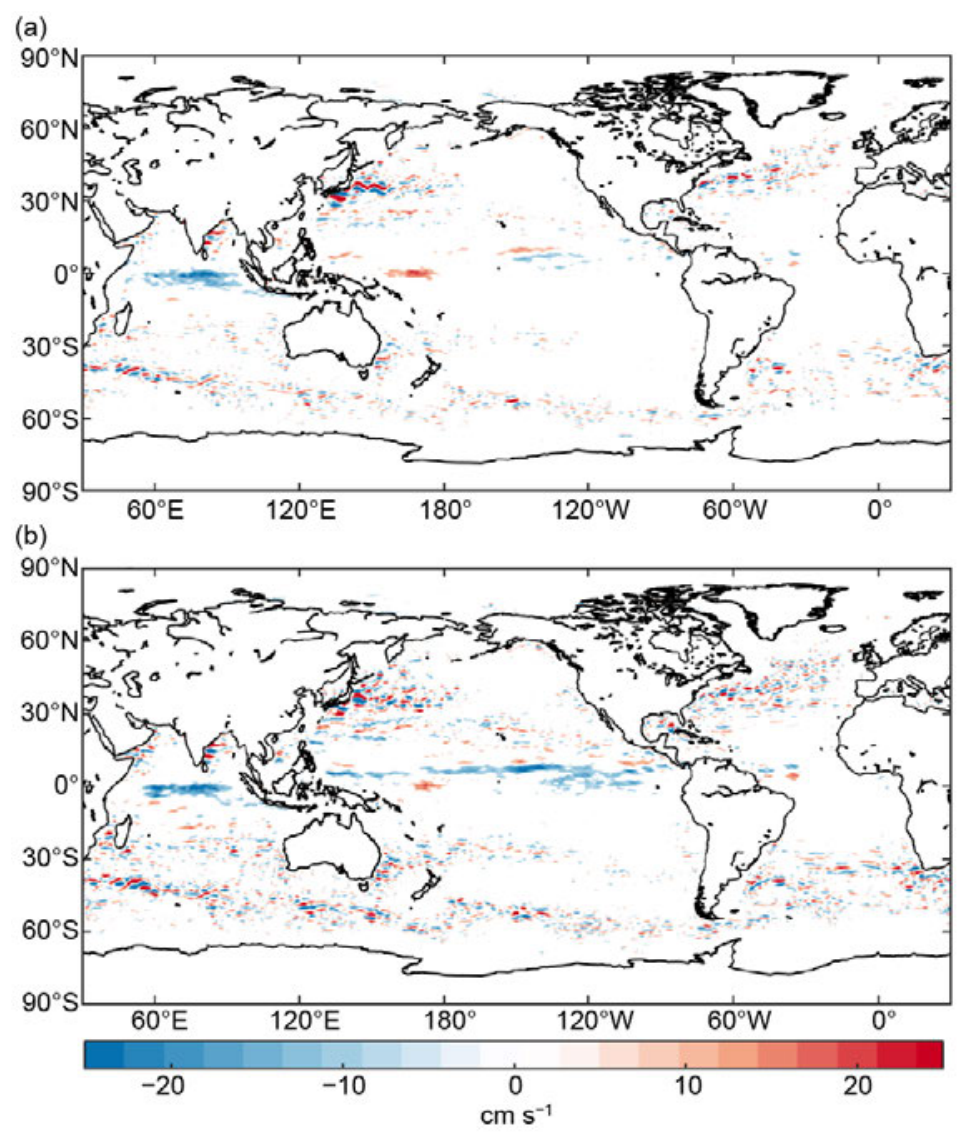

Fig. 3.17. Annually averaged geostrophic zonal current anomalies $\left(\mathrm{cm} \mathrm{s}^{-1}\right)$ with respect to 1993-2007 climatology for (a) 2019 and (b) 2019 minus 2018 derived from a synthesis of drifters, altimetry, and winds. Values not shown where they are not significantly different from zero. 
an anomalously strong NECC spanning much of the basin, the 2019 minus 2018 anomaly difference (Fig. 3.17b) primarily reflects a weakening from the 2018 anomalies.

Figure 3.18 shows the development of zonal geostrophic current anomalies with respect to monthly climatology, averaged season by season. Eastward anomalies of $\sim 10 \mathrm{~cm} \mathrm{~s}^{-1}$ along the path of the NECC, seen earlier in 2018, persisted in December-February 2018/19 (Fig. 3.18a), indicating a stronger-than-average current. Eastward anomalies exceeding $10 \mathrm{~cm} \mathrm{~s}^{-1}$ were present from $155^{\circ}-160^{\circ} \mathrm{E}, 2^{\circ} \mathrm{N}-3^{\circ} \mathrm{S}$, with peak anomalies of $28 \mathrm{~cm} \mathrm{~s}^{-1}$ on the equator. These anomalies weakened significantly in March-May (Fig. 3.18b). In June-August (Fig. 3.18c), westward anomalies of 10-12 $\mathrm{cm} \mathrm{s}^{-1}$ developed in the northern core of the South Equatorial Current (nSEC) at $180^{\circ}-110^{\circ} \mathrm{W}, 0^{\circ}-4^{\circ} \mathrm{N}$, a strengthening of this westward current. Westward anomalies were present across much of the basin by September-November (Fig. 3.18d) from $4^{\circ}-8^{\circ} \mathrm{N}$, but had weakened to $2-6 \mathrm{~cm} \mathrm{~s}^{-1}$; north of this, eastward anomalies of $5-6 \mathrm{~cm} \mathrm{~s}^{-1}$ were centered on $10^{\circ} \mathrm{N}$. These anomalies indicated a stronger-than-average nSEC and a northward shift of the nSEC and NECC.

Away from the equator, the largest surface velocity anomalies in the Pacific were observed in the Kuroshio region. Shifts in the location of the Kuroshio Jet are associated with a decadal stable/unstable oscillation (Qiu and Chen 2005). The Kuroshio shifts to the north when it intensifies and becomes stable, thus lowering eddy kinetic energy (EKE). Averaged in the downstream Kuroshio Jet region $141^{\circ}-153^{\circ} \mathrm{E}$, $32^{\circ}-38^{\circ} \mathrm{N}$ (Qiu and Chen 2005), EKE was low in 1993-95, elevated in 1999-2001, low in 2002-04, high in 2005-08, and low in 2015-18 (not shown). EKE increased from $0.094 \mathrm{~m}^{2} \mathrm{~s}^{-2}$ in 2018 to $0.129 \mathrm{~m}^{2} \mathrm{~s}^{-2}$ in 2019, compared to the 1993-2019 average of $0.117 \mathrm{~m}^{2} \mathrm{~s}^{-2}$, while the annually averaged strength of the Kuroshio Jet decreased slightly but remained above its climatological mean. The location of the jet also remained north of its climatological mean, inconsistent with a phase shift of this decadal mode. Weakening of the Kuroshio and North Pacific Subtropical Gyre has been driven by the positive phase of the Atlantic Multidecadal Oscillation (AMO) since 1989/90 (Wu et al. 2019).

(a)

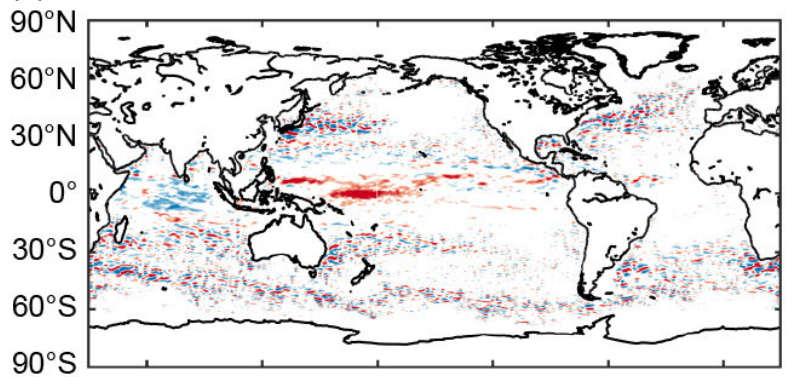

(c)

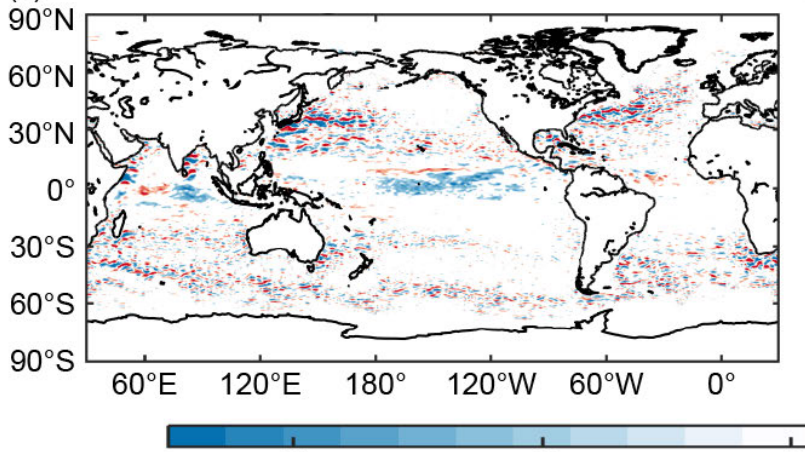

(b)

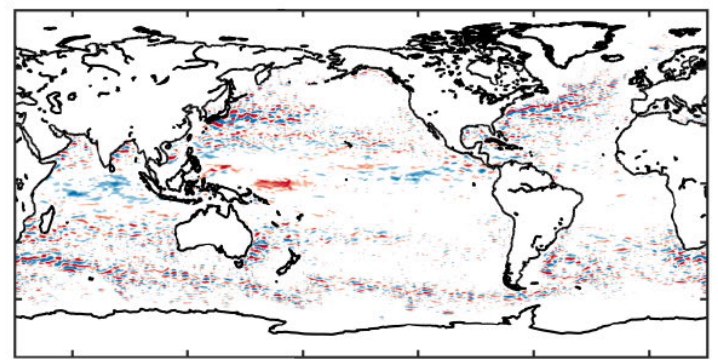

(d)

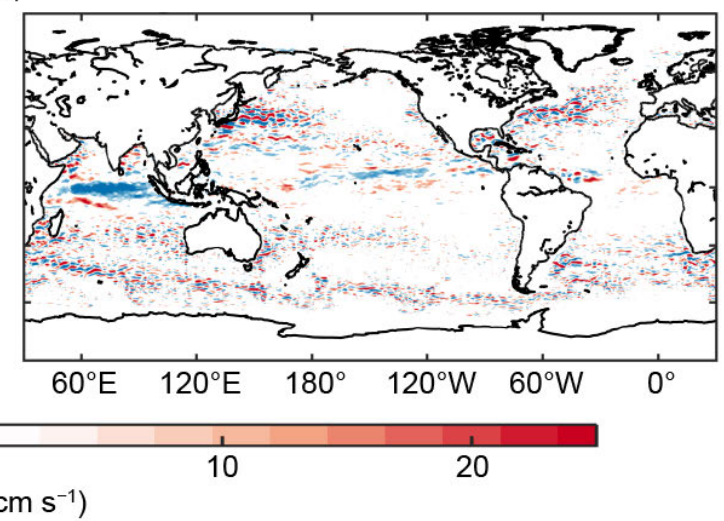

Fig. 3.18. Seasonally averaged zonal geostrophic anomalies with respect to seasonal climatology for (a) Dec-Feb 2018/19, (b) Mar-May 2019, (c) Jun-Aug 2019, and (d) Sep-Nov 2019. Values not shown where they are not significantly different from zero. 


\section{2) Indian Ocean}

Annually averaged zonal currents in the Indian Ocean demonstrated $10-16 \mathrm{~cm} \mathrm{~s}^{-1}$ westward anomalies at $55^{\circ}-95^{\circ} \mathrm{E}, 1^{\circ} \mathrm{N}-2^{\circ} \mathrm{S}$, with weaker westward anomalies extending south to $10^{\circ} \mathrm{S}$ (Fig. 3.17a). Because 2018 was close to climatology, the 2019 - 2018 annual anomaly map (Fig. 3.17b) is dominated by the 2019 anomalies. These anomalies first developed in December-February 2018/19 (Fig. 3.18a) when they exceeded $5 \mathrm{~cm} \mathrm{~s}^{-1}$ from $1^{\circ} \mathrm{N}-9^{\circ} \mathrm{S}$ and reached $10 \mathrm{~cm} \mathrm{~s}^{-1}$ at $4^{\circ} \mathrm{S}$. These westward anomalies persisted in March-May (Fig. 3.18b) with maximum anomalies of $10 \mathrm{~cm} \mathrm{~s}^{-1}$ westward on the equator and in June-August (Fig. 3.18c), with two maxima of $10-12 \mathrm{~cm} \mathrm{~s}^{-1}$ at $0^{\circ}-1^{\circ} \mathrm{S}$ and $4^{\circ}-5^{\circ} \mathrm{S}$ coinciding with the IOD reaching its highest value in more than two decades (Figs. 3.2c,d). The westward anomalies dramatically increased in September-November (Fig. $3.18 \mathrm{~d}$ ), strengthening to exceed $10 \mathrm{~cm} \mathrm{~s}^{-1}$ at $2^{\circ} \mathrm{N}-5^{\circ} \mathrm{S}$, and reached a dramatic $40 \mathrm{~cm} \mathrm{~s}^{-1}$ at $1^{\circ} \mathrm{S}$; these anomalies led to the development of the intense east-to-west sea level anomaly gradient across the Indian Ocean basin (Fig. 3.15d). In this latitude band, where the Southwest Monsoon Current is $10-20 \mathrm{~cm} \mathrm{~s}^{-1}$ eastward in seasonal climatology, the total current was instead $20-30 \mathrm{~cm} \mathrm{~s}^{-1}$ westward.

\section{3) Atlantic Ocean}

Annual mean zonal currents in the tropical Atlantic Ocean were close to their climatological values in 2019 (Fig. 3.17a) and in each of the seasonal averages (Fig. 3.18).

Atlantic Ocean changes in baroclinic transport and in the location of several surface currents, and the mesoscale rings associated with them, are continuously monitored using satellite altimetry observations (www.aoml.noaa.gov/phod/altimetry/cvar/index.php). We summarize here the state of four key dynamic features in the Atlantic Ocean: 1) During 2019, satellite altimetry observations indicated that the number of rings shed by the Agulhas Current into the South Atlantic remained similar to the 1993-2019 mean of four to six rings per year. The transport by these rings, which represents a portion of the water mass exchange between the Indian and Atlantic Oceans, is thus expected to have remained unchanged. 2) In the southwest Atlantic Ocean, the separation of the Brazil Current front from the continental shelf break (located at $37.6^{\circ} \mathrm{S}$ in the mean) reveals the intrusion of subtropical waters into the subpolar region (c.f., Lumpkin and Garzoli 2010; Goni et al. 2011). In 1998, the annual mean latitude of this separation shifted abruptly southward and remained anomalously south afterward, apart from a one-year northward shift in 2016 (Fig. 3.19). In 2017 the separation latitude shifted south by $2^{\circ}$ latitude to its most southward location in the altimeter time period (1993-present). In 2018-19, the separation latitude was slightly north of its 2017 location but remained well south of the 1993-2019 mean (Fig. 3.19). 3) The North Brazil Current, which transports waters from the South Atlantic into the North Atlantic basin, continued shedding a large number of rings (approximately six rings). These rings may eventually make their way into the Caribbean Sea, carrying with them fresh waters from the Amazon River; this fresh water creates barrier layers in the Caribbean Sea that often contribute to Atlantic hurricane intensification and may be associated with the fresh water anomalies seen here in late 2019 (Balaguru et al. 2012; see Fig. 3.8). 4) Altimetry-derived annual averaged transports of the Yucatan and Florida current for 2019 do not show significant deviation from their climatological annual means of 24-26 Sv and 28-30 Sv, respectively. Nearly all of the transport of the Florida Current enters

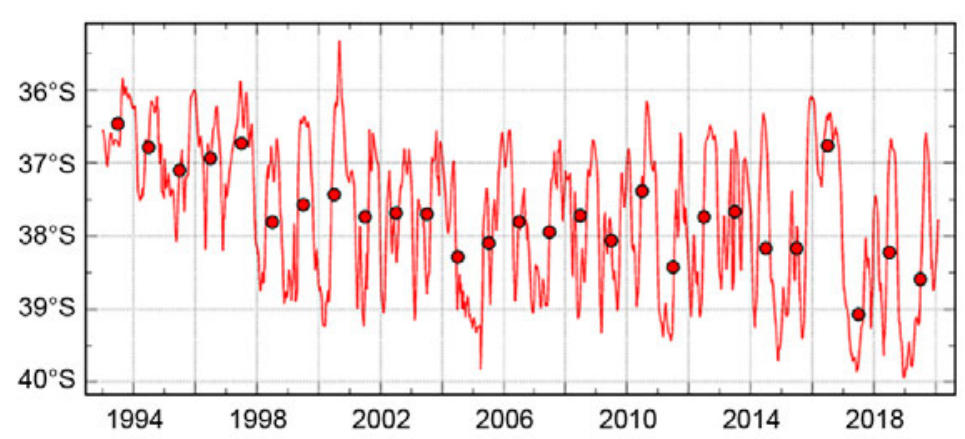

Fig. 3.19. Time series of the latitude of separation of the Brazil Current (BC) front from the continental shelf, defined as the intersection between the $-1000-\mathrm{m}$ bathymetry contour and the contour when the $10^{\circ} \mathrm{C}$ isotherm is $200 \mathrm{~m}$ deep. Solid red curve: 28-day running mean. Red dots: annual averages. The mean latitude of separation is $37.7^{\circ} \mathrm{S} \pm 0.1^{\circ}$. (Source: www .aoml.noaa.gov/phod/altimetry/cvar/mal/BM_ts.php.) 
the Gulf of Mexico via the Yucatan Channel, according to transport measurements at key locations including the Northwest Providence Channel (Candela et al. 2019). One recent study (Domingues et al. 2019) demonstrated that westward-propagating eddies play a key role in modulating the phase of the Florida Current transport interannual variability, but not its amplitude.

h. Atlantic meridional overturning circulation and associated heat transport-D. L. Volkov, C. S. Meinen, C. Schmid, B. Moat, M. Lankhorst, S. Dong, F. Li, W. Johns, S. Lozier, R. Perez, G. Goni, M. Kersalé, E. Frajka-Williams, M. Baringer, D. Smeed, D. Rayner, A. Sanchez-Franks, and U. Send

The Atlantic meridional overturning circulation (AMOC) is a key component of the ocean circulation system that is constantly moving water, heat, salt, carbon, nutrients, and other substances around the globe. The AMOC impacts the Atlantic Ocean in a unique way, making it the only ocean basin where heat is carried northward in both hemispheres. Recognizing the role of the AMOC in Earth's climate and, hence, the importance of monitoring and understanding it, several AMOC-observing systems have been established over the last two decades (e.g., Frajka-Williams et al. 2019; McCarthy et al.2020; Fig. 3.20). This section describes the most recent findings derived from the existing observations of the volume (MOC) and the associated meridional heat transports (MHT). Because some of the key boundary current arrays have been observed for longer than the fully trans-basin arrays, key results on those boundary currents are also reviewed.

Due to the complexities of measuring meridional flows across an entire ocean basin, early observations of the MOC were generally done via direct and indirect calculations using data from trans-basin hydrographic cruises (e.g., Bryden et al. 2005; Lumpkin and Speer 2007; Dong et al. 2009). Continuous measurements of the overturning circulation began with systems measuring the western boundary components of

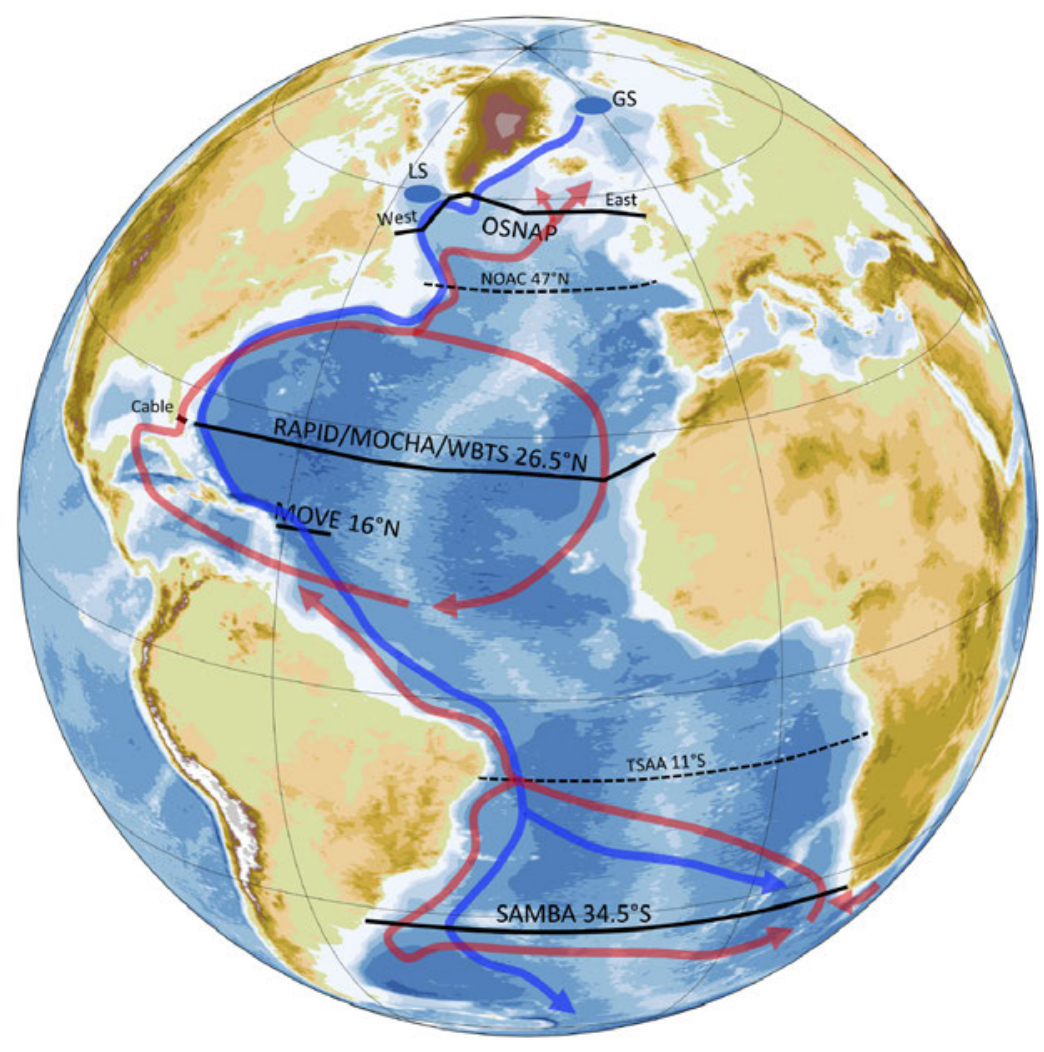

Fig. 3.20. AMOC continuous observing arrays producing transport estimates today (black lines) or expected to produce data soon (dashed lines). Arrows represent a simple schematic of the upper (red) and lower (blue) limbs of the overturning circulation. The conventional deep water formation regions in the Greenland (GS) and Labrador (LS) Seas are shown by blue-shaded circles. the AMOC, such as the Florida Current (FC) at $27^{\circ} \mathrm{N}$ since 1982, part of the upper limb of the MOC (e.g., Meinen et al. 2010), and the Deep Western Boundary Current (DWBC) of the lower limb of the MOC at $53^{\circ} \mathrm{N}$ since 1997 (Zantopp et al. 2017) and at $16^{\circ} \mathrm{N}$ since 2000 (MOVE array; Send et al. 2011). Direct continuous fully trans-basin AMOC monitoring started in 2004, when the first-ever basin-wide array was established at approximately $26.5^{\circ} \mathrm{N}$ (now known as Rapid Climate Change/Meridional Overturning Circulation Heat-flux Array/ Western Boundary Time Series [RAPID/ MOCHA/WBTS] array; e.g., Smeed et al. 2018). Since then, continuous trans-basin AMOC observations have expanded to the South Atlantic, with the South AMOC Basin-wide Array (SAMBA) at $34.5^{\circ} \mathrm{S}$ since 2009 (Meinen et al. 2013, 2018), and the subpolar North Atlantic with the Overturning in the Subpolar North Atlantic Program (OSNAP) array since 2014 (Lozier et al. 2017, 2019a,b). Significant efforts have also been made to obtain near-continuous estimates of 
the AMOC using combinations of satellite altimetry and in situ (mainly Argo and eXpendable BathyThermographs [XBT]) data (e.g., Hobbs and Willis 2012; Dong et al. 2015; Majumder et al. 2016). Furthermore, new AMOC arrays have been developed based on long-term western boundary arrays at both $47^{\circ} \mathrm{N}$ (NOAC; e.g., Rhein et al. 2011; Mertens et al. 2014; Roessler et al. 2015) and $11^{\circ} \mathrm{S}$ (e.g., Schott et al. 2005; Hummels et al. 2015) and are expected to produce AMOC estimates soon. Note that the methodologies used to estimate the AMOC and boundary current transports are dictated by array design and instrumentation used and, therefore, differ from one array to another.

The Florida Current, a regional name for the Gulf Stream as it passes through the Florida Straits, carries the bulk of the northward upper-limb of the overturning transport in the subtropical North Atlantic. Its daily transport has been measured almost continuously since 1982 using a submarine cable between Florida and the Bahamas (e.g., Larsen and Sanford 1985; Baringer and Larsen 2001; Meinen et al. 2010), which makes it perhaps the longest climate record of a boundary current in existence. The record-length time-mean FC transport is $31.8 \pm 0.4 \mathrm{~Sv}$ (henceforth the \pm uncertainty shows $95 \%$ confidence limits for monthly averaged data) and the standard deviation of the monthly mean values is $2.5 \mathrm{~Sv}$ (Fig. 3.21a). Over the entire observational period, the FC transport has been rather stable with a statistically insignificant mean negative trend of $-0.03 \pm 0.04 \mathrm{~Sv}$ per year. In 2019, the annual mean FC transport was $30.2 \pm 1.1 \mathrm{~Sv}$, which is lower than the $32.4 \pm 2.3 \mathrm{~Sv}$ observed in 2018 and the $31.7 \pm 1.4 \mathrm{~Sv}$ observed in 2017 (but the differences are not significant based on the estimated uncertainties). Not all variations in the FC transport record are necessarily associated with variations in the overturning circulation. For example, the lower mean transport in 2019 was partly due to Hurricane Dorian passing over the Bahamas and along the U.S. southeast coast between 31 August and 6 September, causing a pronounced FC slowdown that helped to establish the new record minimum FC transport of 17.1 Sv on 4 September. Earlier studies have demonstrated that hurricanes passing over the Gulf Stream can dramatically reduce the flow of the current (e.g., Todd et al. 2018), and the previous record low was set during

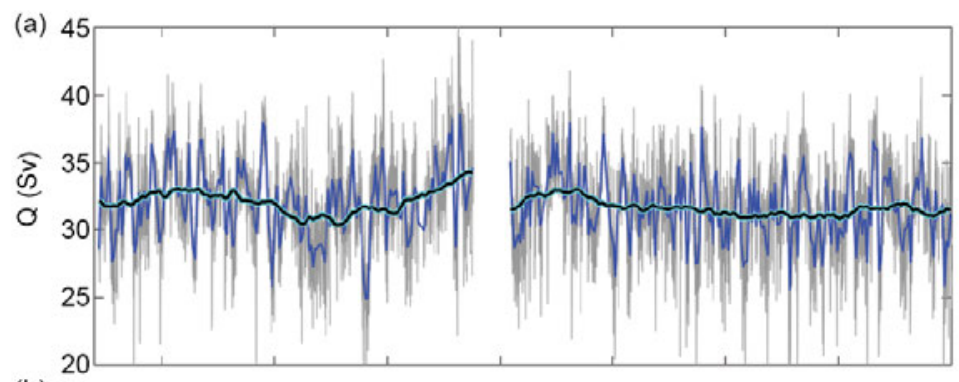

(b)

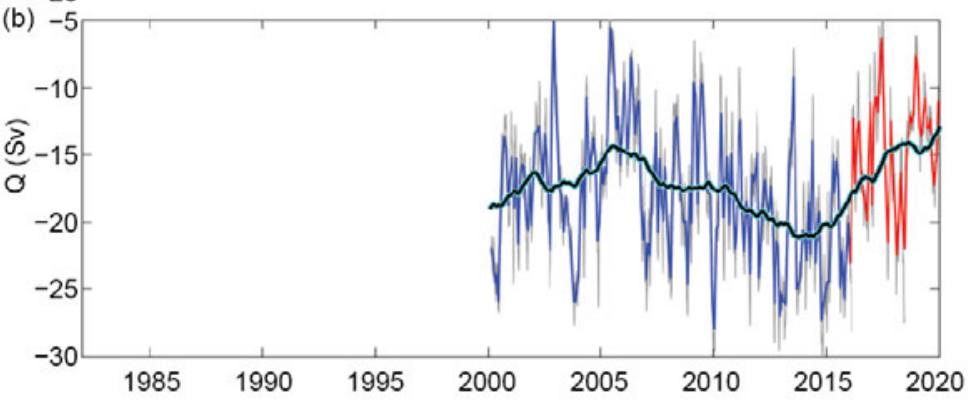

Fig. 3.21. Daily (gray) and monthly mean (blue and red) estimates of the volume transport of (a) the FC at $27^{\circ} \mathrm{N}$ (WBTS) and (b) the DWBC at $16^{\circ} \mathrm{N}$ (MOVE). Note, the period with remaining calibration issues for MOVE array after Feb 2016 is shown by red curve in panel (b). The black curves with cyan edges show the moving averages with a 3-year window, with the window size reduced at the endpoints.
Hurricane Sandy on 28 October 2012 with a value of $17.2 \mathrm{~Sv}$.

The longest continuous observational record of the DWBC transport has been collected in the tropical western Atlantic by the MOVE array at about $16^{\circ} \mathrm{N}$. At this location, the basin geometry is particularly well suited for monitoring the deep branch of the AMOC with a small number of moorings (currently three). The records have been updated to the end of 2019 (Fig. 3.21b), although there are still remaining issues with calibration after February 2016 (highlighted in red in Fig. 3.21b). Furthermore, records since mid-2018 are estimates based on the two western moorings only, because data from the eastern mooring have not yet been collected. For transport estimates, the eastern mooring data were kept constant using the average of the last six months of available data (the first half of 2018). The record-length time mean and the standard deviation of the monthly time series are $-17.3 \pm 1.4 \mathrm{~Sv}$ and $4.8 \mathrm{~Sv}$, respectively. As documented in 
previous State of the Climate reports, the $16^{\circ} \mathrm{N}$ observations continue to demonstrate decadal-scale variability (see the low-pass filtered time series in Fig. 3.21b). The years immediately prior to 2016 had stronger southward flow, and since then a weaker southward flow has been observed. In 2019, the southward flow was particularly weak, possibly suggesting a minimum value of the decadal variability. A similar swing from stronger to weaker southward flow occurred in the 2000-07 time frame (Send et al. 2011).

The RAPID/MOCHA/WBTS array at $26.5^{\circ} \mathrm{N}$ targets the latitude of the maximum northward heat transport in the North Atlantic. Presently, the array features 24 tall moorings and includes instruments for direct velocity measurements near the boundaries (e.g., Kanzow et al. 2007; McCarthy et al. 2015). The moorings in this array are recovered and redeployed every 18 months, and here we present the most up-to-date 12-hourly and monthly time series from April 2004 to September 2018 (Fig. 3.22b; Smeed et al. 2019). The record-length time-mean MOC at $26.5^{\circ} \mathrm{N}$ is 17.7 $\pm 0.9 \mathrm{~Sv}$, with a monthly standard deviation of $3.5 \mathrm{~Sv}$. There is a substantial seasonal variability with amplitudes of $2 \mathrm{~Sv}$ and $0.7 \mathrm{~Sv}$ for the annual and semi-annual harmonics, respectively. The interannual variability is larger and has a peak-to-peak range of about $6 \mathrm{~Sv}$. The MHT at $26.5^{\circ} \mathrm{N}$ is strongly correlated with the MOC $(\mathrm{r}=0.96)$, which means that velocity variations dominate over temperature variations. The time-mean MHT is $1.2 \pm 0.1 \mathrm{PW}\left(1 \mathrm{PW}=10^{15} \mathrm{~W}\right)$, which constitutes about two-thirds and one-quarter of the total oceanic and atmospheric MHT, respectively (e.g., Trenberth and Fasulo 2017). From 2004-08 to 2008-12 the MOC and MHT at $26.5^{\circ} \mathrm{N}$ reduced from 18.8 to 15.9 Sv and from 1.3 to 1.1. PW, respectively (significantly different from zero at 95\% confidence; Smeed et al. 2018), and they have remained in a low state compared to the prior period. The latest results (through 2018) conclude that while the MOC at $26.5^{\circ} \mathrm{N}$ has been increasing since 2009 at a rate of $0.3 \pm 0.3 \mathrm{~Sv}$ per year, this trend is not statistically significant (Moat et al. 2019, 2020). One of the main discoveries made possible by the continuous MOC monitoring at $26.5^{\circ} \mathrm{N}$ is that the largest variability is concentrated at sub-annual frequencies (periods from 10 days to months) with a peak-to-peak amplitude exceeding $30 \mathrm{~Sv}$. This indicates that infrequent quasi-synoptic measurements (e.g., snapshots from ship transects) cannot accurately capture the low-frequency variability or establish the annual mean transport, for which continuous monitoring is required.

The MOC anomalies observed in the North Atlantic can either be of a local origin or originate upstream in the South Atlantic and beyond, in the Southern and Indian Oceans. It has been suggested that freshwater

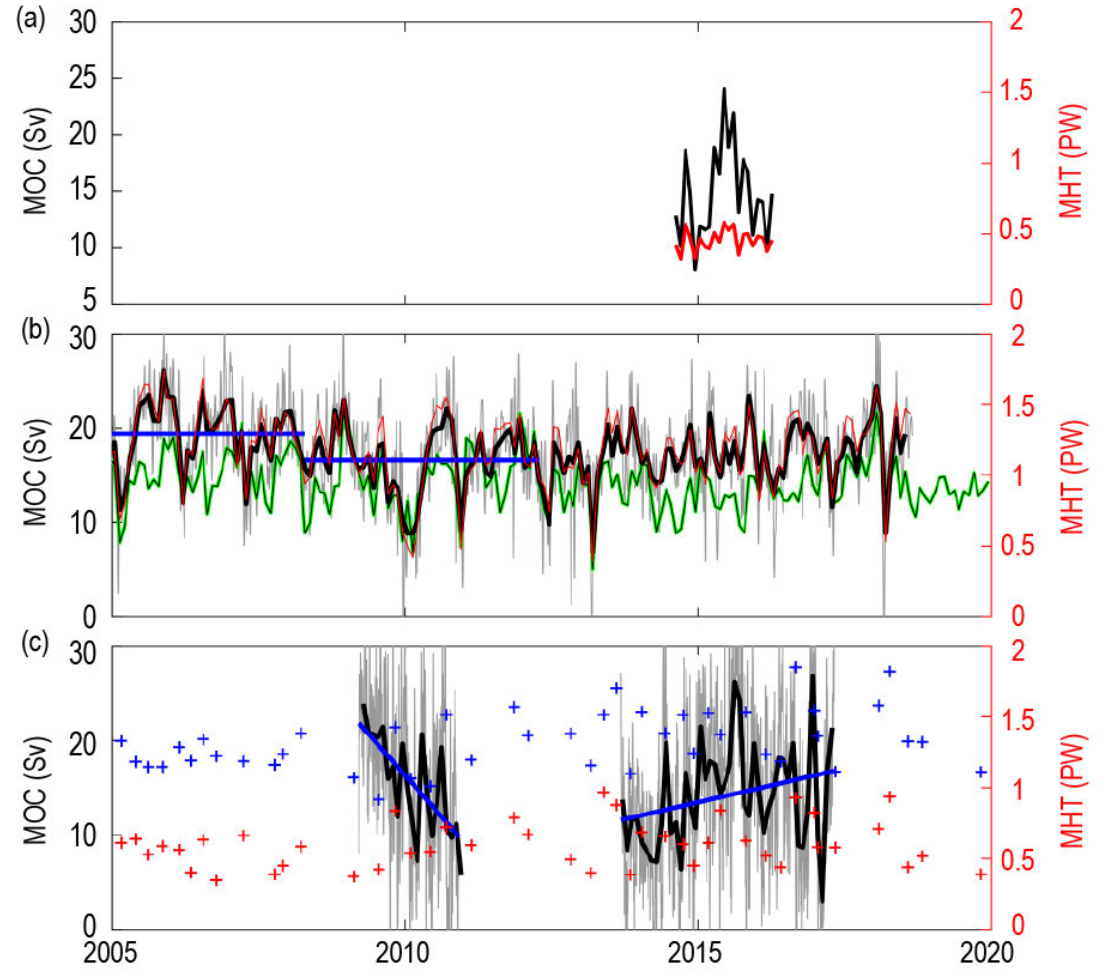

Fig. 3.22. Estimates of the northward MOC and MHT transports: (a) across OSNAP array, (b) at $26.5^{\circ} \mathrm{N}$, and (c) at $34.5^{\circ} \mathrm{S}$. Gray curves show 12-hourly values for RAPID/MOCHA/WBTS in (b) and daily values for SAMBA in (c); black curves show MOC monthly values. The blue lines show averages during 2004-08 and 2008-12 in panel (b) and linear trends in 2009-10 and 2013-17 in panel (c). MHT estimates are shown by red curves for OSNAP and RAPID/MOCHA/WBTS arrays. The green curve in (b) shows the MOC estimate at $26.5^{\circ} \mathrm{N}$ from the combination of altimetry and Argo data. The blue/red crosses in (c) show MOC/ MHT estimates obtained from XBT data along AX18 transect in the South Atlantic. 
flux into the South Atlantic may control the stability of the entire AMOC system (e.g., Rahmstorf 1996; Dijkstra 2007; Drijfhout et al. 2011; Garzoli et al. 2013; Weijer et al. 2019). To monitor the impact of inter-ocean exchanges on the AMOC, the SAMBA moorings at $34.5^{\circ} \mathrm{S}$ began being deployed in 2009 (e.g., Meinen et al. 2013; Ansorge et al. 2014). Similar to what has been found at $26.5^{\circ} \mathrm{N}$, the SAMBA results have demonstrated that continuous measurements are imperative to resolve the annual mean and to avoid aliasing high-frequency signals. Currently, the array includes 20 moorings at $34.5^{\circ} \mathrm{S}$ consisting mostly of pressure-equipped inverted echo sounders (PIES); many of them are also equipped with a near-bottom current meter (CPIES). The available MOC time series at SAMBA is daily and spans the period March 2009-April 2017 (more recent data have not been recovered yet), with a data gap during December 2010-September 2013 (Fig. 3.22c). The record-length time-mean northward transport is $14.7 \mathrm{~Sv}$, and the monthly standard deviation is $5.3 \mathrm{~Sv}$, which is larger than the standard deviation observed at $26.5^{\circ} \mathrm{N}$ and is consistent with previous results showing that the MOC variability decreases northward (Dong et al. 2015; Majumder et al. 2016; Frajka-Williams et al. 2019). Measurements from SAMBA have revealed that the MOC has strong independent barotropic (pressure-driven), baroclinic (density-driven), and Ekman (wind-driven) variations at $34.5^{\circ} \mathrm{S}$ at a wide range of time scales from a few days to seasonal and interannual (Meinen et al. 2018). Seasonal variations are significantly influenced by both baroclinic and barotropic variations near the boundaries, with the strongest contributions coming from the density variations near the eastern boundary. The Ekman and barotropic seasonal anomalies nearly balance one another, so the total MOC seasonality varies nearly in phase with the seasonality of the baroclinic contribution (Meinen et al. 2018). Interannual variations of the MOC at $34.5^{\circ} \mathrm{S}$ are primarily driven by baroclinic and barotropic variations, with the Ekman contributions being quite weak in comparison (Meinen et al. 2018). Although the MOC appears to be strengthening in 2013-17 at a rate of 1.4 \pm 1.9 Sv per year (blue line in Fig. 3.22c), this change is not statistically significant.

It is also important to monitor the AMOC in the proximity of key regions of deep water formation and thus provide direct assessments of the relationships that have been suggested in past modeling studies (Biastoch et al. 2008; Zhang 2010; Yeager and Danabasoglu 2014). These assessments are particularly important in light of dramatic climate changes in the Arctic, including large increases in air and sea temperatures, Greenland glacier melt, and extensive sea ice reduction. The OSNAP array, started in 2014 to make these important measurements (Lozier et al. 2017), consists of 57 moorings supplemented with glider and float measurements along two legs: one extending from southern Labrador to the southwestern tip of Greenland across the mouth of the Labrador Sea (OSNAP West; $\sim 52^{\circ}-60^{\circ} \mathrm{N}$ ), and the second extending from the southeastern tip of Greenland to Scotland (OSNAP East; $~ 57^{\circ}-60^{\circ} \mathrm{N}$ ) (Fig. 3.22a). As of today, the data records span a nearly four-year period from 2014 to 2018, with published estimates of the MOC and MHT being available for the initial 21-month period of the array from August 2014 to April 2016. The MOC across the entire OSNAP section has the time-mean of $14.9 \pm 1.8 \mathrm{~Sv}$ and shows considerable temporal variability, with 30-day means ranging from 8.1 to $24.1 \mathrm{~Sv}$ and a standard deviation of 4.1 Sv (Lozier et al. 2019a,b). One of the main findings over the observational period is that the conversion of warm, salty, shallow Atlantic waters into cold, fresh, deep overflow waters moving southward in the Irminger and Iceland basins is largely responsible for the bulk of the overturning and its variability in the subpolar basin. This result challenges the dominant view that changes in deep water formation in the Labrador Sea dominate the AMOC variability (Lozier et al. 2019a,b). The time-mean MHT across the entire OSNAP is $0.45 \pm 0.04 \mathrm{PW}$ with a standard deviation of 0.08 PW. Similar to $26.5^{\circ} \mathrm{N}$, the MHT and MOC are strongly correlated $(\mathrm{r}=0.9)$. Therefore, the MHT is principally accomplished by the overturning, which is dominated by flows across OSNAP East. Weak overturning in the Labrador Sea during 2014-16 can be explained by strong density compensation of salinity and temperature transformation in that basin (Zou et al. 2020a). Another 
interesting result is that RAFOS floats entering the western subpolar gyre as they exit the Charlie Gibbs Fracture Zone do not show a dominant pathway northward into the Irminger basin, in contradiction to the traditional view of the way the overflow water spreads (Zou et al. 2020b).

Existing time series of the AMOC transports from trans-basin in situ observing arrays are limited in both number and temporal extent due to the cost of maintaining such arrays. So other methods for estimating the AMOC transports still have important roles to play. The long-term observations from XBT ship sections, including the high-density AX18 XBT transect near $34.5^{\circ} \mathrm{S}$, represent some of the longest in situ time series, in the case of AX18 dating back to 2002 (e.g., Dong et al. 2009; Garzoli et al. 2013). Another strength of the XBT transects is that they have high horizontal-resolution information about upper ocean temperatures in the ocean, making them extremely useful for calculating MHT. The time-means of MOC and MHT across AX18 since 2002 are $19.9 \pm 0.8 \mathrm{~Sv}$ and $0.6 \pm 0.1 \mathrm{PW}$, respectively, and the standard deviations are $3.1 \mathrm{~Sv}$ and 0.2 PW (blue and red crosses in Fig. 3.22c). The correlation between the MOC and MHT from AX18 is 0.78. In 2019, there was only one occupation of AX18 yielding MOC and MHT estimates of $16.7 \mathrm{~Sv}$ and $0.4 \mathrm{PW}$, respectively.

Other newer methods for calculating the MOC using blended in situ and satellite observations have also been producing interesting results. Methods combining altimetry (available since 1992) and Argo profiling floats (good spatial coverage since 2004) help in advancing the understanding of the latitudinal connectivity of the MOC system. Willis (2010) and Hobbs and Willis (2012) first combined altimeter-derived surface geostrophic velocities with the Argo-measured temperature and salinity profiles as well as float-drift velocities at 1000-m depth to estimate the MOC/MHT at $41^{\circ} \mathrm{N}$. This time series has not been updated since the 2017 State of the Climate report. Similar blended MOC/MHT estimates based on satellite altimetry and in situ data (XBT, Argo, CTD) covering the period $1993-2020$ have recently been obtained for $26.5^{\circ} \mathrm{N}$ in the North Atlantic, taking into account the FC transport measured by the cable (Fig. 3.22b; McCarthy et al. 2020), and for several latitudes in the South Atlantic between $20^{\circ}$ and $35^{\circ} \mathrm{S}$ (Schmid 2014; Dong et al. 2015; Majumder et al. 2016). The $1993-2019$ mean MOC at $26.5^{\circ} \mathrm{N}$ from the blended product is $14.1 \pm 0.4 \mathrm{~Sv}$, which is lower than the time-mean MOC measured by the RAPID/MOCHA/WBTS array. Nevertheless, the variability is reproduced reasonably well, with the exception that the blended product does not reproduce the higher-than-average MOC state in 2004-09 observed by moorings (Fig. 3.22b). The blended product at $26.5^{\circ} \mathrm{N}$ also shows that the annual mean MOC in 2019 was $13.5 \pm 0.8 \mathrm{~Sv}$, i.e., not statistically different from the full record mean. Comparison of the XBT-based and various blended satellite/in situ estimates at $34.5^{\circ} \mathrm{S}$ (updated from Schmid 2014; Dong et al. 2009, 2015; Majumder et al. 2016) with the SAMBA continuous time series, and with one another, generally yields low correlation values (not shown). On one hand, this can be expected given the differing temporal resolution of the observations in the face of the strong high-frequency variability measured by moored arrays. On the other hand, this suggests that these blended estimates are sensitive to the methodology used to derive them. Reconciling the different estimates made by the multiple AMOC estimation techniques in use today represents an area for ongoing research.

\section{i. Global ocean phytoplankton-B. A. Franz, I. Cetinić, J. P. Scott, D. A. Siegel, and T. K. Westberry}

Photosynthetic production of carbon-containing compounds by marine phytoplankton fuels oceanic ecosystems and drives biogeochemical cycles (e.g. Falkowski et al. 1998; Field et al. 1998), contributing roughly 50\% to global net primary production (NPP). Phytoplankton distribution, growth, and diversity are governed by light and nutrient availability, successively controlled by physical conditions (e.g., Behrenfeld et al. 2006). Spaceborne radiometers such as SeaWiFS (McClain 2009) and MODIS (Esaias et al. 1998) allow detection of spatio-temporal changes in the distribution of phytoplankton, either through near-surface concentration of the phytoplankton pigment chlorophyll- $a$ (Chl $a$; $\left.\mathrm{mg} \mathrm{m}^{-3}\right)$ or phytoplankton carbon $\left(\mathrm{C}_{\mathrm{phy}}, \mathrm{mg} \mathrm{m}^{-3}\right)$. Both parameters are useful tools to quantify variability of phytoplankton biomass in the ocean; discrepancies 
between their distributions (shifts in Chla: $\mathrm{C}_{\text {phy }}$ ratios) are indicators of physiological variability within the cell (due to the changes in light and nutrient conditions) or changes in species composition (Westberry et al. 2016; Dierssen 2010; Geider et al. 1997). The combination of these two measurements thus provides a synoptic view of phytoplankton biomass in the ocean as well as its response to climate-associated variability in the environment.

In this report, we evaluate global Chla and $\mathrm{C}_{\text {phy }}$ distributions for the one-year period from October 2018 through September 2019, within the context of the continuous 22-year record provided through the combined observations of SeaWiFS (1997-2010) and MODIS on Aqua (MODISA, 2002-present). The MODIS-A daytime sea surface temperature (SST; ${ }^{\circ} \mathrm{C}$ ) is also assessed for the same period to provide context on the physical state of the oceans. The Chla product was derived using the ocean color index (OCI) algorithm of $\mathrm{Hu}$ et al. (2012), while $\mathrm{C}_{\text {phy }}$ was derived from the particle backscattering coefficient, $b_{b p}$, at $443 \mathrm{~nm}$ (GIOP algorithm, Werdell et al. 2013) and a linear relationship between $b_{b p}$ and $C_{\text {phy }}$ as described in Graff et al. (2015). In combining the ocean color records, the overlapping period from 2003 through 2010 was used to assess and correct for residual bias between the two mission datasets.

Changes in phytoplankton distribution over the year were evaluated by subtracting monthly climatological means for MODIS-A (October 2002-September 2018) from the mean values for

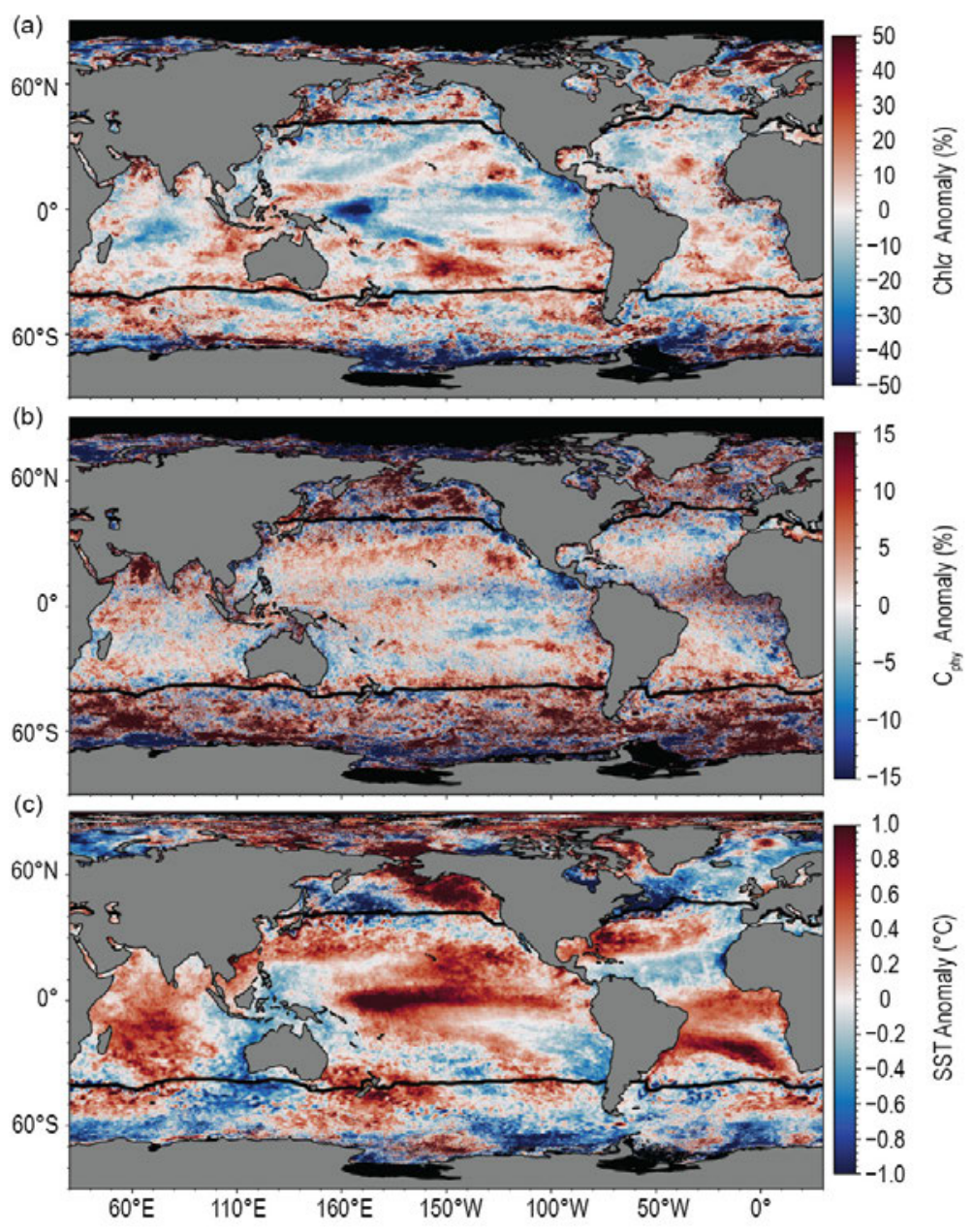

Fig. 3.23. Spatial distribution of average monthly (a) MODIS-A Chla anomalies, (b) MODIS-A $C_{\text {phy }}$ anomalies, and (c) MODIS-A SST anomalies, where monthly differences were derived relative to a MODIS-A 16-year climatological record (Oct 2002-Sep 2018). Chla and $C_{\text {phy }}$ are stated as \% difference from climatology, while SST is shown as an absolute difference. Also shown in each panel is the location of the mean $15^{\circ} \mathrm{C} \mathrm{SST} \mathrm{isotherm} \mathrm{(black} \mathrm{lines)}$ delineating the PSO.
MODIS-A Chl $a$ and $\mathrm{C}_{\text {phy }}$ in each month of the year. These monthly fields were then averaged to produce the global Chl $a$ and $\mathrm{C}_{\text {phy }}$ anomaly maps for 2019 (Figs. 3.23a,b). Similar calculations were performed on MODIS-A SST data to produce an equivalent SST annual mean anomaly for the same time period (Fig. 3.23c). The permanently stratified ocean (PSO) is defined as the region, spanning the tropical and subtropical oceans, where annual average SST is greater than $15^{\circ} \mathrm{C}$ and surface mixed layers are typically low in nutrients and shallower than the nutricline (black lines near $40^{\circ} \mathrm{N}$ and $40^{\circ} \mathrm{S}$ in Fig. 3.23; Behrenfeld et al. 2006).

Chla concentrations for 2019 (Fig. $3.23 a)$ were suppressed $10 \%-30 \%$ relative to the climatological mean $\left(0.142 \mathrm{mg} \mathrm{m}^{-3}\right)$ in the western Pacific warm pool, northern region of the tropical Pacific, western North Pacific, and central Indian Ocean. These locations correspond to regions of strongly elevated SSTs (Fig. 3.23c). Positive SST anomalies in these permanently stratified ocean regions generally coincide with shallower surface mixed layer depths (MLD), which increases light exposure within the mixed layer. Response of the phytoplankton to this increased insolation manifests as a decrease in cellular chlorophyll concentrations (Behrenfeld et al. 2015). This effect, 
in combination with the physiological response to low nutrient conditions, leads to decreased cellular chlorophyll to carbon ratios (Westberry et al. 2016) and thus a decoupling of the Chla and $\mathrm{C}_{\text {phy }}$ anomalies. Like Chla, concentrations of $\mathrm{C}_{\text {phy }}$ within the tropical Pacific show similar but weaker patterns of negative anomalies in the east $(-5 \%)$ but contrasting neutral to positive anomalies $(+5 \%)$ in the west compared to the 22-year average $\left(23.7 \mathrm{mg} \mathrm{m}^{-3}\right)$, with $\mathrm{C}_{\text {phy }}$ anomalies generally more homogeneous across the Atlantic and Pacific Oceans (Fig. 3.23b), consistent with prior-year observations (Franz et al. 2019). Notably, a region of strongly elevated SST in the South Atlantic, extending from the east coast of South America to the Horn of Africa (Fig. 3.23c), shows neutral to positive Chl $a$ anomalies and neutral to negative $C_{\text {phy }}$ anomalies. Elevated phytoplankton biomass, evident from both Chl $a$ and $\mathrm{C}_{\text {phy }}$ anomalies, were visible in the Mediterranean Sea, Arabian Sea, and Bay of Bengal, and the southern Pacific subtropical gyre. Outside of the PSO, a much weaker correlation is generally observed between phytoplankton biomass anomalies and SST anomalies, consistent with past reports (e.g., Franz et al. 2019), with patches of high biomass visible throughout the Southern Ocean and northern subpolar Atlantic (negative SST anomaly) and the northeastern subpolar Pacific (positive SST anomaly).

Seasonal changes in phytoplankton biomass in the PSO typically display two pronounced peaks, reflecting vernal increases in biomass in the Northern Hemisphere (NH) and Southern Hemisphere (SH; Fig. 3.24). Peaks in monthly climatological $\mathrm{C}_{\text {phy }}$ tend to trail behind peaks in Chla with a two-month delay, likely due to a reduction in phytoplankton chlorophyll to carbon
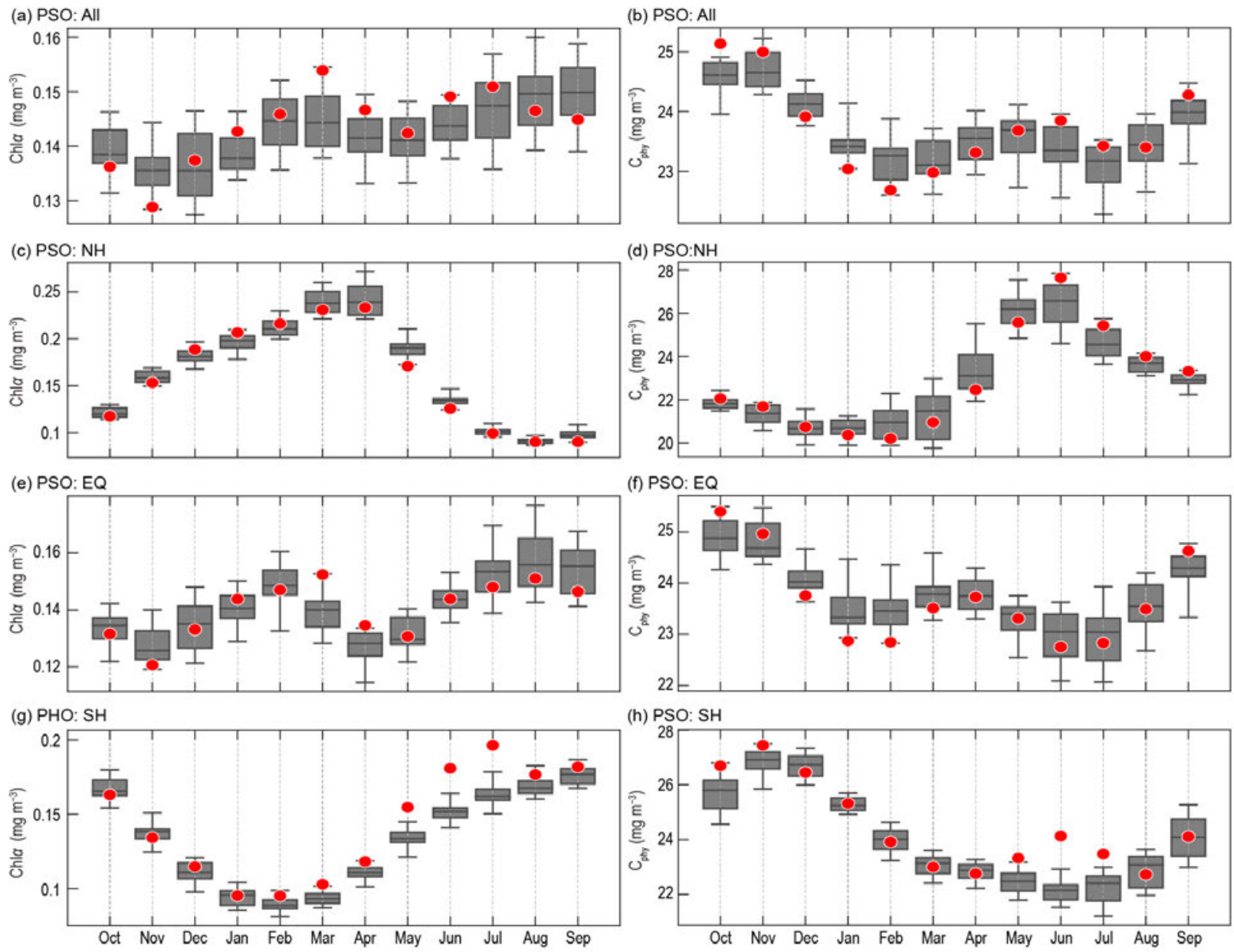

Fig. 3.24. Distribution of Oct 2018-Sep 2019 monthly means (red circles) for (a) MODIS-A Chla and (b) MODIS-A phy $_{\text {for the }}$ PSO region, superimposed on the climatological values as derived from the combined time series of SeaWiFS and MODIS-A over the 20-year period 1998-2017. The gray boxes show the interquartile range of the climatology, with a black line for the median value and whiskers extending to the 5 th and 95 th percentiles. Subsequent panels show latitudinally segregated subsets of the PSO for the NH north of $23^{\circ} \mathrm{N}(\mathrm{c}),(\mathrm{d})$, tropical $\pm 23.5^{\circ}$ latitude subregion (e),(f), and SH south of $23^{\circ} \mathrm{S}(\mathrm{g}),(\mathrm{h})$. 
ratios as the seasonal bloom progresses (e.g., Westberry et al. 2016). During 2019, primary and secondary peaks in Chla (Fig. 3.24a) occurred in March and July, followed by $\mathrm{C}_{\text {phy }}$ maxima in June and October (Fig. 3.24b), corresponding with the associated seasonal cycles of the NH and $\mathrm{SH}$, respectively (Figs. 3.24c-h), and with timing consistent with prior-year observations (Franz et al. 2019). Monthly mean values of Chl $a$ and $C_{\text {phy }}$ for 2019 fell generally within the range of climatological norms, with the notable exception of highly elevated concentrations observed in the SH in May-July.

Over the 22-year time series of spatially integrated monthly mean Chla within the PSO (Fig. 3.25a), concentrations varied by $\sim 15 \%\left( \pm 0.02 \mathrm{mg} \mathrm{m}^{-3}\right)$ around a long-term average of 0.142 $\mathrm{mg} \mathrm{m}^{-3}$ (Fig. 3.25a). This variability includes significant seasonal cycles in Chl $a$ distributions and responses to climatic events, as has been observed previously (e.g., Behrenfeld et al. 2006; Franz et al. 2019). $\mathrm{C}_{\text {phy }}$ over the same 22-year period varied by $\sim 7 \%\left( \pm 1.5 \mathrm{mg} \mathrm{m}^{-3}\right)$ around an average of $23.7 \mathrm{mg} \mathrm{m}^{-3}$ (Fig. 3.25c). The October 2018-September 2019 monthly anomalies varied by $\pm 2 \%$ around that average (Fig. 3.25d), consistent with neutral ENSO conditions. Seasonal cycles in $\mathrm{C}_{\text {phy }}$ are more clearly defined than those of Chla, consistent with the assertion that $\mathrm{C}_{\text {phy }}$ represents true variability in phytoplankton biomass that is insensitive to local and global environmental conditions that alter cell pigmentation through physiological processes.

Chla monthly anomalies within the PSO (Fig. 3.25b) show variations of $\pm 10 \%\left( \pm 0.015 \mathrm{mg} \mathrm{m}^{-3}\right)$ over the multi-mission time series, with largest deviations generally associated with ENSO events. This link between ENSO variability and mean Chl $a$ response in the PSO is demonstrated by the correspondence of anomaly trends with the Multivariate ENSO Index (MEI; Wolter and Timlin 1998), presented in the inverse to illustrate the covariation. For 2019, variability in monthly Chla anomalies was modest $( \pm 6 \%)$ and centered around zero, consistent with neutral to weak ENSO conditions during this year (Fig 3.1b). Similar observations can be made of the $\mathrm{C}_{\text {phy }}$ anomalies $( \pm 2 \%$ ), which also track well with the MEI over the 22-year timeseries.

Observed trends and variability in $\mathrm{C}_{\text {phy }}$ reflect changes in phytoplankton biomass, while Chla variability reflects changes in both biomass and physiology (or health). These two properties are mechanistically linked to physical conditions of the upper ocean, as well as to ecological interactions between phytoplankton and their zooplankton predators. Our ability to track subtle variations in the distribution of Chla and $\mathrm{C}_{\text {phy }}$ on the global scale thus contributes to our
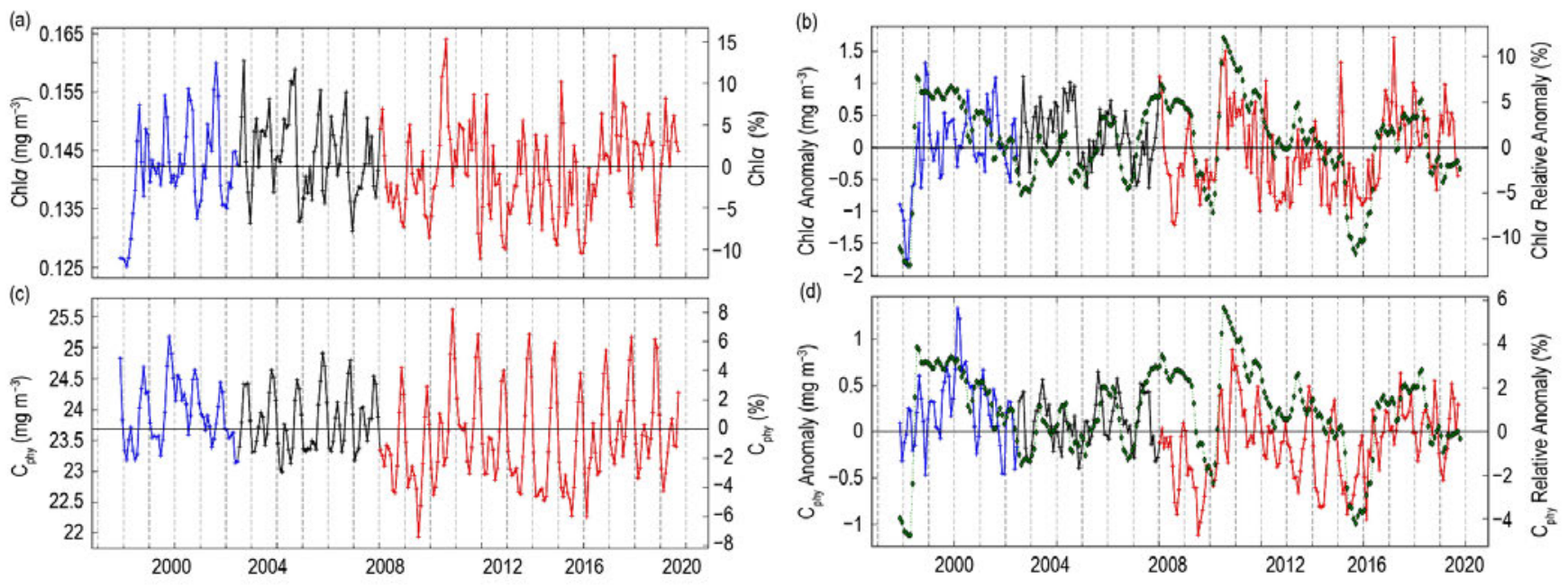

Fig. 3.25. The 22-year, multi-mission record of Chla and $C_{\text {phy }}$ averaged over the PSO for SeaWiFS (blue), MODIS-A (red), and combined (black). (a) Shows Chla from each mission, with the horizontal line indicating the multi-mission mean Chla concentration for the region. (b) Shows the monthly Chla anomaly from SeaWiFS and MODIS-A after subtraction of the 20-year multi-mission climatological mean (Fig. 3.24). Both (c) and (d) show the same as (a) and (b), respectively, but for $\mathrm{C}_{\mathrm{phy}}$. Green diamonds show the MEI, inverted and scaled to match the range of the Chla and $\mathrm{C}_{\mathrm{phy}}$ anomalies. 
understanding of climate-driven changes in the functionality of the ocean. Unraveling the diversity and covariation of factors that influence Chla concentrations, however, is essential for correctly interpreting the implications of Chla anomalies on ocean biogeochemistry and food webs. An additional complication is that measured changes in ocean color often contain a contribution from chromophoric dissolved organic matter (Siegel et al. 2005) or from the changing phytoplankton population (with its type-specific optical characteristics; Dierssen 2010) that can be mistakenly attributed to changes in Chla (Siegel et al. 2013). $\mathrm{C}_{\text {phy }}$ provides a more direct measurement of phytoplankton biomass and thus offers complementary information on the state of the oceans. Future satellite missions, such as the upcoming hyperspectral Plankton, Aerosol, Cloud, ocean Ecosystem mission (PACE), will enable the rigorous separation of phytoplankton absorption features from non-algal features, as well as the assessment of changes in phytoplankton species or functional group distributions (Werdell et al.2019). Such data will provide a major step forward in our ability to disentangle the impacts of climate forcing on global phytoplankton communities.

Sidebar 3.1: BioGeoChemical Argo-K. S. JOHNSON, M. B. BIF, S. M. BUSHINSKY, A. J. FASSBENDER, AND Y. TAKESHITA

As atmospheric $\mathrm{CO}_{2}$ rises, the ocean warms, winds shift, and ice melts (IPCC 2019). Numerical models suggest that large changes in ocean chemistry and biology will result (Beaugrand et al. 2019; IPCC 2019). Traditionally, the biogeochemical (BGC) measurements used to identify such changes have been made from research vessels, particularly for the ocean interior, which is not accessible by satellite remote sensing and not sampled by voluntary observing ships. However, the number of basic BGC properties observed from ships has been steadily declining over the past three decades as science objectives have changed (Boyer et al. 2013; K. S. Johnson et al. 2015), making it more difficult to observe these ocean changes in this critical moment.

Declining trends in the number of ship-based temperature and salinity observations have been mitigated through the global profiling float array established by the Core-Argo program (Riser et al. 2016). The BGC-Argo array of profiling floats is beginning a similar revolution for BGC processes (Johnson and Claustre 2016; Claustre et al. 2020). The accuracy and stability of the BGC sensor observations from profiling floats have been demonstrated by recent studies (Johnson et al. 2017; Mignot et al. 2019), and an implementation plan for a global array of 1000 BGC-floats has been developed by the BiogeochemicalArgo Planning Group (BAPG 2016; Roemmich et al. 2019). The remainder of this sidebar focuses on two of the longer-term records from BGC-Argo profiling floats to illustrate the applicability of such datasets in climate related studies.

\section{North Pacific nitrate}

Primary production in the sub-Arctic northeast Pacific Ocean mainly takes place during spring and summer months, fueled by vertical nutrient inputs from previous wintertime mixing events as well as increasing seasonal light levels (Wong et al. 2002). This region is directly affected by climate processes, such as El Niño-Southern Oscillation (ENSO) and the Pacific Decadal Oscillation (PDO). These events lead to changing heat content and stratification of the upper ocean (Wong et al. 2007; Bond et al. 2015), which alters the seasonal vertical nutrient exchanges (Bif et al. 2019). BGC-Argo profiling floats equipped with nitrate sensors have been deployed since 2008 at Ocean Station Papa (OSP; $50^{\circ} \mathrm{N}, 145^{\circ} \mathrm{W}$ ), one of the oldest ocean time-series monitoring programs still in operation. These floats record annual cycles of net community production (NCP) based on seasonal nitrate depletion (Plant et al. 2016).

A significant warm anomaly developed in the region beginning in 2013 (Bond et al. 2015) and was intensified by an extreme El Niño in 2015 (Bif et al. 2019). Changes in physical and chemical properties before, during, and after the warm event were recorded by the BGC floats near OSP (Fig. SB3.1).

Float observations revealed that the potential density anomaly of $25.5 \mathrm{~kg} \mathrm{~m}^{-3}$ did not reach the surface during the warm years of 2013-15 as usually happens (Bif and Hansell 2019; Bif et al. 2019; Fig. SB3.1). Enhanced stratification restricted vertical mixing between the upper ocean and the deeper, nutrient-enriched 
waters, resulting in anomalously low nitrate concentrations in the upper ocean (Fig. SB3.1). NCP computed from the nitrate record shows unusually low values in 2015 (Bif et al. 2019) that led to an unprecedented ecosystem response including shifts in plankton community composition (Peterson et al. 2017), impacts on fisheries (Richerson and Holland 2017), and large-scale mortality in seabirds (Piatt et al. 2020).

Similar warming conditions in the region since September 2018 can be clearly seen in the most recent data (Fig. SB3.1). The extended time series shows persistent winter stratification in 2018/19 and 2019/20 and reduced surface nitrate concentrations. As the ongoing warm event continues to evolve in 2020, one can only wonder if organic carbon production in the upcoming spring and summer months will respond as previously observed.

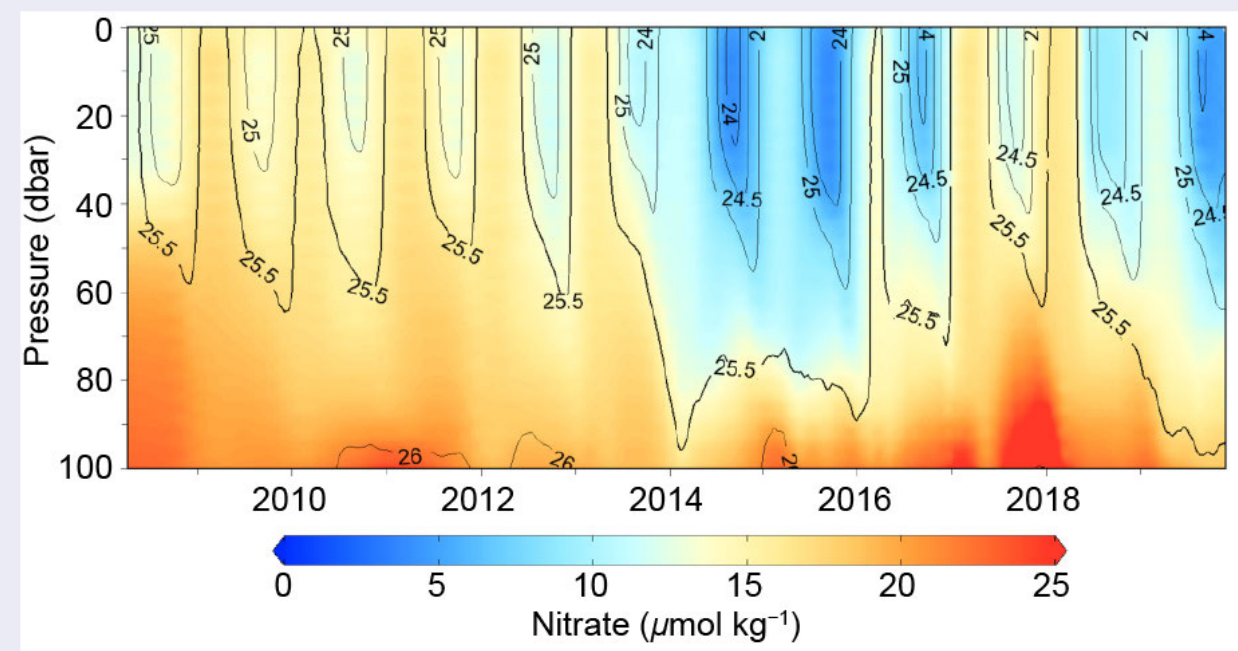

Fig. SB3.1. Nitrate concentrations $\left(\mu \mathrm{mol} \mathrm{kg}{ }^{-1}\right)$ in the upper $100 \mathrm{~m}$ measured since 2008 by BGC-Argo profiling floats launched at Ocean Station Papa $\left(48^{\circ}-54^{\circ} \mathrm{N}\right.$, $135^{\circ}-152^{\circ} \mathrm{W}$ ) in the North Pacific. Contours show the density anomaly (sigma theta, $\mathrm{kg} \mathrm{m}^{-3}$ ). Data were collected with $5-\mathrm{m}$ vertical resolution every 5 days, with the exception of a gap from 27 Mar 2018 to 16 Aug 2018 that was filled by contouring. Updated from Fig. 9 in Bif and Hansell (2019).

\section{Southern Ocean oxygen}

Significant oxygen concentration decreases have occurred in the world ocean (Oschlies et al. 2018; Breitburg et al. 2018) and continued decreases are "very likely" (IPCC 2019). Some of the largest oxygen declines in the mesopelagic zone (200-1000 $\mathrm{m}$ below the surface) of the open ocean have occurred in the Southern Ocean (Helm et al. 2011). However, this region is not well sampled from ships. BGC-Argo profiling floats can produce the high-quality measurements needed to fill this gap.

Initial deployments of BGC-Argo floats equipped with oxygen sensors began in 2002 (Riser and Johnson 2008). These early data demonstrated the need for systematic corrections to oxygen data that result from calibration errors (Emerson and Bushinsky 2014; Bittig and Körtzinger 2015). Protocols to correct the early data using ocean climatologies were developed (Takeshita et al. 2013; Drucker and Riser 2016). Starting in 2014, the Southern Ocean Carbon and Climate Observations and Modeling program has deployed BGC-Argo floats that use atmospheric oxygen as an absolute in situ calibration, i.e., independent of ocean climatologies (K. S. Johnson et al. 2015; Bittig and Körtzinger 2015; Bushinsky et al. 2016). These developments allowed the first direct estimate of the Southern Ocean annual air-sea oxygen flux (Bushinsky et al. 2017) and revealed a much larger transfer of oxygen to the Southern Ocean than was previously estimated
(Gruber et al. 2001). This is significant because the Southern Ocean represents one of the main ventilation pathways for the global interior ocean.

The float oxygen record defines clear seasonal cycles throughout Southern Ocean surface waters (not shown). Here we update the float oxygen record published in Bushinsky et al. (2017) for the Polar Frontal Zone (PFZ; Fig. SB3.2). Monthly mean oxygen values are displayed when mean float-determined sea surface temperatures (SSTs) agree with the NOAA Optimal Interpolation record. This was done to remove variance due to under-sampling. From records such as these, we can now determine an annual mean value and the associated variance at the surface and in the subsurface. Here we have shown the lightest layer of water that does not seasonally outcrop in the PFZ (Fig. SB3.2), but such results can be obtained down to 2000-m depth. Understanding the statistical variability in ocean oxygen is the first step in using the data to understand possible change linked to climate variation. Comparable assessments of oxygen variability are much more difficult to obtain from ships. Such observations are essential for quantifying interior ocean oxygen declines over time and the mechanisms that might drive any change (Bronselaer et al. 2020). 


\section{Conclusions}

BGC sensors on profiling floats can now provide the highquality and long-term observations needed to detect climate signals in the ocean; however, the current system is based on a framework of independent science experiments and operates with only a small fraction of the desired number of floats (BAPG 2016). A fully realized system would be transformative. As with Core-Argo salinity measurements, a reference database of deep (1000-2000 m) measurements is required to correct
BGC pH and nitrate sensors for offsets or drifts (Johnson et al. 2017). Research programs that can accommodate float deployments will be essential partners to BGC-Argo. Programs such as GO-SHIP (Talley et al. 2016), which provide high-quality BGC observations in the deep sea, will become even more valuable as they provide the data needed to validate a distributed network of sensor observations.

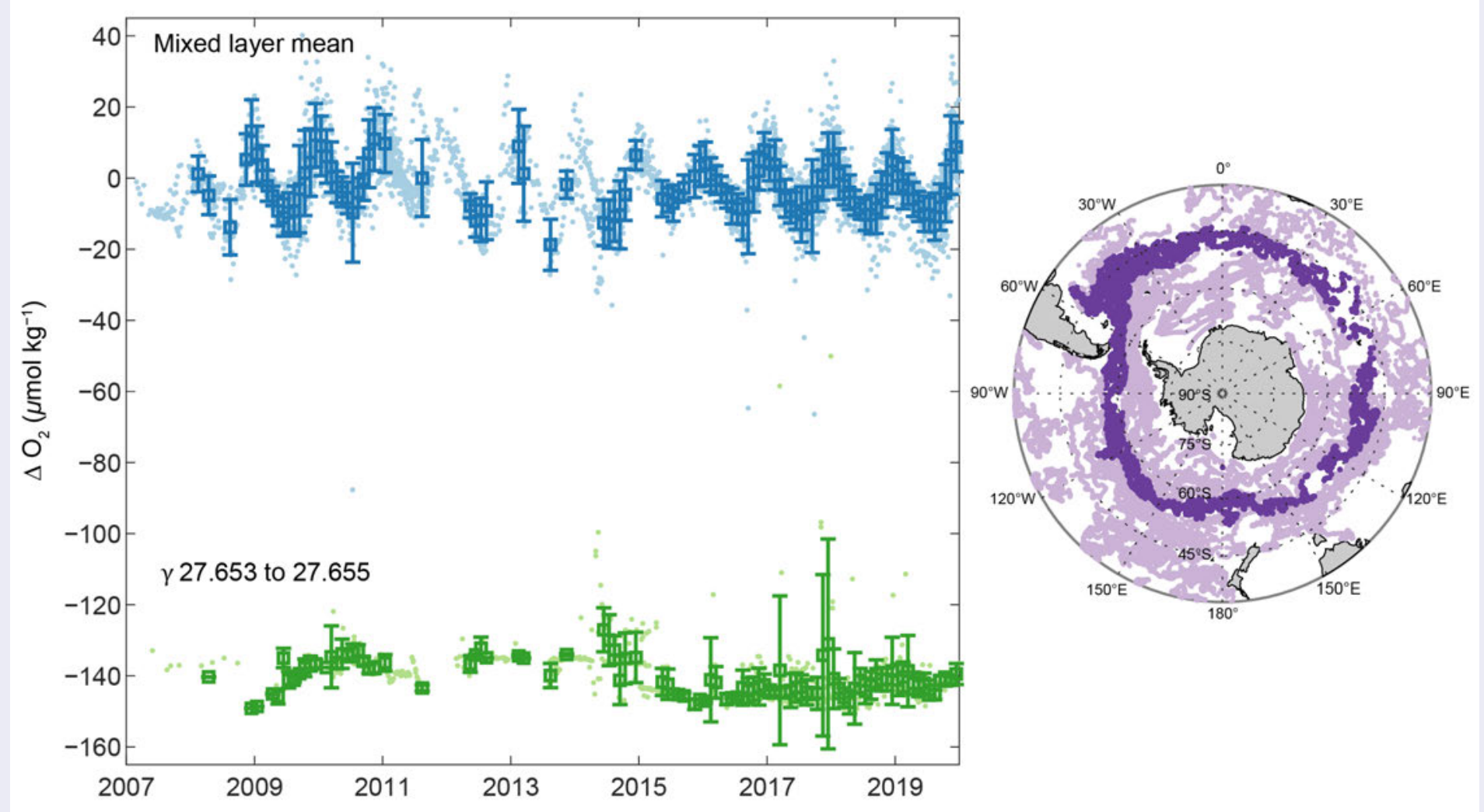

Fig. SB3.2. Time series of $\Delta \mathrm{O}_{2}\left(\left[\mathrm{O}_{2}\right]-\left[\mathrm{O}_{2}\right]_{\mathrm{sat}}\right)$ for the Polar Frontal Zone of the Southern Ocean. Blue dots represent individual float profile mixed layer mean values and blue boxes with error bars represent monthly mean values \pm 1 std. dev. Green dots and boxes are profile and monthly means for samples between neutral density $(\gamma)$ surfaces 27.653 and 27.655 , which represent the lightest waters for this zone that do not outcrop seasonally. Inset map indicates the spatial distribution of surface samples from the Polar Frontal Zone (dark purple) and the entire Southern Ocean (light purple) for 2002-19. Monthly values are only shown for months where mean float temperatures agreed with NOAA Optimal Interpolation SSTs (see Bushinsky et al. 2017 for more detail). 
j. Global ocean carbon cycle-R. A. Feely, R. Wanninkhof, P. Landschützer, B. R. Carter, and J. A. Triñanes

\section{1) Introduction}

The oceans play a major role in the global carbon cycle by taking up a significant fraction of the excess carbon dioxide that humans release into the atmosphere. As a consequence of humankind's collective release of $\mathrm{CO}_{2}$ emissions into the atmosphere from fossil fuel burning, cement production, and land use changes over the last two-and-a-half centuries, commonly referred to as "anthropogenic $\mathrm{CO}_{2}$ " $\left(\mathrm{C}_{\text {anth }}\right)$ emissions, the atmospheric $\mathrm{CO}_{2}$ concentration has risen from pre-industrial levels of about $278 \mathrm{ppm}$ (parts per million) to $410 \mathrm{ppm}$ in 2019. The atmospheric concentration of $\mathrm{CO}_{2}$ is now $47 \%$ higher than preindustrial levels (Friedlingstein et al. 2019). As discussed in previous State of the Climate reports, marine $\mathrm{C}_{\text {anth }}$ is the major cause of anthropogenic ocean acidification. Here the discussion is updated to include recent estimates of the ocean $\mathrm{C}_{\text {anth }}$ sink. Over the last decade the global ocean has continued to take up a substantial fraction of the $\mathrm{C}_{\text {anth }}$ emissions and therefore is a major mediator of global climate change. Of the $11( \pm 0.9) \mathrm{Pg} \mathrm{C} \mathrm{yr}^{-1}$ $\mathrm{C}_{\text {anth }}$ released during the period 2009-18, about 2.5 $( \pm 0.6) \mathrm{Pg} \mathrm{C} \mathrm{yr}^{-1}(23 \%)$ accumulated in the ocean, $3.2( \pm 0.6) \mathrm{Pg} \mathrm{C} \mathrm{yr}^{-1}(29 \%)$ accumulated on land, and $4.9( \pm 0.1) \mathrm{Pg} \mathrm{C} \mathrm{yr}^{-1}(44 \%)$ remained in the atmosphere with an imbalance of $0.4 \mathrm{Pg} \mathrm{C} \mathrm{yr}^{-1}$ (4\%; Fig. 2 of Friedlingstein et al. 2019). This decadal ocean carbon uptake estimate is a consensus view from a combination of measured decadal $\mathrm{CO}_{2}$ inventory changes, models, and global air-sea $\mathrm{CO}_{2}$ flux estimates based on surface ocean partial pressure of $\mathrm{CO}_{2}\left(p \mathrm{CO}_{2}\right)$ measurements from ships and moorings. Using ocean circulation models that include biogeochemical parameterizations and inverse models that are validated against or fit to observed air-sea exchange fluxes and basin-scale ocean inventories, Friedlingstein et al.

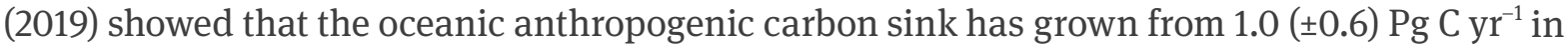
the decade of the 1960 s to $2.6( \pm 0.6) \mathrm{Pg} \mathrm{C} \mathrm{yr}^{-1}$ in 2018. Riverine contributions supply an additional 0.45 to $0.78 \mathrm{Pg} \mathrm{C} \mathrm{yr}^{-1}$ of natural carbon to the ocean.

\section{2) Air-sea carbon dioxide fluxes}

Ocean uptake of $\mathrm{CO}_{2}$ is estimated from the net air-sea $\mathrm{CO}_{2}$ flux derived from the bulk flux formula with air-sea differences in $\mathrm{CO}_{2}$ partial pressure $\left(\Delta p \mathrm{CO}_{2}\right)$ and gas transfer coefficients as input. Gas transfer is parameterized with wind as described in Wanninkhof (2014). This provides a net flux estimate. To determine the $\mathrm{C}_{\text {anth }}$ fluxes into the ocean, several other processes need to be taken into account. A steady contribution of carbon from riverine runoff, originating from organic and inorganic detritus from land, recently revised upward from 0.45 to $0.78 \mathrm{Pg} \mathrm{C} \mathrm{yr}^{-1}$ (Resplandy et al. 2018) needs to be included. Other factors, such as natural carbon deposition into/onto the sea floor and margins and natural variations in the balance of $\mathrm{CO}_{2}$ between the atmosphere and ocean, are assumed to be small. $\mathrm{C}_{\text {anth }}$ is therefore defined as the sum of the net flux and the riverine contribution. The data sources for $p \mathrm{CO}_{2}$ are annual updates of surface water $p \mathrm{CO}_{2}$ observations from the Surface Ocean $\mathrm{CO}_{2}$ Atlas (SOCAT) composed of mooring and ship-based observations (Bakker et al. 2016) and the Lamont-Doherty Earth Observatory (LDEO) database with ship-based observations (Takahashi et al. 2017). The increased observations and improved mapping techniques including neural network methods (Rödenbeck et al. 2015) provide annual global $p \mathrm{CO}_{2}$ fields on a $1^{\circ}$ latitude $\times 1^{\circ}$ longitude grid at monthly time scales. This allows investigation of variability on sub-annual to decadal time scales.

The monthly $2019 \Delta p \mathrm{CO}_{2}$ maps are based on the observation-trained neural network approach of Landschützer et al. (2013, 2014). The 2019 values are projections based on observed sea surface temperature (SST), sea surface salinity (SSS), satellite chlorophyll- $a$, and atmospheric $\mathrm{CO}_{2}$ for 2019; climatological mixed layer depths (MLD); and a neural network approach for $p \mathrm{CO}_{2}$ developed from the data from 1982 through January 2019. The 2019 estimate uses the monthly wind fields from 2018, but changes in winds over time have a small effect on annual global air-sea $\mathrm{CO}_{2}$ fluxes (Wanninkhof and Triñanes 2017). The $C_{\text {anth }}$ fluxes from 1982 to 2019 suggest a decreasing ocean sink in the first part of the record and a strong increase from 2001 onward that continued 
unabated into 2019 with a 0.2 Pg C yr ${ }^{-1}$ increase from 2018 to the 2019 estimate (Fig. 3.26). The amplitude of seasonal variability is large $\left(\approx 1 \mathrm{Pg} \mathrm{C} \mathrm{yr}^{-1}\right)$ compared to the long-term trend with minimum uptake in the June-September timeframe. The $\mathrm{C}_{\text {anth }}$ air-sea flux of $3.2 \mathrm{Pg} \mathrm{C} \mathrm{yr}^{-1}$ in 2019 is 33\% more than the revised 1997-2017 average of $2.40( \pm 0.46) \mathrm{Pg} \mathrm{C} \mathrm{yr}^{-1}$.

The average fluxes in 2019 (Fig. 3.27a) show the characteristic pattern of effluxes (ocean-to-air fluxes) in the tropical regions, in coastal upwelling zones, and in the high-latitude Southern Ocean around $60^{\circ} \mathrm{S}$. Coastal upwelling regions include the Arabian Sea, off the west coasts of North and South America, and the coast of Mauritania. The western Bering Sea in the northwest Pacific was a strong $\mathrm{CO}_{2}$ source as well in 2019, particularly in the March-April timeframe. The region with the largest efflux is the upwelling region of the eastern equatorial Pacific. The regions of effluxes are significant $\mathrm{CO}_{2}$ sources to the atmosphere. The primary uptake regions are in the subtropical and subpolar regions. The largest sinks are observed poleward of the sub-tropical fronts. The frontal positions determine the location of the maximum uptake. This position is farther south and weaker in the Pacific sector of the Southern Ocean compared to the other basins.

In the Northern Hemisphere (NH), there is a significant asymmetry in fluxes in the sub-Arctic gyre, with the North Atlantic being a large sink while the North Pacific is a source of $\mathrm{CO}_{2}$. This is, in part, due to the position of the western boundary currents that are known $\mathrm{CO}_{2}$ sinks at high latitudes. The Gulf Stream/North Atlantic Drift in the Atlantic extends farther north than the Kuroshio in the Pacific.

Ocean carbon uptake anomalies (Fig. 3.27c) in 2019 relative to the 1997-2017 average are attributed to the increasing ocean $\mathrm{CO}_{2}$ uptake with time (Fig. 3.26) and to variations in large-scale climate modes. The long-term air-sea flux trend since the minimum uptake in 2000 is $0.75 \mathrm{Pg} \mathrm{C}$ decade ${ }^{-1}$, which leads to greater ocean $\mathrm{CO}_{2}$ uptake (blue colors in Fig. 3.27a). Despite this trend, there are several large regions showing positive anomalies (efflux) for 2019, notably the eastern equatorial Pacific, the sub-polar Northwest Pacific (centered at $\approx 40^{\circ} \mathrm{N}$ ), and the high-latitude Southern Ocean. The increased effluxes in the eastern equatorial Pacific are related to a mostly negative sign of the Oceanic Niño Index (ONI) that followed an extensive period of predominantly positive ONI (i.e., more El Niño-like) conditions in the preceding 20 years. The neutral sea surface temperature anomaly (SSTA; see Fig. 3.1a) indicates normal upwelling of waters with high $\mathrm{CO}_{2}$ content has returned after a period of lower-than-normal upwelling. Positive anomalies (efflux) in the northwest Pacific regions, including the western Bering Sea, are related to the positive SSTA over the past year compared to the long-term average (Fig. 3.27c). 
The differences between the air-sea $\mathrm{CO}_{2}$ fluxes in 2019 compared to 2018 (Fig. 3.27b) are relatively small compared to previous years with anomalies roughly in the same regions as the difference of 2019 from the 20-year average. This indicates that conditions in 2019 resemble conditions in 2018. The increase in $\mathrm{CO}_{2}$ effluxes in the northwest Pacific from 2018 to 2019 are associated with increased temperature and associated increase in $p \mathrm{CO}_{2}$ caused by the return of the marine heatwave in this area (see also Fig. SB3.1). The Southern Ocean (south of $40^{\circ} \mathrm{S}$ ) shows a decreasing sink in the polar front region $\left(\approx 50^{\circ} \mathrm{S}\right)$ and increasing source to the south for the Atlantic sector of the Southern Ocean compared to 2018. The correlations with SSTA (2019 minus 2018) are more nuanced. The large positive SSTAs in the northwest Pacific from $30^{\circ}$ to $60^{\circ} \mathrm{N}$ are indicative of the warm water anomaly and associated positive $\mathrm{CO}_{2}$ flux anomaly (efflux; Fig. 3.27b). The large negative $\mathrm{CO}_{2}$ flux anomaly (uptake) in the southeastern Pacific has a positive SSTA associated with it, and the positive flux anomaly around $45^{\circ} \mathrm{S}$ in the South Atlantic is associated with a negative SSTA. These flux differences are not readily explained in terms of SSTA and suggest that in this band, SSTAs and flux anomalies are decoupled. The North Atlantic near Greenland shows a large increase in sink strength with a positive SSTA that again cannot be readily explained in terms of local SSTA. Rather, it appears that changes in the ocean currents and biological productivity changes between 2019 and 2018 are the cause of the greater uptake.
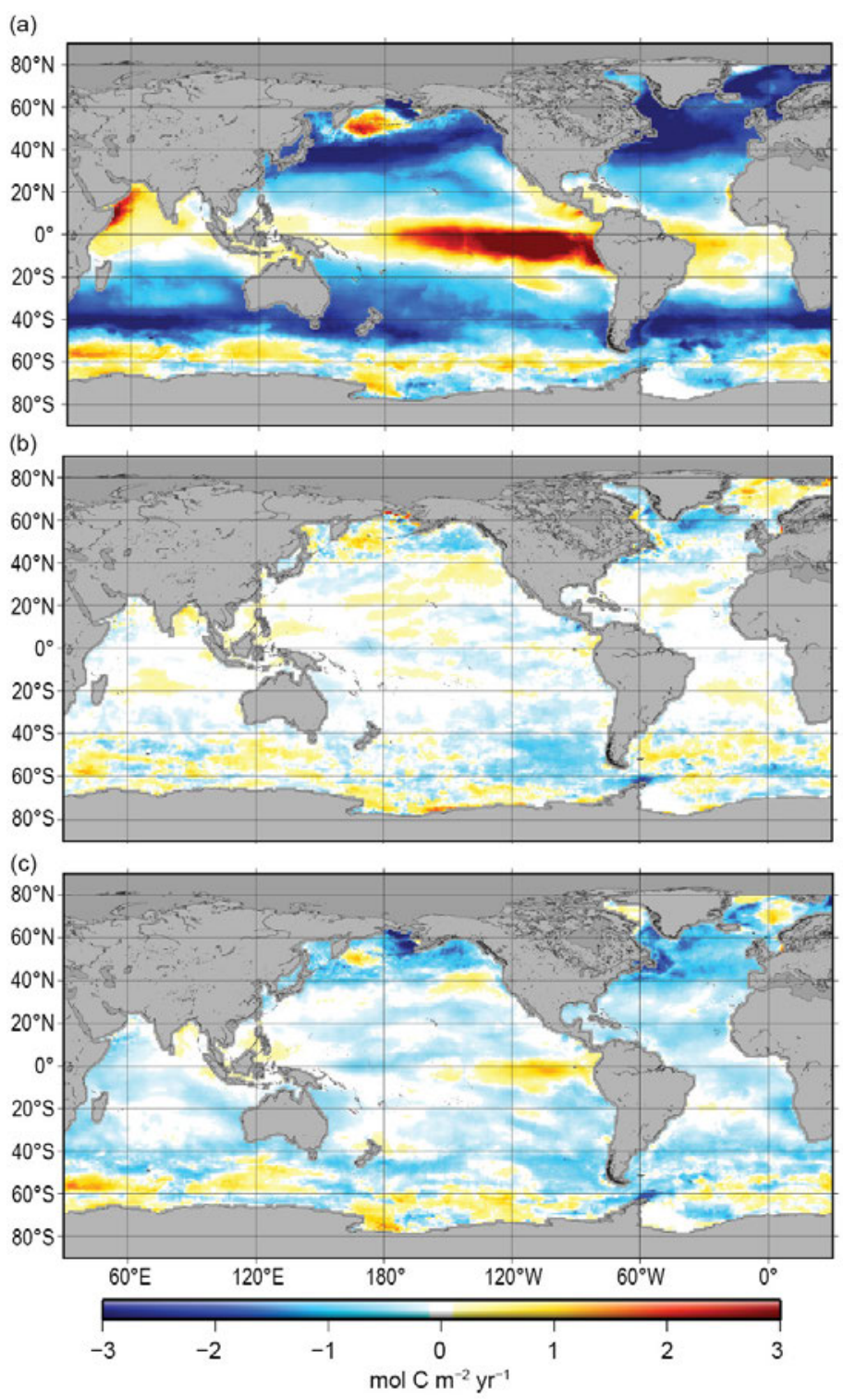

Fig. 3.27. Global map of (a) net air-sea $\mathrm{CO}_{2}$ fluxes for 2019, with ocean $\mathrm{CO}_{2}$ uptake regions shown in the blue colors, (b) net air-sea $\mathrm{CO}_{2}$ flux anomalies for 2019 minus 2018 values following the method of Landschützer et al. (2013), and (c) net air-sea $\mathrm{CO}_{2}$ flux anomalies for 2019 relative to a 1997-2017 average. All maps have units of $\mathrm{mol} \mathrm{C} \mathrm{m}^{-2} \mathrm{yr}^{-1}$.

Some of the $\mathrm{pCO}_{2}$ and $\mathrm{CO}_{2}$ flux anomalies can be attributed to variations in large-scale climate modes and associated physical anomalies, notably temperature, but the causality is often complex. For example, the behavior of $p \mathrm{CO}_{2}$ with respect to temperature includes competing processes: thermodynamics dictate decreasing $p \mathrm{CO}_{2}$ with decreasing SST, but waters originating from the deep with a cold temperature signal will have a high $p \mathrm{CO}_{2}$. As the equilibration time of $p \mathrm{CO}_{2}$ in surface seawater with atmospheric $\mathrm{CO}_{2}$ is on the order of a year, $\mathrm{CO}_{2}$ and $\mathrm{CO}_{2}$ flux anomalies can be propagated by ocean currents. Moreover, the drawdown of $p \mathrm{CO}_{2}$ due to biology is often associated with increasing temperature, but this depends on region and season. The strong trend of increasing $\mathrm{CO}_{2}$ uptake since 2000-02 has continued through 2019, with an increase in 2019 of 0.2 $\mathrm{Pg} \mathrm{C} \mathrm{yr}^{-1}$ above the 2018 estimate. This increase meets the overall expectation that the ocean will remain an increasing sink if atmospheric $\mathrm{CO}_{2}$ levels continue to rise. The sequestration of $\mathrm{CO}_{2}$ by the ocean partially mitigates the atmospheric $\mathrm{CO}_{2}$ rise but it comes at a cost of increased acidification of surface and subsurface waters (Feely et al., 2016; Carter et al. 2017; Lauvset et al. 2020). 


\section{3) Large-scale carbon and $\mathrm{pH}$ changes in the ocean interior}

Global-scale $\mathrm{CO}_{2}$ emissions from human activities are causing ocean interior $\mathrm{C}_{\text {anth }}$ increases and acidification. These large-scale changes can affect marine organisms and impact fisheries with implications for food security (Gattuso et al. 2015). Delineating how the biogeochemical processes in the ocean interior will be affected by the changing heat content and $\mathrm{C}_{\text {anth }}$ uptake is essential for developing future mitigation and adaptation responses to climate change. A major aim of the international Global Oceans Ship-based Investigations Program (GO-SHIP) is to determine the $\mathrm{C}_{\text {anth }}$ input to the ocean interior and the changing patterns of oceanic $\mathrm{CO}_{2}$ over time (Talley et al. 2016; Sloyan et al. 2019). Field observations and inverse models have provided estimates of the uptake of $\mathrm{C}_{\text {anth }}$ into the ocean both over the last 250 years and over the last two decades. Simulations of $\mathrm{C}_{\text {anth }}$ inventories with models suggest that the ocean accumulated 24-34 Pg of $\mathrm{C}_{\text {anth }}$ between 1994 and 2007 (Gruber et al. 2019; Fig. 3.28a), accounting for about 25\% of the total anthropogenic $\mathrm{CO}_{2}$ emissions over that time period. This uptake has increased the total inventory of $\mathrm{C}_{\text {anth }}$ since 1750 from $118 \pm 20 \mathrm{Pg} \mathrm{C}$ in 1994 to $170 \pm 20 \mathrm{Pg} \mathrm{C}$ in 2018 (Sabine et al. 2004; Friedlingstein et al. 2019). Change in $C_{\text {anth }}$ storage is determined by the change in $C_{a n t h}$ between repeat surveys. This approach utilizes several newly developed methods and procedures for determining $\mathrm{C}_{\text {anth }}$ from the often much larger changes in the natural carbon content due to changes in transport ventilation

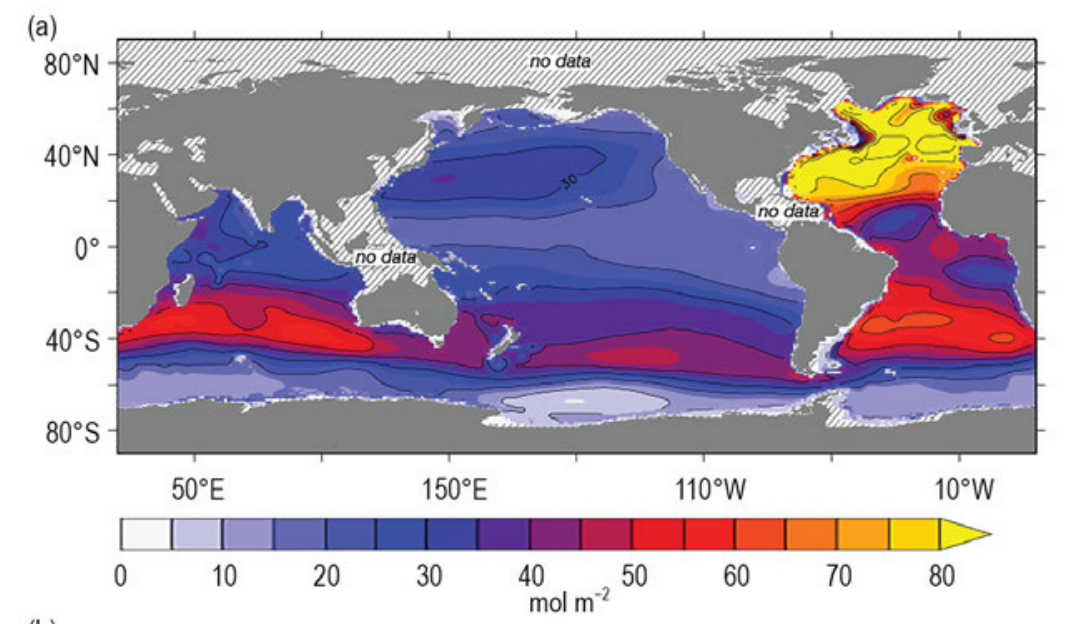

(b)

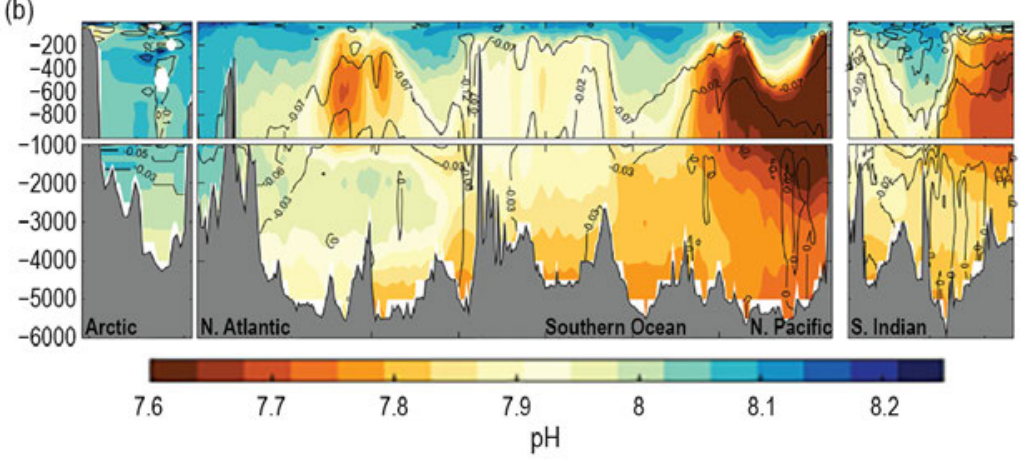

Fig. 3.28. (a) Change in full water column inventory of anthropogenic $\mathrm{CO}_{2}$ in $\mathrm{mol} \mathrm{m}^{-2}$ from 1994 to 2007 , based largely on WOCE and GO-SHIP BGC data in the GLODAPv2 data product (modified from Gruber et al. 2019). (b) Vertical cross sections of $\mathrm{pH}$ (color) in the major ocean basins, from GO-SHIP transects from the Arctic (left) south through the Atlantic to the Southern Ocean (middle), then north through the Pacific along $152^{\circ} \mathrm{W}$ (middle, right) and north through the Indian Ocean along $85^{\circ} \mathrm{E}$ (right). The pH (total scale) is reported for in situ temperature and pressure and are normalized to year 2002 as in the GLODAPv2 data product (Lauvset et al. 2015). Anthropogenic change in pH from preindustrial to year 2002 is contoured (after Lauvset et al. 2020). and remineralization (e.g., Woosley et al. 2016; Clement and Gruber 2018; Carter et al. 2017, 2019). The approaches have been extended to allow for estimation of global ocean $\mathrm{C}_{\text {anth }}$ as well as extrapolation into coastal regions (Feely et al. 2016). These approaches have indicated that significant variability at interannual and decadal time scales occurs in some regions, particularly in the tropics due to El Niño-Southern Oscillation (ENSO) forcing, and in the subtropics and highlatitude regions due to changing ventilation processes that can alter the globally integrated sink (Carter et al. 2017, 2019; Rödenbeck et al. 2015; Landschützer et al. 2016; DeVries et al. 2017; Friedlingstein et al. 2019).

The GO-SHIP surveys have also been used to determine the long-term biogeochemical changes in carbonate chemistry including $\mathrm{pH}$ and calcium carbonate saturation state in the global oceans (Carter et al. 2017, 2019; Lauvset et al. 2015, 2020). From 1750 through 2018, surface ocean $\mathrm{pH}$ has declined by $0.018 \pm 0.004$ units decade ${ }^{-1}$ in $70 \%$ of the ocean basins (Fig. 3.28b), and the surface aragonite saturation state has fallen by an average rate of $0.34 \%$ per year, causing more stress on carbonate mineral-forming organisms. The sensitivity of $\mathrm{pH}$ to changing atmospheric $\mathrm{CO}_{2}$ 
concentration increases as temperature decreases. Hence the magnitude of $\Delta \mathrm{pH}$ is largest in cold high-latitude waters. Anthropogenic changes in $\mathrm{pH}$ are amplified at depths where $\mathrm{pH}$ is naturally lower and dissolved inorganic carbon (DIC) is naturally higher, implying a larger change in $p \mathrm{CO}_{2}$ and $\mathrm{pH}$ for a given change in DIC. As atmospheric $\mathrm{CO}_{2}$ concentration increases, changes in the carbonate system and the individual carbonate system species will be directly affected with the changing buffer capacity of seawater (Feely et al. 2018). Continued observations and modeling studies are needed to determine how oceans keep pace with the atmospheric $\mathrm{CO}_{2}$ increase.

\section{Sidebar 3.2: Ocean Obs'19 —S. CHIBA, M. DAI, T. LEE, E. LINDSTROM, N. ROME, S. SPEICH,}

\section{VISBECK, AND W. YU}

\section{OceanObs: A thirty-year history}

Every 10 years, the ocean-observing community convenes to evaluate opportunities for innovation and improved collaboration to sustain and enhance global observations of the ocean. The third, and most ambitious, community-driven conferenceOceanObs'19-convened in Honolulu, Hawaii, on 16-20 September 2019. It brought together people from all over the world to communicate the decadal advances made in observing technologies and the remarkable science that observing networks have enabled - and to chart innovative solutions to society's growing needs for ocean information and ways in which collaborations can accelerate progress. The first OceanObs' 99 conference, held October 1999 in Saint Raphaël, France, was a galvanizing force for ocean observations and climate. Ten years later, OceanObs'09, held September 2009 in Venice, Italy, moved the community toward a common vision for the acquisition of routine and sustained global information on the marine environment sufficient to meet society's needs for describing, understanding, and forecasting marine and climate variability and weather; sustainably managing living marine resources; and assessing longer-term trends.

\section{OceanObs'19: An ocean of opportunity}

OceanObs'19 assembled more than 1500 ocean scientists, engineers, and users of ocean observing technologies from 74 countries and across many disciplines. The community submitted 140 community white papers (CWPs) with over 2500 contributing authors. The conference goal was to improve governance of a global ocean observing system by improving advocacy, funding, and alignment with best practices, encompassed by the conference statement (www.oceanobs19.net/statement/) with the following key points:

1. Engage observers, data integrators, information providers, and users from the scientific, public, private, and policy sectors in the continuous process of planning, implementation and review of an integrated and effective ocean observing system;

2. Focus the ocean-observing system on addressing critical human needs, scientific understanding of the ocean and the linkages to the climate system, real-time ocean information services, and promotion of policies that sustain a healthy, biologically diverse, and resilient ocean ecosystem;

3. Harness the creativity of the academic research and engineering communities, and work in partnership with the private and public sectors to evolve sensors and platforms, better integrate observations, revolutionize information products about the ocean, increase efficiency, and reduce costs at each step of the ocean-observing value chain;

4. Advance the frontiers of ocean-observing capabilities from the coast to the deep ocean, all aspects of the marine biome, disease vectors, pollutants, and exchanges of energy, chemicals and biology at the boundaries between the ocean and air, seafloor, land, ice, freshwater, and human populated areas;

5. Improve the uptake of ocean data in models for understanding and forecasting of the Earth system;

6. Ensure that all elements of the observing system are interoperable and that data are managed wisely, guided by open data policies and that data are shared in a timely manner; 
7. Use best practices, standards, formats, vocabularies, and the highest ethics in the collection and use of ocean data;

8. Involve the public through citizen-engaged observations, information products, outreach, and formal education programs;

9. Evolve ocean-observing governance to learn and share, coordinate, identify priorities, increase diversity, promote partnerships, and resolve conflicts through a process of continuing assessment to improve observing; and

10. Promote investments in ocean observing and information delivery and sustain support.

\section{OceanObs'19: Ocean and climate observing focus}

Two of the themes of OceanObs'19 focused on 1) climate change and variability and 2) ocean, weather, and climate forecasting. One of the primary recommendations is improving the connection between observations, models, and reanalysis to enhance our ability to detect, monitor, understand, and predict climate. Enhanced effort is needed to study oceanic physical processes and their relationships with the atmosphere, cryosphere, land, and biosphere to inform Earth prediction. These processes, linked to ocean circulation, heat, and carbon storage and exchange, among others, also deepen our understanding of the ocean's biogeochemical and ecosystem function. The progress since Ocean Obs'99 is reflected by the evolution from a platform-based ocean observing system to the current, integrated observing system featured in OceanObs'19. Meeting expanding end-user needs is the next major challenge facing our ocean and climate observing systems (e.g., Sloyan et al. 2019).

Forecasting abilities have progressed substantially over the past two decades thanks to the advances in ocean observing systems, prediction models, and data assimilation methods. Operational data streams, such as those from satellite altimetry and Argo profiling floats, have played key roles in these advances.
Yet the ocean climate observing system must be sustained and evolved over long periods of time to adapt to new sampling needs and to take advantage of technological innovations. Ensuring better integration of data, technology, and standards also requires substantial coordination and capacity building across regional and international communities (Heimbach et al. 2019). These priorities will guide the actions of programs such as Global Ocean Observing System (GOOS) and OceanPredict to leverage the synergy of the integrated observing networks to maximize their value, improving services to users, and gaining scientific and technical efficiencies.

\section{OceanObs living action plan}

The OceanObs'19 organizers and sponsors will launch several efforts during 2020 and 2021 to facilitate ongoing post-conference actions by the community, in coordination with community organizations such as the Research Coordination Network, Global Climate Observing System (GCOS), GOOS, and Ocean Observations Panel for Climate. These efforts help determine more effective pathways for cooperation, sharing, and funding sustained and integrated ocean observations. The outcomes of this process will inform a growing GOOS and provide critical energy toward the United Nation's Decade of Ocean Science for Sustainable Development (2021-30).

All recommendations from the conference, including those from the CWPs, are being incorporated into a "Living Action Plan," which will organize outcomes from continuous engagement with the OceanObs community. This categorization is not meant to restrict or confine the substance of outcomes in any way; instead, the community will capture present and future aspirations of those involved in sustained ocean observing. The ultimate objective is to inform governance of the GOOS, mobilize communities of practice, and strengthen partnerships for enhanced ocean science and technology moving forward. 


\section{APPENDIX: Acronym List}

ACC

AMO

AMOC

BAPG

BASS

BGC

CERES

Chla

Chy

CWPs

DIC

DJF

DMI

DOISST

DWBC

E

EBAF

EKE

ENSO

ERSSTV5

FC

FLASHFlux

GCOS

GMSL

GOOS

GO-SHIP

GPCP

GRACE

GRACE-FO

HadSST

IOD

ITCZ

JIMAR

JJA

$J P L$

LDEO

$\mathrm{LH}$

LW

MAM

MEI

MHHW

MHT

MLD

MOC

NAO

NCP

NECC
Atlantic Circumpolar Current

Atlantic Multidecadal Oscillation

Atlantic meridional overturning circulation

Biogeochemical-Argo Planning Group

Blended Analysis of Surface Salinity

biogeochemical

Clouds and the Earth's Radiant Energy Systems

chlorophyll- $a$

phytoplanktonic carbon

community white papers

dissolved inorganic carbon

December-February

Dipole Mode Index

Daily Optimum Interpolation SST version 2

Deep Western Boundary Current

evaporation

Energy Balanced and Filled

eddy kinetic energy

El Niño-Southern Oscillation

Extended Reconstruction Sea-Surface Temperature version 5

Florida Current

Fast Longwave And Shortwave Radiative Fluxes

Global Climate Observing System

global mean sea level

Global Ocean Observing System

Global Oceans Ship-based Investigations Program

Global Precipitation Climatology Project

Gravity Recovery and Climate Experiment

GRACE Follow-On

U.K. Met Office Hadley Centre SST

Indian Ocean dipole

Intertropical Convergence Zone

Joint Institute for Marine and Atmospheric Research

June-August

Jet Propulsion Laboratory

Lamont-Doherty Earth Observatory

latent heat flux

longwave radiation

March-May

Multivariate ENSO Index

mean higher high water

meridional heat transports

mixed layer depths

meridional overturning circulation

North Atlantic Oscillation

net community production

North Equatorial Countercurrent 


$\begin{array}{ll}\text { NH } & \text { Northern Hemisphere } \\ \text { NPP } & \text { net primary production } \\ \text { nSEC } & \text { northern core of the South Equatorial Current } \\ \text { OAFlux2 } & \text { Objectively Analyzed air-sea Fluxes second generation } \\ \text { OCI } & \text { ocean color index } \\ \text { OHC } & \text { ocean heat content } \\ \text { OHCA } & \text { ocean heat content anomaly } \\ \text { ONI } & \text { Oceanic Niño Index } \\ \text { OSNAP } & \text { Overturning in the Subpolar North Atlantic Program } \\ \text { OSP } & \text { Ocean Station Papa } \\ \text { P } & \text { precipitation } \\ \text { PACE } & \text { Plankton, Aerosol, Cloud, ocean Ecosystem } \\ \text { PDO } & \text { Pacific Decadal Oscillation } \\ \text { PFZ } & \text { Polar Frontal Zone } \\ \text { PIES } & \text { pressure-equipped inverted echo sounders } \\ \text { PMEL } & \text { Pacific Marine Environmental Laboratory } \\ \text { PMM } & \text { Pacific Meridional Mode } \\ \text { ppm } & \text { parts per million } \\ \text { PSO } & \text { permanently stratified ocean } \\ \text { PSS-78 } & \text { Practical Salinity Scale-78 } \\ \text { Q } & \text { net surface heat flux } \\ \text { SAMBA } & \text { South AMOC Basin-wide Array } \\ \text { SH } & \text { sensible heat flux } \\ \text { SH } & \text { Southern Hemisphere } \\ \text { SMAP } & \text { Soil Moisture Active Passive } \\ \text { SMOS } & \text { Soil Moisture and Ocean Salinity } \\ \text { SOCAT } & \text { Surface Ocean CO } \text { Atlas } \\ \text { SON } & \text { September-November } \\ \text { SPCZ } & \text { South Pacific Convergence Zone } \\ \text { SSM/I } & \text { Special Sensor Microwave Imager } \\ \text { SSS } & \text { sea surface salinity } \\ \text { SST } & \text { sea surface temperature } \\ \text { SSTA } & \text { sea surface temperature anomaly } \\ \text { Std. dev. } & \text { standard deviation } \\ \text { SW } & \text { shortwave radiation } \\ \text { WOA13v2 } & \text { World Ocean Atlas 2013 version 2 } \\ \text { XBT } & \text { eXpendable BathyThermographs } \\ \text { ZJ } & \text { Zettajoules } \\ & \end{array}$




\section{References}

Abraham, J. P., and Coauthors, 2013: A review of global ocean temperature observations: Implications for ocean heat content estimates and climate change. Rev. Geophys., 51, 450-483, https://doi.org/10.1002/rog.20022.

Adler, R. F., and Coauthors, 2018: The Global Precipitation Climatology Project (GPCP) monthly analysis (new version 2.3) and a review of 2017 global precipitation. Atmosphere, 9, 138, https://doi.org/10.3390/atmos9040138.

Amaya, D. J., J. Miller, S.-P. Xie, and Y. Kosaka, 2020: Physical drivers of the summer 2019 North Pacific marine heatwave. Nat. Commun., 11, 1903, https://doi. org/10.1038/s41467-020-15820-w.

Ansorge, I., and Coauthors, 2014: Basin-wide oceanographic array bridges the South Atlantic. Eos, Trans. Amer. Geophys. Union, 95, 53-54, https://doi. org/10.1002/2014E0060001.

Babcock, R. C., and Coauthors, 2019: Severe continental-scale impacts of climate change are happening now: Extreme climate events impact marine habitat forming communities along 45\% of Australia's coast. Front. Mar. Sci., 6, 411, https://doi.org/10.3389/fmars.2019.00411.

Bakker, D. C. E., and Coauthors, 2016: A multi-decade record of high-quality fCO2 data in version 3 of the Surface Ocean CO2 Atlas (SOCAT). Earth Syst. Sci. Data, 8, 383-413, https://doi.org/10.5194/essd-8-383-2016.

Balaguru, K., P. Chang, R. Saravanan, L. Ruby Leung, Z. Xu, M. Li, and J.-S. Hsieh, 2012: Ocean barrier layers' effect on tropical cyclone intensification. Proc. Natl. Acad. Sci. USA, 109, 14343-14347, https://doi.org/10.1073/ pnas.1201364109.

Baringer, M. O., and J. Larsen, 2001: Sixteen years of Florida current transport at $27^{\circ} \mathrm{N}$. Geophys. Res. Lett., 28, 3179-3182, https://doi. org/10.1029/2001GL013246.

Beaugrand, G., and Coauthors, 2019: Prediction of unprecedented biological shifts in the global ocean. Nat. Climate Change, 9, 237-243, https://doi. org/10.1038/s41558-019-0420-1.

Behrenfeld, M. J., and Coauthors, 2006: Climate-driven trends in contemporary ocean productivity. Nature, 444, 752-755, https://doi.org/10.1038/nature05317.

—_ and Coauthors, 2015: Revaluating ocean warming impacts on global phytoplankton. Nat. Climate Change, 6, 323-330, https://doi.org/10.1038/nclimate2838.

Biastoch, A., C. W. Böning, J. Getzlaff, J. Molines, and G. Madec, 2008: Causes of interannual-decadal variability in the meridional overturning circulation of the midlatitude North Atlantic Ocean. J. Climate, 21, 6599-6615, https://doi. org/10.1175/2008JCLI2404.1.

Bif, M. B., and D. A. Hansell, 2019: Seasonality of dissolved organic carbon in the upper northeast Pacific Ocean. Global Biogeochem. Cycles, 33, 526-539, https://doi.org/10.1029/2018GB006152.

_ L. L. Siqueira, and D. A. Hansell, 2019: Warm events induce loss of resilience in organic carbon production in the northeast Pacific Ocean. Global Biogeochem. Cycles, 33, 1174-1186, https://doi.org/10.1029/2019GB006327.

BAPG, 2016: The scientific rationale, design and implementation plan for a Biogeochemical-Argo float array. Biogeochemical-Argo Planning Group Tech. Rep., K. S. Johnson and H. Claustre, Eds., 58 pp., https://doi.org/10.13155/46601.

Bittig, H. C., and A. Körtzinger, 2015: Tackling oxygen optode drift: Near-surface and in-air oxygen optode measurements on a float provide an accurate in-situ reference. J. Atmos. Oceanic Technol., 32, 1536-1543, https://doi. org/10.1175/JTECH-D-14-00162.1.

Bond, N. A., M. F. Cronin, H. Freeland, and N. Mantua, 2015: Causes and impacts of the 2014 warm anomaly in the NE Pacific. Geophys. Res. Lett., 42, 34143420, https://doi.org/10.1002/2015GL063306.

Boyer, T. P., and Coauthors, 2013: World Ocean Database 2013. NOAA Atlas NESDIS 72, 209 pp.

— , and Coauthors, 2018: World Ocean Database 2018. NOAA Atlas NESDIS $87,207 \mathrm{pp}$.

Breitburg, D., and Coauthors, 2018: Declining oxygen in the global ocean and coastal waters. Science, 359, eaam7240, https://doi.org/10.1126/science. aam7240.

Broeker, W. S., 1991: The great ocean conveyor. Oceanography, 4, 79-89, https:// doi.org/10.5670/oceanog.1991.07.

Bronselaer, B., and Coauthors, 2020: Importance of wind and meltwater for observed chemical and physical changes in the Southern Ocean. Nat. Geosci., 13, 35-42, https://doi.org/10.1038/s41561-019-0502-8.

Bryden, H. L., H. R. Longworth, and S. A. Cunningham, 2005: Slowing of the Atlantic meridional overturning circulation at $25^{\circ} \mathrm{N}$. Nature, $438,655-657$, https:// doi.org/10.1038/nature04385.

Bushinsky, S. M., S. R. Emerson, S. C. Riser, and D. D. Swift, 2016: Accurate oxygen measurements on modified Argo floats using in situ air calibrations. Limnol. Oceanogr:: Methods, 14, 491-505, https://doi.org/10.1002/lom3.10107.

_ A. R. Gray, K. S. Johnson, and J. L. Sarmiento, 2017: Oxygen in the Southern Ocean from Argo floats: Determination of processes driving air-sea fluxes. J. Geophys. Res. Oceans, 122, 8661-8682, https://doi. org/10.1002/2017JC012923.

Calafat, F. M., T. Wahl, F. Lindsten, J. Williams, and E. Frajka-Williams, 2018: Coherent modulation of the sea-level annual cycle in the United States by Atlantic Rossby waves. Nat. Commun., 9, 2571, https://doi.org/10.1038/s41467-01804898-y.

Candela, J., and Coauthors, 2019: The flow through the Gulf of Mexico. J. Phys. Oceanogr., 49, 1381-1401, https://doi.org/10.1175/JPO-D-18-0189.1.

Carter, B. R., and Coauthors, 2017: Two decades of Pacific anthropogenic carbon storage and ocean acidification along Global Ocean Ship-based Hydrographic Investigations Program sections P16 and P02. Global Biogeochem. Cycles, 31, 306-327, https://doi.org/10.1002/2016GB005485.

_ 2017. Global Biogeochem. Cycles, 33, 597-617, https://doi.org/10.1029 /2018GB006154.

Castro de la Guardia, L., X. Hu, and P. G. Myers, 2015: Potential positive feedback between Greenland Ice Sheet melt and Baffin Bay heat content on the west Greenland shelf. Geophys. Res. Lett., 42, 4922-4930, https://doi. org/10.1002/2015GL064626.

Chang, P., and Coauthors, 2006: Climate fluctuations of tropical coupled systems-The role of ocean dynamics. J. Climate, 19, 5122-5174, https://doi. org/10.1175/JCLI3903.1.

Cheng, L., and Coauthors, 2020: Record-setting ocean warmth continued in 2019. Adv. Atmos. Sci., 37, 137-142, https://doi.org/10.1007/s00376-020-9283-7.

Chiang, J., and D. Vimont, 2004: Analogous Pacific and Atlantic meridional modes of tropical atmosphere-ocean variability. J. Climate, 17, 4143-4158, https:// doi.org/10.1175/JCLI4953.1.

Claustre, H., K. S. Johnson, and Y. Takeshita, 2020: Observing the global ocean with Biogeochemical-Argo. Annu. Rev. Mar. Sci., 12, 23-48, https://doi. org/10.1146/annurev-marine-010419-010956.

Clement, D., and N. Gruber, 2018: The eMLR(C*) method to determine decadal changes in the global ocean storage of anthropogenic CO2. Global Biogeochem. Cycles, 32, 654-679, https://doi.org/10.1002/2017GB005819.

DeVries, T., M. Holzer, and F. Primeau, 2017: Recent increase in oceanic carbon uptake driven by weaker upper-ocean overturning. Nature, 542, 215-218, https://doi.org/10.1038/nature21068.

Dierssen, H. M., 2010: Perspectives on empirical approaches for ocean color remote sensing of chlorophyll in a changing climate. Proc. Natl. Acad. Sci. USA, 107, 17073-17078, https://doi.org/10.1073/pnas.0913800107.

Dijkstra, H. A., 2007: Characterization of the multiple equilibria regime in a global ocean model. Tellus, 59A, 695-705, https://doi.org/10.1111/j.16000870.2007.00267.x.

Domingues, C. M., J. A. Church, N. J. White, P. J. Gleckler, S. E. Wijffels, P. M. Barker, and J. R. Dunn, 2008: Improved estimates of upper-ocean warming and multidecadal sea-level rise. Nature, 453, 1090-1093, https://doi.org/10.1038/nature07080. 
Domingues, R. M., W. E. Johns, and C. S. Meinen, 2019: Mechanisms of eddydriven variability of the Florida current. J. Phys. Oceanogr., 49, 1319-1338, https://doi.org/10.1175/JPO-D-18-0192.1.

Dong, S., S. L. Garzoli, M. O. Baringer, C. S. Meinen, and G. J. Goni, 2009: Interannual variations in the Atlantic meridional overturning circulation and its relationship with the net northward heat transport in the South Atlantic. Geophys. Res. Lett., 36, L20606, https://doi.org/10.1029/2009GL039356.

_- G. Goni, and F. Bringas, 2015: Temporal variability of the South Atlantic meridional overturning circulation between $20^{\circ} \mathrm{S}$ and $35^{\circ} \mathrm{S}$. Geophys. Res. Lett., 42, 7655-7662, https://doi.org/10.1002/2015GL065603.

Drijfhout, S. S., S. L. Weber, and E. van der Swaluw, 2011: The stability of the MOC as diagnosed from model projections for pre-industrial, present and future climates. Climate Dyn., 37, 1575-1586, https://doi.org/10.1007/s00382-0100930-z.

Drucker, R., and S. C. Riser, 2016: In situ phase-domain calibration of oxygen Optodes on profiling floats. Methods Oceanogr., 17, 296-318, https://doi. org/10.1016/j.mio.2016.09.007.

Durack, P. J., 2015: Ocean salinity and the global water cycle. Oceanography, 28, 20-31, https://doi.org/10.5670/oceanog.2015.03.

_ S. E. Wijffels, and R. J. Matear, 2012: Ocean salinities reveal strong global water cycle intensification during 1950 to 2000. Science, 336, 455-458, https://doi.org/10.1126/science.1212222.

Edson, J., and Coauthors, 2013: On the exchange of momentum over the open ocean. J. Phys. Oceanogr., 43, 1589-1610, https://doi.org/10.1175/JPOD-12-0173.1.

Emerson, S., and S. Bushinsky, 2014: Oxygen concentrations and biological fluxes in the open ocean. Oceanography, 27, 168-171, https://doi.org/10.5670/ oceanog.2014.20.

Esaias, W. E., and Coauthors, 1998: An overview of MODIS capabilities for ocean science observations. IEEE Trans. Geosci. Remote Sens., 36, 1250-1265, https://doi.org/10.1109/36.701076.

Falkowski, P. G., R. T. Barber, and V. Smetacek, 1998: Biogeochemical controls and feedbacks on ocean primary production. Science, 281, 200-206, https://doi. org/10.1126/science.281.5374.200.

Fasullo, J. T., and R. S. Nerem, 2018: Altimeter-era emergence of the patterns of forced sea-level rise in climate models and implications for the future. Proc. Natl. Acad. Sci. USA, 115, 12944-12 949, https://doi.org/10.1073/ pnas.1813233115.

Feely, R.A., and Coauthors, 2016: Chemical and biological impacts of ocean acidification along the west coast of North America. Estuarine Coastal Shelf Sci., 183, 260-270, https://doi.org/10.1016/j.ecss.2016.08.043.

— , R. R. Okazaki, W.-J. Cai, N. Bednaršek, S. R. Alin, R. H. Byrne, and A. Fassbender, 2018: The combined effects of acidification and hypoxia on $\mathrm{pH}$ and aragonite saturation in the coastal waters of the Californian Current ecosystem and the northern Gulf of Mexico. Cont. Shelf Res., 152, 50-60, https:// doi.org/10.1016/j.csr.2017.11.002.

Field, C. B., M. J. Behrenfeld, J. T. Randerson, and P. Falkowski, 1998: Primary production of the biosphere: Integrating terrestrial and oceanic components. Science, 281, 237-240, https://doi.org/10.1126/science.281.5374.237.

Fofonoff, N. P., and E. L. Lewis, 1979: A practical salinity scale. J. Oceanogr. Soc. Japan, 35, 63-64, https://doi.org/10.1007/BF02108283.

Font, J., and Coauthors, 2013: SMOS first data analysis for sea surface salinity determination. Int. J. Remote Sens., 34, 3654-3670, https://doi.org/10.1080/ 01431161.2012 .716541$.

Fore, A. G., S. H. Yueh, W. Q. Tang, B. W. Stiles, and A. K. Hayashi, 2016: Combined active/passive retrievals of ocean vector wind and sea surface salinity with SMAP. IEEE Trans. Geosci. Remote Sens., 54, 7396-7404, https://doi. org/10.1109/TGRS.2016.2601486.

Frajka-Williams, E., and Coauthors, 2019: Atlantic meridional overturning circulation: Observed transports and variability. Front. Mar. Sci., 6, 260, https://doi. org/10.3389/fmars.2019.00260.
Franz, B. A., I. Cetinić, E. M. Karaköylü, D. A. Siegel, and T. K. Westberry, 2019: Global ocean phytoplankton [in "State of the Climate in 2018"]. Bull. Amer. Meteor. Soc., 100 (9), S92-S94, https://doi.org/10.1175/2019BAMSStateofth eClimate.1.

Friedlingstein, P., and Coauthors, 2019: Global carbon budget 2019. Earth Syst. Sci. Data, 11, 1783-1838, https://doi.org/10.5194/essd-11-1783-2019.

Garzoli, S., M. O. Baringer, S. Dong, R. Perez, and Q. Yao, 2013: South Atlantic meridional fluxes. Deep-Sea Res. I, 71, 21-32, https://doi.org/10.1016/j. dsr.2012.09.003.

Gattuso, J.-P., and Coauthors, 2015: Contrasting futures for ocean and society from different anthropogenic CO2 emission scenarios. Science, 349, aac4722, https://doi.org/10.1126/science.aac4722.

Geider, R. J., H. L. MacIntyre, and T. M. Kana, 1997: Dynamic model of phytoplankton growth and acclimation: Responses of the balanced growth rate and the chlorophyll a: Carbon ratio to light, nutrient limitation and temperature. Mar. Ecol. Prog. Ser., 148, 187-200, https://doi.org/10.3354/meps148187.

Gentemann, C. L., M. R. Fewings, and M. García-Reyes, 2017: Satellite sea surface temperatures along the West Coast of the United States during the 20142016 northeast Pacific marine heat wave. Geophys. Res. Lett., 44, 312-319, https://doi.org/10.1002/2016GL071039.

Goni, G. J., and Coauthors, 2009: Applications of satellite-derived ocean measurements to tropical cyclone intensity forecasting. Oceanography, 22, 190-197, https://doi.org/10.5670/oceanog.2009.78.

_ F. Bringas, and P. N. Di Nezio, 2011: Observed low frequency variability of the Brazil current front. J. Geophys. Res., 116, C10037, https://doi. org/10.1029/2011JC007198.

Gordon, A. L., 1986: Interocean exchange of thermocline water. J. Geophys. Res., 91, 5037-5046, https://doi.org/10.1029/JC091iC04p05037.

Graff, J. R., T. K. Westberry, A. J. Milligan, M. B. Brown, G. Dall'Olmo, V. van Dongen-Vogels, K. M. Reifel, and M. J. Behrenfeld, 2015: Analytical phytoplankton carbon measurements spanning diverse ecosystems. Deep-Sea Res. I, 102, 16-25, https://doi.org/10.1016/j.dsr.2015.04.006.

Gruber, N., M. Gloor, S.-M. Fan, and J. L. Sarmiento, 2001: Air-sea flux of oxygen estimated from bulk data: Implications for the marine and atmospheric oxygen cycles. Global Biogeochem. Cycles, 15, 783-803, https://doi. org/10.1029/2000GB001302.

_ to 2007. Science, 363, 1193-1199, https://doi.org/10.1126/science.aau5153.

Hamlington, B. D., J. T. Fasullo, R. S. Nerem, K.-Y. Kim, and F. W. Landerer, 2019: Uncovering the pattern of forced sea level rise in the satellite altimeter record. Geophys. Res. Lett., 46, 4844-4853, https://doi.org/10.1029/2018GL081386.

Heimbach, P., and Coauthors, 2019: Putting it all together: Adding value to the global ocean and climate observing systems with complete self-consistent ocean state and parameter estimates. Front. Mar. Sci., 6, 55, https://doi. org/10.3389/fmars.2019.00055.

Helm, K. P., N. L. Bindoff, and J. A. Church, 2011: Observed decreases in oxygen content of the global ocean. Geophys. Res. Lett., 38, L23602, https://doi. org/10.1029/2011GL049513.

Hobbs, W. R., and J. K. Willis, 2012: Midlatitude North Atlantic heat transport: A time series based on satellite and drifter data. J. Geophys. Res., 117, C01008, https://doi.org/10.1029/2011JC007039.

Hu, C., Z. Lee, and B. A. Franz, 2012: Chlorophyll a algorithms for oligotrophic oceans: A novel approach based on three-band reflectance difference. J. Geophys. Res., 117, C01011, https://doi.org/10.1029/2011JC007395.

Huang, B., and Coauthors, 2015: Extended Reconstructed Sea Surface Temperature version 4 (ERSST.v4). Part I: Upgrades and intercomparisons. J. Climate, 28, 911-930, https://doi.org/10.1175/JCLI-D-14-00006.1.

_ version 5 (ERSSTV5): Upgrades, validations, and intercomparisons. J. Climate, 30, 8179-8205, https://doi.org/10.1175/JCLI-D-16-0836.1.

— and land surface air temperature in NOAAGlobalTemp version 5. J. Climate, 33, 1351-1379, https://doi.org/10.1175/JCLI-D-19-0395.1. 
Hummels, R., P. Brandt, M. Dengler, J. Fischer, M. Araujo, D. Veleda, and J. V. Durgadoo, 2015: Interannual to decadal changes in the western boundary circulation in the Atlantic at $11^{\circ} \mathrm{S}$. Geophys. Res. Lett., 42, 7615-7622, https://doi. org/10.1002/2015GL065254.

IPCC, 2019: Summary for policymakers. IPCC Special Report on the Ocean and Cryosphere in a Changing Climate, H.-O. Pörtner et al., Eds., IPCC, in press.

Ishii, M., Y. Fukuda, S. Hirahara, S. Yasui, T. Suzuki, and K. Sato, 2017: Accuracy of global upper ocean heat content estimation expected from present observational datasets. SOLA, 13, 163-167, https://doi.org/10.2151/sola.2017-030.

Johnson, G. C., and J. M. Lyman, 2012: Sea surface salinity [in "State of the Climate in 2011"]. Bull. Amer. Meteor. Soc., 93 (7), S68-S69, https://doi.org/10. 1175/2012BAMSStateoftheClimate.1.

— ocean gains more heat. Geophys. Res. Lett., 44, 438-445, https://doi. org/10.1002/2016GL071767.

_ J. M. Lyman, J. K. Willis, T. Boyer, J. Antonov, S. A. Good, C. M. Domingues, and N. Bindoff, 2014: Ocean heat content [in "State of the Climate in 2013"]. Bull. Amer. Meteor. Soc., 95 (7), S54-S57, https://doi.org/10.1175/2014BAM SStateoftheClimate.1.

_ 2014"]. Bull. Amer. Meteor. Soc., 96 (7), S64-S66, https://doi.org/10.1175/20 15BAMSStateoftheClimate.1.

_ J. M. Lyman, and N. G. Loeb, 2016: Improving estimates of Earth's energy imbalance. Nat. Climate Change, 6, 639-640, https://doi.org/10.1038/ nclimate3043.

- and Coauthors, 2019: Ocean heat content [in "State of the Climate in 2018"]. Bull. Amer. Meteor. Soc., 100 (9), S74-S77, https://doi.org/10.1175/2 019BAMSStateoftheClimate.1.

Johnson, K. S., and H. Claustre, 2016: Bringing biogeochemistry into the Argo age. Eos, Trans. Amer. Geophys. Union, 97, https://doi.org/10.1029/2016E0062427.

_ , J. N. Plant, S. C. Riser, and D. Gilbert, 2015: Air oxygen calibration of oxygen optodes on a profiling float array. J. Atmos. Oceanic Technol., 32, 2160-2172, https://doi.org/10.1175/JTECH-D-15-0101.1.

—_ and Coauthors, 2017: Biogeochemical sensor performance in the SOCCOM profiling float array. J. Geophys. Res. Oceans, 122, 6416-6436, https://doi. org/10.1002/2017JC012838.

Kanzow, T., and Coauthors, 2007: Observed flow compensation associated with the MOC at $26.5^{\circ} \mathrm{N}$ in the Atlantic. Science, 317, 938-941, https://doi. org/10.1126/science.1141293.

Kato, S., and Coauthors, 2018: Surface irradiances of edition 4.0 Clouds and the Earth's Radiant Energy System (CERES) Energy Balanced and Filled (EBAF) data product. J. Climate, 31, 4501-4527, https://doi.org/10.1175/JCLID-17-0523.1.

Kennedy, J. J., N. A. Rayner, R. O. Smith, D. E. Parker, and M. Saunby, 2011: Reassessing biases and other uncertainties in sea surface temperature observations measured in situ since 1850: 1. Measurement and sampling uncertainties. J. Geophys. Res., 116, D14103, https://doi.org/10.1029/2010JD015218.

-, N. A. Rayner, C. P. Atkinson, and R. E. Killick, 2019: An ensemble data set of sea surface temperature change from 1850: The Met Office Hadley Centre HadSST.4.0.0.0 data set. J. Geophys. Res. Atmos., 124, 7719-7763, https://doi. org/10.1029/2018jd029867.

Kent, E. C., and Coauthors, 2017: A call for new approaches to quantifying biases in observations of sea surface temperature. Bull. Amer. Meteor. Soc., 98, 1601-1616, https://doi.org/10.1175/BAMS-D-15-00251.1.

Landschützer, P., N. Gruber, D. C. E. Bakker, U. Schuster, S. Nakaoka, M. R. Payne, T. P. Sasse, and J. Zeng, 2013: A neural network-based estimate of the seasonal to inter- annual variability of the Atlantic Ocean carbon sink. Biogeosciences, 10, 7793-7815, https://doi.org/10.5194/bg-10-7793-2013.

,$- \ldots$, , and _ -2014 : Recent variability of the global ocean carbon sink. Global Biogeochem. Cycles, 28, 927-949, https://doi.org/10.1002 /2014GB004853.
- - , and,- 2016 : Decadal variations and trends of the global ocean carbon sink. Global Biogeochem. Cycles, 30, 1396-1417, https://doi. org/10.1002/2015GB005359.

Larsen, J. C., and T. B. Sanford, 1985: Florida Current volume transports from voltage measurements. Science, 227, 302-304, https://doi.org/10.1126/science.227.4684.302.

Lauvset, S. K., N. Gruber, P. Landschützer, A. Olsen, and J. Tjiputra, 2015: Trends and drivers in global surface ocean $\mathrm{pH}$ over the past 3 decades. Biogeosciences, 12, 1285-1298, https://doi.org/10.5194/bg-12-1285-2015.

— B. R. Carter, F. F. Perez, L.-Q. Jiang, R. A. Feely, A. Velo, and A. Olsen, 2020: Processes driving global interior ocean $\mathrm{pH}$ distribution. Global Biogeochem. Cycles, 34, e2019GB006229, https://doi.org/10.1029/2019GB006229.

Leuliette, E. W., and J. K. Willis, 2011: Balancing the sea level budget. Oceanography, 24, 122-129, https://doi.org/10.5670/oceanog.2011.32.

Le Vine, D. M., E. P. Dinnat, G. S. E. Lagerloef, P. de Matthaeis, S. Abraham, C. Utku, and H. Kao, 2014: Aquarius: Status and recent results. Radio Sci., 49, 709-720, https://doi.org/10.1002/2014RS005505.

Levitus, S., and Coauthors, 2012: World ocean heat content and thermosteric sea level change (0-2000 m), 1955-2010. Geophys. Res. Lett., 39, L10603, https://doi.org/10.1029/2012gl051106.

Liu, W., S.-P. Xie, Z. Liu, and J. Zhu, 2017: Overlooked possibility of a collapsed Atlantic meridional overturning circulation in warming climate. Sci. Adv., 3, e1601666, https://doi.org/10.1126/sciadv.1601666.

Loeb, N. G., and Coauthors, 2018: Clouds and the Earth's Radiant Energy System (CERES) Energy Balanced and Filled (EBAF) top-of-atmosphere (TOA) edition-4.0 data product. J. Climate, 31, 895-918, https://doi.org/10.1175/ JCLI-D-17-0208.1.

Long, X., M. J. Widlansky, F. Schloesser, P. R. Thompson, H. Annamalai, M. A. Merrifield, and H. Yoon, 2020: Higher sea levels at Hawaii caused by strong El Niño and weak trade winds. J. Climate, 33, 3037-3059, https://doi.org/10.1175/ JCLI-D-19-0221.1.

Lozier, M. S., and Coauthors, 2017: Overturning in the subpolar North Atlantic program: A new international ocean observing system. Bull. Amer. Meteor. Soc., 98, 737-752, https://doi.org/10.1175/BAMS-D-16-0057.1.

- and Coauthors, 2019a: Meridional overturning circulation and the associated heat and freshwater transports observed by the OSNAP (Overturning in the Subpolar North Atlantic Program) array from 2014 to 2016. Duke Digital Repository, accessed November 2019, https://doi.org/10.7924/r4z60gfof.

- , and Coauthors, 2019b: A sea change in our view of overturning in the subpolar North Atlantic. Science, 363, 516-521, https://doi.org/10.1126/science.aau6592.

Lukas, R., and E. Lindstrom, 1991: The mixed layer of the western equatorial Pacific Ocean. J. Geophys. Res., 96, 3343-3357, https://doi.org/10.1029/90JC01951.

Lumpkin, R., and K. Speer, 2007: Global ocean meridional overturning. J. Phys. Oceanogr., 37, 2550-2562, https://doi.org/10.1175/JP03130.1.

- and S. Garzoli, 2011: Interannual to decadal changes in the western South Atlantic's surface circulation. J. Geophys. Res., 116, C01014, https://doi. org/10.1029/2010JC006285.

Lyman, J. M., and G. C. Johnson, 2014: Estimating global ocean heat content changes in the upper $1800 \mathrm{~m}$ since 1950 and the influence of climatology choice. J. Climate, 27, 1945-1958, https://doi.org/10.1175/JCLI-D-12-00752.1.

-, S. A. Good, V. V. Gouretski, M. Ishii, G. C. Johnson, M. D. Palmer, D. M. Smith, and J. K. Willis, 2010: Robust warming of the global upper ocean. Nature, 465, 334-337, https://doi.org/10.1038/nature09043.

Majumder, S., C. Schmid, and G. Halliwell, 2016: An observation and model based analysis of meridional transports in the South Atlantic. J. Geophys. Res. Oceans, 121, 5622-5638, https://doi.org/10.1002/2016JC011693.

Mantua, N. J., and S. R. Hare, 2002: The Pacific decadal oscillation. J. Oceanogr., 58, 35-44, https://doi.org/10.1023/A:1015820616384.

McCarthy, G. D., and Coauthors, 2015: Measuring the Atlantic meridional overturning circulation at $26^{\circ} \mathrm{N}$. Prog. Oceanogr., 130, 91-111, https://doi. org/10.1016/j.pocean.2014.10.006. 
McCarthy, G. D., and Coauthors, 2020: Sustainable observations of the AMOC: Methodology and technology. Rev. Geophys., 58, e2019RG000654, https:// doi.org/10.1029/2019RG000654.

McClain, C. R., 2009: A decade of satellite ocean color observations. Annu. Rev. Mar. Sci., 1, 19-42, https://doi.org/10.1146/annurev.marine.010908.163650.

Meinen, C. S., M. O. Baringer, and R. F. Garcia, 2010: Florida current transport variability: An analysis of annual and longer- period signals. Deep-Sea Res. I, 57, 835-846, https://doi.org/10.1016/j.dsr.2010.04.001.

— ing circulation at $34.5^{\circ} \mathrm{S}$ : Results from two pilot boundary arrays in the South Atlantic. J. Geophys. Res. Oceans, 118, 6461-6478, https://doi. org/10.1002/2013JC009228.

— ability at $34.5^{\circ} \mathrm{S}$ during $2009-2017$ : Baroclinic and barotropic flows and the dueling influence of the boundaries. Geophys. Res. Lett., 45, 4180-4188, https://doi.org/10.1029/2018GL077408.

Merrifield, M., 2011: A shift in western tropical Pacific sea level trends during the 1990s. J. Climate, 24, 4126-4138, https://doi.org/10.1175/2011JCLI3932.1.

Mertens, C., M. Rhein, M. Walter, C. W. Böning, E. Behrens, D. Kieke, R. Steinfeldt, and U. Stöber, 2014: Circulation and transports in the Newfoundland Basin, western subpolar North Atlantic. J. Geophys. Res. Oceans, 119, 7772-7793, https://doi.org/10.1002/2014JC010019.

Mignot, A., F. D'Ortenzio, V. Taillandier, G. Cossarini, and S. Salon, 2019: Quantifying observational errors in Biogeochemical-Argo oxygen, nitrate and chlorophyll a concentrations. Geophys. Res. Lett., 46, 4330-4337, https://doi. org/10.1029/2018GL080541.

Moat, B. I., and Coauthors, 2019: Insights into decadal North Atlantic sea surface temperature and ocean heat content variability from an eddy-permitting coupled climate model. J. Climate, 32, 6137-6161, https://doi.org/10.1175/ JCLI-D-18-0709.1.

- , and Coauthors, 2020: Pending recovery in the strength of the meridional overturning circulation at $26^{\circ} \mathrm{N}$. Ocean Sci., https://doi.org/10.5194/os-2019134 , in press.

Nerem, R. S., B. D. Beckley, J. T. Fasullo, B. D. Hamlington, D. Masters, and G. T. Mitchum, 2018: Climate-change-driven accelerated sea-level rise detected in the altimeter era. Proc. Natl. Acad. Sci. USA, 115, 2022-2025, https://doi. org/10.1073/pnas.1717312115.

Oliver, E. C., J. A. Benthuysen, N. L. Bindoff, A. J. Hobday, N. J. Holbrook, C. N. Mundy, and S. E. Perkins-Kirkpatrick, 2017: The unprecedented 2015/16 Tasman Sea marine heatwave. Nat. Commun., 8, 16101, https://doi.org/10.1038/ ncomms16101.

Oschlies, A., P. Brandt, L. Stramma, and S. Schmidtko, 2018: Drivers and mechanisms of ocean deoxygenation. Nat. Geosci., 11, 467-473, https://doi. org/10.1038/s41561-018-0152-2.

Palmer, M. D., K. Haines, S. F. B. Tett, and T. J. Ansell, 2007: Isolating the signal of ocean global warming. Geophys. Res. Lett., 34, L23610, https://doi. org/10.1029/2007GL031712.

Perkins-Kirkpatrick, S. E., A. D. King, E. A. Cougnon, N. J. Holbrook, M. R. Grose, E. C. J. Oliver, S. C. Lewis, and F. Pourasghar, 2019: The role of natural variability and anthropogenic climate change in the 2017/18 Tasman Sea marine heatwave [in "Explaining Extremes of 2017 from a Climate Perspective"] . Bull. Amer. Meteor. Soc., 100 (1), S105-S110, https://doi.org/10.1175/BAMSD-18-0116.1.

Peterson, W. T., J. L. Fisher, P. T. Strub, X. Du, C. Risien, W. J. Peterson, and C. T. Shaw, 2017: The pelagic ecosystem in the Northern California Current off Oregon during the 2014-2016 warm anomalies within the context of the past 20 years. J. Geophys. Res. Oceans, 122, 7267-7290, https://doi. org/10.1002/2017JC012952.

Piatt, J. F., and Coauthors, 2020: Extreme mortality and reproductive failure of common murres resulting from the northeast Pacific marine heatwave of 2014-2016. PLOS ONE, 15, e0226087, https://doi.org/10.1371/journal. pone.0226087.
Plant, J. N., K. S. Johnson, C. M. Sakamoto, H. W. Jannasch, L. J. Coletti, S. C. Riser, and D. D. Swift, 2016: Net community production at Ocean Station Papa observed with nitrate and oxygen sensors on profiling floats. Global Biogeochem. Cycles, 30, 859-879, https://doi.org/10.1002/2015GB005349.

Purkey, S. G., and G. C. Johnson, 2010: Warming of global abyssal and deep Southern Ocean waters between the 1990s and 2000s: Contributions to global heat and sea level rise budgets. J. Climate, 23, 6336-6351, https://doi. org/10.1175/2010JCLI3682.1.

Qiu, B., and S. Chen, 2005: Variability of the Kuroshio extension jet, recirculation gyre, and mesoscale eddies on decadal time scales. J. Phys. Oceanogr., 35, 2090-2103, https://doi.org/10.1175/JP02807.1.

Rahmstorf, S., 1996: On the freshwater forcing and transport of the Atlantic thermohaline circulation. Climate Dyn., 12, 799-811, https://doi.org/10.1007/ s003820050144.

Reagan, J., T. Boyer, C. Schmid, and R. Locarnini, 2017: Subsurface salinity [in "State of the Climate in 2016"]. Bull. Amer. Meteor. Soc., 98 (8), S72-S75, https://doi.org/10.1175/2017BAMSStateoftheClimate.1.

$\ldots, \ldots$, _ and _ _ 2018: Subsurface salinity [in "State of the Climate in 2017"]. Bull. Amer. Meteor. Soc., 99 (8), S79-S81, https://doi.org/10.1175/ 2018BAMSStateoftheClimate.1.

$\longrightarrow,-, \ldots$, and -2019 : Subsurface salinity [in "State of the Climate in 2018"]. Bull. Amer. Meteor. Soc., 100 (9), S79-S81, https://doi.org/10.1175 /2019BAMSStateoftheClimate.1.

— A. S. Gardner, J. S. Famiglietti, D. N. Wiese, A. Eicker, and M.-H. Lo, 2016: A decade of sea level rise slowed by climate-driven hydrology. Science, 351, 699-703, https://doi.org/10.1126/science.aad8386.

Ren, L., K. Speer, and E. P. Chassignet, 2011: The mixed layer salinity budget and sea ice in the Southern Ocean. J. Geophys. Res., 116, C08031, https://doi. org/10.1029/2010JC006634.

Resplandy, L., and Coauthors, 2018: Revision of global carbon fluxes based on a reassessment of oceanic and riverine carbon transport. Nat. Geosci., 11, 504-509, https://doi.org/10.1038/s41561-018-0151-3.

Reynolds, D., T. M. Smith, C. Liu, D. B. Chelton, K. S. Casey, and M. G. Schlax, 2007: Daily high-resolution blended analyses for sea surface temperature. J. Climate, 20, 5473-5496, https://doi.org/10.1175/2007JCLI1824.1.

Rhein, M., and Coauthors, 2011: Deep-water formation, the subpolar gyre, and the meridional overturning circulation in the subpolar North Atlantic. DeepSea Res. II, 58, 1819-1832, https://doi.org/10.1016/j.dsr2.2010.10.061.

- , and Coauthors, 2013: Observations: Ocean. Climate Change 2013: The Physical Science Basis, T. F. Stocker et al., Eds., Cambridge University Press, 255315, https://doi.org/10.1017/CB09781107415324.010.

Richerson, K., and D. S. Holland, 2017: Quantifying and predicting responses to a US West Coast salmon fishery closure. ICES J. Mar. Sci., 74, 2364-2378, https://doi.org/10.1093/icesjms/fsx093.

Riser, S. C., and K. S. Johnson, 2008: Net production of oxygen in the subtropical ocean. Nature, 451, 323-325, https://doi.org/10.1038/nature06441.

_ Argo array. Nat. Climate Change, 6, 145-153, https://doi.org/10.1038/nclimate2872.

Rödenbeck, C., and Coauthors, 2015: Data-based estimates of the ocean carbon sink variability-First results of the surface ocean pCO2 mapping intercomparison (SOCOM). Biogeosciences, 12, 7251-7278, https://doi.org/10.5194/ bg-12-7251-2015.

Roemmich, D., and J. Gilson, 2009: The 2004-2008 mean and annual cycle of temperature, salinity, and steric height in the global ocean from the Argo Program. Prog. Oceanogr., 82, 81-100, https://doi.org/10.1016/j.pocean.2009.03.004.

— L13606, https://doi.org/10.1029/2011GL047992.

—, and Coauthors, 2019: On the future of Argo: A global, full-depth, multi-disciplinary array. Front. Mar. Sci., 6, 439, https://doi.org/10.3389/ fmars.2019.00439. 
Roessler, A., M. Rhein, D. Kieke, and C. Mertens, 2015: Long-term observations of North Atlantic Current transport at the gateway between western and eastern Atlantic. J. Geophys. Res. Oceans, 120, 4003-4027, https://doi. org/10.1002/2014JC010662.

Sabine, C.L., and Coauthors, 2004: The oceanic sink for anthropogenic CO2. Science, 305, 367-371, https://doi.org/10.1126/science.1097403.

Saji, N. H., B. N. Goswami, P. N. Vinayachandran, and T. Yamagata, 1999: A dipole mode in the tropical Indian Ocean. Nature, 401, 360-363, https://doi. org/10.1038/43854.

Schlesinger, M. E., and N. Ramankutty, 1994: An oscillation in the global climate system of period 65-70 yr. Nature, 367, 723-726, https://doi. org/10.1038/367723a0.

Schmid, C., 2014: Mean vertical and horizontal structure of the subtropical circulation in the South Atlantic from three-dimensional observed velocity fields. Deep-Sea Res. I, 91, 50-71, https://doi.org/10.1016/j.dsr.2014.04.015.

Schmidtko, S., K. J. Heywood, A. F. Thompson, and S. Aoki, 2014: Multidecadal warming of Antarctic waters. Science, 346, 1227-1231, https://doi. org/10.1126/science.1256117.

Schott, F. A., M. Dengler, R. Zantopp, L. Stramma, J. Fischer, and P. Brandt, 2005: The shallow and deep western boundary circulation of the South Atlantic at $5^{\circ}-11^{\circ} \mathrm{S}$. J. Phys. Oceanogr., 35, 2031-2053, https://doi.org/10.1175/ JP02813.1.

Send, U., M. Lankhorst, and T. Kanzow, 2011: Observation of decadal change in the Atlantic meridional overturning circulation using 10 years of continuous transport data. Geophys. Res. Lett., 38, L24606, https://doi. org/10.1029/2011GL049801.

Siegel, D. A., S. Maritorena, N. B. Nelson, M. J. Behrenfeld, and C. R. McClain, 2005: Colored dissolved organic matter and its influence on the satellite-based characterization of the ocean biosphere. Geophys. Res. Lett., 32, L20605, https://doi.org/10.1029/2005GL024310.

dynamics from the SeaWiFS mission. Remote Sens. Environ., 135, 77-91, https://doi.org/10.1016/j.rse.2013.03.025.

Skliris, N., R. Marsh, S. A. Josey, S. A. Good, C. Liu, and R. P. Allan, 2014: Salinity changes in the World Ocean since 1950 in relation to changing surface freshwater flux. Climate Dyn., 43, 709-736, https://doi.org/10.1007/s00382014-2131-7.

Sloyan, B. M., and Coauthors, 2019: Evolving the physical global ocean observing system for research and application services through international coordination. Front. Mar. Sci., 6, 449, https://doi.org/10.3389/fmars.2019.00449.

Smeed, D. A., and Coauthors, 2018: The North Atlantic Ocean is in a state of reduced overturning. Geophys. Res. Lett., 45, 1527-1533, https://doi. org/10.1002/2017GL076350.

— B. Moat, D. Rayner, W. E. Johns, M. O. Baringer, D. Volkov, and E. FrajkaWilliams, 2019: Atlantic meridional overturning circulation observed by the RAPID-MOCHA-WBTS (RAPID-Meridional Overturning Circulation and Heat flux Array-Western Boundary Time Series) array at 26N from 2004 to 2018. British Oceanographic Data Centre, Natural Environment Research Council, accessed November 2019, https://doi.org/10.5285/8cd7e7bb-9a20-05d8e053-6c86abc012c2.

Stackhouse, P. W., D. P. Kratz, G. R. McGarragh, S. K. Gupta, and E. B. Geier, 2006: Fast Longwave and Shortwave Radiative Flux (FLASHFlux) products from CERES and MODIS measurements. 12th Conf. on Atmospheric Radiation, Madison, WI, Amer. Meteor. Soc., P1.10, https://ams.confex.com/ams/Madison2006/webprogram/Paper113479.html.

Sweet, W.V., J. Park, J. J. Marra, C. Zervas, and S. Gill, 2014: Sea level rise and nuisance flood frequency changes around the United States. NOAA Tech. Rep. NOS CO-OPS 73, 53 pp., https://tidesandcurrents.noaa.gov/publications/ NOAA_Technical_Report_NOS_COOPS_073.pdf.
Takahashi, T., S. C. Sutherland, and A. Kozyr, 2017: Global Ocean Surface Water Partial Pressure of CO2 Database: Measurements Performed During 19572018 (LDEO Database Version 2018) (NCEl Accession 0160492). NOAA/National Centers for Environmental Information, accessed January 2020, https:// doi.org/10.3334/cdiac/otg.ndp088(v2015).

Takeshita, Y., T. R. Martz, K. S. Johnson, J. N. Plant, D. Gilbert, S. C. Riser, C. Neill, and B. Tilbrook, 2013: A climatology-based quality control procedure for profiling float oxygen data. J. Geophys. Res. Oceans, 118, 5640-5650, https://doi. org/10.1002/jgrc.20399.

Talley, L. D., 2003: Shallow, intermediate, and deep overturning components of the global heat budget. J. Phys. Oceanogr., 33, 530-560, https://doi. org/10.1175/1520-0485(2003)033<0530:SIADOC>2.0.C0;2.

lation: A review of the first decade of GO-SHIP global repeat hydrography. Annu. Rev. Mar. Sci., 8, 185-215, https://doi.org/10.1146/annurev-marine-052915-100829.

Terray, L., L. Corre, S. Cravatte, T. Delcroix, G. Reverdin, and A. Ribes, 2012: Nearsurface salinity as nature's rain gauge to detect human influence on the tropical water cycle. J. Climate, 25, 958-977, https://doi.org/10.1175/JCLID-10-05025.1.

Todd, R. E., T. G. Asher, J. Heiderich, J. M. Bane, and R. A. Luettich, 2018: Transient response of the Gulf Stream to multiple hurricanes in 2017. Geophys. Res. Lett., 45, 10509-10519, https://doi.org/10.1029/2018GL079180.

Trenberth, K. E., and J. T. Fasullo, 2017: Atlantic meridional heat transports computed from balancing Earth's energy locally. Geophys. Res. Lett., 44, 19191927, https://doi.org/10.1002/2016GL072475.

von Storch, H., and F. W. Zwiers, 1999: Statistical Analysis in Climate Research. Cambridge University Press, 484 pp.

Wanninkhof, R., 2014: Relationship between wind speed and gas exchange over the ocean revisited. Limnol. Oceanogr.: Methods, 12, 351-362, https://doi. org/10.4319/lom.2014.12.351.

fer and its effect on global air-sea CO2 fluxes. Global Biogeochem. Cycles, 31, 961-974, https://doi.org/10.1002/2016GB005592.

WCRP Global Sea Level Budget Group, 2018: Global sea-level budget 1993-present. Earth Syst. Sci. Data, 10, 1551-1590, https://doi.org/10.5194/essd-101551-2018.

Weijer, W., and Coauthors, 2019: Stability of the Atlantic meridional overturning circulation: A review and synthesis. J. Geophys. Res. Oceans, 124, 5336-5375, https://doi.org/10.1029/2019JC015083.

Werdell, P. J., and Coauthors, 2013: Generalized ocean color inversion model for retrieving marine inherent optical properties. Appl. Opt., 52, 2019-2037, https://doi.org/10.1364/A0.52.002019.

— (PACE) mission: Status, science, advances. Bull. Amer. Meteor. Soc., 100, 1775-1794, https://doi.org/10.1175/BAMS-D-18-0056.1.

Westberry, T. K., P. Schultz, M. J. Behrenfeld, J. P. Dunne, M. R. Hiscock, S. Maritorena, J. L. Sarmiento, and D. A. Siegel, 2016: Annual cycles of phytoplankton biomass in the subarctic Atlantic and Pacific Ocean. Global Biogeochem. Cycles, 30, 175-190, https://doi.org/10.1002/2015GB005276.

Willis, J. K., 2010: Can in situ floats and satellite altimeters detect long-term changes in Atlantic Ocean overturning? Geophys. Res. Lett., 37, L06602, https://doi.org/10.1029/2010GL042372.

_ D. Roemmich, and B. Cornuelle, 2004: Interannual variability in upper ocean heat content, temperature, and thermosteric expansion on global scales. J. Geophys. Res., 109, C12036, https://doi.org/10.1029/2003JC002260.

Wolter, K., and M. S. Timlin, 1998: Measuring the strength of ENSO events: How does 1997/98 rank? Weather, 53, 315-324, https://doi. org/10.1002/j.1477-8696.1998.tb06408.x. 
Wong, C. S., N. A. D. Waser, Y. Nojiri, F. A. Whitney, J. S. Page, and J. Zeng, 2002: Seasonal cycles of nutrients and dissolved inorganic carbon at high and mid latitudes in the North Pacific Ocean during the Skaugran cruises: Determination of new production and nutrient uptake ratios. Deep-Sea Res. II, 49, 5317-5338, https://doi.org/10.1016/s0967-0645(02)00193-5.

- L. Xie, and W. W. Hsieh, 2007: Variations in nutrients, carbon and other hydrographic parameters related to the $1976 / 77$ and 1988/89 regime shifts in the sub-Arctic Northeast Pacific. Prog. Oceanogr., 75, 326-342, https://doi. org/10.1016/j.pocean.2007.08.002.

Woosley, R. J. W., F. J. Millero, and R. Wanninkhof, 2016: Rapid anthropogenic changes in $\mathrm{CO} 2$ and pH in the Atlantic: 2003-2014. Global Biogeochem. Cycles, 30, 70-90, https://doi.org/10.1002/2015gb005248.

Wu, C., Y.-F. Lin, Y.-L. Wang, N. Keenlyside, and J.-Y. Yu, 2019: An Atlantic-driven rapid circulation change in the North Pacific Ocean during the late 1990s. Sci. Rep., 9, 14411, https://doi.org/10.1038/s41598-019-51076-1.

Xie, P., and Coauthors, 2014: An in situ-satellite blended analysis of global sea surface salinity. J. Geophys. Res. Oceans, 119, 6140-6160, https://doi. org/10.1002/2014JC010046.

Yeager, S., and G. Danabasoglu, 2014: The origins of late-twentieth-century variations in the large-scale North Atlantic circulation. J. Climate, 27, 3222-3247, https://doi.org/10.1175/JCLI-D-13-00125.1.
Yu, L., X. Jin, S. Kato, N. G. Loeb, P. W. Stackhouse, R. A. Weller, and A. C. Wilber, 2019: Global ocean heat, freshwater, and momentum fluxes [in "State of Climate in 2018"]. Bull. Amer. Meteor. Soc., 100 (9), S81-S84, https://doi.org/10 .1175/2019BAMSStateoftheClimate.1.

Zantopp, R., J. Fischer, M. Visbeck, and J. Karstensen, 2017: From interannual to decadal: 17 years of boundary current transports at the exit of the Labrador Sea. J. Geophys. Res. Oceans, 122, 1724-1748, https://doi. org/10.1002/2016JC012271.

Zhang, R., 2010: Latitudinal dependence of Atlantic meridional overturning circulation (AMOC) variations. Geophys. Res. Lett., 37, L16703, https://doi. org/10.1029/2010GL044474.

Zou, S., M. S. Lozier, F. Li, R. Abernathey, and L. Jackson, 2020a: Density-compensated overturning in the Labrador Sea. Nat. Geosci., 13, 121-126, https://doi. org/10.1038/s41561-019-0517-1.

- A. Bower, H. Furey, M. S. Lozier, and X. Xu, 2020b: Redrawing the IcelandScotland overflow water pathways in the North Atlantic. Nat. Commun., 11, 1890, https://doi.org/10.1038/s41467-020-15513-4.

Zweng, M. M., and Coauthors, 2013: Salinity. Vol. 2, World Ocean Atlas 2013, NOAA Atlas NESDIS 74, 39 pp., http://data.nodc.noaa.gov/woa/WOA13/DOC/ woa13_vol2.pdf. 


\section{STATE OF THE CLIMATE IN 2019 THE TROPICS}

H. J. Diamond and C. J. Schreck, Eds.

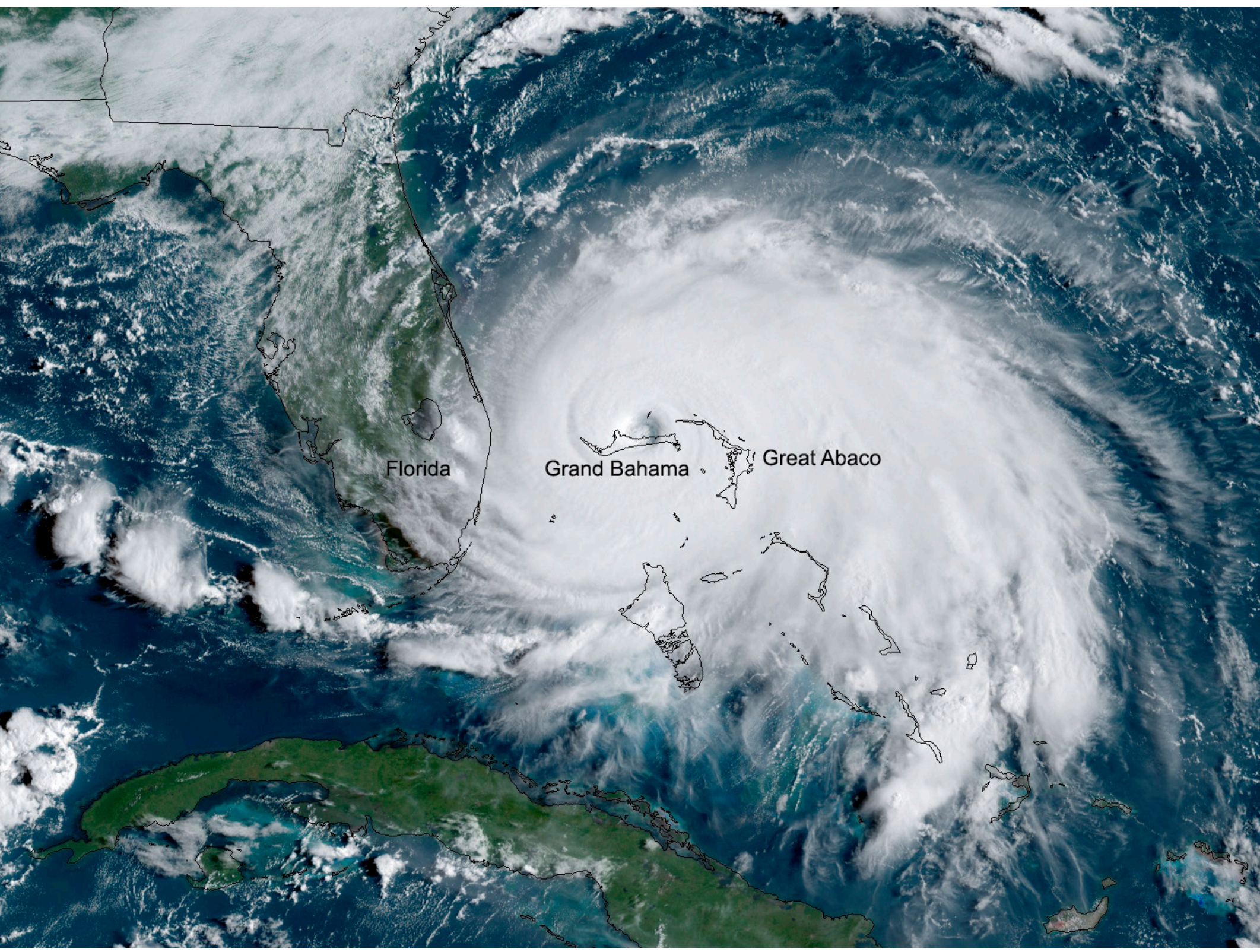

Special Online Supplement to the Bulletin of the American Meteorological Society, Vol.101, No. 8, August, 2020

https://doi.org/10.1175/BAMS-D-20-0077.1

Corresponding author: Howard J. Diamond / howard.diamond@noaa.gov

(02020 American Meteorological Society

For information regarding reuse of this content and general copyright information, consult the AMS Copyright Policy. 


\title{
STATE OF THE CLIMATE IN 2019 The Tropics
}

\author{
Editors \\ Jessica Blunden \\ Derek S. Arndt

\section{Chapter Editors} \\ Peter Bissolli \\ Howard J. Diamond \\ Matthew L. Druckenmiller \\ Robert J. H. Dunn \\ Catherine Ganter \\ Nadine Gobron \\ Rick Lumpkin \\ Jacqueline A. Richter-Menge \\ Tim Li \\ Ademe Mekonnen \\ Ahira Sánchez-Lugo \\ Ted A. Scambos \\ Carl J. Schreck III \\ Sharon Stammerjohn \\ Diane M. Stanitski \\ Kate M. Willett \\ Technical Editor \\ Andrea Andersen
}

BAMS Special Editor for Climate

Richard Rosen

American Meteorological Society 


\section{Cover credit:}

Catastrophic Hurricane Dorian slowed to a crawl over Grand Bahama Island overnight and into Labor Day. On Monday, September 2, 2019, GOES East captured a view of the Category 5 storm over Grand Bahama.

This GeoColor-enhanced imagery was created by NOAA's partners at the Cooperative Institute for Research in the Atmosphere. The GOES East geostationary satellite, also known as GOES-16, provides coverage of the Western Hemisphere, including the United States, the Atlantic Ocean and the eastern Pacific. The satellite's high-resolution imagery provides optimal viewing of severe weather events, including thunderstorms, tropical storms, and hurricanes. (c) NOAA

The Tropics is one chapter from the State of the Climate in 2019 annual report and is available from https://doi.org/10.1175/BAMS-D-20-0077.1. Compiled by NOAA's National Centers for Environmental Information, State of the Climate in 2019 is based on contributions from scientists from around the world. It provides a detailed update on global climate indicators, notable weather events, and other data collected by environmental monitoring stations and instruments located on land, water, ice, and in space. The full report is available from https://doi.org/10.1175/2020BAMSStateoftheClimate.1.

\section{How to cite this document:}

\section{Citing the complete report:}

Blunden, J. and D. S. Arndt, Eds., 2020: State of the Climate in 2019. Bull. Amer. Meteor. Soc., 101 (8), Si-S429, https://doi.org/10.1175/2020BAMSStateoftheClimate.1.

\section{Citing this chapter:}

Diamond, H.J. and C. J. Schreck, Eds., 2020: The Tropics [in "State of the Climate in 2019"]. Bull. Amer. Meteor. Soc., 101 (8), S185-S238, https://doi.org/10.1175/BAMS-D-20-0077.1.

\section{Citing a section (example):}

Chen, L., J. -J Luo, and A. D. Magee, 2020: Indian Ocean dipole [in "State of the Climate in 2019"]. Bull. Amer. Meteor. Soc., 101 (8), S229-S232, https://doi.org/10.1175/BAMS-D-20-0077.1. 
Baxter, Stephen, NOAA/NWS Climate Prediction Center, College Park, Maryland

Bell, Gerald D., NOAA/NWS Climate Prediction Center, College Park, Maryland

Blake, Eric S., NOAA/NWS National Hurricane Center, Miami, Florida

Bringas, Francis G., NOAA/OAR Atlantic Oceanographic and Meteorological Laboratory, Miami, Florida

Camargo, Suzana J., Lamont-Doherty Earth Observatory, Columbia University, Palisades, New York

Chen, Lin, Institute for Climate and Application Research (ICAR)/KLME/ILCEC/ CIC-FEMD, Nanjing University of Information Science and Technology, Nanjing, China

Coelho, Caio A. S., CPTEC/INPE Center for Weather Forecasts and Climate Studies, Cachoeira Paulista, Brazil

Diamond, Howard J., NOAA/OAR Air Resources Laboratory, College Park, Maryland

Domingues, Ricardo, Cooperative Institute for Marine and Atmospheric Studies, University of Miami, Miami, Florida

Goldenberg, Stanley B., NOAA/OAR/AOML Hurricane Research Division, Miami, Florida

Goni, Gustavo, NOAA/OAR/AOML Hurricane Research Division, Miami, Florida

Fauchereau, Nicolas, National Institute of Water and Atmospheric Research, Ltd., Auckland, New Zealand

Halpert, Michael S., NOAA/NWS Climate Prediction Center, College Park, Maryland

He, Qiong, Earth System Modeling Center, Nanjing University of Information Science and Technology, Nanjing, China

Klotzbach, Philip J., Department of Atmospheric Science, Colorado State University, Fort Collins, Colorado

Knaff, John A., NOAA/NESDIS Center for Satellite Applications and Research, Fort Collins, Colorado

L'Heureux, Michelle, NOAA/NWS Climate Prediction Center, College Park, Maryland
Landsea, Chris W., NOAA/NWS National Hurricane Center, Miami, Florida Lin, I.-I., National Taiwan University, Taipei, Taiwan

Lorrey, Andrew M., National Institute of Water and Atmospheric Research, Ltd., Auckland, New Zealand

Luo, Jing-Jia, Institute for Climate and Application Research (ICAR)/KLME/ ILCEC/CIC-FEMD, Nanjing University of Information Science and Technology, Nanjing, China

Magee, Andrew D., Centre for Water, Climate and Land, School of Environmental and Life Sciences, University of Newcastle, Callaghan, NSW, Austrailia

Pasch, Richard J., NOAA/NWS National Hurricane Center, Miami, Florida

Pearce, Petra R., National Institute of Water and Atmospheric Research, Ltd., Auckland, New Zealand

Pezza, Alexandre B., Greater Wellington Regional Council, Wellington, New Zealand

Rosencrans, Matthew, NOAA/NWS Climate Prediction Center, College Park, Maryland

Schreck III, Carl J., North Carolina State University, Cooperative Institute for Climate and Satellites - North Carolina (CICS-NC), Asheville, North Carolina

Trewin, Blair C., Australian Bureau of Meteorology, Melbourne, Victoria, Australia

Truchelut, Ryan E., "WeatherTiger," Tallahassee, Florida

Wang, Bin, Department of Atmospheric Science and IPRC, University of Hawaii, Honolulu, Hawaii

Wang, H., NOAA/NWS Climate Prediction Center, College Park, Maryland

Wood, Kimberly M., Department of Geosciences, Mississippi State University, Starkville, Mississippi

Woolley, John-Mark, National Institute of Water and Atmospheric Research, Ltd., Auckland, New Zealand

\section{Editoral and Production Team}

Andersen, Andrea, Technical Editor, Innovative Consulting and Management Services, LLC, NOAA/NESDIS National Centers for Environmental Information, Asheville, North Carolina

Griffin, Jessicca, Graphics Support, Cooperative Institute for Satellite Earth System Studies, North Carolina State University, Asheville, North Carolina

Hammer, Gregory, Content Team Lead, Communications and Outreach, NOAA/ NESDIS National Centers for Environmental Information, Asheville, North Carolina

Love-Brotak, S. Elizabeth, Lead Graphics Production, NOAA/NESDIS National Centers for Environmental Information, Asheville, North Carolina
Misch, Deborah J., Graphics Support, Innovative Consulting and Management Services, LLC, NOAA/NESDIS National Centers for Environmental Information, Asheville, North Carolina

Riddle, Deborah B., Graphics Support, NOAA/NESDIS National Centers for Environmental Information, Asheville, North Carolina

Veasey, Sara W., Visual Communications Team Lead, Communications and Outreach, NOAA/NESDIS National Centers for Environmental Information, Asheville, North Carolina 


\section{Table of Contents}

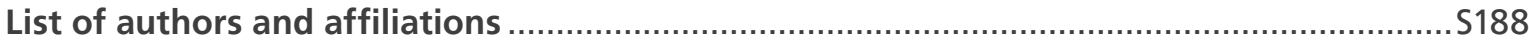

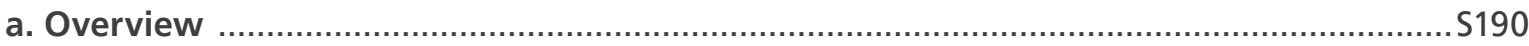

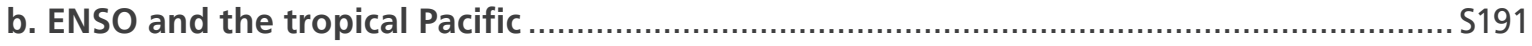

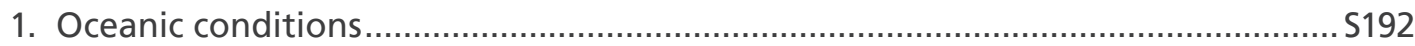

2. Atmospheric circulation, temperature, and precipitation anomalies during December-February 2018/19.................................................. 193

3. Atmospheric circulation, temperature, and precipitation anomalies during March-May through September-November 2019 ............................................S194

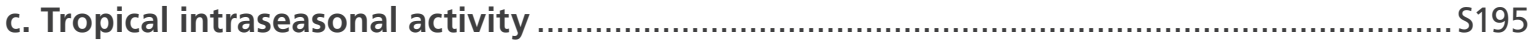

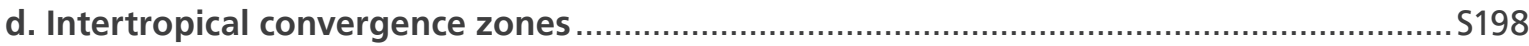

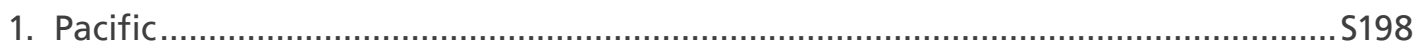

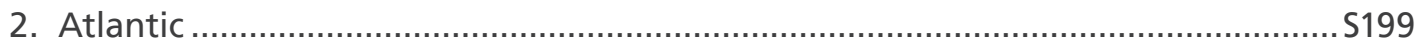

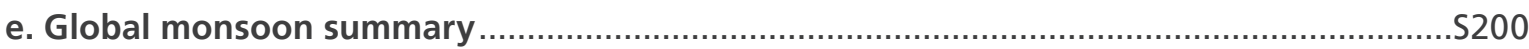

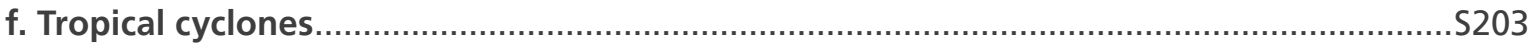

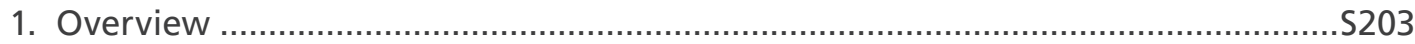

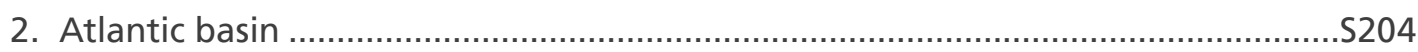

Sidebar 4.1: Hurricane Dorian: A devastating hurricane
$\quad$ for the northwest Bahamas ................................................................................ 5210

3. Eastern North Pacific and Central North Pacific basins......................................S212

4. Western North Pacific basin .............................................................................. 2214

5. North Indian Ocean basin ............................................................................... 219

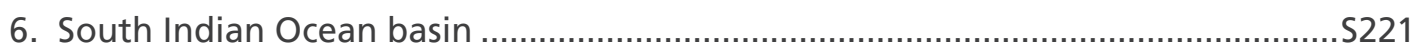

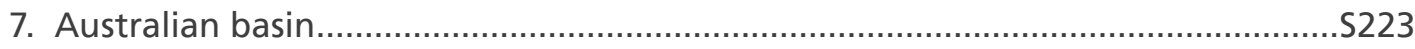

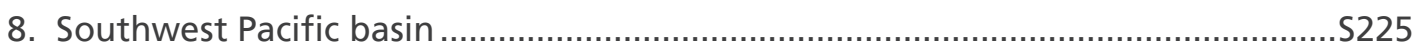

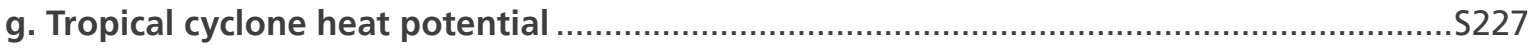

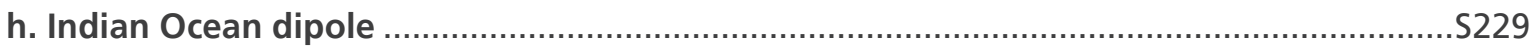

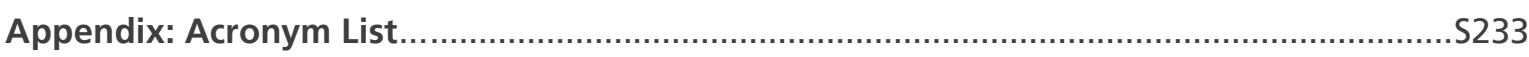

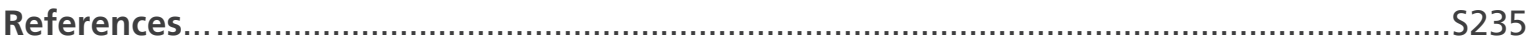

*Please refer to Chapter 8 (Relevant datasets and sources) for a list of all climate variables and datasets used in this chapter for analyses, along with their websites for more information and access to the data. 


\section{THE TROPICS}

H. J. Diamond and C. J. Schreck, Eds.

\section{a. Overview-H. J. Diamond and C. J. Schreck}

The tropics in 2019 featured a weak El Niño event that began in January and ended in July. Neutral ENSO conditions prevailed for the remainder of the year, although sea surface temperatures (SSTs) remained above normal in the central Pacific. The Oceanic Niño Index (ONI) met the $+0.5^{\circ} \mathrm{C}$ threshold for El Niño during September-December 2018 and November-December 2019. However, the ocean-atmosphere coupling, normally an intrinsic aspect of El Niño, was missing during both periods.

For the global tropics, combined land and ocean surface temperatures (measured $20^{\circ} \mathrm{N}-20^{\circ} \mathrm{S}$ ) registered $+0.47^{\circ} \mathrm{C}$ above the $1981-2010$ average. This makes 2019 the third-warmest year for the tropics since records began in 1880, and the warmest since 2016. Data from the Global Precipitation Climatology Project indicate a mean annual total precipitation value of $1317 \mathrm{~mm}$ across the $20^{\circ} \mathrm{N}-20^{\circ} \mathrm{S}$ latitude band over land. This is $11 \mathrm{~mm}$ above the $1981-2010$ average and ranks in the middle tercile of the 1979-2019 period of record.

Globally, 96 named tropical cyclones (TCs; $\geq 34$ kt; or $17 \mathrm{~m} \mathrm{~s}^{-1}$ ) were observed during the 2019 Northern Hemisphere (NH) season (January-December 2019) and the 2018/19 Southern Hemisphere (SH) season (July-June 2018/19; Table 4.2), as documented in IBTrACSv4 (Knapp et al. 2010). Overall, this number was well above the 1981-2010 global average of 82 TCs and similar to the 95 TCs reported during 2018 (Diamond and Schreck 2019).

In terms of Accumulated Cyclone Energy (ACE; Bell et al. 2000), each NH basin was above its 1981-2010 average. The North and South Indian Ocean basins were in the top 10\% of ACE recorded for those basins at $85 \times 10^{4} \mathrm{kt}^{2}$ and $154 \times 10^{4} \mathrm{kt}^{2}$, respectively; and in fact, the ACE value in the North Indian Ocean was the highest on record. In the western North Pacific, seven storms (six of Category 5 intensity) out of a total of 28 accounted for $71 \%$ of the above-average seasonal ACE of $341 \times 10^{4} \mathrm{kt}^{2}$. The North Atlantic basin had an ACE of nearly 145\% of its 1981-2010 median value but was well below the 241\% of median recorded in 2017 (Bell et al. 2018). Category 5 Hurricanes Dorian and Lorenzo alone accounted for $>60 \%$ of the 2019 total. The Australian and southwest Pacific basins were fairly quiet; each had an ACE that was below normal but still within the middle tercile. The global total was near normal for 1981-2010 with $795 \times 10^{4} \mathrm{kt}^{2}$. Five TCs across the globe reached Saffir-Simpson Hurricane Wind Scale (SSHWS) Category 5 intensity level-two in the North Atlantic and three in the western North Pacific.

From a socio-economic standpoint, the five Category 5 storms were significant in their effects. Hurricane Dorian caused unprecedented and tremendous devastation, with over 70 fatalities and damages totaling $\$ 3.4$ billion (U.S. dollars). Hurricane Lorenzo as a post-tropical/extratropical cyclone was the second-deadliest storm of the 2019 North Atlantic season, causing 19 deaths. However, major impacts are not relegated to Category 5 storms, and Super Typhoon Faxai demonstrated that with total damages estimated at $\$ 9.3$ billion (U.S. dollars). Faxai was one of the strongest typhoons on record to affect Tokyo, Japan, killing three people and injuring 147, causing extensive blackouts, and damaging more than 40000 homes

The Indian Ocean dipole (IOD), an inherent air-sea coupling mode in the tropical Indian Ocean, exhibited its greatest magnitude recorded since 1997, which was under extremely strong El Niño conditions. The unique feature of the 2019 IOD event was that it occurred during neutral ENSO conditions. 
In addition, tropical intraseasonal variability was especially prominent, with three distinct periods of Madden-Julian Oscillation (MJO) activity spanning a total of approximately eight months.

The editors of this chapter would like to insert a personal note recognizing the passing of a past author of the Tropics Chapter. Our colleague and good friend A. Brett Mullan died of cancer on 22 April 2020. Brett was a mainstay of this chapter having stewarded the section on the Pacific Intertropical Convergence Zone from 2006 to 2018. Brett worked for New Zealand's National Institute of Water and Atmosphere and made significant contributions and authored seminal papers in meteorology. These included the analysis of SH climate and circulation variability over interannual (El Niño-Southern Oscillation [ENSO]) to interdecadal (interdecadal Pacific Oscillation) timescales. His work in documenting the relationships of climate variability to long-term global teleconnections has been a basis for seasonal climate prediction for New Zealand commencing in the 1990s. He carried out research into climate change and modeling, with particular emphasis on SH and New Zealand regional effects (Southern Oscillation, greenhouse warming, ocean-atmosphere coupled models and decadal variability, and integrated climate impact models). Over his 40-year career, Brett's contributions to meteorology and climate science and beyond were tremendous. His outstanding work and significant scientific contributions will be his legacy, and he will be greatly missed.

\section{b. ENSO and the tropical Pacific-M. L'Heureux, G. D. Bell, and M. S. Halpert}

The El Niño-Southern Oscillation (ENSO) is a coupled ocean-atmosphere climate phenomenon over the tropical Pacific Ocean, with opposite phases called El Niño and La Niña. For historical purposes, NOAA's Climate Prediction Center (CPC) classifies and assesses the strength and duration of El Niño and La Niña using the Oceanic Niño Index (ONI; shown for mid-2018 through 2019 in Fig. 4.1). The ONI is the 3-month (seasonal) running average of sea surface temperature (SST) anomalies in the Niño-3.4 region $\left(5^{\circ} \mathrm{N}-5^{\circ} \mathrm{S}, 170^{\circ}-120^{\circ} \mathrm{W}\right)$, currently calculated as the departure from the $1986-2015$ base period mean. El Niño is classified when the $\mathrm{ONI} \geq+0.5^{\circ} \mathrm{C}$ for at least five consecutive, overlapping seasons. La Niña is similarly defined but for $\mathrm{ONI} \leq-0.5^{\circ} \mathrm{C}$.

Using the ONI, the minimum threshold for El Niño was reached in September-November (SON) 2018, but the CPC did not declare the onset of El Niño until ocean-atmosphere coupling became evident in January 2019 (Bell et al. 2019). ONI values peaked and remained near $+0.8^{\circ} \mathrm{C}$ for five overlapping seasons (October-December [OND] until March-May [MAM]), then decreased before El Niño ended in May-July (MJJ) 2019. This episode was categorized as weak because the ONI remained between $+0.5^{\circ} \mathrm{C}$ and $+0.9^{\circ} \mathrm{C}$.

The ONI remained positive throughout 2019, and the central Pacific remained warmer than usual. However, the remainder of the year was classified as ENSO-neutral as ONI values decreased to a minimum of $+0.1^{\circ} \mathrm{C}$ during July-September (JAS) and August-October (ASO). During the autumn and early winter, the $\mathrm{ONI}$ increased to $+0.5^{\circ} \mathrm{C}$ in OND and $+0.6^{\circ} \mathrm{C}$ in November-January (NDJ), but the ocean-atmosphere coupling, which is normally an intrinsic aspect of El Niño, was not present during this season.

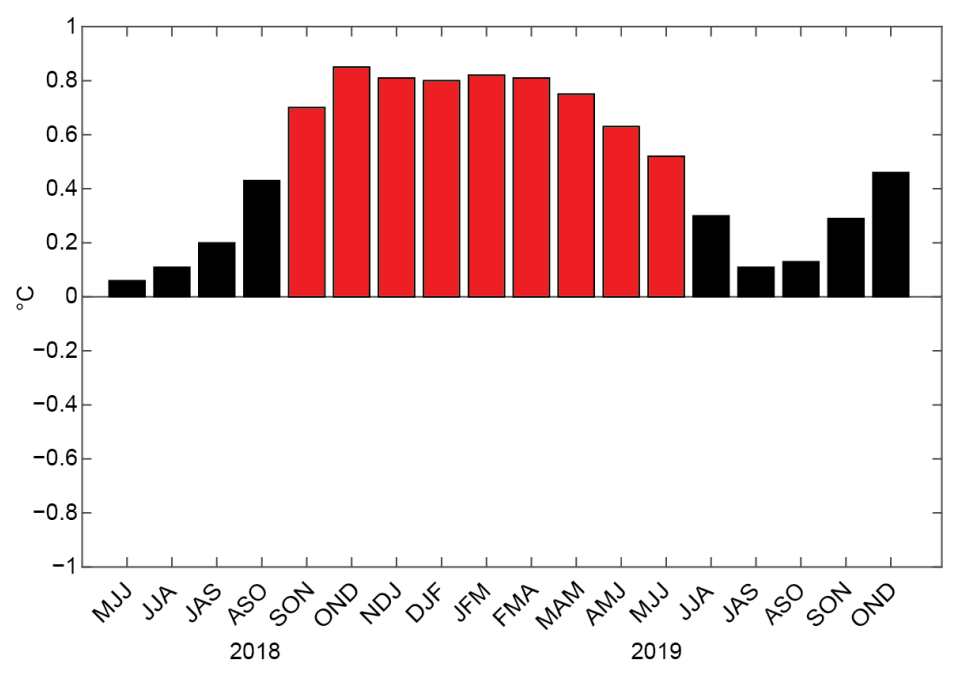

Fig. 4.1. Time series of the ONI $\left({ }^{\circ} \mathrm{C}\right)$ from mid-2018 through 2019. Overlapping 3-month seasons are labeled on the x-axis, with initials indicating the first letter of each month in the season. Red bars indicate positive values in excess of $+0.5^{\circ} \mathrm{C}$. ONI values are derived from the ERSST-v5 dataset (Huang et al. 2017) and are based on departures from the 1986-2015 period monthly means. 


\section{1) Oceanic conditions}

Seasonal sea surface temperatures (SSTs) and anomalies during December-February (DJF) 2018/19 through SON 2019 are shown in Fig. 4.2. The El Niño during DJF and MAM is indicated by positive SST anomalies across the central and eastern equatorial Pacific Ocean (Figs. 4.2a-d). Throughout the event, anomalies exceeding $+1.0^{\circ} \mathrm{C}$ were seen in the central and east-central equatorial Pacific. These conditions reflected a weaker-than-average equatorial cold tongue in the eastern Pacific and an eastward expansion of the western Pacific warm pool (approximated by SSTs above $29^{\circ} \mathrm{C}$ ) to well east of the date line (near $160^{\circ} \mathrm{W}$; Fig. $4.2 \mathrm{~d}$ ).

Following the demise of El Niño, equatorial SST anomalies in the central Pacific Ocean remained quite high (near or above $+1.0^{\circ} \mathrm{C}$ ) throughout the year, while the anomalies decreased in the eastern equatorial Pacific, returning to near zero during June-August (JJA) and SON 2019 (Figs. 4.2f,h). A sizable region of $30^{\circ} \mathrm{C}$ temperatures covered the western equatorial Pacific Ocean, extending to the date line (Figs. 4.2e,g). Correspondingly, SST anomalies increased to $+1.5^{\circ} \mathrm{C}$ in the western equatorial Pacific $\left(\sim 170^{\circ} \mathrm{E}\right)$ during SON (Fig. 4.2h).

Consistent with the SST evolution, subsurface temperatures during DJF 2018/19 and MAM 2019 were above average across most of the equatorial Pacific (Figs. 4.3a,b). This warming reflected deepening of the oceanic thermocline and reduced upwelling that accompanies El Niño. Although ENSO-neutral conditions returned by summer, temperature anomalies near the date line remained greater than $+1.0^{\circ} \mathrm{C}$ between the surface and 150-m depth (Figs. 4.3c,d).

In contrast, in the far eastern equatorial Pacific, the thermocline was shallower than average, consistent with the below-average temperatures in this region during JJA (Fig. 4.3c). By SON, the thermocline and subsurface temperatures were near average across most of the equatorial Pacific Ocean.

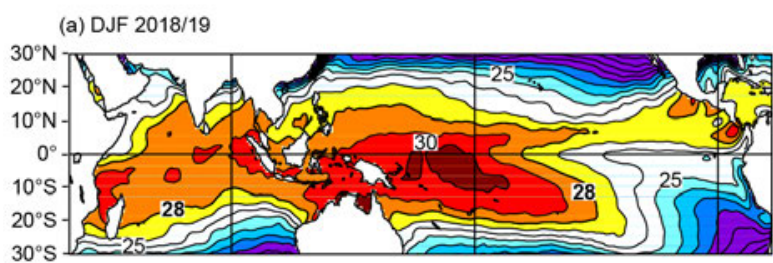

(b) DJF 2018/19

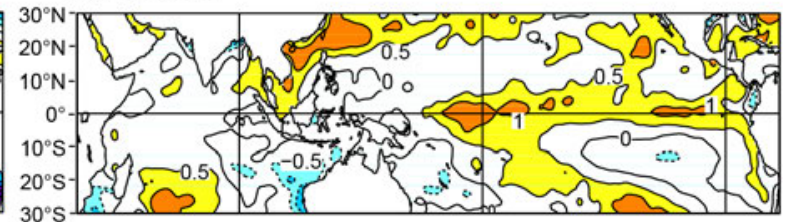

(d) MAM 2019

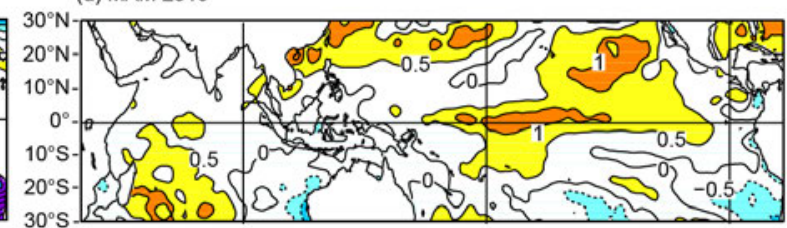

(f) JJA 2019

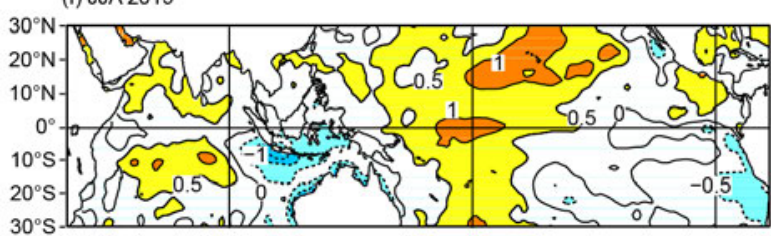

(h) SON 2019

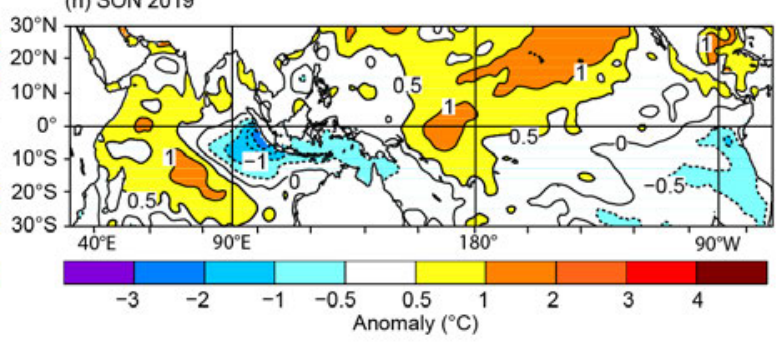

Fig. 4.2. Seasonal SST (left) and anomaly (right) for (a),(b) DJF 2018/19, (c),(d) MAM 2019, (e),(f) JJA 2019, and (g),(h) SON 2019. Contour interval for SST is $1^{\circ} \mathrm{C}$. For SST anomaly, contour interval is $0.5^{\circ} \mathrm{C}$ for anomalies between $\pm 1^{\circ} \mathrm{C}$, and $1^{\circ} \mathrm{C}$ for anomalies $>1{ }^{\circ} \mathrm{C}$ and $<-1^{\circ} \mathrm{C}$. Anomalies are departures from the 1981-2010 seasonal adjusted OI climatology (Reynolds et al. 2002). 

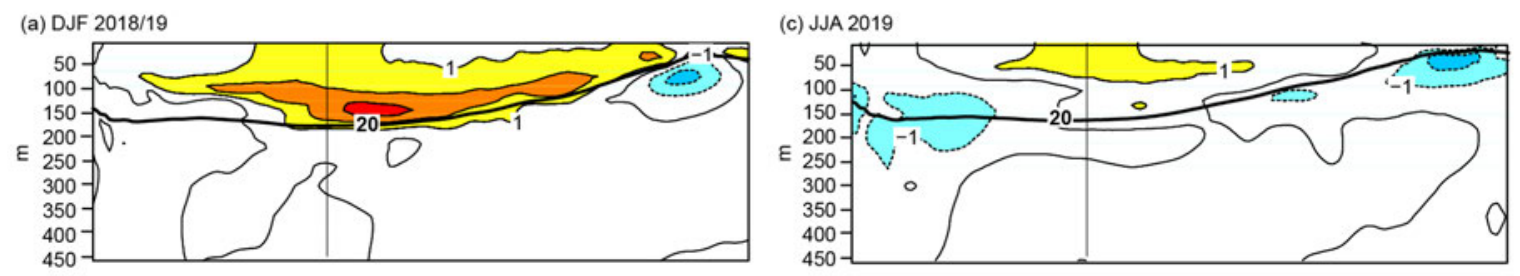

(b) MAM 2019

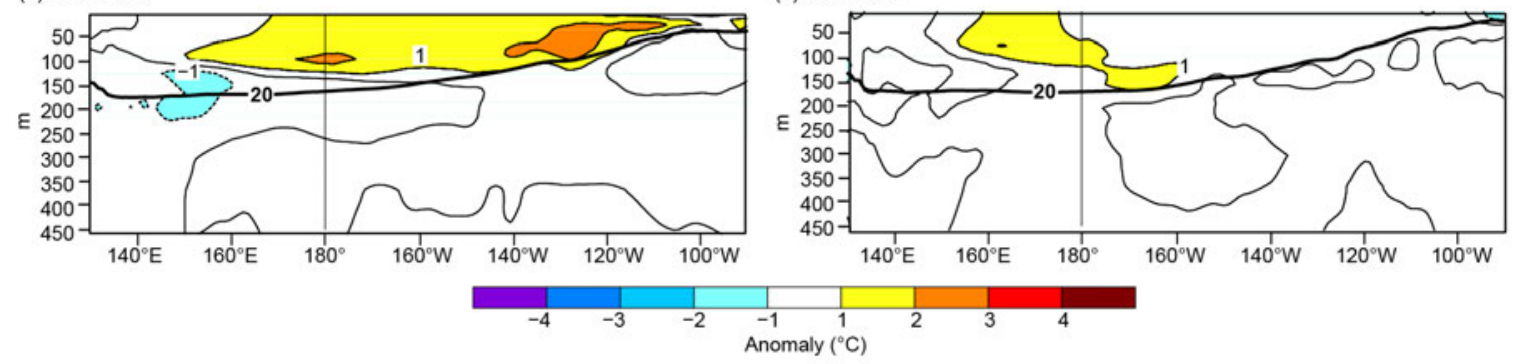

Fig. 4.3. Equatorial depth-longitude section of Pacific Ocean temperature anomalies $\left({ }^{\circ} \mathrm{C}\right)$ from the 1981-2010 mean averaged between $5^{\circ} \mathrm{N}$ and $5^{\circ} \mathrm{S}$ during (a) DJF 2018/19, (b) MAM 2019, (c) JJA 2019, and (d) SON 2019. The $20^{\circ} \mathrm{C}$ isotherm (thick solid line) approximates the center of the thermocline. The data are derived from an analysis system that assimilates oceanic observations into an oceanic general circulation model (Behringer et al. 1998).

\section{2) Atmospheric circulation, temperature, and precipitation anomalies during December- February 2018/19}

The patterns of tropical convection and winds during DJF 2018/19 generally reflected El Niño (Figs. 4.4a, 4.5a). In particular, tropical convection (measured by Outgoing Longwave Radiation [OLR]) was enhanced near the date line (green shading) and suppressed over Indonesia (brown shading). Low-level (850 hPa) tropical wind anomalies were westerly over the western Pacific Ocean during DJF (Fig. 4.4a), reflecting a weakening of the trade winds, an indicator of a weaker Pacific Walker circulation (Bjerknes 1969).

In the upper atmosphere $(200 \mathrm{hPa})$, tropical wind anomalies were mostly cross-equatorial during DJF 2018/19, with flow from the Northern Hemisphere (NH) subtropics to the Southern Hemisphere (SH) over the eastern Pacific (Fig. 4.5a). Upper-level wind anomalies reflected anomalous divergence in association with the enhanced convection near the date line. Adjacent to this region, two anomalous upper-level anticyclones flanked the equator, consistent with El Niño.

Over the Pacific-North American region, anomalies of 500-hPa heights and upper-level winds during DJF 2018/19 generally did not match those conventionally associated with El Niño. The strengthened and southern-shifted
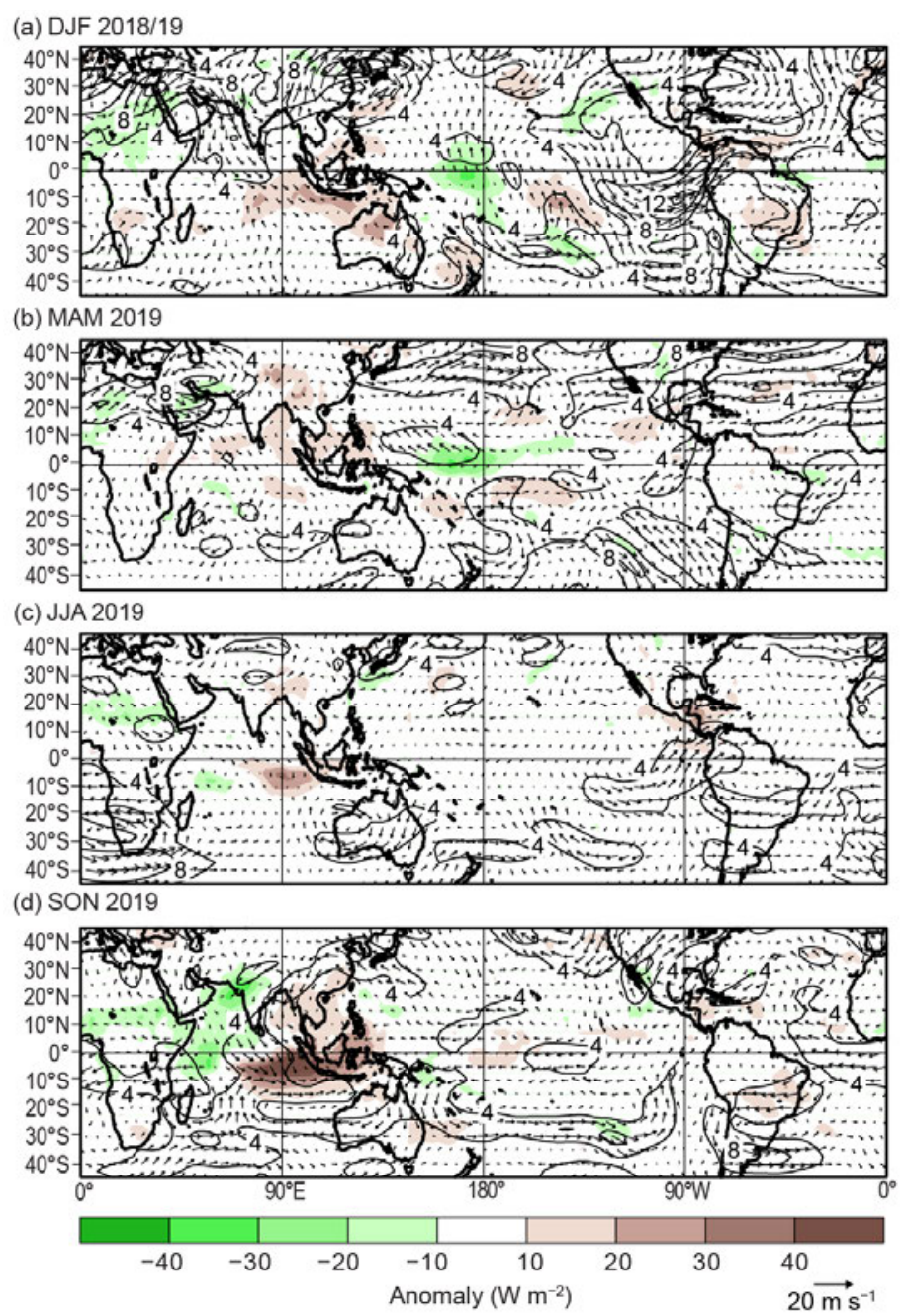

Fig. 4.4. Anomalous $850-\mathrm{hPa}$ wind vectors and speed (contour interval is $2 \mathrm{~m} \mathrm{~s}^{-1}$ ) and anomalous OLR (shaded, $\mathrm{W} \mathrm{m}^{-2}$ ) during (a) DJF 2018/19, (b) MAM 2019, (c) JJA 2019, and (d) SON 2019. Reference wind vector is below right of color bar. Anomalies are departures from the 1981-2010 period monthly means. (Source: NCEP-NCAR reanalysis [Kalnay et al. 1996].) 
jet stream was only evident over the far eastern North Pacific Ocean instead of across the central North Pacific Ocean as expected with El Niño (Fig. 4.5a). Despite the lack of a clear El Niño footprint, the anomalous circulation was linked to increased precipitation over California, the southeastern United States, and Florida. However, enhanced precipitation was also widespread over the entire contiguous United States, with the exception of the Pacific Northwest and most of Texas, where near- to slightly-below-average precipitation occurred. As with the 500-hPa height anomalies, the temperature anomalies over North America were also not consistent with El Niño with below-average temperatures over western Canada and the north-central United States, and above-average temperatures over the southern tier of the United States (see sections $7 \mathrm{~b} 1$ and $7 \mathrm{~b} 2)$.

In other parts of the world, El Niño during DJF is historically associated with positive temperature anomalies over the northern half of South America, Australia, Indonesia, southeast Asia, and southern Africa (Halpert and Ropelewski 1992). All of these were apparent during DJF 2018/19 (see relevant temperature sections in Chapter 7 for details), though undoubtedly with a partial contribution from the long-term climate change warming signal as well (see section 2b1). El Niño was also likely associated with above-average precipitation across most of the southern tier of the United
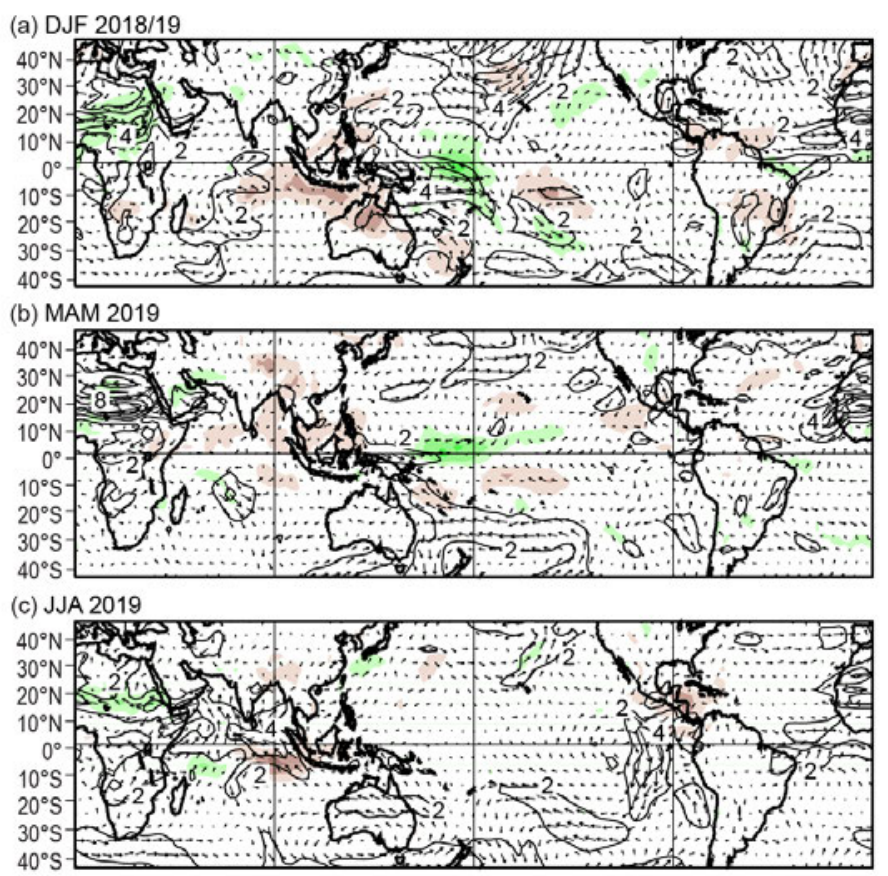

(d) SON 2019

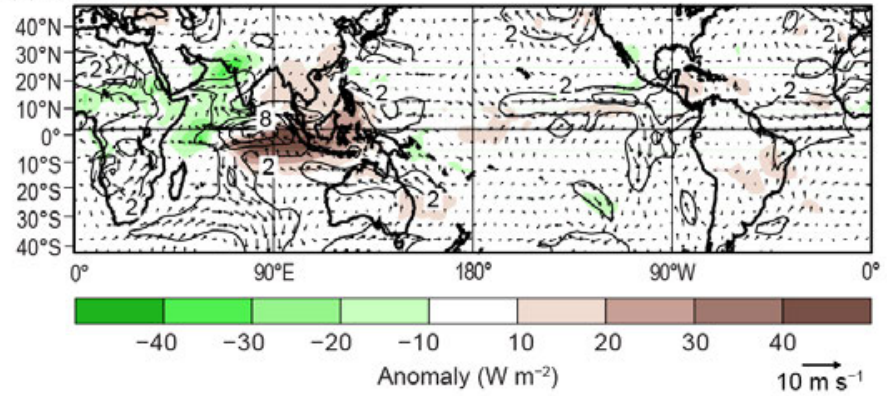

Fig. 4.5. Anomalous 200-hPa wind vectors and speed (contour interval is $4 \mathrm{~m} \mathrm{~s}^{-1}$ ), and anomalous OLR (shaded, $\mathrm{W} \mathrm{m}^{-2}$ ), during (a) DJF 2018/19, (b) MAM 2019, (c) JJA 2019, and (d) SON 2019. Reference wind vector is below right of color bar. Anomalies are departures from the 1981-2010 period monthly means. (Source: NCEP-NCAR reanalysis [Kalnay et al. 1996].)

States, Uruguay, and southeastern China during DJF 2018/19 (see relevant precipitation sections in Chapter 7 for details; Ropelewski and Halpert 1989). Likewise, El Niño likely played some role in below-average precipitation over parts of southern Chile, northern South America, South Africa, Indonesia, and Australia.

\section{3) Atmospheric circulation, temperature, and precipitation anomalies during March-May through September-November 2019}

The pattern of wind anomalies over the equatorial Pacific Ocean changed from DJF to MAM 2019, with mostly near-average low-level winds (Fig. 4.4b) and anomalous upper-level easterlies over the western Pacific Ocean during MAM (Fig. 4.5b). By this season, the El Niño was weakening from its boreal winter maximum. However, the East Asia-North Pacific jet stream was stronger than average across most of the extratropical oceans (Fig. 4.5b), which is typical of El Niño. Likewise, enhanced precipitation continued over California and much of the contiguous United States (see section 7b2). Temperatures over the United States, however, were largely a continuation of the DJF anomalies and not consistent with El Niño. Later in the year, the lowerlevel and upper-level winds were mostly near average over the equatorial Pacific (Figs. 4.4c,d and $4.5 \mathrm{c}, \mathrm{d})$. During SON, convection was suppressed over the Maritime Continent, mostly in 
association with the strengthening of the Indian Ocean dipole (IOD; section 4h). While SST anomalies were positive over the western and central equatorial Pacific Ocean, there was no corresponding increase in convection. In fact, OLR was weakly suppressed near the date line (Figs. 4.4d, 4.5d).

\section{c. Tropical intraseasonal activity-S. Baxter, C. Schreck, and G. D. Bell}

Tropical intraseasonal variability was especially prominent during 2019. Two leading aspects of this variability were the Madden-Julian Oscillation (MJO; Madden and Julian 1971, 1972, 1994; Zhang 2005) and convectively coupled equatorial waves (Wheeler and Kiladis 1999; Kiladis et al. 2009), which include equatorial Rossby waves and atmospheric Kelvin waves. There were three distinct periods of MJO activity in 2019 spanning a total of approximately eight months (Fig. 4.6), which were interspersed with the convectively coupled waves (Fig. 4.7). Between the MJO periods, the tropical convective anomalies were dominated by lower frequency variability and convectively coupled waves.

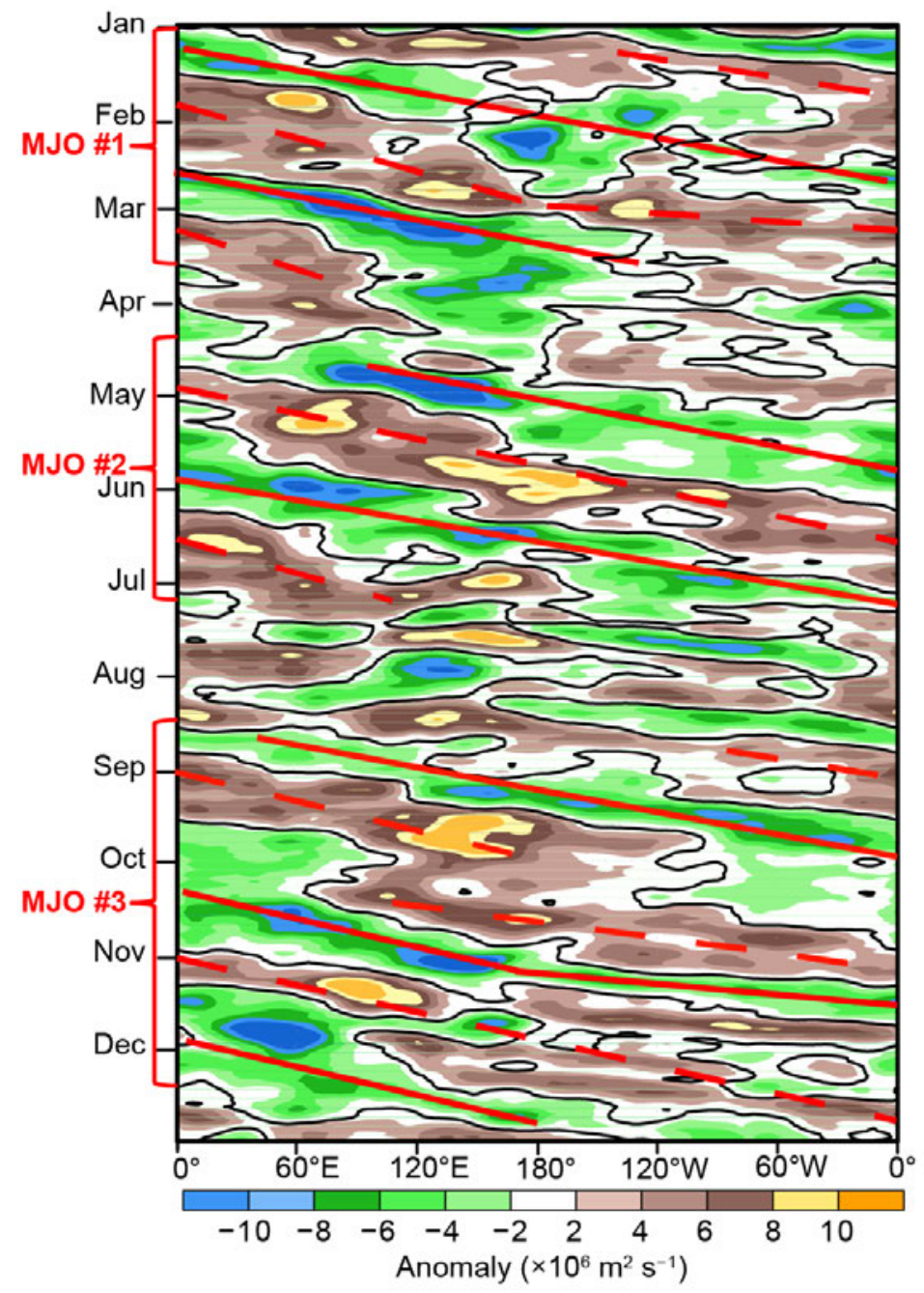

Fig. 4.6. Time-longitude section for 2019 of 5-day running anomalous $200-\mathrm{hPa}$ velocity potential $\left(\times 10^{6} \mathrm{~m}^{2} \mathrm{~s}^{-1}\right)$ averaged between $5^{\circ} \mathrm{N}-5^{\circ} \mathrm{S}$. For each day, the period mean is removed prior to plotting. Green (brown) shading highlights likely areas of anomalous divergence and rising motion (convergence and sinking motion). Red lines and labels highlight the main MJO episodes. Anomalies are departures from the 1981-2010 base period daily means. (Source: NCEP-NCAR reanalysis [Kalnay et al. 1996].)

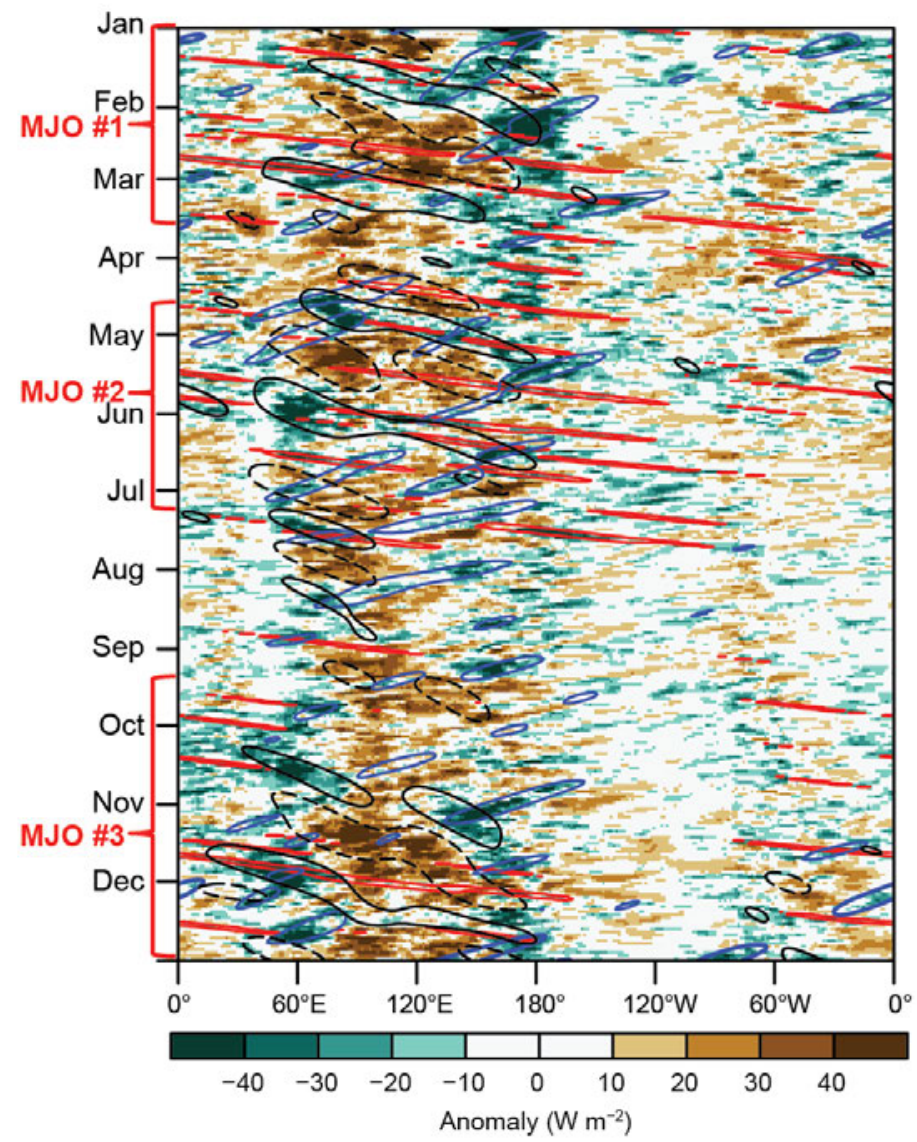

Fig. 4.7. Time-longitude section for 2019 of anomalous OLR $\left(\mathrm{W} \mathrm{m}^{-2}\right)$ averaged between $10^{\circ} \mathrm{N}-10^{\circ} \mathrm{S}$. Negative anomalies indicate enhanced convection, positive anomalies indicate suppressed convection. Contours identify anomalies filtered for the MJO (black) and atmospheric Kelvin waves (red), and equatorial Rossby waves (blue). Red labels highlight the main MJO episodes. Contours are drawn at $\pm 10 \mathrm{~W} \mathrm{~m}^{-2}$, with the enhanced (suppressed) convective phase of these phenomena indicated by solid (dashed) contours. Anomalies are departures from the 1981-2010 base period daily means. 
The MJO is a leading intraseasonal climate mode of tropical convective variability. Its convective anomalies often have a similar spatial scale to El Niño-Southern Oscillation (ENSO) but differ in that they exhibit a distinct eastward propagation and generally traverse the globe in 30-60 days. The MJO affects weather patterns around the globe (Zhang 2013), including monsoons (Krishnamurti and Subrahmanyam 1982; Lau and Waliser 2012), tropical cyclones (TCs; Mo 2000; Frank and Roundy 2006; Camargo et al. 2007; Schreck et al. 2012; Diamond and Renwick 2015), and extratropical circulations (Knutson and Weickmann 1987; Kiladis and Weickmann 1992; Mo and Kousky 1993; Kousky and Kayano 1994; Kayano and Kousky 1999; Cassou 2008; Lin et al. 2009; Riddle et al. 2012; Schreck et al. 2013; Baxter et al. 2014). The MJO is often episodic, with periods of moderate-to-strong activity followed by little or no activity. The MJO tends to be most active during ENSO-neutral and weak ENSO periods and is often absent during strong El Niño events (Hendon et al. 1999; Zhang and Gottschalck 2002; Zhang 2005). Common metrics for identifying the MJO include time-longitude plots of anomalous 200-hPa velocity potential (Fig. 4.6) and Outgoing Longwave Radiation (OLR; Fig. 4.7), as well as the Wheeler-Hendon (2004) Real-time Multivariate MJO (RMM) index (Fig. 4.8). In the time-longitude plots, the MJO exhibits eastward propagation from upper-left to lower-right. In the RMM, the MJO propagation and intensity are seen as large, counter-clockwise circles around the origin. When considered together, these diagnostics point to three prolonged MJO episodes during 2019. MJO \#1 was a strong and long-lasting episode that continued from late 2018 (Baxter et al. 2019) through mid-March 2019. MJO \#2 began in mid-April and persisted into early July, while MJO \#3 began in mid-August and lasted through late December. All three MJO periods were associated with either westerly wind bursts (WWBs) or trade wind surges (TWS) over the central Pacific (Fig. 4.9a).

MJO \#1 featured a zonal wave1 pattern of strong convective anomalies. Its periodicity was approximately 30 days during January, slowing to about 45 days during February and March (Figs. 4.6, 4.8a). The plot of anomalous velocity potential (Fig. 4.6) shows that MJO \#1 circumnavigated the globe nearly two times during January-March. The RMM index indicates the event was strongest in late February and early March (Fig. 4.8a). During late March, coherent eastward propagation gave way to a more stationary convective pattern with upperlevel divergence (convergence) centered over the west-central Pacific Ocean (eastern Indian Ocean).

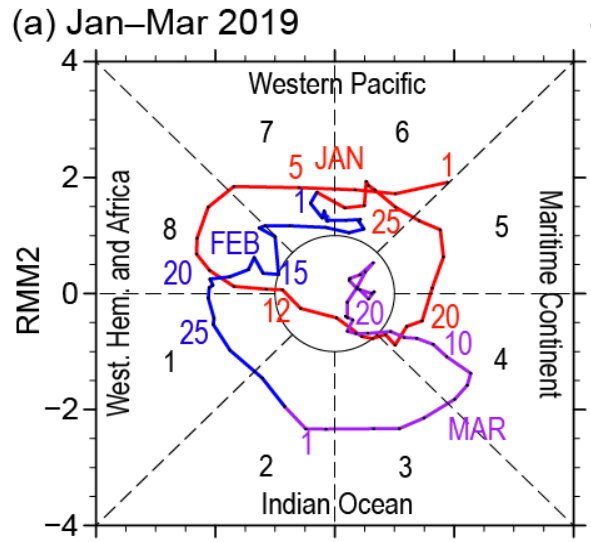

(b) Apr-Jun 2019
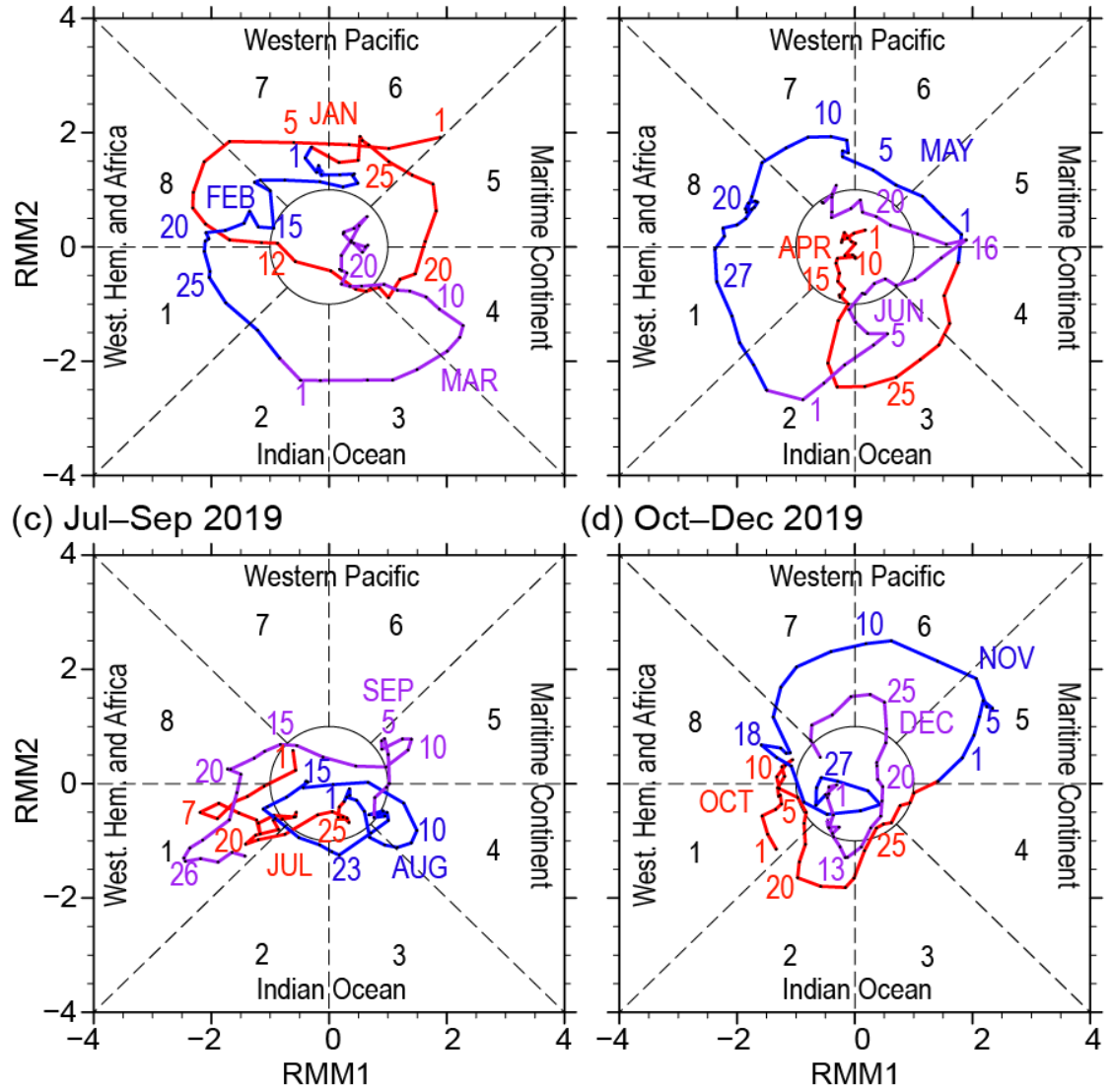

(d) Oct-Dec 2019

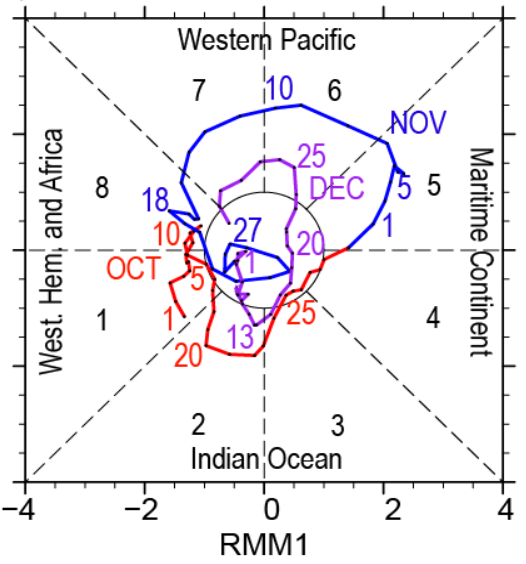

Fig. 4.8. Wheeler-Hendon (2004) Real-time Multivariate MJO (RMM) index for (a) Jan-Mar, (b) Apr-Jun, (c) Jul-Sep, and (d) Oct-Dec 2019. Each point represents the MJO amplitude and location on a given day, and the connecting lines illustrate its propagation. Amplitude is indicated by distance from the origin, with points inside the circle representing weak or no MJO. The eight phases around the origin identify the region experiencing enhanced convection, and counter-clockwise movement is consistent with eastward propagation. 
Impacts from MJO \#1 included notable WWB activity over the equatorial Pacific during January and February (Fig. 4.9a). These WWBs initiated and reinforced the strongest downwelling oceanic Kelvin wave observed in 2019 (dashed line, Fig. 4.9b), which resulted in positive heat content anomalies exceeding $2^{\circ} \mathrm{C}$ in early March. This downwelling wave reached the west coast of South America during April. Prominent TWS were notably absent during early 2019.

MJO \#2 occurred from mid-April to early July. Its periodicity was about 45 days, with nearly canonical eastward propagation throughout its duration. The RMM index showed peak amplitude during mid- to late May (Fig. 4.8b). Eastward propagation broke down during July, giving way to less coherent convective anomalies punctuated by westward-moving equatorial Rossby waves.

MJO \#2 resulted in alternating low-level zonal wind anomalies over the western and central Pacific (Fig. 4.9a) that gave rise to both upwelling and downwelling oceanic Kelvin waves. TWS events in April and June, respectively, resulted in upwelling oceanic Kelvin waves seen as local minima in heat content anomalies (dotted lines, Fig. 4.9b). A WWB in May resulted in a downwelling oceanic Kelvin wave observed between the aforementioned upwelling periods.

The third and final MJO period of 2019 was associated with the emergence of a wave-1 convective pattern in late August. Both the RMM index and velocity potential anomalies reveal relatively slow propagation during mid-September through mid-October, when a westward-moving equatorial Rossby wave (Figs. 4.7, 4.9a) interfered with the overall MJO signal. This interference is seen as a distinct split in the MJO-suppressed phase during late September and early October (Fig. 4.6). A similar split is visible but less prominent in the enhanced MJO phase at the same time. Eastward propagation with a periodicity of nearly 40 days resumed in mid- to late October. MJO

\#3 reached peak amplitude in November (Fig. 4.8) as a very strong suppressed phase propagated across the Indian Ocean (Fig. 4.7). Canonical eastward propagation gave way to a fast-moving atmospheric Kelvin wave in late December.

MJO \#3 resulted in two prominent WWB events and associated downwelling oceanic Kelvin waves in September and November, respectively. The first downwelling wave reached the South American coast in early December. A modest TWS in late October and the resulting upwelling separated the two downwelling waves. MJO \#3 also appears to have played a role in modulating Atlantic hurricane activity. During 4-14 September, no new named storm formations occurred when the MJO was producing enhanced upper-level divergence over the central and eastern Pacific
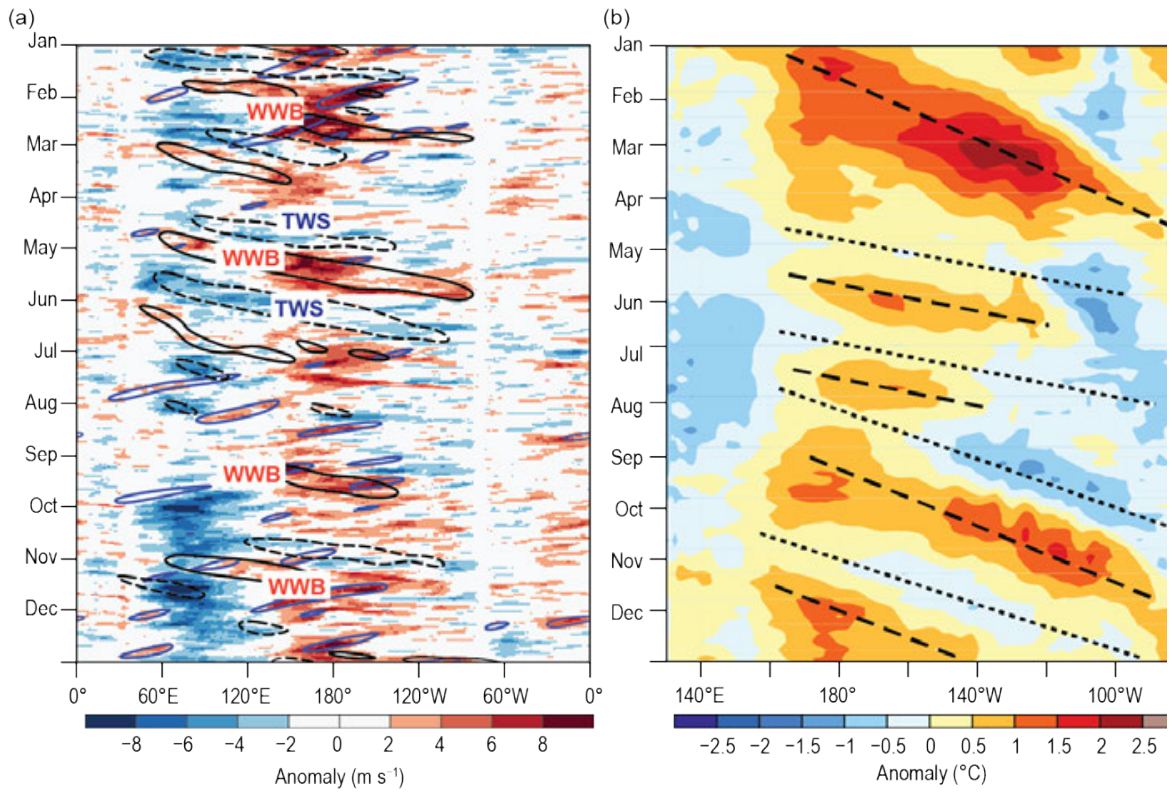

Fig. 4.9. (a) Time-longitude section for 2019 of anomalous 850 -hPa zonal wind $\left(\mathrm{m} \mathrm{s}^{-1}\right)$ averaged between $10^{\circ} \mathrm{N}-10^{\circ} \mathrm{S}$. Contours identify anomalies filtered for the MJO (black), atmospheric Kelvin waves (red), and equatorial Rossby waves (blue). Significant WWB and TWS over the equatorial Pacific that resulted in notable downwelling and upwelling oceanic Kelvin waves are labeled. (b) Time-longitude section for 2019 of the anomalous equatorial Pacific Ocean heat content, calculated as the mean temperature anomaly between $0-300 \mathrm{~m}$ depth. Yellow/red (blue) shading indicates above(below-) average heat content. Relative warming (dashed lines) and cooling (dotted lines) due to downwelling and upwelling equatorial oceanic Kelvin waves are indicated. Anomalies are departures from the 1981-2010 base period pentad means. Data in (b) are derived from an analysis system that assimilates oceanic observations into an oceanic general circulation model (Behringer et al. 1998). 
(Fig. 4.6), a pattern known to increase vertical wind shear over the tropical Atlantic and be unfavorable for tropical cyclogenesis (Klotzbach 2010). In contrast, the MJO likely contributed to enhanced Atlantic TC activity during 14 September-2 October (five Atlantic named storms) and 18-30 October (four Atlantic named storms). In both periods, the suppressed phase of the MJO produced anomalous upper-level convergence over the central equatorial Pacific, a pattern that acts to decrease the vertical wind shear and increase activity over the tropical Atlantic.

\section{d. Intertropical convergence zones \\ 1) Pacific - N. Fauchereau}

Tropical Pacific rainfall patterns are dominated by two convergence zones, the Intertropical Convergence Zone (ITCZ; Schneider et al. 2014) north of the equator and the South Pacific Convergence Zone (SPCZ; Vincent 1994). Figure 4.10 summarizes their combined behavior during 2019 using rainfall estimated from satellite microwave and infrared data in a product known as CMORPH (Joyce et al. 2004). Rainfall transects over $20^{\circ} \mathrm{N}-30^{\circ} \mathrm{S}$ are presented for each quarter of the year, averaged across successive $30^{\circ}$-longitude bands, starting in the western Pacific at $150^{\circ} \mathrm{E}-180^{\circ}$. The 2019 seasonal variation is compared against the 1998-2018 climatology.

From January through March, the positive sea surface temperature (SST) anomalies in the central Pacific were associated with considerable increases in precipitation around the date line. During this time, large departures from normal rainfall were recorded in February just south of the equator (Figs. 4.10a, 4.11a) within the SPCZ. A strongly intensified ITCZ developed in March (Fig. 4.11b). Conversely, well-below-normal rainfall was recorded in the western Pacific and the Maritime Continent in February. Persistent dryness affected many islands within Micronesia during the first quarter of 2019 (PEAC 2019, Pacific ENSO update).

Figure 4.12 shows a more detailed comparison of the western Pacific CMORPH rainfall transect during January-March (JFM) 2019 relative to all other years in the satellite dataset. During JFM, the ITCZ was quite strong, with the most exceptional rainfall anomaliesapproaching and exceeding the largest values in the CMORPH dataset-recorded within the ITCZ in the northern Pacific between $150^{\circ} \mathrm{E}$

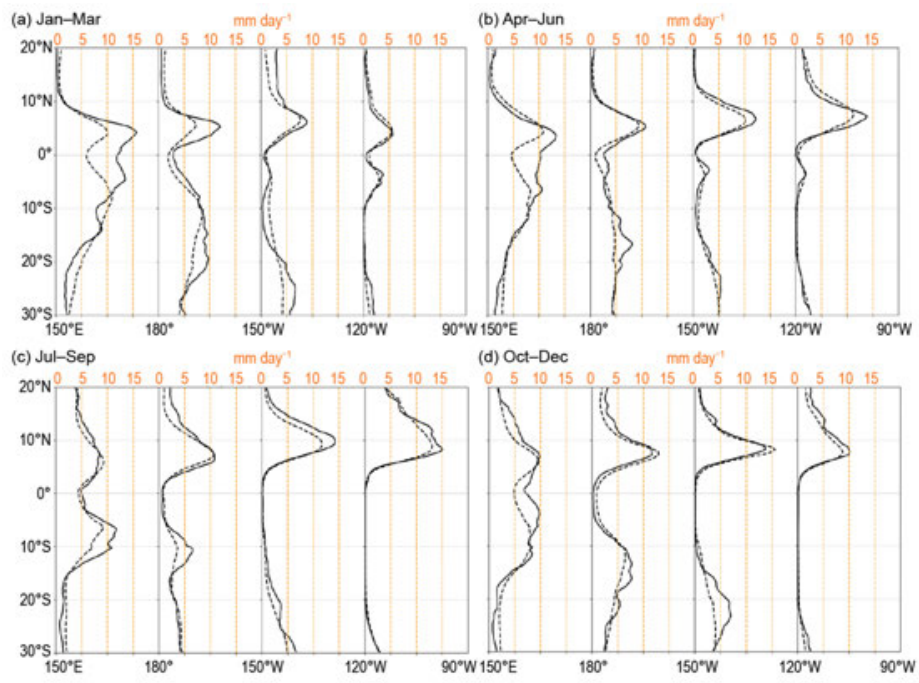

Fig. 4.10. Rainfall rate $\left(\mathrm{mm} \mathrm{day}^{-1}\right)$ from CMORPH analysis for the cross-section between $20^{\circ} \mathrm{N}$ and $30^{\circ} \mathrm{S}$, for (a) Jan-Mar, (b) Apr-Jun, (c) Jul-Sep, and (d) Oct-Dec 2019. Each quarter's panels show the 2019 rainfall (solid line), and the 1998-2018 climatology (dotted line), for four $30^{\circ}$ sectors from $150^{\circ} \mathrm{E}-180^{\circ}$ to $120^{\circ}-90^{\circ} \mathrm{W}$. (Source: $\mathrm{CMORPH}$ [Joyce et al. 2004].)

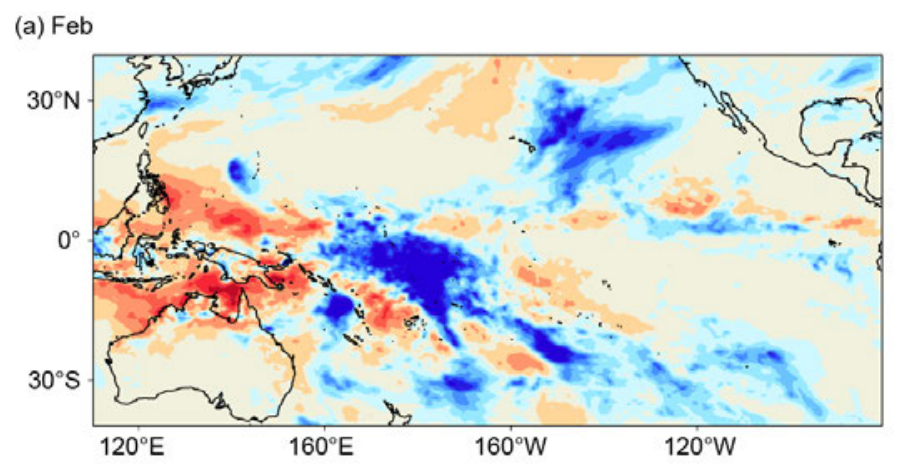

(b) Mar

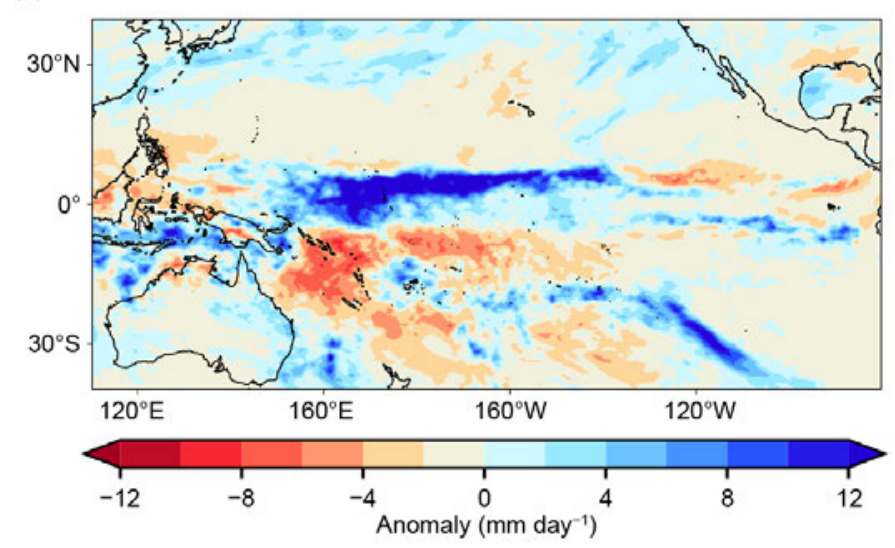

Fig. 4.11. Rainfall anomalies ( $m m^{-1} \mathrm{day}^{-1}$ ) for (a) Feb and (b) Mar 2019. The anomalies are calculated with respect to the 1998-2018 climatology. (Source: CMORPH [Joyce et al. 2004].) 
and $180^{\circ}$. This pattern is atypical of the composite anomalies associated with more canonical El Niño conditions. However, it is consistent with an atmospheric response to positive SST anomalies centered around and west of the date line, noting the amplitude of the rainfall anomalies observed are still somewhat unprecedented.

Rainfall anomalies broadly consistent with weak El Niño conditions persisted until about July, after which most El Niño-Southern Oscillation (ENSO) indicators dipped below El Niño thresholds

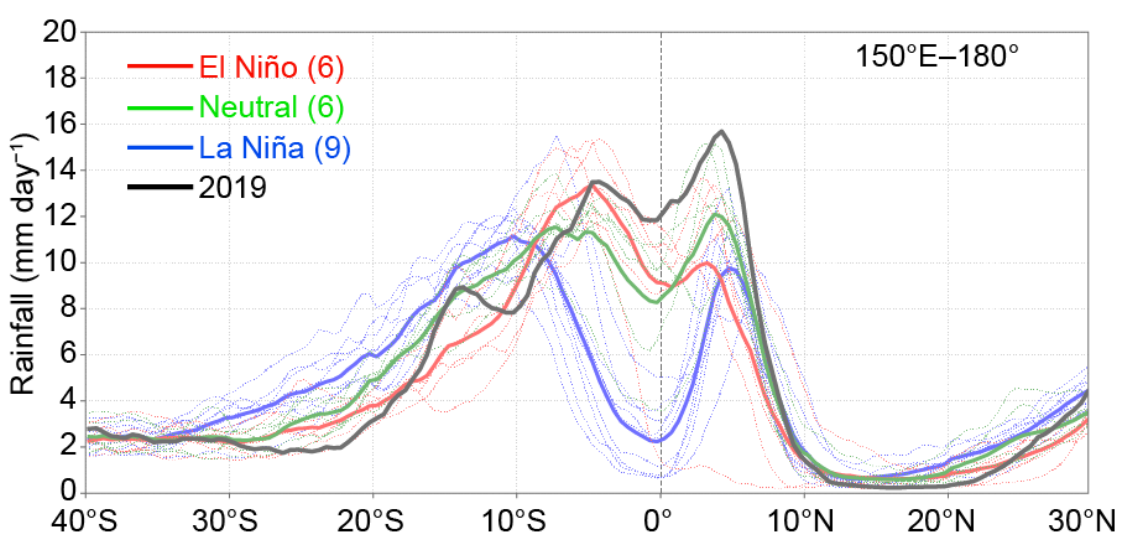

Fig. 4.12. Rainfall rate ( $\mathrm{mm} \mathrm{day}^{-1}$ ) for Jan-Mar, for each year 1998 to 2018, averaged over the longitude sector $150^{\circ} \mathrm{E}-180^{\circ}$. The cross-sections are color-coded according to NOAA's ONI, except 2019, which is shown in black. Dotted lines are individual years, and solid lines are the average over all years in each ENSO phase. Inset legend indicates how many years went into each composite. (Source: CMORPH [Joyce et al. 2004].) and ENSO-neutral conditions took

hold. However, the continued development of a positive Indian Ocean dipole (IOD; one of the strongest on record) influenced rainfall patterns from September through the end of the year, especially in the western Pacific (section 4h). During this period, dry conditions developed and impacted some areas of the western Pacific and Maritime Continent again. At the same time, the ITCZ shifted north of its climatological position in the central and eastern equatorial Pacific east of the date line.

In November 2019, SST anomalies increased in the central and western Pacific. The continuation of positive IOD conditions well into December led to dry conditions forming across parts of the western Pacific and the Maritime Continent. The SPCZ was clearly shifted northeast of its climatological position in the southwest Pacific during December, leading to dry conditions across Papua New Guinea, the Solomon Islands, Vanuatu, and New Caledonia.

\section{2) Atlantic-A. B. Pezza and C. A. S. Coelho}

The Atlantic ITCZ is a well-organized convective band that oscillates between approximately $5^{\circ}-12^{\circ} \mathrm{N}$ during July-November and $5^{\circ} \mathrm{N}-5^{\circ} \mathrm{S}$ during January-May (Waliser and Gautier 1993; Nobre and Shukla 1996). Equatorial atmospheric Kelvin waves can modulate ITCZ intraseasonal variability (Guo et al. 2014). ENSO and the Southern Annular Mode (SAM) can also influence the ITCZ on interannual time scales (Münnich and Neelin 2005). The SAM, also known as the Antarctic Oscillation, describes the north-south movement of the westerly wind belt that circles Antarctica, dominating the middle to higher latitudes of the Southern Hemisphere (SH). The changing position of the westerly wind belt influences the strength and position of cold fronts and midlatitude storm systems. During a positive SAM event, the belt of strong westerly winds contracts toward Antarctica. Conversely, a negative SAM event reflects an expansion of the belt of strong westerly winds towards the equator. The SAM, which was mostly positive in recent years, started to oscillate between predominantly neutral and negative phases in 2019, with negative values developing late in the year (see section $6 \mathrm{~b}$ ). This was consistent with an El Niño-like state in the Pacific, with weak coupling between equatorial Pacific oceanic and atmospheric conditions.

This transition state was associated with an Atlantic ITCZ oscillating around its climatological position. Occasional southern excursions during March and April contributed to positive rainfall anomalies offshore and in some small areas of northeastern Brazil during the first half of the year (Fig. 4.13). These bursts were associated with an anomalously warm Atlantic Ocean south of the equator and a cool North Atlantic during the first half of the year. This SST pattern reverted to a 
(a)

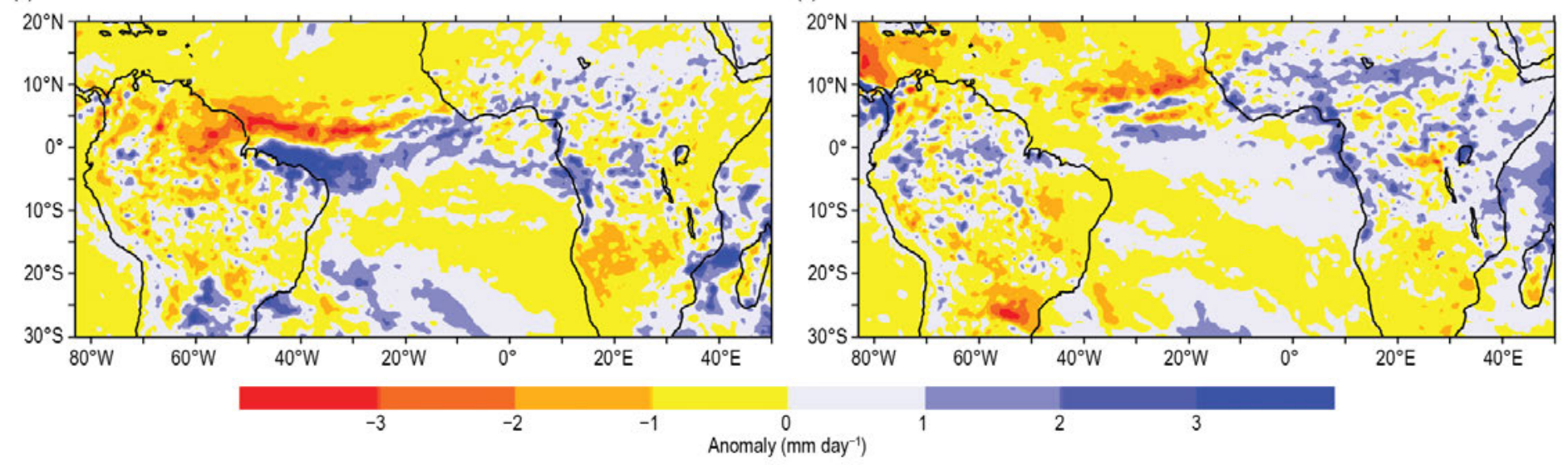

Fig. 4.13. Observed precipitation anomaly for tropical and subtropical South America $\left(\mathrm{mm}^{\mathrm{day}}{ }^{-1}\right)$ during (a) Jan-Jun and (b) Jul-Dec 2019. Anomalies are calculated based on a 1998-2018 climatology. (Source: CMORPH [Joyce et al. 2004].) more neutral set up from June to October, and then re-intensified toward the end of the year.

The Atlantic Index (Pezza and Coelho 2019), as defined by the SST south of the equator minus the SST north of the equator over key areas of influence for the ITCZ, reflects well the role of the north-south gradient mechanism highlighted above for 2019, with the ITCZ tending to shift toward the warmer side of this gradient (Fig. 4.14). A weaker subtropical South Atlantic anticyclone associated with a negative SAM also contributed to re-establish a positive SST anomaly pattern south of the equator toward the end of the year. This pattern resulted in an abrupt increase in the Atlantic Index (Fig. 4.14). This increase is also consistent with possible atmospheric Kelvin wave propagation, although the ITCZ was too far north to be impacted.

\section{e. Global monsoon summary-B. Wang and Q. He}

The global monsoon is the dominant mode of annual tropical-subtropical precipitation and circulation variability and thus a critical part of Earth's climate system (Wang and Ding 2008). Figure 4.15 shows global precipitation anomalies, focusing on monsoon rainfall anomalies, especially over the land monsoon region, for the monsoon seasons in the (a) Southern Hemisphere (SH; November 2018-April 2019) and (b) Northern Hemisphere (NH; May-October 2019), which constitute the global monsoon year of 2018/19. Figure 4.16 shows the time series of monsoon precipitation and low-level circulation indices (Yim et al. 2014) for each of the eight regional monsoons. Note that these precipitation

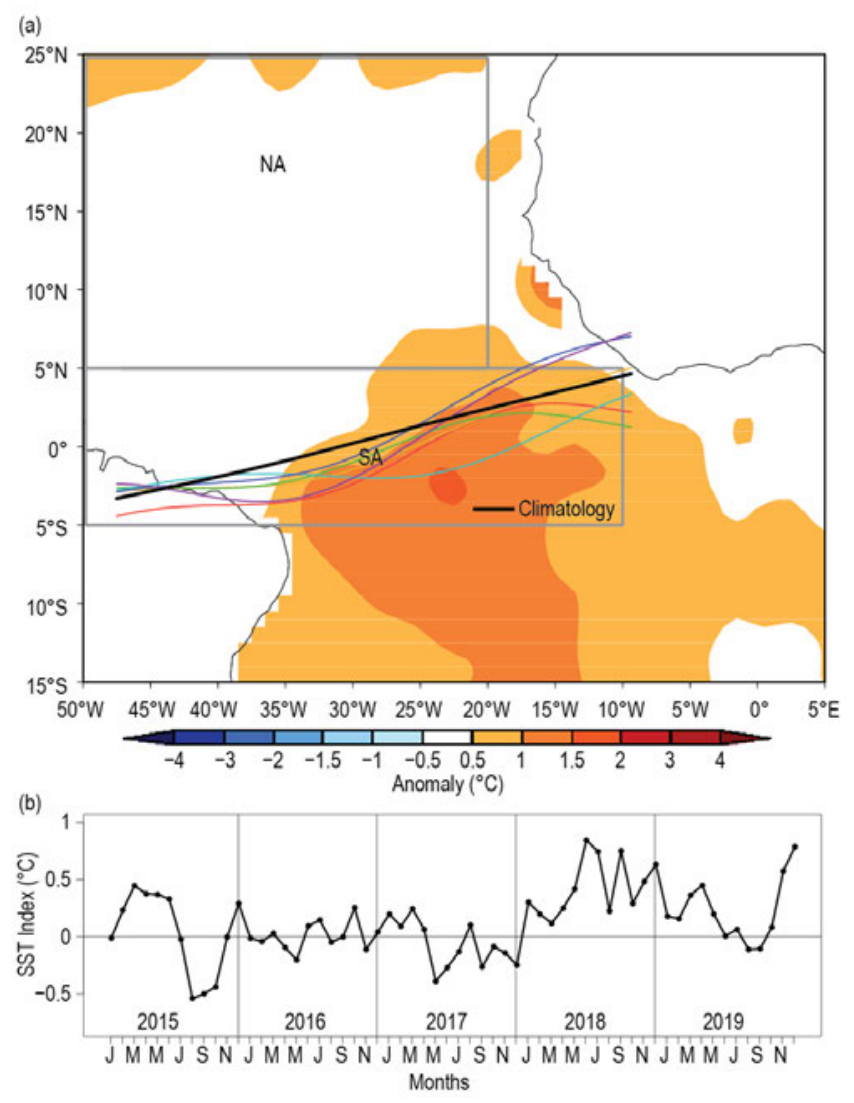

Fig. 4.14. (a) Atlantic ITCZ position inferred from OLR (Liebmann and Smith 1996) during Mar 2019. The colored thin lines indicate the approximate position for the six pentads of the month. The black thick line indicates the climatological position for Mar. SST anomalies for Mar 2019 based on the 1982-2018 climatology are shaded $\left({ }^{\circ} \mathrm{C}\right)$. Boxes indicate areas used to calculate the Atlantic index. (b) Atlantic index for 2015-19, based on monthly OISST (Smith et al. 2008) anomaly time series averaged over the South Atlantic sector (SA box, $10^{\circ}-50^{\circ} \mathrm{W}, 5^{\circ} \mathrm{N}-$ $\left.5^{\circ} \mathrm{S}\right)$ minus the same averaged over the North Atlantic sector (NA box, $20^{\circ}-50^{\circ} \mathrm{W}, 5^{\circ}-25^{\circ} \mathrm{N}$ ). A positive index indicates favorable conditions for enhanced Atlantic ITCZ activity south of the equator. 


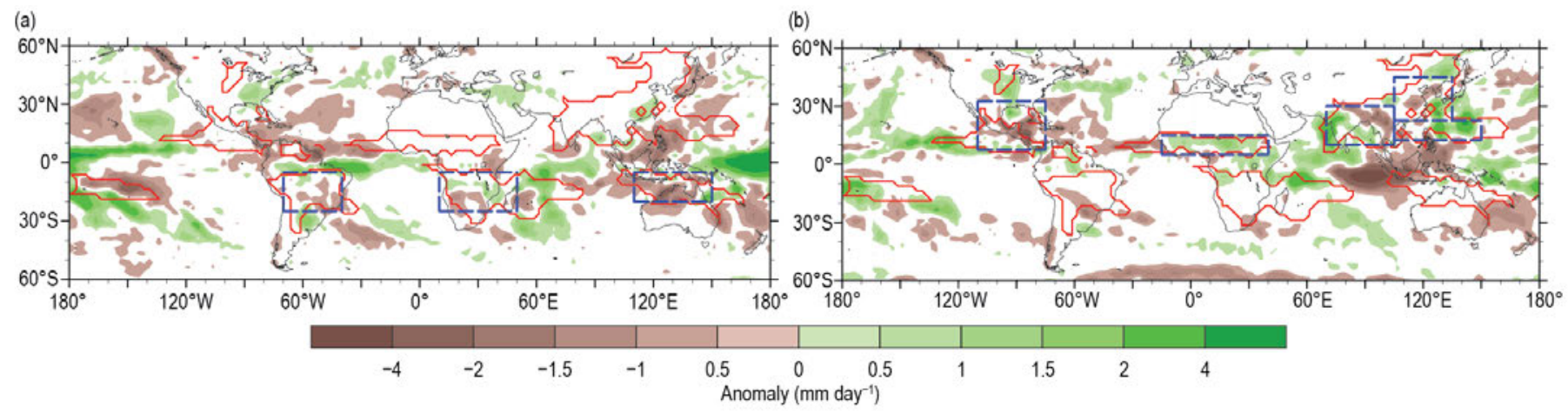

Fig. 4.15. Precipitation anomalies ( $\mathrm{mm} \mathrm{day}^{-1}$ ) averaged for (a) the SH monsoon season: Nov 2018-Apr 2019 and (b) the NH monsoon season: May-Oct 2019. Red lines outline the global monsoon precipitation domain defined by two climatological conditions: first, the local monsoon season precipitation minus that of the cool season exceeds 300 mm and second, the monsoon season precipitation constitutes at least $55 \%$ of the total annual amount (Wang and Ding 2008). Precipitation indices for each regional monsoon are defined by the areal mean precipitation in the corresponding rectangular regions (dashed blue), which are highly correlated with that of the corresponding real regional monsoon domains (Table 4.1). (Source: GPCP [Huffman et al. 2009].)

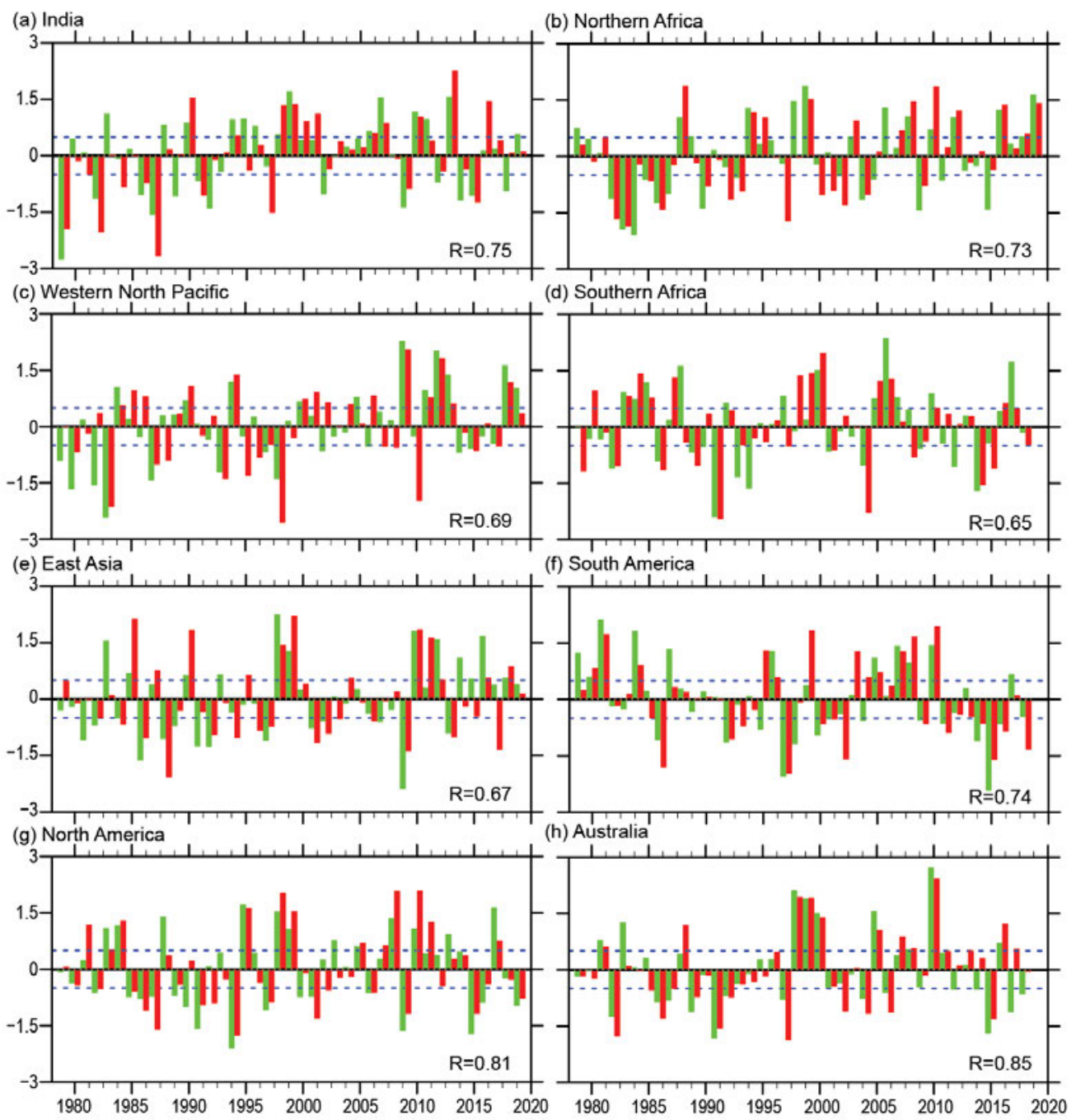

Fig. 4.16. Summer mean precipitation (green) and circulation (red) indices for each of eight regional monsoons defined in Table 4.1, normalized by their corresponding std. dev. In each panel, $\mathrm{R}$ denotes the correlation coefficient between the seasonal mean precipitation and circulation indices (sample size: 40). Dashed lines indicate $\pm 0.5 \mathrm{std}$. dev. The monsoon seasons are May-Oct for the NH and Nov-Apr for the SH. The normalization method is discussed in Yim et al. (2014). (Source: GPCP for precipitation; ERA-5 for circulation.) 
indices represent the average precipitation amount over both land and ocean areas in the boxed regions shown in Fig. 4.16. The definitions of the circulation indices for each monsoon region are provided in Table 4.1. In most regions, the precipitation and circulation indices are well correlated, with correlation coefficients ranging from 0.68 to 0.86 , except for the southern African monsoon. The correlation coefficients in Table 4.1 were computed using monthly mean data from 1979 to 2018 (sample size is 160). The precipitation and circulation indices together provide consistent measurements of the strength of each regional monsoon system.

Global land monsoon precipitation is strongly influenced by tropical sea surface temperature (SST) anomalies, especially those associated with the El Niño-Southern Oscillation (ENSO; Wang et al. 2012). As shown in Fig. 4.15a, during the SH monsoon season, precipitation increased over the central-western Pacific and was suppressed over the Maritime Continent-Australian monsoon region (Fig. 4.15a). This pattern was consistent with the SST anomalies associated with the weak El Niño that occurred from January to July 2019. The South American monsoon was characterized by below-normal precipitation and circulation intensity, especially a significant weakening of the South American monsoon circulation (Fig. 4.16g). The Australian summer monsoon region also received markedly less precipitation than normal, but the strength of the corresponding circulation was near normal (Fig. 4.16h). The southern African summer monsoon precipitation was near normal, but the circulation intensity was below normal (Fig. 4.16f). Overall, the SH summer monsoon was generally below normal with reduced precipitation and monsoon circulation, although the degree of weakening varied in the three SH regional monsoons.

During the NH monsoon season, precipitation over the Maritime Continent was significantly below normal with a prominent reduction of precipitation to the west of Sumatra over the tropical eastern Indian Ocean (Fig. 4.15b). On a regional scale, the northern African monsoon was characterized by above-normal precipitation and circulation intensity, both of which reached $\sim 1.5$ std. dev. (Fig. 4.16e) above normal, indicating a strong monsoon year over northern Africa.

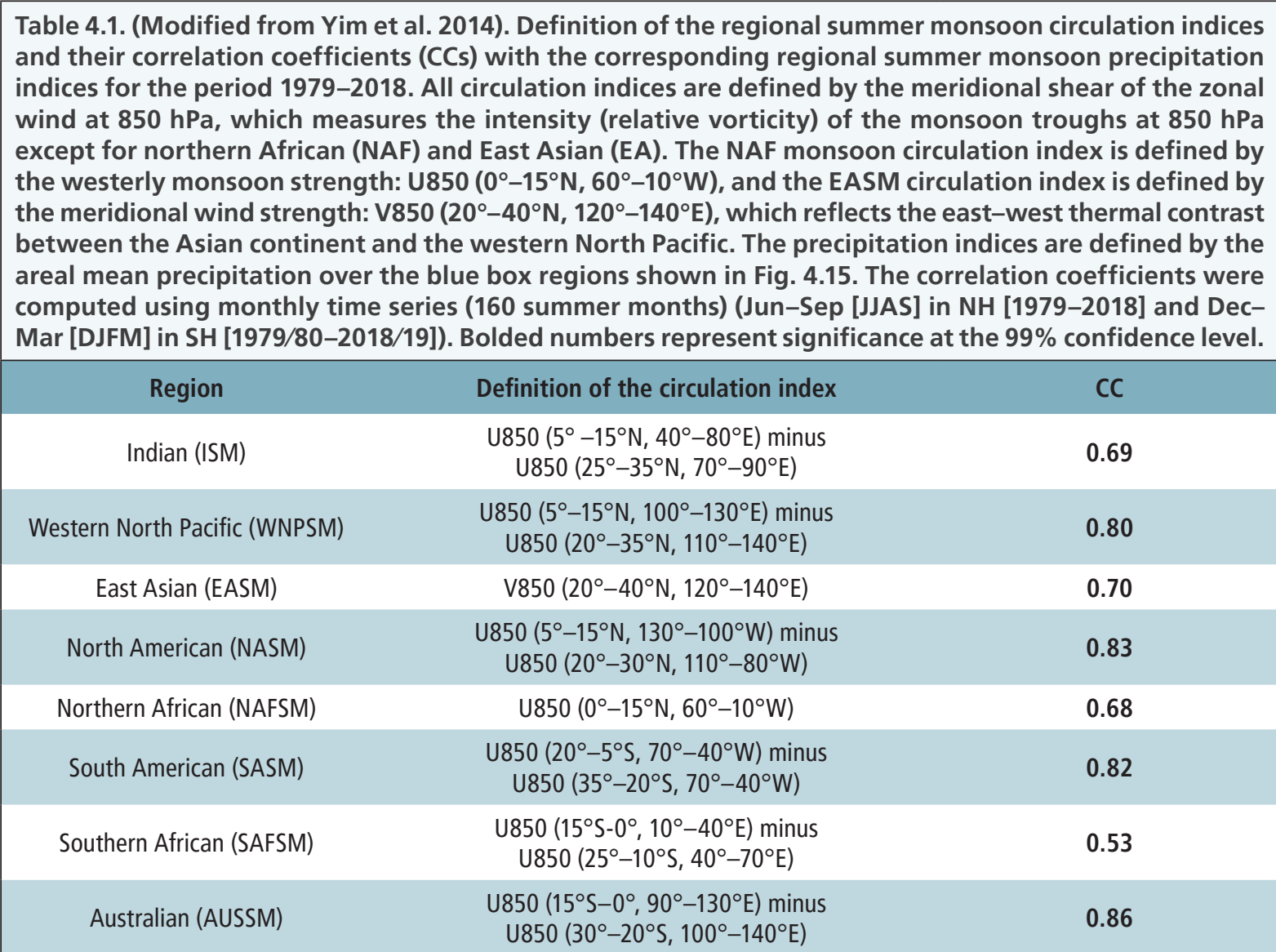


Boreal summer precipitation over India was significantly above normal, but precipitation over Bangladesh and the Indo-China peninsula was below normal. The western North Pacific monsoon precipitation was $\sim 1$ std. dev. above normal (Fig. 4.16b). Both the East Asian summer monsoon rainfall and its circulation were near normal (Fig. 4.16c) with a dipolar pattern: above-normal precipitation over the East China Sea to western Japan and below-normal precipitation along the subtropical frontal zone extending from the middle Yangtze River Valley to the Korean peninsula (Fig. 4.15b). The North American monsoon was characterized by both below-normal precipitation and circulation intensity (Fig. 4.16d). Overall, total monsoon precipitation was above normal in the $\mathrm{NH}$ and below normal in the SH. There was a notable contrast between the Eastern and Western Hemispheres, with increased rainfall over the Eastern Hemisphere tropical monsoon regions and reduced rainfall over those of the Western Hemisphere (e.g., the American monsoon regions).

\section{f. Tropical cyclones}

1) Overview-H. J. Diamond and C. J. Schreck

The IBTrACS dataset comprises historical tropical cyclone (TC) best-track data from numerous sources around the globe, including all of the World Meteorological Organization (WMO) Regional Specialized Meteorological Centers (RSMCs; Knapp et al. 2010). This dataset represents the most complete compilation of global TC data. From these data, Schreck et al. (2014) compiled 1981-2010 climatological values of TC activity for each basin using statistics from both the WMO RSMCs and the Joint Typhoon Warning Center (JTWC). These values are referenced in each subsection.

Tallying the global TC numbers is challenging and involves more than simply adding up basin totals, because some storms cross TC basin boundaries, some TC basins overlap, and multiple agencies track and categorize TCs. Compiling the activity using preliminary IBTrACS data over all seven TC basins from NOAA's National Hurricane Center and the JTWC (Fig. 4.17), the 2019 season (2018/19 in the Southern Hemisphere [SH]) had 96 named storms (sustained wind speeds $\geq 34 \mathrm{kt}$ or 17 $\mathrm{m} \mathrm{s}^{-1}$ ), which is one more than last season (Diamond and Schreck 2019) and above the 1981-2010 average of 82 (Schreck et al. 2014). The 2019 season also featured 53 hurricanes/ typhoons/cyclones (HTC; sustained wind speeds $\geq 64 \mathrm{kt}$ or $33 \mathrm{~m} \mathrm{~s}^{-1}$ ), which is above the climatological average of 46 (Schreck et al. 2014). During the 2019 season, 31 storms reached major HTC status (sustained wind speeds $\geq 96 \mathrm{kt}$ or $49 \mathrm{~m} \mathrm{~s}^{-1}$ ), which is also above the long-term average of 21 and five more than the 2018 season (Diamond and Schreck 2019). All of these metrics were in the top 10\% relative to 1981-2010 (Table 4.2).
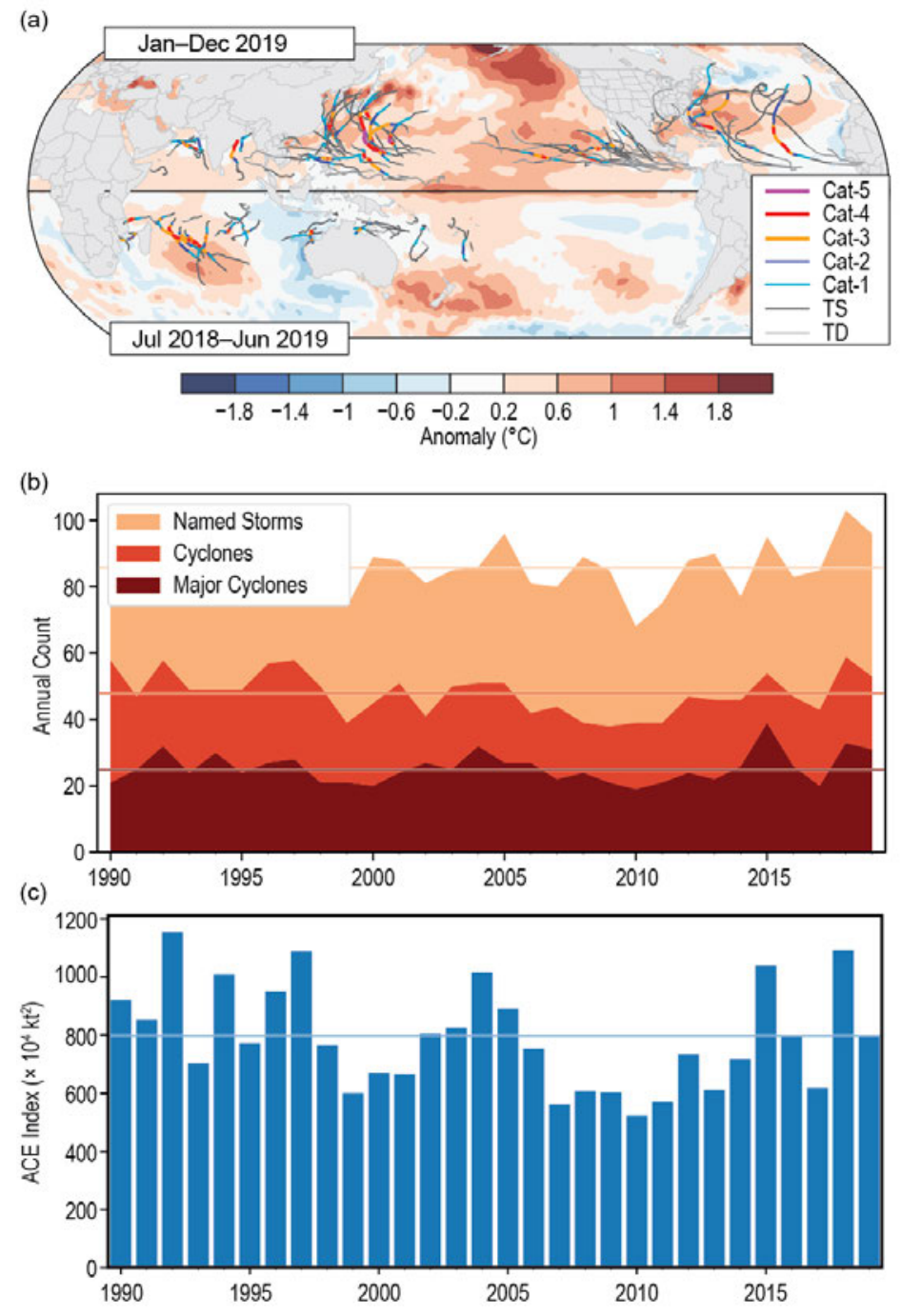

Fig. 4.17. (a) Global summary of TC tracks overlaid on associated OISST anomalies ( ${ }^{\circ} \mathrm{C}$; Reynolds et al. 2002) for the 2019 season relative to 1982-2010; (b) global TC counts; and (c) global ACE values. Horizontal lines on (b) and (c) are 1981-2010 normals. 
In sections 4f2-4f8, 2018/19 and 2019 seasonal TC activity is described and compared to the historical record for each of the seven WMO-defined hurricane basins. For simplicity, all counts are broken down by the U.S. Saffir-Simpson Hurricane Wind Scale (SSHWS). The overall picture of global TCs during 2019 is shown in Fig. 4.17; actual counts by category are documented in Table 4.2.

Globally, five storms during the year reached SSHWS Category 5 strength (sustained wind speeds $\geq 137 \mathrm{kt}$ or 70.5 $\mathrm{m} \mathrm{s}^{-1}$ ). This was one fewer than recorded in 2016 (Diamond and Schreck 2017), equal to the number recorded in 2017 (Diamond and Schreck 2018), and six fewer than the total of 11 recorded in 2018 (Diamond and Schreck 2019). The alltime record of 12 Category 5 global TCs was set in 1997 (Schreck et al. 2014). ${ }^{1}$

The five Category 5 storms were: Super Typhoons Wutip, Hagibis, and Halong in the western North Pacific and Hurricanes Dorian and Lorenzo in the North Atlantic. Dorian caused unprecedented and tremendous devastation, with approximately 70 fatalities reported in the northwest Bahamas and over $\$ 3.4$ billion (U.S. dollars) in damages generated there. Dorian was responsible for six fatalities in Florida and three in North Carolina and caused over \$1 billion (U.S. dollars) in damages in the United States. As a post-tropical cyclone, Dorian also caused considerable damages in Nova Scotia, Canada, with over $\$ 100$ million (U.S. dollars) in damages reported. While Lorenzo was a Category 5 storm for a short period of time, it was more deadly as a post-tropical/ extratropical cyclone. Lorenzo produced tropical storm force winds across portions of Ireland, and was the second deadliest storm of the 2019 North Atlantic season, causing 19 deaths both at sea and along the U.S. coast as a result of high-surf conditions. Sidebar 4.1 details the recordsetting and devastating local impacts of Hurricane Dorian.

2) Atlantic basin-G. D. Bell, E. S. Blake, C. W. Landsea, M. Rosencrans, H. Wang, S. B. Goldenberg, and R. J. Pasch (I) 2019 SEASONAL ACTIVITY

The 2019 Atlantic hurricane season produced 18 named storms, of which six became hurricanes and three achieved major hurricane status (Fig. 4.18a). The HURDAT2 1981-2010 seasonal averages (included in IBTrACS) are 11.8 named storms, 6.4 hurricanes, and 2.7 major hurricanes (Landsea and Franklin 2013). The 2019 seasonal Accumulated Cyclone Energy (ACE) value (Bell et al. 2000) was $134 \%$ of the $1981-2010$ median (which is $92.4 \times 10^{4} \mathrm{kt}^{2}$; Fig. 4.18b), above NOAA's threshold

${ }^{1}$ SSHWS is based on 1-minute averaged winds, and the categories are defined at: https://www.weather.gov/mfl/saffirsimpson; the Australian category scale is based on 10-minute averaged winds, and those categories are defined at: https://australiasevereweather .com/cyclones/tropical_cyclone_intensity_scale.htm 
(120\%) for an above-normal season. The numbers of named storms and major hurricanes were also both above average. Therefore, the 2019 season was designated as above normal by NOAA. This makes 2019 the fourth consecutive above-normal season, tying the record set in 1998-2001. This also marks the 17th above-normal season of the 25 since the current Atlantic high-activity era began in 1995 (Goldenberg et al. 2001; Bell et al. 2019).

The previous high-activity era for which fairly reliable data on TC counts and overall hurricane strengths exist is 1950-70. That period also featured numerous abovenormal seasons (10 out of 21 ), while the intervening low-activity era of 1971-94 had only 2 out of 24 (Bell et al. 2018). Note that the hurricane record is considered far less reliable before 1950, with exact season-toseason comparisons for ACE considered less reliable before the mid-1970s and the start of the geostationary satellite era (Landsea et al. 2006). Given these caveats, the best estimates suggest that the previous highactivity era actually spanned the period from 1926-70 (Goldenberg et al. 2001).

The 18 named storms during 2019 are the sixth highest on record since 1950, while the 2019 ACE value is only the 24th highest in that 69-year record. This disparity is in

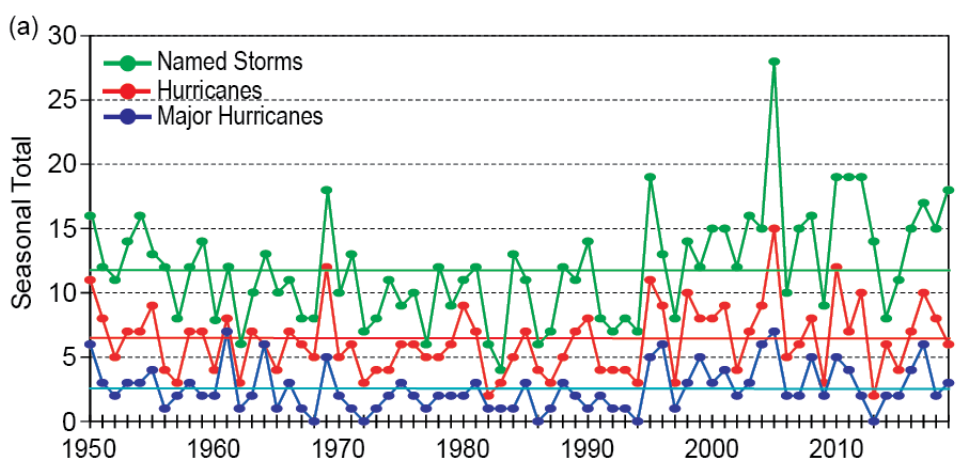

(b)

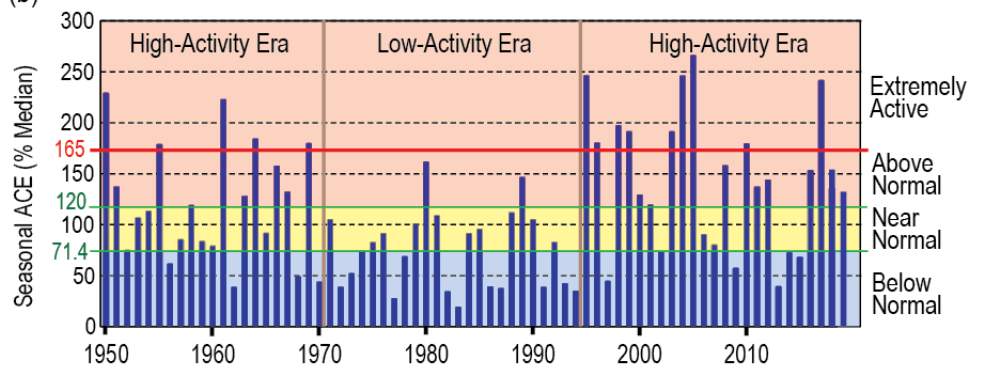

Fig. 4.18. Seasonal Atlantic hurricane activity during 1950-2019. (a) Numbers of named storms (green), hurricanes (red), and major hurricanes (blue); 1981-2010 seasonal means shown by solid colored lines. (b) ACE (Bell et al. 2000) index expressed as percent of the 1981-2010 median value. Red, yellow, and blue shadings correspond to NOAA classifications for above-, near-, and below-normal seasons, respectively (http://www.cpc .ncep.noaa.gov/products/outlooks/background_information .shtml). Thick red horizontal line at $165 \%$ ACE value denotes the threshold for an extremely active season. Vertical brown lines separate high- and low-activity eras. Note: There is a low bias in activity during the 1950 s to the early 1970 s due to the lack of satellite imagery and technique (Dvorak) to interpret TC intensity for systems over the open ocean. (Source: HURDAT2 [Landsea and Franklin 2013] for TC counts.)

part because two storms (Category 5 Hurricanes Dorian and Lorenzo) produced about $60 \%$ of the season's ACE. Meanwhile, eight of the named storms were very short-lived ( $<2$ days). There has been a large artificial increase in these "shorties" since 2000, with seasons averaging about five per year since that time (Landsea et al. 2010). The increased ability to record these storms primarily reflects new observational capabilities such as scatterometers, Advanced Microwave Sounding Units, and the Advanced Dvorak Technique. Villarini et al. (2011) confirmed the lack of association of the shorties' time series with any known climate variability.

\section{(II) STORM FORMATION REGIONS AND LANDFALLS}

The vast majority of Atlantic TCs typically form during the peak months (August-October, ASO) of the hurricane season. During 2019, 15 of the 18 named storms, five of the six hurricanes, and all three major hurricanes formed during ASO.

Historically, the primary cause for an above-normal season is a sharp increase in activity associated with storms that form within the Main Development Region (MDR), which spans the tropical Atlantic Ocean and Caribbean Sea between $9.5^{\circ} \mathrm{N}$ and $21.5^{\circ} \mathrm{N}$ (Goldenberg and Shapiro 1996; Goldenberg et al. 2001; Bell and Chelliah 2006; Bell et al. 2017, 2018, 2019). For above-normal seasons during 1981-2010, the ACE value associated with storms first named in the MDR averaged $155 \%$ of the median (Fig. 4.19a), compared to only 15.8\% during below-normal seasons. During 2019, the MDR-related ACE value was $101 \%$ of the median. 
The nearly tenfold increase in ACE that occurs on average during above-normal seasons reflects the fact that far more MDR-initiated storms eventually become hurricanes (6.4 compared to 1.0) and major hurricanes (4.4 compared to 0.4). These differences not only reflect a nearly four-fold increase in the number of named storms that form within the MDR during above-normal seasons (9.3 compared to 2.5), but also a significantly higher percentage of those storms that become hurricanes (72\% compared to 39\%) and major hurricanes (44\% compared to $17 \%$; Fig. 4.19b). These results are consistent with those of Goldenberg et al. (2001), who noted a five-fold increase in the number of Caribbean hurricanes for high- versus low-activity eras. During 2019, six named storms formed within the MDR, with three (50\%) eventually becoming hurricanes and two (33\%) eventually becoming major hurricanes. Thus, the MDR-related activity during 2019 was relatively modest for an above-normal season in the entire basin, and no Caribbean hurricanes were recorded.

Two-thirds (67\%) of the named storms during 2019 formed outside of the MDR, which is a far higher percentage than the 1981-2010 average of $42 \%$ for above-normal seasons. (a)

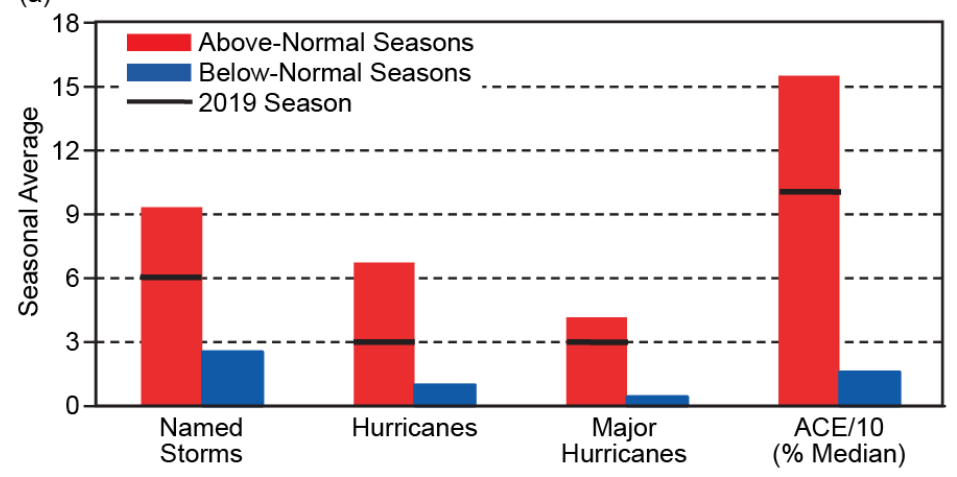

(b) 80

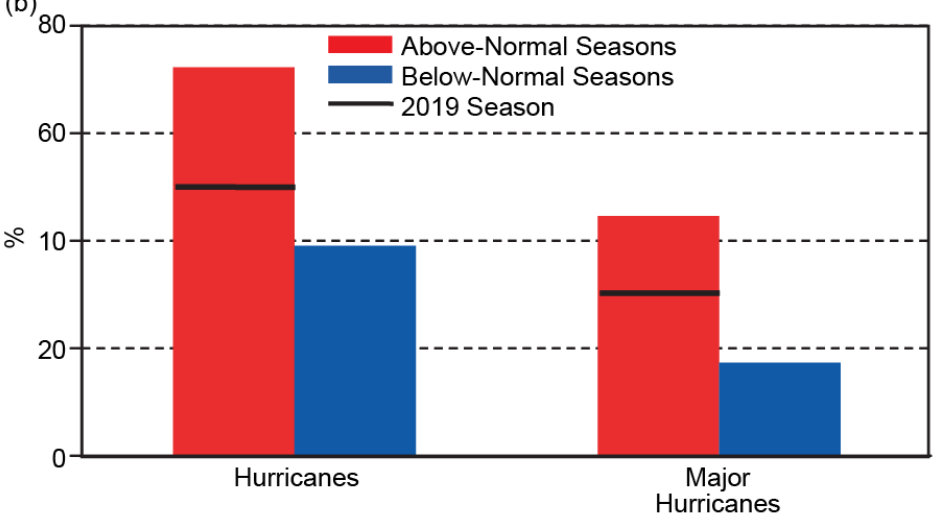

Fig. 4.19. (a) Seasonal averages of specified storm metrics during 1981-2010 associated with named storms initiated within the MDR. (b) Percentage of MDR-initiated named storms during 1981-2010 that eventually became hurricanes (left) and major hurricanes (right). Red (blue) bars show results for above-normal (below-normal) seasons. (Source: HURDAT2 [Landsea and Franklin 2013].)

Five of those storms during 2019 formed over the Gulf of Mexico, tying a record with 2003 and 1957 for the most storms to form in that region. The other seven named storms (including one hurricane) during 2019 formed over the North Atlantic north of the MDR, with all but one tropical storm forming over the western North Atlantic (west of $55^{\circ} \mathrm{W}$ and north of $21.5^{\circ} \mathrm{N}$ ). A relatively high level of TC formation (six named storms including two hurricanes) also occurred over the western North Atlantic in 2018 (Bell et al. 2019).

Regarding landfalls, the most significant landfalling storm of the 2019 Atlantic hurricane season was Major Hurricane Dorian, which stalled over Abaco Island and Grand Bahama Island in the northwest Bahamas during 1-2 September. Dorian spent much of this period at Category 5 intensity, resulting in widespread destruction and death. Dorian tied the Labor Day 1935 hurricane for the strongest on record to make landfall (based on maximum wind speed) anywhere in the Atlantic basin. While the intensity of Dorian was continually observed via satellite and extensively measured by numerous NOAA and Air Force Reserve aircraft reconnaissance flights, the intensity of the 1935 Labor Day storm was only approximated based on a reading from a single land-based barometer, and the estimated maximum surface wind speed was derived using pressure-wind relationships from that one observation.

By 6 September, Dorian weakened to a Category 1 hurricane and made landfall in North Carolina. Two other storms also made landfall in the United States during 2019. These storms were Barry, which made landfall as a Category 1 hurricane in Louisiana on 13 July, and Tropical Storm Imelda, which made landfall in Texas on 17 September. 


\section{(III) SEA SURFACE TEMPERATURES}

The MDR sea surface temperatures (SSTs) were above average with an area-averaged SST anomaly of $+0.40^{\circ} \mathrm{C}$ (Fig. $4.20 \mathrm{~b}$ ). Most locations had departures between $+0.25^{\circ} \mathrm{C}$ and $+0.50^{\circ} \mathrm{C}$. However, this anomaly was only slightly higher (by $0.1^{\circ} \mathrm{C}$ ) than the remainder of the global tropics (Fig. 4.20c).

On multi-decadal time scales, the presence of higher SST anomalies in the MDR compared to the global tropics typifies the warm phase of the Atlantic Multidecadal Oscillation (AMO; Enfield and Mestas-Nuñez 1999; Bell and Chelliah 2006) and is characteristic of Atlantic high-activity eras such as 1950-70 and 1995-present (Goldenberg et al. 2001; Vecchi and Soden 2007; Bell et al. 2018). On interannual time scales, large fluctuations in the relative anomalous warmth of the MDR can also be seen. This variability can have nothing to do with the AMO itself and instead reflect factors such as fluctuations in the wind patterns across the MDR, El Niño-Southern Oscillation (ENSO), the Pacific-Decadal Oscillation, and Indian Ocean SST variability. During ASO 2019, area-averaged SSTs in both the tropical Indian and tropical Pacific Oceans were the second highest (anomalies were $+0.73^{\circ} \mathrm{C}$ and $+0.50^{\circ} \mathrm{C}$, respectively) in the $1950-2019$ record. The reduction in the relative anomalous MDR warmth, especially when compared to most years since 1995, reflected these conditions and should not be interpreted as an indicator that the warm AMO phase has ended.

Another important SST signal during ASO reflected above-average SSTs in the western North Atlantic (red box, Fig. 4.20a), where six TCs formed. The area-averaged SST anomaly in this region $\left(+0.60^{\circ} \mathrm{C}\right)$ indicates a continuation of exceptional warmth in that area that began in 2014 (Fig. 4.20d).

\section{(IV) ATMOSPHERIC CONDITIONS}

Consistent with the ongoing high-activity era for Atlantic hurricanes, an interrelated set of conditions during ASO 2019 favored increased TC activity in the
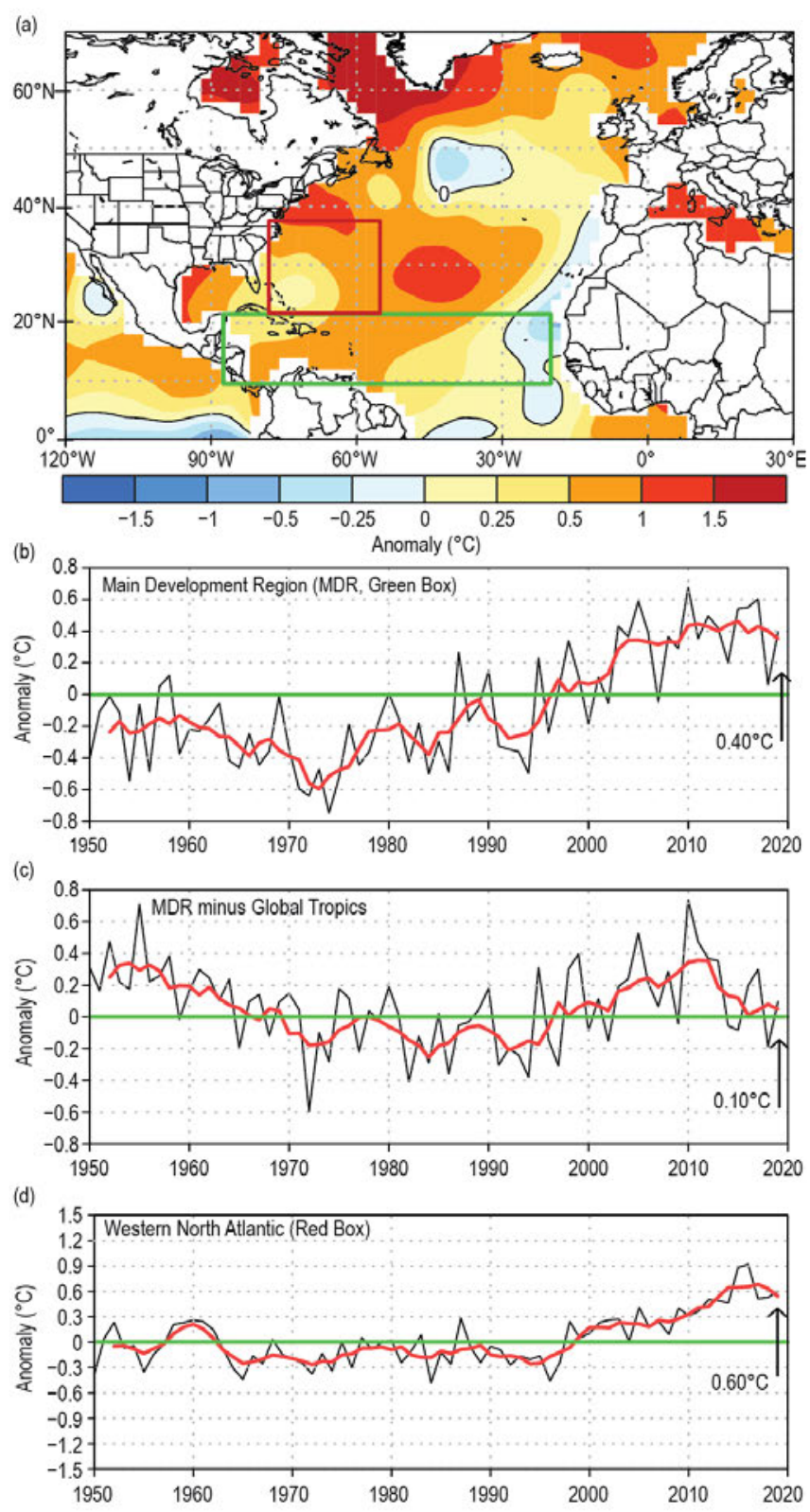

Fig. 4.20. (a) Aug-Oct (ASO) $2019 \mathrm{SST}$ anomalies $\left({ }^{\circ} \mathrm{C}\right)$. (b)-(d) Time series of ASO area-averaged SST anomalies (black) and 5-point running mean of the time series (red): (b) in the MDR (green box in (a), spanning $20^{\circ}-87.5^{\circ} \mathrm{W}$ and $9.5^{\circ}-21.5^{\circ} \mathrm{N}$ ), (c) difference between the MDR and the global Tropics $\left(20^{\circ} \mathrm{N}-20^{\circ} \mathrm{S}\right)$, and (d) in the western North Atlantic (red box in (a), spanning $55^{\circ}-77.5^{\circ} \mathrm{W}$ and $21.5^{\circ}-37.5^{\circ} \mathrm{N}$ ). Anomalies are departures from the 1981-2010 period means. (Source: ERSST-v5 [Huang et al. 2017].)

MDR even if that region was relatively quiet in 2019. These included upper tropospheric anticyclonic streamfunction anomalies across the subtropical North Atlantic, in association with an enhanced subtropical ridge (Fig. 4.21a). A similar anomaly pattern was present across the subtropical South Atlantic Ocean. This pronounced inter-hemispheric symmetry of the anticyclonic anomalies is typical of an enhanced West African monsoon system (Bell and Chelliah 2006), which is the JuneSeptember portion of the North African monsoon.

During 2019, these conditions were associated with upper-level easterly wind anomalies across the MDR and lower-level westerly wind anomalies over the eastern half of the MDR (Fig. 4.21b). This 
overall pattern resulted in anomalously weak vertical wind shear across the MDR (Figs. 4.22a,b). The area-averaged magnitude of the vertical wind shear within the MDR was $7.0 \mathrm{~m} \mathrm{~s}^{-1}$ (Fig. 4.22c), which is below the $8 \mathrm{~m} \mathrm{~s}^{-1}$ threshold considered conducive to hurricane formation on a monthly time scale (Bell et al. 2017).

Over the eastern half of the MDR, the lower-level westerly wind anomalies reflected weaker easterly trade winds (Fig. 4.21b). These anomalies extended upward to at least the 700-hPa level (Fig. 4.21c), the approximate level of the African Easterly Jet (AEJ). This contributed to a deep layer of anomalous cyclonic relative vorticity (i.e., increased horizontal cyclonic shear) along the equatorward flank of the AEJ. These conditions are known to favor increased TC activity within the MDR by helping African easterly waves to be better maintained and by providing an inherent cyclonic rotation to their embedded convective cells (Bell et al. 2004, 2006, 2017, 2018).

All of the above conditions are typical of an enhanced West African monsoon system (Gray 1990; Hastenrath 1990; Landsea et al. 1992; Bell and Chelliah 2006; Bell et al. 2018). The strength of that monsoon is a major factor contributing to observed multidecadal fluctuations in Atlantic hurricane activity because it directly impacts atmospheric conditions and TC formation and intensification within the MDR. During August-September, one indicator of the enhanced monsoon was an extensive area of anomalous 200-hPa divergence across western Africa, with an associated core of negative velocity potential anomalies (Fig. 4.23a). Another indicator was enhanced convection (shown by negative Outgoing Longwave Radiation [OLR] anomalies) in the African Sahel region (red box, Fig. 4.23b). During August-September, OLR values in this region averaged $237 \mathrm{~W} \mathrm{~m}^{-2}$ (Fig. 4.23c). Values below $240 \mathrm{~W} \mathrm{~m}^{-2}$ indicate deep tropical convection. These values are typical of the current high-activity era, whereas OLR values generally above $240 \mathrm{~W} \mathrm{~m}^{-2}$ (indicating a weaker monsoon) were typical of the low-activity period of the 1980s and early 1990s. These multidecadal fluctuations in monsoon strength coincide with opposing phases (warm and cold, respectively) of the AMO.
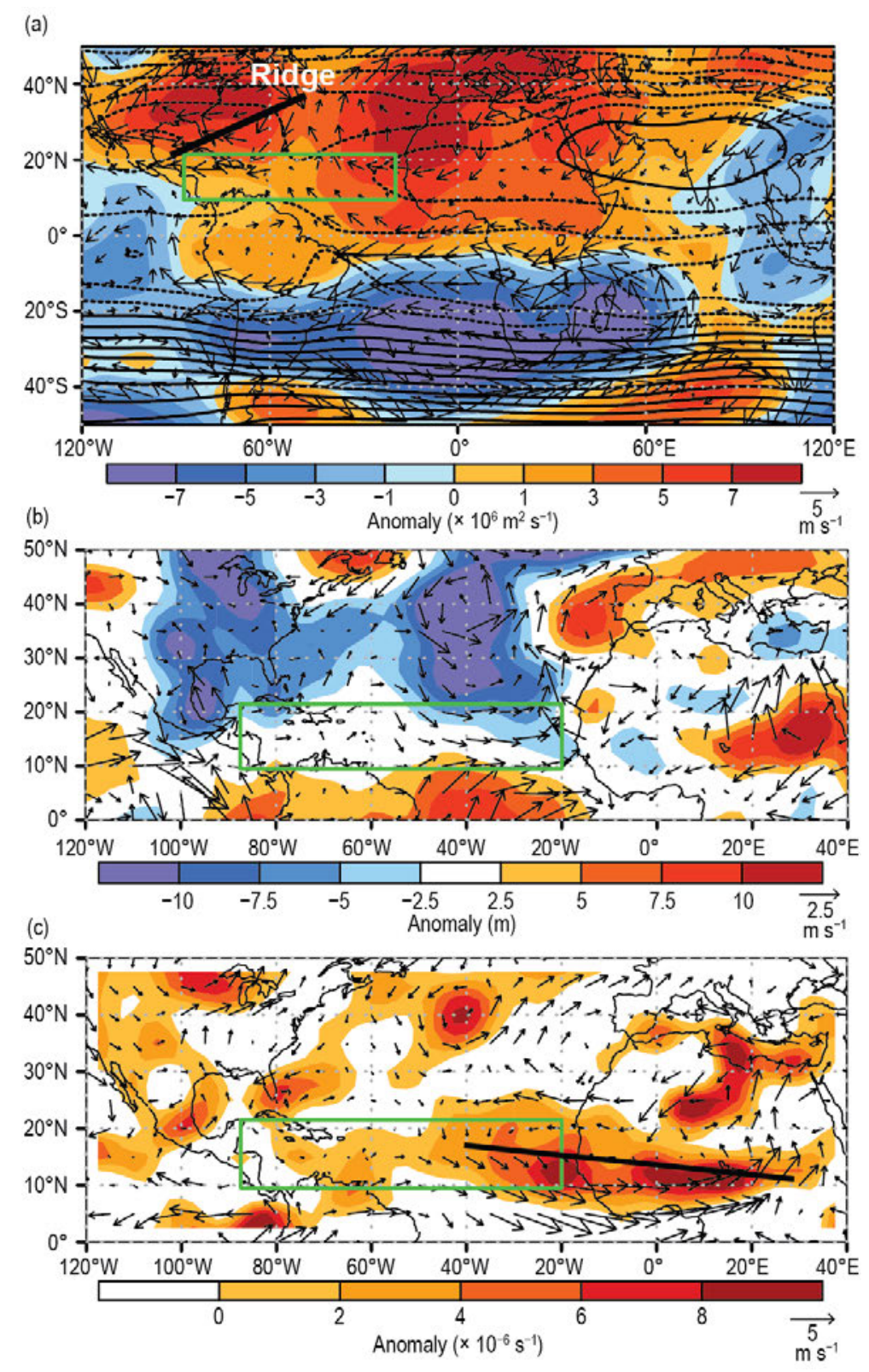

Fig. 4.21. Aug-Oct 2019: (a) 200-hPa streamfunction (contours, interval is $5 \times 10^{6} \mathrm{~m}^{2} \mathrm{~s}^{-1}$ ) and anomalies (shaded), and anomalous vector winds $\left(\mathrm{m} \mathrm{s}^{-1}\right)$; (b) anomalous 1000-hPa heights (shaded, $\mathrm{m}$ ) and vector winds; and (c) anomalous $700-\mathrm{hPa}$ cyclonic relative vorticity (shaded, $\times 10^{-6} \mathrm{~s}^{-1}$ ) and vector winds. In (a), the upperlevel ridge discussed in the text is labeled and denoted by the thick black line. In (c), the thick solid line indicates the axis of the mean African Easterly Jet, hand-drawn based on total seasonal wind speeds (not shown). Vector scales differ for each panel, and are below right of the color bar. The green box denotes the MDR. Anomalies are departures from the 1981-2010 means. (Source: NCEP-NCAR reanalysis [Kalnay et al. 1996].) 

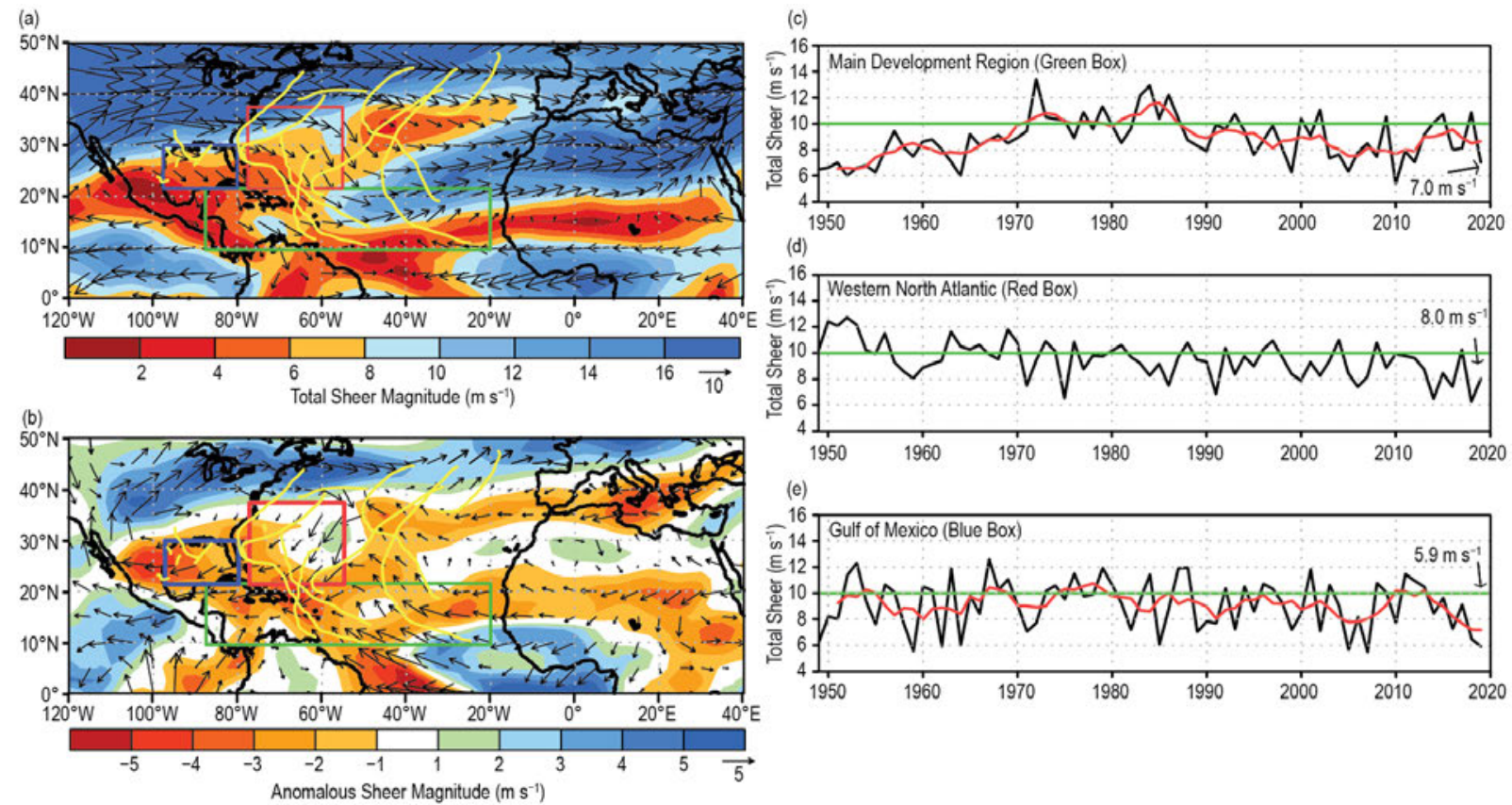

Fig. 4.22. Aug-Oct (ASO) magnitude of the 200-850-hPa vertical wind shear ( $\mathrm{ms}^{-1}$ ): (a) 2019 total magnitude and vector and (b) 2019 anomalous magnitude and vector versus 1981-2010 means. (c)-(e) Time series of ASO vertical shear magnitude (black) and 5-point running mean of the time series (red) averaged over (c) the MDR (green box in (a), (b) spanning $87.5^{\circ}-20^{\circ} \mathrm{W}$ and 9.5 $-21.5^{\circ} \mathrm{N}$ ); (d) the western North Atlantic (red box in (a), (b) spanning $77.5^{\circ}-55^{\circ} \mathrm{W}$ and $21.5^{\circ}-37.5^{\circ} \mathrm{N}$ ); and (e) the Gulf of Mexico (blue box in (a), (b) spanning $97.5^{\circ}-80^{\circ} \mathrm{W}$ and $21.5^{\circ}-30^{\circ} \mathrm{N}$ ). In (a) and (b), 2019 TC tracks (yellow lines) are shown and vector scale $\left(\mathrm{m} \mathrm{s}^{-1}\right)$ is below right of color bar. (Source: NCEP-NCAR reanalysis [Kalnay et al. 1996].)
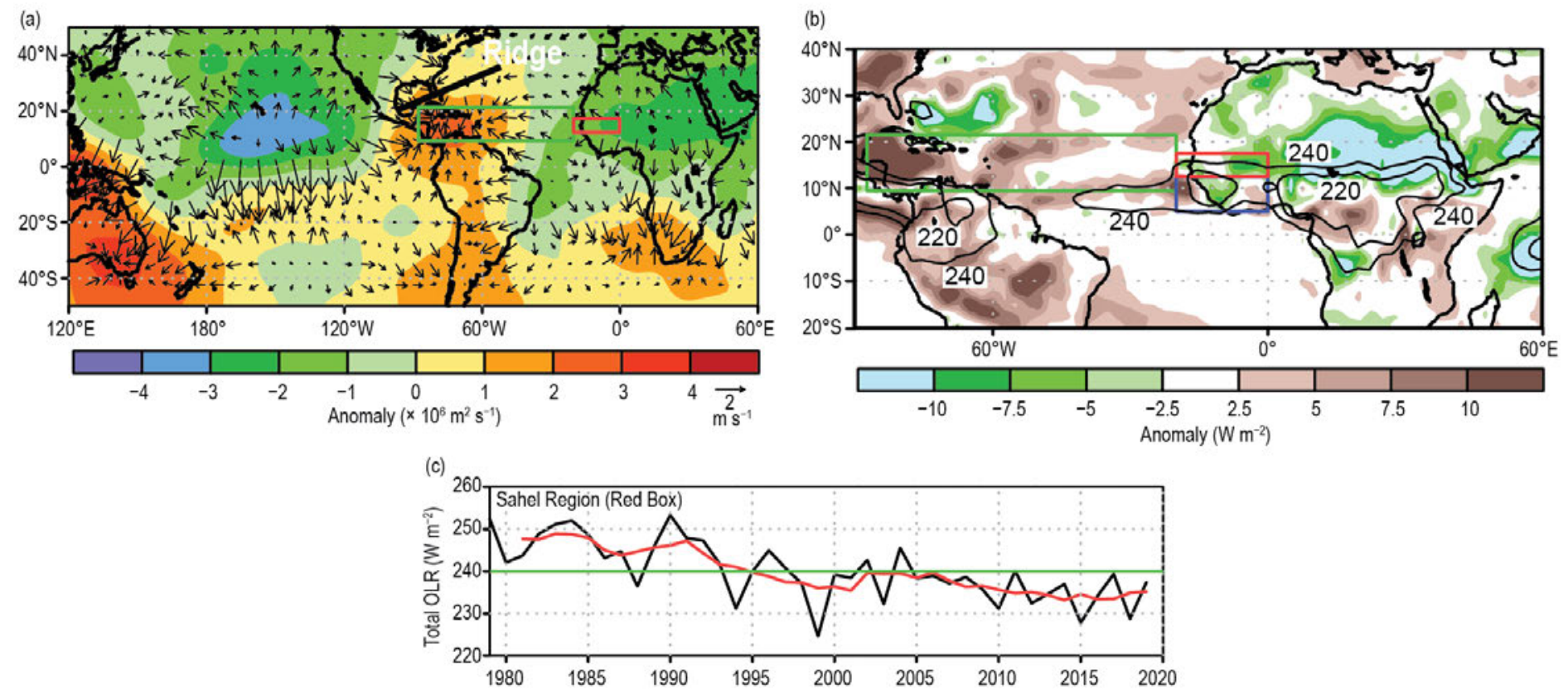

Fig. 4.23. (a) Aug-Sep 2019 anomalous 200-hPa velocity potential $\left(\times 10^{6} \mathrm{~m}^{2} \mathrm{~s}^{-1}\right)$ and divergent wind vectors $\left(\mathrm{m} \mathrm{s}^{-1}\right)$. (b) Aug-Sep 2019 anomalous OLR $\left(\mathrm{W} \mathrm{m}^{-2}\right)$, with negative (positive) values indicating enhanced (suppressed) convection. (c) Time series of Aug-Sep total OLR (black) and 5-point running mean of the time series (red) averaged over the African Sahel region (red box in (a) and (b) spanning $20^{\circ} \mathrm{W}-0^{\circ}$ and $12.5^{\circ}-17.5^{\circ} \mathrm{N}$ ). In (a) the upper-level ridge discussed in the text is labeled and denoted by the thick black line. In (b), contours show total OLR values of $220 \mathrm{~W} \mathrm{~m}^{-2}$ and $240 \mathrm{~W} \mathrm{~m}^{-2}$. In (a) and (b), the green box denotes the MDR. Anomalies are departures from the 1981-2010 means. (Source: NCEP-NCAR reanalysis [Kalnay et al. 1996] for velocity potential and wind.) 


\section{SIDEBAR 4.1: Hurricane Dorian: A devastating hurricane for the northwest Bahamas-}

\section{P. J. KLOTZBACH AND R. E. TRUCHELUT}

The 2019 Atlantic hurricane season ended up slightly above normal for most tropical cyclone (TC) parameters, with a total of 18 named storms, six hurricanes, and three major hurricanes occurring. By far, the most significant and devastating hurricane of the 2019 season was Hurricane Dorian. Dorian will be most remembered for the devastation that it caused in the northwest Bahamas, especially on the Abaco Islands and on Grand Bahama Island. It was also the longest-lived (14 days as a named storm and 10 days as a hurricane) and most intense (1-minute maximum sustained winds of $160 \mathrm{kt}\left(82 \mathrm{~ms}^{-1}\right)$ hurricane of the 2019 season (Avila et al. 2020). Dorian also generated the most Accumulated Cyclone Energy (ACE) of any Atlantic hurricane, accounting for $\sim 40 \%$ of basinwide ACE accrued in 2019. This sidebar summarizes the meteorological history of Dorian along with the notable records that the hurricane achieved during its track across the Atlantic. Historical landfall records from 1851present are taken from the National Hurricane Center/Atlantic Oceanographic and Meteorological Laboratory archive located at: http://www.aoml.noaa.gov/hrd/hurdat/All_U.S._Hurricanes. html, and Dorian's observed values are taken from Avila et al (2020).

Dorian became a tropical depression (TD) on 24 August in the central tropical Atlantic and was upgraded to a tropical storm (TS) shortly thereafter (Fig. SB4.1). Despite moving through an environment of relatively low wind shear and a warm sea surface $\left(28^{\circ}-29^{\circ} \mathrm{C}\right)$, considerable mid-level dry air inhibited Dorian's intensification early in its lifetime. Dorian passed through the Windward Islands on 27 August as a TS. Dorian's center reformed farther north after interacting with Saint Lucia, and its center also reformed downshear (i.e., to the east) due to moderate westerly shear. This northeastward shift in track from where the models were originally forecasting the storm allowed it to avoid the elevated terrain of Hispaniola and Puerto Rico, which would have likely weakened the storm. It then turned northwestward and intensified as it moved into a more moisture-rich environment. Dorian became a hurricane as it tracked over Saint Croix on 28 August and reached major hurricane intensity on 30 August as it approached the Bahamas.
From 0600 UTC on 30 August to 1800 UTC on 31 August, Dorian underwent rapid intensification from $90 \mathrm{kt}\left(46 \mathrm{~m} \mathrm{~s}^{-1}\right)$ to $130 \mathrm{kt}$ $\left(67 \mathrm{~m} \mathrm{~s}^{-1}\right)$ with 24-hour intensification rates ranging between $30 \mathrm{kt}\left(15 \mathrm{~ms}^{-1}\right)$ and $35 \mathrm{kt}\left(18 \mathrm{~ms}^{-1}\right)$. Dorian slowed as it approached the northwest Bahamas, then underwent another burst of rapid intensification, becoming a Category 5 hurricane as it approached Great Abaco Island.

Soon thereafter, Dorian reached its maximum intensity of $160 \mathrm{kt}\left(82 \mathrm{~m} \mathrm{~s}^{-1}\right)$ as it made landfall on Great Abaco Island on 1 September. In doing so, Dorian became the strongest hurricane on record to make landfall in the Bahamas and tied with the Labor Day Hurricane of 1935 for the strongest landfalling hurricane on record anywhere in the Atlantic basin. The $160 \mathrm{kt}\left(82 \mathrm{~m} \mathrm{~s}^{-1}\right)$ intensity achieved by Dorian was also the strongest on record by any Atlantic hurricane outside of the tropics $\left(>23.5^{\circ} \mathrm{N}\right)$ in the satellite era (since 1966). Dorian tracked slowly over Great Abaco as the steering currents collapsed, and the system effectively stalled after making landfall on Grand Bahama Island with maximum sustained winds of $155 \mathrm{kt}\left(80 \mathrm{~m} \mathrm{~s}^{-1}\right.$ ) (Fig. SB4.2). Dorian was the first Category 5 hurricane on record to make landfall on Grand Bahama Island. Its extremely slow forward movement caused devastating wind, rain, and storm surge impacts over these islands. During its first 24 hours over Grand Bahama Island, Dorian

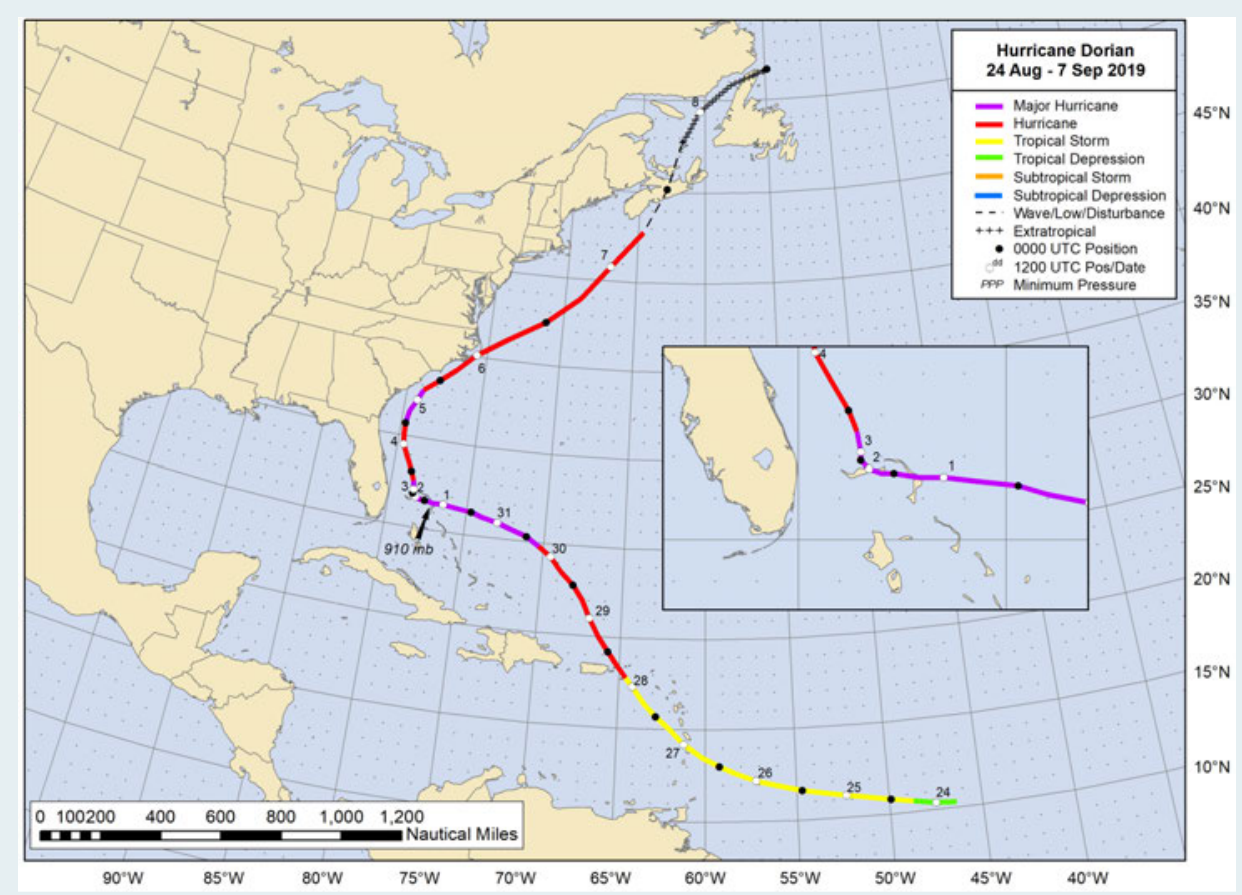

Fig. SB4.1. NOAA's National Hurricane Center Best Track Plot for Hurricane Dorian (Avila et al. 2020). 
weakened extremely slowly-from a $155 \mathrm{kt}\left(80 \mathrm{~m} \mathrm{~s}^{-1}\right)$ Category 5 hurricane to a $115 \mathrm{kt}\left(59 \mathrm{~m} \mathrm{~s}^{-1}\right)$ Category 4 hurricane. Because of this stalling motion and maintenance of strong hurricane intensity, Dorian generated the most ACE in a $1^{\circ} \times 1^{\circ}$ grid box in the Atlantic basin in the satellite era (i.e., since 1966; Wood et al. 2020).

Land interaction, an increase in vertical wind shear, and cold water upwelling continued to slowly reduce Dorian's wind strength, and it weakened below major hurricane strength late on 3 September. Dorian tracked northward offshore of the southeast United States and briefly regained major hurricane strength on 5 September before weakening as it encountered lower sea surface temperatures (SSTs) and stronger vertical wind shear. It brushed the South Carolina and North Carolina coasts, and Dorian made landfall on Cape Hatteras at 1230 UTC on 6 September as a Category 2 hurricane, with winds estimated at $85 \mathrm{kt}\left(44 \mathrm{~m} \mathrm{~s}^{-1}\right)$, although most of the strongest winds remained over water to the east of the center (Avila et al. 2020). At the time of its North Carolina landfall, Dorian's central pressure was $956 \mathrm{hPa}$, tying it with Floyd (1999) and Florence (2018) for the sixth lowest central pressure for a landfalling North Carolina hurricane since 1950. Dorian became extratropical as it accelerated northeastward, but it also strengthened slightly during this time. It made a final landfall as a post-tropical cyclone in Nova Scotia on 7 September, bringing hurricane-force winds to portions of Atlantic Canada. Dorian made a final landfall as a post-tropical storm in Newfoundland on 8 September.

Dorian was an extremely long-lived storm and set several records due to both its intensity and longevity. Its $160 \mathrm{kt}\left(82 \mathrm{~m} \mathrm{~s}^{-1}\right)$ winds were tied with Gilbert (1988) and Wilma (2005) for the second strongest on record for an Atlantic hurricane in the satellite era (since 1966), trailing only the $165 \mathrm{kt}\left(85 \mathrm{~m} \mathrm{~s}^{-1}\right)$ winds recorded by Allen (1980). Its lifetime minimum central pressure of $910 \mathrm{hPa}$ was tied with Ivan for the ninth-lowest lifetime minimum central pressure since 1980 . Dorian generated $49 \times 10^{4} \mathrm{kt}^{2}$ ACE during its lifetime-the fifth most for an August TC in the satellite era. It also generated 14 named storm days, tying it with Felix (1995) for third place for most named storm days by a storm forming in August in the satellite era.

Given its extreme intensity and slow forward speed over both Great Abaco Island and Grand Bahama Island, Dorian caused tremendous devastation, with over 70 fatalities reported by the Bahamian Health Minister and \$3.4 billion (U.S. dollars) in damage generated (Avila et al. 2020). Dorian was responsible for four indirect fatalities in the United States and caused \$1.6 billion (U.S. dollars) in damage. Dorian as a post-tropical cyclone also caused considerable damage in Nova Scotia, with over \$100 million (U.S. dollars) in damage being reported.

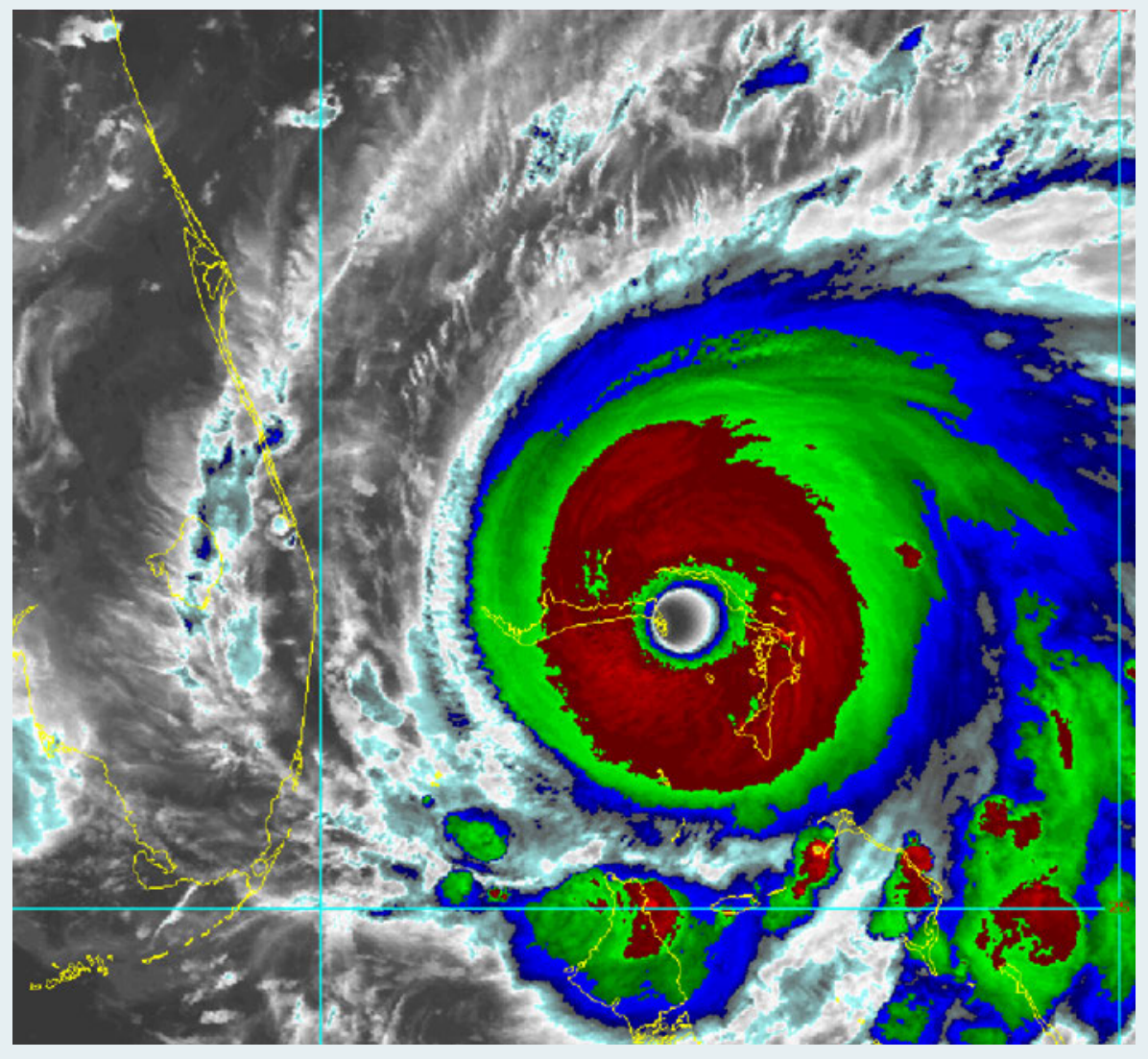

Fig. SB4.2. NOAA-18 infrared satellite image of Hurricane Dorian making landfall on Grand Bahama Island at 154 UTC on 2 Sep 2019.

Despite the above conditions, the 2019 TC activity for the MDR as a whole was relatively modest. This signal partly reflected the limited activity (two tropical storms) over the Caribbean Sea due in part to anomalously strong upperlevel convergence (Fig. 4.23a) and sinking motion there. The modest activity was also associated with the synoptic scale sinking motion typically found downstream of the mean ridge axis, which in this case extended across the Gulf of Mexico and western subtropical North Atlantic (indicated by thick black line in Figs. 4.21a, 4.23a).

Two other aspects of the interannual variability during ASO 2019 include the relatively high number of six TC formations over the western subtropical North Atlantic and five over the Gulf of Mexico (yellow lines, Fig. 4.22). These 
are roughly double the 1981-2010 averages seen during above-normal seasons. In addition to anomalously warm SSTs during ASO (Fig. 4.20a), both regions experienced below-average vertical wind shear (Fig. 4.22b) with area-averaged shear values at or below $8 \mathrm{~m} \mathrm{~s}^{-1}$ (Figs. 4.22d,e). For the Gulf of Mexico, the area-averaged shear was less than $6 \mathrm{~m} \mathrm{~s}^{-1}$ (Fig. 4.22e), which is comparable to some of the lowest values in the record. These conditions were linked to the persistent, anomalous upper-level ridge that extended across both regions (Fig. 4.21a).

\section{3) Eastern North Pacific and Central North Pacific basins-K. M. Wood and C. J. Schreck}

(I) SEASONAL ACTIVITY

Two agencies are responsible for issuing advisories and warnings in the eastern North Pacific (ENP) basin: NOAA's National Hurricane Center in Miami, Florida, covers the region from the Pacific coast of North America to $140^{\circ} \mathrm{W}$, and NOAA's Central Pacific Hurricane Center in Honolulu, Hawaii, covers the central North Pacific (CNP) region between $140^{\circ} \mathrm{W}$ and the date line. This section combines statistics from both regions.

A total of 19 named storms formed in the combined ENP/CNP basin, seven of which became hurricanes and four became major hurricanes. The 1981-2010 IBTrACS seasonal averages for the basin are 16.5 named storms, 8.5 hurricanes, and 4.0 major hurricanes (Schreck et al. 2014). Thus, 2019 storm counts were near normal (Fig. 4.24a). These storms occurred between the official start date of the ENP season of 15 May and end date of 30 November. Hurricane Alvin first reached tropical storm strength on 29 June-the latest first storm formation since 2016's Tropical Storm Agatha was named on 2 July. The final named storm, Raymond, dissipated on 17 November. Four
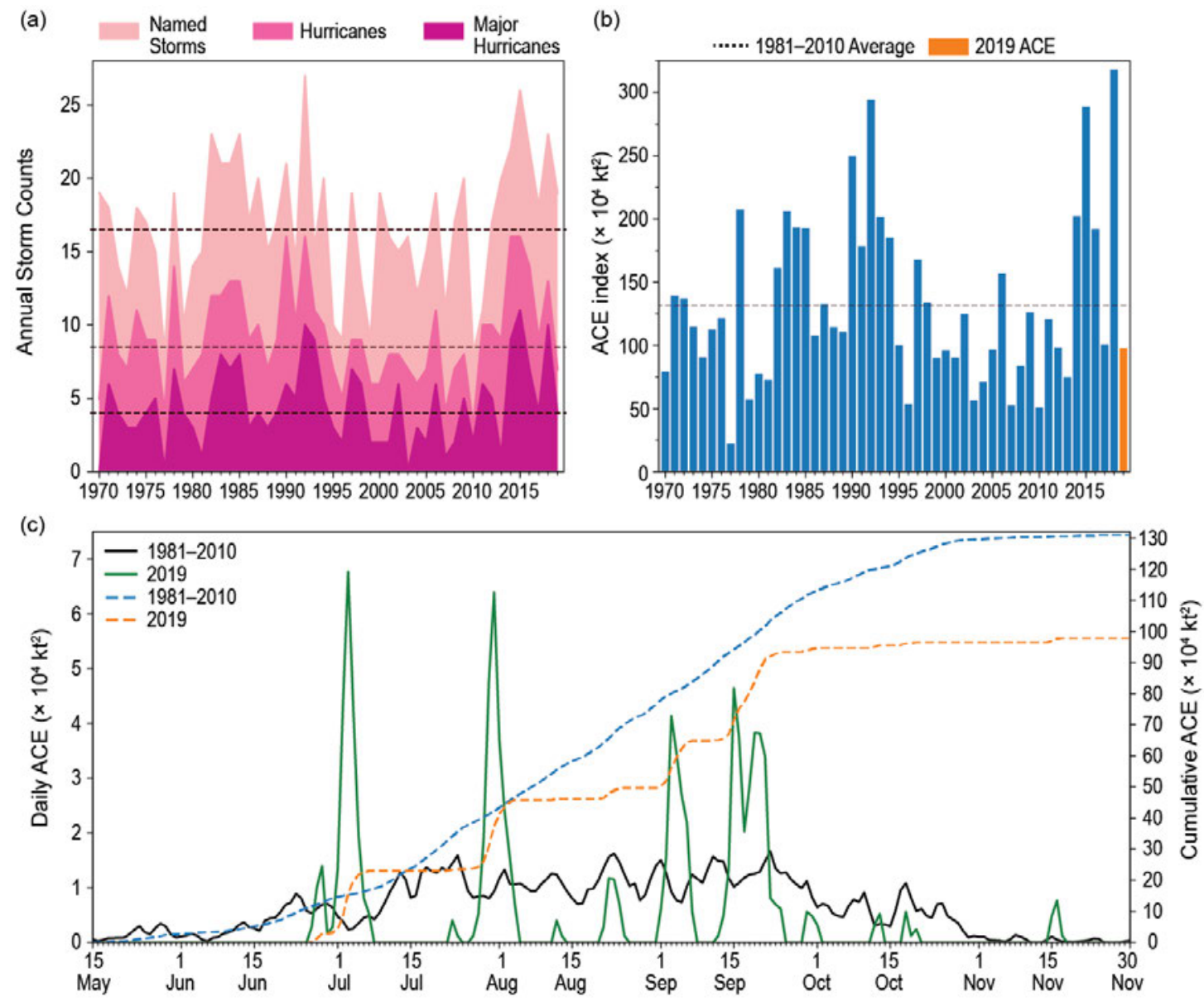

Fig. 4.24. (a) Annual storm counts for the eastern North Pacific by category during 1970-2019, with 1981-2010 average denoted as dashed lines. (b) Annual ACE during 1970-2019, with 2019 in orange and the 1981-2010 average denoted by the dashed line. (c) Daily ACE during 1981-2010 (solid black) and 2019 (solid green); accumulated daily ACE during 1981-2010 (dashed blue) and 2019 (dashed orange). 
of the 19 storms either formed within or entered the CNP basin from the east, placing 2019 slightly below the 1981-2010 IBTrACS seasonal average of 4.7 named storms for the CNP.

Unlike 2018, which set a new record for basin-wide ACE (318 $\times 10^{4} \mathrm{kt}^{2}$; Wood et al. 2019), the 2019 seasonal ACE index was $98 \times 10^{4} \mathrm{kt}^{2}$, or $74 \%$ of the $1981-2010$ mean of $132 \times 10^{4} \mathrm{kt}^{2}$ (Fig. 4.24b; Bell et al. 2000; Schreck et al. 2014). The bulk of TC activity was confined to late June through late September (Fig. 4.24c); no hurricanes developed in October or November.

Three TCs contributed more than half of 2019's total ACE and reached Category 4 intensity on the SSHWS. Each underwent rapid intensification ( $\geq 30 \mathrm{kt}$ or $15.4 \mathrm{~m} \mathrm{~s}^{-1}$ in 24 hours) prior to reaching peak intensity and then rapidly weakened ( $\leq-30 \mathrm{kt}$ or $-15.4 \mathrm{~m} \mathrm{~s}^{-1}$ in 24 hours; Wood and Ritchie 2015). The strongest storm of the season, Hurricane Barbara (30 June-6 July) peaked at $135 \mathrm{kt}\left(69 \mathrm{~m} \mathrm{~s}^{-1}\right)$, just shy of Category 5 strength. Hurricane Erick (27 July-3 August) intensified by $50 \mathrm{kt}\left(26 \mathrm{~m} \mathrm{~s}^{-1}\right)$ in 24 hours, and Hurricane Kiko (12-24 September) reached Category 4 intensity $\left(115 \mathrm{kt} ; 59 \mathrm{~m} \mathrm{~s}^{-1}\right.$ ) after similarly explosive intensification from $60 \mathrm{kt}$ to $115 \mathrm{kt}$ in 24 hours. All three TCs maintained peak intensity for only 12 hours before weakening rapidly.

\section{(II) ENVIRONMENTAL INFLUENCES ON THE 2019 SEASON}

The El Niño of 2018/19 transitioned to a neutral state in mid-2019, and seasonal SSTs were about average near most TC formation locations (Fig. 4.25a). Anomalous warmth dominated the western part of the basin, particularly north of $10^{\circ} \mathrm{N}$, but few storms crossed this region. Below-average OLR was largely colocated with TC tracks (Fig. 4.25b), and vertical wind shear was slightly weaker than normal where most TCs formed (Fig. 4.25c). As in 2018, the strongest easterly wind shear anomalies occurred in the central Pacific, but few 2019 TCs reached that region. Again, enhanced low-level westerlies dominated west of $140^{\circ} \mathrm{W}$, and the enhanced $850-\mathrm{hPa}$ easterly flow west of Central America (Fig. $4.25 d$ ) resembles the pattern in 2018 that was attributed to anomalously strong gap winds influenced by the Sierra Madre mountain range (Kruk and Schreck 2019).

Both the Madden Julian Oscillation (MJO) and convectively-coupled Kelvin waves are known to affect ENP TC activity, particularly cyclogenesis (e.g., Maloney and Hartmann 2001; Aiyyer and Molinari 2008; Schreck and Molinari 2011; Ventrice et al. 2012a,b; Schreck 2015, 2016). To examine convective variability during the 2019 ENP hurricane season, Fig. 4.26 shows unfiltered, MJO-filtered, and Kelvin wave-filtered OLR anomalies computed using the methodology of Kiladis et al. (2005, 2009). In general, the MJO remained weak in the ENP for much of the hurricane season. However, a strong convectively suppressed MJO phase in June likely contributed to the late start to the season. The subsequent weaker convective envelope

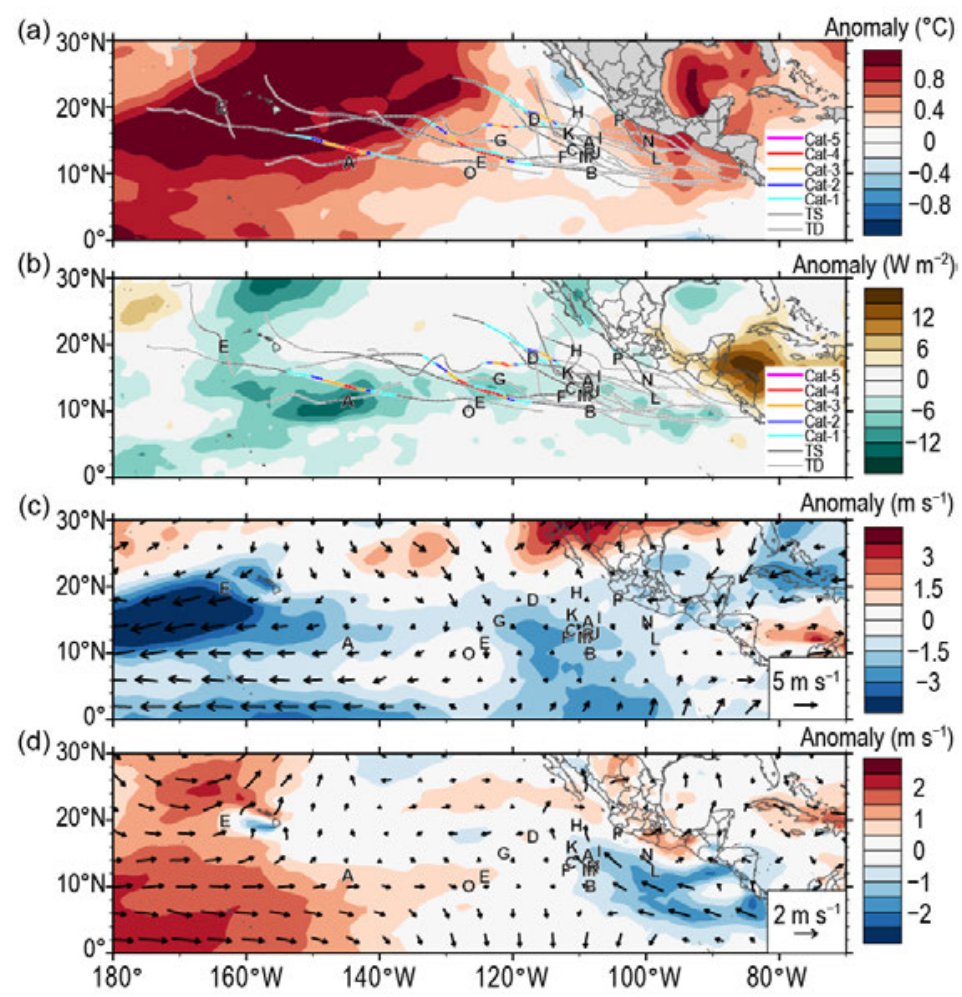

Fig. 4.25. 15 May-30 Nov 2019 anomaly maps of (a) SST ( ${ }^{\circ} \mathrm{C}$; Banzon and Reynolds 2013); (b) OLR (W m ${ }^{-2}$; Schreck et al. 2018); (c) 200-850-hPa vertical wind shear $\left(\mathrm{m} \mathrm{s}^{-1}\right)$ vector (arrows) and scalar (shading) anomalies; and (d) 850-hPa wind ( $\mathrm{m} \mathrm{s}^{-1}$; arrows) and zonal wind (shading) anomalies. Anomalies are relative to the annual cycle from 1981-2010, except for SST, which is relative to 1982-2010. Letters denote where each ENP TC attained tropical storm intensity. Wind data are obtained from CFSR (Saha et al. 2014). The more westward A represents "Akoni" and the more westward E "Ema." 


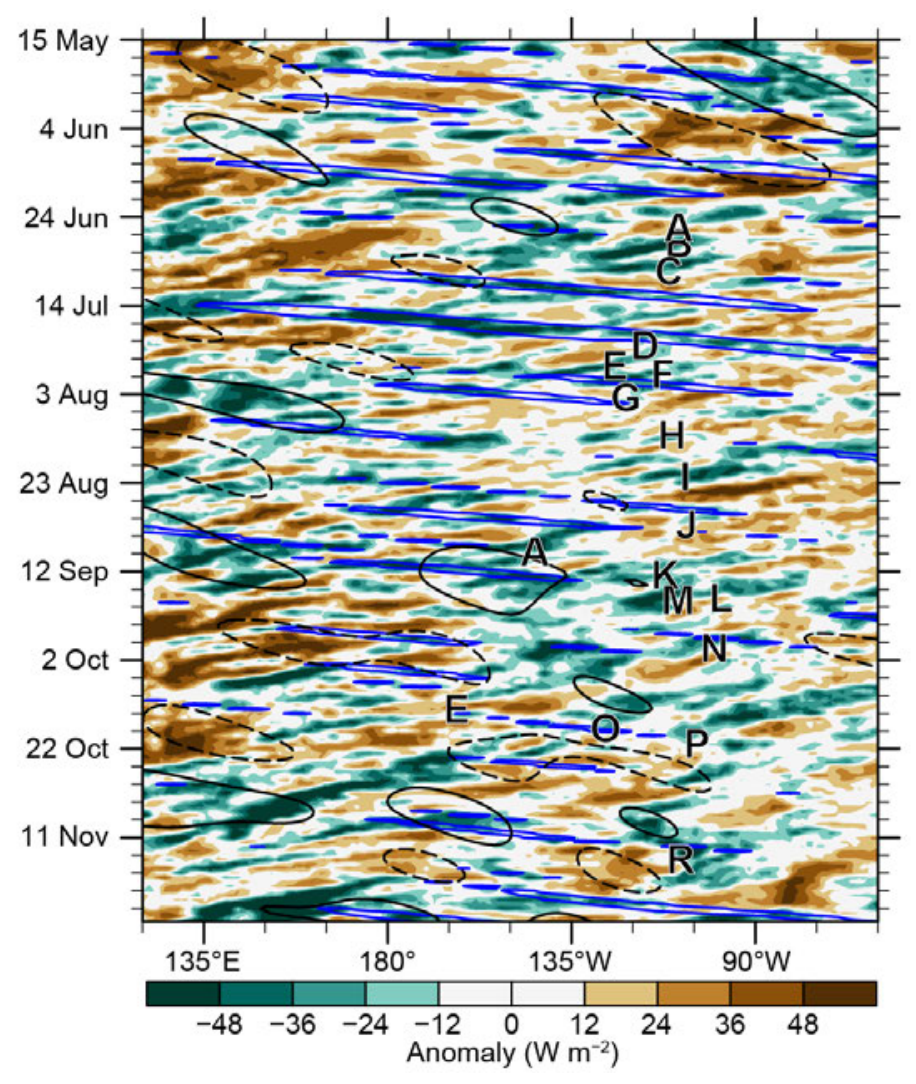

Fig. 4.26. Longitude-time Hovmöller diagram of $5^{\circ}-15^{\circ} \mathrm{N}$ average OLR ( $\mathrm{W} \mathrm{m}^{-2}$; Schreck et al. 2018). Unfiltered anomalies from a daily climatology are shaded. Negative anomalies (green) indicate enhanced convection. Anomalies filtered for Kelvin waves are contoured in blue at -10 $\mathrm{W} \mathrm{m}^{-2}$ and MJO-filtered anomalies in black at $\pm 10 \mathrm{~W} \mathrm{~m}^{-2}$. Letters denote the longitude and time when each ENP TC attained tropical storm intensity. The second $A$ represents "Akoni" and the second E "Ema."

may have contributed to the formations of Alvin, Barbara, and Cosme. Multiple Kelvin waves crossed the ENP, potentially influencing the development of Dalila, Gil, Juliette, Narda, Octave, Priscilla, and Raymond. Beyond these influences, easterly waves-shown in Fig. 4.26 as westward-moving negative anomalies-likely supported the genesis of multiple storms including Ivo, Priscilla, and Raymond.

\section{(III) TROPICAL CYCLONE IMPACTS}

Three TCs directly impacted land in 2019. Hurricane Lorena (17-22 September) made two landfalls in Mexico as a Category 1 hurricane, once in Jalisco and once in Baja California Sur, with one reported death (Avila 2019). In addition, Lorena's remnant moisture reached the southwestern United States where it likely contributed to thunderstorms and heavy rain. Tropical Storm Narda (29 September-1 October) also made landfall twice in Mexico, both times as a tropical storm, causing six fatalities largely attributed to freshwater flooding (Blake 2019). Short-lived Tropical Storm Priscilla (20 October) made landfall hours after being named and dumped more than $150 \mathrm{~mm}$ of rain in Nayarit. Its remnant moisture may have contributed to severe weather in the south-central United States (Stewart 2019). Though none produced significant damage, three landfalling storms in Mexico is well above the long-term average of 1.8 each year (Raga et al. 2013). Beyond landfalls, remnants of Tropical Storm Raymond (15-17 November) may have influenced the development of a low-pressure system that subsequently produced wind, rain, and flooding in the southwestern United States (NOAA 2019).

\section{4) Western North Pacific basin-S. J. Camargo \\ (I) OVERVIEW}

The 2019 TC season in the western North Pacific (WNP) was slightly above normal by most measures of TC activity. The data used here are primarily from JTWC best-track data for 1945-2018 and preliminary operational data for 2019. All statistics are based on the 1981-2010 climatological period with the exception that landfall statistics use 1951-2010. 
A total of $28 \mathrm{TCs}$ (climatological median $=26$ ) reached tropical storm $(\mathrm{TS}$ ) intensity in the WNP during 2019, including Pabuk, which formed in December 2018. Of these, 17 reached typhoon intensity (median $=16)$, with 4 reaching super typhoon status $(\geq 130 \mathrm{kt}$, median $=3.5)$. There were also three tropical depressions (TDs; median 3.5). While $61 \%$ of the tropical storms became typhoons (median 64\%), 23\% of the typhoons intensified to super typhoons (median 24\%). In Fig. 4.27a, the number of storms in each category is shown for the period 1945-2019.

The Japan Meteorological Agency (JMA) total for 2019 was 29 storms (top tercile $\geq 29$ ), also including 2018 Tropical Storm Pabuk. While the JMA and JTWC totals are very close, there were some differences between the two agencies. ${ }^{2}$ Kajiki was considered a TS by JMA but a depression by JTWC. Matmo was considered a severe TS by JMA and a typhoon by JTWC. Tapah was classified as a TS for JTWC and a typhoon for JMA. Tropical Storm Sepat was not included as a TC by JTWC, and Tropical Storm Four was not classified as a TC by JMA. Of the 29 TCs recorded by JMA, nine were tropical storms (top quartile $\geq 7$ ); three were severe tropical storms (bottom quartile $\leq 4$ ); and 17 were typhoons (top quartile $\geq 17$ ). Fifty-nine percent of the storms reached typhoon intensity (median 58\%). The number of all TCs (1951-76) and TSs, severe TSs, and typhoons (1977-2019) according to the JMA are shown in Fig. 4.27b. The Philippine Atmospheric, Geophysical and Astronomical Services Administration (PAGASA) named all 20 TCs that entered its area of responsibility, including Tropical Depressions Amang, Chedeng, Goring, and Marilyn, which were not named by JMA.

\section{(II) SEASONAL ACTIVITY}

The season started with Tropical Storm Pabuk, which formed on 30 December 2018 and lasted until 7 January 2019, reaching TS status on 1 January. Super Typhoon Wutip was the season's next named storm and the second TC to reach super typhoon intensity in February in the historical record, following Super Typhoon Higos (2005). Typhoon Mitag (2002) also formed in February, but reached super typhoon intensity in March. No named storms formed during March-May (bottom quartile = 0 for each month). Only Tropical Storm Four was active in the month of June according to the JTWC (bottom quartile $\leq 1$ ), while JMA named Tropical Storm Sepat that month. Three TSs were active during July: Mun, Danas, and Nari (bottom quartile $\leq 2$ ). Tropical Storm Wipha formed at the end of July, but was mostly active in August and therefore was considered as an August storm. Besides Wipha, five other TCs occurred in August: Tropical Storms Bailu and Podul, Typhoons Francisco and Krosa, and Super Typhoon Lekima. August had a total of six named storms (top quartile $\geq 6$ ), three typhoons (median $=3$ ), and one super typhoon (top quartile $\geq 1$ ). Five more named storms formed in September (median = 5): Tropical Storms Peipah and Tapah and typhoons Faxai, Lingling, and Mitag (median = 3). October was an active month with four typhoons: Hagibis, Neoguri, Bualoi, and Matmo (top quartile $\geq 4$ ), with Hagibis reaching super typhoon intensity. The basin continued to be very active in November with six named storms (top quartile $\geq 3$ ): Tropical Storm Fung-Wong and Typhoons Halong (super typhoon), Nakri, Fengshen, Kalmaegi, and Kammuri (top quartile $\geq$ 2). The six named storms and five typhoons matched the historical record for November, set in 1964 and 1968, respectively. The season ended with Typhoon Phanphone in December (median =1).

As shown in Figs. 4.27c-f, the early season (January-June) was relatively quiet, with only three tropical storms (bottom quartile $\leq 2.5$ ) and one typhoon (bottom quartile $\leq 1$ ) which reached super typhoon intensity. The peak season (July-October) had near-normal activity with 18 named storms (median =17), 10 typhoons (bottom quartile $\leq 9$ ), and two super typhoons (median $=2$ ). In contrast, the late season (November-December) was quite active, with seven named storms (top quartile $\geq$ 4.5, maximum $=7$ ) and six typhoons (top quartile $\geq 3$ ) including one super typhoon (top quartile $=1$ ). The occurrence of six typhoons during November and December is a historical record. This

${ }^{2}$ It is well known that there are systematic differences between the JMA and the JTWC datasets, which have been extensively documented in the literature (e.g. Wu et al. 2006; Nakazawa and Hoshino 2009; Song et al. 2010; Ying et al. 2011; Yu et al. 2012; Knapp et al. 2013; Schreck et al. 2014). 

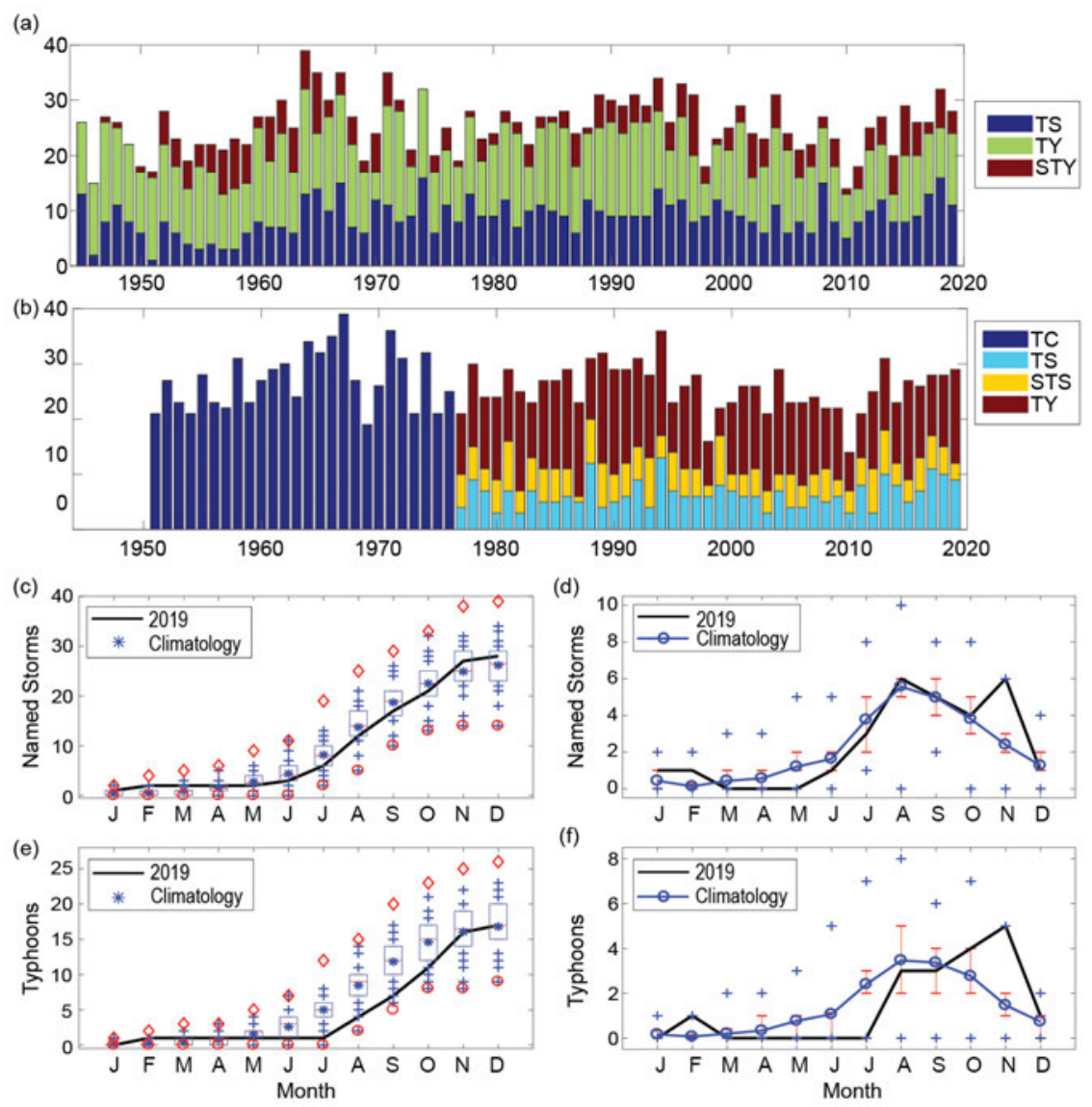

Fig. 4.27. (a) Number of tropical storms (TS) typhoons (TY) and super typhoons (STY) per year in the WNP for 1945-2019 based on JTWC. (b) Number of tropical cyclones (TC, all storms which reach TS intensity or higher) for 1951-1976; number of TSs, severe tropical storms (STS) and TY for 1977-2019 based on JMA. Panel (c) shows the cumulative number of TCs per month in the WNP in 2019 (black line) and climatology (1981-2010) as box plots (interquartile range: box, median: red line, mean: blue asterisk, values in the top or bottom quartile: blue crosses, high [low] records in the 1945-2018 period: red diamonds [circles]). Panel (e) is similar to panel (c) but for the number of TYs. Panels (d) and (f) show the number of TCs and TYs per month in 2019 (black line) and the climatological mean (blue line); blue "+"signs denote the maximum and minimum monthly historical records and the red error bars show the climatological interquartile range for each month. In the case of no error bars, the upper and/or lower percentiles coincide with the median. (Sources: 1945-2018 JTWC best-track dataset, 2019 JTWC preliminary operational track data, except for panel [b], which is 1951-2019 JMA best-track dataset.)

active late season compensated for the quiet early season, leading to a slightly above-average typhoon season in terms of the JTWC numbers of named storms $(28$, median $=26)$, typhoons (17, median $=16)$ and super typhoons $(4$, median $=3.5)$.

The total ACE in 2019 (Fig. 4.28a) was slightly below normal. As seen in Fig. 4.28b, the value for February, however, was the highest in the historical record. From March until July, the monthly ACE was in the bottom quartile of the monthly climatologies, with zero ACE values for March, April, and May. The August ACE was in the below-average quartile (25\%-50\%), and the September ACE was also in the bottom quartile of the monthly climatological distribution. The October and December ACE values were in the above-average quartile (50\%-75\%) of the climatological distributions, while November ACE was in the top quartile. The five months of October, November, August, September, and February contributed 26\%, 22\%, 16\%, 14\%, and 15\% of the ACE respectively, summing to $93 \%$ of the seasonal ACE. In descending order of storm ACE, Super Typhoons Hagibis (top 5\%), Wutip (top decile), and Halong, Typhoons Bualoi and Kammuri, and Super Typhoon Lekima placed in the top quartile of historical ACE per storm. Together, these six storms contributed 57\% of the seasonal ACE, with Hagibis and Wutip contributing 14\% and $12 \%$, respectively. 
(a)

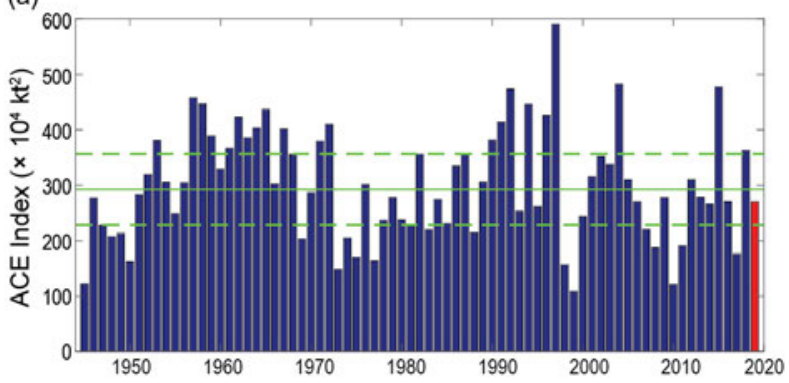

(b)

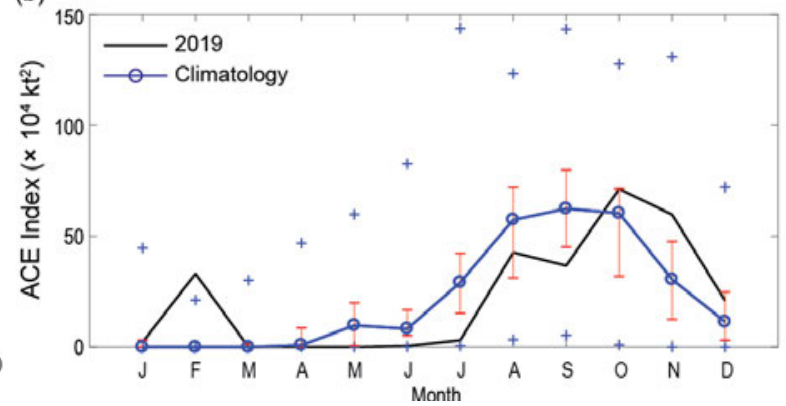

Fig. 4.28. (a) ACE per year in the WNP for 1945-2019. The solid green line indicates the median for 1981-2010; dashed lines show the climatological 25th and 75th percentiles. (b) ACE per month in 2019 (black line) and the 1981-2010 median (blue line); red error bars indicate the 25th and 75th percentiles. In case of no error bars, the upper and/or lower percentiles coincide with the median. The blue " + " signs denote the maximum and minimum values during the 1945-2018. (Source: 1945-2018 JTWC best-track dataset; 2019 JTWC preliminary operational track data.)

The mean genesis location in 2019 was $14.4^{\circ} \mathrm{N}, 138.4^{\circ} \mathrm{E}$, slightly northwest of the climatological mean of $13.2^{\circ} \mathrm{N}, 142.8^{\circ} \mathrm{E}$ (std. dev. of $1.9^{\circ}$ latitude and $5.6^{\circ}$ longitude). The mean track position in 2019 was $19.0^{\circ} \mathrm{N}, 133.9^{\circ} \mathrm{E}$, similarly northwest of the climatology mean of $17.3^{\circ} \mathrm{N}, 136.6^{\circ} \mathrm{E}$ (std. dev. of $1.4^{\circ}$ latitude and $4.7^{\circ}$ longitude). There is a well-known connection between genesis and track shifts in the WNP basin and ENSO phase (Chia and Ropelewski 2002; Camargo et al. 2007). However, the 2019 northwest shift in TC genesis and track cannot be attributed to El Niño, as there were neutral ENSO conditions during the peak typhoon season.

There were 110.25 named storm days in the WNP in 2019 (median = 113 days). The WNP had 50.25 typhoon days (bottom quartile $\leq 49.5$ days) and 21.5 major typhoon days (SSHWS Categories $3-5$; median $=21$ ). The percentage of days with typhoons and major typhoons was $32 \%$ (bottom quartile $\leq 33 \%$ ) and $14 \%$ (median $=13.9 \%$ ) respectively. The median lifetime for TCs reaching TS intensity was 6.25 days (bottom percentile $\leq 6.25$ days) and for those reaching typhoon intensity was eight days (bottom quartile $\leq 7.75$ days). The longest-lived named storm in 2019 was Typhoon Matmo (12.25 days), followed by Major Typhoons Krosa (11.25 days), Wutip (11 days), and Kammuri (10.5 days) -all of which were in the top quartile ( $\geq 10.5$ days). Tropical depression One was very long-lived as well (18 days). Of the 28 tropical storms and typhoons, 17 had a lifetime at or below the median (7.75 days), with 12 in the bottom quartile ( $\leq 5.25$ days). The maximum number of TCs (and typhoons) active simultaneously in 2019 was three and occurred 7-9 November (Super Typhoon Halong and Typhoons Matmo and Nakri). The historical record is six (14-15 August 1996).

Including TDs, 23 storms made landfall in 2019, above the 90th percentile compared with the 1951-2010 climatology. Landfall here is defined when the storm track is over land, and the previous location was over the ocean. In order to include landfall over small islands, tracks were interpolated from 6-hourly to 15-minute intervals, using a high-resolution land mask. Seven storms made landfall as TDs (above the 95th percentile $\geq 7$ ) and eight as tropical storms (top quartile $\geq$ 8). Six TCs made landfall as Category 1-2 typhoons on the SSHWS scale (median = 5): Francisco, Lekima, Faxai, Hagibis, Matmo, and Phanphone. Super Typhoons Lingling and Kammuri made landfall as major typhoons (Category $\geq 3$; median $=2$ ). Lingling affected both South and North Korea-the latter of which is not hit frequently by typhoons. Kammuri made landfall in the Bicol region of the Philippines on 2 December, followed by Typhoon Phanphone's landfall in the country's eastern Samar region on 24 December. Five storms made landfall in Japan in 2019 (top quartile $\geq 5$ ), with the strongest being Typhoons Faxai and Hagibis.

\section{(III) ENVIRONMENTAL CONDITIONS}

Figures 4.29a-e show the July-October (JASO) environmental conditions associated with typhoon activity in 2019. The 2018/19 El Niño transitioned to near- to below-normal SSTs in the eastern Pacific during the beginning of the peak typhoon season (July to mid-September). From mid-September 


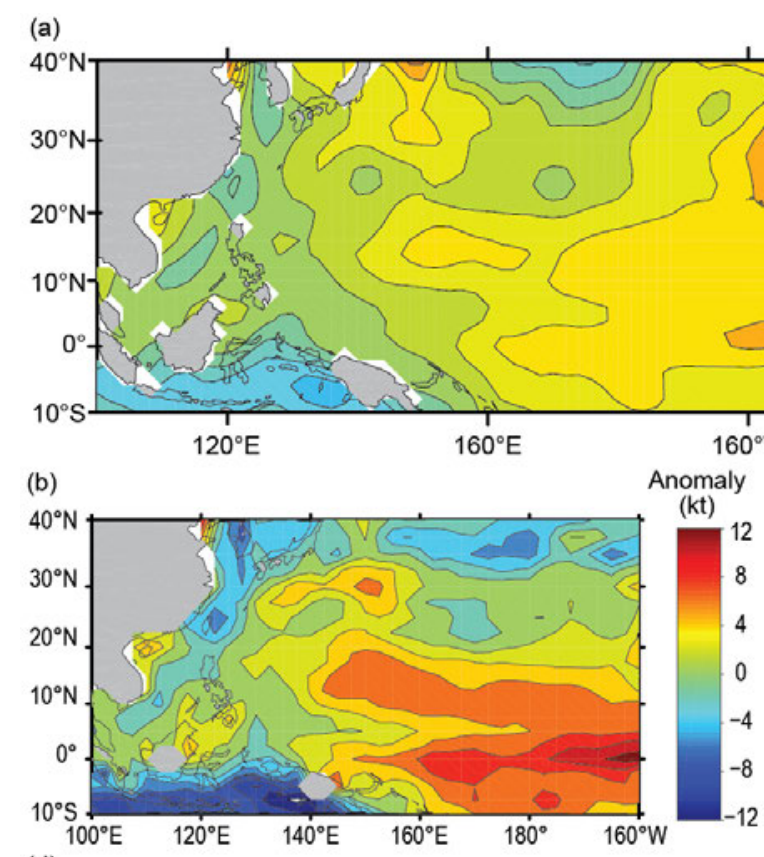

(d)
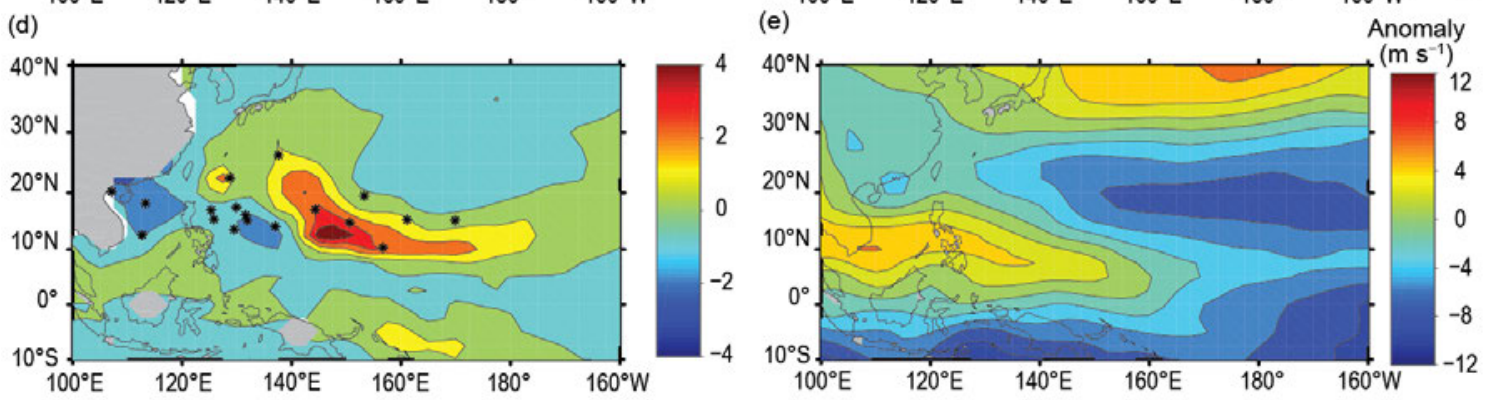

Fig. 4.29. (a) SST anomalies ( $\left.{ }^{\circ} \mathrm{C}\right)$ for Jul-Oct (JASO) 2019. (b) Potential intensity anomalies in JASO 2019 (kt). (c) Relative humidity (\%) 600-hPa anomalies in JASO 2019. (d) Genesis potential index (unitless) anomalies in JASO 2019. First position of storms in JASO 2019 are marked with an asterisk. (e) 850-hPa zonal winds (m s ${ }^{-1}$ ) in JASO 2019. (Source: atmospheric variables: NCEP-NCAR reanalysis data [Kalnay et al. 1996]; SST [Smith et al. 2008].)

until the end of the calendar year, above-normal SSTs expanded from the date line into the eastern Pacific. Below-normal eastern Pacific SSTs are clearly seen in the JASO SST anomalies (Fig. 4.29a), with above-average SST anomalies extending northeastward from the equatorial central Pacific around these cold anomalies. The above-average SST anomalies in the central Pacific are reflected in other environmental variables, such as positive potential intensity anomalies (Fig. 4.29b) in the eastern part of the basin near the date line. There was also a positive band of 600-hPa relative humidity anomalies between $130^{\circ}-160^{\circ} \mathrm{E}$ extending from the equatorial region to $\sim 40^{\circ} \mathrm{N}$ (Fig. 4.29c). For the genesis potential index (GPI; Fig. 4.29d; Emanuel and Nolan 2004; Camargo et al. 2007), anomalies are observed in a recurving narrow band between $10^{\circ}-20^{\circ} \mathrm{N}$. Many TC genesis locations occurred close to or just southwest of this region. The extent of the monsoon trough, defined by 850$\mathrm{hPa}$ zonal winds (Fig. 4.29e), extended to $150^{\circ} \mathrm{E}$, despite below-normal SSTs in the eastern Pacific. Several cases of TC genesis occurred just north of these westerly anomalies.

\section{(IV) TROPICAL CYCLONE IMPACTS}

Many storms had social and economic impacts in Asia in 2019, particularly Typhoons Lekima, Faxai, and Hagibis. Typhoon Lekima made landfall in China as the fifth-strongest landfalling typhoon to affect the country since 1949, according to the China Meteorological Administration. Lekima's heavy rainfall and long duration over China led to many historical daily precipitation records across the country, particularly in Zhejiang Province, where the typhoon made its first landfall. Lekima then passed over Shanghai and Jiangsu Province, before making a second landfall in Shangdong Province. Lekima left 48 dead and 21 missing, and displaced 1.7 million 
people. Damages were estimated to be $\$ 9.3$ billion (U.S. dollars). Typhoon Faxai impacted Japan as one of the strongest typhoons on record to affect Tokyo, killing three people and injuring 147, causing extensive blackouts, and damaging more than 40000 homes. Japan's economic losses across several sectors due to Faxai are estimated at $\$ 7$ billion (U.S. dollars). In October, Super Typhoon Hagibis affected the Tokyo region. The storm's record-breaking rainfall led to extensive flooding of rivers and dams and multiple landslides. At least 95 people were killed, 460 injured, and economic losses exceeded $\$ 10$ billion (U.S. dollars).

\section{5) North Indian Ocean basin-A. D. Magee and C. J. Schreck}

\section{(I) SEASONAL ACTIVITY}

The North Indian Ocean (NIO) TC season typically occurs between April and December, with two peaks of activity: May-June and October-December, due to the presence of the monsoon trough over tropical waters of the NIO during these periods. Tropical cyclone genesis typically occurs in the Arabian Sea and Bay of Bengal between $8^{\circ}-15^{\circ} \mathrm{N}$. The Bay of Bengal, on average, experiences four times more TCs than the Arabian Sea (Dube et al. 1997).

The 2019 NIO TC season was a particularly active and record-breaking TC season with eight named storms, six cyclones, and three major cyclones (tied 1999), compared to the IBTrACS-JTWC 1981-2010 climatology of 4.9, 1.5, and 0.7, respectively (Fig 4.30a). One event, Cyclone Kyarr, was the second-most intense cyclone ever observed in the Arabian Sea. The 2019 NIO TC season was also the second-costliest on record with losses exceeding \$11 billion (U.S. dollars).

Record-breaking ACE index values and a strongly positive Indian Ocean dipole (IOD) event characterized the 2019 NIO TC season (refer to the legend of Fig. 4.38 for the definition of IOD and its polarity). The 2019 seasonal ACE index was $85 \times 10^{4} \mathrm{kt}^{2}$. It nearly doubled the previous record holders (2007 and 2013 each had about $\left.45 \times 10^{4} \mathrm{kt}^{2}\right)$ and was over four times the 1981-2010 ACE climatology $\left(19 \times 10^{4} \mathrm{kt}^{2}\right.$; Fig $\left.4.30 \mathrm{~b}\right)$. The strong positive IOD event that marked the latter half of the 2019 season is clearly seen in Fig 4.31a, where anomalously warm SSTs occurred in the western tropical Indian Ocean $\left(10^{\circ} \mathrm{N}-10^{\circ} \mathrm{S}, 50^{\circ}-70^{\circ} \mathrm{E}\right)$. In addition, enhanced convection (Fig 4.31b) and negative vertical wind shear anomalies (Fig 4.31c) provided favorable conditions in the Arabian Sea, contributing to the high number of events there. Although positive IOD events historically result in fewer TCs in the NIO (Yuan and Cao 2012), this was not the case for the 2019 TC season.

\section{(II) NOTEWORTHY TROPICAL CYLONES AND IMPACTS}

The first severe cyclonic storm of the 2019 NIO cyclone season, Cyclone Fani (27 April-3 May), developed unusually close to the equator, at $2.7^{\circ} \mathrm{N}$, just west of Sumatra. Strong vertical wind shear impeded further development until 29 April when Fani intensified into a severe cyclonic storm. On 30 April, favorable conditions aided further intensification before Fani recurved north-northeastward toward India. It then underwent additional intensification, reaching its peak intensity of $135 \mathrm{kt}\left(69 \mathrm{~m} \mathrm{~s}^{-1}\right)$ and a minimum central

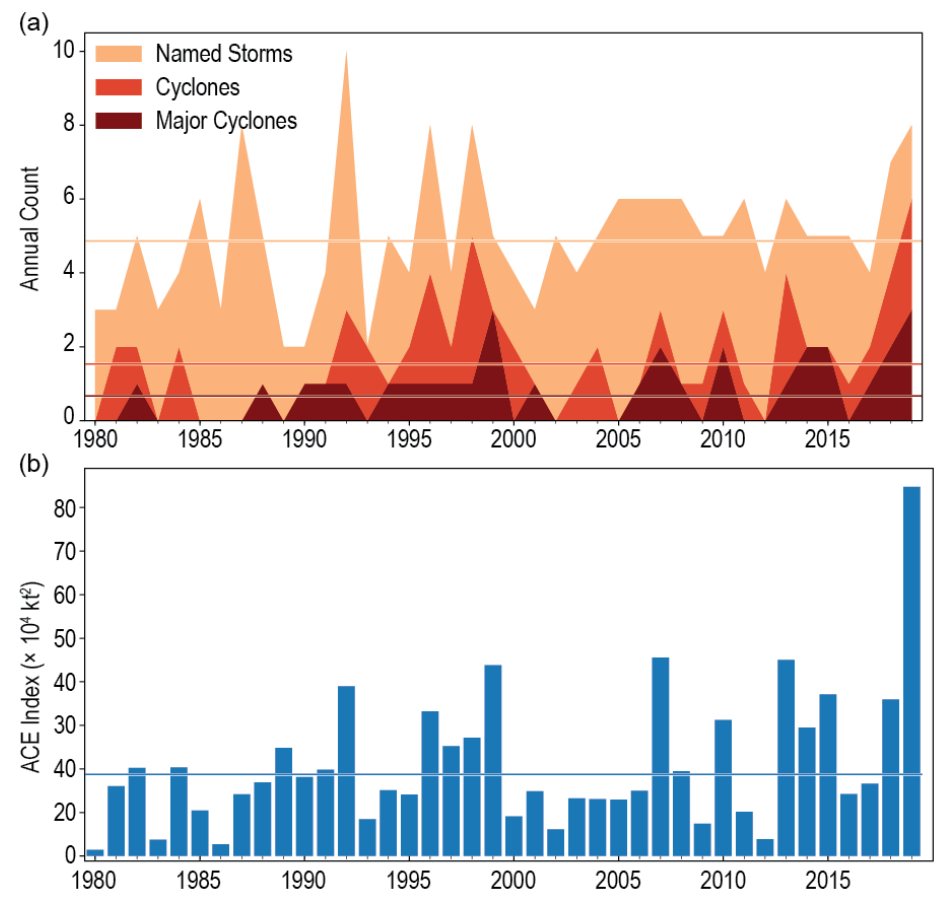

Fig. 4.30. Annual TC statistics for the NIO for 1980-2019: (a) number of named storms, cyclones, and major cyclones and (b) estimated annual ACE index $\left(\times 10^{4} \mathrm{kt}^{2}\right)$ for all TCs during which they were at least tropical storm strength or greater intensity (Bell et al. 2000). Horizontal lines represent 1981-2010 climatology. 

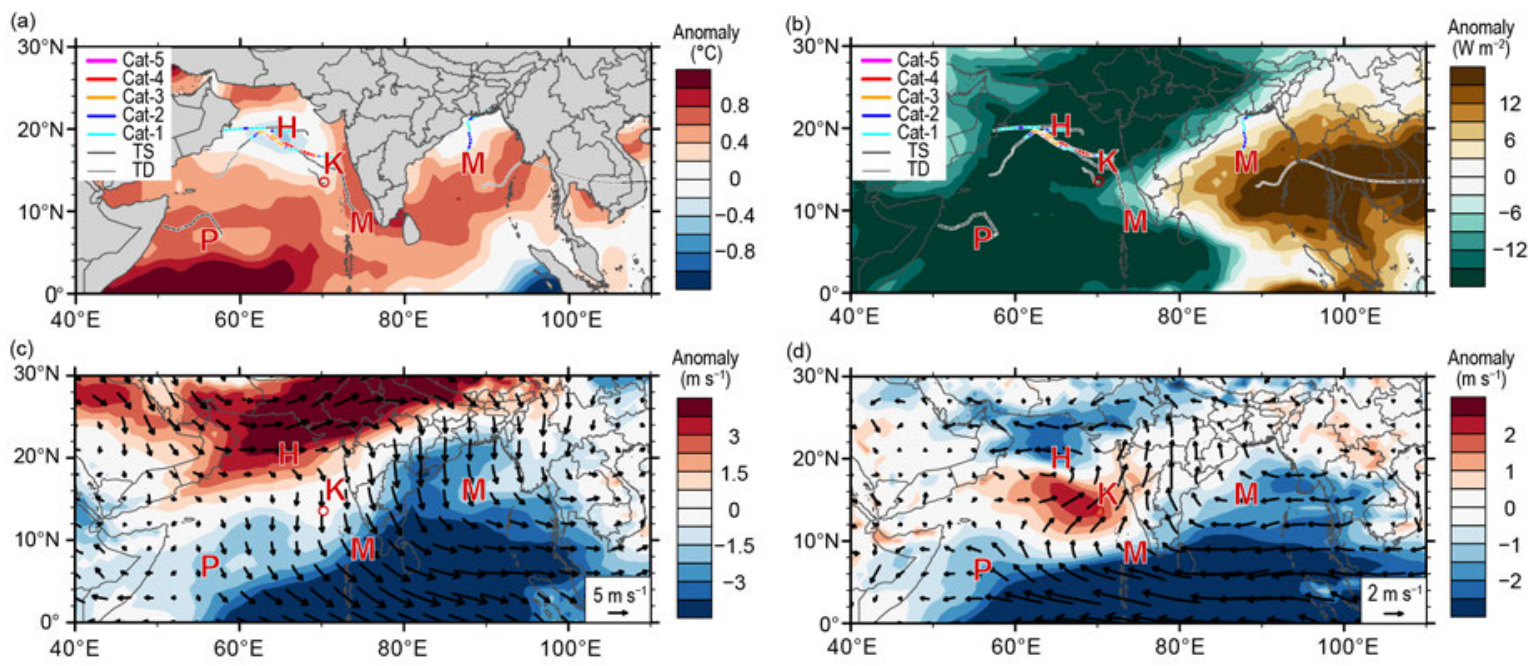

Fig. 4.31. 15 Sep 2019-15 Dec 2019 NIO anomaly maps of (a) SST ( ${ }^{\circ}$ C; Banzon and Reynolds 2013), (b) OLR (W m ${ }^{-2}$; Schreck et al. 2018), (c) 200-850-hPa vertical wind shear $\left(\mathrm{m} \mathrm{s}^{-1}\right)$ vector (arrows) and scalar (shading) anomalies, and (d) $850-\mathrm{hPa}$ winds ( $\mathrm{m} \mathrm{s}^{-1}$, arrows) and zonal wind (shading) anomalies. Anomalies are relative to the annual cycle from 1981-2010, except for SST, which is relative to 1982-2010 due to data availability. Letter symbols denote where each NIO TC attained its initial tropical storm intensity. Wind data are obtained from CFSR (Saha et al. 2014).

pressure of $917 \mathrm{hPa}$, equivalent to a strong Category 4 system on the SSHWS. Fani made landfall near Odisha, India, on 3 May with 1-minute maximum sustained wind speeds of $120 \mathrm{kt}\left(62 \mathrm{~m} \mathrm{~s}^{-1}\right)$. Fani eventually weakened and moved into Bangladesh on 4 May before dissipating the following day. In total, 89 people were killed with estimated damages of approximately $\$ 8.1$ billion (U.S. dollars). A storm surge of approximately $1.5 \mathrm{~m}$ and heavy rainfall resulted in extensive damage, including to agricultural land, where more than 30\% of crops were damaged. In Bangladesh, 17 people were killed, many by lightning. Around 160000 acres of farmland was destroyed, with agricultural losses in Bangladesh totaling \$4.6 million (U.S. dollars).

Cyclone Vayu (10-17 June) formed in the southeastern Arabian Sea, aided by a strong convective pulse of the MJO. Vayu reached peak intensity on 13 June, with 1-minute maximum sustained winds of $95 \mathrm{kt}\left(48 \mathrm{~m} \mathrm{~s}^{-1}\right)$, and a minimum central pressure of $950 \mathrm{hPa}$, a Category 2 SSHWS equivalent system. During its lifetime, Vayu's track recurved several times before weakening to a tropical low off the coast of Gujarat, India, and passed over the coast on 18 June. Vayu's proximity to Gujarat and surrounding regions resulted in eight deaths and an estimated \$140000 (U.S. dollars) in damages. Cyclone-generated waves and swells resulted in flooding of low-lying areas in Oman and Pakistan. Vayu contributed to an approximate one-week delay in the northward migration of the Indian monsoon, which was already delayed by weakening El Niño conditions that persisted during the early part of the 2019 monsoon season.

The fourth cyclone of the season, Hikaa (22-25 September), developed in the Arabian Sea and intensified into a severe cyclonic storm, reaching peak intensity of $85 \mathrm{kt}\left(43 \mathrm{~m} \mathrm{~s}^{-1}\right)$ and a minimum central pressure of $972 \mathrm{hPa}$, a Category 2 SSHWS equivalent system. Hikaa tracked toward the west before making landfall near Duqm, Oman, on 24 September. As a result of Hikaa, a boat carrying 11 Indian fishermen reportedly sank, while another boat sank off the coast of Duqm.

Super Cyclone Kyarr (24 October-1 November) was the second-most intense cyclone ever observed in the Arabian Sea with a peak intensity of $135 \mathrm{kt}\left(69 \mathrm{~m} \mathrm{~s}^{-1}\right)$ and a minimum central pressure of $923 \mathrm{hPa}$. After forming in the southeastern Arabian Sea, high SSTs and low vertical wind shear favored rapid intensification. Kyarr reached Super Cyclonic Storm strength (India Meteorological Department 2020) on 27 October-the first in the Arabian Sea since Cyclone Gonu in 2007. Unfavorable conditions resulted in a weakening of Kyarr, and it later dissipated on 1 November. No fatalities were recorded as a result of Kyarr; however, strong winds and intense rainfall caused flash flooding in Goa, India. High tide and extreme sea levels associated with 
Kyarr caused coastal flooding in Oman, with extensive damage to the Muttrah Corniche as well as a portion of the coastline of the United Arab Emirates.

Cyclone Maha (30 October-6 November), the season's fourth cyclonic storm to originate in the Arabian Sea (compared to an average of one), intensified in a similar fashion to, and occurred concurrently with, Cyclone Kyarr. Maha underwent rapid intensification from depression to cyclonic storm within a 12-hour period. The peak intensity of Maha on 4 November was $105 \mathrm{kt}\left(54 \mathrm{~m} \mathrm{~s}^{-1}\right)$ and a minimum central pressure of $959 \mathrm{hPa}$, a Category 3 SSHWS equivalent system. Maha generally tracked toward the northwest throughout its lifetime, parallel to the west coast of India, and generated storm surge up to $0.5 \mathrm{~m}$ (at Asarsa and Tankaria) on 2 November. Upwelling of cooler SSTs weakened Maha, and it made landfall as a depression near Gujarat and dissipated shortly thereafter.

Cyclone Bulbul (7-10 November) originated in the Bay of Bengal from a previous disturbance, Severe Tropical Storm Matmo, and emerged into the north Andaman Sea. After tracking westnorthwestward toward the central Bay of Bengal, Bulbul moved to the north, intensifying to a very severe cyclonic storm on 8 November, with 1-minute maximum wind speeds of $85 \mathrm{kt}\left(43 \mathrm{~m} \mathrm{~s}^{-1}\right)$ and a minimum central pressure of $971 \mathrm{hPa}$, a Category 2 SSHWS equivalent system. Bulbul made landfall near the Sagar Islands of West Bengal on 9 November. It brought significant rainfall, with reports of 24-hour accumulations of up to $202 \mathrm{~mm}$ in Canning, West Bengal. In total, 41 people died, with estimated damage totaling $\$ 3.38$ billion (U.S. dollars). In the state of Odisha, rainfall caused agricultural damage, including an estimated 200000 ha of damaged crops. In Bangladesh, more than two million people fled to shelters, 25 people died, and approximately $14 \%$ of Bangladesh's total farmland was damaged, equating to agricultural losses of approximately \$31 million (U.S. dollars).

\section{6) South Indian Ocean basin-A. D. Magee and C. J. Schreck}

(I) SEASONAL ACTIVITY

The South Indian Ocean (SIO) TC basin extends south of the equator and from the African coastline to $90^{\circ} \mathrm{E}$. In the SIO, TC genesis typically occurs south of $10^{\circ} \mathrm{S}$. While the SIO TC season extends year-round, from July to June, the majority of activity occurs between November and April when the ITCZ is located in the SH. The 2018/19 TC season includes TCs that occurred from July 2018-June 2019. Landfalling TCs typically impact Madagascar, Mozambique, and the Mascarene Islands, including Mauritius and Réunion Island. The Regional Specialized Meteorological Centre (RSMC) on La Réunion is the official monitoring agency for TC activity within the SIO basin.

The 2018/19 SIO season had 11 named storms, 10 cyclones, and eight major cyclones (Fig 4.32a), compared to the IBTrACS-JTWC 1981-2010 mean of 9.1, 5.5, and 2.9, respectively (Schreck et al., 2014). The eight major cyclones broke the previous record of seven in $1993 / 94$. The $2018 / 19$ SIO season also had a record-breaking number of cyclone days, 39 days in total, overtaking the previous records of 1993/94 (36 days) and 2001/02 (35 days). Unfortunately, the season also set records for deaths and economic losses with over 1300 fatalities and total damage exceeding $\$ 2.3$ billion (U.S. dollars). Cyclone Idai caused the majority of deaths and damage and was one of the worst natural disasters on record to impact southern Africa.

The 2018/19 seasonal ACE index was $154 \times 10^{4} \mathrm{kt}^{2}$, above the $1981-2010$ SIO average of $92 \times 10^{4}$ $\mathrm{kt}^{2}$ (Fig. 4.32b). Cyclone-favorable environmental conditions, including anomalously warm SSTs (Fig. 4.33a), enhanced convection (Fig. 4.33b), and anomalously weak shear (Fig. 4.33c) were present where the majority of TCs developed. The presence of low-level westerly anomalies along $10^{\circ} \mathrm{S}$ enhanced cyclonic vorticity for many systems, excluding TCs east of $70^{\circ} \mathrm{E}$, where easterly anomalies predominated.

\section{(II) NOTEWORTHY TROPICAL CYCLONES AND IMPACTS}

The first named cyclone of the season intensified to a Category 3 SSHWS equivalent system, with maximum 1-minute sustained winds of $100 \mathrm{kt}\left(51 \mathrm{~m} \mathrm{~s}^{-1}\right)$ and a minimum central pressure of 

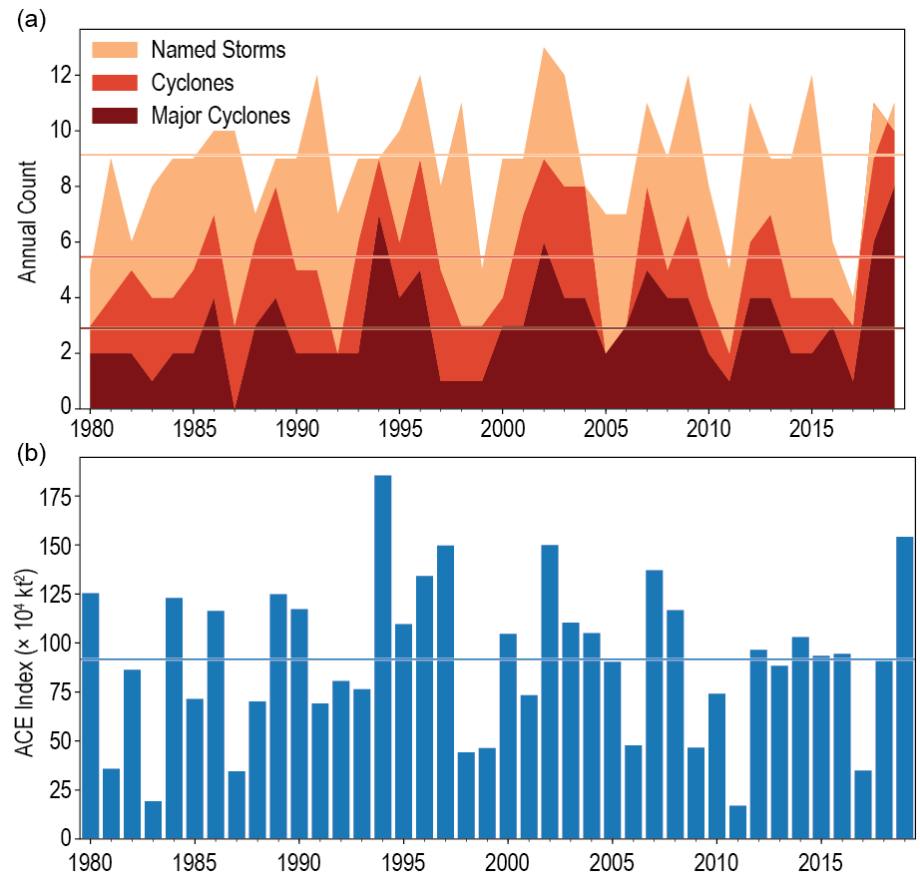

Fig. 4.32. Annual TC statistics for the SIO for 1980-2019: (a) number of named storms, cyclones, and major cyclones and (b) estimated annual ACE index $\left(\times 10^{4} \mathrm{kt}^{2}\right)$ for all TCs during which they were at least tropical storm strength or greater intensity (Bell et al. 2000). Horizontal lines represent 1981-2010 climatology.

$965 \mathrm{hPa}$. After tracking in a west-southwesterly direction toward Madagascar, Cyclone Alcide (6-13 November 2018) quickly weakened due to less favorable conditions and did not make landfall, although it did cause minor damage on the Mauritian island of Agaléga.

Cyclone Desmond (20-22 January 2019) formed as a TD off the east coast of Mozambique and recurved several times before tracking toward the northeast. Desmond intensified into a moderate TS with a peak intensity of $45 \mathrm{kt}\left(23 \mathrm{~m} \mathrm{~s}^{-1}\right)$ and minimum central pressure of $993 \mathrm{hPa}$. Desmond made landfall in Mozambique approximately $200 \mathrm{~km}$ north of Beira, bringing $277 \mathrm{~mm}$ of rainfall over a 24-hour period. Significant flooding resulted in deaths of over 1000 livestock and affected approximately 60000 ha of crops.
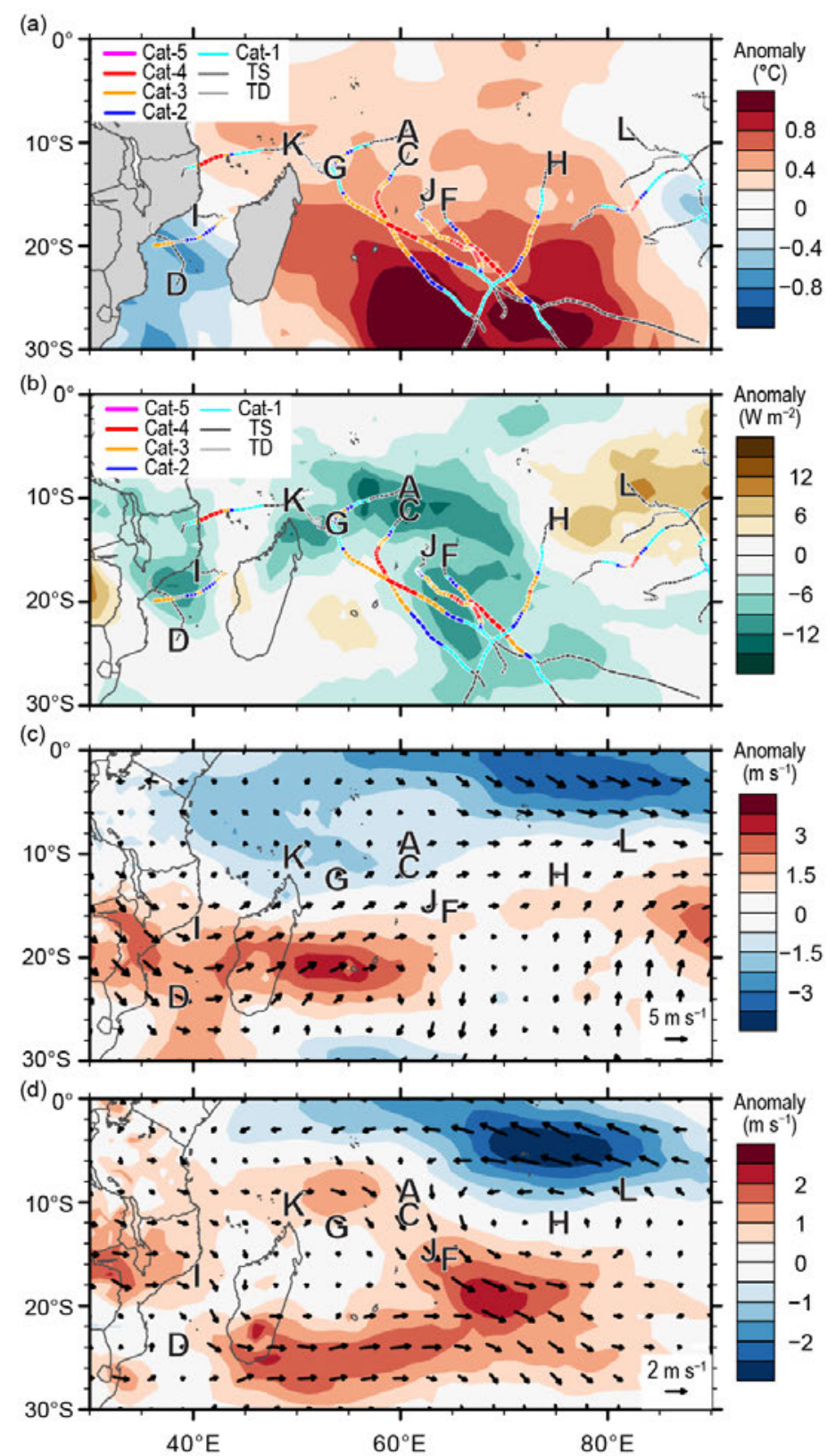

Fig. 4.33. Nov 2018-Apr 2019 SIO anomaly maps of (a) SST ( ${ }^{\circ} \mathrm{C}$; Banzon and Reynolds 2013); (b) OLR ( $\mathrm{W} \mathrm{m}^{-2}$; Schreck et al. 2018); (c) 200-850-hPa vertical wind shear $\left(\mathrm{m} \mathrm{s}^{-1}\right)$ vector (arrows) and scalar anomalies (shading), and (d) 850-hPa winds ( $\mathrm{m} \mathrm{s}^{-1}$ arrows) and zonal wind anomalies (shading). Anomalies are relative to the annual cycle from 1981-2010, except for SST, which is relative to 1982-2010. Letter symbols denote where each SIO TC attained its initial tropical storm intensity. (Source: Wind data from CFSR [Saha et al. 2014].)

Cyclone Galena (6-15 February) intensified northeast of Mauritius and reached a peak intensity of $120 \mathrm{kt}\left(61 \mathrm{~m} \mathrm{~s}^{-1}\right)$ with a minimum central pressure of $933 \mathrm{hPa}$, a Category 4 SSHWS equivalent system. It passed within $35 \mathrm{~km}$ of Rodrigues where wind gusts of $90 \mathrm{kt}\left(46 \mathrm{~m} \mathrm{~s}^{-1}\right)$ were recorded. Winds associated with Galena devastated the agricultural sector on Rodrigues and damaged approximately $90 \%$ of the island's electricity grid.

Cyclone Idai (4-16 March), a Category 3 SSHWS equivalent system, was the deadliest TC ever recorded in the SIO basin. Over 1300 people lost their lives, and 3 million people were affected or displaced across Mozambique, Zimbabwe, Malawi, and Madagascar. Idai made two landfalls over 
Mozambique. It remained over Mozambique for five days after its first landfall ( $4 \mathrm{March}$ ) before moving offshore. Just before Idai's second landfall, the system intensified, reaching peak intensity with maximum 1-minute sustained winds of $105 \mathrm{kt}\left(54 \mathrm{~m} \mathrm{~s}^{-1}\right)$ and minimum central pressure of $944 \mathrm{mb}$. Its second landfall was near Beira, Mozambique, on 15 March, and it remained over Mozambique for three days. Multiple landfalls amplified the impacts associated with Idai, which are described in Sidebar 7.3.

Cyclone Joaninha (22-31 March), a Category 4 SSHWS equivalent system, formed to the east of Madagascar. On 24 March, Joaninha achieved peak intensity, with maximum 1-minute sustained winds of $115 \mathrm{kt}\left(59 \mathrm{~m} \mathrm{~s}^{-1}\right)$ and a minimum central pressure of $937 \mathrm{hPa}$. Cyclone Joaninha was a slow-moving storm and passed within $\sim 80 \mathrm{~km}$ of Rodrigues, Mauritius, with cyclonic conditions persisting there for more than 34 hours. Wind gusts up to $100 \mathrm{kt}\left(51 \mathrm{~m} \mathrm{~s}^{-1}\right)$ and rainfall accumulations of $200 \mathrm{~mm}$ were recorded, resulting in widespread power cuts and flooding.

Cyclone Kenneth (23-26 April) was the most intense landfalling TC in Mozambique's observational record and also resulted in significant damage to the Comoro Islands, Tanzania, and Mozambique. At its peak, Kenneth reached a maximum intensity of $125 \mathrm{kt}\left(64 \mathrm{~m} \mathrm{~s}^{-1}\right)$, a category 4 SSHWS equivalent system. It passed $\sim 60 \mathrm{~km}$ north of Grande Comore Island and resulted in significant impacts there, which are described in Sidebar 7.3. Kenneth made landfall on 25 April, north of Pemba, Mozambique, with 1-minute sustained winds of $120 \mathrm{kt}\left(61 \mathrm{~m} \mathrm{~s}^{-1}\right)$. Kenneth's widespread destruction in Mozambique came as the nation was still coming to terms with the substantial impacts of TC Idai, just six weeks before.

\section{7) Australian basin-B.C. Trewin}

(I) SEASONAL ACTIVITY

The 2018/19 TC season was near normal in the broader Australian basin (areas south of the equator and between $90^{\circ} \mathrm{E}$ and $160^{\circ} \mathrm{E},{ }^{3}$ which includes Australian, Papua New Guinea, and Indonesian areas of responsibility). The season produced 11 TCs, which is near the 1983/84-2010/11 average $^{4}$ of 10.8, and is consistent with neutral ENSO conditions. The 1981-2010 IBTrACS seasonal averages for the basin are 9.9 named storms, 7.5 TCs, and 4.0 major TCs, which compares with the 2018/19 counts of 10, six, and two, respectively (Fig 4.34).

There were six TCs in the western sector ${ }^{5}$ of the broader Australian region during 2018/19, four in the northern sector, and five in the eastern sector. ${ }^{6}$ Three systems made landfall in Australia as TCs (two on multiple occasions), affecting Queensland and the Northern Territory, while a fourth approached the coast closely enough to have major impacts on land on the Pilbara coast in Western Australia. All cyclone categories referred to in this section are based on the Australian cyclone categorization scale.

\section{(II) LANDFALLING AND OTHER SIGNIFICANT TROPICAL CYCLONES}

The strongest cyclone of the season was Veronica, which approached the Pilbara coast in late March. Veronica was named at $1800 \mathrm{UTC}$ on 19 March near $15^{\circ} \mathrm{S}, 120^{\circ} \mathrm{E}$. It intensified rapidly over the following 24 hours while moving generally west-southwest, and it reached Australian Category 5 intensity at $0000 \mathrm{UTC}$ on $21 \mathrm{March}$, near $17^{\circ} \mathrm{S}, 118^{\circ} \mathrm{E}$, with maximum sustained 10 -minute wind speeds of $115 \mathrm{kt}\left(59 \mathrm{~m} \mathrm{~s}^{-1}\right)$ and a central pressure of $928 \mathrm{hPa}$. It weakened slightly as it moved toward

\footnotetext{
${ }^{3}$ The Australian Bureau of Meteorology's warning area overlaps both the southern Indian Ocean and southwest Pacific.

${ }^{4}$ Averages are taken from 1983/84 onward as that is the start of consistent satellite coverage of the region.

${ }^{5}$ The western sector covers areas between $90^{\circ} \mathrm{E}$ and $125^{\circ} \mathrm{E}$. The eastern sector covers areas east of the eastern Australian coast to $160^{\circ} \mathrm{E}$, as well as the eastern half of the Gulf of Carpentaria. The northern sector covers areas from $125^{\circ} \mathrm{E}$ east to the western half of the Gulf of Carpentaria. The western sector incorporates the Indonesian area of responsibility, while the Papua New Guinea area of responsibility is incorporated in the eastern sector.

${ }^{6}$ Trevor and Owen passed through both the northern and eastern sectors, Wallace through both the northern and western sectors, and Lili through both the northern sector and the Indonesian warning area of responsibility, which is included with the western sector.
} 
the coast but was still at Category 4 intensity near the coast, about $100 \mathrm{~km}$ northeast of Karratha, at 0000 UTC on 24 March. Veronica then remained near-stationary, moving less than $50 \mathrm{~km}$ in 24 hours, while slowly weakening, before resuming its movement west, parallel to the Pilbara coast. It weakened below TC intensity by 0000 UTC on 26 March. The remnant low crossed North West Cape later that day before dissipating to the west.

While Veronica did not make landfall as a TC, its prolonged presence caused extended shutdowns of mining, oil, and gas industries in the region, with economic losses from lost production estimated at over $\$ 1.4$ billion (U.S. dollars). There was also heavy rain in the Pilbara region, with 72-hour totals for 24-26 March of $634 \mathrm{~mm}$ at Indee, $572 \mathrm{~mm}$ at Sherlock, $539 \mathrm{~mm}$ at Mallina, $470 \mathrm{~mm}$ at Upper North Pole (near Marble Bar), and 356 $\mathrm{mm}$ at Port Hedland. Local and river flooding caused traffic disruptions and some livestock losses.

On 17 March, TC Trevor formed in the Coral
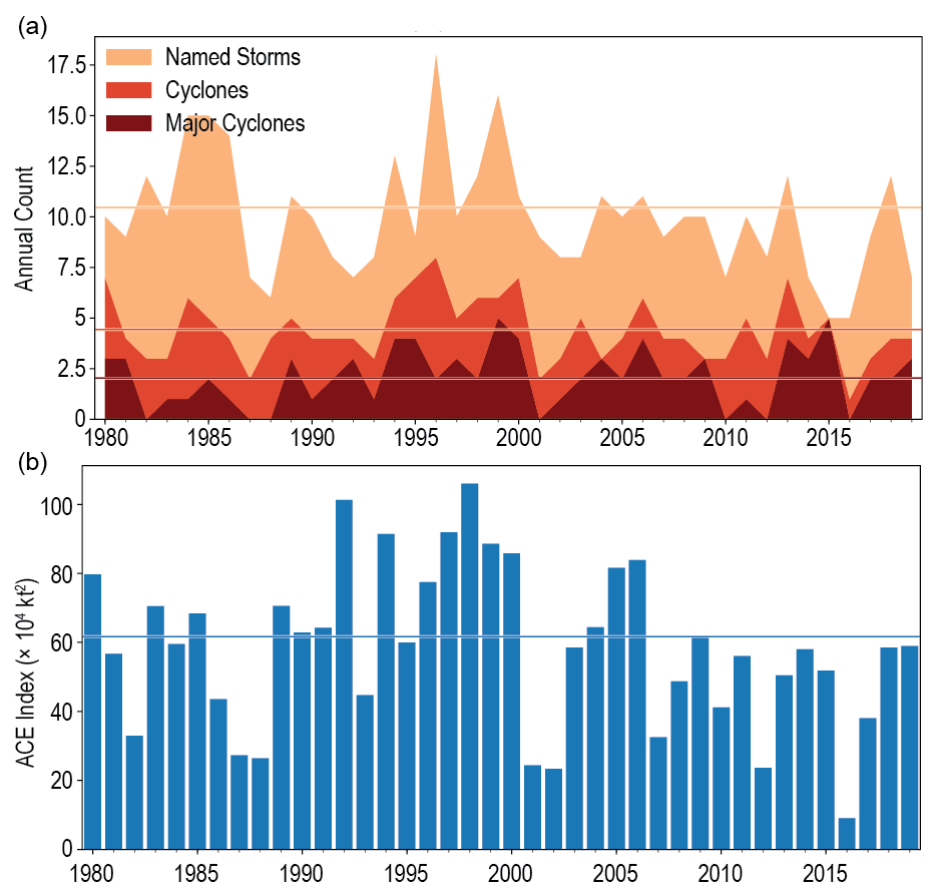

Fig. 4.34. Annual TC statistics for the Australian basin for 1980-2019: (a) number of named storms, cyclones, and major cyclones and (b) the estimated annual ACE $\left(\times 10^{4} \mathrm{kt}^{2}\right)$ for all TCs at least tropical storm strength or greater intensity (Bell et al. 2000). The 1981-2010 means (horizontal lines) are included in both (a) and (b).

Sea at 1800 UTC. It moved west while intensifying and made its initial landfall as a Category 3 system near Lockhart River, on the Cape York Peninsula, around 0900 UTC on 19 March. It weakened to a Category 1 system while crossing the Peninsula, before re-emerging south of Weipa on the morning of 21 March. Once over the Gulf of Carpentaria, Trevor reintensified rapidly while moving southwest, reaching Category 4 intensity early on 23 March with maximum sustained winds of $95 \mathrm{kt}\left(49 \mathrm{~m} \mathrm{~s}^{-1}\right)$ while off the coast west of the Northern Territory-Queensland border. It made landfall around 0000 UTC at slightly below-peak intensity, east of Port McArthur on the Northern Territory coast. The system weakened below TC intensity that evening as it moved inland, but it remained as a remnant low for several days, initially moving south through the eastern Northern Territory and then east through Queensland, finally dissipating near Richmond on 28 March.

There was substantial tree and some building damage near the point of Trevor's initial landfall at Lockhart River. The second landfall was in a sparsely populated area, and few impacts were reported. Storm surge heights east of that landfall reached $1.8 \mathrm{~m}$ at Burketown and $1.7 \mathrm{~m}$ at Mornington Island. Precautionary evacuations were carried out in a number of communities on the island of Groote Eylandt and parts of the Northern Territory coast. The heaviest rainfalls from Trevor were near the point of its Cape York Peninsula landfall, with $302 \mathrm{~mm}$ (and a two-day total of $421 \mathrm{~mm}$ ) at Lockhart River on 20 March and $211 \mathrm{~mm}$ at Aurukun on 21 March. East of Trevor's second landfall, Westmoreland Station received $282 \mathrm{~mm}$ on 24 March. Following landfall, numerous daily rainfalls exceeding $100 \mathrm{~mm}$ were recorded in the eastern Northern Territory and far western Queensland, including $178 \mathrm{~mm}$ on 27 March at Trepell Airport, north of Boulia. The postlandfall rains caused widespread flooding on both sides of the Northern Territory-Queensland border, with significant cattle losses in some areas. Floodwaters moved south and eventually contributed to a partial filling of Lake Eyre.

TC Owen initially formed in the Coral Sea on 2 December, but soon weakened and moved west before making landfall near Port Douglas as a tropical low early on 10 December. The system crossed Cape York Peninsula and emerged over the Gulf of Carpentaria, moving west and 


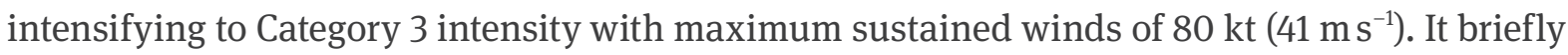
touched the Northern Territory coast north of Port McArthur early on 13 December, at peak intensity, before beginning to move east and almost retracing its path across the Gulf. It made landfall again on the east coast of the Gulf, near the mouth of the Gilbert River, at slightly below-peak intensity, at about 1900 UTC on 14 December. Owen weakened to a tropical low that crossed Cape York Peninsula a second time and re-emerged into the Coral Sea. The two cyclone-intensity landfalls of Owen were both in remote, sparsely populated areas, and few impacts were reported. The major impacts were from flooding on the east coast during its tropical low phases. On 10 December, Kirrama Range (west of Cardwell) received $349 \mathrm{~mm}$, but the most extreme rainfall occurred where the low moved offshore late in its lifetime. On 16 December, $681 \mathrm{~mm}$ fell at Halifax, the heaviest daily total recorded in Australia in December, and a number of other sites on the east coast exceeded $500 \mathrm{~mm}$. There was substantial local flooding and some crop damage was reported.

The season's other landfall was Penny, which peaked at Category 2 intensity in the Coral Sea after crossing Cape York Peninsula from the west and reforming. It made landfall near Weipa as a Category 1 system on the afternoon of 1 January. Savannah remained well off the coast of western Australia while peaking at Category 4 intensity in mid-March, but the precursor low brought heavy rain to the Indonesian island of Java, with substantial flooding and some loss of life.

\section{8) Southwest Pacific basin-J.-M. Woolley, P. R. Pearce, A. M. Lorrey, and H. J. Diamond}

(I) SEASONAL ACTIVITY

The 2018/19 TC season in the southwest Pacific officially began in November 2018 and ended in April 2019; however there was both early and late activity in this region with "out of season" storms. Storm track data for 2018/19 were gathered from the Fiji Meteorological Service, Australian Bureau of Meteorology, and New Zealand MetService, Ltd. The southwest Pacific basin (defined by Diamond et al. 2012 as $135^{\circ} \mathrm{E}-120^{\circ} \mathrm{W}$ ) had nine TCs, including four severe TCs (based on the Australian TC intensity scale). As noted in section 4e1, Fig. 4.35 shows the standardized TC distribution based on the basin spanning the area from $160^{\circ} \mathrm{E}-120^{\circ} \mathrm{W}$ to avoid overlaps with the Australian basin that could result in double counting of storms. However, it is important to use the definition of the southwest Pacific basin of Diamond et al. (2012) as that is how annual TC outlooks are produced and disseminated.

The 1981-2010 Southwest Pacific Enhanced Archive of Tropical Cyclones (SPEArTC) indicates a seasonal average of 10.4 named TCs and 4.3 severe TCs. The 2018/19 TC season therefore had near-normal activity with nine named TCs, of which four were severe. The first and last storm formed outside of the formally defined TC season, with TC Liua occurring in the Solomon Sea in late September 2018 and TC Ann developing in May 2019. The ratio of severe TCs relative to the total number of named TCs in 2018/19 was 44\%, which is $6 \%$ lower than the previous season.

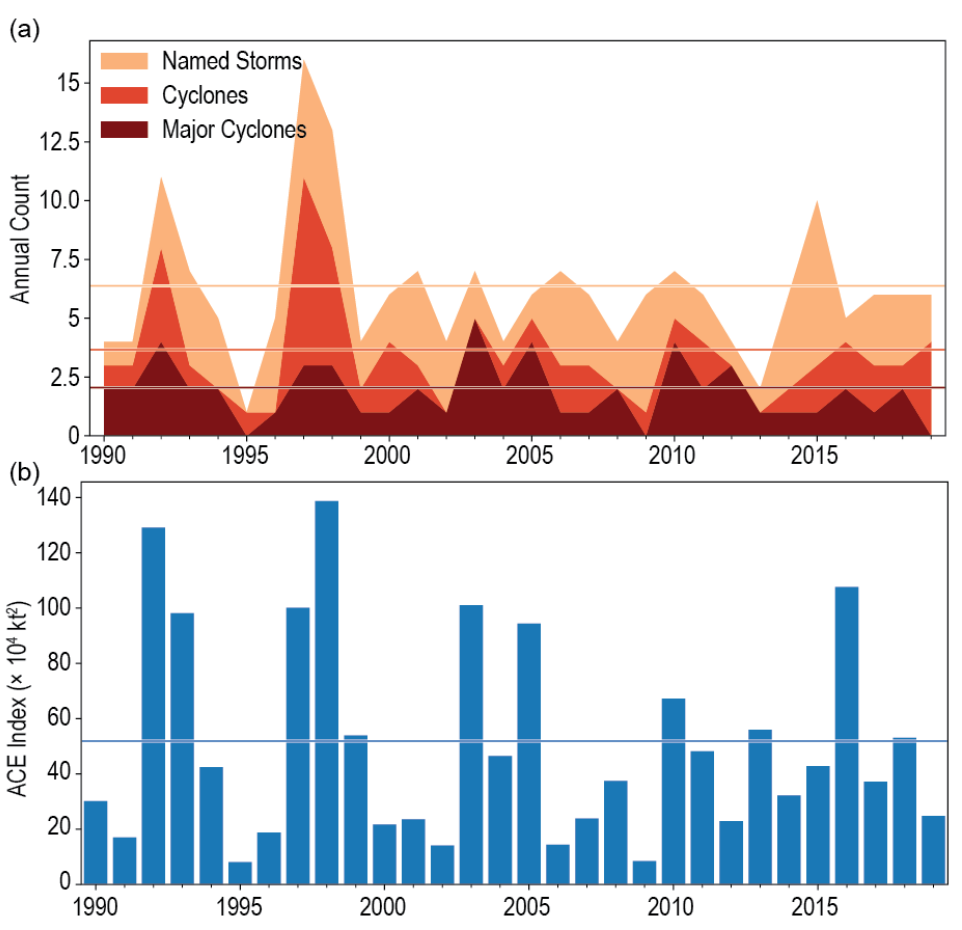

Fig. 4.35. Annual TC statistics for the southwest Pacific for 1980-2019: (a) number of named storms, cyclones, and major cyclones and (b) the estimated annual ACE index $\left(\times 10^{4} \mathrm{kt}^{2}\right)$ for all TCs at least tropical storm strength or greater intensity (Bell et al. 2000). The 1981-2010 means (horizontal lines) are included in both (a) and (b). 
(II) LANDFALLING AND OTHER SIGNIFICANT TROPICAL CYCLONES

The first named TC of the 2018/19 season was reported as a tropical disturbance on 24 September 2018 to the east-northeast of Port Moresby in Papua New Guinea. On 26 September, the system moved southeast and intensified into a Category 1 TC named TC Liua. After intensifying to Category 1, TC Liua turned west and began to track toward Port Moresby, weakening into a TD on 28 September and further dissipating over the northern Coral Sea over the following days. TC Liua's peak 10-minute sustained winds were $40 \mathrm{kt}\left(21 \mathrm{~m} \mathrm{~s}^{-1}\right)$ and its minimum central pressure was $994 \mathrm{hPa}$.

Severe TC Owen began as a low-pressure system over the Solomon Islands that developed into a tropical low on 29 November. The system became more organized the following day as it tracked southwest toward Tagula Island, then strengthened further as it tracked over the Coral Sea in favorable conditions. On 2 December, the system was classified as a Category 1 TC, but Owen weakened rapidly on 4 December and was downgraded to a tropical low. The degradation into a tropical low was temporary, as this system made landfall north of Cardwell, Queensland, on 10 December and re-attained Category 1 intensity on 11 December over the Gulf of Carpentaria. TC Owen looped and tracked back east, peaking as a Category 3 severe TC with maximum 10-minute

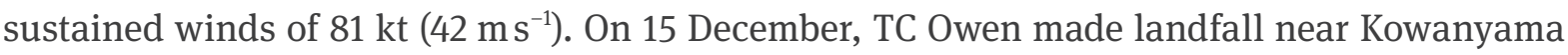
as a low-end Category 3 severe TC. TC Owen's passage over northern Queensland brought heavy rainfall to the region.

Penny was the third TC of the season, which began as a tropical low located near the eastern coastline of Cape York Peninsula, Queensland, in late December 2018. The system tracked westward, emerging in the Gulf of Carpentaria on 31 December before turning eastward and strengthening into a Category 1 storm on the same day. On 1 January, TC Penny made landfall on the western Cape York Peninsula coastline, south of Weipa and was downgraded to a gale-force tropical low as it weakened over land. On 2 January, TC Penny achieved Category 1 status again after reorganizing over the Coral Sea. TC Penny's peak 10-minute sustained winds were $51 \mathrm{kt}$ (26 $\mathrm{m} \mathrm{s}^{-1}$ ), and its minimum central pressure was $987 \mathrm{hPa}$.

TC Mona began as a tropical low near the southern Solomon Islands in a trough stretching across the northern Coral Sea. On 3 January, TC Mona achieved Category 1 status, north of Fiji. Mona intensified to Category 2 status the following day. It then tracked south toward Fiji and dissipated on 7 January. Approximately 2000 people took shelter in evacuation centers, and 30 roads were closed, mostly due to floods and some landslides. TC Mona's peak 10-minute sustained winds were $51 \mathrm{kt}\left(26 \mathrm{~m} \mathrm{~s}^{-1}\right)$, and its minimum central pressure was $985 \mathrm{hPa}$.

Severe TC Oma began as a tropical low which had developed within an active monsoon trough along the coast of Vanuatu on 7 February. On 11 February, Oma intensified into a TC, quickly reaching Category 2 TC intensity. Oma achieved Category 3 TC status on 16 February, and again on 19 February following a brief weakening. Oma's peak 10-minute sustained winds were $70 \mathrm{kt}$ $\left(36 \mathrm{~m} \mathrm{~s}^{-1}\right)$, and its minimum central pressure was $974 \mathrm{hPa}$. Oma weakened to a Category $2 \mathrm{TC}$ as it tracked southwest toward the Australian coast. On 22 February, TC Oma transitioned into a subtropical cyclone while turning to the northeast and continued to weaken further over the following days as it tracked farther in this direction. On 27 February, Oma turned eastward, while situated over Vanuatu, and dissipated on 28 February.

During early February, TC Oma pushed a bulk carrier freighter aground on a coral reef in the Solomon Islands, resulting in an oil spill, with an estimated cleanup cost of $\$ 50$ million (U.S. dollars). Vanuatu was affected for several days by persistent heavy rain, damaging surf, and strong winds, particularly in the northern provinces of Malampa, Sanma, and Torba. Storm surge reportedly extended up to $50 \mathrm{~m}$ inland in some locations, impacting houses along the coast, particularly those constructed using traditional methods. In Torba, communications and transport links to the north were disrupted while flooding cut off road access to main services such as the hospital. New Caledonia was also impacted by heavy rain and damaging winds from TC Oma. 
Thousands of people there were left without power while flooding made some roads impassable. Agriculture in New Caledonia was significantly affected, and the French government released \$1.43 million (U.S. dollars) for recovery. Queensland was hit by large swells for about one week, causing significant beach erosion. More than 30 people required rescue, with some hospitalized, due to turbulent waters. One person drowned just off North Stradbroke Island. Heavy winds also damaged Cavendish banana plantations in Cudgen, New South Wales.

Severe TC Pola began as a tropical disturbance that formed northeast of Tonga on 23 February. Pola intensified into a TD while moving slowly southward. Pola became a Category 1 TC on 26 February and intensified into a Category 2 TC later that day. On 27 February, the system became a severe TC. On 28 February, Pola reached its peak intensity as a Category 4 TC with 10-minute sustained winds of $89 \mathrm{kt}\left(46 \mathrm{~m} \mathrm{~s}^{-1}\right)$ and a minimum central pressure of $950 \mathrm{hPa}$.

Severe TC Trevor originated as a tropical low which formed off of the east coast of Papua New Guinea on 15 March. The system tracked southeast, crossing Papua New Guinea south of Port Moresby on 16 March. On 19 March, Trevor made landfall on the far northeast of the Queensland coast as a Category 3 severe TC and crossed Cape York Peninsula, downgrading to a Category 1 storm as it did so. As TC Trevor tracked southwest across the Gulf of Carpentaria, it intensified rapidly to a Category 4 system and then made landfall on the Northern Territory's Gulf coastline east of Borroloola on 23 March. The storm weakened as it moved inland. TC Trevor's peak 10-minute sustained winds were $94 \mathrm{kt}\left(49 \mathrm{~m} \mathrm{~s}^{-1}\right)$, and its minimum central pressure was $950 \mathrm{hPa}$. Flooding in Queensland associated with the cyclone caused a farm to suffer loss of cattle and damage to equipment estimated to cost at least $\$ 710000$ (U.S. dollars). There was little reported in terms of major damage or injuries in the Northern Territory.

TC Ann originated from a tropical low that formed on 7 May, east of Honiara in the Solomon Islands. The low tracked slowly toward the southwest in a favorable environment, passing close to Honiara on 8 May and then moved southward, passing between the Australian cyclone region and South Pacific cyclone region three times over several days. On 11 May, the system intensified into a Category $1 \mathrm{TC}$ before turning west-northwest and further strengthening over the Coral Sea. On 12 May, Ann reached peak intensity as a Category 2 TC with 10-minute sustained winds of 51 $\mathrm{kt}\left(26 \mathrm{~m} \mathrm{~s}^{-1}\right)$ and a central barometric pressure of $993 \mathrm{hPa}$. TC Ann weakened to a gale-force tropical low on 14 May and made landfall near Lockhart River on Cape York Peninsula on 15 May. The system continued to track west-northwest for several days and dissipated as a tropical low near East Timor on 18 May. Impacts associated with TC Ann were relatively minor, with heavy rainfall and gusts experienced in many areas south of where the system made landfall as a tropical low.

\section{g. Tropical cyclone heat potential-R. Domingues, G. J. Goni, J. A. Knaff, I-I Lin, and F. Bringas}

Upper-ocean thermal conditions observed during 2019 within the seven tropical cyclone (TC) basins are described here with respect to the long-term mean (1993-2018) and to conditions observed in 2018. The analysis focuses on vertically integrated temperature conditions based on the Tropical Cyclone Heat Potential (TCHP; e.g., Goni et al. 2009, 2017) which is calculated as the integrated heat content between the sea surface and the depth of the $26^{\circ} \mathrm{C}$ isotherm (the minimum temperature required for genesis and intensification, Leipper and Volgenau 1972; Dare and McBride 2011). The TCHP is an indicator of the amount of heat stored in the upper ocean and available to fuel TC intensification and modulates TC-induced sea surface temperature (SST) cooling and ocean-hurricane enthalpy fluxes (e.g., Lin et al. 2013). Areas in the ocean with TCHP values above $50 \mathrm{~kJ} \mathrm{~cm}^{-2}$ have been associated with TC intensification and rapid intensification (e.g., Shay et al. 2000; Mainelli et al. 2008; Lin et al. 2014; Knaff et al. 2018), provided that atmospheric conditions are also favorable. Salinity in the upper layers also modulates upper-ocean turbulent mixing and, thus, can also impact the depth of the $26^{\circ} \mathrm{C}$ isotherm and the corresponding TCHP values (e.g., Balaguru et al. 2015; Domingues et al. 2015). 
The analysis developed here focuses primarily on seasonal TCHP anomalies (Fig. 4.36) calculated as departures from the long-term mean (1993-2019) for the primary months of TC activity in each hemisphere: June-November 2019 in the Northern Hemisphere (NH) and November 2018-April 2019 in the Southern Hemisphere (SH). Differences between the 2019 and 2018 seasons are also analyzed (Fig. 4.37). In any given TC basin, TCHP anomalies can exhibit large spatial and temporal variability linked with large mesoscale ocean features, and short-term, interannual (e.g., El Niño-Southern Oscillation [ENSO]), and longer-term ocean variability, such as the Pacific Decadal Variability.

The 2019 TC season exhibited abovenormal TCHP anomalies, which are favorable for TC development and intensification, in most TC basins (Fig. 4.36). TCHP values also increased in

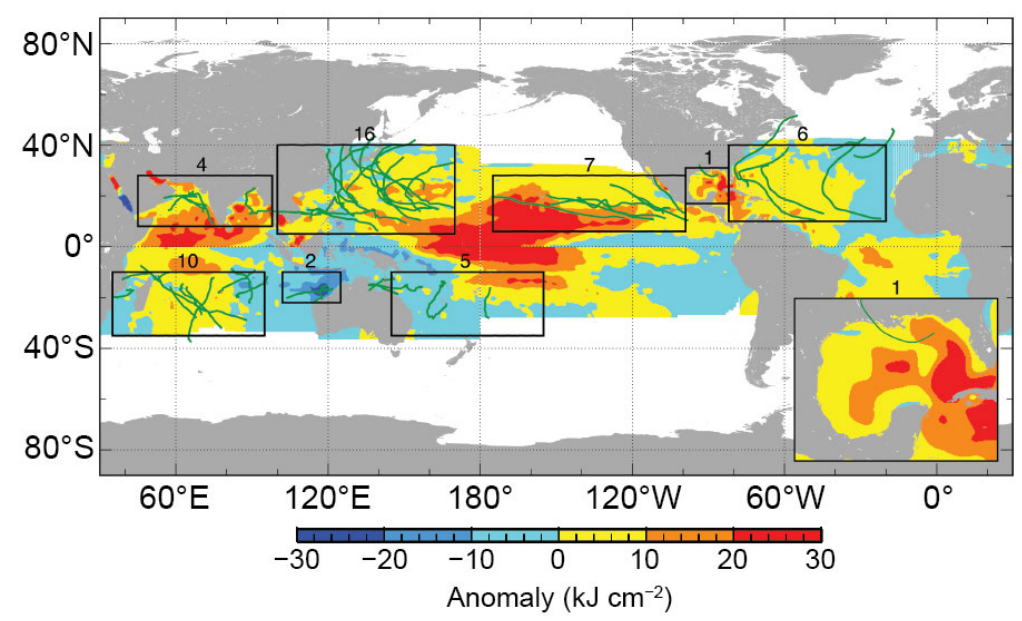

Fig. 4.36. Global anomalies of TCHP during 2019 computed as described in the text. Boxes indicate the seven regions where TCs occur: from left to right, Southwest Indian, North Indian, West North Pacific, Southeast Indian, South Pacific, East Pacific, and North Atlantic (shown as Gulf of Mexico and tropical Atlantic separately). The green lines indicate the trajectories of all TCs reaching at least Category-1 (1-min average wind $\geq 64 \mathrm{kts}, 34$ $\mathrm{m} \mathrm{s}^{-1}$ ) and above during Nov 2018-Apr 2019 in the SH and JunNov 2019 in the NH. The numbers above each box correspond to the number of Category-1 and above cyclones that travel within each box. The Gulf of Mexico conditions are shown in the inset in the lower right corner. most basins from 2018 to 2019 (Fig. 4.37), with notable warming of $20 \mathrm{~kJ} \mathrm{~cm}^{-2}$ with respect to 2018 observed at: (1) portions of the Gulf of Mexico associated with Loop Current dynamics; (2) large areas in the South and North Indian Ocean basins; and (3) the western North Pacific basin Main Development Region (MDR; Lin et al. 2014), i.e., east of the Philippines between $5^{\circ} \mathrm{N}$ and $20^{\circ} \mathrm{N}$, and $100^{\circ}-170^{\circ} \mathrm{E}$. Negative TCHP anomalies with respect to long-term conditions (Fig. 4.36) and the 2018 season (Fig. 4.37) were only observed in the southeast Indian basin and near the eastern portion of the South Pacific basin.

Both the North and southwest Indian Ocean basins exhibited considerably large TCHP values in 2019 (Fig. 4.36), with anomalies as large as $\sim 30 \mathrm{~kJ} \mathrm{~cm}^{-2}$ larger than the long-term average in most of the North Indian basin, including the Bay of Bengal and Arabian Sea; and $20 \mathrm{~kJ} \mathrm{~cm}^{-2}$ in the southeast Indian basin. In particular, TCHP values were consistently larger than $90 \mathrm{~kJ} \mathrm{~cm}^{-2}$ in the North Indian basin and $70 \mathrm{~kJ} \mathrm{~cm}^{-2}$ in the southeast basin (not shown). Consistent with these

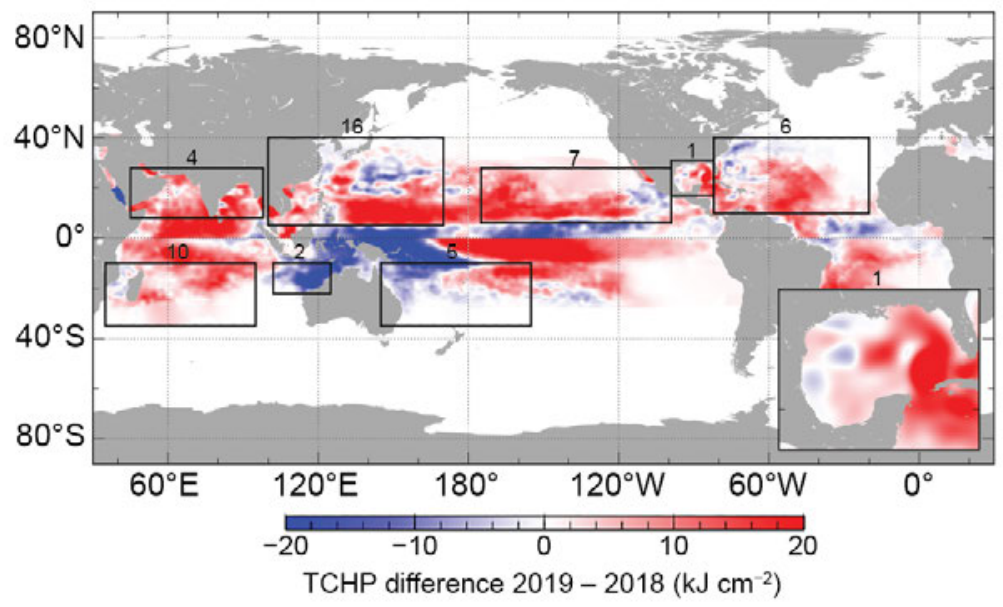

Fig. 4.37. TCHP difference between the 2019 and 2018 tropical cyclone seasons (Jun-Nov in the NH and Nov-Apr in the SH). substantially warmer conditions, both the North and southwest Indian basins were characterized by above-normal TC activity. In the North Indian basin, the 2019 TC season was one of the most active on record (see section 4f5; Fig. 4.36). In the southwest Indian basin, the 2019 TC season was the most active, costliest, and deadliest on record (see section 4f6).

In the North Pacific, upper-ocean thermal conditions are largely modulated by the state of ENSO (e.g., Lin et al. 2014, 2020; Zheng et al. 2015), which can impact conditions both in the western and eastern North Pacific basins. During 
the 2019 TC season, ENSO conditions switched from neutral in late 2018 to a weak El Niño in early 2019 and back to neutral conditions by mid-2019. Associated with the neutral ENSO state, the MDR within the western North Pacific basin exhibited TCHP values approximately 10-20 kJ $\mathrm{cm}^{-2}$ larger than the long-term mean (Fig. 4.36) and $\sim 20 \mathrm{~kJ} \mathrm{~cm}^{-2}$ larger than 2018 conditions (Fig. 4.37). These anomalies led to absolute TCHP values of $120 \mathrm{~kJ} \mathrm{~cm}^{-2}$ or larger over the MDR and of at least $70 \mathrm{~kJ} \mathrm{~cm}^{-2}$ over most of this basin. Among the TCs that formed in this basin, Super Typhoon Hagibis was a notable TC that experienced rapid intensification while traveling over areas with TCHP of $100 \mathrm{~kJ} \mathrm{~cm}^{-2}$ or larger, where it became Category 5 (not shown). Another notable case is Super Typhoon Halong, which also rapidly intensified over the MDR in areas with large TCHP values $\left(100 \mathrm{~kJ} \mathrm{~cm}^{-2}\right)$ in November, reaching a maximum wind speed of $155 \mathrm{kts}\left(80 \mathrm{~m} \mathrm{~s}^{-1}\right)$. Halong was the most intense TC globally in 2019, but fortunately did not make landfall.

In the eastern North Pacific basin, TCHP values were consistently larger than long-term average conditions by $10-30 \mathrm{~kJ} \mathrm{~cm}^{-2}$ (Fig. 4.36). Compared to 2018 conditions, TCHP values were 20 $\mathrm{kJ} \mathrm{cm}^{-2}$ larger in 2019 over the central part of the basin between $180^{\circ} \mathrm{W}$ and $120^{\circ} \mathrm{W}$ and slightly cooler by less than $10 \mathrm{~kJ} \mathrm{~cm}^{-2}$ closer to Central America. Of note, Major Hurricane Erick's rapid intensification west of $140^{\circ} \mathrm{E}$ was aided by the higher TCHP in this region.

Finally, in the North Atlantic basin, TCHP values were $\sim 10 \mathrm{~kJ} \mathrm{~cm}^{-2}$ above the long-term average (Fig. 4.36) in most parts of the basin, and warmer than 2018 in the central part of the basin between $60^{\circ} \mathrm{W}$ and $30^{\circ} \mathrm{W}$ and in the Gulf of Mexico, where the Loop Current extended northward and shed a warm core ring. Associated with these conditions, the North Atlantic basin exhibited above-normal hurricane activity for the fourth consecutive year. Higher TCHP values over the central portion of the basin likely contributed to the rapid intensification of five of the total six hurricanes that developed in that region of the North Atlantic in 2019 (Fig. 4.36). Hurricane Dorian, now regarded as the most powerful hurricane on record for the Atlantic outside of the tropics $\left(>23.5^{\circ} \mathrm{N}\right)$ in the satellite era (since 1966), reached its peak intensity while traveling over areas with TCHP values consistently above $70 \mathrm{~kJ} \mathrm{~cm}^{-2}$ and as large as $90 \mathrm{~kJ} \mathrm{~cm}^{-2}$ (not shown). These conditions are well above the $50 \mathrm{~kJ} \mathrm{~cm}^{-2}$ minimum threshold required to support Atlantic hurricane intensification (Mainelli et al. 2008). In addition to high TCHP values, Dorian traveled and intensified over areas with low surface salinity values associated with the Amazon and Orinoco riverine plumes (not shown). Areas with this type of low surface salinity are known for favoring TC intensification by creating barrier layer conditions that suppress upper-ocean mixing, maintaining enthalpy fluxes from the ocean into the hurricane (e.g., Balaguru et al. 2015; Domingues et al. 2015).

In summary, upper-ocean conditions conducive for TC development and intensification observed in 2019 were associated with higher-than-normal values of TCHP in most TC basins in 2019. Notable warming with respect to 2018 was also recorded in most basins, especially in the Gulf of Mexico, the west North Pacific, and the Indian Ocean, particularly the Arabian Sea. These warmer-than-usual conditions contributed to the more intense and above-normal TC activity in most of these basins.

\section{h. Indian Ocean dipole-L. Chen, J.-J. Luo, and A.D. Magee}

The Indian Ocean dipole (IOD) is an inherent air-sea coupling mode in the tropical Indian Ocean. It originates from local air-sea interaction in the Indian Ocean and/or the forcing associated with the El Niño-Southern Oscillation (ENSO) in the tropical Pacific (Saji et al. 1999; Luo et al. 2010). Typically, IOD events develop in boreal summer, peak in boreal autumn, and terminate

rapidly in early boreal winter. During the late boreal spring to autumn 2019, a positive IOD (pIOD) with extreme intensity occurred for the first time since 1997. Prior to the pIOD event in 1997, the previous extreme pIOD event occurred in 1994 (Luo et al. 2007, 2008).

In the tropical Pacific, a weak El Niño occurred in the boreal winter of 2018/19 and returned to neutral conditions by the boreal summer of 2019, but the sea surface anomalously warmed there during the autumn of 2019 (Fig. 4.38c). In the tropical Indian Ocean, a weak pIOD occurred during 
the autumn of 2018 but rapidly deteriorated early in the winter of 2018/19 (Figs. 4.38a,b; Chen and Luo 2019). For the first four months of 2019 (Figs. 4.38 a,b), IOD-related sea surface temperature (SST) anomalies were near zero. Meanwhile, weak surface easterly wind anomalies prevailed over the central equatorial Indian Ocean during the boreal winter of 2018/19 (partly due to the remote influence of the weak El Niño). These anomalies weakened to near zero in March-April 2019 (Fig. 4.38b). Both pIODrelated SST anomalies (SSTA) and easterly wind anomalies started to grow sharply beginning in May 2019 (Fig. 4.38b). The initial SSTA in the southeastern Indian Ocean exhibited cooling along the south coast of Java in May 2019, and then the cooling signal gradually strengthened and expanded toward the west coast of Sumatra and eastern equatorial Indian Ocean (Figs. 4.39b-d). The positive SSTA in the western equatorial Indian Ocean can be traced back to the persistent warming SSTA associated with the Indian Ocean basin mode throughout the late 2018/19 boreal winter and early 2019 spring (Figs. 4.39a,b). Then the anomalously warm SSTA in the western Indian Ocean maintained its intensity throughout June-October 2019 (Figs. 4.38a, 4.39c,d). The negative SSTA in the eastern pole started to grow from May and continued to increase quickly until October (Figs. 4.38a, 4.39b-d).

Since the pIOD started to grow in May, positive precipitation anomalies developed near the western pole with dry anomalies near the eastern pole (Fig. 4.38a). This pattern indicates that the precipitation anomalies in the equatorial Indian Ocean were well coupled with the easterly wind anomalies in the central equatorial Indian Ocean and SSTA throughout the development of this pIOD event. Before the development of the IOD-related SSTA, a positive precipitation anomaly occurred near the eastern pole of the IOD in April (Fig. 4.38a), which might be associated with atmospheric high-frequency "noise." This positive precipitation near the eastern pole may have played a role in inducing the initial southeasterly wind anomaly along the south coast of Java and southwest coast of Sumatra in April, which caused the positive Bjerknes feedback (Bjerknes 1969) over the following months, ultimately leading to the pIOD event.

The pIOD in 2019, whose Dipole Mode Index (DMI) attained $\sim 2.1^{\circ} \mathrm{C}$ in October 2019, exhibited the greatest magnitude in the observational record since 1997 (Fig. 4.40c). The surface zonal wind anomaly in the central equatorial Indian Ocean related to the pIOD in 2019 ranked only second to the extraordinary pIOD event in 1997 (Fig. 4.40d). In contrast to the extreme pIOD in 1997 that occurred with an extremely strong El Niño, the 2019 pIOD event was accompanied by a 
neutral ENSO state in the tropical Pacific (Fig. 4.40e). There is no clear evidence supporting that remote processes in the tropical Pacific played an essential role in generating the pIOD event in 2019. Rather, it appears that the development of this extreme pIOD event was largely generated by local processes in the Indian Ocean. This is different from the majority of pIOD events, which have often co-occurred with El Niño events (e.g., 6 out of 10 past pIOD events since 1980 co-occurred with El Niño, as shown in Fig. 4.40). It is also worth noting that the positive SSTA in the western pole reached $\sim 0.8^{\circ} \mathrm{C}$ and the negative SSTA in the eastern pole reached $-1.3^{\circ} \mathrm{C}$ in late autumn of 2019 (Figs. 4.40a,b). The former ranked first among all historical pIOD events, which may be traced back to the continuous enhancement of tropical Indian Ocean warming during recent decades (Luo et al. 2012).

Impacts associated with this strong pIOD event were widespread and preconditioned a number of events across the globe. In Australia, the austral spring of 2019 was the driest on record, and along with a particularly dry austral winter, fueled an unusually early start to the bushfire season (see section 7h4 and Sidebar 7.6 for details). Fires continued to burn into early 2020. This strong pIOD event resulted in significant flooding in eastern Africa, with some regions in the Horn of Africa seeing up to $300 \%$ above-average rainfall between October and mid-November, ranking among the wettest rainfall seasons in east Africa in at least 40 years. Approximately Warning Systems Network 2020). The strong pIOD has also been associated with the ongoing drought and smoke haze in Indonesia.

In summary, the strongest pIOD event since 1997 occurred in October 2019. During the course of the growth of this pIOD event, equatorial zonal wind, precipitation, and SST anomalies in the equatorial Indian Ocean all coupled well with each other. As shown in Fig. 4.40f, in April-May, low-level southeasterly anomalies prevailed near the south coasts of Java and Sumatra, and the negative SSTA near the eastern pole started to grow rapidly. Concurrently, weak, warm SSTA persisted near the western pole (which may be associated with the prolonged Indian Ocean basin warming during early 2019). As a result, low-level easterly wind anomalies started to grow in the central equatorial Indian Ocean in May. Through the positive Bjerknes feedback, the pIOD event was generated, and the corresponding anomaly signal peaked during the autumn of 2019. In December, the IOD-related SST, precipitation, and wind anomalies quickly deteriorated. The extreme pIOD event in 2019 seems to have originated from air-sea feedback processes in the 
Indian Ocean itself, rather than being induced by the remote influence of El Niño. Interestingly, such a unique development feature of the pIOD in 2019 differs from many of the past pIOD events that co-occurred with El Niño events.

(a) IODW SSTA

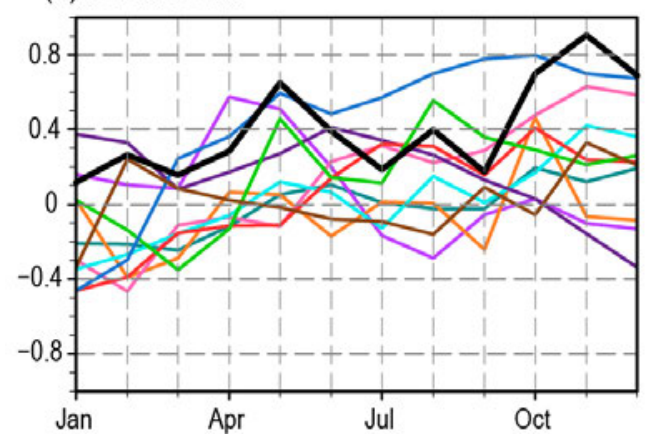

(c) IOD Index

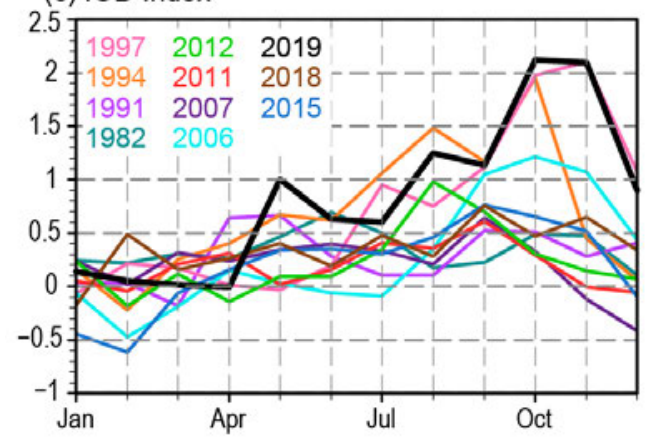

(e) Niño-3.4

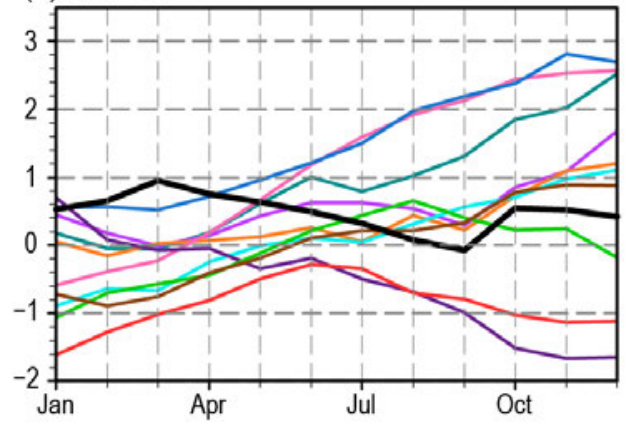

(b) IODE SSTA

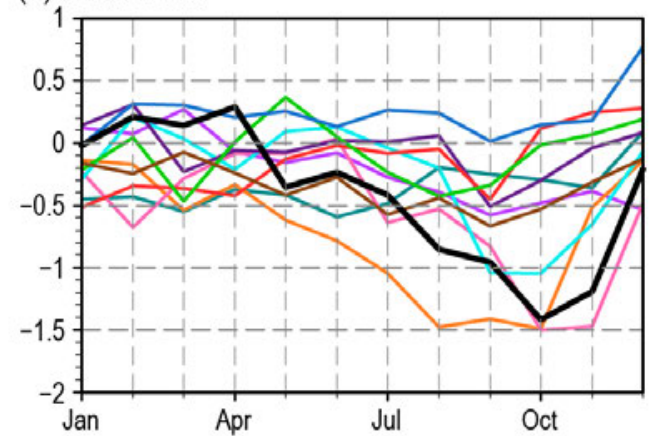

(d) $\mathrm{U} 10 \mathrm{~m}$ in central IO

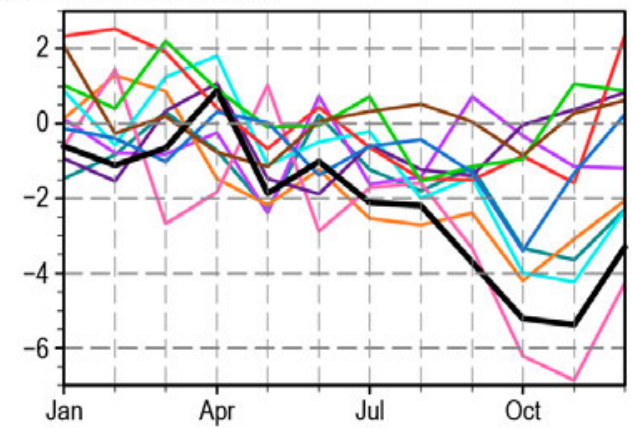

(f) IOB

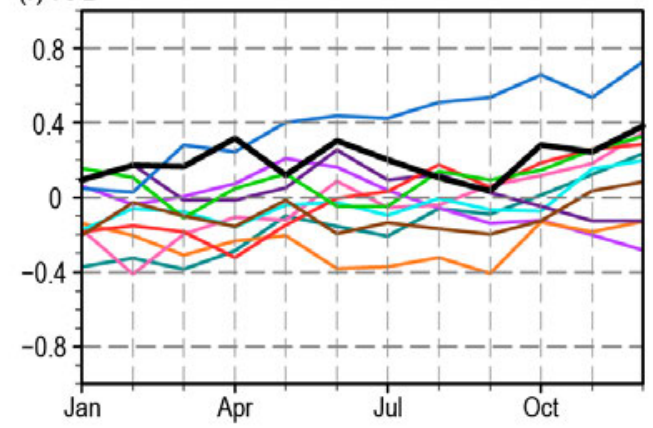

Fig. 4.40. Monthly SST anomalies in the (a) IODW, (b) IODE, and (c) the Dipole Mode Index (DMI, the SST anomaly difference between the IODW and the IODE) during 11 pIOD events since the 1980s. (d) As in (c) but for the surface zonal wind anomaly $\left(\mathrm{m} \mathrm{s}^{-1}\right)$ in the central equatorial Indian Ocean $\left(70^{\circ}-90^{\circ} \mathrm{E} ; 5^{\circ} \mathrm{N}-5^{\circ} \mathrm{S}\right)$. (e)-(f) As in (a)-(b), but for the monthly SST anomalies in the Niño-3.4 region $\left(170^{\circ}-120^{\circ} \mathrm{W} ; 5^{\circ} \mathrm{N}-5^{\circ} \mathrm{S}\right)$ and the tropical Indian Ocean basin $\left(40^{\circ}-120^{\circ} \mathrm{E} ; 20^{\circ} \mathrm{N}-20^{\circ} \mathrm{S}\right)$. (Sources: NOAA OISST [Reynolds et al. 2002]; GPCP precipitation [Huffman et al. 2009]; and JRA-55 atmospheric reanalysis [Ebita et al. 2011].) 


\section{APPENDIX: Acronym List}

\begin{tabular}{|c|c|}
\hline ACE & Accumulated Cyclone Energy \\
\hline AEJ & African Easterly Jet \\
\hline AMO & Atlantic Multidecadal Oscillation \\
\hline ASO & August-October \\
\hline CMORPH & Climate Prediction Center morphing method \\
\hline CNP & central North Pacific \\
\hline CPC & Climate Prediction Center \\
\hline DJF & December-February \\
\hline DMI & Dipole Mode Index \\
\hline ENP & eastern North Pacific \\
\hline ENSO & El Niño-Southern Oscillation \\
\hline GPI & genesis potential index \\
\hline HTC & hurricanes/typhoons/cyclones \\
\hline HURDAT2 & (National Hurricane Center's) Hurricane Database \\
\hline IBTrACS & International Best Track Archive for Climate Stewardship \\
\hline IOD & Indian Ocean dipole \\
\hline ITCZ & Intertropical Convergence Zone \\
\hline JAS & July-September \\
\hline JASO & July-October \\
\hline JFM & January-March \\
\hline JJA & June-August \\
\hline JMA & Japan Meteorological Agency \\
\hline JTWC & Joint Typhoon Warning Center \\
\hline MAM & March-May \\
\hline MDR & Main Development Region \\
\hline MJJ & May-July \\
\hline MJO & Madden Julian Oscillation \\
\hline NDJ & November-January \\
\hline $\mathrm{NH}$ & Northern Hemisphere \\
\hline $\mathrm{NIO}$ & North Indian Ocean \\
\hline OLR & Outgoing Longwave Radiation \\
\hline OND & October-December \\
\hline ONI & Oceanic Niño Index \\
\hline PAGASA & $\begin{array}{l}\text { Philippine Atmospheric, Geophysical and Astronomical Services } \\
\text { Administration }\end{array}$ \\
\hline pIOD & positive Indian Ocean dipole \\
\hline RMM & Real-time Multivariate MJO \\
\hline RMSCs & Regional Specialized Meteorological Centers \\
\hline SAM & Southern Annular Mode \\
\hline $\mathrm{SH}$ & Southern Hemisphere \\
\hline $\mathrm{SIO}$ & South Indian Ocean \\
\hline SON & September-November \\
\hline SPCZ & South Pacific Convergence Zone \\
\hline SPEArTC & Southwest Pacific Enhanced Archive of Tropical Cyclones \\
\hline SSHWS & Saffir-Simpson \\
\hline SSHWS & Saffir-Simpson Hurricane Wind Scale \\
\hline SST & sea surface temperature \\
\hline
\end{tabular}


TC

TCHP

TD

TS

TWS

WMO

WNP

WWBs tropical cyclone

Tropical Cyclone Heat Potential

tropical depression

tropical storm

trade wind surges

World Meteorological Organization

western North Pacific

westerly wind bursts 


\section{References}

Aiyyer, A., and J. Molinari, 2008: MJO and tropical cyclogenesis in the Gulf of Mexico and eastern Pacific: Case study and idealized numerical modeling. J. Atmos. Sci., 65, 2691-2704, https://doi.org/10.1175/2007JAS2348.1.

Avila, L. A., 2019: Hurricane Lorena. National Hurricane Center Tropical Cyclone Rep., 20 pp., www.nhc.noaa.gov/data/tcr/EP152019_Lorena.pdf.

_ , S. A. Stewart, R. Berg, and A. B. Hagen, 2020: Hurricane Dorian. National Hurricane Center Tropical Cyclone Rep., 74 pp., www.nhc.noaa.gov/data/ tcr/AL052019_Dorian.pdf.

Balaguru, K., G. R. Foltz, L. R. Leung, E. A. D'Asaro, K. A. Emanuel, H. Liu, and S. E. Zedle, 2015: Dynamic potential intensity: An improved representation of the ocean's impact on tropical cyclones. Geophys. Res. Lett., 42, 67396746, https://doi.org/10.1002/2015GL064822.

Banzon, V. F., and R. W. Reynolds, 2013: Use of WindSat to extend a microwavebased daily optimum interpolation sea surface temperature time series. J. Climate, 26, 2557-2562, https://doi.org/10.1175/JCLI-D-12-00628.1.

Baxter, S., S. Weaver, J. Gottschalck, and Y. Xue, 2014: Pentad evolution of wintertime impacts of the Madden-Julian Oscillation over the contiguous United States. J. Climate, 27, 7356-7367, https://doi.org/10.1175/JCLID-14-00105.1.

_ C. Schreck, and G. D. Bell, 2019: ttTropical intraseasonal activity [in "State of the Climate in 2018"]. Bull. Amer. Meteor. Soc., 100 (9), S105S107, https://doi.org/10.1175/2019BAMSStateoftheClimate.1.

Behringer, D. W., M. Ji, and A. Leetmaa, 1998: An improved coupled model for ENSO prediction and implications for ocean initialization. Part I: The ocean data assimilation system. Mon. Wea. Rev., 126, 1013-1021, https:// doi.org/10.1175/1520-0493(1998)126<1013:AICMFE>2.0.C0;2.

Bell, G. D., and M. Chelliah, 2006: Leading tropical modes associated with interannual and multi-decadal fluctuations in North Atlantic hurricane activity. J. Climate, 19, 590-612, https://doi.org/10.1175/JCLI3659.1.

,Bull. Amer. Meteor. Soc.100_ _ and Coauthors, 2000: The 1999 North Atlantic hurricane season: A climate perspective [in "State of the Climate in 1999"]. Bull. Amer. Meteor. Soc., 81 (6), S1-S68, https://doi. org/10.1175/1520-0477(2000)81[s1:CAF]2.0.CO;2.

— mate perspective [in "State of the Climate in 2003"]. Bull. Amer. Meteor. Soc., 85 (6), S1-S68, https://doi.org/10.1175/1520-0477-85.6s.S1.

_ mate perspective [in "State of the Climate in 2005"]. Bull. Amer. Meteor. Soc., 86 (6), S1-S68, https://doi.org/10.1175/1520-0477-87.6.S1.

_ season: A climate perspective [in "State of the Climate in 2016"]. Bull. Amer. Meteor. Soc., 98 (8), S109-S112, https://doi.org/10.1175/2017BAM SStateoftheClimate.1.

_ season: A climate perspective [in "State of the Climate in 2017"]. Bull. Amer. Meteor. Soc., 99 (8), S114-S118, https://doi.org/10.1175/2018BAM SStateoftheClimate.1.

- M. S. Halpert, and M. L'Heureux, 2019: ENSO and the tropical Pacific [in "State of the Climate in 2018"]. Bull. Amer. Meteor. Soc., 100 (9), S101S104, https://doi.org/10.1175/2019BAMSStateoftheClimate.1.

Bjerknes, J., 1969: Atmospheric teleconnections from the equatorial Pacific. Mon. Wea. Rev., 97, 163-172, https://doi.org/10.1175/15200493(1969)097<0163:ATFTEP>2.3.C0;2.

Blake, E. S., 2019: Tropical Storm Narda. National Hurricane Center Tropical Cyclone Rep., 14 pp., www.nhc.noaa.gov/data/tcr/EP162019_Narda.pdf.

Camargo, S. J., K. A. Emanuel, and A. H. Sobel, 2007: Use of a genesis potential index to diagnose ENSO effects on tropical cyclone genesis. J. Climate, 20, 4819-4834, https://doi.org/10.1175/JCLI4282.1.

Cassou, C., 2008: Intraseasonal interaction between the Madden Julian oscillation and the North Atlantic oscillation. Nature, 455, 523-527. Letter, https://doi.org/10.1038/nature07286.
Chen, L., and J.-J. Luo, 2019: Indian Ocean dipole [in "State of the Climate in 2018"]. Bull. Amer. Meteor. Soc., 100 (9), S138-S140, https://doi.org/10.11 75/2019BAMSStateoftheClimate.1.

Chia, H. H., and C. F. Ropelewski, 2002: The interannual variability in the genesis location of tropical cyclones in the northwest Pacific. J. Climate, 15, 2934-2944, https://doi.org/10.1175/1520-0442(2002)015<2934:TIVITG>2 $0 . \mathrm{CO} ; 2$.

CDare, R. A., and J. L. McBride, 2011: Sea surface temperature response to tropical cyclones. Mon. Wea. Rev., 139, 3798-3808, https://doi.org/10.1175/ MWR-D-10-05019.1.

Diamond, H. J., and J. A. Renwick, 2015: The climatological relationship between tropical cyclones in the southwest Pacific and the Madden-Julian Oscillation. Int. J. Climatol., 35, 676-686, https://doi.org/10.1002/joc.4012.

_ and C. J. Schreck III, Eds, 2017: The tropics [in "State of the Climate in 2016"]. Bull. Amer. Meteor. Soc., 98 (8), S93-S128, https://doi.org/10.1175/ 2017BAMSStateoftheClimate.1..

— Amer. Meteor. Soc., 99 (8), S101-S141, https://doi.org/10.1175/2018BAMS StateoftheClimate.1..

— Amer. Meteor. Soc., 100 (9), S101-S140, https://doi.org/10.1175/2019BAM SStateoftheClimate.1..

_ , A. M. Lorrey, K. R. Knapp, and D. H. Levinson, 2012: Development of an enhanced tropical cyclone tracks database for the southwest Pacific from 1840 to 2011. Int. J. Climatol., 32, 2240-2250, https://doi.org/10.1002/ joc. 2412 .

Domingues, R., G. Goni, F. Bringas, G. Halliwell, S.-K. Lee, H.-S. Kim, J. Morell, and J. Dong, 2015: Upper ocean response to Hurricane Gonzalo (2014): Results from unique observations by underwater gliders. Geophys. Res. Lett., 42, 7131-7138, https://doi.org/10.1002/2015GL065378.

Dube, S. K., D. Rao, P. C. Sinha, T. S. Murty, and N. Bahuluyan, 1997: Storm surge in the Bay of Bengal and Arabian Sea: The problem and its prediction. Mausam, 48, 288-304.

Ebita, A., and Coauthors, 2011: The Japanese 55-year reanalysis "JRA-55": An interim report. SOLA, 7, 149-152, https://doi.org/10.2151/SOLA.2011-038.

Emanuel, K. A., and D. S. Nolan, 2004: Tropical cyclone activity and the global climate system. Proc. 26th Conf. on Hurricanes and Tropical Meteorology, Miami, FL, Amer. Meteor. Soc., 10A.2, https://ams.confex.com/ ams/26HURR/techprogram/paper_75463.htm.

Enfield, D. B., and A. M. Mestas-Nuñez, 1999: Multiscale variabilities in global sea surface temperatures and their relationships with tropospheric climate patterns. J. Climate, 12, 2719-2733, https://doi.org/10.1175/15200442(1999)012<2719:MVIGSS>2.0.C0;2.

Famine Early Warning Systems Network, 2020: 2019 short rains in East Africa among the wettest on historical record,. FEWS NET, , https://fews.net/eastafrica/special-report/january-29-2020.

Frank, W. M., and P. E. Roundy, 2006: The role of tropical waves in tropical cyclogenesis. Mon. Wea. Rev., 134, 2397-2417, https://doi.org/10.1175/ MWR3204.1.

Goldenberg, S. B., and L. J. Shapiro, 1996: Physical mechanisms for the association of El Niño and West African rainfall with Atlantic major hurricane activity. J. Climate, 9, 1169-1187, https://doi.org/10.1175/1520-0442(1996)009<1169:PM FTAO $>2.0 . C 0 ; 2$.

_ C. W. Landsea, A. M. Mestas-Nuñez, and W. M. Gray, 2001: The recent increase in Atlantic hurricane activity: Causes and implications. Science, 293, 474-479, https://doi.org/10.1126/science.1060040.

Goni, G. J., and Coauthors, 2009: Applications of satellite-derived ocean measurements to tropical cyclone intensity forecasting. Oceanography, 22, 190-197, https://doi.org/10.5670/oceanog.2009.78. 
- and Coauthors, 2017: Autonomous and Lagrangian Ocean observations for Atlantic tropical cyclone studies and forecasts. Oceanography, 30, 92103, https://doi.org/10.5670/oceanog.2017.227.

Gray, W. M., 1990: Strong association between West African rainfall and U.S. landfall of intense hurricanes. Science, 249, 1251-1256, https://doi. org/10.1126/science.249.4974.1251.

Guo, Y., X. Jiang, and D. E. Waliser, 2014: Modulation of the convectively coupled Kelvin waves over South America and the tropical Atlantic Ocean in association with the Madden-Julian oscillation. J. Atmos. Sci., 71, 1371-1388, https://doi.org/10.1175/JAS-D-13-0215.1.

Halpert, M. S., and C. F. Ropelewski, 1992: Surface temperature patterns associated with the southern oscillation. J. Climate, 5, 577-593, https://doi. org/10.1175/1520-0442(1992)005<0577:STPAWT>2.0.C0;2.

Hastenrath, S., 1990: Decadal-scale changes of the circulation in the tropical Atlantic sector associated with Sahel drought. Int. J. Climatol., 10, 459472, https://doi.org/10.1002/joc.3370100504.

Hendon, H., C. Zhang, and J. Glick, 1999: Interannual variation of the MaddenJulian oscillation during austral summer. J. Climate, 12, 2538-2550, https:// doi.org/10.1175/1520-0442(1999)012<2538:IVOTMJ>2.0.C0;2.

Huang, B., and Coauthors, 2017: Extended Reconstructed Sea Surface Temperature, version 5 (ERSSTv5): Upgrades, validations, and intercomparisons. J. Climate, 30, 8179-8205, https://doi.org/10.1175/JCLI-D-16-0836.1.

Huffman, G. J., R. F. Adler, D. T. Bolvin, and G. Gu, 2009: Improving the global precipitation record: GPCP version 2.1. Geophys. Res. Lett., 36, L17808, , https://doi.org/10.1029/2009GL040000.

India Meteorological Department, 2020: Statement on climate of India during 2019. India Meteorological Department Climate Research and Services.A, accessed 14 January 2020, https://mausam.imd.gov.in/backend/assets/ press_release_pdf/Statement_on_Climate_of_India_during_2019.pdf.

Joyce, R. J., J. E. Janowiak, P. A. Arkin, and P. Xie, 2004: CMORPH: A method that produces global precipitation estimates from passive microwave and infrared data at high spatial and temporal resolution. J. Hydrometeor., 5, 487-503, https://doi.org/10.1175/1525-7541(2004)005<0487:CAMTPG>2. $0 . \mathrm{CO} ; 2$.

Kalnay, E., and Coauthors, 1996: The NCEP/NCAR 40-Year Reanalysis Project. Bull. Amer. Meteor. Soc., 77, 437-471, https://doi.org/10.1175/15200477(1996)077<0437:TNYRP>2.0.C0;2.

Kayano, M., and V. Kousky, 1999: Intraseasonal (30-60 day) variability in the global tropics: Principal modes and their evolution. Tellus, 51A, 373-386, https://doi.org/10.3402/tellusa.v51i3.13459.

Kiladis, G. N., and K. M. Weickmann, 1992: Circulation anomalies associated with tropical convection during northern winter. Mon. Wea. Rev., 120, 1900-1923, https://doi.org/10.1175/1520-0493(1992)120<1900:CAAWTC $>2.0 . \mathrm{CO} ; 2$.

- K. H. Straub, and P. T. Haertel, 2005: Zonal and vertical structure of the Madden-Julian oscillation. J. Atmos. Sci., 62, 2790-2809, https://doi. org/10.1175/JAS3520.1.

Kiladis, G. N., M. C. Wheeler, P. T. Haertel, K. H. Straub, and P. E. Roundy, 2009: Convectively coupled equatorial waves. Rev. Geophys., 47, RG2003, https:// doi.org/10.1029/2008RG000266.

Klotzbach, P. J., 2010: On the Madden-Julian oscillation-Atlantic hurricane relationship. J. Climate, 23, 282-293, https://doi.org/10.1175/2009JCLI2978.1.

Knaff, J. A., C. R. Sampson, and K. D. Musgrave, 2018: An operational rapid intensification prediction aid for the western North Pacific. Wea. Forecasting, 33, 799-811, https://doi.org/10.1175/WAF-D-18-0012.1.

Knapp, K. R., M. C. Kruk, D. H. Levinson, H. J. Diamond, and C. J. Neumann, 2010: The International Best Track Archive for Climate Stewardship (IBTrACS): Unifying tropical cyclone data. Bull. Amer. Meteor. Soc., 91, 363376, https://doi.org/10.1175/2009BAMS2755.1.

— , J. A. Knaff, C. R. Sampson, G. M. Riggio, and A. D. Schnapp, 2013: A pressure-based analysis of the historical western North Pacific tropical cyclone intensity record. Mon. Wea. Rev., 141, 2611-2631, https://doi.org/10.1175/ MWR-D-12-00323.1.
Knutson, T. R., and K. M. Weickmann, 1987: 30-60 day atmospheric oscillations: Composite life cycles of convection and circulation anomalies. Mon. Wea. Rev., 115, 1407-1436, https://doi.org/10.1175/15200493(1987)115<1407:DAOCLC $2.0 . C 0 ; 2$.

Kousky, V. E., and M. T. Kayano, 1994: Principal modes of outgoing longwave radiation and 250-mb circulation for the South American sector. J. Climate, 7, 1131-1143, https://doi.org/10.1175/1520-0442(1994)007<1131:PMOOLR $>2.0 . \mathrm{CO} ; 2$.

Krishnamurti, T. N., and D. Subrahmanyam, 1982: The 30-50 day mode at $850 \mathrm{mb}$ during MONEX. J. Atmos. Sci., 39, 2088-2095, https://doi. org/10.1175/1520-0469(1982)039<2088:TDMAMD>2.0.C0;2.

Kruk, M. C., and C. J. Schreck, 2019: tEastern North Pacific basin [in "State of the Climate in 2018"]. Bull. Amer. Meteor. Soc., 100 (9), S121-S124, https:// doi.org/10.1175/2019BAMSStateoftheClimate.1.

Landsea, C. W., and J. L. Franklin, 2013: Atlantic hurricane database uncertainty and presentation of a New database format. Mon. Wea. Rev., 141, 3576-3592, https://doi.org/10.1175/MWR-D-12-00254.1.

— , W. M. Gray, P. W. Mielke, and K. J. Berry, 1992: Long-term variations of western Sahelian monsoon rainfall and intense U.S. landfalling hurricanes. J. Climate, 5, 1528-1534, https://doi.org/10.1175/15200442(1992)005<1528:LTVOWS >2.0.C0;2.

_ B. A. Harper, K. Hoarau, and J. A. Knaff, 2006: Can we detect trends in extreme tropical cyclones? Science, 313, 452-454, https://doi.org/10.1126/ science.1128448.

-, G. A. Vecchi, L. Bengtsson, and T. R. Knutson, 2010: Impact of duration thresholds on Atlantic tropical cyclone counts. J. Climate, 23, 2508-2519, https:// doi.org/10.1175/2009JCLI3034.1.

Lau, W. K.-M., and D. E. Waliser, 2012: Intraseasonal Variability in the Atmosphere-Ocean Climate System. Springer, 642 pp.

Leipper, D. F., and D. Volgenau, 1972: Hurricane heat potential of the Gulf of Mexico. J. Phys. Oceanogr., 2, 218-224, https://doi.org/10.1175/15200485(1972)002<0218:HHPOTG>2.0.C0;2.

Liebmann, B., and C. A. Smith, 1996: Description of a complete (interpolated) outgoing longwave radiation dataset. Bull. Amer. Meteor. Soc., 77, 12751277, https://doi.org/10.1175/1520-0477-77.6.1274.

Lin, H., G. Brunet, and J. Derome, 2009: An observed connection between the North Atlantic oscillation and the Madden-Julian oscillation. J. Climate, 22, 364-380, https://doi.org/10.1175/2008JCLI2515.1.

Lin, I.-I., and Coauthors, 2013: An ocean coupling potential intensity index for tropical cyclones. Geophys. Res. Lett., 40, 1878-1882, https://doi. org/10.1002/grl.50091.

— I.-F. Pun, and C.-C. Lien, 2014: "Category-6" super-typhoon Haiyan in global warming hiatus: Contribution from subsurface ocean warming. Geophys. Res. Lett., 41, 8547-8553, https://doi.org/10.1002/2014GL061281.

_- and Coauthors, 2020: ENSO and tropical cyclones. El Niño Southern Oscillation in a Changing Climate, Geophys. Monogr., Vol. 254, Amer. Geophys. Union, 377-408.

Luo, J.-J., S. Masson, S. Behera, and T. Yamagata, 2007: Experimental forecasts of the Indian Ocean dipole using a coupled OAGCM. J. Climate, 20, 2178-2190, https://doi.org/10.1175/JCLI4132.1.

_ - S. Behera, Y. Masumoto, H. Sakuma, and T. Yamagata, 2008: Successful prediction of the consecutive IOD in 2006 and 2007. Geophys. Res. Lett., 35 L14S02, https://doi.org/10.1029/2007GL032793.

_- R. Zhang, S. K. Behera, Y. Masumoto, F.-F. Jin, R. Lukas, and T. Yamagata, 2010: Interaction between El Niño and extreme Indian Ocean dipole. J. Climate, 23, 726-742, https://doi.org/10.1175/2009JCLI3104.1.

— W. Sasaki, and Y. Masumoto, 2012: Indian Ocean warming modulates Pacific climate change. Proc. Natl. Acad. Sci. USA, 109, 18701-18706, , https://doi.org/10.1073/pnas.1210239109.

Madden, R., and P. Julian, 1971: Detection of a 40-50 day oscillation in the zonal wind in the tropical Pacific. J. Atmos. Sci., 28, 702-708, https://doi. org/10.1175/1520-0469(1971)028<0702:DOADOI>2.0.C0;2. 
- and _ 1972: Description of global-scale circulation cells in the tropics with a 40-50 day period. J. Atmos. Sci., 29, 1109-1123, https://doi. org/10.1175/1520-0469(1972)029<1109:DOGSCC>2.0.C0;2.

-, and -1994 : Observations of the 40-50-day tropical oscillation: A review. Mon. Wea. Rev., 122, 814-837, https://doi.org/10.1175/15200493(1994)122<0814:00TDT0>2.0.C0;2.

Mainelli, M., M. DeMaria, L. Shay, and G. Goni, 2008: Application of oceanic heat content estimation to operational forecasting of recent Atlantic category 5 hurricanes. Wea. Forecasting, 23, 3-16, https://doi. org/10.1175/2007WAF2006111.1.

Maloney, E. D., and D. L. Hartmann, 2001: The Madden-Julian oscillation, barotropic dynamics, and North Pacific tropical cyclone formation. Part I: Observations. J. Atmos. Sci., 58, 2545-2558, https://doi.org/10.1175/15200469(2001)058<2545:TMJOBD>2.0.C0;2.

Masters, J., 2019: Africa's Hurricane Katrina: Tropical Cyclone Idai causes an extreme catastrophe. Weather Underground, accessed 14 January 2020, www.wunderground.com/cat6/Africas-Hurricane-Katrina-Tropical-Cyclone-Idai-Causes-Extreme-Catastrophe.

Mo, K. C., 2000: The association between intraseasonal oscillations and tropical storms in the Atlantic basin. Mon. Wea. Rev., 128, 4097-4107, https:// doi.org/10.1175/1520-0493(2000)129<4097:TABIOA>2.0.C0;2.

_ culation anomaly patterns and tropical convection. J. Geophys. Res., 98, 5103-5113, https://doi.org/10.1029/92JD02952.

Münnich, M., and J. D. Neelin, 2005: Seasonal influence of ENSO on the Atlantic ITCZ and equatorial South America. Geophys. Res. Lett., 32, L21709, https://doi.org/10.1029/2005GL023900.

Nakazawa, T., and S. Hoshino, 2009: Intercomparison of Dvorak parameters in the tropical cyclone datasets over the western North Pacific. SOLA, 5, 33-36, https://doi.org/10.2151/SOLA.2009-009.

NOAA, 2019: Synoptic discussion, November 2019., NOAA/NCEl, www.ncdc. noaa.gov/sotc/synoptic/201911\#November-16-22.

Nobre, P., and J. Shukla, 1996: Variations of sea surface temperature, wind stress and rainfall over the tropical Atlantic and South America. J. Climate, 9, 2464-2479, https://doi.org/10.1175/1520-0442(1996)009<2464:VOSST W>2.0.CO;2.

PEAC, 2019: Pacific ENSO update. Pacific ENSO Applications Center, www. weather.gov/peac/update.

Pezza, A. B., and C. A. S. Coelho, 2019: The Atlantic Intertropical convergence zone [in "State of the Climate in 2018"]. Bull. Amer. Meteor. Soc., 100 (9), S109-S110, https://doi.org/10.1175/2019BAMSStateoftheClimate.1.

Raga, G. B., B. Bracamontes-Ceballos, L. Farfán, and R. Romero-Centeno, 2013: Landfalling tropical cyclones on the Pacific coast of Mexico: 1850-2010. Atmósfera, 26, 209-220, https://doi.org/10.1016/S0187-6236(13)71072-5.

Reynolds, R. W., N. A. Rayner, T. M. Smith, D. C. Stokes, and W. Wang, 2002: An improved in situ and satellite SST analysis for climate. J. Climate, 15, 1609-1625, https://doi.org/10.1175/1520-0442(2002)015<1609:AllSAS>2. 0.CO;2.

Riddle, E., M. Stoner, N. Johnson, M. L'Heureux, D. Collins, and S. Feldstein, 2012: The impact of the MJO on clusters of wintertime circulation anomalies over the North American region. Climate Dyn., 40, 1749-1766, https://doi. org/10.1007/S00382-012-1493-Y.

Ropelewski, C. F., and M. S. Halpert, 1989: Precipitation patterns associated with the high index phase of the Southern Oscillation. J. Climate, 2, 268284, https://doi.org/10.1175/1520-0442(1989)002<0268:PPAWTH>2.0. $\mathrm{CO} ; 2$.

Saha, S., and Coauthors, 2014: The NCEP Climate Forecast System version 2. J. Climate, 27, 2185-2208, https://doi.org/10.1175/JCLI-D-12-00823.1.

Saji, N. H., B. N. Goswami, P. N. Vinayachandran, and T. Yamagata, 1999: A dipole mode in the tropical Indian ocean. Nature, 401, 360-363, https:// doi.org/10.1038/43854.
Schneider, T., T. Bischoff, and G. H. Haug, 2014: Migrations and dynamics of the intertropical convergence zone. Nature, 513, 45-53, https://doi. org/10.1038/nature13636.

Schreck, C. J., 2015: Kelvin waves and tropical cyclogenesis: A global survey. Mon. Wea. Rev., 143, 3996-4011, https://doi.org/10.1175/MWRD-15-0111.1.

_ 2016: Convectively coupled Kelvin waves and tropical cyclogenesis in a semi-Lagrangian framework. Mon. Wea. Rev., 144, 4131-4139, https://doi. org/10.1175/MWR-D-16-0237.1.

_ and the Madden-Julian oscillation. Mon. Wea. Rev., 139, 2723-2734, https://doi.org/10.1175/MWR-D-10-05060.1.

- - , and A. Aiyyer, 2012: A global view of equatorial waves and tropical cyclogenesis. Mon. Wea. Rev., 140, 774-788, https://doi.org/10.1175/ MWR-D-11-00110.1.

— J. M. Cordeira, and D. Margolin, 2013: Which MJO events affect North American temperatures? Mon. Wea. Rev., 141, 3840-3850, https://doi. org/10.1175/MWR-D-13-00118.1.

_ K. R. Knapp, and J. P. Kossin, 2014: The impact of best track discrepancies on global tropical cyclone climatologies using IBTrACS. Mon. Wea. Rev., 142, 3881-3899, https://doi.org/10.1175/MWR-D-14-00021.1.

_ , H.-T. Lee, and K. R. Knapp, 2018: HIRS outgoing longwave radiation-daily climate data record: Application toward identifying tropical subseasonal variability. Remote Sens., 10, 1325, https://doi.org/10.3390/ rs10091325.

Shay, L. K., G. J. Goni, and P. G. Black, 2000: Effects of a warm oceanic feature on Hurricane Opal. Mon. Wea. Rev., 128, 1366-1383, https://doi. org/10.1175/1520-0493(2000)128<1366:EOAWOF>2.0.C0;2.

Smith, T. M., R. W. Reynolds, T. C. Peterson, and J. Lawrimore, 2008: Improvements to NOAA's historical merged land-ocean surface temperature analysis (1880-2006). J. Climate, 21, 2283-2296, https://doi. org/10.1175/2007JCLI2100.1.

Song, J.-J., Y. Wang, and L. Wu, 2010: Trend discrepancies among three best track data sets of western North Pacific tropical cyclones. J. Geophys. Res., 115, D12128, https://doi.org/10.1029/2009JD013058.

Stewart, S. R., 2019: Tropical Storm Priscilla. National Hurricane Center Tropical Cyclone Rep., 9 pp., www.nhc.noaa.gov/data/tcr/EP192019_Priscilla.pdf.

Vecchi, G. A., and B. J. Soden, 2007: Effect of remote sea surface temperature change on tropical cyclone potential intensity. Nature, 450, 1066-1070, https://doi.org/10.1038/NATURE06423.

Ventrice, M. J., C. D. Thorncroft, and M. A. Janiga, 2012a: Atlantic tropical cyclogenesis: A three-way interaction between an African easterly wave, diurnally varying convection, and a convectively coupled atmospheric Kelvin wave. Mon. Wea. Rev., 140, 1108-1124, https://doi.org/10.1175/MWRD-11-00122.1.

_ _ - and C. J. Schreck, 2012b: Impacts of convectively coupled Kelvin waves on environmental conditions for Atlantic tropical cyclogenesis. Mon. Wea. Rev., 140, 2198-2214, https://doi.org/10.1175/MWR-D-11-00305.1.

Villarini, G., G. A. Vecchi, T. R. Knutson, and J. A. Smith, 2011: Is the recorded increase in short duration North Atlantic tropical storms spurious? J. Geophys. Res., 116, D10114, https://doi.org/10.1029/2010JD015493.

Vincent, D. G., 1994: The South Pacific Convergence Zone (SPCZ): A review. Mon. Wea. Rev., 122, 1949-1970, https://doi.org/10.1175/15200493(1994)122<1949:TSPCZA>2.0.C0;2.

Waliser, D. E., and C. Gautier, 1993: A satellite-derived climatology of the ITCZ. J. Climate, 6, 2162-2174, https://doi.org/10.1175/15200442(1993)006<2162:ASDCOT>2.0.C0;2.

Wang, B., and Q. Ding, 2008: Global monsoon: Dominant mode of annual variation in the tropics. Dyn. Atmos. Ocean, 44, 165-183, https://doi.org/10.1016/J. DYNATMOCE.2007.05.002.

— I. Liu, H. J. Kim, P. J. Webster, and S. Y. Yim, 2012: Recent change of the global monsoon precipitation (1979-2008). Climate Dyn., 39, 1123-1135, https://doi.org/10.1007/s00382-011-1266-z. 
Wheeler, M., and G. N. Kiladis, 1999: Convectively coupled equatorial waves: Analysis of clouds and temperature in the wavenumber-frequency domain. J. Atmos. Sci., 56, 374-399, https://doi.org/10.1175/15200469(1999)056<0374:CCEWAO>2.0.C0;2.

- , and H. H. Hendon, 2004: An all-season real-time multivariate MJO index: Development of an index for monitoring and prediction. Mon. Wea. Rev., 132, 1917-1932, https://doi.org/10.1175/1520-0493(2004)132<1917:AAR $\mathrm{MMl}>2.0 . \mathrm{CO} ; 2$.

Wood, K. M., and E. A. Ritchie, 2015: A definition for rapid weakening in the North Atlantic and eastern North Pacific. Geophys. Res. Lett., 42, $10091-$ 10097, https://doi.org/10.1002/2015GL066697.

- P. J. Klotzbach, J. M. Collins, and C. J. Schreck, 2019: The record-setting 2018 eastern North Pacific hurricane season. Geophys. Res. Lett., 46, 10072-10081, https://doi.org/10.1029/2019GL083657.

_ - _ - L.-P. Caron, R. E. Truchelut, and C. J. Schreck III, 2020: Factors affecting the 2019 Atlantic hurricane season and the role of the Indian Ocean Dipole. Geophys. Res. Lett., 47, e2020GL087781, https://doi. org/10.1029/2020GL087781.

Wu, M.-C., K.-H. Yeung, and W.-L. Chang, 2006: Trends in western North Pacific tropical cyclone intensity. Eos, Trans. Amer. Geophys. Union, 87, 537-548, https://doi.org/10.1029/2006E0480001.

Yim, S. Y., B. Wang, J. Liu, and Z. W. Wu, 2014: A comparison of regional monsoon variability using monsoon indices. Climate Dyn., 43, 1423-1437, https://doi.org/10.1007/s00382-013-1956-9.
Ying, M., E.-J. Cha, and H. J. Kwon, 2011: Comparison of three western North Pacific tropical best track datasets in a seasonal context. J. Meteor. Soc. Japan, 89, 211-224, https://doi.org/10.2151/jmsj.2011-303.

Yu, H., Y. Lu, P.-Y. Chen, and W. C. Zhou, 2012: Intensity change characteristics of tropical cyclones in the western North Pacific as revealed by three different datasets. J. Trop. Meteor., 18, 119-126.

Yuan, J., and J. Cao, 2012: North Indian Ocean tropical cyclone activities influenced by the Indian Ocean Dipole mode. Sci. China Earth Sci., 56, 855-865, https://doi.org/10.1007/s11430-012-4559-0.

Zhang, C., 2005: Madden-Julian oscillation. Rev. Geophys., 43, RG2003, https://doi.org/10.1029/2004RG000158.

_ 2013: Madden-Julian oscillation: Bridging weather and climate. Bull. Amer. Meteor. Soc., 94, 1849-1870, https://doi.org/10.1175/BAMSD-12-00026.1.

_ and J. Gottschalck, 2002: SST anomalies of ENSO and the Madden-Julian oscillation in the equatorial Pacific. J. Climate, 15, 2429-2445, https://doi. org/10.1175/1520-0442(2002)015<2429:SAOEAT>2.0.CO;2.

Zheng, Z.-W., I.-I. Lin, B. Wang, H.-C. Huang, and C.-H. Chen, 2015: A long neglected damper in the El Nino-Typhoon relationship: A 'Gaia-like' process. Sci. Rep., 5, 11103, https://doi.org/10.1038/srep11103. 


\section{STATE OF THE CLIMATE IN 2019}

\section{THE ARCTIC}

J. Richter-Menge and M. L. Druckenmiller, Eds.

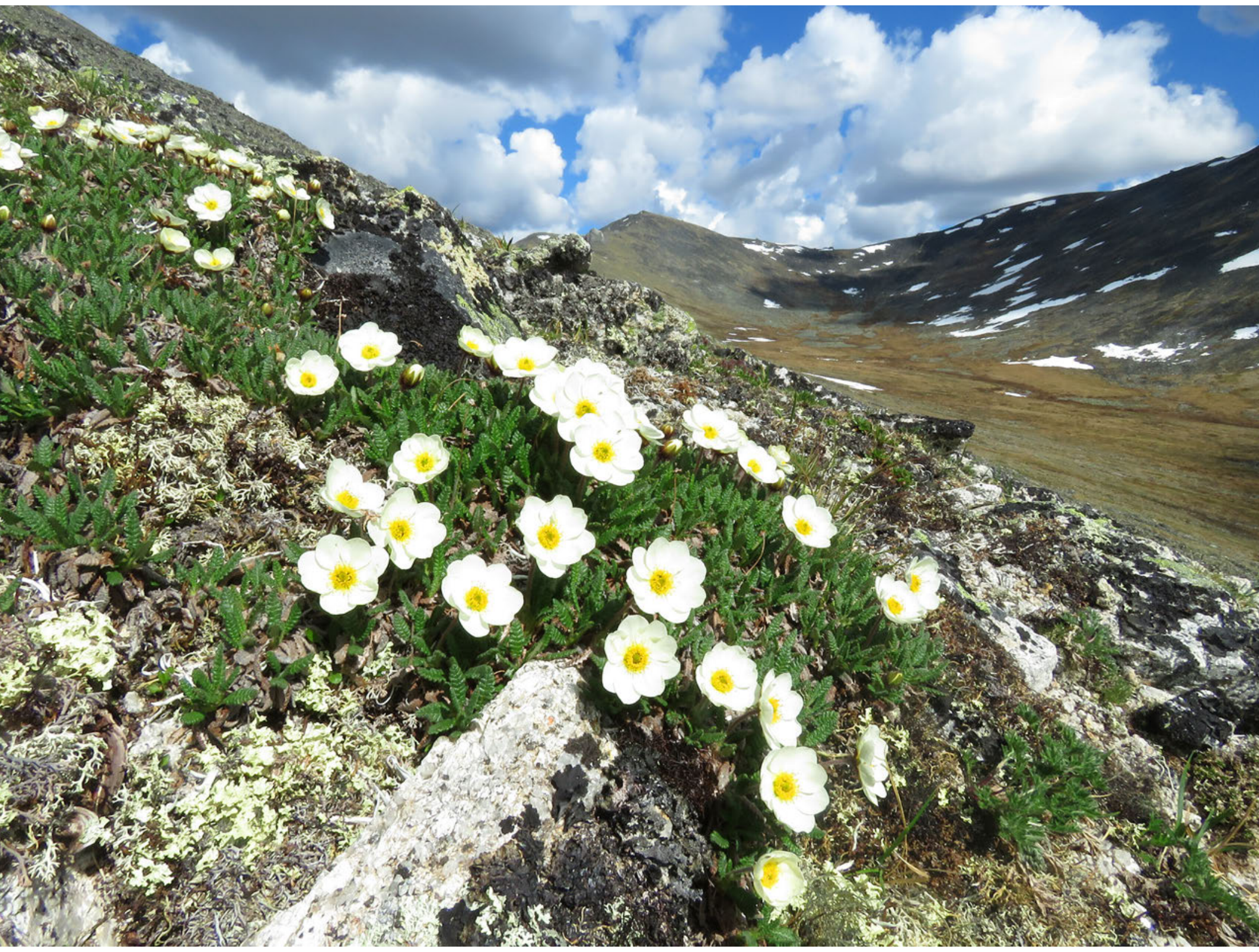

Special Online Supplement to the Bulletin of the American Meteorological Society, Vol.101, No. 8, August, 2020

https://doi.org/10.1175/BAMS-D-20-0086.1

Corresponding author: Matthew L. Druckenmiller / druckenmiller@nsidc.org

(0)2020 American Meteorological Society

For information regarding reuse of this content and general copyright information, consult the AMS Copyright Policy. 


\title{
STATE OF THE CLIMATE IN 2019 \\ The Arctic
}

\author{
Editors \\ Jessica Blunden \\ Derek S. Arndt \\ Chapter Editors \\ Peter Bissolli \\ Howard J. Diamond \\ Matthew L. Druckenmiller \\ Robert J. H. Dunn \\ Catherine Ganter \\ Nadine Gobron \\ Rick Lumpkin \\ Jacqueline A. Richter-Menge \\ Tim Li \\ Ademe Mekonnen \\ Ahira Sánchez-Lugo \\ Ted A. Scambos \\ Carl J. Schreck III \\ Sharon Stammerjohn \\ Diane M. Stanitski \\ Kate M. Willett \\ Technical Editor \\ Andrea Andersen
}

BAMS Special Editor for Climate

Richard Rosen

American Meteorological Society 
Cover credit:

A patch of eightpetal mountain-avens (Dryas octopetala) bloom on a tundra hillslope in the Brooks Range near Atigun Pass, northern Alaska, 2 June 2019. Photo by Gerald V. Frost.

The Arctic is one chapter from the State of the Climate in 2019 annual report and is available from https://doi.org/10.1175/BAMS-D-20-0086.1. Compiled by NOAA's National Centers for Environmental Information, State of the Climate in 2019 is based on contributions from scientists from around the world. It provides a detailed update on global climate indicators, notable weather events, and other data collected by environmental monitoring stations and instruments located on land, water, ice, and in space. The full report is available from https://doi.org/10.1175/2020BAMSStateoftheClimate.1.

\section{How to cite this document:}

\section{Citing the complete report:}

Blunden, J. and D. S. Arndt, Eds., 2020: State of the Climate in 2019. Bull. Amer. Meteor. Soc., 101 (8), Si-S429, https://doi.org/10.1175/2020BAMSStateoftheClimate.1.

\section{Citing this chapter:}

Richter-Menge, J. and M. L. Druckenmiller, Eds., 2020: The Arctic [in "State of the Climate in 2019"]. Bull. Amer. Meteor. Soc., 101 (8), S239-S285, https://doi.org/10.1175/BAMS-D-20-0086.1.

\section{Citing a section (example):}

Mudryk, L., R. Brown, C. Derksen, K. Luojus, and B. Decharme, 2020: Terrestrial snow cover [in "State of the Climate in 2019"]. Bull. Amer. Meteor. Soc., 101 (8), S263-S265, https://doi.org/10.1175/BAMS-D-20-0086.1. 
Andersen, J. K., Geological Survey of Denmark and Greenland, Copenhagen, Denmark

Andreassen, Liss M., Section for Glaciers, Ice and Snow, Norwegian Water Resources and Energy Directorate, Oslo, Norway

Baker, Emily H., U.S. Geological Survey, Alaska Science Center, Anchorage, Alaska

Ballinger, Thomas J., International Arctic Research Center, University of Alaska Fairbanks, Fairbanks, Alaska

Berner, Logan T., School of Informatics, Computing, and Cyber Systems, Northern Arizona University, Flagstaff, Arizona

Bernhard, Germar H., Biospherical Instruments Inc., San Diego, California

Bhatt, Uma S., Geophysical Institute, University of Alaska Fairbanks, Fairbanks, Alaska

Bjerke, Jarle W., Norwegian Institute for Nature Research, FRAM - High North Research Centre for Climate and the Environment, Tromsø, Norway

Box, Jason E., Geological Survey of Denmark and Greenland, Copenhagen, Denmark

Britt, L., NOAA/NMFS Alaska Fisheries Science Center, Seattle, Washington

Brown, R., Climate Research Division, Environment and Climate Change Canada, Montréal, Quebec, Canada

Burgess, David, Geological Survey of Canada, Ottawa, Ontario, Canada

Cappelen, John, Danish Meteorological Institute, Copenhagen, Denmark

Christiansen, Hanne H., Geology Department, University Centre in Svalbard, The University Center in Svalbard, Longyearbyen, Norway

Decharme, B., Centre National de Recherches Météorologiques, France

Derksen, C., Climate Research Division, Environment and Climate Change Canada,Downsview, Ontario, Canada

Drozdov, D. S., Earth Cryosphere Institute, and Tyumen State University, Tyumen, Russia

Druckenmiller, Matthew L., National Snow and Ice Data Center, Boulder Colorado

Epstein, Howard E., Department of Environmental Sciences, University of Virginia, Charlottesville, Virginia

Farquharson, L. M., Geophysical Institute, University of Alaska Fairbanks, Fairbanks, Alaska

Farrell, Sinead L., NOAA Earth System Science Interdisciplinary Center, University of Maryland, College Park, Maryland

Fausto, Robert S., Geological Survey of Denmark and Greenland, Copenhagen, Denmark

Fettweis, Xavier, SPHERES research unit, University of Liège, Liège, Belgium

Fioletov, Vitali E., Environment and Climate Change Canada, Toronoto, Ontario, Canada

Forbes, Bruce C., Arctic Centre, University of Lapland, Rovaniemi, Finland

Frost, Gerald V., ABR, Inc. Environmental Research \& Services, Fairbanks, Alaska

Gerland, Sebastian, Norwegian Polar Institute, Fram Centre, Tromsø, Norway

Goetz, Scott J., School of Informatics, Computing, and Cyber Systems, Northern Arizona University, Flagstaff, Arizona

Grooß, Jens-Uwe, Forschungszentrum Jülich, Jülich, Germany

Hanna, Edward, School of Geography and Lincoln Centre for Water and Planetary Health, University of Lincoln, Lincoln, United Kingdom

Hanssen-Bauer, Inger, Norwegian Meteorological Institute, Blindern, Oslo, Norway

Hendricks, Stefan, Alfred Wegener Institute, Helmholtz Centre for Polar and Marine Research, Bremerhaven, Germany

Ialongo, Iolanda, Finnish Meteorological Institute, Helsinki, Finland

Isaksen, K., Norwegian Meteorlogical Institute, Blindern, Oslo, Norway

Johnsen, Bjørn, Norwegian Radiation and Nuclear Safety, Østerås, Norway

Kaleschke, L., Alfred Wegener Institute, Helmholtz Centre for Polar and Marine Research, Bremerhaven, Germany
Kholodov, A. L., Geophysical Institute, University of Alaska Fairbanks, Fairbanks, Alaska

Kim, Seong-Joong, Korea Polar Research Institute, Incheon, Republic of Korea Kohler, Jack, Norwegian Polar Institute, Tromsø, Norway

Labe, Zachary, University of California at Irvine, Irvine, California

Ladd, Carol, NOAA/OAR Pacific Marine Environmental Laboratory, Seattle, Washington

Lakkala, Kaisa, Finnish Meteorological Institute, Sodankylä, Finland

Lara, Mark J., Department of Plant Biology and Department of Geography, University of Illinois at Urbana-Champaign, Urbana, Illinois

Loomis, Bryant, NASA Goddard Space Flight Center, Greenbelt, Maryland

Luks, Bartłomiej, Institute of Geophysics, Polish Academy of Sciences, Warsaw, Poland

Luojus, K., Arctic Research Centre, Finnish Meteorological Institute, Helsinki, Finland

Macander, Matthew J., ABR, Inc. Environmental Research \& Services, Fairbanks, Alaska

Malkova, G. V., Earth Cryosphere Institute, Tyumen Science Center, Tyumen, Russia

Mankoff, Kenneth D., Geological Survey of Denmark and Greenland, Copenhagen, Denmark

Manney, Gloria L., NorthWest Research Associates, and New Mexico Institute of Mining and Technology, Socorro, New Mexico

Marsh, J. M., College of Fisheries and Ocean Sciences, University of Alaska Fairbanks, Fairbanks, Alaska

Meier, Walt, National Snow and Ice Data Center, Cooperative Institute for Research in Environment Sciences at the University of Colorado, Boulder, Colorado

Moon, Twila A., National Snow and Ice Data Center, Cooperative Institute for Research in Environmental Sciences at the University of Colorado, Boulder, Colorado

Mote, Thomas, Department of Geography, University of Georgia, Athens, Georgia

Mudryk, L., Climate Research Division, Environment and Climate Change Canada, Downsview, Ontario, Canada

Mueter F. J., College of Fisheries and Ocean Sciences, University of Alaska Fairbanks, Alaska

Müller, Rolf, Forschungszentrum Jülich, Jülich, Germany

Nyland, K. E., Department of Geography, George Washington University, Washington, D.C.

O'Neel, Shad, U.S. Geological Survey, Alaska Science Center, Anchorage, Alaska

Overland, James E., NOAA/OAR Pacific Marine Environmental Laboratory, Seattle, Washington

Perovich, Don, Thayer School of Engineering, Dartmouth College, Hanover, New Hampshire

Phoenix, Gareth K., Department of Animal and Plant Sciences, University of Sheffield, Sheffield, United Kingdom

Raynolds, Martha K., Institute of Arctic Biology, University of Alaska Fairbanks, Alaska

Reijmer, C. H., Institute for Marine and Atmospheric Research Utrecht, Utrecht University, Utrecht, The Netherlands

Richter-Menge, Jacqueline, University of Alaska Fairbanks, Institute of Northern Engineering, Fairbanks, Alaska

Ricker, Robert, Alfred Wegener Institute, Helmholtz Centre for Polar and Marine Research, Bremerhaven, Germany

Romanovsky, Vladimir E., Geophysical Institute, University of Alaska Fairbanks, Fairbanks, Alaska; Earth Cryosphere Institute, Tyumen Science Center, Tyumen, Russia

Schuur, E. A. G., Center for Ecosystem Science and Society, Northern Arizona University, Flagstaff, Arizona 
Sharp, Martin, Department of Earth and Atmospheric Sciences, University of Alberta, Edmonton, Alberta, Canada

Shiklomanov, Nikolai I., Department of Geography, George Washington University, Washington, D.C.

Smeets, C. J. P. P., Institute for Marine and Atmospheric Research Utrecht, Utrecht University, Utrecht, The Netherlands

Smith, Sharon L., Geological Survey of Canada, Natural Resources Canada, Ottawa, Ontario, Canada

Streletskiy, Dimitri A., Department of Geography, George Washington University, Washington, D.C.

Tedesco, Marco, Lamont Doherty Earth Observatory, Columbia University, Palisades, New York, and NASA Goddard Institute of Space Studies, New York, New York

Thoman, Richard L., International Arctic Research Center, University of Alaska Fairbanks, Fairbanks, Alaska

Thorson, J. T., NOAA/NMFS Alaska Fisheries Science Center, Seattle, Washington

Tian-Kunze, X., Alfred Wegener Institute, Helmholtz Centre for Polar and Marine Research, Bremerhaven, Germany

Timmermans, Mary-Louise, Yale University, New Haven, Connecticut

Tømmervik, Hans, Norwegian Institute for Nature Research, Tromsø, Norway

Tschudi, Mark, Aerospace Engineering Sciences, University of Colorado, Boulder, Colorado

van As, Dirk, Geological Survey of Denmark and Greenland, Copenhagen, Denmark van de Wal, R. S. W., Institute for Marine and Atmospheric Research Utrecht, Utrecht University, Utrecht, The Netherlands

Walker, Donald A., Institute of Arctic Biology, University of Alaska Fairbanks, Alaska

Walsh, John E., International Arctic Research Center, University of Alaska Fairbanks, Fairbanks, Alaska

Wang, Muyin, NOAA/OAR Pacific Marine Environmental Laboratory, and Joint Institute for the Study of the Atmosphere and Ocean, University of Washington, Seattle, Washington

Webster, Melinda, Geophysical Institute, University of Alaska Fairbanks, Fairbanks, Alaska

Winton, Øyvind, Geological Survey of Denmark and Greenland, Copenhagen, Denmark

Wolken, Gabriel J., Alaska Division of Geological \& Geophysical Surveys; University of Alaska Fairbanks, Fairbanks, Alaska

Wood, K., Joint Institute for the Study of the Atmosphere and Ocean, University of Washington, and NOAA/OAR Pacific Marine Environmental Laboratory, Seattle, Washington

Wouters, Bert, Institute for Marine and Atmospheric Research, Utrecht University, Utrecht, Netherlands; Department of Geoscience \& Remote Sensing, Delft University of Technology, Delft, The Netherlands

Zador, S., NOAA/NMFS Alaska Fisheries Science Center, Seattle, Washington

\section{Editorial and Production Team}

Andersen, Andrea, Technical Editor, Innovative Consulting Management Services, LLC, NOAA/NESDIS National Centers for Environmental Information, Asheville, North Carolina

Griffin, Jessicca, Graphics Support, Cooperative Institute for Satellite Earth System Studies, North Carolina State University, Asheville, North Carolina

Hammer, Gregory, Content Team Lead, Communications and Outreach, NOAA/NESDIS National Centers for Environmental Information, Asheville, North Carolina
Love-Brotak, S. Elizabeth, Lead Graphics Production, NOAA/NESDIS National Centers for Environmental Information, Asheville, North Carolina

Misch, Deborah J., Graphics Support, Innovative Consulting Management Services, LLC, NOAA/NESDIS National Centers for Environmental Information, Asheville, North Carolina

Riddle, Deborah B., Graphics Support, NOAA/NESDIS National Centers for Environmental Information, Asheville, North Carolina

Veasey, Sara W., Visual Communications Team Lead, Communications and Outreach, NOAA/NESDIS National Centers for Environmental Information, Asheville, North Carolina 


\section{Table of Contents}

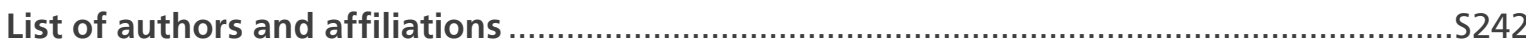

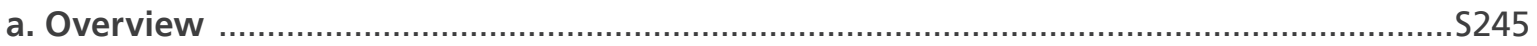

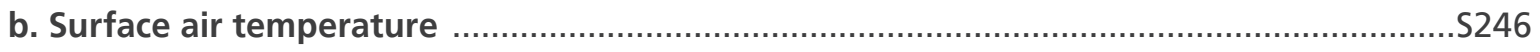

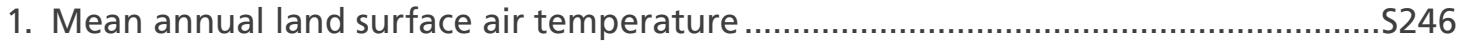

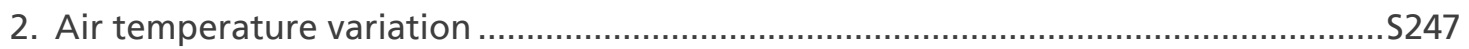

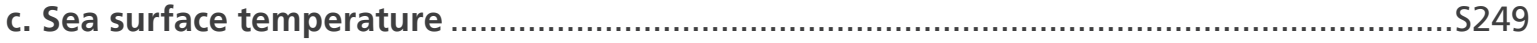

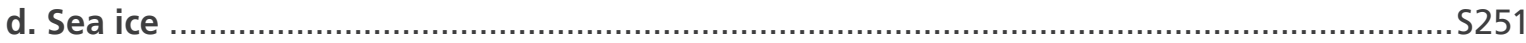

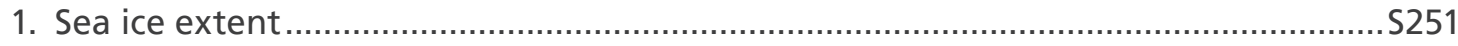

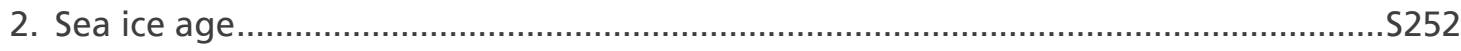

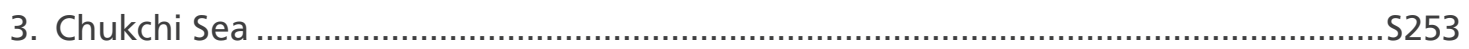

Sidebar 5.1: Shifting fish distributions in the Bering Sea. ............................................. 254

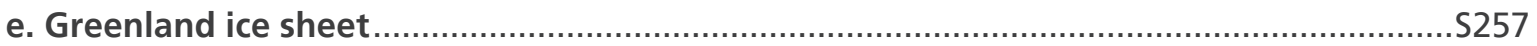

1. Surface air temperatures, surface mass balance, and albedo .................................... 257

2. Glacier retreat and ice discharge .......................................................................... 259

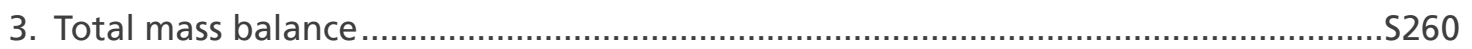

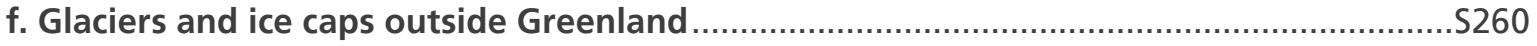

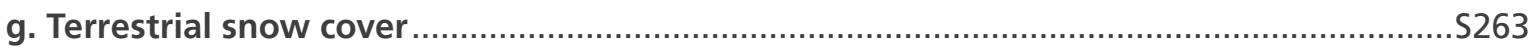

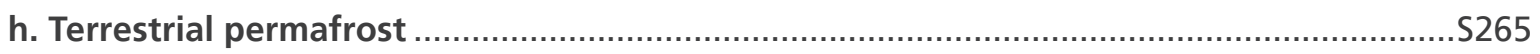

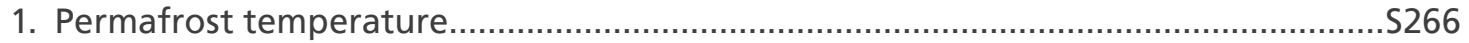

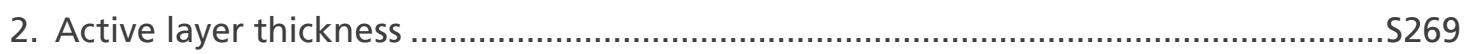

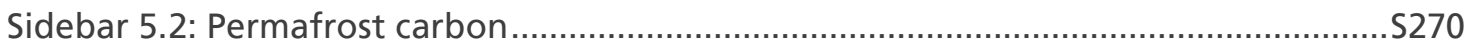

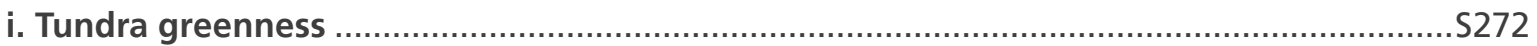

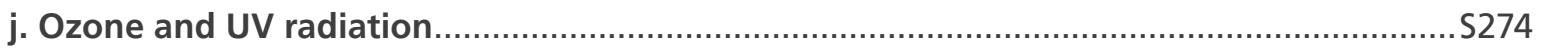

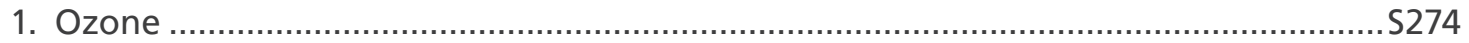

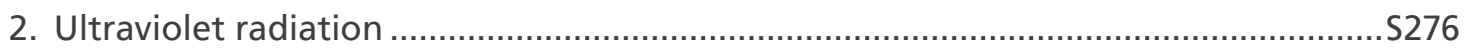

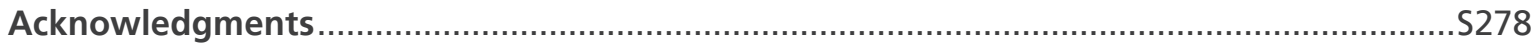

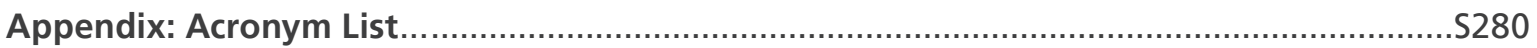

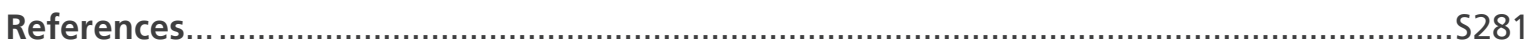

*Please refer to Chapter 8 (Relevant datasets and sources) for a list of all climate variables and datasets used in this chapter for analyses, along with their websites for more information and access to the data. 


\section{THE ARCTIC}

J. Richter-Menge and M. L. Druckenmiller, Eds.

\section{a. Overview-M. L. Druckenmiller and J. Richter-Menge}

Mean annual Arctic surface air temperatures (SAT) over land have increased more than twice as fast as the global mean since the mid-1980s. Observations from 2019 continue to highlight prolonged changes across key and connected features of the Arctic's land, ice, ocean, and atmosphere. Through these connections, the changing Arctic environment has a magnified impact on ecosystems and societies on regional and global scales.

Central to observed changes throughout the Arctic system is the persistent and pronounced increase in Arctic SAT, which in 2019 was the second highest in the 120-year observational record. In particular, the southward displacement of the polar vortex over North America-a repeat of conditions from 2018-brought record-high SATs to Alaska and northwest Canada. These conditions contributed to the second winter in a row when sea ice coverage in the Bering Sea was by far the lowest in observed or reconstructed records dating back to 1850 (Richter-Menge et al. 2019; Walsh et al. 2019). More generally, warming air temperatures are linked to the continued Arctic-wide decline in the extent and thickness of the sea ice cover. In March 2019, when the ice reached its maximum extent for the year, thin, first-year ice predominated at $77 \%$, compared to about 55\% in the 1980s. This transformation toward thinner and more mobile ice makes the sea ice cover more vulnerable to melting out in summer and, therefore, diminishes the ice cover's role in cooling the Arctic region by reflecting incoming solar radiation back to space. In September 2019, the minimum sea ice extent at the end of summer was tied with 2007 and 2016 for the second smallest in the 41-year satellite record.

The declining trend in the extent of the sea ice cover is driving changes in sea surface temperatures (SSTs) in the Arctic Ocean and adjacent seas, largely caused by direct solar heating of exposed, ice-free-and thus darker (i.e., lower albedo)-Arctic waters. A warmer ocean, in turn, melts more sea ice. This feedback, known as the ice-albedo feedback, contributes to the continued and accelerated warming of the Arctic region. August mean SSTs show significant warming for 1982-2019 in most regions of the Arctic Ocean that are ice-free in August. On a regional scale, the Chukchi and Bering Seas continue to exhibit larger warming trends in August than the Arctic-wide August mean, with the Chukchi Sea mean SSTs in August 2019 being the second highest on record.

Increased ocean temperatures and reduced sea ice in the Bering Sea are leading to shifts in fish distributions within some of the most valuable fisheries in the world. On the Bering Sea shelf, the summer distribution of fishes living on the seafloor is closely tied to the extent of the cold pool (bottom water temperatures $<2^{\circ} \mathrm{C}$ ), which forms during autumn freeze-up when cold dense water sinks to the seafloor where it persists throughout the following summer. As this cold pool was considerably reduced during summers 2018 and 2019 in association with the record low winter sea ice coverage, southern fish species expanded northward. As a result, larger and more abundant boreal (southern Bering Sea) species, as opposed to smaller and less abundant Arctic species, dominated a large portion of the shelf in 2018 and 2019. These shifts in populations present challenges for the management of commercial and subsistence fisheries alike, while illuminating the potential for further cascading changes to the ecosystem.

On land, the increasing SATs are causing a decrease in the extent of the Arctic spring snow cover, an increase in the overall amount of Arctic vegetation, and the warming and thawing of perennially-frozen ground, known as permafrost. These components of the Arctic environment interconnect to influence hydrology, surface stability, wildlife, infrastructure, and the livelihoods 
of Indigenous Peoples. Permafrost thaw also promotes the release of carbon dioxide and methane from soils to the atmosphere through the microbial conversion of permafrost carbon that has accumulated over hundreds to thousands of years. New evidence suggests that the increasing release of these sequestered greenhouse gases may be shifting permafrost soils from being a net carbon sink to being a net carbon source, thereby further accelerating global climate warming.

Land-based ice across the Arctic is similarly responding to the persistent rise of SATs. Melt across the Greenland ice sheet (GrIS) is contributing to global average sea level rise at a current rate of about $0.7 \mathrm{~mm} \mathrm{yr}^{-1}$. During the 2019 melt season, the extent and magnitude of ice loss over the GrIS rivaled 2012, the previous year of record ice loss. Observations from 2018 and 2019 reveal a continuing trend of significant ice loss from glaciers and ice caps across the Arctic, especially in Alaska and Arctic Canada. The Arctic-wide mass loss from glaciers and ice caps outside of Greenland is estimated to contribute approximately $0.4 \mathrm{~mm} \mathrm{yr}^{-1}$ to global sea level rise, which, if normalized by area, represents more melt water per area than the GrIS.

Long-term observing in the Arctic has revealed a region undergoing sustained and often rapid change. Yet, throughout this chapter, observations are also often marked by regional differences (e.g., continental-scale differences in snow cover and terrestrial greening), indicating a complex and variable system, tied in part to its global connections via the ocean and atmosphere. The Arctic plays a critical role in regulating global climate, primarily through the reflective properties of sea ice, land ice, and snow. As these features diminish in extent, the Arctic will increasingly exert its influence on the rest of Earth in other ways, too. Through global sea level rise, the release of permafrost carbon, and its role in steering global weather patterns, the Arctic is vitally connected to people worldwide.

(This chapter includes a focus on glaciers and ice caps outside Greenland, section $\mathrm{f}$, which

alternates yearly with a section on Arctic river discharge, as the scales of regular observation for both of these climate components are best suited for reporting every two years.)

b. Surface air temperature-J. E. Overland, T. J. Ballinger, E. Hanna, I. Hanssen-Bauer, S.-J. Kim, J. E. Walsh, M. Wang, U. S. Bhatt, and R. L. Thoman

Arctic surface air temperature (SAT) is a leading indicator of global climate change. Although there are year-to-year and regional differences in SATs that are driven by natural variability, the magnitude, persistence, and Arctic-wide patterns of recent temperature increases are indicators of global climate warming due to increasing concentrations of atmospheric greenhouse gases (Overland 2009; Notz and Stroeve 2016). Increasing atmospheric temperatures also act as a driver of Arctic changes in the ocean and on land. For instance, a linear relationship between global temperature change and Arctic sea ice cover decline (section $5 \mathrm{~d}$ ) suggests a direct climate forcing (Mahlstein and Knutti 2012). Similarly, tundra greening (section 5i), especially along coastlines, and glacier mass loss (sections 5e,f) are also results of air temperature increases (Box et al. 2019).

Highlights from 2019 include a mean annual SAT over Arctic land that was the second highest in the observational record (1900-present). On the regional scale, Alaska experienced higherthan-normal air temperatures throughout the year, especially in winter, that were associated with unusual southerly winds and a lack of sea ice in the Bering Sea (section 5d). West Greenland experienced especially warm localized air temperatures during spring and summer, which supported extensive ice sheet melt events (section 5e) and early regional snow melt. In autumn, a major northward jet stream displacement resulted in extreme high temperatures in northern Greenland.

\section{1) Mean annual land surface air temperature}

At $+1.7^{\circ} \mathrm{C}$, the mean annual SAT anomaly for January-December 2019 for land weather stations north of $60^{\circ} \mathrm{N}$, relative to the 1981-2010 mean, is the second-highest value after 2016 in the observational record starting in 1900. Since the mid-1980s, Arctic warming has consistently outpaced global mean temperature increases, leading to an Arctic that has now warmed more than twice as much as the 


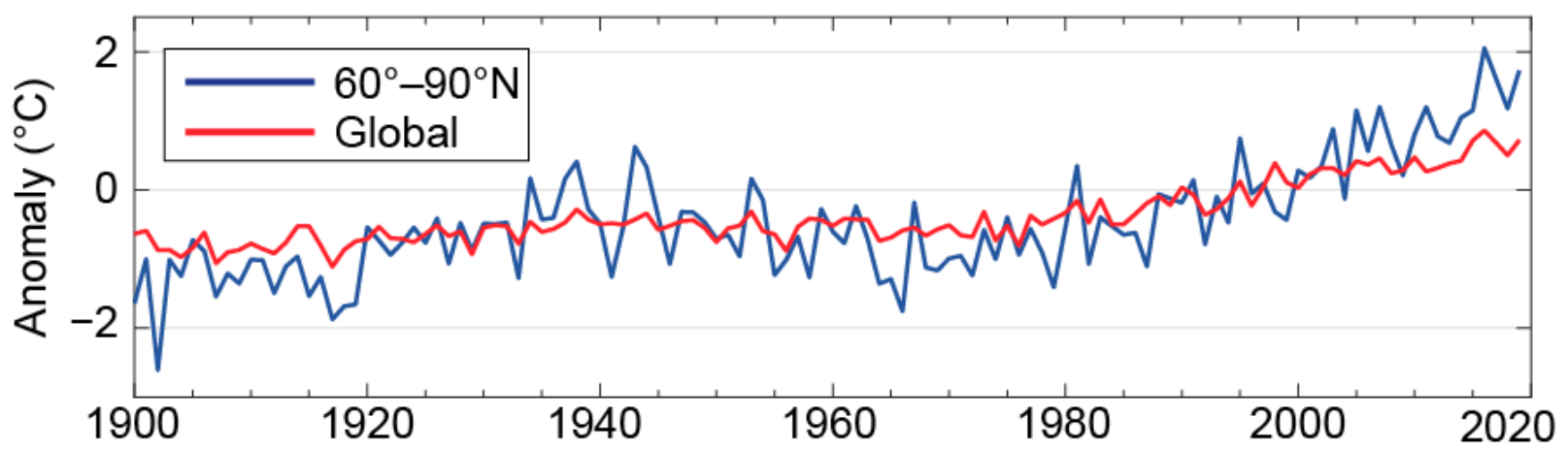

Fig. 5.1. Arctic (land stations north of $60^{\circ} \mathrm{N}$; blue line) and global (red line) mean annual land SAT anomalies (in ${ }^{\circ} \mathrm{C}$ ) for the period 1900-2019 relative to the 1981-2010 mean value. Note that there were few stations in the Arctic, particularly in northern Canada, before 1940. (Source: CRUTEM4 dataset.)

globe-a phenomenon known as Arctic amplification (Fig. 5.1). While there is currently no consensus on the relative importance of several factors contributing to Arctic amplification, mechanisms include: reduced summer albedo due to sea ice and snow cover loss (Pithan and Mauritsen 2014); the increase of water vapor and clouds in the Arctic atmosphere (Dufour et al. 2016; Kim et al. 2017); lapse-rate feedback (decreases in tropospheric temperature with height [Stuecker et al. 2018]); ocean heat transport (Langenbrunner 2020); and decreased air pollution (Acosta Navarro et al. 2016).

\section{2) Air temperature variation}

Seasonal air temperature variations during 2019 are divided into winter (January, February, March [JFM]); spring (April, May, June [AMJ]); summer (July, August, September [JAS]); and autumn (October, November, December [OND]) (Fig. 5.2). These SAT divisions are chosen to coincide with the seasonal cycles of key Arctic variables. For instance, the summer sea ice minimum extent occurs in September and autumn cooling continues through December.

Winter 2019 (JFM). A major Arctic warming event in winter (Fig. 5.2a) was observed in Alaska and its adjacent seas, where monthly temperature anomalies reached more than $6^{\circ} \mathrm{C}$ above normal. Over the Bering Sea, this event was similar, yet even warmer than the event observed in winter 2018, and contributed to low sea ice extent and ecological impacts to fisheries (Sidebar 5.1) and marine mammals (RichterMenge et al. 2019). In both cases, this pattern of SAT was supported by the displacement of the stratospheric polar vortex to over North America (Fig. 5.3b). March was exceptionally warm over much of Alaska, the Yukon, and western Northwest Territories, where most places set all-time record high monthly means, in some cases $3^{\circ} \mathrm{C}$ higher than any previous March.

In February and March 2019 (Fig 5.3a), as in winter 2018, strong, warm winds from the south over the Bering Sea greatly delayed sea ice advances (section 5d) and moved warm air
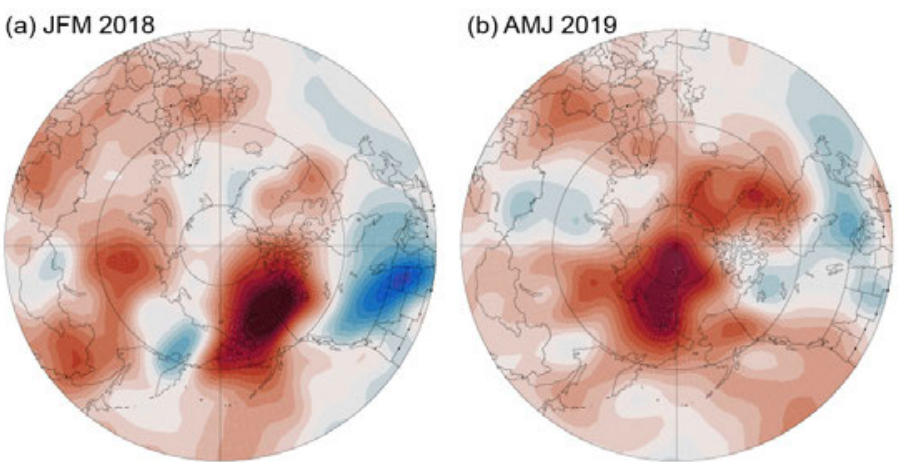

(c) JAS 2019

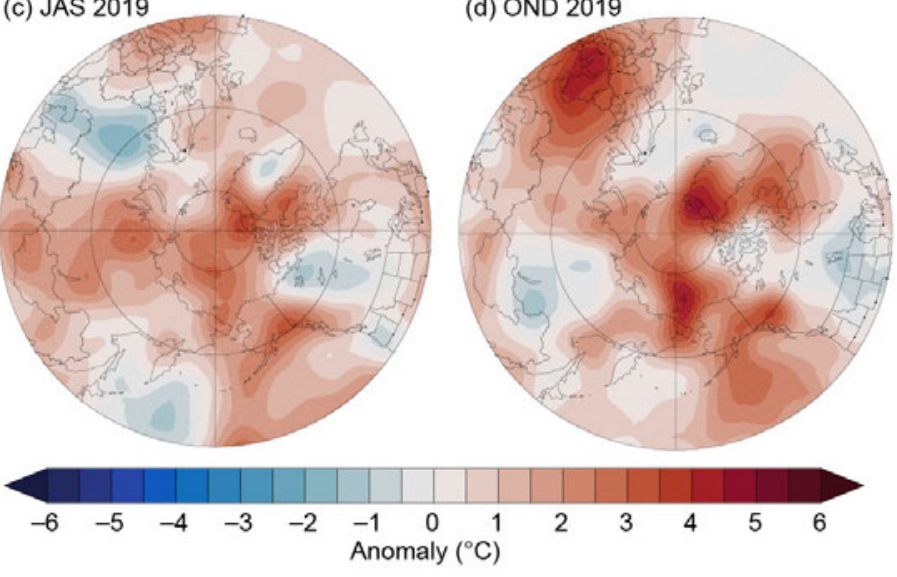

Fig. 5.2. Seasonal anomaly patterns during 2019 for nearSAT (in ${ }^{\circ} \mathrm{C}$ ) relative to the baseline period 1981-2010 in (a) winter, (b) spring, (c) summer, and (d) autumn. Temperature anomalies are from slightly above the surface layer (at 925 $\mathrm{hPa}$ level) to emphasize large spatial patterns rather than local features. (Source: NCAR/NCEP reanalysis via NOAA/ESRL.) 
(a) 2019 Feb-Mar, $\mathbf{z 7 0 0}$

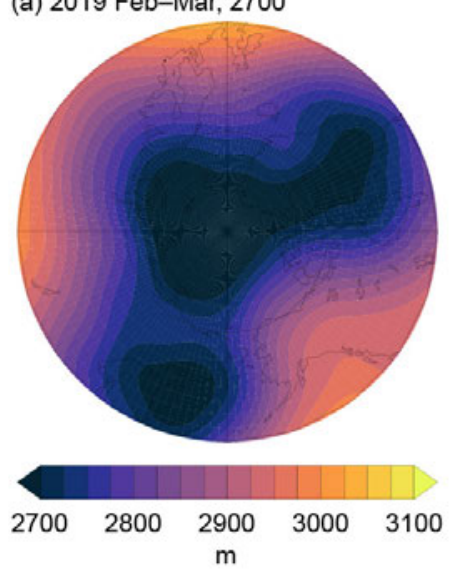

(c) 2019 May-Aug, z700

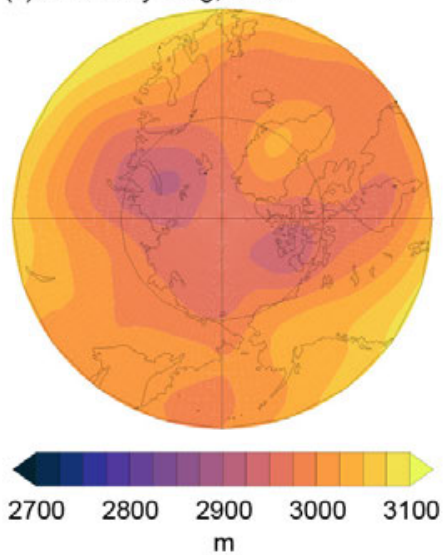

(b) 2019 Feb-Mar, z100

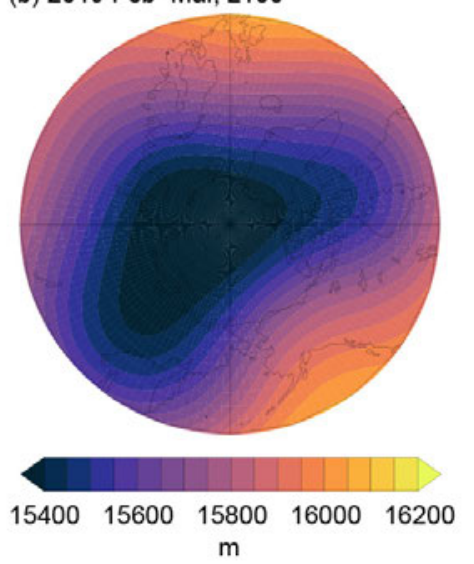

(d) 2019 Oct-Dec, z700

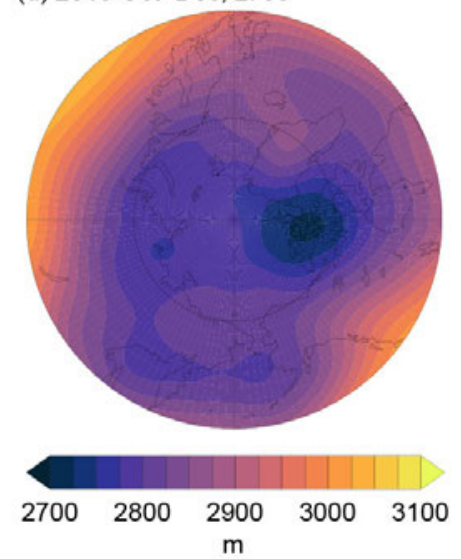

Fig. 5.3. The geopotential height pattern (m) (a), (c), (d) at $700 \mathrm{hPa}$ and (b) $100 \mathrm{hPa}$ for selected 2019 time periods that also reflect Arctic-wide wind patterns. The $700-\mathrm{hPa}$ geopotential height field is used to characterize atmospheric wind circulation about a third of the way up in the troposphere; winds tend to follow the contours of geopotential heights anticlockwise around low values. (a) Feb-Mar 2019 and (b) the polar vortex at $100 \mathrm{hPa}$ in Feb-Mar 2019, which supported the winter wind pattern shown in Fig. 5.3a. (c) May-Aug geopotential height at 700 $\mathrm{hPa}$. There is a low geopotential height center and cyclonic flow near the Kara Sea and Canadian Arctic Archipelago and high geopotential heights and anticyclonic winds over Greenland, which acted in tandem to transport warm air from lower latitudes into the central Arctic. The persistent ridges over the Pacific Arctic and Greenland caused southerly winds and warm air temperatures over Alaska and the southern Yukon Territory and over areas to the north and west of Greenland, respectively. (d) Rare displacement of the jet stream over the Canadian Arctic Archipelago and Baffin Bay in Oct-Dec 2019 led to extremely high northern Greenland temperatures. (Source: NCAR/ NCEP reanalysis via NOAA/ESRL.)

northward along the date line into the central Arctic. The lower-level atmospheric wind pattern (Fig. 5.3a) was connected to patterns higher in the atmosphere (i.e., the polar vortex; Fig. 5.3b) that contributed to the persistence of the wind pattern over Alaska and the rest of North America.

Spring 2019 (AMJ). Spring (Fig. 5.2b) showed warm temperature anomalies, especially in the East Siberian Sea extending into the central Arctic where temperatures were $5^{\circ} \mathrm{C}$ above average and were associated with offshore winds, as also seen during 2017 and 2018. In April, record high temperatures occurred at several sites in Scandinavia and in many parts of Iceland. Localized extreme temperatures off the west coast of Greenland triggered an early and extensive snow melt season (sections 5e,g). Stations along the Greenland coast, especially the west and northwest coasts, had near-record high temperature maxima of $\sim 22^{\circ} \mathrm{C}$ in June due to localized southerly winds (Fig. 5.3c). Similar high temperatures continued into the summer.

Summer 2019 (JAS). Unlike summers 2016, 2017, and 2018, summer 2019 returned to the relatively warm conditions observed in much of the previous decade (Fig. 5.2c). Low surface pressures, particularly over the Canadian Archipelago and Kara Sea, combined with high pressure over Greenland to advect warm, southerly air into the central Arctic, causing early summer melting (section 5d). June and especially July were very warm over much of Alaska and the southern Yukon $\left(+4^{\circ} \mathrm{C}\right.$ anomalies). At Anchorage, all three months were the warmest on record over the last 69 years, caused by a persistent ridge of high pressure and southerly winds over the Pacific Arctic (Fig. 5.3c). Similarly, July was the warmest month on record in Reykjavik, Iceland, since records began there in 1871 (Trausti Jónsson, Icelandic Met. Office, personal communication).

Autumn 2019 (OND). Positive temperature anomalies stretched across the central Arctic with the largest temperature anomalies $\left(+3^{\circ} \mathrm{C}\right)$ in the Chukchi Sea and north Greenland (Fig. 5.2d). Like autumn 2017 and 2018, the sustained warming pattern in the Chukchi Sea during 2019 was associated with a delayed autumn sea ice freeze-up (section 5d). During autumn 2019, the Northern Hemisphere jet stream pattern was relatively zonal and well to the south of Arctic regions, with strong westerly winds over North America and Europe and little penetration of Arctic air toward 
the south. The exception was the location of low 700-hPa geopotential heights displaced from the North Pole to northern Canada, centered in the Canadian Arctic Archipelago, which created the strongest high-pressure Greenland blocking episode (above-average mid-tropospheric geopotential heights and anticyclonic winds over Greenland) in October since 2006 (Fig. 5.3d). This blocking pattern led to southerly winds advecting relatively warm air to northern Greenland, resulting in the observed large temperature anomalies.

\section{Sea surface temperature-M.-L. Timmermans, Z. Labe, and C. Ladd}

Summer sea surface temperatures (SSTs) in the Arctic Ocean are driven mainly by the amount of incoming solar radiation absorbed by the sea surface. Solar warming of the Arctic surface ocean is influenced by the distribution of sea ice (with greater warming occurring in ice-free regions), cloud cover, ocean optical properties, and upper-ocean stratification. In the Barents and Chukchi Seas, there is an additional source of ocean heat contributed by the advection of warm water from the North Atlantic and North Pacific Oceans, respectively. Arctic SSTs are an essential indicator of the role of the ice-albedo feedback mechanism in any given summer melt season. As the area of sea ice cover decreases (section $5 \mathrm{~d}$ ), more incoming solar radiation is absorbed by the ocean and, in turn, the warmer ocean melts more sea ice. In addition, higher SSTs are associated with delayed autumn freeze-up and increased ocean heat storage throughout the year. Marine ecosystems are influenced by SST, which affects the timing and development of primary and secondary production cycles, as well as available habitat for upper-trophic and temperature-sensitive species.

Sea surface temperature data presented in this section are a blend of in situ and satellite measurements from December 1981 to present, taken from the OISSTv2 (Reynolds et al. 2002, 2007). Compared to purely in situ temperature measurements, the OISSTv2 product explains about 80\% of the variance, with an overall cold bias via its tendency to underestimate SST by $-0.02^{\circ} \mathrm{C}$ (Stroh et al. 2015). The OISSTv2 product uses a linear relationship with sea ice concentration to infer SST, with SST constrained to $-1.8^{\circ} \mathrm{C}$ (the freezing point of seawater with a salinity of $33 \mathrm{~g} \mathrm{~kg}^{-1}$ at the sea surface) where ice concentration is 100\% (Reynolds et al. 2007). Variations in freezing temperature as a result of variations in sea surface salinity (not accounted for in the algorithm) imply that OISSTv2 SSTs under sea ice can be too cool by up to $0.2^{\circ} \mathrm{C}$, with the highest errors in the fresher surface waters of the Canada Basin (see Timmermans and Proshutinsky 2015). August mean SSTs provide the most appropriate representation of Arctic Ocean summer SSTs, because they are not affected by the cooling and subsequent sea ice growth that typically takes place in the latter half of September. The period 1982-2010 is used as a climatological reference mean.

August 2019 mean SSTs ranged from $8^{\circ}$ to $9^{\circ} \mathrm{C}$ in the southern Chukchi and Barents Seas to approximately $1^{\circ} \mathrm{C}$ in the interior Arctic Ocean near the mean sea ice edge for that month (Fig. 5.4a). Sea surface temperatures in August 2019 were consistent with sustained mean August SST

(a)

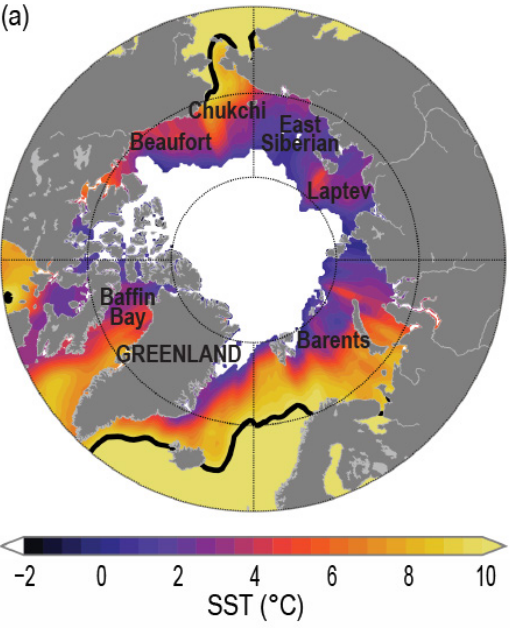

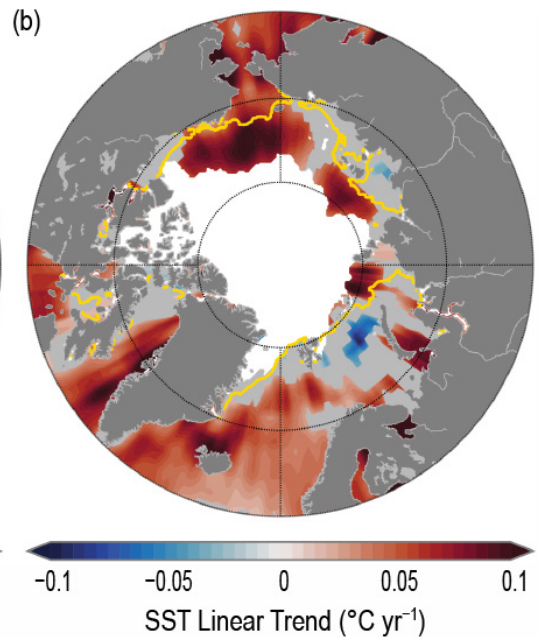

Fig. 5.4. (a) Mean SST $\left({ }^{\circ} \mathrm{C}\right)$ in Aug 2019. White shading is the Aug 2019 mean sea ice extent, and black contours indicate the $10^{\circ} \mathrm{C}$ SST isotherm. (b) Linear SST trend $\left({ }^{\circ} \mathrm{C} \mathrm{yr}^{-1}\right)$ for Aug of each year from 1982-2019. The trend is shown only for values that are statistically significant at the $95 \%$ confidence interval; the region is gray otherwise. The yellow line indicates the median ice edge for Aug 1982-2010. White shading is the Aug 2019 mean sea ice extent. (Sources: SST data are from the NOAA OISSTv2; sea ice extent and ice-edge data are from NOAA/NSIDC Climate Data Record of Passive Microwave Sea Ice Concentration, Version 3; Peng et al. 2013; Meier et al. 2017.) 


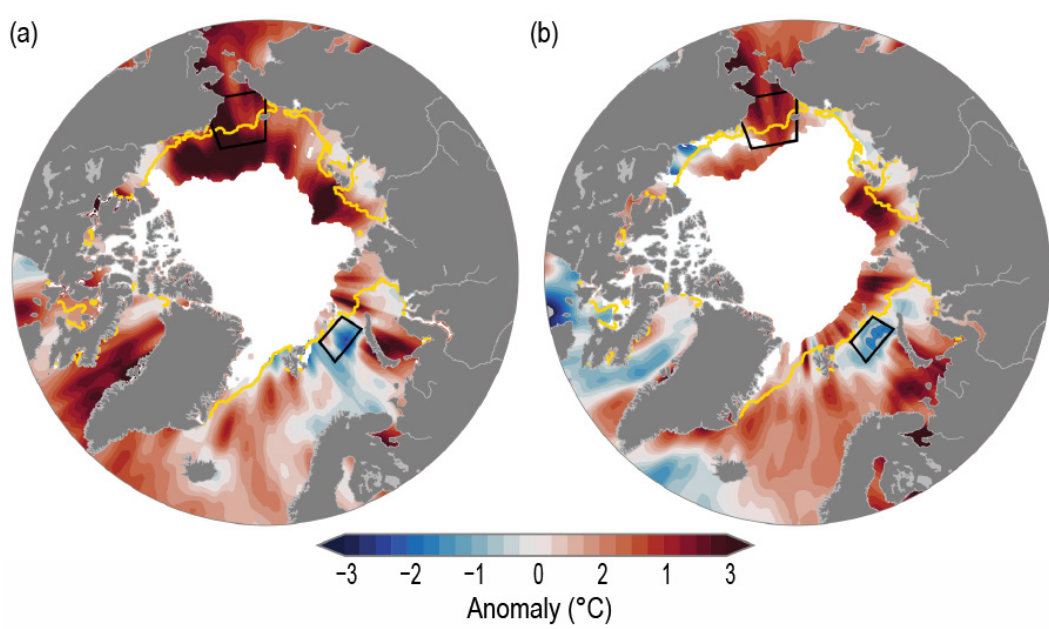

Fig. 5.5. SST anomalies $\left({ }^{\circ} \mathrm{C}\right)$ in (a) Aug 2019 and (b) Aug 2018 relative to the Aug 1982-2010 mean. The yellow line indicates the median ice edge for Aug 1982-2010 and white shading indicates the mean sea ice extent in (a) Aug 2019 and (b) Aug 2018. The two regions marked by black boxes relate to data presented in Figs. 5.6 and 5.7. (Sources: SST data are from the NOAA OISSTV2; sea ice extent and ice-edge data are from NOAA/NSIDC Climate Data Record of Passive Microwave Sea Ice Concentration, Version 3; Peng et al. 2013; Meier et al. 2017.) warming trends from 1982 to 2019 over much of the Arctic Ocean, with statistically significant (at the 95\% confidence interval) linear warming trends of up to $+1^{\circ} \mathrm{C}$ decade ${ }^{-1}$ (Fig. 5.4b). A notable exception was the cooling trend in the northern Barents Sea region, discussed later.

August 2019 mean SSTs were around $1^{\circ}-7^{\circ} \mathrm{C}$ higher than the 1982-2010 August mean in the Beaufort, Chukchi, and Laptev Seas and Baffin Bay (Fig. 5.5a). The anomalously high SSTs in the vicinity of the August 2019 mean sea ice edge are linked to anomalously low sea ice extent throughout summer, which allowed for direct solar heating of the exposed surface waters (Fig. 5.5a). Conversely, the entire Barents Sea region was marked by anomalously low August 2019 SSTs that were around $0.5^{\circ}-2^{\circ} \mathrm{C}$ lower than the 1982-2010 mean. Relative to August 2018, August 2019 SSTs were up to $4^{\circ} \mathrm{C}$ higher in the Beaufort Sea and Baffin Bay, while SSTs were a few degrees lower in the Barents Sea in August 2019 compared to August 2018 (Fig. 5.5b).

The Chukchi Sea region continues to exhibit larger warming trends than the Arctic mean (Figs. 5.6a,b), with August 2019 mean SSTs in the region being the second highest on record (Fig. 5.6b). The Bering Sea exhibits a similar warming trend to the Chukchi Sea in August (Fig. 5.6c; see Thoman et al. 2019). A marked exception to the prevalent August SST warming trends across the Arctic is the cooling trend $\left(-0.06 \pm 0.03^{\circ} \mathrm{C} \mathrm{yr}^{-1}\right)$ in the northern Barents Sea (Fig. 5.7a). The statistically significant northern Barents Sea cooling trend is not observed in all months; annually-averaged northern Barents
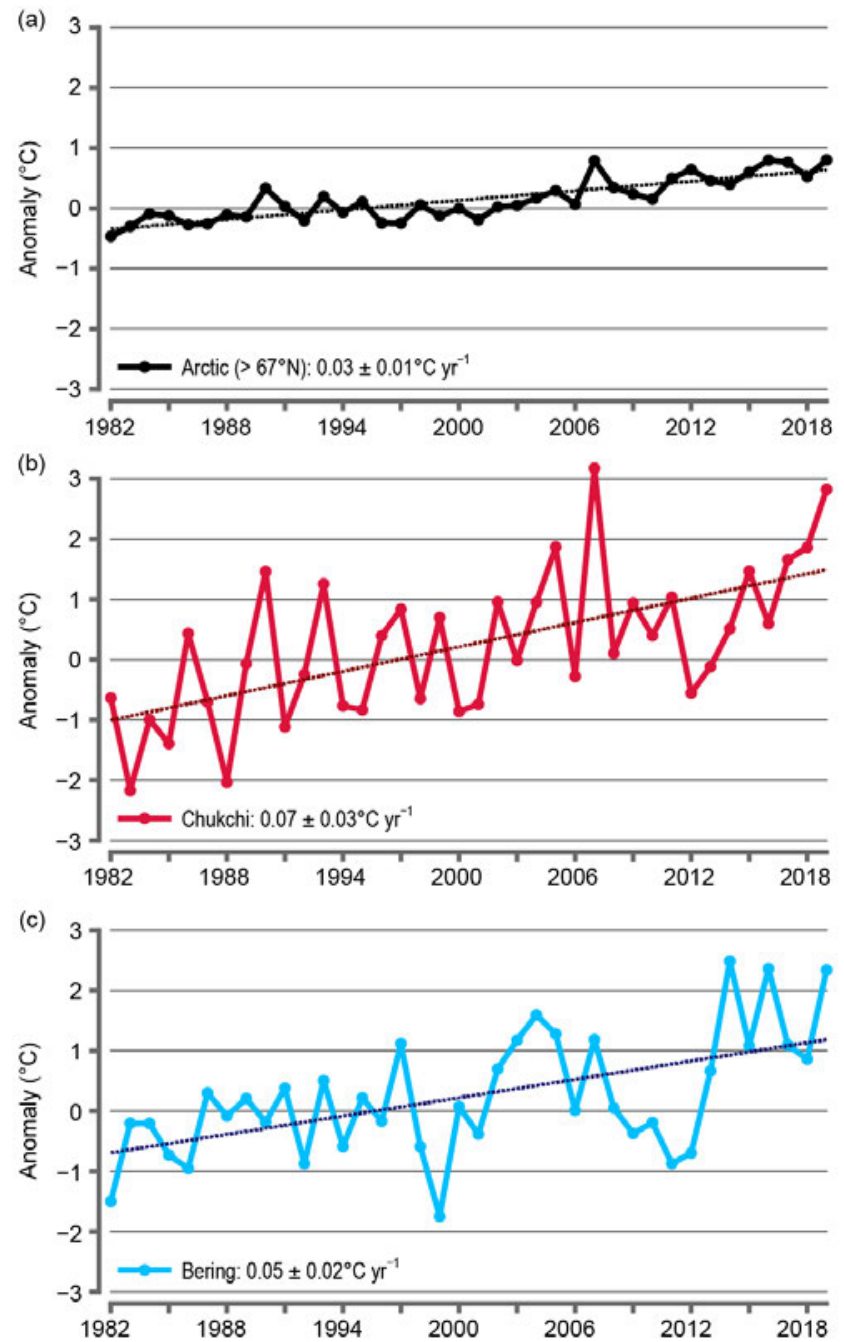

Fig. 5.6. Area-averaged SST anomalies $\left({ }^{\circ} \mathrm{C}\right)$ for Aug of each year (1982-2019) relative to the 1982-2010 Aug mean for (a) the Arctic Ocean north of $67^{\circ} \mathrm{N}$; (b) the Chukchi Sea region shown by black box in Fig. 5.5; and (c) the Bering Sea domain bounded by $54^{\circ}-64^{\circ} \mathrm{N}$ and $180^{\circ}-200^{\circ} \mathrm{E}$ (see Thoman et al. 2019). The dotted lines show the linear SST anomaly trends over the period shown. Numbers in the legends correspond to linear trends in ${ }^{\circ} \mathrm{C} \mathrm{yr}^{-1}$ (with $95 \%$ confidence intervals). 
Sea SSTs exhibit a warming trend, which has been attributed to changes in Atlantic water influence in the region (e.g., see Barton et al. 2018). August mean sea ice extent over the entire Barents Sea domain has been generally declining over 1982-2019 (Fig. 5.7b). If only the northern Barents Sea is considered, there has been little-to-no August sea ice for most years in the past two decades. The interplay between sea ice cover, solar absorption, and lateral ocean heat transport that results in lower August SSTs in the Barents Sea region requires further study.

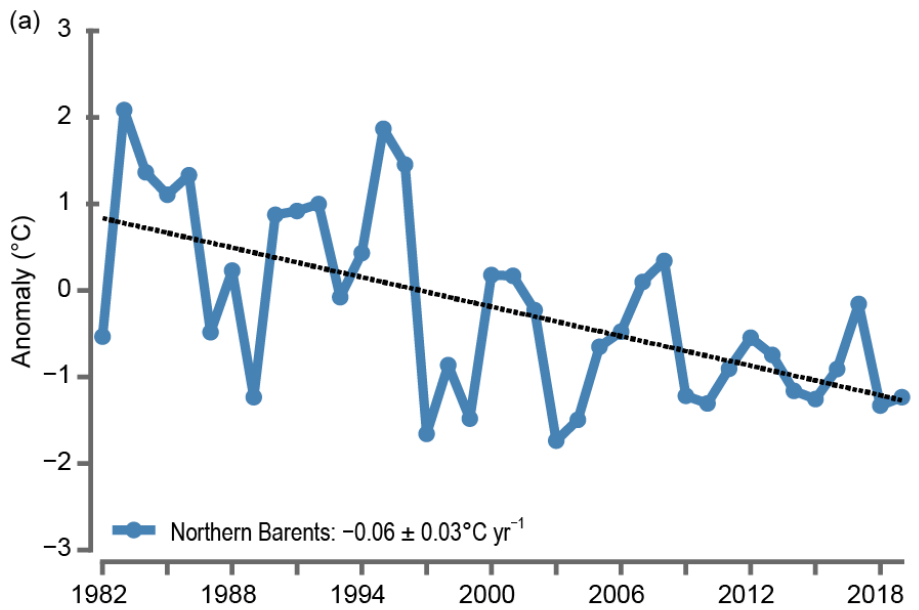

(b) Barents: Mean Sea Ice Extent

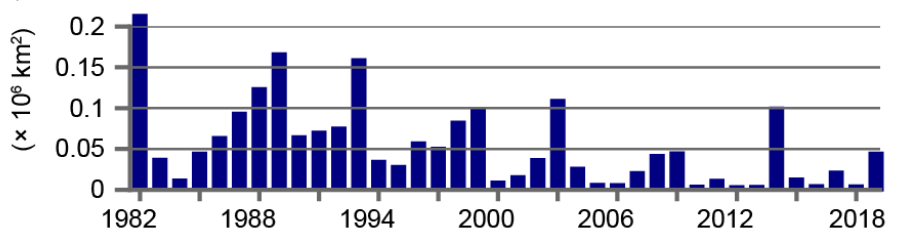

Fig. 5.7. (a) Area-averaged SST anomalies $\left({ }^{\circ} \mathrm{C}\right)$ for Aug of each year (1982-2019) relative to the 1982-2010 Aug mean for the northern Barents Sea region shown by black box in Fig. 5.5. The dotted line shows the linear SST anomaly trend over the period shown. Numbers in the legend indicate the statistically significant linear cooling trend in ${ }^{\circ} \mathrm{C}$ year ${ }^{-1}$ (with $95 \%$ confidence interval). (b) Aug sea ice extent calculated over the entire Barents Sea domain. Sea ice extent data are from NSIDC Sea Ice Index, Version 3 (Fetterer et al. 2017) using a regional mask introduced by Meier et al. (2007), available at nsidc.org.

d. Sea ice-D. Perovich, W., Meier, M. Tschudi, K. Wood, S. Farrell, S. Hendricks, S. Gerland, L. Kaleschke, R. Ricker, X. Tian-Kunze, and M. Webster

\section{1) Sea ice extent}

Sea ice is an important component of the Arctic system, because it limits the amount of absorbed solar energy due to its high albedo, acts as a barrier between the underlying ocean and the atmosphere, provides a habitat for biological activity, and serves as a platform for Indigenous community hunting and travel. The extent of the Arctic sea ice cover varies substantially during the year, with the end-of-winter ice cover generally being two to three times as large as that at the end of summer. Sea ice extent has been continuously monitored by passive microwave instruments on satellite platforms since 1979, providing a consistent long-term perspective on changing coverage over the last four decades. The sea ice extent estimates used in this report are based on products from the National Snow and Ice Data Center (NSIDC) Sea Ice Index (Fetterer et al. 2017), derived from NASA's gridded sea ice concentration fields (Cavalieri et al. 1996; Maslanik and Stroeve 1999). Other similar products exist and, while absolute numbers vary, they all show general consistency in trends and variability (e.g., Meier and Stewart 2019).

March and September are of particular interest in sea ice time series because Arctic sea ice maximum and minimum extents, respectively, typically occur during these months. Figure 5.8 shows monthly average ice extents in March and September 2019. The sea ice cover reached a winter maximum extent of 14.78 million $\mathrm{km}^{2}$ on 13 March 2019. This tied with 2007 as the seventh-lowest maximum extent in the 41-year satellite record and was 5.9\% below the 1981-2010 average. The previous four years (2015-18) are the four lowest years in the record. From year to year, the regions with a reduced winter sea ice 
cover extent are not consistent. For example, in March 2019, the winter maximum sea ice extent in some marginal seas was near normal, such as in the Sea of Okhotsk, while the Bering Sea was $70 \%-80 \%$ lower than normal.

The sea ice cover reached a summer minimum extent of 4.15 million $\mathrm{km}^{2}$ on 18 September 2019. This tied with 2007 and 2016 as the second-lowest extent of the satellite record and was 2.04 million $\mathrm{km}^{2}$ (33\%) less than the 1981-2010 average minimum ice extent. The September minimum ice extent has not returned to pre-2007 levels; the 13 lowest extents in the satellite record have all occurred in the last 13 years (2007-19).

Observations of Arctic sea ice extent have shown decreasing trends in all months and virtually all regions (Meier et al. 2014). The September monthly average trend for the entire Arctic Ocean is now $-12.9 \pm 2.2 \%$ decade $^{-1}$
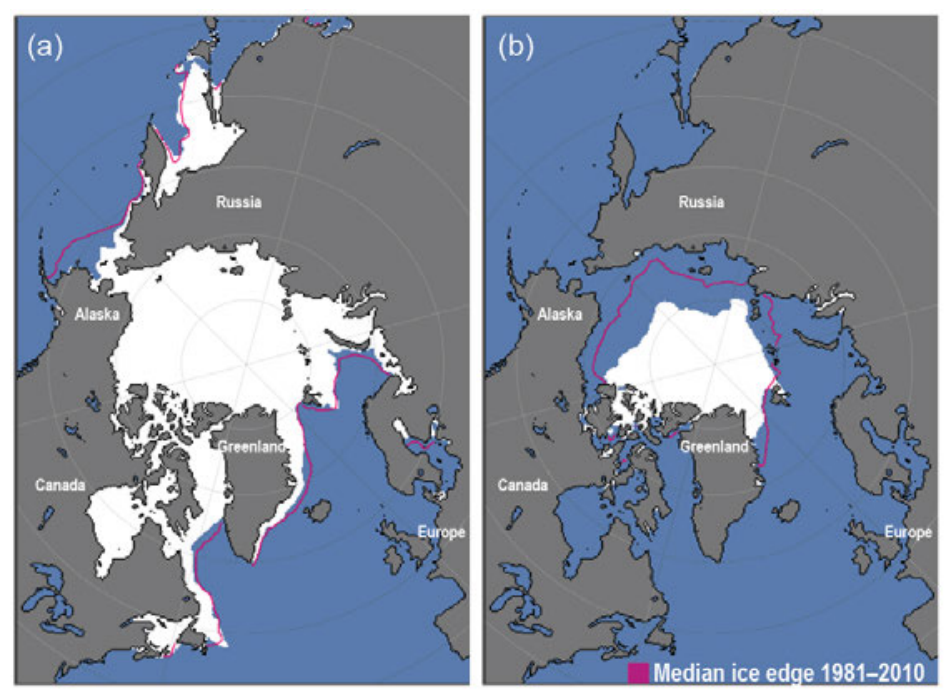

Fig. 5.8. Average monthly sea ice extent in Mar 2019 (left) and Sep 2019 (right) illustrate the respective monthly winter maximum and summer minimum extents. The magenta line indicates the median ice extents in Mar and Sep, respectively, during the period 1981-2010. Maps are from NSIDC at http:// nsidc.org/data/seaice_index/(Fetterer et al. 2017).

relative to the 1981-2010 average (Fig. 5.9), statistically significant at the $99 \%$ confidence level. Trends are smaller during March $\left(-2.7 \%\right.$ decade $\left.^{-1}\right)$, but the decrease is also statistically significant. In 2019, the seasonal reduction between the March maximum and September minimum extent was 10.63 million $\mathrm{km}^{2}$, a change of roughly $72 \%$. The difference between maximum and minimum extents in the satellite record has increased in recent years.

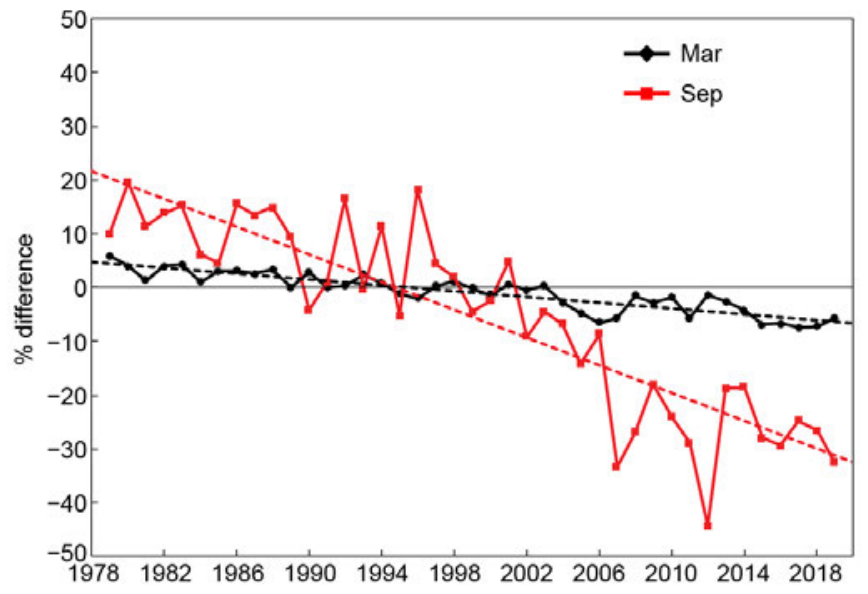

Fig. 5.9. Time series of sea ice extent anomalies in Mar (the month of maximum ice extent, in black) and Sep (the month of minimum ice extent, in red). The anomaly value for each year is the difference (in \%) in ice extent relative to the mean values for the period 1981-2010. The black and red dashed lines are leastsquares linear regression lines. The slopes of these lines indicate ice losses of $-2.7 \pm 0.4 \%$ and $-12.9 \pm 2.2 \%$ decade $^{-1}$ in Mar and Sep, respectively. Both trends are statistically significant at the 99\% confidence level. (Source: NSIDC Sea Ice Index [Fetterer et al. 2017].)

\section{2) Sea ice age}

The age of sea ice is also a key descriptor of the state of the sea ice cover. It serves as an indicator for ice physical properties including snow cover, surface roughness, optical properties, melt pond coverage, salinity, and thickness (Tschudi et al. 2016). Older ice tends to be thicker and thus more resilient to changes in atmospheric and oceanic forcing compared to younger ice. The age of the ice has been determined using satellite observations and drifting buoy records that track ice parcels over several years (Maslanik et al. 2011). This method has been used to provide a record of the age of the ice since the mid-1980s (Tschudi et al. 2019 a,b).

The area of the oldest ice ( $>4$ years old) was a substantial fraction of the winter sea ice cover within the Arctic Ocean in the mid-1980s (2.52 million km², 33\% of the ice pack in March 1985). In 
contrast, in 2019 the $>4$ year-old ice category made up just a small fraction $\left(90000 \mathrm{~km}^{2}, 1.2 \%\right.$ in March 2019) of the Arctic Ocean ice pack (Fig. 5.10). Firstyear ice now dominates the sea ice cover, comprising $~ 70 \%$ of the March 2019 ice pack, compared to approximately $35 \%-50 \%$ in the 1980 s. Given that older ice tends to be thicker and stronger, the sea ice cover has transformed from a strong, thick ice mass in the 1980s to a younger, more fragile, and thinner ice mass in recent years. The distribution of ice age in March 2019 was generally similar to that in March of the previous year.

\section{3) Chukchi Sea}

The Chukchi Sea has experienced particularly large changes in sea ice coverage and is a representative example of extreme sea ice conditions in the Arctic. The September 2019 Arctic sea ice minimum extent was characterized by profound sea ice loss in the Chukchi Sea (Fig. 5.11), due to multiple factors. First, the Bering Sea had extremely low ice cover for much of the winter 2019 (see Sidebar 5.1), which may have acted as a precursor to the summer Chukchi Sea conditions. In spring 2019, melt onset across the Chukchi Sea occurred 20-35 days earlier than the 1981-2010 average. Sea ice began a rapid and accelerating retreat from the south in early May, leading to a record low sea ice extent in the Chukchi Sea that lasted until early August, with negative sea ice concentration anomalies of 50\%. A combination of anomalously warm air temperatures $\left(1^{\circ}-5^{\circ} \mathrm{C}\right.$ above the $1981-2010$ average) and southerly winds promoted this precipitous loss of ice (section 5b). As the sea ice retreated northward, exposed open water areas warmed, leading to anomalous SSTs in summer 2019 greater than $5^{\circ} \mathrm{C}$ above average (section $5 \mathrm{c}$ ).

The dearth of sea ice continued into the autumn season, accompanied by anomalously warm air temperatures of $4^{\circ}$ to $5^{\circ} \mathrm{C}$ above the 1981-2010 average during October and November 2019 (section 5b). The warm air temperatures were partly due to very warm ocean waters, with SSTs remaining at $5^{\circ} \mathrm{C}$ or more above average in the Chukchi Sea well into November. The Chukchi Sea did not fully freeze over until 24 December, about a month later than average, with only 2007 and 2016 showing similarly late freeze-up dates since modern satellite observations began in 1979.

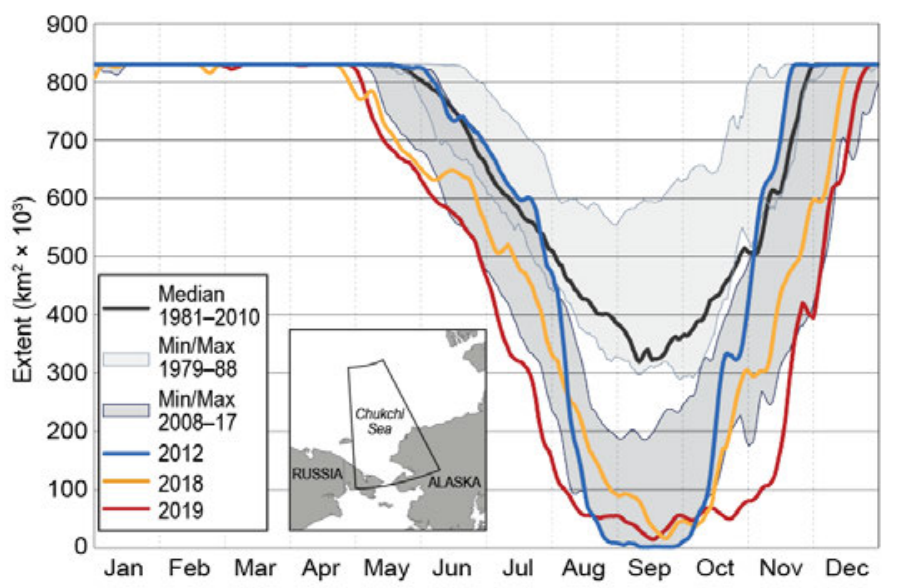

(a)

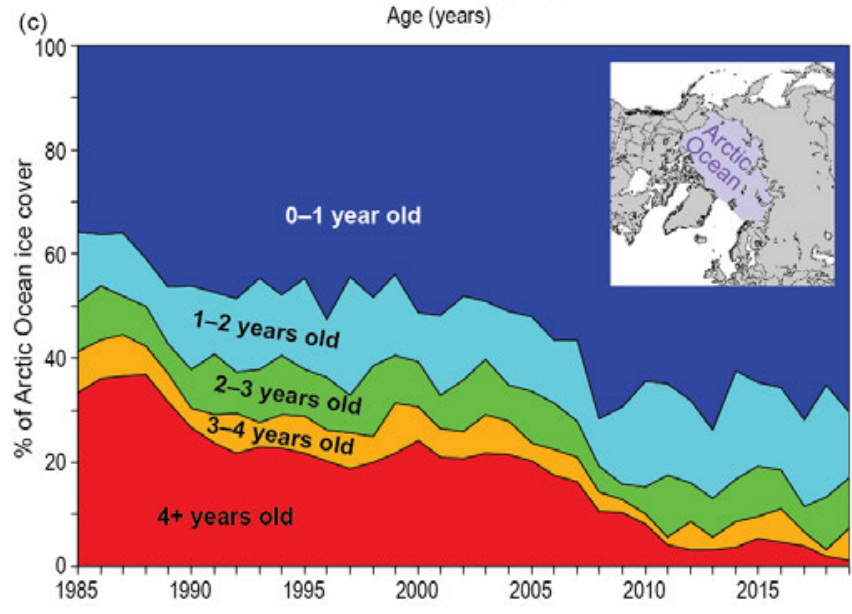

Fig. 5.10. Late winter sea ice age coverage map for the week of (a) 12-18 Mar 1985 (b) and 12-18 Mar 2019 (c) Sea ice age percentage within the Arctic Ocean region (purple shaded region in inset image) for the week of 12-18 Mar 1985 and 2019. (Source: NSIDC [Tschudi et al. 2019a,b].)
Fig. 5.11. Time series of 2019 sea ice extent in the Chukchi Sea (see inset) through $12 \mathrm{Nov}$ (red line) compared to the previous year (2018; yellow line); the record minimum year (2012, blue line), and the climatological median (1981-2010; black line), derived from satellite passive-microwave data. The gray shaded areas show the maximum range of variability of sea ice extent for the first decade of the satellite era (1979-88) and the most recent decade (2008-17), illustrating the long-term change in sea ice extent over the entire period since 1979. (Source: NSIDC Sea Ice Index, version 3 [Fetterer et al. 2017].) 


\section{SIDEBAR 5.1: Shifting fish distributions in the Bering Sea-J. M. MARSH, F. J. MUETER,}

\section{J. T. THORSON, L. BRITT, AND S. ZADOR}

The eastern Bering Sea is a highly productive ecosystem that supports many subsistence and commercial fisheries. These commercial fisheries are some of the most valuable in the world, with annual wholesale revenue exceeding \$1 billion (U.S. dollars; Fissel et al. 2019). To support sustainable management and assess overall ecosystem health, yearly summer bottom-trawl surveys in the southeastern Bering Sea have monitored the abundance and biomass of demersal (living on the seafloor) fishes and invertebrates since 1982 (NPFMC 2018). To study impacts of the loss of seasonal sea ice on the Bering Sea ecosystem, the surveys were expanded in 2010 and 2017-19 to include the northern Bering Sea, a transitional zone between the North Pacific Ocean and the Arctic Chukchi Sea.

On the Bering Sea shelf, the summer distribution of demersal fishes and invertebrates is tied to the extent of the cold pool (bottom water temperatures $<2^{\circ} \mathrm{C}$ ). The cold pool forms during autumn freeze-up when cold dense water sinks to the seafloor where it persists throughout the following summer, even as the surface waters undergo seasonal warming. The size of the cold pool is dependent on the extent of sea ice in the Bering Sea during the preceding winter (Wyllie-Echeverria and Wooster 1998), and it can serve as a thermal barrier to boreal (southern Bering Sea) fish expansion into the Arctic. Until recently, it was expected that sea ice would continue to persist throughout the winter over the shallow northern Bering Sea and southern Chukchi Sea shelf, enabling the formation of the cold pool (Stabeno et al. 2012). However, latent heat in the water column from the warm conditions of summer 2016, combined with less sea ice formation in the 2016/17 winter (Thoman et al. 2020), resulted in an unusually narrow cold pool on the eastern Bering Sea shelf during summer 2017. Sea ice extent was further reduced in the 2017/18 and 2018/19 winters with the lowest coverage on record for February and March, respectively $(<40 \%$ of average conditions; Stabeno and Bell 2019; Stabeno et al. 2019). This led to a considerable reduction $(>75 \%)$ in the size of the cold pool during the summers of 2018 and 2019 (Fig. SB5.1).

These changes in the physical environment are expected to affect the distribution of fish and invertebrate communities. In general, fish populations are expected to remain within their preferred thermal conditions by shifting their spatial distributions to track changes in ocean temperatures (Pinsky et al. 2013). Therefore, within a warming marine environment, boreal fish populations in the Bering Sea are expected to expand northward into new areas (Hollowed et al. 2013), while cold-adapted species may contract.

We compare the spatial distribution of five assemblages (groups of co-occurring species) in the Bering Sea during the 2017-19 warm period, relative to the cooler conditions of 2010 (Fig. SB5.1). These assemblages represent three boreal fish communities from the outer, middle, and inner shelf, a mixed community in Norton Sound, and an Arctic community on the northern shelf. Following a drastic reduction in the size of the
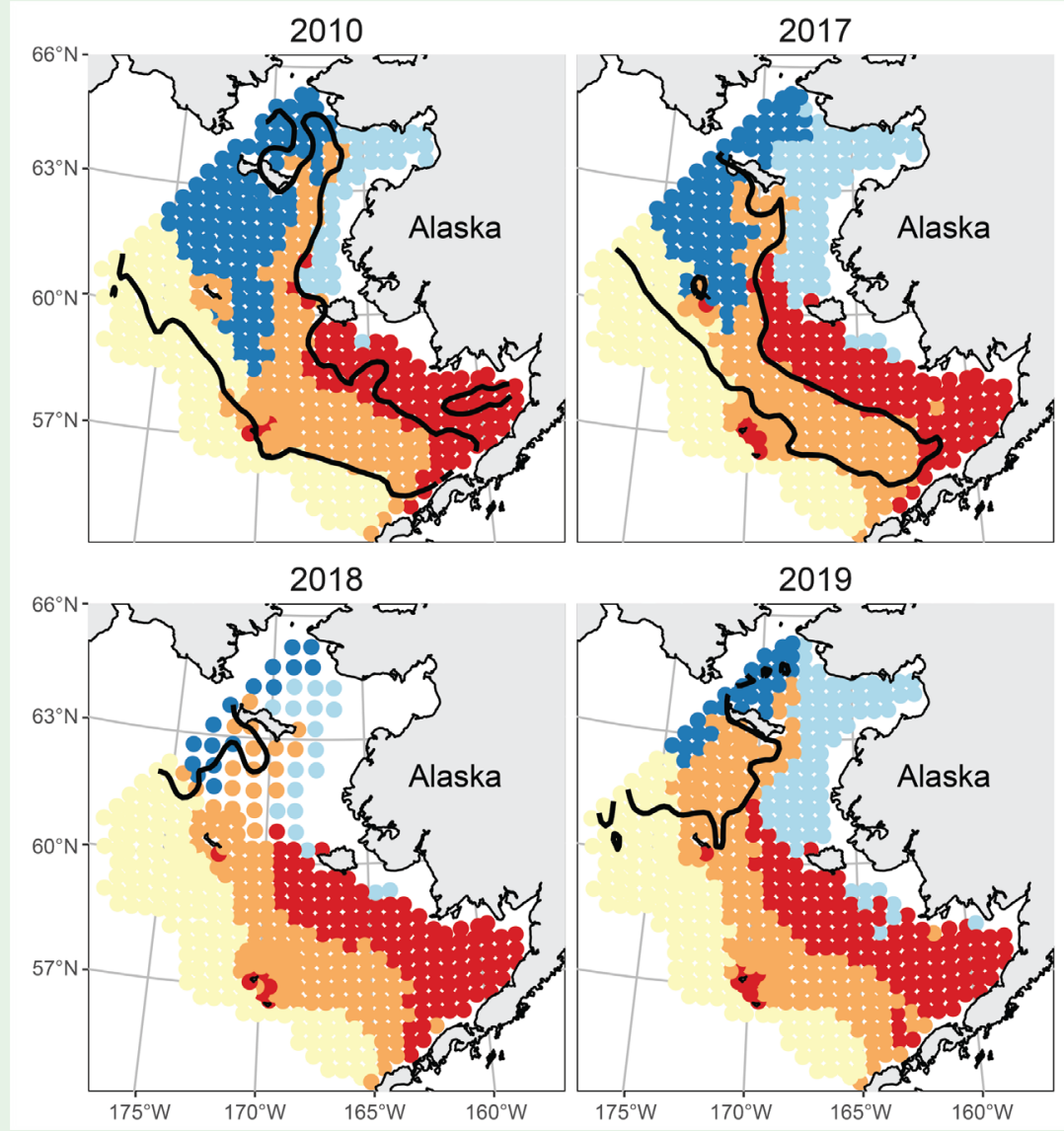

Fig. SB5.1. Distribution of major species assemblages identified in the eastern Bering Sea during the summers of 2010, 2017, 2018, and 2019, including three boreal assemblages on the southern inner shelf (red), middle shelf (orange), and outer shelf/slope region (yellow), as well as a mixed Norton Sound (light blue) and an Arctic/northern shelf assemblage (dark blue). See Thorson et al. (2019) for a description of clustering methods used on catch-per-unit-effort $\left(\mathrm{kg} \mathrm{ha}^{-1}\right)$ of 44 common species caught in 1983 hauls. The contour (black) denotes the $2^{\circ} \mathrm{C}$ isotherm of bottom water temperature, which marks the boundary of the cold pool. 
cold pool in 2018 and 2019, the middle-shelf (boreal) assemblage expanded northward while the northern shelf (Arctic) assemblage retracted. At the same time, the inner shelf and Norton Sound assemblages expanded offshore in 2018 and 2019, coinciding with warmer coastal water temperatures, particularly in 2019. These community-level shifts, which reflect changes in the distribution of individual species, result in a large portion of the shelf transitioning from an Arctic community, dominated by relatively smaller and less abundant species (e.g., Arctic cod; Boregadus saida), to a community dominated by larger and more abundant boreal species (e.g., Pacific cod; Gadus macrocephalus).

Changing distributions are also illustrated by mapping the density (biomass per unit area) of four individual gadid (cod family) species in the Bering Sea (Fig. SB5.2). We selected two boreal species that support high-value commercial fisheries, walleye pollock (Gadus chalcogrammus) and Pacific cod, and two smaller gadids, Arctic cod and saffron cod (Eleginus gracilis), which are key indicator species for the northern shelf (Arctic) and Norton Sound assemblages, respectively. Both walleye pollock and Pacific cod shifted northward between bottom-trawl surveys conducted in 2010 and repeated in 2017, 2018, and 2019. Hotspots of increased density in the later years are apparent for Pacific cod south of St. Lawrence Island $\left(63^{\circ} \mathrm{N}, 170^{\circ} \mathrm{W}\right)$ and for pollock south of the Bering Strait $\left(64^{\circ} \mathrm{N}\right.$, $172^{\circ} \mathrm{W}$ ). The locations of these hotspots on the northern Bering Sea shelf have contributed to a rapid northward shift in the center of population for these commercially important species (Stevenson and Lauth 2019). These results also show that the areas with the greatest changes vary from species to species, and that northward shifts in boreal species can occur even while their densities remain high within the southern portion of their range. A similar "borealization" of the fish community has occurred in the Barents Sea, as increasing water temperatures and retreating ice cover have opened new feeding habitats for Atlantic cod (Gadus morhua) and haddock (Melanogrammus aeglefinus), two commercially important cod species (Fossheim et al. 2015; Thorson et al. 2019).

Compared to these boreal species, Arctic taxa tend to be more sensitive to habitat changes. Arctic cod in particular can serve as a sentinel species that responds quickly to changes in water temperature and sea ice extent (Alabia et al. 2018; Marsh and Mueter 2019). Correspondingly, we saw roughly $92 \%$ and $78 \%$ reductions in the area occupied by Arctic cod when comparing 2010 to 2018 and 2019, respectively (Figs. SB5.2i-I), while saffron cod, an indicator for the Norton Sound assemblage, has expanded westward and southward along the coast (Figs. SB5.2m-p).

The expansion of nearshore "Norton Sound" and southern shelf species into the northern Bering Sea is likely to have profound effects from predation on the benthic ecology of the northern Bering Sea-effects that are yet undocumented. The observed high densities of fish in the Bering Strait suggest that boreal species may shift their summer feeding migrations into the Chukchi Sea, which has also seen large decreases in summer and autumn sea ice extent (section $5 d$ ). Such potential movement northward into the Chukchi Sea highlights the need for additional fisheries surveys north of the Bering Strait, as well as continued surveys in the Bering Strait region and a synthesis of data from both the United States and Russian waters. In this report, we have presented only a limited four years of survey data from the U.S. Bering Sea. 

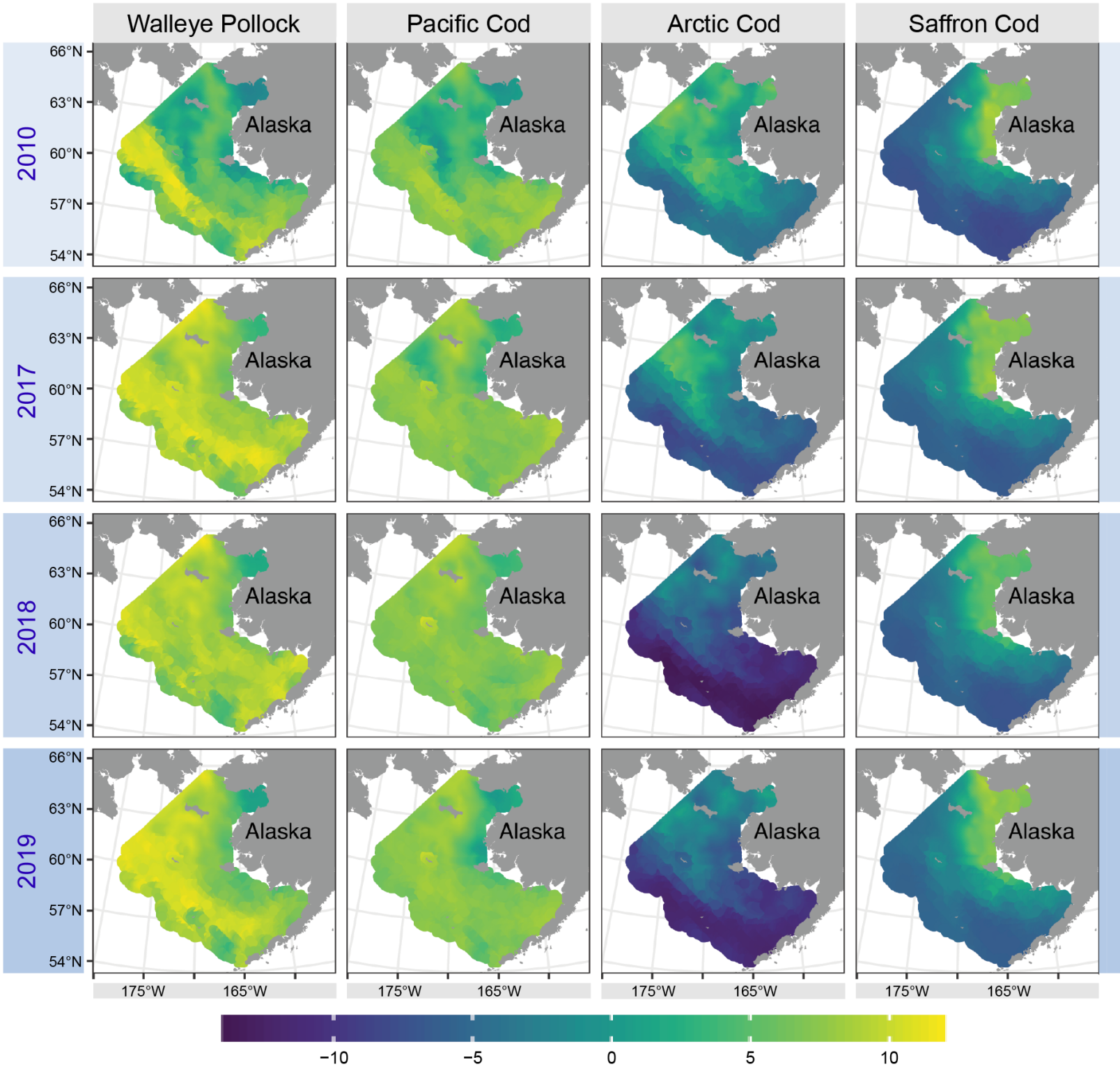

$-5$

log density

Fig. SB5.2. Density estimates ( $\mathrm{kg} \mathrm{km}^{-2}$, log-scale) for four gadids (cod family) on the eastern and northern Bering Sea shelf in 2010 and 2017-19, the only years with standardized bottom-trawl survey data for the northern Bering Sea. The highest densities for each species are depicted in yellow, intermediate in green, and the lowest are blue. Estimates are generated using a spatio-temporal delta-model (Thorson 2019 using methods in Thorson et al. 2019). 
e. Greenland ice sheet-T. A. Moon, M. Tedesco, J. K. Andersen, J. E. Box, J. Cappelen, R. S. Fausto, X. Fettweis, B. Loomis, K. D. Mankoff, T. Mote, C. H. Reijmer, C. J. P. P. Smeets, D. van As, R. S. W. van de Wal, and Ø. Winton The Greenland ice sheet (GrIS) sits atop the largest island in the world and contains the equivalent of $7.4 \mathrm{~m}$ of global mean sea level rise (Morlighem et al. 2017). While the GrIS was likely in balance (i.e., ice mass gain was balancing ice mass loss) during the 1970s, 1980s, and early 1990s, it began to lose mass in earnest in the mid- to late-1990s (Mouginot et al. 2019). As Greenland loses ice, cold, fresh meltwater is added to the ocean, which increases sea levels and also impacts ocean properties and circulation (e.g., Luo et al. 2016); alters nutrient and sediment fluxes (e.g., Cape et al. 2018; Overeem et al. 2017); and influences local ecosystems (e.g., Hopwood et al. 2018). Observations of the GrIS over the "balance year" of accumulation and loss, from September 2018 through August 2019, reveal another year of dramatic ice melt. The extent and magnitude of ice loss in 2019 rivaled 2012, the previous record year of ice loss.

\section{1) Surface air temperatures, surface mass balance, and albedo}

During September 2018-August 2019, overall high air temperatures, low snow accumulation, extensive ice melt, and low surface albedo led to strong deficits in ice sheet surface mass balance. Measurements at 20 Danish Meteorological Institute (DMI) Program for Monitoring of the Greenland Ice Sheet (PROMICE) weather stations near the ice sheet periphery indicated widespread above- or near-average air temperatures during winter 2018/19 (December-February, DJF), spring 2019 (MarchMay, MAM), and summer 2019 (June-August, JJA) (Cappelen 2020). At Summit Station, located in the high-elevation ice cap interior (elevation 3162 m), autumn 2018 and winter 2018/19 were colder than average, while spring and summer 2019 were warmer than average.

Roughly 95\% of the GrIS surface experienced melting at some point during the 2019 melt season, which is significantly greater than the 1981-2010 average melt extent of $\sim 64 \%$. While the maximum daily extent of ice sheet surface melt in 2019 only reached 60.3\% on 31 July (Fig. 5.12a), compared to $90 \%$ in 2012 on 11 July, the cumulative 2019 summer melt extent matched the 2012 values (the previous record melt year). Satellite-derived observations indicate that surface melt in 2019 started in mid-April, six to eight weeks before the long-term average (1981-2010 average). Similar conditions occurred in 2012, when melting started as early as the beginning of April. Except for a small area in the southeast, melt duration in 2019 also exceeded the 1981-2010 mean across the ice sheet ablation zone, the area of net surface ice loss around the ice sheet periphery (Fig. 5.12b).

(b)

(a)
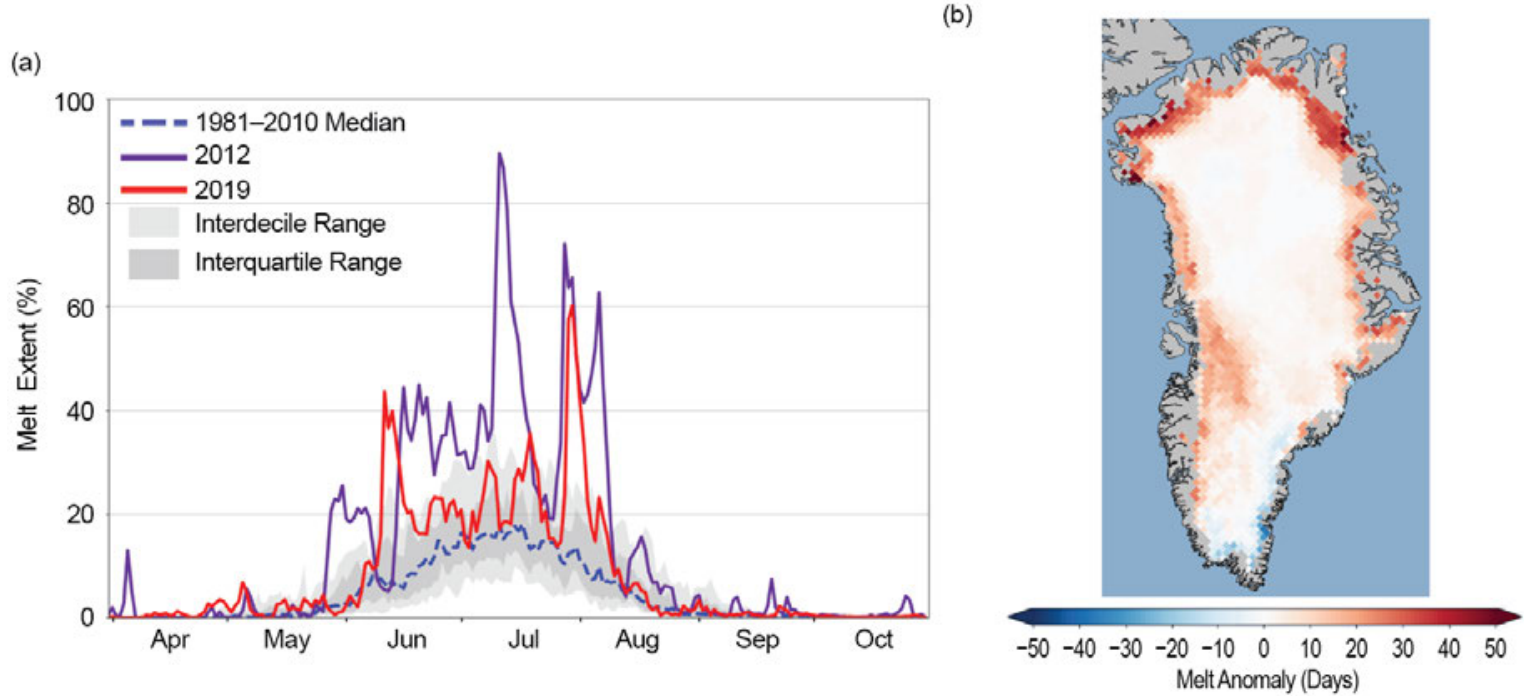

Fig. 5.12. (a) Surface melt area as a percentage of the ice sheet area during 2019 (solid red) and 2012 (solid purple). Also shown are the 1981-2010 median (dashed blue) and interdecile and interquartile ranges (shaded). (b) Summer 2019 melt anomaly (in number of melting days) with respect to the 1981-2010 period. (Source: Observations derived from brightness temperatures measured by the SSMIS passive microwave radiometer [e.g., Mote 2007; Tedesco et al. 2013].) 

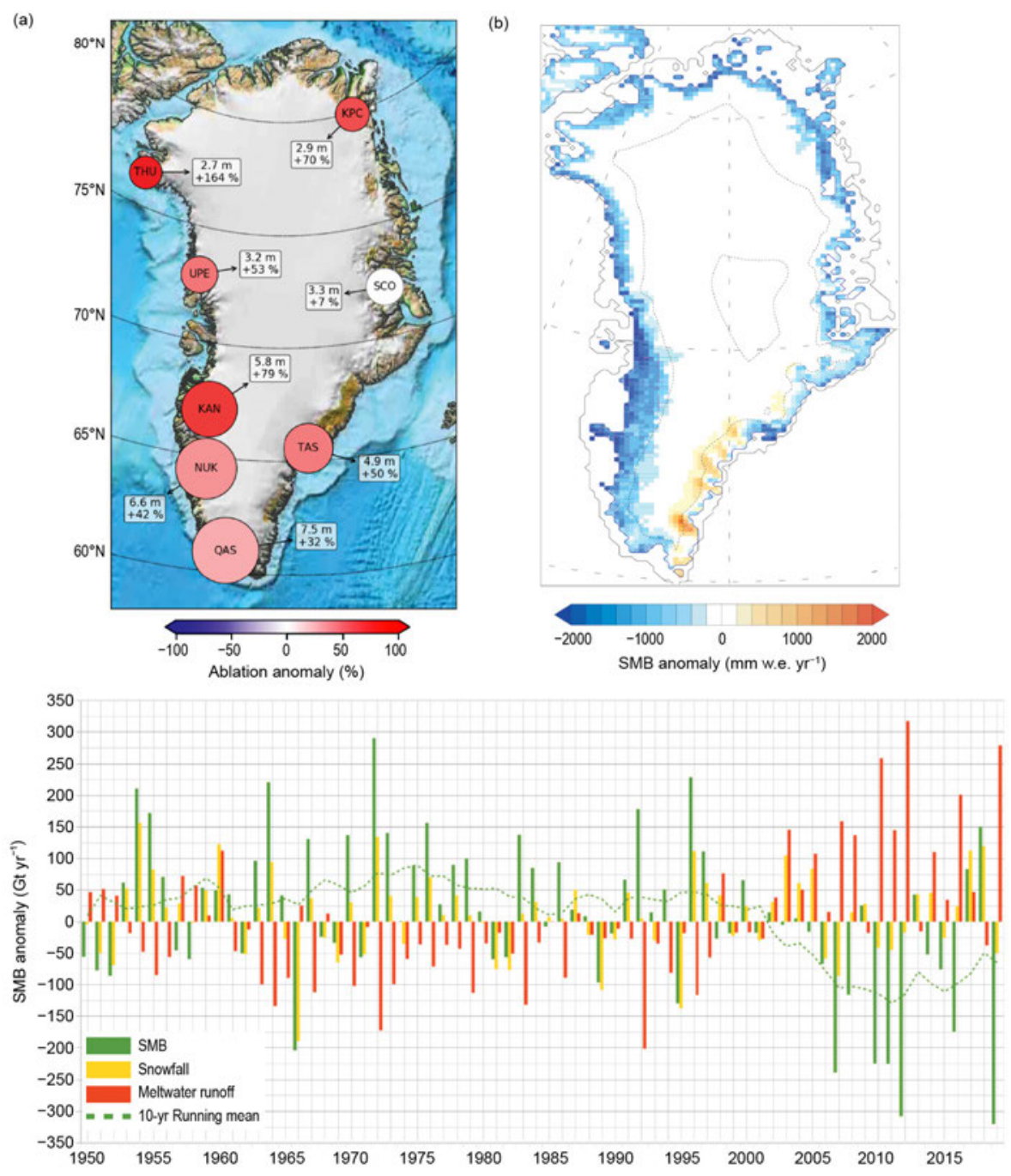

Fig. 5.13. (a) Net ablation in 2019 measured by PROMICE weather stations along the GrIS margin, following van As et al. (2016; https://www.promice.dk/). Circle size represents the ablation in meters of ice equivalent (m), and color represents anomaly value (\%). White circles indicate anomaly values not exceeding methodological and measurement uncertainty. (b) 2019 Greenland surface mass balance anomaly (mm w.e. $\mathrm{yr}^{-1}$ ) simulated by MARv3.10. (c) Surface mass balance anomaly (Gt yr-1) for Sep-Aug balance year using MARv3.10 forced by the reanalysis NCEPNCARv1 climate data during 1948-2019. All plots are relative to 1981-2010 reference period.

Observations from the DMI-PROMICE ablation area weather stations provide additional evidence of the high degree of surface melt during 2019 (Fausto and van As 2019). The 2019 net ice ablation exceeded the 2008-19 PROMICE average at all 18 sites, as well as the 1981-2010 average; melting was particularly notable in the southwest $(+79 \pm 20 \%)$, northwest $(+164 \pm 49 \%)$, and northeast $(+70 \pm 30 \%)$ (Fig. 5.13a).

Surface mass balance simulations from the Modèle Atmosphérique Régionale (MAR; Fettweis 2007) show that the September 2018-August 2019 total surface mass balance was the lowest since 1948, with a normalized anomaly of -3.2 with respect to the 1981-2010 mean. The normalized anomaly is the anomaly divided by the 1981-2010 interannual variability (Figs. 5.13b,c), gauged here by the standard deviation, and is considered statistically significant for values $>+2$ or $<-2$ (i.e., more than two times the interannual variability). Low surface mass balance is mainly due to lower accumulation than average (normalized anomaly of -0.8) and significantly higher surface melt than normal (normalized anomaly of +3.0 ; the second record high after 2012; Tedesco and Fettweis 2019).

Surface albedo, which is the fraction of incident sunlight reflected by a surface, is estimated from spaceborne Moderate Resolution Imaging Spectroradiometer (MODIS) measurements (after 
Box et al. 2017). The surface albedo in JJA 2019 averaged 77.7\% over Greenland land ice, the second lowest in the 20-year record (2000-19) after 2012 (76\%). Especially low albedo along the western and northern ice sheet margins is consistent with the thin snow cover and significant early melt in 2019. The 2000-19 trend for summer broadband albedo from MODIS is $-1.0 \% \pm 1.0$ per year, although this is insignificant at the $5 \%$ level.

During JJA 2019, a mean normalized North Atlantic Oscillation (NAO) index value of -1.8 suggests a dominance of anticyclonic atmospheric circulation, which favored (1) dry, sunny conditions over the south and central part of the ice sheet, enhancing the surface melt-albedo feedback (Tedesco and Fettweis 2019); and (2) advection of warm and moist air masses through the Baffin Sea toward the northern ice sheet. The MAR regional climate simulations suggest a record loss in the surface mass balance in 2019, although meltwater runoff was lower in 2019 than 2012 (Figs. 5.13b,c; section 5b). Exceptional northern melt was driven by anomalously high longwave downward radiation due to clouds, while exceptional southern and central melt was a consequence of lower albedo and higher solar incoming radiation due to reduced cloudiness (normalized anomaly for JJA solar radiation was +3.0 , which is statistically significant).

\section{2) Glacier retreat and ice discharge}

Along with losing ice mass via surface melt, Greenland also loses mass through the direct discharge or loss (calving) of solid ice (icebergs) into the ocean from marine-terminating glaciers. PROMICE estimates for the GrIS indicate that 2019 solid ice discharge averaged $498 \pm 50 \mathrm{Gt} \mathrm{yr}^{-1}$, $\sim 4 \%$ above the 1986-2010 average of $480 \pm 48 \mathrm{Gt} \mathrm{yr}^{-1}$. The discharge from most regions has been approximately steady or declining for the past decade, pointing to mass balance associated with surface melting as the major source for increasing ice loss (Figs. 5.14a,c). The largest discharge
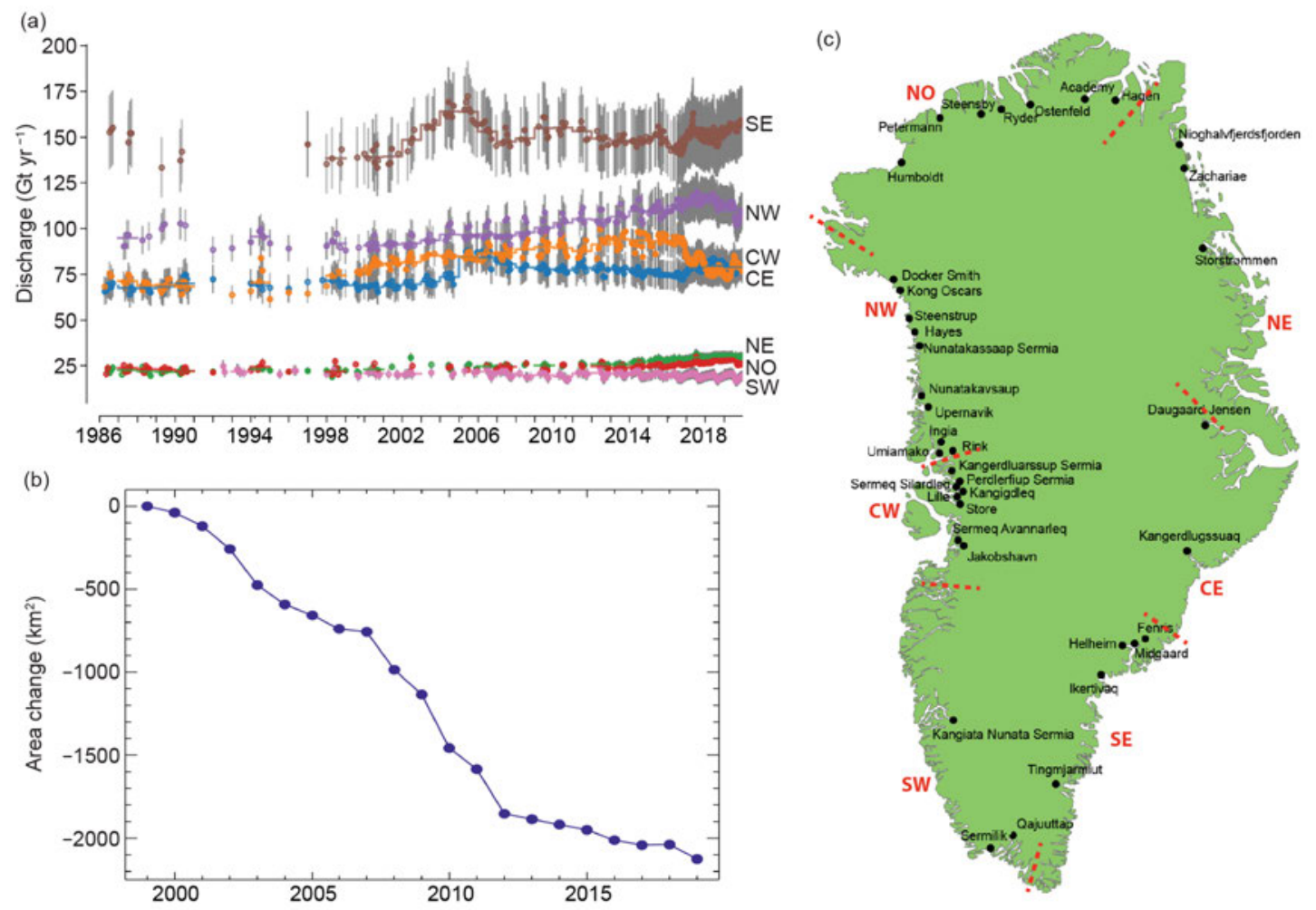

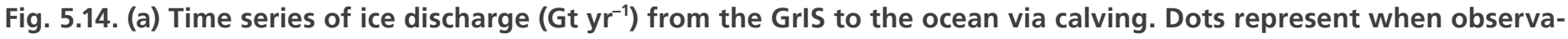
tions occurred. Gray bars show $\pm 10 \%$ uncertainty range. (b) Cumulative annual net glacier area change $\left(\mathrm{km}^{2}\right)$ at 47 major marine-terminating glaciers of the GrIS ice sheet from 1999/2000 to 2018/19, measured using Sentinel-2, LANDSAT, and ASTER satellite optical imagery (after Andersen et al. 2019). (c) GrIS map indicating the regions used for (a) with red dashed border zones and red labels for the southeast (SE), southwest (SW), central west (CW), northwest (NW), north (NO), northeast (NE), and central east (CE), and the 47 glaciers used for (b) with black dots and labels. 
is from the southeast, which discharged a high of $164 \pm 19 \mathrm{Gt}$ in 2004, dropped to $145 \pm 18 \mathrm{Gt}$ in 2016, and then increased to $158 \pm 18 \mathrm{Gt}$ in 2019. The northwest exhibited a relatively persistent increase in discharge from the 1990s through 2016, with a slight decrease during 2017-19. The 1998 discharge was $~ 89 \mathrm{Gt} \mathrm{yr}^{-1}$ compared to a 2019 discharge of $115 \mathrm{Gt} \mathrm{yr}^{-1}$ (23\% increase). The discharge in the central west, which is dominated by Sermeq Kujalleq (Jakobshavn Isbræ), has seen an almost $20 \%$ decrease over the past two years.

Satellite-derived measurements of annual advance or retreat at 47 marine-terminating glaciers since 1999 (Figs. 5.14b,c) indicate that the 2018/19 average net area change was a loss of $87.2 \pm 1.7$ $\mathrm{km}^{2}$ (i.e., glacier retreat) with a cumulative net area loss of $2125.6 \pm 42.5 \mathrm{~km}^{2}$. The $2018 / 19$ area loss is a slight uptick over year-to-year changes during 2013-18.

\section{3) Total mass balance}

NASA's Gravity Recovery and Climate Experiment (GRACE; 2002-17) and GRACE-Follow-On (FO; 2018-present) satellite missions have revolutionized our ability to monitor ice loss by providing monthly estimates of total ice sheet mass (surface mass balance plus solid ice discharge). The GRACE-FO mission was launched on 22 May 2018, creating a measurement gap from July 2017 through May 2018. The total ice mass loss trend for the GRACE period (April 2002-June 2017) is -282 $\pm 14 \mathrm{Gt} \mathrm{yr}^{-1}$ (Fig. 5.15). The updated mass loss trend for the combined GRACE and GRACE-FO period (April 2002-December 2019) is $-269 \pm$ $19 \mathrm{Gt} \mathrm{yr}^{-1}$, indicating continuing substantial ice loss equal to roughly $0.7 \mathrm{~mm} \mathrm{yr}^{-1}$ of global

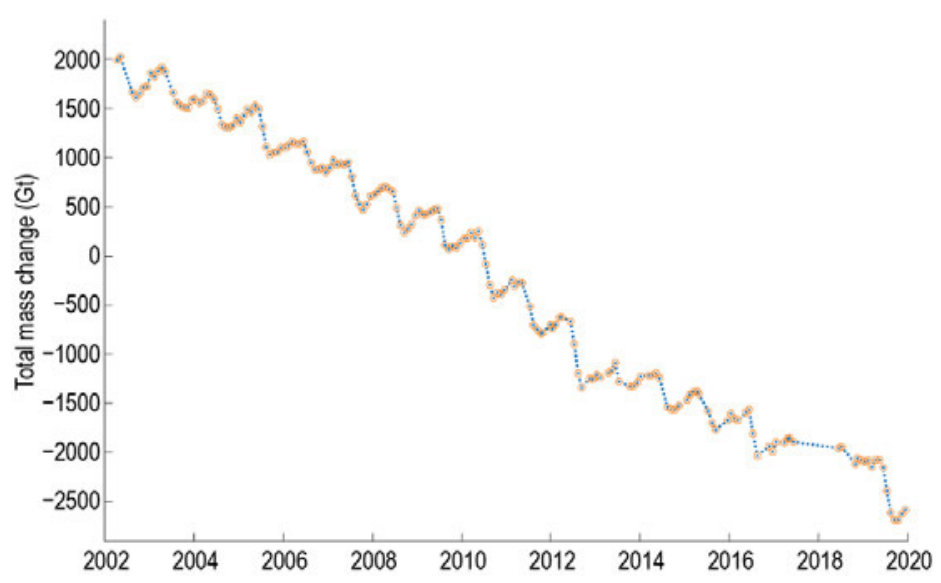

Fig. 5.15. Gravity-derived estimates (blue dots with yellow circles) of total mass change (Gt) of the GrIS between Apr 2002 and Dec 2019 determined from GRACE (2002-17) and GRACEFO (2018-19) JPL RL06 Level 2 solutions (using techniques from Wahr et al. (1998); 2-std. dev. model fit uncertainties reported), with linear interpolation (blue dots). The following corrections have been applied: Geocenter (Technical Note 13); C20 and C30 (Technical Note 14); glacial isostatic adjustment (ICE-6G_D). average sea level rise. While there are no GRACE measurements prior to 2002, a recent study of Greenland mass loss during 1972-2000 (Mouginot et al. 2019) suggests that decadal mass change rates during this time ranged from $+47 \pm 21 \mathrm{Gt} \mathrm{yr}^{-1}$ (mass gain) during 1972-80 to $-51 \pm$ $17 \mathrm{Gt} \mathrm{yr}^{-1}$ (mass loss) during 1980-90. Across all metrics, 2019 has proved to be another year of substantial Greenland ice loss.

f. Glaciers and ice caps outside Greenland-G. J. Wolken, B. Wouters, M. Sharp, L. M. Andreassen,

E. H. Baker, D. Burgess, J. Kohler, B. Luks, and S. O'Neel

Land areas in the Arctic, outside Greenland, host numerous glaciers and ice caps. Although their potential, longer-term contribution to sea level rise is small compared to the ice sheets of Antarctica and Greenland, these smaller land ice masses are sensitive to changes in climate and have been a large contributor to recent sea level rise in response to continued atmospheric warming (Gardner et al. 2011, 2013; Jacob et al. 2012; Millan et al. 2017; Wouters et al. 2019). Observations of glaciers and ice caps from 2018 and 2019 show regional variations in mass change and a continuing trend of significant ice loss throughout the Arctic and especially in Alaska and Arctic Canada.

Glaciers gain mass by snow accumulation and lose mass through surface melt and runoff as well as iceberg calving, where they terminate in the ocean or a lake. The annual climatic mass balance $\left(\mathrm{B}_{\text {clim }}\right)$ is a widely used index that describes the state, or health, of a glacier. $\mathrm{B}_{\text {clim }}$ is defined as the difference between the annual mass gain by snow accumulation and the annual mass loss by surface melting and runoff. The annual mass balance is traditionally measured over 


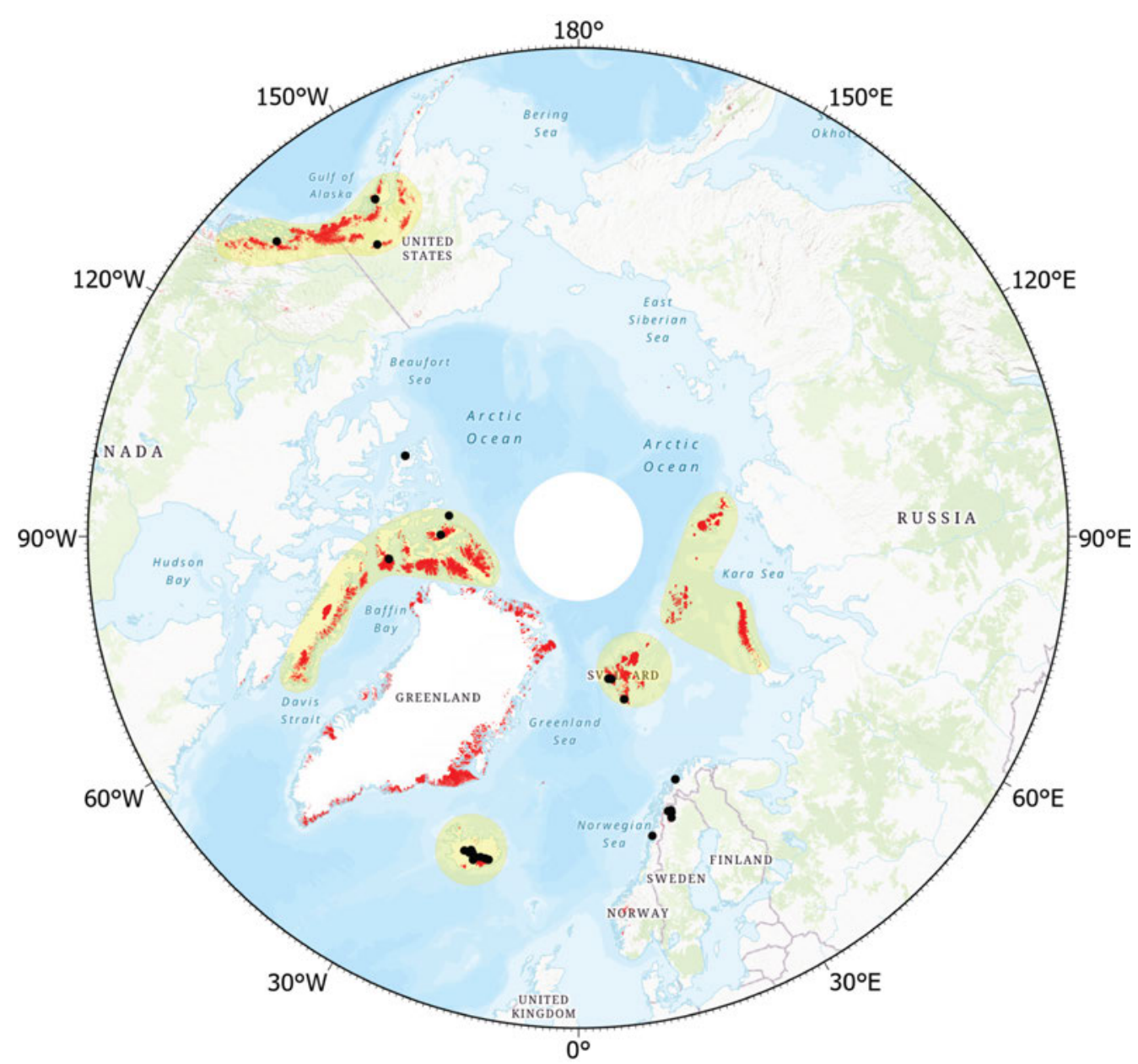

Fig. 5.16. Arctic glaciers and ice caps (red), including ice caps in Greenland separate from the ice sheet. Yellow shading shows the GRACE- and GRACE-FO-derived mass anomaly domains used to estimate changes in regional annual glacier mass balance for the heavily glacierized regions of the Arctic.

a "balance year" that, in the Arctic, is often operationally defined to extend from September to August of the following year. Positive annual mass balance values indicate a gain in mass over the balance year, whereas negative mass balance values indicate a loss in mass. The total mass balance is given by the mass gain by snow accumulation plus the mass losses by runoff and iceberg calving. Of the 27 glaciers currently monitored for mass balance across the Arctic (Fig. 5.16), only three (Kongsvegen, Hansbreen, and Devon Ice Cap) are tidewater glaciers, which lose mass by iceberg calving into the ocean.

In this section, we report on $B_{\text {clim }}$ measurements for the mass balance year 2018/19 from 10 of the 27 monitored Arctic glaciers (three in Alaska, four in Svalbard, two in Norway, and one in Arctic Canada). The limited data availability of measurements for 2018/19 is due to latency in seasonal measurements at some glaciers and because some of these data are still provisional. To provide a more complete picture, we also report on 25 glaciers for the mass balance year 2017/18 (World Glacier Monitoring Service [WGMS] 2017; Kjøllmoen et al. 2019), building on observations for the mass balance years 2015/16 and 2016/17, which were reported the last time this section appeared, in State of the Climate in 2017 (Sharp et al. 2018). For the Arctic as a whole, the mean $B_{\text {clim }}$ values for 2017/18 and 2018/19 were negative, indicating overall mass loss.

In 2017/18, 16 of the 25 glaciers (64\%) registered negative balances (in Alaska, Svalbard, and northern Scandinavia) and nine (36\%) registered positive balances (in Arctic Canada and Iceland). Relative to the long-term (1985-2015) mean values of $B_{\text {clim }}, 12$ of the 25 were more negative and 13 were more positive than the mean. The $B_{\text {clim }}$ values reported for glaciers in 2018/19 (Alaska, Svalbard, Norway, and Arctic Canada) were all more negative than the long-term mean, with mass 
balance data from Alaska showing extremely negative values. This was the seventh consecutive year of strongly negative anomalies in the Alaska region. The positive anomalies observed for the nine individual glaciers during 2017/18 contrast with the mainly negative annual mass balance anomalies that have driven the current trend of continued mass loss observed throughout the Arctic since the mid-1950s (Fig. 5.17). With the exception of the Svalbard region (where there has been no obvious recent acceleration of mass loss rates), rapid mass loss across the five regions generally began during the 1990s (van Pelt et al. 2019; Zemp et al. 2019).

Air temperature exerts a strong control on surface mass balance in the Arctic. Positive balance anomalies in Arctic Canada and Iceland during 2017/18 were likely influenced by frequent low-pressure systems in the central Arctic generating persistent cloud cover that

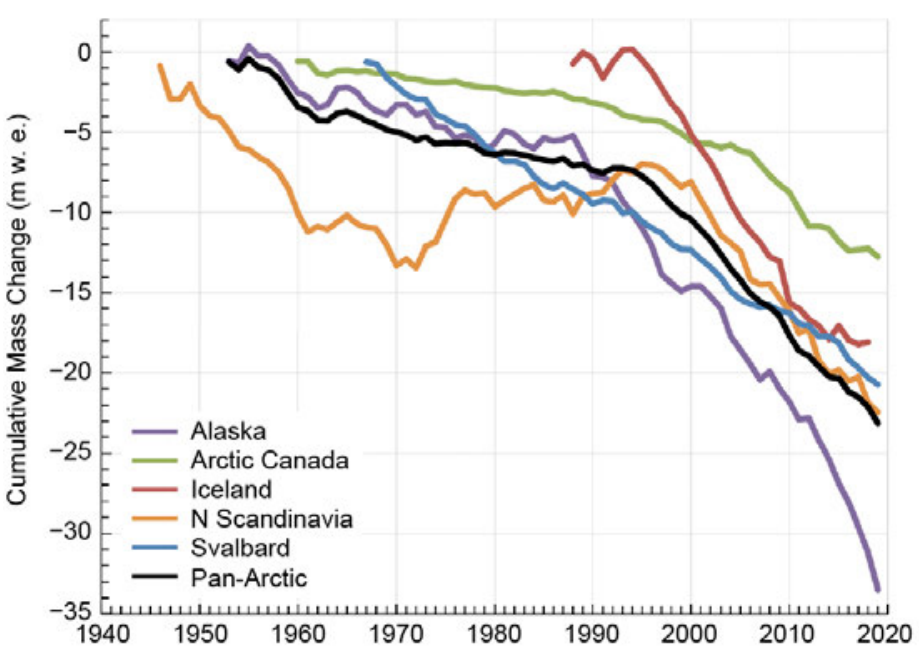

Fig. 5.17. Cumulative $B_{\text {clim }}$ in meters of water equivalent ( $m$ w.e.) for monitored glaciers in five regions of the Arctic and for the Arctic as a whole (Pan-Arctic). Mean balances are calculated for glaciers monitored in each region in each year and these means are summed over the period of record. Note that monitoring periods vary between regions and that the number and identity of glaciers monitored in a given region may vary between years. (Source: WGMS 2017.) reduced solar heating during summer (Overland et al. 2019). The negative balances of glaciers in Alaska, northern Scandinavia, and Svalbard in 2017/18 were most likely linked to melt increases caused by positive air temperature anomalies during autumn from the surface to $850 \mathrm{hPa}$, relative to the 1981-2010 climatology (data from NCEP-NCAR Reanalysis; Overland et al. 2019). Negative balance values reported for glaciers in Alaska, Arctic Canada, and Svalbard in 2018/19 were also associated with anomalously high air temperatures at $850 \mathrm{hPa}$ and persistent ridges of high pressure over Arctic Russia, Arctic Canada, and Alaska. Strongly positive air temperature anomalies $\left(2.5^{\circ}-3.5^{\circ} \mathrm{C}\right.$ at $\left.1000-850 \mathrm{hPa}\right)$ in $2018 / 19$, associated with southerly winds and warm air (section $5 b)$, produced the most negative mass balance year on record for the combined Alaska glaciers. For example, the 2019 average summer air temperature at Wolverine Glacier in south-central Alaska was $11.1^{\circ} \mathrm{C}$, marking the hottest summer in the 52 -year record and $3.2^{\circ} \mathrm{C}$ higher than the $1981-2010$ climatological mean (Fig. 5.18). Over the period of record at Wolverine Glacier (1967-2019), mean

(a)

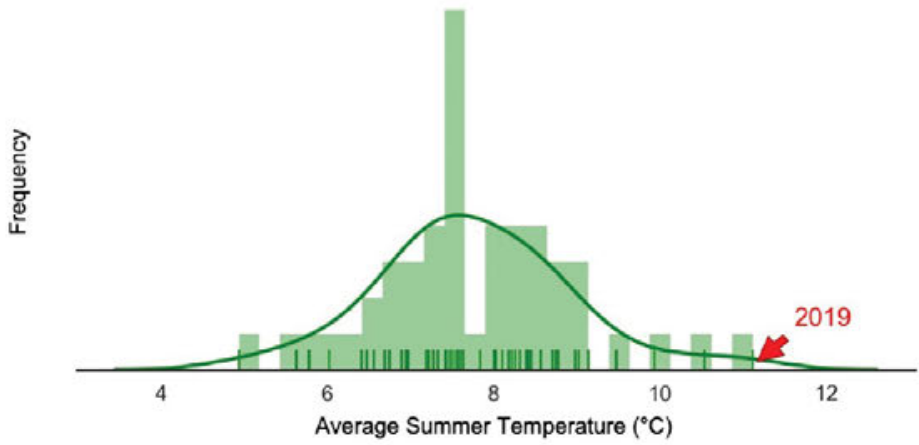

(b)

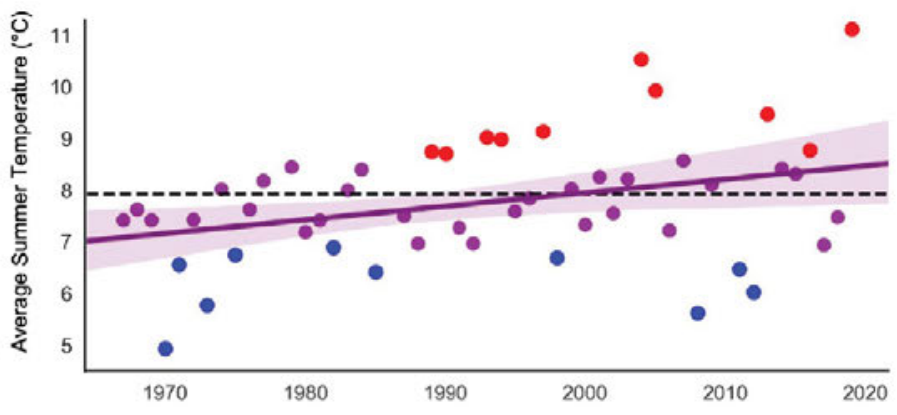

Fig. 5.18. Summer air temperatures at Wolverine Glacier, Alaska, from 1967 to 2019, at $990-\mathrm{m}$ a.s.I. The summer season is defined as Jun, Jul, and Aug following Bieniek (2017). (a) Distribution of mean summer temperatures, shown with a histogram (bar plot) and kernel density estimate (smoothed curve). Small vertical lines show each individual year's summer temperature. Summer 2019 is labeled for emphasis. (b) Time series of mean summer temperature, with the 10 warmest years shown as red dots and the 10 coldest years shown as blue dots. An ordinary least squares trend line is fit through all data and is shown in purple ( $p<0.02$ for Kendall-tau trend test). Light purple shading indicates uncertainty. 
summer temperatures have increased $1^{\circ} \mathrm{C}$, at a rate of $0.02^{\circ}{\mathrm{C} \mathrm{yr}^{-1}}(p<0.02$ for Kendall-tau trend test; O’Neel et al. 2019).

Time series of cumulative regional mass anomalies, derived using GRACE (2002-17) and GRACE-FO (2018-present) satellite gravimetry (see also section 5e), can be used to estimate changes in regional annual glacier mass balance for the heavily glacierized regions of the Arctic (Fig. 5.16; Wouters et al. 2019). For the Arctic glaciers and ice caps as a whole, the overall mass balance was strongly negative during the combined GRACE and GRACE-FO period (2002-19), with the signal dominated largely by ice mass loss from Alaska and Arctic Canada (Fig. 5.19). The estimated mass loss trends during this period for five regions in the Arctic are: $-66 \pm 10 \mathrm{Gt}$

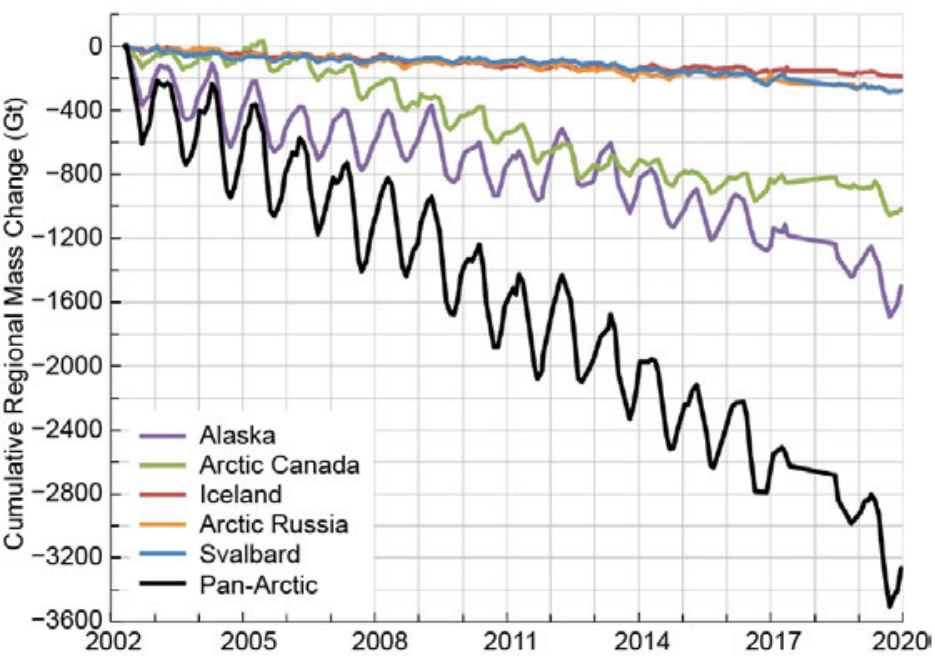

Fig. 5.19. Cumulative changes in regional total stored water for 2002-19 (Gt), derived using GRACE and GRACE-FO satellite gravimetry. A measurement gap exists between the GRACE and GRACE-FO missions from Jul 2017 to May 2018 through which linear interpolation is applied. $\mathrm{yr}^{-1}$ (Alaska); $-63 \pm 8.2 \mathrm{Gt} \mathrm{yr}^{-1}$ (Arctic Canada); $-9 \pm 1.8 \mathrm{Gt} \mathrm{yr}^{-1}$ (Iceland); $-14 \pm 3.2 \mathrm{Gt} \mathrm{yr}^{-1}$ (Arctic Russia); and $-12 \pm 0.6 \mathrm{Gt} \mathrm{yr}^{-1}$ (Svalbard), with estimated uncertainties (at $2 \mathrm{std}$. dev.) including corrections for glacial isostatic adjustment and terrestrial hydrology. The Arctic-wide estimate for mass loss from glaciers and ice caps outside of Greenland is equal to a global sea level rise contribution of approximately $0.4 \mathrm{~mm} \mathrm{yr}^{-1}$. By comparison, Greenland currently contributes about $0.7 \mathrm{~mm} \mathrm{yr}^{-1}$ (section 5e). If normalized by area, glaciers and ice caps outside Greenland are currently producing more melt per area than Greenland itself. For the Arctic as a whole (glaciers and ice caps plus the Greenland ice sheet), the current rate of contribution to global sea level rise is $1.1 \mathrm{~mm} \mathrm{yr}^{-1}$.

\section{g. Terrestrial snow cover-L. Mudryk, R. Brown, C. Derksen, K. Luojus, and B. Decharme}

Snow covers the Arctic land surface (areas north of $60^{\circ} \mathrm{N}$ ) for up to nine months each year, influencing the surface energy budget, ground thermal regime, and freshwater budget of the Arctic (Brown et al. 2017). Snow also impacts terrestrial and aquatic ecosystems through interactions with vegetation, influences on biogeochemical cycles, and effects on migration and access to forage for wildlife (Callaghan et al. 2011). Pan-Arctic monitoring of snow cover extent, duration, depth, and water equivalent provides a suite of indicators broadly relevant across physical and ecological systems. All of these indicators exhibit negative trends over long time periods (e.g., three decades or more), albeit with varying levels of interannual variability consistent with a strong response to increasing temperatures (Mudryk et al. 2020).

Figure 5.20 shows May and June snow cover extent (SCE) anomalies (difference from 1981-2010 average) for the North American and Eurasian sectors of the Arctic. After two years of above- or nearaverage anomalies, spring 2019 saw a return in both sectors to the below-average SCE anomalies that were predominant over the 2005-16 time period. In particular, North American Arctic SCE anomalies were the fifth lowest in May and third lowest in June, in the 53-year record.

Snow cover onset (Fig. 5.21a) was earlier than normal over the eastern Canadian Arctic and later than normal over the Eurasian Arctic and Alaska, relative to the 1998-2017 average. These deviations from the average correspond to a pattern of warm surface temperature anomalies over Eurasia and cold anomalies over eastern Canada during September and October. Snow-off dates (Fig. 5.21b) were near normal over most of the Eurasian Arctic. Over North America, earlier-than-usual melt occurred in March across northwestern Canada and Alaska and in May and June over northeastern Canada 

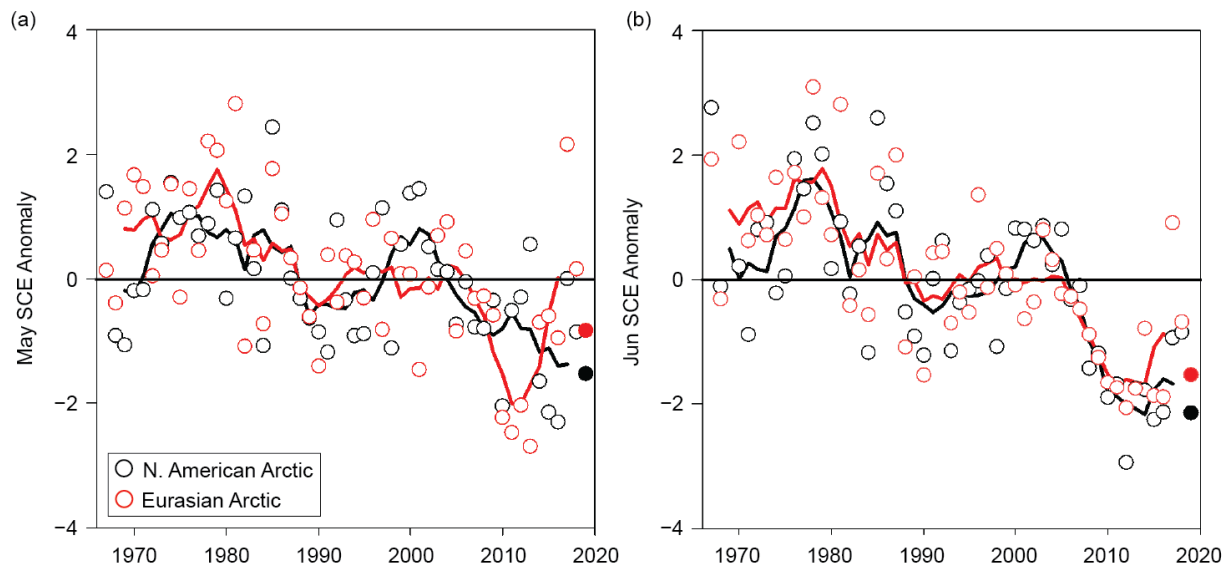

Fig. 5.20. Monthly snow cover extent (SCE) for Arctic land areas $\left(>60^{\circ} \mathrm{N}\right)$ for (a) May and (b) Jun from 1967 to 2019, a 53-year record. Anomalies are relative to the 1981-2010 average and standardized (each observation differenced from the mean and divided by the std. dev. and thus unitless). Solid black and red lines depict 5-year running means for North America and Eurasia, respectively. Filled circles are used to highlight 2019 anomalies. (Source: NOAA snow chart Climate Data Record [Estilow et al. 2015].)

(Baffin Island and northern Quebec). These patterns are linked to warm air advection from over the North Pacific and North Atlantic, respectively (section 5b).

Snow depths over the 2019 spring season were near normal over Eurasia, relative to the 1999-2017 average. Over North America, unusually early and rapid snowmelt, driven by above-average temperatures in March over northwestern Canada and Alaska, resulted in below-average snow depth starting in March (Fig. 5.21c) and continuing through June (Fig. 5.21d), consistent with the shorter-than-average spring snow cover duration (SCD) observed in the region (Fig. 5.21b). Lower-than-normal June snow depth was also observed across Baffin Island, northern Quebec, and eastern Siberia (Fig. 5.21d).

Figure 5.22 shows a time series of April snow water equivalent (SWE) anomalies. The SWE provides a measure of how much water is stored in solid form by the snowpack. April 2019 SWE estimates indicate near-normal snow accumulation over the Eurasian Arctic relative to the 1981-2010 average. Lower-than-normal SWE is observed across the North American Arctic, consistent with negative snow depth anomalies that emerged in March (Fig. 5.21c). Note that snow conditions over the North American Arctic (north of $60^{\circ} \mathrm{N}$ ) were in contrast to the North American midlatitude regions, which experienced an unusually deep March snowpack (Fig. 5.21c) and associated longer SCD (Fig. 5.21b).

In summary, snow accumulation during the 2018/19 winter was close to normal over the Eurasian Arctic. Over the North American Arctic, earlier-than-normal snow melt in northwestern Canada and Alaska resulted in below-average April SWE and below-average snow depth from March through June. Earlier-than-normal snow melt also occurred over Baffin Island during May

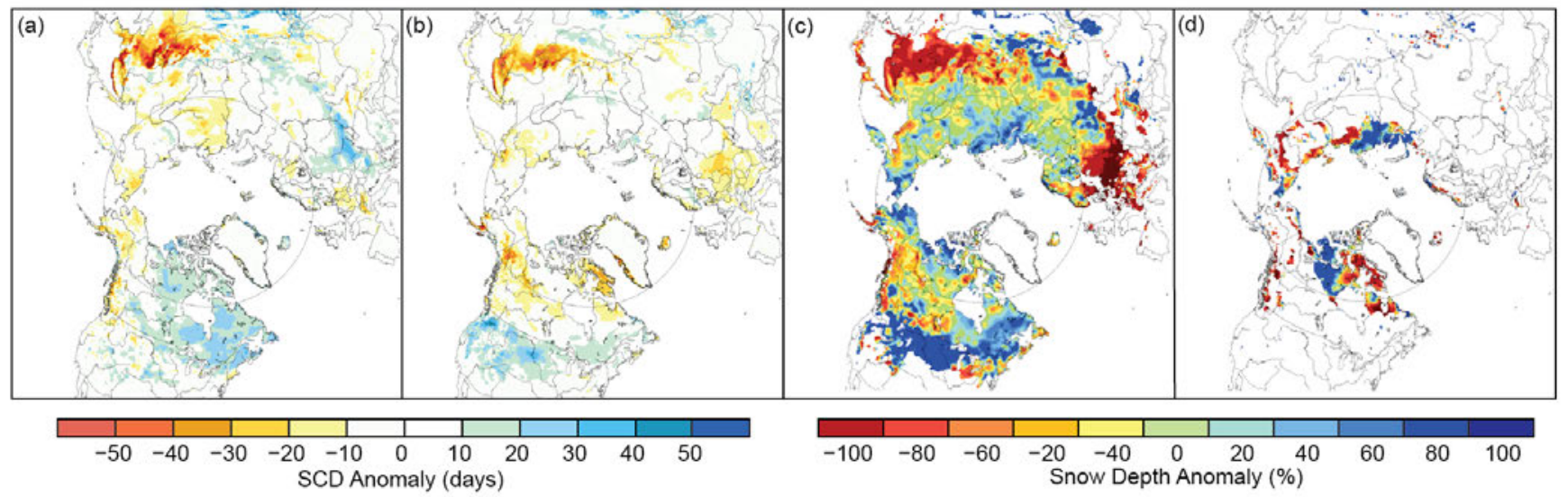

Fig. 5.21. Snow cover duration (SCD) anomaly (days, difference from 1998-2017 mean; red = shorter SCD than average; blue = longer SCD than average) for the 2018/19 snow year's (a) snow onset period (Aug-Jan) and (b) snow melt period (Feb-Jul); and snow depth anomaly (\%, difference from the 1999-2017 average) for (c) Mar and (d) Jun 2019. Gray circles mark the latitude $60^{\circ} \mathrm{N}$. (Source: [a,b] NOAA IMS data record [Helfrich et al. 2007; U.S. National Ice Center 2008] and [c,d] CMC snow depth analysis [Brasnett 1999].) 


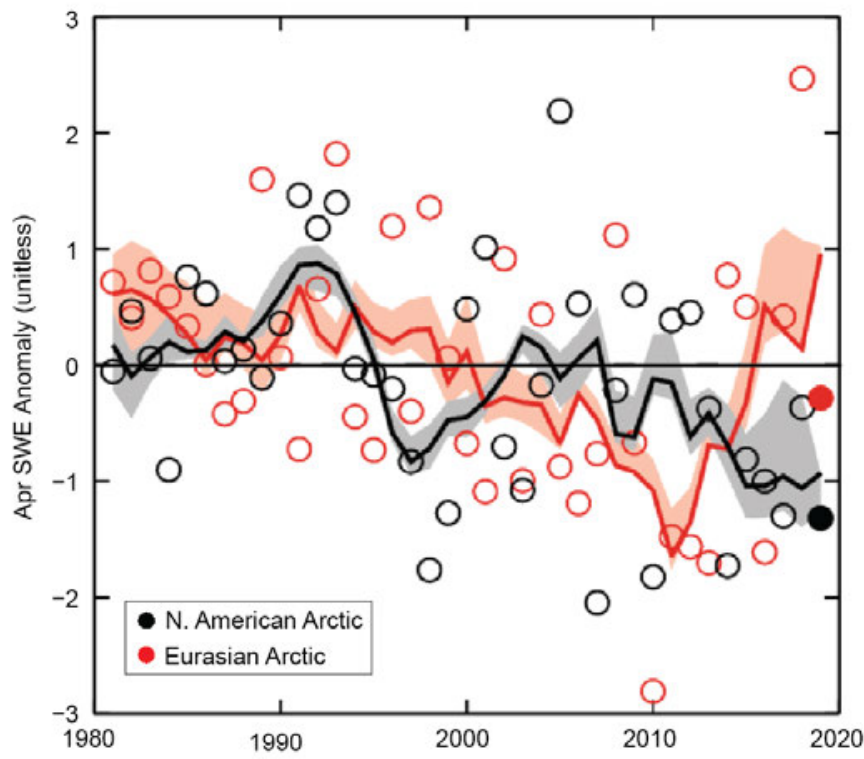

Fig. 5.22. Mean Apr snow water equivalent (SWE) anomalies for Arctic land areas calculated for North American (black) and Eurasian (red) sectors. Anomalies are relative to the average for 1981-2010 and standardized (each observation differenced from the mean and divided by the std. dev. and thus unitless). Filled circles are used to highlight 2019 anomalies. Solid black and red lines depict 5-year running means for North America and Eurasia, respectively. The spread among the running means for individual datasets is shown in shading. (Source: Suite of four independent analyses: [1] modern atmospheric reanalysis [MERRA-2; Reichle et al. 2017]; [2] reconstructed snow accumulation driven by ERA-interim meteorology with the temperature index model described by Brown et al. [2003]; [3] the physical snowpack model Crocus [Brun et al. 2013]; and [4] the European Space Agency GlobSnow product derived through a combination of satellite passive microwave data and climate station observations [Takala et al. 2011]. Note that Crocus data was unavailable for 2019 so SWE estimates for this year are calculated from only three sources.)

and June. These anomalies over the western and eastern sectors of the North American Arctic combined to cause the fifth- and third-lowest SCE in May and June, respectively, since 1967.

h. Terrestrial permafrost-V. E. Romanovsky, S. L. Smith, K. Isaksen, K. E. Nyland, A. L. Kholodov, N. I. Shiklomanov,

D. A. Streletskiy, L. M. Farquharson, D. S. Drozdov, G. V. Malkova, and H. H. Christiansen

Permafrost refers to Earth materials (e.g., bedrock, mineral soil, organic matter) that remain at or below $0^{\circ} \mathrm{C}$ for two years or longer. Overlying the permafrost is the active layer, which thaws and refreezes annually. Permafrost underlies extensive regions of the high-latitudelandscape and can be found within $24 \%$ of the landmass in the Northern Hemisphere (NH; Brown et al. 1997). The presence of permafrost, especially where it contains large volumes of ground ice, can play a critical role in the stability of Arctic landscapes. Permafrost warming, active layer thickening, and ground ice melt cause changes in surface topography, hydrology, and landscape stability, posing a major threat to Arctic infrastructure, such as buildings, roads, pipelines, and airports, as well as ecosystem integrity (Romanovsky et al. 2017; Bjella 2019). Changes in permafrost-laden regions also affect the rate of release of $\mathrm{CO}_{2}$ and $\mathrm{CH}_{4}$ to the atmosphere, with the potential to accelerate global climate warming (see Sidebar 5.2).

Permafrost conditions respond to shifts in the surface energy balance through a combination of interrelated changes in ground temperature and active layer thickness (ALT). Close to the surface, ground temperatures fluctuate seasonally, while below the depth of seasonal temperature variation, ground temperature reflects longer-term changes in climate. Monitoring sites across the Arctic have been recording ground temperature in the upper $30 \mathrm{~m}$ for up to half a century (Fig. 5.23), providing critical data on changes in permafrost stability. Observed changes in the thickness of the active layer relate to shorter-term fluctuations in climate and are especially sensitive to changes in summer air temperature and precipitation. 


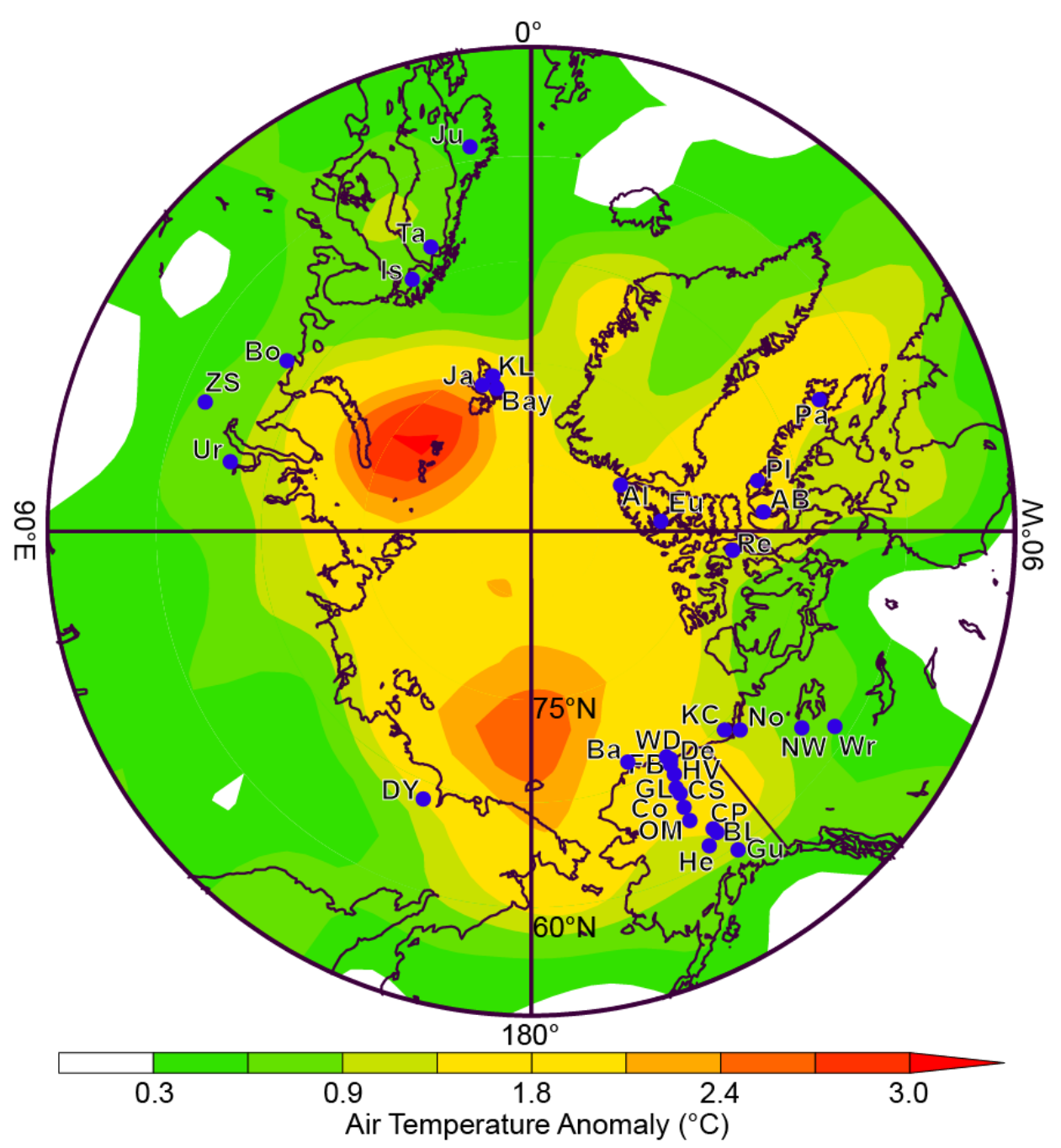

Fig. 5.23. Location of the permafrost temperature-monitoring sites, for which data are shown in Fig. 5.24, superimposed on average SAT anomalies during 2000-19 (with respect to the 1981-2010 mean) from the NCEP-reanalysis (Kalnay et al. 1996). Reanalysis data provided by the NOAA/ESRL Physical Sciences Division, Boulder, CO (www.esrl.noaa.gov/psd/). Sites shown in Fig. 5.24 are: a) Barrow (Ba), West Dock (WD), KC-07 (KC), Duvany Yar (DY), Deadhorse (De), Franklin Bluffs (FB), Galbraith Lake (GL), Happy Valley (HV), Norris Ck (No); b) College Peat (CP), Old Man (OM), Chandalar Shelf (CS), Birch Lake (BL), Coldfoot (Co), Norman Wells (NW), Wrigley 2 (Wr), Healy (He), Gulakana (Gu), Wrigley 1 (Wr); c) Eureka EUK4 (Eu), Alert BH2 (Al), Alert BH5 (Al), Resolute (Re), Alert BH1 (Al), Arctic Bay (AB), Pond Inlet (PI), Pangnirtung (Pa); d) Janssonhaugen (Ja), Bayelva (Bay), Kapp Linne 1 (KL), Urengoy \#15-10 (Ur), Juvvasshøe (Ju), Tarfalaryggen (Ta), Polar Ural (ZS), Bolvansky \#59 (Bo), Bolvansky \#65 (Bo), Urengoy \#15-06 (Ur), Bolvansky \#56 (Bo), Iskoras Is-B-2 (Is). Information about these sites is available at: http://gtnpdatabase.org/, http://permafrost.gi.alaska.edu/sites_map, https://www2.gwu.edu/ calm/data/data-links.html.

\section{1) Permafrost temperatures}

Recent long-term trends in permafrost temperatures are driven mostly by long-term air temperature changes (Romanovsky et al. 2017). In general, the increase in permafrost temperatures observed since the 1980 s is more significant in the relatively colder permafrost at higher latitudes, where the largest increase in air temperature is observed (Fig. 5.23). Permafrost temperature trends also show local variability, due to other important influences such as snow depth, density, and timing (snow-on/snow-off date and duration; section 5g); vegetation characteristics; and soil moisture. Observed changes in mean annual permafrost temperatures through 2019 are presented for sites throughout the Arctic in Fig. 5.24. Table 5.1 summarizes the rate of change for each region.

In 2019, record high permafrost temperatures were observed at a majority of the observation sites (Table 5.1). For example, in northern Alaska, temperatures in 2019 were $0.1^{\circ}-0.2^{\circ} \mathrm{C}$ higher than in 2018 and in the Alaskan interior, the 2019 temperature at one site (Old Man) was $0.26^{\circ} \mathrm{C}$ higher 
than in 2018 (Fig. 5.24b). At sites on Svalbard, a significant temperature increase in recent years was detected down to 80-m depth (not shown), reflecting a multi-decadal permafrost warming, with 2019 clearly the warmest year in the observational record.

Also widely observed are recent increases in the rate of permafrost warming (Fig. 5.24, Table 5.1). For example, in the Canadian High Arctic, warming rates in the twenty-first century are almost twice those for the entire 40-year record. It is worth noting that throughout the Arctic, the response of permafrost with temperatures close to $0^{\circ} \mathrm{C}$ (i.e., warm permafrost sites) is slower than in permafrost with lower temperatures due to latent heat effects related to melting ground ice. For instance, at cold continuous permafrost sites in the Beaufort-Chukchi region, records of more than four decades in northern Alaska indicate that permafrost temperatures have increased by $0.3^{\circ}-0.8^{\circ} \mathrm{C}$ decade $^{-1}$ (Fig. 5.24a). Shorter records of about a decade for northwest Canada and northeastern Siberia show cold permafrost temperatures have increased by $0.4^{\circ}-0.8^{\circ} \mathrm{C}$ decade ${ }^{-1}$, similar to the twenty-firstcentury rate for northern Alaska. On Svalbard, at the Janssonhaugen site (Fig. 5.24d), cold permafrost has warmed by $0.8^{\circ} \mathrm{C}$ decade ${ }^{-1}$ since 1998. In contrast, at sites farther south in the warm discontinuous permafrost of interior Alaska and the central Mackenzie Valley, permafrost over the last three to four decades has warmed at a lower rate, generally less than $0.3^{\circ} \mathrm{C}$ decade ${ }^{-1}$ (Fig. 5.24b). Lower rates of warming are also observed at sites in the warm discontinuous permafrost regions of Scandinavia (e.g., Iskoras) and Russia (e.g., Bovansky \#56; Fig. 5.24d).
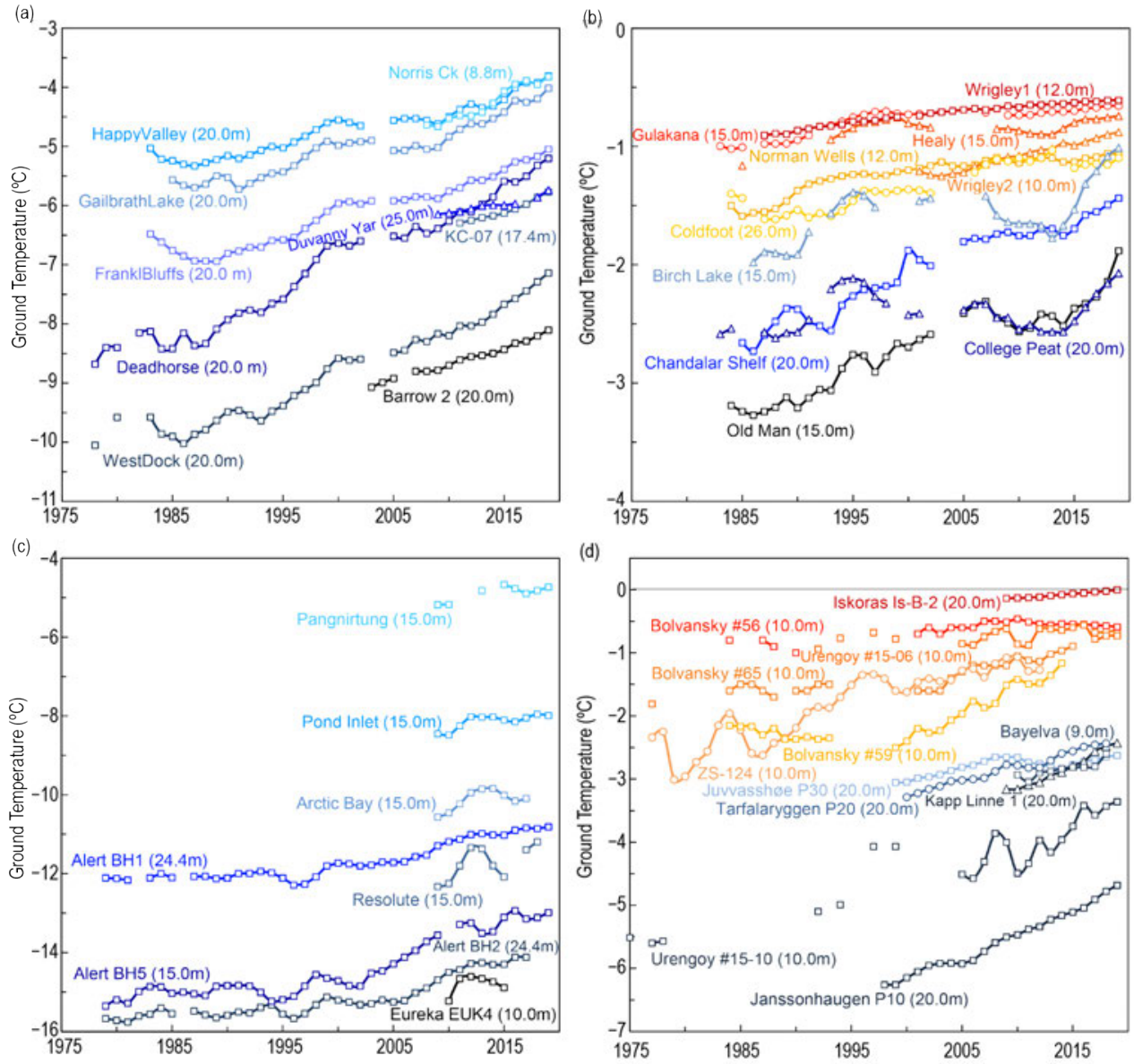

Fig. 5.24. Time series of mean annual ground temperature $\left({ }^{\circ} \mathrm{C}\right)$ at depths of $9-26 \mathrm{~m}$ below the surface at selected measurement sites that fall roughly into priority regions of the Adaptation Actions for a Changing Arctic Project (AMAP 2015): (a) cold continuous permafrost of NW North America and NE East Siberia (Beaufort-Chukchi region); (b) discontinuous permafrost in Alaska and northwestern Canada; (c) cold continuous permafrost of eastern and High Arctic Canada (Baffin Davis Strait); (d) continuous to discontinuous permafrost in Scandinavia, Svalbard, and Russia/Siberia (Barents region). Temperatures are measured at or near the depth of zero annual amplitude where the seasonal variations of ground temperature are less than $0.1^{\circ} \mathrm{C}$. The locations of each borehole are shown in Fig. 5.23. Data are updated from Christiansen et al. 2010; Romanovksy et al. 2017; Smith et al. 2019, 2018; Ednie and Smith 2015; Boike et al. 2017. 


\begin{tabular}{|c|c|c|c|}
\hline Subregion & Sites & Entire Record & Since 2000 \\
\hline \multicolumn{4}{|c|}{ Beaufort-Chukchi Region } \\
\hline North of East Siberia & Duvany Yar (DY) & NA & $\begin{array}{c}+0.37 \\
(2009-19)\end{array}$ \\
\hline Alaskan Arctic plain & $\begin{array}{l}\text { West Dock (WD), Deadhorse (De), } \\
\text { Franklin Bluffs (FB), Barrow (Ba) }\end{array}$ & $\begin{array}{c}+0.39 \text { to }+0.83 \\
(1978-2019)\end{array}$ & $\begin{array}{c}+0.46 \text { to }+0.72 \\
(2000-19)\end{array}$ \\
\hline $\begin{array}{c}\text { Northern foothills of the Brooks } \\
\text { Range, Alaska }\end{array}$ & $\begin{array}{l}\text { Happy Valley (HV), Galbraith Lake } \\
\text { (GL) }\end{array}$ & $\begin{array}{c}+0.33 \text { to }+0.44 \\
(1983-2019)\end{array}$ & $\begin{array}{c}+0.37 \text { to }+0.48 \\
(2000-19)\end{array}$ \\
\hline Northern Mackenzie Valley & Norris Ck (No), KC-07(KC) & NA & $\begin{array}{l}+0.6 \text { to }+0.8 \\
(2008-19)\end{array}$ \\
\hline \multicolumn{4}{|c|}{ Discontinuous Permafrost Alaska and NW Canada } \\
\hline $\begin{array}{l}\text { Southern foothills of the Brooks } \\
\text { Range, Alaska }\end{array}$ & $\begin{array}{c}\text { Coldfoot (Co), Chandalar Shelf (CS), } \\
\text { Old Man (OM) }\end{array}$ & $\begin{array}{c}+0.08 \text { to }+0.36 \\
(1983-2019)\end{array}$ & $\begin{array}{c}+0.14 \text { to }+0.41 \\
(2000-19)\end{array}$ \\
\hline Interior Alaska & $\begin{array}{c}\text { College Peat (CP), Birch Lake (BL), } \\
\text { Gulkana (Gu), Healy (He) }\end{array}$ & $\begin{array}{c}+0.09 \text { to }+0.28 \\
(1983-2019)\end{array}$ & $\begin{array}{c}+0.04 \text { to }+0.27 \\
(2000-19)\end{array}$ \\
\hline Central Mackenzie Valley & Norman Wells (NW), Wrigley (Wr) & $\begin{array}{c}\text { Up to }+0.1 \\
(1984-2019)\end{array}$ & $\begin{array}{c}<+0.1 \text { to }+0.2 \\
(2000-19)\end{array}$ \\
\hline \multicolumn{4}{|c|}{ Baffin Davis Strait Region } \\
\hline Baffin Island & Pangnirtung (Pa), Pond Inlet (PI) & NA & $\begin{array}{c}+0.4 \\
(2009-19)\end{array}$ \\
\hline High Canadian Arctic & Resolute (Re) & NA & $\begin{array}{c}+0.7 \\
(2009-18)\end{array}$ \\
\hline High Canadian Arctic & $\begin{array}{l}\text { Alert (Al) } \\
@ 15 \mathrm{~m} \\
@ 24 \mathrm{~m}\end{array}$ & $\begin{array}{c}+0.6 \\
+0.4 \\
(1979-2019)\end{array}$ & $\begin{array}{c}+1.1 \\
+0.6 \\
(2000-19)\end{array}$ \\
\hline \multicolumn{4}{|c|}{ Barents Region } \\
\hline North of West Siberia & Urengoy $15-06$ and 15-08 (Ur) & $\begin{array}{c}+0.31 \text { to }+0.47 \\
(1974-2019)\end{array}$ & $\begin{array}{c}+0.1 \text { to }+0.19 \\
(2000-19)\end{array}$ \\
\hline Russian European North & Bolvansky 56, and 65 (Bo) & $\begin{array}{c}+0.18 \text { to }+0.46 \\
(1984-2019)\end{array}$ & $\begin{array}{c}+0.1 \text { to }+0.83 \\
(2000-19)\end{array}$ \\
\hline Svalbard & $\begin{array}{c}\text { Janssonhaugen (Ja), Bayelva (Bay), } \\
\text { Kapp Linne } 1 \text { (KL) }\end{array}$ & $\begin{array}{c}+0.8 \\
(1998-2019)\end{array}$ & $\begin{array}{c}+0.6 \text { to }+0.8 \\
(2000-19)\end{array}$ \\
\hline Northern Scandinavia & Tarfalarggen (Ta), Iskoras Is-B-2 (Is) & NA & $\begin{array}{c}+0.1 \text { to }+0.5 \\
(2000-19)\end{array}$ \\
\hline Southern Norway & Juvvasshøe (Ju) & $\begin{array}{c}+0.2 \\
(1999-2019)\end{array}$ & $\begin{array}{c}+0.2 \\
(2000-19)\end{array}$ \\
\hline
\end{tabular}




\section{2) Active layer thickness}

In 2019, standardized, mechanical probing of ALT was conducted at 64 Circumpolar Active Layer Monitoring (CALM) program sites in Alaska, Greenland, Svalbard, and Russia (Fig. 5.25). Sites consist of a spatial grid varying from $0.01 \mathrm{~km}^{2}(1 \mathrm{ha})$ to $1 \mathrm{~km}^{2}$ in size in landscapes representative of the region (Shiklomanov et al. 2012). Additional active-layer observations are available for 25 sites in the Mackenzie Valley, northwestern Canada, where ALT is obtained from thaw tubes (Duchesne et al. 2015). The thaw tube ALT record is complete through 2018 and some of the thaw tube data are in the CALM data archive.

In all regions, as described in Fig. 5.25, the average ALT in 2019 was above the mean value for the 10-year reference period 2003-12. All regions have also experienced an overall increase in ALT over the period of record. However, there is significant variability in the magnitude of the deviation above the mean and the rate of increase. For instance, for the North Slope of Alaska, the average ALT in 2019 was $0.04 \mathrm{~m}$ above the 2003-12 mean. At sites in interior Alaska, which have experienced a more pronounced ALT increase, the average ALT was $0.30 \mathrm{~m}$ above the mean and set a new record of $0.84 \mathrm{~m}$ for the 23-year record. A new mean ALT maximum was also reached in southern Greenland, which was at least $0.07 \mathrm{~m}$ higher than the 2003-12 mean. At sites in Svalbard, where the summer of 2019 was particularly warm, ALT values were similar to the maximum recorded in 2016.

As a result of long-term permafrost warming and relatively mild and snowy winters in 2017/18 and 2018/19, the active layer did not freeze completely down to the underlying permafrost table by the end of these winters at 26 sites in interior Alaska and the Seward Peninsula. This marks the first time in the observational record that the active layer did not freeze completely in this region. Similarly, the summer thawed layer has not been refreezing completely during the last several winters at more than 10 study sites in the Russian European North and western Siberian Arctic.
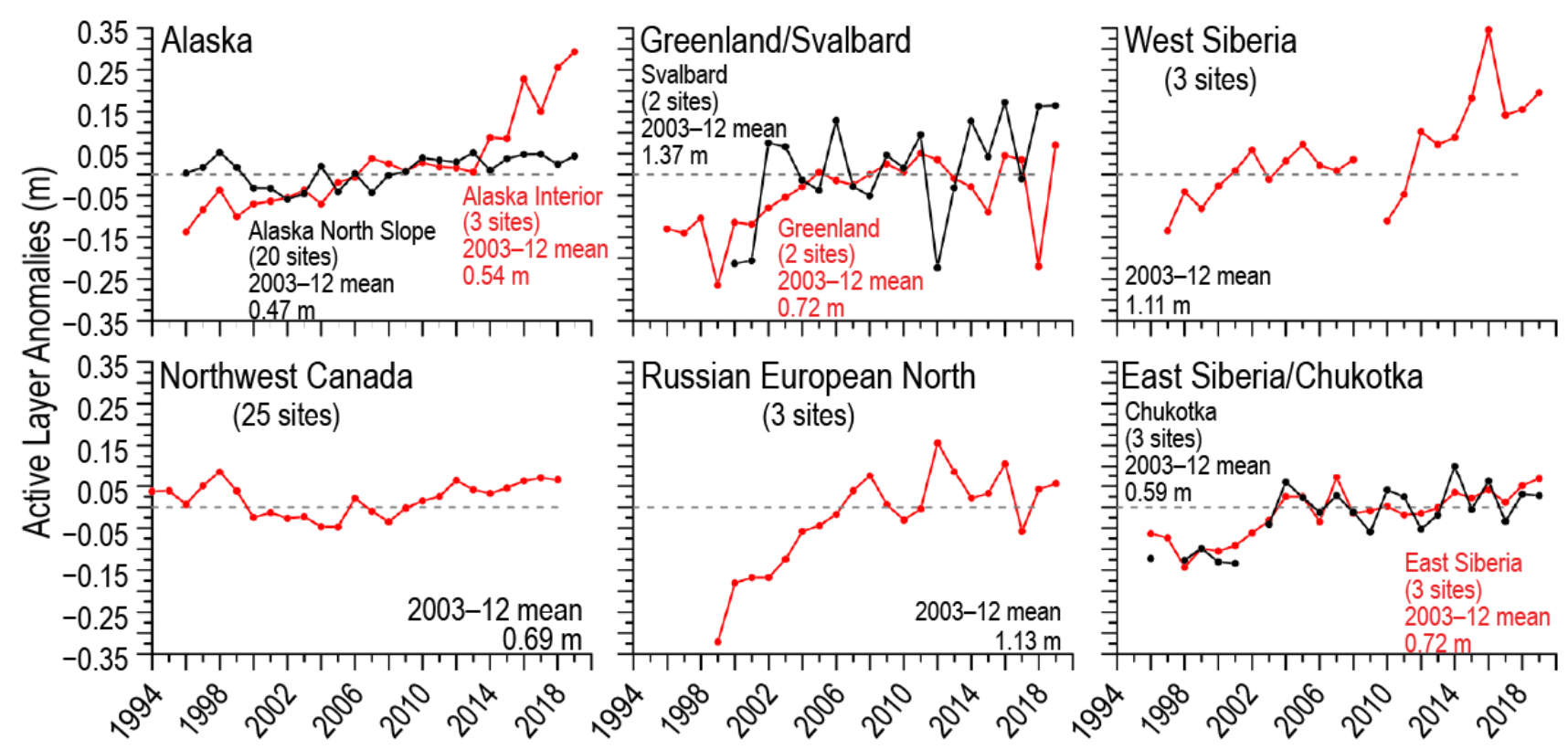

Fig. 5.25. Long-term change in the ALT in six different Arctic regions as observed by the CALM program at the end of the thawing season. The data are presented as annual anomalies $(\mathrm{m})$ relative to the mean value for the 10 -year reference period (2003-12). Positive and negative anomaly values indicate the active layer is thicker or thinner than these 10-year means, respectively. Only sites with at least 20 years of continuous thaw depth observations are included in this analysis. The number of sites used for each region varies and is shown in the figure. Site-specific data are available at www.gwu .edu/ calm. 


\section{SIDEBAR 5.2: Permafrost carbon-E.A.G. SCHUUR}

Permafrost carbon is the remnants of plants, animals, and microbes that have lived and died in tundra and boreal ecosystems, accumulating over hundreds to thousands of years in frozen soils (Schuur et al. 2008). The northern permafrost region holds almost twice as much carbon as is currently in the atmosphere, representing a climate-sensitive organic carbon reservoir that is susceptible to release with warming air and ground temperatures (Schuur et al. 2015). As permafrost warms and thaws, additional net releases of $\mathrm{CO}_{2}$ and $\mathrm{CH}_{4}$ to the atmosphere as a result of faster microbial decomposition of this permafrost carbon have the potential to accelerate climate warming. This summary focuses specifically on recent changes in the exchange of $\mathrm{CO}_{2}$ between tundra and boreal ecosystems and the atmosphere. While the change in net releases of $\mathrm{CH}_{4}$ is also critical to understand, it is beyond the scope here.

The best mean estimate of the amount of organic carbon stored in the northern circumpolar permafrost region is 14601600 petagrams ( $\mathrm{Pg} ; 1 \mathrm{Pg}=1$ billion metric tons; Schuur et al. 2015; Hugelius et al. 2014). Of this inventory, 65\%-70\% (1035 \pm $150 \mathrm{Pg}$ ) of the carbon is within the surface layer (0-3 m depth; Fig. SB5.3). Soils in the top $3 \mathrm{~m}$ of the rest of Earth's biomes (excluding Arctic and boreal biomes) contain 2050 Pg of organic carbon (Jobbagy and Jackson 2000). Thus, the soil carbon from the northern permafrost region adds another $50 \%$ to this 3-m inventory, even though it occupies only $15 \%$ of the total global soil area (Schuur et al. 2015).

A significant amount of permafrost carbon $(25 \%-30 \%)$ is also stored deeper ( $>3 \mathrm{~m}$ depth) due to unique processes that bury carbon in permafrost region soils. In particular, the Yedoma region of Siberia and Alaska remained ice-free during the last ice age and accumulated silt (loess) soils, which buried large quantities of organic matter deep into the permafrost (Strauss et al. 2013). Recent work has reconciled several estimates for the Yedoma region, placing $327-466 \mathrm{Pg} \mathrm{C}$ in these deep loess deposits, which can be tens of meters thick (Anthony et al. 2014; Strauss et al. 2017; Schuur et al. 2018).

Northern tundra and boreal ecosystems have historically gained carbon (carbon sink). Carbon is stored in plant biomass and new soil organic matter during the short summer growing season, when plant photosynthesis and growth is greater than carbon respired by plants and soil back to the atmosphere. In any given year, individual ecosystems can have gains or losses in net carbon due to changes in the physical and biological environment, and also depending on the successional stage of the ecosystem. However, what matters to future climate is the aggregate response across the permafrost region over years to decades.

Recent measurements of atmospheric greenhouse gas concentrations over Alaska by NASA aircraft have estimated the net regional impact on the atmosphere by Arctic tundra and boreal forest ecosystems (Commane et al. 2017). This NASA campaign, conducted during different parts of the year from 2012 to 2014, provided important insight into the aggregate influence of the carbon exchange for the Alaska permafrost region, across tundra, boreal forests, and wetland/lake/freshwater ecosystems as a whole. During this three-year period, the tundra region of Alaska was found to be a consistent net $\mathrm{CO}_{2}$ source to the atmosphere, whereas the boreal forest region was either neutral or a net $\mathrm{CO}_{2}$ sink. The boreal forest region exhibited larger interannual variability due both to changes in the balance of photosynthesis and respiration and to the amount of combustion emissions by wildfire.

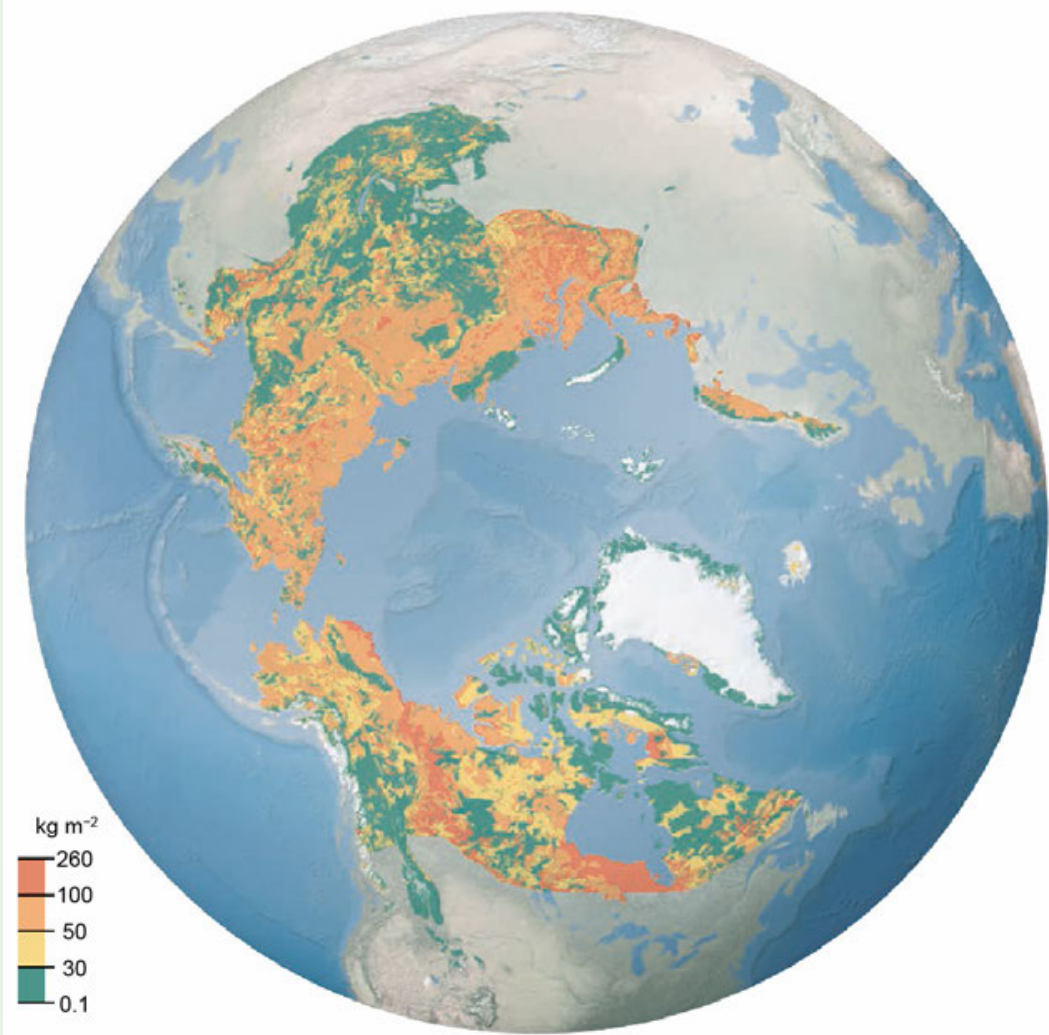

Fig. SB5.3. Soil organic carbon pools $\left(\mathrm{kg} \mathrm{m}^{-2} ; 0-3 \mathrm{~m}\right.$ depth) for the northern circumpolar permafrost region. (Modified from Scientific American, Nov 2016.) 
The Alaska study region as a whole was estimated to be a net carbon source of $0.025 \pm 0.014$ $\mathrm{Pg} C$ per year, averaged over the land area of both tundra and boreal forest regions for the three-year study period. If this Alaskan region $\left(1.6 \times 10^{6} \mathrm{~km}^{2}\right)$ was representative of the entire northern circumpolar permafrost region soil area $\left(17.8 \times 10^{6} \mathrm{~km}^{2}\right)$, this amount would be equivalent to a circumpolar net source of $0.3 \mathrm{Pg} \mathrm{C}$ per year. For comparison, recent estimates of annual $\mathrm{CO}_{2}$ emissions from land use change (largely tropical deforestation) are 1.5 \pm 0.7 Gt C (Le Quere et al. 2018). Historically (over hundreds to thousands of years), the Arctic region was accumulating carbon in soils and vegetation and thus was acting as a net sink of atmospheric $\mathrm{CO}_{2}$. Assuming this three-year snapshot provided by NASA aircraft monitoring is indicative of the Arctic's current physical and biological environment, a significant and major threshold has been crossed in the high latitude region whereas the aggregate effect of terrestrial ecosystems is now contributing to, rather than slowing, climate change.

Aircraft measurements of atmospheric greenhouse gas concentrations help to describe the combined regional impact of changing permafrost region ecosystems. However, the long cold Arctic winter (or non-summer) season limits observations from the air, just as it has limited ground-based observations in the past due to the difficult operating conditions. The summer growing season is typically a time when net carbon is stored within growing ecosystems acting as a seasonal carbon sink. However, summer carbon sequestration is partially offset by carbon losses in autumn, winter, and spring when microbes remain metabolically active and release $\mathrm{CO}_{2}$ during a period where plants are largely dormant. While absolute levels of $\mathrm{CO}_{2}$ flux are low during the non-summer season, the long period of more than 250 days can be enough to offset the net carbon that accumulated during summer.

A new comprehensive synthesis study of non-summer ecosystem $\mathrm{CO}_{2}$ fluxes across the circumpolar region shows that carbon release during the Arctic winter was two to three times higher than previously estimated from ground-based measurements

(Fig.SB5.4; Natali et al. 2019). This circumpolar estimate suggests that carbon release in the cold season offsets net carbon uptake during the growing season (derived from models) such that the region as a whole could already be a source of $0.6 \mathrm{Pg}$ $C$ per year to the atmosphere. It was not possible to determine whether these higher flux estimates were a result of changing environmental conditions or the aggregation of more observations during this scarcely observed non-summer period. Regardless, similar to the regional extrapolation made by aircraft, this winter flux synthesis supports the idea that the accelerating feedback from changing permafrost ecosystems to climate change may already be underway.

(Text in this essay was drawn from a longer 2019 Arctic Report Card essay [Schuur 2019].) 
i. Tundra greenness-G. V. Frost, U. S. Bhatt, H. E. Epstein, L. T. Berner, J. W. Bjerke, B. C. Forbes, S. J. Goetz,

M. J. Lara, M. J. Macander, G. K. Phoenix, M. K. Raynolds, H. Tømmervik, and D. A. Walker

One of the most widespread and conspicuous manifestations of Arctic climatic and environmental change has been an increase in the productivity and biomass of tundra vegetation, a phenomenon commonly termed "the greening of the Arctic." Trends in the productivity of tundra ecosystems, however, have not been uniform in direction or magnitude across the circumpolar Arctic, and there has been substantial inter-annual variability (Bhatt et al. 2013, 2017; National Academies of Sciences, Engineering and Medicine 2019). This variability arises from a web of interactions that link the vegetation, atmosphere, sea ice, seasonal snow cover, ground (soils, permafrost, and topography), disturbance processes, and herbivores of the Arctic system (Duncan et al. 2019; Piao et al. 2019; Myers-Smith et al. 2020).

Many of the changes observed in tundra ecosystems are producing a cascade of effects on Earth's subsurface, surface, and atmosphere within and beyond the far north (Post et al. 2019). For example, changes in the composition and height of tundra vegetation impact the cycling of carbon and nutrients (Blume-Werry et al. 2019; Hewitt et al. 2019; Mörsdorf et al. 2019; Salmon et al. 2019; Treharne et al. 2019), as well as energy exchanges between the atmosphere and permafrost (Wilcox et al. 2019). The latter has implications for permafrost stability, geomorphology, and surface wetness, which, coupled with changing vegetation structure, strongly alters landscape properties important to wildlife (Cray and Pollard 2018; Tape et al. 2018; Taylor et al. 2018; Ims et al. 2019; Farquharson et al. 2019; Andruko et al. 2020) and the subsistence activities of Arctic peoples (Brinkman et al. 2016; Veldhuis et al. 2018; Herman-Mercer et al. 2019). Continued monitoring of the Arctic tundra biome both from space and in situ field studies improves our understanding of these complex interactions.

Since 1982, Earth-observing satellites have provided a continuous record of global vegetation productivity using the Normalized Difference Vegetation Index (NDVI), a metric that exploits the unique spectral properties of live vegetation. NDVI is strongly correlated with the quantity of above-ground vegetation, or "greenness," of Arctic tundra (Raynolds et al. 2012). The data reported here come from the Global Inventory Modeling and Mapping Studies (GIMMS)-3g dataset (Pinzon and Tucker 2014). Two metrics based on NDVI are used: (1) MaxNDVI, the peak annual NDVI value that corresponds to the maximum above-ground biomass of vegetation reached in
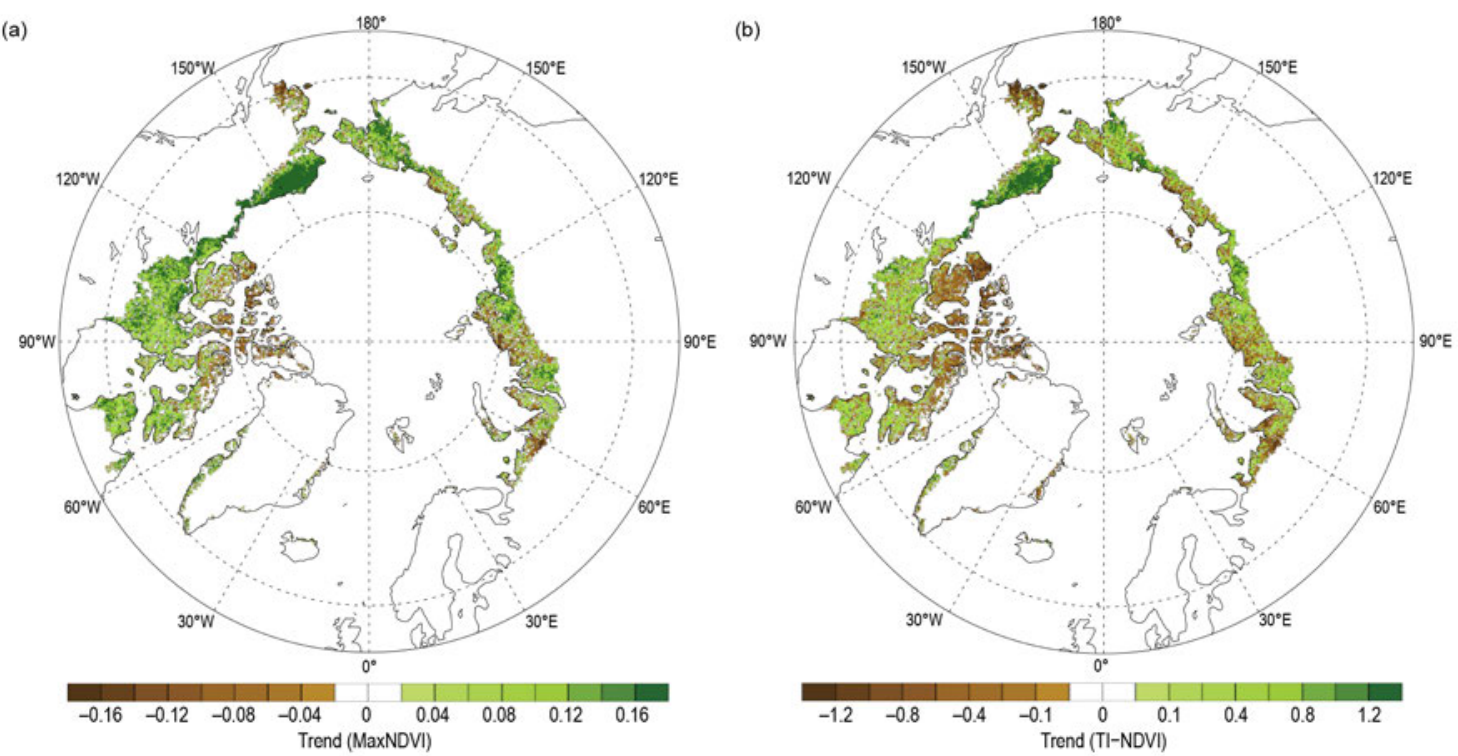

Fig. 5.26. Magnitude of the trend (calculated as the total change over a least squares, linear fit trend line) in (a) MaxNDVI and (b) TI-NDVI for 1982-2019. (Source: GIMMS-3g, a biweekly, maximum-value composited dataset of the NDVI derived from the AVHRR sensor with a spatial resolution of $1 / 12^{\circ}$ [approximately $40 \mathrm{~km}$; Pinzon and Tucker 2014].) 
midsummer; and (2) TI-NDVI, the time-integrated NDVI that is the sum of the biweekly NDVI values for the growing season and is correlated with the total above-ground productivity of vegetation.

The GIMMS-3g dataset now provides a 38-year record (1982-2019) that indicates increasing MaxNDVI and TI-NDVI across most of the Arctic tundra biome (Figs. 5.26a,b). The strongest greening has occurred in northern Alaska, mainland Canada, and the Russian Far East. Tundra greenness appears to have declined, however, in parts of western Alaska, the Canadian Arctic Archipelago, northeastern Europe, and northwestern Siberia. In recent years, similar NDVI datasets have been compiled from other satellite sensors, such as those on the Landsat satellites, which can be used to corroborate the GIMMS-3g record. These datasets suggest that Arctic greening may be even more widespread than the GIMMS$3 \mathrm{~g}$ record indicates, albeit with a shorter period of record. For example, a recent analysis of the Landsat record indicates widespread increases in MaxNDVI from 1985 to 2018; significant greening was evident at $37 \%$ of sampling sites distributed across the Pan-Arctic, and significant browning occurred at only $5 \%$ of sampling sites (L. Berner, personal communication, 2020).

In 2019, the mean MaxNDVI value for the circumpolar Arctic declined slightly from the previous year (Fig. 5.27a). This marks the third straight year of declining MaxNDVI across the region, following the record high value in 2016. However, trends in MaxNDVI have differed strongly by continent, especially over the last three years. In the Eurasian Arctic, the 2019 value was similar to the preceding four years, and was above the 1982-2019 mean. In the North American Arctic, however, the 2019 value was the lowest in the record since 1996 and fell below the long-term mean. In contrast to MaxNDVI, TI-NDVI increased substantially from the previous year (Fig. 5.27b) for the circumpolar Arctic, and particularly in the North American Arctic where late snowmelt and relatively cool summer temperatures contributed to record low TI-NDVI values in 2018 (Schmidt et al. 2019). The increase in TI-NDVI from the previous year in the North American Arctic was the third-largest single-year increase in the entire record. Nonetheless, the 2019 TI-NDVI value for the circumpolar region was well below the 1982-2019 mean and was the second-lowest value since 2009. It should be noted that mean NDVI values for North American tundra average lower than those for Eurasian tundra because a much larger proportion of the North American Arctic experiences a cold, dry High Arctic climate (Walker et al. 2005).

Spaceborne observations of land surface temperature-a key control of tundra productivity-provide

(a)
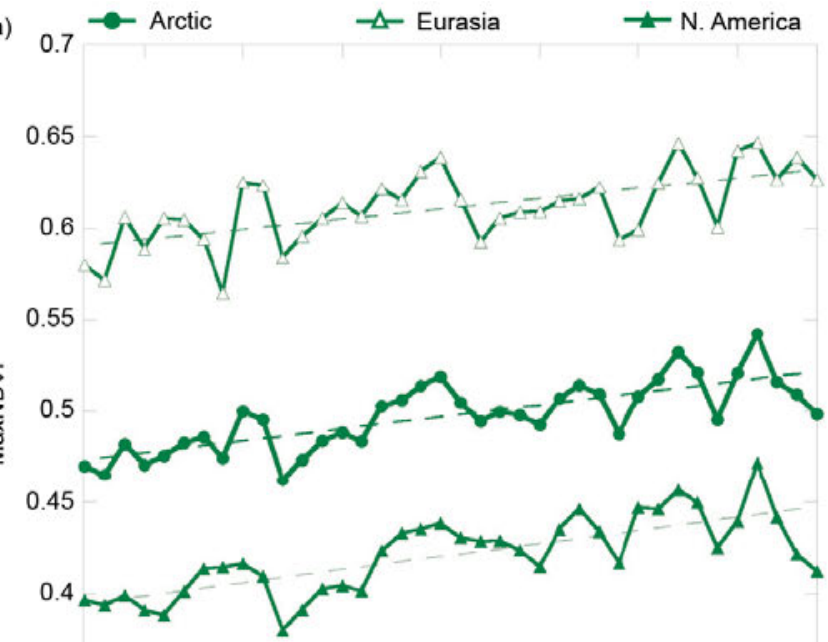

0.35

0.3

(b)
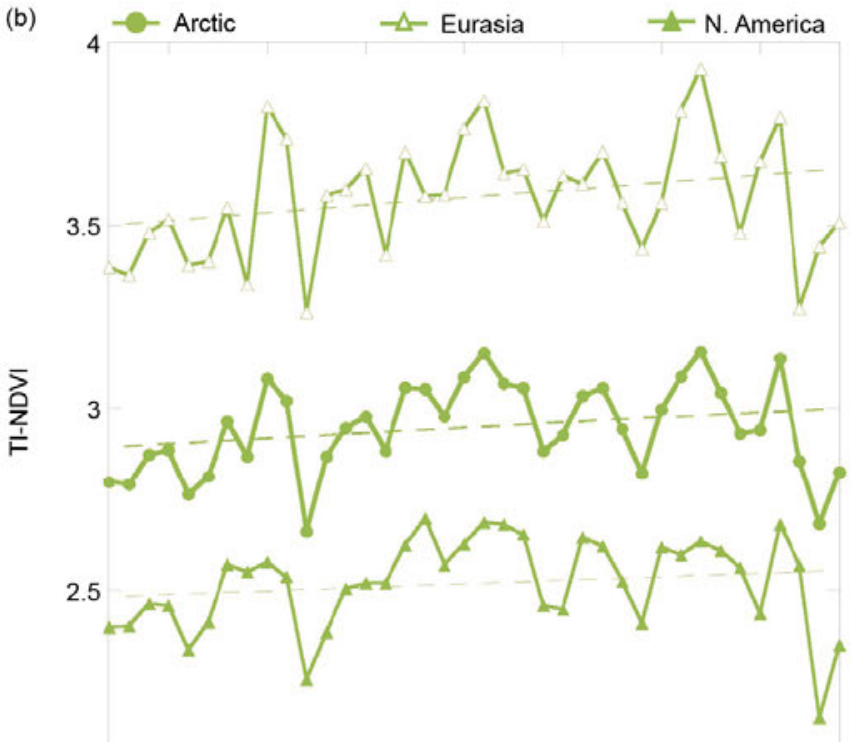

2

$\begin{array}{lllllll}1985 & 1990 & 1995 & 2000 & 2005 & 2010 & 2015\end{array}$

Fig. 5.27. (a) MaxNDVI and (b) TI-NDVI for the Eurasian Arctic (top), the full circumpolar Arctic (middle), and the North American Arctic (bottom) for 1982-2019. Dashed lines indicate linear trends; MaxNDVI trends are highly significant $(p<0.001)$ but TI-NDVI trends are not $(p>0.05)$. (Source: GIMMS-3g, a biweekly, maximum-value composited dataset of the NDVI derived from the AVHRR sensor with a spatial resolution of $1 / 12^{\circ}$ [approximately $40 \mathrm{~km}$; Pinzon and Tucker 2014].) 
context for understanding spatio-temporal patterns of tundra productivity and are available from the same satellite sensors that record NDVI for the GIMMS-3g dataset. We summarize the land surface temperature observations as the Summer Warmth Index (SWI), the sum of mean monthly temperatures for all months with mean temperatures above freezing $\left(>0^{\circ} \mathrm{C}\right)$. The 2019 growing season was the warmest in the entire record; the mean SWI for the full circumpolar region $\left(39.0^{\circ} \mathrm{C}\right.$-months) broke the previous record set in $2016\left(34.9^{\circ} \mathrm{C}\right.$-months). The tundra regions of both continents experienced record warmth (section 5b). The 2019 SWI exceeded previous highs set in North America and Eurasia in 1994 and 2016, respectively. This warmth was not, however, accompanied by strong increases in NDVI, possibly due to lag effects arising from the below-normal summer temperatures experienced in 2018. Within the 38-year record, MaxNDVI values for 2019 ranked 19th, 9th, and 26th for the circumpolar Arctic, Eurasian Arctic, and North American Arctic, respectively. TI-NDVI values ranked 31st, 26th, and 35th for the circumpolar Arctic, Eurasian Arctic, and North American Arctic respectively.

j. Ozone and UV radiation-G. Bernhard., V. Fioletov, J.-U. Grooß, I. Ialongo, B. Johnsen, K. Lakkala, G. Manney, and R. Müller

Past emissions of chlorine-containing substances, such as chlorofluorocarbons (CFCs), have substantially contributed to the chemical destruction of ozone in the atmosphere (WMO 2018). The resulting ozone loss has led to increased ultraviolet (UV) radiation with adverse effects on human health and Earth's environment (EEAP 2019). The chemical destruction of polar ozone occurs within a cold low-pressure system (i.e., cyclone) known as the polar vortex, which forms over the North Pole every year during winter and spring (WMO 2018). Hence, the period of December 2018-April 2019 is emphasized in this report. As explained in more detail below, unusual conditions during this period enabled ozone concentrations in February and early March 2019 to reach the highest values in at least the past 15 years of satellite observations. In March 2019, the minimum Arctic daily total ozone column (TOC; i.e., ozone amounts integrated from the surface to the top of the atmosphere) was the highest value since 1988, for years when a well-defined polar vortex existed in March. With some exceptions, UV index (UVI) anomalies during this period were generally within the typical range of variability.

\section{1) Ozone}

Chemical processes that drive ozone depletion in the polar stratosphere are initiated at temperatures below about $195 \mathrm{~K}\left(-78^{\circ} \mathrm{C}\right)$ at altitudes of approximately 15 to $25 \mathrm{~km}$. These low temperatures lead to the formation of polar stratospheric clouds (PSCs), which act as a catalyst to transform inactive forms of chlorine-containing substances to active, ozone-destroying chlorine species. At the beginning of December 2018, temperatures in the lower Arctic stratosphere dropped below the threshold for PSC formation and remained below this threshold and near the mean of the observational record (1979-2017) during the first three weeks of December. On 2 January 2019, a major sudden stratospheric warming (SSW) occurred, which led to a rapid rise of polar stratospheric temperatures over the course of a few days. During this event, the polar vortex split into three “offspring” vortices. As a result, stratospheric temperatures rose above the threshold for PSCs and remained well above this threshold for the remainder of the winter. The offspring vortices recombined in early March such that the polar vortex observed on 12 March was the strongest of the winter/spring 2018/19 period (Lee and Butler 2020). However, stratospheric temperatures at this time were too high for PSC formation.

Because of the early SSW event, chemical destruction of ozone was unusually low over the winter/ spring period of 2018/19, as is confirmed by satellite-based observations. Measurements by the Microwave Limb Sounder (MLS) show that chlorine activation started in mid-December, resulting in a small decline in ozone concentrations, as expressed by the ozone mixing ratio (Fig. 5.28). Chlorine deactivation began in early January 2019 and was complete by late that month-consequently no chemical 


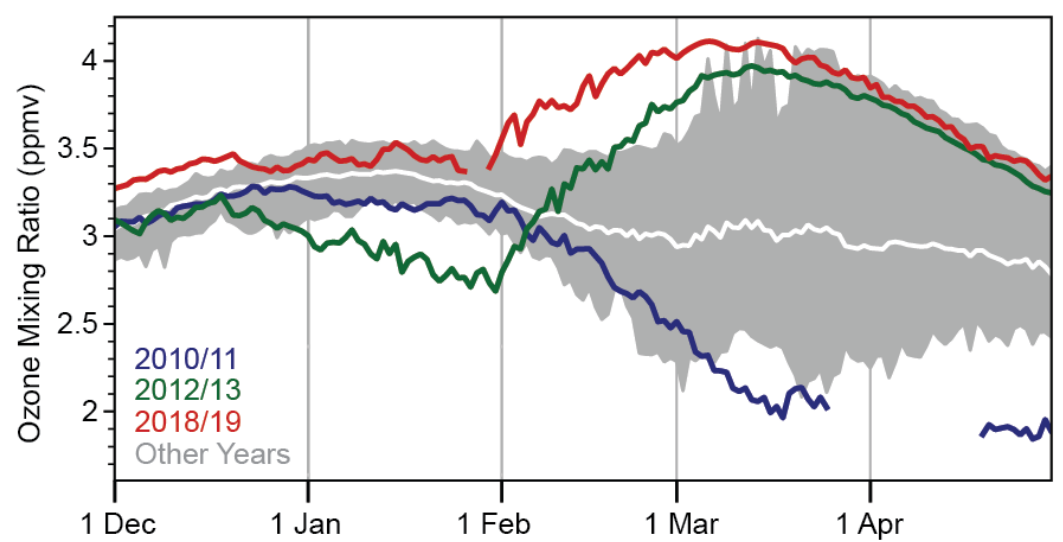

Fig. 5.28. Average ozone mixing ratios (ppmv) at an altitude of $\sim 18 \mathrm{~km}$ for the area bounded by the polar vortex, as measured by Aura MLS. Data from 2018/19 (red), 2012/13 (green), and 2010/11 (blue) are compared with the average (solid white) and minimum/maximum range (gray shading) from 2004/05 to 2017/18, excluding 2010/11, 2012/13, and 2018/19. Gaps in the record for 2010/11 and 2018/19 are due to missing data.

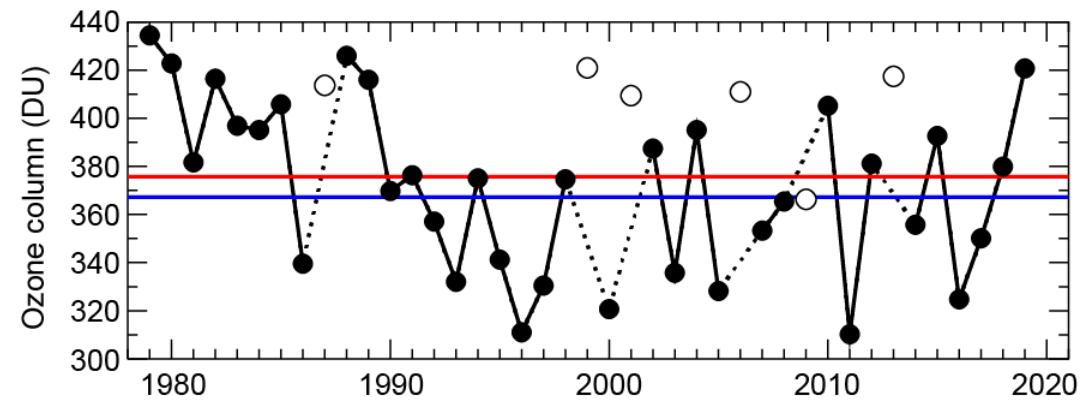

Fig. 5.29. Minimum of the daily average column ozone for Mar poleward of $63^{\circ} \mathrm{N}$ equivalent latitude (Butchart and Remsberg 1986). Open circles represent years in which the polar vortex was not well-defined in Mar, resulting in relatively high values due to mixing with lower latitude air masses and a lack of significant chemical ozone depletion. Red and blue lines indicate the average TOC for 1979-2018 and 2005-18, respectively. Ozone data for 1979-2016 are based on the combined total column ozone database version 3.4 produced by Bodeker Scientific (www.bodekerscientific.com/data/total-column-ozone). Ozone data for 2017-19 are from the OMI. The graph is adapted from Müller et al. (2008) and WMO (2018), updated using ERA-Interim reanalysis data (Dee et al. 2011) for determining equivalent latitude. ozone loss occurred after about midJanuary. This sequence of conditions enabled ozone concentrations in February and early March 2019 to reach the highest values in at least the past 15 years, the period of the MLS observational record. The conditions in 2018/19 were similar to those in 2012/13 (Manney et al. 2015), although the strong SSW started a few days earlier in 2019 (Fig. 5.28). Unlike December 2018, December 2012 temperatures in the lower Arctic stratosphere were unusually cold, resulting in greater chlorine activation and much larger ozone loss in 2012/13 compared to 2018/19. The largest chemical ozone loss observed to date occurred in the winter of 2010/11 and was associated with an unusually prolonged cold period lasting through early April 2011, with temperatures in the lower stratosphere remaining low enough for PSC formation (Manney et al. 2011).

The evolution of Arctic TOC in March 2019 is compared to the satellite-derived observational record (1979-2018) in Fig. 5.29 using the minimum of the daily averages for March. March TOC is evaluated because chemically-induced Arctic ozone loss has the largest variability in this month (Fig. 5.28; WMO 2018). In March 2019, the minimum Arctic daily TOC was 421 Dobson units (DU), which was the highest value since 1988 for years when

a well-defined polar vortex existed in March. The value was 12.0\% (45 DU) above the average of the observational record (376 DU) and 14.6\% (54 DU) above the average when MLS data are available (2005-18).

Spatial deviations of monthly average TOCs from historical (2005-18) averages (Figs. 5.30a,b) were estimated from the Ozone Monitoring Instrument (OMI; co-located with MLS on the Aura satellite) measurements. With the exception of an area centered over northwestern Canada, TOCs in March 2019 were above the mean over sunlit regions of the Arctic (Fig. 5.30a), consistent with the high ozone concentrations inside the lower stratospheric polar vortex during March 2019 (Fig. 5.28). These anomalies ranged between $0 \%$ over Scandinavia to $12 \%$ over Siberia. In midApril, TOC departures exhibited a distinct geographical pattern with positive anomalies of up to $17 \%$ over Canada, the North Pole, and Siberia, and negative anomalies as large as $-17 \%$ over Scandinavia and the North Sea (Fig. 5.30b). 
(a) Mar

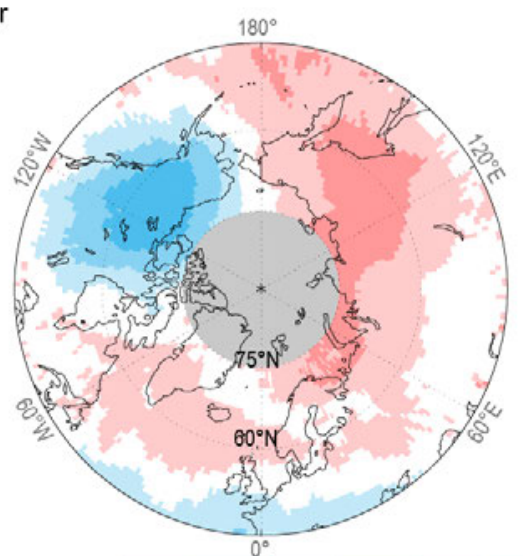

(b) $15-30 \mathrm{Apr}$

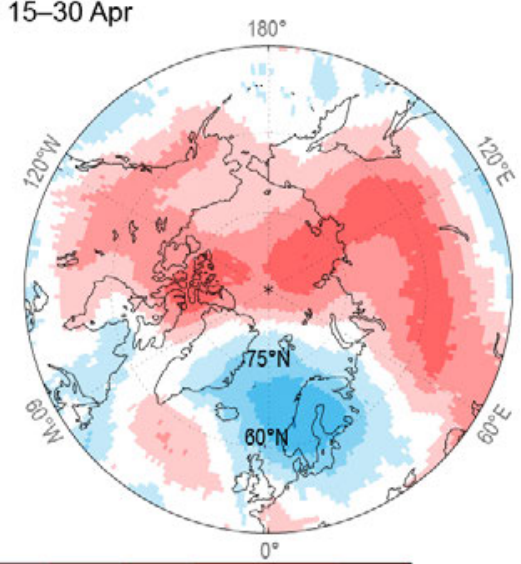

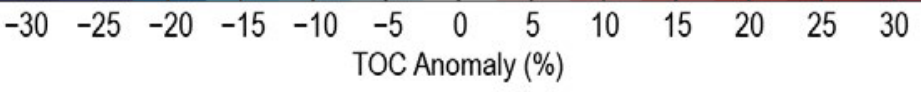

(c) Mar

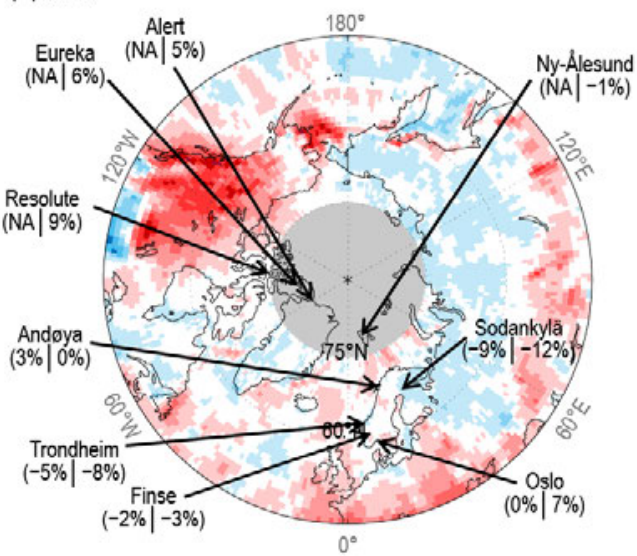

(d) 15-30 Apr

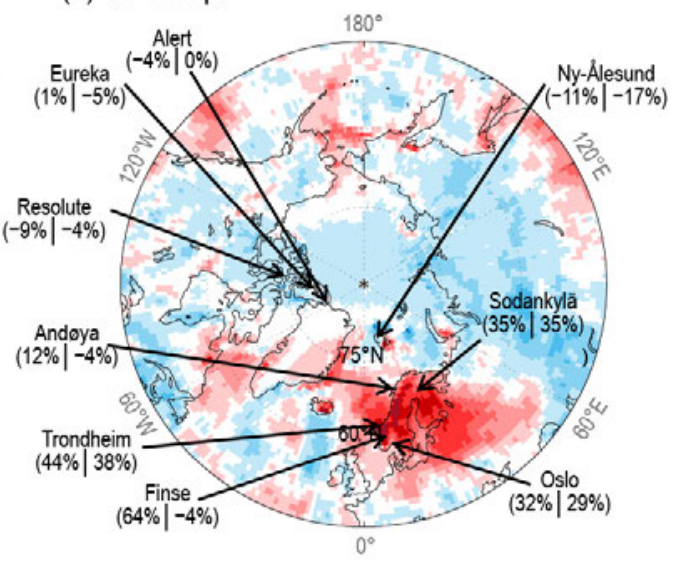

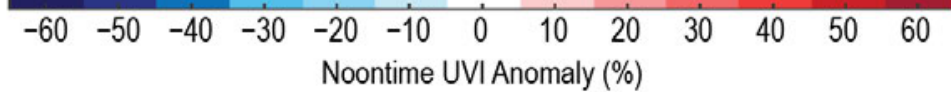

Fig. 5.30. Anomalies of TOC (\%) for (a) Mar and (b) 15-30 Apr 2019. Anomalies of noontime UVI (\%) for (c) Mar and (d) 15-30 Apr 2019. Anomalies are relative to 2005-18 averages. Maps are based on the OMTO3 Level 3 total ozone product (Bhartia and Wellemeyer 2002). (c) and (d) also compare UVI anomalies from OMI (first value in parenthesis) with ground-based measurements at nine locations (second value). Gray, solid circles centered at the North Pole indicate the areas where no OMI data are available due to the lack of sunlight at this time of year.

\section{2) Ultraviolet radiation}

UV radiation is quantified with the UVI, which is a measure of the capacity of UV radiation to cause erythema (sunburn) in human skin (WHO 2002). In addition to its dependence on TOC, the UVI depends on the sun angle, clouds, and surface albedo (Weatherhead et al. 2005). In the Arctic, the UVI scale ranges from 0 to about 7, with the smallest annual peak radiation levels (UVI values $<4$ ) observed at sites closest to the North Pole. UVI values $\leq 5$ indicate low-to-moderate risk of erythema (WHO 2002).

UVI anomalies are assessed using both OMI and ground-based measurements, with the former providing better spatial coverage and the latter providing greater regional accuracy (Bernhard et al. 2015). Figures 5.30c,d quantify the spatial differences in monthly average noontime UVIs from historical (2005-18) averages based on measurements by OMI and by ground-based instruments at nine research stations located in the Arctic and Scandinavia. Areas with high UVIs roughly match areas with low TOCs and vice versa, but UVI anomalies have larger spatial variability because of their added dependence on clouds. In the following discussion, we emphasize 
March 2019 and 15-30 April 2019. During the latter period, unusually large UVI anomalies over the Nordic countries occurred, while ozone and UVI anomalies for other months were generally within the typical range of variability.

In March 2019, monthly average noontime UVIs calculated from OMI observations over northwestern Canada were up to 55\% above the 2005-18 mean (Fig. 5.30c). This region of unusually high UVIs coincided with the area of low TOCs in Fig. 5.30a. Large UVI anomalies of up to 50\% were also observed west of Alaska. UVI anomalies for the remainder of the Arctic computed from OMI and ground-based measurements were below 15\%. Because of the low solar zenith angle in March, absolute anomalies did not exceed 1.9 UVI units for latitudes higher than $60^{\circ} \mathrm{N}$.

During the period of 15-30 April, a persistent high-pressure system was centered over the Nordic countries, and the ensuing periods of clear skies contributed to large UVI anomalies of up to $65 \%$ (Fig. 5.30d). Anomalies calculated from OMI and ground-based data agreed to within $\pm 8 \%$ at almost all locations. Exceptions included Andøya and Finse due to local weather (cloudiness) and ground conditions (low albedo due to unusually wet snow cover), respectively. The influence of local conditions creates inconsistencies between satellite and ground-based measurements and illustrates the limitations of estimating UV radiation from space. These inconsistencies are largest at locations that are either affected by variable conditions within the satellite instrument's field of view (cloudiness, albedo, topography) or differences between the actual surface albedo and the albedo climatology used by OMI (Tanskanen et al. 2004). 


\section{Acknowledgments}

The editors thank Dr. Martin Jeffries, USACE Cold Regions Research and Engineering Laboratory, and Florence Fetterer, National Snow and Ice Data Center, for providing an initial review of the full chapter. Their careful read and thoughtful input improved each of the sections and, importantly, led to better coherency between the sections.

\section{a. Overview}

- Jackie Richter-Menge appreciates support from NOAA's Arctic Research Office.

- Matthew Druckenmiller was supported by the Study of Environmental Arctic Change (SEARCH, NSF grant PLR-1331100).

\section{b. Surface air temperature}

- Jim Overland has support from the NOAA Arctic Research Program.

- Tom Ballinger acknowledges support from the Experimental Arctic Prediction Initiative at the University of Alaska Fairbanks.

\section{d. Sea ice}

Walt Meier's contribution was supported by the NASA Snow and Ice Distributed Active Archive Center (DAAC) at NSIDC, part of the NASA Earth Science Data and Information System (ESDIS) Project.

\section{e. Greenland ice sheet}

Macro Tedesco acknowledges financial support by the National Science Foundation (PLR-1603331, PLR1713072), NASA (NNX17AH04G, 80NSSC17K0351) and the Heising-Simons Foundation. Financial support for measurements along the K-transect has been received from the Dutch Polar Program of NWO. Data from the Programme for Monitoring of the Greenland Ice Sheet (PROMICE) and the Greenland Analogue Project (GAP) were provided by the Geological Survey of Denmark and Greenland (GEUS) at http://www.promice.dk. Computational resources for running the MAR model have been provided by the Consortium des Équipements de Calcul Intensif (CÉCI), funded by the Fonds de la Recherche Scientifique de Belgique (F.R.S.FNRS) under grant no. 2.5020.11 and the Tier-1 supercomputer (Zenobe) of the Fédération Wallonie Bruxelles infrastructure funded by the Wallonia region under grant agreement no. 1117545 .

\section{j. Ozone and UV Radiation}

Germar Bernhard and coauthors acknowledge the support of Biospherical Instruments, San Diego; the Research Council of Norway through its Centers of Excellence funding scheme, project number 223268/F50; the Academy of Finland for supporting UV measurements through the FARPOCC and SAARA projects; the European Space Agency for supporting the DACES project; and the European Union for supporting e-shape. We also thank the Microwave Limb Sounder team at NASA's Jet Propulsion Laboratory for data processing and analysis support; Tove Svendby from the Norwegian Institute for Air Research and Arne Dahlback from the University of Oslo for overseeing UV measurements at Oslo, Andøya, and Ny-Ålesund; and Juha M. Karhu, Tomi Karppinen, and Markku Ahponen from the Finnish Meteorological Institute for operating the Brewer UV spectroradiometer at Sodankylä.

\section{Sidebar 5.1. Shifting fish distributions in the Bering Sea}

We'd like to thank the scientists and crews who took part in these long-term groundfish surveys in the eastern and northern Bering Sea. We also thank R. Haehn for pulling the 2019 survey data. 


\section{Sidebar 5.2 Permafrost carbon}

Support provided by:

- NSF Research, Synthesis, and Knowledge Transfer in a Changing Arctic: Science Support for the Study of Environmental Arctic Change (SEARCH) Grant \# 1331083. (2014-2020)

- NSF PLR Arctic System Science Research Networking Activities (RNA) Permafrost Carbon Network: Synthesizing Flux Observations for Benchmarking Model Projections of Permafrost Carbon Exchange (2019-2023). 


\section{APPENDIX: Acronym List}

\begin{tabular}{|c|c|}
\hline ALT & active layer thickness \\
\hline AMJ & April, May, June \\
\hline CFCs & chlorofluorocarbons \\
\hline CALM & Circumpolar Active Layer Monitoring \\
\hline DMI & Danish Meteorological Institute \\
\hline DJF & December-February \\
\hline DU & Dobson units \\
\hline GrIS & Greenland ice sheet \\
\hline JFM & January, February, March \\
\hline JAS & July, August, September \\
\hline$J J A$ & June-August \\
\hline MAM & March-May \\
\hline MLS & Microwave Limb Sounder \\
\hline MAR & Modèle Atmosphérique Régionale \\
\hline MODIS & Moderate Resolution Imaging Spectroradiometer \\
\hline NSIDC & National Snow and Ice Data Center \\
\hline NDVI & Normalized Difference Vegetation Index \\
\hline NAO & North Atlantic Oscillation \\
\hline $\mathrm{NH}$ & Northern Hemisphere \\
\hline OND & October, November, December \\
\hline OMI & Ozone Monitoring Instrument \\
\hline $\mathrm{Pg}$ & petagrams \\
\hline PSCs & polar stratospheric clouds \\
\hline PROMICE & Program for Monitoring of the Greenland Ice Sheet \\
\hline SSTS & sea surface temperatures \\
\hline SCD & snow cover duration \\
\hline SCE & snow cover extent \\
\hline SWE & snow water equivalent \\
\hline SSW & sudden stratospheric warming \\
\hline SWI & Summer Warmth Index \\
\hline SAT & surface air temperature \\
\hline TOC & total ozone column \\
\hline UV & ultraviolet \\
\hline UVI & UV index \\
\hline WGMS & World Glacier Monitoring Service \\
\hline
\end{tabular}




\section{References}

Acosta Navarro, J. C., and Coauthors, 2016: Amplification of Arctic warming by past air pollution reductions in Europe. Nat. Geosci., 9, 277-281, https://doi. org/10.1038/ngeo2673.

Alabia, I. D., J. G. Molinos, S.-I. Saitoh, T. Hirawake, T. Hirata, and F. J. Mueter, 2018: Distribution shifts of marine taxa in the Pacific Arctic under contemporary climate changes. Divers. Distrib., 24, 1583-1597, https://doi. org/10.1111/ddi.12788.

Andersen, J. K., and Coauthors, 2019: Update of annual calving front lines for 47 marine terminating outlet glaciers in Greenland (1999-2018). Geol. Surv. Den. Greenl. Bull., 43, e2019430202, https://doi.org/10.34194/ GEUSB-201943-02-02.

Andruko, R., R. Danby, and P. Grogan, 2020: Recent growth and expansion of birch shrubs across a low Arctic landscape in continental Canada: Are these responses more a consequence of the severely declining caribou herd than of climate warming? Ecosystems, https://doi.org/10.1007/s10021-01900474-7, in press.

Anthony, K. M. W., and Coauthors, 2014: A shift of thermokarst lakes from carbon sources to sinks during the Holocene epoch. Nature, 511, 452-456, https://doi.org/10.1038/nature13560.

Barton, B. I., Y. Lenn, and C. Lique, 2018: Observed Atlantification of the Barents Sea causes the Polar Front to limit the expansion of winter sea ice. J. Phys. Oceanogr., 48, 1849-1866, https://doi.org/10.1175/JPO-D-18-0003.1.

Bernhard, G., and Coauthors, 2015: Comparison of OMI UV observations with ground-based measurements at high northern latitudes. Atmos. Chem. Phys., 15, 7391-7412, https://doi.org/10.5194/acp-15-7391-2015.

Bhartia, P. K., and C. W. Wellemeyer, 2002: TOMS-V8 total 03 algorithm. OMI Algorithm Theoretical Basis Document, Vol. II, NASA Goddard Space Flight Center Tech. Doc. ATBD-OMI-02, 15-31, http://eospso.nasa.gov/sites/default/files/atbd/ATBD-OMI-02.pdf.

Bhatt, U. S., and Coauthors, 2013: Recent declines in warming and vegetation greening trends over Pan-Arctic tundra. Remote Sens., 5, 4229-4254, https://doi.org/10.3390/rs5094229.

_ , and Coauthors, 2017: Changing seasonality of panarctic tundra vegetation in relationship to climatic variables. Environ. Res. Lett., 12, 055003, https://doi.org/10.1088/1748-9326/aa6b0b.

Bieniek, P. A., and J. E. Walsh, 2017: Atmospheric circulation patterns associated with monthly and daily temperature and precipitation extremes in Alaska. Int. J. Climatol., 37, 208-217, https://doi.org/10.1002/joc.4994.

Bjella, K., 2019: Warming and thawing permafrost and impacts on infrastructure [in "State of the Climate in 2018"]. Bull. Amer. Meteor. Soc., 100 (9), S157-S159., https://doi.org/10.1175/2019BAMSStateoftheClimate.1.

Blume-Werry, G., A. Milbau, L. M. Teuber, M. Johansson, and E. Dorrepaal, 2019: Dwelling in the deep - Strongly increased root growth and rooting depth enhance plant interactions with thawing permafrost soil. New Phytol., 223, 1328-1339, https://doi.org/10.1111/nph.15903.

Boike, J., and Coauthors, 2018: A 20-year record (1998-2017) of permafrost, active layer, and meteorological conditions at a High Arctic permafrost research site (Bayelva, Spitsbergen). Earth Syst. Sci. Data, 10, 355-390, https://doi.org/10.5194/essd-10-355-2018.

Box, J. E., D. van As, and K. Steffen, 2017: Greenland, Canadian and Icelandic land ice albedo grids (2000-2016). Geol. Surv. Den. Greenl. Bull., 38, 53-56, https://doi.org/10.34194/geusb.v38.4414.

_ - and Coauthors, 2019: Key indicators of Arctic climate change: 1971-2017. Environ. Res. Lett., 14, 045010, https://doi.org/10.1088/1748-9326/aafc1b.

Brasnett, B., 1999: A global analysis of snow depth for numerical weather prediction. J. Appl. Meteor., 38, 726-740, https://doi.org/10.1175/15200450(1999)038<0726:AGAOSD>2.0.C0;2.

Brinkman, T. J., W. D. Hansen, F. S. Chapin, G. Kofinas, S. BurnSilver, and T. S. Rupp, 2016: Arctic communities perceive climate impacts on access as a critical challenge to availability of subsistence resources. Climatic Change, 139, 413-427, https://doi.org/10.1007/s10584-016-1819-6.
Brown, J., O. J. Ferrians Jr., J. A. Heginbottom, and E. S. Melnikov, 1997: CircumArctic map of permafrost and ground-ice conditions. U.S. Geological Survey Circum-Pacific Map CP-45, 1:10,000,000, https://doi.org/10.3133/cp45.

Brown, R., B. Brasnett, and D. Robinson, 2003: Gridded North American monthly snow depth and snow water equivalent for GCM evaluation. Atmos.Ocean, 41, 1-14, https://doi.org/10.3137/ao.410101.

— D. Vikhamar Schuler, O. Bulygina, C. Derksen, K. Luojus, L. Mudryk, L. Wang, and D. Yang, 2017: Arctic terrestrial snow cover. Snow, Water, Ice and Permafrost in the Arctic (SWIPA) 2017, Arctic Monitoring and Assessment Programme, 25-64, www.amap.no/documents/doc/snow-water-iceand-permafrost-in-the-arctic-swipa-2017/1610.

Brun, E., V. Vionnet, A. Boone, B. Decharme, Y. Peings, R. Valette, F. Karbou, and S. Morin, 2013: Simulation of Northern Eurasian local snow depth, mass, and density using a detailed snowpack model and meteorological reanalyses. J. Hydrometeor., 14, 203-219, https://doi.org/10.1175/JHMD-12-012.1.

Butchart, N., and E. E. Remsberg, 1986: The area of the stratospheric polar vortex as a diagnostic for tracer transport on an isentropic surface. J. Atmos. Sci., 43, 1319-1339, https://doi.org/10.1175/1520-0469(1986)043<1319:TA OTSP>2.0.CO;2.

Callaghan, T., and Coauthors, 2011: The changing face of Arctic snow cover: A synthesis of observed and projected changes. $A M B I O, 40,17-3131$, https:// doi.org/10.1007/s13280-011-0212-y.

Cape, M. R., F. Straneo, N. Beaird, R. M. Bundy, and M. A. Charette, 2019: Nutrient release to oceans from buoyancy-driven upwelling at Greenland tidewater glaciers. Nat. Geosci., 12, 34-39, https://doi.org/10.1038/\$41561-018-02684.

Cappelen, J., Ed., 2020: Greenland - DMI historical climate data collection 17842019. DMI Rep. 20-04, Danish Meteorological Institute, 119 pp., www.dmi. dk/fileadmin/Rapporter/2020/DMIRep20-04.pdf.

Cavalieri, D. J., C. L. Parkinson, P. Gloersen, and H. J. Zwally, 1996: Sea ice concentrations from Nimbus-7 SMMR and DMSP SSM/I-SSMIS passive microwave data, version 1 (updated yearly). NASA NSIDC DAAC, accessed 1 November 2019, https://doi.org/10.5067/8GQ8LZQVLOVL.

Christiansen, H. H., and Coauthors, 2010: The thermal state of permafrost in the Nordic area during the International Polar Year 2007-2009. Permafrost Periglacial Processes, 21, 156-181, https://doi.org/10.1002/ppp.687.

Commane, R., and Coauthors, 2017: Carbon dioxide sources from Alaska driven by increasing early winter respiration from Arctic tundra. Proc. Natl. Acad. Sci. USA, 114, 5361-5366, https://doi.org/10.1073/pnas.1618567114.

Cray, H. A., and W. H. Pollard, 2018: Use of stabilized thaw slumps by Arctic birds and mammals: Evidence from Herschel Island, Yukon. Can. Field Nat. 132, 279-284, https://doi.org/10.22621/cfn.v132i3.1988.

Dee, D. P., and Coauthors, 2011: The ERA-Interim reanalysis: Configuration and performance of the data assimilation system. Quart. J. Roy. Meteor. Soc., 137, 553-597, https://doi.org/10.1002/qj.828.

Duchesne, C., S. L. Smith, M. Ednie, and P. P. Bonnaventure, 2015: Active layer variability and change in the Mackenzie Valley, Northwest Territories. 68th Canadian Geotechnical Conf./7th Canadian Conf. on Permafrost, Quebec, Canada, GEOQuébec, Paper 117.

Dufour, A., O. Zolina, and S. K. Gulev, 2016: Atmospheric moisture transport to the Arctic. J. Climate, 29, 5061-5081, https://doi.org/10.1175/JCLID-15-0559.1.

Duncan, B. N., and Coauthors, 2019: Space-based observations for understanding changes in the Arctic-Boreal zone. Rev. Geophys., 58, e2019RG000652, https://doi.org/10.1029/2019RG000652.

Ednie, M., and S. L. Smith, 2015: Permafrost temperature data 2008-2014 from community based monitoring sites in Nunavut. Geological Survey of Canada Open File 7784, 18 pp., https://doi.org/10.4095/296705. 
EEAP, 2019: Environmental effects and interactions of stratospheric ozone depletion, UV radiation, and climate change. 2018 Assessment Rep. Nairobi: Environmental Effects Assessment Panel, United Nations Environment Programme (UNEP), 390 pp., https://ozone.unep.org/sites/default/ files/2019-04/EEAP_assessment-report-2018\%20\%282\%29.pdf.

Estilow, T. W., A. H. Young, and D. A. Robinson, 2015: A long-term Northern Hemisphere snow cover extent data record for climate studies and monitoring. Earth Syst. Sci. Data, 7, 137-142, https://doi.org/10.5194/essd-7-1372015.

Farquharson, L. M., V. E. Romanovsky, W. L. Cable, D. A. Walker, S. V. Kokelj, and D. Nicolsky, 2019: Climate change drives widespread and rapid thermokarst development in very cold permafrost in the Canadian High Arctic. Geophys. Res. Lett., 46, 6681-6689, https://doi.org/10.1029/2019GL082187.

Fausto, R. S. and D. van As, 2019: Programme for monitoring of the Greenland ice sheet (PROMICE): Automatic weather station data, v03. Geological Survey of Denmark and Greenland, accessed 10 January 2020, https://doi. org/10.22008/promice/data/aws.

Fetterer, F., K. Knowles, W. N. Meier, M. Savoie, and A. K. Windnagel, 2017: Sea ice index, version 3: Regional daily data (updated daily). NSIDC, accessed 1 February 2020, https://doi.org/10.7265/N5K072F8.

Fettweis, X., 2007: Reconstruction of the 1979-2006 Greenland ice sheet surface mass balance using the regional climate model MAR. Cryosphere, 1 , 21-40, https://doi.org/10.5194/tc-1-21-2007.

Fissel, B., and Coauthors, 2019: Stock assessment and fishery evaluation report for the groundfish fisheries of the Gulf of Alaska and Bering Sea/Aleutian Island Area. Economic Status of the Groundfish Fisheries off Alaska, NOAA, 297 pp., www.fisheries.noaa.gov/resource/data/2018-economic-statusgroundfish-fisheries-alaska.

Fossheim, M., R. Primicerio, E. Johannesen, R. B. Ingvaldsen, M. M. Aschan, and A. V. Dolgov, 2015: Recent warming leads to a rapid borealization of fish communities in the Arctic. Nat. Climate Change, 5, 673-677, https:// doi.org/10.1038/nclimate2647.

Gardner, A. S., and Coauthors, 2011: Sharply increased mass loss from glaciers and ice caps in the Canadian Arctic Archipelago. Nature, 473, 357-360, https://doi.org/10.1038/nature10089.

- - and Coauthors, 2013: A reconciled estimate of glacier contributions to sea level rise: 2003-2009. Science, 340, 852-857, https://doi.org/10.1126/ science. 1234532.

Helfrich, S., D. McNamara, B. Ramsay, T. Baldwin, and T. Kasheta, 2007: Enhancements to, and forthcoming developments in the Interactive Multisensor Snow and Ice Mapping System (IMS). Hydrol. Processes, 21, 1576-1586, https://doi.org/10.1002/hyp.6720.

Herman-Mercer, N. M., M. Laituri, M. Massey, E. Matkin, R. Toohey, K. Elder, P. F. Schuster, and E. Mutter, 2019: Vulnerability of subsistence systems due to social and environmental change: A case study in the Yukon-Kuskokwim Delta, Alaska. Arctic, 72, 258-272, https://doi.org/10.14430/arctic68867.

Hewitt, R. E., D. L. Taylor, H. Genet, A. D. McGuire, and M. C. Mack, 2019: Below-ground plant traits influence tundra plant acquisition of newly thawed permafrost nitrogen. J. Ecol., 107, 950-962, https://doi.org/10.1111/13652745.13062.

Hollowed, A. B., and Coauthors, 2013: Projected impacts of climate change on marine fish and fisheries. ICES J. Mar. Sci., 70, 1023-1037, https://doi. org/10.1093/icesjms/fst081.

Hopwood, M. J., D. Carroll, T. J. Browning, L. Meire, J. Mortensen, S. Krisch, and E. P. Achterberg, 2018: Non-linear response of summertime marine productivity to increased meltwater discharge around Greenland. Nat. Commun., 9, 3256, https://doi.org/10.1038/S41467-018-05488-8.

Hugelius, G., and Coauthors, 2014: Improved estimates show large circumpolar stocks of permafrost carbon while quantifying substantial uncertainty ranges and identifying remaining data gaps. Biogeosciences, 11, 6573-6593, https://doi.org/10.5194/bg-11-6573-2014.
Ims, R. A., J.-A. Henden, M. A. Strømeng, A. V. Thingnes, M. J. Garmo, and J. U. Jepsen, 2019: Arctic greening and bird nest predation risk across tundra ecotones. Nat. Climate Change, 9, 607-610, https://doi.org/10.1038/ s41558-019-0514-9.

Jacob, T., J. Wahr, W. T. Pfeffer, and S. Swenson, 2012: Recent contributions of glaciers and ice caps to sea level rise. Nature, 482, 514-518, https://doi. org/10.1038/nature10847.

Jobbágy, E. G., and R. B. Jackson, 2000: The vertical distribution of soil organic carbon and its relation to climate and vegetation. Ecol. Appl., 10, 423-436, https://doi.org/10.1890/1051-0761(2000)010[0423:TVDOSO]2.0.CO;2.

Kalnay, E., and Coauthors, 1996: The NCEP/NCAR 40-Year Reanalysis Project. Bull. Amer. Meteor. Soc., 77, 437-471, https://doi.org/https://doi. org/10.1175/1520-0477(1996)077<0437:TNYRP>2.0.C0;2.

Kim, B.-M., and Coauthors, 2017: Major cause of unprecedented Arctic warming in January 2016: Critical role of an Atlantic windstorm. Sci. Rep., 7, 40051, https://doi.org/10.1038/srep40051.

Kjøllmoen, B., L. M. Andreassen, H. Elvehøy, and M. Jackson, 2019: Glaciological investigations in Norway 2018. NVE Rep. 46.2019, 84 pp., http:// publikasjoner.nve.no/rapport/2019/rapport2019_46.pdf.

Le Quéré, C., and Coauthors, 2018: Global Carbon Budget 2018. Earth Syst. Sci. Data, 10 (4), 2141-2194, https://doi.org/10.5194/essd-10-2141-2018.

Langenbrunner, B., 2020: Ocean-driven Arctic warming. Nat. Climate Change, 10, 184, https://doi.org/10.1038/s41558-020-0730-3.

Lee, S. H., and A. H. Butler, 2020: The 2018-2019 Arctic stratospheric polar vortex. Weather, 75, 52-57, https://doi.org/10.1002/wea.3643.

Luo, H., R. M. Castelao, A. K. Rennermalm, M. Tedesco, A. Bracco, P. L. Yager, and T. L. Mote, 2016: Oceanic transport of surface meltwater from the southern Greenland ice sheet. Nat. Geosci., 9, 528-532, https://doi. org/10.1038/ngeo2708.

Mahlstein, I., and R. Knutti, 2012: September Arctic sea ice predicted to disappear near $2^{\circ} \mathrm{C}$ global warming above present. J. Geophys. Res., 117, D06104, https://doi.org/10.1029/2011JD016709.

Manney, G. L., and Coauthors, 2011: Unprecedented Arctic ozone loss in 2011. Nature, 478, 469-475, https://doi.org/10.1038/nature10556.

Manney, G. L., Z. D. Lawrence, M. L. Santee, N. J. Livesey, A. Lambert, and M. C. Pitts, 2015: Polar processing in a split vortex: Arctic ozone loss in early winter 2012/2013. Atmos. Chem. Phys., 15, 5381-5403, https://doi. org/10.5194/acp-15-5381-2015.

Marsh, J. M., and F. J. Mueter, 2020: Influences of temperature, predators, and competitors on polar cod (Boreogadus saida) at the southern margin of their distribution. Polar Biol., https://doi.org/10.1007/s00300-019-02575-4, in press.

Maslanik, J., and J. Stroeve, 1999: Near-real-time DMSP SSMIS daily polar gridded sea ice concentrations, version 1. NASA NSIDC DAAC, accessed 1 February 2020, https://doi.org/10.5067/U8C09DWVX9LM.

- _ - C. Fowler, and W. Emery, 2011: Distribution and trends in Arctic sea ice age through spring 2011. Geophys. Res. Lett., 38, L13502, https:// doi.org/10.1029/2011GL047735.

Meier, W. N., and J. S. Stewart, 2019: Assessing uncertainties in sea ice extent climate indicators. Environ. Res. Lett., 14, 035005, https://doi. org/10.1088/1748-9326/aaf52c.

_ _ - and F. Fetterer, 2007: Whither Arctic sea ice? A clear signal of decline regionally, seasonally and extending beyond the satellite record. Ann. Glaciol., 46, 428-434, https://doi.org/10.3189/172756407782871170.

observed changes and impacts on biology and human activity. Rev. Geophys., 52, 185-217, https://doi.org/10.1002/2013RG000431.

- F. Fetterer, M. Savoie, S. Mallory, R. Duerr, and J. Stroeve, 2017: NOAA/ NSIDC climate data record of passive microwave sea ice concentration, version 3. NSIDC, accessed 1 November 2019, https://doi.org/10.7265/N59P2ZTG. 
Millan, R., J. Mouginot, and E. Rignot, 2017: Mass budget of the glaciers and ice caps of the Queen Elizabeth Islands, Canada, from 1991 to 2015. Environ. Res. Lett., 12, 024016, https://doi.org/10.1088/1748-9326/aa5b04.

Morlighem, M., and Coauthors, 2017: BedMachine v3: Complete bed topography and ocean bathymetry mapping of Greenland from multibeam echo sounding combined with mass conservation. Geophys. Res. Lett., 44, 11 051-11 061, https://doi.org/10.1002/2017GL074954.

Mörsdorf, M. A., N. S. Baggesen, N. G. Yoccoz, A. Michelsen, B. Elberling, P. L. Ambus, and E. J. Cooper, 2019: Deepened winter snow significantly influences the availability and forms of nitrogen taken up by plants in High Arctic tundra. Soil Biol. Biochem., 135, 222-234, https://doi.org/10.1016/j. soilbio.2019.05.009.

Mote, T., 2007: Greenland surface melt trends 1973-2007: Evidence of a large increase in 2007. Geophys. Res. Lett., 34, L22507, https://doi. org/10.1029/2007GL031976.

Mouginot, J., and Coauthors, 2019: Forty-six years of Greenland Ice Sheet mass balance from 1972 to 2018. Proc. Natl. Acad. Sci. USA, 116, 9239-9244, https://doi.org/10.1073/pnas.1904242116.

Mudryk, L., M. Santolaria-Otín, G. Krinner, M. Ménégoz, C. Derksen, C. BrutelVuilmet, M. Brady, and R. Essery, 2020: Historical Northern Hemisphere snow cover trends and projected changes in the CMIP- 6 multi-model ensemble. Cryosphere Discuss., https://doi.org/10.5194/tc-2019-320.

Müller, R., J.-U. Grooß, C. Lemmen, D. Heinze, M. Dameris, and G. Bodeker, 2008: Simple measures of ozone depletion in the polar stratosphere. Atmos. Chem. Phys., 8, 251-264, https://doi.org/10.5194/acp-8-251-2008.

Myers-Smith, I. H., and Coauthors, 2020: Complexity revealed in the greening of the Arctic. Nat. Climate Change, 10, 106-117, https://doi.org/10.1038/ s41558-019-0688-1.

Natali, S., and Coauthors, 2019: Large loss of CO2 in winter observed across the northern permafrost region. Nat. Climate Change, 9, 852-857, https://doi. org/10.1038/s41558-019-0592-8.

National Academies of Sciences, Engineering, and Medicine, 2019: Understanding Northern Latitude Vegetation Greening and Browning: Proceedings of a Workshop. National Academies Press, 62 pp., https://doi. org/10.17226/25423.

Notz, D., and J. Stroeve, 2016: Observed Arctic sea-ice loss directly follows anthropogenic CO2 emission. Science, 354, 747-750, https://doi.org/10.1126/ science.aag2345.

NPFMC, 2018: Fishery management plan for groundfish of the Bering Sea and Aleutian Islands Management Area. North Pacific Fishery Management Council, 152 pp., www.npfmc.org/wp-content/PDFdocuments/fmp/BSAl/ BSAlfmp.pdf.

O'Neel, S., and Coauthors, 2019: Reanalysis of the US Geological Survey Benchmark Glaciers: Long-term insight into climate forcing of glacier mass balance. J. Glaciol., 65, 850-866, https://doi.org/10.1017/jog.2019.66.

Overeem, I., B. D. Hudson, J. P. M. Syvitski, A. B. Mikkelsen, B. Hasholt, M. R. Van Den Broeke, B. P. Y. Noël, and M. Morlighem, 2017: Substantial export of suspended sediment to the global oceans from glacial erosion in Greenland. Nat. Geosci., 10, 859-863, https://doi.org/10.1038/ngeo3046.

Overland, J. E., 2009: The case for global warming in the Arctic. Influence of Climate Change on the Changing Arctic and Sub-Arctic Conditions, J. C. J. Nihoul and A. G. Kostianoy, Eds., Springer, 13-23.

- , E. Hanna, I. Hanssen-Bauer, S.-J. Kim, J. E. Walsh, M. Wang, and U. S. Bhatt, 2019: Surface air temperature [in "State of the Climate in 2018"]. Bull. Amer. Meteor. Soc., 100 (9), S142-S143., https://doi.org/10.1175/2019 BAMSStateoftheClimate.1.

Peng, G., W. N. Meier, D. J. Scott, and M. H. Savoie, 2013: A long-term and reproducible passive microwave sea ice concentration data record for climate studies and monitoring. Earth Syst. Sci. Data, 5, 311-318, https://doi. org/10.5194/essd-5-311-2013.

Piao, S., and Coauthors, 2019: Characteristics, drivers and feedbacks of global greening. Nat. Rev. Earth Environ., 1, 14-27, https://doi.org/10.1038/s43017019-0001-x.
Pinsky, M. L., B. Worm, M. J. Fogarty, J. L. Sarmiento, and S. A. Levin, 2013: Marine taxa track local climate velocities. Science, 341, 1239-1242, https:// doi.org/10.1126/science.1239352.

Pinzon, J., and C. Tucker, 2014: A non-stationary 1981-2012 AVHRR NDVI3g time series. Remote Sens., 6, 6929-6960, https://doi.org/10.3390/ rs6086929.

Pithan, F., and T. Mauritsen, 2014: Arctic amplification dominated by temperature feedbacks in contemporary climate models. Nat. Geosci., 7, 181-184, https://doi.org/10.1038/ngeo2071.

Post, E., and Coauthors, 2019: The polar regions in a $2^{\circ} \mathrm{C}$ warmer world. Sci. Adv., 5, eaaw9883, https://doi.org/10.1126/sciadv.aaw9883.

Raynolds, M. K., D. A. Walker, H. E. Epstein, J. E. Pinzon, and C. J. Tucker, 2012: A new estimate of tundra-biome phytomass from trans-Arctic field data and AVHRR NDVI. Remote Sens. Lett., 3, 403-411, https://doi.org/10.1080/014 31161.2011.609188.

Reichle, R., C. Draper, Q. Liu, M. Girotto, S. Mahanama, R. Koster, and G. De Lannoy, 2017: Assessment of MERRA-2 land surface hydrology estimates. J. Climate, 30, 2937-2960, https://doi.org/10.1175/JCLI-D-16-0720.1.

Reynolds, R. W., N. A. Rayner, T. M. Smith, D. C. Stokes, and W. Wang, 2002: An improved in situ and satellite SST analysis for climate. J. Climate, 15, 1609-1625, https://doi.org/10.1175/1520-0442(2002)015<1609:AllSAS>2. $0 . \mathrm{CO} ; 2$.

_ T. M. Smith, C. Liu, D. B. Chelton, K. S. Casey, and M. G. Schlax, 2007: Daily high-resolution-blended analyses for sea surface temperature. J. Climate, 20, 5473-5496, https://doi.org/10.1175/2007JCLI1824.1.

Richter-Menge, J., M. L. Druckenmiller, and M. Jeffries, Eds., 2019: Arctic Report Card 2019. NOAA, www.arctic.noaa.gov/Report-Card.

Romanovsky, V. E., and Coauthors, 2017: Changing permafrost and its impacts. Snow, Water, Ice and Permafrost in the Arctic (SWIPA) 2017, Arctic, Monitoring and Assessment Programme, 65-102, www.amap.no/documents/ doc/snow-water-ice-and-permafrost-in-the-arctic-swipa-2017/1610.

Salmon, V. G., A. L. Breen, J. Kumar, M. J. Lara, P. E. Thornton, S. D. WulIschleger, and C. M. Iversen, 2019: Alder distribution and expansion across a tundra hillslope: Implications for local N cycling. Front. Plant Sci., 10, 1099, https://doi.org/10.3389/fpls.2019.01099.

Schmidt, N. M., J. Reneerkens, J. H. Christensen, M. Olesen, and T. Roslin, 2019: An ecosystem-wide reproductive failure with more snow in the Arctic. PLOS Biol., 17, e3000392, https://doi.org/10.1371/journal.pbio.3000392.

Schuur, E. A. G., 2019: Permafrost and the global carbon cycle. Arctic Report Card 2019, J. Richter-Menge, M. L. Druckenmiller, and M. Jeffries, Eds., NOAA, www.arctic.noaa.gov/Report-Card.

change: Implications for the global carbon cycle. BioScience, 58, 701-714, https://doi.org/10.1641/B580807.

_ back. Nature, 520, 171-179, https://doi.org/10.1038/nature14338.

_- and Coauthors, 2018: Chapter 11: Arctic and boreal carbon. Second State of the Carbon Cycle Report (SOCCR2): A Sustained Assessment Report, N. Cavallaro et al., Eds., U.S. Global Change Research Program, 428-468.

Sharp, M., and Coauthors, 2018: Glaciers and ice caps outside Greenland [in "State of the Climate in 2017"]. Bull. Amer. Meteor. Soc., 99 (8), S156-S161, https://doi.org/10.1175/2018BAMSStateoftheClimate.1.

Shiklomanov, N. I., D. A. Streletskiy, and F. E. Nelson, 2012: Northern Hemisphere component of the global Circumpolar Active Layer Monitoring (CALM) program. Proc. 10th Int. Conf. on Permafrost, Vol. 1, Salekhard, Russia, Tyumen Oil and Gas University, 377-382.

Smith, S. L., J. Chartrand, and C. Duchesne, 2018: Report on 2017 field activities and collection of ground-thermal and active-layer data in the Mackenzie corridor, Northwest Territories. Geological Survey of Canada Open File 8492, 109 pp., https://doi.org/10.4095/313036. 
- C. Duchesne, and A. G. Lewkowicz, 2019: Tracking changes in permafrost thermal state in Northern Canada. Cold Regions Engineering 2019, J.-P. Bilodeau et al. Eds., American Society of Civil Engineers, 670-677, https://doi. org/10.1061/9780784482599.

Stabeno, P. J., and S. W. Bell, 2019: Extreme conditions in the Bering Sea (20172018): Record breaking low sea-ice extent. Geophys. Res. Lett., 46, 89528959, https://doi.org/10.1029/2019GL083816.

and southern shelves of the eastern Bering Sea and some implications for the ecosystem. Deep-Sea Res. II, 65, 14-30, https://doi.org/10.1016/j. dsr2.2012.02.019.

_ R. L. Thoman, and K. Wood, 2019: Recent warming in the Bering Sea and its impact on the ecosystem. Arctic Report Card 2019, J. Richter-Menge, M. L. Druckenmiller, and M. Jeffries, Eds., NOAA, www.arctic.noaa.gov/ Report-Card.

Stevenson, D. E., and R. R. Lauth, 2019: Bottom trawl surveys in the northern Bering Sea indicate recent shifts in the distribution of marine species. Polar Biol., 42, 407-421, https://doi.org/10.1007/s00300-018-2431-1.

Strauss, J., L. Schirrmeister, G. Grosse, S. Wetterich, M. Ulrich, U. Herzschuh, and H.-W. Hubberten, 2013: The deep permafrost carbon pool of the Yedoma region in Siberia and Alaska. Geophys. Res. Lett., 40, 6165-6170, https://doi.org/10.1002/2013GL058088.

_ tional characteristics and carbon vulnerability. Earth-Sci. Rev., 172, 75-86, https://doi.org/10.1016/j.earscirev.2017.07.007.

Stroh, J. N., G. Panteleev, S. Kirillov, M. Makhotin, and N. Shakhova, 2015: Sea-surface temperature and salinity product comparison against external in situ data in the Arctic Ocean. J. Geophys. Res. Oceans, 120, 7223-7236, https://doi.org/10.1002/2015JC011005.

Stuecker, M. F., and Coauthors, 2018: Polar amplification dominated by local forcing and feedbacks. Nat. Climate Change, 8, 1076-1081, https://doi. org/10.1038/s41558-018-0339-y.

Takala, M., K. Luojus, J. Pulliainen, C. Derksen, J. Lemmetyinen, J.-P. Kärnä, and J. Koskinen, 2011: Estimating northern hemisphere snow water equivalent for climate research through assimilation of space-borne radiometer data and ground-based measurements. Remote Sens. Environ., 115, 3517-3529, https://doi.org/10.1016/j.rse.2011.08.014.

Tanskanen, A., 2004: Lambertian surface albedo climatology at $360 \mathrm{~nm}$ from TOMS data using moving time-window technique. Proceedings of the XX Quadrennial Ozone Symposium, C. S. Zerefos, Ed., Vol. II, International Ozone Commission, 1159-1160.

Tape, K. D., B. M. Jones, C. D. Arp, I. Nitze, and G. Grosse, 2018: Tundra be dammed: Beaver colonization of the Arctic. Global Change Biol., 24, 44784488, https://doi.org/10.1111/gcb.14332.

Taylor, A. R., R. B. Lanctot, and R. T. Holmes, 2018: An evaluation of 60 years of shorebird response to environmental change at Utqiagivik (Barrow). Alaska. Trends and Traditions: Avifaunal Change in Western North America, W. D. Shuford, R. E. Gill, and C. M. Handel, Eds., Western Field Ornithologists, 312-330.

Tedesco, M., and X. Fettweis, 2020: Unprecedented atmospheric conditions (1948-2019) drive the 2019 exceptional melting season over the Greenland ice sheet. Cryosphere, 14, 1209-1223, https://doi.org/10.5194/tc-14-12092020.

_ _ - T. Mote, J. Wahr, P. Alexander, J. Box, and B. Wouters, 2013: Evidence and analysis of 2012 Greenland records from spaceborne observations, a regional climate model and reanalysis data. Cryosphere, 7, 615630, https://doi.org/10.5194/tc-7-615-2013.

Thoman, R. L., and Coauthors, 2020: The record low Bering Sea ice extent in 2018: Context, impacts, and an assessment of the role of anthropogenic climate change [in "Explaining Extreme Events of 2018 from a Climate Perspective"]. Bull. Amer. Meteor. Soc., 101 (1), S53-S58, https://doi.org/10.1175/BAMSD-19-0175.1.
Thorson, J. T., 2019: Guidance for decisions using the Vector Autoregressive Spatio-Temporal (VAST) package in stock, ecosystem, habitat and climate assessments. Fish. Res., 210, 143-161, https://doi.org/10.1016/j. fishres.2018.10.013.

— rapid community and population shifts in Bering and Barents Seas. Arctic Report Card 2019, J. Richter-Menge, M. L. Druckenmiller, and M. Jeffries, Eds., NOAA, www.arctic.noaa.gov/Report-Card.

Timmermans, M.-L., and A. Proshutinsky, 2015: The Arctic: Sea surface temperature [in "State of the Climate in 2014"]. Bull. Amer. Meteor. Soc., 96 (7), S147-S148, https://doi.org/10.1175/2015BAMSStateoftheClimate.1.

Treharne, R., J. W. Bjerke, H. Tømmervik, L. Stendardi, and G. K. Phoenix, 2019: Arctic browning: Impacts of extreme climatic events on heathland ecosystem CO2 fluxes. Global Change Biol., 25, 489-503, https://doi.org/10.1111/ gcb.14500.

Tschudi, M. A., J. C. Stroeve, and J. S. Stewart, 2016: Relating the age of Arctic sea ice to its thickness, as measured during NASA's ICESat and IceBridge Campaigns. Remote Sens., 8, 457, https://doi.org/10.3390/rs8060457.

_ W. W. Meier, J. S. Stewart, C. Fowler, and J. Maslanik, 2019a: EASE-Grid sea ice age, version 4. NASA NSIDC DAAC, accessed 1 November 2019, https:// doi.org/10.5067/UTAV7490FEPB.

—_ _ - and _ _ 2019b: Quicklook Arctic weekly EASE-Grid sea ice age, version 1. NASA NSIDC DAAC, accessed 1 November 2019, https://doi. org/10.5067/2XXGZY3DUGNQ.

U.S. National Ice Center, 2008: IMS daily Northern Hemisphere snow and ice analysis at $1 \mathrm{~km}, 4 \mathrm{~km}$, and $24 \mathrm{~km}$ resolutions, version 1 [24km] (updated daily). NSIDC, accessed 1 November 2019, https://doi.org/10.7265/N52R3PMC.

van As, D., R. S. Fausto, J. Cappelen, R. S. W. van de Wal, R. J. Braithwaite, and H. Machguth, 2016: Placing Greenland ice sheet ablation measurements in a multi-decadal context. Geol. Surv. Den. Greenl. Bull., 35, 71-74, https:// doi.org/10.34194/geusb.v35.4942.

van Pelt, W., and Coauthors, 2019: A long-term dataset of climatic mass balance, snow conditions, and runoff in Svalbard (1957-2018). Cryosphere, 13, 2259-2280, https://doi.org/10.5194/tc-13-2259-2019.

Veldhuis, D., P. Tejsner, F. Riede, T. T. Høye, and R. Willerslev, 2018: Arctic disequilibrium: Shifting human-environmental systems. Cross-Cultural Res., 53, 243-251, https://doi.org/10.1177/1069397118815132.

Wahr, J., M. Molenaar, and F. Bryan, 1998: Time variability of the Earth's gravity field: Hydrological and oceanic effects and their possible detection using GRACE. J. Geophys. Res., 103, 30205-30229, https://doi.org/10.1029/98JB02844.

Walsh, J. E., W. L. Chapman, F. Fetterer, and J. S. Stewart, 2019: Gridded monthly sea ice extent and concentration, 1850 onward, version 2. NSIDC, accessed 1 November 2019, https://doi.org/10.7265/jj4s-tq79.

Walker, D. A., and Coauthors, 2005: The circumpolar Arctic vegetation map. J. Veg. Sci., 16, 267-282, https://doi.org/10.1111/j.1654-1103.2005.tb02365.x.

Weatherhead, B., A. Tanskanen, and A. Stevermer, 2005: Ozone and ultraviolet radiation. Arctic Climate Impact Assessment, Cambridge University Press, 152-182. www.amap.no/documents/download/1086/inline.

WGMS, 2017: Global Glacier Change Bulletin. M. Zemp et al., Eds., Bulletin 2 (2014-2015),ICSU(WDS)/IUGG(IACS)/UNEP/UNESCO/WMO, 244 pp., https:// doi.org/10.5904/wgms-fog-2017-1.

WHO, 2002: Global solar UV index: A practical guide. WHO/SDE/OEH/02.2, WHO/WMO,UNEP/ICNIRP, 28 pp., www.who.int/uv/publications/en/GlobalUVI.pdf.

Wilcox, E. J., D. Keim, T. de Jong, B. Walker, O. Sonnentag, A. E. Sniderhan, P. Mann, and P. Marsh, 2019: Tundra shrub expansion may amplify permafrost thaw by advancing snowmelt timing. Arct. Sci., 5, 202-217, https://doi.org/10.1139/ as-2018-0028.

WMO, 2018: Scientific assessment of ozone depletion: 2018. Global Ozone Research and Monitoring Project Rep. 58, World Meteorological Organization, 588 pp., www.esrl.noaa.gov/csl/assessments/ozone/2018/ downloads/20180zoneAssessment.pdf. 
Wouters, B., A. S. Gardner, and G. Moholdt, 2019: Global glacier mass loss during the GRACE satellite mission (2002-2016). Front. Earth Sci., 7, 96, https://doi.org/10.3389/feart.2019.00096.

Wyllie-Echeverria, T., and W. S. Wooster, 1998: Year-to-year variations in Bering Sea ice cover and some consequences for fish distributions. Fish. Oceanogr., 7, 159-170, https://doi.org/10.1046/j.1365-2419.1998.00058.x.
Zemp, M., and Coauthors, 2019: Global glacier mass changes and their contributions to sea-level rise from 1961 to 2016. Nature, 568, 382-386, https:// doi.org/10.1038/s41586-019-1071-0. 


\section{STATE OF THE CLIMATE IN 2019 ANTARCTICA AND THE SOUTHERN OCEAN}

T. Scambos and S. Stammerjohn, Eds.

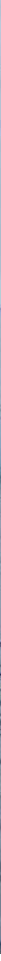

Special Online Supplement to the Bulletin of the American Meteorological Society, Vol.101, No. 8, August, 2020

https://doi.org/doi:10.1175/BAMS-D-20-0090.1

Corresponding author: Ted Scambos / tascambos@colorado.edu

For information regarding reuse of this content and general copyright information, consult the AMS Copyright Policy. 


\title{
STATE OF THE CLIMATE IN 2019 Antarctica and the Southern Ocean
}

\author{
Editors \\ Jessica Blunden \\ Derek S. Arndt \\ Chapter Editors \\ Peter Bissolli \\ Howard J. Diamond \\ Matthew L. Druckenmiller \\ Robert J. H. Dunn \\ Catherine Ganter \\ Nadine Gobron \\ Rick Lumpkin \\ Jacqueline A. Richter-Menge \\ Tim Li \\ Ademe Mekonnen \\ Ahira Sánchez-Lugo \\ Ted A. Scambos \\ Carl J. Schreck III \\ Sharon Stammerjohn \\ Diane M. Stanitski \\ Kate M. Willett \\ Technical Editor \\ Andrea Andersen
}

BAMS Special Editor for Climate

Richard Rosen

American Meteorological Society 
Cover credit:

Adélie penguin on a floating piece of glacier ice near Jenny Island (a few kilometers from the British Antarctic Survey base at Rothera) west of the Antarctic Peninsula. The photo was taken by Ted Scambos on 31 January 2020.

Antarctica and the Southern Ocean is one chapter from the State of the Climate in 2019 annual report and is available from https://doi.org/10.1175/BAMS-D-20-0090.1. Compiled by NOAA's National Centers for Environmental Information, State of the Climate in 2019 is based on contributions from scientists from around the world. It provides a detailed update on global climate indicators, notable weather events, and other data collected by environmental monitoring stations and instruments located on land, water, ice, and in space. The full report is available from https://doi.org/10.1175/2020BAMSStateoftheClimate.1.

\section{How to cite this document:}

Citing the complete report:

Blunden, J. and D. S. Arndt, Eds., 2020: State of the Climate in 2019. Bull. Amer. Meteor. Soc., 101 (8), Si-S429, https://doi.org/10.1175/2020BAMSStateoftheClimate.1.

\section{Citing this chapter:}

Scambos, T. and S. Stammerjohn, Eds., 2020: Antarctica and the Southern Ocean [in "State of the Climate in 2019"]. Bull. Amer. Meteor. Soc., 101 (8), S287-S320, https://doi.org/10.1175/BAMS-D-20-0090.1.

\section{Citing a section (example):}

Reid, P., S. Stammerjohn, R. A. Massom, S. Barreira, T. Scambos, and J. L. Lieser, 2020: Sea ice extent, concentration, and seasonality [in "State of the Climate in 2019"]. Bull. Amer. Meteor. Soc., 101 (8), S304-S306, https://doi.org/10.1175/BAMS-D-20-0090.1. 
Abrahamsen, E. Povl, Polar Oceans Group, British Antarctic Survey, Cambridge, United Kingdom

Barreira, Sandra, Argentine Naval Hydrographic Service, Buenos Aires, Argentina

Bitz, Cecilia M., Atmospheric Sciences Department, University of Washington, Seattle, Washington

Butler, Amy, NOAA/ESRL Chemical Sciences Division, Boulder, Colorado

Clem, Kyle R., School of Geography, Environment and Earth Sciences, Victoria University of Wellington, Wellington, New Zealand

Colwell, Steve, British Antarctic Survey, Cambridge, United Kingdom

Coy, Lawrence, Science Systems and Applications, Inc., NASA Goddard Space Flight Center, Greenbelt, Maryland

de Laat, Jos, Royal Netherlands Meteorological Institute (KNMI), DeBilt, Netherlands

du Plessis, Marcel D., Department of Marine Science, University of Gothenburg, Gothenburg, Sweden and Southern Ocean Carbon and Climate Observatory, CSIR, South Africa

Fogt, Ryan L., Department of Geography, Ohio University, Athens, Ohio

Fricker, Helen Amanda, Scripps Institution of Oceanography, University of California-San Diego, San Diego, California

Fyfe, John, Canadian Centre for Climate Modelling and Analysis, University of Victoria, Victoria, British Columbia, Canada

Gardner, Alex S., Jet Propulsion Laboratory, California Insitute of Technology, Pasadena, California

Gille, Sarah T., Scripps Institution of Oceanography, University of California at San Diego, La Jolla, California

Gorte, Tessa, Department of Atmospheric and Oceanic Sciences, University of Colorado-Boulder, Boulder, Colorado

Gregor, L., ETH, Zürich, Switzerland

Hobbs, Will, Australian Antarctic Program Partnership and ARC Centre of Excellence for Climate Extremes (CLEX), University of Tasmania, Hobart, Tasmania, Australia

Johnson, Bryan, NOAA/OAR Earth System Research Laboratory, Global Monitoring Division, and University of Colorado, Boulder, Colorado

Keenan, Eric, Department of Atmospheric and Oceanic Sciences, University of Colorado-Boulder, Boulder, Colorado

Keller, Linda M., Department of Atmospheric and Oceanic Sciences, University of Wisconsin-Madison, Madison, Wisconsin

Kramarova, Natalya A., NASA Goddard Space Flight Center, Greenbelt, Maryland

Lazzara, Matthew A., Department of Physical Sciences, School of Arts and Sciences, Madison Area Technical College, and Space Science and Engineering Center, University of Wisconsin-Madison, Madison, Wisconsin

Lenaerts, Jan T. M., Department of Atmospheric and Oceanic Sciences, University of Colorado-Boulder, Boulder, Colorado
Lieser, Jan L., Bureau of Meteorology, Hobart, Tasmania, Australia, and Institute for Marine and Antarctic Studies, University of Tasmania, Hobart, Tasmania, Australia

Liu, Hongxing, Department of Geography, University of Cincinnati, Cincinnati, Ohio

Long, Craig S., NOAA/NWS National Centers for Environmental Prediction, College Park, Maryland

Maclennan, Michelle, Department of Atmospheric and Oceanic Sciences, University of Colorado-Boulder, Boulder, Colorado

Massom, Robert A., Australian Antarctic Division and Australian Antarctic Program Partnership (AAPP), Hobart, Tasmania, Australia

Massonnet, François, Centre de Recherches sur la Terre et le Climat Georges Lemaître (TECLIM), Earth and Life Institute, Université Catholique de Louvain, Louvain-la-Neuve, Belgium

Mazloff, Matthew R., Scripps Institution of Oceanography, University of California-San Diego, San Diego, California

Mikolajczyk, David, Space Science and Engineering Center, University of Wisconsin-Madison, Madison, Wisconsin

Narayanan, A., Indian Institute of Technology, Madras, Chennai, India

Nash, Eric R., Science Systems and Applications, Inc., NASA Goddard Space Flight Center, Greenbelt, Maryland

Newman, Paul A., NASA Goddard Space Flight Center, Greenbelt, Maryland

Petropavlovskikh, Irina, Cooperative Institute for Research in Environmental Sciences, University of Colorado Boulder, and NOAA/OAR Earth System Research Laboratory, Boulder, Colorado

Pitts, Michael, NASA Langley Research Center, Hampton, Virginia

Queste, Bastien Y., Department of Marine Sciences, University of Gothenburg, Gothenburg, Sweden

Reid, Phillip, Australian Bureau of Meteorology and Australian Antarctic Program Partnership (AAPP), Hobart, Tasmania, Australia

Roquet, F., Department of Marine Sciences, University of Göteborg, Göteborg, Sweden

Santee, Michelle L., NASA Jet Propulsion Laboratory, California Institute of Technology, Pasadena, California

Scambos, Ted A., Earth Science and Observation Center, CIRES, University of Colorado, Boulder Colorado

Stammerjohn, Sharon, Institute of Arctic and Alpine Research, University of Colorado, Boulder, Colorado

Strahan, Susan, Universities Space Research Association, NASA Goddard Space Flight Center, Greenbelt, Maryland

Swart, Sebastiann, Department of Marine Sciences, University of Gothenburg, Gothenburg, Sweden and Department of Oceanography, University of Cape Town, Rondebosch, South Africa

Wang, Lei, Department of Geography and Anthropology, Louisiana State University, Baton Rouge, Louisiana

\section{Editorial and Production Team}

Andersen, Andrea, Technical Editor, Innovative Consulting Management Services, LLC, NOAA/NESDIS National Centers for Environmental Information, Asheville, North Carolina

Griffin, Jessicca, Graphics Support, Cooperative Institute for Satellite Earth System Studies, North Carolina State University, Asheville, North Carolina

Hammer, Gregory, Content Team Lead, Communications and Outreach, NOAA/NESDIS National Centers for Environmental Information, Asheville, North Carolina
Love-Brotak, S. Elizabeth, Lead Graphics Production, NOAA/NESDIS National Centers for Environmental Information, Asheville, North Carolina

Misch, Deborah J., Graphics Support, Innovative Consulting Management Services, LLC, NOAA/NESDIS National Centers for Environmental Information, Asheville, North Carolina

Riddle, Deborah B., Graphics Support, NOAA/NESDIS National Centers for Environmental Information, Asheville, North Carolina

Veasey, Sara W., Visual Communications Team Lead, Communications and Outreach, NOAA/NESDIS National Centers for Environmental Information, Asheville, North Carolina 


\section{Table of Contents}

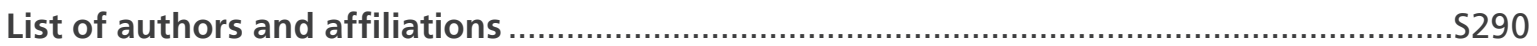

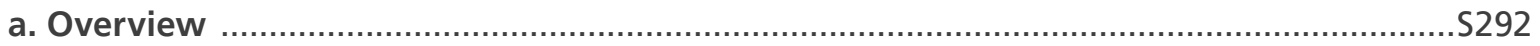

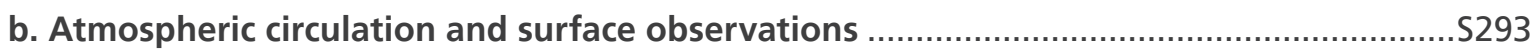

Sidebar 6.1: The 2019 southern stratospheric warming ..............................................S297

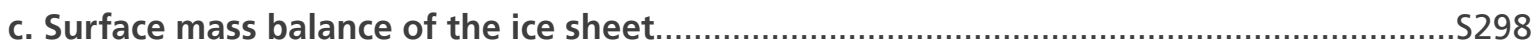

d. Seasonal melt extent and duration for the ice sheet ....................................................... S300

Sidebar 6.2: Recent changes in the Antarctic ice sheet .............................................S302

e. Sea ice extent, concentration, and seasonality ............................................................. S304

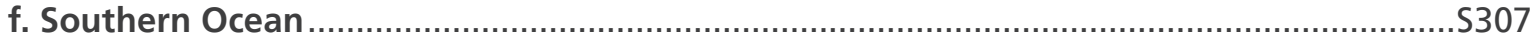

1. Variability in the decline of Antarctic bottom water volume................................S307

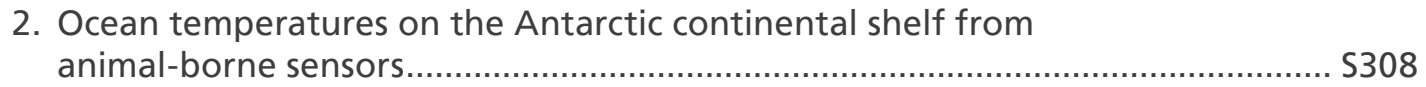

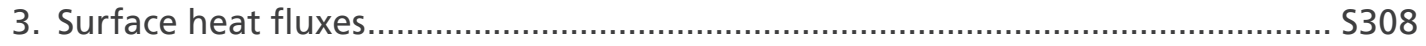

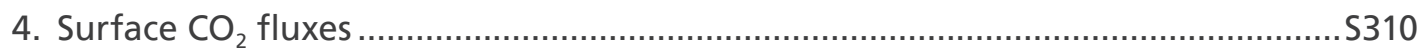

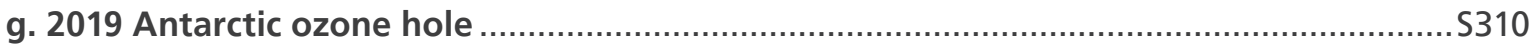

Sidebar 6.3: Sea Ice Prediction Network-South: coordinating seasonal

predictions of sea ice for the Southern Ocean............................................................... 3313

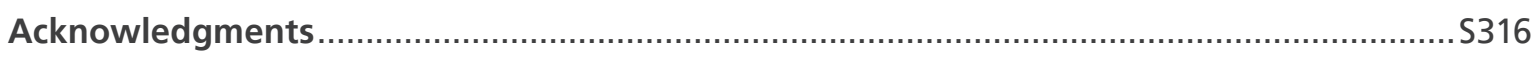

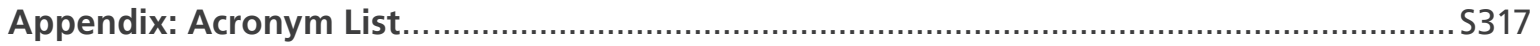

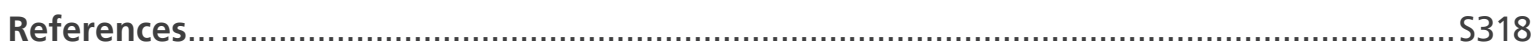

*Please refer to Chapter 8 (Relevant datasets and sources) for a list of all climate variables and datasets used in this chapter for analyses, along with their websites for more information and access to the data. 


\section{ANTARCTICA AND THE SOUTHERN OCEAN}

T. Scambos and S. Stammerjohn, Eds.

\section{a. Overview-T. Scambos and S. Stammerjohn}

Antarctica experienced a dramatic stratospheric warming event in early September 2019 that strongly affected climate patterns in the final four months of the year, and led to the smallest ozone hole since the early 1980s. The event was caused by a series of upward-propagating tropospheric waves in late August, resulting in above-average temperatures in the stratosphere that inhibited polar stratospheric cloud formation and greatly reduced ozone loss. In the troposphere, the Southern Annular Mode (SAM) was strongly negative in the last three months of the calendar year, reflective of anomalously high pressure conditions south of $60^{\circ} \mathrm{S}$ and weak westerly winds. Together, the stratospheric warming in September and related surface conditions starting thereafter contributed to anomalous warm surface spring conditions, setting several hightemperature records. Meanwhile, anomalously low sea ice extent (below the 1981-2010 mean) persisted throughout 2019, continuing a succession of negative Antarctic sea ice extent anomalies since September 2016. The year 2019 was also characterized by warm surface ocean conditions and large positive net ocean heat flux anomalies (into the ocean) south of $35^{\circ} \mathrm{S}$. In contrast, ice sheet surface mass balance was near normal for the year (compared with 1981-2010), though with high monthly variability due to variable precipitation, sublimation, and summer surface melt. However, the ice sheet continued to lose mass in 2019, not due to surface changes but rather ocean-ice sheet interactions, with the highest rates of mass loss occurring in West Antarctica and Wilkes Land, East Antarctica.

The state of Antarctica's climate, weather, ice, ocean, and ozone in 2019 is presented below. Most sections compare the 2019 anomalies with the 1981-2010 climatology wherever there are available data to do so. The ozone section and the sidebar on stratospheric warming compare the 2019 anomaly to the full record (1980-2019) when such data are available to better emphasize how unusual stratospheric conditions were in 2019. We also include a sidebar on ice sheet changes this year that reviews ice sheet and ice shelf trends over the past three decades. In coming years, this sidebar topic will develop into a separate section detailing annual preliminary assessments of Antarctica's ice mass balance. New subsections on ocean heat uptake and ocean $\mathrm{CO}_{2}$ uptake are included in our Southern Ocean section. Place names for data sites or climate events noted in this chapter are provided in Fig. 6.1.

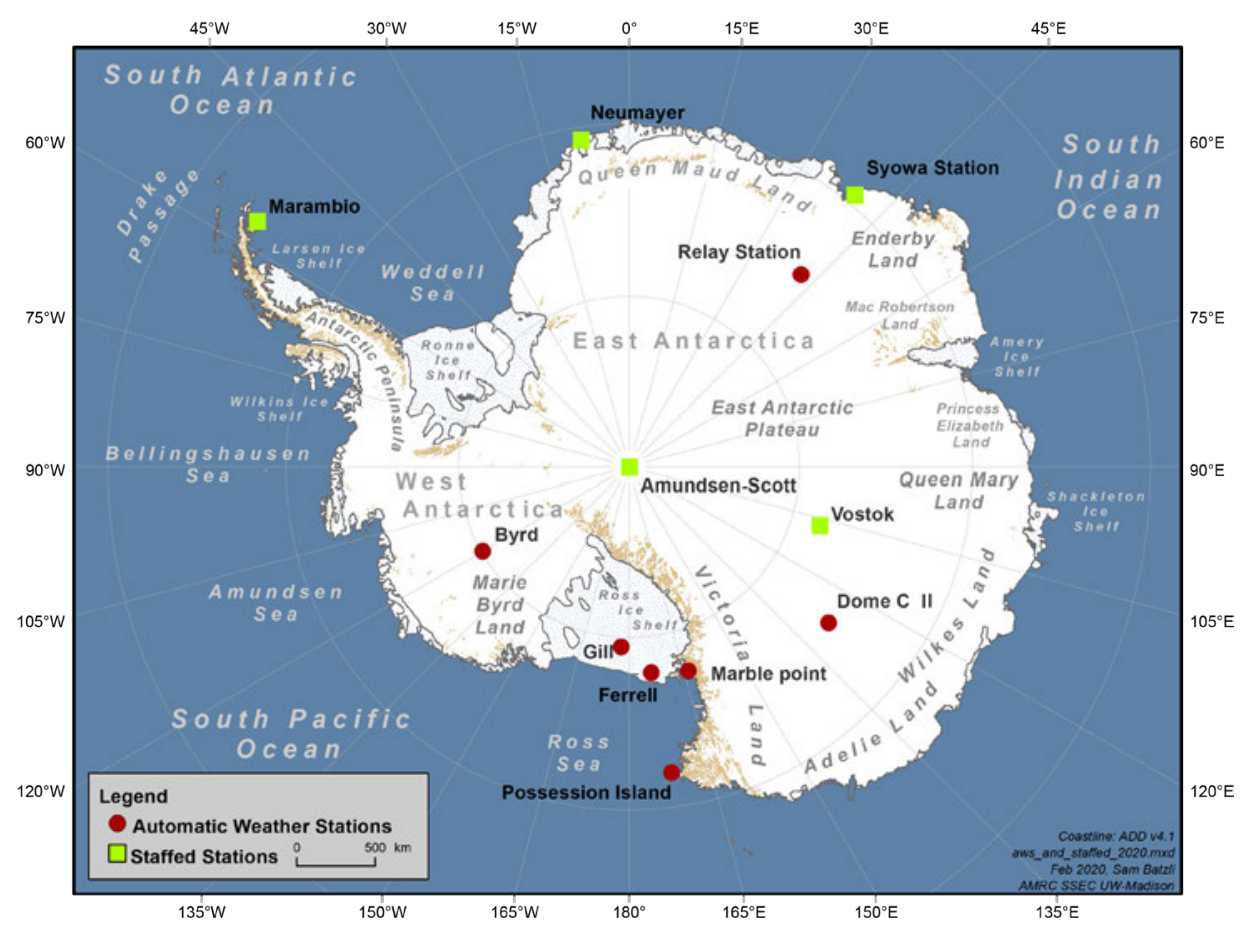

Fig. 6.1. Map of stations and other regions discussed in the chapter. 
b. Atmospheric circulation and surface observations-K. R. Clem, S. Barreira, R. L. Fogt, S. Colwell,

L. M. Keller, M. A. Lazzara, and D. Mikolajczyk

The stratospheric warming anomaly in September was the main circulation feature of 2019 (see Sidebar 6.1), resulting in a record weak stratospheric vortex, an earlier-than-normal seasonal breakdown of the stratospheric vortex (section 6g), and many record-setting positive pressure and temperature anomalies in the troposphere and surface layer during October-December. Prior to the stratospheric warming event, the circulation exhibited typical month-to-month and regional variability. June was characterized by record low temperature and pressure anomalies across the continent. For the Antarctic continent as a whole, 2019 was the second-warmest year on record (since 1979), $+0.55^{\circ} \mathrm{C}(+2.1 \mathrm{std}$. dev.) above the 1981-2010 climatology (based on reanalysis described below and as presented in Fig. 6.2b). This surpasses 2018, which is now the third-warmest year on record. The warmest year in the record is 1980 . We used the European Centre for Medium-Range Weather Forecast (ECMWF) fifth-generation atmospheric reanalysis (ERA5; Copernicus Climate Change Service [C3S] 2017) to evaluate atmospheric circulation for the year. Figure 6.2 shows the monthly geopotential height (Fig. 6.2a) and temperature (Fig. 6.2b) anomalies averaged over the polar cap $\left(60^{\circ}-90^{\circ} \mathrm{S}\right)$, and the monthly circumpolar zonal wind anomalies (Fig. 6.2c) averaged over $50^{\circ}-70^{\circ} \mathrm{S}$. The anomalies are contoured, with standard deviations relative to the 1981-2010 monthly climatology overlain as color shading. To investigate the surface climate anomalies, the year was split into five periods, with the periods characterized by differing yet

(a) 2019 polar-cap $\left(60^{\circ}-90^{\circ} \mathrm{S}\right)$ averaged geopotential height anomalies $(\mathrm{m})$

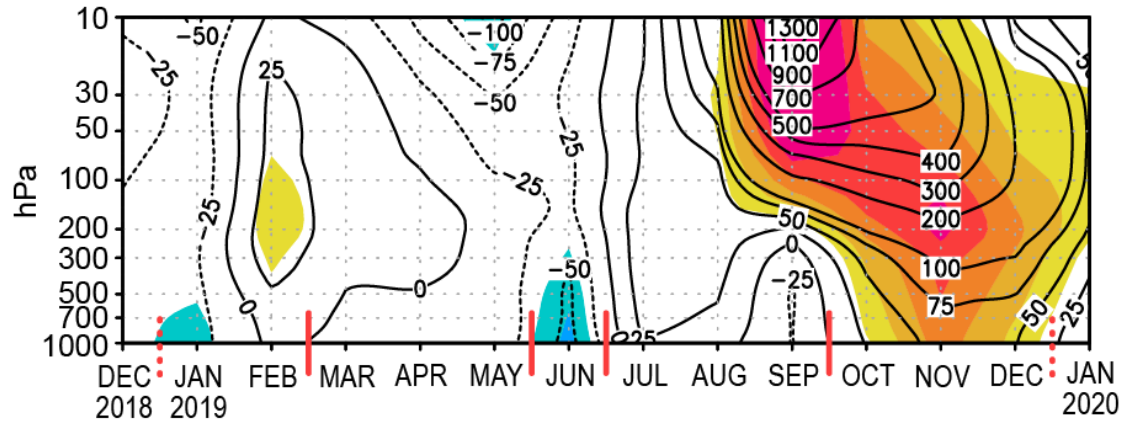

(b) 2019 polar-cap $\left(60^{\circ}-90^{\circ} \mathrm{S}\right)$ averaged temperature anomalies $\left({ }^{\circ} \mathrm{C}\right)$

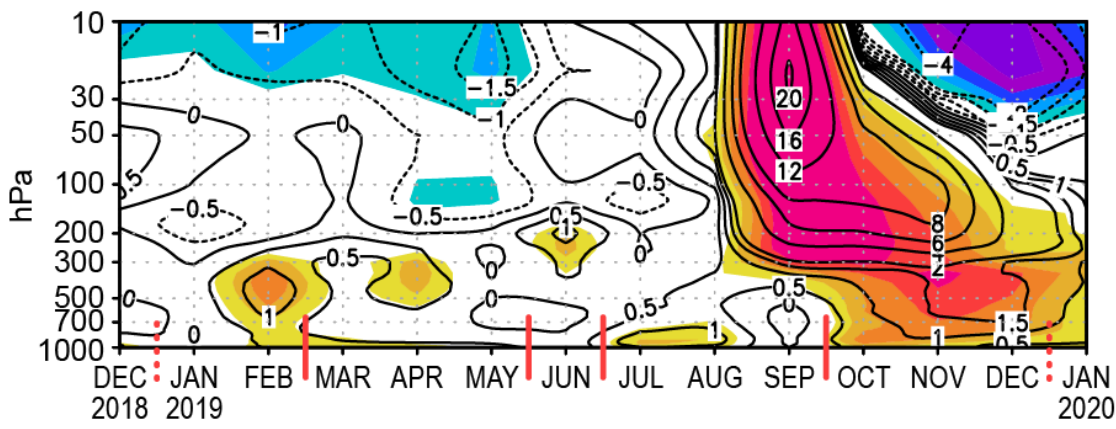

(c) 2019 circumpolar $\left(50^{\circ}-70^{\circ} \mathrm{S}\right)$ averaged zonal wind anomalies $\left(\mathrm{m} \mathrm{s}^{-1}\right)$

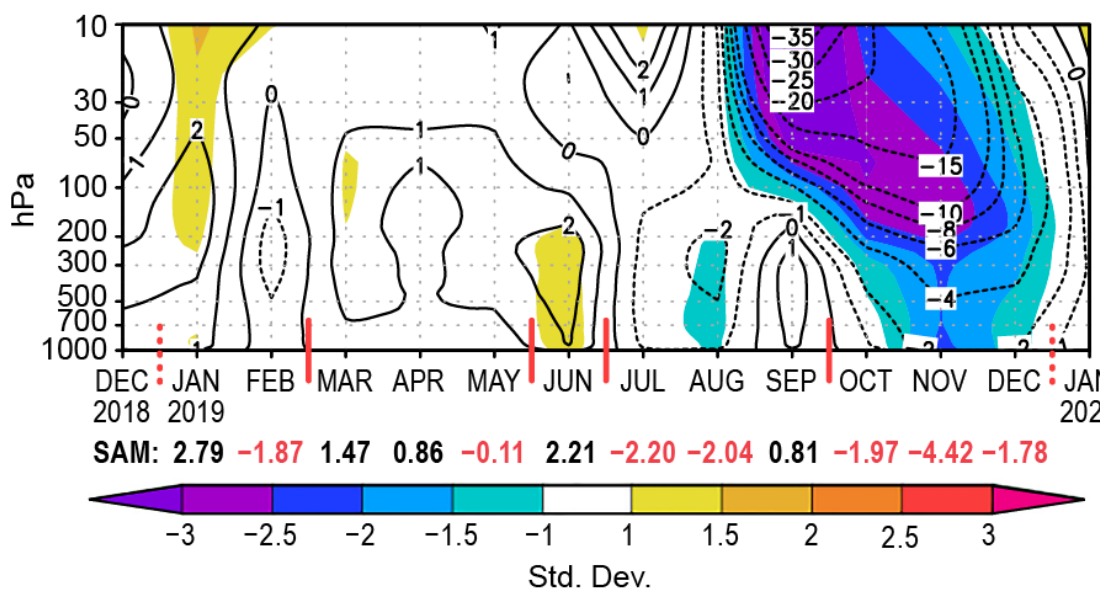

Fig. 6.2. Area-averaged (weighted by cosine of latitude) monthly anomalies over the southern polar region in 2019 relative to 19812010. Vertical axes are pressure in $\mathrm{hPa}$. (a) Polar cap $\left(60^{\circ}-90^{\circ} \mathrm{S}\right)$ averaged geopotential height anomalies (contour interval is $25 \mathrm{~m}$ up to $\pm 100 \mathrm{~m}, 100 \mathrm{~m}$ from \pm 100 to $\pm 500 \mathrm{~m}$, and $200 \mathrm{~m}$ after $\pm 500 \mathrm{~m}$ ). (b) Polar cap averaged temperature anomalies (contour interval is $0.5^{\circ} \mathrm{C}$ up to $\pm 2^{\circ} \mathrm{C}, 2^{\circ} \mathrm{C}$ between $\pm 2^{\circ} \mathrm{C}$ and $\pm 8^{\circ} \mathrm{C}$, and $4^{\circ} \mathrm{C}$ after $\pm 8^{\circ} \mathrm{C}$ ). (c) Circumpolar $\left(50^{\circ}-70^{\circ} \mathrm{S}\right)$ averaged zonal wind anomalies (contour interval is $2 \mathrm{~m} \mathrm{~s}^{-1}$ from $\pm 2 \mathrm{~m} \mathrm{~s}^{-1}$ to $\pm 10 \mathrm{~m} \mathrm{~s}^{-1}$ and $5 \mathrm{~m} \mathrm{~s}^{-1}$ after $10 \mathrm{~m} \mathrm{~s}^{-1}$, with additional contour at $\pm 1 \mathrm{~m} \mathrm{~s}^{-1}$ ). Shading depicts std. dev. of monthly anomalies from the 1981-2010 climatological average as indicated by color bar at bottom. (Source: ERA5 reanalysis.) Red vertical bars indicate the five climate periods used in Fig. 6.3; the dashed lines near Dec 2018 and Dec 2019 indicate circulation anomalies wrapping around the calendar year. Values from the Marshall (2003) SAM index are shown below (c) in black (positive values) and red (negative values). 
relatively persistent circulation and temperature anomaly patterns: (1) January-February, (2) March-May, (3) June, (4) July-September, and (5) October-December. Standardized surface pressure (contours) and temperature (color shaded) anomalies averaged for each period relative to the 1981-2010 climatology are shown in Fig. 6.3. Monthly temperature and pressure anomalies from select Antarctic staffed (Amundsen-Scott, Marambio, Neumayer, and Syowa) and automated (Gill AWS, Relay Station AWS) weather stations are shown in Fig. 6.4.

The year 2019 began with two centers of anomalous low pressure during January and February (Fig. 6.3a), one located in the southwest South Pacific ( -1.5 std. dev.) and one in the South Atlantic (-3 std. dev.). These low-pressure
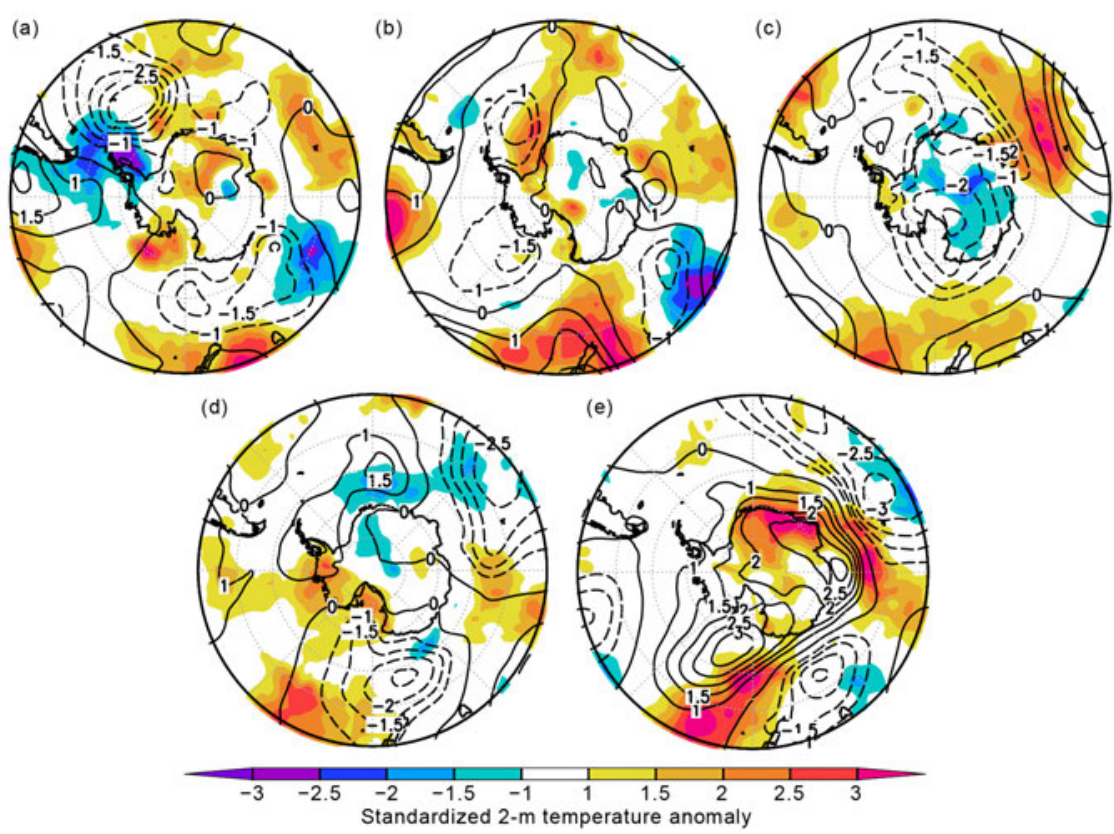

Fig. 6.3. Standardized surface pressure (contours) and 2-m temperature (shaded) anomalies relative to 1981-2010 for (a) Jan-Feb 2019; (b) Mar-May 2019; (c) Jun 2019; (d) Jul-Sep 2019; (e) Oct-Dec 2019. Contour interval is $0.5 \mathrm{std}$. dev. for surface pressure anomalies with the \pm 0.5 contour omitted. Shading represents standard deviation of 2-m temperature anomalies. (Source: ERA5 reanalysis.) anomalies produced above-average temperatures on the Ross Ice Shelf and the East Antarctic Plateau, but below-average temperatures across the Antarctic Peninsula; the polar cap average mid-tropospheric temperature was $+1^{\circ} \mathrm{C}$ ( 2 std. dev.) above normal in February (Fig. 6.2b). On the eastern side of the Plateau, Relay Station AWS (Fig. 6.4e) set a record high monthly mean temperature for February $\left(-31.7^{\circ} \mathrm{C},+6.1^{\circ} \mathrm{C}\right.$ above normal) and a record high monthly mean wind speed for February (8.2 $\mathrm{m} \mathrm{s}^{-1}$, not shown). Monthly mean temperatures on the Antarctic Peninsula (i.e., Marambio Station; Fig. 6.4b) were below normal for January and February, but no records were set.

The austral autumn months (March-May) were relatively quiescent, with pressures and temperatures close to the climatological average across most of the continent (Figs. 6.2, 6.3b). The exception was over the far southern Atlantic Ocean where low-pressure systems were present most of the period, resulting in a deep low-pressure anomaly $(-1.5 \mathrm{std}$. dev.) in the Weddell Sea. This produced above-average temperatures (+2.5 std. dev.) over much of the eastern Weddell Sea, while another low-pressure anomaly ( $-1.5 \mathrm{std}$. dev.) over the eastern Ross Sea advected the anomalous warm air from the Weddell Sea across interior West Antarctica and onto the Ross Ice Shelf. The cyclonic conditions in the Weddell Sea dissipated temporarily during March and were replaced by anomalous high pressure over the southern Atlantic Ocean (not shown). During this time, Neumayer Station reported a record low monthly mean temperature of $-17^{\circ} \mathrm{C}\left(-4.2^{\circ} \mathrm{C}\right.$ below normal) in March (Fig. 6.4c).

During June, the circulation became quite anomalous. Pressures were generally $1.5-2.5 \mathrm{std}$. dev. below normal, temperatures were 1-2 std. dev. below normal across most of the continent (Fig. 6.3c), and the circumpolar zonal winds in the troposphere were more than $2 \mathrm{~m} \mathrm{~s}^{-1}$ (1 std. dev.) above normal (Fig. 6.2c). The station-based Southern Annular Mode (SAM) index (Marshall 2003), which measures the anomalous pressure gradient between the Southern Hemisphere (SH) middle latitudes and Antarctica, was strongly positive in June, reaching +2.21 (10th highest for June on record since 1957). The Ferrell, Marble Point, and Gill AWSs on the Ross Ice Shelf (Fig. 6.4f) as well as Possession Island AWS in the Ross Sea, all reported record low monthly mean pressures in June that were 13-14.5 hPa below normal. On the Plateau, Dome C II AWS (631.4 hPa, $-16.0 \mathrm{hPa}$ below 
(a) Amundsen-Scott

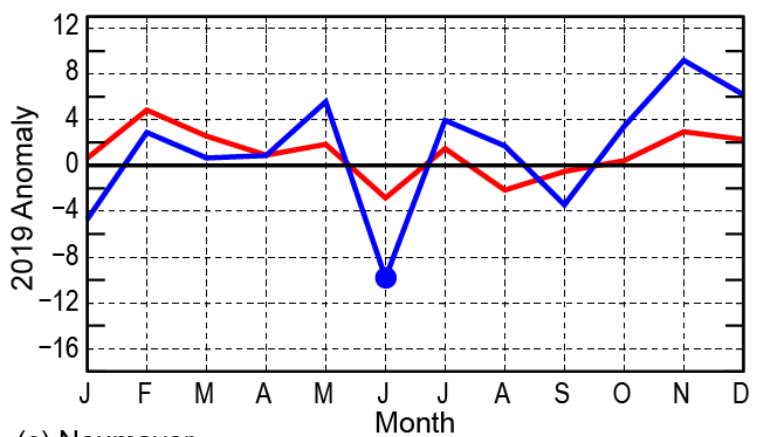

(c) Neumayer

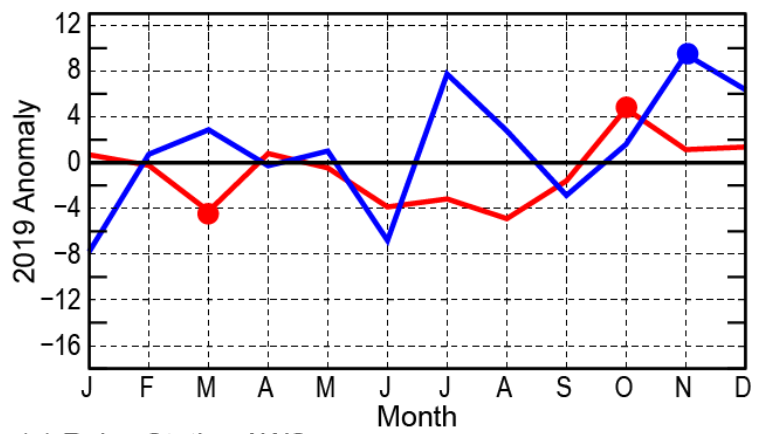

(e) Relay Station AWS

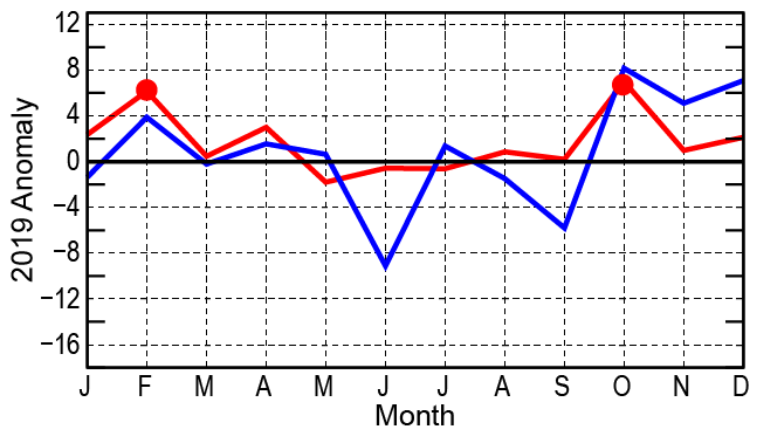

- Temperature Anomaly $\left({ }^{\circ} \mathrm{C}\right)$ (b) Marambio

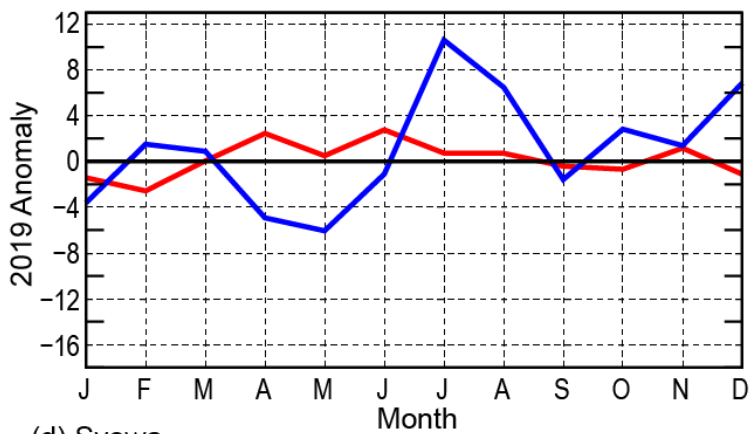

(d) Syowa

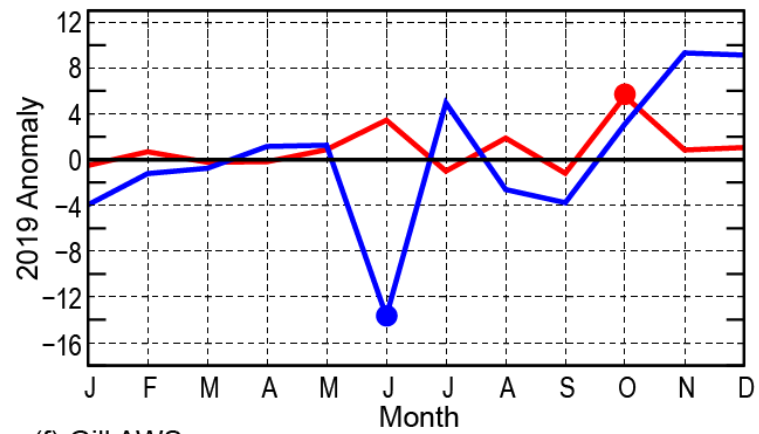

(f) Gill AWS

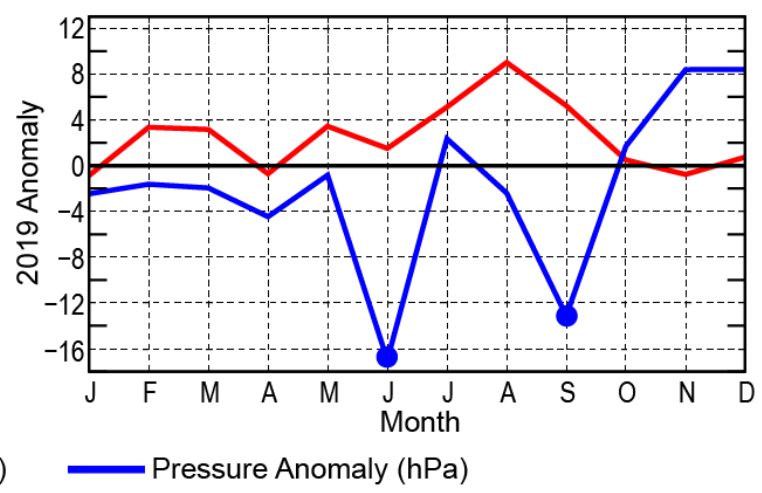

Fig. 6.4. Monthly Antarctic climate anomalies during 2019 at six representative stations (four staffed [a]-[d], and two automatic [e]-[f]). Anomalies for temperature $\left({ }^{\circ} \mathrm{C}\right)$ are shown in red and anomalies for MSLP/surface pressure $(\mathrm{hPa})$ are shown in blue, with filled circles denoting record anomalies for a given month. Anomalies for the four staffed stations are based on differences from the monthly 1981-2010 averages; for AWS, Gill is based on 1985-2014 averages and Relay Station is based on 1995-2010 averages. Observational data used to calculate record values start in 1957 for Amundsen-Scott and Syowa, 1970 for Marambio, 1981 for Neumayer, 1985 for Gill AWS, and 1995 for Relay Station AWS. The surface station data are available online at https://legacy.bas.ac.uk/met/READER/data.html (Turner et al. 2004) and ftp://amrc.ssec.wisc.edu/pub/aws.

normal); Vostok (612.4 hPa, -11.7 hPa); and Amundsen-Scott (671.0 hPa, -9.8 hPa, Fig. 6.4a) all had record low monthly mean pressures in June, as did Syowa Station $(973.5 \mathrm{hPa},-13.7 \mathrm{hPa})$ on the Queen Maud Land coast. Relay Station AWS had very low monthly mean pressure $(626.8 \mathrm{hPa}$, $-9.1 \mathrm{hPa}$ ), but no record was set. In contrast to the below-average temperatures and pressures over the main Antarctic continent, the Antarctic Peninsula experienced slightly negative pressure anomalies and above-average temperatures in June due to relatively warm west-northwesterly flow from the Bellingshausen Sea.

The overall circulation pattern quickly changed during July-September when it became marked by a weakening of the tropospheric zonal winds (Fig. 6.2c), positive pressure anomalies over the Antarctic Peninsula, and a very strong negative pressure anomaly ( $-2.5 \mathrm{std}$. dev.) south of New Zealand that stretched poleward into the Ross Sea. Much of the South Pacific experienced 
warm, northerly flow that brought positive temperature anomalies over the Ross Ice Shelf and Marie Byrd Land (Fig. 6.3d). Possession Island AWS observed a record high monthly mean temperature of $-11.7^{\circ} \mathrm{C}\left(+8.6^{\circ} \mathrm{C}\right.$ above normal) for July. In West Antarctica, Byrd AWS had positive temperature anomalies of +2.9 and $+4.9^{\circ} \mathrm{C}$ during July and August, respectively. In September, strong negative pressure anomalies briefly developed at the surface across most of the continent with a pronounced zonal wave-3 structure (not shown). These pressure anomalies were strongest over the Ross Ice Shelf where Ferrell $(971.6 \mathrm{hPa},-9.8 \mathrm{hPa})$, Gill (965.1 hPa, $-9.8 \mathrm{hPa}$; Fig. 6.4f), and Possession Island $(966.6 \mathrm{hPa},-8.3 \mathrm{hPa})$ AWSs all had record low monthly mean pressures for September. Ferrell also set a record high monthly mean wind speed of $9.5 \mathrm{~m} \mathrm{~s}^{-1}$ in September (not shown).

The most dramatic feature of the 2019 circulation was a record-setting stratospheric warming event that developed during September (Fig. 6.2; see Sidebar 6.1 for more details). Initially confined mainly above $300 \mathrm{hPa}$ and averaged poleward of $60^{\circ} \mathrm{S}$, this event was marked by strong positive geopotential height anomalies of up to $1300 \mathrm{~m}$ and a positive temperature anomaly of $20^{\circ} \mathrm{C}$ at the 30-20 hPa level. This was associated with a significant weakening of the stratospheric polar vortex by up to $35 \mathrm{~m} \mathrm{~s}^{-1}$. All three anomalies in Fig. 6.2 exceeded $3 \mathrm{std}$. dev. from the climatological mean, and at the 30-10 hPa level, all three anomalies were the largest on record in the ERA5 data beginning in 1979.

The circulation anomalies in the stratosphere progressed downward into the troposphere during October-December (Fig. 6.2). In October, higher-than-normal pressures and temperatures at the surface (Fig. 6.3e) reversed the general trend of the preceding months. The strongest warming (>3 std. dev.) occurred across Queen Maud Land. Neumayer $\left(-13.2^{\circ} \mathrm{C},+4.7^{\circ} \mathrm{C}\right.$; Fig. $\left.6.4 \mathrm{C}\right)$ and Syowa $\left(-8.0^{\circ} \mathrm{C},+5.5^{\circ} \mathrm{C}\right.$; Fig. $\left.6.4 \mathrm{~d}\right)$ stations, as well as Relay Station AWS $\left(-42.3^{\circ} \mathrm{C},+7.0^{\circ} \mathrm{C}\right.$; Fig. $\left.6.4 \mathrm{e}\right)$, all set record high temperatures for October, with Neumayer also setting a record high pressure in November $(994.2 \mathrm{hPa},+9.5 \mathrm{hPa})$. There was a very strong anticyclonic ( $>3 \mathrm{std}$. dev.) anomaly over the Ross Sea region. Marble Point AWS tied its record high pressure for November $(982.8 \mathrm{hPa}$, $+11.0 \mathrm{hPa}$ ), while Ferrell, Possession Island, and Gill AWSs (Fig. 6.4f) had near-record high pressure for November (8-11.5 hPa above normal). The SAM index reached its largest negative mean monthly value of the year in November of -4.42 (second lowest for November on record since 1957). In the Antarctic interior, Relay Station AWS, Amundsen-Scott (Fig. 6.4a), and Vostok stations all had higher-than-normal pressure for October through December, but no records were set. In the Weddell Sea region, Halley Station set a record high monthly mean temperature of $-3.1^{\circ} \mathrm{C}\left(+2.1^{\circ} \mathrm{C}\right)$ in December. 


\section{Sidebar 6.1: The $\mathbf{2 0 1 9}$ southern stratospheric warming-P. NEWMAN, E. R. NASH,}

\section{N. KRAMAROVA, A. BUTLER}

The Southern Hemisphere (SH) polar stratosphere is typically quite cold in the JulySeptember period with temperatures well below $195 \mathrm{~K}$ in the lower stratosphere $(\sim 50 \mathrm{hPa})$. In September 2019, the southern polar stratosphere was disrupted by a sudden warming event. While warmings are typical in the Northern Hemisphere (NH), there has been only one major stratospheric warming observed in the SH historical record, in 2002. Warmings are characterized by a dramatic warm-up of the polar stratosphere, a deceleration of the westerly polar night jet, and an increase of polar ozone. Warmings are driven by planetary-scale waves that propagate from the troposphere into the stratosphere on a time-scale of a few days.

There were a series of wave events that drove the changes seen in September and October 2019. Figure SB6.1a shows the $45^{\circ}-75^{\circ} \mathrm{S}$ eddy heat flux (scaled by the square root of the pressure) from $1000 \mathrm{hPa}$ (near surface) to $1 \mathrm{hPa}$, determined from MERRA-2 reanalysis data (Gelaro et al. 2017). The magnitude of the eddy heat flux is proportional to the vertical component of the wave activity, with upward wave events denoted by negative numbers. Vertical dashed lines are drawn for each of the eddy heat flux events (or minima) observed over the August-November period. There are 10 notable events in this period: 10, 19, 26 August; 4, 15, 30 September; 8, 17, 29 0ctober; 10 November. The peaks of eddy heat flux at $100 \mathrm{hPa}$ then extend, within a few days, up to higher levels (10-1 hPa) as these waves propagate vertically into the middle stratosphere.

The wave events strongly decelerated the polar night jet by depositing easterly momentum in the middle stratosphere. Figure SB6.1b displays the deviation of the zonal wind at $60^{\circ} \mathrm{S}$ from a daily 1980-2018 climatology. The wave events led to large decelerations. At $60^{\circ} \mathrm{S}$ and $10 \mathrm{hPa}$, the wind decelerated from $87 \mathrm{~m} \mathrm{~s}^{-1}$ on 25 August, to $53 \mathrm{~m} \mathrm{~s}^{-1}$ on 2 September. This was followed by a deceleration to $26 \mathrm{~m} \mathrm{~s}^{-1}$ on 11 September. By 17 September, the zonal wind at $10 \mathrm{hPa}$ had fallen to $11 \mathrm{~m} \mathrm{~s}^{-1}$. Because the wind did not reverse to easterlies at $10 \mathrm{hPa}$ (a major warming is defined by a reversal of easterly winds at $10 \mathrm{hPa}, 60^{\circ} \mathrm{S}$ ), the 2019 August-September
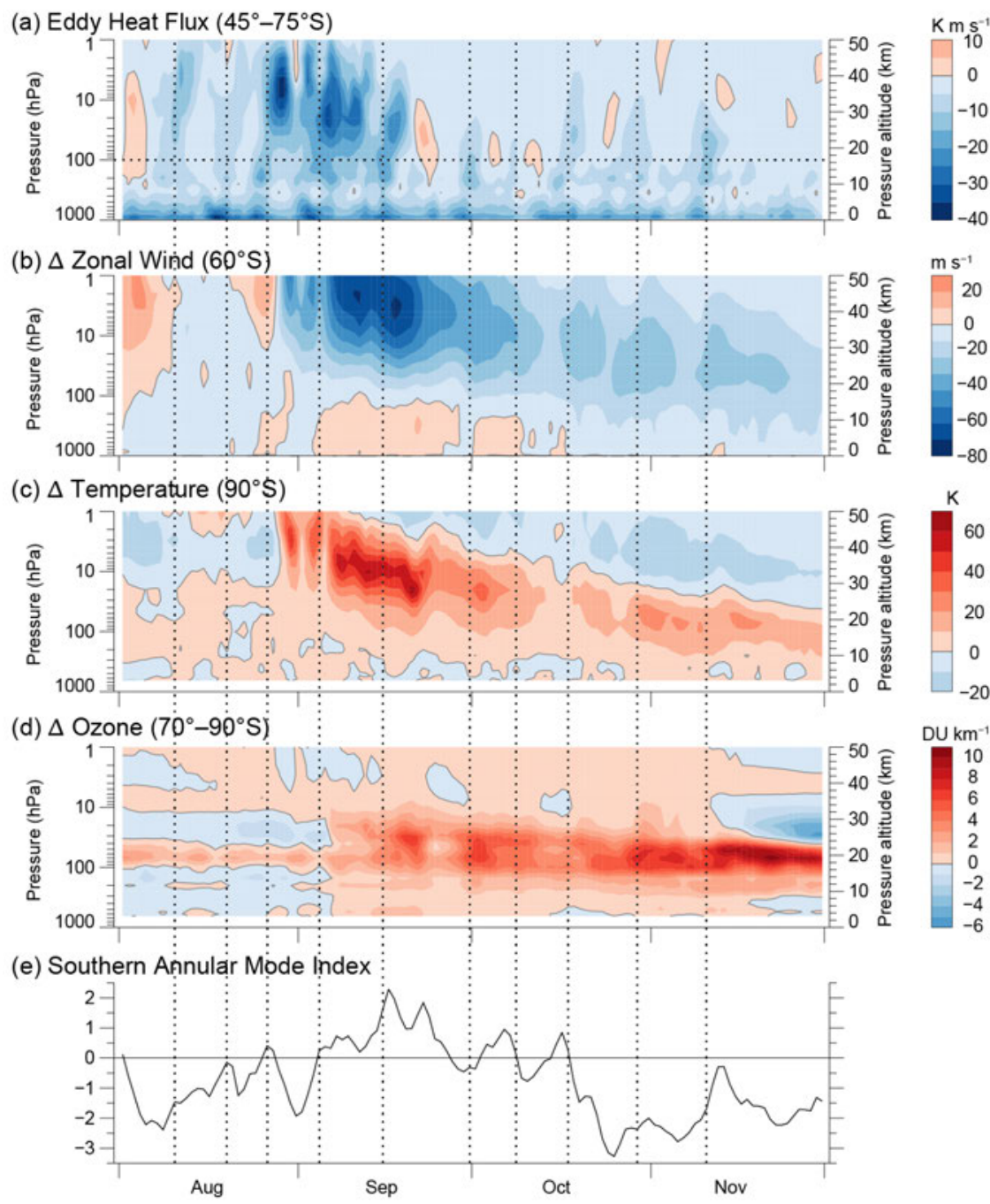

Fig. SB6.1. Daily averaged zonal-mean MERRA-2 quantities for 1 Aug-30 Nov 2019. (a) Eddy heat flux over $45^{\circ}-75^{\circ} \mathrm{S}\left(\mathrm{K} \mathrm{m}^{-1} \mathrm{~s}^{-1}\right)$; departures of: (b) $60^{\circ} \mathrm{S}$ zonal wind ( $\mathrm{m} \mathrm{s}^{-1}$ ); (c) South Pole temperature (K); and (d) polar cap ozone (DU km-1) from the 1980-2018 mean. (e) Daily SAM index (Marshall 2003). Eddy heat flux values (a) are vertically scaled by the square root of pressure. Vertical dashed lines indicate peaks in the strength of the eddy heat flux at $100 \mathrm{hPa}$, indicated by the horizontal line in (a).

warming cannot be categorized as a major warming. However, this large deceleration was unprecedented for this period in the historical record.

The 2019 wave events warmed the polar stratosphere by driving descending motion in the core of the Antarctic polar vortex. Figure SB6.1c displays the deviation of the temperature at $90^{\circ} \mathrm{S}$ from a daily 1980-2018 climatology, illustrating the warming of the polar stratosphere as a result of the wave events. At the pole, 10-hPa temperature increased from $192 \mathrm{~K}$ on 25 August, to $221 \mathrm{~K}$ on 2 September, followed by a warming to $267 \mathrm{~K}$ on 
11 September. The large warming reversed the $90^{\circ}-50^{\circ} \mathrm{S}$ thermal gradient as of 6 September and was the earliest reversal in the historical record, even earlier than the September 2002 warming.

The wave events also dramatically increased ozone over the polar region during the key period of ozone depletion in August and September. Figure SB6.1d shows deviations of the ozone density from the 1980-2018 climatology in Dobson Units (DU) per kilometer. The highest ozone density is found in the lower stratosphere (below $10 \mathrm{hPa}$ ). Again, large changes of column ozone are associated with the individual wave events, increasing ozone well beyond the 1980-2018 average levels for the dates.

The downward influence of the stratospheric warming on the Southern Annular Mode (SAM; Lim et al. 2018, 2019) did not appear until mid-October (Fig. SB6.1e), when the SAM index went from a positive to a negative value. The SAM variations are in reasonable agreement with Fig. SB6.1b and Fig. 6.2c (below the x-axis), showing how the phase and strength of the annular mode are related to the zonal mean wind in the troposphere. The negative phase of the SAM, which is associated with anomalously hot and dry conditions in eastern Australia (Lim et al. 2019), persisted through at least mid-December and may have contributed to the extreme wildfire and heat conditions observed there during this time.

The series of wave events in August-October 2019 had a profound effect on the $\mathrm{SH}$. The 10 wave events were dominated by a planetary-scale wave-1 pattern and propagated vertically from the troposphere to the stratosphere. These waves decelerated the flow, eroded the polar vortex, warmed the polar region (section 6b), and dramatically increased ozone over Antarctica (section 6h). While this event was not categorized as a major stratospheric sudden warming, it was the largest warming event observed in the August-September record since 1980.

\section{c. Surface mass balance of the ice sheet-J. Lenaerts, E. Keenan, M. Maclennan and T. Gorte}

The grounded portion of the Antarctic Ice Sheet (AIS) is characterized by a frigid continental climate. Even in peak summer, atmospheric temperatures on the main continent are low enough to prevent widespread surface melt (section 6d) or liquid precipitation, unlike the Greenland Ice Sheet (section 5e). With few exceptions (e.g., on the northern Antarctic Peninsula), any meltwater that is produced refreezes locally in the firn. Meltwater runoff is a negligible component of ice sheet mass change on the AIS. On the other hand, sublimation is a significant component of AIS surface mass balance (SMB; Lenaerts and Van Den Broeke 2012; Agosta et al. 2019; Mottram et al. 2020), especially in summer and in the windy escarpment zones of the ice sheet, where blowing snow occurs frequently ( $>50 \%$ of the time; Palm et al. 2018). By far the dominant contributor

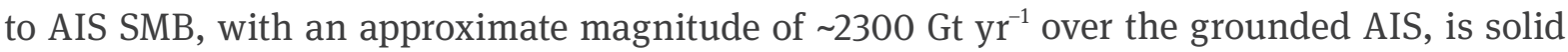
precipitation, i.e., snowfall.

Atmospheric reanalysis products are important tools for analyzing AIS SMB and its two dominant components, snowfall and sublimation, in near-real time. Here we use the MERRA-2at $0.5^{\circ}$ $\times 0.625^{\circ}$ horizontal resolution (Gelaro et al. 2017) and ERA-5 (ERA-Interim's successor, employing $0.25^{\circ}$ horizontal resolution; Copernicus Climate Change Service [C3S] 2017) reanalysis data to analyze the 2019 AIS SMB, its spatial and seasonal characteristics, and also to compare it to the climatological record (1981-2010). Based on recent work comparing reanalysis products with in situ observations on Antarctica, MERRA-2 and ERA-5 stood out as best-performing (Wang et al. 2016; Gossart et al. 2019; Medley and Thomas 2019); however, important biases remain, which are associated with the relatively low resolution of the reanalysis products and poor/no representation of important SMB processes (e.g., blowing snow, clear-sky precipitation).

Acknowledging these limitations, we use these two reanalysis products to provide a time series of (grounded) AIS SMB from 1980 to 2019 (Fig. 6.5a). The 1981-2010 mean SMB is $2159 \pm 131$

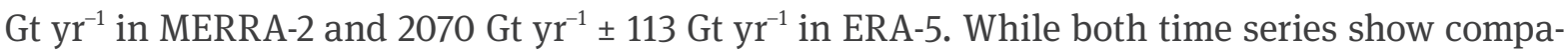
rable interannual variations, with year-to-year SMB differences of $>300 \mathrm{Gt} \mathrm{yr}^{-1}$ between dry and wet years, neither of the reanalyses suggest a significant long-term trend in SMB (not shown). Further, although there is apparent better agreement in some periods relative to others, there is no significant trend in the difference between MERRA-2 and ERA-5 over the entire 1980-2019 period $(p=0.62)$. 


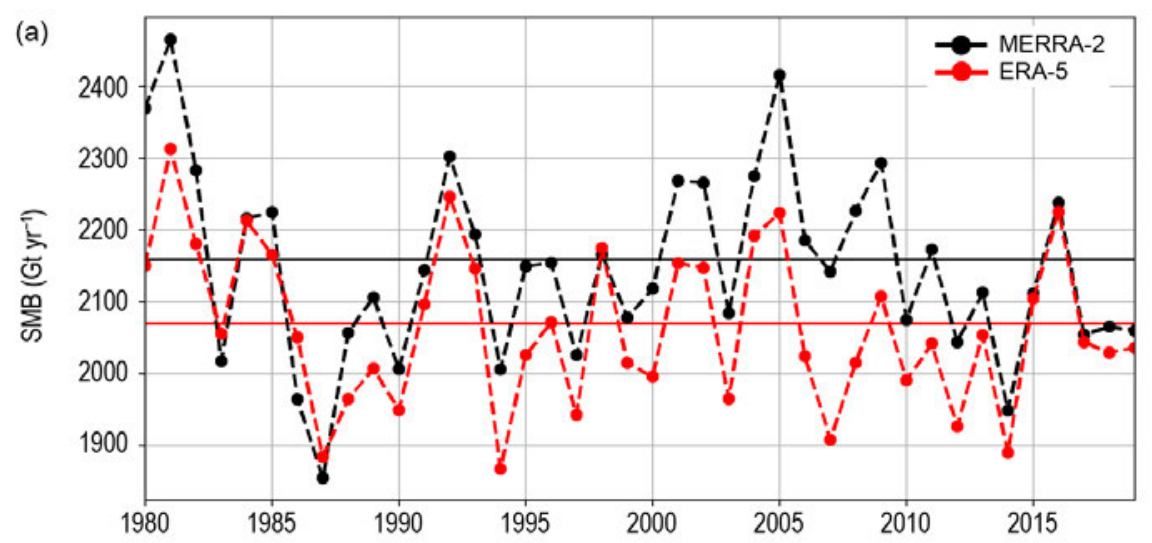

(b)

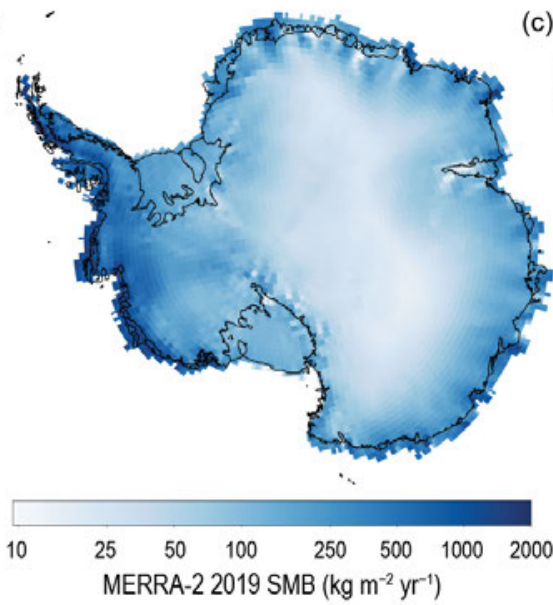

(c)

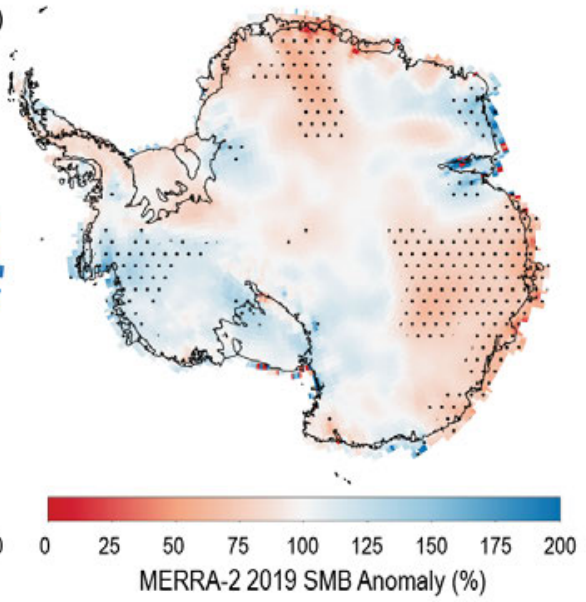

Fig. 6.5. Antarctic surface mass balance (SMB) in 2019. (a) Time series of annual (grounded) Antarctic Ice Sheet (AIS) integrated SMB (in Gt yr $^{-1}$ ) from 1980 to 2019, according to MERRA-2 (black) and ERA-5 (in red); horizontal lines are 1981-2010 means, respectively. (b) and (c) 2019 SMB and SMB anomaly relative to 1981-2010 according to MERRA-2. In (c), 2019 SMB anomaly is higher than the 1981-2010 std. dev. in the stippled areas.
The 2019 SMB total and SMB anomaly were $2060 \mathrm{Gt}$ and $-99 \mathrm{Gt}$, respectively, for MERRA-2, and 2036 Gt and -34 Gt, respectively, for ERA5 , thus showing near-normal conditions for 2019 (compared with the 1981-2010 climatology). Because both reanalysis datasets produce similar results, we use MERRA-2 hereafter to focus on spatial and seasonal characteristics of the 2019 SMB. As described by various studies, AIS SMB is typically relatively high $(>500$ $\mathrm{mm}$ w.e.) in the coastal areas of the ice sheet and decreases sharply from the coast upward and poleward on the ice sheet; the same was true for 2019 (Fig. 6.5b) with SMB values being $<50 \mathrm{~mm}$ w.e. in the highelevation interior of the East Antarctic Ice Sheet (EAIS). According to MERRA-2, both snowfall and sublimation in 2019 were close to the AIS 1981-2010 mean.

While the 2019 AIS SMB was close to average, the MER-

RA-2 results indicate substantial regional variability in the 2019 snowfall relative to the mean (Fig. 6.5c). While some AIS regions were characterized by relatively dry conditions, the 2019 SMB was relatively high in other regions. In particular, 2019 SMB was substantially higher than climatology $(>125 \%)$ in the Amundsen and Bellingshausen glacial basins, thus offsetting part of the dynamic mass loss that is ongoing in that area (Sidebar 6.2). On the other hand, 2019 SMB was exceptionally low compared with the climatology $(<75 \%)$ in western Queen Maud Land and Wilkes Land, marking a reversal (for this year) of recent high-accumulation trends there (Lenaerts et al. 2013).

Throughout the year, the climatological AIS SMB varies considerably (Fig. 6.6), with a minimum in austral summer (120-140 Gt month $\left.{ }^{-1}\right)$ and maximum in austral autumn and winter (200-220 Gt month ${ }^{-1}$ ). In 2019, this seasonal cycle was amplified, with January-May and September-December being drier than average, while the 2019 winter months (June-August) were characterized by greater-than-average snowfall. Comparing the 2019 anomaly with the long-term mean and standard deviation (black line and gray shading, Fig. 6.6) indicates that the low SMB values in January, May, and December were significant (>1 std. dev.), while

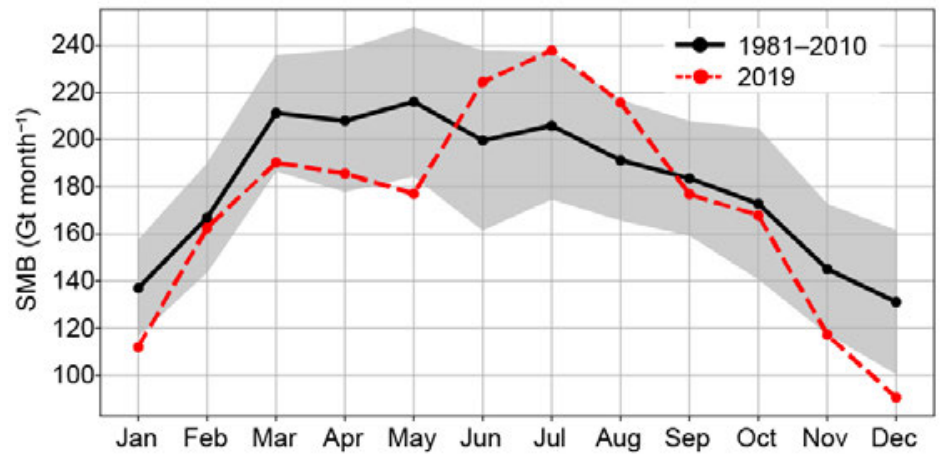

Fig. 6.6. Seasonal cycle of (grounded) Antarctic Ice Sheet (AIS) integrated surface mass balance (SMB) according to MERRA-2 for 2019 (red) and 1981-2010 (black line = mean, gray shading: std. dev.). 
July 2019 had substantially more snowfall than climatology. The December dry anomaly, which was preceded by a dry November ( $60 \mathrm{Gt}$ cumulative snowfall deficit), may have contributed to early indications of an anomalously high surface melt year for 2019-20 (as mentioned in section $6 \mathrm{~d}$ and consistent with section 6b). It appears that low snowfall reduced the amount of highly reflective fresh snow on the surface, which lowered the albedo and enhanced the melt-albedo feedback effect early in the 2019/20 melt season.

\section{d. Seasonal melt extent and duration for the ice sheet-L. Wang and $\mathrm{H}$. Liu}

Surface melt of the Antarctic Ice Sheet (AIS) is largely confined to the coastal region where it can contribute to surface mass balance (SMB) changes (section 6c). Here, we report on the austral spring-summer 2018/19 melt season; therefore, this analysis does not include the extensive melting that occurred later in 2019 in response to widespread warming (section 6b, Figs. 6.2b, 6.3e). Since Antarctica's melt season extends well into the first few months of the calendar year, a complete assessment of the more recent austral melt season (2019/20) is not yet available but will be highlighted in next year's annual report.

Surface melt of the AIS can be mapped using satellite passive microwave data obtained from the Defense Meteorological Satellite Program (DMSP; Zwally and Fiegles 1994). A nearly continuous record of surface melt exists for the period 1978-present from the DMSP satellite series and earlier Nimbus series satellites. Daily passive microwave brightness temperature observations, using the $19 \mathrm{GHz}$ channel at horizontal polarization acquired by the Special Sensor MicrowaveImager Sounder (SSMIS) onboard the DMSP F17 satellite (ascending passes only), were used to
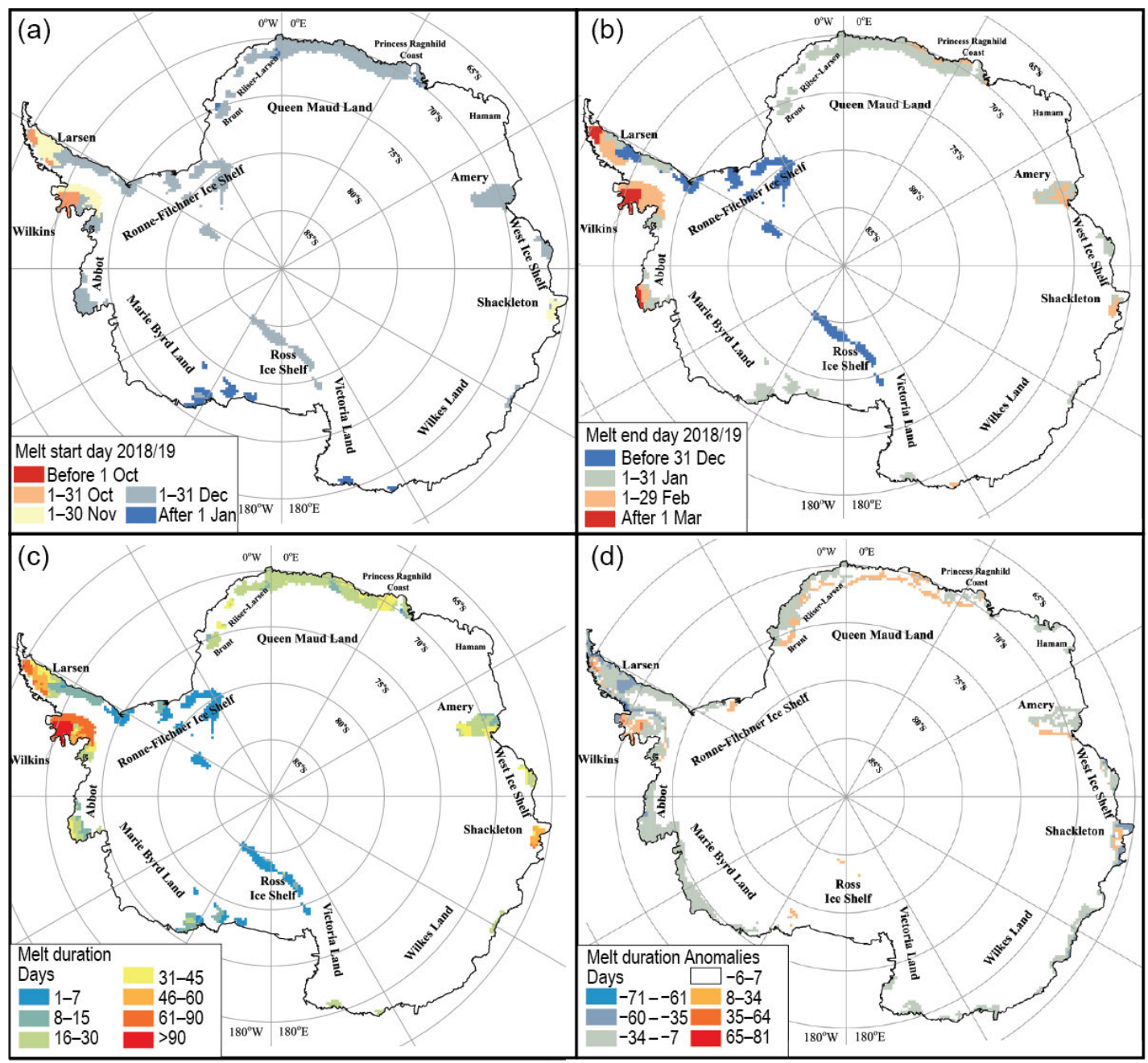

Fig. 6.7. Estimated surface melt for the 2018/19 austral summer: (a) melt start day, (b) melt end day, (c) melt duration, and (d) melt duration anomalies (day) relative to the 1981-2010 mean. 
compute surface melt at a spatial resolution of $25 \mathrm{~km}$. The data were preprocessed and provided by the U.S. National Snow and Ice Data Center (NSIDC) at level-3 EASE-Grid format (Armstrong et al. 1994) and were analyzed using a wavelet transform-based edge detection method (Liu et al. 2005). The wavelet transform detects for every satellite pixel the abrupt change in brightness temperature when melt first commences and when melt ends (and freezing commences).

Figure 6.7 shows (a) the start day of the melt season and (b) the end day of the melt season during austral summer 2018/19. The melt duration map shows the total number of melt days at each grid cell location during the melt season (Fig. 6.7c). The melt anomaly map (Fig. 6.7d) is in reference to the 30-year mean (1981-2010).

The earliest melt occurred in October 2018 on portions of the Larsen and Wilkins Ice Shelves (east and west of the Antarctic Peninsula, respectively), which continued into November. Surface melting elsewhere began in November on the Shackleton Ice Shelf in East Antarctica. This extended to the Queen Maud Land coast and Amery Ice Shelf, with brief events on the Ronne and Ross Ice Shelves, which ended by late December (Figs. 6.7a,b). Melt events lasted longer on the Larsen, Wilkins, and Abbot Ice Shelves, i.e., through February and March of 2019, and on the Amery and Shackleton Ice Shelves until February 2019 (Fig. 6.7b).

Ice shelves with longer total melt season duration ( $>45$ days; Fig. 6.7c, orange-red color) include Larsen, Wilkins, and Shackleton (Fig. 6.7c). Areas with moderate melt duration (14-45 days; Fig. 6.7.c, green-yellow color) include the coast of Queen Maud Land and the Abbot and Amery Ice Shelves, while sporadic short-term melt (<16 days; Fig. 6.7c, blue color) occurred on the Ross and Ronne-Filchner Ice Shelves. The melt anomalies (Fig. 6.7d) show that the melt season was generally within \pm 34 days of the 1982-2010 mean, except for a few small areas on Wilkins Ice Shelf. Therefore, the austral summer of 2018/19 is classified as a low-melt year overall.

Trends in both melt extent (ME) and melt index (MI; Zwally and Fiegles 1994; Liu et al. 2006) show high variability and a general trend toward less melting in the satellite record (since 1978). Melt extent (in $\mathrm{km}^{2}$ ) is the total area that experienced surface melt for at least one day during the melt season. The MI (in day. $\mathrm{km}^{2}$ ) is the sum of the daily MEs for Antarctica for the entire season. The 2018/19 melt season continued the negative trends observed since 1978 (Fig. 6.8). Both ME and MI trends are significant at $p<0.05$. Melt extent has decreased by $17700 \mathrm{~km}^{2}$ per year and MI has decreased by $322300 \mathrm{day} \cdot \mathrm{km}^{2}$ per year over the 43-year record. The 2018/19 austral melt season had the seventh-smallest ME and the third-smallest MI in the satellite record. The negative trends are consistent with our previous reports (Liu et al. 2006; Tedesco 2009a,b). We also note that a majority of the surface melting generally occurs along the Antarctic Peninsula, but a recent weakening of warming trends there (Turner et al. 2016) has contributed to the downward trend in total ME (e.g., Fig. 6.8).

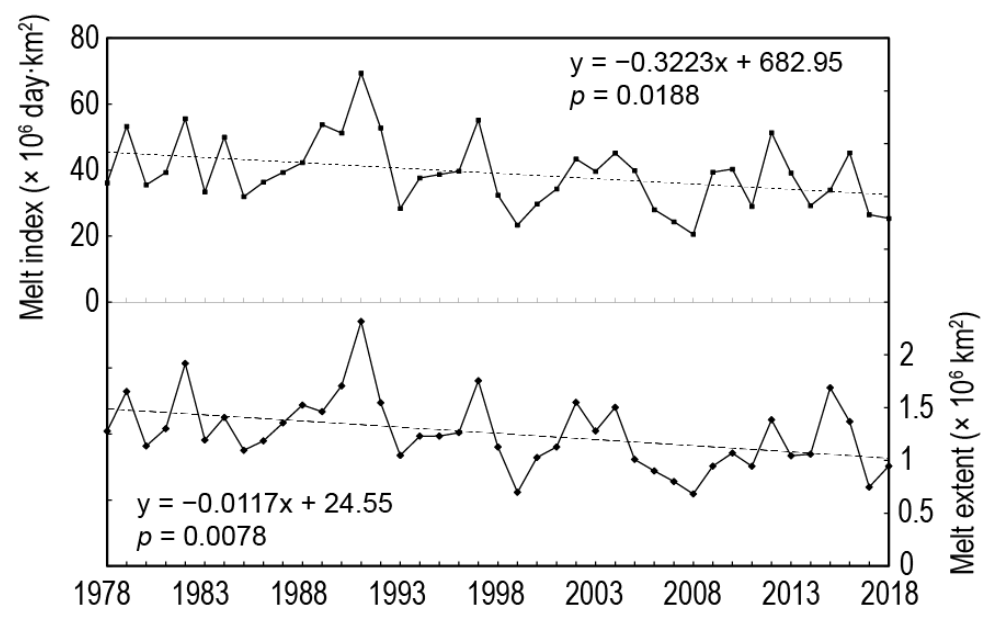

Fig. 6.8. Upper panel: Melt index $\left(\times 10^{6}\right.$ day $\left.\cdot \mathrm{km}^{2}\right)$ from $1978 / 79$ to 2018/19, showing a negative trend (322 $300 \mathrm{day} \cdot \mathrm{km}^{2} \mathrm{yr}^{-1}$, $p<0.05 \%)$. Lower panel: Melt extent $\left(\times 10^{6} \mathrm{~km}^{2}\right)$ from $1978 / 79$ to 2018/19, showing a negative trend (11700 $\left.\mathrm{km}^{2} \mathrm{yr}^{-1}, p<0.05 \%\right)$. A record low melt was observed during 2008/09. The year marked on the $\mathrm{x}$-axis corresponds to the start of the austral summer. For example, 2008 corresponds to austral summer of 2008/09. 
In recent decades the Antarctic Ice Sheet (AIS) has experienced a rapid increase in grounded ice discharge to the ocean. This increase is largely driven by changes in ocean-driven melting and ice shelf thinning.

The AIS gains mass through snowfall (section $6 \mathrm{c}$ ) and exports mass primarily via two processes at the margins: iceberg calving (episodic) from the ice fronts and basal melting (continuous) under ice shelves (Lazarra et al. 1999; Depoorter et al. 2013). The net balance between competing mass transfers depends on interactions between ice, ocean, and atmosphere. Averaged over long time scales, the contributions from these mass loss processes occur in approximate equal proportions (Rignot et al. 2013), and their sum offsets the mass gain to maintain AIS in steady state. However, since 1992, many ice shelves have experienced net mass loss due to ocean-driven basal melting in excess of the steady state, which has pushed the ice sheet mass balance negative (Adusumilli et al. 2020). The SAM index reached its largest negative mean monthly value of the year in November of -4.42 (2nd lowest for November on record since 1957). Major tabular calving events occur on long time scales (50-70 years), and since 1992 there have been major calving events on several ice shelves: Ross (March and April 2000), Ronne (October 1998, May 2000), Larsen-C (July 2017), Pine Island (years), and Amery (September 2019). There have also been several climate change-related collapse events of Antarctic Peninsula ice shelves: Larsen A (January 1995), Larsen B (March 2002), and Wilkins (February-July 2008). These are not cyclical, but represent semi-permanent adjustments of ice shelf extent in light of warmer temperatures and increased melt.

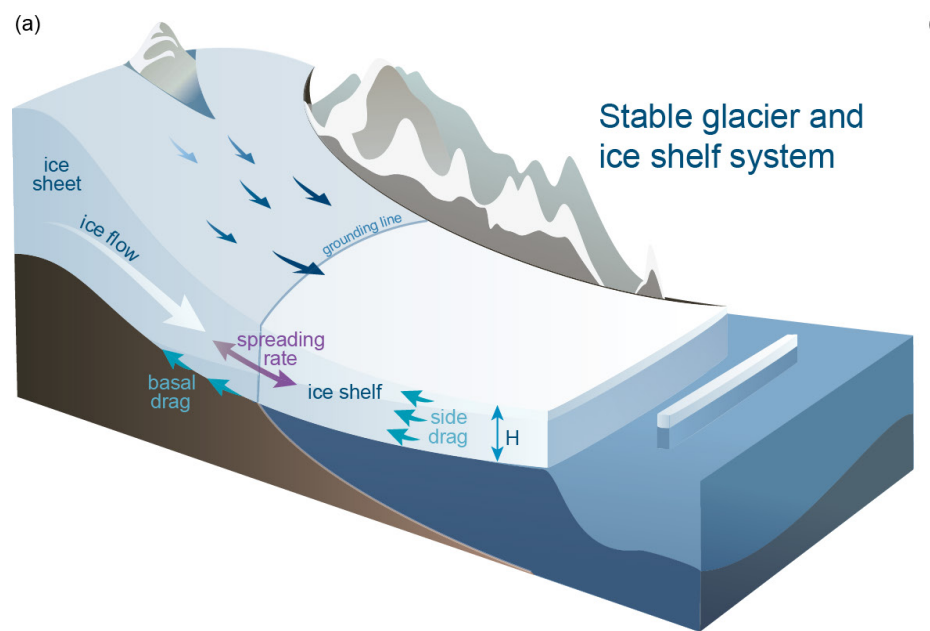

Observing changes in AIS mass is challenging because it is vast and the signals are small, requiring accurate and consistent measurements over a wide range of spatial and temporal scales. Three independent satellite-based techniques are used to estimate AIS mass changes: (a) gravimetry, based on the GRACE and GRACE-FO satellites (e.g., Chen et al. 2009; Velicogna et al. 2009, 2020), which directly measure changes in ice sheet mass at coarse spatial scale $(\sim 300 \mathrm{~km})$ in successive satellite passes, but cannot detect changes in floating ice; (b) mass budget method (MBM), which uses estimates of ice velocity and thickness to determine the amount of solid ice that passes across the grounding line and subtracts these against estimates of total snow accumulation over the outlet glacier catchments as determined from atmospheric reanalyses (Gardner et al. 2018; Rignot et al. 2019); and (c) satellite altimetry using either radar or laser altimeters that measure ice sheet surface elevation change over time, combined with model output of changing snow and firn density (that lead to elevation changes without a change in mass) to infer mass changes (e.g., Shepherd et al. 2019; Smith et al. 2020).

Satellite radar (since 1992) and laser altimetry (since 2003) have provided evidence for widespread elevation loss of outlet glaciers in West Antarctica (Pritchard et al. 2009; Wingham et al. 1998), particularly in the Amundsen Sea sector (Pritchard et al. 2012; Shepherd et al. 2001). Soon after the launch of NASA's GRACE satellites in 2002, these data confirmed that the perimeter of the ice sheet was losing mass (Chen et al. 2009; Velicogna 2009) and later revealed evidence of an acceleration in rates of loss (Velicogna et al. 2014). Early application of the MBM (Rignot et al. 2008) confirmed large West Antarctic losses

Fig. SB6.2. Schematic showing relationship between ice shelf buttressing and grounding line flux before (a) and after (b) the occurrence of ice shelf thinning. (Figure adapted from Gudmundsson et al. 2019.) 
that can be largely attributed to accelerated flow of the Pine Island and Thwaites Glaciers (Gardner et al. 2018; Rignot et al. 2019). Estimates disagree on the sign of recent mass change across East Antarctica, where small changes in net accumulation may greatly impact the net balance (because of its large area). However, the magnitude of the disagreement there is smaller than the mass loss signal elsewhere on the ice sheet.

It can be misleading to directly compare independent published estimates from the three techniques, because they are generally made over different time periods. Recognizing this, a community Ice-sheet Mass Balance Inter-comparison Experiment (IMBIE) was established in 2011 to reconcile estimates for 1992 to 2011 as part of an assessment of the cryosphere for the Intergovernmental Panel on Climate Change (IPCC) Fourth Assessment Report. This showed broad agreement among the three techniques for periods of overlapping measurement and concluded that the ice sheet had an overall negative mass balance (71 $\pm 56 \mathrm{Gt} \mathrm{yr}^{-1}$; Shepherd et al. 2012). IMBIE2 (IMBIE Team 2018) updated the mass change time series through 2017 and showed that Antarctica lost mass at an average rate of 109 $\pm 56 \mathrm{Gt} \mathrm{yr}^{-1}$ between 1992 and 2017. The rates of ice loss from West Antarctica increased by a factor of three (from $53 \pm 29 \mathrm{Gt}$ $\mathrm{yr}^{-1}$ during 1992-97 to $159 \pm 26 \mathrm{Gt} \mathrm{yr}^{-1}$ during 2012-17); from the Antarctic Peninsula, the rate increased from $7 \pm 13 \mathrm{Gt} \mathrm{yr}^{-1}$ to $33 \pm 16 \mathrm{Gt} \mathrm{yr}^{-1}$, in part due to accelerated discharge from outlet glaciers after several ice shelf collapse events. IMBIE2 and Shepherd et al. (2019) also showed that inland thinning is becoming more widespread.

ICESat laser altimetry (2003-08) showed that elevation changes in grounded ice are linked to ocean-driven ice shelf thinning (Pritchard et al. 2009, 2012). The largest thinning rates were observed for coastal West Antarctica, attributed to an enhanced upwelling of warmer Circumpolar Deep Water (CDW) driven by increased westerly winds at the continental shelf break that promoted enhanced melting at depth near the grounding zone of the largest glaciers (Thoma et al. 2008; Steig et al. 2012; Holland et al. 2019). This reduces ice shelf "buttressing", i.e., the back-stress that an ice shelf exerts on the seaward flow of grounded ice behind it (Thomas 1979; Fig. SB6.2). Subsequent analysis of an 18-year (1994-2012) altimetry record from four radar altimeter missions concluded that Antarctic ice shelves are thinning at an accelerating rate, and that their volume has declined by $166 \pm 48 \mathrm{~km}^{3} \mathrm{yr}^{-1}$ between 1994 and 2012 (Paolo et al. 2015).
A recent study (Smith et al. 2020) differenced laser altimetry data from NASA's ICESat (2003-09) and ICESat-2 (2018-19) laser altimeters to estimate the mass change over Antarctica's grounded ice sheet and floating ice shelves from 2003 to 2019. The comparison showed pervasive mass loss in both West Antarctica and the Antarctic Peninsula, partially offset by mass gains in East Antarctica; overall, losses outpaced gains, resulting in a net grounded ice mass loss of $118 \mathrm{Gt} \mathrm{yr}^{-1}$ for Antarctica (adding a total of $5.2 \mathrm{~mm}$ to sea level). In West Antarctica and the Antarctic Peninsula, mass loss from the ice shelves accounted for more than $30 \%$ of those regions' total loss, reinforcing the notion of a strong link between ice shelf thinning and loss of grounded ice (Fig. SB6.3). The highest ice shelf thinning rates were in Thwaites Glacier basin in the Amundsen Sea sector.

Early analysis of GRACE-FO satellite gravimetry, combined with GRACE data, shows reduced acceleration of grounded ice loss (i.e., a leveling off) since 2016 (Velicogna et al. 2020). This leveling off stems from an increase in accumulation in Queen Maud Land, George VI land, and the Antarctic Peninsula since 2016. Glacier losses for the Amundsen Sea sector and Wilkes Land were approximately constant since $\sim 2009$.

We anticipate that annual assessments of Antarctic mass balance will be available for future State of the Climate reports, likely derived from NASA's satellite gravimeter (GRACE-FO) and laser altimeter (ICESat-2).

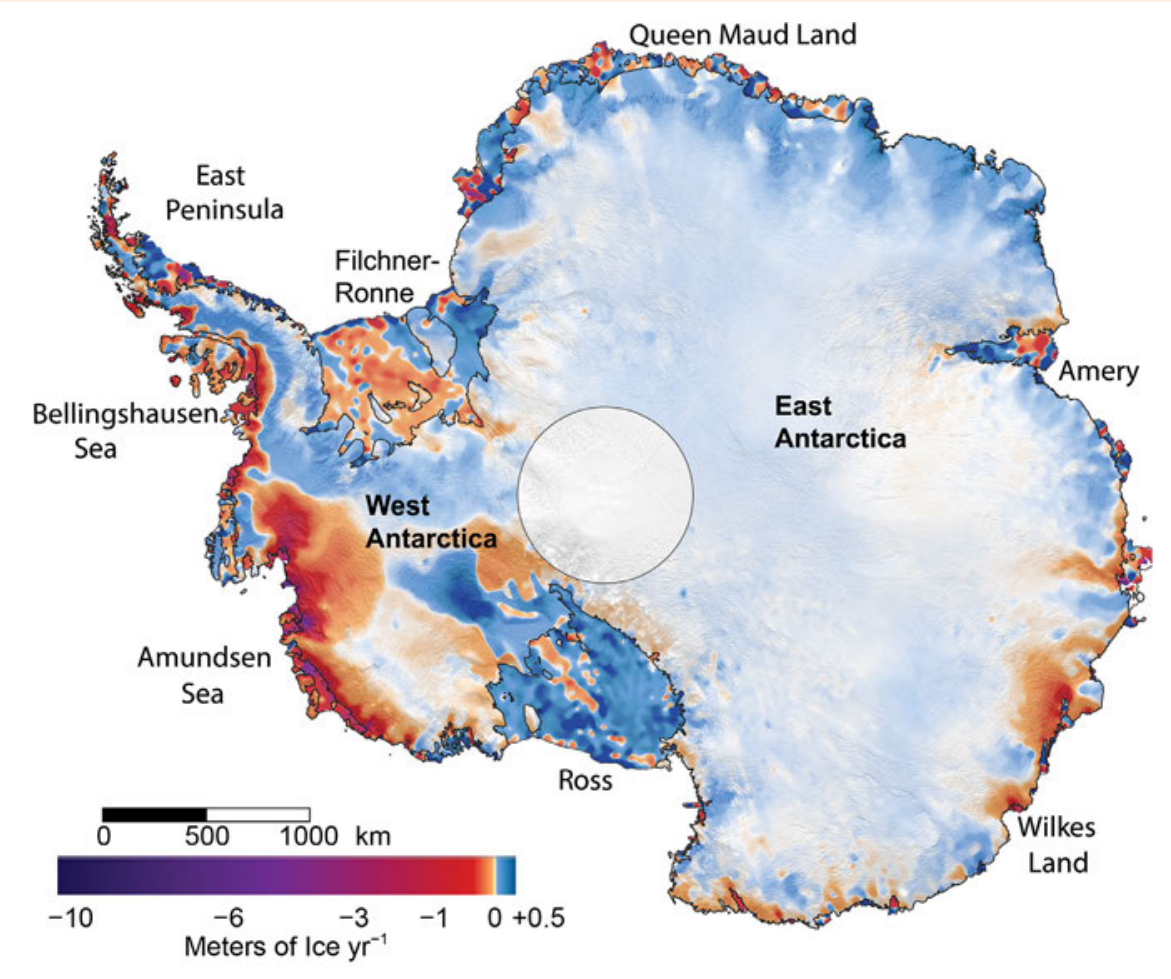

Fig. SB6.3. Mass change of floating and grounded ice (top) from ICESat (2003-09) and ICESat-2 (2018-19) data. (Figure adapted from Smith et al. 2020.) 
e. Sea ice extent, concentration, and seasonality-P. Reid, S. Stammerjohn, R. A. Massom, S. Barreira,

T. Scambos, and J. L. Lieser

Antarctic sea ice plays a pivotal role in the global climate system. Forming a highly reflective, dynamic, and insulative blanket that varies seasonally in its areal coverage from $\sim 3 \times 10^{6} \mathrm{~km}^{2}$ to $\sim 19-20 \times 10^{6} \mathrm{~km}^{2}$, sea ice and its snow cover strongly modifies ocean-atmosphere fluxes and interaction processes (Bourassa et al. 2013). Moreover, brine rejection into the underlying ocean during sea ice formation on some continental shelf areas leads to the formation of Antarctic Bottom Water that contributes to the global ocean overturning circulation (Johnson 2008). Antarctic sea ice also acts as a protective buffer for ice shelves against destructive ocean swells (Massom et al. 2018) and modulates the interaction of warm ocean waters with ice shelf basal cavities to affect basal melt there (Timmermann and Hellmer 2013). Finally, it also forms a key habitat for a myriad of biota-ranging from microorganisms to whales (Thomas 2017)-that are strongly affected by changes in the presence and seasonal rhythms of the sea ice cover (e.g., Massom and Stammerjohn 2010).

To place 2019 in context, net Antarctic sea ice extent (SIE, the area enclosed by the ice edge consisting of $\geq 15 \%$ sea ice concentration [SIC]) showed a slight increasing trend over 1979-2015 (Comiso et al. 2016) that was then marked by increased interannual variability since 2012. Record high SIE values during 2012-14 (Reid and Massom 2015) were followed by record lows from 2016 through 2019 (Figs. 6.9a,c). The persistent record-breaking low SIE since 2016 suggests a response to a change in the underlying ocean conditions (Meehl et al. 2019), particularly for the
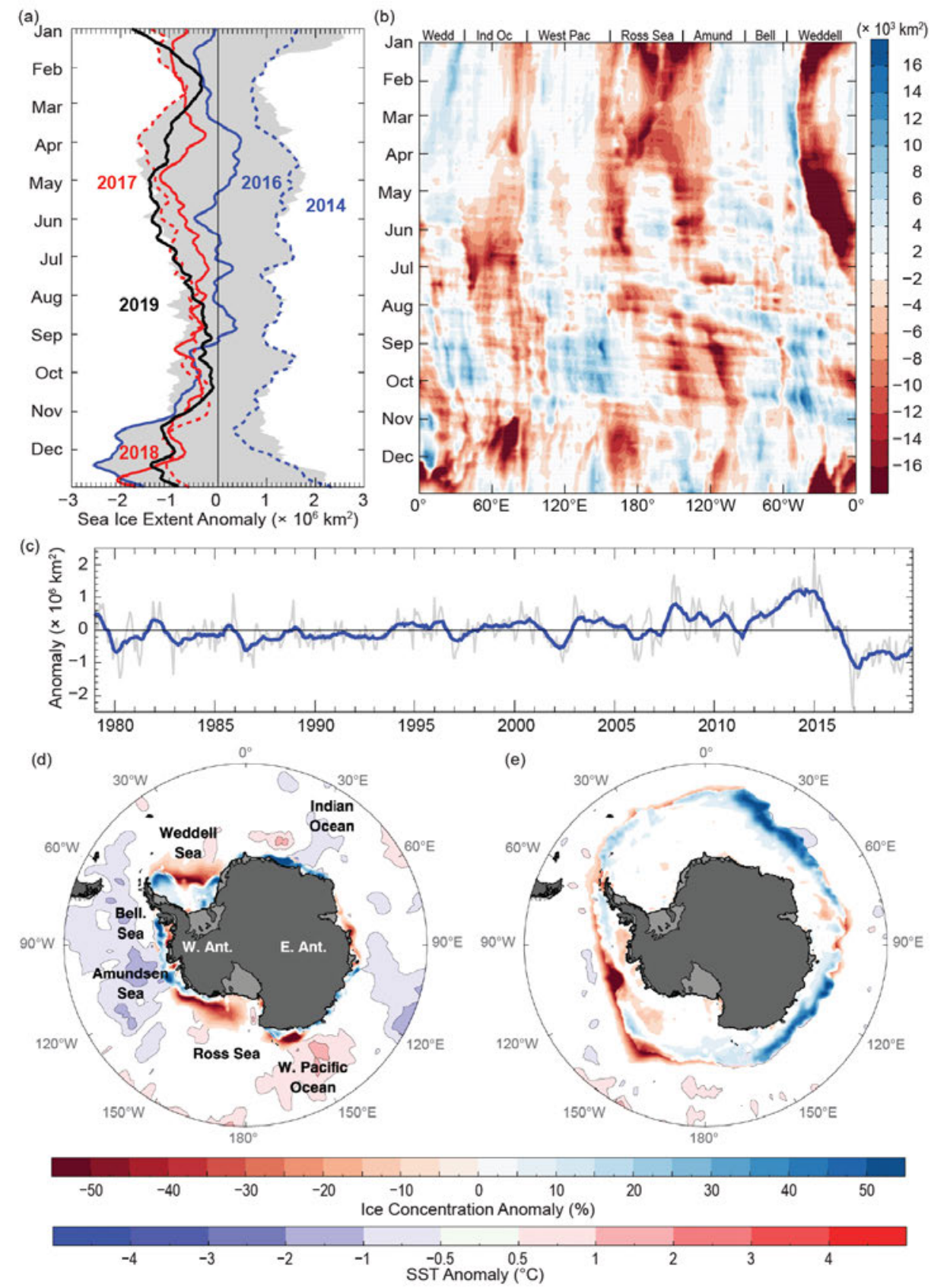

Fig. 6.9. Antarctic sea ice in 2019. (a) Time series of net SIE anomalies for 2014 (dashed blue line), 2016 (solid blue line), 2017 (dashed red line), 2018 (solid red line), and 2019 (solid black line) (all relative to the 1981-2010 climatology). Gray shading represents the historical range (1979-2018) in SIE anomalies. (b) Hovmöller (time-longitude) representation of SIE anomalies $\left(\times 10^{3} \mathrm{~km}^{2}\right.$ per degree of longitude) for 2019. (c) Time series (1979-2019) of monthly average SIE anomalies (light blue) and their 11-month running mean (dark blue). Maps of SIC anomaly (\%) and SST anomaly $\left({ }^{\circ} \mathrm{C}\right)$ for (d) Feb and (e) Sep 2019 (all relative to 1981-2010). Sea ice concentration is based on satellite passive-microwave ice concentration data. 
Ross Sea and western Weddell Sea (Fig. 6.9b; Reid et al. 2018, 2019). Also persistent over the last few years (from mid-2017 through 2019) are positive anomalies in both SIE (e.g., Fig. 6.9a) and duration (e.g., Fig. 6.10c) in the eastern Amundsen and Bellingshausen Seas (ABS) region. These persistent positive SIE anomalies could be the result of enhanced sea ice melt (Haumann et al. 2020) together with regional freshening of the upper ocean from observed enhanced melting of Thwaites Glacier and the adjacent outlet glaciers (Bintanja et al. 2013; St-Laurent et al. 2017). Below-normal sea surface temperatures (SSTs) were also observed more frequently off the ABS region since 2017 (e.g., Fig. 6.9d). This region previously showed strong decreases in both sea ice coverage and duration over 1979-2014 (Fig. 6.10d; Stammerjohn et al. 2015).

Highlights from 2019 include record low monthly mean SIE recorded in both January and June (Fig. 6.9a), with 59 record low daily values of SIE also occurring in January, May, June, and July. Indeed, net SIE was below the long-term average (1981-2010) for all days in 2019 (Fig. 6.9c), with 11 days (all in January) also showing the lowest sea ice area (SIA; the actual area covered by sea ice) on record (not shown). The annual daily minimum SIE for 2019 occurred on 28 February (at $2.44 \times 10^{6} \mathrm{~km}^{2}$, the seventh lowest on record), while the daily maximum was on 30 September (18.46 $\times 10^{6} \mathrm{~km}^{2}$, 10th lowest on record).

In addition to these highlights, Antarctic sea ice coverage during 2019 was characterized by high spatial and seasonal variability, consistent with variability in the overlying atmospheric and underlying oceanic conditions. The seasonal and regional progression of SIE anomalies during the year can be broken into four phases based on spatio-temporal analysis (Fig. 6.9b): January-February; March-June; July-midOctober; and mid-October-December. These four phases of SIE anomaly patterns are described below, together with associated atmospheric and/or oceanic features drawn from sections $6 \mathrm{~b}$ and $6 \mathrm{~g}$, respectively.

The net circumpolar SIE at the start of 2019 was at record low values until about mid-January, after which the negative net circumpolar SIE anomaly weakened into mid-February (though remained negative; Fig. 6.9a). During this time, a distinct and persistent zonal wave-3 pattern was observed in the regional SIE anomalies (Fig. 6.9b), despite a

(a) $40^{\circ} \mathrm{W}$

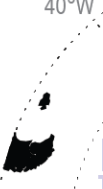

$20 \circ \mathrm{W}$

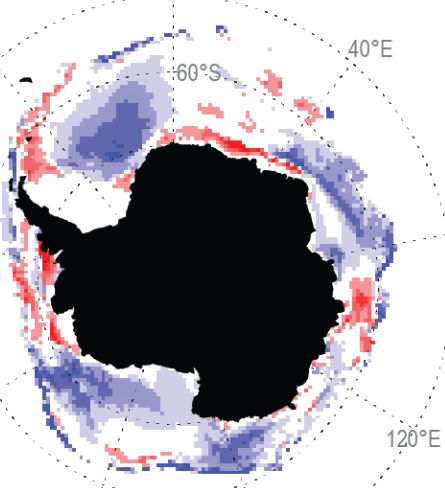

(b)
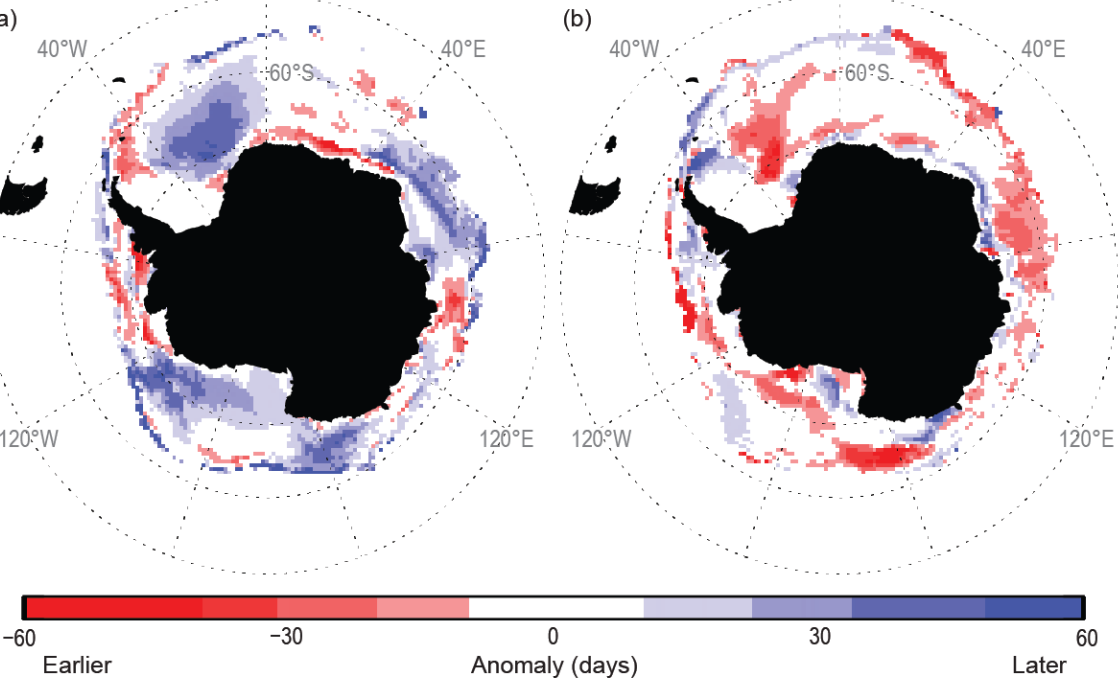

(c)

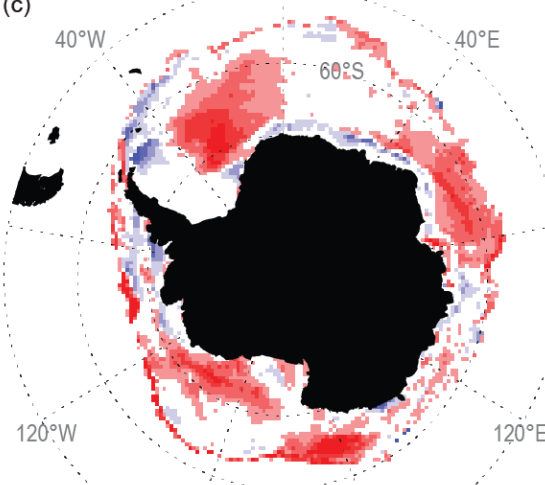

(d) $40^{\circ} \mathrm{W}$
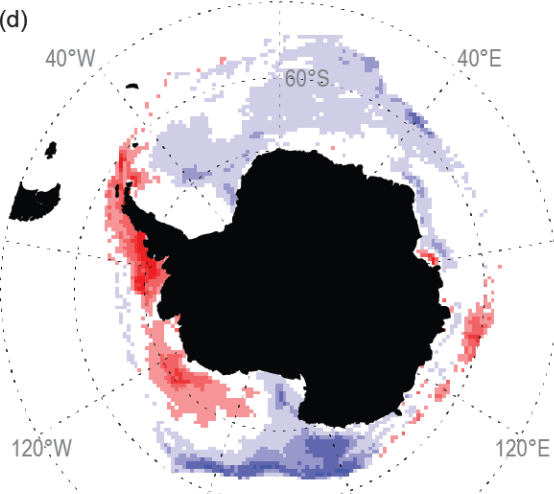

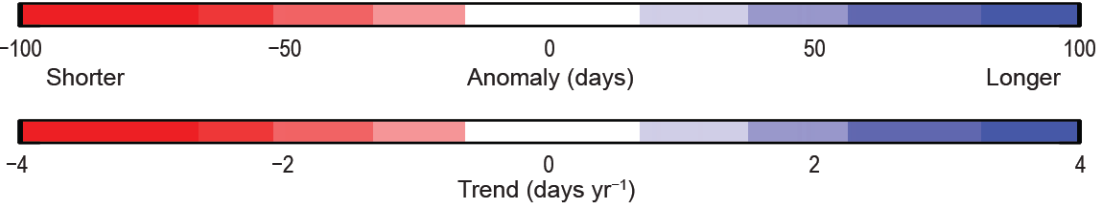

Fig. 6.10. Antarctic sea ice seasonality in 2019. Maps showing 2019 anomalies of days of (a) advance and (b) retreat, (c) total duration, and (d) duration trend (following Stammerjohn et al. 2008). Both the climatology (for computing the anomaly) and trend are based on 1981/82-2010/11 data (Cavalieri et al. 1996 [updated yearly]), while the 2019/20 duration-year data are from the NASA Team NRTSI dataset (Maslanik and Stroeve 1999). 
prevalent zonal wave-2 pattern in atmospheric pressure (section 6b; Fig. 6.3a). Dominant factors during this initial period were strong and persistent negative SIE anomalies in: (1) the eastern Indian Ocean; (2) the eastern side of the west Pacific through to the Ross Sea and western Amundsen Sea sectors; and (3) the western Weddell Sea. The weakening of negative circumpolar SIE anomalies in February coincided with a weakening of the strong positive SIE anomalies across extensive parts of the ABS, western Indian Ocean $\left(\sim 0^{\circ}-50^{\circ} \mathrm{E}\right)$, and western Pacific Ocean $\left(\sim 90^{\circ}-150^{\circ} \mathrm{E}\right)$, which also coincided with negative SST anomalies immediately north of the ice edge (Fig. 6.9d).

The short-lived period of near-average circumpolar SIE in February rebounded to become strongly negative again, resulting in record negative anomalies in May-June (Fig. 6.9a). This stalling of the annual autumn sea ice advance was dominated by strong negative anomalies in the Ross and western Weddell Seas and the eastern Indian Ocean sector (Figs. 6.9b, 6.10a). These regional negative anomalies effectively overrode lower-magnitude positive SIE anomalies in the intervening eastern Weddell Sea-western Indian Ocean, western Pacific Ocean, and eastern ABS sector. As the autumn sea ice advance progressed, a major low-pressure system to the north of the Ross Sea during April led to an abrupt change to greater-than-average ice formation and iceedge advance in the central Ross Sea $\left(150^{\circ} \mathrm{W}-180^{\circ}\right)$ starting in mid-April. Contemporaneously, there was a westward zonal broadening of the negative SIE anomaly in the Indian Ocean sector and an intensification of the western Weddell Sea negative anomaly.

During July, sea ice coverage expanded rapidly in the western Weddell Sea and to a lesser extent in the central Ross Sea, which was likely a delayed response to June's strong atmospheric anomalies (Fig. 6.3c) and an associated increase in westerly winds (Fig. 6.2c) near the sea ice edge. Meanwhile, the major negative anomalies in the Indian Ocean and the eastern Ross Sea propagated eastward. In August through the end of September, the strong negative net SIE anomaly again weakened (though still remained negative), with above-normal SIE within the eastern Weddell to western Indian Ocean sector $\left(\sim 10^{\circ}-50^{\circ} \mathrm{E}\right)$, the western Pacific $\left(\sim 110^{\circ}-150^{\circ} \mathrm{E}\right)$, and (to a lesser extent) in the Bellingshausen to western Weddell Seas sector $\left(\sim 60^{\circ}-90^{\circ} \mathrm{E}\right.$; Fig. 6.9e).

From mid-October onward, there was another sudden decrease in net SIE (Fig. 6.9a). Anomalously early seasonal retreat extended eastward from $\sim 30^{\circ} \mathrm{W}$ to $\sim 130^{\circ} \mathrm{E}$, and within the western Ross Sea and Amundsen Sea, to persist through the end of the year (Fig. 6.10b). These regional sea ice decreases were in response to substantial changes in atmospheric forcing (Figs. 6.2, 6.3 and Sidebar 6.1). Part of those changes involved increased cyclogenesis to the south of South Africa caused by enhanced Rossby wave activity associated with a strengthening of the Indian Ocean dipole (IOD; e.g., as described by Yuan et al. 2018; see also section 4h). Antarctica also experienced a strong stratospheric warming at this time (Sidebar 6.1), which led to an overall decline in the strength of the dominant westerly wind field.

In terms of annual ice season duration (ISD; February-February, Fig. 6.10c), 2019/20 was overall quite a departure from the long-term linear trends (Fig. 6.10d). This is particularly the case in the western Weddell Sea and the Ross Sea, where long-term trends since 1979 have been positive, in contrast to the distinctly negative ISD anomalies in 2019 (Figs. 6.10c,d). Similarly, the positive 2019 ISD anomalies in the Bellingshausen and northwestern Weddell Seas were also in marked contrast to the observed strongly negative long-term trends there. For ISD, the only area consistent with the long-term trend was the eastern Ross Sea to western Amundsen Sea region. 
f. Southern Ocean-B. Y. Queste, E. P. Abrahamsen, M. D. du Plessis, S. T. Gille, L. Gregor, M. R. Mazloff,

A. Narayanan, F. Roquet, and S. Swart

To quantify changes in shelf regional temperature anomalies, we assess Southern Ocean 2019 anomalies in the context of the past two decades from conventional ship-based campaigns and from the Marine Mammals Exploring the Oceans Pole to Pole (MEOP) database, the latter illustrating the capabilities of animal-borne sensors. We then analyze 2019 data illustrating the importance and variability in both heat and carbon flux anomalies at the surface of the Southern Ocean over seasonal time scales.

\section{1) Variability in the decline of Antarctic bottom water volume}

Several studies have described warming and freshening of deep and bottom water layers in the Weddell and Ross Seas (Jullion et al. 2013; Jacobs and Giulivi 2010) and in basins farther north (Desbruyères et al. 2016; Menezes et al. 2017; Purkey and Johnson 2013; Purkey et al. 2019), along with a decrease in the volume of the densest bottom waters (Purkey and Johnson 2012). However, recent repeat hydrographic measurements have shown that the volume of Weddell Sea Bottom Water has increased from 2014 to 2018 (Fig. 6.11a; Abrahamsen et al. 2019), while measurements in the Ross Sea show a rebound in salinity of shelf waters that form precursors to Ross Sea Bottom Water (Castagno et al. 2019). These are the first observations suggesting a deviation from a monotonic decline in volume and salinity in recent years.

Salinity decreases in the Ross Sea shelf waters have been attributed to changes in sea ice and increased basal melting of ice shelves in the upstream Amundsen Sea (Jacobs and Giulivi 2010). In contrast, trends in Weddell Sea Bottom Water have been smaller, though also showing a decreased salinity through the 2010s, with a subsequent increase since 2016 (Gordon et al. 2020). With both regions affected by large-scale climate modes (e.g., Southern Annular Mode [SAM] and El Niño-Southern Oscillation [ENSO]), albeit through different mechanisms (e.g., Gordon et al. 2020; McKee et al. 2011; Paolo et al. 2018; Steig et al. 2012), it remains to be seen if the recently observed variations are merely a temporary lull in a longer-term trend or not.
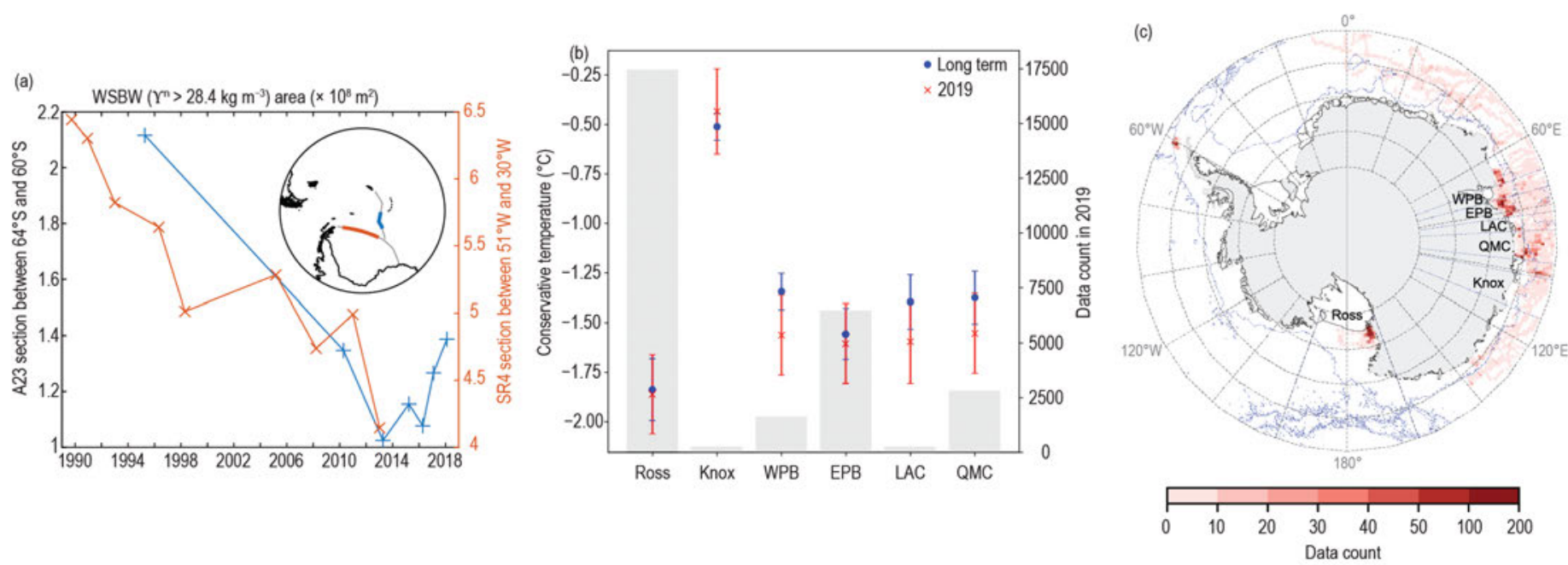

Fig. 6.11. Southern Ocean abyssal and coastal anomalies in 2019. (a) Areas of Weddell Sea Bottom Water water masses on hydrographic sections. (b) Mean conservative temperatures for depths below $\mathbf{2 5 0} \mathrm{m}$. Averages are taken for each region using profiles at least $75 \mathrm{~km}$ from the coast or ice shelf edge and where depths are shallower than $3000 \mathrm{~m}$ (i.e., only over the continental shelf; the 3000-m bathymetry contour is shown in blue). The blue meridional lines denote the boundaries of each analysis region. Gray bars denote the data count (on the right axis) of 2019 data. Region names along the $x$ axis are: Ross Sea (Ross, $\left.160^{\circ} \mathrm{E}-160^{\circ} \mathrm{W}\right)$ : Knox Coast (Knox, $\left.101^{\circ}-112^{\circ} \mathrm{E}\right)$; western Prydz Bay (WPB, $\left.70^{\circ}-75^{\circ} \mathrm{E}\right)$; eastern Prydz Bay (EPB, $\left.75^{\circ}-82^{\circ} \mathrm{E}\right)$; Leopold and Astrid Coast (LAC, $\left.82^{\circ}-87^{\circ} \mathrm{E}\right)$; and Wilhelm II Coast and Queen Mary Coast (QMC, $87^{\circ}-96.5^{\circ} \mathrm{E}$ ). Red denotes 2019 data, and blue denotes 2004-17 data. The whiskers are the combined nominal instrument error and the standard error of the mean measurements within the box. For more on the methods see Narayanan et al. (2019). (c) Data count for the year 2019 aggregated in grid cells of $0.5^{\circ} \times 0.5^{\circ}$ cells. 
2) Ocean temperatures on the Antarctic continental shelf from animal-borne sensors

The 2004-17 MEOP data (Roquet et al. 2014; Treasure et al. 2017) offer a means to investigate Antarctic shelf water masses. Narayanan et al. (2019) showed that the presence of dense shelf waters coincides with an absence of warmer Circumpolar Deep Water. As part of that study, mean temperatures were quantified at depths ranging from $250 \mathrm{~m}$ to the bottom, and from the coast or ice shelf edge (75 km and beyond) to the continental shelf and slope (shallower than $3000 \mathrm{~m}$ ). Here we take the available 2019 MEOP data and repeat that analysis (Fig. 6.11b). In 2019, there were two regions with relatively good data coverage (Fig. 6.11c): the coastal areas off Princess Elizabeth Land and the Ross Sea (Ross). The observed 2019 Antarctic shelf temperatures are, on average, slightly lower than the 2004-17 temperatures in almost all the regions investigated, although the difference is not statistically significant (Fig.6.11b). This result, implying somewhat stable temperatures on the Antarctic shelf, demonstrates that MEOP-CTD data now enable us to monitor a large portion of this sensitive and climatically impactful region.

\section{3) Surface heat fluxes}

We use NCEP-II reanalysis data (Kanamitsu et al. 2002) to evaluate the seasonal and annual state of the surface net heat flux in 2019 compared with the 1981-2010 climatology south of $35^{\circ}$ S. Positive values denote a heat flux into the ocean. We note that there remains large inter-product spread in net heat flux estimates in the Southern Ocean (Liu et al. 2011; Josey et al. 2013; Swart et al. 2019) with no consensus on which product best represents Southern Ocean conditions. NCEPII, however, is considered a robust global heat flux product.

The 2019 anomaly (Fig. 6.12c) shows mostly positive values (10-40 $\mathrm{W} \mathrm{m}^{-2}$ ), particularly in the Indian and Pacific sectors of the Antarctic Circumpolar Current (ACC), with weak positive anomalies in the Atlantic. The mean net heat flux over the Southern Ocean during 2019 was 4.8 $\mathrm{W} \mathrm{\textrm {m } ^ { - 2 }}$ larger than the climatological mean, the largest yearly-averaged positive difference over the last 30 years (Fig. 6.12a). We also note the general upward trend in annual heat flux since the late 1990s and the positive atmosphere-to-ocean heat flux every year since 2010. Large negative
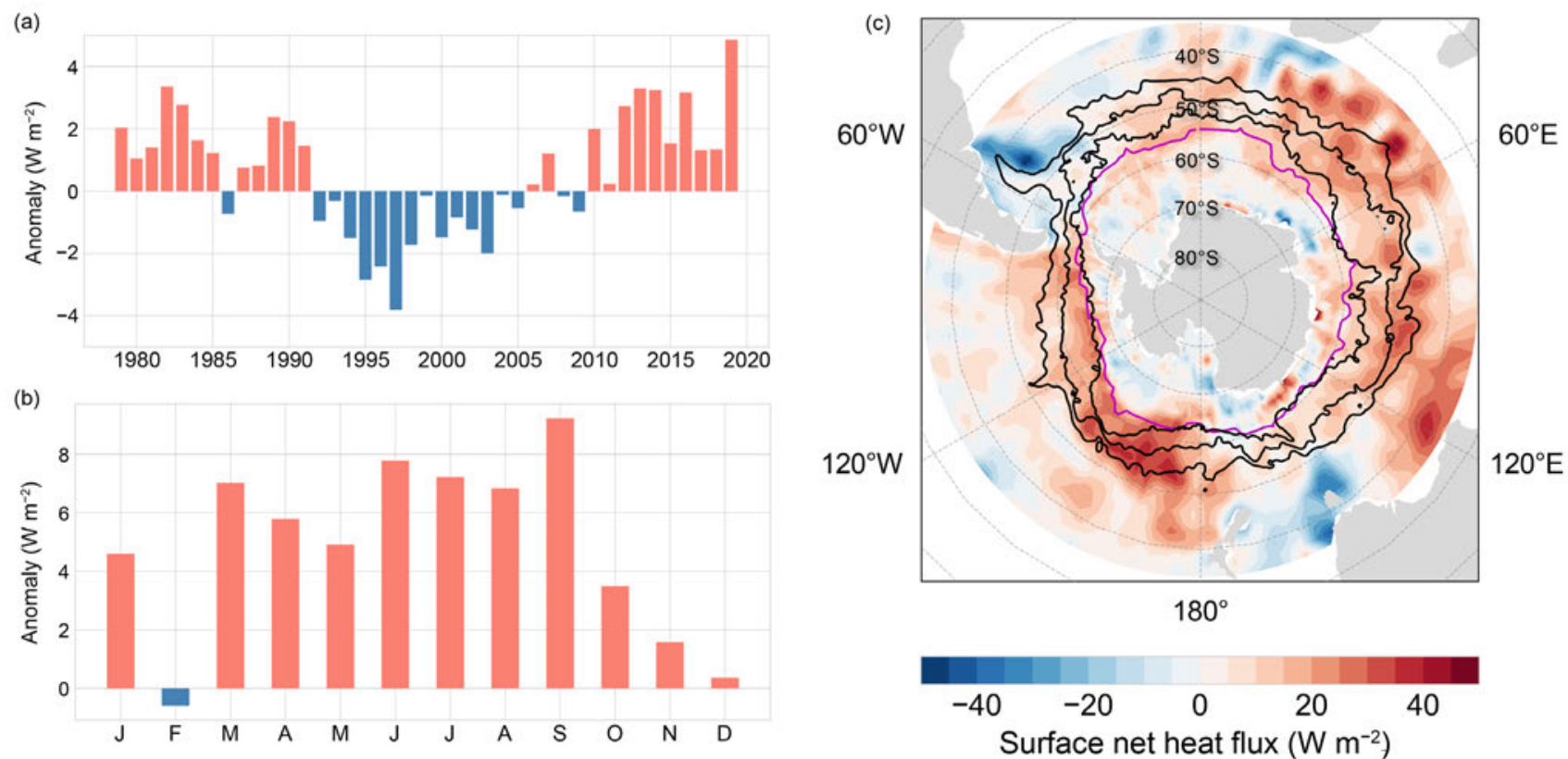

Fig. 6.12. (a) 30-year time series of heat flux anomalies for the Southern Ocean south of $35^{\circ} \mathrm{S}$ from NCEP-II reanalysis data. (b) Monthly net heat flux anomalies during 2019 south of $35^{\circ} \mathrm{S}$. (c) The mean surface net heat flux (positive denotes into the ocean; in $\mathrm{W} \mathrm{m}^{-2}$ ) anomaly for 2019 (minus the 30-year climatology) from NCEP-II reanalysis data. The main ACC fronts are depicted as black contours, from north to south, as the Subantarctic Front and the Antarctic Polar Front from AVISO Mean Absolute Dynamic Topography (as in Swart et al. 2010), while the maximum SIE (15\% SIC from NCEP/DOE AMIP-II Reanalysis) is shown as the magenta contour. 
anomalies $\left(-20 \mathrm{~W} \mathrm{~m}^{-2}\right)$ were confined to the confluence of the northern ACC boundaries and western boundary currents south of Africa, Tasmania, and the Falklands. The seasonal ice zone did not, on average, experience any significant heat flux anomalies during 2019. The 2019 monthly heat flux anomalies (Fig. 6.12b) were positive in all months except February $\left(-0.6 \mathrm{~W} \mathrm{~m}^{-2}\right)$. Autumn to winter anomalies (March-September) are significantly more positive ( 4.9 to $9.2 \mathrm{~W} \mathrm{~m}^{-2}$ ), with a maximum in September. It is uncertain why such positive anomalies exist in autumn-winter, but they may be associated with anomalies of surface air temperature and with the phase and intensity of the SAM index during 2019 (Figs. 6.2c, 6.3).

\section{4) Surface $\mathrm{CO}_{2}$ fluxes}

Over the last five years, floats have increased the number of perennial $\mathrm{CO}_{2}$ flux observations in the Southern Ocean (Johnson et al. 2017; Williams et al. 2017). Bushinsky et al. (2019) incorporated these float data into a neural network approach to predict surface $\mathrm{CO}_{2}$ fluxes (MPI-SOMFFN by Landschützer et al. 2016), affirming that the Southern Ocean sink may be $35 \%$ weaker than previously estimated (Gray et al. 2018). The interannual comparison is done using an adaptation of the CSIR-ML6 method that incorporates the available Southern Ocean Carbon and Climate Observations and Modeling (SOCCOM) project's float data (Gregor et al. 2019).

Estimates of the net flux of $\mathrm{CO}_{2}\left(\mathrm{FCO}_{2}\right)$ show that there was a statistically insignificant decrease in the Southern Ocean sink when comparing 2016-18 with 2019 ( $-0.63 \mathrm{Pg} \mathrm{C} \mathrm{yr}^{-1}$ to $-0.62 \mathrm{Pg} \mathrm{C} \mathrm{yr}^{-1}$, respectively). This variation does not contradict the findings by Keppler and Landschützer (2019) who found a weakening Southern Ocean sink from 2012. A seasonal breakdown shows that differences in winter and spring were zonally consistent compared with summer and autumn (Fig. 6.13). Winter showed weaker $\mathrm{CO}_{2}$ sources in the Atlantic and Indian sectors but a stronger $\mathrm{CO}_{2}$ source in the central Pacific (Fig. 6.13e). Regional variability is large in summer (Fig. 6.13g), where $\mathrm{CO}_{2}$ uptake increased in the Atlantic and south of Australia. The increased uptake in summer was likely caused by interannual variability in primary production (Gregor et al. 2018). Finally, in autumn, the eastern Pacific sector became a strong $\mathrm{CO}_{2}$ source region (Fig. 6.13h).
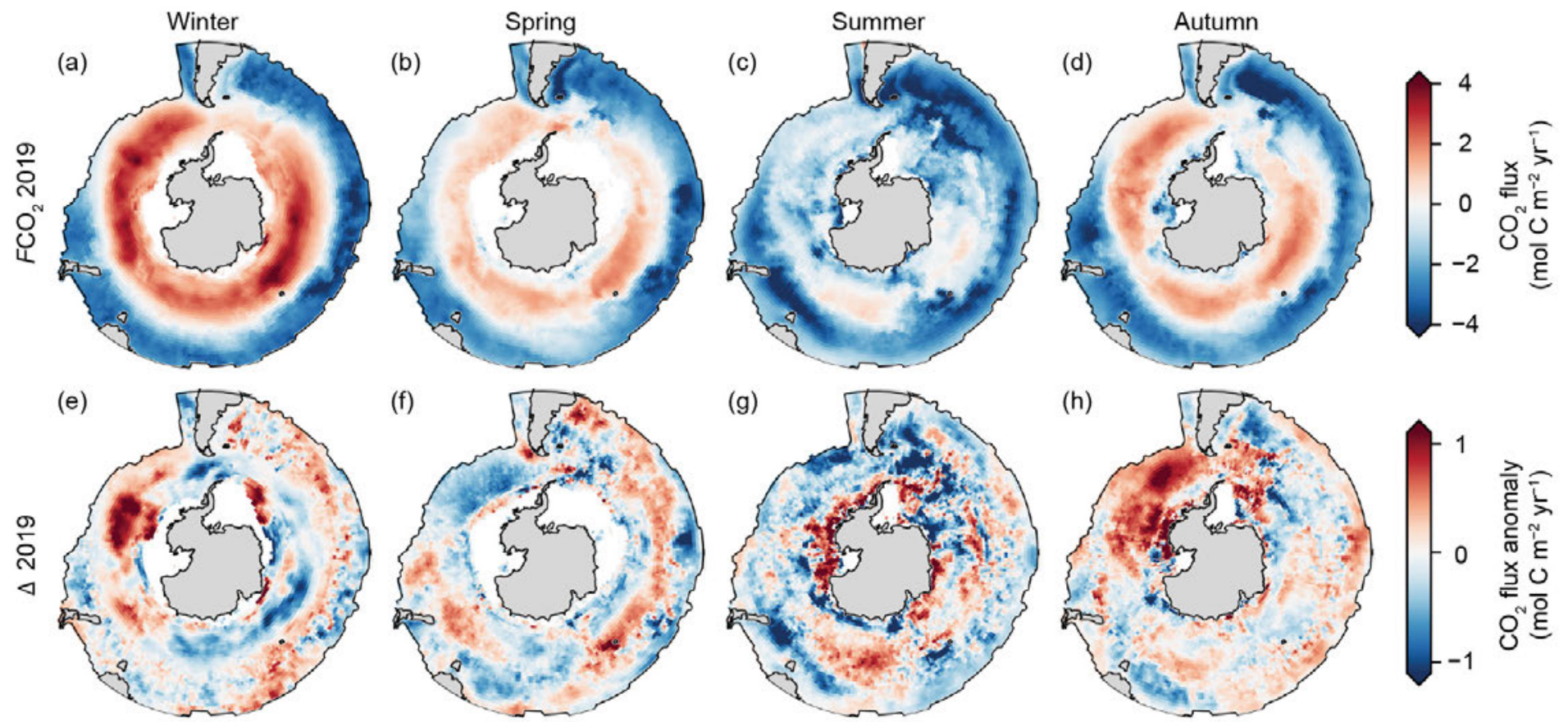

Fig. 6.13. Southern Ocean $\mathrm{CO}_{2}$ fluxes in 2019. (a)-(d) the total air-sea $\mathrm{CO}_{2}$ fluxes in 2019 for each of the seasons of $\mathrm{FCO}_{2}$ between 2019 and the comparison period (2016 to 2018), where positive (red) values are out of the ocean into the atmosphere. (e)-(h) the difference between 2019 and the comparison period (2016-18); blue/red shows less/more $\mathrm{CO}_{2}$ has exchanged between the ocean and the atmosphere. The maps have been limited to the Southern Ocean region as defined by Fay and McKinley (2014). 
g. 2019 Antarctic Ozone hole-N. Kramarova, P. A. Newman, E. R. Nash, S. E. Strahan, C. S. Long, B. Johnson, M. Pitts, M. L. Santee, I. Petropavlovskikh, L. Coy, and J. de Laat

The weakest Antarctic ozone hole since the early 1980s occurred in 2019. This weak hole was caused by atypically strong planetary-scale waves that propagated upward from the troposphere (Sidebar 6.1). These waves displaced and weakened the stratospheric polar vortex, slowing the 10-hPa zonal mean wind from $87 \mathrm{~m} \mathrm{~s}^{-1}$ to $11 \mathrm{~m} \mathrm{~s}^{-1}$ between 25 August and 17 September. The increased descent of stratospheric air, associated with the vortex weakening (section $6 \mathrm{~b}$ and Sidebar 6.1), warmed the stratosphere such that the 2019 September 50-hPa Antarctic temperature was $16 \mathrm{~K}$ above average, setting a record for 2019. These unusually above-normal lower stratospheric temperatures reduced polar stratospheric clouds (PSCs) and slowed catalytic ozone depletion.

Strong planetary wave events dominated the 2019 ozone hole evolution and affected ozone in two ways. First, these events forced downward motion in the polar region, bringing ozone down to the lower stratosphere. Second, they increased meridional transport of ozone-rich air from midlatitudes into the Antarctic mid-to-upper stratosphere above the ozone hole (Sidebar 6.1).

Lower stratospheric temperatures increased in mid-August, and by early September, they were well above the 2005-18 average (Fig. 6.14a). This stratospheric warming occurred at the pivotal time for ozone depletion. Substantial Antarctic ozone depletion begins in August during the Southern Hemisphere (SH) late winter as the sun's rays return to polar latitudes, activating

(a) Temperature

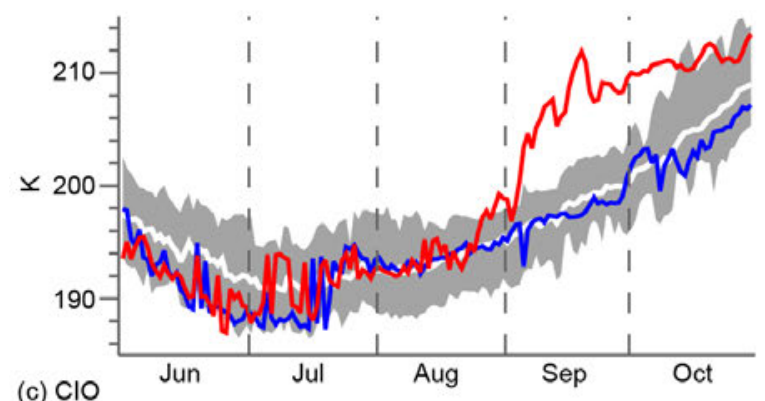

(c) $\mathrm{ClO}$

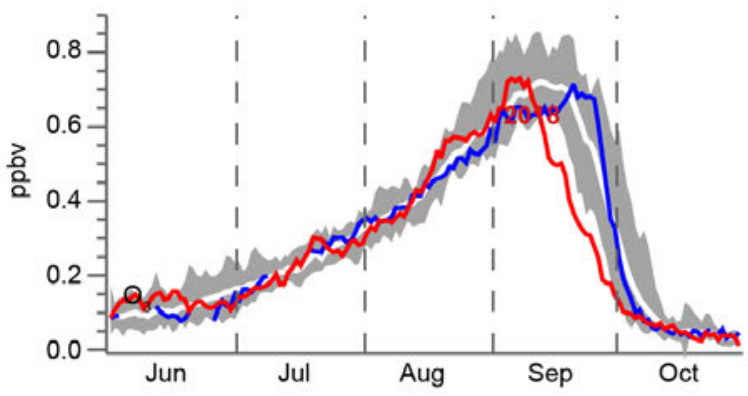

(e) Hole area

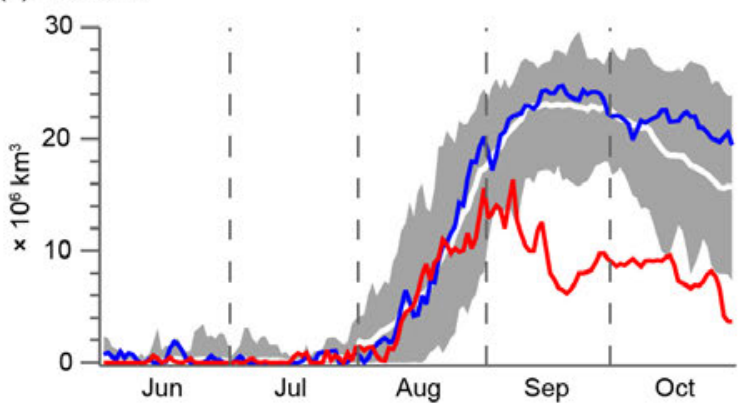

(b) PSC Vol.
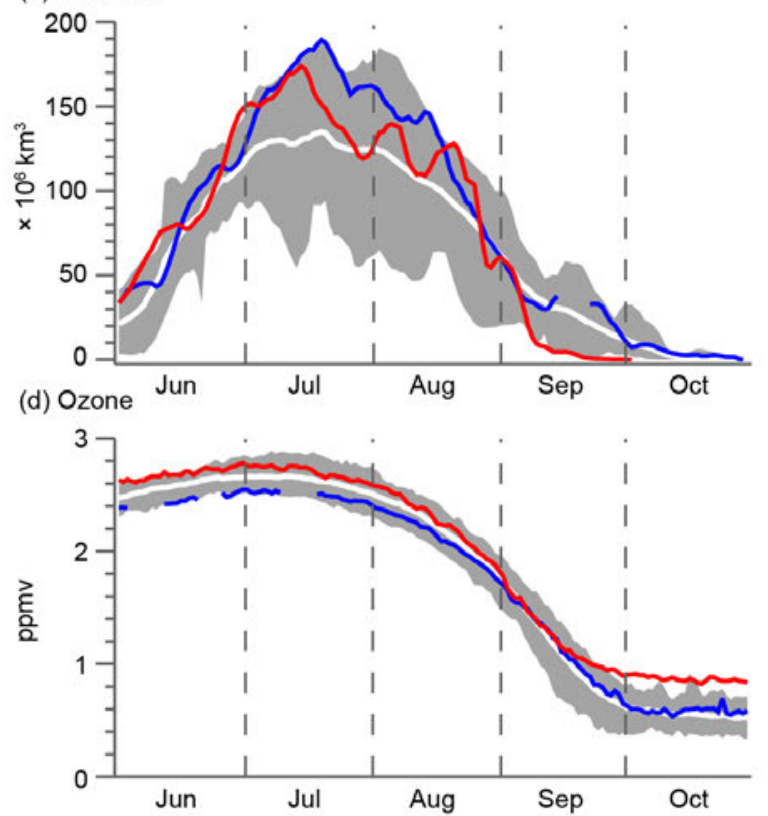

Fig. 6.14. Antarctic 2019 (red curves) and 2018 (blue curves) values of (a) vortex-averaged MERRA-2 temperature (K); (b) CALIPSO PSC volume $\left(\times 10^{6} \mathrm{~km}^{3}\right.$; updated from Pitts et al. 2018); vortex-averaged concentrations of (c) $\mathrm{ClO}$ (ppbv) and (d) $\mathrm{O}_{3}$ (ppmv) measured by MLS (updated from Manney et al. 2011); and (e) OMI/OMPS Antarctic ozone hole area $\left(\times 10^{6} \mathrm{~km}^{3}\right.$; area with ozone total column less than $220 \mathrm{DU})$. MERRA-2 temperature and MLS averages are made inside the polar vortex on the 440-K potential temperature surface $(19 \mathrm{~km}$ or $60 \mathrm{hPa})$. Gray shading shows the range of daily values, and the white curves indicate the long-term mean for 2005-18, except for (b) that uses the period 2006-18. 
chlorine and bromine chemistry that depletes ozone. PSC particles provide surfaces for heterogeneous chemical reactions that release chlorine and catalytically destroy ozone. The wave events led to earlier-than-usual PSC disappearance over Antarctica (PSC volume dropped to almost zero by mid-September), suppressing ozone depletion far earlier than usual (Fig. 6.14b).

The 2019 chlorine monoxide (ClO) concentrations from the Aura Microwave Limb Sounder (MLS) rapidly declined in early September, and by late September they reached the lowest values observed in the 2005-19 record (Fig. 6.14c). ClO is directly related to the rate of ozone depletion. Typically, ClO steadily increases as sunlight returns to Antarctica, and its enhancement continues until mid-October. Because of low $\mathrm{ClO}$ in 2019, ozone levels (Fig. 6.14d) in mid-September to October were 13\%-55\% above the seasonal average. The early August hole area (Fig. 6.14e) grew normally, but growth slowed in late August, reaching its peak extent of 16.4 million $\mathrm{km}^{2}\left(\mathrm{Mkm}^{2}\right)$ on 8 September. It shrank below $10 \mathrm{Mkm}^{2}$ by 15 September and remained low through October. In contrast, the 2018 area with lower temperatures and higher $\mathrm{ClO}$ was relatively large (Fig. 6.14e, blue curves).

Antarctic total ozone column is determined by two main parameters: abundances of ozonedepleting substances (ODS) and Antarctic lower stratospheric temperatures. The effective equivalent stratospheric chlorine (EESC) is an estimate of the amount of human-made ODS in the stratosphere. EESC has gradually declined from its peak in 2000. The September Antarctic polar cap $\left(60^{\circ}-90^{\circ} \mathrm{S}\right)$ total ozone follows EESC changes (EESC fit shown as magenta in Fig. 6.15b). In 2019, satellite measurements show that polar cap total column ozone had the highest concentrations over the 40-year period (Fig. 6.15b). The 2019 September average of the minimum total ozone values over Antarctica (Fig. 6.15c) was the highest observed since 1988, but not a record high. Antarctic ozone continued an upward trend since 1999, consistent with decreasing stratospheric EESC levels (blue line in Fig. 6.15c).

Dynamical variability in September stratospheric ozone over the South Pole is typically weak, and lower stratospheric ozone partial columns are mostly controlled by the photochemical

(a) Temperature $\left(60^{\circ}-90^{\circ} \mathrm{S}, 50 \mathrm{hPa}\right)$

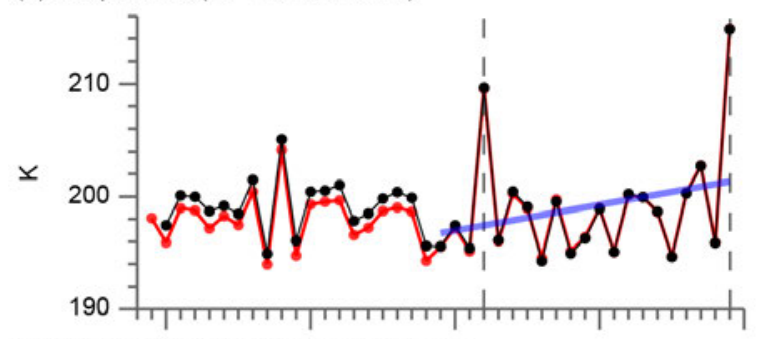

(c) Antarctic minimum total column ozone

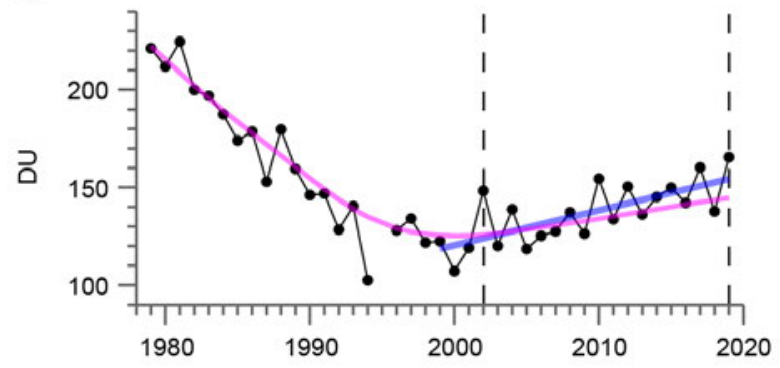

(b) Total column ozone $\left(60^{\circ}-90^{\circ} \mathrm{S}\right)$

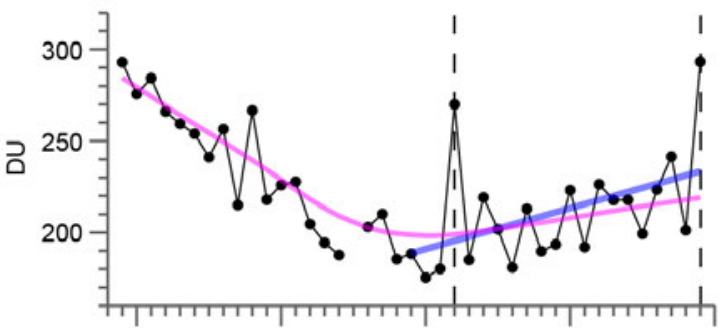

(d) South Pole $12-20 \mathrm{~km}$ column ozone

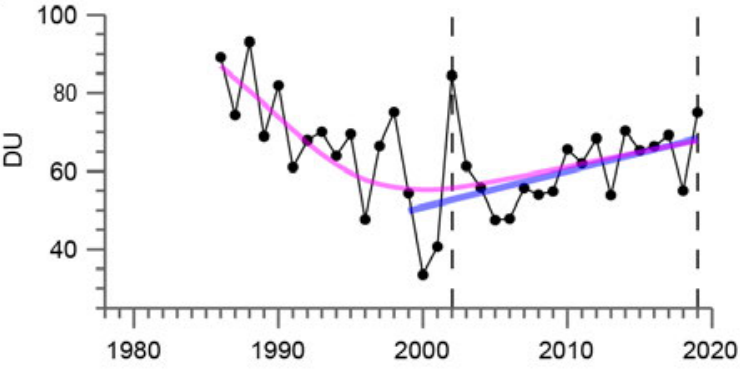

Fig. 6.15. Long-term variability of ozone and atmospheric temperature. (a) 50-hPa Sep mean temperature (K) over $60^{\circ}-90^{\circ} \mathrm{S}$ from MERRA-2 (black) and ERA5 reanalyses (red). Note that the ERA5 and MERRA-2 values exhibit a consistent bias for the period up to 1998, but the two datasets are in excellent agreement from 1999 to the present. (b) Sep mean total ozone column (DU) over $60^{\circ}-90^{\circ} \mathrm{S}$ and (c) minimum total ozone column over Antarctica derived from NASA satellite sensors (TOMS, OMI, and OMPS). (d) Sep mean partial ozone column (DU) measured within the primary depletion layer (12-20 km) by NOAA South Pole ozone sondes. Blue lines indicate linear trends for the time period 1999-2019. The magenta curve in (b), (c), and (d) is the quadratic fit of ozone columns to effective equivalent stratospheric chlorine (EESC). The vertical lines indicate the anomalous years 2002 and 2019. 
depletion rates. The September South Pole ozone partial columns between 12 and $20 \mathrm{~km}$ (Fig. 6.15d; derived from NOAA balloon profiles) have higher correlations with Antarctic minimum column ozone than with polar cap averages. In September 2019, the mid-to-upper stratospheric polar vortex was displaced from the South Pole, resulting in large stratospheric temperature and ozone profile variability and anomalies. The lowest 2019 South Pole total ozone was recorded earlier than usual (24 September), with a polar-centered vortex, and the lowest partial column ozone was observed a half month later (10 October). As with the minimum total column ozone, the South Pole partial column ozone shows an upward trend since the late 1990s.

Interannual variations in Antarctic stratospheric temperature influence observed ozone trends. Antarctic ozone anomalies are highly correlated with lower stratospheric temperatures (Fig. 6.16). Anomalies are derived by subtracting a quadratic EESC fit from the observed September mean total ozone over the Antarctic polar cap (black line in Fig. 6.15b). Record high column ozone in 2019 resulted from record high September temperatures (Sidebar 6.1). In 2002, Antarctic ozone rapidly declined until mid-September, when the wave events disturbed the polar vortex and caused rising temperatures. The 1988 and 2017 holes were also small because of higher temperatures, while the 2018 hole was large because of lower-than-average Antarctic temperatures (Fig. 6.15). Strong wave events occurred infrequently in the Antarctic during the past 40 years (Langematz and Tully 2018). When they do occur, the impact from strong wave events, like those observed in September 2002 and 2019 (indicated by vertical dashed lines in Fig. 6.15), are revealed by strong extremes in the observations (Fig. 6.15).

An upward temperature trend contributes to an upward ozone trend (i.e., a shift toward the upper right of Fig. 6.16). There is a non-statistically significant $+2.3 \mathrm{~K} \mathrm{decade}^{-1}$ trend (76\% confidence, two-sided test) in the September mean Antarctic lower stratospheric temperature since 1999 (blue line in Fig. 6.15a), with non-significance likely reflecting the short record. Nevertheless, this upward temperature trend adds to observed ozone increases arising from EESC decline (Figs. 6.15b-d). Antarctic polar cap ozone (blue line in Fig. 6.15b) has a +22.3 DU decade ${ }^{-1}$ trend since 1999 (94\% confidence). Positive trends are also apparent in the Antarctic minimum column ozone (+17.9 DU decade ${ }^{-1}$ with $>99 \%$ confidence; Fig. 6.15c) and South Pole observations (+9.2 DU decade ${ }^{-1}$ with 95\% confidence; Fig. 6.15d). While declining ODS levels contributed to the smaller 2019 ozone hole, the primary cause was the unusually strong dynamical waves, similar to 2002 conditions.

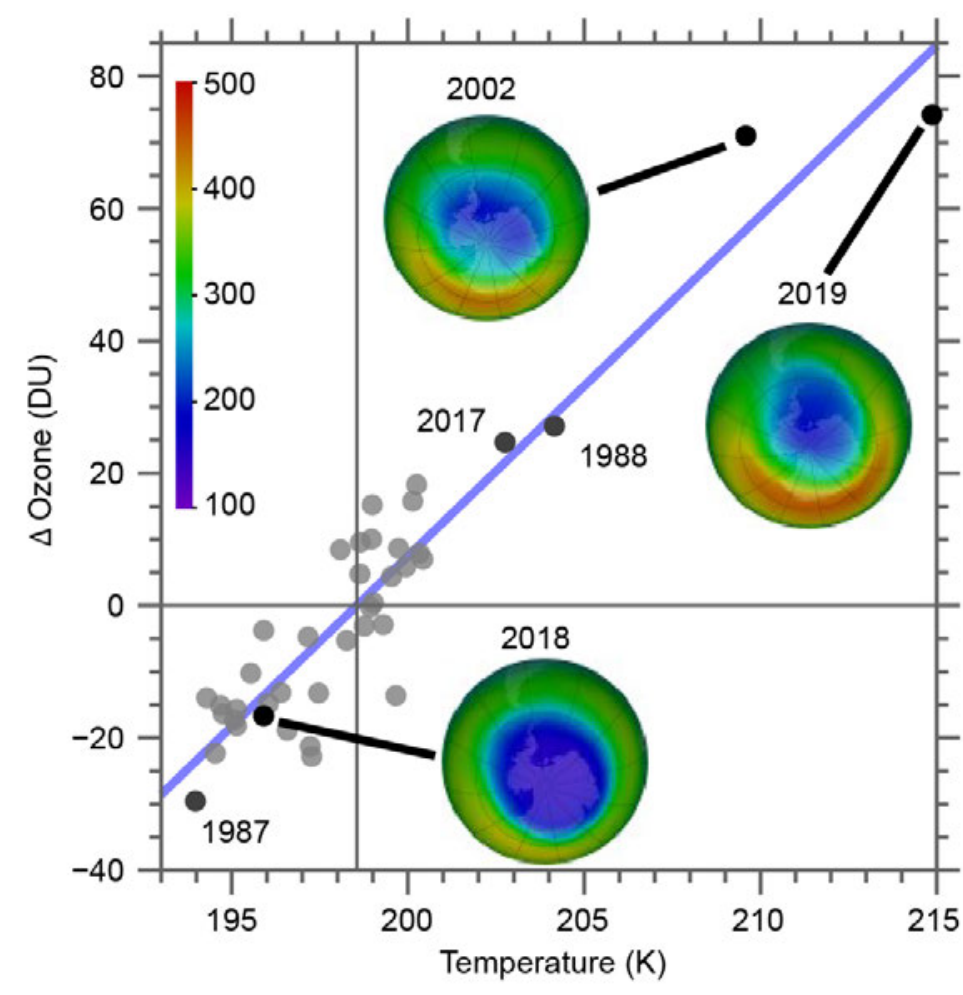

Fig. 6.16. Column ozone anomalies (DU) vs. ERA5 50-hPa Sep mean temperatures $(\mathrm{K})$ in the $60^{\circ}-90^{\circ} \mathrm{S}$ region (values from Figs. 6.15a,b). The ozone anomalies for each year are calculated by subtracting a quadratic EESC fit (magenta line in Fig. 6.15b) from the observed Sep mean total ozone over the Antarctic polar cap (black line in Fig. 6.15b). The inset false-color images are Sep mean total column ozone. The horizontal line indicates the zero anomaly for column ozone, while the vertical line indicates the temperature at this zero-ozone anomaly. The blue line shows the linear fit. 


\section{SIDEBAR 6.3: Sea Ice Prediction Network-South: Coordinating seasonal predictions of sea ice for the Southern Ocean-J. L. LIESER, F. MASSONNET, W. HOBBS, J. FYFE,}

\section{M. BITZ, AND P. REID}

The Sea Ice Predication Network (SIPN) is a community-wide effort to assess seasonal sea ice forecasts for the Arctic. It has been in operation since 2008, when it started life as the SEARCH Sea Ice Outlook (Hamilton and Stroeve 2016). This international initiative has created a strong community of researchers from various backgrounds with a common interest in forecasting sea ice conditions in the Arctic Ocean.

SIPN-South now expands this prediction network by providing seasonal sea ice forecasts for the Southern Ocean. Endorsed by the Year of Polar Prediction project (Jung et al. 2016), SIPNSouth provides a focal point for a seasonal forecast of Antarctic sea ice, which is thought to be less predictable than Arctic sea ice. However, recent research (Marchi et al. 2018) suggests that, in fact, the large thermal inertia of the Southern Ocean together with atmospheric teleconnections from outside the immediate Antarctic realm (Pope et al. 2017) could represent the key factors for Southern Hemisphere (SH) sea ice predictability.

Highly variable sea ice extent is one of the many challenges that vessels face when operating in the Antarctic coastal region, and this can substantially impact science, science support, and logistic operations as well as fishing and tourist activities in those regions. These logistical challenges were highlighted during a dedicated workshop held by the Council of Managers of National Antarctic Programs (COMNAP 2015). Advance notice of seasonal sea ice conditions could help reduce risks to the operations and the environment and costs associated with providing alternative operational logistics. In 2017, the provision of sea ice outlooks became even more relevant when the International Maritime Organization's (IMO) International Code for Ships Operating in Polar Waters (known as the Polar Code) came into force (IMO 2017). The Polar Code provides polar ship operators with a framework for mandatory measures as well as recommended provisions covering safety and pollution prevention. One of these measures is voyage planning, which is ideally informed by the best-possible observations of current sea ice conditions but also predictions of conditions in the near- and medium-term future. SIPN-South's key role in this is to provide a forum within which research organizations and individuals may openly discuss their model's performance against other similar endeavours. Hence, the initiative will help inform the development of suitable sea ice forecasting models for the Antarctic.

SIPN-South has now successfully completed two campaigns of solicited Antarctic summer sea ice predictions. These predictions are featured in two published reports that evaluate forecasts against observed sea ice states (Massonnet et al. $2018,2019)$. For the summer 2019/20 season, the third installment of the project received 11 submissions at the beginning of December 2019 (Table SB6.1). Figure SB6.4a shows the total

\begin{tabular}{|c|c|c|c|c|c|c|}
\hline \multicolumn{2}{|c|}{ Contributor name } & \multirow{2}{*}{$\begin{array}{c}\text { Short name } \\
\text { (in figures) } \\
\text { NicoSun }\end{array}$} & \multirow{2}{*}{$\begin{array}{l}\text { Forecasting method } \\
\text { Statistical model }\end{array}$} & \multirow{2}{*}{$\begin{array}{c}\text { Number of } \\
\text { forecasts } \\
3\end{array}$} & \multirow{2}{*}{$\begin{array}{c}\text { Initialization } \\
\text { date } \\
30 \mathrm{Nov}\end{array}$} & \multirow{2}{*}{$\begin{array}{l}\text { Diagnotstics provided } \\
\qquad S I A+S I C\end{array}$} \\
\hline 1. & Nico Sun & & & & & \\
\hline 2. & NASA-GMAO & nasa-gmao & Coupled dynamical model & 10 & $27 \mathrm{Nov}$ & $S I A+S I C$ \\
\hline 3. & FIO-ESM & FIO-ESM & Coupled dynamical model & 1 & 15 Nov & SIA \\
\hline 4. & ECMWF & ecmwf & Coupled dynamical model & 51 & $30 \mathrm{Nov}$ & $S I A+r S I A$ \\
\hline 5. & $\begin{array}{l}\text { Lamont Sea } \\
\text { Ice Group }\end{array}$ & Lamont & Statistical model & 1 & 31 Oct & $\begin{array}{c}\text { SIA + rSIA + SIC } \\
\text { (monthly, interp. daily) }\end{array}$ \\
\hline 6. & NASA-GSFC & NASA-GSFC & Statistical model & 1 & $30 \mathrm{Nov}$ & SIA \\
\hline 7. & $\begin{array}{l}\text { Modified_- } \\
\text { CanSIPS }\end{array}$ & $\begin{array}{l}\text { Modified_Can- } \\
\text { SIPS }\end{array}$ & Coupled dynamical model & 20 & $30 \mathrm{Nov}$ & $S I A+r S I A$ \\
\hline 8. & Met Office & MetOffice & Coupled dynamical model & 42 & $25 \mathrm{Nov}$ & $S I A+r S I A+S I C$ \\
\hline 9. & CNRM & CNRM & Coupled dynamical model & 51 & $30 \mathrm{Nov}$ & $S I A+r S I A+S I C$ \\
\hline 10. & UCLouvain & ucl & $\begin{array}{l}\text { Ocean-Sea Ice dynamical } \\
\text { model }\end{array}$ & 10 & $1 \mathrm{Jul}$ & $S I A+r S I A+S I C$ \\
\hline 11. & $\begin{array}{l}\text { Sandra } \\
\text { Barreira }\end{array}$ & barreira & Statistical model & 1 & 30 Nov & $S I A+S I C$ \\
\hline
\end{tabular}



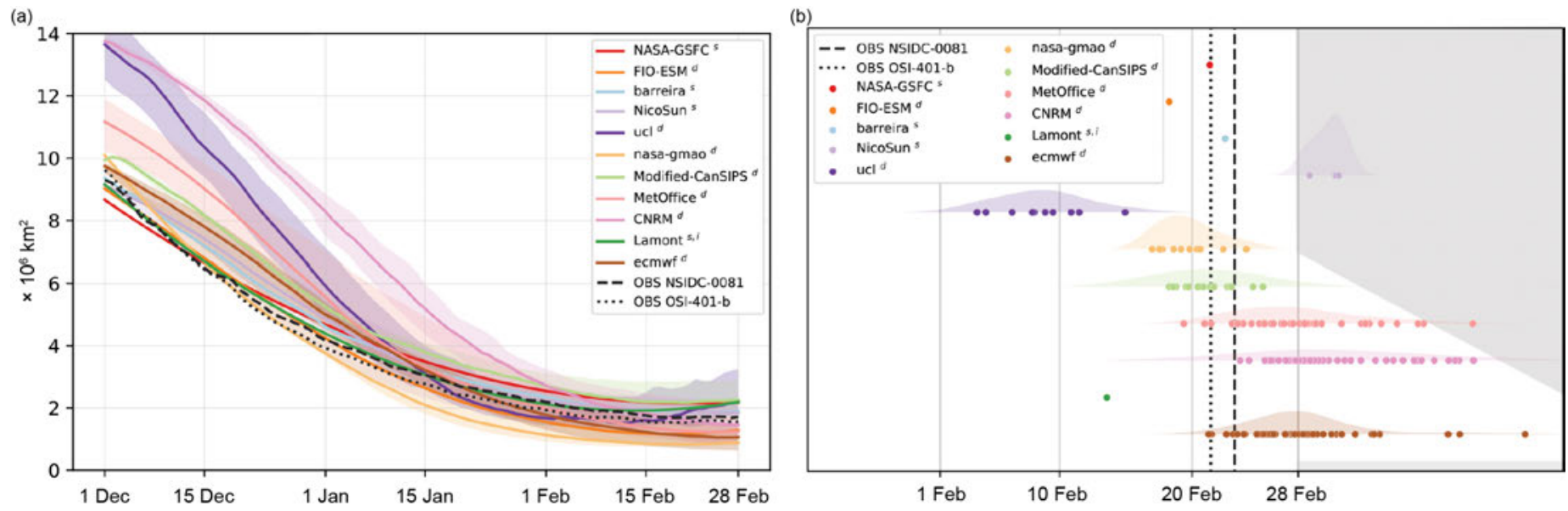

Fig. SB6.4. (a) Total (circumpolar) Antarctic SIA $\left(\times 10^{6} \mathrm{~km}^{2}\right)$ of the 11 forecasts for each day of Dec-Feb 2019/20. The superscripts in the legend indicate whether the submission is based on a statistical or a dynamical approach. The black dashed lines are two observational references up to 21 Dec 2019. (b) Timing of the 2020 annual minimum Antarctic SIA from forecasts (colors) and two observational references (Maslanik and Stroeve 1999; Tonboe et al. 2017). To filter out the effects of synoptic variability, the minimum was determined from a quadratic fit of the Feb daily SIA time series. Superscripts in the legend indicate whether the submission is based on a statistical or a dynamical approach and, possibly, if monthly data has been interpolated to daily resolution.

SIA forecast for each day of December-February 2019/20. We understand that SIA may not be the most suitable geophysical diagnostic to assess model performance, but it gives a valuable first indication of how the forecasts behave. Figure SB6.4a also includes SIA from two observational sources, the NSIDC-0081 product (Near-Real-Time DMSP SSMIS Daily Polar Gridded Sea Ice Concentrations; Maslanik and Stroeve 1999) and the OSI-401-b product (Global Sea Ice Concentration; Tonboe et al. 2017) for comparison. (Two SIPN-South forecasts based on dynamical coupled models appear to be biased high at the time of initialization.)

Seven groups submitted spatial information of daily SIC for each day of December-February 2019/20. These groups provided several forecast members (from 1 to 42) to sample uncertainty associated with the (unpredictable) evolution of the climate system, so that each member of a given model can be seen as a possible realization of that model. Based on these forecasts, Fig. SB6.5 shows the modeled daily probability of sea ice presence on 15 February 2020, which can serve as useful information to ship operators when assessing potential areas of operation. Green pixels are those where the sea ice is unlikely to be present, while red ones are those where the sea ice is likely to be present.

The model ensembles are designed to sample weather variability, and results from Fig. SB6.5 indicate that weather can drive sea ice variability in key sectors like the Ross Sea, a region that proved very difficult to forecast during the previous two exercises. Whether those forecasts are correctly calibrated can be investigated once more retrospective forecasts are available, although this is beyond the scope of the SIPN-South project.

Figure SB6.4b illustrates the timing of the 2020 annual minimum Antarctic SIA from forecasts (colors) and two observational references. The minimum was correctly predicted by four forecasts when compared with the OSI-401-b observations and two forecasts when assessed against the NSIDC-0081 observations. 
In summary, while we acknowledge that more hindcasts are necessary to ensure the robustness of the results, the analysis (a) NASA-GMAO

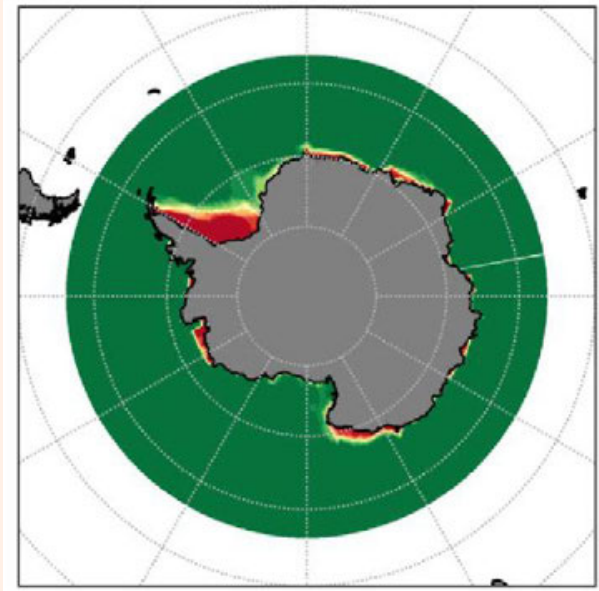

(c) NicoSun
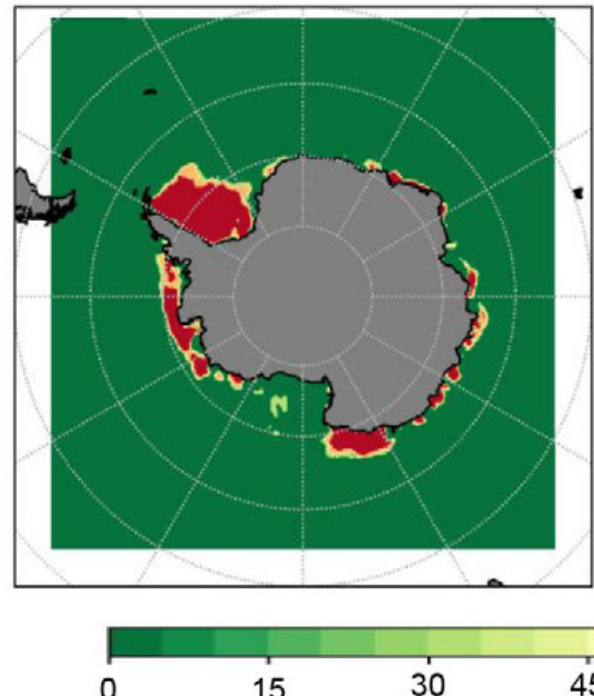

15

0

30 (b) MetOffice

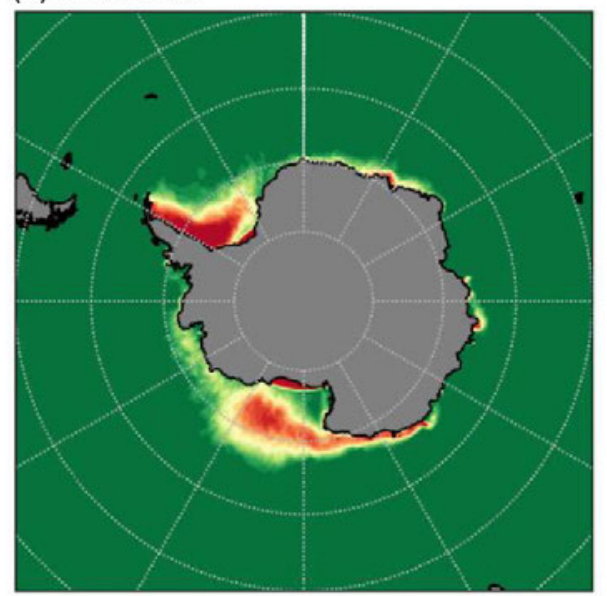

(d) UCL

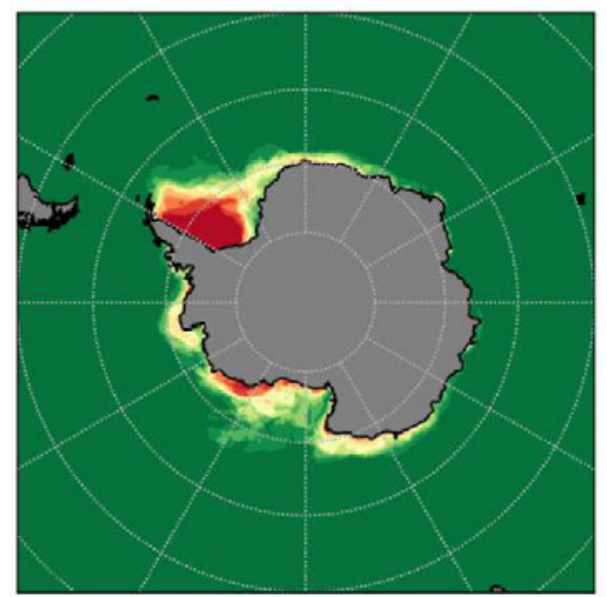

of three forecast exercises has already revealed several key outcomes:

- When viewed as an ensemble, the range of multi-model forecast of total February Antarctic SIA includes the actual observed state (Massonnet et al. 2018, 2019). However, errors can be large for individual submissions. Observational uncertainty alone cannot explain the forecast-observation mismatch (Maslanik and Stroeve 1999; Tonboe et al. 2017);

- The timing of minimum Antarctic SIA is not well predicted by the ensemble. The date of the minimum is in part driven by the seasonal change in insolation (which is predictable) but can be modulated by a few days by the passage of synoptic weather systems. Models, regardless of their nature, should capture weather uncertainty, but it appears that the ensemble spread is generally too narrow;

- In the first two SIPN-South experiments, the statistical contributions outperformed other contributions with respect to prediction of the timing of the annual minimum;

- At this stage of development, the SIPN-South data set is not yet mature enough for practical application to field experiment planning or maritime route forecasting in the Antarctic sea ice zone. Long records of retrospective forecasts are lacking in order to properly identify the origin of systematic forecast errors. 


\section{Acknowledgments}

Ted Scambos was supported under NASA grant 17-MEASURES-0075, ITS_LIVE and NSF ANT 0944763, the Antarctic Glaciological Data Center.

Sharon Stammerjohn was supported under NSF PLR 1440435; she also thanks the Institute of Arctic and Alpine Research and the National Snow and Ice Data Center, both at the University of Colorado Boulder, for institutional and data support.

The work of Phil Reid and Rob Massom was supported by the Australian Government's Australian Antarctic Partnership Program, and contributes to AAS Project 4116. Phil Reid and Jan Lieser were also supported through the Australian Bureau of Meteorology, and Rob Massom by the Australian Antarctic Division.

Sandra Barreira was supported by the Argentine Hydrographic Service - Naval Meteorological Service.

Helen Amanda Fricker was supported by the NASA Cryospheric Sciences Program in support of the ICESat-2 mission under awards NNX15AC80G.

Alex Gardner was supported by funding from the NASA Cryosphere and MEaSUReS programs.

Povl Abrahamsen was supported by NERC grant NE/N018095/1.

Support for Linda Keller, David Mikolajczyk, and Matt Lazzara is courtesy of the National Science Foundation, Office of Polar Programs, Grants \#1543305 and \#1924730.

The marine mammal data were collected and made freely available by the International MEOP Consortium and the national programs that contribute to it (http://www.meop.net). We acknowledge in particular major contributions in the Southern Ocean in 2019 from IMOS (Integrated Marine Observing System, Australia) and from SO-MEMO (Observing System - Mammals as samplers of the Ocean Environment, France).

Seb Swart was supported by a Wallenberg Academy Fellowship (WAF 2015.0186) and by the Swedish Research Council (VR 2019-04400). Swart and Marcel du Plessis are supported by the South African National Research Foundation (SANAP - SNA14071475720). NCEP_Reanalysis 2 data provided by the NOAA/OAR/ESRL PSD, Boulder, Colorado, USA, from their website at https://www.esrl.noaa.gov/psd/

The authors of Sidebar 6.3 appreciate the contributions to all the forecast exercises, particularly those presented here from Nico Sun, NASA-GMAO (Richard Cullather, Anna Borovikov, Eric Hackert, Robin Kovach, Zhao Li, Jelena Marshak, Andrea Molod, Steven Pawson, Yury Vikhliaev, Bin Zhao), FIO-ESM (Fangli Qiao, Zhenya Song, Xunqiang Yin, Yajuan Song), NASA-GSFC (Alek Petty), Met Office (Ed Blockley, GloSea5 Seasonal Forecast team), Sandra Barreira and Alvaro Scardilli, as well as UC Louvain (Sylvain Marchi, François Massonnet). 


\section{APPENDIX: Acronym List}

\begin{tabular}{|c|c|}
\hline ABS & Amundsen and Bellingshausen Seas \\
\hline ACC & Antarctic Circumpolar Current \\
\hline AIS & Antarctic Ice Sheet \\
\hline $\mathrm{ClO}$ & chlorine monoxide \\
\hline CDW & Circumpolar Deep Water \\
\hline DMSP & Defense Meteorological Satellite Program \\
\hline DU & Dobson Units \\
\hline EAIS & East Antarctic Ice Sheet \\
\hline EESC & effective equivalent stratospheric chlorine \\
\hline ENSO & El Niño-Southern Oscillation \\
\hline ECMWF & European Centre for Medium-Range Weather Forecast \\
\hline ISD & ice season duration \\
\hline IMBIE & Ice-sheet Mass Balance Inter-comparison Experiment \\
\hline IOD & Indian Ocean dipole \\
\hline IPCC & Intergovernmental Panel on Climate Change \\
\hline IMO & International Maritime Organization \\
\hline MEOP & Marine Mammals Exploring the Oceans Pole to Pole \\
\hline MBM & mass budget method \\
\hline ME & melt extent \\
\hline MI & melt index \\
\hline MLS & Microwave Limb Sounder \\
\hline NSIDC & National Snow and Ice Data Center \\
\hline $\mathrm{NH}$ & Northern Hemisphere \\
\hline ODS & ozone-depleting substances \\
\hline PSCs & polar stratospheric clouds \\
\hline SIA & sea ice area \\
\hline SIC & sea ice concentration \\
\hline SIE & sea ice extent \\
\hline SIPN & Sea Ice Predication Network \\
\hline SST & sea surface temperature \\
\hline SAM & Southern Annual Mode \\
\hline $\mathrm{SH}$ & Southern Hemisphere \\
\hline SOCCOM & Southern Ocean Carbon and Climate Observations and Modeling \\
\hline SSMIS & Special Sensor Microwave-Imager Sounder \\
\hline SMB & surface mass balance \\
\hline
\end{tabular}




\section{References}

Abrahamsen, E. P., and Coauthors, 2019: Stabilization of dense Antarctic water supply to the Atlantic Ocean overturning circulation. Nat. Climate Change, 9, 742-746, https://doi.org/10.1038/s41558-019-0561-2.

Agosta, C., and Coauthors, 2019: Estimation of the Antarctic surface mass balance using the regional climate model MAR (1979-2015) and identification of dominant processes. Cryosphere, 13, 281-296, https://doi.org/10.5194/ tc-13-281-2019.

Armstrong, R., K. Knowles, M. J. Brodzik, and M. A. Hardman, 1994: DMSP SSM/I-SSMIS pathfinder daily EASE-grid brightness temperatures, version 2. NASA NSIDC DAAC, accessed 12 February 2020, https://doi. org/10.5067/3EX2U1DV3434.

Bintanja, R., G. J. van Oldenborgh, S. S. Drijfhout, B. Wouters, and C. A. Katsman, 2013: Important role for ocean warming and increased ice-shelf melt in Antarctic sea-ice expansion. Nat. Geosci., 6, 376-379, https://doi. org/10.1038/ngeo1767.

Bourassa, M. A., and Coauthors, 2013: High-latitude ocean and sea ice surface fluxes: Challenges for climate research. Bull. Amer. Meteor. Soc., 94, 403-423, https://doi.org/10.1175/BAMS-D-11-00244.1.

Bushinsky, S. M., and Coauthors, 2019: Reassessing Southern Ocean airsea $\mathrm{CO} 2$ flux estimates with the addition of biogeochemical float observations. Global Biogeochem. Cycles, 33, 1370-1388, https://doi. org/10.1029/2019GB006176.

Castagno, P., V. Capozzi, G. R. DiTullio, P. Falco, G. Fusco, S. R. Rintoul, G. Spezie, and G. Budillon, 2019: Rebound of shelf water salinity in the Ross Sea. Nat. Commun., 10, 5441, https://doi.org/10.1038/s41467-019-13083-8.

Cavalieri, D. J., and Coauthors, 1996: Sea ice concentrations from Nimbus-7 SMMR and DMSP SSM/I-SSMIS passive microwave data, version 1. NASA NSIDC DAAC, accessed 12 February 2020, https://doi.org /10.5067/8GQ8LZQVLOVL.

Chen, J. L., C. R. Wilson, D. N. D. Blankenship, and B. D. Tapley, 2009: Accelerated Antarctic ice loss from satellite gravity measurements. Nat. Geosci., 2, 859-862, https://doi.org/10.1038/nge0694.

Comiso, J. C., R. A. Gersten, L. V. Stock, J. Turner, G. J. Perez, and K. Cho, 2016: Positive trend in the Antarctic sea ice cover and associated changes in surface temperature. J. Climate, 30, 2251-2267, https://doi.org/10.1175/JCLID-16-0408.1.

COMNAP, 2015: COMNAP Sea Ice Challenges Workshop. Workshop Rep., Council of Managers of National Antarctic Programs, 71 pp., www.comnap.aq/ documents/COMNAP_Sea_Ice_Challenges_BKLT_Web_Final_Dec2015. pdf.

Copernicus Climate Change Service 2017: ERA5: Fifth generation of ECMWF atmospheric reanalyses of the global climate. Copernicus Climate Change Service Climate Data Store, accessed 4 May 2018, https://cds.climate.copernicus.eu/cdsapp\#!/home/.

Depoorter, M. A., J. L. Bamber, J. A. Griggs, J. T. M. Lenaerts, S. R. M. Ligtenberg, M. R. van den Broeke, and G. Moholdt, 2013: Calving fluxes and basal melt rates of Antarctic ice shelves. Nature, 502, 89-92, https://doi. org/10.1038/nature12567.

Desbruyères, D. G., S. G. Purkey, E. L. McDonagh, G. C. Johnson, and B. A. King, 2016: Deep and abyssal ocean warming from 35 years of repeat hydrography. Geophys. Res. Lett., 43, 10356-10365, https://doi. org/10.1002/2016GL070413.

Fay, A. R., G. A. McKinley, and N. S. Lovenduski, 2014: Southern Ocean carbon trends: Sensitivity to methods. Geophys. Res. Lett., 41, 6833-6840, https:// doi.org/10.1002/2014GL061324.

Gardner, A. S., G. Moholdt, T. Scambos, M. Fahnstock, S. Ligtenberg, M. Van Den Broeke, and J. Nilsson, 2018: Increased West Antarctic and unchanged East Antarctic ice discharge over the last 7 years. Cryosphere, 12, 521-547, https://doi.org/10.5194/tc-12-521-2018.
Gelaro, R., and Coauthors, 2017: The Modern-Era Retrospective Analysis for Research and Applications, version 2 (MERRA-2). J. Climate, 30, 5419-5454, https://doi.org/10.1175/JCLI-D-16-0758.1.

Gordon, A. L., B. A. Huber, and E. P. Abrahamsen, 2020: Interannual variability of the outflow of Weddell Sea Bottom Water. Geophys. Res. Lett., 47, e2020GL087014, https://doi.org/10.1029/2020GL087014.

Gossart, A., S. Helsen, J. T. M. Lenaerts, S. Vanden Broucke, N. P. M. van Lipzig, and N. Souverijns, 2019: An evaluation of surface climatology in state-ofthe-art reanalyses over the Antarctic ice sheet. J. Climate, 32, 6899-6915, https://doi.org/10.1175/JCLI-D-19-0030.1.

Gray, A. R., and Coauthors, 2018: Autonomous biogeochemical floats detect significant carbon dioxide outgassing in the high-latitude Southern Ocean. Geophys. Res. Lett., 45, 9049-9057, https://doi.org/10.1029/2018GL078013.

Gregor, L., S. Kok, and P. M. S. Monteiro, 2018: Interannual drivers of the seasonal cycle of CO2 in the Southern Ocean. Biogeosciences, 15, 2361-2378, https://doi.org/10.5194/bg-15-2361-2018.

— A. D. Lebehot, , S. Kok, and P. M. S. Monteiro, 2019: A comparative assessment of the uncertainties of global surface ocean $\mathrm{CO}_{2}$ estimates using a machine-learning ensemble (CSIR-ML6 version 2019a) - Have we hit the wall? Geosci. Model Dev., 12, 5113-5136, https://doi.org/10.5194/gmd-125113-2019.

Gudmundsson, G. H., F. S. Paolo, S. Adusumilli, and H. A. Fricker, 2019: Instantaneous Antarctic ice sheet mass loss driven by thinning ice shelves. Geophys. Res. Lett., 46, 13903-13909, https://doi.org/10.1029/2019GL085027.

Hamilton, L. C., and J. Stroeve, 2016: 400 predictions: The search sea ice outlook 2008-2015. Polar Geogr., 39, 274-287, https://doi.org/10.1080/10889 37X.2016.1234518.

Haumann, F. A., N. Gruber, and M. Münnich, 2020: Sea-ice induced Southern Ocean subsurface warming and surface cooling in a warming climate. AGU Adv., 1, e2019AV000132, https://doi.org/10.1029/2019AV000132.

Holland, P. R., T. J. Bracegirdle, P. Dutrieux, A. Jenkins, and E. J. Steig, 2019: West Antarctic ice loss influenced by internal climate variability and anthropogenic forcing. Nat. Geosci., 12, 718-724, https://doi.org/10.1038/s41561019-0420-9.

IMBIE Team, 2018: Mass balance of the Antarctic ice sheet from 1992 to 2017. Nature, 558, 219-222, https://doi.org/10.1038/s41586-018-0179-y.

IMO, 2017: International code for ships operating in polar waters (polar code). International Maritime Organization, www.imo.org/en/MediaCentre/HotTopics/polar/Pages/default.aspx.

Jacobs, S. S., and C. F. Giulivi, 2010: Large multidecadal salinity trends near the Pacific-Antarctic continental margin. J. Climate, 23, 4508-4524, https:// doi.org/10.1175/2010JCLI3284.1.

Johnson, G. C., 2008: Quantifying Antarctic bottom water and North Atlantic deep water volumes. J. Geophys. Res., 113, C05027, https://doi. org/10.1029/2007JC004477.

Johnson, K. S., and Coauthors, 2017: Biogeochemical sensor performance in the SOCCOM profiling float array. J. Geophys. Res. Oceans, 122, 6416-6436, https://doi.org/10.1002/2017JC012838.

Josey, S. A., S. Gulev, and L. Yu, 2013: Exchanges through the ocean surface. Ocean Circulation and Climate: A 21st Century Perspective, G. Siedler et al., Eds., Academic Press, 115-140, https://doi.org/10.1016/b978-0-12-391851-2.00005-2.

Jullion, L., A. C. Naveira Garabato, M. P. Meredith, P. R. Holland, P. Courtois, and B. A. King, 2013: Decadal freshening of the Antarctic bottom water exported from the Weddell Sea. J. Climate, 26, 8111-8125, https://doi. org/10.1175/JCLI-D-12-00765.1.

Jung, T., and Coauthors, 2016: Advancing polar prediction capabilities on daily to seasonal time scales. Bull. Amer. Meteor. Soc., 97, 1631-1647, https://doi. org/10.1175/BAMS-D-14-00246.1.

Kanamitsu, M., W. Ebisuzaki, J. Woollen, S. Yang, J. J. Hnilo, M. Fiorino, and G. L. Potter, 2002: NCEP-DOE AMIP-II Reanalysis (R-2). Bull. Amer. Meteor. Soc., 83, 1631-1644, https://doi.org/10.1175/BAMS-83-11-1631. 
Keppler, L., and P. Landschützer, 2019: Regional wind variability modulates the Southern Ocean carbon sink. Sci. Rep., 9, 7384, https://doi.org/10.1038/ s41598-019-43826-y.

Landschützer, P., N. Gruber, and D. C. E. Bakker, 2016: Decadal variations and trends of the global ocean carbon sink. Global Biogeochem. Cycles, 30, 1396-1417, https://doi.org/10.1002/2015GB005359.

Langematz, U., and Coauthors 2018: Polar stratospheric ozone: Past, present, and future. Scientific assessment of ozone depletion: 2018, Global Ozone Research and Monitoring Project Rep. 58, World Meteorological Organization, 4.1-4.63, https://ozone.unep.org/sites/default/files/2019-05/SAP2018-Assessment-report.pdf.

Lazzara, M. A., K. C. Jezek, T. A. Scambos, D. R. MacAyeal, and C. J. Van der Veen, 1999: On the recent calving of icebergs from the Ross Ice Shelf. Polar Geogr., 23, 201-212, https://doi.org/10.1080/10889379909377676.

Lenaerts, J. T. M., and M. R. Van Den Broeke, 2012: Modeling drifting snow in Antarctica with a regional climate model: 2. Results. J. Geophys. Res., 117, D05109, https://doi.org/10.1029/2010JD015419.

— , E. van Meijgaard, M. R. van den Broeke, S. R. M. Ligtenberg, M. Horwath, and E. Isaksson, 2013: Recent snowfall anomalies in Dronning Maud Land, East Antarctica, in a historical and future climate perspective. Geophys. Res. Lett., 40, 2684-2688, https://doi.org/10.1002/grl.50559.

Lim, E.-P., H. H. Hendon, and D. W. J. Thompson, 2018: Seasonal evolution of stratosphere-troposphere coupling in the Southern Hemisphere and implications for the predictability of surface climate. J. Geophys. Res. Atmos., 123, 12 002-12 016, https://doi.org/10.1029/2018JD029321.

- _ , G. Boschat, D. Hudson, D. W. Thompson, A. J. Dowdy, and J. M. Arblaster, 2019: Australian hot and dry extremes induced by weakenings of the stratospheric polar vortex. Nat. Geosci., 12, 896-901, https://doi. org/10.1038/s41561-019-0456-x.

Liu, H., L. Wang, and K. Jezek, 2005: Wavelet- transform based edge detection approach to derivation of snowmelt onset, end and duration from satellite passive microwave measurements. Int. J. Remote Sens., 26, 4639-4660, https://doi.org/10.1080/01431160500213342.

—, - , and - 2006: Spatio-temporal variations of snow melt zones in Antarctic Ice Sheet derived from satellite SMMR and SSM/I data (1978-2004). J. Geophys. Res., 111, F01003, https://doi.org/10.1029/2005JF000318.

Liu, J., X. Tingyin, and L. Chen, 2011: Intercomparisons of air-sea heat fluxes over the Southern Ocean. J. Climate, 24, 1198-1211, https://doi. org/10.1175/2010jcli3699.1.

Manney, G. L., and Coauthors, 2011: Unprecedented Arctic ozone loss in 2011. Nature, 478, 469-475, https://doi.org/10.1038/nature10556.

Marchi, S., T. Fichefet, H. Goosse, V. Zunz, S. Tietsche, J. J. Day, and, E. Hawkins, 2018: Reemergence of Antarctic sea ice predictability and its link to deep ocean mixing in global climate models. Climate Dyn., 52, 2775-2797, https://doi.org/10.1007/S00382-018-4292-2.

Marshall, G. J., 2003: Trends in the southern annular mode from observations and reanalyses. J. Climate, 16, 4134-4143, https://doi.org/10.1175/15200442(2003)016\%3C4134:TITSAM\%3E2.0.CO;2.

Maslanik, J., and J. Stroeve, 1999: Near-Real-Time DMSP SSM/I-SSMIS daily polar gridded sea ice concentrations, version 1. Updated daily, NASA NSIDC DAAC, accessed 12 February 2020, https://doi.org/10.5067/U8C09DWVX9LM.

Massom, R. A., and S. E. Stammerjohn, 2010: Antarctic sea ice change and variability - Physical and ecological implications. Polar Sci., 4, 149-186, https:// doi.org/10.1016/j.polar.2010.05.001.

—, T. A. Scambos, L. G. Bennetts, P. Reid, V. A. Squire, and S. E. Stammerjohn, 2018: Antarctic ice shelf disintegration triggered by sea ice loss and ocean swell. Nature, 558, 383-389, https://doi.org/10.1038/s41586018-0212-1.

Massonnet, F., P. Reid, J. L. Lieser, C. M. Bitz, J. Fyfe, and W. Hobbs, 2018: Assessment of February 2018 sea-ice forecasts for the Southern Ocean. Antarctic Climate and Ecosystems Cooperative Research Centre Tech. Rep., University of Tasmania, 12 pp., https://doi.org/10.4226/77/5b343caab0498.
—, - , - —, - and - 2019: Assessment of summer 2018-2019 sea-ice forecasts for the Southern Ocean. Antarctic Climate and Ecosystems Cooperative Research Centre Tech. Rep., University of Tasmania, 13 pp., https://doi. org/10.25959/100.00029984.

McKee, D. C., X. Yuan, A. L. Gordon, B. A. Huber, and Z. Dong, 2011: Climate impact on interannual variability of Weddell Sea bottom water. J. Geophys. Res., 116, C05020, https://doi.org/10.1029/2010JC006484.

Medley, B., and E. R. Thomas, 2019: Increased snowfall over the Antarctic Ice Sheet mitigated twentieth-century sea-level rise. Nat. Climate Change, 9, 34-39, https://doi.org/10.1038/s41558-018-0356-x.

Meehl, G. A., and Coauthors, 2019: Sustained ocean changes contributed to sudden Antarctic sea ice retreat in late 2016. Nat. Commun., 10, 14, https:// doi.org/10.1038/s41467-018-07865-9.

Menezes, V. V., A. M. Macdonald, and C. Schatzman, 2017: Accelerated freshening of Antarctic bottom water over the last decade in the Southern Indian ocean. Sci. Adv., 3, e1601426, https://doi.org/10.1126/sciadv.1601426.

Mottram, R., and Coauthors, 2020: What is the surface mass balance of Antarctica? An intercomparison of regional climate model estimates. Cryosphere Discuss., https://doi.org/10.5194/tc-2019-333.

Narayanan, A., S. T. Gille, M. R. Mazloff, and K. Murali, 2019: Water mass characteristics of the Antarctic margins and the production and seasonality of Dense Shelf Water. J. Geophys. Res. Oceans, 124, 9277-9294, https://doi. org/10.1029/2018JC014907.

Palm, S. P., V. Kayetha, and Y. Yang, 2018: Toward a satellite-derived climatology of blowing snow over Antarctica. J. Geophys. Res. Atmos., 123, $10301-$ 10313, https://doi.org/10.1029/2018JD028632.

Paolo, F. S., H. A. Fricker, and L. Padman, 2015: Volume loss from Antarctic ice shelves is accelerating. Science, 348, 327-331, https://doi.org/10.1126/ science.aaa0940.

- L. Padman, H. A. Fricker, S. Adusumilli, S. Howard, and M. R. Siegfried, 2018: Response of Pacific-sector Antarctic ice shelves to the El Niño/Southern Oscillation. Nat. Geosci., 11, 121-126, https://doi.org/10.1038/s41561017-0033-0.

Pitts, M. C., L. R. Poole, and R. Gonzalez, 2018: Polar stratospheric cloud climatology based on CALIPSO spaceborne lidar measurements from 2006 to 2017. Atmos. Chem. Phys., 18, 10881-10913, https://doi.org/10.5194/ acp-18-10881-2018.

Pope, J. O., P. R. Holland, A. Orr, G. J. Marshall, and T. Phillips, 2017: The impacts of El Niño on the observed sea ice budget of West Antarctica. Geophys. Res. Lett., 44, 6200-6208, https://doi.org/10.1002/2017GL073414.

Pritchard, H. D., R. J. Arthern, D. G. Vaughan, and L. A. Edwards, 2009: Extensive dynamic thinning on the margins of the Greenland and Antarctic ice sheets. Nature, 461, 971-975, https://doi.org/10.1038/NATURE08471.

_ S. R. M. Ligtenberg, H. A. Fricker, D. G. Vaughan, M. R. van den Broeke, and L. Padman, 2012: Antarctic ice-sheet loss driven by basal melting of ice shelves. Nature, 484, 502-505, https://doi.org/10.1038/nature10968.

Purkey, S. G., and G. C. Johnson, 2012: Global contraction of Antarctic bottom water between the 1980s and 2000s. J. Climate, 25, 5830-5844, https:// doi.org/10.1175/JCLI-D-11-00612.1.

_ tributions to sea level rise, ocean freshwater budgets, and global heat gain. J. Climate, 26, 6105-6122, https://doi.org/10.1175/JCLI-D-12-00834.1.

_- and Coauthors, 2019: Unabated bottom water warming and freshening in The south Pacific Ocean. J. Geophys. Res. Oceans, 124, 1778-1794, https://doi.org/10.1029/2018JC014775.

Reid, P. A., and R. A. Massom, 2015: Successive Antarctic sea ice extent records during 2012, 2013 and 2014 [in "State of the Climate in 2014"]. Bull. Amer. Meteor. Soc., 96 (7), S163-S164, https://doi.org/10.1175/2015BAMSStateo ftheClimate.1.

- S. Stammerjohn, R. A. Massom, S. Barreira, T. Scambos, and J. Lieser, 2018: Sea ice extent, concentration and seasonality [in "State of the Climate in 2017"]. Bull. Amer. Meteor. Soc., 99 (8), S183-S185, https://doi.org/10.1 175/2018BAMSStateoftheClimate.1. 
,,,,----- , and -2019 : Sea ice extent, concentration and seasonality [in "State of the Climate in 2018"]. Bull. Amer. Meteor. Soc., 100 (9), S178-S181, https://doi.org/10.1175/2019BAMSStateoftheCli mate.1.

Reynolds, R. W., N. A. Rayner, T. M. Smith, D. C. Stokes, and W. Wang, 2002: An improved in situ and satellite SST analysis for climate. J. Climate, 15, 1609-1625, https://doi.org/10.1175/1520-0442(2002)015<1609:AllSAS>2. $0 . \mathrm{CO} ; 2$.

Rignot, E., J. L. Bamber, M. R. Van Den Broeke, C. Davis, Y. Li, W. J. Van De Berg, and E. Van Meijgaard, 2008: Recent Antarctic ice mass loss from radar interferometry and regional climate modelling. Nat. Geosci., 1(2), 106-110, https://doi.org/10.1038/ngeo102

- S. Jacobs, J. Mouginot, and B. Scheuchl, 2013: Ice-shelf melting around Antarctica. Science, 341, 266-270, https://doi.org/10.1126/science.1235798.

- J. Mouginot, B. Scheuchl, M. van den Broeke, M. J. van Wessem, and M. Morlighem, 2019: Four decades of Antarctic ice sheet mass balance from 1979-2017. Proc. Natl. Acad. Sci. USA, 116, 1095-1103, https://doi. org/10.1073/pnas.1812883116.

Roquet, F., and Coauthors, 2014: A Southern Indian Ocean database of hydrographic profiles obtained with instrumented elephant seals. Nature, 1, 140028, https://doi.org/10.1038/sdata.2014.28.

Shepherd, A., D. J. Wingham, J. A. D. Mansley, and H. F. J. Corr, 2001: Inland thinning of pine Island glacier, West Antarctica. Science, 291, 862-864, https:// doi.org/10.1126/SCIENCE.291.5505.862.

_ - and Coauthors, 2012: A reconciled estimate of ice-sheet mass balance. Science, 338, 1183-1189, https://doi.org/10.1126/science.1228102.

- and Coauthors, 2019: Trends in Antarctic ice sheet elevation and mass. Geophys. Res. Lett., 46, 8174-8183, https://doi.org/10.1029/2019GL082182.

Smith, B., and Coauthors, 2020: Pervasive ice sheet mass loss reflects competing ocean and atmosphere processes. Science, 368, 1239-1242, https://doi. org/10.1126/SCIENCE.AAZ5845.

Smith, T. M., R. W. Reynolds, T. C. Peterson, and J. Lawrimore, 2008: Improvements to NOAA's historical merged land-ocean surface temperature analysis (1880-2006). J. Climate, 21, 2283-2296, https://doi. org/10.1175/2007JCLI2100.1.

St-Laurent, P., P. L. Yager, R. M. Sherrell, S. E. Stammerjohn, and M. S. Dinniman, 2017: Pathways and supply of dissolved iron in the Amundsen Sea (Antarctica). J. Geophys. Res. Oceans, 122, 7135-7162, https://doi. org/10.1002/2017JC013162.

Stammerjohn, S. E., D. G. Martinson, R. C. Smith, X. Yuan, and D. Rind, 2008: Trends in Antarctic annual sea ice retreat and advance and their relation to El Niño-Southern Oscillation and southern annular mode variability. J. Geophys. Res., 113, C03S90, https://doi.org/10.1029/2007JC004269.

_ Antarctica, over the period of 1979-2014. Elementa, 3, 00005, https://doi. org/10.12952/JOURNAL.ELEMENTA.000055.

Steig, E. J., Q. Ding, D. S. Battisti, and A. Jenkins, 2012: Tropical forcing of circumpolar deep water inflow and outlet glacier thinning in the Amundsen Sea embayment, west Antarctica. Ann. Glaciol., 53, 19-28, https://doi. org/10.3189/2012AoG60A110.

Swart, S., S. Speich, I. J. Ansorge, and J. R. E. Lutjeharms, 2010: An altimetrybased gravest empirical mode south of Africa: 1. Development and validation. J. Geophys. Res., 115, C03002, https://doi.org/10.1029/2009JC005299.

—, and Coauthors, 2019: Constraining Southern Ocean air-sea-ice fluxes through enhanced observations. Front. Mar. Sci., 6, 421, https://doi. org/10.3389/fmars.2019.00421.
Tedesco, M., 2009a: Assessment and development of snowmelt retrieval algorithms over Antarctica from K-band spaceborne brightness temperature (1979-2008). Remote Sens. Environ., 113, 979-997, https://doi. org/10.1016/j.rse.2009.01.009.

_ 2009b: An updated Antarctic melt record through 2009 and its linkages to high-latitude and tropical climate variability. Geophys. Res. Lett., 36, L18502, https://doi.org/10.1029/2009GL039186.

Thoma, M., A. Jenkins, D. Holland, and S. Jacobs, 2008: Modelling circumpolar deep water intrusions on the Amundsen Sea continental shelf, Antarctica. Geophys. Res. Lett., 35, L18602, https://doi.org/10.1029/2008GL034939.

Thomas, D. N., Ed., 2017: Sea Ice. 3rd ed. Wiley-Blackwell, 645 pp.

Thomas, R. H., 1979: The dynamics of marine ice sheets. J. Glaciol., 24, 167177, https://doi.org/10.3189/S0022143000014726.

Timmermann, R., and H. H. Hellmer, 2013: Southern Ocean warming and increased ice shelf basal melting in the twenty-first and twenty-second centuries based on coupled ice-ocean finite-element modelling. Ocean Dyn., 63, 1011-1026, https://doi.org/10.1007/s10236-013-0642-0.

Tonboe, R., J. Lavelle, R. H. Pfeiffer, and E. Howe, 2017: Product user manual for OSI SAF Global Sea Ice Concentration (Product OSI-401-b), version 1.6. OSI SAF, 25 pp., http://osisaf.met.no/docs/osisaf_cdop3_ss2_pum_iceconc_v1p6.pdf.

Treasure, A. M., and Coauthors, 2017: Marine mammals exploring the oceans pole to pole: A review of the MEOP consortium. Oceanography, 30, 132-138, https://doi.org/10.5670/oceanog.2017.234.

Turner, J., and Coauthors, 2004: The SCAR READER project: Toward a highquality database of mean Antarctic meteorological observations. J. Climate, 17, 2890-2898, https://doi.org/10.1175/1520-0442(2004)017<2890:TSRPT A $>2.0 . \mathrm{CO} ; 2$.

_ insula consistent with natural variability. Nature, 535, 411-415, https://doi. org/10.1038/nature18645.

Velicogna, I., 2009: Increasing rates of ice mass loss from the Greenland and Antarctic ice sheets revealed by GRACE. Geophys. Res. Lett., 36, L19503, https://doi.org/10.1029/2009GL040222.

— , T. C. Sutterley, and M. R. van den Broeke, 2014: Regional acceleration in ice mass loss from Greenland and Antarctica using GRACE timevariable gravity data. Geophys. Res. Lett., 41, 8130-8137, https://doi. org/10.1002/2014GL061052.

- , and Coauthors, 2020: Continuity of ice sheet mass loss in Greenland and Antarctica from the GRACE and GRACE follow-on missions. Geophys. Res. Lett., 47, e2020GL087291, https://doi.org/10.1029/2020GL087291.

Wang, Y., and Coauthors, 2016: A comparison of Antarctic Ice Sheet surface mass balance from atmospheric climate models and in situ observations. J. Climate, 29, 5317-5337, https://doi.org/10.1175/JCLI-D-15-0642.1.

Williams, N. L., and Coauthors, 2017: Calculating surface ocean pCO2 from biogeochemical Argo floats equipped with pH: An uncertainty analysis. Global Biogeochem. Cycles, 31, 591-604, https://doi.org/10.1002/2016GB005541.

Wingham, D. J., A. J. Ridout, R. Scharroo, R. J. Arthern, and C. K. Shum, 1998: Antarctic elevation change from 1992 to 1996. Science, 282, 456-458, https://doi.org/10.1126/science.282.5388.456.

Yuan, X., M. R. Kaplan, and M. A. Cane, 2018: The interconnected global climate system-a review of tropical-polar teleconnections. J. Climate, 31, 5765-5792, https://doi.org/10.1175/JCLI-D-16-0637.1.

Zwally, H. J., and S. Fiegles, 1994: Extent and duration of Antarctic surface melting. J. Glaciol., 40, 463-475, https://doi.org/10.3189/S0022143000012338. 


\section{STATE OF THE CLIMATE IN 2019 REGIONAL CLIMATES}

P. Bissolli, C. Ganter, T. Li, A. Mekonnen, and A. Sánchez-Lugo, Eds.

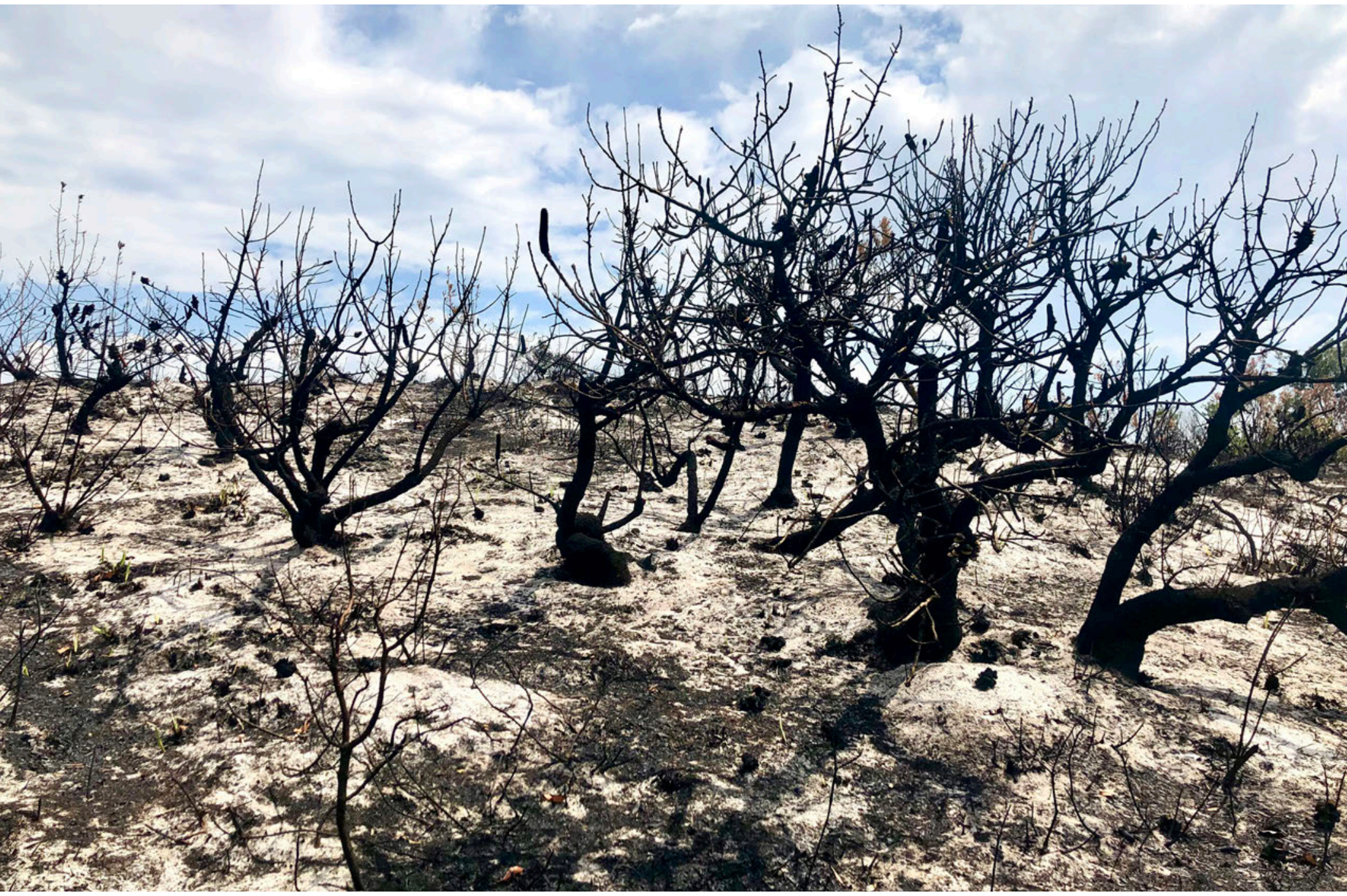

Special Online Supplement to the Bulletin of the American Meteorological Society, Vol.101, No. 8, August, 2020

https://doi.org/10.1175/2020BAMSStateoftheClimate_Chapter7.1

Corresponding authors:

North America: Ahira Sánchez-Lugo / Ahira.Sanchez-Lugo@noaa.gov.

Central America and the Caribbean: Ahira Sánchez-Lugo / Ahira.Sanchez-Lugo@noaa.gov

South America: Ahira Sánchez-Lugo / Ahira.Sanchez-Lugo@noaa.gov

Africa: Ademe Mekonnen / amekonne@ncat.edu

Europe: Peter Bissolli / Peter.Bissolli@dwd.de

Asia:Tim Li / timli@hawaii.edu

Oceania: Catherine Ganter / Catherine.Ganter@bom.gov.au

@2020 American Meteorological Society

For information regarding reuse of this content and general copyright information, consult the AMS Copyright Policy. 


\title{
STATE OF THE CLIMATE IN 2019 Regional Climates
}

\author{
Editors \\ Jessica Blunden \\ Derek S. Arndt \\ Chapter Editors \\ Peter Bissolli \\ Howard J. Diamond \\ Matthew L. Druckenmiller \\ Robert J. H. Dunn \\ Catherine Ganter \\ Nadine Gobron \\ Rick Lumpkin \\ Jacqueline A. Richter-Menge \\ Tim Li \\ Ademe Mekonnen \\ Ahira Sánchez-Lugo \\ Ted A. Scambos \\ Carl J. Schreck III \\ Sharon Stammerjohn \\ Diane M. Stanitski \\ Kate M. Willett \\ Technical Editor \\ Andrea Andersen \\ BAMS Special Editor for Climate \\ Richard Rosen
}

American Meteorological Society 
Cover credit:

Front: () Lynnebeclu/Royalty-free/iStock / Getty Images Plus

Horizontal landscape of burnt, scorched and blackened coastal forest trees and ash-scattered sandy ground after bushfires ravaged the coastal landscape near Yamba, New South Wales Australia in 2019.

Regional Climates is one chapter from the State of the Climate in 2019 annual report. Compiled by NOAA's National Centers for Environmental Information, State of the Climate in 2019 is based on contributions from scientists from around the world. It provides a detailed update on global climate indicators, notable weather events, and other data collected by environmental monitoring stations and instruments located on land, water, ice, and in space. The full report is available from https://doi.org/10.1175/2020BAMSStateoftheClimate.1.

How to cite this document:

Citing the complete report:

Blunden, J. and D. S. Arndt, Eds., 2020: State of the Climate in 2019. Bull. Amer. Meteor. Soc., 101 (8), Si-S429, https://doi.org/10.1175/2020BAMSStateoftheClimate.1.

\section{Citing this chapter:}

Bissolli, P., C. Ganter, T. Li, A. Mekonnen, and A. Sánchez-Lugo, Eds., 2020: Regional Climates [in "State of the Climate in 2019"]. Bull. Amer. Meteor. Soc., 101 (8), S321-S420, https://doi.org/10.1175/2020BAMSStateoftheClimate_Chapter7.1.

\section{Citing a section (example):}

Amador, J. A., H. G. Hidalgo, E. J. Alfaro, B. Calderón, and N. Mora, 2020: Central America [in "State of the Climate in 2019"]. Bull. Amer. Meteor. Soc., 101 (8), S338-\$339,

https://doi.org/10.1175/2020BAMSStateoftheClimate_Chapter7.1. 
Abida, Abdallah, Agence Nationale de l'Aviation Civile et de la Météorologie de I'Union des Comores, Moroni, Comoros

Aldeco, Laura S., Servicio Meteorológico Nacional, Buenos Aires, Argentina

Alfaro, Eric J., Center for Geophysical Research and School of Physics, University of Costa Rica, San José, Costa Rica

Alves, Lincoln M., Centro de Ciencia do Sistema Terrestre/Instituto Nacional de Pesquisas Espaciais, São Paulo, Brazil

Amador, Jorge A., Center for Geophysical Research and School of Physics, University of Costa Rica, San José, Costa Rica

Andrade, B., Seychelles Meteorological Authority, Mahe, Seychelles

Baez, Julian, Universidad Católica Nuestra Senora de la Asunción, Asunción, Paraguay

Bardin, M. Yu., Yu. A. Izrael Institute of Global Climate and Ecology, and Institute of Geography, Russian Academy of Sciences, Moscow, Russia

Bekele, Endalkachew, NOAA/NWS Climate Prediction Center, College Park, Maryland

Bissolli, Peter, Deutscher Wetterdienst, WMO RA VI Regional Climate Centre Network, Offenbach, Germany

Broedel, Eric, Centro Nacional de Monitoramento e Alertas de Desastres Naturais CEMADEN, São Paulo, Brazil

Bukunt, Brandon, NOAA/NWS Weather Forecast Office, Guam

Calderón, Blanca, Center for Geophysical Research, University of Costa Rica, San José, Costa Rica

Campbell, Jayaka D., Department of Physics, The University of the West Indies, Jamaica

Campos Diaz, Diego A., Dirección Meteorológica de Chile, Santiago de Chile, Chile

Carvajal, Gilma, Instituto Nacional de Meteorología e Hidrología de Ecuador (INAMHI), Quito, Ecuador

Chandler, Elise, Bureau of Meteorology, Melbourne, Victoria, Australia

Cheng, Vincent. Y. S., Environment and Climate Change Canada, Toronto, Ontario, Canada

Choi, Chulwoon, Climate Prediction Division, Korea Meteorological Administration, South Korea

Clarke, Leonardo A., Department of Physics, The University of the West Indies, Jamaica

Correa, Kris, Servicio Nacional de Meteorología e Hidrología del Perú, Lima, Perú

Costa, Felipe, Centro Internacional para la Investigación del Fenómeno El Niño (CIIFEN), Guayaquil, Ecuador

Cunha, A. P., Centro Nacional de Monitoramento e Alertas de Desastres Naturais CEMADEN, São Paulo, Brazil

Demircan, Mesut, Turkish State Meteorological Service, Ankara, Turkey

Dhurmea, R., Mauritius Meteorological Service, Vacoas, Mauritius

Díaz, Eliecer A., Instituto de Hidrología de Meteorología y Estudios Ambientales de Colombia (IDEAM), Bogotá, Colombia

ElKharrim, M., Direction de la Météorologie Nationale Maroc, Rabat, Morocco

Enyew, Bantwale D., Department of Physics, North Carolina A \& T State University, Greensboro, North Carolina

Espinoza, Jhan C., Instituto Geofisico del Perú, Lima, Perú, and Université Grenoble Alpes, Grenoble, France

Fazl-Kazem, Amin, National Center for Drought Monitoring and Crisis Management, Islamic Republic of Iranian Meteorological Organization, Tehran, Iran

Fedaeff, Nava, National Institute of Water and Atmospheric Research, Ltd. (NIWA), Auckland, New Zealand

Feng, Z., Atmospheric Sciences and Global Change Division, Pacific Northwest National Laboratory, Richland, Washington
Fenimore, Chris, NOAA/NESDIS National Centers for Environmental Information, Asheville, North Carolina

Francis, S. D., National Weather Forecasting and Climate Research Centre, Nigerian Meteorological Agency, Abuja, Nigeria

Ganter, Catherine, Bureau of Meteorology, Melbourne, Victoria, Australia

Gleason, Karin, NOAA/NESDIS National Centers for Environmental Information, Asheville, North Carolina

Guard, Charles "Chip" P., Tropical Weather Sciences, Sinajana, Guam

Gustari, Indra, Climate Variability Analysis Division, Center for Climate Change Information, BMKG, Indonesia

Hagos, S., Atmospheric Sciences and Global Change Division, Pacific Northwest National Laboratory, Richland, Washington

Heim, Jr., Richard R., NOAA/NESDIS National Centers for Environmental Information, Asheville, North Carolina

Hernández, Rafael, Instituto Nacional de Meteorología e Hidrología de Venezuela (INAMEH), Caracas, Venezuela

Hidalgo, Hugo G., Center for Geophysical Research and School of Physics, University of Costa Rica, San José, Costa Rica

ljampy, J. A., Nigerian Meteorological Agency, Abuja, Nigeria

Joseph, Annie C., Dominica Meteorological Service, Canefield Airport, Canefield, Dominica

Jumaux, Guillaume, Météo France, Direction Interrégionale pour l'Océan Indien, Réunion

Kabidi, Khadija, Direction de la Météorologie Nationale Maroc, Rabat, Morocco

Kaiser, Johannes W., Deutscher Wetterdienst, Satellite-Based Climate Monitoring Division, Offenbach, Germany

Kamsu-Tamo, Pierre-Honore, NOAA/NWS Climate Prediction Center, College Park, Maryland

Kennedy, John, Met Office Hadley Centre, Exeter, United Kingdom

Khan, Valentina, Hydrometcenter of Russia, WMO North EurAsia Climate Center, Moscow, Russia

Khiem, Mai Van, Viet Nam National Center of Hydro-Meteorology Forecasting, Viet Nam Meteorology Hydrology Administration, Ha Noi, Viet Nam

Kokosadze, Khatuna, National Environmental Agency, Tbilisi, Georgia

Korshunova, Natalia N., All-Russian Research Institute of Hydrometeorological Information - World Data Center, Obninsk, Russia

Kruger Andries C., South African Weather Service, Pretoria, South Africa

Kutaladze, Nato, National Environmental Agency, Tbilisi, Georgia

Labbé, L., Météo France, Direction Interrégionale pour l'Océan Indien, Réunion

Lakatos, Mónika, Climatology Unit, Hungarian Meteorological Service, Budapest, Hungary

Lam, Hoang Phuc, Viet Nam National Center of Hydro-Meteorology Forecasting, Viet Nam Meteorology Hydrology Administration, Ha Noi, Viet Nam

Lander, Mark A., University of Guam, Mangilao, Guam

Lavado-Casimiro, Waldo, Servicio Nacional de Meteorología e Hidrología del Perú, Lima, Perú

Lee, T. C., Hong Kong Observatory, Hong Kong, China

Leung, Kinson H. Y., Environment and Climate Change Canada, Toronto, Ontario, Canada

Li, Tim, Department of Atmospheric Sciences, University of Hawai'i, Honolulu, Hawai'i, USA

Magee, Andrew D., Centre for Water, Climate and Land, School of Environmental and Life Sciences, University of Newcastle, Callaghan, NSW, Australia

Mamen, Jostein, Climate Division, Norwegian Meteorological Institute, Oslo, Norway

Marengo, José A., Centro Nacional de Monitoramento e Alertas aos Desastres Naturais, Cachoeira Paulista, São Paulo, Brazil

Marín, Dora, Servicio Nacional de Meteorología e Hidrología (SENAMHI), Lima, Perú 
McBride, Charlotte, South African Weather Service, Pretoria, South Africa Megrelidze, Lia, National Environmental Agency, Tbilisi, Georgia

Mekonnen, Ademe, Department of Physics, North Carolina A \& T State University, Greensboro, North Carolina

Misevicius, Noelia, Instituto Uruguayo de Meteorología, Montevideo, Uruguay

Mochizuki, Y., Tokyo Climate Center, Japan Meteorological Agency, Japan

Moise, Aurel, Centre for Climate Research Singapore, Meteorological Service, Singapore

Molina-Carpio, Jorge, Universidad Mayor de San Andrés, La Paz, Bolivia

Mora, Natali, Center for Geophysical Research and School of Physics, University of Costa Rica, San José, Costa Rica

Mostafa, Awatif E., Department of Seasonal Forecast and Climate Research, Cairo Numerical Weather Prediction, Egyptian Meteorological Authority, Cairo, Egypt

Nieto, Juan José, Centro Internacional para la Investigación del Fenómeno El Niño (CIIFEN), Guayaquil, Ecuador

Oyunjargal, Lamjav, National Agency for Meteorology, Hydrology and Environmental Monitoring, Ulaanbaatar, Mongolia

Pascual Ramírez, Reynaldo, National Meteorological Service of Mexico, Mexico

Pastor Saavedra, Maria Asuncion, Agencia Estatal de Meteorología, Madrid, Spain

Pfeifroth, Uwe, Deutscher Wetterdienst, Satellite-Based Climate Monitoring Division, Offenbach, Germany

Phillips, David, Environment and Climate Change Canada, Toronto, Ontario, Canada

Rajeevan, Madhavan, Earth System Science Organization, Ministry of Earth Sciences, New Delhi, India

Ramos, Andrea M., Instituto Nacional de Meteorologia, Brasilia, Brazil

Revadekar, Jayashree V., Indian Institute of Tropical Meteorology, Pune, India

Robjhon, Miliaritiana, NOAA/NWS Climate Prediction Center, College Park, Maryland

Rodriguez Camino, Ernesto, Agencia Estatal de Meteorología, Madrid, Spain

Rodriguez Guisado, Esteban, Agencia Estatal de Meteorología, Madrid, Spain

Ronchail, Josyane, Université Paris Diderot/Laboratoire LOCEAN-IPSL, Paris, France

Rösner, Benjamin, Laboratory for Climatology and Remote Sensing, Faculty of Geography, University of Marburg, Marburg, Germany

Salinas, Roberto, Dirección de Meteorología e Hidrología/Dirección Nacional de Aeronáutica Civil, Asunción, Paraguay

Sánchez-Lugo, Ahira, NOAA/NESDIS National Centers for Environmental Information, Asheville, North Carolina
Sayouri, Amal, Direction de la Météorologie Nationale Maroc, Rabat, Morocco

Schreck III, Carl J., North Carolina State University, Cooperative Institute for Climate and Satellites - North Carolina (CICS-NC), Asheville, North Carolina

Sensoy, Serhat, Turkish State Meteorological Service, Ankara, Turkey

Shimpo, A., Tokyo Climate Center, Japan Meteorological Agency, Tokyo, Japan

Sima, Fatou, Division of Meteorology, Department of Water Resources, Banjul, The Gambia

Smith, Adam, NOAA/NESDIS National Centers for Environmental Information, Asheville, North Carolina

Spence, Jacqueline, Meteorological Service, Kingston, Jamaica

Spillane, Sandra, Met Éireann, Irish Meteorological Service, Dublin, Ireland

Spitzer, Arne, Deutscher Wetterdienst, Satellite-Based Climate Monitoring Division, Offenbach, Germany

Srivastava, A. K., India Meteorological Department, Pune, India

Stella, José L., Servicio Meteorológico Nacional, Buenos Aires, Argentina

Stephenson, Kimberly A., Department of Life Sciences, The University of the West Indies, Jamaica

Stephenson, Tannecia S., Department of Physics, The University of the West Indies, Jamaica

Taylor, Michael A., Department of Physics, The University of the West Indies, Jamaica

Thiaw, Wassila, NOAA/NWS Climate Prediction Center, College Park, Maryland

Tobin, Skie, Bureau of Meteorology, Melbourne, Victoria, Australia

Todey, Dennis, Agricultural Research Service, USDA Midwest Climate Hub, Ames, lowa

Trachte, Katja, Brandenburg University of Technology (BTU), Cottbus, Germany

Trotman, Adrian R., Caribbean Institute for Meteorology and Hydrology, Bridgetown, Barbados

van der Schrier, Gerard, Royal Netherlands Meteorological Institute (KNMI), De Bilt, Netherlands

Van Meerbeeck, Cedric J., Caribbean Institute for Meteorology and Hydrology, Bridgetown, Barbados

Vazifeh, Ahad, National Center for Drought Monitoring and Crisis Management, Islamic Republic of Iranian Meteorological Organization, Tehran, Iran

Vicencio Veloso, José, Dirección Meteorológica de Chile, Santiago de Chile, Chile

Wang, Wei, Minhang Meteorological Bureau, Shanghai, China

Xin, Fei, Shanghai Climate Center, Shanghai, China

Zhang, Peiqun, Beijing Climate Center, Beijing, China

Zhu, Zhiwei, Nanjing University of Information Science and Technology, China

Zucule, Jonas, Mozambique National Institute of Meteorology, Maputo, Mozambique

\section{Editorial and Production Team}

Andersen, Andrea, Technical Editor, Innovative Consulting Management Services, LLC, NOAA/NESDIS National Centers for Environmental Information, Asheville, North Carolina

Griffin, Jessicca, Graphics Support, Cooperative Institute for Satellite Earth System Studies, North Carolina State University, Asheville, North Carolina

Hammer, Gregory, Content Team Lead, Communications and Outreach, NOAA/ NESDIS National Centers for Environmental Information, Asheville, North Carolina

Love-Brotak, S. Elizabeth, Lead Graphics Production, NOAA/NESDIS National Centers for Environmental Information, Asheville, North Carolina
Misch, Deborah J., Graphics Support, Innovative Consulting Management Services, LLC, NOAA/NESDIS National Centers for Environmental Information, Asheville, North Carolina

Riddle, Deborah B., Graphics Support, NOAA/NESDIS National Centers for Environmental Information, Asheville, North Carolina

Veasey, Sara W., Visual Communications Team Lead, Communications and Outreach, NOAA/NESDIS National Centers for Environmental Information, Asheville, North Carolina 


\section{Table of Contents}

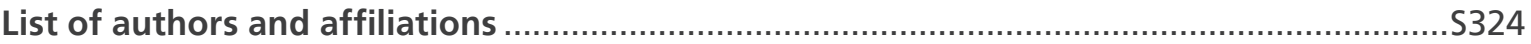

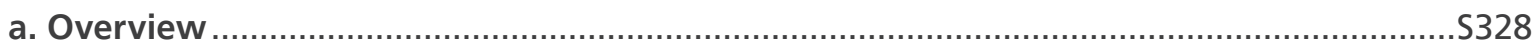

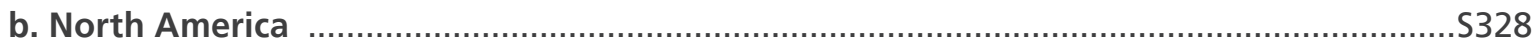

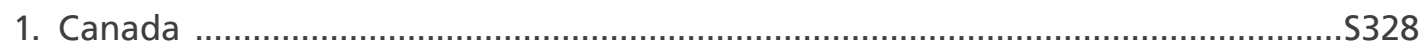

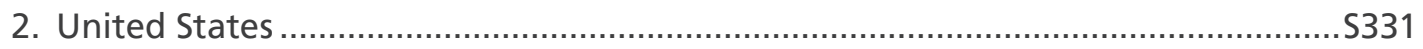

Sidebar 7.1: Record wetness and the impact on U.S. Midwest/Plains

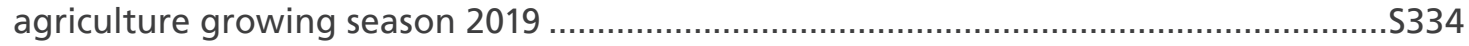

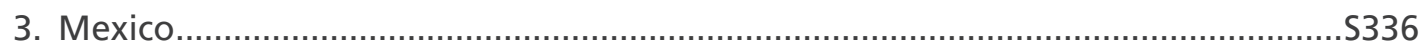

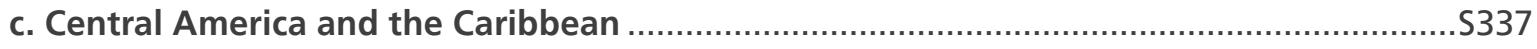

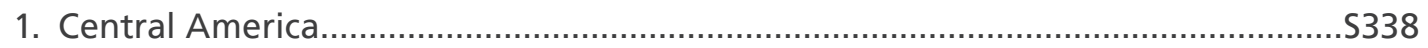

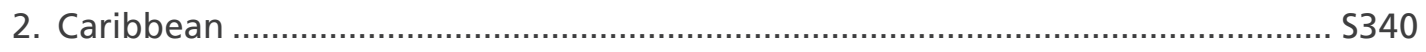

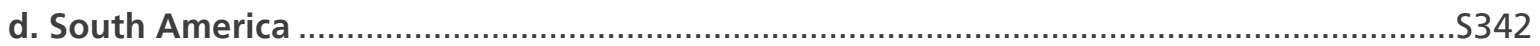

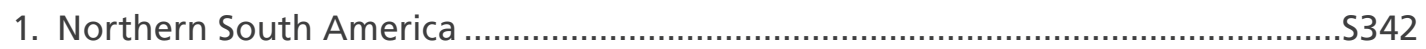

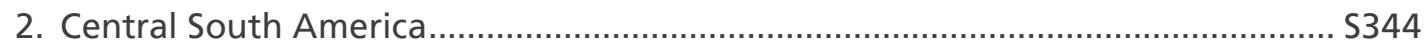

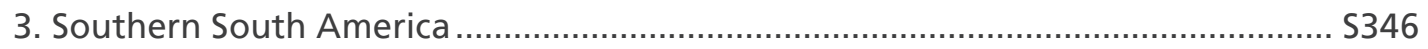

Sidebar 7.2: Fires in southern Amazonia in the dry season of 2019............................. S348

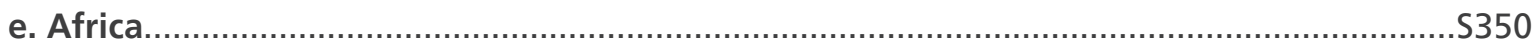

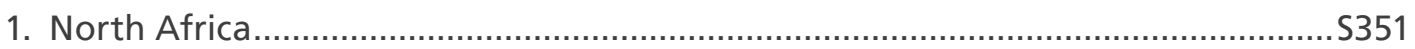

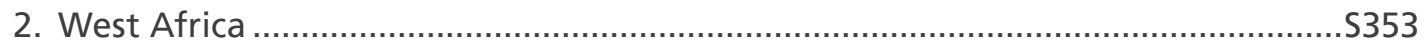

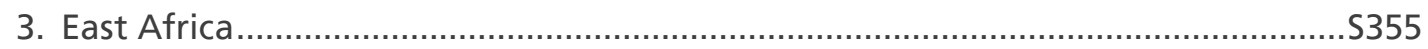

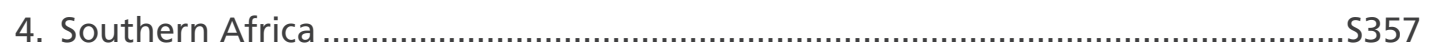

5. Western Indian Ocean Island countries .......................................................... 5358

Sidebar 7.3: Record-breaking tropical cyclone landfalls

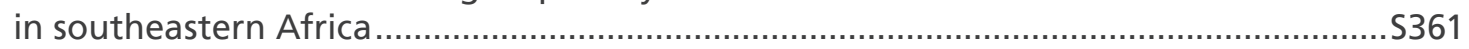

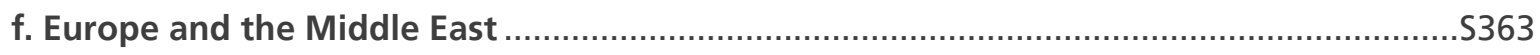

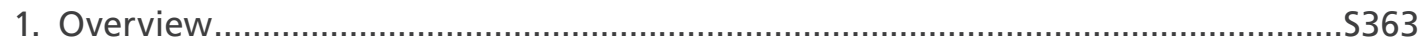

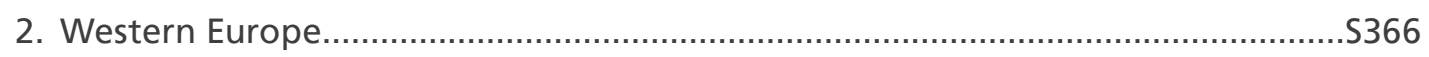

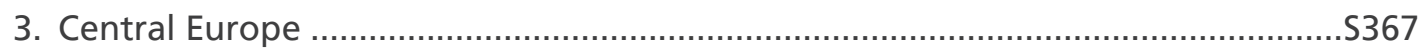

Sidebar 7.4: Record June and July heat waves across western

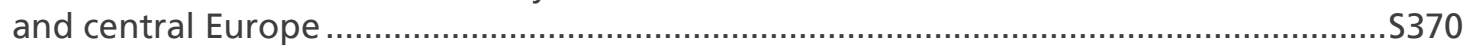

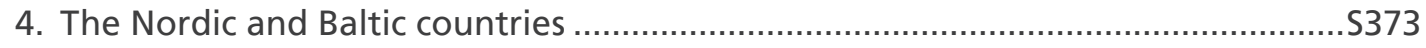

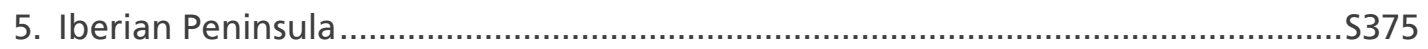

6. Central Mediterranean region and Turkey............................................................ 376

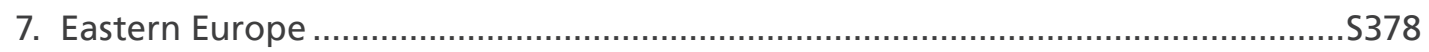

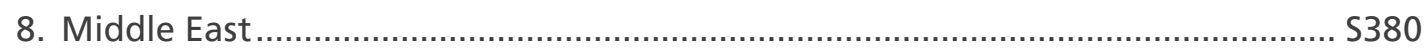

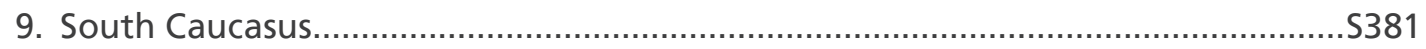

g. Asia

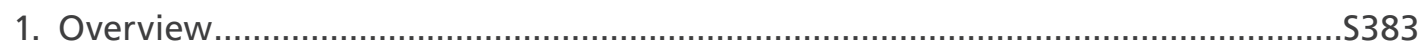

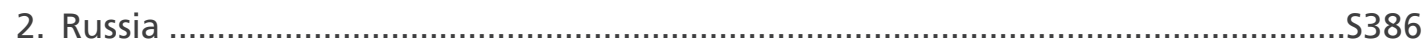

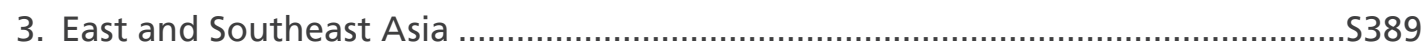

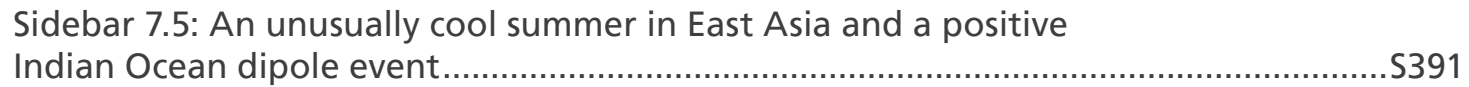

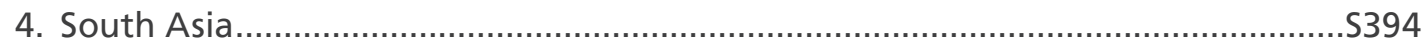

5. Southwest Asia ................................................................................................ 3997 


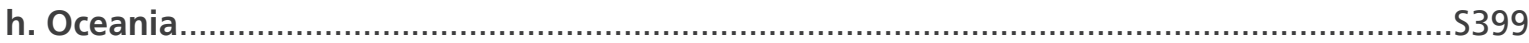

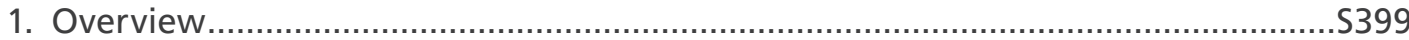

2. Northwest Pacific and Micronesia.................................................................... $\$$

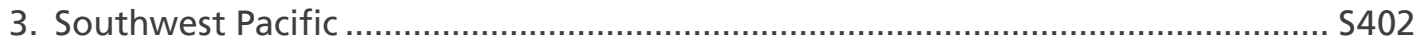

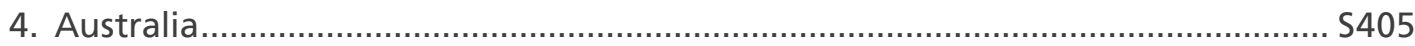

Sidebar 7.6: An early start to an extreme bushfire season in Australia.......................... 5408

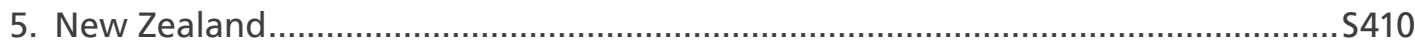

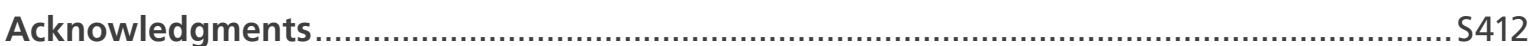

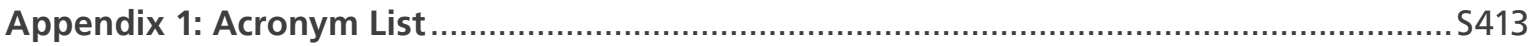

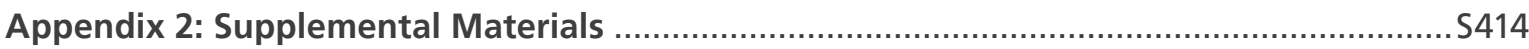

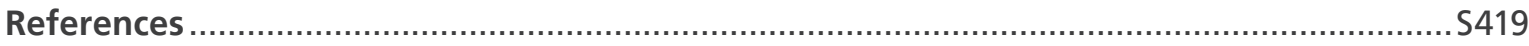

*Please refer to Chapter 8 (Relevant datasets and sources) for a list of all climate variables and datasets used in this chapter for analyses, along with their websites for more information and access to the data. 


\section{REGIONAL CLIMATES}

P. Bissolli, C. Ganter, T. Li, A. Mekonnen, and A. Sánchez-Lugo, Eds.

\section{a. Overview}

This chapter provides summaries of the 2019 temperature and precipitation conditions across seven broad regions: North America, Central America and the Caribbean, South America, Africa, Europe, Asia, and Oceania. In most cases, summaries of notable weather events are also included. Local scientists provided the annual summary for their respective regions and, unless otherwise noted, the source of the data used is typically the agency affiliated with the authors. The primary base period used for these analyses is 1981-2010. However, please note that on occasion different nations, even within the same section, may use unique periods to define their normals. Section introductions typically define the prevailing practices for that section, and exceptions will be noted within the text. In a similar way, many contributing authors use languages other than English as their primary professional language. To minimize additional loss of fidelity through re-interpretation after translation, editors have been conservative and careful to preserve the voice of the author. In some cases, this may result in abrupt transitions in style from section to section.

\section{b. North America-A. Sánchez-Lugo, Ed.}

This section is divided into three subsections: Canada, the United States, and Mexico. Unless otherwise noted, the reference period is 1981-2010. The meteorological seasons follow Northern Hemisphere (NH) midlatitude conventions, such as December-February for winter, March-May for spring.

Above-average temperatures were present across much of northern Canada, the southeastern and mid-Atlantic United States, and Mexico during 2019, while much of central North America had near- to below-average temperatures. Canada observed its 15th warmest year, the United States its 34th warmest, and Mexico its second warmest for their respective historical records. The United States observed its second-wettest year on record, while Mexico experienced its 19th driest. Notable events across the region include spring floods across parts of Canada and the contiguous United States, Hurricane Dorian impacts on parts of the United States and Canada, and the lack of tropical storms affecting southern Mexico.

\section{1) Canada-K. H. Y. Leung, V. Y. S. Cheng, and D. Phillips}

In 2019, mean annual temperatures were above the 1981-2010 average across most of northern Canada (north of $60^{\circ} \mathrm{N}$ ) and below average over most of southern Canada (south of $60^{\circ} \mathrm{N}$ ). The mean temperatures were much higher than average in northwestern Canada during winter and spring, and in northeastern Canada (closer to $80^{\circ} \mathrm{N}$ ) during summer and autumn. The Canadian Prairies consistently experienced below-average temperatures during all four seasons; portions of northwestern Canada experienced below-average temperatures during summer as well.

\section{(I) TEMPERATURE}

The 2019 annual average temperature for Canada was $0.2^{\circ} \mathrm{C}$ above the $1981-2010$ national average and the 15th warmest year since nationwide records began in 1948 (Fig. 7.1). Four of the 10 warmest years have occurred during the last decade, with 2010 experiencing all-time record warmth $\left(+2.2^{\circ} \mathrm{C}\right)$. The national annual average temperature has increased $1.7^{\circ} \mathrm{C}$ over the past 72 years (updated from Vincent et al. 2015). Spatially, annual temperature departures above $+1.5^{\circ} \mathrm{C}$ 
were recorded in the north and northwest, whereas annual departures below $-1^{\circ} \mathrm{C}$ were experienced across Canada's southern border from British Columbia's interior eastward through to New Brunswick (Fig. 7.2). Three provinces/ territories experienced an average annual temperature that ranked among their 10 highest since 1948: Yukon (third highest), Nunavut (fifth highest), and Northwest Territories (seventh highest).

Winter $2018 / 19$ was $0.1^{\circ} \mathrm{C}$ below average and the 44th coolest on record since nationwide records began in 1948. The national winter average temperature has increased by $3.3^{\circ} \mathrm{C}$ over the past

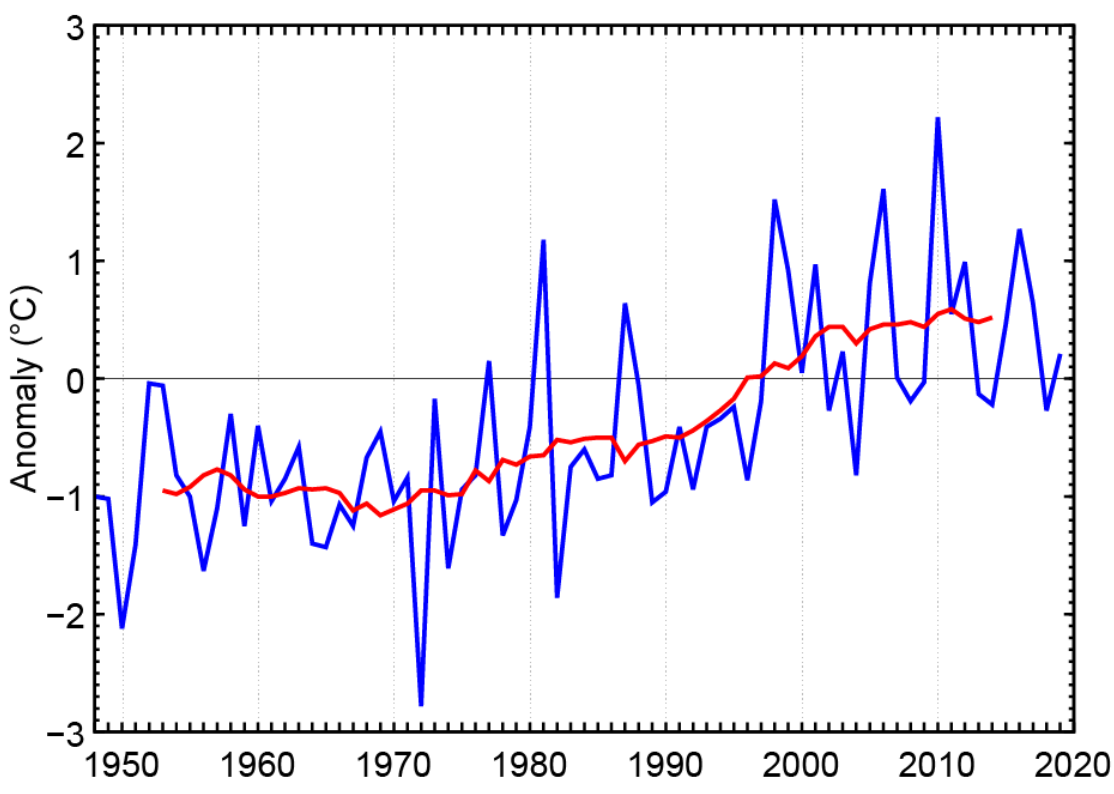

Fig. 7.1. Annual average temperature anomalies ( ${ }^{\circ} \mathrm{C} ; 1981-2010$ base period) in Canada for 1948-2019. Red line is the 12-year running mean. (Source: Environment and Climate Change Canada.) 72 years. Winter anomalies more than $+3.5^{\circ} \mathrm{C}$ above average were recorded in northwestern Canada, with the Northwest Territories having its 10th warmest winter on record. The remainder of the provinces experienced winter temperature anomalies more than $-0.5^{\circ} \mathrm{C}$ below average.

During spring, below-average temperatures were recorded from southeastern British Columbia eastward to the Atlantic provinces. Above-average temperatures were observed over northern Canada, with northwestern parts of Canada notably above average by more than $3.5^{\circ} \mathrm{C}$. The national average temperature for spring 2019 was $0.3^{\circ} \mathrm{C}$ above the $1981-2010$ average and the 13 th

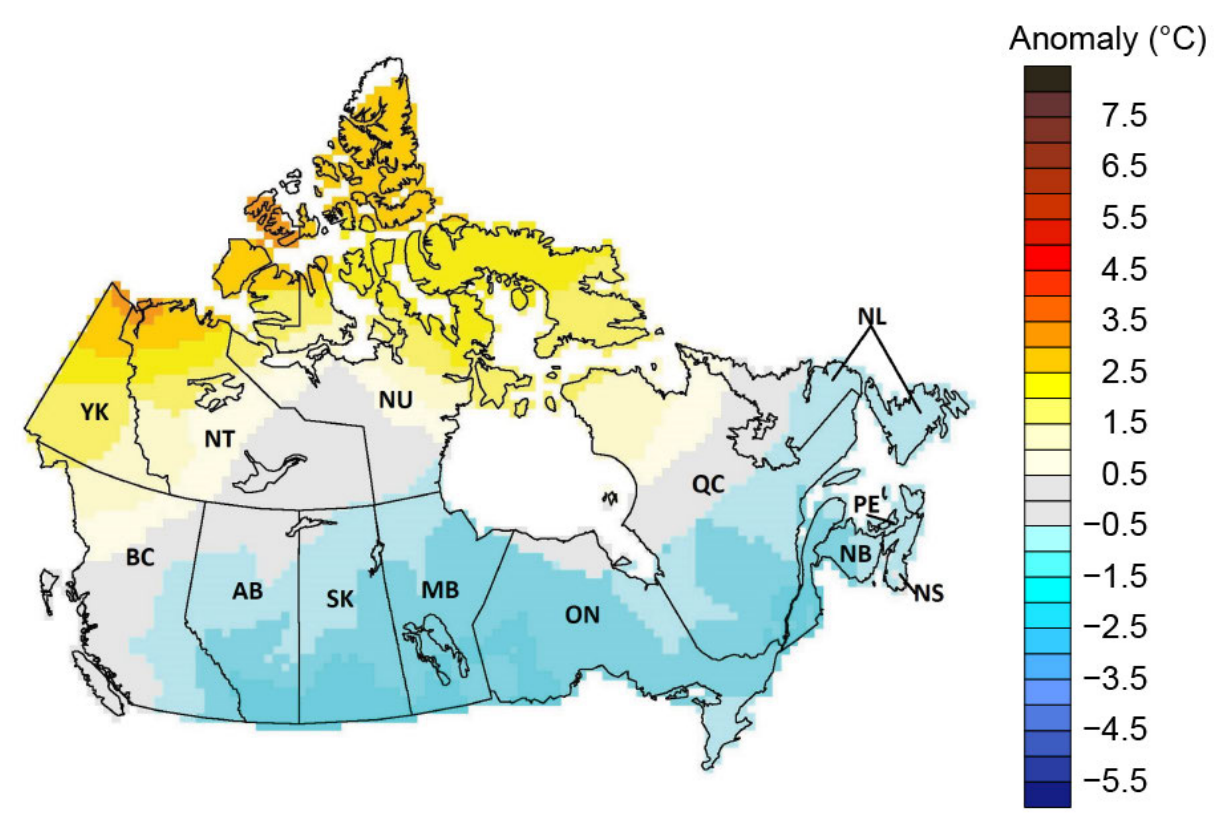

Fig. 7.2. Annual average temperature anomalies $\left({ }^{\circ} \mathrm{C} ; 1981-2010\right.$ base period) in Canada for 2019. YK=Yukon; NT=Northwest Territories; NU=Nunavut; $\mathrm{QC}=\mathrm{Quebec}$; NL=Newfoundland and Labrador; $\mathrm{PE}=$ Prince Edward Island; NS=Nova Scotia; NB=New Brunswick; ON=Ontario; $M B=$ Manitoba; SK=Saskatchewan; $\mathrm{AB}=\mathrm{Alberta}$; and $\mathrm{BC}=\mathrm{British}$ Columbia. (Source: Environment and Climate Change Canada.) highest in the 72-year record. The national average spring temperature has increased by $1.7^{\circ} \mathrm{C}$ over the past 72 years. Four provinces/territories experienced an average spring temperature that ranked among the 10 highest since 1948: Yukon (second highest), Northwest Territories (third highest), Nunavut (fourth highest), and British Columbia (10th highest).

The national average temperature for summer 2019 was $0.1^{\circ} \mathrm{C}$ above average and the 25th highest since 1948. Parts of Yukon and northeastern Canada experienced summer anomalies above $+1^{\circ} \mathrm{C}$, with Nunavut and Quebec having their sixth- and 10th-warmest summers on 
record, respectively. In contrast, below-average summer temperatures were experienced in the Northwest Territories, Alberta, Saskatchewan, and Labrador, with the Northwest Territories and Alberta having their 8th- and 10th-coolest summer on record, respectively. The national average summer temperature has increased by $1.4^{\circ} \mathrm{C}$ over the past 72 years.

The national average temperature for autumn 2019 was $0.9^{\circ} \mathrm{C}$ above average and the 13 th highest since 1948. Above-average temperatures were experienced across northern Canada, with three provinces/territories having autumn average temperatures among their 10 highest: Northwest Territories (third highest), Nunavut (third highest), and Yukon (fifth highest). Conversely, autumn anomalies of $-1^{\circ} \mathrm{C}$ or lower were experienced along the southern border from southeastern British Columbia to Atlantic Canada. The national autumn temperature has increased by $1.7^{\circ} \mathrm{C}$ over the past 72 years.

\section{(II) PRECIPITATION}

Over the past decade, precipitation-monitoring technology has evolved, and Environment and Climate Change Canada (ECCC) and its partners implemented a transition from manual observations to the use of automatic precipitation gauges. Extensive data integration is required to link the current precipitation observations to the long-term historical manual observations. The update and reporting of historical adjusted precipitation trends and variations will be on temporary hiatus pending the extensive data reconciliation, and resumed thereafter. ECCC remains committed to providing credible climate data to inform adaptation decision making, while ensuring the necessary data reconciliation occurs as monitoring technology evolves.

\section{(III) NOTABLE EVENTS AND IMPACTS}

The year 2019 will be remembered as the year of the big flood in eastern Canada. The country experienced a catastrophic spring flood along the Ottawa and St. Lawrence Rivers, with recordbreaking discharge. This was even larger than the 2017 event, which was considered at the time to be the flood of the century. A number of factors contributed to the flood. The region experienced seven straight months of below-normal temperatures from October 2018 through April 2019. These temperatures ensured that the ground froze deeply and thawed late, preventing the infiltration of rain and snowmelt runoff. In addition, snowfall accumulation was 50\% greater than normal in upstream catchments of the Ottawa River and, with little melting by mid-spring, the deep and icy snowpack remained for longer than normal. Multiple rounds of heavy spring rains fell over a five-week period between mid-April and mid-May, adding $150 \mathrm{~mm}$ of additional rainwater to the already heavily saturated region. All of these ingredients coincided, causing this catastrophic event that claimed at least two lives and flooded about 6000 dwellings and other infrastructure.

A similar situation also occurred in the spring of 2019 in the Fredericton-Saint John Region of New Brunswick. During April, precipitation in the region was nearly double the monthly average with six more wet days than normal and twice the number of heavy rain days (days with $>10 \mathrm{~mm}$ ) recorded. Up to $130 \mathrm{~mm}$ of rain fell along the Saint John River region within 10 days in late April. Mild temperatures and significant rains combined to rapidly melt the snowpack in New Brunswick. The Saint John River at the Maine-New Brunswick border had its largest peak streamflow in 67 years. Farther downstream, the peak river level in Fredericton was over $8.3 \mathrm{~m}$, the second-highest level on record (behind 1973). As a result, more than 5500 dwellings were flooded or at risk, and over 4000 hectares of land were flooded.

Canada was hit directly by Category 2 Hurricane Dorian during the active 2019 Atlantic hurricane season. By the time Dorian entered Canadian waters near Nova Scotia, the hurricane had weakened from its peak wind speed of $300 \mathrm{~km} \mathrm{~h}^{-1}$ to about $160 \mathrm{~km} \mathrm{~h}^{-1}$. Dorian made landfall in Halifax on 7 September as a post-tropical cyclone and brought sustained winds of $155 \mathrm{~km} \mathrm{~h}^{-1}$, torrential rains, storm surges, and over 20-m waves for more than a 24-hour period. High winds toppled trees and power lines, and storm surges caused widespread flooding. More than 500000 
homes and businesses were without electricity at the peak of the storm, and over $100 \mathrm{~mm}$ of rain fell across the Atlantic region during the storm.

In contrast to the record-breaking wildfire seasons experienced in British Columbia in the last two years, statistics from the Canadian Interagency Forest Fire Centre revealed a relatively quiet fire season in 2019. The area consumed by wildfires in British Columbia was about $0.02 \%$ of the area burned in each of the past two summers. A notable exception to the quiet wildfire season was in Alberta. The number of fires there was on par with 2018, but the area that fire consumed was nearly 14 times greater. In May, the "spring dip," when trees and grasses have low moisture content, was underway, and hot, very dry, strong gusty winds came early. Around mid-May, the Chuckegg Creek fire erupted near the town of High Level in far northwestern Alberta. It burned over 350000 hectares and lasted over 100 days, making it one of the longest wildfires on record. Over 10000 Albertans were displaced from their homes as a result of this fire. Overall, wildfires in Alberta burned 883000 hectares in 2019, making it the second-greatest area burned in 60 years and four times greater than the 25 -year average.

\section{2) United States—K. Gleason, C. Fenimore, R. R. Heim Jr., and A. Smith}

During 2019, above-normal temperatures were observed across much of the Southeast and

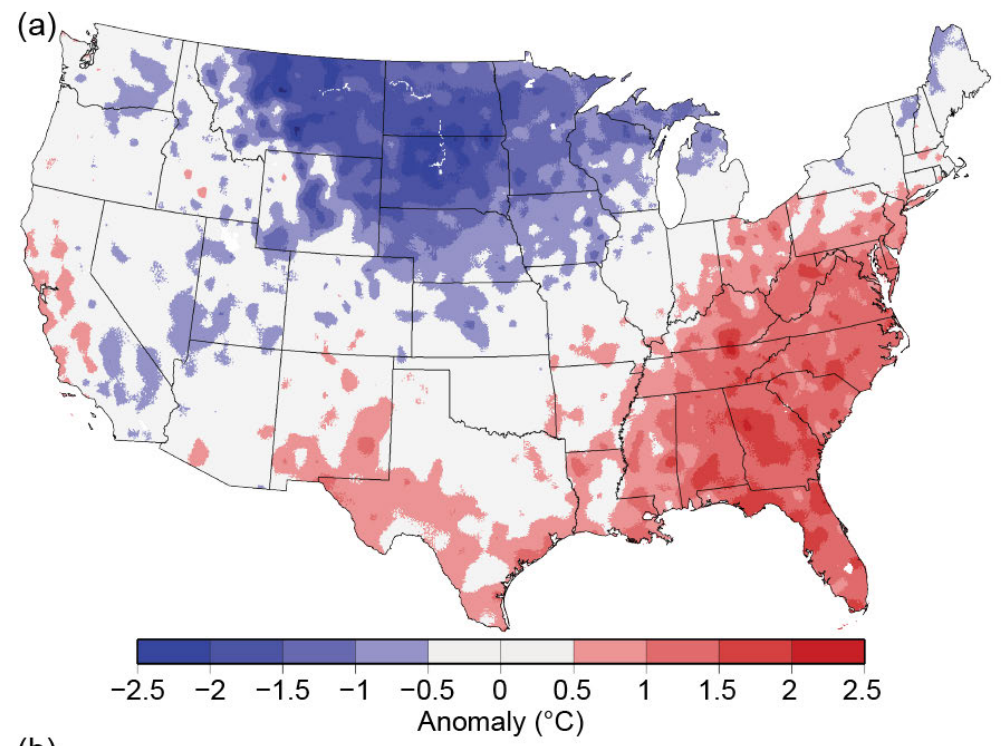

(b)

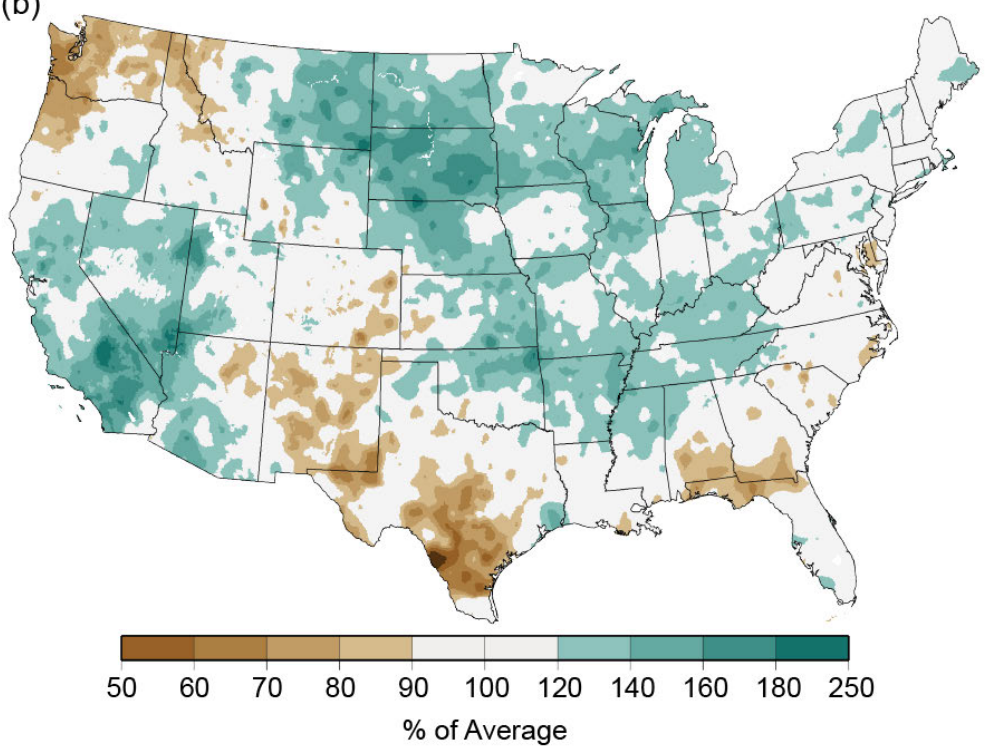

Fig. 7.3. Annual (a) average temperature anomalies $\left({ }^{\circ} \mathrm{C}\right)$ and $(\mathrm{b})$ total precipitation (\% of average) in the CONUS for 2019 (1981-2010 base period). (Source: NOAA/NCEI.) parts of the Mid-Atlantic, while belownormal temperatures were present across the northern and central Plains and part of the Great Lakes (Fig. 7.3a). Overall, the 2019 annual average temperature for the contiguous United States (CONUS) was $11.5^{\circ} \mathrm{C}$, which is $0.1^{\circ} \mathrm{C}$ below the $1981-2010$ average (Fig. 7.4). The annual CONUS temperature trend over the 125-year period of record is increasing at an average rate of $0.08^{\circ} \mathrm{C}$ decade ${ }^{-1}, 0.26^{\circ} \mathrm{C}$ decade $^{-1}$ since 1970. Above-normal precipitation was observed across much of the nation, with a large portion of the central United States and parts of the West receiving above- to much-abovenormal precipitation. Below-normal annual precipitation was observed across parts of the Northwest and the South (Fig. 7.3b). Average precipitation totaled $883 \mathrm{~mm}$, which is $112 \%$ of the 1981-2010 average and the secondlargest value in the 125-year record, behind 1973. The annual precipitation total is increasing at an average rate of $5 \mathrm{~mm}$ decade ${ }^{-1}$ since 1970. Alaska had its warmest year $\left(+2.8^{\circ} \mathrm{C}\right.$ departure; $0.2^{\circ} \mathrm{C}$ warmer than previous warmest year of 2016) since statewide records began in 1925. Precipitation across Alaska was near normal at $104 \%$ of average. 


\section{(I) TEMPERATURE}

Across the CONUS, 2019 was the coolest year since 2014 and the first year since then in which some states ranked in the lowest third of their historical record for annual temperatures. Nevertheless, 2019 ranked in the warmest third of the 125-year historical distribution for the CONUS as a whole. South Dakota recorded its 12th coldest year on record, one of six states across the northern Plains that ended the year in the coldest third of their historical distribution. In contrast, it was a warm year from the Gulf Coast to the mid-Atlantic region. Georgia and North Caro-

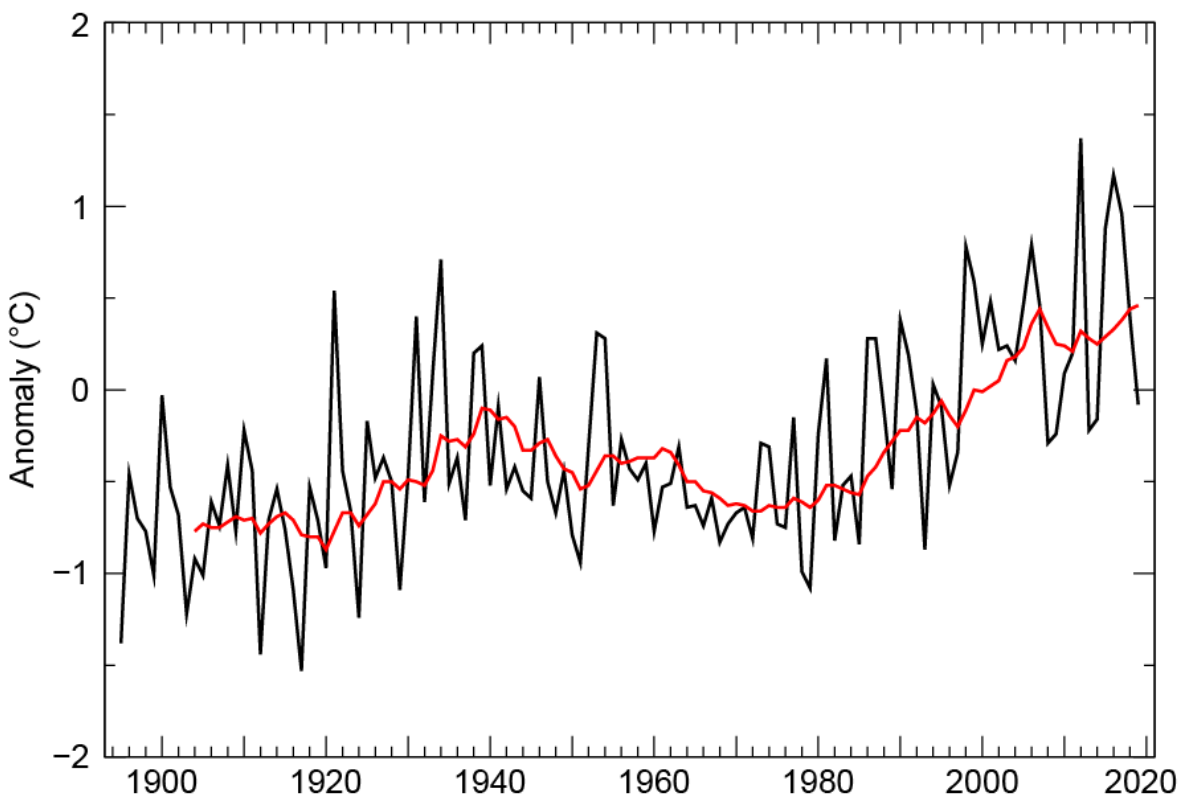

Fig. 7.4. Annual mean temperature anomalies $\left({ }^{\circ} \mathrm{C} ; 1981-2010\right.$ base period) for the CONUS for 1895-2019. Red line is the lagged 10-year running mean. (Source: NOAA/NCEI; for precipitation time series, see www.ncdc.noaa .gov/cag/national/time-series.)

lina each ranked warmest on record, with Florida, South Carolina, and Virginia ranking second warmest.

The winter $2018 / 19$ CONUS temperature was $0.1^{\circ} \mathrm{C}$ below the base period average, but still ranking in the warmest third of its record. Above-average warmth was confined to portions of the Southeast, while average- to below-average temperatures were evident from the Great Lakes and central Plains to the West Coast. The CONUS spring temperature was $0.6^{\circ} \mathrm{C}$ below average, ranking in the middle third of the record. Above-average temperatures were observed across the Pacific Northwest and the Southeast. Florida had its warmest spring season on record with Georgia, South Carolina, and North Carolina all having their second-warmest spring season on record. Below-average spring temperatures were present from the West Coast to the Great Lakes and into parts of New England. Summer CONUS temperatures were $0.3^{\circ} \mathrm{C}$ above average, ranking in the warmest third of the 125-year record. Florida and Delaware ranked fifth warmest while much of the central United States had near-average temperatures. The autumn CONUS temperature was $0.1^{\circ} \mathrm{C}$ below average, ranking in the middle third of the record. Below-average temperatures were present across the northern tier, while above-average temperatures were observed from California to the Southeast and into the mid-Atlantic states. Florida ranked sixth warmest for the season.

\section{(II) PRECIPITATION}

At the start of 2019, nearly 22\% of the CONUS was in drought, according to the U.S. Drought Monitor, mostly concentrated across the West and Southwest. Abundant precipitation during the first few months of the year, especially over the western drought areas, helped improve conditions, bringing the drought to its minimum extent of approximately 2\% in April. Winter precipitation across the CONUS was a record $134 \%$ of average. Much of the Ohio and Tennessee Valleys, as well as the central Plains and Great Lakes received above-average precipitation during this period. Both Wisconsin and Tennessee had a record wet winter. Below-average precipitation was confined to parts of the Northwest, central Rockies, and Texas.

Spring 2019 precipitation was 122\% of average and ranked fifth wettest on record. Aboveaverage precipitation occurred from parts of the West to the Great Lakes. Kansas observed its wettest spring season on record. Precipitation was below average from the state of Washington to northern Minnesota as well as across much of the Southeast. Record flooding along the 
Missouri, Mississippi, Platte, and Arkansas Rivers during the spring and summer months was the result of rapid snowmelt in the spring as well as heavy and frequent precipitation throughout the first six months of 2019.

Summer precipitation was $104 \%$ of average across the CONUS, with the wettest conditions occurring across much of the Plains, as well as the Mississippi and Ohio Valleys. Conditions were dry across much of the western United States and portions of the Midwest. By August, the weather pattern turned dry and hot across parts of the country, increasing the drought footprint to $9 \%$ of the CONUS, and continued to expand across the Southwest into October.

The autumn CONUS precipitation total was 101\% of average and ranked in the wettest third of the historical record. North Dakota, Minnesota, and Wisconsin were record wet for this period, with dry conditions observed across the West, the central Rockies and Plains, as well as parts of Texas and Florida. Five states had their wettest annual period on record, namely North Dakota, South Dakota, Minnesota, Wisconsin, and Michigan (Fig. 7.3b). For the year, the CONUS ranked second wettest behind 1973. Dry conditions were not as extensive or as frequent as the wet conditions, except during the late summer to early autumn. By the end of the year, drought was mainly confined to the Pacific Northwest, the Southwest, and parts of the southern Plains, accounting for $11 \%$ of the country.

\section{(III) NOTABLE EVENTS AND IMPACTS}

There were 14 weather and climate events during 2019 with losses exceeding $\$ 1$ billion (U.S. dollars) each across the United States and yielding 44 fatalities (www.ncdc.noaa.gov/billions): three inland flooding events, eight severe storm events, two tropical cyclone events (Dorian and Imelda), and one wildfire event (Fig. 7.5). The year's loss total of $\$ 45.0$ billion (U.S. dollars) was above average, as the 40-year (1980-2019) annual cost average, adjusted for inflation, is $\$ 43.9$ billion (U.S. dollars). The combined cost of $\$ 20.0$ billion (U.S. dollars) associated with the Missouri, Arkansas, and Mississippi River flooding was nearly half of the U.S. cost total during 2019. The total cost of U.S. billion-dollar disasters over the last five years (2015-19) exceeds \$525

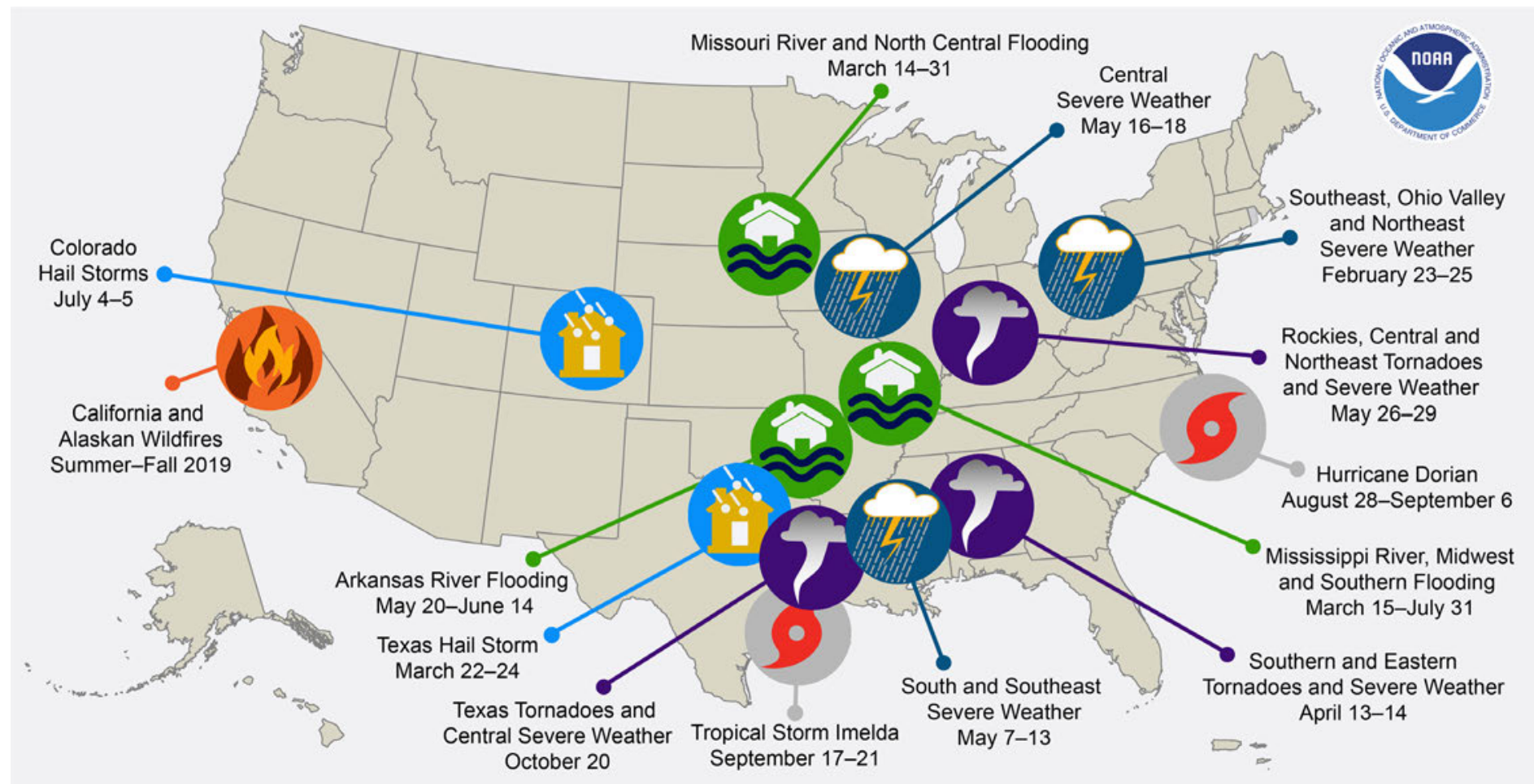

Fig. 7.5. Map depicting date, approximate location, and type of the 14 weather and climate disasters in the United States in 2019 with losses for each exceeding \$1 billion (U.S. dollars). (Source: NOAA/NCEI.) 
billion (U.S. dollars), with a five-year annual cost average of $\$ 106.3$ billion (CPI-adjusted U.S. dollars), both of which are records. The damage costs from 2010 to 2019 for the United States were also historically large-exceeding \$800 billion (U.S. dollars) from 119 separate billion-dollar events (Smith 2020).

During 2019, there were 1520 tornado reports, including preliminary numbers for September-December. This was well above the 1991-2010 U.S. annual average of 1251 tornadoes. Once preliminary numbers are finalized, it is likely that 2019 will rank among the top five years for tornado counts since 1950.

Nearly 50000 wildfires were recorded across the CONUS in 2019. Since 2000, only 2013 had fewer wildfires than what was observed during 2019. The 2019 fires consumed approximately 1.9 million hectares, which was the sixth-smallest area in the last 20 years.

\section{SIDEBAR 7.1: Record wetness and the impact on U.S. Midwest/Plains agriculture growing season 2019-D. TODEY}

The U.S. flooding issues of 2019 were well-reported nationally, capturing a great deal of attention because of their widespread impacts on the Missouri and Mississippi River systems. There were direct flooding impacts to agriculture (including livestock, soil damage, and loss of grain in flooded bins) due to the flooding associated with the March Bomb Cyclone (Bosart et al.

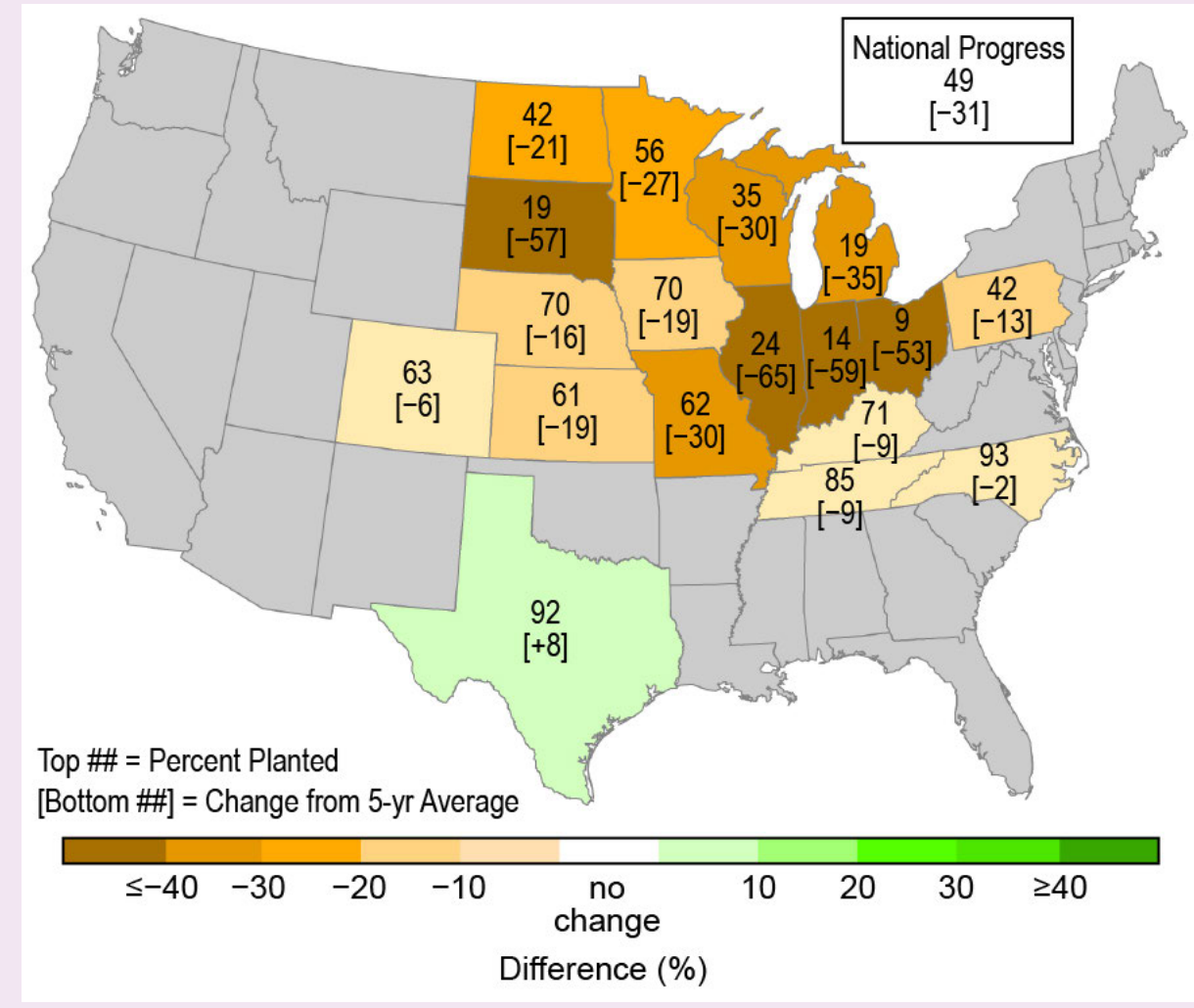

Fig. SB7.1. State corn emergence numbers as of 19 May 2019 and a comparison to the 5-year average. Corn is usually nearly half emerged by mid-May. (Image courtesy Brad Rippey [USDA-OCE].)
2020) and season-long flooding along many rivers throughout the Corn Belt and Northern Plains. However, the wider-spread agricultural impacts were due more to overall soil wetness than direct flooding (Todey et al. 2020).

Because autumn 2018 and spring 2019 were very wet across the Midwest and Plains, extremely wet soils were present in the region early in the year. This resulted in delayed planting, because excessively wet soils limit field access to plant crops as soils can be damaged by compaction from large equipment traversing fields. Excessively wet fields can also limit crop development and increase disease risk. Due to the preseason precipitation and a wet, cool spring, planting moved at a record slow pace for corn, soybeans, small grains, and other crops. Typically, corn is nearly half emerged by mid-May. Figure SB7.1 depicts how far behind corn emergence was in mid-May 2019.

Many hectares went unplanted because of the excess wetness. Federal crop insurance plans cover, among other losses, "prevented planting," where conditions are too wet to plant during the crop planting time frame. The Upper Midwest set a record number of prevented planting hectares with nearly eight million hectares unplanted. Large areas of corn 
were planted well into June, much later than is usually recommended. A sampling of crop records are:

- Least amount of corn planted by 2 June (67\% planted).

- Least amount of corn emerged by 2 June ( $46 \%$ emerged), which broke established records between $70 \%$ and $80 \%$.

- Least amount of soybeans emerged by 2 June (19\% emerged). The most affected areas included (Fig. SB7.2, highest indemnity): northwest Ohio, northern Illinois, the Missouri River valley, and the eastern Dakotas/western Minnesota. Some counties in these areas planted less than half of their agricultural hectares.

Because of the widespread late planting, crops had a shorter season to complete development. For crops such as soybeans, a shortened season is a minor issue. Corn, however, requires a certain amount of heat (measured by Growing Degree Days) to complete phenological development. The late start and moderate temperatures, which would be good for crop development in an on-time planting year, slowed crop progress through the season. Wet years do not limit grain production (yield) as much as drought years. The issues during wet seasons tend to be limited development time, excessively wet crops at harvest,

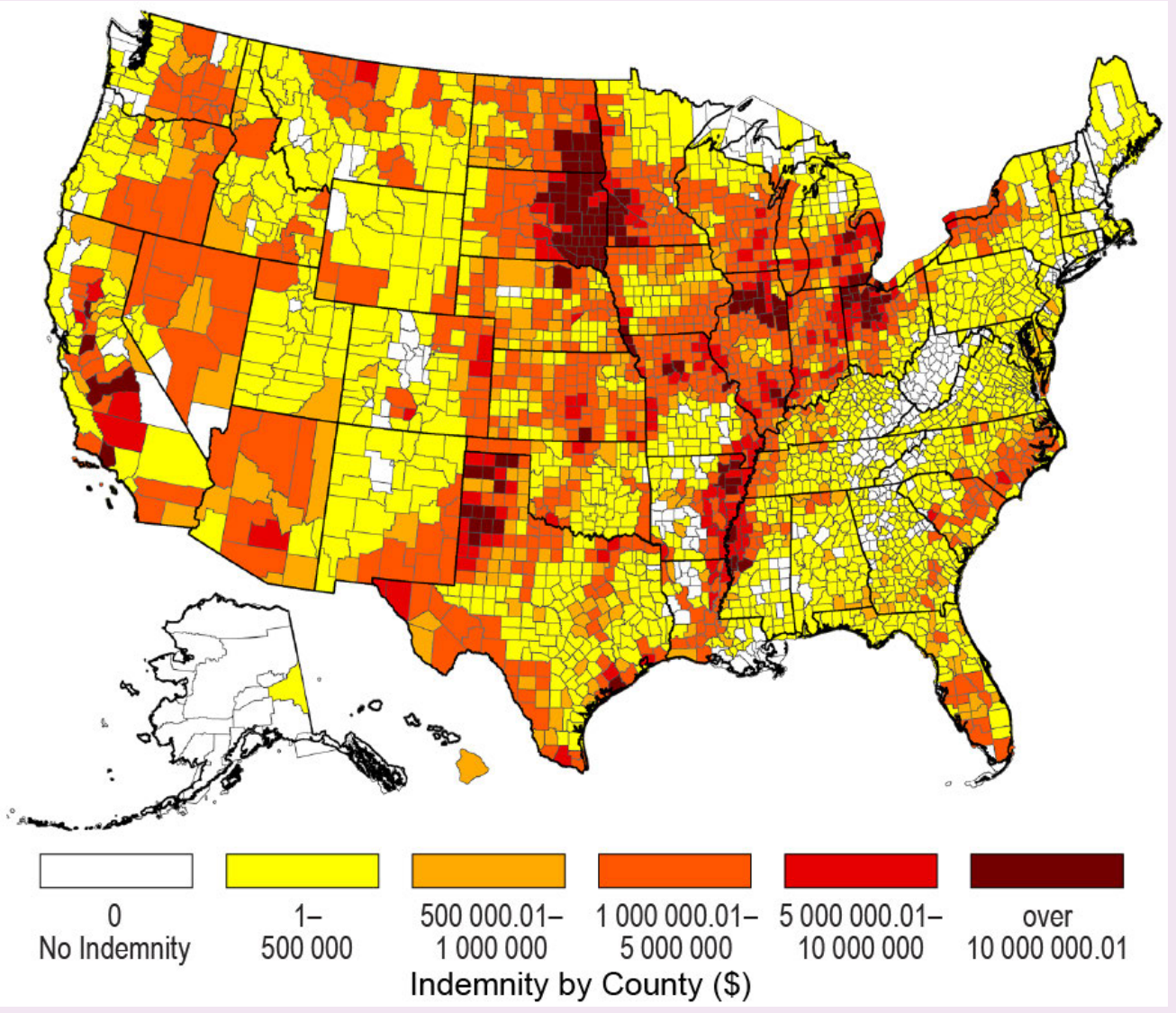

Fig. SB7.2. USDA Risk Management Agency Crop county-level indemnities (insurance payments for unplanted crops) paid. The darker the color, the higher the indemnitymostly crop insurance payments for spring prevented planting across the Midwest and Plains. and poor grain quality. In addition, wetness leads to additional disease issues.

Despite the delays, most row crops (i.e., corn/soybeans) did reach maturity but had not dried down in the field as much as producers would like. This resulted in a large amount of time and management to dry the grain after harvesting it, which in turn slowed the harvest progress. The additional drying costs (propane/electricity) further reduced profit during a time of very limited profit margins on most crops. Above-average precipitation occurred during harvest, further slowing crop harvest.

Relatively early snow in the Dakotas limited harvest, leaving some sunflowers and nearly half the corn in North Dakota still in the field at the end of the year, according to the USDA National Agricultural Statistics Service. The crops with the largest yield losses were corn (3\% below trend) and soybeans ( $4 \%$ below trend). Winter wheat, grown more extensively in the Plains, was able to utilize the additional moisture and cooler spring conditions in 2019, leading to larger yields (7\% above trend).

The additional grain-handling issues also produced associated impacts. The heavy drying requirement, along with an early cold event, caused shortages of propane needed for drying. Handling wet grain can lead to packed grain, which is dangerous to dislodge from within grain bins. Several deaths were reported because of people accidentally becoming entrapped in grain bins. The additional stress of a difficult growing season, along with low grain prices, led to many Midwestern states setting up state efforts to deal with rural/farm stress and mental health issues.

Additional stress occurred in the spring of 2019 when several blizzards covered the Plains during calving periods. Most cattle on rangeland are not housed inside. Consequently, blizzards during calving are very dangerous. Beef cattle losses during the spring in Nebraska and South Dakota were significant. Reports on losses are still being developed at the time of this writing. 
3) Mexico-R. Pascual Ramírez

The 2019 precipitation total for Mexico was near average at $96.8 \%$ of normal, making it the 19th-driest year since records began in 1941 . Regionally, the entire coastal zone of the Gulf of Mexico, the southeast, the Yucatan Peninsula, as well as several regions of the Pacific, had the greatest rainfall deficits for the year. Above-average precipitation fell in the northwest and parts of the central and northern regions of the country. Temperatures were higher than average during all months of the year, tying with 2016 as the second-warmest year on record.

\section{(I) TEMPERATURE}

The 2019 national mean temperature of $22.4^{\circ} \mathrm{C}$ was $1.5^{\circ} \mathrm{C}$ above the 1981-2010 average and tied with 2016 as the second-warmest year since records began in 1953 (Fig. 7.6). The year 2017 is the warmest year on record. The year 2019 also marked the 15th consecutive year with temperatures above average. All months of the year were warmer than average, with August being exceptionally warm. The national August 2019 average temperature was $27.0^{\circ} \mathrm{C}$, or $3.3^{\circ} \mathrm{C}$ above average-the warmest August on record and the warmest month for any month since 1953.

The 2019 mean temperature was above average across much of the country, with a few exceptions across the northwest and the Baja California Peninsula, as well as southern parts bordering the Pacific (Fig. 7.7a). Twelve states across central to southern Mexico had their warmest year on record. Meanwhile, no state had a top-10 cold year on record.

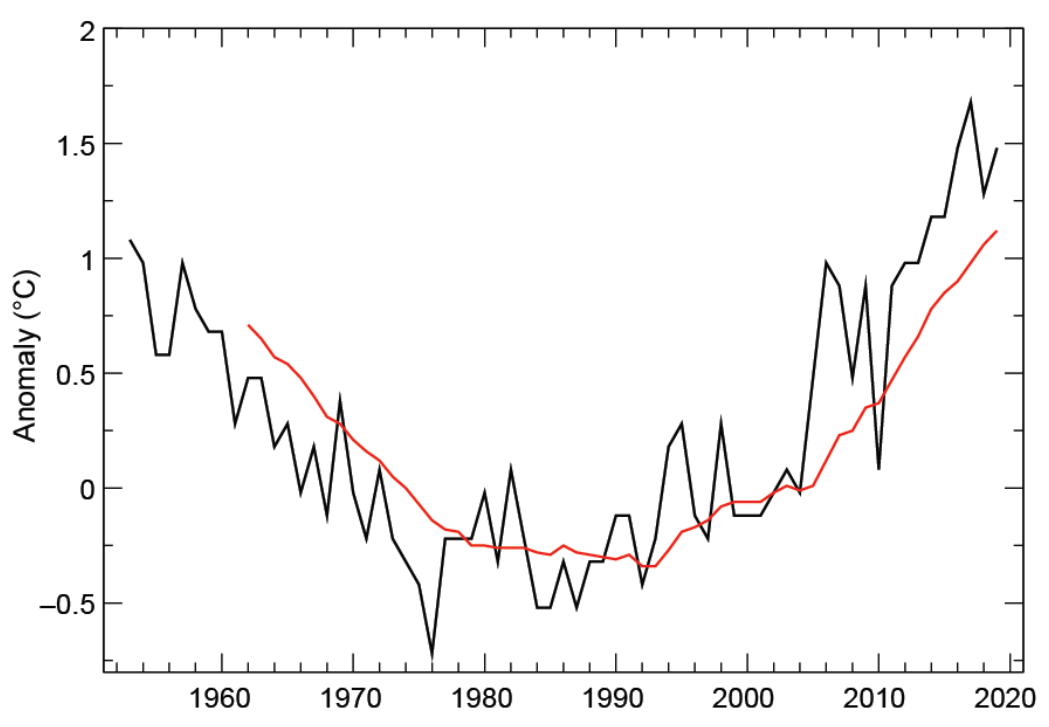

Fig. 7.6. Annual mean temperature anomalies $\left({ }^{\circ} \mathrm{C}\right.$, black line; $1981-$ 2010 period) for Mexico for 1953-2019. Red line depicts the lagged 10-year running mean. (Source: National Meteorological Service of Mexico.)

(a)
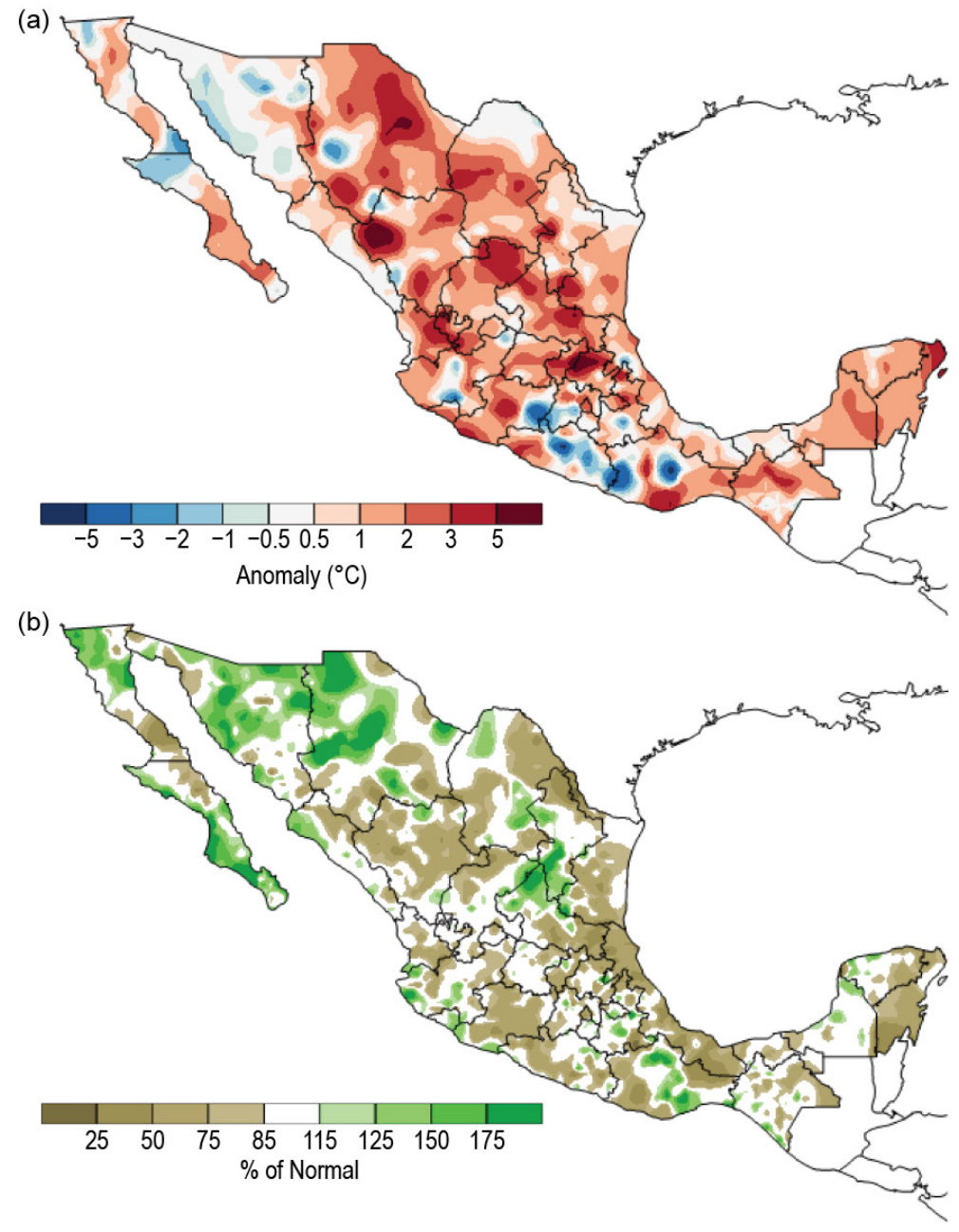

Fig. 7.7. 2019 annual (a) mean temperature anomalies $\left({ }^{\circ} \mathrm{C}\right)$ and (b) precipitation anomalies (\% of normal; 1981-2010 base period) over Mexico. (Source: National Meteorological Service of Mexico.) 


\section{(II) PRECIPITATION}

Rainfall distribution varied regionally (Fig. 7.7b), with above-normal precipitation across the northwest, especially parts of Chihuahua and Sonora. Other regions with above-average rainfall include the northeast, specifically southern Nuevo León and northern San Luis Potosí, along with small regions in the central Pacific and a small area in central Oaxaca. The rest of the country had below-average precipitation, with the three eastern states of San Luis Potosí, Veracruz, and Hidalgo having their driest, second-driest, and third-driest year on record, respectively.

The first three months of the year produced two dry months and a wet one, resulting in the 28th-driest January-March period. However, dry conditions persisted across much of the rest of the year. The three-month period of April-June is the transition from the dry season to the rainy season; it ranked ninth-driest such period on record. The July-September period was the eighthdriest such period on record. Beneficial rains returned during the last three months of the year, giving way to the fourth-wettest October-December period on record. The dry conditions across eastern Mexico were mostly attributed to the lack of tropical cyclones affecting the region.

Climatologically, September is the nation's rainiest month of the year, contributing about $18.4 \%$ of the annual rainfall. September was indeed the nation's rainiest month of 2019, and it contributed $20.1 \%$ of the annual rainfall. Much of September's rainfall was associated with three tropical cyclones: Hurricane Lorena and Tropical Storm Narda, both on the Pacific side, and Tropical Storm Fernand along the Gulf of Mexico. Tropical Storm Fernand was the only storm to affect the country's Gulf of Mexico coast, with copious rain in early September. The storm's rainfall benefited only northeastern Mexico, farther north from drought-stricken areas in the east. On the Pacific side, Hurricane Lorena made landfall along the nation's coasts three times, but its greatest rainfall occurred across the central-western part of Mexico.

Climatologically, March is the driest month of the year, contributing only $1.8 \%$ to the annual rainfall. However, in 2019, April was the driest month of the year, contributing only $0.9 \%$ of the total annual rainfall.

\section{(III) NOTABLE EVENTS AND IMPACTS}

Typically winds and rains from tropical cyclones (TCs) begin to significantly affect Mexico when they come within $100 \mathrm{~km}$ of the coast. Five TCs affected Mexico during 2019. Four storms approached within $100 \mathrm{~km}$ of, or made landfall on, the nation's Pacific coast, while one TC made landfall from the Gulf of Mexico, as noted above. Five storms affecting Mexico is near the long-term average, but it is low when compared to the very active recent years. Considering only the decade of 2010-19, 2019 tied with 2016 for the second-fewest (to 2015, with three) number of active TCs.

For a third consecutive year, drought conditions deteriorated in southern Mexico due to the absence of TCs near this region. Hidalgo, San Luis Potosi, Veracruz, and Tabasco, some of Mexico's rainiest states, each reported a September among their eight driest, with Hidalgo having its thirddriest September on record. Drought impacts for the region included water shortages in southern Veracruz and Tabasco, lack of pasture forage and water supplies, and reduced runoff in streams (made worse by higher temperatures). In Chiapas, Sumidero Canyon was closed in February to recreational navigation due to the very low water levels in the Grijalva River.

\section{c. Central America and the Caribbean-A. Sánchez-Lugo, Ed.}

During 2019, much of Central America and the Caribbean had near- to above-normal temperatures and near- to below-normal precipitation. Several tropical systems impacted the region; however, only two named storms formed in the Caribbean Sea.

Unless otherwise noted, all anomalies are with respect to the 1981-2010 base period. 
1) Central America-J. A. Amador, H. G. Hidalgo, E. J. Alfaro, B. Calderón, and N. Mora

For this region, nine stations from five countries were analyzed (see Fig. 7.8 for data and station list). The station distribution covers precipitation (Magaña et al. 1999), wind (Amador 2008), and temperature (Hidalgo et al. 2019) on the Caribbean and Pacific slopes of Central America. Precipitation and temperature records for the stations analyzed and regional wind were provided either by Central America National Weather Services (NWS), National Oceanic and Atmospheric Administration (NOAA), or the University of Costa Rica. Anomalies are reported using a 1981-2010 base period and were calculated using Central America-NWS data. The methodologies used for all variables can be found in Amador et al. (2011).

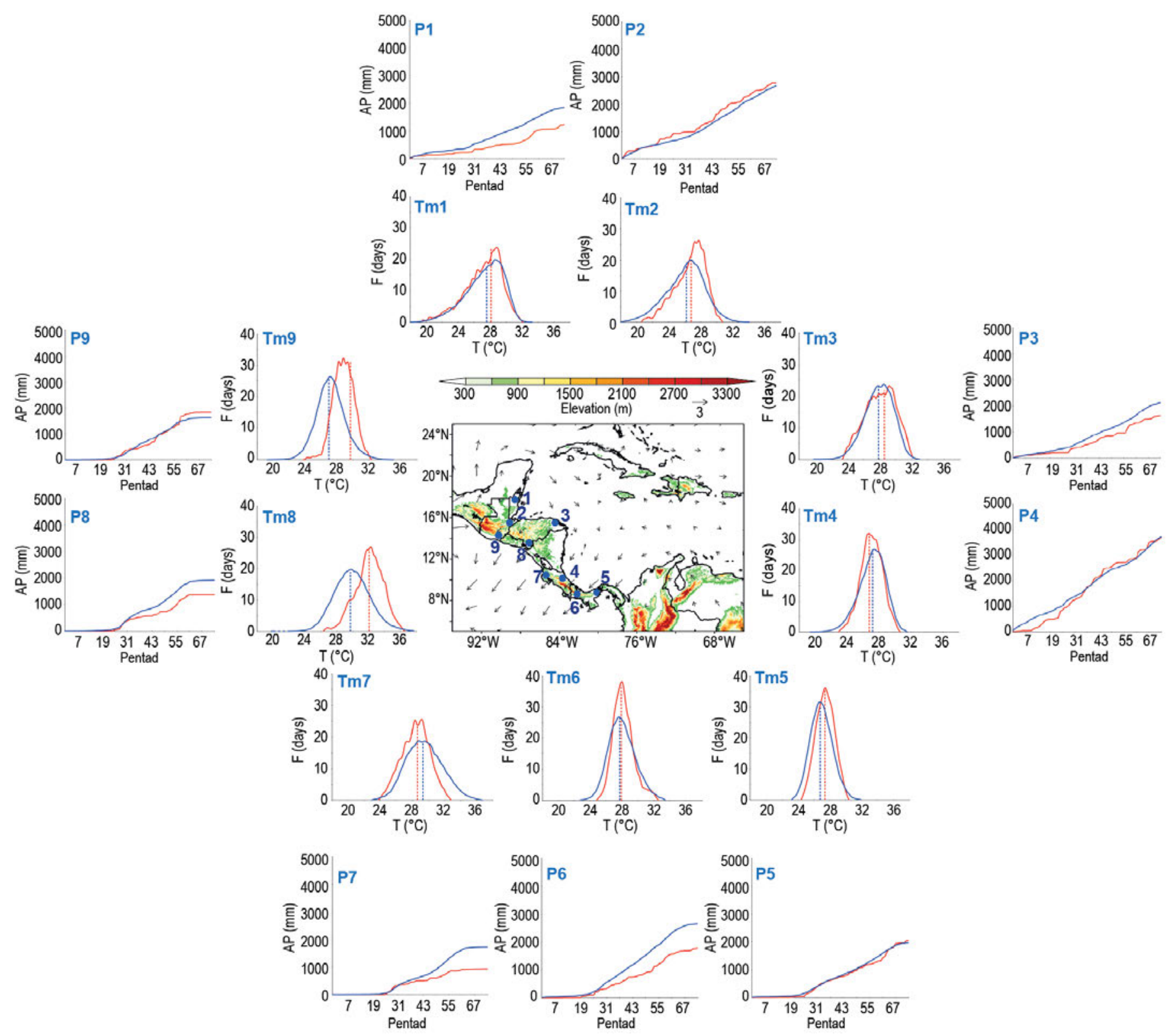

Fig. 7.8. Mean surface temperature $\left(\mathrm{Tm} ;{ }^{\circ} \mathrm{C}\right)$ frequency (F; pentads), and accumulated pentad precipitation $(\mathrm{P} ; \mathrm{mm})$ time series are shown for nine stations (blue dots) in Central America: (1) Philip Goldson International Airport, Belize; (2) Puerto Barrios, Guatemala; (3) Puerto Lempira, Honduras; (4) Puerto Limón, Costa Rica; (5) Tocumen International Airport, Panamá; (6) David, Panamá; (7) Liberia, Costa Rica; (8) Choluteca, Honduras; and (9) Puerto San José, Guatemala. The solid red line shows 2019 values; the solid blue line represents the 1981-2010 average values. Vertical dashed lines show the mean temperature for 2019 (red) and the 1981-2010 period (blue). Vectors indicate Jul wind anomalies ( $\left.\mathrm{m} \mathrm{s}^{-1}\right)$ at $925 \mathrm{hPa}(1981-2010$ base period). Shading depicts regional elevation $(m)$. (Sources: NOAA/NCEI and Central America-NWS.) 


\section{(I) TEMPERATURE}

The mean temperature (Tm) frequency pentad distribution for the climatology and for all stations analyzed in 2019 is shown in Fig. 7.8. During 2019, most stations had a discernible shift in their distribution toward warmer-than-normal conditions. Puerto Limón (Tm4 in Fig. 7.8) and Liberia (Tm5), both in Costa Rica, were the only two stations that observed slightly below-normal temperatures in 2019. The 2019 temperature means of Choluteca (Tm8) and Puerto San José (Tm9) were significantly different compared to their climatology when using the two-sample t-tests, with 2019 having a mean $2^{\circ}-4^{\circ} \mathrm{C}$ higher than the $1981-2010$ base period. All other stations showed no significant differences in their means with respect to the base period. When comparing the 2019 Tm pentad distributions to the 1981-2010 base period, most stations failed two-sample Kolmogorov-Smirnov tests (KS2; Wilks 2011) at the 95\% confidence level, suggesting that 2019 was distributed significantly different from climatology. It should be noted for some stations that there is a great difference in the tail densities and shapes of the probability density functions between the climatology and the 2019 curves, suggesting the degree to which 2019 was an atypical year.

\section{(II) PRECIPITATION}

The accumulated pentad precipitation (P) time series for the nine stations in Central America are presented in Fig. 7.8. Precipitation showed different probability distributions throughout the year for all stations according to KS2, with most stations having near- to below-normal precipitation by the end of 2019. Only Puerto Barrios (P2) and Puerto San José (P9), both in Guatemala, had slightly above-normal annual precipitation. However, no station had annual rainfall deficits or excess beyond the $95 \%$ confidence interval of the normal distributions constructed from the base period annual precipitation totals. Even though 2019 will not be considered an extreme year at that significance level, the precipitation deficits in some of the stations were nevertheless considerably large. Of note, Philip Goldson International Airport (P1), David (P6), Liberia (P7), and Choluteca (P8) received $54 \%-71 \%$ of normal precipitation for the year. Low-level circulation anomalies in the westernmost Caribbean Sea and Pacific regions displayed slightly above-average values during July (vectors in Fig. 7.8) in the trade wind system. This condition is usually associated with above-normal precipitation along the Caribbean slopes and with below-normal precipitation on the Pacific slopes during summer, where it is especially related to the mid-summer drought condition impacting hydropower generation, tourism, and agriculture, among other sectors (Amador 1998, 2008; Magaña et al. 1999; Hidalgo et al. 2019).

\section{(III) NOTABLE EVENTS AND IMPACTS}

Tropical cyclone activity during 2019 was below normal in the Caribbean basin and the eastern tropical Pacific (ETP). In the Caribbean basin, there were only two named tropical storm systems: Dorian (27-28 August; see Sidebar 4.1 for details) and Karen (22-24 September; see Notable events and impacts in section 7c2). On 23 October, Tropical Depression Seventeen developed near Belize, intensifying over the Gulf of Mexico to become Tropical Storm Olga. In the ETP, no tropical storms made landfall in the isthmus; however, during 21-27 May, a significant low-pressure system was generated offshore the Pacific Coast of Costa Rica and Nicaragua. Heavy rainfall associated with the low-pressure system was recorded in the North Pacific region of Costa Rica. During 2019, a total of 21 fatalities were reported and at least 41 people were injured by lightning (Table A7.1). Additional information on regional impacts from hydrometeorological events during 2019 can be found in Table A7.2. 
2) Caribbean-T. S. Stephenson, M. A. Taylor, A. R. Trotman, J. M. Spence, K. A. Stephenson, A. C. Joseph, C. J. Van Meerbeeck, J. D. Campbell, and L. A. Clarke

Temperatures are drawn from the Global Historical Climatological Network-Monthly version 4 (GHCN-M-v4), with a climatological baseline of 1981-2010.

\section{(I) TEMPERATURE}

In 2019, the Caribbean experienced above-average annual mean surface temperatures with the largest positive anomalies over the north and, in contrast, below-normal temperatures over the U.S. Virgin Islands, Guadeloupe, and Monserrat (Fig. 7.9a). The average temperature anomaly over the domain was approximately $+0.81^{\circ} \mathrm{C}$ higher than baseline and represents the greatest departure from this mean since records began in 1891 (Fig. 7.10). The warmth persisted throughout the year, although a few locations in the southern Caribbean experienced cooler-than-normal conditions during the first six months. Notably, 2019 was the warmest year on record since the start of the record in 1977 for Sangster, Jamaica $\left(32.5^{\circ} \mathrm{C}\right)$, and Grand Cayman $\left(31.1^{\circ} \mathrm{C}\right)$.

Monthly Caribbean sea surface temperatures (SSTs) exhibited increasingly warm anomalies as the year progressed. By December, most areas recorded SSTs $0.5^{\circ}-1.0^{\circ} \mathrm{C}$ above average.
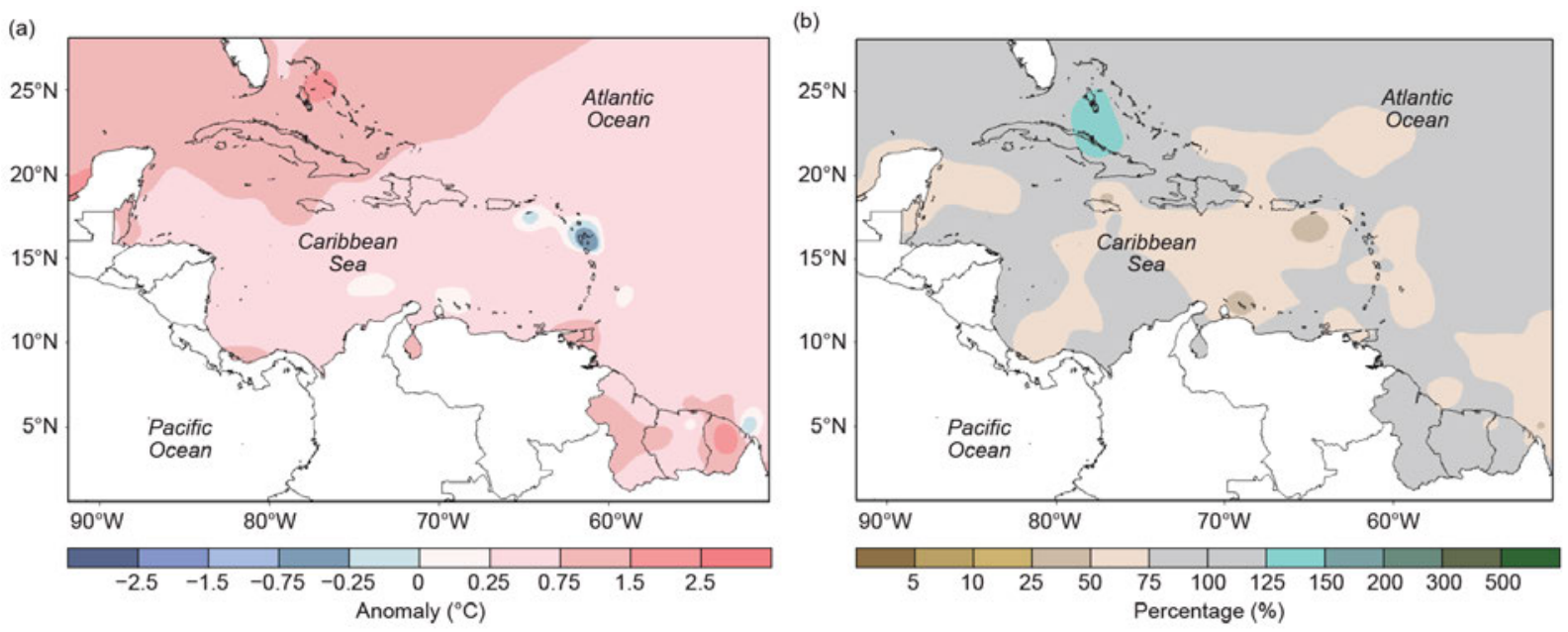

Fig. 7.9. Annual (a) mean temperature anomalies $\left({ }^{\circ} \mathrm{C}\right)$ and $(\mathrm{b})$ total precipitation anomalies (\% of normal) relative to the 1981-2010 base period. (Source: Caribbean Climate Outlook Forum and the Caribbean Institute for Meteorology and Hydrology.)

\section{(II) PRECIPITATION}

Normal to below-normal rainfall anomalies were observed over the region in 2019 (Fig. $7.9 \mathrm{~b})$, continuing from relatively dry conditions in late 2018, related to a weak El Niño event that began in January and ended in July (see section $4 \mathrm{~b}$ for details). During January-March 2019, normal to below-normal rainfall was observed across the region. During these climatologically dry months, the northern islands exhibited slightly dry to very wet anomalies, while eastern islands were slightly dry to exceptionally dry (Fig. 7.9b). This pattern of a wetter northern and drier eastern Caribbean is a signature pattern of El Niño events (e.g., Spence et al. 2004). March 2019 was the driest

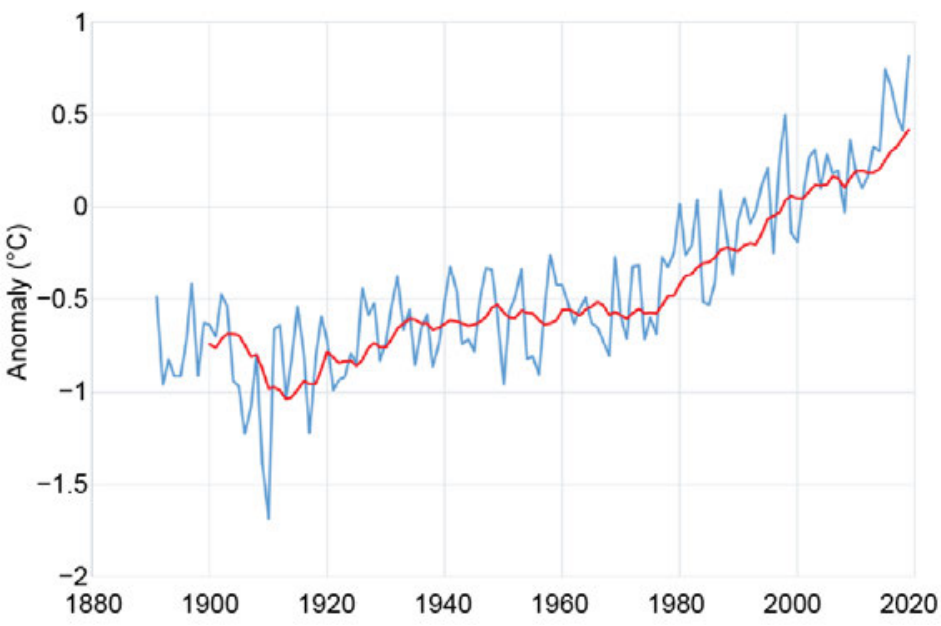

Fig. 7.10. Annual average 2-m temperature anomalies (blue line, $\left.{ }^{\circ} \mathrm{C}\right)$ for the Caribbean $\left(9^{\circ}-27^{\circ} \mathrm{N} ; 5^{\circ}-90^{\circ} \mathrm{W}\right)$ for $1891-2019$ relative to the 1981-2010 average. The red line is the 10-year running mean. (Source: NOAA/NCEI from the KNMI Climate Explorer.) 
March since 1951 at the Henry E. Rohlsen Airport, Saint Croix (0.5 mm), contributing to its fourthdriest year on record $(618.7 \mathrm{~mm})$.

For April-June, which is climatologically the start of the rainy season, rainfall ranged from normal to below normal across the eastern islands, with the exception of Antigua and Guadeloupe, which were normal to slightly wet. The northern and larger Caribbean countries (e.g., Jamaica, Hispaniola, and Puerto Rico) showed oppositely signed anomalies. Countries in the far north, e.g., The Bahamas and Cuba, showed normal to moderately wet anomalies. The extent of drier-than-normal conditions expanded in the third quarter, coinciding with the climatological mid-summer dryness experienced by northern Caribbean countries. The overall dry Caribbean basin was interspersed with normal to above-normal anomalies over much of the northern and northeastern Caribbean. For October-December, normal to below-normal anomalies were recorded over many of the islands. Of 113 Caribbean rainfall stations, seven stations recorded their driest year on record, 47 recorded totals in the 10th percentile, and two in the 90th percentile. Stations recording their driest year are noted in Table 7.1.

Table 7.1. Record low annual rainfall totals for 2019.

\begin{tabular}{|c|c|c|c|}
\hline Country & Station & $\begin{array}{c}\text { Rainfall Total } \\
\text { (mm) }\end{array}$ & $\begin{array}{c}\text { Starting year } \\
\text { of record }\end{array}$ \\
\hline Barbados & $\begin{array}{c}\text { Caribbean Institute for } \\
\text { Meteorology and } \\
\text { Hydrology }\end{array}$ & 804.5 & 1969 \\
\hline Barbados & $\begin{array}{c}\text { Grantley Adams } \\
\text { International Airport }\end{array}$ & 736.5 & 1942 \\
\hline Belize & Punta Gorda Airport & 1245.6 & 1971 \\
\hline Belize & Spanish Lookout & 900.0 & 1984 \\
\hline Curaçao & Hato International Airport & 248.9 & 1972 \\
\hline Dominican Republic & Monte Cristo & 311.1 & 1973 \\
\hline Trinidad & Piarco & 1413.4 & 1971 \\
\hline
\end{tabular}


(III) NOTABLE EVENTS AND IMPACTS

Short- and long-term drought conditions were observed across several Caribbean islands during the year. Additionally, June-December was generally characterized by dry and warm conditions that resulted in heat waves in most locations. From August to October, ocean warming levels necessitated Level 1 (bleaching expected) and Level 2 (widespread bleaching and some mortality expected) coral bleaching heat stress alerts for the region (Caribbean Coral Reef Watch October 2019).

The slow-moving Category 5 Hurricane Dorian hit the Bahamas on 1 September with winds of $160 \mathrm{kt}\left(82 \mathrm{~m} \mathrm{~s}^{-1}\right)$ and storm surges of approximately $6.1-7.6 \mathrm{~m}$. This was the strongest hurricane on record to impact the Bahamas. Destructive winds, extensive flooding, and storm surges led to 67 deaths, with over 300 missing as of December 2019. Homes, essential services, telecommunications, boats, cars, and government infrastructures were destroyed. Total damage was estimated over \$3.4 billion (U.S. dollars). Please refer to Sidebar 4.1 for more details about this storm.

Tropical Storm Karen formed on 22 September and was briefly downgraded to a tropical depression as it traversed the region. Karen caused flooding and storm surges in parts of the southeastern and northeastern Caribbean, impacting Trinidad and Tobago, Dominica, Puerto Rico, and other islands (NOAA 2019). In Trinidad and Tobago, flooding caused damage to roadways and other critical infrastructure, power outages, landslides, fallen trees, and overflowing rivers. The storm impacted Puerto Rico the day after the island experienced a 6.0 earthquake on the Richter scale. The combined effects resulted in destruction of infrastructure, landslides, flooding, and the closure of government offices and schools.

Flooding occurred in northern Dominica in relation to a tropical wave impacting the island on 4 October. A series of troughs over Jamaica and the central Caribbean in late 2019 caused thunderstorms, flooding, and landslides across most of island. Lightning strikes led to the postponement of several sporting activities. At least six players were struck at two football matches.

\section{d. South America-A. Sánchez-Lugo, Ed.}

Much of South America had above-average temperatures during 2019, resulting in the secondwarmest year on record at $0.69^{\circ} \mathrm{C}$ above the 1981-2010 normal, behind only 2015. The last five years were South America's warmest years in the continent's 110-year record. Precipitation varied spatially, with the most notable anomalous wet conditions across Peru and parts of Venezuela. The most notable precipitation deficits were observed across southern South America. Unless otherwise noted, the reference period is 1981-2010.

1) Northern South America-J. J. Nieto, F. Costa, E. A. Díaz, D. Marín, R. Hernández, and G. Carvajal

This region includes Colombia, Ecuador, French Guiana, Guyana, Suriname, and Venezuela.

\section{(I) TEMPERATURE}

The year 2019 was characterized by warmer-than-average conditions across much of northern South America, with mean temperatures $0.50^{\circ}-0.75^{\circ} \mathrm{C}$ above the $1981-2010$ normal (Fig. 7.11). The warmer-than-average conditions in the region coincided with above-normal sea surface temperatures (SSTs) that were present in the tropical Pacific Ocean, especially during the first half of the year (see Fig. 4.2).

Northern Colombia, Suriname, French Guiana, Guyana, and Venezuela all had annual maximum temperatures that were $1.0^{\circ}-1.5^{\circ} \mathrm{C}$ above normal, while southern Colombia and most of Ecuador had near-normal annual maximum temperatures. Most of northern South America also experienced above-normal annual minimum temperatures, ranging from $0.5^{\circ} \mathrm{C}$ to $1.5^{\circ} \mathrm{C}$ above normal. Minimum temperature anomalies were more than $+1.5^{\circ} \mathrm{C}$ in the Andes of Colombia, Ecuador, and Venezuela. 
Above-average mean temperatures prevailed in Colombia during the first quarter of the year (January-March), while the rest of the region had near-normal temperatures. During March-September, temperatures were $0.75^{\circ} \mathrm{C}$ above normal on average across the region. During the last quarter of the year (October-December), temperature anomalies were as much as $+1.0^{\circ} \mathrm{C}$ above normal

\section{(II) PRECIPITATION}

Much of northern South America had near- to below-normal precipitation during 2019 (Fig. 7.12), while parts of central and northern Venezuela, as well as Guyana, had above-normal precipitation (20\%-30\% above normal). The largest precipitation deficits occurred during February-April when monthly precipitation totals were $75 \%-80 \%$ below normal in French Guiana, Guyana, and Venezuela, and isolated parts of the Colombian and Ecuadorian Andes. During the rest of the year, above-normal rainfall prevailed in eastern Colombia, Guyana, French Guiana, Suriname, and Venezuela.

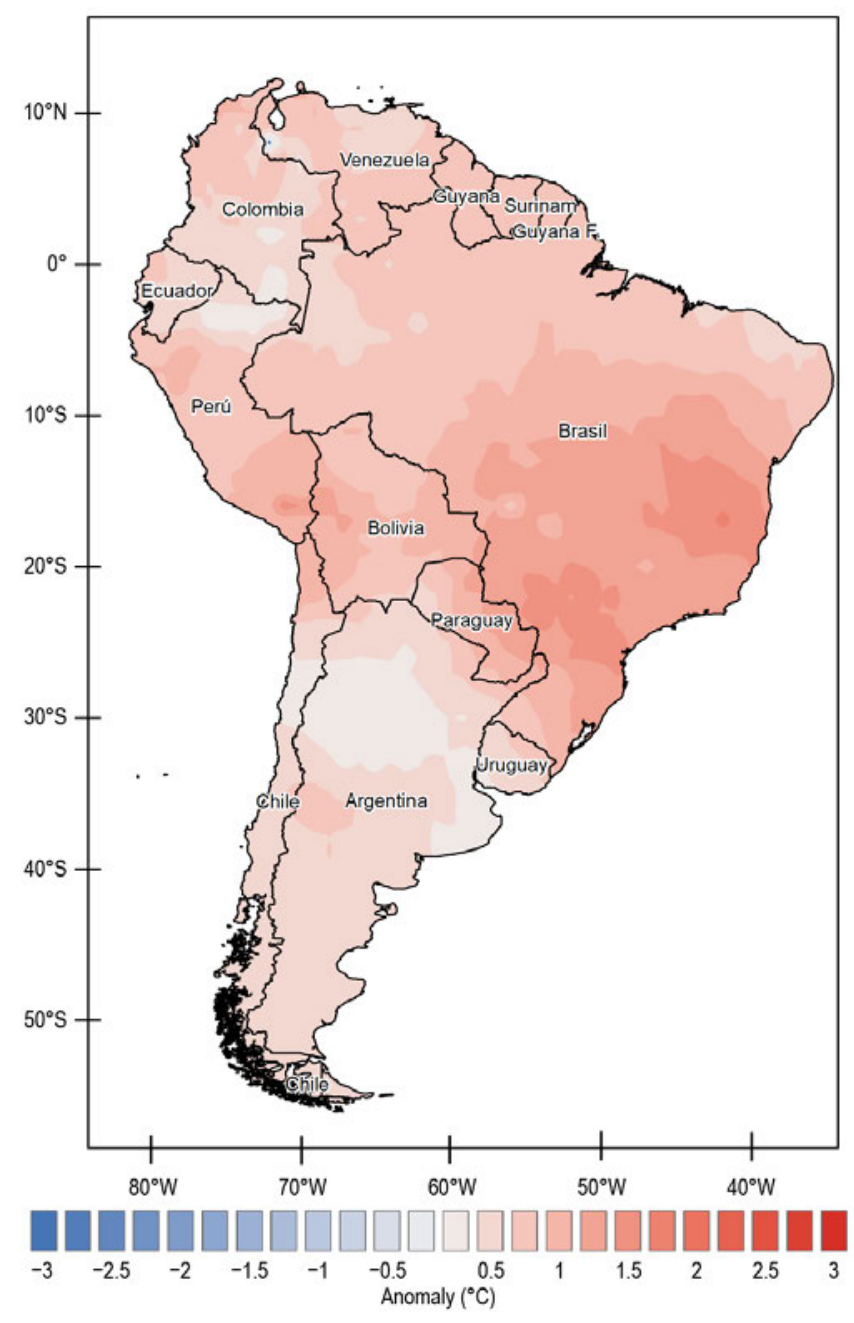

Fig. 7.11. 2019 Annual mean temperature anomalies ( ${ }^{\circ} \mathrm{C} ; 1981-2010$ base period). (Source: Data from NMHSs of Argentina, Bolivia, Brazil, Chile, Colombia, Ecuador, Paraguay, Peru, Suriname, and Venezuela; processed by CIIFEN.)

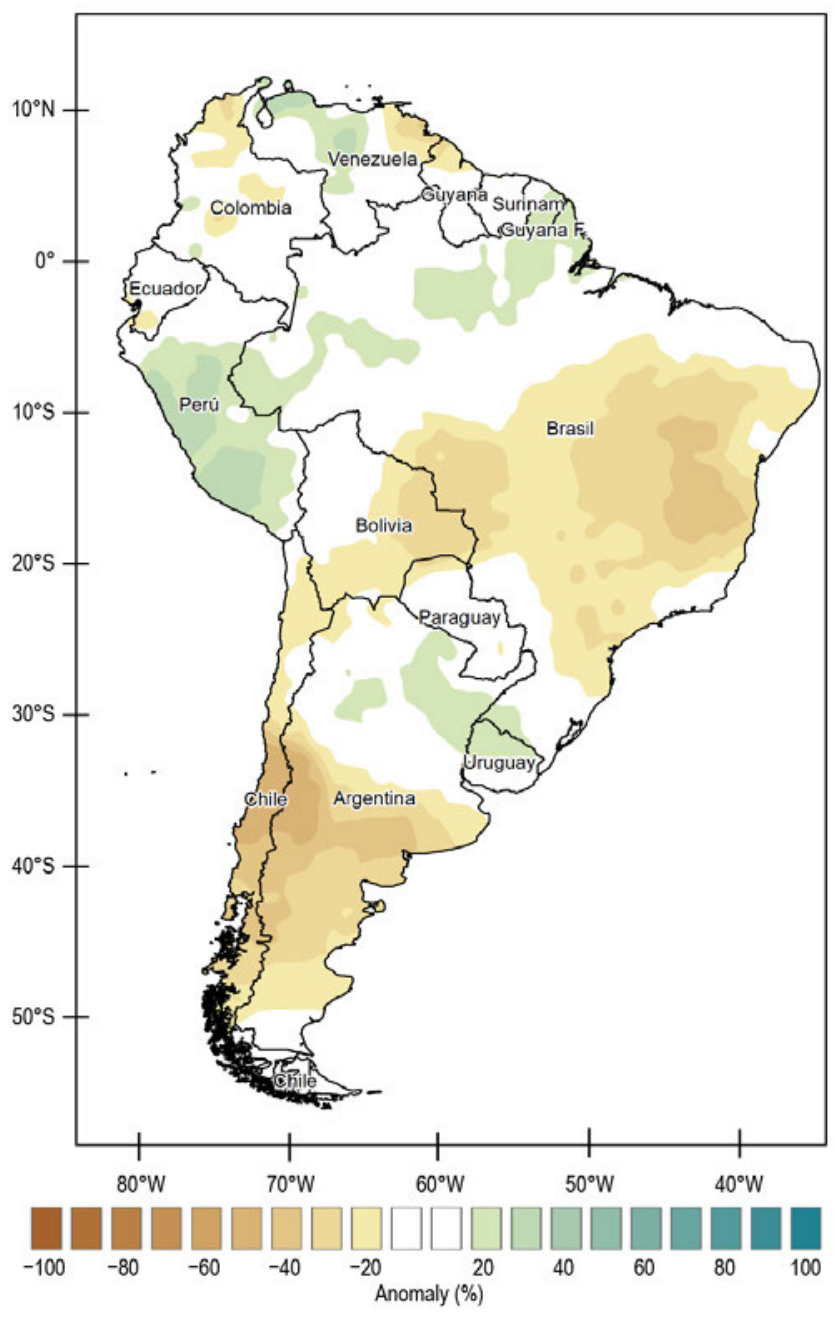

Fig. 7.12. 2019 Annual precipitation anomalies (\%; 1981-2010 base period). (Source: Data from NMHSs of Argentina, Bolivia, Brazil, Chile, Colombia, Ecuador, Paraguay, Peru, Suriname, and Venezuela; processed by CIIFEN.) 
(III) NOTABLE EVENTS AND IMPACTS

Very dry conditions affected parts of northern South America early in the year, with several locations experiencing drought. The marked water deficit across much of Venezuela favored the occurrence of a large number of forest fires, especially during February-March. Drought affected 108 of Colombia's 1103 municipalities during January-March, resulting in water shortages. In the department of Cordoba in Colombia, drought caused the loss of $60 \%$ of its plantain crops. In Guyana, drought in the region of Rupununi and Barima-Waini caused a sugar cane yield loss of $35 \%$, water scarcity for human consumption and irrigation, and forest fires.

Even though much of Colombia was affected by drought, several significant rainfall events occurred in western Colombia during the year, affecting thousands of people and damaging hundreds of houses. Colombia's municipality of Rosas (department of Cauca) had a very wet April, receiving $450 \mathrm{~mm}$ of rain, double its monthly average rainfall, in just 20 days. On 21 April, a landslide was triggered in the region, causing 14 fatalities. In May, Colombia's municipality of Pereira, Risaralda, had a total of $485 \mathrm{~mm}$ of rain, which is nearly twice its normal May monthly precipitation.

Heavy precipitation and floods also affected Ecuador during the year. Of note, flooding in the Province of Los Ríos affected 733 families and damaged more than 4000 ha of crops. In the Province of Santo Domingo, a landslide in mid-January and a second one in mid-February blocked the main road that connects the Coast and Highland regions, causing economic losses and food supply chain problems. A landslide was triggered in late April after $80 \mathrm{~mm}$ of rain fell in one hour in Riobamba, resulting in 20 collapsed homes and blocked roads.

Hurricanes had a significant impact in the region during the season. Hurricane Dorian (27-28 August, for this region) affected Venezuela's northeast and north coastal regions and its Caribbean territory, including Islas Las Aves and Nuevo Esparta, with heavy rainfall, lightning, wind gusts, and large swells (see Sidebar 4.1 for more details). Hurricane Karen (15-22September) formed from a tropical wave, affecting Venezuela with intense rainfall, lightning, wind gusts, and strong swells.

In Guyana, flooding during the last week of September in Mahaica-Berbice, Demerara-Mahaica, and Essequibo Islands severely affected several small farms and more than 300 homes across seven villages.

October rainfall totals in the municipality of Jericó, in the northwestern department of Antioquia, Colombia, were $400-470 \mathrm{~mm}$, followed by an additional $270-280 \mathrm{~mm}$ in November. The heavy rainfall in the region caused total and partial losses in the agricultural and infrastructure sectors, as well as problems in food security and public health.

In Venezuela, a short-lived but high-intensity rainfall event caused the Kunana River (also known as the Negro River) to overflow in October, causing mudslides in the Sierra de Perijá of Zulia state. These affected six Indigenous communities.

2) Central South America-J. A. Marengo, J. C. Espinoza, L. M. Alves, J. Ronchail, W. Lavado-Casimiro,

A. M. Ramos, J. Molina-Carpio, K. Correa, J. Baez, and R. Salinas

This region includes Brazil, Perú, Paraguay, and Bolivia.

\section{(I) TEMPERATURE}

Central South America had higher-than-normal annual mean temperatures during 2019 (Fig. 7.11). The most notable warmth was observed across much of southeastern Brazil, where temperature anomalies were at least $+1.0^{\circ} \mathrm{C}$.

During 2019, the most notable positive temperature anomalies occurred in January, February, June, and September-December. Mean temperatures in January were $1.5^{\circ}-2.5^{\circ} \mathrm{C}$ above normal in southeastern Bolivia and Paraguay, while the northern coast of Peru and tropical Brazil had temperatures $2.0^{\circ}-5.0^{\circ} \mathrm{C}$ above normal. Unusually warm temperatures affected the southern region of central South America at the end of January, with several locations observing daily 
maximum temperatures that were their warmest on record for January. Some locations surpassed the previous record by $5.0^{\circ}-8.0^{\circ} \mathrm{C}$. During $25-28$ January, the northern coast of Peru experienced its most intense heat wave of the last 30 years. Paraguay observed its hottest days on record on 23-24 January, when maximum temperatures soared to $39.4^{\circ}-43.0^{\circ} \mathrm{C}$. Another significant heat wave affected Bolivia, southeastern Brazil, and Paraguay in mid-September. The region-wide heat produced several record-breaking maximum temperatures.

Several cold fronts affected parts of central South America during May, July, August, and October. During 7-11 May and 7-8 July, minimum temperatures dropped more than $10^{\circ} \mathrm{C}$ in southeastern Brazil. The lowest temperatures of 2019 were recorded across most of Bolivia during 3-7 August. Below-freezing temperatures were also recorded in Peru's departments of Pasco, Huánuco, Apurimac, and Huancavelica.

\section{(II) PRECIPITATION}

Annual precipitation was spatially variable across the region, with much of Peru and parts of northern Brazil experiencing wetter-than-normal conditions, while much of the southern half of Brazil and Bolivia were drier than normal. Paraguay had near-normal conditions for the year (Fig. 7.12).

During the 2019 austral summer, there were six episodes of the South Atlantic Convergence Zone (SACZ; Rosa et al. 2020), contributing to exceptionally wet conditions in the second half of January through February across Bolivia and Peru east of the Andes (see Notable events and impacts section). Northern Paraguay had extremely wet conditions in March, receiving over 300\% more precipitation than normal. Furthermore, the Atlantic Intertropical Convergence Zone (ITCZ) was active in March, producing intense rainfall in northeast Brazil. After seven years of drought, the semiarid region of northeast Brazil recorded near-normal rainfall during November 2018-April 2019, but hydrological deficits persisted across most of the region. During November-December 2019, drought varied from severe to extreme in the northeast Brazilian semiarid region, particularly for the states of Piaui and Bahia, and in southern Brazil (see Fig. SB7.4). Below-normal precipitation was observed from July to October across most of Peru, Paraguay, and the Bolivian lowlands. The number of forest fires in those countries and the southern Brazilian Amazonia significantly surpassed the figures for the same period in the past four years (see Sidebar 7.2).

\section{(III) NOTABLE EVENTS AND IMPACTS}

Heavy rainfall events were observed in January along the dry southern coast of Peru, resulting in some locations breaking precipitation records of more than 30 years. Heavy rainfall during February led to 42 landslides across Peru and, by the end of summer, 77 people were reported dead, 165 wounded, and 3285 affected. More than 2600 homes were destroyed by floods and landslides.

In the Bolivian Andes, an intense rainfall event triggered flash floods when $55 \mathrm{~mm}$ fell in Cochabamba on 20 February. This was Cochabamba's fourth-highest daily precipitation on record and produced 2019's biggest flood on the Rocha River.

In Paraguay, daily precipitation exceeding $100 \mathrm{~mm} \mathrm{day}^{-1}$ was observed in March, with $142 \mathrm{~mm}$ day $^{-1}$ in Puerto Casado. On 10-11 May, extreme rainfall and floods were reported in the city of Pilar with $297 \mathrm{~mm}$ in two days, affecting about 10000 families.

In Brazil, several episodes of intense rainfall occurred during summer and autumn, producing flash floods and landslides that affected homes and blocked roads. São Paulo's February 2019 precipitation was 137\% of normal and was the wettest February in 15 years. On 6 February, $162 \mathrm{~mm}$ of rain fell in Rio de Janeiro in just 24 hours, which is more than half the normal monthly precipitation of $273 \mathrm{~mm}$ for February. On 8-9 April, another intense rainfall event affected Rio de Janeiro when a total of $189 \mathrm{~mm}$ of rain fell in 24 hours, almost double the monthly normal of $101 \mathrm{~mm}$, producing landslides in the area. Similarly, on 10 April, rainfall was nearly twice the month's climatology in São Paulo. During 17-19 May, a total of $308 \mathrm{~mm}$ of rain was reported in 
Santos, which is a little over twice May's normal precipitation total of $148 \mathrm{~mm}$. On 12 June, 117 $\mathrm{mm}$ of rain fell in just six hours in Recife (monthly climatology of $389.6 \mathrm{~mm}$ ). More than a month's worth of rain fell in a three-hour period in Salvador, capital of the Bahia State, on 26 November, with a total of $169 \mathrm{~mm}$ of rain (climatology of $106.5 \mathrm{~mm}$ ). The heavy rains produced flooding and landslides across the city, leaving streets flooded and around 100 homes damaged.

3) Southern South America—L. Aldeco, J. L. Stella, N. Misevicius, D. Campos Díaz, and J. Vicencio Veloso

This region includes Argentina, Chile, and Uruguay.

\section{(I) TEMPERATURE}

The 2019 mean temperatures across most of southern South America (SSA) were slightly above normal (Fig. 7.11). Above-normal temperatures were limited to central and northern parts of Argentina and central Chile. Annual mean temperature anomalies ranged between $-0.5^{\circ} \mathrm{C}$ and $+1.2^{\circ} \mathrm{C}$ across the region. The 2019 national mean temperature anomaly for Argentina $\left(+0.32^{\circ} \mathrm{C}\right)$ and Chile $\left(+0.24^{\circ} \mathrm{C}\right)$ were each 12 th highest of their respective national records dating back to 1961, while Uruguay had a near-average temperature, making it the 27th-warmest year on record, which also extends back to 1961 (Fig. 7.13).

Summer (December-February) 2018/19 was characterized by normal to below-normal temperatures across much of the region with pronounced sub-seasonal variability. Several episodes of extreme warm temperatures occurred during the season, with the most significant episode occurring in February. Southern Argentina and Chile set new daily maximum temperature records. On 4 February, the maximum temperature in Río Grande, Tierra del Fuego, rose to $30.8^{\circ} \mathrm{C}$, marking the first time on record a temperature above $30^{\circ} \mathrm{C}$ was recorded so far south in South America.

Below-normal temperatures dominated the beginning of austral autumn (MarchMay). March was particularly cold over Argentina and Uruguay, with mean temperature anomalies ranging between $-3^{\circ} \mathrm{C}$ and $-1^{\circ} \mathrm{C}$ across a large area. Meanwhile, April and May had normal to above-normal temperatures across SSA.

Winter (June-August) was slightly warmer than normal across the region. However, the above-normal seasonal anomalies were driven by the well-above-normal temperatures in June. Uruguay and Argentina national temperature anomalies during June were $+2.8^{\circ} \mathrm{C}$ and $+1.5^{\circ} \mathrm{C}$, respectively. June 2019 was Argentina's fifth-warmest June since 1961. Daily maximum temperatures were extremely high over Uruguay and northeastern Argentina. Artigas, Uruguay,
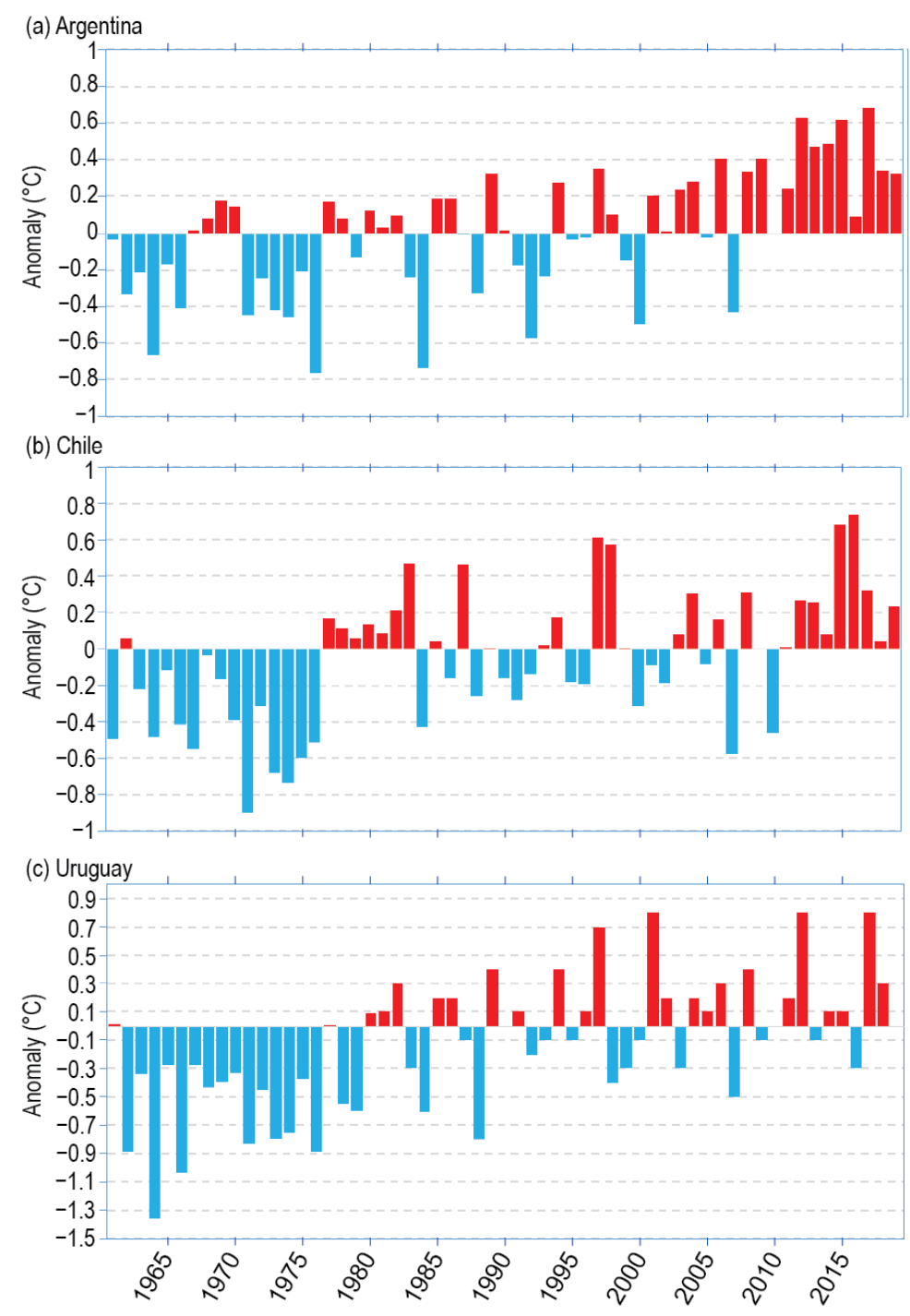

Fig. 7.13. Annual temperature anomaly $\left({ }^{\circ} \mathrm{C} ; 1981-2010\right.$ base period) time series from 1961-2019 for (a) Argentina, (b) Chile, and (c) Uruguay. 
recorded a maximum temperature of $29.6^{\circ} \mathrm{C}$ on 13 June-the second-highest June daily temperature since 1981 for this location. A daily record was set in Posadas, Misiones, with a maximum temperature of $31.2^{\circ} \mathrm{C}$ on 29 June. Meanwhile, extreme cold conditions affected eastern Argentina and Uruguay during 1-9 July. August was particularly cold over Uruguay, which had an August national mean temperature anomaly of $1.2^{\circ} \mathrm{C}$ below normal.

Intraseasonal variability dominated during spring (September-November). Several cold eruptions, mixed with short warmer-than-normal periods, prevailed during September and October. Several daily records were broken in Argentina during this period. Orán, in the province of Salta, recorded its highest maximum temperature on record $\left(44.5^{\circ} \mathrm{C}\right.$ on 28 October). The cities of Pehuajó and Junín (Buenos Aires province) recorded their lowest minimum temperatures on record for September $\left(-5.8^{\circ} \mathrm{C}\right.$ and $-5.4^{\circ} \mathrm{C}$, respectively). November temperatures were well above average across the region, particularly over Uruguay and the central and northern parts of Chile and Argentina.

\section{(II) PRECIPITATION}

Much of central and southern SSA had below-average annual rainfall during 2019. Chile and central Argentina had the largest rainfall deficits, with $20 \%-60 \%$ of normal precipitation (Fig. 7.12). In south-central Chile, rainfall deficits in 2019 added to a prolonged drought that began there in 2010. The cities of Valparaiso and Curicó (Chile) and Bahía Blanca (Argentina) had their driest year on record since 1961. For Santiago, Chile, 2019 was the third-driest year since records began in 1866. Meanwhile, northeastern SSA experienced a wetter-than-normal year, with the most significant anomalies ranging between $120 \%$ and $140 \%$ of normal across Uruguay and scattered areas in Argentina.

Despite the weak El Niño present in the tropical Pacific Ocean at the beginning of the year, sub-seasonal forcings were quite active and modulated precipitation patterns. While January 2019 had heavy rainfall and flooding over northeastern SSA, February turned particularly dry in the same region.

During austral autumn, the lack of precipitation continued to affect the central parts of Chile and Argentina, reinforcing drought. In addition, Uruguay had drier-than-normal conditions. Meanwhile, northern SSA had above-normal rainfall.

Winter and spring were characterized by below-normal precipitation across much of SSA, while Uruguay and adjacent areas in Argentina had above-average precipitation.

\section{(III) NOTABLE EVENTS AND IMPACTS}

Figure 7.14 depicts extreme climate and weather events that affected the region, several of which are described in further detail below.

The year 2019 began with extraordinary precipitation over northeastern Argentina and Uruguay, producing major damage, flooding, and forcing evacuations. During 6-17 January, several storms with daily rainfall totals of up to $250 \mathrm{~mm}$ severely affected this region. Monthly precipitation amounts of more than $500 \mathrm{~mm}$ led to new January precipitation records: Artigas (670.3 mm) and Paysandú (541.3 mm) in Uruguay; Monte Caseros (644.0 mm), Paso de los Libres $(622.0 \mathrm{~mm})$, and Resistencia $(554.8 \mathrm{~mm})$ in Argentina.

In the Atacama Desert in northern Chile, intense rainfall and storms during the first half of February caused flooding, affecting thousands of people and cutting off roads, especially for coastal locations between Arica and Antofagasta. At the same time, southern Chile and Argentina were affected by intense heat waves. Twelve locations in Chile and five in Argentina set new all-time high daily maximum temperature records, including $38.5^{\circ} \mathrm{C}$ in Valdivia, $38.2^{\circ} \mathrm{C}$ in Perito Moreno, $35.8^{\circ} \mathrm{C}$ in Río Gallegos, $35.4^{\circ} \mathrm{C}$ in Bariloche, and $35.1^{\circ} \mathrm{C}$ in Puerto Montt. The extreme high temperatures over Patagonia triggered severe bush fires near the city of Cochrane. This was one of the largest and most destructive bushfire events in Chile's history, lasting three months and burning about 15000 ha of native forest (Fig. 7.14). 
At the end of May, central and southern Chile experienced an unprecedented occurrence of at least seven tornadoes recorded between 30 and 31 May. These produced major damage to infrastructure, buildings, homes, and vehicles. The unusual phenomenon injured hundreds of people, caused one fatality, and produced massive power outages. Two tornadoes reached F2 category in Los Angeles on 30 May, and one reached F1 in Concepción on 31 May (Fig. 7.14).

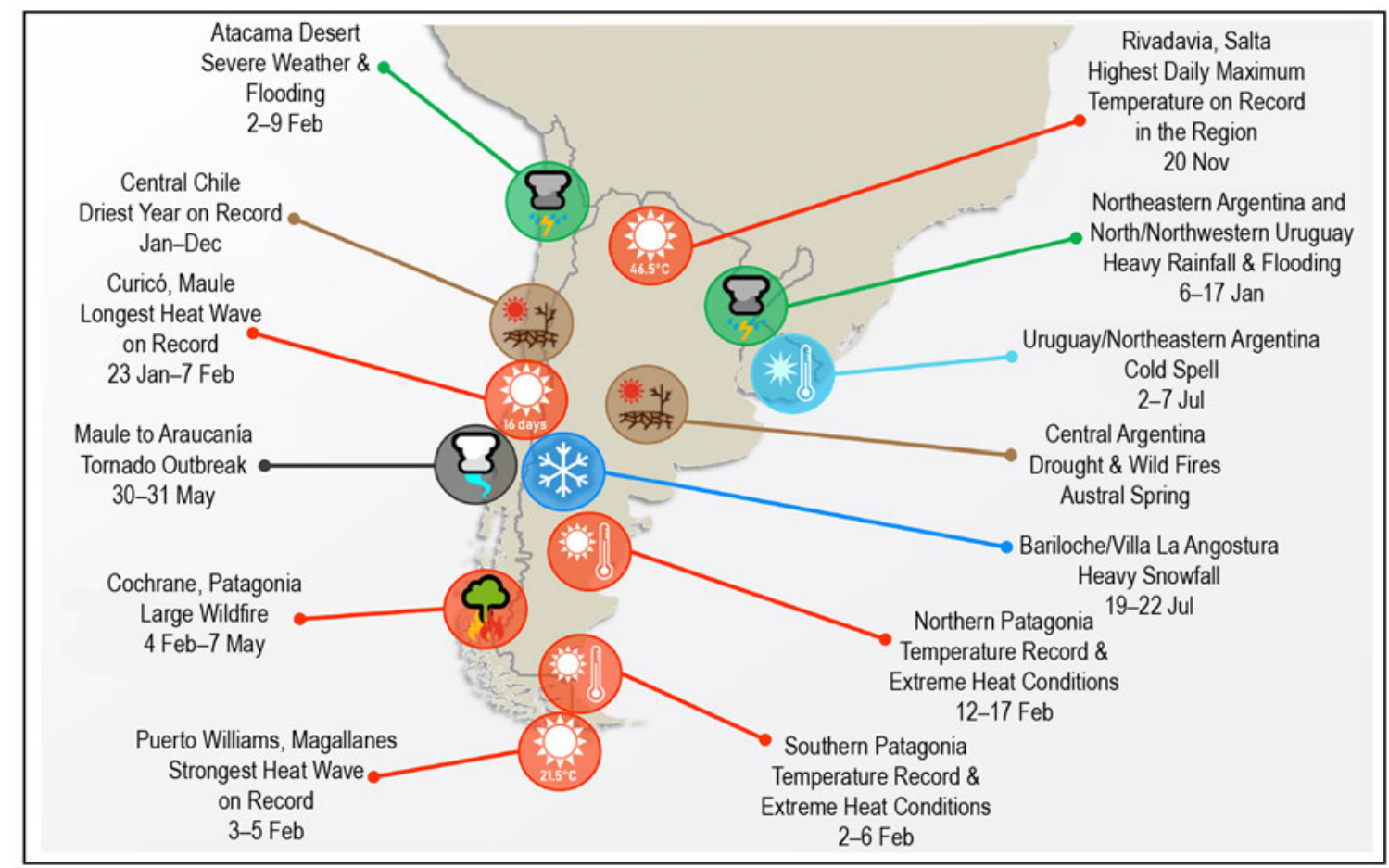

Fig. 7.14. Map depicting date, approximate location, and type of extreme weather events across SSA.

\section{SIDEBAR 7.2: Fires in southern Amazonia in the dry season of 2019-J. MARENGO, L. ALVES,}

\section{J. MOLINA, E. BROEDEL, AND A. P. CUNHA}

Forest wildfires are common in the Amazon. Fire activity in the Amazon varies considerably from month to month and year to year, and it peaks during Brazil's dry season from July to October. Fires are primarily driven by drier seasonal conditions and occur in association with human management-farmers or ranchers clearing existing farmland, or illegal land-grabbers destroying trees. As witnessed in 2019, wildfires scorched vast areas of the southern Amazon region and northern Paraguay. According to the Monitoring of the Andean Amazon Project (MAAP 2019), fires burned in the Amazonian forest in Bolivia, Brazil, and Peru during the year.

The number of fires detected in the Brazilian Amazon region was 89178 in 2019, compared to 68345 fires in 2018. The number of fires in 2019 significantly surpassed the figures of the past four years. The number of fires peaked in August, with 30868 fires widespread across the southern and eastern Amazon. The fire-monitoring program of the National Institute for Space Research also identified a larger-than-normal number of fires in 2019 in other Brazilian ecosystems such as Pantanal (a wetland in the upper reaches of the Paraguay River basin) and Cerrado (a large tropical savanna across central Brazil). In addition, the Brazilian Amazon experienced deforestation of 976200 hectares in 2019 compared to 753600 hectares in 2018.

Other Amazonian countries were affected by wildfires to some degree. Brazil and Bolivia struggled to curb massive forest fires in 2019. Fires affected 6.4 million hectares in Bolivia in 2019 , significantly above the 3.5 million hectares yearly average, and the second largest surface burned in a year (FAN 2019). The most affected Bolivian region was Santa Cruz (65\% of the burned surface), followed by Beni (29\%), and northern La Paz (5\%). In Santa Cruz, forests represented $31 \%$ of the burned surface, particularly the Chiquitanian dry forest (1.46 million hectares). These losses resulted in the death of millions of trees and wild animals, and in some cases, caused local extinctions. National protected areas were also affected (1.25 million hectares). Five firefighters and several hundred cattle died, and hundreds of homes were burned. In Paraguay, blazes destroyed tens of thousands of hectares of protected wetlands and other areas. 
Beginning in mid-August, the country lost roughly 40000 ha of forest from the perennial floodplains in the north of its sparsely populated western Chaco region (SEN 2019).

In 2019, the large number of monthly burned areas was related to a weak El Niño event, associated with below-average precipitation during the austral summer in some locations in southern Amazonia. (It was identified, but the illegal burning worsened that situation.) This, in turn, caused droughts and significant water reduction in the forest due to higher temperatures and lower atmospheric humidity. The illegal burning of land and crops complicated the situation by augmenting the risk of forest fires.

Figure SB7.3 shows a time series of rainfall from January 2015 to December in 2019 in southern Amazonia. The drought during the 2015/16 El Niño is clear in the figure, with 50-100 mm month $^{-1}$ below normal from November 2015 to February 2016 (with the exception of January 2019 that was $20 \mathrm{~mm} \mathrm{month}^{-1}$ above normal). From December 2018 to January 2019, rainfall was about $50 \mathrm{~mm}$ month $^{-1}$ below normal, while rainfall during the rest of the year was near normal, with small negative rainfall anomalies in August and September. The below-normal rainfall during December 2018-January 2019-the peak of the rainy season-probably contributed to drier-than-normal soil conditions at the end of the rainy season. Figure SB7.4 shows monthly maps of drought intensity for Brazil in 2019. The maps from January to March depict mostly weak-to-moderate drought in southern Brazilian Amazonia, consistent with below-normal rainfall that persisted through August. Figure SB7.3 shows that rainfall deficits during the dry season were small.

Therefore, rainfall reductions during the summertime peak of the rainy season may be in part responsible for the fires during the winter season, while during the dry season (fire season), drought across the southern Amazonia was mostly weak.

According to the International Federation of Red Cross and Red Crescent, no human injuries or fatalities were reported due to the 2019's forest fires. However, these fires affected biodiversity, fauna, flora, and generated et al. (2019).

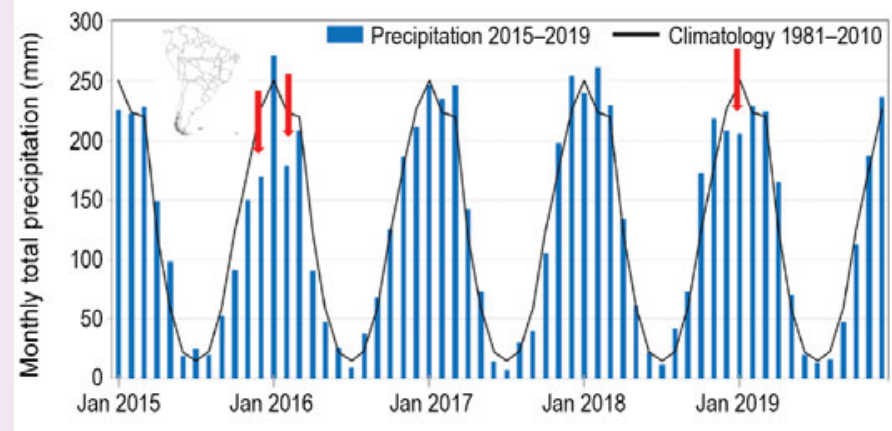

Fig. SB7.3. Mean monthly rainfall and rainfall anomalies $(\mathrm{mm})$ in southern Amazonia (see map with location of the region under analysis in upper left corner). Red arrows show the drought of 2015-16 and the less-rainy-thannormal peak of the rainy season from Dec 2018 to Jan 2019. (Source: CHIRPS dataset [Funk et al 2014].)

negative impacts on the Amazon biome. Wildfires have the potential to be extremely destructive, burning large areas of forests and regions recently deforested and producing smoke that affects ecosystems and people even outside the Amazon region. On 19 August, smoke from wildfires burning about $3000 \mathrm{~km}$ away in the Amazon shrouded the megacity of São Paulo in darkness. This was caused by a cold front from the southeast running into warm winds bringing fire smoke particles from southern Amazonia and Paraguay over the city of São Paulo.

Drought-induced fires may be partially offsetting reductions in Amazonian deforestation fires since $\sim 2000$. Preserving rainforests and restoring former forested land, together with wildfire management, are economical ways to meet climate change mitigation targets (Aragão et al. 2018).

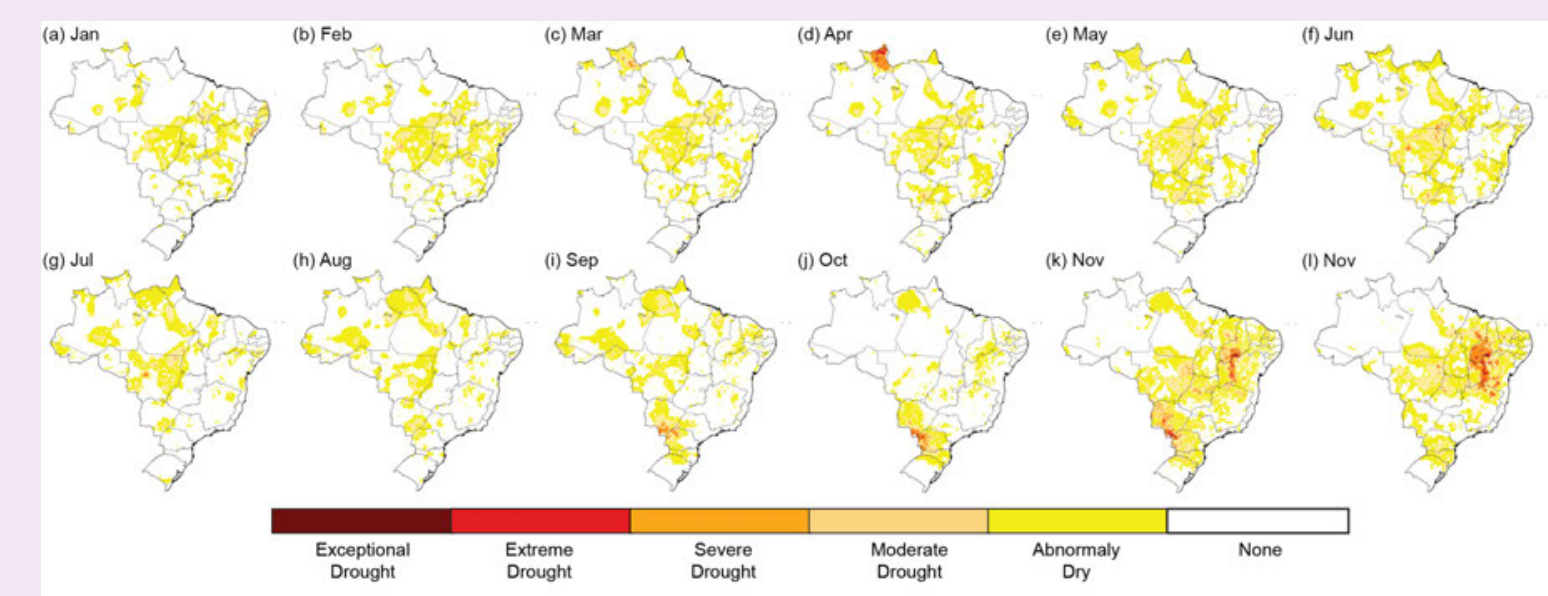

Fig. SB7.4. Monthly maps of drought characterization for Brazil in 2019, based on the Standard Precipitation Index-6 month (SPI-06, provided by CPTEC INL) and the Vegetation Health Index (VHI, provided by NOAA). The methodology for drought characterization is explained in Cunha 


\section{e. Africa-A. Mekonnen, Ed.}

This report was compiled using observational records from the meteorological and hydrological services of Morocco, Algeria, Tunisia, Egypt, Nigeria, South Africa, and the southern Indian Ocean island countries of Seychelles, Mayotte (France), La Réunion (France), Mauritius, and Rodrigues (Mauritius). Global Precipitation Climatology Project (GPCP) rainfall data and reanalysis data from the National Centers for Environmental Prediction/National Center for Atmospheric Research (NCEP/NCAR) were also used. Fatalities and flooding hazards are as reported in news outlets or by official agencies. The climatological base period used is 1981-2010.

In 2019, most of Africa (south of $10^{\circ} \mathrm{N}$ and east of $20^{\circ} \mathrm{E}$ ) experienced above-normal surface air temperatures. Northern Nigeria, southern Niger, and southwestern Chad experienced belownormal air temperatures (Fig. 7.15). Annual rainfall was generally above normal over the Sahel and savannas north of the equator, equatorial Africa, and the region between the equator and $15^{\circ} \mathrm{S}$. Excessive rainfall in 2019 was observed over the eastern half of Tanzania, Mozambique, and onshore over the Indian Ocean north of Madagascar. Southern Africa south of $15^{\circ} \mathrm{S}$ experienced mostly below-normal rainfall in 2019 (Fig. 7.16). Below-normal rainfall was observed over southeastern Nigeria, southwestern Cameroon, Equatorial Guinea, and northwestern Gabon.

Extreme weather events were reported in several African countries. In August, September, and October, North Africa reported storm events and flooding that resulted in deaths and property damage. West Africa received 24-hour rainfall totals ranging from about $69 \mathrm{~mm}$ to $110 \mathrm{~mm}$, which caused widespread flooding and the Niger River to overflow. Many people died and hundreds of others were displaced. Severe damage to property and croplands was also reported. Extreme rainfall was reported from the Greater Horn of Africa countries in October. Mombasa (Kenya)

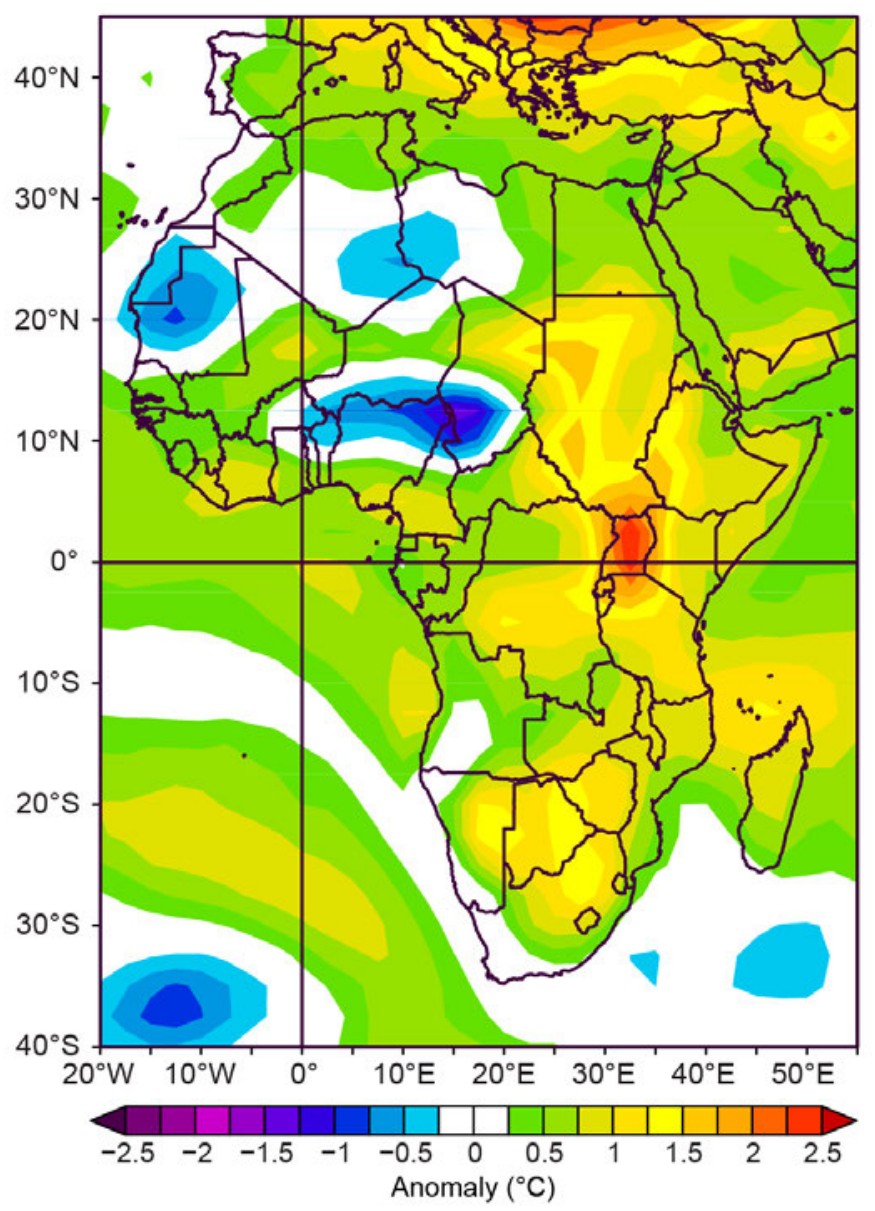

Fig. 7.15. Mean annual air temperature anomaly $\left({ }^{\circ} \mathrm{C}\right.$; 1981-2010 base period) for 2019 over Africa. (Source: NOAA/NCEP.)

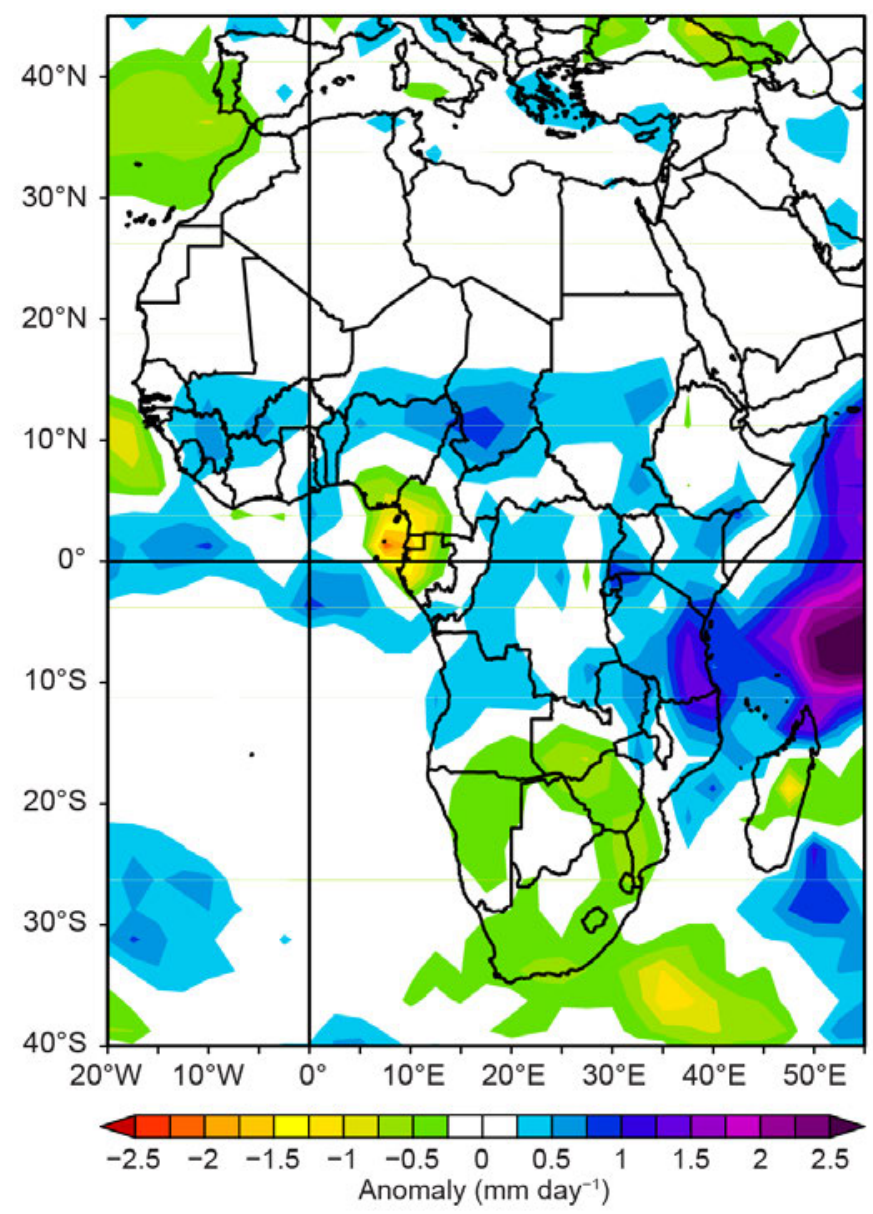

Fig. 7.16. Mean annual rainfall anomaly $\left(\mathrm{mm}\right.$ day $^{-1}$; 1981-2010 base period) for 2019 over Africa. (Source: NOAA/NCEP.) 
reported more than five times its normal October rainfall, as did Kinshasa and Pt. Noire in the Republic of Congo. Windstorms in The Gambia affected many communities and caused numerous deaths. Heat waves, with daytime temperatures exceeding $40^{\circ} \mathrm{C}$, were also reported in North African countries, and Morocco and Algeria reported forest fires.

This year, due to unforeseen circumstances, the Southern Africa section contains analyses for South Africa only. We hope to return to a fuller analysis of the region next year, to once again include the countries of Angola, Botswana, Zimbabwe, Namibia, Malawi, Zambia, Lesotho, Swaziland, and Mozambique. We do include a sidebar that describes the impacts of Cyclones Idai and Kenneth to southeastern Africa and the southwest Indian Ocean islands.

\section{1) North Africa-K. Kabidi, A. Sayouri, M. ElKharrim, and A. E. Mostafa}

Countries considered in this section are Morocco, Algeria, Tunisia, Libya, and Egypt.

In 2019, the annual temperature over Morocco was about $0.3^{\circ} \mathrm{C}$ above normal, while annual precipitation was about $136 \%$ of normal (54\% less than in 2018). The annually averaged temperatures in southern and central Algeria were near normal, while northern Algeria and Tunisia were above normal. Several climate stations in Egypt observed above-normal temperatures during the summer. Severe storms, heat waves, and forest fires were reported in Morocco and Algeria.

\section{(I) TEMPERATURE}

Winter (December 2018-February 2019) mean temperatures over Morocco, Algeria, Tunisia, and Libya were below normal, while above-normal temperatures were observed over Egypt (Fig. 7.17a). In January and February, temperatures approximately $2.8^{\circ} \mathrm{C}$ below normal were reported in the mountain regions while temperatures $0.5^{\circ}-2^{\circ} \mathrm{C}$ below normal were reported across Morocco's coastal and interior regions. Stations from southern Algeria and Libya reported temperatures up to $3^{\circ} \mathrm{C}$ below normal in February.
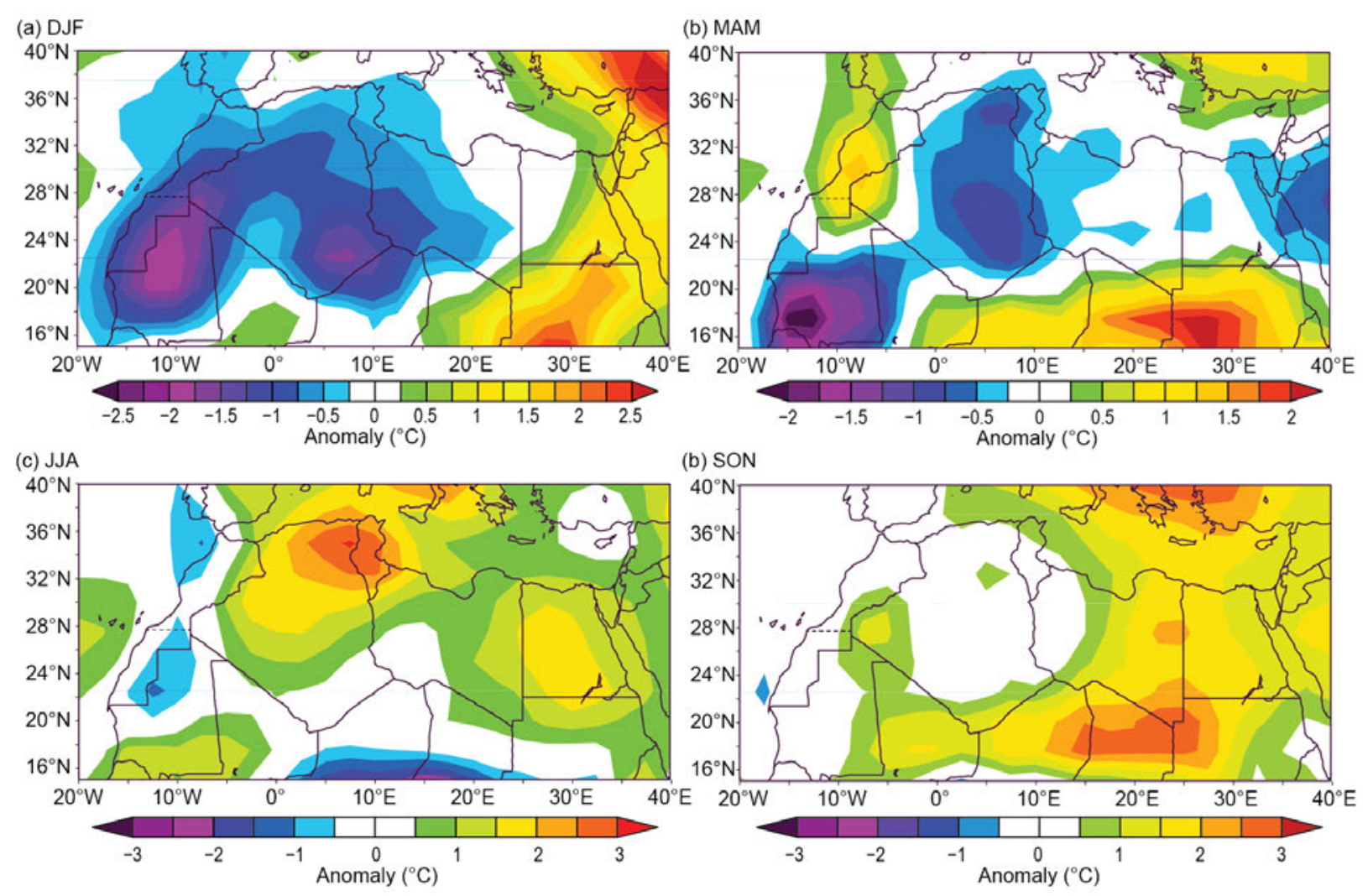

Fig. 7.17. North Africa seasonally averaged mean temperature anomalies ( ${ }^{\circ} \mathrm{C} ; \mathbf{1 9 8 1 - 2 0 1 0}$ base period) for (a) DJF 2018/19, (b) MAM 2019, (c) JJA 2019, and (d) SON 2019. (Source: NOAA/NCEP.) 
Spring (March-May) temperatures over most of Morocco were $1^{\circ} \mathrm{C}$ above normal, while temperatures over most of Algeria, Tunisia, and western Libya remained below average (Fig. 7.17b), and those across Egypt were mainly near normal. Southern Morocco and adjoining southwestern Algeria experienced temperatures more than $3.5^{\circ} \mathrm{C}$ above average in May (not shown). In contrast, May temperatures of about $2.5^{\circ} \mathrm{C}$ below normal were observed in northeastern Algeria-Tunisia (not shown).

Summer (June-August) temperatures over the region were above normal-more than $2.5^{\circ} \mathrm{C}$ above normal over the Algeria-Tunisia border. Most of Egypt experienced summer temperatures $1.5^{\circ} \mathrm{C}$ above average (Fig. 7.17c). Some stations in Tunisia, Algeria, and Libya reported summer temperatures $4^{\circ} \mathrm{C}$ above normal. Record high temperatures of $47^{\circ} \mathrm{C}$ were recorded in Egypt in June. More record temperatures, ranging from $43.5^{\circ}-50^{\circ} \mathrm{C}$, were reported at several stations in Algeria during July.

Autumn (September-November) temperatures were near to above normal, with generally warmer-than-normal conditions across eastern portions of the region (Fig. 7.17d). Most of Libya and Egypt saw temperatures between $1^{\circ} \mathrm{C}$ and $2^{\circ} \mathrm{C}$ above normal.

\section{(III) PRECIPITATION}

Winter precipitation over Morocco, western Algeria, and northern Tunisia was below normal. Pockets of southeast Tunisia bordering Libya received above-average rainfall, as did northern Egypt near Alexandria (Fig. 7.18a). Heavy rains were reported at Alexandria and several stations in northern Egypt.

Below-normal rainfall occurred in spring over northern and coastal parts of Morocco and northwestern Algeria, while a small area in northern Egypt recorded slightly above-average precipitation (Fig. 7.18b). Several April storms that produced copious rainfall helped alleviate the dryness in Morocco. Different parts of Morocco received above-average rainfall for the month, ranging from $114 \%$ to $225 \%$ of normal in the south, $139 \%$ to $174 \%$ in the north, and $139 \%$ to $198 \%$ in central Morocco.

Summer rainfall over North Africa was near normal (Fig. 7.18c), although station reports indicated strong monthly variability. Autumn brought near-normal rainfall to most of the region
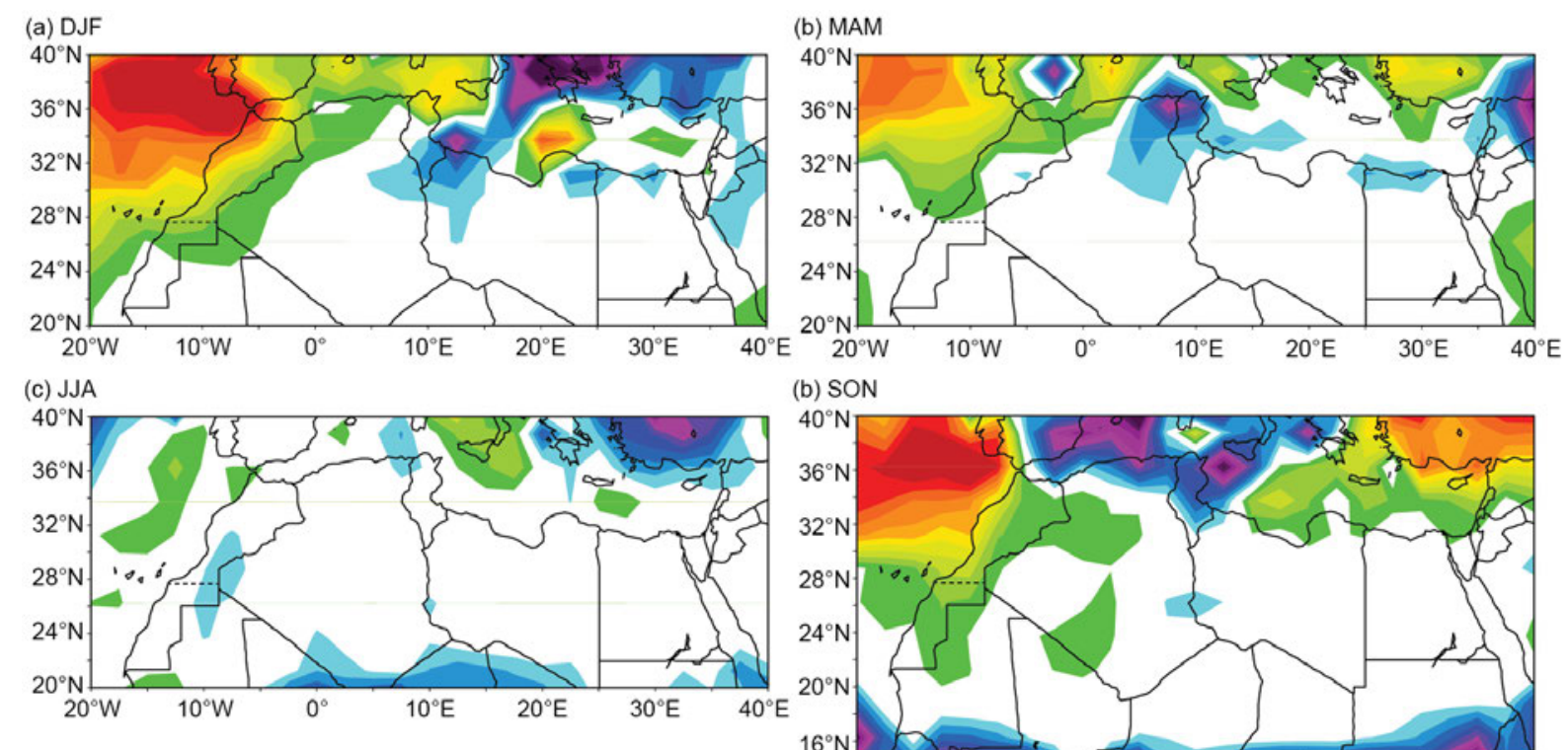

(b) $\mathrm{SON}$

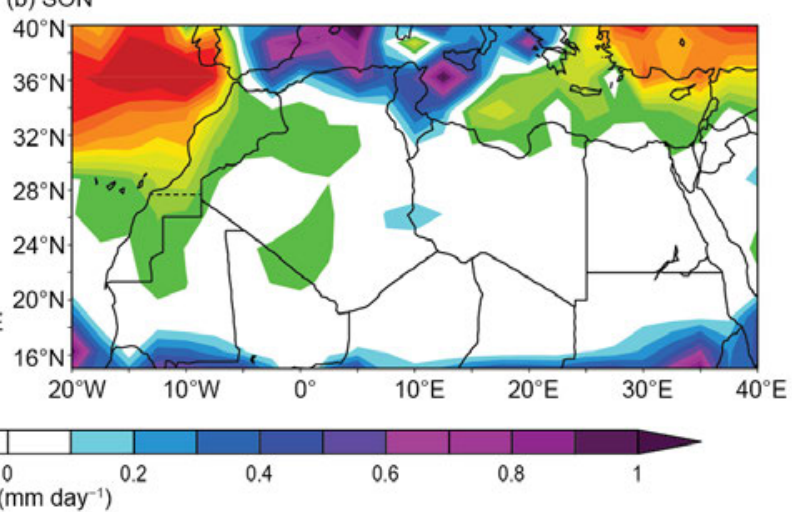

Fig. 7.18. North Africa seasonally averaged rainfall anomalies (mm day ${ }^{-1} ; 1981-2010$ base period) for (a) DJF 2018/19, (b) MAM 2019, (c) JJA 2019, and (d) SON 2019. (Source: NOAA/NCEP.) 
(Fig. 7.18d), except for Morocco's Atlantic coast, which saw a dry start to its wet season with deficient November rains, relative to climatology.

\section{(III) NOTABLE EVENTS AND IMPACTS}

A succession of heat waves (temperatures $\geq 40^{\circ} \mathrm{C}$ ) occurred in Morocco, Algeria, and Tunisia during May and July. As a result of the heat, along with dry conditions, more than 200 fires caused significant damage in northern Morocco, while more than 20000 hectares were burned in eastern Algeria.

In August, southern Morocco experienced several storms that resulted in floods. Deaths and property damage associated with this extreme weather were reported. During September and October, severe storms that brought heavy rain were reported in Algeria (for example, $147 \mathrm{~mm}$ of rain fell on 1 September in the town of Skikda, which is close to five times its September average and about $20 \%$ of its annual total).

\section{2) West Africa-S. Hagos, Z. Feng, I. A. ljampy, F. Sima, and S. D. Francis}

For this report, West Africa is defined as the region between $17.5^{\circ} \mathrm{W}$ (the eastern Atlantic coast) and approximately $15^{\circ} \mathrm{E}$ (along the western border of Chad) and from $5^{\circ} \mathrm{N}$ (near the Guinean coast) to $20^{\circ} \mathrm{N}$. It is typically divided into two climatically distinct sub-regions: the Sahel region (north of about $12^{\circ} \mathrm{N}$ ) and the coast of Guinea region to the south. The Sahel is semi-arid, while the coast of Guinea region has a wet tropical climate. West Africa's rainy period (the West African monsoon [WAM] season) is associated with the latitudinal movement of a section of the deep convective zone, and the season extends from June through September. Variations of the north-south movement of the deep convective zone are controlled by the El Niño-Southern Oscillation (ENSO), cross-equatorial sea surface temperature (SST) contrasts over the equatorial Atlantic, as well as SSTs over the Mediterranean Sea (Rodriguez-Fonseca et al. 2015). The boreal spring and summer of 2019 had near-neutral ENSO conditions with a Niño 3.4 index of around 0.5 (see section 4b for details). In general, the SSTs over the tropical Atlantic Ocean and the Mediterranean Sea were close to the climatological average, except for the region off the coast of Senegal, which was cooler by up to $-1.0^{\circ} \mathrm{C}$ throughout the summer season.

\section{(I) TEMPERATURE}

In 2019, annual temperatures in the region west of the prime meridian and south of about $15^{\circ} \mathrm{N}$ in West Africa were generally above average, while the border areas between Niger, Nigeria, and Chad were below average (Fig. 7.15).

Overall, the 2019 hot season (March-May) was generally warmer than normal in northern Nigeria, except in Ilorin, where it was cooler. Daily maximum temperatures of $44^{\circ} \mathrm{C}$ were recorded in the Nigerian cities of Maiduguri, Sokoto, and Yola between 4 and 6 April, about $3^{\circ} \mathrm{C}$ above average. Notably, Maiduguri reported daily maximum temperatures of $40^{\circ}-44^{\circ} \mathrm{C}$ for 26 days in April.

The summer temperature over much of West Africa was slightly above average, with muchwarmer-than-average conditions over northern Senegal, southern Mauritania, and the Niger Delta region (not shown). Figure 7.19 shows the average temperature anomaly in June, which was particularly high over central Cameroon, southern Mali, southern Mauritania, and Guinea. These regions experienced temperatures at least $2^{\circ} \mathrm{C}$ above average for the month. Meteorological stations across Nigeria reported monthly mean maximum temperatures ranging from $31.7^{\circ} \mathrm{C}$ in Jos in the Middle Belt to $41.0^{\circ} \mathrm{C}$ in Sokoto and Maiduguri in the north. In southern Nigeria, Eket and Oshogobo recorded mean maximum temperatures of $30.2^{\circ} \mathrm{C}$ and $36.7^{\circ} \mathrm{C}$, respectively. 


\section{(II) PRECIPITATION}

Precipitation over the Sahel region was significantly higher than normal during the WAM season (Fig. 7.20), while southern (Guinean) and western coastal regions were drier. This pattern is a typical mode of precipitation variability over West Africa. In 2019, it was likely related to persistent below-average SSTs off the coast of West Africa. Several single-day rainfall values of $100 \mathrm{~mm}$ and above were observed in northern Nigeria during the season.

\section{(III) NOTABLE EVENTS AND IMPACTS}

In 2019, extreme events started early before the summer season. On 13 May, several areas in Ghana experienced heavy rain. The national capital, Accra, recorded $75 \mathrm{~mm}$ and Tema observed $52 \mathrm{~mm}$ of rainfall over two days, about half and one-third of their average monthly totals for May, respectively. At least 14 people died in flash flooding triggered by sudden torrential rain in Mali's capital city of Bamako on 16 May. According to the Red Cross, the floods also destroyed two houses and 10 cars while several people were forced to move to temporary shelters. According to the International Organization for Migration (IOM), in June heavy rains in Mali’s Mopti region caused floods, exacerbating the dire conditions of internally displaced persons. Local news outlets in Sierra Leone reported that four people died after flash floods in the capital, Freetown, on 2 August. In the same week, rainstorms and flooding occurred over northeastern Nigeria. The News Agency of Nigeria (NAN) reported that seven people died while dozens of houses were damaged in Yola. In the southeastern part of the country, heavy rain on 4 August caused flooding in Oguta, displacing about 6000 people and damaging 200 homes. In late August and early September, northeastern Nigeria was once again affected by floods. The United Nations Office for the Coordination of Humanitarian Affairs (UNOCHA) reported that at least 10 people died, with thousands displaced in Borno, Adamawa, and Yobe states. In Ngala, over 600 homes were destroyed. The total number of affected persons was estimated to be 3500. In Niger, the UNOCHA reported that floods caused by heavy rains dating to June killed 57 people and affected 211000 because the Niger River reached flood stage. Overflow from dams in neighboring Burkina Faso and Mali contributed to the surging waters.

In The Gambia, on 19 June, a windstorm hit five districts in the Upper River Region-Jimara, Tumanna, Wuli East, Wuli West, and Sandu-and three districts of the Central River RegionUpper Fulado East, Upper Fulado West, and Niani. This storm affected 67 communities according to the International Federation of Red Cross and Red Crescent Societies. The Gambia Red Cross Society and National Disaster Management Agency reported that over 15000 people were 
affected, including 1425 people who were displaced. Per their report, there were four fatalities due to building collapse and flying debris. In addition, 101 people were injured, and more than 900 houses were damaged or destroyed. According to the National Meteorological Department of The Gambia and authorities in the affected regions, this was the first time in recorded history that Gambia had experienced such a windstorm disaster with this scale of destruction. On 31 August, heavy downpours caused flooding in many households in Ebo-Town.

Similarly, in Mauritania, the country's news agency reported that at least five people died in floods there, and dozens of homes were damaged or destroyed in the Guidimaka Region following heavy rains that began around 25 August. Fatalities were reported in Sélibaby City, the regional capital with a population of around 26000 . Roads, bridges, and other infrastructure were also damaged.

\section{3) East Africa-B. D. Enyew and A. Mekonnen}

The East African region includes Kenya, South Sudan, Sudan, Uganda, Tanzania, Ethiopia, Eritrea, and Djibouti (an area within $10^{\circ} \mathrm{S}-15^{\circ} \mathrm{N}, 20^{\circ}-50^{\circ} \mathrm{E}$, also referred to as the Horn of Africa). The region has complex terrain, with elevations ranging from about $100 \mathrm{~m}$ below sea level at Ethiopia's Afar triangle to more than $4000 \mathrm{~m}$ above sea level at the Semien Mountains and Mount Kilimanjaro in Tanzania-Kenya.

The complex terrain and the geographic placement of East Africa give rise to different climatic zones-from very dry and arid to wet and humid. The rainfall climatology is also complex. Lower latitude regions such as Kenya, Uganda, southern Ethiopia, and parts of Somalia and Tanzania have two peak rainy seasons during March-May and October-December. Central, western, and northern Ethiopia, Sudan, and South Sudan have a single dominant peak rainfall season during June-September (JJAS). In western, northwestern, and northern Ethiopia, climatologically, over $70 \%$ of annual rainfall is received during JJAS, locally referred to as "Kiremt." Central and northeastern Ethiopia also receive short rains during mid-February to mid-May, a time locally referred to as "Belg." Therefore, while the temperature analysis is based on four seasons (winter, spring, summer, and autumn), the 2019 rainfall analysis is presented based on January-February (JF), March-May (MAM), June-September (JJAS), and October-December (OND). As in West Africa, rainfall over East Africa is influenced by SST changes over the equatorial Atlantic, equatorial east Pacific, and Indian Oceans (Bahaga et al. 2019). Temporal and spatial variability of the deep convective zone associated with seasonal rainfall over East Africa are also determined by largescale circulation systems and moisture transport from the southern Atlantic and Indian Oceans.

\section{(I) TEMPERATURE}

Generally, annual temperatures for 2019 in East Africa were above normal, with Uganda and bordering areas observing temperatures more than $2^{\circ} \mathrm{C}$ above normal (Fig. 7.15).

The region experienced above-normal temperatures during winter (December 2018-February 2019), spring (March-May), and autumn (September-November), with some areas more than $3^{\circ} \mathrm{C}$ above normal (Fig. 7.21). Largely near-normal temperatures dominated the region during summer (June-August), except pockets of central Sudan, where temperatures were below normal, and southwest Ethiopia and Uganda, where temperatures were about $1^{\circ} \mathrm{C}$ above normal.

\section{(II) PRECIPITATION}

Figures 7.22a-d show the 2019 rainfall anomaly for the four rainfall seasons defined above. East Africa north of $5^{\circ} \mathrm{N}$ is normally a dry season during JF. During JF, below-normal rainfall dominates the Lake Victoria region (eastern Uganda-western Kenya-northwestern Tanzania). During MAM, below-normal rainfall was observed over the region around Lake Victoria, including most of Kenya, Uganda, and northern Tanzania. Southeastern coastal Tanzania experienced aboveaverage rainfall (Fig. 7.22b). During JJAS, central Sudan and northern South Sudan experienced 
above-normal rainfall, while the western-most parts of Ethiopia experienced below-average rainfall (Fig. 7.22c). The Kiremt (JJAS) rainfall over most of Ethiopia was near normal. For equato-

rial countries such as Kenya, JJAS is normally dry.

Rainfall was above normal from the southern half of Ethiopia southward to Tanzania during OND (Fig. 7.22d). Rainfall of more than $3 \mathrm{~mm}_{\text {day }^{-1}}$ above normal was observed around the Lake Victoria region and eastern Tanzania. The Famine Early Warning System Network (FEWS-NET; https://fews.net/east-africa/) reported that the OND rainfall total was among the highest in the region since 1981. The FEWS-NET report indicated excessive rains were associated with the positive Indian Ocean dipole (IOD), which was the strongest since 1997 (see section $4 \mathrm{~h}$ for more details).

\section{(III) NOTABLE EVENTS AND IMPACTS}

The following notable events are based on information from FEWSNET during OND 2019.

Widespread flooding over South Sudan caused extensive damage to crops and livestock, affected several hundred people, and displaced nearly half a million citizens. Similar damage was reported from Somalia. In southern Ethiopia, Kenya, and Uganda, loss of human lives, crop damage, and extensive flooding affected communities.

Widespread locust invasion was reported from Eritrea southward through eastern Ethiopia, Kenya, and Sudan to Somalia. The following conditions were favorable for locust invasions during the season: heavy rainfall, moist soil conditions, abundant vegetation, and dominant northerly/northeasterly persistent winds. The locust infestation led to extensive crop and vegetation damage over the region.
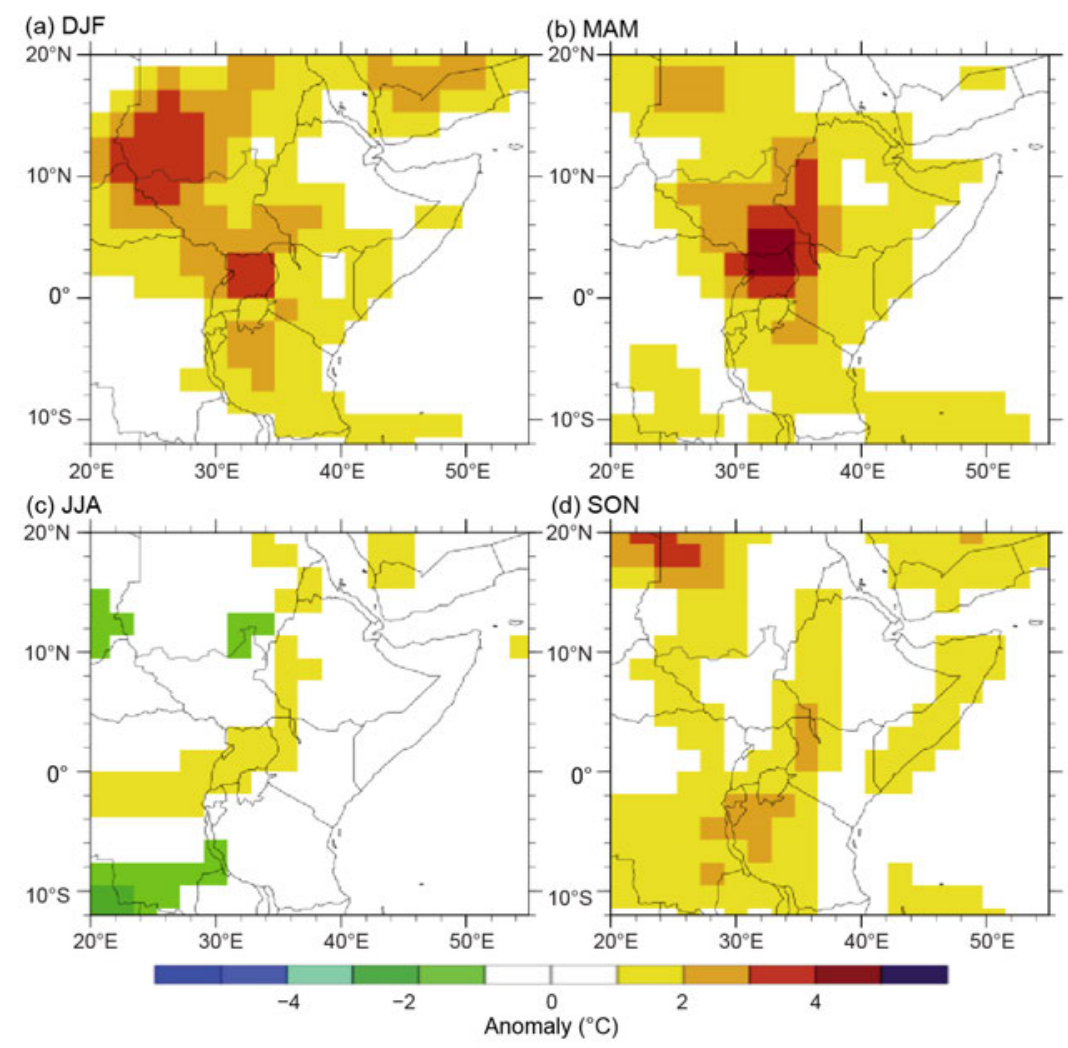

Fig. 7.21. Temperature anomaly ( ${ }^{\circ} \mathrm{C} ; 1981-2010$ base period) for (a) Dec 2018-Feb 2019, (b) Mar-May 2019, (c) Jun-Jul 2019, and (d) SepNov 2019 over East Africa. (Source: NCEP/NCAR reanalysis.)
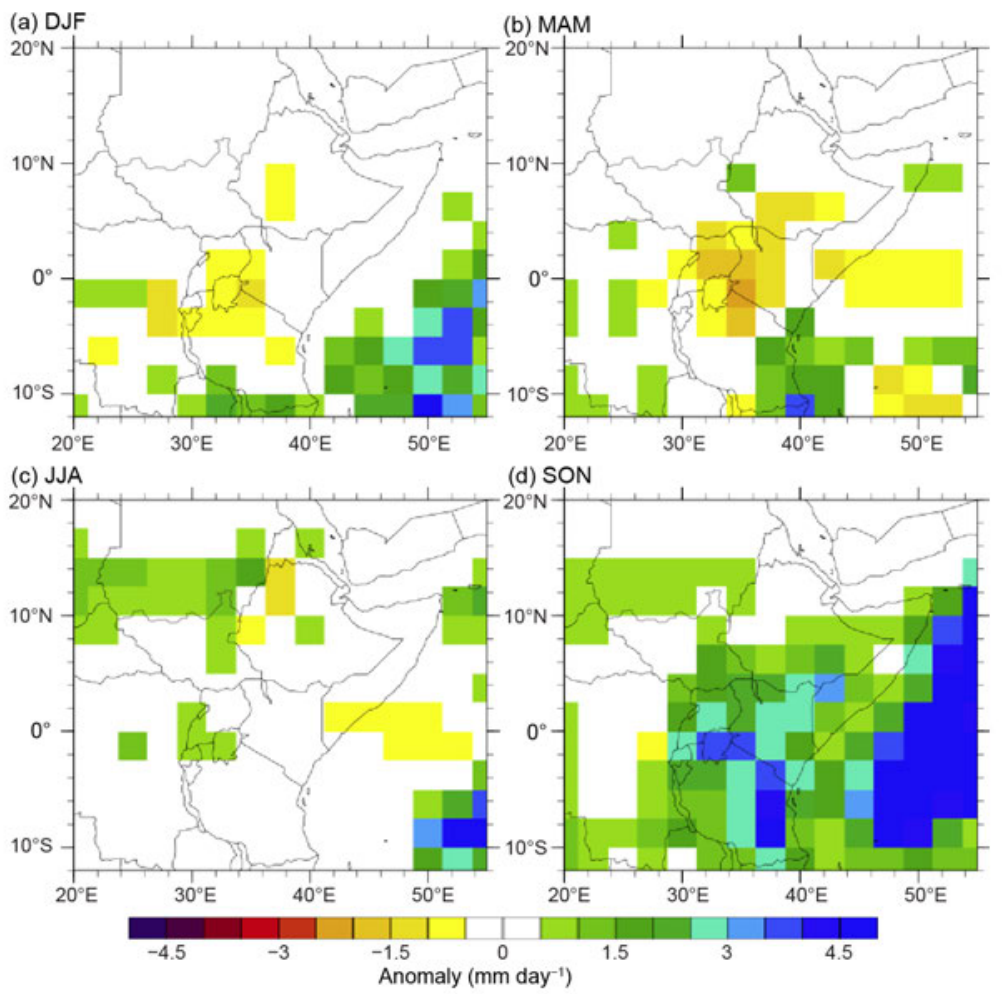

Fig. 7.22. East Africa rainfall anomaly (mm day-1; 1981-2010 base period) in 2019 for (a) Jan-Feb, (b) Mar-May, (c) Jun-Sep, and (d) Oct-Dec over East Africa. (Source Global Precipitation Climatology Project [GPCP].) 


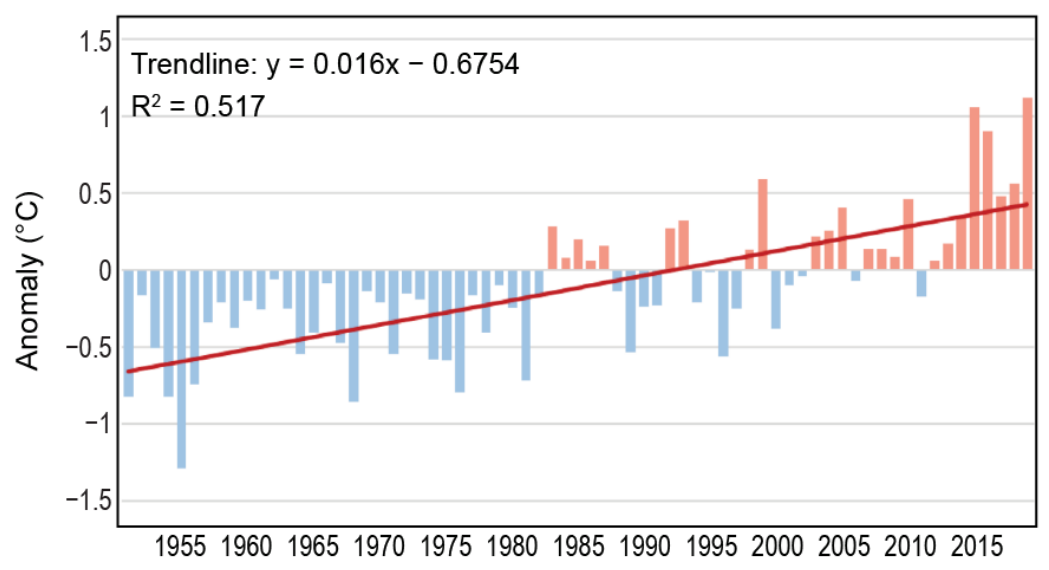

Fig. 7.23. Average surface temperature deviation ( ${ }^{\circ} \mathrm{C} ;$ 1981-2010 base period) over South Africa based on 26 climate stations: 1951-2019. The linear trend is indicated. (Source: South African Weather Service.)

\section{2) South Africa-A. C. Kruger and C. McBride (I) TEMPERATURE}

South Africa experienced a very hot year. The 2019 annual mean temperature anomalies, based on data from 26 climate stations, was about $1.1^{\circ} \mathrm{C}$ above the reference period (19812010), an approximate tie with 2015 for the warmest year on record since 1951 (Fig. 7.23). The nation's warming trend of $0.16^{\circ} \mathrm{C}$ decade $^{-1}$ is statistically significant at 5\%.

\section{(II) PRECIPITATION}

The dry conditions in western South Africa were the most significant feature of the rainfall during 2019 (Fig. 7.24). A substantial area received less than $50 \%$ of normal rainfall, while the southwestern part and eastern half of the country received rainfall amounts close to normal. Figure 7.25 presents the 12-month standardized precipitation index (SPI), a widely used index to characterize meteorological drought, for 2019. Somewhat dry to moderately dry conditions dominated the northern and northeastern parts of the country. No significant area of South Africa received substantially more than the normal amount of rainfall.

\section{(III) NOTABLE EVENTS AND IMPACTS}

Dry conditions persisted over larger parts of western South Africa, in some parts having continued for approximately seven years. The effects of these prolonged dry conditions are mainly agricultural, resulting in no significant production on many farms, with the subsequent layoffs of farm workers.

In January, these dry conditions persisted

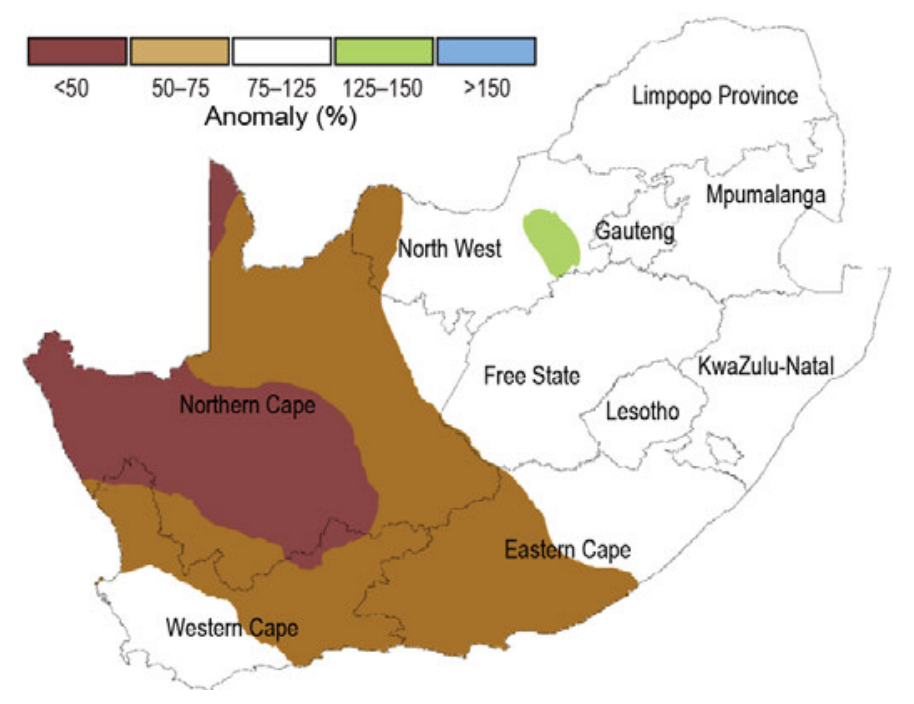

Fig. 7.24. Rainfall anomalies (expressed as percentage of 1981-2010 base period) for South Africa for 2019. (Source: South African Weather Service.)

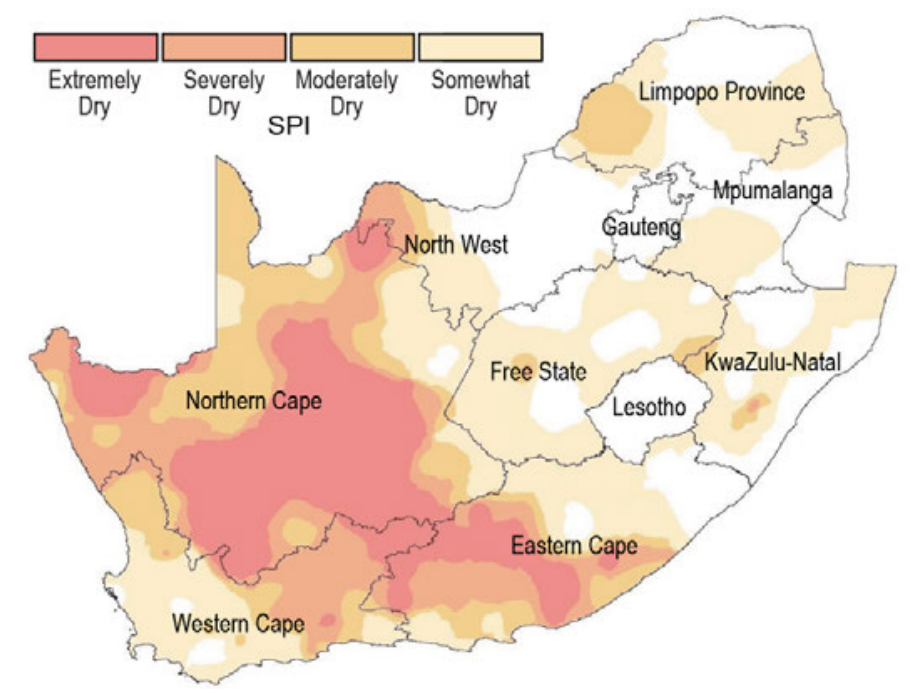

Fig. 7.25. Twelve-month SPI map for South Africa for 2019. (Source: South African Weather Service.) 
in most parts of the western interior, with warmer-than-usual conditions in the central parts. Good rains were received in the Limpopo province with several weather stations breaking daily and monthly rainfall records. By March, the eastern parts received good rains that persisted into April. However, heavy rain in the KwaZulu-Natal province on 22 and 23 April caused severe flooding that resulted in extensive damage to infrastructure and about 70 deaths. An additional 50 people were injured and 1469 people were displaced. The estimated damage was R1.1 billion (South African Rand; \$66 million U.S. dollars), with damage in eThekwini (Durban) alone estimated to be more than R685 million ( $\$ 41.2$ million U.S. dollars).

By austral winter a clear pattern emerged from the previous year's rainfall, which was below normal in most parts of the west and above normal in most of the eastern half of the country. Temperatures followed similar patterns, with very high temperatures recorded in the west, especially in May. June brought strong cold fronts reaching the southwestern Cape with accompanying flooding and displacement of people in the Cape Town metropolitan area. These incidents continued into July. High maximum temperatures were reported in the east during June and July, with places in extreme eastern South Africa more than $3^{\circ} \mathrm{C}$ above normal.

During the spring months, dry conditions persisted over the western interior. November saw a number of tornadoes in the eastern parts, with at least four occurring in the KwaZulu-Natal province. On 12 November, a tornado destroyed several houses in Mpolweni village near New Hanover in KwaZulu-Natal. Two people died and 20 sustained injuries. The village's power substation was also structurally damaged. On 26 November, 13 houses and several schools were damaged after a tornado hit Ulundi in KwaZulu-Natal, one day after a tornado hit Utrecht, which is roughly 120 $\mathrm{km}$ northwest of Ulundi.

In December several large flood events were reported in the east. The worst of these occurred on 9 December when several parts of northern Gauteng province were underwater following five days of persistent rain. Rivers overflowed, causing devastating floods that damaged roads and local buildings. Hundreds of people were left homeless and infrastructure was severely damaged. Several cars were swept away during intense flooding in Centurion, Pretoria. Several roads were closed, causing traffic delays in most parts of the city. At least 700 shacks were destroyed in the Eerste Fabriek informal settlement in Mamelodi, displacing thousands of people.

\section{5) Western Indian Ocean island}

countries-G. Jumaux, K. R. Dhurmea,

B. Andrade, A. Abida, and L. Labbé

Western Indian Ocean island countries consist of Madagascar, Seychelles, Comoros, Mayotte (France), Réunion (France), Mauritius, and Rodrigues (Mauritius).

Positive SST anomalies over the region during the summer (January-April) and a very strong positive IOD during the last quarter (October-December) contributed to making 2019 the warmest year on record in the region, while rainfall was more varied (Fig. 7.26).

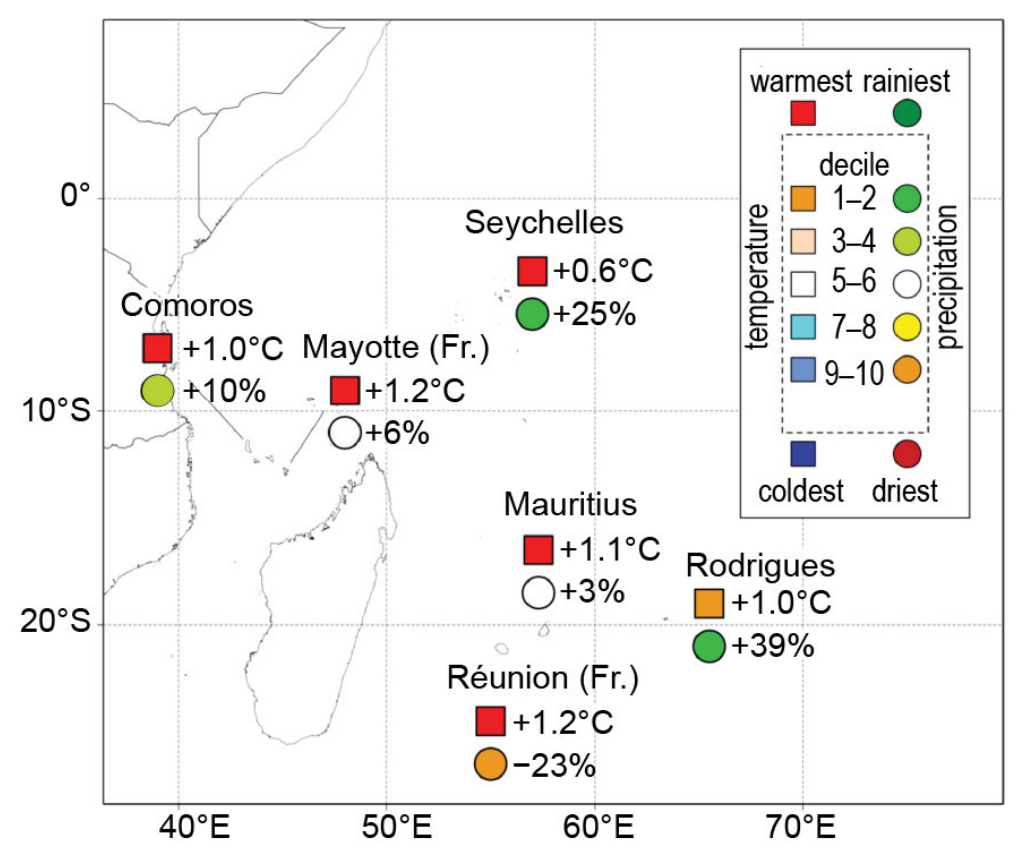

Fig. 7.26. Mean annual temperature anomalies $\left({ }^{\circ} \mathrm{C} ; 1981-2010\right.$ base period), annual rainfall anomalies (\% of average), and their respective deciles for the Western Indian Ocean islands countries in 2019. (Sources: Météo France; and Meteorological Services of Mauritius, Seychelles and Comoros.) 


\section{(1) TEMPERATURE}

Based on data from three stations, the annual mean temperature anomaly for Réunion Island was $+1.2^{\circ} \mathrm{C}$, the highest since 1968 when recordkeeping began and $0.3^{\circ} \mathrm{C}$ higher than the former highest in 2017. Monthly records for mean temperature were broken for six months of the year, in January, March, April, and October through December (Fig. 7.27). The highest all-time maximum temperature for Réunion Island $-37.0^{\circ} \mathrm{C}$ at Pointe des Trois-Bassins-was recorded on 25 January.

In Mauritius, the average temperature over the island was the highest on record since $1960\left(1.1^{\circ} \mathrm{C}\right.$ higher than the 1981-2010 normal; Fig. 7.28). The mean maximum temperature was $1.0^{\circ} \mathrm{C}$ above normal while the minimum was $1.2^{\circ} \mathrm{C}$ above average, indicating greater nighttime warming compared to daytime. Over the central part of the island, the mean temperature was more than $1.5^{\circ} \mathrm{C}$ above normal. March and December 2019 were the warmest for their respective months since records began in 1971, while April, August, and November were among their five warmest for the same period. In December, both nighttime and daytime temperatures were at least $2^{\circ} \mathrm{C}$ above normal for more than 10 consecutive days. Warm conditions also prevailed at Rodrigues with a mean temperature anomaly of $+1.0^{\circ} \mathrm{C}$ compared to normal. This made 2019 the fourth-warmest year on record since records began in 1960.

For Mayotte, the annual mean temperature was $1.2^{\circ} \mathrm{C}$ above normal, the highest since records began in 1961 and $0.3^{\circ} \mathrm{C}$ warmer than the previous record set in 2017. Monthly mean temperature records were broken for nine consecutive months, from April through December. In Comoros, the annual mean temperature was $27.6^{\circ} \mathrm{C}$, which is $1.0^{\circ} \mathrm{C}$ above normal. It was also the warmest year since records began in 1981, ahead of 2017.

At Seychelles International Airport, the annual mean temperature anomaly for 2019 was $0.6^{\circ} \mathrm{C}$ above normal, which was the highest since records began in 1972, surpassing 2009. All months were above normal, especially December, which was the warmest on record. April, June, and July were second warmest.

\section{(II) PRECIPITATION}

The annual rainfall total over Réunion Island was 77\% of average, making 2019 the sixth-driest year since 1972. With high cyclonic activity in the southwestern Indian Ocean basin (15 tropical storms or cyclones) during the 2018/19 season, one might have expected above-normal rainfall. However, the trajectories of these tropical depression systems largely spared Réunion Island, resulting in the driest rainy season (December-April) recorded on the island, at $52 \%$ of average. 
However, the dry season (May-November) was slightly above average, and the last quarter of the year was the fifth wettest, related to the strong positive IOD.

In Mauritius, the mean annual rainfall total was close to normal with $2054 \mathrm{~mm}$, compared to the long-term average of 1999 $\mathrm{mm}$. This made 2019 fall near the middle of the record, which dates to 1904. The intra-annual variability in rainfall was rather marked (Fig. 7.29), with deficient rainfall during the peak of rainy season (JanuaryMarch) while April, June, and December had notably excessive rainfall. The mean annual rainfall at Rodrigues (based on the station at Pointe Canon) was $1541 \mathrm{~mm}$, compared to the 1981-2010 mean of 1105 mm. This made 2019's total rainfall amount the sixth highest since records began in 1954.

For Mayotte, the total annual rainfall amount (an average of two stations) was 1579 $\mathrm{mm}$, which is $106 \%$ of average. The total rainfall during the rainy season (November-April 2018/19) and the dry season (May-October) was $91 \%$ and $77 \%$ of average, respectively. The July-September quarter was $23 \%$ of average and the driest of the 59-year record, causing concern about drought. However, rainfall related to the strong positive IOD during November and December ameliorated the accumulated deficits. On the Comoros archipelago, the islands to the northwest, particularly Grande Comore, were comparatively wetter, making 2019 among the wettest recorded.

In Seychelles, annual rainfall (2948 mm) was 125\% of average, making 2019 the second-wettest year on record (since 1972), behind 1997 (Fig. 7.30). This is also related to the positive IOD. January, May, and June were among their five rainiest months on record.

\section{(III) NOTABLE EVENTS AND IMPACTS}

In Mayotte, two cyclones passed close to the island in 2019, which is very unusual. Tropical Cyclone Kenneth passed $180 \mathrm{~km}$ north on 24 April, mainly causing damage to food crops with wind gusts close to $30 \mathrm{~m} \mathrm{~s}^{-1}$. Tropical Cyclone Belna passed $100 \mathrm{~km}$ east on 8 December, causing almost no damage on the island because of its very compact size, despite a maximum recorded rainfall of $131 \mathrm{~mm}$ in 24 hours (see section 4f6).

Kenneth also affected the Comoros and, more particularly, the Grande Comore Island. During the night of 24-25 April, its eye passed within $50 \mathrm{~km}$ of the coast of Grande Comore. The storm caused severe flooding, killed six people, and injured 200. Almost 5000 houses were severely affected or destroyed. Livestock and agricultural production were heavily impacted, jeopardizing food security and local livelihoods. A total of 185000 people were impacted. The last mature cyclone to have affected Grande Comore was likely in December 1959 (see section $4 \mathrm{f6}$ and Sidebar 7.3 for more details on Kenneth). 


\section{Sidebar 7.3: Record-breaking tropical cyclone landfalls in southeastern Africa-}

W. M. THIAW, J. ZUCULE, E. BEKELE, M. ROBJHON, P.-H. KAMSU-TAMO, A. D. MAGEE, AND C. J. SHRECK

Late in the southern Africa rainfall season of 2018/19, two tropical cyclones (TC) - each record-breaking storms in their own right-made landfall over Mozambique, marking the first time since the advent of reliable satellite imagery over the western Indian Ocean in 1979 that two intense (Category 2 and Category 4) TCs made landfall over the country in a single season. Tropical Cyclone Idai (4-16 March) was the longest-lived tropical system on record in the Mozambique Channel, while Kenneth (23-26 April) became the strongest storm on record to make landfall in Mozambique.

According to the Regional Specialized Meteorological Centre (RSMC) La Réunion Forecast Center tropical storm track, Idai was a long-lived disturbance with an unprecedented path with multiple landfalls that affected all central Mozambique provinces spanning more than $700 \mathrm{~km}$ north-south (Fig. SB7.5). Idai formed as a tropical depression (TD) off the east coast of Mozambique on 4 March, then intensified and moved slowly to the northwest and became a tropical storm (TS) just prior to making its first landfall near the town of Namacurra in the Zambézia Province that same day. Upon landfall, the storm immediately weakened to a TD and continued northward, then veering northwest near $16^{\circ} \mathrm{S}$. As Idai crossed the border of Mozambique and Malawi on 7 March, it turned southeastward, exiting offshore into the Mozambique Channel at Pebane in the Nampula Province on 9 March. Between 4 and 8 March, the TD dumped extremely heavy rainfall amounts in several areas. In the Zambézia Province, the town of Mocuba observed a 3-day rainfall total of $375 \mathrm{~mm}$ on 5-7 March, while Milange recorded a 2-day rainfall total of 290 $\mathrm{mm}$ on 6-7 March. To the northwest, in the Tete Province, the town of Ulongue received a total of $448 \mathrm{~mm}$ during 7-8 March, while the northwestern district of Tsangano received 438 $\mathrm{mm}$ during 6-8 March. The heavy rains caused massive flooding in the region, killing more than 60 people and destroying 6000 houses.

The storm moved back over the warm waters of the Mozambique Channel (sea surface temperature [SST] anomalies $>1^{\circ} \mathrm{C}$ ) and intensified rapidly as it re-approached the country. The Joint Typhoon Warning Center (JTWC) formally named Tropical Storm Idai on 10 March. On 11 March, Idai moved southwestward over the
Mozambique Channel. The JTWC upgraded the storm to major TC status (see section $4 \mathrm{f} 6$ for details), but it weakened to a TS just before making a second landfall on 15 March near Beirathe fourth-largest city in Mozambique-in Sofala Province with extremely heavy rains, maximum sustained winds of 160-180 $\mathrm{km} \mathrm{h}^{-1}$, minimum central pressure of about $980 \mathrm{hPa}$, and a storm surge of $4.4 \mathrm{~m}$. The storm was so powerful that it destroyed the weather stations in Beira and surrounding areas. A weather station in Espungabera, a town located about $400 \mathrm{~km}$ southwest of Beira, recorded a two-day rainfall total of $584 \mathrm{~mm}$ on 15-16 March, $69 \%$ of its monthly total. About $200 \mathrm{~km}$ northwest of Beira, the station at Chimoio Airport observed $310 \mathrm{~mm}$ during the same period. Once inland, Idai continued to weaken into a TD in its westward movement into central Mozambique, entering Zimbabwe on 15 March and finally dissipating on 16 March.

According to the Mozambique National Institute of Disaster Management, the storm affected 1.2 million people in Sofala Province, over 200000 in Manica Province, over 6000 in Zambézia Province, and about 55000 people in Tete Province. In Beira, hundreds of people were trapped in their homes due to the high water level from the storm surge, contributing to over 500 deaths. Strong winds and flooding across large areas of central

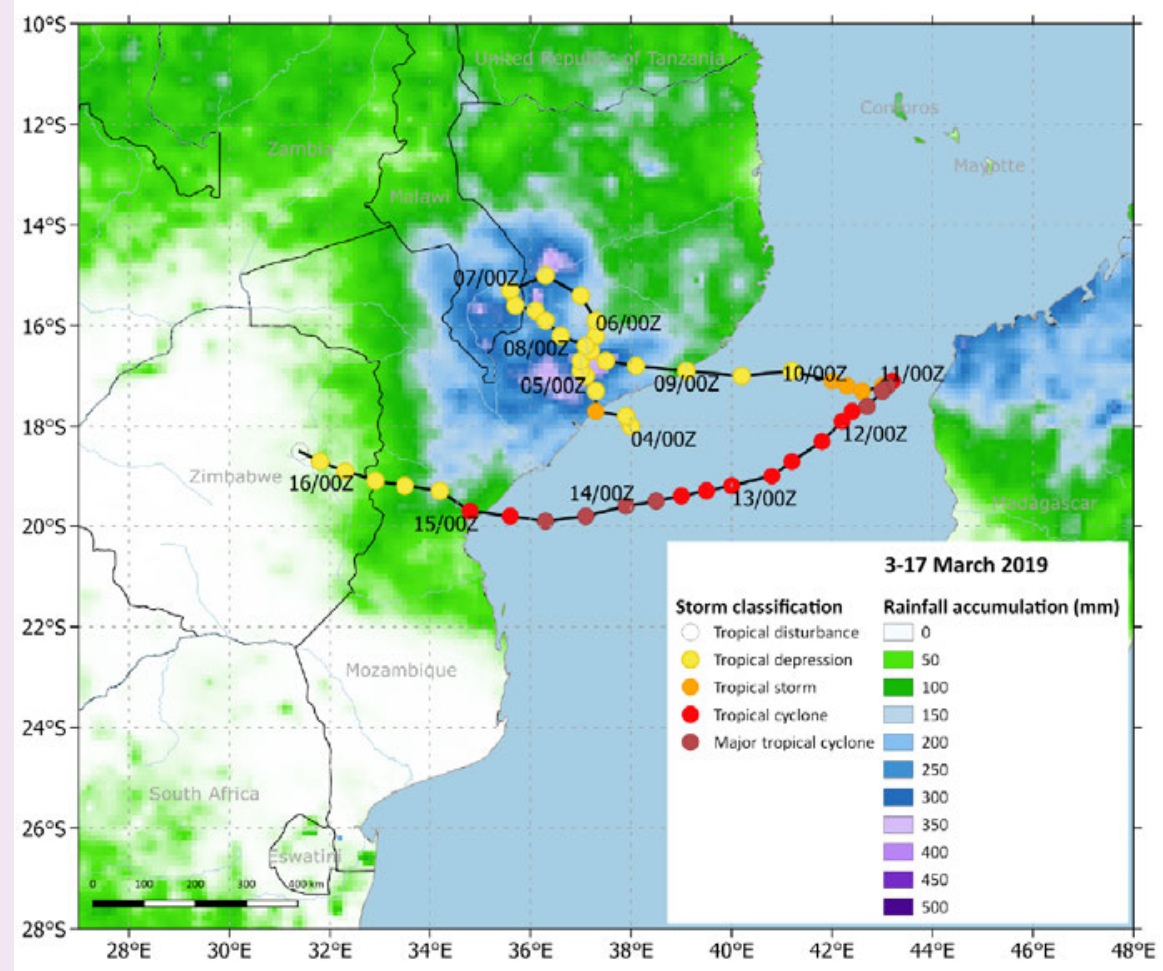

Fig. SB7.5. GIS-reconstructed RSMC La Réunion track of TC Idai overlaid with cumulative satellite rainfall estimate (mm; RFE 2.0) during 3-17 Mar 2019. (Source: NOAA/NCEP.) 
and western Mozambique destroyed more than 100000 homes and wiped out 700000 ha of crops that were nearing harvest, placing pressure on food reserves. A major cholera outbreak ensued, with over 4000 confirmed cases in total. Malawi was also significantly affected by flooding, killing 60 people and affecting a further 900000 nationwide. In Zimbabwe, Idai dumped massive amounts of rain, resulting in widespread flash flooding, claiming the lives of at least 630 people and displacing 15000. A major humanitarian relief effort was triggered to assist affected people and communities. Idai resulted in total damages of at least $\$ 2.2$ billion (U.S. dollars), the costliest TC on record for the South Indian Ocean basin, as well as the deadliest.

As Mozambique was recovering and assessing the damages and rebuilding costs from Idai, TC Kenneth made landfall on 25 April over the Macomia coastal district less than $100 \mathrm{~km}$ north of Pemba, the largest city in the Cabo Delgado Province in northern Mozambique. According to the RSMC La Réunion Forecast Center TS track, Kenneth formed as a tropical disturbance northeast of Madagascar and organized over the warm waters of the Indian Ocean into a TD by 23 April (Fig. SB7.6). Unlike Idai, the TD rapidly intensified the same day, with a fast westward motion. The JTWC upgraded Kenneth to TC status on 24 April as the storm approached the Comoros Islands. Kenneth was the strongest storm on record to affect the Islands. It passed $\sim 60 \mathrm{~km}$ north of Grande Comore Island and resulted in significant impacts there, including multiple fatalities, the permanent or partial destruction of 10000 homes, loss of $64 \%$ of food crops, and the displacement of up to 15000 people. Kenneth then amplified swiftly to gain major TC status on 25 April as it approached the northern Mozambique coastline, making landfall the same day near Pemba, as noted above. With a maximum wind speed of $220 \mathrm{~km} \mathrm{~h}^{-1}$ and minimum central pressure of $988 \mathrm{hPa}$ (equivalent of a Category 4 hurricane), Kenneth became the most intense storm to make landfall in Mozambique's recorded history.

Soon after landfall, on 26 April, Kenneth weakened into a TD while continuing to dump heavy rains over the region, moving southward and then drifting northward before finally dissipating south of Pemba on 29 April. The NOAA Climate Prediction Center African Rainfall Estimation Algorithm Version 2 (RFE 2.0) estimated a 7-day rainfall total of about $485 \mathrm{~mm}$ near Pemba, bringing cumulative seasonal rainfall estimates there to about $975 \mathrm{~mm}$, approximately $140 \%$ of its 2001-18 average. Kenneth caused widespread flooding in northern Mozambique, with estimated damages of $\$ 100$ million (U.S. dollars) and over 40 fatalities. Over 250000 people in Cabo Delgado Province and almost 40000 people in Nampula Province were affected. The storm also caused damage in southeastern Tanzania.

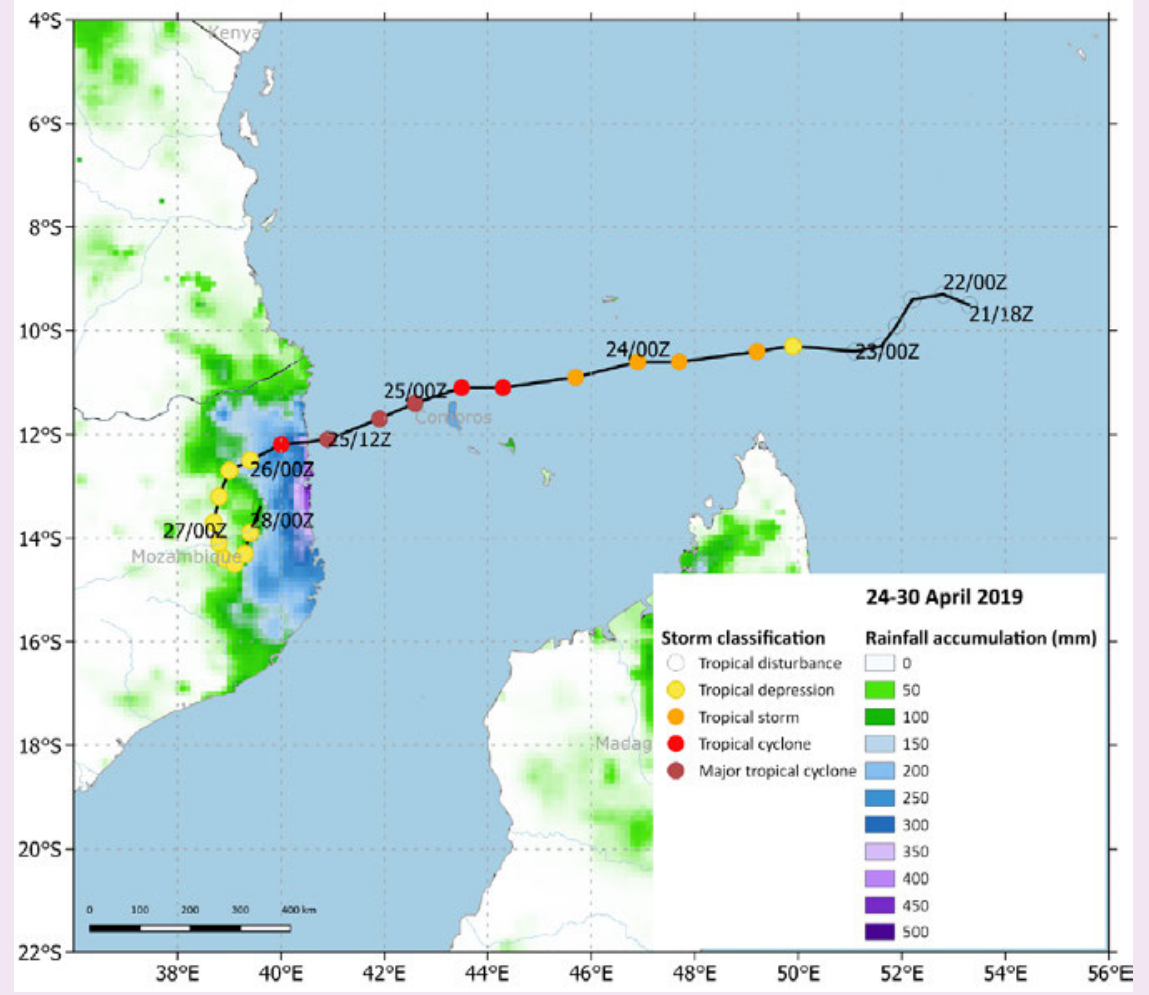

Fig. SB7.6. GIS-reconstructed RSMC La Réunion track of TC Kenneth overlaid with cumulative satellite rainfall estimate (mm; RFE 2.0) during 24-30 Apr 2019. (Source: NOAA/NCEP.) 
f. Europe and the Middle East—P. Bissolli (Ed.), B. Rösner, M. Demircan, J. Kennedy, V. Khan, K. Kokosadze, N. Kutaladze, M. Lakatos, J. Mamen, L. Megrelidze, M. A. Pastor Saavedra, E. Rodriguez Camino, E. Rodriguez Guisado, S. Sensoy, S. Spillane, K. Trachte, and G. van der Schrier

Countries in this section are part of the World Meteorological Organization (WMO) RA VI region. Throughout this section, 1981-2010 is the base period used for both temperature and precipitation, unless otherwise specified. European countries conform to different standards applied by their individual national weather services. The precision of anomalies reported may vary by country.

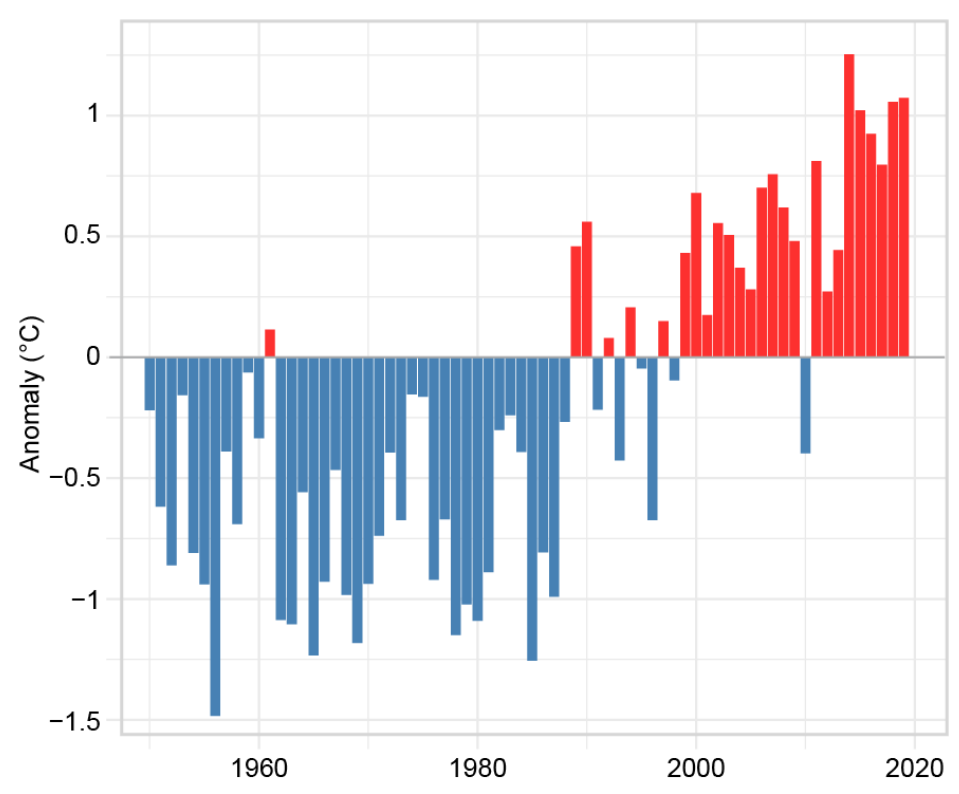

Fig. 7.31. Annual average land surface air temperature anomalies for $1950-2019$ for Europe $\left(35^{\circ}-75^{\circ} \mathrm{N}, 10^{\circ} \mathrm{W}-30^{\circ} \mathrm{E}\right)$ relative to the 1981-2010 base period. (Source: GHCN version 4.0.1 dataset [Menne et al. 2018].)

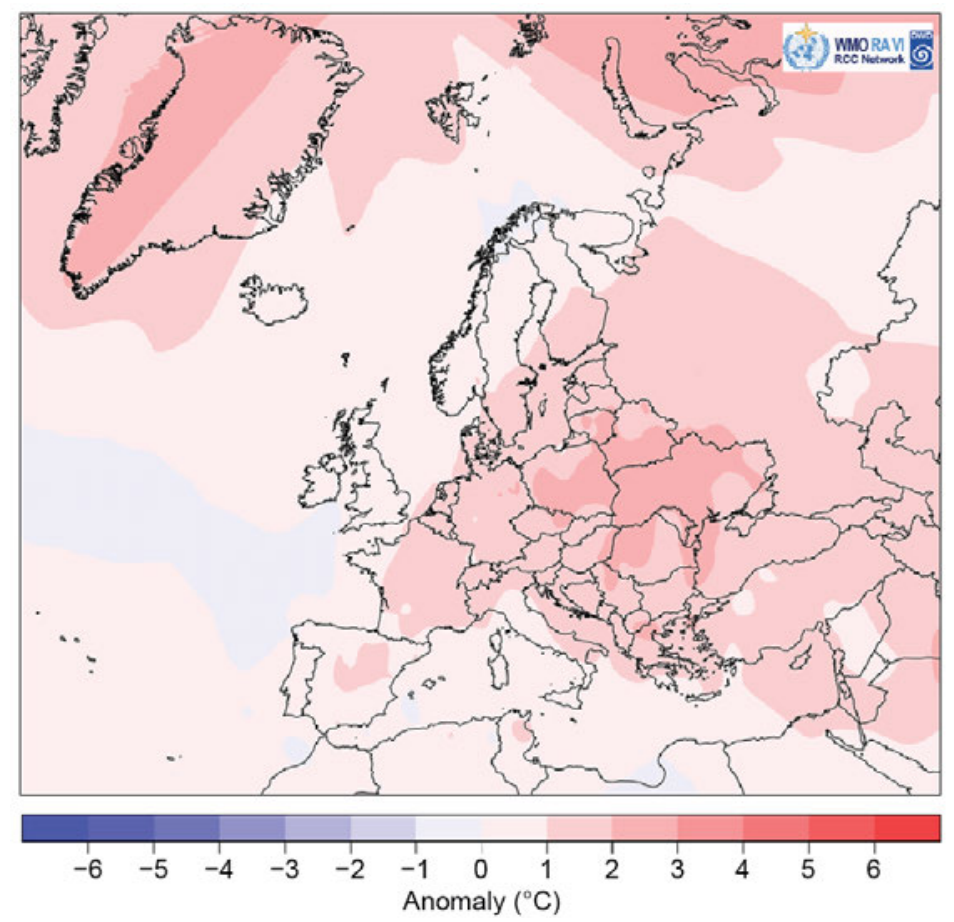

Fig. 7.32. Annual mean air temperature anomalies $\left({ }^{\circ} \mathrm{C} ; 1981-\right.$ 2010 base period) in 2019. (Source: interpolated climate station data, Deutscher Wetterdienst [DWD].)
All seasons mentioned in this section refer to the Northern Hemisphere (NH). More detailed information can be found in the Monthly and Annual Bulletins on the Climate in RA VI - Europe and the Middle East, provided by WMO RA VI Regional Climate Centre Node on Climate Monitoring (RCC Node-CM; www. dwd.de/rcc-cm). Anomaly information was taken from Figs. 7.32-7.36 and aggregations of CLIMAT station data when national reports are not available.

The North Atlantic Oscillation (NAO) index used throughout the chapter is based on Jones et al. (1997). A positive NAO index value refers to an above-normal mean sea level pressure difference between the Azores high and the Icelandic low and, hence, a stronger-than-normal flow of mild and humid maritime air to the colder continent in winter. The relationship between the NAO and European temperature and precipitation, especially in winter, has long been known (e.g., Uvo 2003). A positive NAO index value is mostly associated with a warmer- and wetterthan-normal winter in northern and central Europe and a colder- and drier-than-normal winter in southern Europe; a negative NAO index value is generally associated with opposite effects.

Table A7.3 lists the beginning years of each country's national temperature and precipitation records for reference, if not otherwise mentioned in the text.

\section{1) Overview}

Based on the Global Historical Climate Network (GHCN) v4.0.1 dataset (Menne et al. 2018), Europe $\left(35^{\circ}-75^{\circ} \mathrm{N}, 10^{\circ} \mathrm{W}-30^{\circ} \mathrm{E}\right)$ experienced its second-warmest year since at least 1950 with an anomaly of $+1.1^{\circ} \mathrm{C}$, very close to 2018 (Fig. 7.31). Other datasets, e.g., Copernicus (https://climate.copernicus.eu /surface-air-temperature-maps), show 
slightly different results, dependent on the data basis and the definition of the area of Europe. Nevertheless, 2019 generally ranked among the four warmest years on record of Europe mean temperature, together with 2014, 2015, and 2018.

Overall, the year was exceptionally warm and almost all of Europe reported temperatures higher than normal (Fig. 7.32). With the exception of most of the Iberian Peninsula and Italy, Ireland, the United Kingdom, Iceland, Norway, and the northern parts of Sweden and Finland, Europe showed anomalies well above $+1.0^{\circ} \mathrm{C}$. For many countries the year proved to be the warmest (Estonia $+1.6^{\circ} \mathrm{C}$ [tied with 2015], Serbia $+1.7^{\circ} \mathrm{C}$, Belarus $+1.5^{\circ} \mathrm{C}$, Poland $+1.8^{\circ} \mathrm{C}$, Latvia $+1.4^{\circ} \mathrm{C}$, Lithuania $+1.5^{\circ} \mathrm{C}$, Ukraine $+1.6^{\circ} \mathrm{C}$, Romania $+1.6^{\circ} \mathrm{C}$ ).

The average annual precipitation total in 2019 was $7 \mathrm{~mm}$ above normal for Europe and considerably higher than in 2018, which was $32 \mathrm{~mm}$ below normal (Fig. 7.33). Annual totals were above $125 \%$ of normal in some northern areas (Fig. 7.34) such as small parts of the United Kingdom and

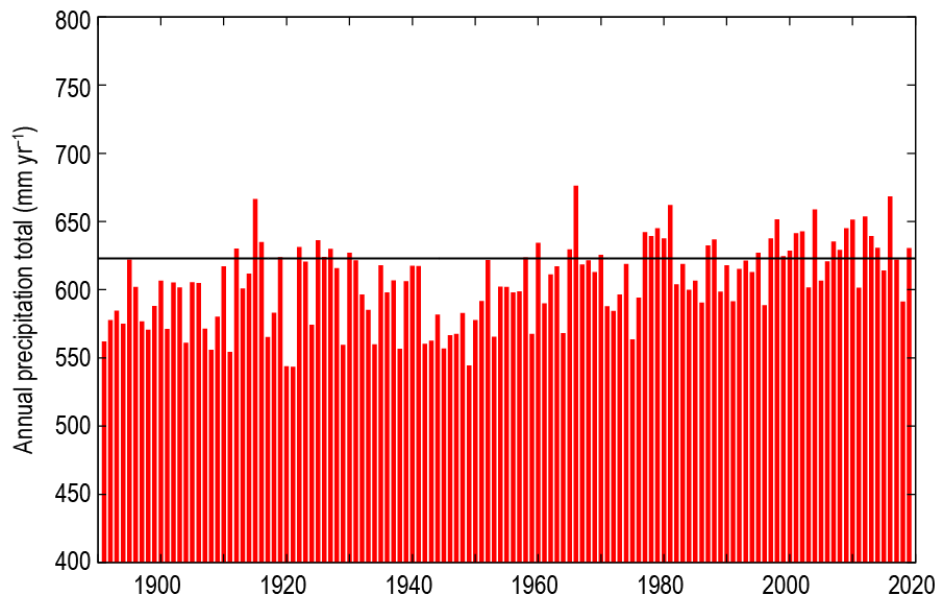

Fig. 7.33. Annual average precipitation totals (bars) for the period $1891-2019$ for Europe $\left(36^{\circ}-72^{\circ} \mathrm{N}, 23^{\circ} \mathrm{W}-60^{\circ} \mathrm{E}\right)$ with the 1981-2010 base period (horizontal solid black line: 1981-2010 average is $623 \mathrm{~mm}$ ). (Source: GPCC, created by DWD.)

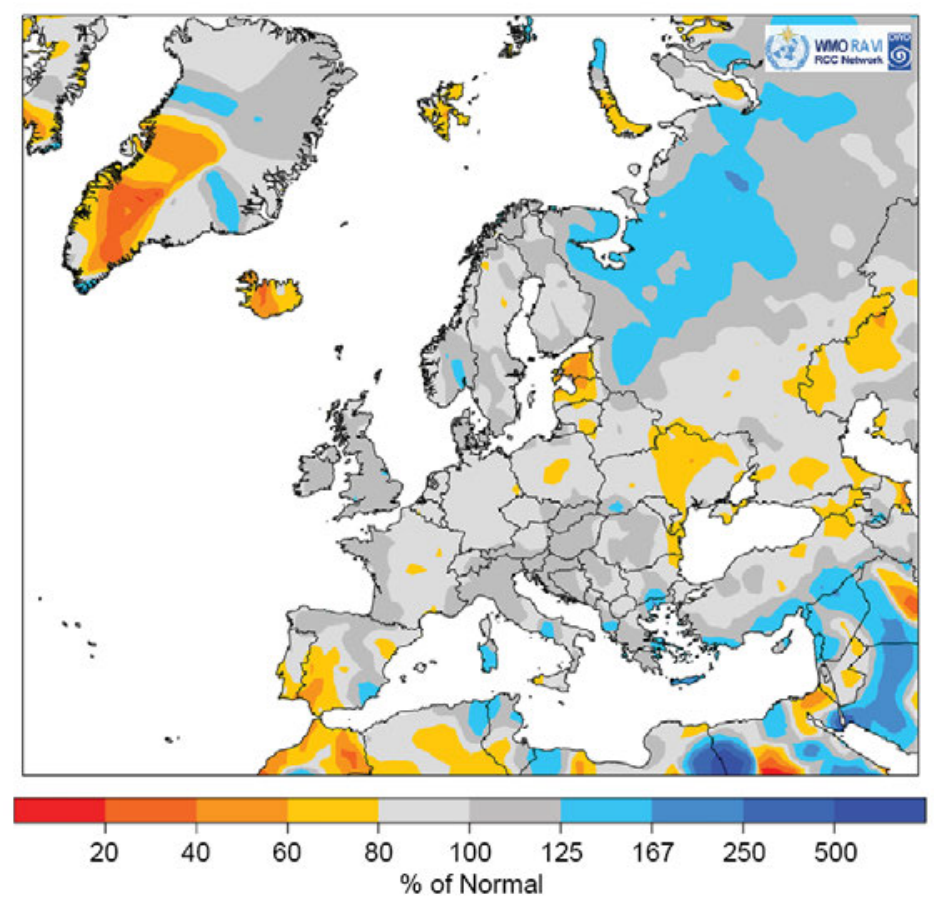

Fig. 7.34. European precipitation totals (\% of 1981-2010 average) for 2019. (Source: GPCC, created by DWD.)
Norway and much of northern European Russia, and in the south around the Mediterranean due to locally heavy rain. Dry areas with less than $80 \%$ of normal precipitation were observed in other places in the north (Iceland, Svalbard, Baltic States) but also in southern Iberia. The middle latitudes, too, were generally mostly drier than normal due to a longer drought period in the summer half year (April-September), where limited areas observed precipitation less than $80 \%$ of normal.

Meteorological winter 2018/19 (December 2018-February 2019) was mild in much of Europe (Fig. 7.35a) with an associated NAO index of +1.2 (whole winter average). Winter 2018/19 was Ireland's warmest on record since 1900 . February was exceptionally warm (anomalies of $+2.0^{\circ}$ to $+4.0^{\circ} \mathrm{C}$ in eastern Europe, and even higher in places) due to a strong positive NAO and a blocking high-pressure system over Russia. Many parts of western Europe received only $60 \%-80 \%$ of normal precipitation that winter (Fig. $7.36 a$ ) and only $20 \%-60 \%$ in parts of the Iberian Peninsula. In southern central Europe, eastern Europe, and parts of the eastern Mediterranean, precipitation was $125 \%-250 \%$ of normal. Snow was frequent in many parts of Europe in January, but less frequent in February. In parts of central, eastern, and southeastern Europe, the snow frequency (number of days with snow cover) was 125\%-150\% of normal in January, but $50 \%-75 \%$ of normal in February according to data from the Rutgers Global Snow Lab (https://climate.rutgers.edu/snowcover /index.php; see section 2c2). 
Above-normal temperatures continued with the start of spring (Fig. 7.35b). In May, temperatures from Italy to the Nordic countries were below normal by $-2.0^{\circ}$ to $-3.0^{\circ} \mathrm{C}$ in many regions, making it one of the coldest Mays in a long time for many countries. Many parts of France and the Iberian Peninsula were drier than normal in spring with precipitation $60 \%-80 \%$ of normal while in the rest of Europe it was closer to normal or wetter, with $125 \%-167 \%$ of normal in Scandinavia, Italy, and the northern Balkans (Fig. 7.36b).

Summer was warmer than normal in much of Europe (Fig. 7.35c). June proved to be full of records for many countries with widespread anomalies of $+2.0^{\circ}$ to $+4.0^{\circ} \mathrm{C}$. Summer was broadly drier than normal, with 60\%-100\% of normal precipitation across much of Europe (Fig. 7.36c), except for the eastern Mediterranean, the United Kingdom, Ireland, and southern parts of Norway.

Autumn was also warmer than normal (Fig. 7.35d) except for the Nordic countries, Ireland, and the United Kingdom. The Balkan states were particularly warm, with anomalies well above $+2.0^{\circ} \mathrm{C}$. For eastern Europe, Turkey, and southwestern Iberia, autumn was rather dry while central and western Europe mostly received above-normal precipitation between $100 \%$ and $167 \%$ of normal (Fig. 7.36d). December 2019 was mild with anomalies increasing from west to east and mostly wetter than normal except in some limited areas, e.g., parts of central Europe, the Baltic States, the eastern Balkan Peninsula, southern European Russia and South Caucasus, and parts of Italy.

Snow cover frequency was above normal in northern Europe in October and November, while it was below normal in central and eastern Europe in November and December 2019.

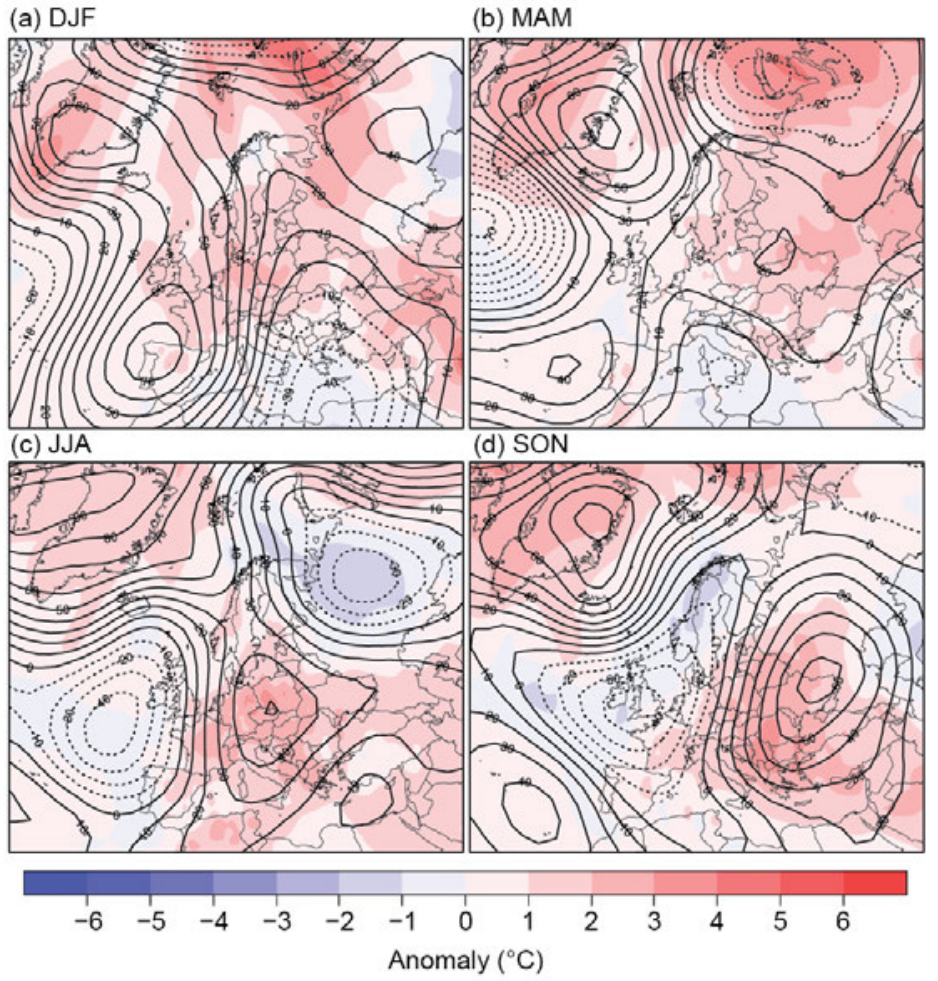

Fig. 7.35. Seasonal anomalies (1981-2010 base period) of 500$\mathrm{hPa}$ geopotential height (contour; $\mathrm{m}$ ) and surface air temperature (shading; ${ }^{\circ} \mathrm{C}$ ) using data from the NCEP/NCAR reanalysis and DWD, respectively, for (a) DJF 2018/19, (b) MAM 2019, (c) JJA 2019, and (d) SON 2019.

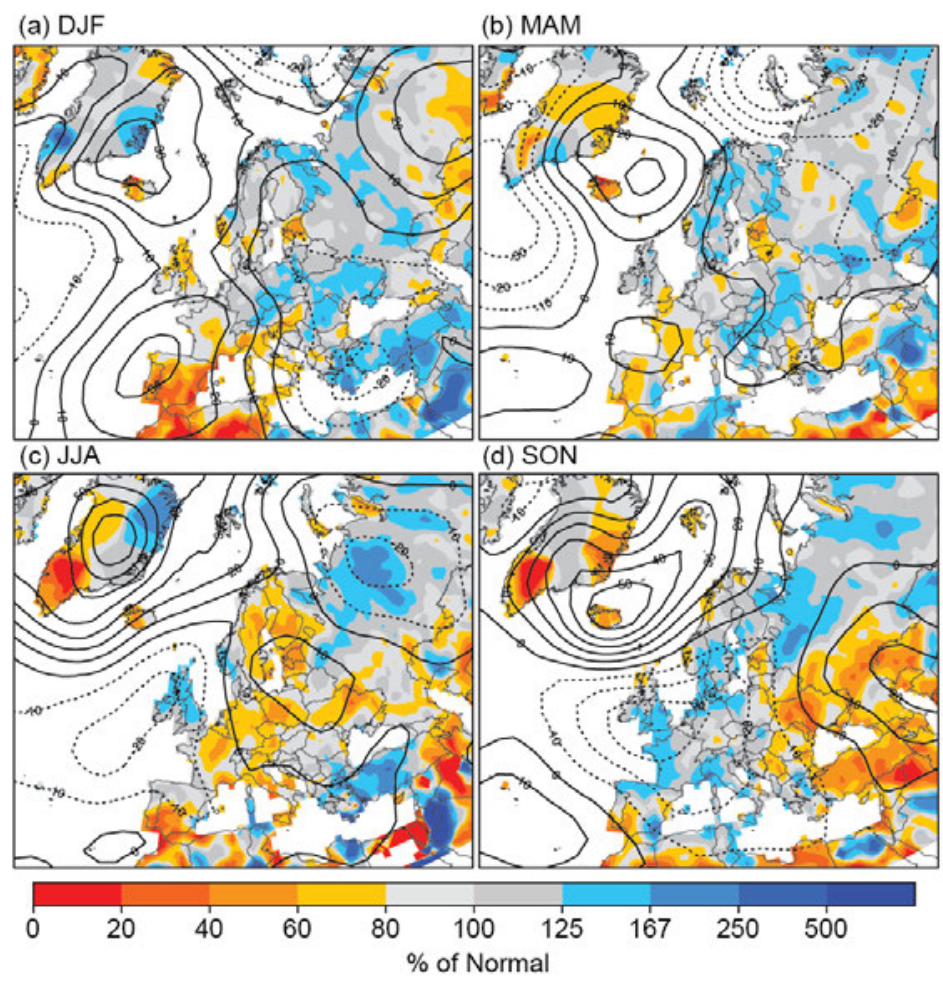

Fig. 7.36. Seasonal anomalies for 2019 (1981-2010 base period) of sea level pressure $(\mathrm{hPa})$ from NCAR/NCEP reanalysis (contours) for (a) DJF 2018/19, (b) MAM 2019, (c) JJA 2019, and (d) SON 2019. Colored shading represents the percentage of seasonal mean precipitation for 2019 compared with the 1981-2010 mean from GPCC (Schneider et al. 2018). 


\section{2) Western Europe}

This region includes Ireland, the United Kingdom, the Netherlands, Belgium, Luxembourg, and France.

\section{(I) TEMPERATURE}

The year was characterized by well-above-normal temperatures for western Europe with anomalies greater than $+1.0^{\circ} \mathrm{C}$, except for the United Kingdom and Ireland, which were lower but still above normal. For the continental countries, the year ranked third or fourth warmest.

Due mainly to a very warm December 2018 and exceptionally warm February, winter 2018/19 was very mild, with large positive temperature anomalies: United Kingdom $+1.4^{\circ} \mathrm{C}$ above normal, Netherlands $+1.8^{\circ} \mathrm{C}$, Luxembourg $+1.8^{\circ} \mathrm{C}$, France $+1.3^{\circ} \mathrm{C}$, Ireland $+1.8^{\circ} \mathrm{C}$ (highest on record). The United Kingdom reported its second-warmest February on record $\left(+2.4^{\circ} \mathrm{C}\right.$ above normal), and Luxembourg and Ireland their third warmest $\left(+3.7^{\circ} \mathrm{C}\right.$ and $+2.4^{\circ} \mathrm{C}$, respectively). In France, the countrywide average maximum temperature was $+4.1^{\circ} \mathrm{C}$ above normal, making it the secondwarmest February (after 1990). Similarly in Ireland, it was the warmest winter on record for many stations, and more than half of Irish stations set new monthly maximum temperature records on 25 and 26 February. Other countries in western Europe reported new records as well in late February (see Notable events and impacts for details).

Spring was also mild. Anomalies ranged from $+0.3^{\circ} \mathrm{C}$ in France, to $+0.7^{\circ} \mathrm{C}$ in the Netherlands, to $+0.8^{\circ} \mathrm{C}$ in the United Kingdom. Only May had below-normal temperatures, with anomalies below $-1.0^{\circ} \mathrm{C}$ in the Benelux countries and in eastern and southern France.

Summer was close to normal $\left(+0.4^{\circ} \mathrm{C}\right)$ in Ireland and only slightly warmer in the United Kingdom (anomaly of $+0.8^{\circ} \mathrm{C}, 12$ th warmest). Belgium $\left(+1.5^{\circ} \mathrm{C}\right)$, Luxembourg $\left(+2.4^{\circ} \mathrm{C}\right)$, and France $\left(+1.7^{\circ} \mathrm{C}\right)$ each observed their third-warmest summer on record. The Netherlands observed its fourthwarmest summer with an anomaly of $+1.4^{\circ} \mathrm{C}$ at De Bilt. June was very warm for most of Europe. It was the warmest June in the Netherlands, second warmest in Luxembourg (anomaly $+3.6^{\circ} \mathrm{C}$ ), and fifth warmest in France (anomaly $+1.8^{\circ} \mathrm{C}$ ). Ireland was below normal with an anomaly of $-0.3^{\circ} \mathrm{C}$. It was the fourth-warmest July on record for France $\left(+2.2^{\circ} \mathrm{C}\right)$, and many daily maximum temperature records were broken, especially on 25 July (see Sidebar 7.4 for more details).

While autumn brought below-normal temperatures to Ireland (anomaly $-0.4^{\circ} \mathrm{C}$ ) and the United Kingdom (anomaly $-0.3^{\circ} \mathrm{C}$ ) and slightly-above-normal temperatures in the Benelux countries (Netherlands $+0.2^{\circ} \mathrm{C}$, Belgium $+0.3^{\circ} \mathrm{C}$, Luxembourg $+0.7^{\circ} \mathrm{C}$ above normal), France reported its sixth-warmest autumn since 1900 with an anomaly of $+1.0^{\circ} \mathrm{C}$. December 2019 was mild with anomalies of $+0.8^{\circ} \mathrm{C}$ in Ireland, around $+1^{\circ} \mathrm{C}$ in the United Kingdom, and $+2^{\circ} \mathrm{C}$ in the Benelux and France.

\section{(II) PRECIPITATION}

The year as a whole was wetter than normal in the western parts of western Europe. Precipitation of 100\%-125\% of normal was reported for Ireland, the United Kingdom, and western France, while much of the Benelux, and central and eastern France had below-normal precipitation (80\%-100\%).

Winter precipitation was close to normal or below normal. The United Kingdom and Ireland reported $77 \%$ and $66 \%$ of normal precipitation, respectively. In the Benelux and most of France, precipitation was close to normal, and only portions of western, central, and southern France recorded precipitation less than $60 \%$ of normal.

While Ireland and the United Kingdom reported slightly-above-normal totals for the spring season, March was very wet in both countries. The United Kingdom reported its eighth-wettest March since 1910, at 136\% of normal. The Benelux countries were slightly drier than normal in spring with around $90 \%$ of normal precipitation. Parts of France remained dry with amounts as low as $50 \%-80 \%$ of normal. 
Summer was predominantly characterized by low pressure, leading to a rather wet season in Ireland and the United Kingdom. The United Kingdom reported its 10th-wettest summer with $138 \%$ of normal precipitation as well as some new seasonal records, including $425.4 \mathrm{~mm}$ in South Yorkshire, which is double its seasonal average. In contrast, summer was drier than normal in France and the Benelux, with only $80 \%-90 \%$ of normal precipitation on average and less in localized areas.

Autumn was wetter than normal in the Netherlands and Luxembourg with precipitation around $115 \%$ of normal. Belgium reported $95 \%$ of normal. France, with $130 \%$ of normal, had its fifth-wettest autumn (since 1959), although its countrywide average for September was only 60\% of normal. December 2019 was wetter than normal in western Scotland, southern England, and France, with some areas observing more than 125\% of normal; the Netherlands received only around $80 \%$ of its normal precipitation.

\section{(III) NOTABLE EVENTS AND IMPACTS}

A warm spell during 21-27 February brought exceptionally mild weather and record high temperatures to many areas in the United Kingdom. Kew Gardens in London reached $21.2^{\circ} \mathrm{C}$ on 26 February. This was the first temperature above $20^{\circ} \mathrm{C}$ recorded in winter in the United Kingdom. Achnagart (Highland) set a new highest daily minimum temperature record for the winter for the United Kingdom with temperatures not dropping below $13.9^{\circ} \mathrm{C}$ on 23 February. More than half of France's 150 measurement stations broke maximum temperature records for February-for example, Istres (Provence region in southeastern France) with $23.4^{\circ} \mathrm{C}$ on 28 February (previous record $23.3^{\circ} \mathrm{C}$ on 27 February 1960) and Cazaux (military airport near the Atlantic coast) with $26.2^{\circ} \mathrm{C}$ on 27 February (previous record $26.0^{\circ} \mathrm{C}$ on 23 February 1929). Similarly, a run of new records was set at De Bilt in the Netherlands with $18.3^{\circ} \mathrm{C}$ on 25 February, rising to $18.9^{\circ} \mathrm{C}$ the following day, and finally $20.5^{\circ} \mathrm{C}$ on the 27th, also breaking the monthly and winter record for all Dutch stations. In Uccle, Belgium, 26 February was an extremely early first spring day-defined as daily maximum temperature above $20^{\circ} \mathrm{C}$-making it the first winter day meeting this definition of a spring day in Belgium's history.

On 9 August, a tornado classified as EF-2, with wind speeds between $178 \mathrm{~km} \mathrm{~h}^{-1}$ and 217 $\mathrm{km} \mathrm{h}^{-1}$, formed from a supercell thunderstorm and brought considerable damage to northeastern France and southwestern Luxembourg. Almost 500 buildings were damaged in the communities of Pétange and Käerjeng, Luxembourg, and 30 buildings were damaged in the province of Meurthe-et-Moselle, northeastern France. Trees were knocked down, roads blocked, cars damaged, and 19 people in Luxembourg were injured.

\section{3) Central Europe}

This region includes Germany, Switzerland, Austria, Poland, Czechia, Slovakia, and Hungary.

\section{(I) TEMPERATURE}

Temperatures for the year were well above normal by $+1.0^{\circ}$ to $+2.0^{\circ} \mathrm{C}$ in central Europe, with 2019 among the five warmest years for all countries of the region. Hungary reported its warmest year on record with an anomaly of $+1.9^{\circ} \mathrm{C}$. Germany $\left(+1.4^{\circ} \mathrm{C}\right)$, Slovakia $\left(+1.8^{\circ} \mathrm{C}\right)$, and Czechia $\left(+1.6^{\circ} \mathrm{C}\right)$ were second warmest, while Austria $\left(+1.4^{\circ} \mathrm{C}\right)$ and Switzerland $\left(+1.1^{\circ} \mathrm{C}\right)$ had their fourth- and fifthwarmest year, respectively.

Winter was mild in the region with anomalies between $+1.0^{\circ}$ and $+2.0^{\circ} \mathrm{C}$. Germany reported its ninth-warmest winter with an anomaly of $+1.9^{\circ} \mathrm{C}$. February, with an NAO index value of +1.9 , was unusually warm with anomalies of $+2.0^{\circ} \mathrm{C}$ and above: Austria $+2.0^{\circ} \mathrm{C}$, Slovakia $+2.9^{\circ} \mathrm{C}$, Czechia $+2.6^{\circ} \mathrm{C}$, Hungary $+3.0^{\circ} \mathrm{C}$, Germany $+3.1^{\circ} \mathrm{C}$. An NAO index value of +1.9 indicates a nearly twice standard deviation difference between the normalized sea level pressures of the Azores high and Icelandic low, which is regarded as relatively high. Prior to 2019, the last time a February NAO index value surpassed +1.9 was in 2014 . 
Spring was slightly warmer than normal for Switzerland and Austria, at $+0.1^{\circ} \mathrm{C}$ and $+0.2^{\circ} \mathrm{C}$ above normal, respectively, $+0.5^{\circ} \mathrm{C}$ in Germany, and $+0.7^{\circ} \mathrm{C}$ for the rest of the countries in the region. While March and April brought widespread temperatures up to $+3.0^{\circ} \mathrm{C}$ above normal, May was far colder than normal due to a northwesterly circulation and below-average solar radiation with anomalies between $-2.2^{\circ} \mathrm{C}$ and $-2.6^{\circ} \mathrm{C}$, ranking among the 10 coldest Mays for most countries (see Table A7.3 for temperature record lengths of individual countries).

Summer was exceptionally warm. Slovakia and Czechia reported their warmest summer on record with anomalies of $+2.4^{\circ} \mathrm{C}$ and $+2.5^{\circ} \mathrm{C}$, respectively. Hungary and Austria reported their second-warmest summer $\left(+2.2^{\circ} \mathrm{C}\right.$ and $+2.7^{\circ} \mathrm{C}$ above normal), and Germany and Switzerland their third warmest $\left(+2.1^{\circ} \mathrm{C}\right.$ and $\left.+2.3^{\circ} \mathrm{C}\right)$. All summer months were warmer than normal in the region, but June in particular was the warmest month on record for all but Switzerland, where it was second warmest. Anomalies in June were well above $+3.0^{\circ} \mathrm{C}$, and close to $+5.0^{\circ} \mathrm{C}$ in places. Many maximum temperature records were broken. In Germany, the previous countrywide record of $40.3^{\circ} \mathrm{C}$, measured in summer 2015, was beaten by 14 different stations during the peak of the heat wave on 25 June, and a new countrywide record of $42.6^{\circ} \mathrm{C}$ was set in Lingen (Emsland region, northwestern Germany). The Austrian meteorological service reported new June records at more than half of its 269 stations.

The year continued with a warmer-than-usual autumn, especially for southeastern parts of the region. Hungary $\left(+2.4^{\circ} \mathrm{C}\right.$ anomaly), Slovakia $\left(+2.1^{\circ} \mathrm{C}\right)$, and Czechia $\left(+1.6^{\circ} \mathrm{C}\right)$ reported their warmest autumns; Austria $\left(+1.6^{\circ} \mathrm{C}\right)$ its fourth warmest; Switzerland $\left(+1.1^{\circ} \mathrm{C}\right)$ its sixth warmest; and Germany, with $1.0^{\circ} \mathrm{C}$ above normal, its 10 th warmest. December 2019 was also a mild month with anomalies ranging from about $+1^{\circ} \mathrm{C}$ in western Germany to $+3^{\circ} \mathrm{C}$ in eastern Poland.

\section{(II) PRECIPITATION}

Overall, the year was close to normal or drier. Some places in eastern Germany and Poland received less than $80 \%$ of normal precipitation.

The winter season was wetter than normal, except in Hungary, which received $73 \%$ of its normal. Germany and Slovakia reported about 110\% and Czechia 148\% (eighth wettest) of normal precipitation. While January was wetter than normal with widespread precipitation between $125 \%$ and $167 \%$ of normal, February was dry, especially in Germany, with most of the country receiving between $20 \%$ and $60 \%$ of normal precipitation, and in Hungary, which received $41 \%$ of its normal.

For Germany (98\%), Switzerland (102\%), and Czechia (103\%), spring precipitation was close to normal while for Slovakia (121\%) and Hungary (129\%), the season was wetter than normal. For Hungary, March was the 10th driest on record with only $28 \%$ of normal precipitation. During April, the precipitation deficit shifted to Germany, Czechia (60\% of normal and ninth-driest April), and northern parts of Poland where precipitation reached only $20 \%-40 \%$ of normal. At the end of May, there was still snow cover with depths of $270 \mathrm{~cm}$ in the Swiss Alps at about 2500 m elevation (Weissfluhjoch), a new seasonal record.

Summer was drier than normal for the whole region. Germany reported $73 \%$ of normal precipitation, Slovakia 84\%, Czechia 76\%, Hungary 91\%, and Switzerland 95\%. In particular, Austria reported its driest June since the beginning of measurements in 1767 with only $43 \%$ of normal precipitation, and parts of southern Poland received just $20 \%-40 \%$ of normal precipitation. In Czechia, precipitation was $67 \%$ of normal and the eighth-driest June on record. Germany and Switzerland received $72 \%$ and $88 \%$ of normal precipitation, respectively, during June, with southern Switzerland (south Ticino) receiving only 30\% of its normal.

Autumn precipitation was close to normal in Czechia (99\% of normal), Germany, and Hungary (both 104\% of normal), while for Slovakia (130\%), Switzerland (115\%), and Austria (129\%), it was a wetter-than-normal season. With a sinking snow line in the Alps in November, higher areas on the south-facing slopes of the Alps received substantial amounts of fresh snow. In certain parts, the fresh snow total set new November records, for example, $220 \mathrm{~cm}$ at Segl-Maria station in 
Switzerland (Engadin region, $1804 \mathrm{~m}$ a.s.1.), with measurements dating back to 1864. December was drier than normal in Germany, western Poland, and western Czechia (60\%-100\%), but wetter in the Alps and in eastern and southeastern parts of Central Europe, locally exceeding 125\% of normal.

\section{(III) NOTABLE EVENTS AND IMPACTS}

Between 7 and 14 January, the Alps and other mountainous regions in central Europe experienced extreme snowfall under the influence of northwesterly to northerly flow. Up to $100 \mathrm{~mm}$ of precipitation fell in 72 hours in Germany's Ore Mountains and the northern Alps. Correspondingly, the snow depth increased from 24 to $72 \mathrm{~cm}$ in Zinnwald-Georgenfeld (eastern Ore Mountains, 877 $\mathrm{m}$ a.s.l.) during 8-10 January and from 365 to $465 \mathrm{~cm}$ on Germany's highest mountain, Zugspitze (northern Alps, 2964 m a.s.l.), during 11-13 January. On 13 January, central Europe was within the warm air sector of a low-pressure system, which made the snow line temporarily rise to 1200 $\mathrm{m}$. Rainfall up to $109 \mathrm{~mm} \mathrm{day}^{-1}$ increased the weight of the snow cover dramatically and thus the danger of collapsing buildings or trees. New monthly records of 24-hour precipitation were registered in Saxony (eastern Germany) on 9 January, and new records of snow depth were registered in southern Germany on 11 January. Switzerland recorded up to $160 \mathrm{~cm}$ of fresh snow on northern slopes and wind gusts of up to $180 \mathrm{~km} \mathrm{~h}^{-1}$.

During a warm spell lasting from 21-27 February, exceptionally mild weather brought record high temperatures, with many areas in central Europe exceeding $20^{\circ} \mathrm{C}$. Many local monthly and winter records of maximum temperature were reached or broken, even at stations with time series spanning more than 100 years. For Austria and Hungary, countrywide high-temperature records for February were reported.

At the beginning of March, several storms affected western and central Europe. Storm gusts reached above $200 \mathrm{~km} \mathrm{~h}^{-1}$ in exposed places. Due to storm Bennet (Freya in United Kingdom and France), some carnival parades on 4 March had to be canceled in Germany and neighboring countries. Flight and ferry services were disrupted, trees and rooftops were damaged, and some roads and bridges needed to be closed.

Starting with June, an exceptional three-month drought/dry spell affected most of Germany. Soil moisture in large areas was below long-term minimum values, causing economic losses due to crop failure. On several major rivers, low water levels hindered navigation. This was the second major drought period in consecutive years, following an even longer event in 2018.

As a result of a cut-off low, western and central Europe were affected by unusually strong storm events in June. Exceptionally intense hailstorms with hailstones larger than $6.5 \mathrm{~cm}$ hit southern Germany on 10-11 June. At least six people were injured, and cars, trees, and houses were damaged in Bavaria. Accompanying heavy precipitation led to flooding of homes. In Berlin and surrounding areas, thunderstorms brought daily rain totals of 60-70 $\mathrm{mm}$ on 11 and 12 June, causing road closures. Similarly, northern Poland reported heavy winds and precipitation causing flooding, uprooted trees, and power outages for thousands of households on 10 June. Record large hailstones of $12 \mathrm{~cm}$ were reported in western Poland.

Thunderstorms caused wind damage and flash floods in Hungary during 16-23 June. Daily precipitation totals above $100 \mathrm{~mm}$ were measured at several stations in northeastern Hungary during this period. On 16 June, $144.4 \mathrm{~mm}$ of precipitation was recorded at Rakamaz, nearly twice its normal for the month of June $(73.5 \mathrm{~mm})$. On 20 June, a new daily record of $117.8 \mathrm{~mm}$ of rain was set at Szőlősardó, beating its previous record high for this date of $101.3 \mathrm{~mm}$ set in 1956. 
Summer 2019 was warmer than normal by $+2.0^{\circ} \mathrm{C}$ to $+4.0^{\circ} \mathrm{C}$ for western and central Europe. This was especially the case during the record warm June and July, when two outstanding heat waves occurred.

June 2019 was the warmest June on record, globally as well as for Europe. Similar to previous heat episodes, the extreme temperatures were a result of blocking omega patterns caused by a long-lasting, high-pressure system over Europe, especially during the last week of June. This pattern produced an inflow of warm subtropical air leading to anomalies up to $+10^{\circ} \mathrm{C}$ in France and numerous temperature records for many countries as well as many hours of sunshine.

On 26 June, new German monthly records of $38.6^{\circ} \mathrm{C}$ were set at Coschen and Bad Muskau near the Polish border, surpassing the previous record of $38.5^{\circ} \mathrm{C}$ set in 1947. Just three days later, this record was broken again with $39.6^{\circ} \mathrm{C}$ at Bernburg/Saale in eastern Germany. Apart from the new national

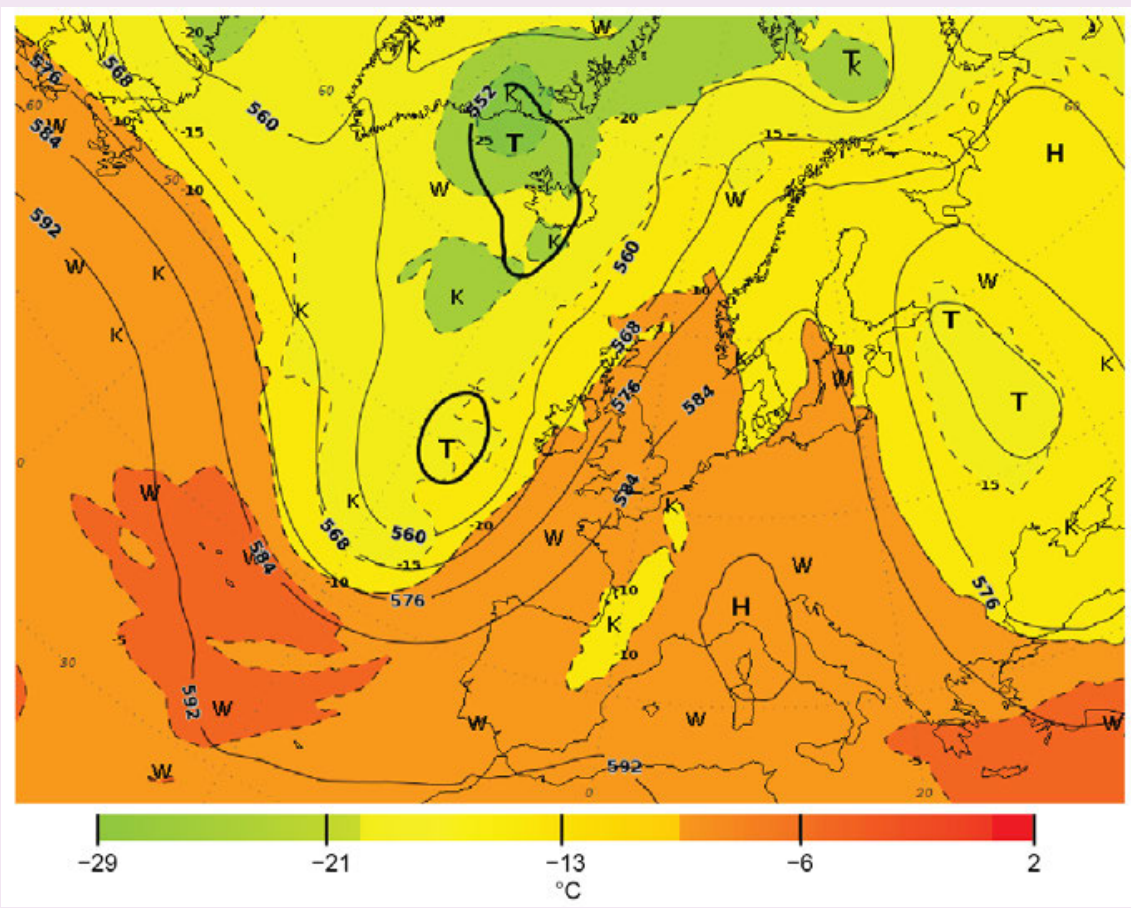

Fig. SB7.7. $500 \mathrm{hPa}$ geopotential (contours) and temperature (color shading) on 25 Jul 2019, 00 UTC. (Source: DWD.) record, new station records were set at 209 of 458 (45\%) DWD (Deutscher Wetterdienst, German Meteorological Service) stations on 26 June. In southern France, 13 stations surpassed France's 2003 records, exceeding a temperature of $44.1^{\circ} \mathrm{C}$, and at Gallargues-le-Montueux (Gard) a new national record of $45.9^{\circ} \mathrm{C}$ was measured. Switzerland, Austria, Italy, Slovenia, and Croatia also reported new June station records, some of which were also all-time records for the stations. Also noteworthy are new temperature records at higher elevations. including new records of $29.8^{\circ} \mathrm{C}$ set on 26 June at Davos, Switzerland (previous record $29.3^{\circ} \mathrm{C}$ in $2015 ; 1637 \mathrm{~m}$ a.s.l.) and $25.0^{\circ} \mathrm{C}$ set on 27 June at Schmittenhohe, Austria (previous record $24.6^{\circ} \mathrm{C}$ in $1952 ; 1973 \mathrm{~m}$ a.s.I.).

In addition to maximum temperature records, new highest minimum and daily mean temperature records also were broken. On 27 June, a new national record with a daily mean temperature of $27.9^{\circ} \mathrm{C}$ was set in France. In Vienna, Austria, a new record of 13 tropical nights (minimum temperature $\geq 20.0^{\circ} \mathrm{C}$ ) was observed during June.

Just a few weeks later, from 24 to 26 July, another omega weather pattern (Fig. SB7.7) and associated heat wave, albeit short, brought additional new records. In western Germany, the temperature at many stations exceeded $40^{\circ} \mathrm{C}$ on

three consecutive days for the first time since measurements began in 1881. On 24 July, a new German national record of $40.5^{\circ} \mathrm{C}$ was set at Geilenkirchen, surpassing the old record measured in July and August 2015 by $0.2^{\circ} \mathrm{C}$. Just one day later, on 25 July, 14 stations beat the old record, with Lingen taking the new German record with a temperature of $42.6^{\circ} \mathrm{C}$. New national all-time record temperatures were also set at Gilze-Rijen (Netherlands) with $40.7^{\circ} \mathrm{C}$, Begijnendijk (Belgium) with $41.8^{\circ} \mathrm{C}$, Steinsel (Luxembourg) with $40.8^{\circ} \mathrm{C}$, and Cambridge Botanic Garden (England) with $38.7^{\circ} \mathrm{C}$. Temperatures above $40.0^{\circ} \mathrm{C}$ had never before been observed in Belgium and the Netherlands. The heat wave extended all the way to Scandinavia, with maximum temperatures locally surpassing $33.0^{\circ} \mathrm{C}$ in southern Finland and $34.0^{\circ} \mathrm{C}$ in Norway. Many other European stations reported temperatures approaching or exceeding $40^{\circ} \mathrm{C}$, with many new local records often beating the old ones by $2^{\circ} \mathrm{C}$ to $3^{\circ} \mathrm{C}$. This large exceedance of previous records made this heat wave extraordinary.

Train services were disrupted in Germany, Switzerland, and Austria due to buckling of tracks. Locally, train tracks were painted white in an attempt to prevent further buckling (and thus closures). Power plants in France and Germany had to be 
shut down when river waters became too warm for use in cooling. In northern Spain and France, where the heat wave was accompanied by dry conditions, wildfires broke out.

\section{Daily temperature records highlight European warming}

The record high temperatures over extensive areas in Europe are consistent with the warming climate. According to an analysis conducted by the World Weather Attribution Project (Vautard et al. 2019) regarding the effects of climate change on the occurrence of such extreme events, the estimated return period of such an event for France and the Netherlands is about 50 to 150 years in the current climate. The analysis concluded that, without climate change, the return period would be at least 10, and perhaps up to 100 , times longer, or more than 1000 years. For the United Kingdom and Germany, the estimate for the return period in the current (changed) climate is around 10 to 30 years, and roughly 10 times (at least three times) longer without climate change. Climate change is simulated either by fitting a Generalized

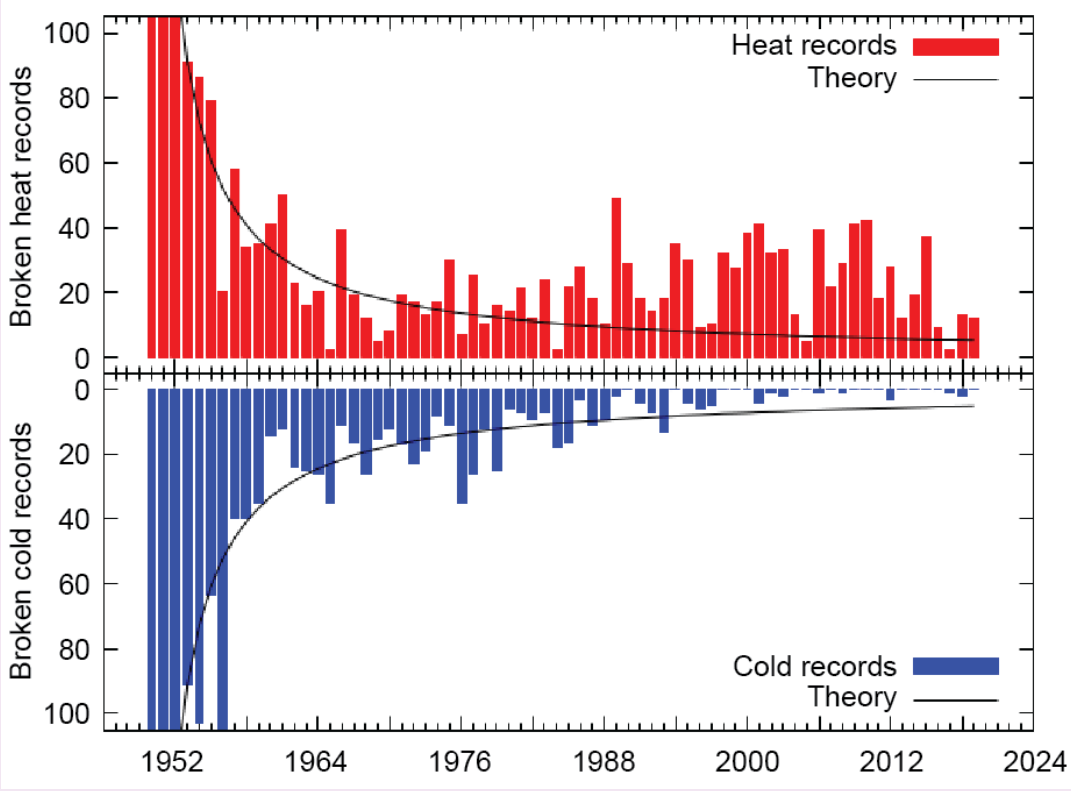

Fig. SB7.8. Number of daily heat and cold records per year for the European averaged temperature since 1950 . The black lines indicate the expected numbers in the absence of climate change. Data are based on the E-OBS daily gridded dataset; underlying station data are daily maximum temperatures from ECA\&D (www.ecad.eu/). (Source: KNMI/ E-OBS, van der Schrier et al. 2013.) The number of underlying stations varies with time but is around 4000 since 1960 and lower prior to that.

Extreme Value distribution of a local time series with a smoothed western European summer temperature (to derive a long-term trend that is assumed to describe the longterm climate change) or by comparing model simulations of a present-day climate with simulations of the past (preindustrial) climate or an "artificial" climate without anthropogenic forcing (see Vautard et al. 2019 for more details).

Another approach to evaluate the effect of climate change is to analyze whether the number of new records in a specific year is particularly high or low, compared with the theoretical value in the absence of climate change. The theoretical construction (Benestad 2004) is the following: in the first year of a time series, all days break a record (because there are no previous values), so the number of records is 365 . In the second year, the theoretical number of records is $365 / 2$ (one-half occurring in the first year, the other half in the second year, assuming records have an equal distribution over the years without climate change). In the third year, one in three days sets a record: the theoretical number is 365/3, etc. For a series starting in 1950, the theoretical number of records in year $Y$, in the absence of climate change, is $365 /(Y-1949)$. Figure SB7.8 provides this theoretical number and the observed number of heat and cold records since 1950 . In the last 30 years, the number of daily high

temperature records is much larger than the theoretical value (more than twice, partly multiples), and the number of daily low temperature records is much smaller. This clearly highlights the warming of Europe in recent decades and its effect on the frequency of broken daily heat records.

Benestad (2004) analyzed the statistical significance of the number of record values in long time series and found that the mean number of records from 17 climate stations spread around the globe was significantly higher than the expected theoretical value by the end of the twentieth century, which is in line with Fig. SB7.8. Since then, in the twenty-first century, the number of European daily records per year has remained relatively steady, although the theoretical value decreases with time, suggesting it is significant that the values remain steady. This does not exclude the fact that there are a couple of years since 2000 with fewer records compared to the theoretical expectation. Notably, this is a regional time series; warming with new heat records has occurred elsewhere around the globe. Additionally, the long-term warming is superposed by shorter-scale climate variability due to circulation changes (e.g., El Niño-Southern Oscillation). 


\section{A record sunny year}

Overall, the year was also very sunny in Europe. The sunshine duration in 2019 was longer than the European 1983-2017 average of 2293 hours across almost all of Europe (Fig. SB7.9). The widespread positive anomalies of +150 hours to +250 hours caused the average annual sunshine duration over Europe to reach a new record with 2348 hours in 2019 (Fig. SB7.10). The increased duration of sunshine and hence direct solar radiation, with the enhanced advection of warm subtropical air and increased subsidence associated with persistent high-pressure conditions during the heat waves, contributed further to the warm year 2019.

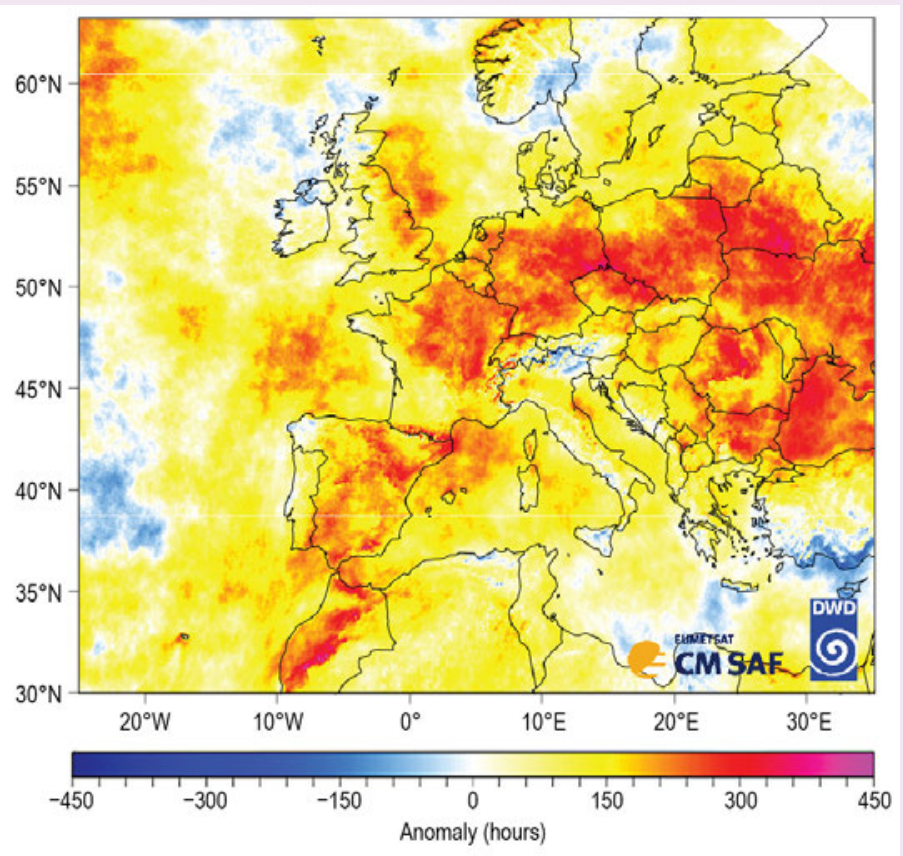

Fig. SB7.9. 2019 anomaly map of sunshine duration (hours) over Europe relative to 1983-2017, derived from EUMETSAT Meteosat satellite observations. (Data source: CM SAF SARAH-2.1 and ICDR, Kothe et al. 2017, Pfeifroth et al. 2019.)
A recent analysis by Imbery at al. (2020) shows an increase of anticyclonic weather types over central Europe since 1980, especially in April. This implies that long-term circulation changes may have contributed to the positive trend of sunshine duration in recent years and decades. However, longer time series of surface solar radiation (e.g., since 1937 in Potsdam, Germany) show a decrease in surface solar radiation (dimming) from 1950 to 1980 and an increase (brightening) since then (Wild 2016). These results suggest that there are multidecadal variations in surface solar radiation, likely caused by aerosols. Related climate model studies are still in progress.

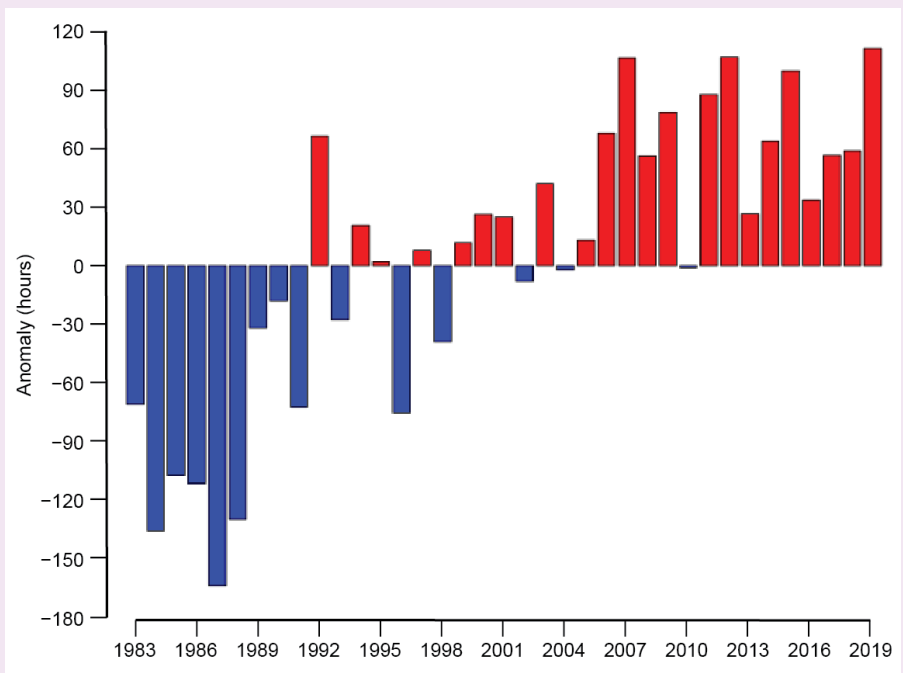

Fig. SB7.10. Annual average anomalies of sunshine duration (hours) over Europe for 1983-2019. The highest value 2019 corresponds to an absolute sunshine duration of 2348 hours. The astronomically maximum possible annual sunshine duration averaged over Europe, defined as the period when the sun is located completely above the horizon (topography neglected), is $\mathbf{4 4 2 6}$ hours. (Same domain and data source as Fig. SB7.9.) 


\section{4) The Nordic and Baltic countries}

This section includes Iceland, Norway, Denmark, Sweden, Finland, Estonia, Latvia, and Lithuania.

\section{(I) TEMPERATURE}

The year was slightly warmer than normal with anomalies around $+0.7^{\circ} \mathrm{C}$ in Norway, Sweden, and Finland. However, in the Baltic States, it was among the five warmest years with temperatures more than $+1.0^{\circ} \mathrm{C}$ above average.

Winter had well-above-normal temperatures. Denmark reported its seventh-warmest winter on record with an anomaly of $+2.9^{\circ} \mathrm{C}$. January, however, was colder than normal in most of the region, especially in northern Finland where temperatures were $-3.0^{\circ}$ to $-4.0^{\circ} \mathrm{C}$ below normal. February, in contrast, was very mild with anomalies of $+4.0^{\circ} \mathrm{C}$ to $+5.0^{\circ} \mathrm{C}$ in the Baltic States and Finland, resulting in many new monthly records of maximum temperature. On 26 February, $15.8^{\circ} \mathrm{C}$ was measured at Tirstrup in Djursland (eastern Denmark mainland), tying the previous record at Copenhagen on 24 February 1990. On the same day, a new Swedish record was measured at Karlshamn with $16.7^{\circ} \mathrm{C}$. In Latvia, at Kolka, a new record of $13.4^{\circ} \mathrm{C}$ was set on 16 February for the highest winter maximum temperature. Estonia reported its seventh-warmest February on record with an anomaly of $+4.3^{\circ} \mathrm{C}$, Latvia its eighth warmest $\left(+4.5^{\circ} \mathrm{C}\right.$ above normal), and Lithuania its sixth warmest $\left(+3.9^{\circ} \mathrm{C}\right.$ above normal).

Spring temperatures were above normal by more than $+1.0^{\circ} \mathrm{C}$ in the whole region (Finland $+1.2^{\circ} \mathrm{C}$, Norway $+0.8^{\circ} \mathrm{C}$, Denmark $+1.5^{\circ} \mathrm{C}$, and Latvia $+1.5^{\circ} \mathrm{C}$ above normal). April was especially warm, with Finland and Norway each reporting its second-warmest April on record $\left(+2.5^{\circ} \mathrm{C}\right.$ and $+2.4^{\circ} \mathrm{C}$ above normal, respectively) and Latvia its third warmest $\left(+2.1^{\circ} \mathrm{C}\right.$ above normal). May was the only spring month colder than normal in the whole region except for Lithuania and Latvia, where May was slightly warmer than usual.

Summer temperatures were more than $+1.0^{\circ} \mathrm{C}$ above normal in most of the northern countries: Estonia $+1.6^{\circ} \mathrm{C}$ (tied with 2015 for warmest of the $1961-2019$ period), Denmark $+1.6^{\circ} \mathrm{C}$ and Latvia $+1.0^{\circ} \mathrm{C}$; only Norway and Finland had lesser anomalies of $+0.8^{\circ} \mathrm{C}$ and $+0.3^{\circ} \mathrm{C}$, respectively. Some new records were set, including a new Norwegian national record high minimum temperature of $26.1^{\circ} \mathrm{C}$ observed at station Sømna - Kvaløyfjellet (Nordland, central Norway) on 28 July. At the northeastern Swedish station Markusvinsa, a new record maximum temperature of $34.8^{\circ} \mathrm{C}$ was measured on 26 July. This was the highest temperature ever reported north of the Arctic Circle in Sweden. On 13 June, a new seasonal record with a temperature of $33.0^{\circ} \mathrm{C}$ was set in Riga, Latvia. Many other stations broke their monthly maximum temperature record during June. In contrast to the warm June, July was colder than normal in the Baltic countries and Finland with anomalies slightly below $-1.0^{\circ} \mathrm{C}$ (Finland $-1.1^{\circ} \mathrm{C}$, Latvia $-1.2^{\circ} \mathrm{C}$, Lithuania $-1.2^{\circ} \mathrm{C}$, Estonia $-1.0^{\circ} \mathrm{C}$ ).

Autumn was colder than normal in Norway $\left(-1.0^{\circ} \mathrm{C}\right.$ below normal), Sweden, and Finland $\left(-0.2^{\circ} \mathrm{C}\right.$ below normal), while the Baltic states and Denmark reported above-normal temperatures (Latvia $+1.6^{\circ} \mathrm{C}$ anomaly, eighth warmest together with 1949 ; Lithuania $+1.9^{\circ} \mathrm{C}$; Estonia $+1.1^{\circ} \mathrm{C}$; Denmark $+0.7^{\circ} \mathrm{C}$ ). On 14 November, daily maximum temperature records were broken at many stations in Estonia; for example, at coastal station Kunda the temperature rose to $12.5^{\circ} \mathrm{C}$ (the previous record was recorded on 14 November 1938). December 2019 was generally mild, with anomalies ranging from below $+1^{\circ} \mathrm{C}$ in Iceland to above $+5^{\circ} \mathrm{C}$ in easternmost parts of the region.

\section{(II) PRECIPITATION}

Overall, 2019 had close-to-normal precipitation in most of the Nordic countries, while some places in southeastern Norway recorded more than $120 \%$ of normal precipitation (fifth wettest on record in these areas). Southeastern Norway is normally less exposed to westerlies, but in 2019 it was temporarily affected by a southerly flow of moist air, particularly notable in autumn. Iceland was remarkably dry with some locations observing around $40 \%$ of normal precipitation. 
Consequently, snow occurred slightly less frequently in the country (e.g., three days fewer than the 1971-2000 average in Reykjavik and five days fewer in Akureyri). The Baltic states also reported below-normal precipitation, particularly Estonia with 60\%-80\% of normal.

Winter was wetter than normal in Denmark with 105\% and Norway with $120 \%$ of normal precipitation. Precipitation in Norway, however, was distributed inhomogeneously. While some stations in the east received $200 \%-300 \%$ of normal, several stations in the west received only about $50 \%$ of normal. Finland was close to normal with countrywide precipitation of $102 \%$ of normal. Estonia and Latvia were drier than normal with about $60 \%-80 \%$ of normal precipitation; western Iceland was even drier. Southern Lithuania recorded locally above $125 \%$ due do some low-pressure systems coming from central Europe. In late January, snow cover with depths up to $33 \mathrm{~cm}$ developed in eastern Lithuania and locally in western areas. A thin snow cover was observed in March.

Spring again was wetter than normal for the Nordic countries except Iceland (Norway 120\%, Denmark 130\%, Finland 118\% of normal), while the Baltic States reported below-normal precipitation (Latvia $82 \%$, Lithuania $75 \%$ of normal). April was extremely dry in the whole region. Latvia reported only $9 \%$ of normal precipitation, its driest April on record. Finland received $42.8 \%$ of normal, ranking fourth driest, and Denmark reported only $36 \%$ of normal precipitation.

The summer season was drier than normal for all countries of the region except for Denmark (115\% of normal) and Norway (105\% of normal). Finland received only 67\%, Latvia and Lithuania $83 \%$, and Estonia $78 \%$ of normal precipitation. June was very dry in Estonia. Countrywide, only $30 \%$ or less of the monthly normal precipitation was received. The monthly total for Kihnu (island southwest of Estonia), was only $0.3 \mathrm{~mm}$, which is $1 \%$ of the month's normal and a record low in a series starting in 1932. July was drier than normal in Finland (48\% of normal, its fifth driest on record), Sweden (52\% of normal), most of Norway (70\% of normal), and Estonia ( $78 \%$ of normal).

Autumn was rather wet in southern Finland and Sweden, southeastern Norway, and Denmark. Denmark reported its wettest autumn on record with 153\% of normal precipitation. While some stations in eastern Norway received $150 \%-200 \%$ of normal, several in the western parts reported less than 50\% of normal. Sweden received 141\%, Finland 124\%, Estonia 123\%, Latvia 118\%, and Lithuania 98\%. The first snow fell earlier than usual in Lithuania in early October.

December 2019 was again a wet month for much of the Nordic countries (locally above $250 \%$ of normal in northern Finland), but closer to normal or drier in the Baltic countries with a scarcity of snow. Iceland was mainly snow-covered in December, with the greatest depth of $130 \mathrm{~cm}$ reported in the north of the country on 23-25 December.

\section{(III) NOTABLE EVENTS AND IMPACTS}

Between 1 and 2 January, an extratropical cyclone led to storms and extensive damage to forests north of Stockholm. Up to one million cubic meters of wood were felled by the storm. In Finland, a record 10-min average wind speed of $32.5 \mathrm{~m} \mathrm{~s}^{-1}$ was measured in the Gulf of Bothnia, and wave heights up to $8.1 \mathrm{~m}$ at the Sea of Bothnia buoy were close to previous records (just $0.1 \mathrm{~m}$ short of the record for any Finnish buoy; the northern Baltic Sea buoy records date to 1996). The storm caused an estimated damage of 10-20 million Euros (\$11-22 million U.S. dollars).

In June, Lithuania saw back-to-back temperature and rainfall extremes. A three-day heat wave starting on 11 June brought an absolute maximum temperature record of $35.7^{\circ} \mathrm{C}$ in the city of Kaisiadorys (southern Lithuania). Days later, on 22 June, an extreme rain event brought 94.4 $\mathrm{mm}$ of precipitation in only 1.5 hours in Ustukiai (northern Lithuania). Many local crops were damaged as a result.

Western Norway experienced intense storms in mid-September, with uprooted trees, downed power lines, floods, landslides, and several road closures. Ships had to stay in harbor in Ålesund, stranding 3400 passengers. 


\section{5) Iberian Peninsula}

This region includes Spain and Portugal mainland. The base period for Spain is 1981-2010, while the base period for Portugal is 1971-2000.

\section{(I) TEMPERATURE}

The yearly mean temperature on the Iberian Peninsula was mostly between $0.0^{\circ} \mathrm{C}$ and $+1.0^{\circ} \mathrm{C}$ above normal. Spain reported a countrywide anomaly of $+0.8^{\circ} \mathrm{C}$, its sixth-warmest year since records began in 1965. Anomalies in some parts of Spain exceeded $+1.0^{\circ} \mathrm{C}$. The annual mean anomaly for the Portuguese mainland was $+0.3^{\circ} \mathrm{C}$. Overall, winter was warmer than normal. Spain reported an anomaly of $+0.8^{\circ} \mathrm{C}$ and Portugal $+0.4^{\circ} \mathrm{C}$. After the year started with colderthan-normal temperatures in January $\left(-0.1^{\circ} \mathrm{C}\right.$ anomaly), a very warm February followed, ending the season with temperatures $+1.2^{\circ} \mathrm{C}$ above normal in Spain. In northern Portugal, about $30 \%$ of the stations registered new maximum temperature records for February.

Spring started with a warmer-than-usual March, with anomalies of around $+0.7^{\circ} \mathrm{C}$. While April was close to normal, May proved to be warm again, especially in southern Spain and Portugal, the latter reporting its seventh-warmest May since 1931. Overall spring anomalies were $+0.5^{\circ} \mathrm{C}$ for Spain and $+1.0^{\circ} \mathrm{C}$ for Portugal.

The summer was warmer than normal by $+0.8^{\circ} \mathrm{C}$ for Spain, contrary to Portugal where temperatures were below normal by $-0.3^{\circ} \mathrm{C}$. During a heat wave from 26 June to 1 July, the highest measured temperatures in Spain reached well above $40.0^{\circ} \mathrm{C}$, including $43.4^{\circ} \mathrm{C}$ in Lleida and $43.2^{\circ} \mathrm{C}$ at Zaragoza Airport, each on 29 June, and $43^{\circ} \mathrm{C}$ at Girona Airport on 28 June (all located in northeastern Spain). Seven primary stations in Spain recorded new seasonal daily maximum temperature records during this heat wave.

With an anomaly of $+0.7^{\circ} \mathrm{C}$, Spain had a warm autumn. Only November (anomaly $+0.1^{\circ} \mathrm{C}$ ) had close-to-normal temperatures, while September and October were warmer than usual with anomalies of $+0.7^{\circ} \mathrm{C}$ and $+1.3^{\circ} \mathrm{C}$. December, too, was a mild month with anomalies above $+2^{\circ} \mathrm{C}$ in central parts of Spain.

\section{(II) PRECIPITATION}

Overall, Spain and Portugal reported a close-to-normal year with countrywide precipitation at 97\% of normal in Spain and 86\% in Portugal (1971-2000 base period for Portugal); however, there were spatial and temporal differences. Although precipitation was above $125 \%$ of normal locally in parts of southeastern Spain, most of Iberia had below-normal precipitation, dropping below $60 \%$ of normal in the southwest. Episodes of intense and persistent precipitation occurred often during the year, sometimes causing flooding. Multiple stations reported new local records of daily maximum precipitation.

It was the fifth-driest winter in Spain with $49 \%$ of normal rainfall. Portugal had $42 \%$ of normal precipitation, its fourth-driest winter since 2000. Only in January did northern parts of Spain receive above-normal precipitation. In February, precipitation across the entire Iberian Peninsula was widely $20 \%-60 \%$ of normal. With a countrywide average of $28 \%$ of normal precipitation, Spain recorded its fourth-driest February since 1965 and driest of the twenty-first century.

Spring started with a very dry March when precipitation ranged from $20 \%$ to $80 \%$ of normal in most parts of the Iberian Peninsula. After a very wet April with $148 \%$ of normal precipitation, the fourth wettest for Spain, the season ended with an extremely dry May. Nearly the whole Iberian Peninsula received 20\%-60\% of normal precipitation, with large parts of Spain below even that, making it the fourth- and sixth-driest May on record for Spain and Portugal, respectively.

The summer started with a dry June, ranking seventh driest for Spain (58\% of normal) and Portugal reporting that $98 \%$ of its territory was under meteorological drought, with $30 \%$ categorized in severe or extreme drought. While July brought above-normal precipitation of $120 \%$ to Spain, the drought situation in Portugal worsened with precipitation of only $20 \%-80 \%$ of normal in the south 
and locally even less. In August, precipitation was distributed heterogeneously in Iberia. Local precipitation totals were more than $250 \%$ of normal due to heavy rain. The drought was slightly relieved in northern and central Portugal by above-normal precipitation while the south stayed dry. Overall, Portugal ended the season with $77 \%$ of normal precipitation and Spain with $86 \%$.

In autumn, Spain reported a countrywide average of $115 \%$ of normal precipitation. Double the normal precipitation was registered in some areas in Spain, such as between Granada and Murcia, while southwestern parts of Iberia were drier than normal with around $60 \%$ of normal precipitation. December was mainly wetter than normal, with $150 \%$ of the long-term average falling in places. Southern Spain recorded monthly totals below $80 \%$ of normal.

\section{(III) NOTABLE EVENTS AND IMPACTS}

In mid-May, a heat wave occurred across southern and western parts of the Iberian Peninsula. Alcácer do Sal, Barrosinha in southern Portugal reached $38.1^{\circ} \mathrm{C}$ on 13 May. Daily maxima at many stations in Portugal and western and southern Spain exceeded $30^{\circ} \mathrm{C}$, more than $10^{\circ} \mathrm{C}$ higher than average daily maxima in places in Portugal.

Torrential rainfall and strong winds in southeastern Spain were observed during 10-15 September due to an almost stationary cut-off low. The most affected areas included Valencia, Alicante, Murcia, Albacete, Almería, and Malaga provinces. Some areas in Alicante and Murcia received more than $400 \mathrm{~mm}$ of rain over 48 hours. The highest total was $521 \mathrm{~mm}$, measured in Orihuela (Alicante province). Six stations reported new 24-hour precipitation records. At Ontinyent, 296.4 $\mathrm{mm}$ of rain was recorded in 24 hours, about half its average annual total. This was the station's second-highest daily rainfall total on record, behind the $316.0 \mathrm{~mm}$ which fell on 4 November 1987. On average for the affected area, the equivalent of a year's rain accumulated in just one 24-hour period-from the morning of 12 September to the morning of the 13th. The storm was exceptional; there are no similar precedents in at least the last 100 years in the Vega Baja del Segura (Murcia province). Consequently, rivers broke their banks in several locations, flash floods damaged several roads, and cars were swept away. Flights, railway, and ship traffic were disrupted, and at least six people died and around 3500 were displaced, including 2000 residents of the town of Santomera (near Murcia).

\section{6) Central Mediterranean region and Turkey}

This region includes Italy (anomalies relative to 1961-90), Malta, Slovenia, Croatia, Serbia, Montenegro, Bosnia and Herzegovina, Albania, North Macedonia, Greece, Bulgaria, and Turkey.

\section{(I) TEMPERATURE}

The year was warmer than normal for the Mediterranean and the Balkan states. Serbia reported its warmest year on record, and Slovenia its second warmest since 1961, both with temperatures $+1.7^{\circ} \mathrm{C}$ above normal. Italy observed its third-warmest year $\left(+1.6^{\circ} \mathrm{C}\right)$, Turkey its fourth warmest $\left(+1.2^{\circ} \mathrm{C}\right)$, and Greece its seventh warmest $\left(+0.9^{\circ} \mathrm{C}\right)$.

Except for Greece (anomaly $-0.2^{\circ} \mathrm{C}$ ), winter was warmer than normal for the region, from $+0.6^{\circ} \mathrm{C}$ above normal for Italy and Serbia to $+1.3^{\circ} \mathrm{C}$ above normal for Slovenia and Turkey. January was colder than normal for some western parts of the region. Serbia and Greece reported January anomalies of $-0.9^{\circ} \mathrm{C}$ and Italy $-0.7^{\circ} \mathrm{C}$. The season ended with a warmer-than-normal February, except for Sicily and Malta, the latter reporting its second-coldest February on record. Slovenia reported $+3.1^{\circ} \mathrm{C}$, Serbia $+2.1^{\circ} \mathrm{C}$, Italy $+1.4^{\circ} \mathrm{C}$, and Greece $+0.7^{\circ} \mathrm{C}$ above normal.

Spring was warmer than normal for almost the entire region. Anomalies mainly ranged from $+0.2^{\circ} \mathrm{C}$ to $+0.7^{\circ} \mathrm{C}$ above normal. The end of the season, due to northwesterly flow and below-average solar radiation, was unusually cold in Italy and the Balkans. Slovenia reported one of its coldest Mays on record (anomaly $-2.8^{\circ} \mathrm{C}$ ), Italy its sixth coldest (anomaly $-1.5^{\circ} \mathrm{C}$ ), Serbia its eighth coldest (anomaly $-2.1^{\circ} \mathrm{C}$ ), and Malta and Greece reported anomalies of $-1.5^{\circ} \mathrm{C}$ and $-0.5^{\circ} \mathrm{C}$ respectively. 
During the summer season, especially the Balkan states experienced widespread temperatures of more than $+2.0^{\circ} \mathrm{C}$ above normal. Slovenia and Italy reported their second-warmest summer on record with anomalies of $+2.5^{\circ} \mathrm{C}$ and $+2.9^{\circ} \mathrm{C}$, respectively, Greece its fourth warmest $\left(+1.3^{\circ} \mathrm{C}\right.$ above normal), and Serbia its fifth warmest $\left(+1.8^{\circ} \mathrm{C}\right)$. June and August featured very high temperatures. It was the hottest June on record for Malta $\left(+2.5^{\circ} \mathrm{C}\right)$, the second warmest for Slovenia $\left(+4.2^{\circ} \mathrm{C}\right)$ and Italy $\left(+3.9^{\circ} \mathrm{C}\right)$, and the fourth warmest for Greece $\left(+1.5^{\circ} \mathrm{C}\right)$. August was the fourth $\left(+1.7^{\circ} \mathrm{C}\right)$ and fifth $\left(+2.7^{\circ} \mathrm{C}\right)$ warmest on record, respectively, for Greece and Italy.

For the Balkan states, an extremely warm autumn followed. For Croatia $\left(+2.1^{\circ} \mathrm{C}\right)$, Serbia $\left(+2.9^{\circ} \mathrm{C}\right)$, and Greece $\left(+1.9^{\circ} \mathrm{C}\right)$, it was their warmest autumn on record, and Slovenia's second warmest with $+1.9^{\circ} \mathrm{C}$ above normal. Turkey and Italy reported their third-warmest autumn, at $+1.9^{\circ} \mathrm{C}$ above normal. December was also very mild with anomalies mostly between $+1^{\circ} \mathrm{C}$ and $+3^{\circ} \mathrm{C}$, highest in northeastern Balkans and eastern Turkey.

\section{(II) PRECIPITATION}

Annual precipitation was mostly near-normal in the region, but locally well above average due to some heavy precipitation events, resulting in mostly above-normal country averages. Italy reported $113 \%$ of its normal precipitation and Slovenia 109\%. In Serbia, precipitation was around normal.

Winter was drier than normal in Italy (63\% of normal), Slovenia (68\%), and Croatia (77\%), while it was wetter for Serbia (120\%) and Turkey (146\%). It was the fifth-wettest winter on record (155\%) for Greece. January was particularly wet across almost all the region; Greece reported its wettest January on record with $244 \%$ of normal precipitation. In Serbia, snow depths up to $39 \mathrm{~cm}$ were observed in the lowlands in mid-January.

Most of the region experienced a wetter-than-normal spring, with Turkey close to normal and Greece reporting slightly-below-normal precipitation of 93\%. May was very wet in most of the region with the exception of Greece and Turkey. Croatia and Slovenia reported 195\% of normal precipitation, Slovenia's wettest May on record. For Serbia, May was the sixth wettest since records began in 1951 (192\% of normal), while Italy reported 185\% of normal precipitation.

In summer, it was wetter than normal around the Aegean Sea and in Turkey, while Italy and the Balkans had near- or less-than-normal precipitation. Serbia was slightly wetter with $102 \%$ of normal. Turkey and Greece reported $136 \%$ and $131 \%$ of normal precipitation, respectively. For Italy, Slovenia, and Croatia, precipitation was between $77 \%$ and $84 \%$ of normal. June was notably dry for these countries with only $34 \%$ of normal in Italy, 50\% of normal in Slovenia, $67 \%$ of normal in Croatia, and Malta reporting no June precipitation for only the fourth time in the last 70 years.

For Serbia, it was the sixth-driest autumn on record with $55 \%$ of normal precipitation. Turkey also reported well-below-normal precipitation for autumn (63\% of normal). All other countries of the region received above-normal precipitation, except for Malta, which was near normal. For Italy and the Balkan states only, November brought a surplus of precipitation, while for Turkey, only September was wetter than normal in the southwestern and northeastern parts. December had a very heterogeneous distribution of precipitation. It was particularly dry in Sicily, North Macedonia, and Bulgaria (40\%-80\% of normal in parts), but very wet in southern Turkey, with above $250 \%$ of normal in places.

\section{(III) NOTABLE EVENTS AND IMPACTS}

Due to heavy snowfall during 3-5 January, many towns and villages were isolated from traffic connections in the central mainland of Greece. Electricity outages occurred mainly in the Thessaly region and Thessaloniki.

In Italy, during an unusual 32-day heat wave from 8 June to 9 July, maximum temperatures exceeded $30^{\circ} \mathrm{C}$ across wide areas and $40^{\circ} \mathrm{C}$ in places. At some locations, new records were set for the highest June minimum temperature (e.g., $27.5^{\circ} \mathrm{C}$ on 27 June in Milan). In Florence, the 
maximum temperature exceeded the 90th percentile on 12 consecutive days, the second-longest heat wave since 1955.

Throughout May, the Emilia Romagna region in Italy experienced an exceptional wet spell. Due to heavy precipitation, severe thunderstorms, hail, and snowfalls, total monthly precipitation (average over Emilia Romagna) reached $228 \mathrm{~mm}$, 40\% higher than the previous record (164 mm in 1984) and three times higher than the 1961-90 climatological average of $73 \mathrm{~mm}$. Consequently, flooding and landslides occurred, and 100 people were displaced.

On 23 September, two days after the strongest earthquakes to strike Albania in 30 years, severe thunderstorms and heavy rain caused flash flooding in some earthquake-affected areas. According to initial assessments, 1550 houses, two health centers, five bridges, and four power facilities were damaged in the floods. The European Civil Protection Mechanism was activated on 24 September following a request for assistance from the Albanian government.

\section{7) Eastern Europe}

This region includes European Russia, Belarus, Ukraine, Moldova, Romania, and West Kazakhstan.

\section{(I) TEMPERATURE}

Eastern Europe had an overall warm year. Romania $\left(+1.7^{\circ} \mathrm{C}\right.$ anomaly), the Ukraine $\left(+1.9^{\circ} \mathrm{C}\right)$, Moldova $\left(+2.1^{\circ} \mathrm{C}\right)$, and Belarus $\left(+2.0^{\circ} \mathrm{C}\right)$ each reported their warmest year on record.

January featured an NAO index value of -0.4 that contributed to below-normal temperatures across most of eastern Europe, with anomalies of $-1.0^{\circ} \mathrm{C}$ in Belarus, $-0.7^{\circ} \mathrm{C}$ in Moldova, and $-0.5^{\circ} \mathrm{C}$ in Ukraine. February (NAO of +1.9 ) was extremely mild, with anomalies ranging from $+3.2^{\circ} \mathrm{C}$ above normal to more than $+4.0^{\circ} \mathrm{C}$ in European Russia $\left(+4.1^{\circ} \mathrm{C}\right)$ and Ukraine $\left(+4.4^{\circ} \mathrm{C}\right)$. A negative NAO phase is often related to a meridional circulation pattern over Europe, causing the advection of cold continental air to eastern Europe, while a positive NAO is generally related to a more intense westerly flow from the North Atlantic Ocean bringing mild air to Europe in winter. Thus, January and February 2019 were very contrasting months in atmospheric circulation, which contributed to correspondingly different temperature anomalies.

Well-above-normal temperatures continued in spring. European Russia and Ukraine reported their eighth- and seventh-warmest spring, respectively, each with an anomaly of $+2.3^{\circ} \mathrm{C}$. Belarus and Moldova reported their fourth- and fifth-warmest spring (anomalies of $+1.7^{\circ} \mathrm{C}$ and $+1.4^{\circ} \mathrm{C}$, respectively). March (NAO of +2.39 ) was especially warm, with anomalies of $+2.9^{\circ} \mathrm{C}$ in both Belarus and Romania to $+3.9^{\circ} \mathrm{C}$ in Ukraine, ranking among the top-10 warmest March months for all countries of the region (see Table A7.3 for temperature record lengths of each country).

June was exceptional. Belarus, Ukraine, and Moldova each reported their warmest June on record with anomalies of $+4.5^{\circ} \mathrm{C},+4.7^{\circ} \mathrm{C}$, and $+3.6^{\circ} \mathrm{C}$ above normal, respectively. Romania also reported its warmest June on record at $+2.5^{\circ} \mathrm{C}$ above normal. Records were broken at several stations. In Belarus, daytime temperatures up to $34.7^{\circ} \mathrm{C}$ were recorded while nighttime temperatures often did not fall below $21.0^{\circ} \mathrm{C}$ between 11 and 26 June.

All three autumn months were warmer than normal for all eastern European countries except West Kazakhstan, which was repeatedly impacted by a northerly inflow of cold air. Belarus reported its second-warmest $\left(+2.2^{\circ} \mathrm{C}\right)$, Moldova its third-warmest $\left(+2.6^{\circ} \mathrm{C}\right)$, and Ukraine its eighthwarmest $\left(+2.4^{\circ} \mathrm{C}\right)$ autumn. It was the warmest October $\left(+2.87^{\circ} \mathrm{C}\right)$ in Belarus since records began. Abnormally warm weather between 14 and 22 October, with anomalies up to $+10.0^{\circ} \mathrm{C}$, was observed across Belarus. The season ended with a warmer-than-normal November, ranking the warmest for Romania $\left(+4.9^{\circ} \mathrm{C}\right)$ and fifth warmest for Belarus $\left(+3.2^{\circ} \mathrm{C}\right)$ and Moldova $\left(+3.8^{\circ} \mathrm{C}\right)$, while for the Ukraine it was only the 12 th warmest $\left(+3 \cdot 1^{\circ} \mathrm{C}\right)$.

December 2019 was extremely mild with highest monthly anomalies between $+8^{\circ} \mathrm{C}$ and $+10^{\circ} \mathrm{C}$ in the Arkhangelsk region in northwestern European Russia, with many new records of daily 
maximum temperature, especially during 18-23 December. It was the second-warmest December averaged across European Russia $\left(+5.3^{\circ} \mathrm{C}\right)$.

\section{(II) PRECIPITATION}

Annual precipitation was below normal for all of eastern Europe except for the northern parts of European Russia. Belarus reported 91\% of normal precipitation, Ukraine 82\% (fifth-driest year), and Moldova 73\% of normal precipitation. Eastern Romania and West Kazakhstan received $60 \%-80 \%$ of their normal precipitation.

Overall, the winter was wetter than normal with up to $126 \%$ of normal precipitation in parts of the region. January brought a precipitation surplus and was the fifth wettest for European Russia (132\% of normal) and Moldova (231\%). February, on the other hand, was the fourth driest in Belarus with locally just $20 \%$ of normal precipitation. Ukraine reported $46 \%$ of normal precipitation, Moldova was close to normal (94\%), and European Russia reported abovenormal precipitation, up to $267 \%$ of normal in the northwest. Snow cover mostly persisted during winter, but in Moldova, February had only some days of snow. In Romania, February snow cover persisted in the mountains throughout the month and even into March above $1200 \mathrm{~m}$ a.s.l. European Russia also reported snowfall in March, even in the south (Krasnodar region, North Caucasus). In the Ukraine, record high snow depths (ranging from 40-50 cm, records dating to 1961) were measured at some stations in January.

Spring was wetter than normal in European Russia and Ukraine while Belarus and Moldova received below-normal precipitation. March was rather dry in Romania, Moldova, and Ukraine. Moldova reported its second-driest March on record with a countrywide average of only $1 \mathrm{~mm}$, $3 \%$ of normal, and Ukraine received $64 \%$ of normal precipitation. In Belarus, it was slightly drier than normal ( $91 \%$ of normal), and European Russia reported a precipitation surplus of $115 \%$. April was drier than normal across all of the region but was driest in European Russia, which reported its sixth-driest April with 66\% of normal precipitation and Belarus recording its driest April on record with only $18 \%$ of normal precipitation. The season ended wet for the whole region with precipitation of $124 \%-161 \%$ of normal May precipitation, the latter being reported by Ukraine as its sixth-wettest May.

Summer precipitation was below normal except for European Russia with 108\% of normal, mainly in the northeast. It was close to normal (97\%) in Belarus. Ukraine and Moldova reported just $68 \%$ and $87 \%$ of their normal precipitation, respectively. Precipitation was distributed inhomogeneously in the summer months as locally extreme amounts were observed.

Autumn was drier than normal in the southern parts and wetter than normal in northern parts. Belarus reported 79\%, Ukraine 67\%, and Moldova only 27\% (sixth driest) of normal precipitation for the season. For Ukraine and Moldova, all autumn months were drier than normal. In Moldova, September (19\% of normal, 11th driest) and November (only 15\% of normal, fifth driest) were outstanding. December had a similar distribution with above-normal precipitation in northern European Russia (up to $250 \%$ of normal), but drier than normal in the south (40\%-80\% of normal in large parts); however, heavy showers were observed at the Black Sea coast on individual days.

\section{(III) NOTABLE EVENTS AND IMPACTS}

On 11 and 12 January, Moldova experienced a cold spell with extreme precipitation totals of 30-190 mm in 48 hours, fallen as snow. Most fell in central and northern parts of the Republic. The snow depth reached up to $40 \mathrm{~cm}$ at meteorological stations. Roads were closed temporarily, and 14 communities in five districts were left without electricity for one day. Temperatures continued to be below normal in Moldova until the end of January. These cold spells also affected central European Russia where daily minima of around $-20^{\circ} \mathrm{C}$ were measured in and around Moscow on 23 January, with some places below $-25^{\circ} \mathrm{C}$. Anomalies fell below $-5^{\circ} \mathrm{C}$. In northern European Russia (near Arkhangelsk), temperatures dropped to around $-40^{\circ} \mathrm{C}$ on 26 January. 
Freezing rain lasted from 2 to 5 February in the Rostov region in the European part of Russia. This damaged the region's electricity supply system and left 2144 buildings without electricity.

Due to the inflow of moist, warm air from the south, heavy thunderstorms developed in late April along a cold front over Romania. On 30 April, a large tornado about $110 \mathrm{~km}$ east of Bucharest damaged homes, agricultural fields, and vehicles. At least seven people were injured, most of them after the twister overturned a bus with 39 people inside. Ten houses were left without their roofs.

At several stations in southern and central Ukraine, new records of daily maximum precipitation totals were set on 3-5 June with 76-104 mm, representing 150\%-200\% of their monthly normal.

A heat wave in the Ukraine lasting from 6 June to 10 July brought record high temperatures and Ukraine's hottest June since records began in 1961, with an average monthly temperature $+4.5^{\circ}$ to $+5.5^{\circ} \mathrm{C}$ above normal. Maximum air temperatures exceeded $30^{\circ} \mathrm{C}$ in most parts of the country, and for up to a week, $35^{\circ} \mathrm{C}$ was exceeded. Locally, anomalies reached up to $+7.0^{\circ} \mathrm{C}$. On 2 July, the highest maximum temperature record, in place since 1929, was broken at Voznesensk in the Ukraine with a temperature of $39.0^{\circ} \mathrm{C}$.

\section{8) Middle East}

This region includes Israel, Cyprus, Jordan, Lebanon, and Syria.

\section{(I) TEMPERATURE}

The year was more than $+1.0^{\circ} \mathrm{C}$ warmer than normal in most of the region. Temperature anomalies below $+1.0^{\circ} \mathrm{C}$ were recorded only in Syria and northern parts of Jordan. It was the seventhwarmest year in the 69-year record for Israel, but also the coolest since 2013.

The Middle East experienced a warmer-than-normal winter, and anomalies in January and February exceeded $+1.0^{\circ} \mathrm{C}$ locally. After a slightly colder-than-normal March, with anomalies down to $-1.0^{\circ} \mathrm{C}$ for most of the region, April brought even stronger anomalies (below $-1.0^{\circ} \mathrm{C}$ ) to the Middle East, except in coastal areas and Cyprus. A warmer-than-normal May followed, with anomalies above $+2.0^{\circ} \mathrm{C}$ in parts of Israel and Jordan. Israel reported its warmest May for at least 50 years. During a prolonged heat spell starting in mid-May, multiple Sharav events (hot and dry winds coming from desert regions) brought very high temperatures to Israel, most notably from 22-24 May when maxima of $43^{\circ}-45^{\circ} \mathrm{C}$ were reached in the coastal plain and up to $47^{\circ} \mathrm{C}$ in the Dead Sea region. Overall, spring was closer to normal except for Cyprus where temperatures were $+0.7^{\circ} \mathrm{C}$ above normal.

Summer was warmer than normal by more than $+1.0^{\circ} \mathrm{C}$. In June, anomalies in the Middle East were close to $+2.0^{\circ} \mathrm{C}$ and exceeded this in Jordan, placing summer 2019 among the warmest five summers for all countries in the region. The warmth continued in autumn and December with anomalies of well above $+1.0^{\circ} \mathrm{C}$ in much of the Middle East in all four months of September-December.

\section{(II) PRECIPITATION}

Overall, the year was drier than normal in southern parts of the Middle East with precipitation $80 \%-100 \%$ of normal in Israel and Jordan, but above normal (above 150\% locally) in Syria, Lebanon, and Cyprus.

During January, Cyprus, Lebanon, and the western parts of Syria received above-normal precipitation, while in Israel and Jordan, precipitation was below normal. February was wet again except for some parts in the east of Syria.

In spring, above-normal precipitation ( $>125 \%$ of normal) was received in northern and western Syria and in Lebanon. Southeastern Syria and eastern Jordan had an early start to the dry season, receiving less than $10 \mathrm{~mm}$ in the whole spring. In May, precipitation was scarce across the entire region. The dry season continued until September. 
In October, the rainy season started in Cyprus, western Syria, Lebanon, and northern Israel, with generally normal rainfall. Rainfall did not increase much in November except some locally heavy showers along the Syrian coast; monthly totals did not exceed $20 \%-80 \%$ of normal. Hence, the whole autumn season was drier than normal. December brought above-normal precipitation in most of the region, except southern Israel and southern and eastern Jordan. Monthly totals exceeding $250 \%$ of normal were recorded in parts of Syria and Israel.

Snow was recorded over the Troodos Mountains in Cyprus from January to April and in December 2019. In Israel, Jerusalem (800 $\mathrm{m}$ a.s.l.) had a thin layer of snow in mid-January; snow fell in February in the northern parts of the Golan Heights and the peaks of the Galilee Mountains, and even in April on Mount Hermon (2814 m a.s.l.) for several successive days, which is unusual for this time of year.

\section{(III) NOTABLE EVENTS AND IMPACTS}

On 8 January, storm Norma brought strong winds, heavy rains and flooding, snowfall, and freezing temperatures in Lebanon and Syria, affecting over 11300 Syrian refugees at more than 360 settlement sites, mainly in the Beqaa valley. The station Houche-Al-Oumara in Lebanon (920 m a.s.l.) recorded gusts up to $76 \mathrm{~km} \mathrm{~h}^{-1}$, thunderstorms, $94 \mathrm{~mm}$ of precipitation in 48 hours, and a snow depth of $3 \mathrm{~cm}$ on the morning of 9 January. Although such storms are not rare in the eastern Mediterranean, the region was vulnerable due to the high number of refugees living in difficult housing conditions.

Between 29 and 31 March, 6500 families in a refugee camp in northern Syria were affected by flooding after torrential rainfall. Tents and personal belongings were destroyed or swept away. As a further consequence, the risk of spreading of illnesses was increased.

During an extreme Sharav event on 17 July, a daily maximum temperature of $49.9^{\circ} \mathrm{C}$ was measured in Sedom (southern Dead Sea region). This was the highest temperature recorded in Israel in more than 70 years. (The highest temperature ever measured in Israel was $54^{\circ} \mathrm{C}$ in Tirat Tzvi on 21 June 1942.)

Starting on 13 October, more than 100 forest fires broke out across central-western and northern Lebanon. Over 1200 hectares of land were burned. At least 72 people were injured. In the districts of Chouf and Nakkar, people were displaced after fires extended to populated areas. Twenty landmines exploded because of the fires. On 15 October, Lebanon requested assistance through the EU Civil Protection Mechanism for aerial forest firefighting capacities.

\section{9) South Caucasus}

This region includes Armenia, Georgia, and Azerbaijan.

\section{(I) TEMPERATURE}

The South Caucasus was warmer than normal by more than $+1.0^{\circ} \mathrm{C}$ in 2019 . It was the fourthwarmest year in Georgia since 1960 , with an anomaly around $+1.5^{\circ} \mathrm{C}$. In the capital, Tbilisi, it was the second-warmest year (after 2018) since records began in 1881.

Winter was exceptionally mild. The whole region experienced anomalies above $+2.0^{\circ} \mathrm{C}$ and nearly $+3.0^{\circ} \mathrm{C}$ in Armenia. During all winter months, anomalies were above $+2.0^{\circ} \mathrm{C}$.

Spring started with a near-normal March in the South Caucasus followed by a colder-thannormal April with anomalies below $-1.0^{\circ} \mathrm{C}$ in Armenia. However, due to well-above-normal temperatures in May, with anomalies above $+2.0^{\circ} \mathrm{C}$ in the whole region, the season overall was warmer than normal.

Summer was characterized by a record warm June (in Georgia, the warmest since 1960) with anomalies of $+3.0^{\circ} \mathrm{C}$ to $+5.0^{\circ} \mathrm{C}$ for the whole region. In July, the western parts of Georgia were slightly colder than normal, and the other parts of South Caucasus had slightly above-normal 
temperatures. This reversed in August when anomalies were below normal in Azerbaijan and above normal in Georgia and Armenia.

Autumn was warmer than usual in Georgia and Armenia, while temperatures in Azerbaijan were close to normal. Temperatures were unusually high in October with anomalies above $+2.0^{\circ} \mathrm{C}$ across the region (third-warmest October since 1960 in Georgia), but cold air in the east caused a drop to slightly below-normal values in November in its eastern parts. Warm air came again in December, and anomalies increased notably to around $+3^{\circ} \mathrm{C}$.

\section{(II) PRECIPITATION}

Overall, the year was drier than normal in Armenia and Georgia, particularly in the east where precipitation was only $50 \%-60 \%$ of normal, while it was close to normal in Azerbaijan on average.

The winter season was wet in Azerbaijan and Armenia, which received 125\%-250\% of normal precipitation and more than $250 \%$ in places. Georgia received below-normal precipitation, below $80 \%$ of normal in places.

During spring, Azerbaijan again recorded above-normal precipitation of 125\% or more while precipitation in Georgia and Armenia was closer to normal. Summer was drier than normal, with the highest deficits in eastern Azerbaijan and totals of only $40 \%$ of normal. The dryness persisted more or less during all three summer months; only Georgia received above-average rain in June and particularly July.

Autumn started with a wet September with heavy rain in places, particularly central Georgia and eastern Armenia. Locally, monthly totals exceeded 125\% of normal, especially in Armenia. October and November, on the other hand, were drier than normal across the region with only $20 \%-60 \%$ of normal precipitation, and below $20 \%$ in places. The deficit continued in December, with a few exceptions; Armenia in particular experienced heavy rain. Due to abnormally dry conditions in December, snow cover in Georgia persisted 18-20 days only in the high-mountainous zone with recorded maximum snow depths up to $10-15 \mathrm{~cm}$. The average snow depths at winter resorts (Bakuriani, Gudauri) were two to three times lower than in previous years.

\section{(III) NOTABLE EVENTS AND IMPACTS}

On 4-5 May, heavy rain and hail affected Georgia's eastern region of Kakheti. Heavy rain up to $150 \mathrm{~mm} \mathrm{day}^{-1}$ in Lagodekhi (near the border to Azerbaijan) flooded entrances, basements, and first floors of many buildings. Infrastructure, such as roads and bridges connecting the villages, as well as riverbank protections, agricultural lands, vineyards, and fruit trees were destroyed. Supplies of drinking water and electricity were interrupted for a short period. In total, more than 5000 people were affected by this disaster.

On 5 August, heavy rain accompanied by a sea storm occurred in Adjara-Guria (southwestern part of Georgia) causing infrastructure damage. One person died.

\section{g. Asia-T. Li, Ed.}

Throughout this section the base periods used vary by region. The current standard is the 1981-2010 average for both temperature and precipitation, but earlier base periods are still used in several countries. All seasons mentioned in this section refer to those of the Northern Hemisphere (NH), with winter referring to December-February 2018/19, unless otherwise noted. 
1) Overview-T. Li, Z. Zhu, P. Zhang, T. C. Lee, I. Gustari, Y. Mochizuki, C.-W. Choi, L. Oyunjargal, A. Moise, M.-V. Khiem, and H.-P. Lam

Annual mean surface air temperatures during January-December 2019 were above normal across most of Asia, with the temperature anomaly exceeding $1.5^{\circ} \mathrm{C}$ from Siberia to northeast Asia and from southwestern China to the Indochina Peninsula (Fig. 7.37). Annual precipitation amounts were above normal ( $>120 \%)$ from the southeastern side of the Caspian Sea to India; in northern China, from central to western Siberia; and in the southwestern part of eastern Siberia. Annual precipitation amounts were below normal ( $<80 \%)$ in the northern part of eastern Siberia, the eastern part of East Asia, northwestern China, and all of Southeast Asia (Fig. 7.38).

In winter, negative temperature anomalies were observed from the southern part of western Siberia to central India; positive temperature anomalies occurred from central Siberia to northeast Asia (Fig. 7.39a). In spring, positive temperature anomalies larger than $3.0^{\circ} \mathrm{C}$ dominated highlatitude Asia (north of $60^{\circ} \mathrm{N}$, Fig. 7.39c). In summer, above-average temperatures continued in Siberia, except in the southern part of eastern Siberia (Fig. 7.39e). In autumn, negative temperature anomalies dominated from central Asia to the southern part of central Siberia (Fig. 7.39g).

Seasonal precipitation amounts varied across the region (Figs. 7.39b,d,f,h). Notably, India experienced positive precipitation anomalies in autumn due to the monsoon season ending late;

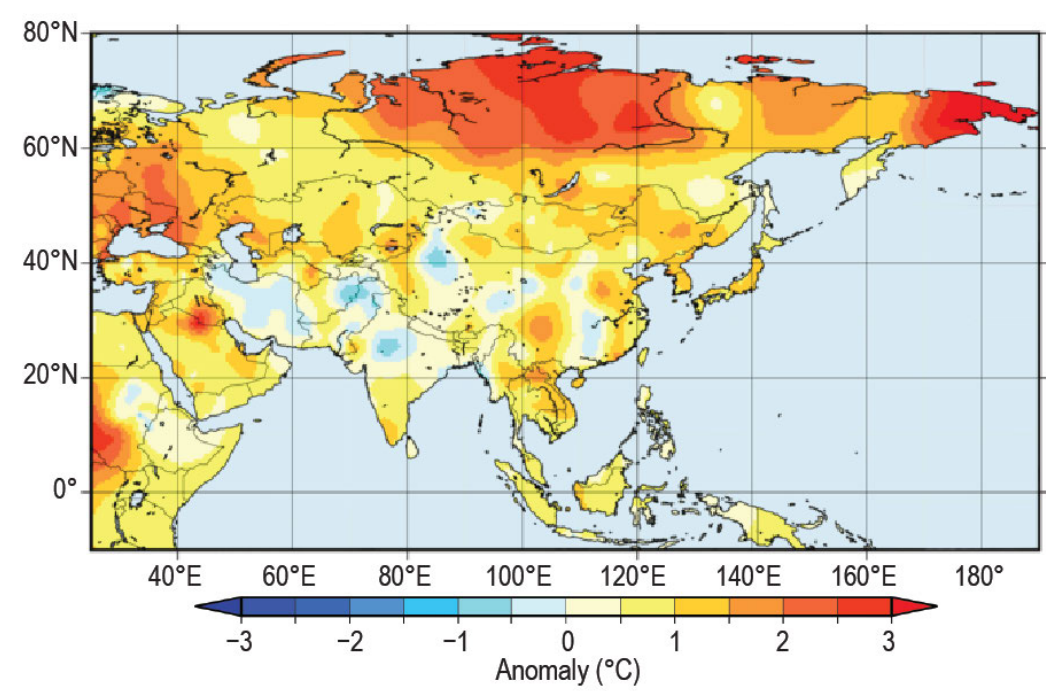

Fig. 7.37. Annual mean surface temperature anomalies $\left({ }^{\circ} \mathrm{C} ; 1981-\right.$ 2010 base period) over Asia in 2019. (Source: Japan Meteorological Agency.)

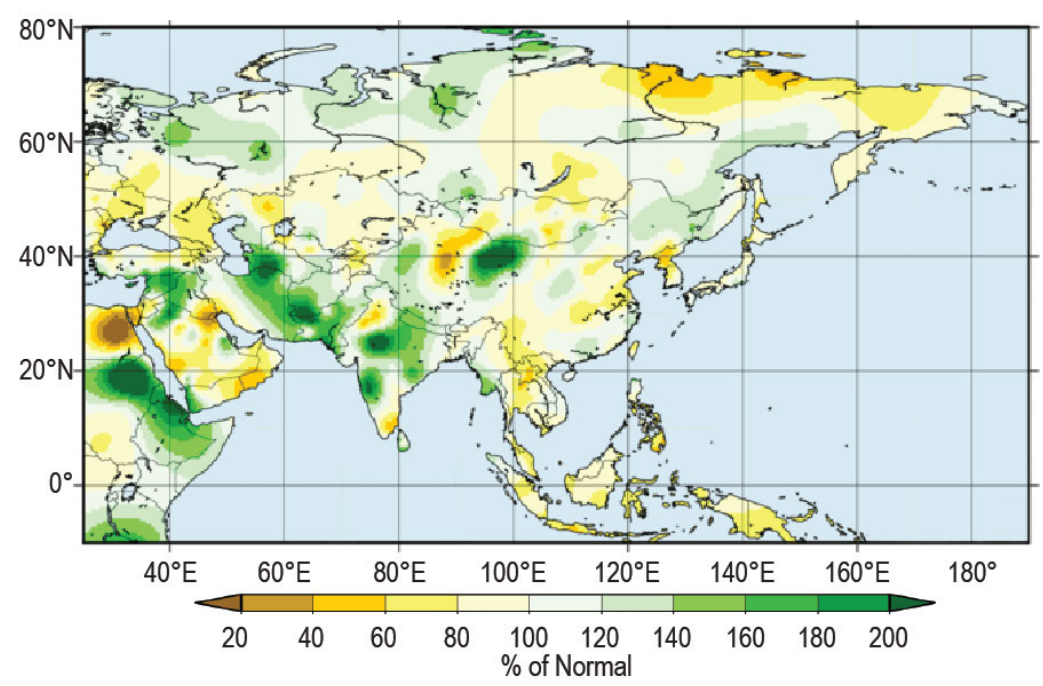

Fig. 7.38. Annual precipitation (\% of normal; $1981-2010$ base period) over Asia in 2019. (Source: Japan Meteorological Agency.) negative precipitation anomalies occurred in Southeast Asia from spring to autumn due to the combined effects of El Niño in spring and a positive Indian Ocean dipole (IOD) in subsequent seasons.

In winter, the East Asia trough weakened and withdrew northward while the subtropical jet stream over Japan shifted northward. Positive anomalies of 500-hPa geopotential height and 850-hPa temperature occurred over the East China Sea (Fig. 7.40a). In spring, low-level cyclonic circulation anomalies straddling the equator over the western tropical Pacific were associated with enhanced convective activity in the western equatorial Pacific (Fig. 7.41b). In summer, negative 500-hPa height anomalies over northeast Asia (Fig. 7.40c), which were associated with the southward shift of the subtropical jet stream, brought belownormal precipitation over northeast Asia. In autumn, low-level anticyclonic anomalies straddling the equator were observed over the tropical Indian Ocean in association with suppressed convective activity over the Maritime Continent and southern tropical central and eastern Indian Ocean (Fig. 7.41d). A positive 500-hPa geopotential height anomaly was observed over Japan (Fig. 7.40d), accompanied by the northward shift of the westerly jet stream. 

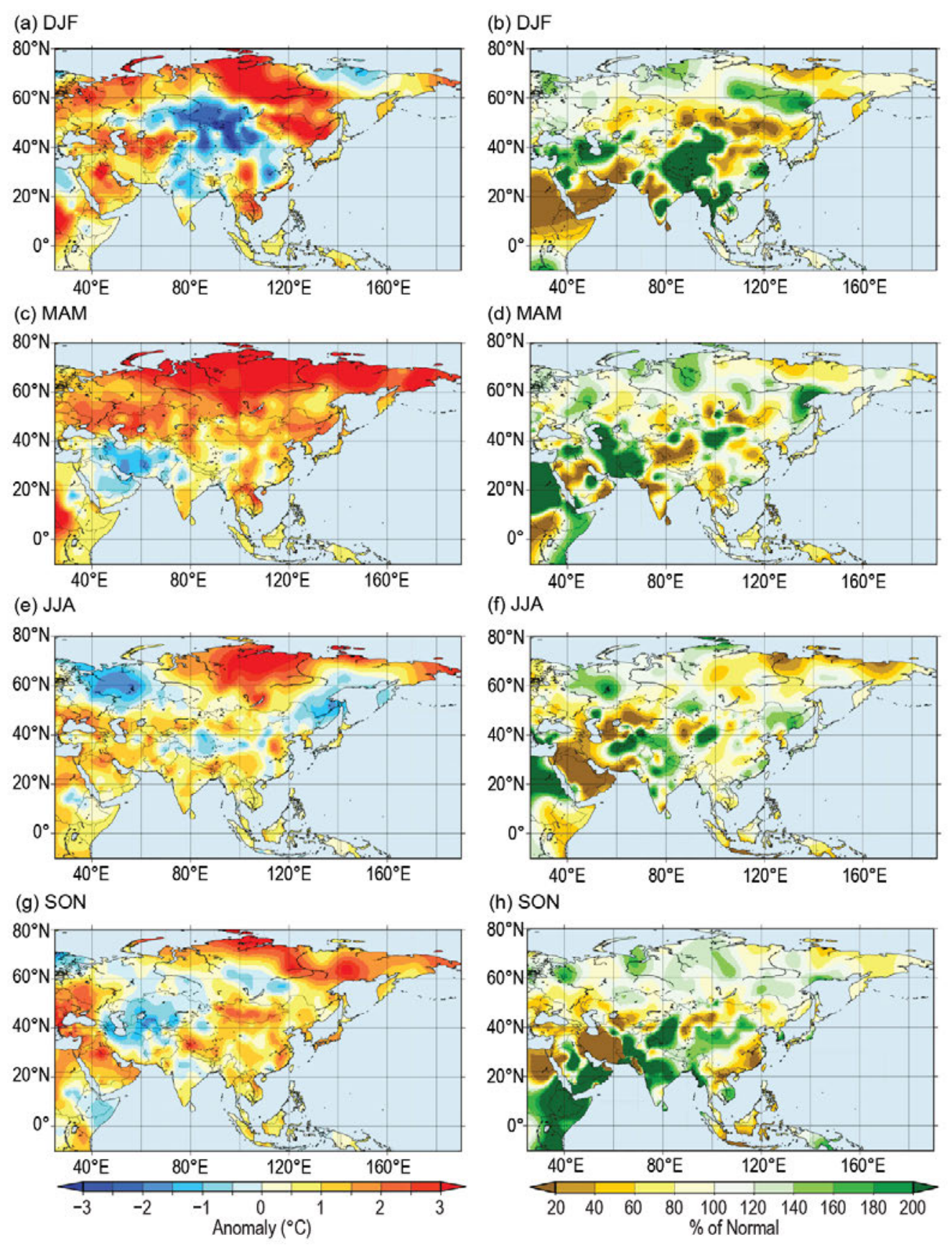

Fig. 7.39. Seasonal mean surface temperature anomalies $\left({ }^{\circ} \mathrm{C}\right.$, left column) and seasonal precipitation (\% of normal, right column) over Asia in 2019 for (a),(b) winter; (c),(d) spring; (e),(f) summer; and (g),(h) autumn. Base period: 1981-2010. (Source: Japan Meteorological Agency.) 


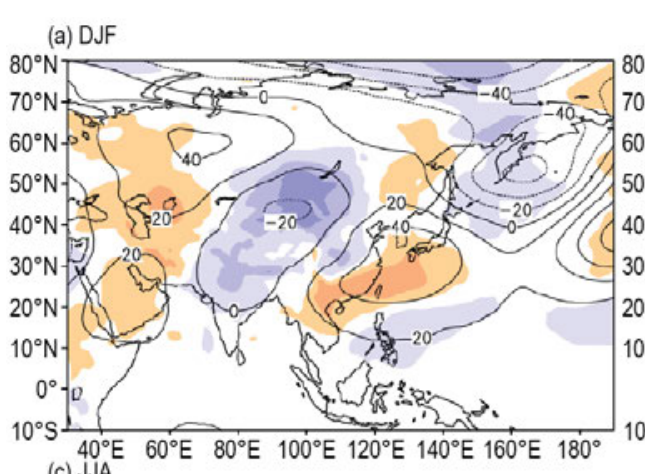

(b) MAM

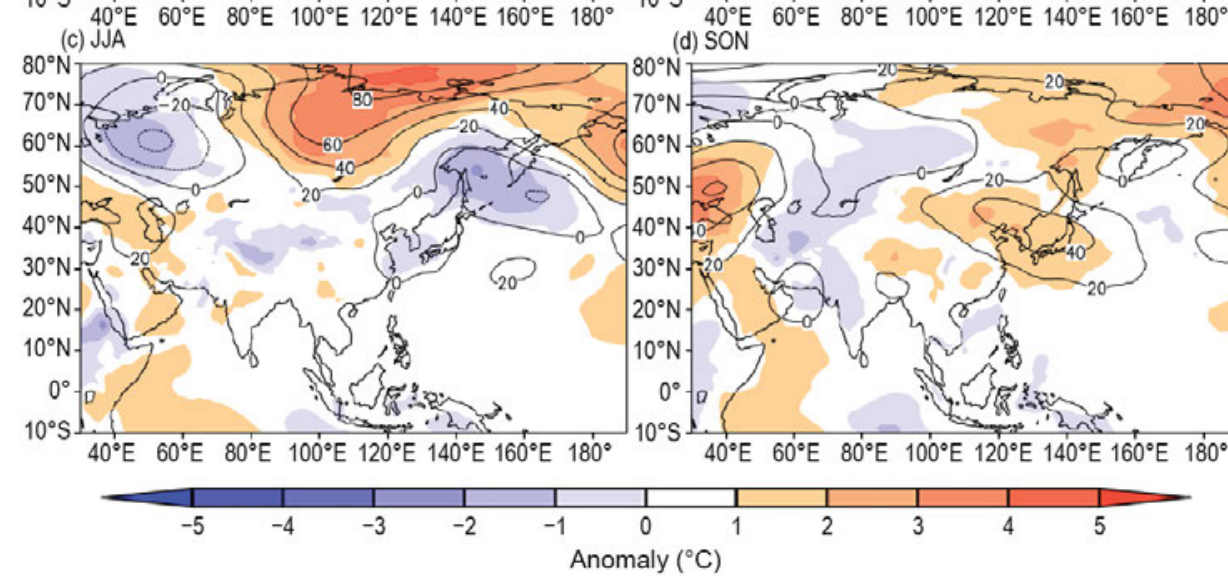

Fig. 7.40. Seasonal mean anomalies of 500-hPa geopotential height (contour; gpm) and 850-hPa temperature (shading; ${ }^{\circ} \mathrm{C}$ ) in 2019 for (a) winter, (b) spring, (c) summer, and (d) autumn. Base period: 1981-2010. (Source: JRA-55 reanalysis, Japan Meteorological Agency.)

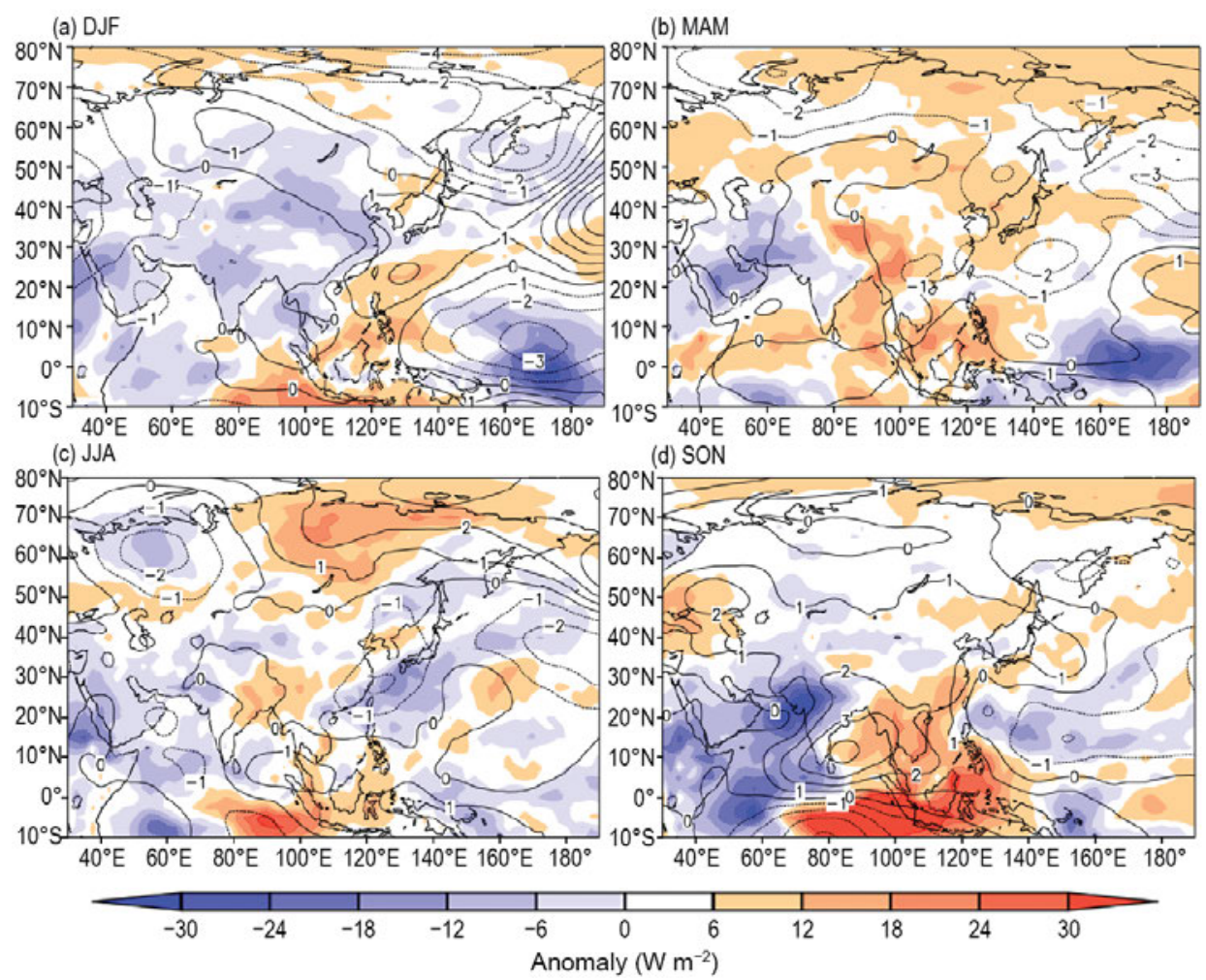

Fig. 7.41. Seasonal mean anomalies of $850-\mathrm{hPa}$ stream function (contour; $\times 10^{6} \mathrm{~m}^{2} \mathrm{~s}^{-1}$ ) using data from the JRA-55 reanalysis and OLR (shading; $\mathrm{W} \mathrm{m}^{-2}$ ) using data originally provided by NOAA in 2019 for (a) winter, (b) spring, (c) summer, and (d) autumn. Base period: 1981-2010. (Source: Japan Meteorological Agency.) 
2) Russia-M. Yu. Bardin and N. N. Korshunova

Estimates of climate features for Russia are obtained from hydrometeorological observations of the Roshydromet Observation Network. Anomalies are relative to the 1961-90 base period, and national rankings and percentiles reflect the 1936-2019 period of record. The boundary between Asian Russia and European Russia is considered to be $60^{\circ} \mathrm{E}$. Notable events and impacts (including damage and losses) are reviewed based on operational teletype reports and outlooks prepared by regional hydrometeorological service offices and collected and processed at the All-Russian Research Institute for Hydrometeorological Information-World Data Center (ARIHMI-WDC), Obninsk.

\section{(I) TEMPERATURE}

The 2019 mean temperature in Russia was $2.07^{\circ} \mathrm{C}$ above normal (Fig. 7.42), the fourth highest on record and almost $0.5^{\circ} \mathrm{C}$ higher than 2018 (the highest temperature on record $\left[2.16^{\circ} \mathrm{C}\right.$ above normal] was reported in 2015). Anomalies above the 95th percentile were observed at most central and southern European Russia stations and over vast territories in Siberia and the northern Far East, where annual mean temperatures exceeded the climatology by $3.5^{\circ}-4^{\circ} \mathrm{C}$. The highest annual temperature anomaly ever recorded, $+2.51^{\circ} \mathrm{C}$, was observed in the Central Federal district (part of western European Russia approximately over $50^{\circ}-57^{\circ} \mathrm{N}, 32^{\circ}-43^{\circ} \mathrm{E}$; Fig. 7.37).

All seasons in Russia have warmed since the mid-1970s. Annual and seasonal trends are statistically significant at 99\%, except for winter when the trend (insignificant even at 95\%) is accompanied by a strong interdecadal variation. Winters were cooling after the mid-1990s and then started to warm again after 2010 (Fig. 7.42).
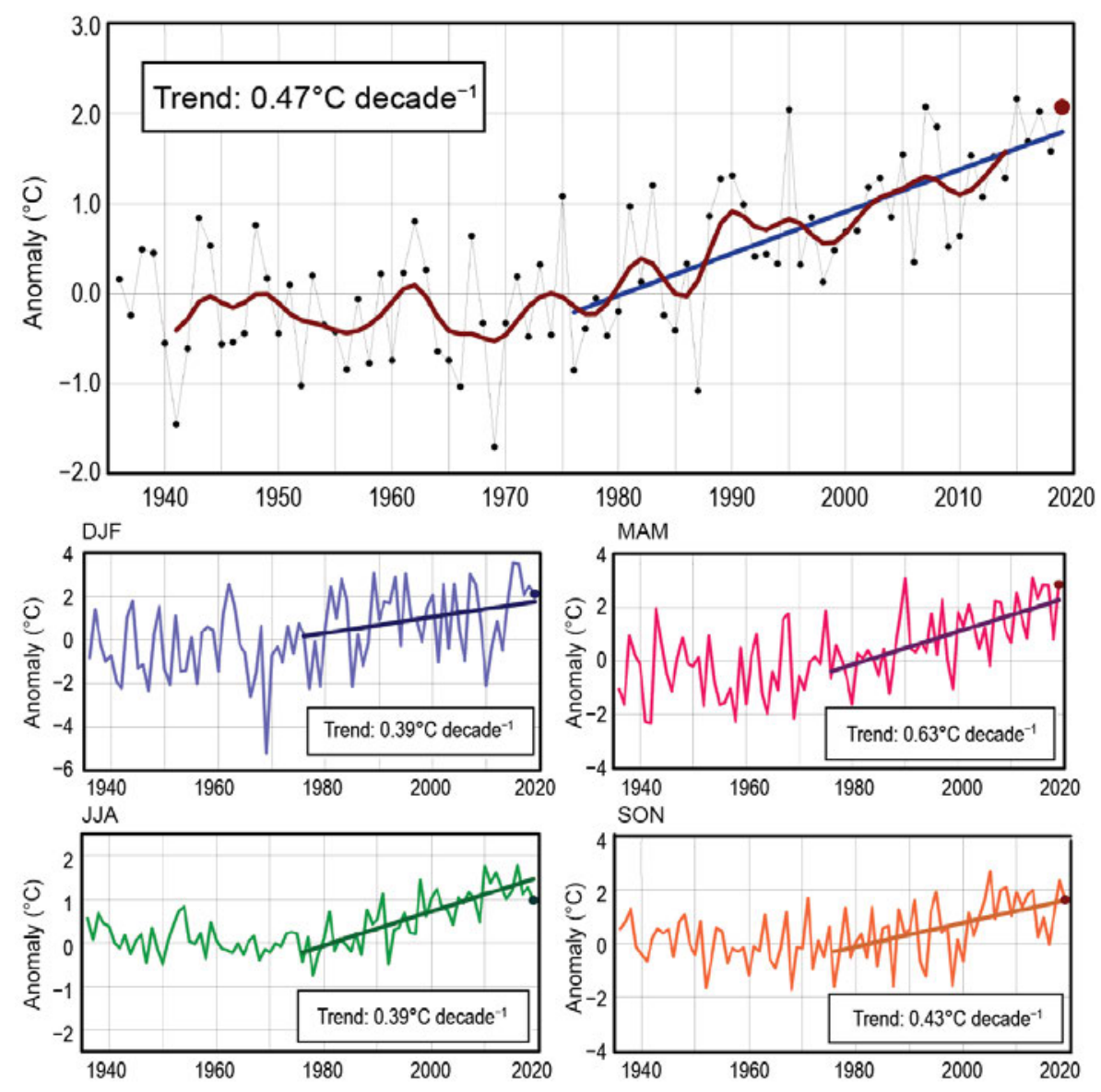

Fig. 7.42. Mean annual and seasonal temperature anomalies ( ${ }^{\circ} \mathrm{C} ; 1961-90$ base period) averaged over the territory of Russia for the period 1936-2019. The bold red line on the annual mean time series is an 11-point binomial filter. Linear trend $\left({ }^{\circ} \mathrm{C}\right.$ decade $\left.^{-1}\right)$ is calculated for the period $1976-2019$. 
With a mean temperature $2.12^{\circ} \mathrm{C}$ above normal, winter $2018 / 19$ was only the 15 th warmest on record but still warmer than expected considering the recent linear trend. Winter was colder than normal in the south of western Siberia (Fig. 7.39a), especially in December 2018, when station temperatures were as much as $-7^{\circ} \mathrm{C}$ below normal.

Spring was very warm: $2.86^{\circ} \mathrm{C}$ above normal, Russia's fourth-warmest spring on record. In March, the temperature was $4.30^{\circ} \mathrm{C}$ above normal, making it the fourth-warmest March on record. It was record warm in western Siberia: $6.30^{\circ} \mathrm{C}$ above normal. The weakened quasi-permanent Siberian anticyclone allowed numerous warm Atlantic cyclones to invade northern Siberia, forming a large warm anomaly in the region: $+10^{\circ}$ to $+12^{\circ} \mathrm{C}$ above normal (Fig. 7.43). Many stations reported above-average temperatures throughout most of March. Uelen $\left(66^{\circ} 36^{\prime} \mathrm{N}, 169^{\circ} 48^{\prime} \mathrm{W}\right.$, the easternmost settlement in Russia) reported a record high monthly temperature during two heat waves that occurred at the beginning of the month and at the end of the month. These heat waves were associated with strong cyclonic activity in the north Pacific.

Summer was moderately warmer than normal, with an overall temperature anomaly of $+0.98^{\circ} \mathrm{C}$ (17th highest). Although Asian Russia was much warmer than normal, with a temperature anomaly of $+1.32^{\circ} \mathrm{C}$ (seventh highest), European Russia observed a temperature anomaly of just $+0.07^{\circ} \mathrm{C}$

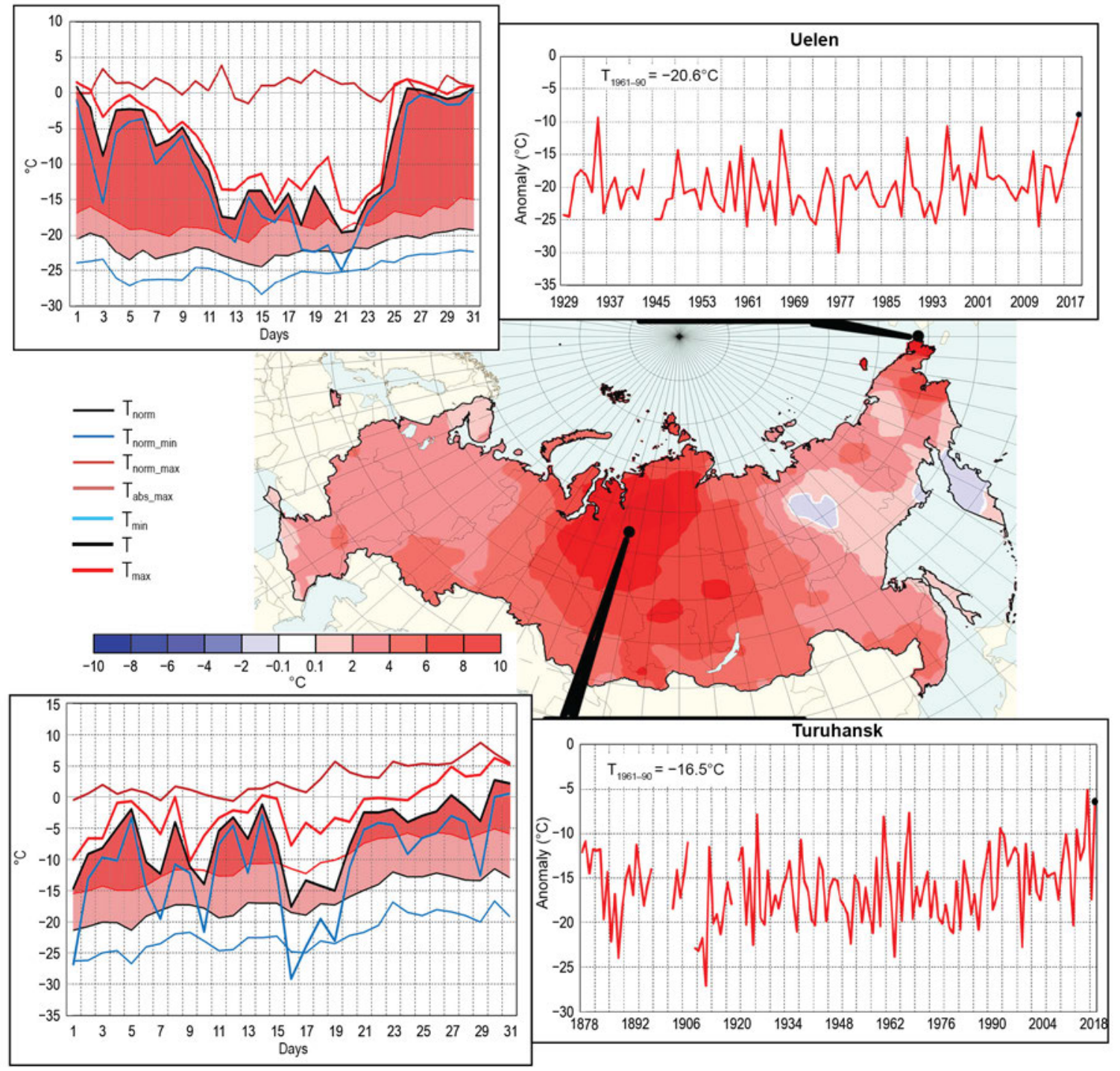

Fig. 7.43. Air temperature anomalies $\left({ }^{\circ} \mathrm{C}\right.$; shaded) in Mar 2019. Insets: Mean monthly and mean daily air temperatures $\left({ }^{\circ} \mathrm{C}\right)$ in Mar 2019 at meteorological stations Turuhansk and Uelen. Plots of daily temperature show observed daily mean (black), minimum (blue), and maximum (red) temperatures along with their climatological normals and absolute maximum temperature; the area between daily mean values above normal and the normal daily mean curve is shaded pink, and where values are above normal daily maximum, shading is red. Periods of record vary. 
(51st-warmest summer, significantly lower than its median). This contrast was even more pronounced in August when Asian Russia experienced its third-warmest August on record $\left(+1.47^{\circ} \mathrm{C}\right)$, while European Russia experienced an August among its 20 coolest $\left(-0.47^{\circ} \mathrm{C}\right)$. June was record warm in the Far Eastern Federal district (Asian Russia east of $110^{\circ} \mathrm{E}$ ) at $2.09^{\circ} \mathrm{C}$ above normal; European Russia south of $50^{\circ} \mathrm{N}$ was more than $4^{\circ} \mathrm{C}$ above normal.

Autumn was moderately warm in Russia as a whole and in Asian Russia, with an area-averaged anomaly of $+1.60^{\circ} \mathrm{C}$ (10th highest). Separately, Asian Russia and European Russia reported seasonal anomalies of $+1.76^{\circ} \mathrm{C}$ (10th highest) and $+1.20^{\circ} \mathrm{C}$ (21st highest), respectively.

\section{(II) PRECIPITATION}

Total precipitation across Russia on average was about 108\% of normal (sixth wettest; Fig. 7.44). The two wettest years occurred in the last decade (2013 and 2017: the only two years with precipitation more than $110 \%$ of normal). European Russia was wetter (110\%, eighth wettest) than Asian Russia (106\%, sharing 13th-15th in the record).

It was the 22nd-wettest winter since 1936 for the country as a whole, with precipitation $107 \%$ of normal. European Russia was wetter (114\%, 14th wettest) than Asian Russia (100\%, 31st wettest) due to excessive precipitation in European Russia north of $57^{\circ} \mathrm{N}$ in January and February (146\%, fourth wettest; $185 \%$, third wettest). This pattern is explained by the higher activity of North Atlantic cyclones, while strong anticyclonic circulation was observed in southern Siberia. In February, extreme precipitation (more than $200 \%$ of normal) was observed in parts of Asian Russia between $58^{\circ}-65^{\circ} \mathrm{N}, 115^{\circ}-130^{\circ} \mathrm{E}$, and east of $165^{\circ} \mathrm{E}$. February precipitation was much below normal in Siberia south of $50^{\circ} \mathrm{N}\left(<40 \%\right.$ of normal) and in European Russia south of $50^{\circ} \mathrm{N}(49 \%$, among the seven driest Februaries on record).

Spring was moderately wet for Russia as a whole, with $112 \%$ of normal precipitation (18th wettest). European Russia was extremely wet in March (161\%; second wettest on record), with the area north of $57^{\circ} \mathrm{N}$ (the Northwestern Federal District) being the wettest on record with $173 \%$ of normal precipitation but dry in April, at 66\% of normal (sixth driest on record for European Russia). In May, the Far Eastern Federal district (Asian Russia east of $110^{\circ}$ E) received $146 \%$ of normal precipitation, its third-wettest May on record.

In summer, Asian Russia received 100\% of its normal precipitation. European Russia was wetter than normal (108\%, 19th wettest), with July precipitation 127\% of normal (fourth wettest). Notably, the Northwestern Federal district received record high precipitation during July: 157\% of normal. There was a significant deficit of precipitation in June in southern European Russia, particularly south of $50^{\circ} \mathrm{N}$, except the North Caucasus (46\%). Along with record high temperatures, this deficit contributed to severe drought in June in this important agricultural region.

Autumn precipitation in Russia was $109 \%$ of normal, sharing 11th on record. Asian Russia was wet with $114 \%$ of normal precipitation (fifth wettest), while European Russia received normal precipitation. In October, precipitation amounts varied widely between northern and southern European Russia. The Northwestern Federal District reported record high precipitation that was $172 \%$ of normal. Conversely, the Southern Federal District (European Russia south

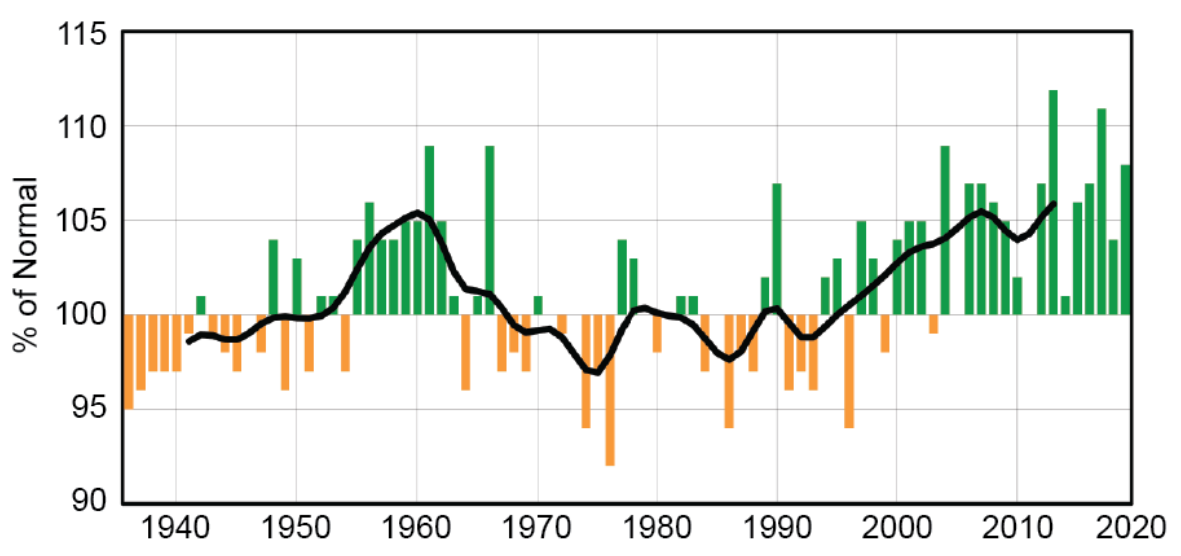

Fig. 7.44. Annual precipitation (\% of normal; $1961-90$ base period) averaged over the Russian territory for 1936-2019. The smoothed time series (11-point binomial filter) is shown as a bold line. 
of $50^{\circ} \mathrm{N}$ ) received only $58 \%$ of its normal precipitation, making October 2019 its fifth-driest October on record. November in the Southern Federal district was also dry: 58\% of normal precipitation was observed, its third-driest November on record.

\section{(III) NOTABLE EVENTS AND IMPACTS}

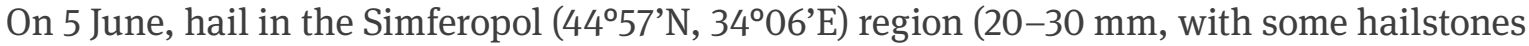
reaching $40 \mathrm{~mm}$ in diameter) damaged cars and greenhouses. In addition, 2055 ha of crops including pea, barley, and wheat were damaged. Damages were estimated to be 156 million rubles (\$2.15 million U.S. dollars).

On 25 June, heavy precipitation in the Irkutsk region in southeastern Siberia caused water levels to rise on the Biryusa, Uda, Iya, Ikeika, and Kirei Rivers. Four regions, 31 settlements, 3700 residential buildings (with more than 9000 residents), 32 social facilities, and over 3700 household plots were inundated. Thirteen highway bridges were damaged and many local roadways were impacted. The flooding killed 26 people and injured 1400.

During 26-29 July, heavy, continuous rains in the Irkutsk region (Sayansk: $103 \mathrm{~mm}$ in 35 hours; Baikalsk: $123 \mathrm{~mm}$ in 24 hours) inundated 20 settlements ( 475 houses) and three sections of highways. A highway bridge over the Solzan River in Baikalsk was destroyed. The Siberian highway in Tulun was closed, with one bridge destroyed and traffic relocated.

Heavy rains during 1-10 November (109 mm, 220\% of the climatological November value) caused flooding on the Yavon, Pola, Uver, Kholova, and Polist Rivers in the Novgorod Oblast region of northwestern Russia. Thirty-five settlements were inundated, with lines of communication cut off to some. Nineteen road sections were damaged and two wooden bridges were destroyed.

3) East and Southeast Asia-P. Zhang, T. C. Lee, I. Gustari, Y. Mochizuki, C.-W. Choi, L. Oyunjargal, A. Moise, M.-V. Khiem, and H.-P. Lam

Countries considered in this section include China, Hong Kong (China), Indonesia, Japan, South Korea, Mongolia, Singapore, and Vietnam. Unless otherwise noted, anomalies refer to the base period of 1981-2010.

\section{(I) TEMPERATURE}

Above-normal temperatures prevailed throughout the year across most of China (Fig. 7.37), with an annual mean temperature anomaly of $+0.79^{\circ} \mathrm{C}$ (fifth highest since 1951), which includes an April mean temperature anomaly of $+1.8^{\circ} \mathrm{C}$ (second highest for April since 1951). Hong Kong reported an annual mean temperature of $24.5^{\circ} \mathrm{C}$, which is $1.2^{\circ} \mathrm{C}$ above the $1981-2010$ normal and the highest since records began in 1884. Seasonally, Hong Kong experienced its warmest winter and autumn on record since 1884 , with mean temperatures reaching $19.1^{\circ} \mathrm{C}$ and $26.1^{\circ} \mathrm{C}$, respectively. There was only one cold day (daily minimum temperature $\leq 12.0^{\circ} \mathrm{C}$ ) in 2019 , which is 16.1 days fewer than normal and the fewest number reported since records began in 1884 . The annual number of hot nights (with daily minimum temperature $\geq 28.0^{\circ} \mathrm{C}$ ) was 46 , which is 28.2 days above average and the most reported since 1884 .

Annual mean temperatures were significantly above normal across Japan, with an annual temperature anomaly of $+0.92^{\circ} \mathrm{C}$, which is the highest since records began in 1898. South Korea's annual mean temperature was $13.5^{\circ} \mathrm{C}\left(+1.0^{\circ} \mathrm{C}\right.$; second highest since national records began in 1973). In May, the monthly mean temperature in South Korea was $18.7^{\circ} \mathrm{C}$ (second only to 2014 since records began in 1973). The annual mean temperature over Mongolia was $1.5^{\circ} \mathrm{C}\left(+1.0^{\circ} \mathrm{C}\right.$ above normal); the country observed its warmest September on record with an average temperature $3.8^{\circ} \mathrm{C}$ above normal. Mongolia experienced the greatest negative anomaly of the year in February, with a mean temperature of $-19.1^{\circ} \mathrm{C}\left(-2.5^{\circ} \mathrm{C}\right.$ below normal).

The mean annual temperature of Indonesia was $0.56^{\circ} \mathrm{C}$ above normal. The highest anomaly recorded was $+1.13^{\circ} \mathrm{C}$ in Kupang, East Nusa Tenggara Province. Singapore's annual mean 
temperature was $28.4^{\circ} \mathrm{C}, 0.9^{\circ} \mathrm{C}$ higher than average and tied with 2016 as the warmest year on record. Four of the past five years are among the country's 10 warmest years since 1929, when records began. Above-average monthly temperatures were recorded every month of 2019, with August $\left(29.1^{\circ} \mathrm{C}\right)$ and September $\left(29.0^{\circ} \mathrm{C}\right)$ each record warm, with anomalies of $+1.2^{\circ} \mathrm{C}$ and $+1.4^{\circ} \mathrm{C}$, respectively. November $2019\left(28.0^{\circ} \mathrm{C}\right)$ tied the record with 2015 and 1998 for warmest November, at $+1.4^{\circ} \mathrm{C}$ above average.

The annual mean temperature for most regions of Vietnam was $1^{\circ}$ to $2^{\circ} \mathrm{C}$ above normal. On 20 April, the temperature in Huong Khe (Ha Tinh) reached $43.4^{\circ} \mathrm{C}$, the highest temperature ever observed in the country. There were also two extended heat waves in north and central Vietnam, lasting 27 days in June and 25 days in July, respectively.

\section{(II) PRECIPITATION}

Figure 7.38 shows the 2019 annual precipitation as a percentage of normal over East and Southeast Asia. China's annual mean precipitation was $645.5 \mathrm{~mm}$ (102.5\% of normal; eighth wettest since records began in 1951). The annual total precipitation over river basins was above normal in the Songhua River (132\% of normal) and below normal in the Huaihe River ( $76 \%$ of normal) and Haihe River (87\%) basins, while near normal in the Yangtze River basin. In 2019, the annual total precipitation in Hong Kong was near normal at $2396.2 \mathrm{~mm}$.

In Japan, annual precipitation amounts were below normal on the Sea of Japan side of northern and eastern Japan, and above normal on the Pacific side of eastern and western Japan and in Okinawa/Amami. Annual total precipitation in South Korea was $1184.3 \mathrm{~mm}$, which is $90.5 \%$ of the normal precipitation amount of $1307.7 \mathrm{~mm}$. Although Mongolia's annual precipitation was near normal at $193.4 \mathrm{~mm}$, January was the driest month since records began in 1981 at 32.2\% of normal.

In Indonesia, annual rainfall was generally below normal, with a national average (from 104 meteorological stations) of $1920 \mathrm{~mm}$. This is about 81\% of normal, making 2019 the fourth-driest year since records began in 1981, behind 1997, 1982, and 2015, all of which are years with strong El Niño events. The largest rainfall deficit, approximately $50 \%$ of normal, was recorded at Tretes Station (East Java Province). The year was particularly dry in Singapore, where the Changi climate station recorded an annual rainfall amount of $1368 \mathrm{~mm}, 63 \%$ of normal, making 2019 the third-driest year for Singapore since records began in 1869.

Annual rainfall for most of Vietnam was $80 \%$ to $90 \%$ of normal, which contributed to widespread drought, water shortages in the south-central and highland regions, and saltwater intrusion in the Me Kong delta region. However, Nghe An to Thua Thien Hue experienced torrential rainfall. From 1 to 5 September, rainfall totals broke precipitation records in Vinh (Nghe An): 878 mm; Huong Khe (Ha Tinh): 933 mm; and Ha Tinh (Ha Tinh): 952 mm.

\section{(III) NOTABLE EVENTS AND IMPACTS}

In 2019, five tropical cyclones (TCs) made landfall in China. Tropical Cyclone Lekima was the fifth-strongest TC to make landfall since 1949 and remained inland for 44 hours. Seventy-four people perished or were missing, and there was approximately $\$ 8.5$ billion (U.S. dollars) of direct economic losses. In early September, Typhoon Faxai made landfall in the Kanto region in eastern Japan, and a record maximum wind gust speed of $57.5 \mathrm{~m} \mathrm{~s}^{-1}$ was observed at Chiba in the Chiba Prefecture. In mid-October, Typhoon Hagibis made landfall on the Izu Peninsula and moved northward to northern Japan. Record heavy rainfall was observed across a wide area, causing severe damage that included flooding from multiple rivers. Seven typhoons affected South Korea during the season, tying with 1950 and 1959 for the most on record. In the South China Sea, six tropical cyclones hit Vietnam directly. Please refer to Chapter 4 for more details about the western North Pacific TC season.

In total, China experienced more high-temperature days (defined as the number of days with daily maximum temperature exceeding $35^{\circ} \mathrm{C}$ ) than normal, with most occurring in the Yunnan 
province of China from mid-spring to early summer, in the Shandong province from early to mid-summer, and in the southern part of China from mid-summer to mid-autumn. Northern China experienced 10 sandstorms in the spring, significantly fewer than normal (17).

In winter, a weak Siberian High due to above-normal surface temperatures over Eurasia prevented cold air from reaching the Korean Peninsula. This resulted in an above-normal $\left(+1.3^{\circ} \mathrm{C}\right)$ monthly mean temperature in December, which in turn contributed to record low snowfall amounts in many regions in the country.

In Mongolia, 99 hydro-meteorological extreme events were reported; during the summer, occurrences of convection with accompanying extreme events such as flood, hail, and lightning were comparatively higher than in recent years. In particular, lightning frequency was the highest on record. Together, these extreme events caused 22 fatalities and about $\$ 5.6$ million (U.S. dollars) in economic losses.

In Indonesia, 2019 was marked by severe drought. The longest dry spell (i.e., no observed rainfall), which occurred in the East Sumba District of the East Nusa Tenggara Province, lasted 263 days. Meanwhile, in June, a rare frost reported in the mountainous region of Dieng, Central Java Province (around $2000 \mathrm{~m}$ above mean sea level), damaged agricultural crops such as potatoes and carrots.

\section{Sidebar 7.5: An unusually cool summer in East Asia and a positive Indian Ocean dipole event- W. WANG, T. LI, F. XIN, AND A. SHIMPO}

In 2019, an unusually cool summer, particularly in June-July, occurred over a vast region of East Asia and expanded from central China to Japan (Fig. SB7.11). In fact, the mean June-July 1000-hPa temperature over the region was among three lowest in the past 20 years (Fig. SB7.11a).

The cause of this extremely cool early summer was attributed to an anomalous low-level cyclone centered over southwest Japan (Fig. SB7.11b). Northeasterly anomalies to the northwest of the cyclone advected drier and cooler air from higher latitudes, leading to large-scale negative temperature and specific humidity anomalies, expanding from central China to southern Japan (Figs. SB7.11b,c). The cold and dry advection led to the decrease of low-level moist static energy (MSE) north of $30^{\circ} \mathrm{N}$ (Fig. SB7.11d), which further reduced local convective instability and caused a precipitation deficit there (Wu et al. 2017; Li et al. 2017). Meanwhile, southwesterly anomalies to the south of the cyclonic center advected higher mean MSE northeastward, increasing the convective instability south of $30^{\circ} \mathrm{N}$ (Fig. SB7.11d). Such a meridional contrast caused a dipole pattern of the rainfall anomaly over East Asia (Fig. SB7.11c).

A further examination of temperature, precipitation, and wind anomalies over a larger domain reveals that a positive 1000-hPa temperature anomaly appeared over the eastern equatorial Pacific (Fig. SB7.12a). In response to this temperature forcing, westerly anomalies occurred in the central equatorial Pacific, and rainfall deficits appeared over the Maritime Continent (Figs. SB7.12a,b). A negative precipitation anomaly also appeared over the Indian subcontinent (from $10^{\circ}$ to $30^{\circ} \mathrm{N}$, Fig. SB7.12b). Meanwhile, a zonally oriented upper-level wave train, characterized by an alternating anomalous low-high-low or cyclone-anticyclone-cyclone pattern, occurred along $38^{\circ} \mathrm{N}$ (Figs. SB7.12b,c). It is speculated that this upper-tropospheric wave train (sometimes called a Silk Road pattern) was triggered by the negative heating anomaly over the Indian subcontinent. According to Gill (1980), a negative heating anomaly could induce a low-pressure anomaly in the upper troposphere, which could perturb the subtropical westerly jet, leading to the downstream development of a synoptic wave train along the jet axis. The wave train had a typical quasi-barotropic vertical structure and a zonal wavelength of about $4000-5000 \mathrm{~km}$. As the wave energy propagated eastward along the jet, a cyclonic anomaly appeared over East Asia (Figs. SB7.12b,c). Note that compared to the location of the upper-level cyclone, the lowlevel cyclonic center shifted slightly southward (Figs. SB7.11b, 7.12b). The cause of this shift is attributed to the advection of low (high) MSE air to the north (south) of the cyclonic center, 


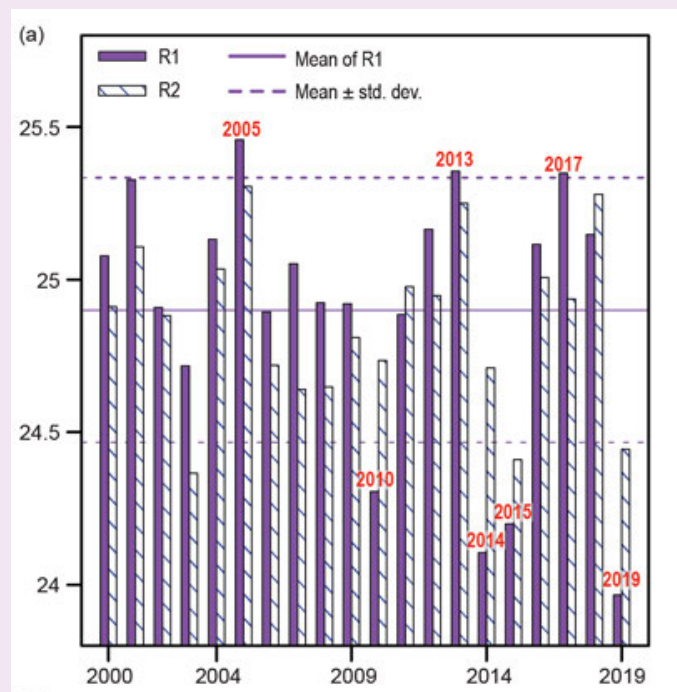

(c)

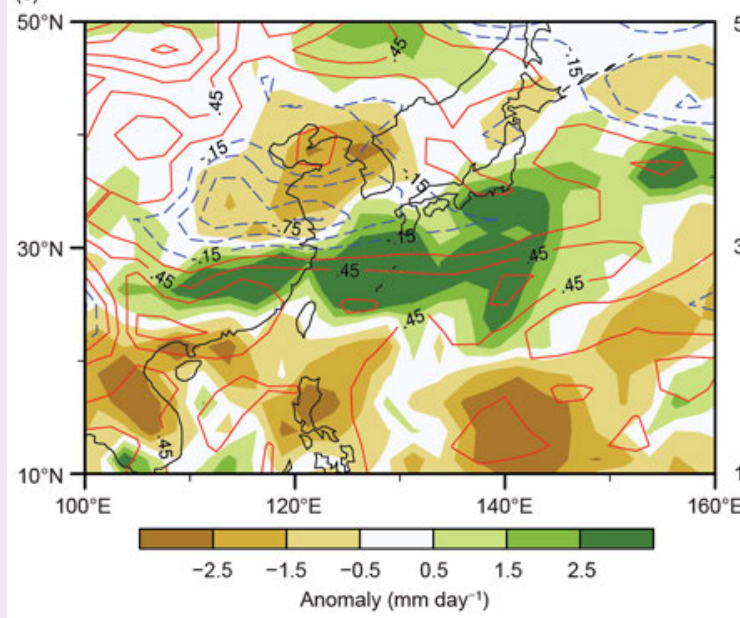

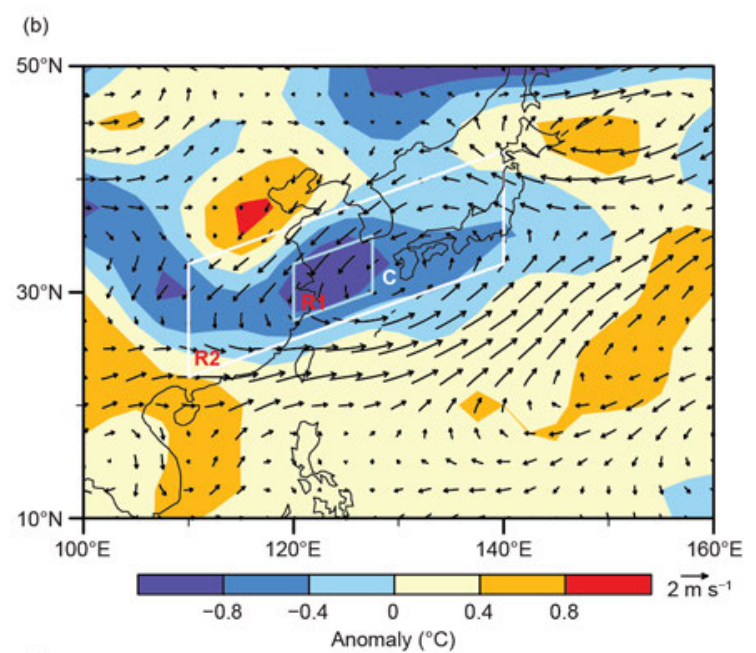

(d)

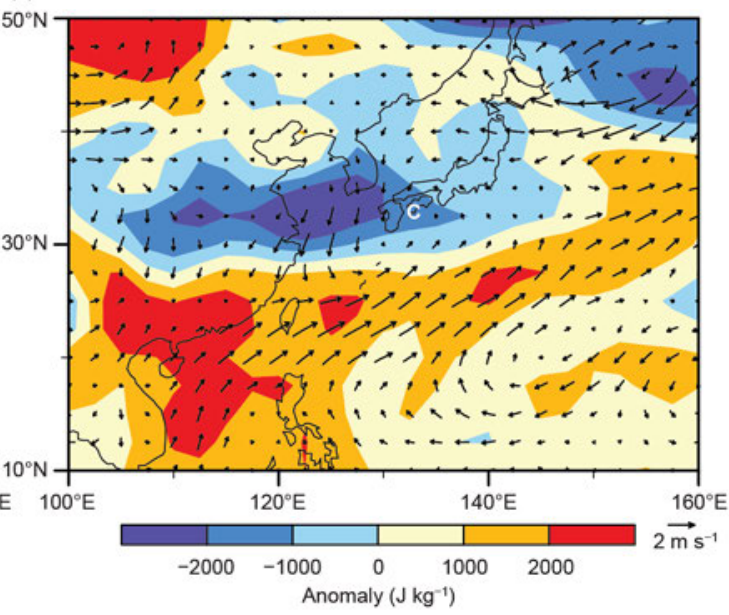

Fig. SB7.11. (a) Time evolution of area-averaged Jun-Jul mean air temperature at $1000 \mathrm{hPa}$ during the past 20 years $(2000-19)$ over the $R 1$ and $R 2$ regions (shown in the white boxes in b). (b) The horizontal patterns of $1000-\mathrm{hPa}$ air temperature (shaded; ${ }^{\circ} \mathrm{C}$ ) and $850-\mathrm{hPa}$ wind (vector; $\mathrm{m} \mathrm{s}^{-1}$ ) anomalies. (c) The horizontal patterns of precipitation (shaded; $\mathrm{mm} \mathrm{day}^{-1}$ ) and 1000-850 hPa averaged specific humidity $\left(\mathrm{g} \mathrm{kg}^{-1}\right.$ ) anomalies. (d) The horizontal patterns of 1000-850 hPa averaged MSE (shaded; $\mathrm{J} \mathrm{kg}^{-1}$ ) and $1000-\mathrm{hPa}$ wind (vector; $\mathrm{m} \mathrm{s}^{-1}$ ) anomaly fields. (Sources: NOAA CMAP precipitation and NCEP/ DOE Reanalysis II.)

which caused the southward shift of a positive rainfall anomaly response away from the original cyclonic center. The shifted rainfall response further affected the low-level circulation through a positive convection-circulation feedback. As a result, the low-level cyclone eventually settled at $33^{\circ} \mathrm{N}$, shifting slightly southward relative to the upper-level cyclonic center.

In the Indian Ocean, positive (negative) sea surface temperature (SST) anomalies were observed in the western (eastern) tropical Indian Ocean, indicating a positive Indian Ocean dipole (IOD; Saji et al. 1999; Saji and Yamagata 2003) during boreal summer 2019, which in fact evolved into one of the strongest positive IOD events of the past three decades by late autumn (see section 4h). In association with positive IOD events, convective activity is generally enhanced over the western Indian
Ocean and suppressed over the eastern tropical Indian Ocean and the Maritime Continent with lower-tropospheric easterly wind anomalies over the tropical Indian Ocean-these characteristic conditions were seen in this 2019 event (see section 4h). Figure SB7.13a shows a time-longitude cross section of outgoing longwave radiation (OLR) anomaly along the equator averaged over $5^{\circ} \mathrm{N}-5^{\circ} \mathrm{S}$ from July to December 2019, indicating a pair of persistent, enhanced convective activities over the western Indian Ocean and a suppressed one over the eastern tropical Indian Ocean and the Maritime Continent. The time-longitude cross section of equatorial $850-\mathrm{hPa}$ zonal wind anomalies (Fig. SB7.13b) indicates easterly wind anomalies in the lower troposphere at the same time, especially in October and November, which can be attributed to the enhanced and 
suppressed convective activities in and around the Indian Ocean. It is noted that the intensity of the $850-\mathrm{hPa}$ easterly wind anomalies over the equatorial Indian Ocean $\left(5^{\circ} \mathrm{N}-5^{\circ} \mathrm{S}\right.$, $60^{\circ}-90^{\circ} \mathrm{E}$ ) during the boreal autumn (September -November) in 2019 was one of the three strongest since 1958, using the Japanese 55-year Reanalysis (JRA-55; Kobayashi et al. 2015; not shown). This highlights one of the important features of this 2019 event.
In summary, an extremely cool summer occurred over a vast region of East Asia in 2019. This cooling stemmed from an upper-level wave train induced by an anomalous cyclone over southern Japan. Meanwhile, an independent phenomenona strong positive IOD event-occurred in the tropical Indian Ocean during boreal summer and autumn 2019.
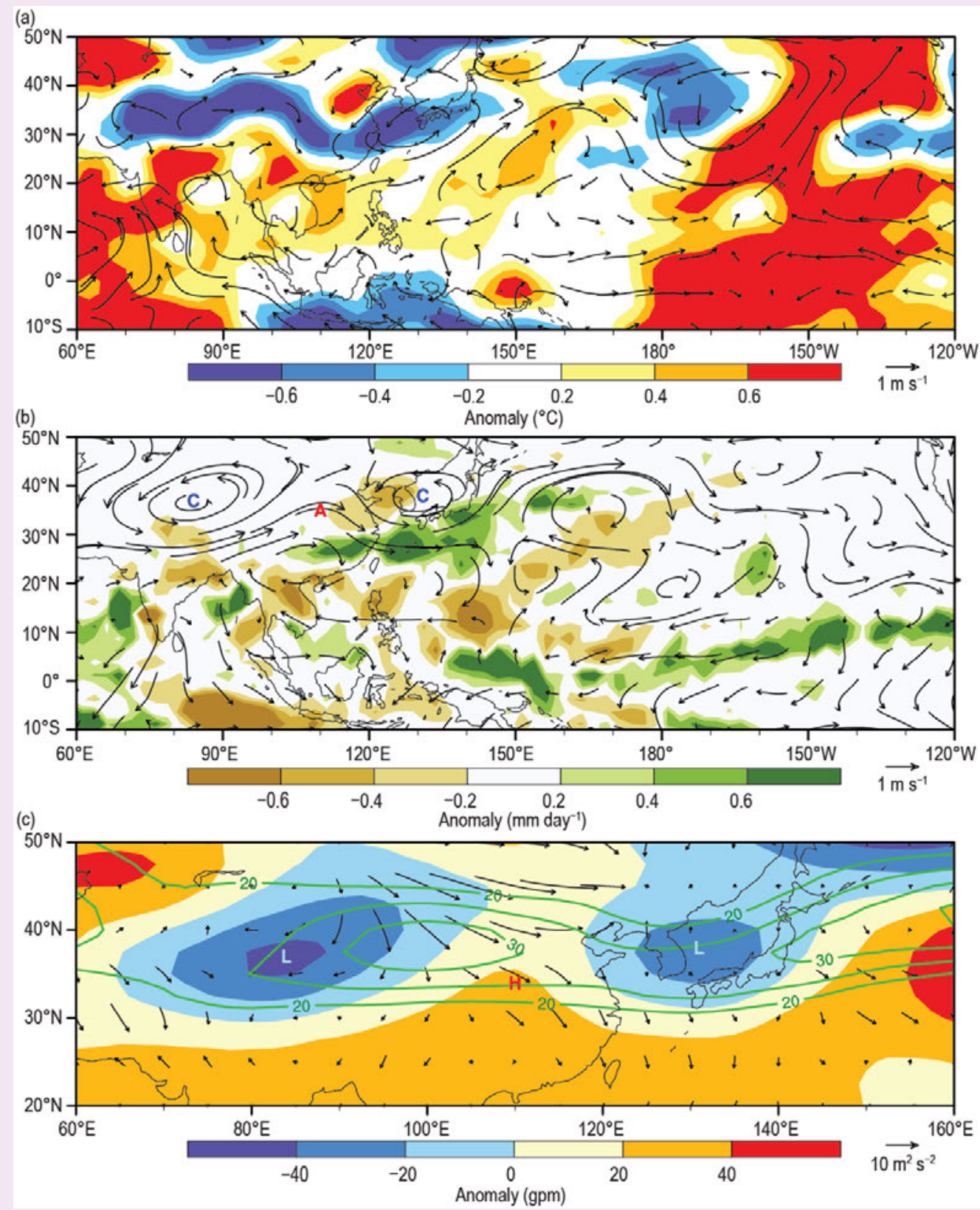

Fig. SB7.12. Horizontal patterns of (a) $1000-\mathrm{hPa}$ temperature (shaded; ${ }^{\circ} \mathrm{C}$ ) and $850-\mathrm{hPa}$ wind (vector; $\mathrm{m} \mathrm{s}^{-1}$ ) anomalies; (b) precipitation (shaded; $\mathrm{mm} \mathrm{day}^{-1}$ ) and 200-hPa wind anomaly fields; and (c) wave activity flux (Takaya and Nakamura, 2001; vector; $\mathrm{m}^{2} \mathrm{~s}^{-2}$ ) and geopotential height (shaded; gpm) anomaly fields at $200 \mathrm{hPa}$ averaged during Jun-Jul 2019 (Base period: 2000-19). Green contours in (c) denote the climatological zonal wind at $200 \mathrm{hPa}$. 

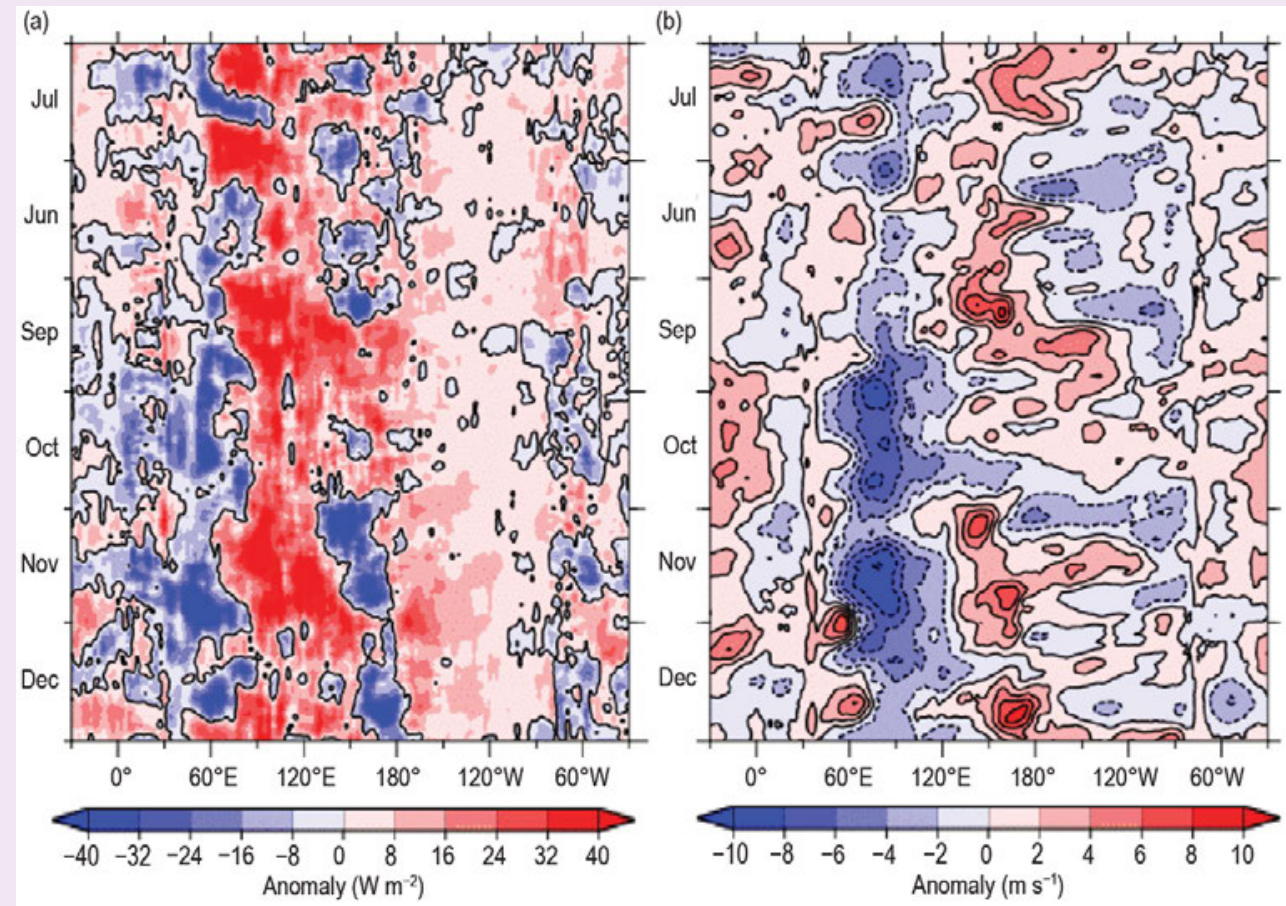

Fig. SB7.13. Time-longitude cross section $\left(5^{\circ} \mathrm{N}-5^{\circ} \mathrm{S}\right)$ of 7-day running mean (a) OLR anomaly and (b) 850 -hPa zonal wind anomaly for Jul-Dec 2019. Intervals are (a) $8 \mathrm{~W} \mathrm{~m}^{-2}$ and (b) $2 \mathrm{~m} \mathrm{~s}^{-1}$, respectively (see color bars). Base period is 1981-2010. (Sources: Tokyo Climate Center; https://ds.data.jma.go.jp/tcc/tcc/products/clisys/ASIA_TCC/mjo_cross.html.)

4) South Asia-A. K. Srivastava, J. V. Revadekar, and M. Rajeevan

Countries in this section include Bangladesh, India, Pakistan, and Sri Lanka. Unless otherwise noted, climate anomalies are relative to the 1981-2010 base period.

\section{(I) TEMPERATURE}

In 2019, South Asia experienced above-normal temperatures. The annual mean surface air temperature averaged over India was $0.36^{\circ} \mathrm{C}$ above average, making 2019 its seventh-warmest year on record since nationwide records began in 1901 (Fig. 7.45). India's seasonal mean temperatures were above normal for all four seasons. Higher-than-normal temperatures during the

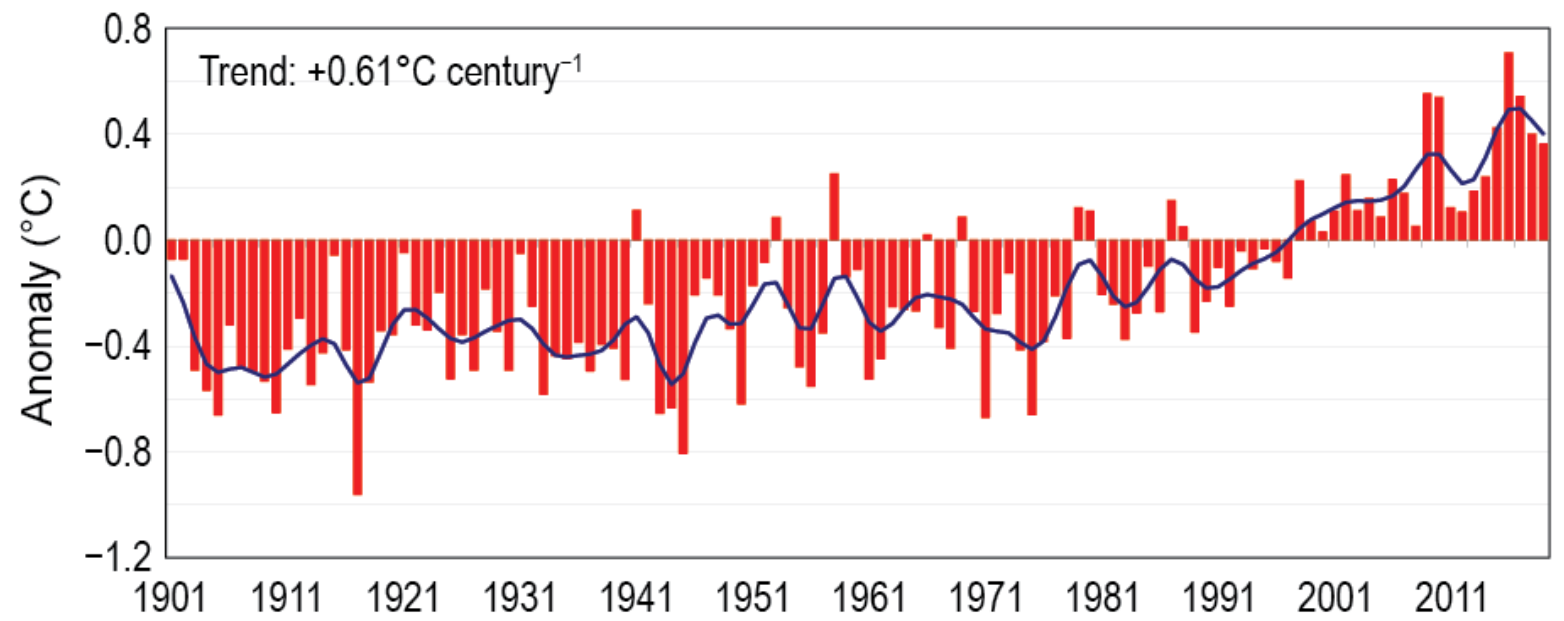

Fig. 7.45. Annual mean temperature anomalies $\left({ }^{\circ} \mathrm{C} ; 1981-2010\right.$ base period) averaged over India for the period 1901-2019. The smoothed time series (9-point binomial filter) is shown as a continuous black line. 
pre-monsoon season (March-May; $+0.39^{\circ} \mathrm{C}$ ) and the monsoon season (June-September; $+0.58^{\circ} \mathrm{C}$, warmest since 1901) largely accounted for the above-normal annual temperature for the year. The 10 warmest years on record are: $2016\left(+0.71^{\circ} \mathrm{C}\right) ; 2009(+0.55) ; 2017(+0.54) ; 2010(+0.53) ; 2015$ (+0.42); 2018 (+0.40); 2019 (+0.36); 1958 (+0.25); 2002 (+0.25); and 2014 (+0.24).

\section{(II) PRECIPITATION}

Summer monsoon season (June-September) rainfall contributes about $75 \%$ of the annual precipitation over South Asia. In 2019, the summer monsoon season set in over Kerala in southern peninsular India on 8 June, seven days later than its climatological normal date (1 June). The monsoon covered the entire country on 19 July, four days later than its climatological normal date (15 July).

The long-term average (LTA) value of the summer monsoon rainfall, calculated using all the data from 1961-2010, is $880 \mathrm{~mm}$. The standard deviation of Indian summer monsoon rainfall (ISMR) is around $10 \%$ of the LTA value. However, over smaller regions, the natural variability of the monsoon is larger (std. dev. around 19\%). During 2019, India as a whole experienced one of its heaviest summer monsoon rains since 1995 despite a delayed and suppressed monsoon during June. The ISMR averaged over the country as a whole was $110 \%$ of its LTA; however, seasonal rainfall was not evenly distributed over the country (Fig. 7.46).

The 2019 ISMR was also characterized by large temporal variability within the season (Fig. 7.47). Table 7.2 lists 24-hour rainfall records during the 2019 ISMR. Seasonal rainfall over the homogeneous regions of central India was 129\% of its LTA; it was 116\% of its LTA over the south peninsula. Northwest India and east and northeast India received 98\% and 88\% of their LTA, respectively. On a monthly scale, rainfall for the country as a whole was significantly below normal during June (57\% of its LTA); near normal during July (105\% of its LTA); and above normal during August (115\% of its LTA). It was substantially above normal during September (152\% of its LTA). During the season, out of 36 meteorological subdivisions, two subdivisions (Saurashtra and Kutch and West Madhya Pradesh) received large excess rainfall (more than 159\% of their LTA), 10 received excess, 19 received normal, and the remaining five subdivisions received deficient rainfall.

During the remainder of the year, precipitation across India was above normal (148\% of LTA) during winter (January-February); below normal (75\% of LTA) during the pre-monsoon season (March-May); and above normal (129\% of LTA) during the post-monsoon season (October-December).

Pakistan, which is at the western edge of the pluvial region of the south Asian monsoon, receives $60 \%-70 \%$ of its annual rainfall during its summer monsoon season (July-September). The summer monsoon sets in over eastern parts of Pakistan around 1 July with a standard deviation of five days. In 2019, summer monsoon rainfall over Pakistan was normal (99\% of the LTA value). The country received near-normal rains during July (92\% of

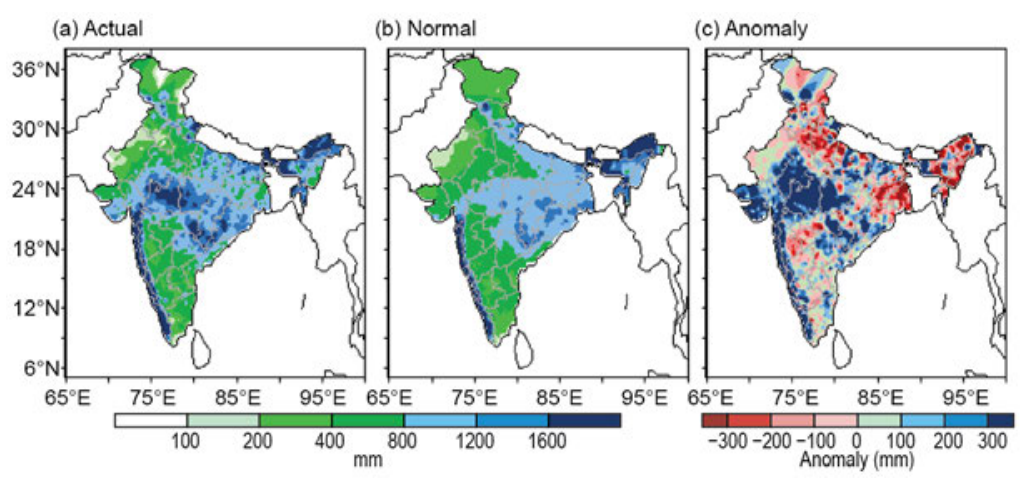

Fig. 7.46. Spatial distribution of (a) actual, (b) normal, and (c) anomalous monsoon seasonal (Jun-Sep) rainfall ( $\mathrm{mm}$ ) over India in 2019.

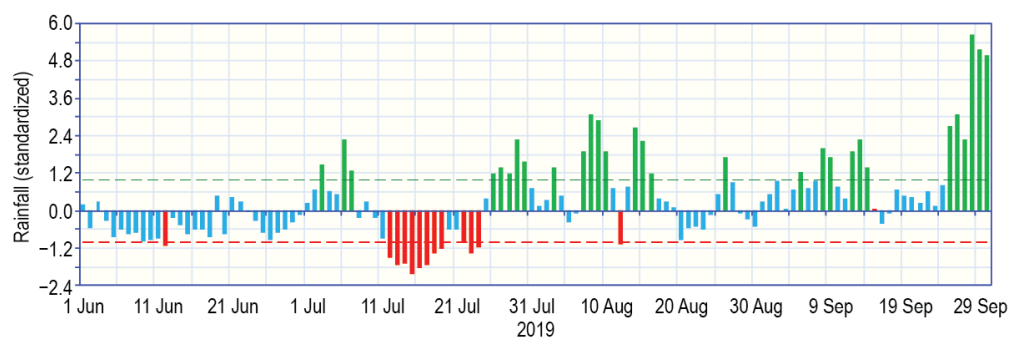

Fig. 7.47. Daily standardized rainfall time series averaged over the core monsoon zone of India (1 Jun-30 Sep 2019). 


\begin{tabular}{|c|c|c|c|c|c|c|}
\hline Number & Station & $\begin{array}{l}\text { Rainfall total } \\
\quad(\mathrm{mm})\end{array}$ & Date & $\begin{array}{l}\text { Previous record } \\
\text { (mm) }\end{array}$ & Date of record & Year of record \\
\hline \multicolumn{7}{|c|}{ Jun 2019} \\
\hline 1 & Long Islands & 308.0 & 13 & 281.9 & 7 & 1957 \\
\hline 2 & Raisen & 115.6 & 30 & 110 & 24 & 1970 \\
\hline 3 & Kodaikanal & 63.0 & 6 & 61.1 & 1 & 1986 \\
\hline \multicolumn{7}{|c|}{ Jul 2019} \\
\hline 1 & Shajapur & 177.0 & 28 & 174.8 & 12 & 1998 \\
\hline 2 & Jagdalpur & 201.8 & 29 & 180.9 & 7 & 1934 \\
\hline \multicolumn{7}{|c|}{ Aug 2019} \\
\hline 1 & Baroda City & 556.8 & 1 & 277.1 & 5 & 1956 \\
\hline 2 & Alibag & 410.9 & 4 & 311.2 & 19 & 1970 \\
\hline 3 & Coimbatore & 120.0 & 9 & 60.8 & 6 & 1964 \\
\hline 4 & Vellore & 165.7 & 17 & 106.2 & 8 & 1909 \\
\hline 5 & Tuticorin & 30.5 & 18 & 30.2 & 12 & 1972 \\
\hline 6 & Uthagamandalam & 183.6 & 9 & 84.2 & 20 & 1971 \\
\hline 7 & Coimbatore AP & 106.4 & 9 & 83.7 & 24 & 1988 \\
\hline 8 & Belgaum (Sambra) AP & 148.2 & 8 & 101.1 & 17 & 1978 \\
\hline 9 & Hassan & 134.0 & 9 & 110 & 28 & 2008 \\
\hline 10 & Karipur & 170.8 & 10 & 153.4 & 7 & 1997 \\
\hline 11 & Cial Cochi & 212.7 & 9 & 66.5 & 12 & 2008 \\
\hline \multicolumn{7}{|c|}{ Sep 2019} \\
\hline 1 & Pant Nagar & 129.4 & 1 & 105 & 10 & 1967 \\
\hline 2 & Seoni & 313.4 & 9 & 208 & 1 & 1947 \\
\hline 3 & Jagdalpur & 288.5 & 6 & 163.8 & 24 & 1911 \\
\hline 4 & Nandyal & 125.8 & 16 & 97.8 & 25 & 1990 \\
\hline 5 & Medikeri & 136.4 & 5 & 110.4 & 1 & 1995 \\
\hline
\end{tabular}

its LTA) and August (103\%), and above-normal rains during September (121\%). Geographically, rainfall was generally normal except over northwestern Pakistan. Bangladesh received normal rainfall during its 2019 summer monsoon season. Sri Lanka also received normal rainfall during its summer monsoon season (May-September).

The northeast monsoon (NEM) normally sets in over southern peninsular India during October and over Sri Lanka in late November. The NEM contributes 30\%-50\% of annual rainfall over southern peninsular India and Sri Lanka as a whole. In 2019, the NEM onset over southern peninsular India occurred on 16 October, four days earlier than its normal onset date. NEM seasonal rainfall over southern peninsular India was normal (109\% of its LTA value). The NEM rainfall activity over Sri Lanka was also normal.

\section{(III) NOTABLE EVENTS AND IMPACTS}

Heavy rain and flood-related incidents claimed over 850 lives in different parts of India during the pre-monsoon, monsoon, and post-monsoon seasons. Of these, 306 casualties were reported from the state of Bihar alone. From Maharashtra, 136 casualties were reported. From the southern Indian state of Kerala, 88 deaths due to heavy rains and landslides were reported during the second week of August. The cyclonic storm Fani, which crossed the Odisha coast on 3 May, claimed around 80 lives in the eastern coastal state of Orissa and neighboring Bangladesh. 
During the first three weeks of July, severe flooding in Bangladesh affected 21 districts, resulting in 120 deaths and causing landslides and widespread destruction of properties and agricultural crops.

Heat wave conditions, which prevailed over northeastern and central India during March-June, claimed about 350 lives. Of these, 292 deaths were reported during 15-18 June from the state of Bihar. Many cities in northern and central India were abnormally warmer in the first three weeks of June, with temperatures surpassing $45^{\circ} \mathrm{C}$ for several days. Some unusually high temperatures observed on 3 June were Churu $\left(50.3^{\circ} \mathrm{C}\right)$, Bikaner $\left(48.4^{\circ} \mathrm{C}\right)$, and Ganganagar $\left(48.8^{\circ} \mathrm{C}\right)$, all of which are in the state of Rajasthan. Temperatures over the capital city of Delhi remained above $45^{\circ} \mathrm{C}$ for 12 days and reached $48.0^{\circ} \mathrm{C}$ on 10 June, an all-time high for the month of June in the city.

Lightning associated with thunderstorm activity reportedly claimed over 380 lives in central, northeastern, northwestern, and the peninsular parts of India during the pre-monsoon, monsoon, and post-monsoon seasons. Snowfall- and avalanche-related incidents claimed 33 lives from Jammu and Kashmir, and 18 lives from Leh (18 January). A cold wave claimed 28 lives from different parts of Uttar Pradesh during the last week of December 2019.

Due to heavy summer monsoon rainfall, Sri Lanka experienced floods in September, which is rare for this month. The floods engulfed 13 districts, affecting about 120000 people. In December, 14 districts across the country were flooded due to heavy northeast monsoon rains.

At least 24 people died and more than 2 million were displaced after Tropical Cyclone (TC) Bulbul hit the coastal areas of Bangladesh on 9 November.

\section{5) Southwest Asia-A. Fazl-Kazem and A. Vazifeh}

This section covers only Iran. Turkey is included in the Europe subsection, 7f. Climate anomalies are relative to a 1997-2017 base period for temperature and 1985-2019 base period for precipitation.

\section{(I) TEMPERATURE}

All seasons in 2019 experienced above-average temperatures (Fig. 7.48), with the greatest anomaly of $+3^{\circ} \mathrm{C}$ in summer, leading to an annual anomaly of $+1.6^{\circ} \mathrm{C}$. The highest temperature anomalies in winter were recorded in northwest to northeast Iran (Ardabil, Gilan, and northern Khorasan-Razavi Provinces). In spring, with daily temperatures ranging from $0^{\circ}$ to $20^{\circ} \mathrm{C}$ in most areas, the average temperature anomaly was $+0.8^{\circ} \mathrm{C}$ for the country (Fig. $\left.7.47 \mathrm{~b}\right)$. The hottest areas in spring were the Dashte-Lut Desert, parts of Sistan and Baluchestan, and some regions of the Kerman Province where average temperatures ranged from $35^{\circ}$ to $40^{\circ} \mathrm{C}$. Average temperatures in the Alborz highlands (the climatological coldest area) ranged from $-10^{\circ}$ to $-5^{\circ} \mathrm{C}$.

The summer temperature anomaly was the highest among the four seasons and more spatially uniform (Fig. 7.48c). In parts of the northern provinces, as well as Isfahan, Khorasan Razavi, Yazd, Sistan and Baluchestan, Hormozgan, Fars, Bushehr, Khuzestan, and western Iran, the average temperature was between $30^{\circ}$ and $40^{\circ} \mathrm{C}$. Eastern and central Iran experienced average temperatures of $25^{\circ}-30^{\circ} \mathrm{C}$.

In autumn the average national temperature was $+0.4^{\circ} \mathrm{C}$ above average. Except for Khorasan Razavi, all provinces experienced above-average temperatures for the season, with most anomalies ranging from $+0.1^{\circ}$ to $+3.0^{\circ} \mathrm{C}$ (Fig. 7.48d). The highest anomalies were over western and southeastern Iran, Semnan and Isfahan Provinces, and a small part of northern Mazandaran.

\section{(II) PRECIPITATION}

Iran received an average of $309 \mathrm{~mm}$ of precipitation in 2019, which is 112\% of normal. Spring and autumn were wetter than normal, while winter and summer were drier than normal in 2019 (Fig. 7.49). The highest mean monthly accumulated precipitation occurred at the following stations: Kalaleh airport in north $(257.4 \mathrm{~mm})$ in April; Kooh-Rang station $(621.5 \mathrm{~mm})$ in March; and Kia-Shahr port city in north $(398.5 \mathrm{~mm})$ in November. 

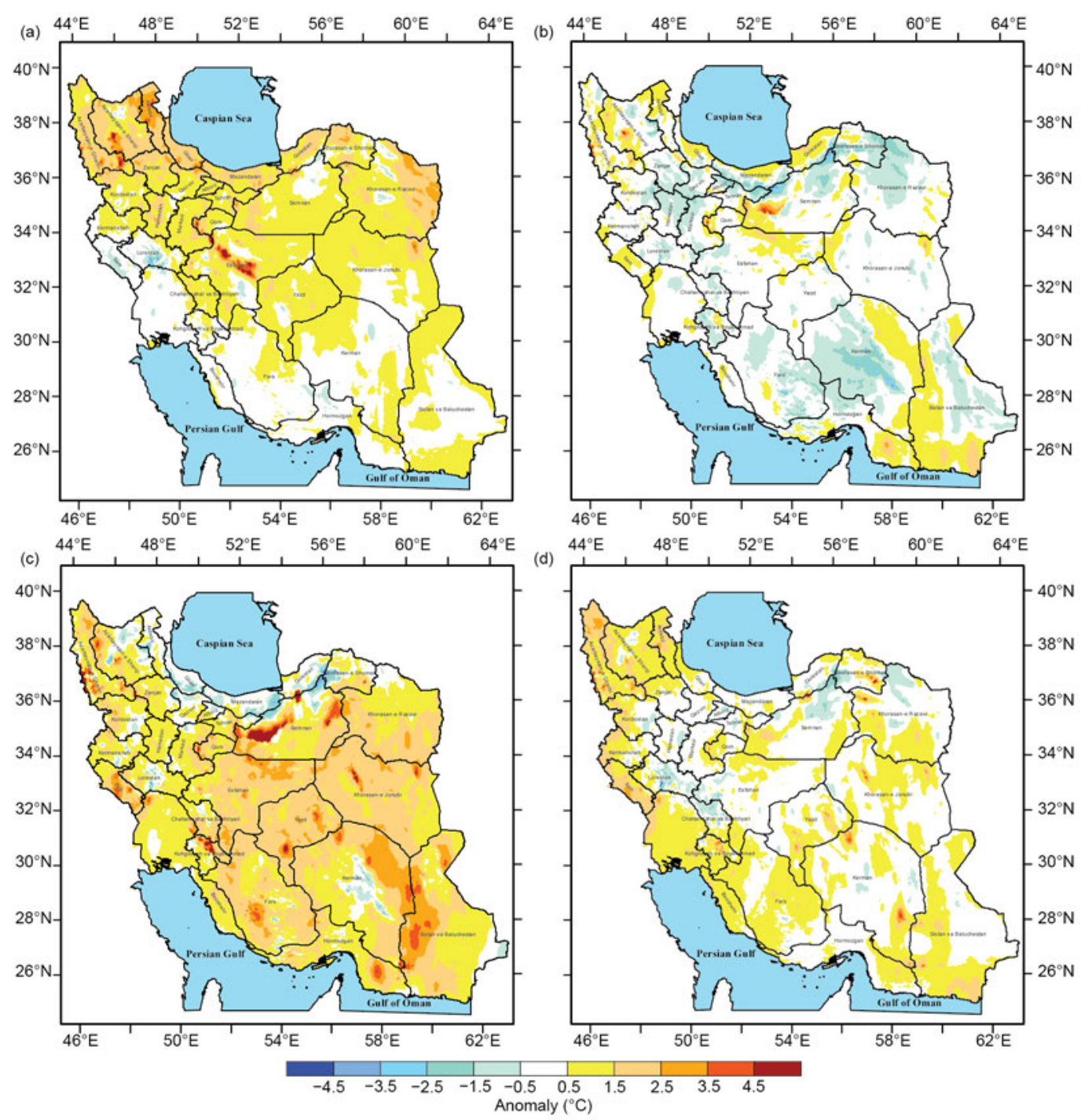

Fig. 7.48. Seasonal mean surface temperature anomalies ( ${ }^{\circ} \mathrm{C}$; 1997-2017 base period) over Iran in (a) winter, (b) spring, (c) summer, and (d) autumn 2019. (Source: I. R. of Iran Meteorological Organization.)

During winter, Iran received $64.7 \mathrm{~mm}$ of precipitation, which is about $33 \%$ of its average. Geographically, precipitation was below average across most of the country except northwestern Iran and some small parts of northern and western Iran.

In spring, the average rainfall across the country was $70.8 \mathrm{~mm}$, which was $227 \%$ of normal. Heavy precipitation from frontal systems mixed with convective instability caused severe floods in the north and from the southwest to the west of the country.

In autumn, total average precipitation was $91.4 \mathrm{~mm}$, which is about $150 \%$ of normal. A new 24hour record of $300.6 \mathrm{~mm}$ was observed at RoodSar station in Gilan Province, which borders the Caspian Sea in northern Iran. Accumulated precipitation in the southwest, west, north, northeast, and parts of Kerman and Fars Provinces was more than 150\% of normal. However, areas over the southeast and the central desert were drier than normal.

\section{(III) NOTABLE EVENTS}

A maximum temperature of $53^{\circ} \mathrm{C}$ was observed in Shahdad of Kerman province in southeast Iran on 2 July. A minimum temperature of $-20.3^{\circ} \mathrm{C}$ occurred in Shahre-Kord station on 1 March, and a minimum temperature of $-20.5^{\circ} \mathrm{C}$ was reported at Kooh-Rang station in the Chahar-Mahal province in western Iran on 20 December 2019. The highest summer minimum daily temperature 

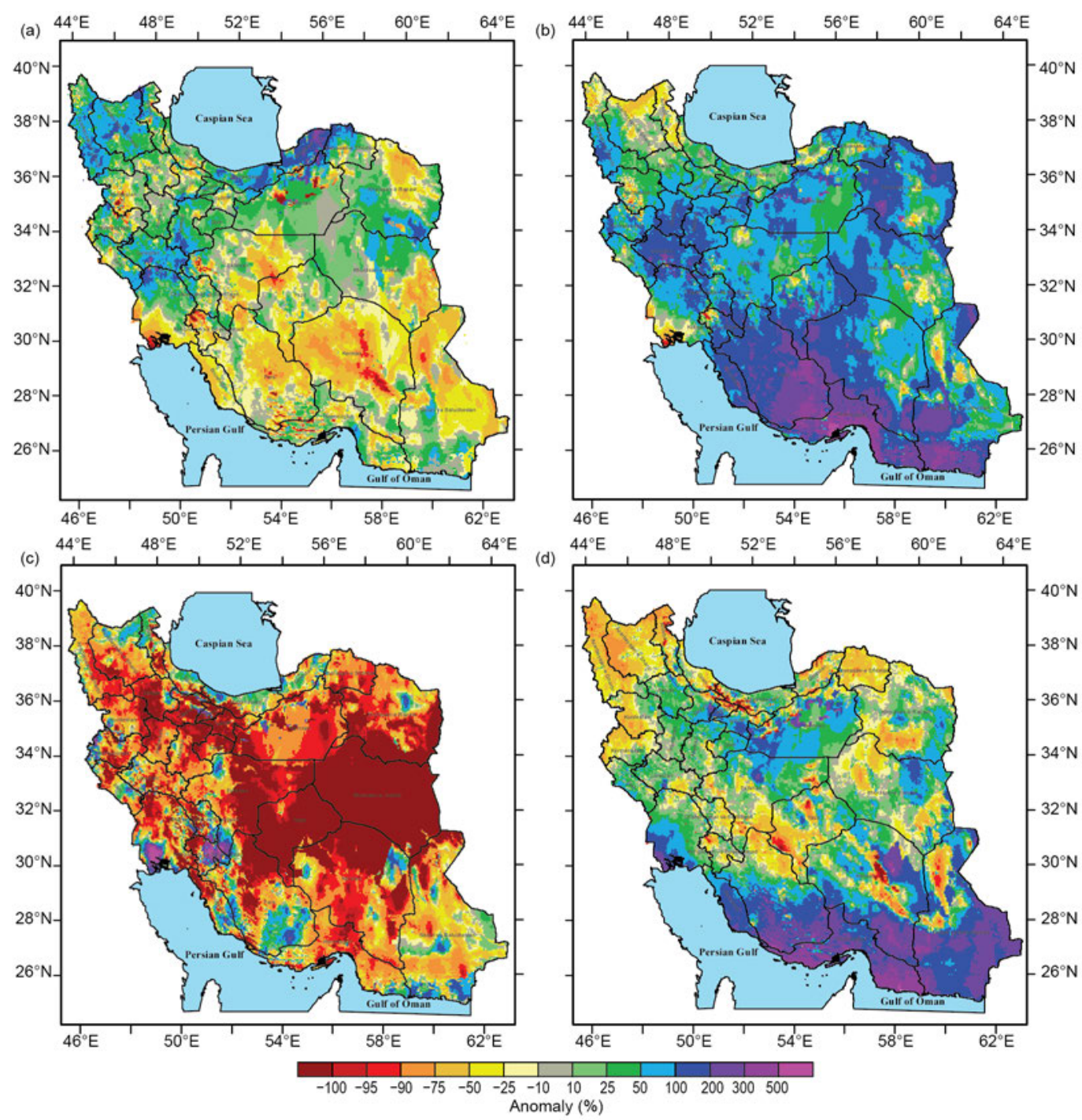

Fig. 7.49. Observed precipitation anomaly percentage (relative to the 1985-2019 base period) over Iran in (a) winter, (b) spring, (c) summer, and (d) autumn 2019. (Source: I. R. of Iran Meteorological Organization.)

$\left(33.8^{\circ} \mathrm{C}\right)$ in Tehran was recorded on 17 July. This new record was $1.2^{\circ} \mathrm{C}$ higher than the original record of $32.6^{\circ} \mathrm{C}$.

In March-April, heavy and record-breaking accumulated precipitation in north and southwest Iran caused devastating disasters with severe life, property, and agricultural damages in the regions.

h. Oceania-C. Ganter, Ed.

\section{1) Overview-C. Ganter}

Oceania was under the influence of El Niño-like conditions early in 2019, although these were weak. In fact, not all countries considered El Niño to be present. Regardless, by mid-year, clear-cut neutral El Niño-Southern Oscillation (ENSO) conditions were in place. The pattern of sea surface temperatures (SSTs) in the Indian Ocean was generally consistent with a positive Indian Ocean dipole (IOD) from late May, with the IOD index firmly in positive territory between August and the end of the year. The 2019 IOD was the strongest in the observational record since 1997 (see section $4 \mathrm{~h}$ for details). During the second half of the year, a rare sudden stratospheric warming (SSW) event also influenced the southern countries of Oceania: Australia and New Zealand. The combination of the positive IOD and negative Southern Annular Mode (SAM) contributed toward Australia's exceptional fire season in the second half of 2019 (see Sidebar 7.6). 
2) Northwest Pacific and Micronesia-M. A. Lander, C. P. Guard, and B. Bukunt

This assessment covers the area from the date line west to $130^{\circ} \mathrm{E}$, between the equator and $20^{\circ} \mathrm{N}$. It includes the U.S.-Affiliated Islands of Micronesia but excludes the western islands of Kiribati and nearby northeastern islands of Indonesia. The reference period used for this assessment is 1981-2010.

For much of Micronesia, the weather and climate of 2019 will be remembered-or largely forgotten-as a quiet year relatively free of extremes of wind, waves, or rainfall. It was somewhat dry in the first half. Several typhoons passed through the region but largely avoided populated islands. Most locations were cooler and/or drier than during 2018.

\section{(I) TEMPERATURE}

Approximately twice as many locations in Micronesia experienced above-average annual mean temperatures as those that experienced below-average annual mean temperatures during 2019 (see Table 7.3 for temperature anomalies for selected locations across Micronesia). Abnormally sunny and dry conditions in the first half of the year likely contributed to the above-average temperatures seen in some of the westernmost islands of Micronesia (Yap, Guam, and Saipan), while cloudy wet weather at some of the easternmost islands (Pohnpei, Kosrae, and Majuro) contributed to some below-average temperatures. During the second half of 2019, the situation reversed with Guam and Saipan becoming cloudy, wet, and cooler.

\begin{tabular}{|c|c|c|c|c|c|c|c|c|c|c|}
\hline \multirow[t]{3}{*}{ Location } & \multicolumn{2}{|c|}{$\begin{array}{l}\text { Max Temp } \\
\text { Min Temp }\end{array}$} & \multicolumn{8}{|c|}{$\begin{array}{c}\text { Rainfall } \\
(\mathrm{mm})\end{array}$} \\
\hline & Jan-Jun & Jul-Dec & Jan-Jun & Jan-Jun & Jan-Jun & Jul-Dec & Jul-Dec & Jul-Dec & Jan-Dec & Jan-Dec \\
\hline & ${ }^{\circ} \mathrm{C}$ & ${ }^{\circ} \mathrm{C}$ & AVG & 2019 & $\%$ & AVG & 2019 & $\%$ & 2019 & $\%$ \\
\hline $\begin{array}{c}\text { Saipan } \\
15^{\circ} \mathrm{N}, 146^{\circ} \mathrm{E}\end{array}$ & $\begin{array}{l}+1.20 \\
+0.21\end{array}$ & $\begin{array}{l}+0.10 \\
-0.70\end{array}$ & 449.1 & 322.3 & 71.8 & 1322.8 & 1921.8 & 145.3 & 2244.1 & 126.7 \\
\hline $\begin{array}{c}\text { Guam } \\
13^{\circ} \mathrm{N}, 145^{\circ} \mathrm{E}\end{array}$ & $\begin{array}{l}+0.79 \\
+0.46\end{array}$ & $\begin{array}{l}+0.44 \\
+0.27\end{array}$ & 691.6 & 471.4 & 68.2 & 1788.4 & 1864.4 & 104.2 & 2335.8 & 94.2 \\
\hline $\begin{array}{c}\text { Yap } \\
9^{\circ} \mathrm{N}, 138^{\circ} \mathrm{E}\end{array}$ & $\begin{array}{l}+0.24 \\
+0.67\end{array}$ & $\begin{array}{r}-0.29 \\
+0.42\end{array}$ & 1169.7 & 1157.2 & 98.9 & 1902.0 & 1533.6 & 80.6 & 2690.9 & 87.6 \\
\hline $\begin{array}{c}\text { Palau } \\
7^{\circ} \mathrm{N}, 134^{\circ} \mathrm{E}\end{array}$ & $\begin{array}{l}-0.55 \\
-0.49\end{array}$ & $\begin{array}{l}-0.13 \\
-0.63\end{array}$ & 1798.1 & 1256.0 & 69.8 & 2279.4 & 1975.6 & 86.7 & 3231.6 & 79.3 \\
\hline $\begin{array}{c}\text { Chuuk } \\
7^{\circ} \mathrm{N}, 152^{\circ} \mathrm{E}\end{array}$ & $\begin{array}{l}+0.36 \\
+1.31\end{array}$ & $\begin{array}{l}+0.35 \\
+1.05\end{array}$ & 1584.2 & 1708.9 & 107.9 & 1833.1 & 1989.1 & 108.5 & 3698.0 & 108.2 \\
\hline $\begin{array}{c}\text { Pohnpei } \\
7^{\circ} \mathrm{N}, 158^{\circ} \mathrm{E}\end{array}$ & $\begin{array}{l}-0.68 \\
+1.95\end{array}$ & $\begin{array}{l}-0.35 \\
+1.53\end{array}$ & 2266.4 & 2256.0 & 99.5 & 2336.6 & 2995.7 & 128.2 & 5251.7 & 114.1 \\
\hline $\begin{array}{c}\text { Kapinga } \\
1^{\circ} \mathrm{N}, 155^{\circ} \mathrm{E}\end{array}$ & $\mathrm{n} / \mathrm{a}$ & $\mathrm{n} / \mathrm{a}$ & 1750.8 & 2691.4 & 153.7 & 1510.5 & 1793.8 & 118.8 & 4485.1 & 137.5 \\
\hline $\begin{array}{c}\text { Kosrae } \\
5^{\circ} \mathrm{N}, 163^{\circ} \mathrm{E}\end{array}$ & $\begin{array}{l}-0.25 \\
-0.35\end{array}$ & $\begin{array}{l}+0.03 \\
+0.33\end{array}$ & 2567.9 & 3112.5 & 121.2 & 2342.5 & 1775.0 & 75.8 & 4887.5 & 99.5 \\
\hline $\begin{array}{c}\text { Majuro } \\
7^{\circ} \mathrm{N}, 171^{\circ} \mathrm{E}\end{array}$ & $\begin{array}{r}-0.27 \\
+0.93\end{array}$ & $\begin{array}{l}+0.38 \\
+1.05\end{array}$ & 1368.3 & 1266.2 & 92.5 & 1868.2 & 1888.5 & 101.1 & 3154.7 & 97.5 \\
\hline $\begin{array}{l}\text { Kwajalein } \\
9^{\circ} \mathrm{N}, 168^{\circ} \mathrm{E}\end{array}$ & $\begin{array}{l}+0.44 \\
+0.51\end{array}$ & $\begin{array}{l}+0.82 \\
+0.62\end{array}$ & 801.4 & 614.43 & 76.7 & 1579.1 & 1382.5 & 87.6 & 1997.0 & 83.9 \\
\hline
\end{tabular}




\section{(II) PRECIPITATION}

Widespread dry conditions were present across much of Micronesia during the first half of 2019 (Table 7.3), likely a typical response to the waning of El Niño conditions. According to NOAA's Oceanic Niño Index (ONI), the El Niño threshold was met in the 3-month period of SeptemberNovember 2018 (see section 4b). The ONI continued above the El Niño threshold through June 2019 and thereafter faded to ENSO-neutral. Dry conditions across most of Micronesia typically occur in the first half of any year during which the ONI begins the year above the $+0.5^{\circ} \mathrm{C}$ El Niño threshold and then steadily decreases over the course of the year (Ropelewski and Halpert 1987).

Rainfall deficits on Guam and Saipan exacerbated their respective wildfire seasons, with Guam in particular experiencing more area burned in the first half of 2019 than during the extreme post-El Niño drought of early 2016. A majority of locations were drier during 2019 than in 2018, for the entire year and also for its first and second halves.

\section{(III) NOTABLE EVENTS AND IMPACTS}

While 2018 saw nearly all of the islands of Micronesia experience at least some moderate impacts from tropical cyclones, 2019 was relatively quiet for the populated islands. However, several significant systems occurred in the region during 2019.

Super Typhoon Wutip (the second tropical cyclone [TC] of 2019) reached its peak intensity of $140 \mathrm{kt}\left(72 \mathrm{~m} \mathrm{~s}^{-1}\right)$ on 25 February, west of Guam. It became the most powerful February typhoon on record, surpassing Typhoon Higos of 2015. The Mariana Islands were spared the wrath of Wutip, with the typhoon passing just far enough west of Guam and Saipan to avoid problematic rains and high winds. Guam did receive 100-150 mm of beneficial dry season rainfall.

Super Typhoon Hagibis passed directly over the uninhabited island of Anatahan $\left(16.3^{\circ} \mathrm{N}\right.$, $145.6^{\circ} \mathrm{E}$ ) on the night of 7 October. At that time, its intensity was $140 \mathrm{kt}$, but less than 24 hours earlier it had been only a tropical storm (24-63 kt or $\left.12.3-32.4 \mathrm{~m} \mathrm{~s}^{-1}\right)$. Hagibis exhibited “...the most intensification by a tropical cyclone in the western North Pacific in 18 hours since Yates in 1996,” (Philip Klotzbach, pers. comm.). Hagibis also possessed a very small eye-small enough to qualify as a "pinhole" eye (i.e., any eye diameter less than 10 nautical miles, representing less than $10 \%$ of the storm size measurements made by aircraft [Musgrave et al. 2008]). After passing Anatahan, Hagibis underwent an eyewall replacement cycle in which the pinhole eye was surrounded and replaced by a new, much larger eye (Fig. 7.50).

Typhoon Kammuri passed westward to the south of Guam on 25 November, bringing gales and heavy rainfall to the island. Kammuri had an unusual structure for a developing tropical cyclone, known as a central cold cover (CCC; Dvorak 1984). At 0420 UTC on 30 November, the NOAA-20 satellite detected a cloud-top infrared brightness temperature of $-109.4^{\circ} \mathrm{C}$ just west of Kammuri's center. This qualifies as the coldest cloud-top temperature on record observed by a meteorological satellite (CIMSS 2019). The previous record for coldest documented brightness temperature of $-102.2^{\circ} \mathrm{C}$ was observed during TC Hilda in 1990 (Ebert and Holland 1992). The
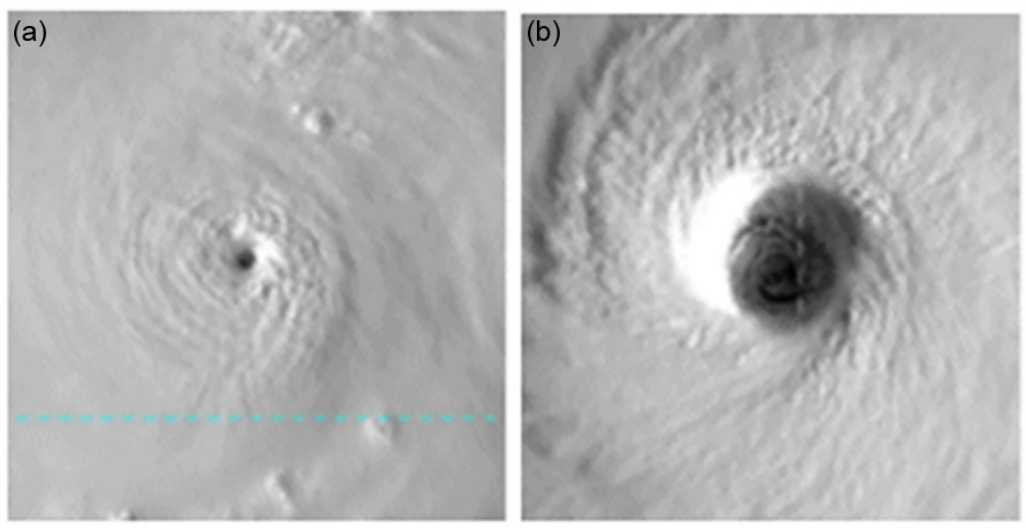

Fig. 7.50. The pinhole eye of Super Typhoon Hagibis on the evening of 7 Oct (left), and with a much larger eye as seen 63 hours later on the morning of 9 Oct (right). The images are at the same scale (220 $\mathrm{km} \times 220 \mathrm{~km})$. 
enormous CCC cloud pattern was described by Dvorak (1984) to be indicative of stalled development, and indeed, during the 3-day time period of Kammuri's possession of a CCC, its intensity held steady at or just below typhoon force.

Please refer to section $4 \mathrm{f} 6$ for additional details and statistics on these tropical cyclones.

\section{3) Southwest Pacific-E. Chandler}

Countries considered in this section include American Samoa, Cook Islands, Fiji, French Polynesia, Kiribati, New Caledonia, Niue, Papua New Guinea (PNG), Samoa, Solomon Islands, Tonga, Tuvalu, Vanuatu, and Wallis and Futuna (see Fig. 7.51). The temperature analysis is based on the Climate Anomaly Monitoring System (CAMS) Monthly Surface Air Temperature Anomalies (https: //iridl.ldeo.columbia.edu/maproom/Global/Atm_Temp/Anomaly.html). Anomalies are with respect to the 1971-2000 base period. The precipitation analysis is based on monthly analyses presented in the Climate and Oceans Support Program in the Pacific (COSPPac) Monthly Bulletin (www .pacificmet.net/products-and-services/climate-bulletin) and COSPPac Online Climate Outlook Forum (www.pacificmet.net/products-and-services/online-climate-outlook-forum). The base period for precipitation is 1979-95.

The year began with a borderline neutral to weak El Niño event. Both atmospheric and oceanic indicators remained at El Niño thresholds until the middle of 2019, before giving way to neutralENSO conditions thereafter. SSTs were persistently above-normal across the Pacific equator through 2019, with a pool of warm water evident on and to the west of the date line for most of the second half of the year. In contrast, atmospheric indicators remained close to neutral with normal rainfall patterns prevailing toward the end of the year.

\section{(I) TEMPERATURE}

Air temperatures were near normal across most of the southwest Pacific during the first quarter of 2019 (Fig. 7.52a), with the exception of $+1^{\circ}$ to $+2^{\circ} \mathrm{C}$ anomalies in a region centered on the date line. By March, the warm anomalies stretched eastward along the equator, covering Nauru, Kiribati, and the northern Cook Islands. This region of above-normal air temperatures was associated with the above-normal equatorial SSTs.

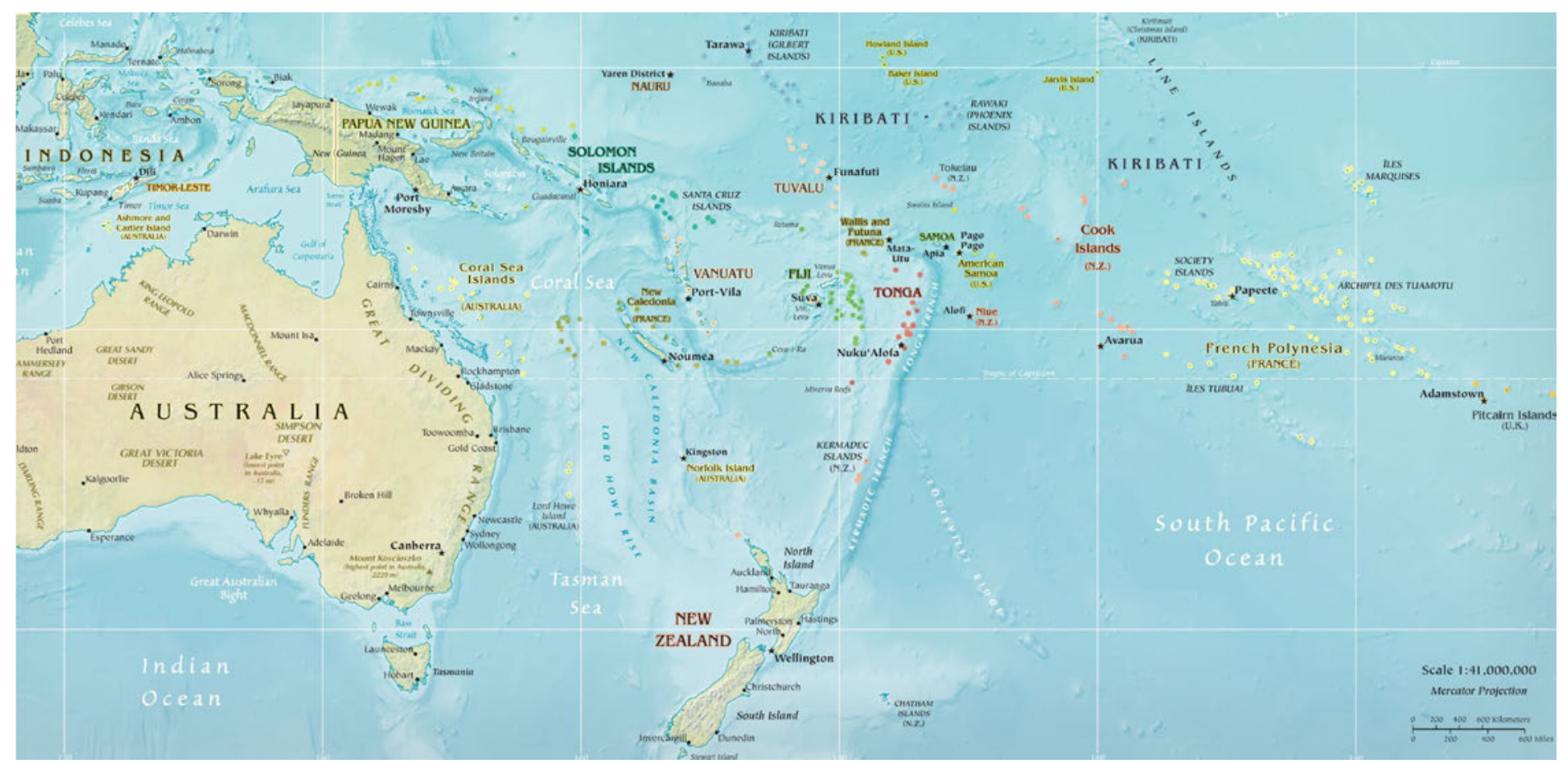

Fig. 7.51. Map of the Southwest Pacific showing the countries considered in this section. (Source: www.geographicguide .com/oceania-map.htm.) 


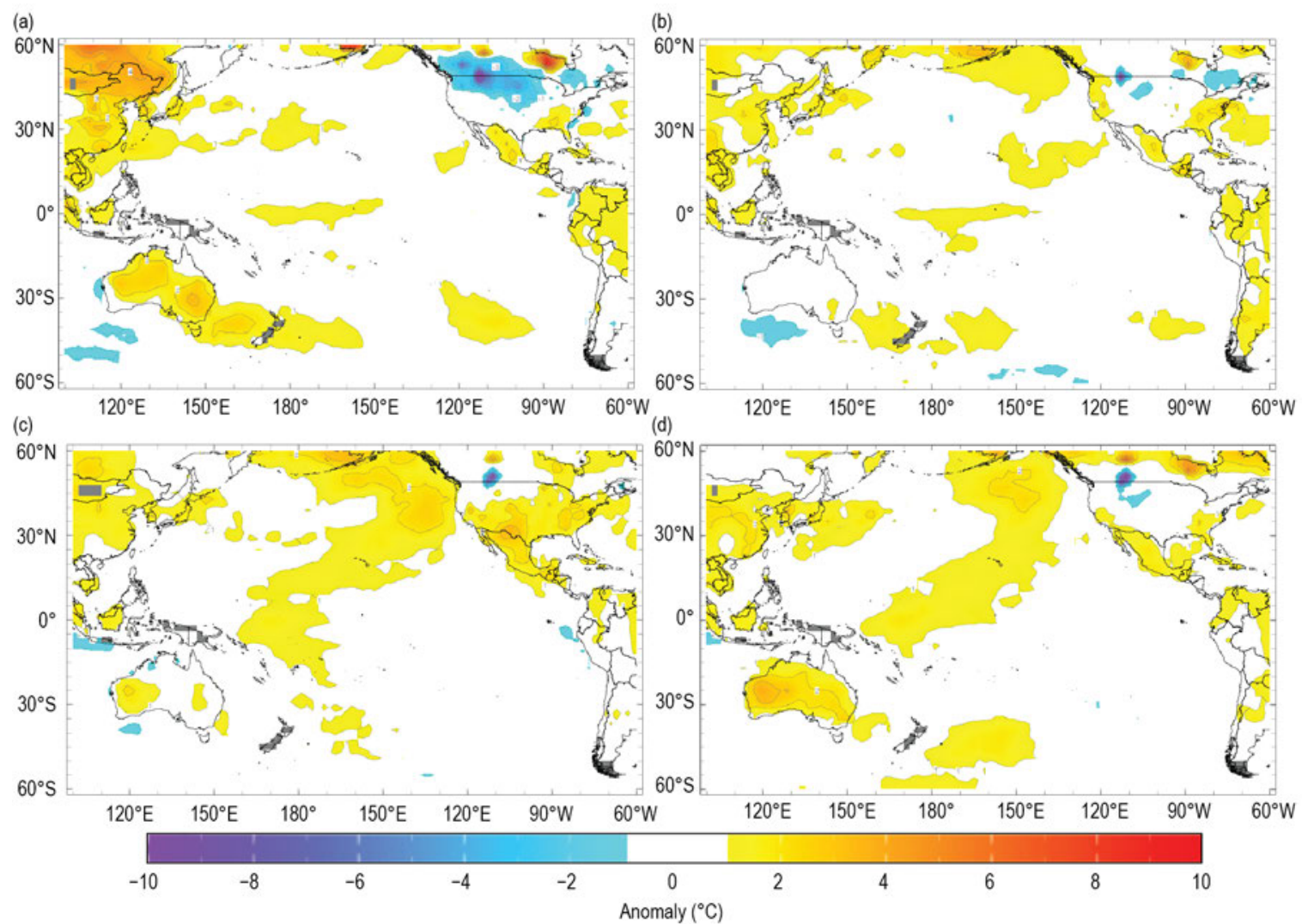

Fig. 7.52. Seasonal temperature anomalies $\left({ }^{\circ} \mathrm{C}\right)$ for (a) JFM, (b) AMJ, (c) JAS, and (d) OND. (Source: CAMS.)

The air temperature anomaly pattern in the southwest Pacific persisted into the second quarter of the year (Fig. 7.52b), with temperatures $1^{\circ}$ to $2^{\circ} \mathrm{C}$ above normal remaining along the equator and extending farther south to include Tuvalu, Samoa, American Samoa, the Cook Islands, and French Polynesia.

In July and August, the warm air temperature pattern shifted farther west, with a large region of anomalies $1^{\circ}$ to $2^{\circ} \mathrm{C}$ above normal in the southwest Pacific extending from the eastern Solomon Islands to the northern Cook Islands, with the southern extent of this region including Fiji, Tonga, and Niue (Fig. 7.52c).

The region of warmth, with air temperatures $1^{\circ}$ to $2^{\circ} \mathrm{C}$ above normal, receded in September and became limited to a region around Nauru, western Kiribati, and Tuvalu, as the underlying above-average SSTs were more localized around and to the west of the date line.

During October-December (OND), an area of air temperatures $1^{\circ}$ to $2^{\circ} \mathrm{C}$ above normal occurred around Nauru, Kiribati, and Tuvalu, while a small region of air temperatures $2^{\circ}$ to $3^{\circ} \mathrm{C}$ above normal was centered on the Gilbert Islands group in western Kiribati (Fig. 7.52d). Above-average air temperature anomalies in OND are consistent with the persistent above-average SSTs in the far western Pacific.

In summary, 2019 experienced near-normal temperature patterns across much of the southwest Pacific, with the notable exception of a region of air temperatures $1^{\circ}$ to $2^{\circ} \mathrm{C}$ above normal centered on the date line; this region was largest in extent during the second half of the year.

\section{(II) PRECIPITATION}

The region experienced a mixed rainfall pattern in the first quarter of 2019, largely a result of the South Pacific Convergence Zone (SPCZ) being shifted southwest in January before moving to a northeast position through February and becoming largely suppressed in March (Fig. 7.53). Rainfall above the 90th percentile for January-March (JFM) was recorded in eastern Fiji, western Kiribati, eastern PNG, northern Vanuatu, and Tonga. Two stations recorded their wettest JFM on 
record: Butaritari in Northern Kiribati $(1830.9 \mathrm{~mm})$ had its wettest JFM in 81 years of record, as did Vava'u in northern Tonga $(1635.3 \mathrm{~mm})$ for its 73-year record.

The SPCZ was close to its long-term average position during April-June (AMJ), in line with a near-neutral ENSO state. A large region of anomalously high rainfall centered on the equator, on and to the west of the date line, was associated with persistently above-average underlying SSTs. This resulted in rainfall above the 90th percentile in eastern Fiji, western and central Kiribati, Samoa, Tuvalu, and southern Vanuatu. Several places recorded their highest AMJ rainfall on record, including Udu Point in northern Fiji (1234.7 mm, 70 years of record), Tarawa (1516.5 mm, 70 years of record) and Beru (1005.1 mm, 62 years of record) in Kiribati, and Niu in Tuvalu (1211.7 $\mathrm{mm}, 74$ years of record).

Despite continuing ENSO-neutral conditions, the SPCZ became more active than usual as the dry season progressed through July, August, and September (JAS), with the SPCZ largely enhanced in the western region over the PNG Islands and Solomon Islands and over Samoa during September. The enhanced rainfall from earlier in the year that was centered on the equator had largely dissipated, leaving a smaller region of enhanced rainfall covering the Solomon Islands and parts of PNG. Rainfall was above the 90th percentile in southeastern PNG, the Solomon Islands, Niue, and Tonga for the JAS period. Taro in the northern Solomon Islands recorded its wettest JAS in 41 years $(1402.5 \mathrm{~mm})$.

There were no large regions of enhanced or decreased rainfall across the region for OND; the SPCZ was somewhat active during this time, sitting south of its climatologically normal position during October and moving northward by December. In northern Fiji, Rotuma was the only station with rainfall above the 90th percentile during OND $(1285.8 \mathrm{~mm}$, 11th highest in 104 years of record); conversely, Madang (PNG), Munda (Solomon Islands), and Port Vila (Vanuatu) all received rainfall below their 10th percentiles for this period.

In summary, rainfall in the southwest Pacific in 2019 was dominated by a large region of enhanced rainfall on and to the west of the date line early in the year. This region of enhanced rainfall was reduced both in terms of geographical size and strength through the year, with rainfall patterns later in 2019 being close to the climatological normal.
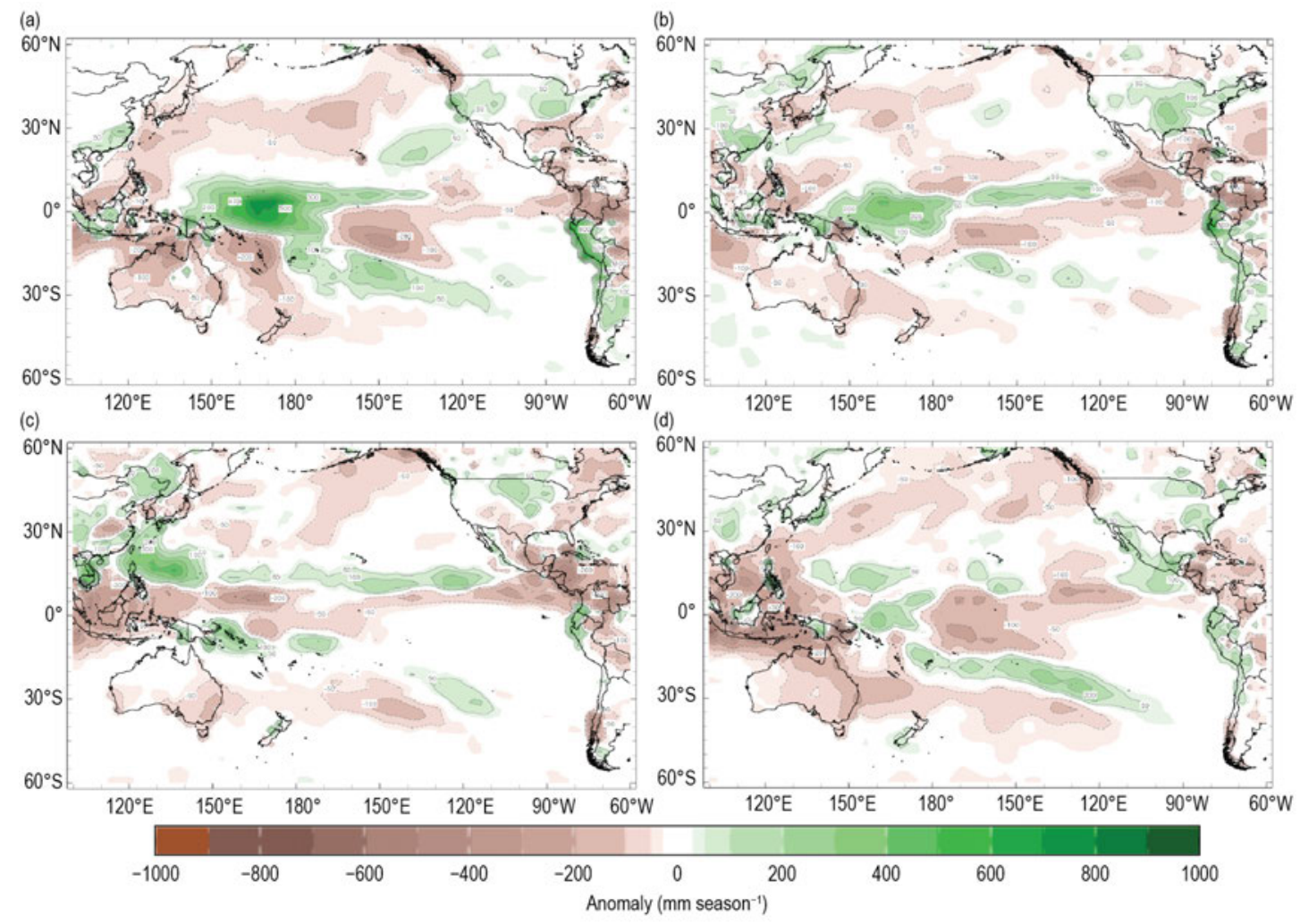

Fig. 7.53. Seasonal precipitation anomalies $\left(m m\right.$ season $\left.^{-1}\right)$ for (a) JFM, (b) AMJ, (c) JAS, and (d) OND. 


\section{(III) NOTABLE EVENTS AND IMPACTS}

On 11 February, TC Oma developed in the Coral Sea, ultimately intensifying to a Category 3 storm as it passed north of New Caledonia. Oma formed northwest of the Solomon Islands and southeast of Vanuatu. The system caused heavy rain, localized flooding, and strong winds in the northern provinces of Vanuatu and Ile Art, the northern archipelago of New Caledonia. Both areas suffered substantial impacts to their agricultural industries. As the system passed near the Solomon Islands, an oil carrier was run aground at Rennell Island, resulting in at least 75 tons of spilled oil, causing reef damage to the world's largest coral atoll.

On 26 February, TC Pola formed to the northeast of Tonga, tracking slowly south over the coming days. It strengthened as it passed between Fiji and Tonga, reaching Category 4 TC status. The storm did not pass over any land areas as it reached its maximum strength with wind gusts over $200 \mathrm{~km} \mathrm{~h}^{-1}$.

TC Sarai moved southwest toward western Fiji on 26 December, then passed about $100 \mathrm{~km}$ south of Kadavu Island (Fiji) and slowly tracked toward Nuku'alofa (Tonga) over coming days. The storm brought damaging winds and rainfall, particularly to the main Fiji Island, Viti Levu, resulting in flooding and two deaths due to drowning. There was also extensive damage to road infrastructure and interruptions to commercial flights and cruises.

Please refer to section $4 \mathrm{f} 6$ for additional details of these storms.

\section{4) Australia-S. Tobin and C. Ganter}

For this section monthly area-averaged temperatures are based on the ACORN-SAT dataset v2 (Trewin 2018), which begins in 1910. Rainfall and daily temperatures are based on the AWAP dataset (Jones et al. 2009), which begins in 1900 for rainfall and 1910 for temperature.

\section{(I) TEMPERATURE}

2019 was Australia's warmest year on record. The area-averaged annual mean temperature was $1.14^{\circ} \mathrm{C}$ above the $1981-2010$ average, well above the previous record of $+0.95^{\circ} \mathrm{C}$ in 2013.

Australian annual mean maximum temperatures (Fig. 7.54) were the highest on record at $1.71^{\circ} \mathrm{C}$ above average, also well above the previous record of $+1.21^{\circ} \mathrm{C}$ in 2013. Annual mean minimum temperatures (Fig. 7.55) were $0.57^{\circ} \mathrm{C}$ above average, the sixth highest on record.

Annual mean temperatures were above average across nearly all of Australia and were the highest on record for a large area of northern and eastern New South Wales, southeast Queensland, most of Western Australia away from the coast, and for areas of the Northern Territory.

The annual mean maximum temperatures were in the highest $10 \%$ of historical observations for nearly all of Australia and above average for a large area of northern and central Queensland. They were the highest on record for most of Western Australia and

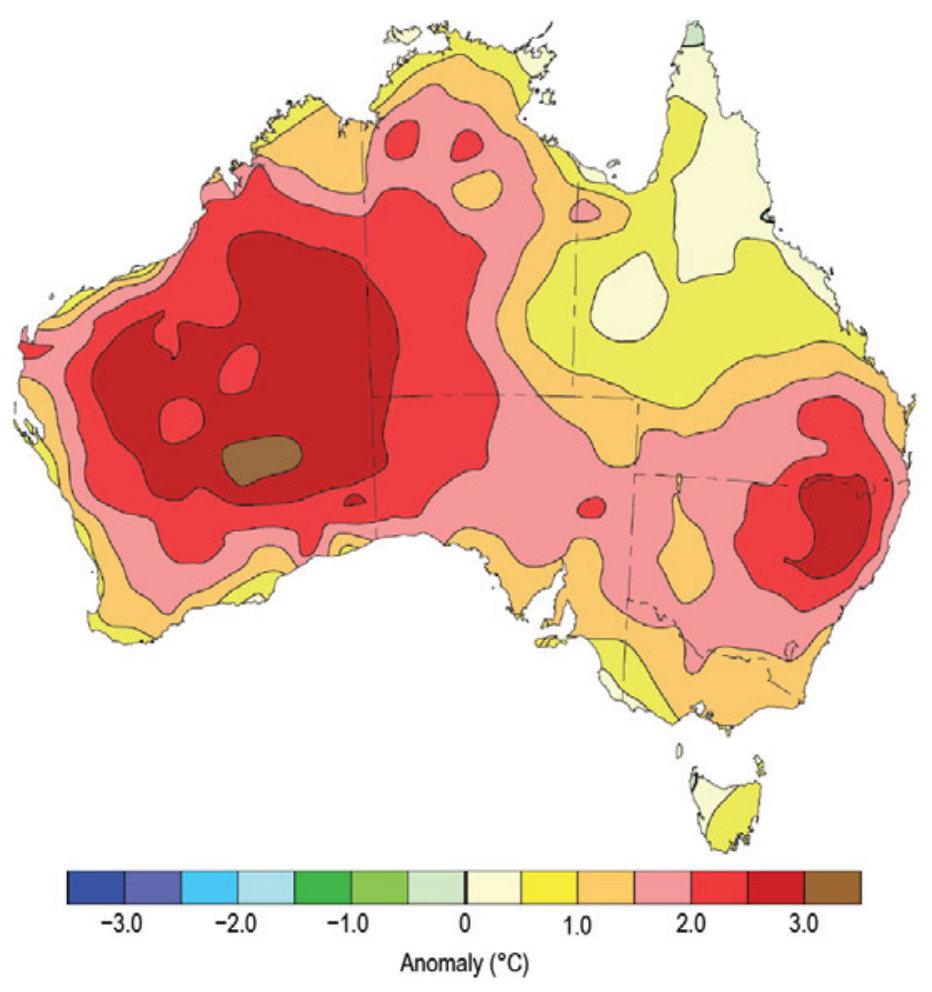

Fig. 7.54. Maximum temperature anomalies $\left({ }^{\circ} \mathrm{C}\right)$ for Australia, averaged over 2019, relative to a 1981-2010 base period. (Source: Australian Bureau of Meteorology.) 
South Australia, the western half of the Northern Territory, and from southeast Queensland to Gippsland in eastern Victoria.

Mean minimum temperatures were also above average for much of the country but close to average for some areas, particularly across the north and some parts of the south of Western Australia and South Australia. Annual mean minima were in the highest $10 \%$ of historical observations for large parts of the northern inland of the Northern Territory and the east and west of the mainland.

Warmth was widespread and persistent through the year-the national mean temperature was among the 10 highest on record for all months except May, June, August, and September. January, March, and December were each the warmest on record for their respective months.

Increased diurnal temperature range and increased occurrence of frost are typical of the cool season in inland eastern Australia during drought (which was present in 2019)

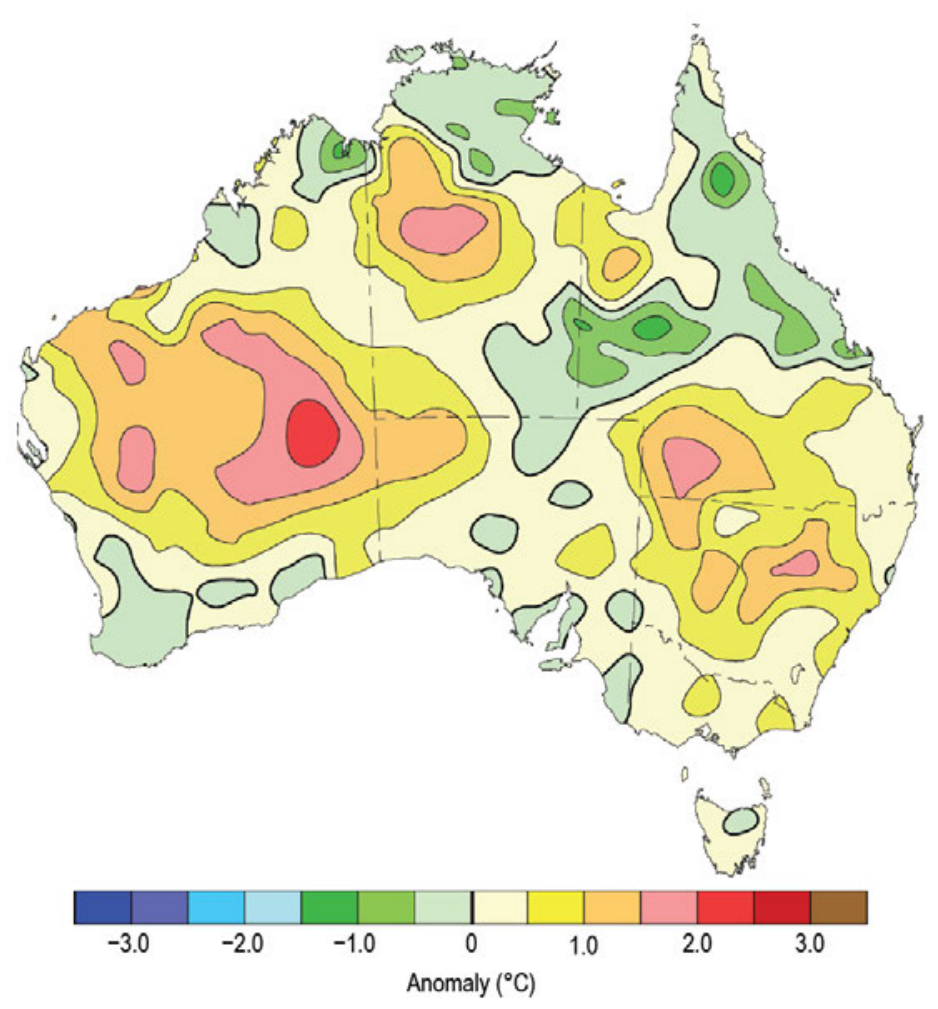

Fig. 7.55. Minimum temperature anomalies $\left({ }^{\circ} \mathrm{C}\right)$ for Australia, averaged over 2019, relative to a 1981-2010 base period. (Source: Australian Bureau of Meteorology.) due to reduced cloud cover, low humidity, and low soil moisture. Areas of the inland southeast observed record low mean monthly minima for August, and nights were also much cooler than average for areas of the mainland southeast and tropics during September, with frost damage in some grain-growing regions.

\section{(II) PRECIPITATION}

Averaged across Australia, rainfall for 2019 was the lowest on record at $277.6 \mathrm{~mm}$, well below the previous record low of $314.5 \mathrm{~mm}$ set in 1902. Rainfall for 2019 was 57\% of the 1981-2010 average.

Rainfall for the year was very much below average over most of Australia and lowest on record for much of northeastern New South Wales and southeastern Queensland, western and northern areas of South Australia, the inland Northern Territory, and southeastern Western Australia (Fig. 7.56). Rainfall had been below average for much of eastern and southwestern Australia since late 2016, with protracted drought affecting large areas and comparable to the driest periods in Australia's recorded history, including the Federation Drought and the Millennium Drought (BoM 2019).

Annual rainfall was above average across parts of Queensland's northwest and northern tropics. This was mostly a result of very much-above-average rainfall during the first quarter of the year.

The monsoon arrived later than usual during 2018/19, with onset at Darwin not occurring until 23 January, tying for the third-latest start since reliable records commenced in 1957. Overall, the northern wet season (October 2018-April 2019) was drier than average for the Northern Territory and Western Australia but wetter than average for parts of Queensland. Monsoon onset was again late in 2019/20, with no monsoonal activity across northern Australia before the end of 2019.

The second half of the year was particularly dry across most of southern Australia. Nationally, each month from August through December was among the 10 driest on record for their respective month, with July ranking 12th driest. The end of the year was especially dry, with November and December the driest on record for their respective months nationally. 
A very strong positive IOD (see section 4h) contributed to very low rainfall across Australia during 2019. Additionally, a negative phase of the SAM was present from late October to late December, amplifying the drying effect of the positive IOD in eastern Australia. ENSO, Australia's other main natural climate driver, remained neutral during 2019 by Australian measures (see Sidebar 7.6 for more detailed discussion).

\section{(III) NOTABLE EVENTS AND IMPACTS}

An extended period of heat waves affecting much of Australia began in early December 2018 and continued into January 2019, which were exacerbated by antecedent dry conditions. January was Australia's warmest month on record for any time of the year, with severe intensity heat wave conditions extending across southern Australia at times, with numerous temperature records set.

Tropical rainfall during late January and early February led to large areas of flooding in tropical coastal Queensland and parts of

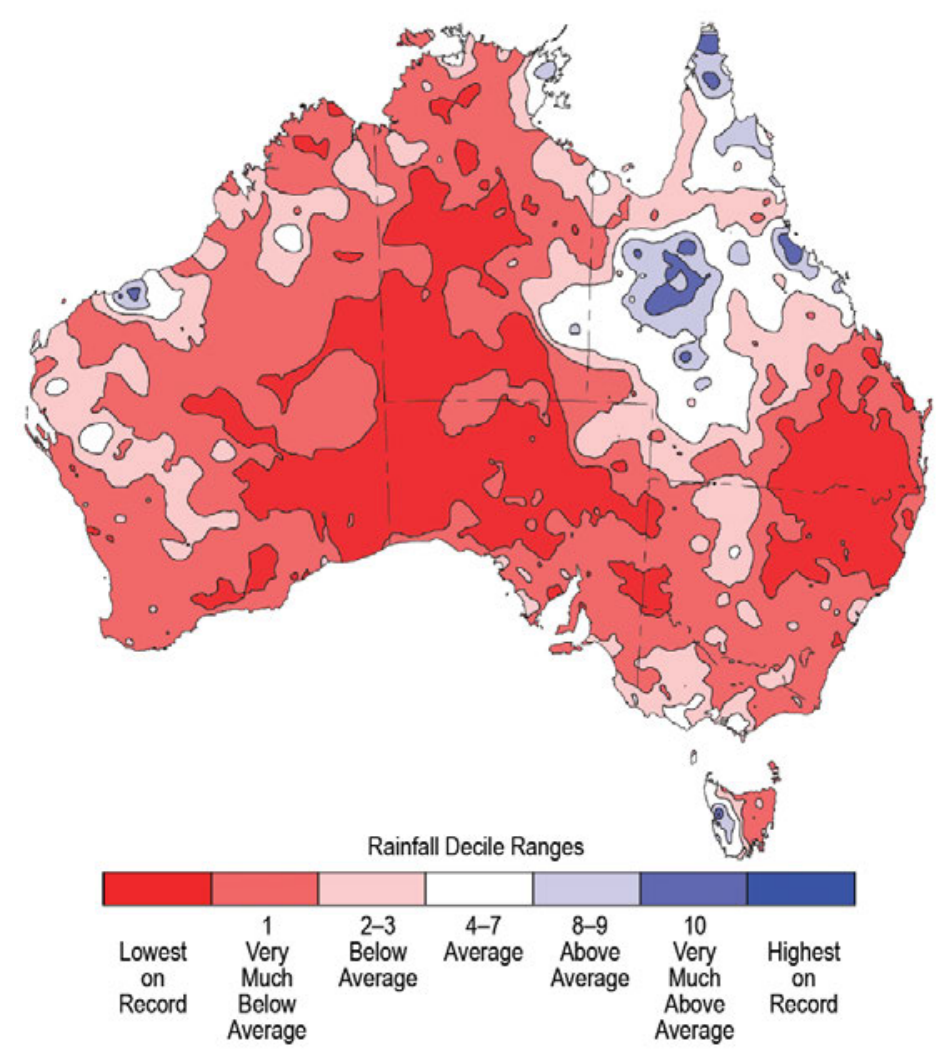

Fig. 7.56. Rainfall deciles for Australia for 2019, based on the 1900-2019 distribution. (Source: Australian Bureau of Meteorology.)

the western Peninsula and Gulf Country. Flooding in low-lying regions of western Queensland continued into April, resulting in stock losses and damage to property; the damage was estimated to be near $\$ 2$ billion Australian dollars ( $\$ 1.3$ billion U.S. dollars), according to a local news source. Floodwaters from the north eventually reached Kati Thanda-Lake Eyre, bringing the most significant filling of the lake since 2010-11.

Widespread warm and dry conditions, on top of well-below-average rainfall over a prolonged period, contributed to elevated fire danger over much of southeastern Australia during summer 2018/19. Large fires affected Gippsland in Victoria and parts of Tasmania from summer into autumn 2019.

The Forest Fire Danger Index (FFDI), a measure of fire weather severity, rose early in September 2019 and remained elevated over spring (Fig. SB7.14). The accumulated monthly FFDI for December was the highest on record when averaged over Australia as a whole. Very large bushfires affected eastern Australia from September through year's end, with fires in southeast Queensland, eastern New South Wales, and northeastern Victoria and Gippsland burning around 5 million ha by the end of 2019 (see Sidebar 7.6 for more information).

On 17 November, severe thunderstorms in southeast Queensland produced hail in excess of $4 \mathrm{~cm}$ in diameter, with early estimates of insured property damage exceeding \$80 million (U.S. dollars). Storms in eastern New South Wales on 26 November caused wind and rain damage across Sydney and the Blue Mountains.

A slow-moving high-pressure system over the Great Australian Bight allowed heat to build over the continent, resulting in record-breaking heat over much of Australia from mid-December 2019. Heat persisted across much of the country with only temporary relief in parts of the south and east, before concluding with extreme heat and dangerous fires in the southeast at the end of the year and lasting into the first days of 2020. Temperature records were set in all states and the Northern Territory but were most numerous in the southeast. These records included Australia's 
hottest day on record, 18 December, when the national area-averaged maximum temperature reached $41.88^{\circ} \mathrm{C}$, easily exceeding the previous record of $40.30^{\circ} \mathrm{C}$ set on 7 January 2013. Six other days in December 2019 also exceeded this previous record.

For further detail on these and other significant events, see Special Climate Statements, Monthly Weather Reviews, and the Annual Climate Statement at www.bom.gov.au/climate/current/.

\section{Sidebar 7.6: An early start to an extreme bushfire season in Australia-C. GANTER AND}

\section{S. TOBIN}

Southern and eastern Australia experienced a significant bushfire season during the second half of 2019, with conditions gaining global attention. Much of the severity of the bushfire conditions seen in Australia during 2019 can be related to the protracted drought across much of the east coupled with record high temperatures.

The year was influenced by a strong positive Indian Ocean dipole (IOD), the strongest event since 1997 (see section 4h for details). This climate driver was a key contributor to the dry conditions experienced in the second half of 2019 that intensified drought conditions already in place following belowaverage rainfall in 2017 and 2018. A strong sudden stratospheric warming (SSW) over Antarctica (which is rare for the Southern Hemisphere [SH], with 2002 the only comparable event in the twenty-first century; see Sidebar 6.1 for details) led to a negative phase of the Southern Annular Mode (SAM), with negative SAM in place for much of October-December. At this time of the year, a negative SAM phase is associated with drier-than-average conditions over parts of eastern Australia (Hendon et al. 2007) and increases the likelihood of extreme heat for much of southern and eastern Australia (Marshall et al. 2014).

In addition to the climate drivers in 2019, much of southern and eastern Australia was experiencing rainfall deficiencies at a range of timescales. In particular, parts of the east had been notably dry for 2-3 years, with a weaker positive IOD occurring in 2018 contributing to the dry conditions.

Historically, bushfire activity across the east coast starts in spring (September-November) across Queensland, extending into northeast New South Wales (NSW), and spreads south progressively as the months warm up. However, trends toward a lengthened fire season have been identified across parts of Australia, with the fire season typically starting earlier and ending later in many parts.

For 2019, while there was some fire activity beforehand, the first big flare up began in early spring.
Areas of southeast Queensland and northeast NSW had aboveaverage daytime temperatures, very low humidity, and gusty winds leading to dangerous fire weather. By 7 September, more than 50 significant fires were burning across Queensland, increasing to 80 fires by 9 September. In NSW, more than 50 fires were active by 9 September. Losses included the iconic Binna Burra Lodge-a place surrounded by green subtropical rainforest that does not usually burn.

In October and November, days of dangerous fire weather conditions affected all Australian states and territories, with fires breaking out across the southern states of Victoria, Tasmania, South Australia, and Western Australia. By the end

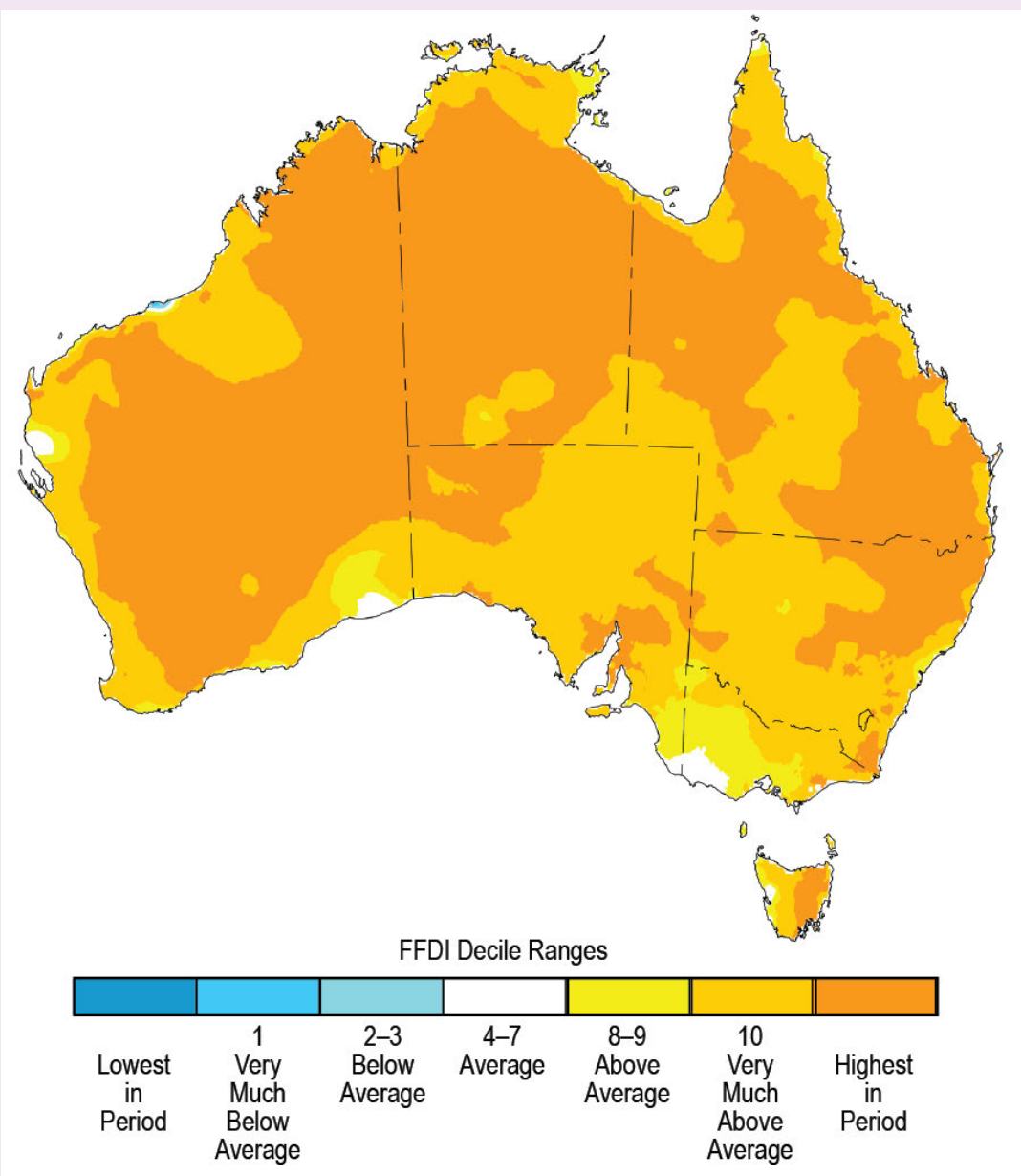

Fig. SB7.14. McArthur Forest Fire Danger Index (FFDI) deciles. Base period 1950-2019. 
of spring, catastrophic fire danger was declared in the Greater Sydney region for the first time since the introduction of this level in 2009.

For spring as a whole, the accumulated McArthur Forest Fire Danger Index (FFDI; McArthur 1967) values were more than twice the average in large areas of eastern Australia, with the area-averaged value for Australia the highest in 50 years of record (see Fig. SB7.14 for spring FFDI deciles).

With a delayed onset of the monsoon moving into the $\mathrm{SH}$, heat built across northern and central Australia from the start of December, with heatwaves repeatedly affecting the fire grounds. The hottest temperature recorded was at Nullarbor, South Australia, on 19 December, when it reached $49.9^{\circ} \mathrm{C}$, a new December record for Australia and the highest temperature recorded for any month since February 1998.

The December national maximum temperature anomaly was $+4.15^{\circ} \mathrm{C}$, well above the previous December record of $+2.41^{\circ} \mathrm{C}$ set in 2018. It was also the highest anomaly for any month (i.e., most above-average month) of the 110-year national record. With numerous large fires in the landscape, record heat, and severe drought, the conditions led to major losses of lives, property, and forests.

In December, the NSW government declared a state of emergency to help deal with the bushfires. On 2 January 2020, the Premier of the state of Victoria declared a state of disaster for parts of Victoria.

December accumulated FFDI values were highest on record for Australia as a whole and also for each state and territory, except Tasmania, which was second highest. The large numbers of fires across much of eastern Australia meant that thick smoke covered many areas of coastal NSW, including Sydney, particularly during November and into December. Smoke also significantly affected many areas of eastern Australia at some point during the fire season. At one point, Australia's capital, Canberra, was the city with the worst air quality in the world.

Conditions began to ease somewhat beginning 4 January 2020, although fires continued into the new year. The area burnt in NSW alone has been estimated to be a record 5.46 million ha, while nationally more than 3000 homes were destroyed and conservative estimates of wildlife death are in the order of 1 billion animals (Christopher Dickman, pers. comm. March $2020^{1}$ ). While there have been previous seasons (for example, 1974/75) where larger areas have been burnt nationally than in 2019/20, in those seasons the fires were predominantly in remote northern and central grassland and savanna areas, often fueled by excess vegetation growth in normally arid areas following heavy rainfall. No previous season compares with 2019/20 for the amount of area burned in Australia's subtropical and temperate forests, with fires extending even to areas where fires were previously exceptionally rare or unknown, such as the rainforests of southeast Queensland.

\footnotetext{
Numbers are estimated for terrestrial mammals, birds, and reptiles, and only for the states of New South Wales and Victoria. Bats, frogs, and other fauna were not included, nor were the fire-related effects assessed for South Australia, Queensland, or Western Australia. Background to the estimate can be found here: https://onlinelibrary.wiley.com/doi/full/10.1111 /emr.12403.
} 


\section{5) New Zealand-N. Fedaeff}

In the following discussion, the base period is 1981-2010, unless otherwise noted. The nationwide average temperature is based upon the National Institute of Water and Atmospheric Research (NIWA)'s seven-station temperature series that began in 1909 (see www.niwa.co.nz/our-science /climate/information-and-resources/nz-temp-record/seven-station-series-temperature-data).

\section{(I) TEMPERATURE}

According to NIWA's seven-station temperature series, 2019 was New Zealand's fourth-warmest year since records began in 1909 . The nationwide average temperature for 2019 was $13.37^{\circ} \mathrm{C}, 0.76^{\circ} \mathrm{C}$ above the annual average. Annual mean temperatures were above average $\left(+0.51^{\circ}\right.$ to $+1.20^{\circ} \mathrm{C}$ above the annual average) across the majority of New Zealand. Areas of well-above-average (more than $1.20^{\circ} \mathrm{C}$ above average) temperatures were observed in the Bay of Plenty and Hawke's Bay. Nearaverage (within $-0.50^{\circ}$ to $+0.50^{\circ} \mathrm{C}$ of average) temperatures occurred in parts of the Wairarapa, the West Coast, Tasman, Nelson, Marlborough, and coastal Canterbury (Fig. 7.57a).

The year began with New Zealand's third-warmest January on record. Widespread heat wave conditions took hold during the end of the month with several locations experiencing their warmest January day on record. The warmest temperature of 2019 was recorded on 31 January at Hanmer Forest. The high of $38.4^{\circ} \mathrm{C}$ tied for New Zealand's fourth-highest January temperature and also tied for the 18th-highest temperature on record for all months. A key climate driver and contributor to the hot start to 2019 was the presence of above-average coastal SSTs. Some areas around Hawke's Bay and Canterbury experienced marine heat wave conditions; marine heat wave conditions also persisted in the Tasman Sea to March.

At the start of August, a strongly negative SAM and stronger-than-normal polar and sub-tropical jet streams fueled a more active weather pattern to end winter. Southwesterly winds and several strong cold fronts during this time brought periods of thunderstorms and snow to southern and western parts of the country. The cooler temperatures at the end of winter and start of spring were also influenced by a rare SSW event, which occurred in the polar stratosphere during late August that peaked in mid-September (see Sidebar 6.1 for details). While this event was not classified as a major SSW event (winds at $10 \mathrm{hPa}, 60^{\circ} \mathrm{S}$ saw an unprecedented deceleration but did not reverse to easterlies - a criteria for the classification of a major event), it was the largest warming event observed in the August-September Southern Hemisphere (SH) record extending back to 1980.

Despite several sharp cold snaps, temperatures as a whole were near average for September and October, before prevailing northwesterlies in November brought unseasonably warm weather and New Zealand's warmest November on record. The lowest air temperature of the year was $-9.2^{\circ} \mathrm{C}$, recorded at Lake Tekapo on 3 June. This was the highest annual minimum temperature recorded in New Zealand this decade.

\section{(II) PRECIPITATION}

Annual rainfall totals for 2019 were below normal (50\% $-79 \%$ of normal) across Northland, Auckland, and the Bay of Plenty as well as parts of
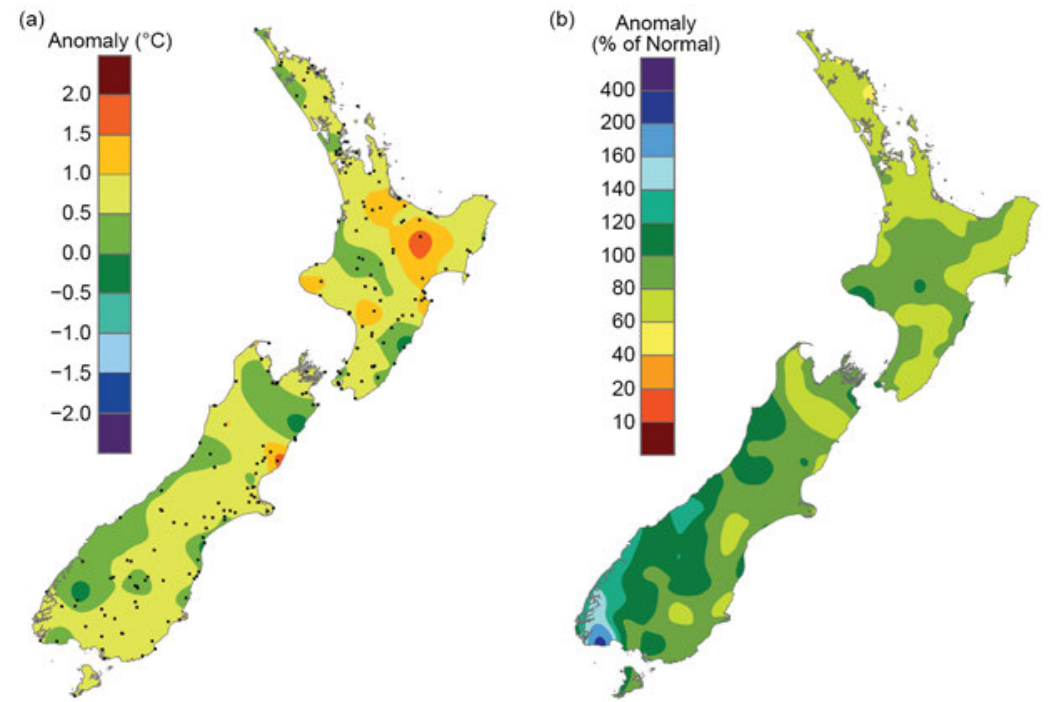

Fig. 7.57. 2019 annual (a) average temperature anomaly $\left({ }^{\circ} \mathrm{C}\right)$ and (b) total rainfall (\%), relative to $1981-2010$. The dots in panel (a) represent the locations of climate stations used to create both the temperature and rainfall maps. (Source: NIWA.) 
Waikato, Hawke's Bay, the Wairarapa, and Marlborough (Fig. 7.57b). On the North Island, 13 locations observed record or near-record low rainfall amounts. Conversely, rainfall was above normal (120\%-149\% of normal) in western Southland and parts of Westland, with four locations observing near-record high rainfall. For Hokitika, it was the fourth-wettest year in the record extending back to 1866. Of the regularly reporting rainfall gauges, the wettest location in 2019 was Cropp River, in the Hokitika River catchment (West Coast, South Island, 975 m a.s.1.), with an annual rainfall total of $14227 \mathrm{~mm}$. The driest of the regularly reporting rainfall sites in 2019 were Clyde and Cromwell (Central Otago), which each recorded $417 \mathrm{~mm}$ of rainfall.

\section{(III) NOTABLE EVENTS AND IMPACTS}

See Fig. 7.58 for a schematic of notable events. By the end of February, Nelson observed a 40-day dry spell, defined as a period of 15 days or more with less than $1 \mathrm{~mm}$ of rain on any one day, its fourth-longest dry spell in the record extending back to 1862. The tinder-dry conditions in the Tasman District fueled a large scrub fire in Pigeon Valley near Wakefield. The fire burned for most of February and into early March, and a Civil Defence State of Emergency was declared. It was reportedly the largest aerial firefight in New Zealand's history, and the cost of the event based on figures from the Insurance Council of New Zealand (ICNZ) was \$3.98 million New Zealand dollars ( $\$ 2.47$ million U.S. dollars).

Regions affected by meteorological drought

Regions where flood State of Emergency was declared

Regions affected by meteorological drought and floods
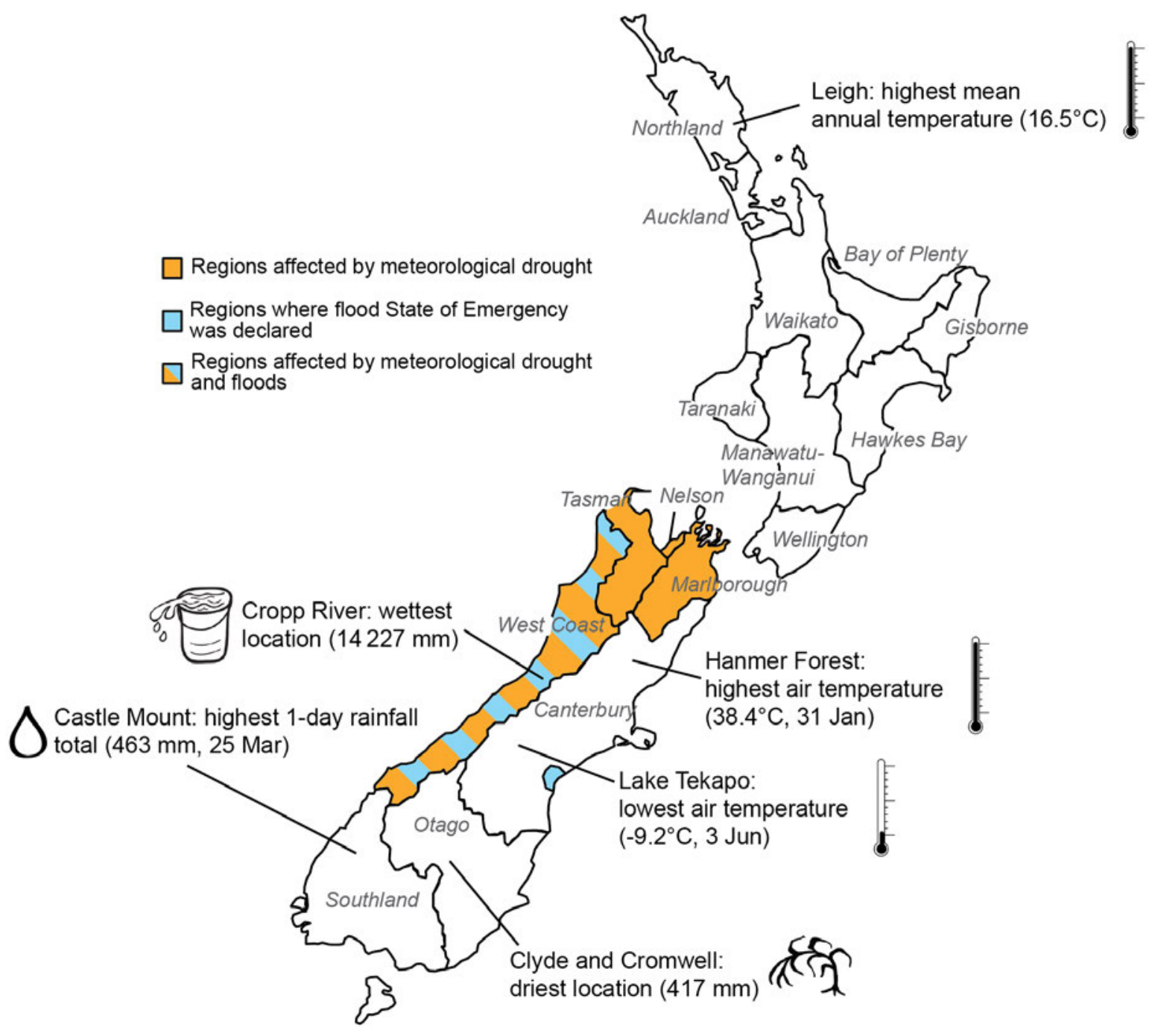

Fig. 7.58. Notable weather events and climate extremes for New Zealand in 2019. (Source: NIWA, https://niwa.co.nz/climate /summaries/annual-climate-summary-2019.) 
Extremely heavy rainfall occurred in the western South Island on 25-27 March. The weather event was associated with an atmospheric river extending from Australian cyclones coupled with extra energy from the Tasman Sea marine heat wave, as well as a strong low-pressure system siphoning moisture toward New Zealand. A State of Emergency was declared in Westland, and the Waiho River bridge on State Highway 6 was claimed by raging floodwaters. A New Zealand 48-hour rainfall record of $1086 \mathrm{~mm}$ was set at the Hokitika catchment of the Cropp River, surpassing the previous record of $1062 \mathrm{~mm}$ at the same site in 2013. The event resulted in $\$ 4.09$ million New Zealand dollars ( $\$ 2.53$ million U.S. dollars) in damages based on figures from ICNZ.

\section{Acknowledgments}

\section{e. Africa}

Samson Hagos was supported by the National Oceanic and Atmospheric Administration (NOAA) Oceanic and Atmospheric Research, Program Climate Program Office (CPO), under NOAA grant number NA170AR4310263.

\section{g. Asia}

Tim Li wishes to thank all authors in the Asia section for their timely contributions and internal and external reviewers and the document editors for their constructive comments. The following grants (China National Key R\&D Program 2018YFC1505806, NSFC grant 41630423, NSF grant AGS-1643297 and NOAA grant NA180AR4310298) are acknowledged. 


\section{APPENDIX 1: Acronym List}

\begin{tabular}{|c|c|}
\hline AMJ & April-June \\
\hline CAMS & Climate Anomaly Monitoring System \\
\hline CONUS & contiguous United States \\
\hline ENSO & El Niño-Southern Oscillation \\
\hline ETP & eastern tropical Pacific \\
\hline FFDI & Forest Fire Danger Index \\
\hline GHCN & Global Historical Climate Network \\
\hline ICNZ & Insurance Council of New Zealand \\
\hline IOD & Indian Ocean dipole \\
\hline ISMR & Indian summer monsoon rainfall \\
\hline JAS & July-September \\
\hline JFM & January-March \\
\hline JRA-55 & Japanese 55-year Reanalysis \\
\hline JTWC & Joint Typhoon Warning Center \\
\hline LTA & long-term average \\
\hline MSE & moist static energy \\
\hline NAO & North Atlantic Oscillation \\
\hline NEM & northeast monsoon \\
\hline $\mathrm{NH}$ & Northern Hemisphere \\
\hline NIWA & National Institute of Water and Atmospheric Research \\
\hline NSW & New South Wales \\
\hline OLR & outgoing longwave radiation \\
\hline OND & October-December \\
\hline ONI & Oceanic Niño Index \\
\hline PNG & Papua New Guinea \\
\hline RSMC & Regional Specialized Meteorological Centre \\
\hline SAM & Southern Annular Mode \\
\hline $\mathrm{SH}$ & Southern Hemisphere \\
\hline SPCZ & South Pacific Convergence Zone \\
\hline SST & sea surface temperature \\
\hline SSW & sudden stratospheric warming \\
\hline $\mathrm{TC}$ & tropical cyclone \\
\hline TD & tropical depression \\
\hline TS & tropical storm \\
\hline WMO & World Meteorological Organization \\
\hline
\end{tabular}




\section{APPENDIX 2: Supplemental Materials}

\begin{tabular}{|c|c|c|c|}
\hline Country & Specific Region & Dates (2019) & Impacts \\
\hline \multirow{3}{*}{ Panamá } & Colón province & 20 Aug & $1 f, 1 i$ \\
\hline & Ngäbe-Buglé Shire & 05 Sep & $2 f$ \\
\hline & Chiriquí province & $180 c t$ & $5 i$ \\
\hline \multirow{3}{*}{ Costa Rica } & Zarcero & 02 Aug & $1 f$ \\
\hline & Aguas Zarcas, San Carlos & 24 Sep & 1f, $3 i$ \\
\hline & Alajuela province & 09 Oct & $5 i$ \\
\hline \multirow{3}{*}{ Nicaragua } & 45 miles east of Bilwi & 16 Aug & $2 f$ \\
\hline & Kayaska, Bocay & 13 Sep & 1f \\
\hline & Matagalpa department & 25 Oct & 1f \\
\hline \multirow{3}{*}{ El Salvador } & Sonsonate department & $25 \mathrm{Jul}$ & $1 f$ \\
\hline & Usulután department & 23 Sep & 1f \\
\hline & El Salvador department & 26 Sep & $1 \mathrm{i}$ \\
\hline \multirow{6}{*}{ Honduras } & Intibucá department & 06 May & $16 i$ \\
\hline & Intibucá department & 05 Jun & 1f \\
\hline & Yoro department & $07 \mathrm{Jul}$ & 1f \\
\hline & Francisco Morazán department & 08 Aug & 1f \\
\hline & Valle department & 17 Aug & $2 f, 5 i$ \\
\hline & Comayagua department & 05 Oct & 1f \\
\hline \multirow{4}{*}{ Guatemala } & Chimaltenango department & 01 Sep & $2 f$ \\
\hline & Antigua Guatemala & 02 Sep & $1 \mathrm{i}$ \\
\hline & Petén department & 04 Sep & 1f \\
\hline & San Marcos department & 27 Oct & $4 i$ \\
\hline \multirow[t]{2}{*}{ Belize } & Armenia Village & $19 \mathrm{Apr}$ & 1f \\
\hline & & Total & 21f, 41i \\
\hline
\end{tabular}


Table A7.2. Summary of events and impacts, including number of fatalities (f), missing people (m), injured people (i), affected people (a), number of affected families $(n)$, and damaged houses (d), by country and specific region. [Data sources: Central American National Weather Services, National Emergency Committees communications and regional newspapers].

\begin{tabular}{|c|c|c|c|c|}
\hline Country & Specific Region & Dates (2019) & $\begin{array}{l}\text { Hydrometeorological } \\
\text { Condition }\end{array}$ & Impacts \\
\hline \multirow{24}{*}{ Guatemala } & $\begin{array}{l}\text { Alta Verapaz, Chimaltenago and San Marcos } \\
\text { departments }\end{array}$ & 02-03 Jun & Heavy rainfall, strong winds and landslides & $3057 a$ \\
\hline & $\begin{array}{l}\text { Alta Verapaz, Petén and San Marcos } \\
\text { departments }\end{array}$ & 03-04 Jun & Heavy rainfall and landslides & $2275 a$ \\
\hline & $\begin{array}{l}\text { Guatemala, Huehuetenango, Sololá and } \\
\text { Schitepéquez departments }\end{array}$ & 09 Jun & Heavy rainfall, landslides, and floods & $30086 a$ \\
\hline & $\begin{array}{l}\text { Jutiapa, Huehuetenango, Jalapa, Alta Verapaz } \\
\text { and Santa Rosa departments }\end{array}$ & $11-12$ Jun & Heavy rainfall and landslides & $21118 a$ \\
\hline & Suchitepéquez and Guatemala departments & 14-15 Jun & Heavy rainfall, landslides and bridge collapse & $604 a$ \\
\hline & Los Naranjales, Colotenango, Huehuetenango & 27 Jun & Heavy rainfall and landslides & $3 f$ \\
\hline & Escuintla and Suchitepéquez departments & $28 \mathrm{Jul}$ & Heavy rainfall and strong winds & $112 a$ \\
\hline & $\begin{array}{l}\text { Guatemala, Quetzaltenango, Retalhuleu and } \\
\text { Sacatepéquez departments }\end{array}$ & 03-04 Aug & $\begin{array}{l}\text { Heavy rainfall, landslides and floods associ- } \\
\text { ated with a low pressure system }\end{array}$ & $412 a$ \\
\hline & Guatemala, and Santa Rosa & 15 Aug & $\begin{array}{l}\text { Heavy rainfall, landslides, overflow of rivers } \\
\text { and floods }\end{array}$ & $1 \mathrm{f}, 1 \mathrm{~m}, 5062 \mathrm{a}$ \\
\hline & $\begin{array}{l}\text { Alta Verapaz, Sololá, Guatemala, Santa Rosa, } \\
\text { Sacatepéquez and Suchitepéquez departments }\end{array}$ & 17-18 Aug & Heavy rainfall, landslides, and floods & $25332 a$ \\
\hline & $\begin{array}{l}\text { Guatemala, Sololá and Suchitepéquez } \\
\text { departments }\end{array}$ & 19 Aug & $\begin{array}{l}\text { Heavy rainfall, landslides, overflow of rivers } \\
\text { and floods }\end{array}$ & $252 a$ \\
\hline & $\begin{array}{l}\text { Chimaltenango, Sacatepéquez, Guatemala, } \\
\text { Zacapa and San Marcos departments }\end{array}$ & 20-21 Aug & Heavy rainfall, landslides, and floods & $2705 a$ \\
\hline & Guatemala and Jalapa departments & 01 Sep & Rainfall and landslides & 1f, 4i, 1037a \\
\hline & Chiquimula and Guatemala departments & 10-11 Sep & Rainfall, strong winds and landslides & $3000 a$ \\
\hline & $\begin{array}{l}\text { Guatemala, Quiché and Suchitepéquez } \\
\text { deaprtments }\end{array}$ & 16 Sep & Rainfall, floods and landslides & $40065 a$ \\
\hline & $\begin{array}{l}\text { Chiquimula, El Progreso, Guatemala, } \\
\text { Quetzaltenango, Sacatepéquez and Santa Rosa }\end{array}$ & 23 Sep & Rainfall, floods and landslides & $1 \mathrm{f}, 1 \mathrm{~m}, 21275 \mathrm{a}$ \\
\hline & $\begin{array}{l}\text { Alta Verapaz, Quiché and Santa Rosa } \\
\text { departments }\end{array}$ & 24 Sep & Rainfall and landslides & $50200 a$ \\
\hline & $\begin{array}{l}\text { Alta Verapaz, Guatemala, Quetzaltenango, } \\
\text { Quiché, Sacatepéquez, Santa Rosa and Sololá } \\
\text { departments }\end{array}$ & 29-30 Sep & Rainfall, floods and landslides & 1f, 20246a \\
\hline & $\begin{array}{l}\text { Petén, Huehuetenango and Santa Rosa } \\
\text { departments }\end{array}$ & 01 Oct & Rainfall, floods and landslides & $350 a, 159 d$ \\
\hline & Nueva Esperanza, Río Escondido & 04 Oct & Rainfall and overflow of rivers & 1f \\
\hline & $\begin{array}{l}\text { Linea C4 Sis, San Andres Villa Seca, Retalhule } \\
\text { department }\end{array}$ & 16 Oct & Rainfall and floods & $122 a$ \\
\hline & $\begin{array}{l}\text { Santa Marta del Mar, Barra Coyolate and } \\
\text { Trocha 8, Escuintla department }\end{array}$ & 16 Oct & Rainfall and floods & $1500 a, 300 d$ \\
\hline & $\begin{array}{l}\text { Quetzaltenango, San Marcos and } \\
\text { Huehuetenango departments }\end{array}$ & 30 Oct & Rainfall, floods and landslides & $4 f, 642 a$ \\
\hline & Provenir, Sayaxché & $08 \mathrm{Nov}$ & Heavy rainfall & $210 a$ \\
\hline
\end{tabular}


(cont) Table A7.2. Summary of events and impacts, including number of fatalities (f), missing people (m), injured people (i), affected people (a), number of affected families ( $n$ ), and damaged houses (d), by country and specific region. [Data sources: Central American National Weather Services, National Emergency Committees communications and regional newspapers].

\begin{tabular}{|c|c|c|c|c|}
\hline Country & Specific Region & Dates (2019) & $\begin{array}{l}\text { Hydrometeorological } \\
\text { Condition }\end{array}$ & Impacts \\
\hline \multirow{4}{*}{ Panamá } & Ngäbe-Buglé Shire & 30 Sep & Rainfall and overflow of rivers & $1 f$ \\
\hline & Panamá and West Panamá provinces & 09 Nov & $\begin{array}{l}\text { Heavy rainfall, landslides, overflow of rivers } \\
\text { and floods }\end{array}$ & $232 a, 99 d$ \\
\hline & $\begin{array}{l}\text { Panamá, Coclé, Colón, and Bocas del Toro } \\
\text { province }\end{array}$ & $28 \mathrm{Nov}$ & Rainfall, strong winds, landslides and floods & $183 a$ \\
\hline & Colón Island and Changuinola & $25 \mathrm{Dec}$ & Rainfall and floods & $1070 a, 215 n$ \\
\hline \multirow{3}{*}{ Costa Rica } & Upala, Alajuela province & $08 \mathrm{Jul}$ & Heavy rainfall and floods & $134 a$ \\
\hline & La Lucha de Lagarto and Río Claro, Golfito & 08 Sep & Heavy rainfall and landslides & $117 n$ \\
\hline & $\begin{array}{l}\text { Santa Cruz, Nicoya, Hojancha, Nandayure in } \\
\text { Guanacaste, Cobano, Lepanto and Paquera of } \\
\text { Puntarenas, Paraíso and Orosí in Cartago }\end{array}$ & 08 Sep & $\begin{array}{l}\text { Heavy rainfall, landslides and floods associ- } \\
\text { ated with a low pressure system }\end{array}$ & $2815 a$ \\
\hline \multirow{4}{*}{ Nicaragua } & Quezalguaque, León department & 19 May & Heavy rainfall and overflow of rivers & 1f \\
\hline & $\begin{array}{l}\text { Carazo, Rivas, Managua, and Boaco } \\
\text { departments }\end{array}$ & 23 May & $\begin{array}{l}\text { Heavy rainfall and floods associated with a } \\
\text { low pressure system }\end{array}$ & $344 n$ \\
\hline & $\begin{array}{l}\text { Matagalpa, Nueva Segovia, Madriz, León and } \\
\text { Managua departments }\end{array}$ & 01 Oct & Rainfall, strong winds, and floods & $300 d$ \\
\hline & $\begin{array}{l}\text { Metagalpa, Madriz, Nueva Segovia, Chontales, } \\
\text { Rio San Juan and Managua }\end{array}$ & $14-150 c t$ & $\begin{array}{l}\text { Heavy rainfall and floods associated with a } \\
\text { low pressure system }\end{array}$ & $2 f, 534 n, 528 d$ \\
\hline \multirow[b]{2}{*}{ El Salvador } & San Salvador department & 17 Aug & Heavy rainfall & $1 \mathrm{i}$ \\
\hline & $\begin{array}{l}\text { La Paz, San Salvador and La Libertad } \\
\text { departments }\end{array}$ & $160 c t$ & Heavy rainfall, landslides, and floods & $4 f, 1 m, 130 n$ \\
\hline Honduras & Choluteca department & $06-080 \mathrm{ct}$ & Rainfall and overflow of rivers & $2 f$ \\
\hline
\end{tabular}




\begin{tabular}{|c|c|c|c|}
\hline Nation & $\begin{array}{l}\text { Temperature } \\
\text { start of record }\end{array}$ & $\begin{array}{l}\text { Precipitation start } \\
\text { of record }\end{array}$ & Source \\
\hline European average & 1950 & 1950 & $\mathrm{GHCN}^{1}$ data \\
\hline Albania (Korce) & 1963 & 1963 & CLIMAT $^{2}$ \\
\hline Andorra & 1950 & 1950 & $\mathrm{NMHS}^{3}$ \\
\hline Armenia & 1935 & 1935 & NMHS \\
\hline Austria & 1767 & 1858 & NMHS \\
\hline Azerbaijan (Astara) & 1991 & 1991 & CLIMAT \\
\hline Belarus & 1881 & 1945 & NMHS \\
\hline Belgium & 1981 & 1981 & NMHS \\
\hline $\begin{array}{c}\text { Bosnia \& Herzegovina } \\
\text { (Banja Luka) }\end{array}$ & 1955 & 1955 & CLIMAT \\
\hline Bulgaria & 1930 & 1954 (Burgas) & NMHS/CLIMAT \\
\hline Croatia (Split/Marjan) & 1949 & 1949 & CLIMAT \\
\hline Cyprus (Nicosia) & 1899 & 1899 & NMHS \\
\hline Czech Republic & 1961 & 1961 & NMHS \\
\hline Denmark & 1873 & 1874 & NMHS \\
\hline Estonia & 1961 & 1961 & NMHS \\
\hline Finland (Helsinki) & 1900 & 1961 & NMHS \\
\hline France & 1900 & 1959 & NMHS \\
\hline Georgia & 1960 & 1881 (Tbilisi) & NMHS \\
\hline Germany & 1881 & 1881 & NMHS \\
\hline Greece & 1960 & 1949 (Athens) & NMHS/CLIMAT \\
\hline Hungary & 1901 & 1901 & NMHS \\
\hline Iceland (Stykkishólmur) & 1900 & 1856 & NMHS \\
\hline Ireland & 1900 & 1900 & NMHS \\
\hline Israel & 1951 & 1935 (Deganya) & NMHS \\
\hline Italy & 1961 & 1949 (Alghero) & NMHS/CLIMAT \\
\hline Jordan (Amman) & 1981 & 1981 & NMHS \\
\hline Kazakhstan & 1941 & 1941 & NMHS \\
\hline Latvia & 1924 & 1924 & NMHS \\
\hline Lebanon (Beirut) & 1949 & 1949 & CLIMAT \\
\hline Lithuania & 1961 & 1887 (Vilnius) & NMHS \\
\hline Luxembourg (Findel) & 1947 & 1947 & NMHS \\
\hline Malta (Luqa) & 1923 & 1949 & NMHS/CLIMAT \\
\hline Moldova (Chisinau) & 1886 & 1891 & NMHS \\
\hline Monaco & not available & not available & - \\
\hline Montenegro (Plevlja) & 1955 & 1955 & CLIMAT \\
\hline Netherlands & 1901 & 1901 & NMHS \\
\hline $\begin{array}{l}\text { North Macedonia } \\
\text { (Bitola) }\end{array}$ & 1955 & 1955 & CLIMAT \\
\hline Norway & 1900 & 1900 & NMHS \\
\hline
\end{tabular}




\begin{tabular}{|c|c|c|c|}
\hline Nation & $\begin{array}{l}\text { Temperature } \\
\text { start of record }\end{array}$ & $\begin{array}{l}\text { Precipitation start } \\
\text { of record }\end{array}$ & Source \\
\hline Poland & 1951 & 1951 & NMHS \\
\hline Portugal & 1931 & 1931 & NMHS \\
\hline Romania & 1961 & 1954 (Bistrita) & NMHS/CLIMAT \\
\hline Russia, European part & 1936 & 1936 & NMHS \\
\hline Serbia & 1951 & 1951 & NMHS \\
\hline Slovakia & 1951 & 1961 & NMHS \\
\hline Slovenia & 1961 & 1961 & NMHS \\
\hline Spain & 1965 & 1965 & NMHS \\
\hline Sweden & 1860 & 1860 & NMHS \\
\hline Switzerland & 1864 & 1864 & NMHS \\
\hline $\begin{array}{c}\text { Syrian Arab Republic } \\
\text { (Aleppo) }\end{array}$ & 1960 & 1960 & CLIMAT \\
\hline Turkey & 1971 & 1949 (Adana) & NMHS \\
\hline Ukraine & 1891 & 1891 & NMHS \\
\hline United Kingdom & 1884 & 1862 & NMHS \\
\hline \multicolumn{4}{|c|}{$\begin{array}{l}{ }^{1} \mathrm{GHCN}=\text { Global Historical Climatology Network (Menne et al. 2018) } \\
{ }^{2} \mathrm{CLIMAT} \text { station data as reported worldwide via the WMO Global Telecommunication System } \\
{ }^{3} \mathrm{NMHS}=\text { National Meteorological and Hydrological Service; for individual names of NMHSs } \\
\text { see https://public.wmo.int/en/about-us/members }\end{array}$} \\
\hline
\end{tabular}




\section{References}

Amador, J. A., 1998: A climatic feature of the tropical Americas: The trade wind easterly jet. Top. Meteor. Oceanogr., 5 (2), 91-102.

- 2008: The Intra-Americas Seas Low-Level Jet (IALLJ): Overview and future research. Ann. N. Y. Acad. Sci., 1146, 153-188, https://doi.org/10.1196/ annals.1446.012.

— E. J. Alfaro, H. G. Hidalgo, and B. Calderón, 2011: Central America [in "State of the Climate in 2010"]. Bull. Amer. Meteor. Soc., 92 (6), S182-S183, https://doi.org/10.1175/1520-0477-92.6.S1.

Aragão L. E. O. C., and Coauthors, 2018: 21st century drought-related fires counteract the decline of Amazon deforestation carbon emissions. Nat. Commun., 9, 536, https://doi.org/10.1038/s41467-017-02771-y.

Bahaga, T. K., A. H. Fink, and P. Knippertz, 2019: Revisiting interannual to decadal teleconnections influencing seasonal rainfall in the Greater Horn of Africa during the 20th century. Int. J. Climatol., 39, 2765-2785, https://doi. org/10.1002/joc.5986.

Benestad, R. E., 2004: Record-values, nonstationarity tests and extreme value distributions. Global Planet. Change, 44, 11-26, https://doi.org/10.1016/J. GLOPLACHA.2004.06.002.

BoM, 2019: Special Climate Statement 70—Drought conditions in Australia and impact on water resources in the Murray-Darling Basin. Bureau of Meteorology, 39 pp., www.bom.gov.au/climate/current/statements/scs70.pdf

Bosart, L. F., T. C. Leicht, and A. K. Mitchell, 2020: The intense High Plains "bomb" cyclone of 12-14 March 2019. 30th Conf. on Weather Analysis and Forecasting/26th Conf. on Numerical Weather Prediction, Boston, MA, Amer. Meteor. Soc., 5B.4, https://ams.confex.com/ams/2020Annual/webprogram /Paper362748.html.

CIMSS, 2019: Typhoon Kammuri in the West Pacific Ocean, with record cold cloud-top temperatures. CIMSS Satellite Blog, https://cimss.ssec.wisc.edu/ satellite-blog/archives/35120.

Cunha, A. P., and Coauthors, 2019: Extreme drought events in over Brazil from 2011 to 2019. Atmosphere, 10, 642, https://doi.org/10.3390/atmos10110642.

Dvorak, V. F., 1984: Tropical cyclone intensity analysis using satellite data. NOAA Tech. Rep. 11, 45 pp.

Ebert, E. E., and G. J. Holland, 1992: Observations of record cold cloud-top temperatures in Tropical Cyclone Hilda (1990). Mon. Wea. Rev., 120, 2240-2251, https://doi.org/10.1175/1520-0493(1992)120<2240:00RCCT>2.0.C0;2.

FAN, 2019: Incendios forestales en Bolivia 2019. Fundación Amigos de la $\mathrm{Na}-$ turaleza, accessed 23 January 2020, http://incendios.fan-bo.org/Satrifo/ publicaciones/\#tab-4.

FloodList, 2019: Thousands affected by flooding in Presidente Hayes, Concepción and Guairá. FloodList, 20 March, accessed 23 January 2020, http:// floodlist.com/america/paraguay-flodds-presidente-hayes-concepcion-guaira-march-2019.

Funk, C. C., and Coauthors, 2014, A quasi-global precipitation time series for drought monitoring. USGS Data Series 832, 4 pp., https://doi.org/10.3133/ DS832.

Gill, A. E., 1980: Some simple solutions for heat-induced tropical circulation. Quart. J. Roy. Meteor. Soc., 106, 447-462, https://doi.org/10.1002/ qj. 49710644905.

Hendon, H. H., D. W. Thompson, and M. C. Wheeler, 2007: Australian rainfall and surface temperature variations associated with the Southern Hemisphere annular mode. J. Climate, 20, 2452-2467, https://doi.org/10.1175/JCLI4134.1.

Hidalgo, H. G., E. J. Alfaro, J. A. Amador, and A. Bastidas, 2019: Precursors of quasi-decadal dry-spells in the Central America dry corridor. Climate Dyn., 53, 1307-1322, https://doi.org/10.1007/s00382-019-04638-y.

Imbery, F., and Coauthors, 2020: Klimatologische Einordnung des Aprils 2020. DWD, 11 pp., www.dwd.de/DE/leistungen/besondereereignisse/temperatur/20200505_klimatologische_einordnung_april.pdf.
Jones, D. A., W. Wang, and R. Fawcett, 2009: High-quality spatial climate datasets for Australia. Aust. Meteor. Oceanogr. J., 58, 233-248, https://doi. org/10.22499/2.5804.003.

Jones, P. D., T. Jonsson, and D. Wheeler, 1997: Extension to the North Atlantic oscillation using early instrumental pressure observations from Gibraltar and south-west Iceland. Int. J. Climatol., 17, 1433-1450, https://doi.org/10.1002/ (SICI)1097-0088(19971115)17:13<1433::AID-J0C203>3.0.C0;2-P.

Kobayashi, S., and Coauthors, 2015: The JRA-55 reanalysis: General specifications and basic characteristics. J. Meteor. Soc. Japan, 93, 5-48, https://doi. org/10.2151/jmsj.2015-001.

Kothe, S., U. Pfeifroth, R. Cremer, J. Trentmann, and R. Hollmann, 2017: A satellite-based sunshine duration climate data record for Europe and Africa. Remote Sens., 9, 429, https://doi.org/10.3390/rs9050429.

Li, T., B. Wang, B. Wu, T. Zhou, C.-P. Chang, and R. Zhang, 2017: Theories on formation of an anomalous anticyclone in western North Pacific during El Niño: A review. J. Meteor. Res., 31, 987-1006, https://doi.org/10.1007/ s13351-017-7147-6.

MAAP, 2019: MAAP\#109: Fires and deforestation in the Brazilian Amazon. Monitoring of the Andean Amazon Project, https://maaproject.org/2019/ fires-deforestation-brazil-2019/.

Magaña, V., J. A. Amador, and S. Medina, 1999: The midsummer drought over Mexico and Central America. J. Climate, 12, 1577-1588, https://doi. org/10.1175/1520-0442(1999)012<1577:TMDOMA>2.0.C0;2.

Marshall, A. G., D. Hudson, M. C. Wheeler, O. Alves, H. H. Hendon, M. J. Pook, and J. S. Risbey, 2014: Intra-seasonal drivers of extreme heat over Australia in observations and POAMA-2. Climate Dyn., 43, 1915-1937, https://doi. org/10.1007/s00382-013-2016-1.

McArthur, A. G., 1967: Fire behaviour in eucalyptus forests. Leaflet 107, Department of National Development, Forest and Timber Bureau, Canberra, Australia, $35 \mathrm{pp}$.

Menne, M. J., C. N. Williams, B. E. Gleason, J. J. Rennie, and R. H. Lawrimore, 2018: The Global Historical Climatology Network monthly temperature dataset, version 4. J. Climate, 31, 9835-9854, https://doi.org/10.1175/JCLID-18-0094.1.

Musgrave, K. D., C. A. Davis, and W. H. Schubert, 2008: Pinhole eyes in tropical cyclones. 28th Conf. on Hurricanes and Tropical Meteorology, Orlando, FL, Amer. Meteor. Soc., 17C.1, https://ams.confex.com/ams/28Hurricanes/webprogram/ Paper138273.html.

NOAA, 2019: Tropical Storm Karen - 24-25 September 2019. NOAA/National Weather Service, www.weather.gov/sju/karen2019.

Pfeifroth, U., S. Kothe, J. Trentmann, R. Hollmann, P. Fuchs, J. W. Kaiser, and M. Werscheck, 2019: Surface radiation data set - Heliosat (SARAH) - edition 2.1. Satellite Application Facility on Climate Monitoring, accessed 14 February 2020, https://doi.org/10.5676/EUM_SAF_CM/SARAH/V002_01.

Rodríguez-Fonseca, B., and Coauthors, 2015: Variability and predictability of West African droughts: A review of the role of sea surface temperature anomalies. J. Climate, 28, 4034-4060, https://doi.org/10.1175/JCLID-14-00130.1.

Rosa, E. B., L. P. Pezzi, M. F. L. de Quadro, and N. Brunsell, 2020: Automated detection algorithm for $\mathrm{SACZ}$, oceanic $\mathrm{SACZ}$, and their climatological features. Front. Environ. Sci., 8, 18, https://doi.org/10.3389/fenvs.2020.00018.

Saji, N. H., and T. Yamagata, 2003: Structure of SST and surface wind variability during Indian Ocean dipole mode events: COADS observations. J. Climate, 16, 2735-2751, https://doi.org/10.1175/1520-0442(2003)016<2735:SOSAS W>2.0.CO;2.

- B. N. Goswami, P. N. Vinayachandran, and T. Yamagata, 1999: A dipole mode in the tropical Indian Ocean. Nature, 401, 360-363, https://doi. org/10.1038/43854. 
Schneider, U., A. Becker, P. Finger, A. Meyer-Christoffer, and M. Ziese, 2018: GPCC monitoring product: Near real-time monthly land-surface precipitation from rain-gauges based on SYNOP and CLIMAT data. DWD, accessed 4 March 2020, https://doi.org/10.5676/DWD_GPCC/MP_M_V6_100.

Smith, A. B., 2020: 2010-2019: A landmark decade of U.S. billion-dollar weather and climate disasters. Climate.gov, www.climate.gov/news-features/blogs/ beyond-data/2010-2019-landmark-decade-us-billion-dollar-weather-and -climate.

Spence, J., M. A. Taylor, and A. A. Chen, 2004: The effect of concurrent sea surface temperature anomalies in the tropical Pacific and Atlantic on Caribbean rainfall. Int. J. Climatol., 24, 1531-1541, https://doi.org/10.1002/ joc.1068.

Takaya, K., and H. Nakamura, 2001: A formulation of a phase-independent wave-activity flux for stationary and migratory quasi-geostrophic eddies on a zonally varying basic flow. J. Atmos. Sci., 58, 608-627, https://doi. org/10.1175/1520-0469(2001)058<0608:AFOAPI>2.0.CO;2.

Todey, D., D. Peck, D. Kluck, and C. Felkley, 2020: Agricultural impacts of the spring and summer extremes of 2019." 25th Conf. on Applied Climatology, Boston, MA, Amer. Meteor. Soc., 7.2, https://ams.confex.com/ams /2020Annual/webprogram/Paper371246.html.

Trewin, B., 2018: The Australian Climate Observations Reference Network - Surface Air Temperature (ACORN-SAT) version 2. Bureau Research Rep. 032, 57 pp., www.bom.gov.au/climate/change/acorn-sat/documents/BRR-032.pdf.
Uvo, C. B., 2003: Analysis and regionalization of Northern European winter precipitation based on its relationship with the North Atlantic Oscillation. Int. J. Climatol., 23, 1185-1194, https://doi.org/10.1002/joc.930.

van der Schrier, G., E. J. M. van den Besselaar, A. M. G. Klein Tank, and G. Verver, 2013: Monitoring European average temperature based on the E-OBS gridded data set. J. Geophys. Res. Atmos., 118, 5120-5135, https:// doi.org/10.1002/JGRD.50444.

Vautard, R., and Coauthors, 2019: Human contribution to the record-breaking July 2019 heat wave in Western Europe. World Weather Attribution, www. worldweatherattribution.org/human-contribution-to-the-record-breakingjuly-2019-heat-wave-in-western-europe/.

Vincent, L. A, D. Phillips, and R. Whitewood, 2015: Canada [in "State of the Climate in 2014"]. Bull. Amer. Meteor. Soc., 96 (7), S169-S171.

Wild, M., 2016: Decadal changes in radiative fluxes at land and ocean surfaces and their relevance for global warming. Wiley Interdiscip. Rev.: Climate Change, 7, 91-107, https://doi.org/10.1002/wcc.372.

Wilks, D., 2011: Statistical Methods in the Atmospheric Sciences. 3rd ed. International Geophysics Series, Vol. 100, Academic Press, 676 pp.

Wu, B., T. Zhou, and T. Li, 2017: Atmospheric dynamic and thermodynamic processes driving the western North Pacific anomalous anticyclone during El Niño. Part I: Maintenance mechanisms. J. Climate, 30, 9621-9635, https:// doi.org/10.1175/JCLI-D-16-0489.1. 


\section{STATE OF THE CLIMATE IN 2019 RELEVANT DATASETS AND SOURCES}

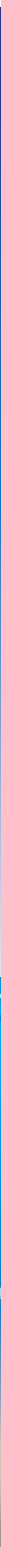

Special Online Supplement to the Bulletin of the American Meteorological Society, Vol.101, No. 8, August, 2020

https://doi.org/10.1175/2020BAMSStateoftheClimate_Chapter8.1

Corresponding author: Jessica Blunden / Jessica.Blunden@noaa.gov

For information regarding reuse of this content and general copyright information, consult the AMS Copyright Policy. 


\section{RELEVANT DATASETS AND SOURCES}

\begin{tabular}{|c|c|c|c|}
\hline $\begin{array}{l}\text { General Variable } \\
\text { or Phenomenon }\end{array}$ & Specific dataset or variable & Source & Section \\
\hline \multirow{3}{*}{ Aerosols } & CAMS Reanalysis & https://atmosphere.copernicus.eu/ & $2 \mathrm{~g} 3$ \\
\hline & GloSSAC v.1. & $\begin{array}{l}\text { https://eosweb.larc.nasa.gov/project } \\
\text { /glossac/glossac_v1.1 }\end{array}$ & SB2.2 \\
\hline & OMPS/LP & https://ozoneaq.gsfc.nasa.gov/data/ozone/ & SB2.2 \\
\hline \multirow{4}{*}{ Air-sea fluxes } & CERES Energy Balanced and Filled & https://ceres.larc.nasa.gov/ & 3e4 \\
\hline & CERES FLASHflux & $\begin{array}{l}\text { https://eosweb.larc.nasa.gov/project/ceres } \\
\text { /ebaf_surface_table }\end{array}$ & $3 e 1$ \\
\hline & NCEP/DOE AMIP-II & $\begin{array}{l}\text { https://www.cpc.ncep.noaa.gov/products } \\
\text { /wesley/reanalysis2/ }\end{array}$ & $6 \mathrm{~g} 3$ \\
\hline & $\begin{array}{l}\text { Woods Hole Oceanographic Institute } \\
\text { OAFlux }\end{array}$ & http://oaflux.whoi.edu & $3 \mathrm{e} 1,3 \mathrm{e} 2,3 \mathrm{e} 3$ \\
\hline Albedo & MODIS & http://ladsweb.nascom.nasa.gov & $2 \mathrm{~h} 1,5 \mathrm{e} 1$ \\
\hline $\begin{array}{l}\text { Atmospheric } \\
\text { fluxes }\end{array}$ & MERRA-2 & https://gmao.gsfc.nasa.gov/reanalysis/MERRA-2/ & SB6.1 \\
\hline \multirow{2}{*}{$\begin{array}{l}\text { Biomass, } \\
\text { Greenness or } \\
\text { Burning }\end{array}$} & GFAS v1.4 & ftp://ftp.mpic.de/GFAS/sc17 & $2 \mathrm{~h} 3$ \\
\hline & $\begin{array}{l}\text { Global Inventory Modeling and Mapping } \\
\text { Studies (GIMMS) 3gv1 }\end{array}$ & https://nex.nasa.gov/nex/projects/1349/ & $5 i$ \\
\hline \multirow{10}{*}{ Cloud Properties } & Aqua MODIS C6 & $\begin{array}{l}\text { https://earthdata.nasa.gov/earth-observation-data } \\
\text { /near-real-time/download-nrt-data/modis-nrt }\end{array}$ & $2 \mathrm{~d} 7$ \\
\hline & CALIPSO & $\begin{array}{l}\text { https://eosweb.larc.nasa.gov/project/calipso } \\
\text { /calipso_table }\end{array}$ & $2 \mathrm{~d} 7,6 \mathrm{~h}$ \\
\hline & CERES MODIS & $\begin{array}{l}\text { https://ceres.larc.nasa.gov/science_information } \\
\text {.php?page=ModisCloudRetr }\end{array}$ & $2 \mathrm{~d} 7$ \\
\hline & CLARA-A2 & $\begin{array}{l}\text { https://climatedataguide.ucar.edu/climate-data } \\
\text { /clara-a1-cloud-properties-surface-albedo-and } \\
\text {-surface-radiation-products-based-avhrr }\end{array}$ & $2 \mathrm{~d} 7$ \\
\hline & CLOUD_CCI & www.esa-cloud-cci.org & $2 \mathrm{~d} 7$ \\
\hline & HIRS & www.ssec.wisc.edu/ donw/PAGE/CLIMATE.HTML & $2 \mathrm{~d} 7$ \\
\hline & MISR & https://I0dup05.larc.nasa.gov/L3Web/ & $2 \mathrm{~d} 7$ \\
\hline & PATMOS-x/AVHRR & $\begin{array}{l}\text { www.ncdc.noaa.gov/cdr/atmospheric } \\
\text { /avhrr-cloud-properties-patmos-x }\end{array}$ & $2 \mathrm{~d} 7$ \\
\hline & PATMOS-x/MODIS C6 & http://ladsweb.nascom.nasa.gov & $2 \mathrm{~d} 7$ \\
\hline & SatCORPS & No public archive & $2 \mathrm{~d} 7$ \\
\hline \multirow{2}{*}{ Drought } & scPSDI & https://crudata.uea.ac.uk/cru/data/drought/ & $2 \mathrm{~d} 11$ \\
\hline & CRU TS 4.03 & https://crudata.uea.ac.uk/cru/data/hrg/ & $2 \mathrm{~d} 11$ \\
\hline $\begin{array}{l}\text { Evaporation, } \\
\text { Interception, } \\
\text { Transpiration, } \\
\text { Sublimation }\end{array}$ & GLEAM & www.gleam.eu/ & $2 \mathrm{~d} 12$ \\
\hline \multirow{3}{*}{ FAPAR } & MERIS & http://earth.esa.int/level3/meris-level3/ & $2 \mathrm{~h} 2$ \\
\hline & MODIS-TIP & http://ladsweb.nascom.nasa.gov/ & $2 \mathrm{~h} 2$ \\
\hline & SeaWiFS v 2010.0 & http://fapar.jrc.ec.europa.eu/ & $2 \mathrm{~h} 2$ \\
\hline
\end{tabular}




\begin{tabular}{|c|c|c|c|}
\hline $\begin{array}{l}\text { General Variable } \\
\text { or Phenomenon }\end{array}$ & Specific dataset or variable & Source & Section \\
\hline \multirow{2}{*}{$\begin{array}{l}\text { Geopotential } \\
\text { Height }\end{array}$} & ERA5 & $\begin{array}{l}\text { https://www.ecmwf.int/en/forecasts/datasets } \\
\text { /reanalysis-datasets/era5 }\end{array}$ & $6 b$ \\
\hline & NCEP/NCAR Reanalysis 1: Pressure & $\begin{array}{l}\text { www.esrl.noaa.gov/psd/data/gridded } \\
\text { /data.ncep.reanalysis.pressure.html }\end{array}$ & $4 f 2,5 b 2$ \\
\hline \multirow{3}{*}{$\begin{array}{l}\text { Glacier Mass, Area } \\
\text { or Volume }\end{array}$} & GRACE / GRACE-FO & https://gracefo.jpl.nasa.gov/data/grace-data/ & $5 e 3,5 f$ \\
\hline & Sentinel-2, LANDSAT, ASTER & - & $5 \mathrm{e} 1$ \\
\hline & World Glacier Monitoring Service & https://wgms.ch/latest-glacier-mass-balance-data/ & $2 c 3,5 f$ \\
\hline $\begin{array}{c}\text { Groundwater and } \\
\text { terrestrial water } \\
\text { storage }\end{array}$ & GRACE / GRACE-FO & https://gracefo.jpl.nasa.gov/data/grace-data/ & $2 d 9$ \\
\hline \multirow{6}{*}{$\begin{array}{l}\text { Humidity, [Near] } \\
\text { Surface }\end{array}$} & ERA5 & $\begin{array}{l}\text { https://www.ecmwf.int/en/forecasts/datasets } \\
\text { /reanalysis-datasets/era5 }\end{array}$ & $2 \mathrm{~d} 1$ \\
\hline & HadISDH & www.metoffice.gov.uk/hadobs/hadisdh & $2 \mathrm{~d} 1$ \\
\hline & JRA-55 Atmospheric Reanalysis & http://jra.kishou.go.jp/JRA-55/index_en.html & $2 \mathrm{~d} 1$ \\
\hline & MERRA-2 & https://gmao.gsfc.nasa.gov/reanalysis/MERRA-2/ & $2 \mathrm{~d} 1$ \\
\hline & $\begin{array}{l}\text { NOAA-CIRES-DOE 20th Century } \\
\text { Reanalysis v3 }\end{array}$ & $\begin{array}{l}\text { https://psl.noaa.gov/data/gridded } \\
\text { /data.20thC_ReanV3.html }\end{array}$ & $2 \mathrm{~d} 1$ \\
\hline & NOCS 2.0 & https://rda.ucar.edu/datasets/ds260.3/ & $2 \mathrm{~d} 1$ \\
\hline \multirow{3}{*}{$\begin{array}{l}\text { Humidity, Upper } \\
\text { Atmosphere }\end{array}$} & ERA5 & $\begin{array}{l}\text { https://www.ecmwf.int/en/forecasts/datasets } \\
\text { /reanalysis-datasets/era5 }\end{array}$ & $2 \mathrm{~d} 3$ \\
\hline & HIRS & $\begin{array}{l}\text { www.ncdc.noaa.gov/cdr/fundamental } \\
\text { /hirs-ch12-brightness-temperature }\end{array}$ & $2 \mathrm{~d} 3$ \\
\hline & UTH, Microwave & by email to Viju.John@eumetsat.int & $2 \mathrm{~d} 3$ \\
\hline \multirow{6}{*}{$\begin{array}{l}\text { Ice Sheet } \\
\text { Characteristics }\end{array}$} & DMSP-SSMIS & http://nsidc.org/data/nsidc-0032 & $5 e 1,6 d$ \\
\hline & ERA5 & $\begin{array}{l}\text { https://www.ecmwf.int/en/forecasts/datasets } \\
\text { /reanalysis-datasets/era5 }\end{array}$ & $6 c$ \\
\hline & ICESat, ICESat-2 & https://nsidc.org/data/icesat-2 & $6 e$ \\
\hline & MERRA-2 & https://gmao.gsfc.nasa.gov/reanalysis/MERRA-2/ & $6 c$ \\
\hline & $\begin{array}{l}\text { Modèle Atmosphérique Régionale surface } \\
\text { mass }\end{array}$ & https://mar.cnrs.fr/ & $5 e 1$ \\
\hline & PROMICE (Greenland) & www.promice.dk/home.html & $5 e 1,5 e 2$ \\
\hline Lake Ice & - & - & SB2.1 \\
\hline \multirow{9}{*}{ Lake Temperature } & ERA5 & $\begin{array}{l}\text { https://www.ecmwf.int/en/forecasts/datasets } \\
\text { /reanalysis-datasets/era5 }\end{array}$ & $2 \mathrm{~b} 2$ \\
\hline & Globolakes & www.globolakes.ac.uk & $2 \mathrm{~b} 2$ \\
\hline & Lake Vättern (Sweden) & Vättern Water Protection Association & $2 b 2$ \\
\hline & Lake Zurich (Switzerland) & $\begin{array}{l}\text { City of Zurich Water Supply and Amt für Abfall, Wasser, } \\
\text { Energie und Luft of the Canton of Zurich }\end{array}$ & $2 \mathrm{~b} 2$ \\
\hline & MetOp A \& B ATSR and AVHRR & $\begin{array}{l}\text { https://www.eumetsat.int/website/home/Satellites } \\
\text { /CurrentSatellites/Metop/index.html }\end{array}$ & $2 \mathrm{~b} 2$ \\
\hline & Mondsee (Austria) & http://hydro.ooe.gv.at/\#Startseite & $2 \mathrm{~b} 2$ \\
\hline & Neusiedler See (Austria) & http://wasser.bgld.gv.at/hydrographie/online-daten.html & $2 b 2$ \\
\hline & Polish Lakes & www.imgw.pl & $2 b 2$ \\
\hline & Wörther See (Austria) & $\begin{array}{l}\text { https://info.ktn.gv.at/asp/hydro/daten/hydroportal } \\
\text { /see_wt.asp }\end{array}$ & $2 \mathrm{~b} 2$ \\
\hline Lake Water Levels & USDA G-REALM & https://ipad.fas.usda.gov/cropexplorer/global_reservoir/ & $2 \mathrm{~d} 6$ \\
\hline
\end{tabular}




\begin{tabular}{|c|c|c|c|}
\hline $\begin{array}{l}\text { General Variable } \\
\text { or Phenomenon }\end{array}$ & Specific dataset or variable & Source & Section \\
\hline \multirow{8}{*}{$\begin{array}{l}\text { Modes of } \\
\text { Variability }\end{array}$} & Arctic Oscillation (AO) & $\begin{array}{l}\text { www.cpc.ncep.noaa.gov/products/precip/CWlink } \\
\text { /daily_ao_index/teleconnections.shtml }\end{array}$ & $2 \mathrm{e} 1$ \\
\hline & Indian Ocean Dipole Mode Index & https://psl.noaa.gov/gcos_wgsp/Timeseries/DMI/ & $4 \mathrm{~h}$ \\
\hline & $\begin{array}{l}\text { Madden-Julian Oscillation (MJO) - Real- } \\
\text { time Multivariate MJO }\end{array}$ & $\begin{array}{l}\text { www.bom.gov.au/climate/mjo/graphics } \\
\text { /rmm.74toRealtime.txt }\end{array}$ & $4 c$ \\
\hline & North Atlantic Oscillation (NAO) & $\begin{array}{l}\text { https://climatedataguide.ucar.edu/climate-data/hurrell } \\
\text {-north-atlantic-oscillation-nao-index-station-based }\end{array}$ & $2 \mathrm{e} 1$ \\
\hline & Oceanic Nino Index (ONI) & $\begin{array}{l}\text { www.cpc.ncep.noaa.gov/products/analysis_monitoring } \\
\text { lensostuff/ensoyears.shtml }\end{array}$ & $4 b$ \\
\hline & Southern Annular Mode (SAM) & www.antarctica.ac.uk/met/gjma/sam.html & 6b, SB6.1 \\
\hline & Southern Annular Mode (SAM, AAO) & $\begin{array}{l}\text { www.cpc.ncep.noaa.gov/products/precip/CWlink } \\
\text { /daily_ao_index/aao/aao.shtml }\end{array}$ & $2 \mathrm{e} 1$ \\
\hline & Southern Oscillation Index (SOI) & $\begin{array}{l}\mathrm{ftp}: / / \mathrm{ftp} . \text { bom.gov.au/anon/home/ncc/www/sco } \\
\text { /soi/soiplaintext.html }\end{array}$ & $2 \mathrm{e} 1$ \\
\hline \multirow{3}{*}{ Ocean Carbon } & MPI-SOM-FFN & $\begin{array}{l}\text { https://www.nodc.noaa.gov/ocads/oceans } \\
\text { /SPCO2_1982_2015_ETH_SOM_FFN.html }\end{array}$ & $6 g 3$ \\
\hline & pCO2 & www.socat.info & $3 \mathrm{i} 2$ \\
\hline & $\begin{array}{l}\text { Global Ocean Ship-Based Hydrographic } \\
\text { Investigations Program }\end{array}$ & www.go-ship.org & $3 \mathrm{i} 3$ \\
\hline \multirow{7}{*}{$\begin{array}{l}\text { Ocean Heat } \\
\text { Content }\end{array}$} & $\begin{array}{l}\text { CLIVAR and Carbon Hydrographic Data } \\
\text { Office }\end{array}$ & https://cchdo.ucsd.edu/ & $3 c$ \\
\hline & CSIRO/ACE CRC/IMAS-UTAS estimate & $\begin{array}{l}\text { www.cmar.csiro.au/sealevel/thermal_expansion } \\
\text { _ocean_heat_timeseries.html }\end{array}$ & $3 c$ \\
\hline & IAP/CAS & $\begin{array}{l}\text { https://climatedataguide.ucar.edu/climate-data/ocean } \\
\text {-temperature-analysis-and-heat-content-estimate } \\
\text {-institute-atmospheric-physics }\end{array}$ & $3 c$ \\
\hline & PMEL/JPL/JIMAR & http://oceans.pmel.noaa.gov & $3 c$ \\
\hline & MRI/JMA & $\begin{array}{l}\text { www.data.jma.go.jp/gmd/kaiyou/english/ohc } \\
\text { lohc_global_en.html }\end{array}$ & $3 c$ \\
\hline & NCEI & www.nodc.noaa.gov/OC5/3M_HEAT_CONTENT/ & $3 c$ \\
\hline & UK Met Office EN4.0.2 & $\begin{array}{l}\text { www.metoffice.gov.uk/hadobs/en4/download } \\
\text {-en4-0-2-I09.html }\end{array}$ & $3 c$ \\
\hline Ocean Mass & $\begin{array}{l}\text { NASA Gravity Recovery and } \\
\text { Climate Experiment }\end{array}$ & $\begin{array}{l}\text { https://grace.jpl.nasa.gov/data/get-data } \\
\text { /monthly-mass-grids-ocean/ }\end{array}$ & $3 f$ \\
\hline \multirow{4}{*}{ Ocean Salinity } & Aquarius V3.0 & http://podaac.jpl.nasa.gov/aquarius & $3 \mathrm{~d} 2$ \\
\hline & Argo & www.argo.ucsd.edu, http://argo.jcommops.org & $3 \mathrm{~d} 2$ \\
\hline & Blended Analysis for Surface Salinity & ftp://ftp.cpc.ncep.noaa.gov/precip/BASS & $3 \mathrm{~d} 2$ \\
\hline & World Ocean Atlas 2013 & www.nodc.noaa.gov/0C5/woa13/ & $3 d 2,3 d 3$ \\
\hline \multirow{2}{*}{$\begin{array}{l}\text { Outgoing } \\
\text { Longwave } \\
\text { Radiation }\end{array}$} & AVHRR & $\begin{array}{l}\text { https://www.esrl.noaa.gov/psd/data/gridded } \\
\text { /data.interp_OLR.html }\end{array}$ & $4 \mathrm{~d} 2,4 \mathrm{f} 2$ \\
\hline & Daily OLR & $\begin{array}{l}\text { www.ncdc.noaa.gov/cdr/atmospheric } \\
\text { loutgoing-longwave-radiation-daily }\end{array}$ & $\begin{array}{l}4 \mathrm{~b} 2,4 \mathrm{~b} 3,4 \mathrm{c}, \\
4 \mathrm{f} 3,4 \mathrm{f5}, 4 \mathrm{f} 6\end{array}$ \\
\hline
\end{tabular}




\begin{tabular}{|c|c|c|c|}
\hline $\begin{array}{l}\text { General Variable } \\
\text { or Phenomenon }\end{array}$ & Specific dataset or variable & Source & Section \\
\hline \multirow{12}{*}{$\begin{array}{c}\text { Ozone, } \\
\text { Total Column } \\
\text { and Stratospheric }\end{array}$} & $\begin{array}{l}\text { GOME/SCIAMACHY/GOME2 (GSG) } \\
\text { Merged Total Ozone }\end{array}$ & www.iup.uni-bremen.de/gome/wfdoas/ & $2 g 4$ \\
\hline & $\begin{array}{l}\text { GOME/SCIAMACHY/GOME2 (GTO) } \\
\text { Merged Total Ozone }\end{array}$ & www.esa-ozone-cci.org & $2 g 4$ \\
\hline & GOZCARDS ozone profiles & https://gozcards.jpl.nasa.gov/info.php & $2 g 4$ \\
\hline & Aura OMI/MLS & $\begin{array}{l}\text { https://disc.sci.gsfc.nasa.gov/Aura/data-holdings/MLS } \\
\text { ftp://toms.gsfc.nasa.gov/pub/omi/data/ozone/ } \\
\text { (for years 2013-2017) } \\
\text { https://disc.gsfc.nasa.gov/datasets/OMTO3d } \\
\text { h003/summary } \\
\text { https://disc.gsfc.nasa.gov/datasets/OMUVBd } \\
\text { _003/summary }\end{array}$ & $5 j 1,6 h$ \\
\hline & $\begin{array}{l}\text { Multi Sensor Reanalysis (MSR-2) } \\
\text { of total ozone }\end{array}$ & www.temis.nl & $2 g 4$ \\
\hline & $\begin{array}{l}\text { NASA BUV/SBUV v8.6 (MOD v8.6) } \\
\text { Merged Ozone }\end{array}$ & http://acdb-ext.gsfc.nasa.gov/Data_services/merged & $2 g 4$ \\
\hline & $\begin{array}{l}\text { NOAA BUVISBUV v8.6 (MOD v8.6) } \\
\text { Merged Ozone }\end{array}$ & ftp://ftp.cpc.ncep.noaa.gov/SBUV_CDR & $2 g 4$ \\
\hline & Ozone Mapping \& Profiler Suite (OMPS) & https://ozoneaq.gsfc.nasa.gov/omps/ & $6 \mathrm{~h}$ \\
\hline & Ozonesonde & www.esrl.noaa.gov/gmd/dv/spo_oz & $6 \mathrm{~h}$ \\
\hline & SAGE II/OSIRIS & dataset linked to Bourassa et al. (2014) & $2 g 4$ \\
\hline & SWOOSH & www.esrl.noaa.gov/csd/groups/csd8/swoosh/ & $2 g 4$ \\
\hline & WOUDC Ground-based Ozone & $\begin{array}{l}\text { https://woudc.org/archive/Projects-Campaigns } \\
\text { /ZonalMeans/ }\end{array}$ & $2 g 4$ \\
\hline \multirow{2}{*}{$\begin{array}{l}\text { Ozone, } \\
\text { Tropospheric }\end{array}$} & Aura OMI/MLS & $\begin{array}{l}\text { http://acd-ext.gsfc.nasa.gov/Data_services } \\
\text { /cloud_slice/new_data.html }\end{array}$ & $2 g 6$ \\
\hline & NOAA Observatory Data & ftp://aftp.cmdl.noaa.gov/data/ozwv/SurfaceOzone/ & $2 g 6$ \\
\hline \multirow{7}{*}{ Permafrost } & Active Layer Thickness & www2.gwu.edu/ calm/ & $2 \mathrm{c} 1,5 \mathrm{~h} 2$ \\
\hline & $\begin{array}{l}\text { Global Terrestrial Network for Permafrost } \\
\text { (GTN-P) }\end{array}$ & http://gtnpdatabase.org/ & $2 \mathrm{c} 1,5 \mathrm{~h} 1$ \\
\hline & Permafrost Temperature & http://permafrost.gi.alaska.edu/sites_map & $5 h 1$ \\
\hline & $\begin{array}{l}\text { Permafrost Temperature at Chinese } \\
\text { (QTP) sites }\end{array}$ & https://nsidc.org/data/GGD700/versions/1 & $2 \mathrm{c} 1$ \\
\hline & Permafrost Temperature at French sites & permafrance.osug.fr & 2c1 \\
\hline & $\begin{array}{l}\text { Permafrost Temperature at Norwegian } \\
\text { sites }\end{array}$ & $\begin{array}{l}\text { www.tspnorway.com } \\
\text { www.met.no }\end{array}$ & $2 \mathrm{c} 1$ \\
\hline & Permafrost Temperature at Swiss sites & www.permos.ch & 2c1 \\
\hline \multirow{4}{*}{ Phenology } & Budburst Quercus robur & https://www.usanpn.org/node/22741 & $2 \mathrm{~h} 4$ \\
\hline & Lake chlorophyll & - & $2 \mathrm{~h} 4$ \\
\hline & NDVI & https://modis.gsfc.nasa.gov/data/dataprod/mod13.php & $2 \mathrm{~h} 4$ \\
\hline & PhenoCam & https://www.neonscience.org/data-collection/phenocams & $2 \mathrm{~h} 4$ \\
\hline \multirow{2}{*}{$\begin{array}{l}\text { Phytoplankton, } \\
\text { Ocean Color }\end{array}$} & MODIS-Aqua R2018.0 & http://oceancolor.gsfc.nasa.gov/cms/reprocessing/ & $3 \mathrm{~h}$ \\
\hline & SeaWiFS R2018.0 & http://oceancolor.gsfc.nasa.gov/cms/reprocessing/ & $3 \mathrm{~h}$ \\
\hline
\end{tabular}




\begin{tabular}{|c|c|c|c|}
\hline $\begin{array}{l}\text { General Variable } \\
\text { or Phenomenon }\end{array}$ & Specific dataset or variable & Source & Section \\
\hline \multirow{8}{*}{ Precipitation } & Climate Extremes Index & https://www.ncdc.noaa.gov/extremes/cei/ & $2 \mathrm{~d} 5$ \\
\hline & CMORPH & $\begin{array}{l}\text { www.cpc.ncep.noaa.gov/products/janowiak } \\
\text { /cmorph_description.html }\end{array}$ & $4 \mathrm{~d} 1$ \\
\hline & ERA5 & $\begin{array}{l}\text { https://www.ecmwf.int/en/forecasts/datasets } \\
\text { /reanalysis-datasets/era5 }\end{array}$ & $2 \mathrm{~d} 5$ \\
\hline & GHCN v4 & $\begin{array}{l}\text { www.ncdc.noaa.gov/temp-and-precip/ghen } \\
\text {-gridded-products/precipitation }\end{array}$ & $2 \mathrm{~d} 4,2 \mathrm{~d} 5$ \\
\hline & GHCNDEX & www.climdex.org/datasets.html & $2 \mathrm{~d} 5$ \\
\hline & GPCP v2.3 & http://precip.gsfc.nasa.gov & $\begin{array}{l}2 \mathrm{~d} 4,3 \mathrm{e} 2,4 \mathrm{e}, \\
4 \mathrm{~h}\end{array}$ \\
\hline & GPCC & www.dwd.de/EN/ourservices/gpcc/gpcc.html & $2 \mathrm{~d} 4,2 \mathrm{~d} 5$ \\
\hline & MERRA-2 & http://gmao.gsfc.nasa.gov/reanalysis/MERRA-2/ & $2 \mathrm{~d} 5$ \\
\hline $\begin{array}{l}\text { Precipitation (net), } \\
\text { Freshwater Flux }\end{array}$ & GPCPv23, OAFlux & $\begin{array}{l}\text { http://precip.gsfc.nasa.gov } \\
\text { http://oaflux.whoi.edu }\end{array}$ & $3 e$ \\
\hline \multirow{3}{*}{$\begin{array}{l}\text { Pressure, Sea } \\
\text { Level or } \\
\text { Near-Surface }\end{array}$} & ERA5 & $\begin{array}{l}\text { https://www.ecmwf.int/en/forecasts/datasets } \\
\text { /reanalysis-datasets/era5 }\end{array}$ & $6 b$ \\
\hline & HadSLP2r & http://hadobs.metoffice.com/hadslp2/ & $2 \mathrm{e} 1$ \\
\hline & NCEP/NCAR Reanalysis & $\begin{array}{l}\text { www.esrl.noaa.gov/psd/data/gridded } \\
\text { /data.ncep.reanalysis.html }\end{array}$ & $4 \mathrm{f} 2$ \\
\hline River Discharge & ELSE & No public archive & $2 \mathrm{~d} 8$ \\
\hline Sea Ice Age & EASE-Grid v3 & http://nsidc.org/data/nsidc-0611/ & $5 \mathrm{~d} 2$ \\
\hline \multirow{2}{*}{ Sea Ice Duration } & $\begin{array}{l}\text { Near-Real-Time DMSP SSM/I-SSMIS Daily } \\
\text { Polar Gridded }\end{array}$ & http://nsidc.org/data/nsidc-0081.html & $6 f$ \\
\hline & $\begin{array}{l}\text { Nimbus-7 SMMR and DMSP SSM/I } \\
\text { (Bootstrap) }\end{array}$ & http://nsidc.org/data/nsidc-0079.html & $6 f$ \\
\hline \multirow{2}{*}{$\begin{array}{c}\text { Sea Ice } \\
\text { Extent/Area/ } \\
\text { Concentration }\end{array}$} & $\begin{array}{l}\text { Nimbus-7 SMMR and DMSP SSM/I } \\
\text { (Bootstrap) }\end{array}$ & http://nsidc.org/data/seaice_index/ & $5 c, 5 d, S B 6.2$ \\
\hline & OSI-401-b & $\begin{array}{l}\text { http://navigator.eumetsat.int/product } \\
\text { /EO:EUM:DAT:DMSP:OSI-401-B }\end{array}$ & SB6.2 \\
\hline \multirow{4}{*}{$\begin{array}{l}\text { Sea Level/Sea } \\
\text { Surface Height }\end{array}$} & GRACE / GRACE-FO & https://gracefo.jpl.nasa.gov/data/grace-data/ & $3 f$ \\
\hline & NOAA/NESDIS/STAR & $\begin{array}{l}\text { www.star.nesdis.noaa.gov/sod//sa/SeaLevelRise } \\
\text { /LSA_SLR_timeseries.php }\end{array}$ & $3 f$ \\
\hline & $\begin{array}{l}\text { Ssalto/Duacs Multimission Altimeter } \\
\text { Products }\end{array}$ & $\begin{array}{l}\text { http://marine.copernicus.eu/services-portfolio } \\
\text { /access-to-products/?option=com } \\
\text { _csw\&view=details\&product_id=SEALEVEL } \\
\text { _GLO_PHY_L4_NRT_OBSERVATIONS_008_046 }\end{array}$ & $3 f$ \\
\hline & Tide Gauge & http://uhslc.soest.hawaii.edu/ & $3 f$ \\
\hline \multirow{5}{*}{$\begin{array}{l}\text { Sea Surface } \\
\text { Current }\end{array}$} & Brazil-Malvina Region Confluence Region & $\begin{array}{l}\text { www.aoml.noaa.gov/phod/altimetry/cvar/mal } \\
\text { /BM_anm.php }\end{array}$ & $3 g$ \\
\hline & $\begin{array}{l}\text { Long Term Time Series of Surface } \\
\text { Currents: Agulhas Current }\end{array}$ & www.aoml.noaa.gov/phod/altimetry/cvar/agu/ & $3 g$ \\
\hline & $\begin{array}{l}\text { Long Term Time Series of Surface } \\
\text { Currents: North Brazil Current }\end{array}$ & www.aoml.noaa.gov/phod/altimetry/cvar/nbc & $3 g$ \\
\hline & $\begin{array}{l}\text { Ocean Surface Current Analysis - Real } \\
\text { time (OSCAR) }\end{array}$ & $\begin{array}{l}\text { https://podaac.jpl.nasa.gov/dataset/OSCAR_L4 } \\
\text { _OC_third-deg }\end{array}$ & $3 g$ \\
\hline & Yucatan Current & $\begin{array}{l}\text { www.aoml.noaa.gov/phod/altimetry/cvar } \\
\text { /yuc/transport.php }\end{array}$ & $3 g$ \\
\hline
\end{tabular}




\begin{tabular}{|c|c|c|c|}
\hline $\begin{array}{l}\text { General Variable } \\
\text { or Phenomenon }\end{array}$ & Specific dataset or variable & Source & Section \\
\hline \multirow{5}{*}{$\begin{array}{l}\text { Sea Surface } \\
\text { Temperature }\end{array}$} & ERSSTv5 & https://doi.org/10.7289/V5T72FNM & $3 b, 4 b, 4 f 2$ \\
\hline & HadSST3.1.1 & www.metoffice.gov.uk/hadobs/hadsst3 & $3 b$ \\
\hline & HadSST4 & https://www.metoffice.gov.uk/hadobs/hadsst4/ & $3 b$ \\
\hline & $\begin{array}{l}\text { NOAA Optimum Interpolation SST } \\
\text { (OISST) v2 }\end{array}$ & $\begin{array}{l}\text { http://apdrc.soest.hawaii.edu/dods/public_data } \\
\text { /NOAA_SST/OISST/monthly }\end{array}$ & $4 \mathrm{~b} 1,4 \mathrm{~d} 2,4 \mathrm{f}$ \\
\hline & $\begin{array}{l}\text { NOAA Optimum Interpolation SST } \\
\text { (OISST) v2 }\end{array}$ & $\begin{array}{l}\text { www.ncei.noaa.gov/data/sea-surface } \\
\text {-temperature-optimum-interpolation/access/ }\end{array}$ & $\begin{array}{l}2 b 3,3 b, 4 f 3, \\
4 f 5,4 f 6,4 h, \\
5 c\end{array}$ \\
\hline \multirow{7}{*}{ Snow Properties } & $\begin{array}{l}\text { Canadian Meteorological Centre Daily } \\
\text { Snow Depth Analysis v1 }\end{array}$ & https://nsidc.org/data/NSIDC-0447 & $5 g$ \\
\hline & Crocus Snowpack Model & http://www.umr-cnrm.fr/spip.php?article265 & $5 g$ \\
\hline & GlobSnow 2 & https://nsidc.org/data/NSIDC-0595/versions/2 & $5 g$ \\
\hline & MERRA-2 & http://gmao.gsfc.nasa.gov/reanalysis/MERRA-2/ & $5 g$ \\
\hline & $\begin{array}{l}\text { NOAA Interactive Multi-sensor Snow and } \\
\text { Ice Mapping System } \\
\text { (Snow Cover Duration) }\end{array}$ & www.natice.noaa.gov/ims/index.html & $5 g$ \\
\hline & $\begin{array}{l}\text { NOAA Snow Chart Data Record } \\
\text { (Snow Cover Extent) }\end{array}$ & www.snowcover.org & $2 \mathrm{c} 2,5 \mathrm{~g}$ \\
\hline & MERRA-2 & http://gmao.gsfc.nasa.gov/reanalysis/MERRA-2/ & $5 g$ \\
\hline Soil Moisture & ESA CCI SM & www.esa-soilmoisture-cci.org/index.php & $2 \mathrm{~d} 10$ \\
\hline \multirow{10}{*}{$\begin{array}{l}\text { Temperature, } \\
\text { [Near] Surface }\end{array}$} & $\begin{array}{l}\text { Antarctic Meteorological Research Center } \\
\text { (AMRC) AWS }\end{array}$ & http://amrc.ssec.wisc.edu/data & $6 b$ \\
\hline & CRUTEM4 & $\begin{array}{l}\text { www.metoffice.gov.uk/hadobs/crutem4 } \\
\text { http://www.cru.uea.ac.uk/cru/data/temperature }\end{array}$ & $5 b 1$ \\
\hline & ERA5 & $\begin{array}{l}\text { https://www.ecmwf.int/en/forecasts/datasets } \\
\text { /reanalysis-datasets/era5 }\end{array}$ & $2 b 1,2 b 3,6 b$ \\
\hline & GHCNDEX & www.climdex.org/datasets.html & $2 b 3$ \\
\hline & HadCRUT4 Global Temperature & www.metoffice.gov.uk/hadobs/hadcrut4/ & $2 \mathrm{~b} 1$ \\
\hline & JRA-55 Atmospheric Reanalysis & http://jra.kishou.go.jp/JRA-55/index_en.html & $2 \mathrm{~b} 1$ \\
\hline & MERRA-2 & http://gmao.gsfc.nasa.gov/reanalysis/MERRA-2/ & 2b1, SB6.1 \\
\hline & NASA/GISS Global Temperature & https://data.giss.nasa.gov/gistemp/ & $2 \mathrm{~b} 1$ \\
\hline & NCEP/NCAR Reanalysis & $\begin{array}{l}\text { https://psl.noaa.gov/data/gridded/data.ncep } \\
\text {.reanalysis.html }\end{array}$ & $5 b 2$ \\
\hline & NOAA/NCEI NOAAGlobalTemp & $\begin{array}{l}\text { www.ncdc.noaa.gov/data-access/marineocean-data } \\
\text { /noaa-global-surface-temperature-noaaglobaltemp }\end{array}$ & $2 \mathrm{~b} 1$ \\
\hline
\end{tabular}




\begin{tabular}{|c|c|c|c|}
\hline $\begin{array}{l}\text { General Variable } \\
\text { or Phenomenon }\end{array}$ & Specific dataset or variable & Source & Section \\
\hline \multirow{10}{*}{$\begin{array}{l}\text { Temperature, } \\
\text { Upper Atmosphere }\end{array}$} & ERA5 & $\begin{array}{l}\text { https://www.ecmwf.int/en/forecasts/datasets } \\
\text { /reanalysis-datasets/era5 }\end{array}$ & $\begin{array}{l}2 b 4,2 b 5,6 b, \\
6 h\end{array}$ \\
\hline & JRA-55 Atmospheric Reanalysis & http://jra.kishou.go.jp/JRA-55/index_en.html & $2 b 4,2 b 5$ \\
\hline & MERRA-2 & http://gmao.gsfc.nasa.gov/reanalysis/MERRA-2/ & $2 b 4,2 b 5,6 h$ \\
\hline & NOAA Extended SSU v3 & https://www.star.nesdis.noaa.gov/smcd/emb/mscat/ & $2 \mathrm{~b} 5$ \\
\hline & RAOBCORE, RICH & www.univie.ac.at/theoret-met/research/raobcore & $2 \mathrm{~b} 4,2 \mathrm{~b} 5$ \\
\hline & RATPAC A2 & $\begin{array}{l}\text { www.ncdc.noaa.gov/data-access/weather-balloon } \\
\text { /radiosonde-atmospheric-temperature-products } \\
\text {-accessing-climate/ratpac-a }\end{array}$ & $2 b 4$ \\
\hline & RSS v4.0 & www.remss.com & $2 \mathrm{~b} 4,2 \mathrm{~b} 5$ \\
\hline & NOAA/NESDIS/STAR & www.star.nesdis.noaa.gov/smcd/emb/mscat/ & $2 \mathrm{~b} 5$ \\
\hline & UAH MSU v6.0 & http://vortex.nsstc.uah.edu/public/msu & $2 \mathrm{~b} 4,2 \mathrm{~b} 5$ \\
\hline & UCAR SSU+MLS+SABER & $\begin{array}{l}\text { https://data.ucar.edu/en/dataset/stratospheric } \\
\text {-temperature-trends-over-1979-2015-derived-from } \\
\text {-combined-ssu-mls-and-saber-satelli }\end{array}$ & $2 \mathrm{~b} 5$ \\
\hline \multirow{2}{*}{$\begin{array}{c}\text { TOA Earth } \\
\text { Radiation Budget }\end{array}$} & CERES EBAF Ed4.1 & $\begin{array}{l}\text { https://eosweb.larc.nasa.gov/project/ceres } \\
\text { /ebaf-toa_ed4.1 }\end{array}$ & $2 \mathrm{f1}$ \\
\hline & CERES FLASHFlux & $\begin{array}{l}\text { https://ceres-tool.larc.nasa.gov/ord-tool/jsp } \\
\text { /FLASH_TISASelection.jsp }\end{array}$ & $2 \mathrm{ff} 1$ \\
\hline $\begin{array}{l}\text { Solar Transmission, } \\
\text { Apparent }\end{array}$ & Mauna Loa Observatory & https://www.esrl.noaa.gov/gmd/grad/mloapt.html & $2 f 2$ \\
\hline \multirow{11}{*}{ Trace Gases } & $\begin{array}{l}\text { Atmospheric Greenhouse Gas Index } \\
\text { (AGGI) }\end{array}$ & www.esrl.noaa.gov/gmd/aggi & $2 g 1$ \\
\hline & Carbon Dioxide (CO2) & www.esrl.noaa.gov/gmd/dv/iadv & $2 g 1$ \\
\hline & Carbon Monoxide (CO) & https://atmosphere.copernicus.eu/ & $2 g 7$ \\
\hline & $\begin{array}{l}\text { Carbon Monoxide (CO) - WMO World } \\
\text { Data Centre for GHGs }\end{array}$ & https://gaw.kishou.go.jp & $2 g 7$ \\
\hline & Chlorine Monoxide (ClO) - Aura MLS & http://mls.jpl.nasa.gov/products/clo_product.php & $6 \mathrm{~h}$ \\
\hline & Halocarbons (CFCs, HFCs, HCFCs) & www.esrl.noaa.gov/gmd/hats/data.html & $2 g 1,2 g 2$ \\
\hline & Methane & www.esrl.noaa.gov/gmd/dv/iadv & $2 g 1$ \\
\hline & Nitrous Oxide & www.esrl.noaa.gov/gmd/hats/combined/N20.html & $2 g 1$ \\
\hline & Ozone-Depleting Gas Index (ODGI) & www.esrl.noaa.gov/gmd/odgi & $2 g 2$ \\
\hline & Perfluorocarbons & http://agage.eas.gatech.edu & $2 g 1$ \\
\hline & Sulfur Hexafluoride & www.esrl.noaa.gov/gmd/hats/combined/SF6.html & $2 g 1$ \\
\hline \multirow{5}{*}{$\begin{array}{l}\text { Tropical Cyclone } \\
\text { Data }\end{array}$} & HURDAT2 & www.aoml.noaa.gov/hrd/hurdat/Data_Storm.html & $4 \mathrm{f} 2$ \\
\hline & $\begin{array}{l}\text { International Best Track Archive for } \\
\text { Climate Stewardship (IBTrACS) }\end{array}$ & www.ncdc.noaa.gov/ibtracs/ & $\begin{array}{l}4 \mathrm{f} 1,4 \mathrm{f} 3,4 \mathrm{f} 5 \\
4 \mathrm{f} 6,4 \mathrm{f} 7\end{array}$ \\
\hline & $\begin{array}{l}\text { JTWC Best-track Dataset } \\
\text { (2011 preliminary) }\end{array}$ & $\begin{array}{l}\text { www.usno.navy.mil/NOOC/nmfc-ph/RSS } \\
\text { /jtwc/best_tracks }\end{array}$ & $4 \mathrm{f} 4,4 \mathrm{f5}$ \\
\hline & RSMC-Tokyo, JMA best-track data & $\begin{array}{l}\text { www.jma.go.jp/jma/jma-eng/jma-center } \\
\text { /rsmc-hp-pub-eg/besttrack.html }\end{array}$ & $4 f 4$ \\
\hline & $\begin{array}{l}\text { Southwest Pacific Enhanced Archive of } \\
\text { Tropical Cyclones (SPEArTC) }\end{array}$ & http://apdrc.soest.hawaii.edu/projects/speartc & $4 f 8$ \\
\hline
\end{tabular}




\begin{tabular}{|c|c|c|c|}
\hline $\begin{array}{l}\text { General Variable } \\
\text { or Phenomenon }\end{array}$ & Specific dataset or variable & Source & Section \\
\hline \multirow{5}{*}{ UV Radation Data } & Canadian sites & $\begin{array}{l}\text { ftp://exp-studies.tor.ec.gc.ca/pub } \\
\text { /uvdata/Preliminary/MSC }\end{array}$ & $5 j 2$ \\
\hline & Greenland site & http://uv.biospherical.com/Version2/data.asp & $5 \mathrm{j} 2$ \\
\hline & Finnish sites & $\begin{array}{l}\text { http://litdb.fmi.fi/soundingst_uvradiation.php } \\
\text { http://uv.fmi.fi/uvdb/ }\end{array}$ & $5 j 2$ \\
\hline & Norwegian sites & https://github.com/uvnrpa/Minute_Data & $5 j 2$ \\
\hline & $\mathrm{OMI}$ & $\begin{array}{l}\text { https://disc.gsfc.nasa.gov } \\
\text { /datasets?page=1\&source=AURA } \% 200 \mathrm{MI}\end{array}$ & $5 j 2$ \\
\hline \multirow{4}{*}{$\begin{array}{l}\text { Water Vapor, } \\
\text { Stratosphere }\end{array}$} & $\begin{array}{l}\text { Frost Point Hygrometer Data } \\
\text { (Boulder, Hilo, Lauder) }\end{array}$ & ftp://aftp.cmdl.noaa.gov/data/ozwv/WaterVapor & $2 g 5$ \\
\hline & $\begin{array}{l}\text { Frost Point Hygrometer Data } \\
\text { (San Jose, Costa Rica) }\end{array}$ & http://physics.valpo.edu/ozone/ticosonde.html & $2 g 5$ \\
\hline & $\begin{array}{l}\text { Frost Point Hygrometer (Lindenberg, } \\
\text { Germany) }\end{array}$ & $\begin{array}{l}\text { https://www.dwd.de/EN/research } \\
\text { /observing_atmosphere/lindenberg } \\
\text { _column/in_situ/in_situ_node.html }\end{array}$ & $2 g 5$ \\
\hline & NASA Aura Microwave Limb Sounder & https://mls.jpl.nasa.gov/products/h2o_product.php & $2 \mathrm{~g} 5$ \\
\hline \multirow{6}{*}{$\begin{array}{l}\text { Water Vapor, Total } \\
\text { Column }\end{array}$} & COSMIC GPS-RO & http://cdaac-www.cosmic.ucar.edu/cdaac/products.html & $2 \mathrm{~d} 2$ \\
\hline & ERA5 & $\begin{array}{l}\text { https://www.ecmwf.int/en/forecasts/datasets } \\
\text { /reanalysis-datasets/era5 }\end{array}$ & $2 \mathrm{~d} 2$ \\
\hline & $\begin{array}{l}\text { GNSS Ground-Based Total Column Water } \\
\text { Vapor }\end{array}$ & https://rda.ucar.edu/datasets/ds721.1/ & $2 \mathrm{~d} 2$ \\
\hline & JRA-55 Atmospheric Reanalysis & http://jra.kishou.go.jp/JRA-55/index_en.html & $2 \mathrm{~d} 2$ \\
\hline & MERRA-2 & http://gmao.gsfc.nasa.gov/reanalysis/MERRA-2/ & $2 \mathrm{~d} 2$ \\
\hline & $\begin{array}{l}\text { RSS SSM/I -AMSR-E Ocean Total Column } \\
\text { Water Vapor }\end{array}$ & www.remss.com & $2 \mathrm{~d} 2$ \\
\hline \multirow{7}{*}{$\begin{array}{l}\text { Wind, [Near] } \\
\text { Surface }\end{array}$} & $\begin{array}{l}\text { NOAA-CIRES-DOE 20th Century } \\
\text { Reanalysis v3 }\end{array}$ & $\begin{array}{l}\text { https://psl.noaa.gov/data/gridded } \\
\text { /data.20thC_ReanV3.html }\end{array}$ & $2 \mathrm{e} 2$ \\
\hline & Australian (McVicar) & http://doi.org/10.4225/08/56A85491DDED2 & 200 \\
\hline & ERA5 & $\begin{array}{l}\text { https://www.ecmwf.int/en/forecasts } \\
\text { /datasets/reanalysis-datasets/era5 }\end{array}$ & $2 \mathrm{e} 2$ \\
\hline & HadISD3 & www.metoffice.gov.uk/hadobs/hadisd/ & $2 \mathrm{e} 2$ \\
\hline & JRA-55 Atmospheric Reanalysis & http://jra.kishou.go.jp/JRA-55/index_en.html & $4 \mathrm{~h}$ \\
\hline & MERRA-2 & http://gmao.gsfc.nasa.gov/reanalysis/MERRA-2/ & $2 \mathrm{e} 2$ \\
\hline & RSS SSM/I Ocean Winds & www.remss.com/measurements/wind & $2 \mathrm{e} 2$ \\
\hline \multirow{6}{*}{$\begin{array}{l}\text { Wind, Upper } \\
\text { Atmosphere }\end{array}$} & Climate Forecast System Reanalysis & $\begin{array}{l}\text { www.ncdc.noaa.gov/data-access/model-data } \\
\text { /model-datasets/climate-forecast-system } \\
\text {-version2-cfsv2 }\end{array}$ & $4 f 3,4 f 5,4 f 6$ \\
\hline & ERA5 & $\begin{array}{l}\text { https://www.ecmwf.int/en/forecasts } \\
\text { /datasets/reanalysis-datasets/era5 }\end{array}$ & $2 \mathrm{e} 3,4 \mathrm{e}, 6 \mathrm{~b}$ \\
\hline & ERA-Interim & $\begin{array}{l}\text { www.ecmwf.int/en/research } \\
\text { /climate-reanalysis/era-interim }\end{array}$ & $2 \mathrm{e} 3$ \\
\hline & JRA-55 Atmospheric Reanalysis & http://jra.kishou.go.jp/JRA-55/index_en.html & $2 \mathrm{e} 3$ \\
\hline & MERRA-2 & http://gmao.gsfc.nasa.gov/reanalysis/MERRA-2/ & $2 \mathrm{e} 3, \mathrm{SB} 6.1$ \\
\hline & NCEP/NCAR Reanalysis & $\begin{array}{l}\text { www.esrl.noaa.gov/psd/data/gridded } \\
\text { /data.ncep.reanalysis.html }\end{array}$ & $\begin{array}{l}4 \mathrm{~b} 2,4 \mathrm{~b} 3,4 \mathrm{c}, \\
4 \mathrm{f} 2\end{array}$ \\
\hline
\end{tabular}


